

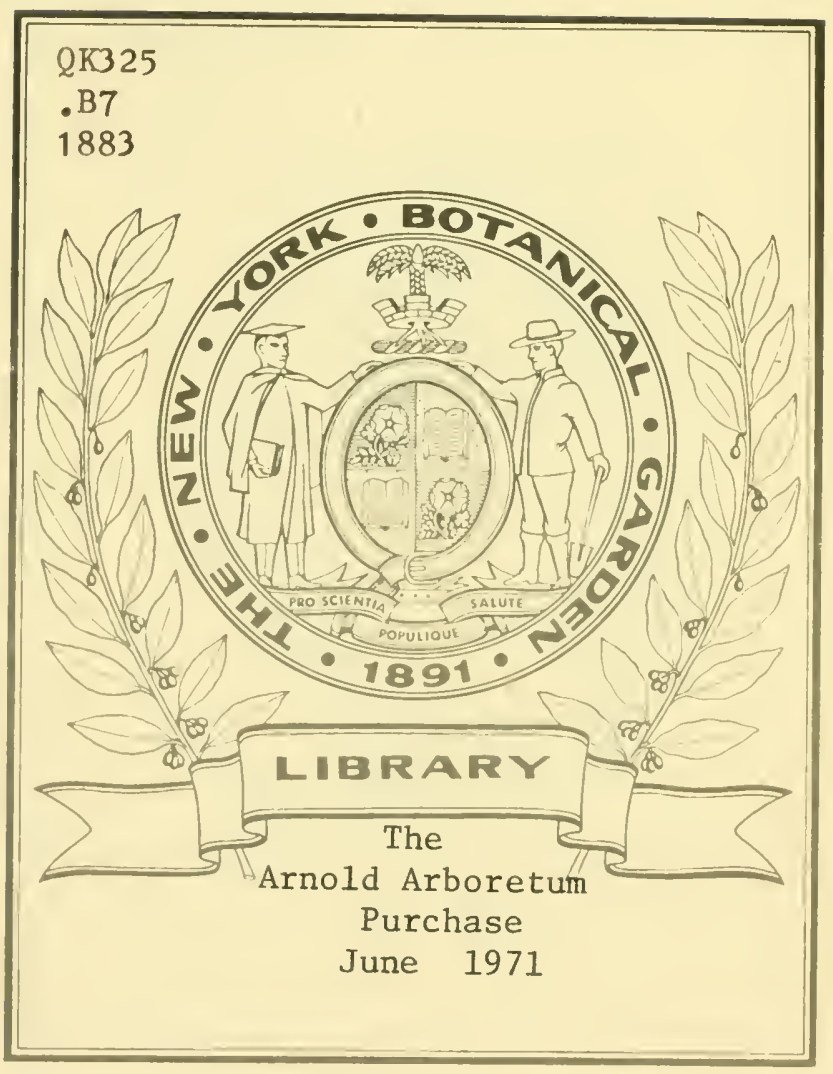





\section{Whomenr \\ erencg \\ hon....., \& h pat e

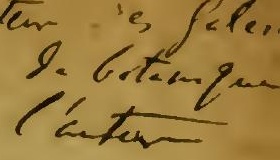

\section{PROLROMUL,}

\section{HLOREİ ROMÂNE}

S.IU

\section{ENUMERAȚIUNEA PLANTELOR}

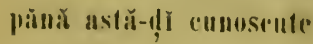

IN

MOLDOVASI VALACHIA

UE:

\section{DOCTORLL D. BRANIZZA}

Membru al Acailemier̆ Române,

P'rofesor de Bolanica la Universitalea din Bucuresci,

l)irector al sectimeĩ holanice din Mluseul de Istorie naturalà

si al Cirădlinni hntanice.

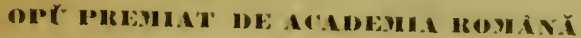

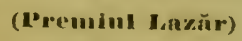

\section{BUCURESCI}

IPOGRAFIA AEADEMIEI ROMANE

(Laboratoru ́romá.:ĩ)

26. STRADA A GADEMIEY. 26.

$$
187 \text {; } 188.3 .
$$




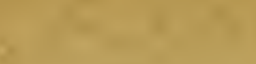
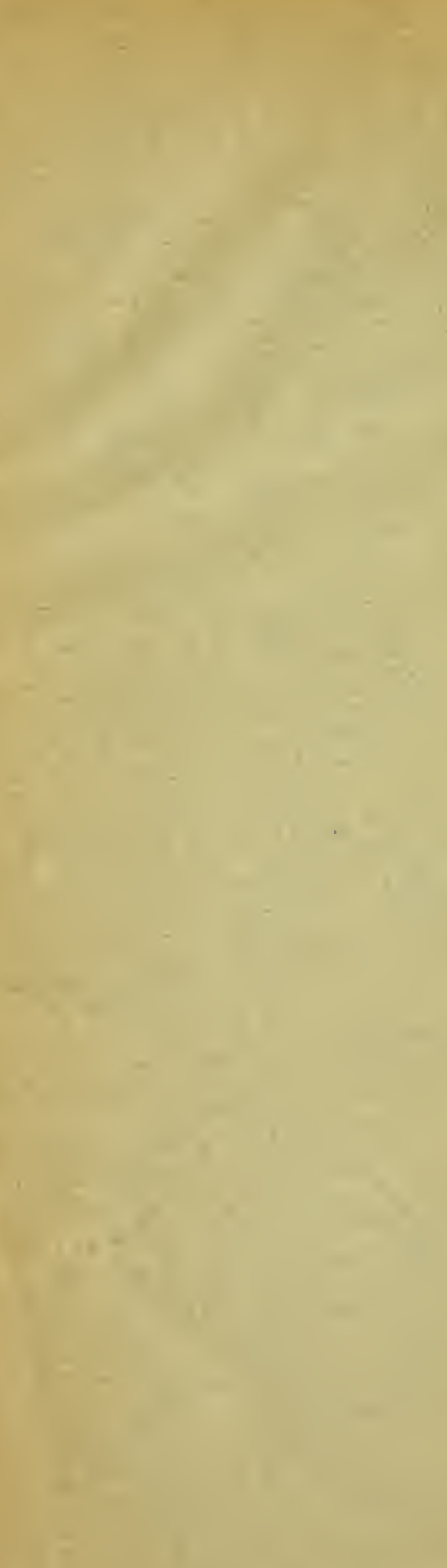

r.

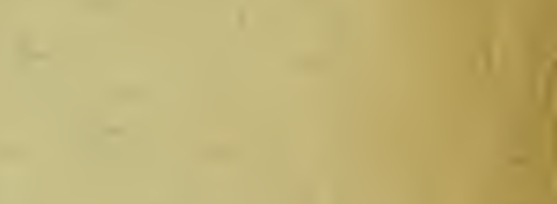

S
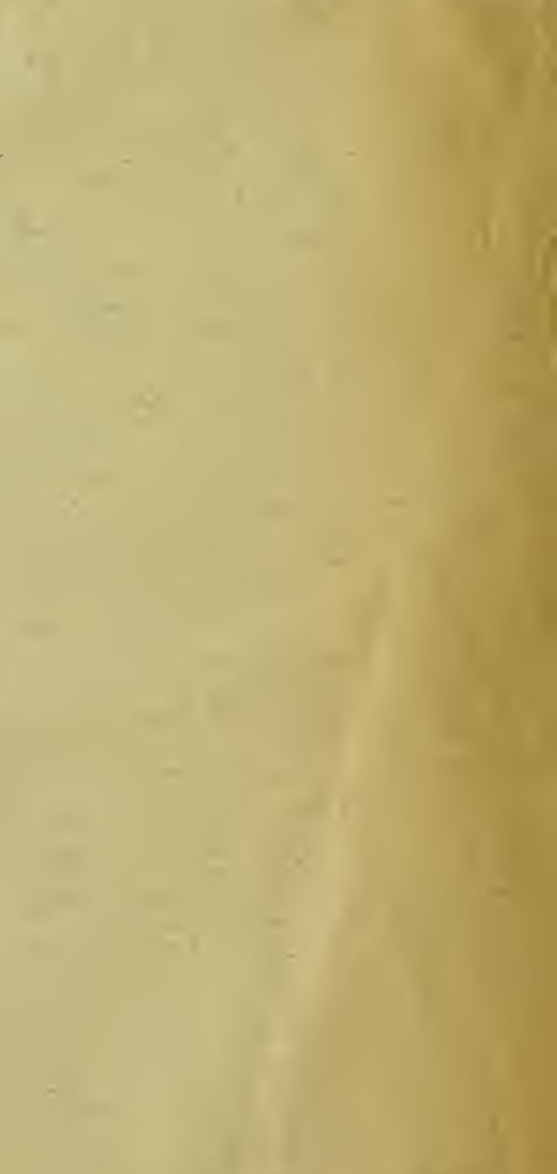

1

$-$

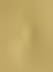<smiles>C1CCCCC1</smiles>
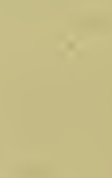
PRODROMUL

FIOREI ROIIANF 



\section{PROTRONUL. \\ FLOREÍ ROMÂNE $S A L$ \\ ENUMERAȚIUNEA PLANTELOR}

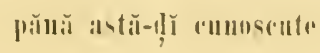

î

$M O L D O V A S I V A L A C H I A$

$1 \%$

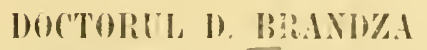

Membru al Acadeniei liomân.

Profesen de Botanică la Universitatea lin Bucurese.

Director al secţiunei botanice din Sluscul de lstorie naturalá

și al Grălinei botanice.

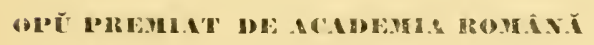

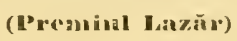

BUCURESCI

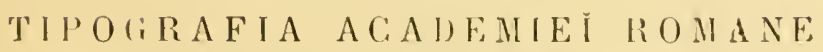

(Lamoratorí Romixi)

26. STRA I A A C A D E I E I.. 26.

$$
1879-1883 .
$$




$$
\begin{aligned}
& \text { Q } 3225 \\
& \text { B } 7 \\
& \text { is } 7
\end{aligned}
$$


Coleyiloi ma clin sectuinere scientifiece a epcratemici OPomiñe 

Pe caind asupra vegetaliureí a mai tuturor tẹrilor vecine cu a nóstră. încă de mult saŭ publicat mà multe Enumerațimu complete și chiar Flore sistematice. România. de și împorlobită cu o vegetațiune, ciıce, după păresea unanimă a tuturor acelora ce aŭ sludiato puțin mă de aprópe. este din cele mă atvule și maŭ interesante, nu numă că nu posedă pînă astă-ḍ̆ nič̆ o scriere de soiul acesta, dară nicĭ măcar o publicatiune. care să cuprindă adunate și coordonale la un loc. cel putin pe acele câte-ra speciŭ de plante, ce se găsesc mentionate în treacĕl de către rariĭ esploratorĭ ce, în diferite epoct, aŭ percurs léra nóstră. Chiar o ast-lél de lucrare, orľ-cât de incompletă. lol ar li lost un început lericit şi nu fălră de o malre importantă ; căč̀. resunând tóte observaliunile făcule pină aslă-d̦̆ în acéslă privinţ̆ă al li pulut prin acésta olèri un fel de batsă mař solidă esploratimuilor viitóre.

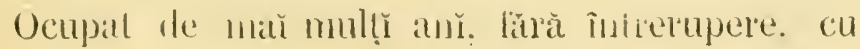

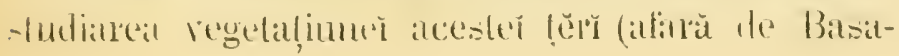


Pabia și Dobrogia). am cred̦ut. prin nrmare. a rèspunde mrĕ lipse reale și de mult simbite. dinnd lit

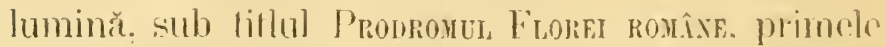
elemente ale mè commerațun generale, cuprin-

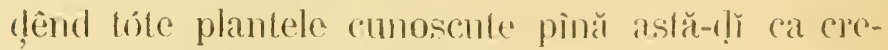
scênd ìn Romannia. Principalnl meŭ scop). läcênd acéstă publicatiune. este mắ cu scimă ca să atrass itentiunea bolaniștilor asupra aviliilor necunoscute. incă ale interesanter̆ nostre filope.

Numerisele epborisatimn ce ann fĭcul in mă tóle

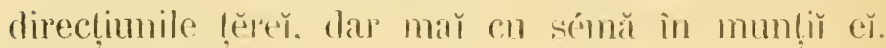
'mŭ-ă̆ perınis de a observa și culege insu-mŭ cea mă̌ mare parte din speciele cuprinse in accišă enımerațiune. Cât drespe acelea ce n'um avui ineă ocasiunea a le observa, dar pe care in 17 mana $17 \mathrm{~mol}^{\circ}$

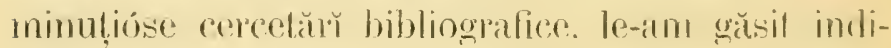
cate de călle altĭ. se va sci că mu le daŭ de cât pe

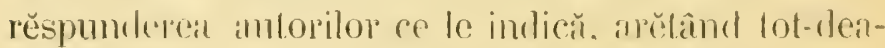
mma, immdial după localitatea fie-coürecia din cle. mumele areluia de cădre care sil menlional arolo, și

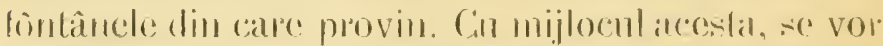
pulea losme dislinge speciele observate de inine, de acelea indicale de altiir. In determinalimmea speciedor: mam feril fol-deauna de a mé pronunţia cu siguranţă. mal inainte de a le li comparal cu lipurile clasice de prin erbariele din Paris și Viena. monde in scopul acesta arr și fost silit a lace repelate călěforiǔ; latr in casurĭ de marí nedumerir. n'irm luat o

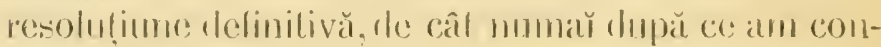

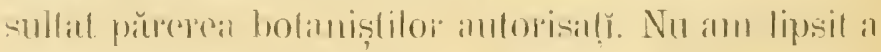
semmala erorile strecurale printre determinaliunile 


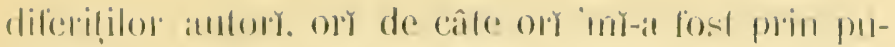

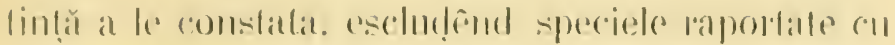

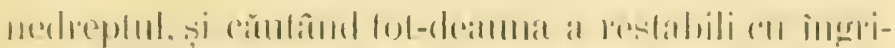

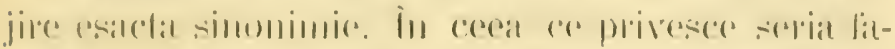

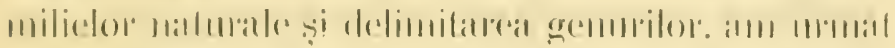

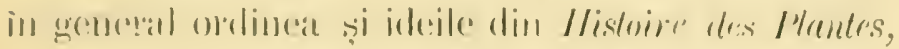

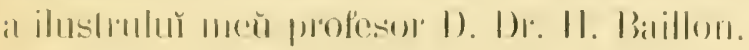

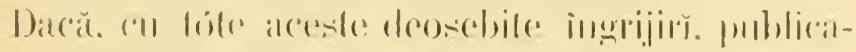

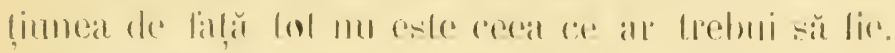

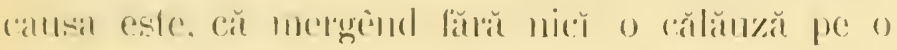

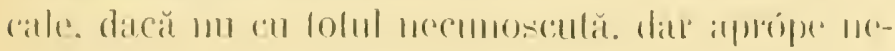

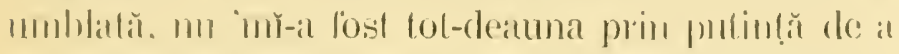
1111 mĕ rălěroj câte-odală. Dar. cu lóle lacmele ĕ.

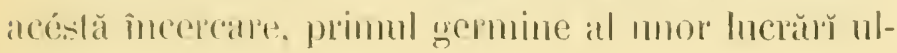
farió) mă complete. va puleal servicel puṭin de

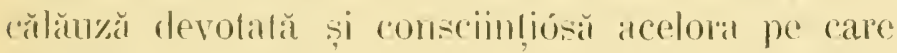
amópea de sciinlăt și de patrie ř va imboleli către nišce e-jplonatiun mă ìntimse.

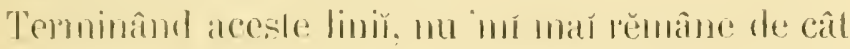
¿ plăli o plăculă datorie, esprinând profundar meat

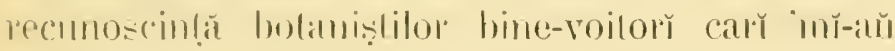

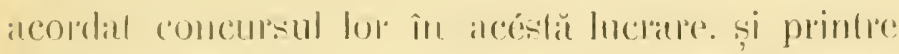
calcesunt lericil de a pulcal mentiona pe tộ̣ distinșĭ invĕtaț ce dirig̨ erbariile museelor din l'aris și Viena. care, nu numă̌ că imh-aŭ deschis lot-cleama cu grăbire și atabilitale uşile acestor celebre sanctuare ale hotanicer̆, dar mắ mult de cail atâl. lor le daforese mulle și pretiose onsiliu asmpar deterninafimnilor dificile. pe DI). Mphonse de Cimdolle din

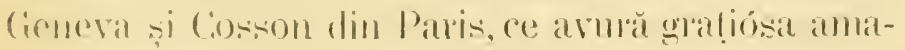

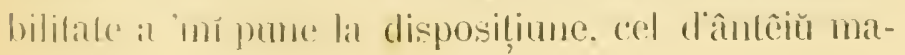


nuscrise e luĭ Ch. Guéthard, impreună cu corespondenta și colectimued plantelor din Moldova al acestur botanist. cel dial doublea colectiunea plantelor din Transilvania a lui schur. in tine. pe D. I. A. Kíntp

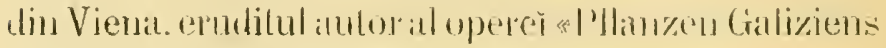

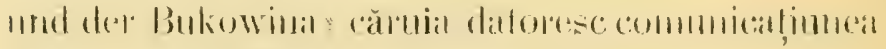
ritol-ral date bibliogralice immorlantle.

\author{
Dr. 1). Brander.
}

Bucueresce, 10 Nocumbir, 1959. 


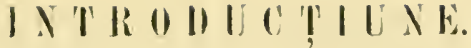

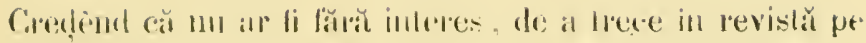

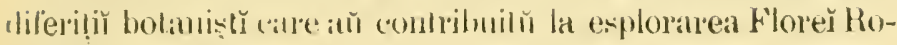

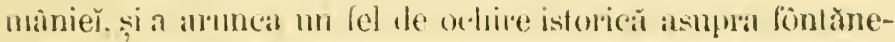

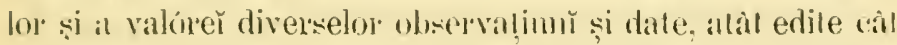

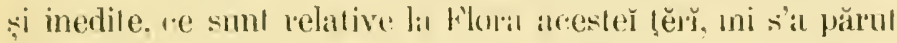

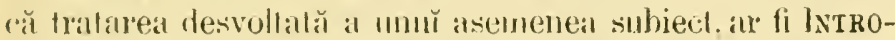
Decpunes cea malı̆ interesintă și mil̆ ulilă ce s'ar putea face Prodromeruí Frore Romáe. În espunerea acésta voiŭ urma. pe cât se pơte; ordinea chronologică. '

Nı voin face de càt a mentiona, relațunile cu privire la

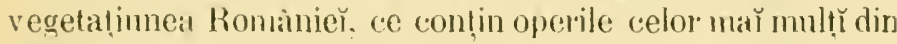
scriitorĭ ce aй descris !éla nostră. să̆ ă lratat despre ea din vre-ın puncl de vedere ire-care, răcĭ aceste relațiunĭ.

(1). DR. А. Feти (Incercarile facute pentru desioltarea sciintelor naturule in Romûnia. An. Soc. Acad. rom. seria l, tom. V, sect. II, 1873, pag. 11-3i3 și 7i--80), este prinul autor, căruja ratorim cele

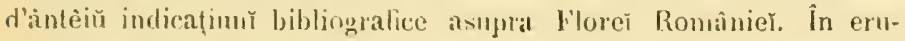
dita lucrare a acestır invĕţatŭ, se vĕd menționaţi întrun rrod su-

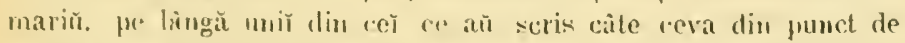

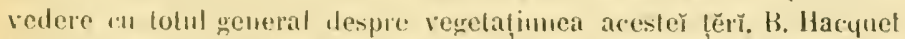

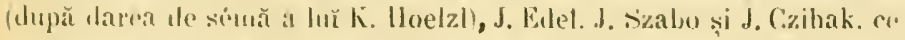

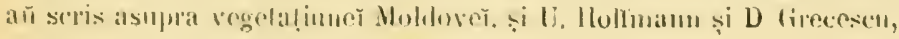

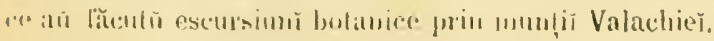




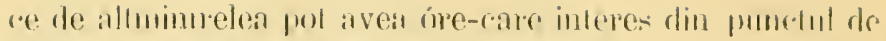

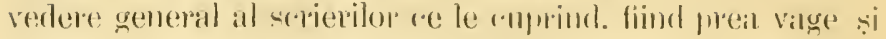

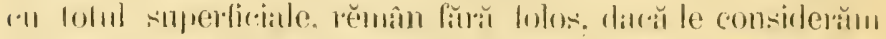

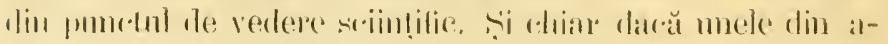

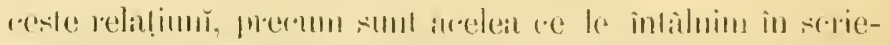

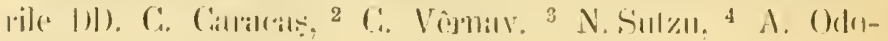

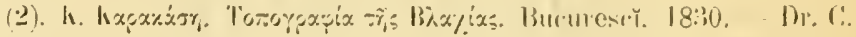

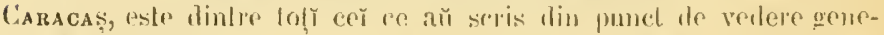
ral despre Valachia, arela rarr. alsslrartimue făcônul te inconve-

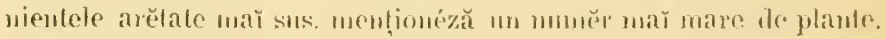
și care prin acéslit, ar da și iflecia cea may esaclă despre regetaḷiw-

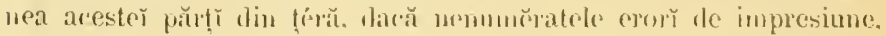

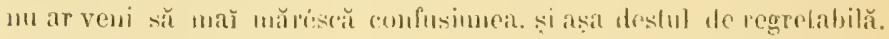

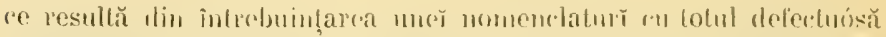
si arlesea făurilă dre el. Numčrul total al plautelor mentionate de

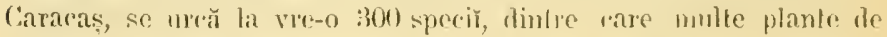
c:ultură. streine Florcy uóstre (1. с. pag. $80-116$ ).

(3). Das. C. Vêrvav. Retulimentum Pheysiographice Moletucire. Budre. 18:36. - Dr. C. Vìnar je lângh diverse dale privilion la in-

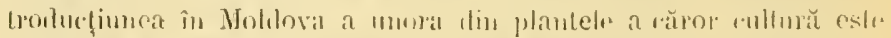

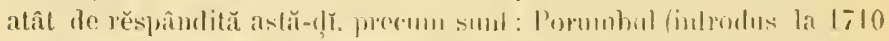
de Principele N. Mavrocordal), varielalua de Meiŏ un fruel roșu (iu-

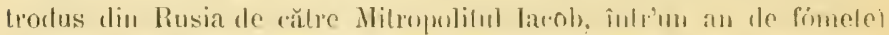

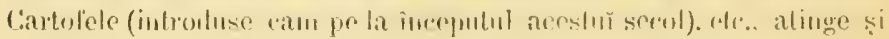

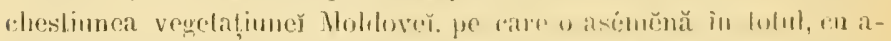

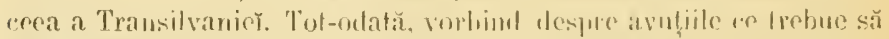

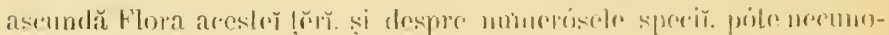

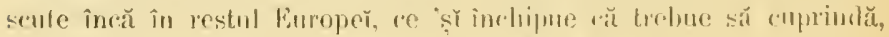

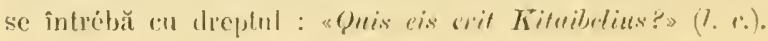

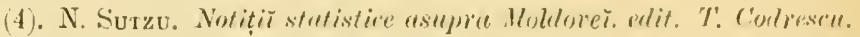
laș̆, 1852. - Relativ la produrele veçelale ale Moldover. af́éstă

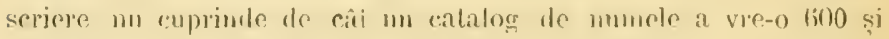

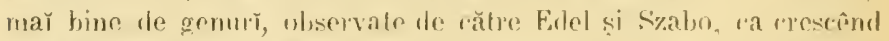

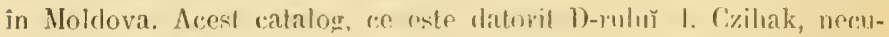

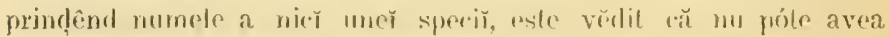

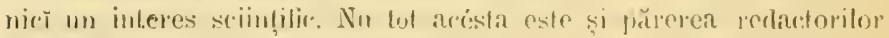

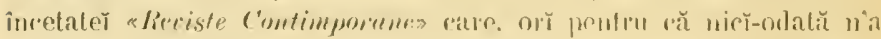

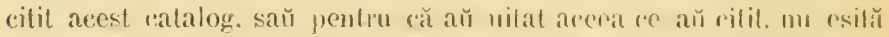

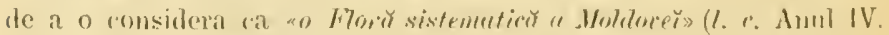
pag. 335). - Catalogul M.julur Cizilak se allă reprodus și în Mr- 


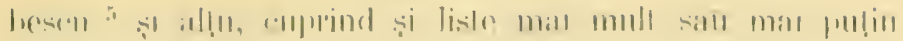

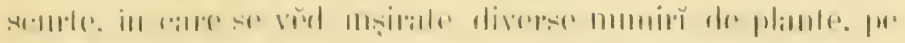

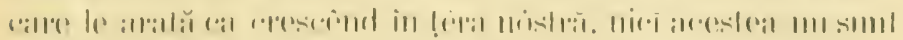

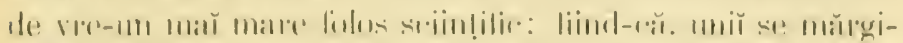

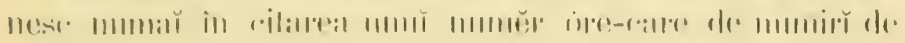

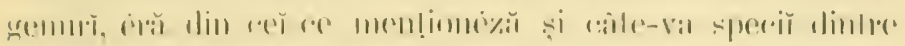

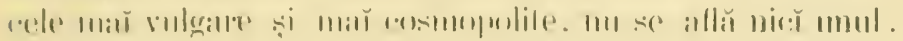

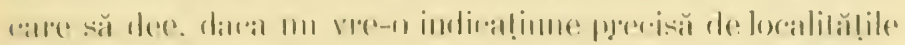
mome le-ill ol

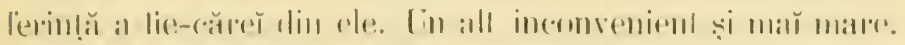

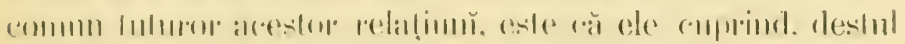

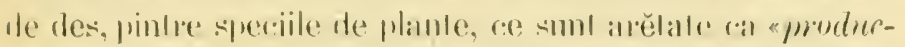

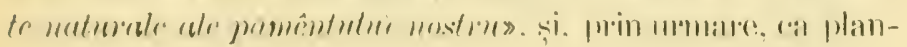

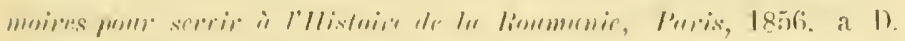

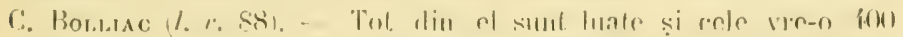

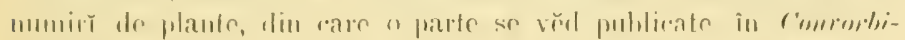

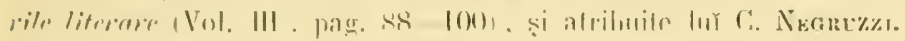

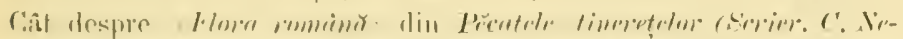

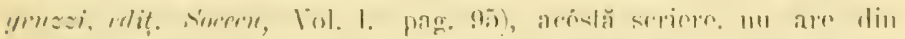

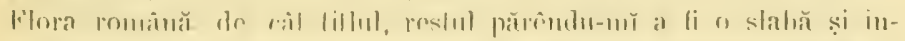

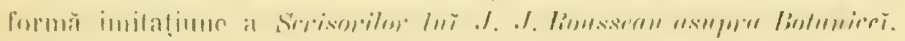

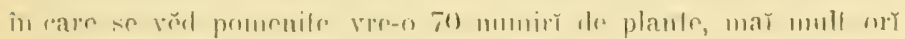

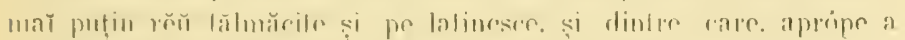

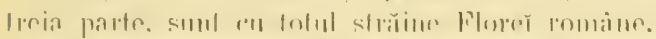

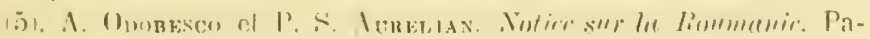

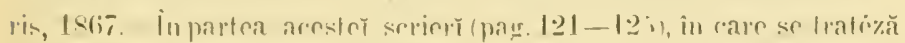

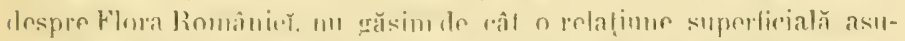

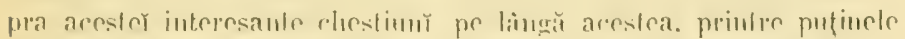

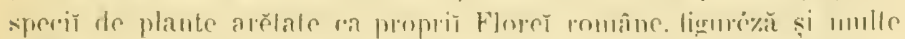

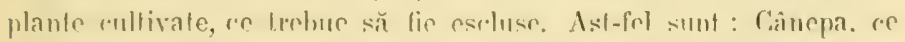

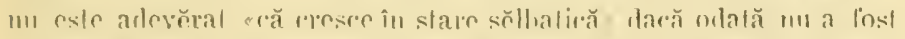

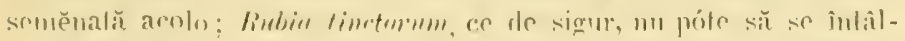

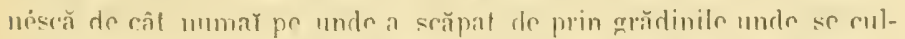

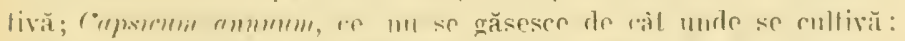

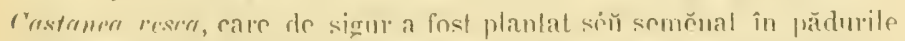

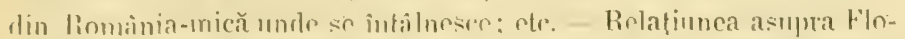

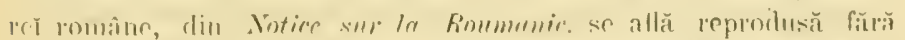

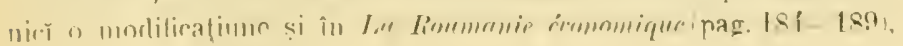

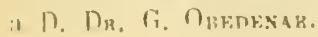




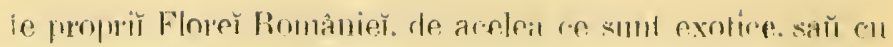

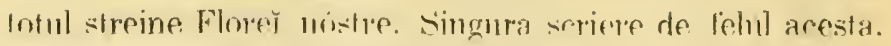
aure, de şi nefraband de rât bot rlin puncl de verlere gene-

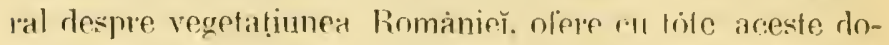

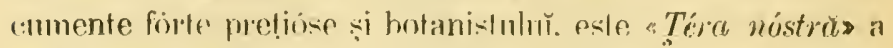
invĕtatulı̆ men̆ amic și ‘nleg 1). I’. š. Amºlianu. Variatele

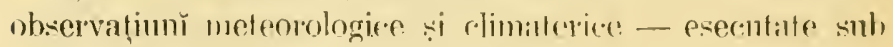
rontrolıl sever al inteligenter sale direrțiunı̌ - re cuprinde acéstă nperă (pag. 26-34), nu mar̆ puṭin cût și interesantul capitul relativ la pădurile; fönefele și păsiojunile Româniě (pag. 109-119), constitue inl atiteil date firte importante si a căıor ulilitale este nerontestahilă. "

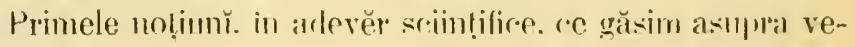
getaţiuner̆ ţĕrĕ̌ nostır. sunt rolative la Nolılıva numă, si Je datorim lı̆ B. Harefuet. ${ }^{7}$ "ate în aniü 1788-1795 călĕtori

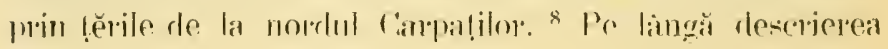

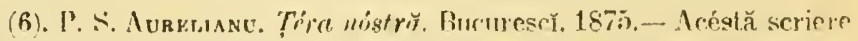
coprinde şi ea, n relaţíume specială respre productele regetale na-

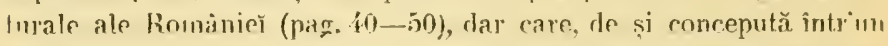
und cu mult mat seiintific, de cât acelca din operile precesteate, cour-

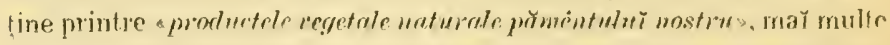
speril cultivate, ce sunt streiue Flnjer innàne, și carp trebuesc escluse. Ast-fel sunt: Zambila, Comirndram satimu, Comrolvulus tricu-

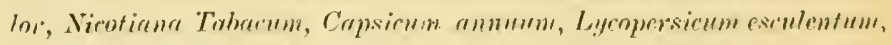
Snlaunu tubrvosum, Digitalis punpuren, Orimum hasilirmm, Artemi-

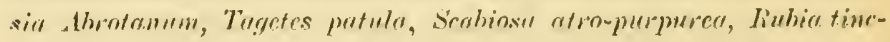
torum, Calosin rristato, Cammbis satira, Burus semperrirens.

(i). Baltuasar Hacquet, magistru in Philosophie și Doctor în medicină (născut la Metz la 1739, mort la Viena la 10 Iamuariŭ 1815), fiı mal̆ ântâin̆ chirurg militar în armata francesă, după aceea prolesor de anatomie si chirurgie la Lỵceul din Leibach, éră de la 1788 profesor la Lemberg. Scrierile sale, relalive mă cu sémă la medicină și mineralogie. sunt fỏrte numeróse (K. Hoelzl).

(8). Ds. B. Haceuet. Neueste physikaliseh-polytisch Reisen dureh. die dacischen und sarmatiselew oder worllichew Karpathen. Nürmberğ, 1790-96. \&. Theile. - Am vĕd̦t acest np (devenit astă-d] cu

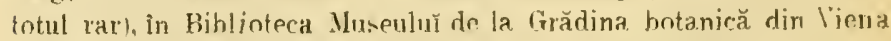

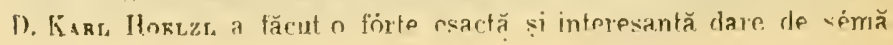




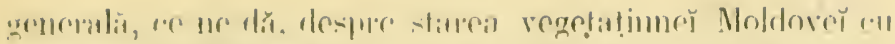

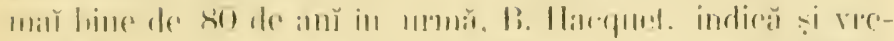

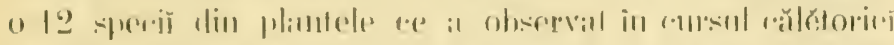

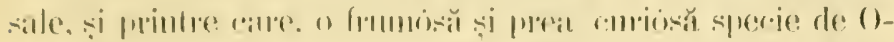

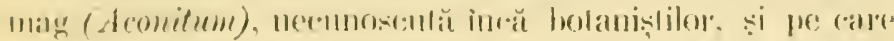

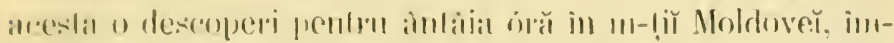

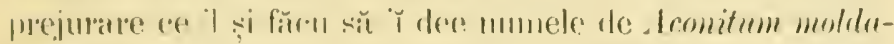

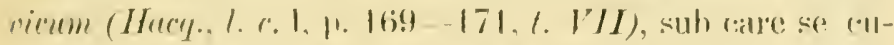

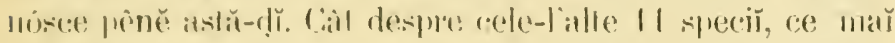

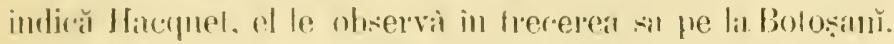

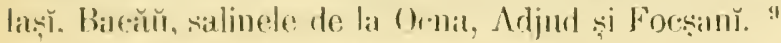

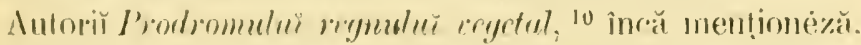

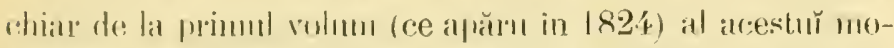

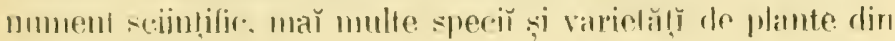
Holdovit. ${ }^{11}$

Penflu a da insă, peste ohselviltiuni mati romplete a-

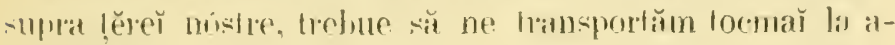

desple Lótă partea hotanică din acéstă scriere (Vorhand. der zool.

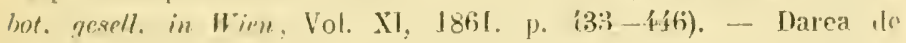

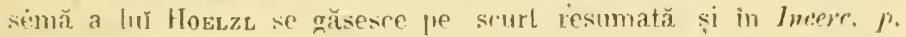
descolt. ser wat. in Tiom. a D. Dr. A. Feru (l. c. 79).

(1). Plantele observate de B. Hacesers, sunt : la Botosaní, (onimin

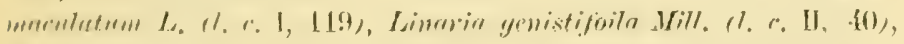

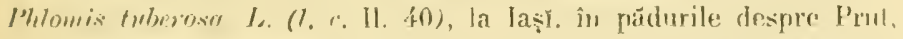

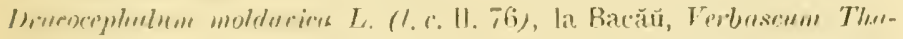

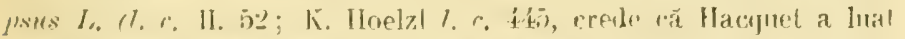

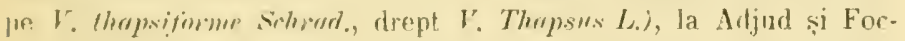

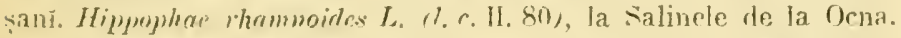

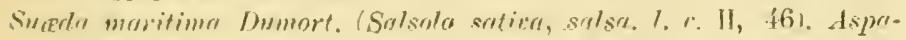

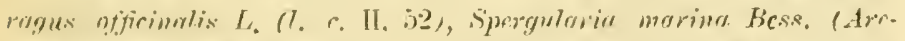

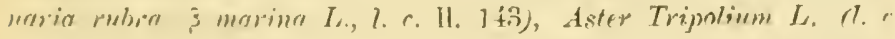
(1. 149). Plantagn maritima L. (1. r. II. 149)).

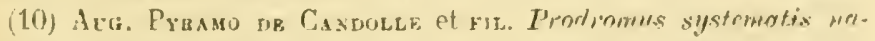
teralis regni irgetabilis. 1821 , etc.

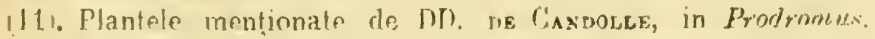

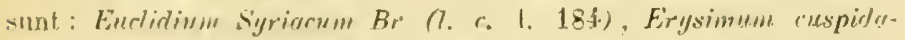

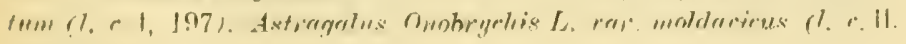
2atis, etc. 
mil 18.5.5. rand, aflüm pe acelea ce ne-it remas de la .1. E-

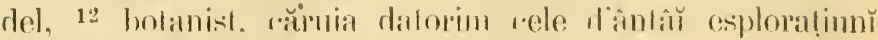
sistemalice asmpła vegelalimney diverselor regimn ale Moldově, pe rare o și divide din aresil puncl de vedere, înlro

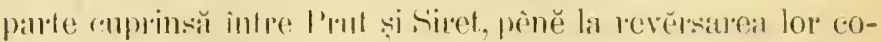

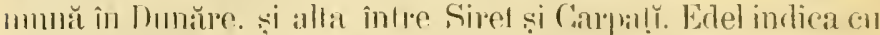
deamĕpmulıl hole speriile de plante re a observal în fie-care

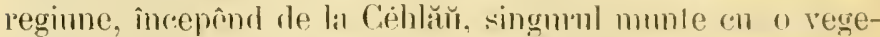
Lațimne alpună proprie, și de pe care a recoltal 202 specoŭ de

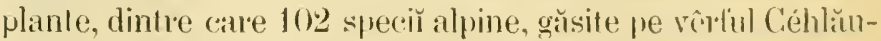
lni. ${ }^{13}$ éră restul in reginnea inferiónă a aceshur munte. 14

(12). Jutus Enes. Bemerlungen über die Vegetation der Moldau, uach eigenen im. Irhre 19.35 gemarhten Beobnehtungen enturorfen.

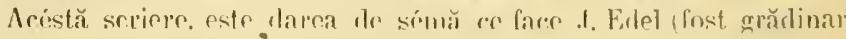

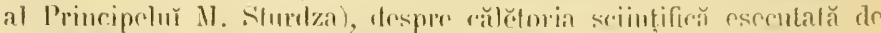

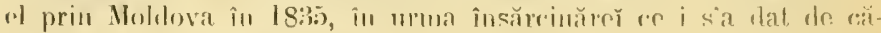

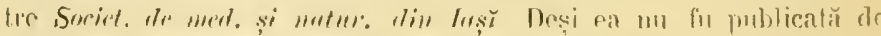

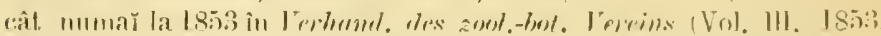

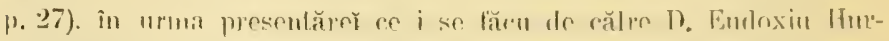

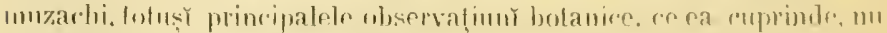

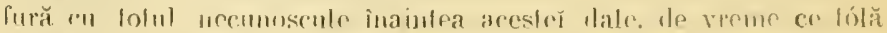
rolerfimuea plautelor abuuate de bilel in enrsul escursiunci sale. fu

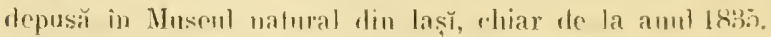

(1:3). Sperible de plante indirate de J. Euva pe verful Coblatulur,

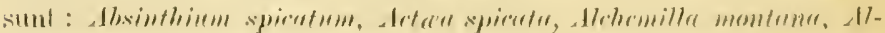

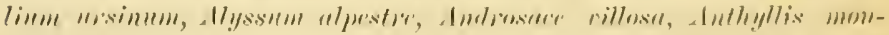

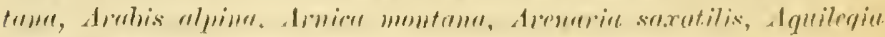

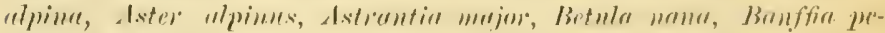

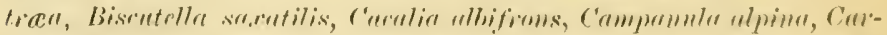

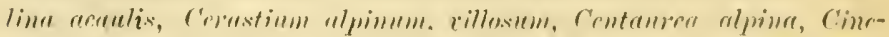

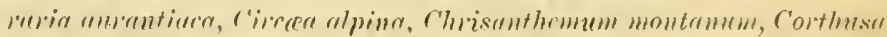

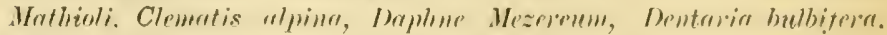

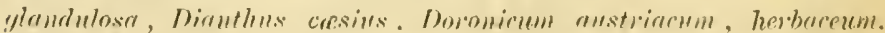

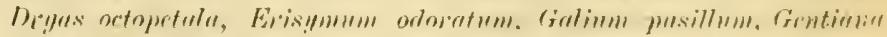

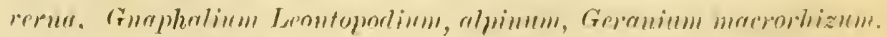

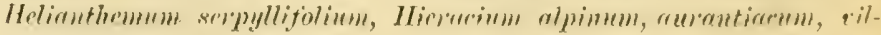

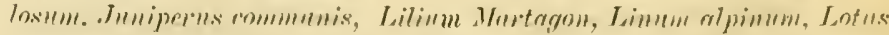

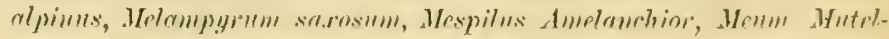
lina, Mynsotis alpestris, nana, Oralis Acetosella, Onobrychis montenu, 


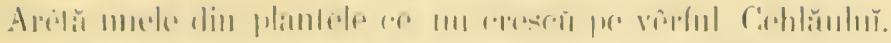

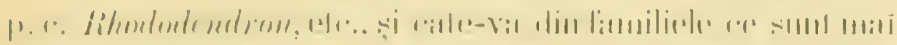

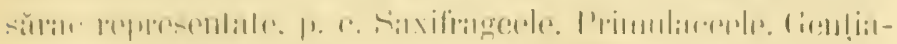

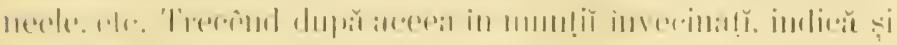

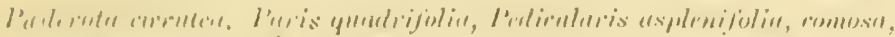

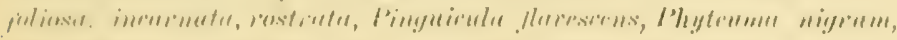

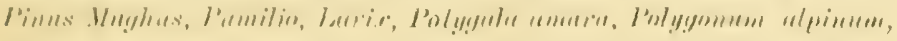

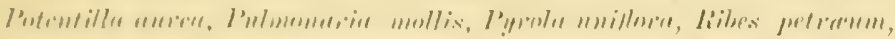

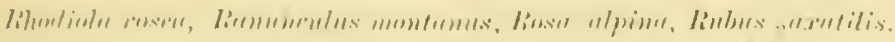

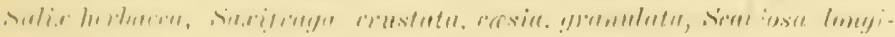

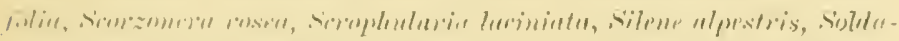

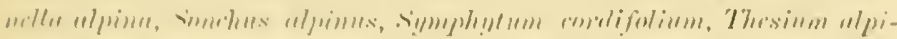

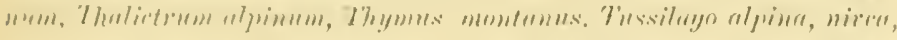

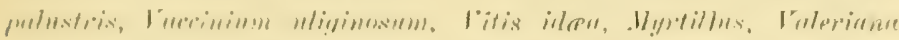

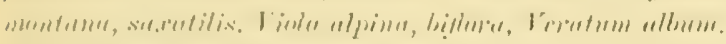

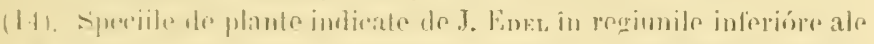

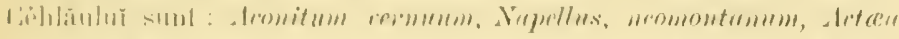

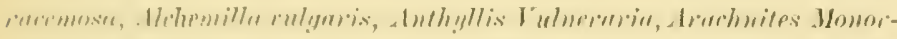

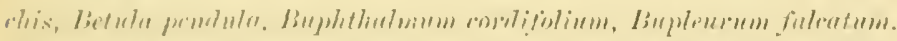

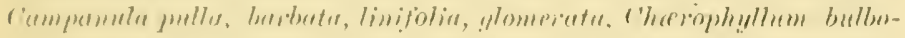

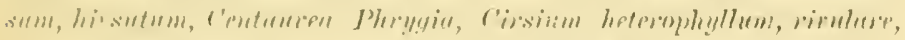

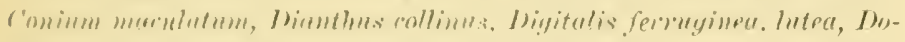

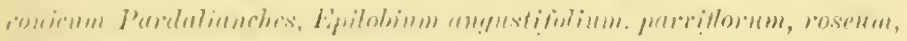

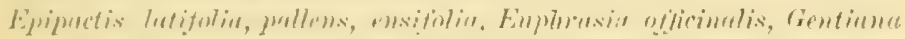

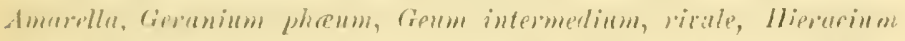

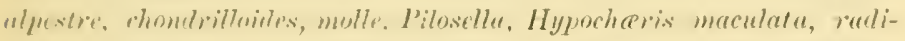

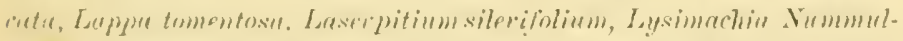

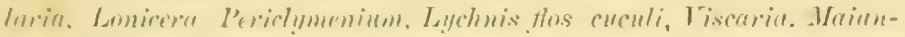

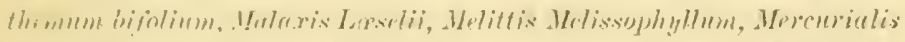

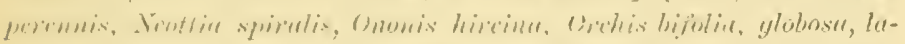

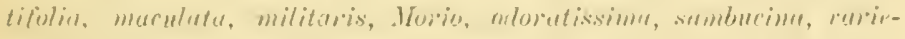

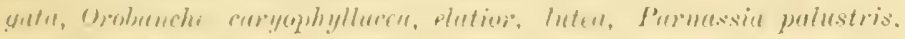

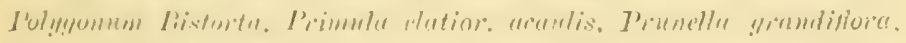

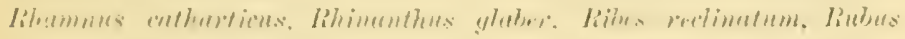

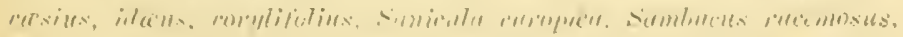

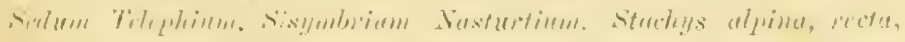

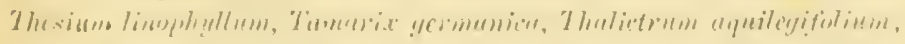

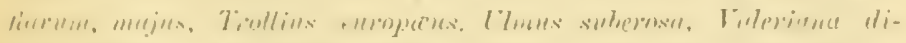

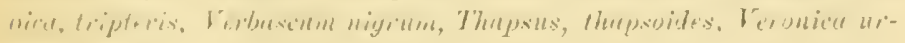
ticeptolir. 


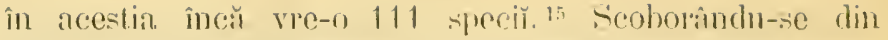
mmulĭ, Edel, rope ce arillă schimbarea dle regetatimne re se

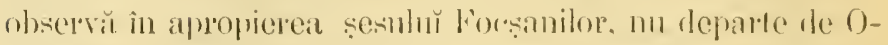

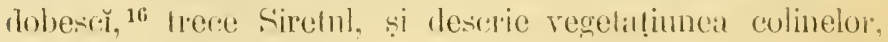

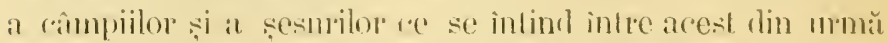

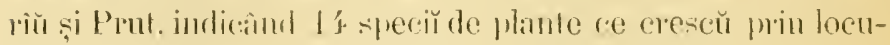

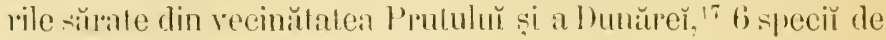

(15). Speciile de plante moticate de J. Enes în cč̌l’alţı ınunţ̧ ă Holdovĕ, sunt: Achiller magmu, Acomitum Lyeortomm, ditoxa Mo-

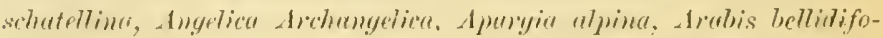

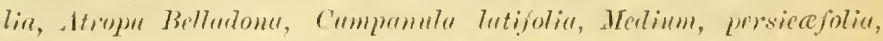

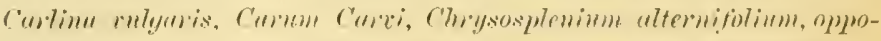
sitifolinm, Cirean hutetiom, C'niens pulustris, Coldhicmm antummalm.

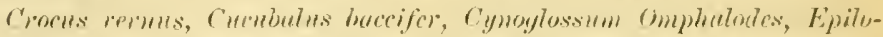

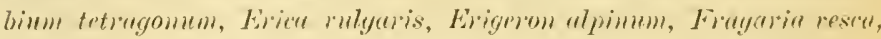
collina, Gentiuna acaulis, usclepianten, cruciata. luten, Glentiolus com-

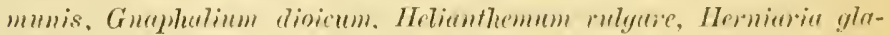

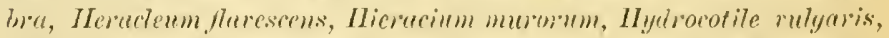
Inula IIclenimm, Isutis timetoriu, Lexcojum revmum, Lignstienm hevisticum, Limen cutharticum, Loventhus europeus, Lotus comirnletus, Lunaria redicire, Lyghnis syllestris, Iycopms ruroprens, Ly-

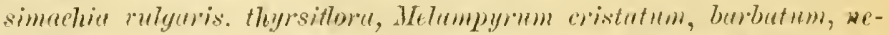

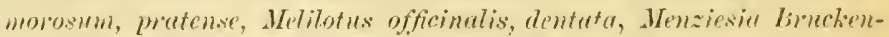
thalii, Mysrhis oforatu. Nepeta meda, QEnothere biennis, Orobus. vernus, rarius, niger, Mhysctis Alkekenyi, Polygonum amphibium.

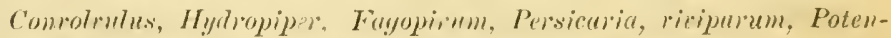
tillu intermedia, Pyrola secunda. Rammenlus uronitifolius, lamagino-

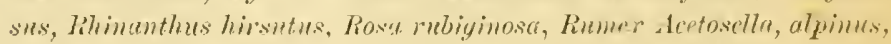

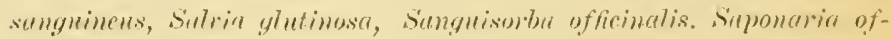

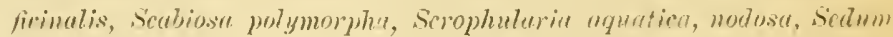

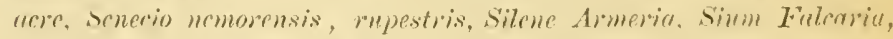

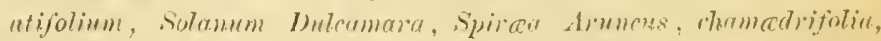
filipenlula, nlmifoliu. Toimentillu esectu, reptans, Trifnlium alpestere, montamum, ochroleusum, pumonicum. Thessilago Earfara, P'etasitas,

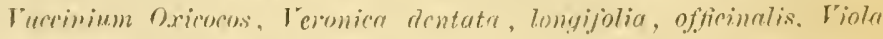
hivtu, Piscagn glutinose, Otites.

16). Speciile de plante găsile în aceste locurŭ, sunt: Tamario.

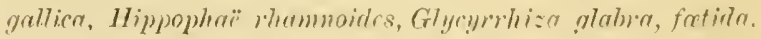

(17). Speciile de plante ce erescŭ prin lncurile sărate din recină-

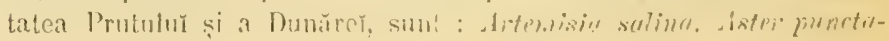




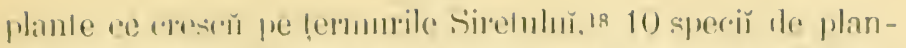

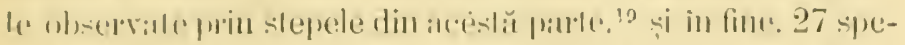

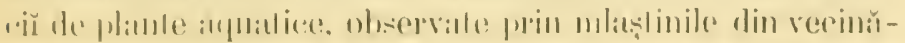

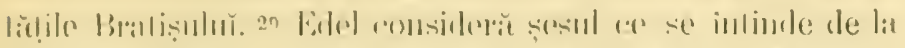

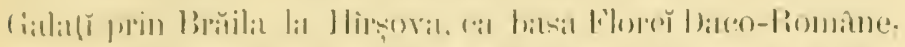

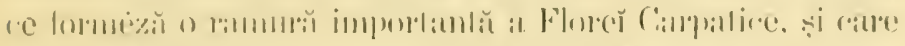

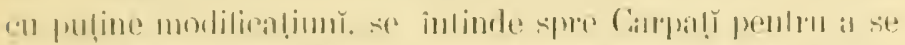

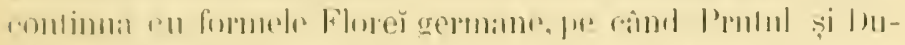

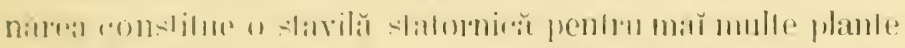

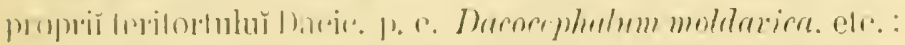

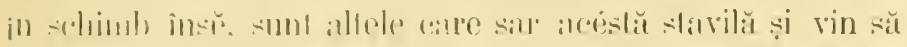

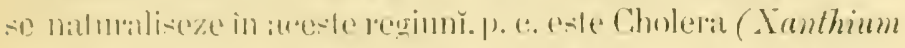

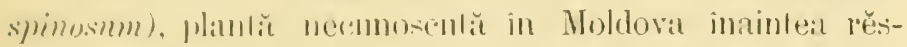

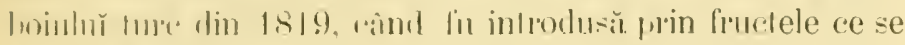
allaù acĭlale de cómele i modile eailor Cazacilor. ${ }^{21}$ Din

tus. Tripolinm, Ativiplex littoralis, mueronatu, Chenopodium maviti-

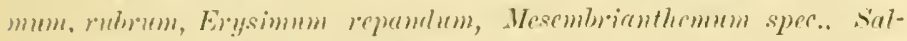
sola prostrata, Luli, lamuta, sintire Limonium, Salicormine herbarea.

(191. Speriile de plaute ce eresen pe țérmurile Siretului, sunt : As-

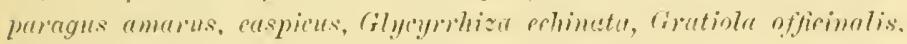

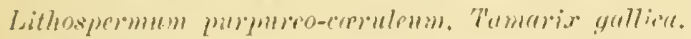

(1). Spcciile de plante ce crescr̆ prin stepele din aréstă parte. sunt : Adonis estimalis, Ajugu chamapitys, Androsure flongata. Are-

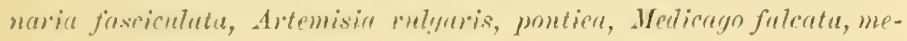
dire, minimu, P'olyenemum arrense.

(20). Speciile de plante aqualice ce ereseŭ prin inlaștinile din veci-

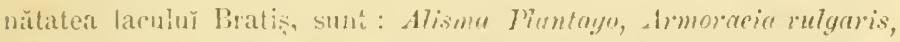
Billens tripartitu, Butomus umbellatus, Cultha palustris, Cieute rirosr. Epilnbium grandiflorum, Euphorbiu palustris, lris pseudacorus, Lythrum Salienrin, Wonthe aquaticu. Symphcen ulba, lutece, Phellambrium rquaticum. lianumculws Lingua. pencedanifolius, sceleratus, Sagittaria sugittifolia, strutiofes alohles. Triglodhin pralustre, Teronice Berrabunga, Anagullis, scutullatr.

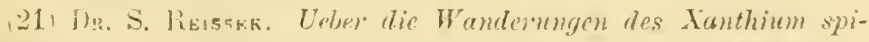
unum. - D. \& Reissek raportéză in acéstă luerare (Virhand. d

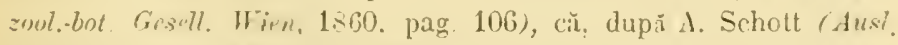

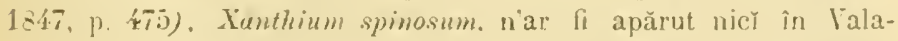

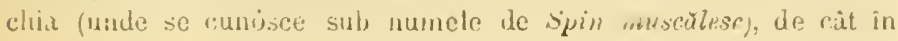




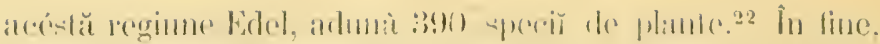

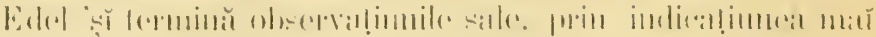

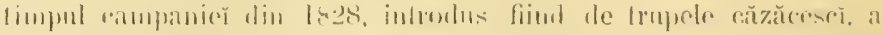

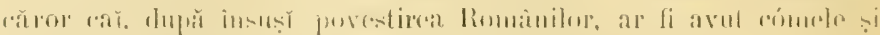

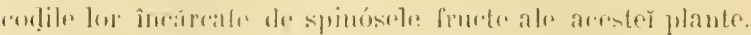

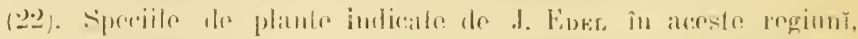

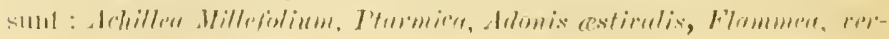

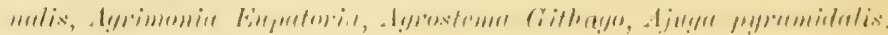

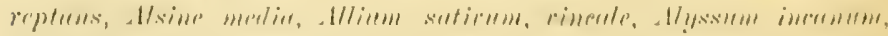

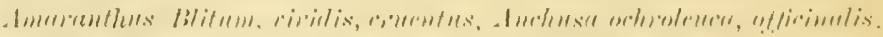

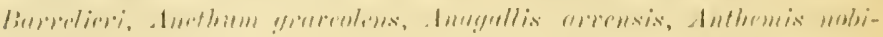

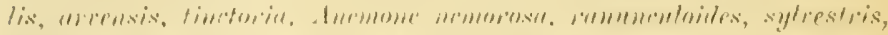

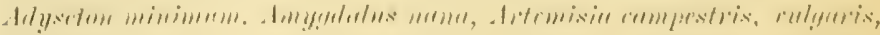

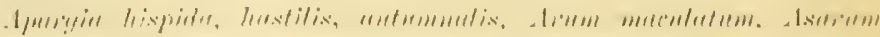

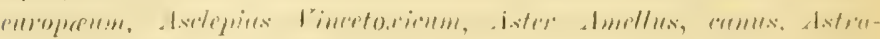

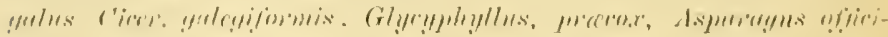

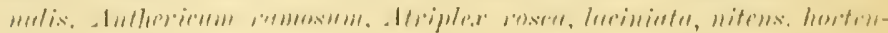

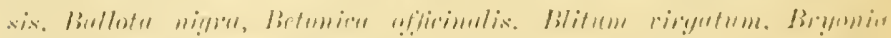

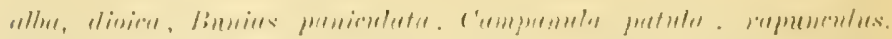

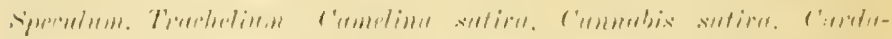

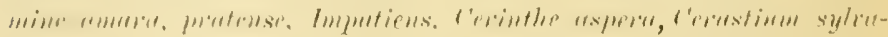

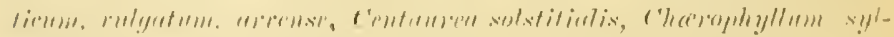

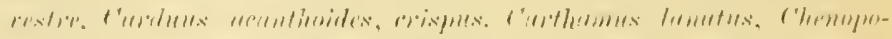

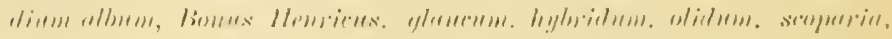

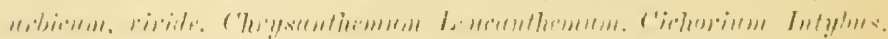

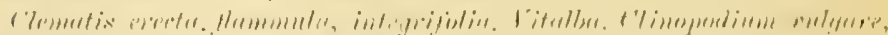

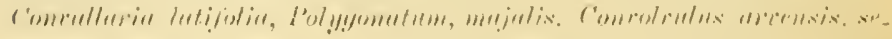

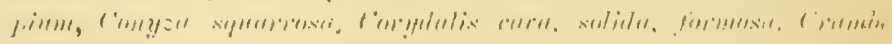

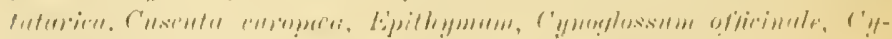

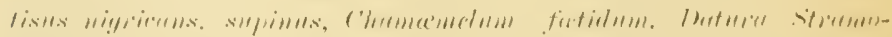

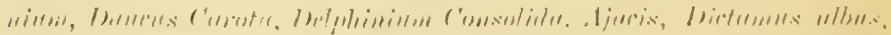

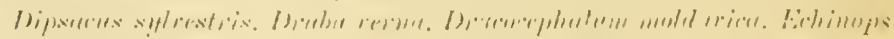

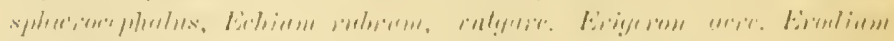

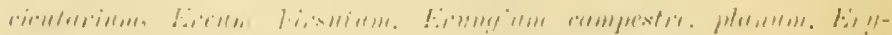

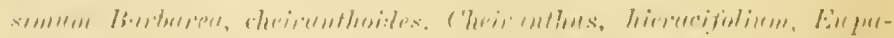

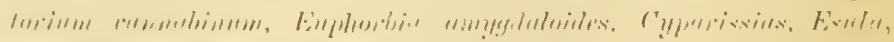

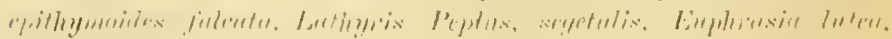

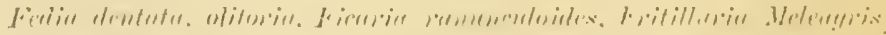

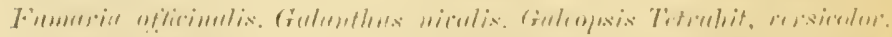

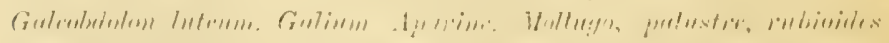

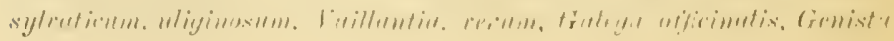




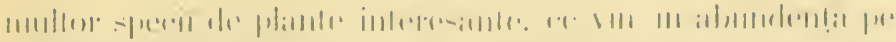

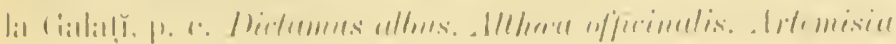

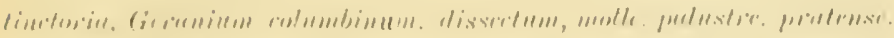

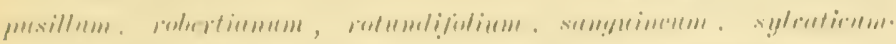

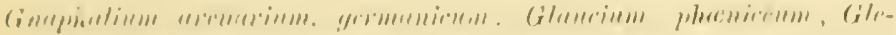

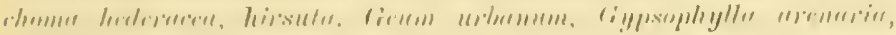

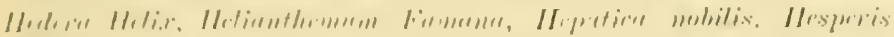

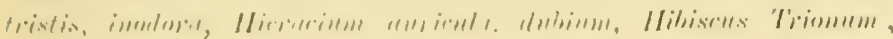

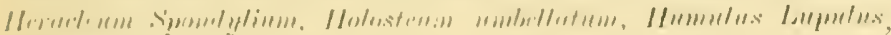

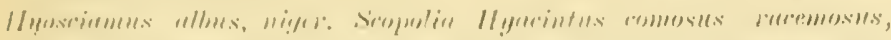

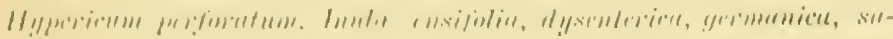

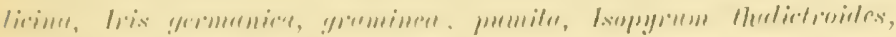

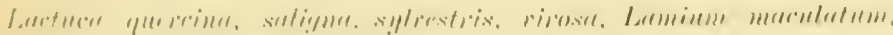

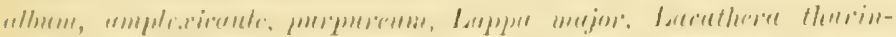

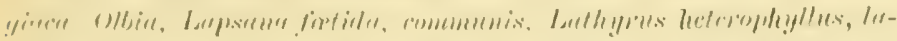

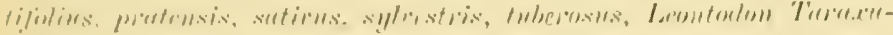

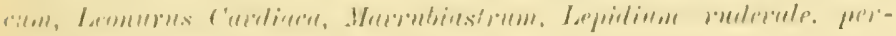

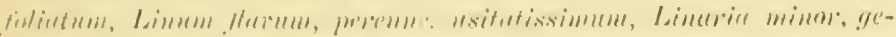

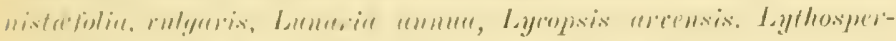

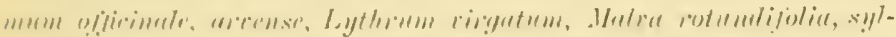

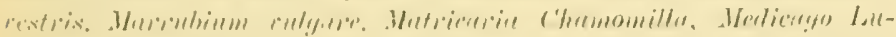

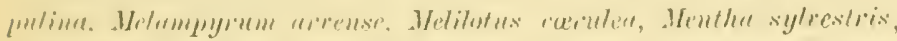

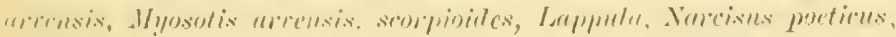

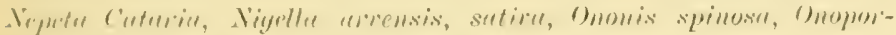

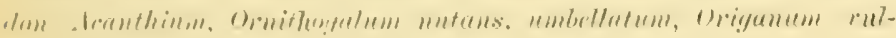

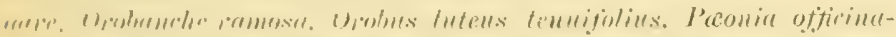

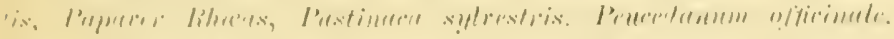

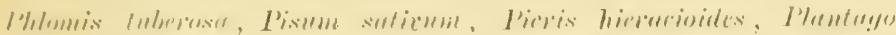

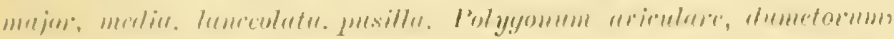

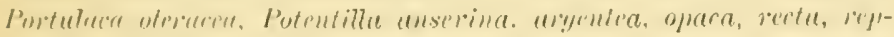

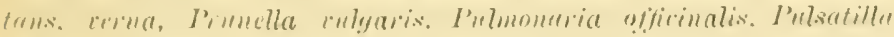

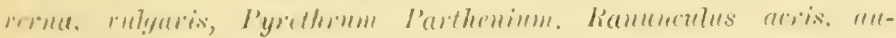

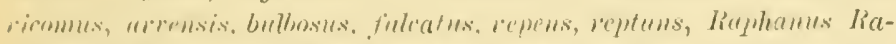

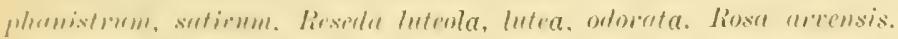

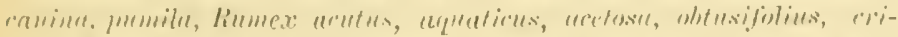

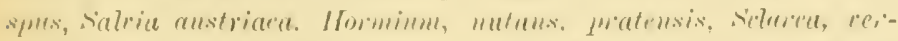

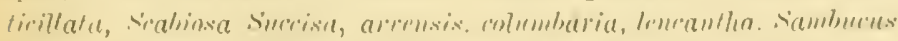

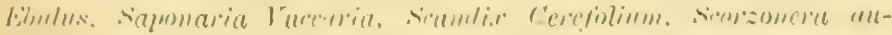

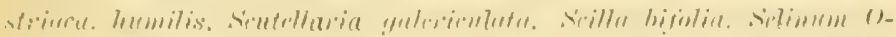

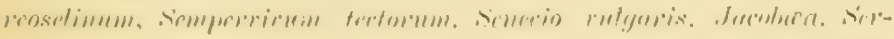

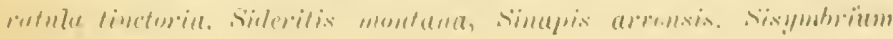


pontica, iulguris, elc., şi is unur specil dintıc plantele sociabile cele mă̌ frequente în regiunea dintre Prut și Siret, precum și a vre 100 speciǔ de arbor și arbuștr̆, ce cresc în pădurile Moldovel. ${ }^{23}$

Al donilea an după escursiunea lŭ Edel, Dr. J. Czihak publică sub titlul Flore moldavice species ac generu hucusque cxcursionibus exploratu ac secundum Linnei systema ordinatu Mus. Maji, 1836; 24 o enumeratiune a 1116 speciǔ de plante culese din Molrlova, ce compun erbariul Museuluŭ din laş̆, și

Columnae, Alliuriu, officinale, strictissimum, Solumum vulgatum, nillosum, Sonehus avensis, oleraceus, stachys sylratica, germanica, palustris, symphytum afficinale, tuberosim, Stcllarin Holosteu, yrominea, Tamus communis, Tanacetum melgave, Teucrium Botrys, Chamodrys, Thlaspi arvense, allinceum, campestre, montamm, Bursapastoris, Thymus serpyllum, lamuginosus. Thagopogon pratensis, undulatres, Tribulus terrestris, Trifolium hybridum, repens, protense, arvense, resupinatum, fiagiferum, campestre, procumbens, Turitis glabia, Virtive niens, dioica, Vaillantie glabia. Vulerienu officinalix.

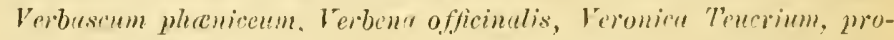

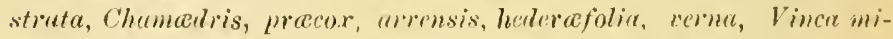
nor, herbaen, Vicia Cracea. Iumetaram, Tiscum, album, Viola orlorata, canima, bicolor, tricolor, Vitis Laburesca, vinifera.

(23). Speciile de arborř și arbuștr indicate de J. Eofr in Moldova : Alnus glutinosa, incana, Amygdalus communis, Persica, Betulu alba, Cornus mascula, sanguinea, Cratagns Oxyucantha, nonogyna, Carpinus Betuius, Corylus Acellana, Cydoniu vulgaris, Eronimus verrucosus, latifolius, Fraximus excelsior, Ornus, Fagus sylvatica, Juglans regia, Ligustrum vulgare, Lonicera alpigena, I'opulus ulba, nigra, tremula, Pliludelplus coronarius, Prunus Armeniaca, spinosa, institia, domestica, Palus, avium, Corasus, Pyrus lomestica, Malus, Pinus sylvestris, Cembra, Picea, Abies. Quercus Robur, pedunculata, Cerris, Rhamuns saxatilis. Frangula. Rhus rotinus, Ribes Grossularia. Uea erispa, Rosa lutea, collina, Rubus nemorosus, finticosus Robinia Pseudecacia, Salix Vitellina. pentandra, fragilis, accipiens, Helix, cincrea, caprea, riminalis, alba, Sambucus nigra, Sosbus Auenparia, Staphyllea pinnata. Syringa vulgaris, Tilia parvifoliu, yrandifolia, tomentosa. Taxus baccata, Viburmem Lantone, Opmlus.

(2'). Flor(, odcr ally. bot. Zeit 1836, II (Beiblätter zur allg. bot. Zeit. p. $58-74)$. 


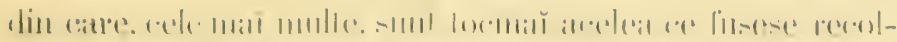

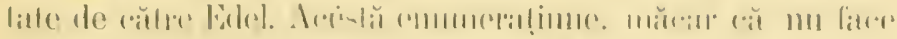

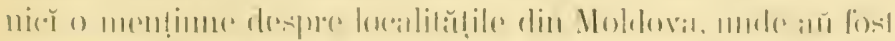

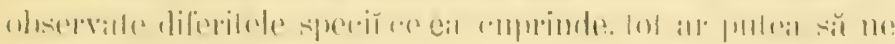
-

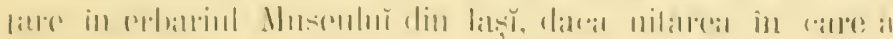

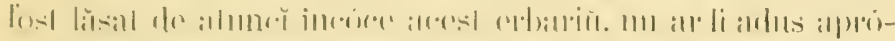

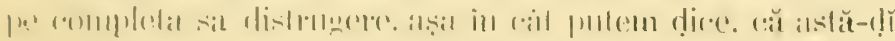

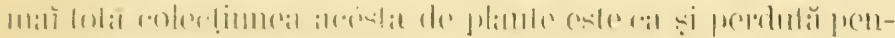

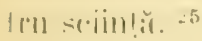

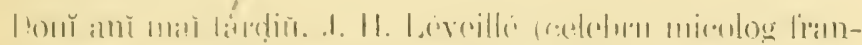

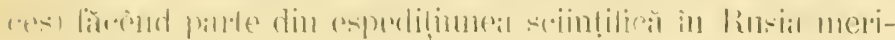

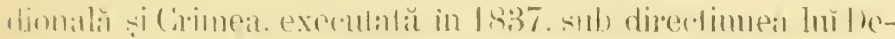

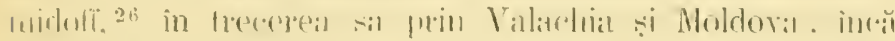

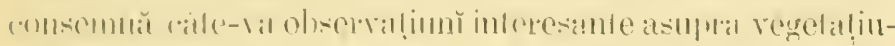

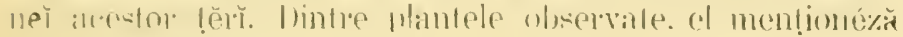

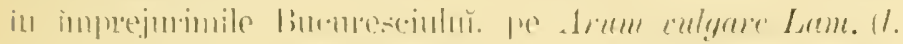

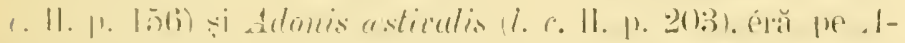

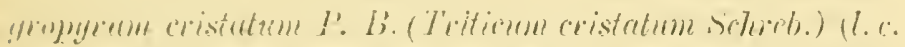

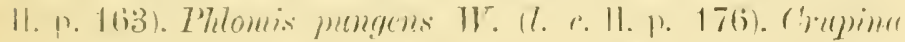

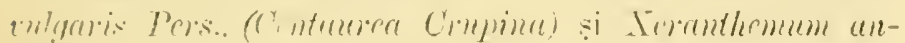

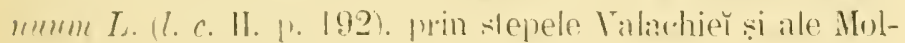
tover. anoperind inlindery̆ considerabile.

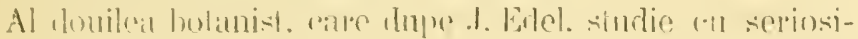

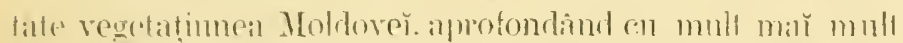

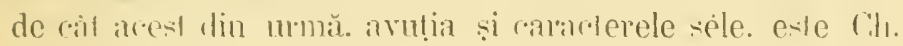

(25. In luna luy̆ August trecuf, profitând de șederea mea iu timp de câte-va ḍile la Iaș̆. am voit să vĕd plantele lır̆ Edel din mı-

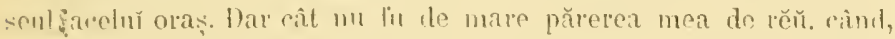

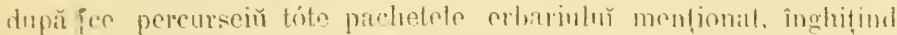

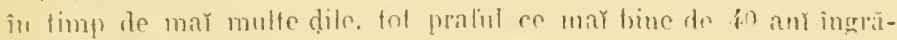

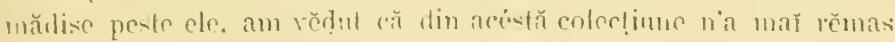

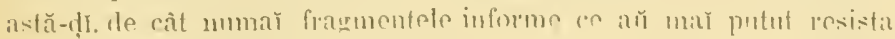
îneă voracitătẹ insectelor.

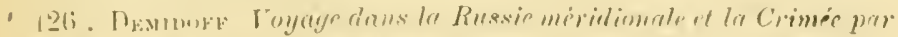

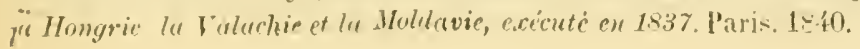




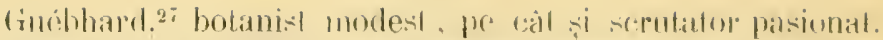

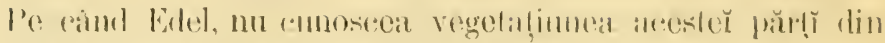

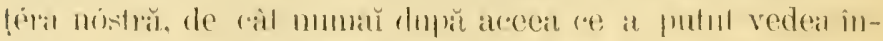

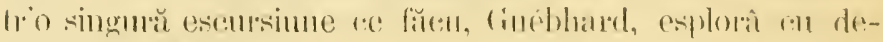

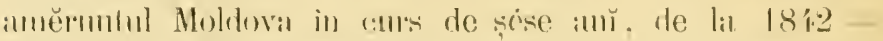

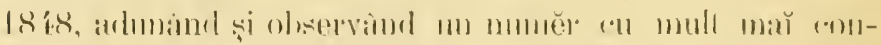

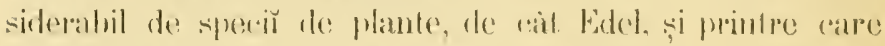

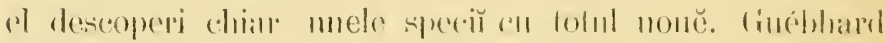

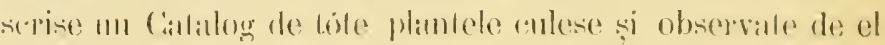

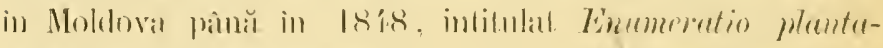

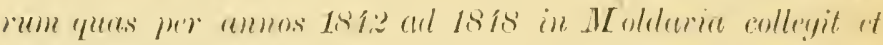

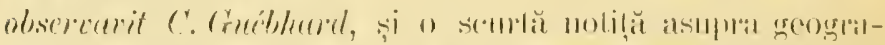

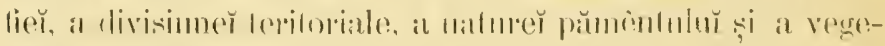

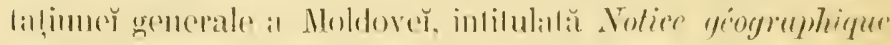

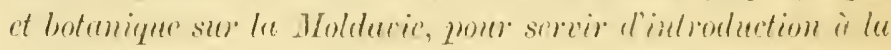

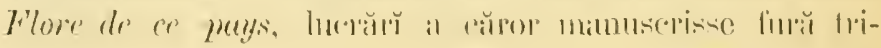

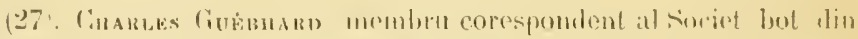
Menburg (Saxonial), nativ diu Nouchatel și fiŭ al umur fostadminislràtor general at Loterio regalo din Neapoli, de și dedal eomortulur ma-

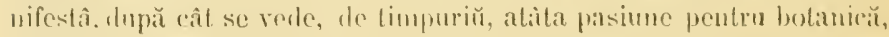
in rît, inc'ĭ de pe la 1812 (ne cinnl se găsea în Neapoli), 1 aflăn indro

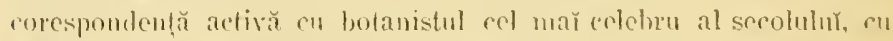

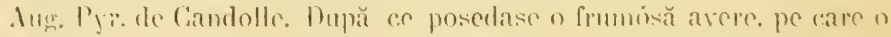

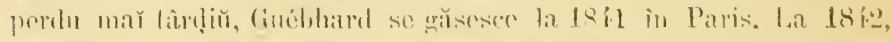

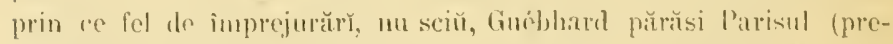

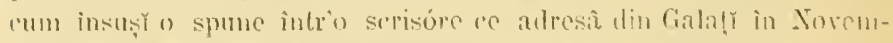

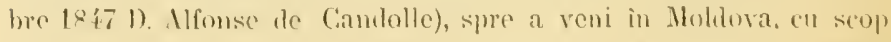

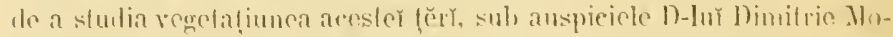

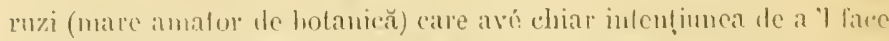

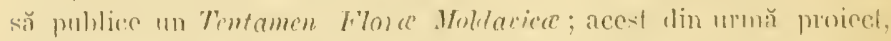

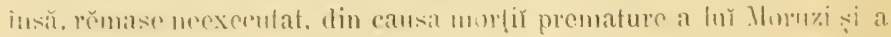

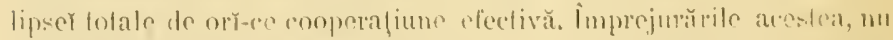

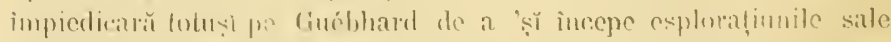

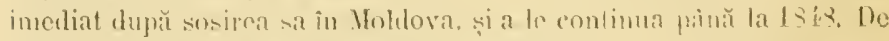

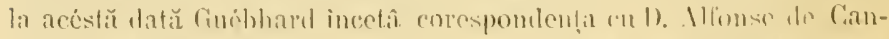

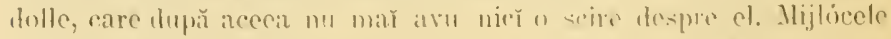

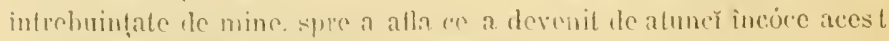
botanist, îwà aŭ remas lărăi nicì um resultil. 


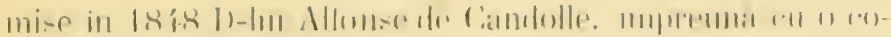

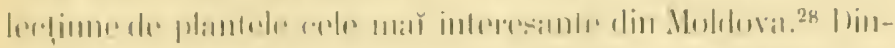

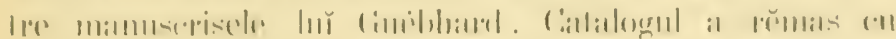

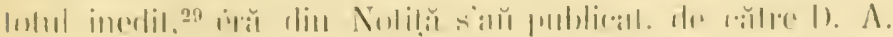

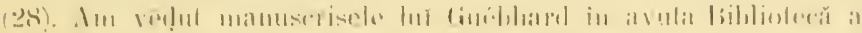

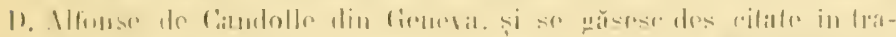

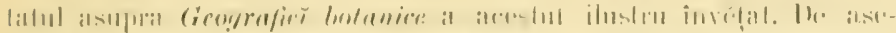

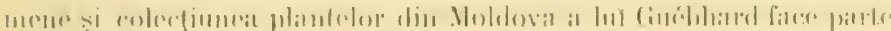

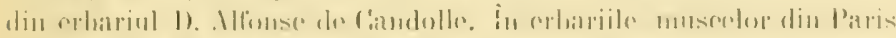

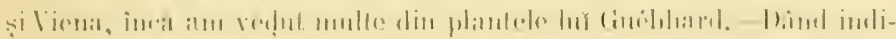

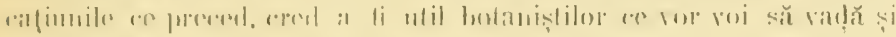

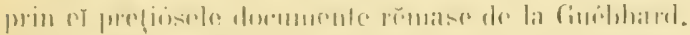

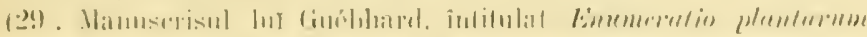

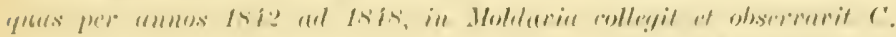

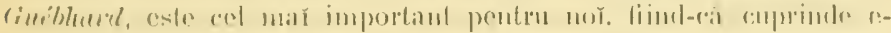

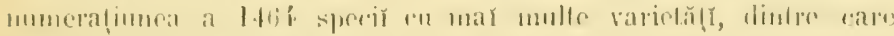

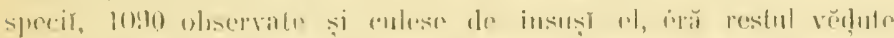

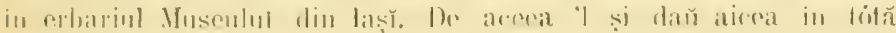

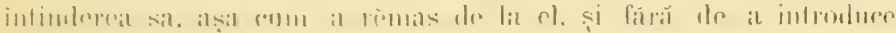

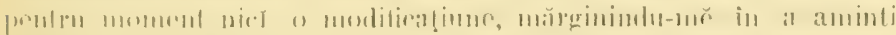

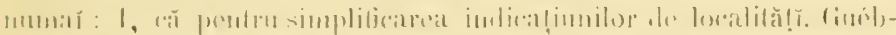

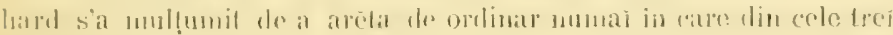

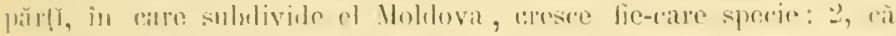

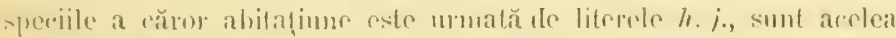

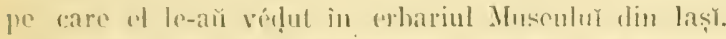

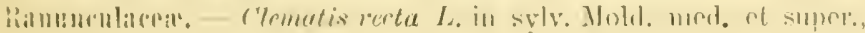

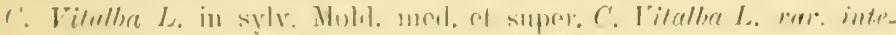

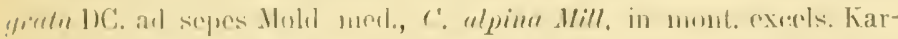

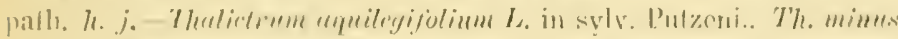

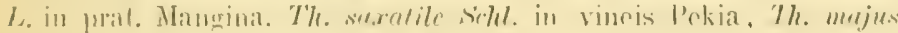

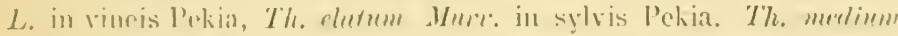

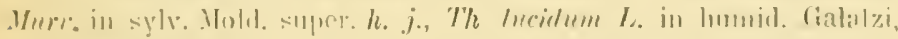

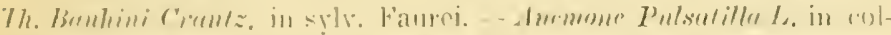

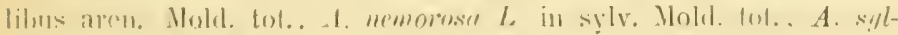

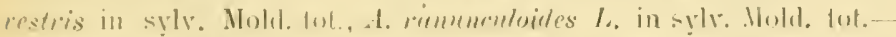

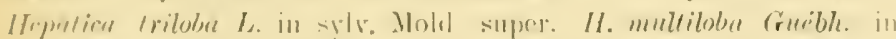

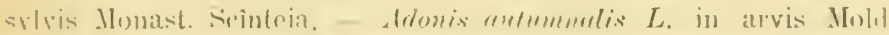

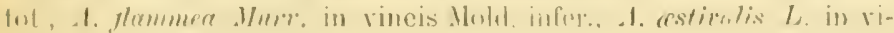

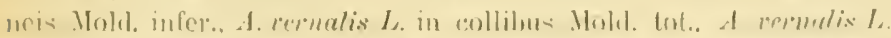
ras, syloutien Guehh. in syls. Molll, infor. - Myosorns minimus $L$. 


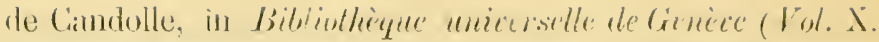

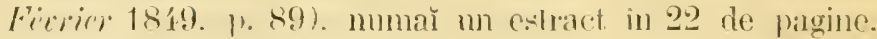

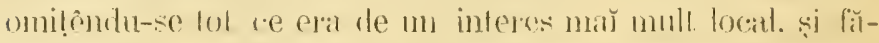

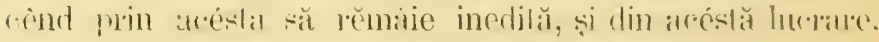

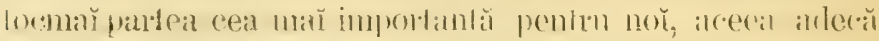

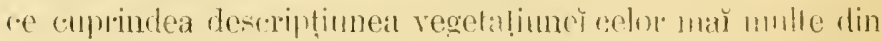

in palud. Mold. infer. Ceratocephalus whthocrese DC: in incultis et ael vias Mold. tot. - Renunculus aguatilis 1 , in aqunis Mold. Lot., R. aquatilis L. var. capillacens, in lossis Galalzi. K. aquatilis 7 . ret) cespitosus in humid. Galatz, $R$. perlutus fit. in palud hisco, $l$. Illyricus L. in sylv. Putzeni, R. Thor a L. in pasc. mont. Karpatls, l. j.. R. Lingua $L$. ad fossis Jassy, $L$. auriconues $L$. in sylyis Mhold. med. et super., R. sceleritus $L$, ad fossis Mold. tot., R. scelerutus L, cur: minimus in arenosis ad fl. Sereth, $R$. acris $L$. in pratis Mtolit. sirlrer., Ii. polycuthemos L. in pratis sice. Galatzi. Li. Stereni lies.s. in lumidis Mangina, R. nemorosus DC. in sylvis Putzeni, $R$. lanminosus $L$. in pratis Mold. tol.. $h$. Constantinopolitanus J)'Tre, in unbrosis J'ekia. R. phitonotis hit. in hmmidis Mold. med.. R. mmica-

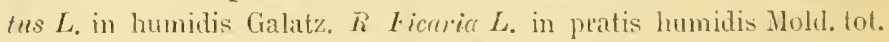
- Caltha pulustris L. all vivulos Mlold. med. et super. - Trollins europans $L$ in pascuis mont. Farpath. h. .. - Isopymm thalisteoi-

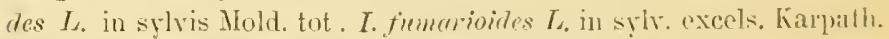
h. j. - Nigellu fonicularea DC. inter. sogetes Nolel. Iot. - Aquiegyia alpina L. in syls, execls. Karpath. h.j. - Deluhininm aconiti L. in arvis Molı. infer.. D. hybrillum Willd in sylvis Pekia. - Aconitum paniculatum Lam. in pascuis edit. Karpalh. h. i.. A. puniculatum Lam. var ermum I. C. in pase. edit Karpath. h. j.. . 1. Tapcl-

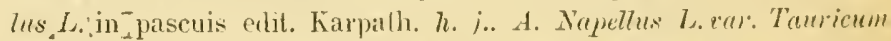
Ser. in pascuis edit. Karpall. h. j., A. neomontumm Keelle in pascuis edit. Karpath. h,j. - Aetea Cimicifuga L. in sylvis Moldaviæ superioræ $h . j . . d{ }^{7}$ spicate $L$. in sylvis Mold. super. $h . j$. Paonia officinalis Retz. in sylvis Molı. infer. et med.

Berberideir. - Betberis rulyaris $L$. secus torrent Mold. tot.

Sympheacer. - Nymplece alba L. in fluv. lente fluent Mold. med. - Nuphar lutea Simith. in fluv. lente fluent. Mohi. met.

Papaveraces.-Popaer alpimm L. in mont. edit. Karpath. h.j., P. flubium $L$, in arvis Mold. tot., P. Rharas L. in arvis Mold. Iol., $I$. somniferum L, cult, ad usus domest. - Glancium cormiculatum Curts in arvis Mold tol. - Cheliflonimm mejus L, in umbrosis Mold. tot. Fumariaces. - Coryglulis Marschalliana Pers. in sylvis Monast. A- 


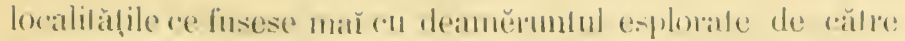

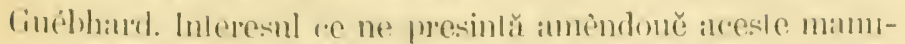

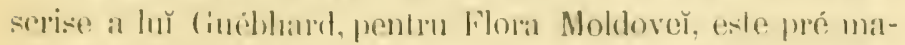

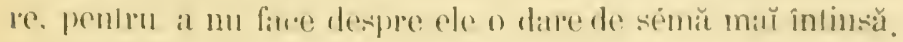

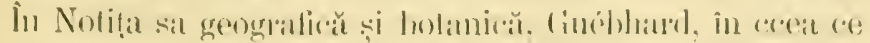

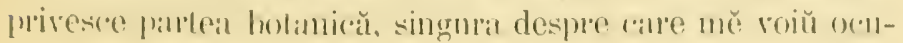

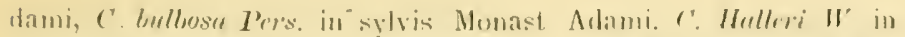

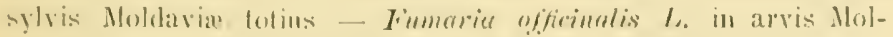

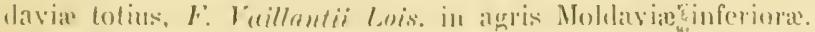

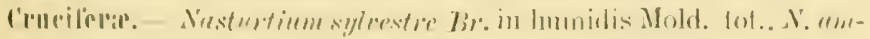

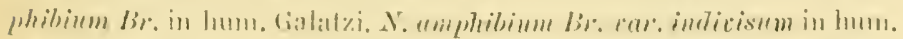

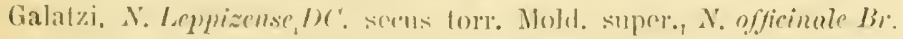

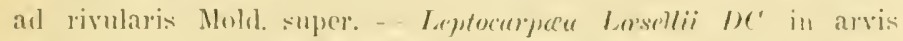

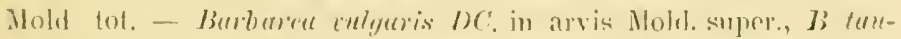

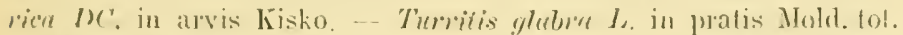

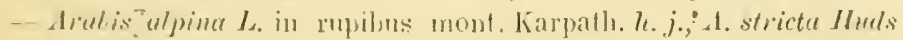

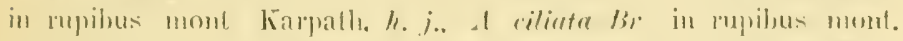

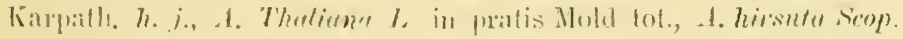
in arvensis Molel. super. $h$ j.. A. memila Hull. in saxosis Molel.

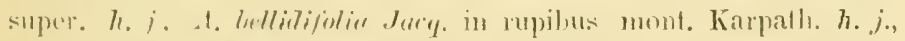

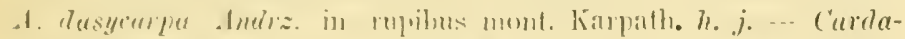

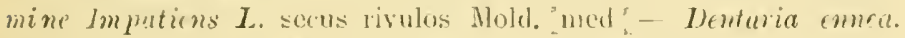
plyylla $I$. in sylyis Mold. super. $h, j . . \$ 1)$. bullifera $L$. in sylvis Molıl. tot. - Luraria rudriva 1.' in sytris. Mohe. super. h. j. Berteroa incana DC. in arvensis Mold. tot. -- Alyssum argenteum l'itm. in lapidosis Okna. A. Ciemanense $L$. in pratis siccis PutzeniA. murnte Kit. in muris vetust. Mold. super. H. i. A campestre $I$ in arvis Mold. super.. A. calycinum $I$. in sylvis Putzeni. A.minimum Willd. in pratis siccis Mold. infer. - Menincus linifolius $J C$. in collilus arenosis Galatxi. - Clypcola Jonthlaspi $L$ in collibus arenosis Galatzi. - Draba Aizonn Wahl. in rupestribus montiun Carpath. 1). stellate ${ }^{2}$ Tueq. in rupestribus montium Carpath., D. nemoralis $L$. in sylvis Mold. tot h. j. ${ }^{5} D$ muatis $L$ in muris Mold. super h $j$. Erophila vulgaris J). in arenosis Mold tot. - Co-

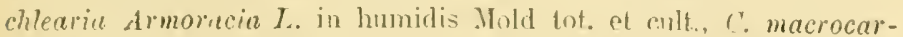
ju hit. in humidis Mold tot. et cult. - SThaspi arvense L in arvis el vineis Mold. tot. Th. alliacmu 1 . in arvis Mold. surner. h. j., Th. perfoliatum L. in arvis et vineis Hold tot. - Capsellu

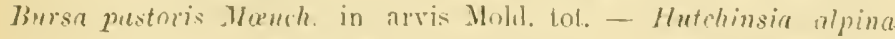
J $r$. in rumestribu montium Carpalls. $h . j$ - Ibe is amaru 1. in 


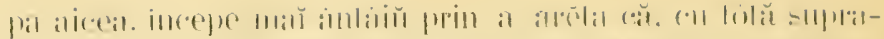

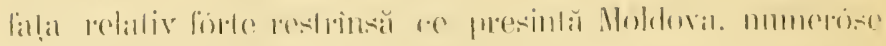

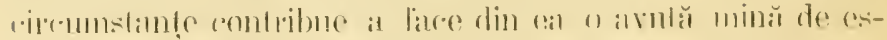

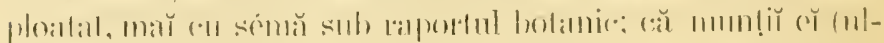

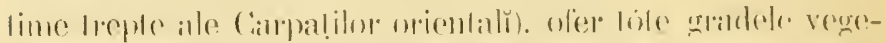

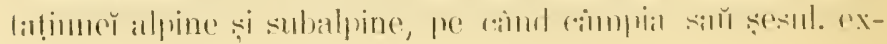

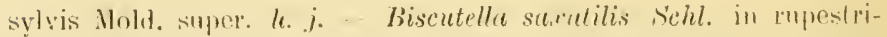

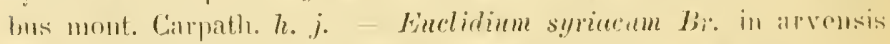
Moll. inler. of mol. - (horispore tenelle Di\% in vineis Muld. infer. of med. Iresperis tristis $L$. anl margines sylvamm Mold. infer.. H. matronalis Lam. in umbrosis Galili, il matronalis Lam. iar. inorlore in umbrosis Mold. super. - Sisymbrinm offecinale Sorop. in

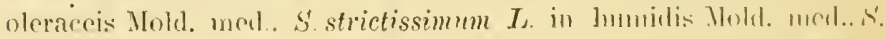
junceum Bieb, in pratis Codallri, S. pennonicum Jeeq. in arvis Moled.

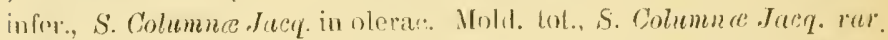
tenuisiliquam in olorareis Mold. tot. S. Sophin L. in oleraceis Mold. iol. S. pimnatifilum DC. in mpestrilms mont. Carpath. h. j.

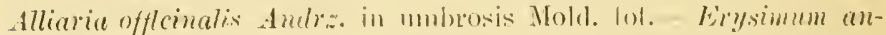
gustifolium lihr. in arvensis Muhl. tol., L. cuspillatum WL. in pratis Putzeni, E. hieracifolium I. in mont. Mol!! super. h. j.. Ji. repundum I. in arvis Molt. super. h. i.. E. canescens lioth. in

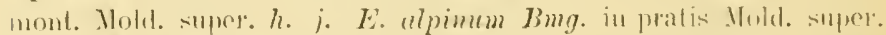
h. j., li. austriacum limg. in pratis Molel. super. l. j. . Cime-

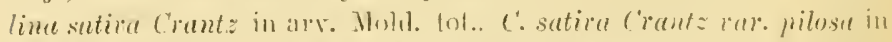
sylvis Muld. Lot., C. dentata Pers. in arvis Molr. Lol., C. austriacu Bi. in arvis Mold. smper $h$. j. - Teslit pamiculata Dest. in arvis Mold. tol. - Lepidium Draba L. in arvensis Mold. Lot., 1. sa-

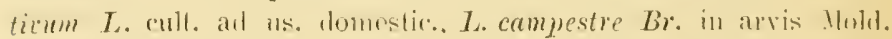
(n). T. ruderale L. all vias Moli. Iot. I. perfoliatum $I_{\text {. }}$ in vineis et pratis Molel. infer.. L. latifolium $I$. in hmmidis Mlold. infer., $I$. - rassifolium Kit. in palud. sals. Kisko. - Tsthionemu saxatile Trr. in rupestribus mont. Carpath. h. j. - Isutis macox Kit. in arris Mold. infer. - Myagrum perfoliatum L, in arvis Moll. super. $l$. $j$.

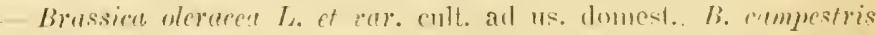

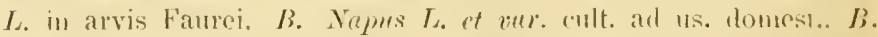
Rerpe L. et retr. eult. ad ns. domest. B. elongate Ehrh. in arvis Molu. inler. - Simupis nigra $L$. in arvis Molıl. supel.. So arrensis l. in arvis Mold. Lot. S. oricntulis L. in umbrosis Galatzi, s. fanrina Fisch. in arvis Mold. med., S. wlbn L. cull. anl us. dumest., S. dissentu Lay. inter lini segetes Mold. infer. - Diplotexis temi- 


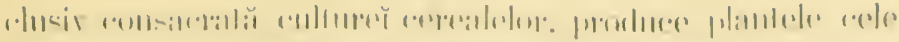

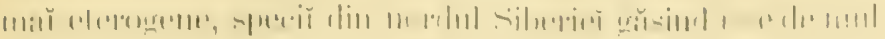

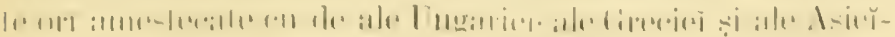

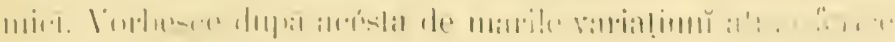

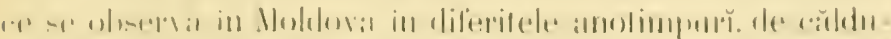

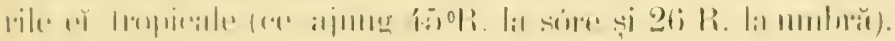

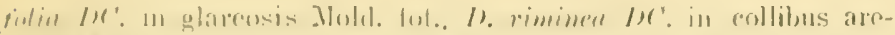

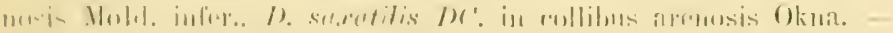

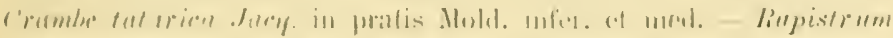

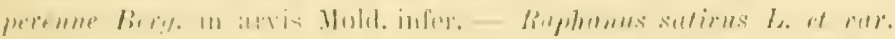

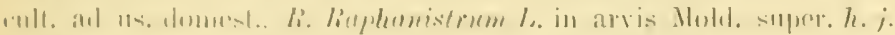

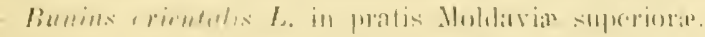

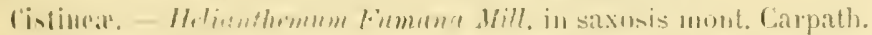

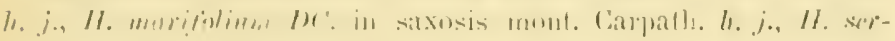

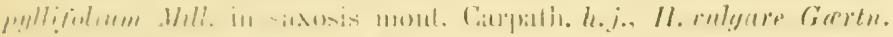

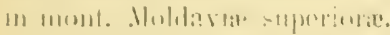

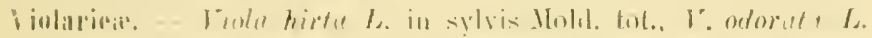

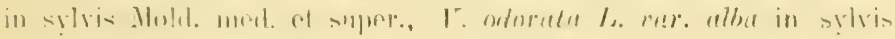

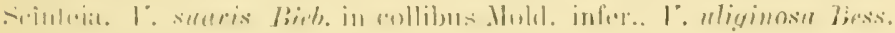

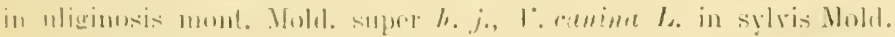

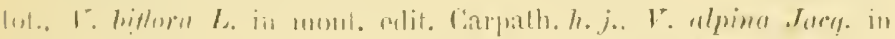

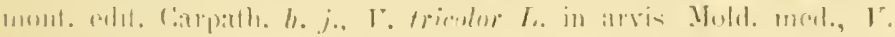

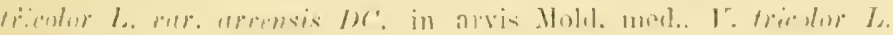

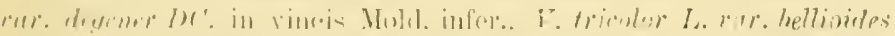

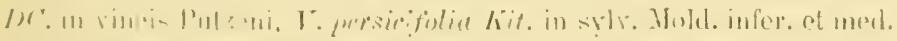

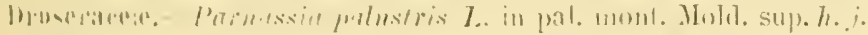

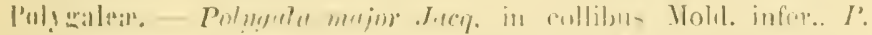

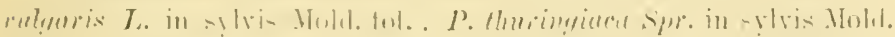

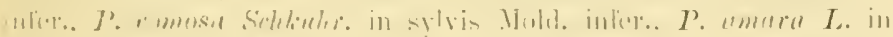

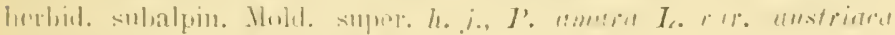

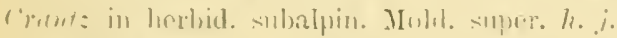

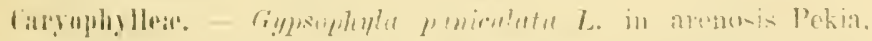

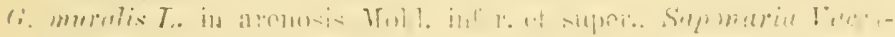

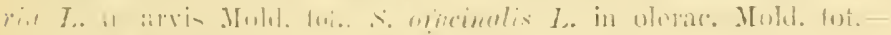

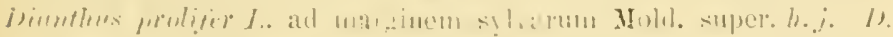

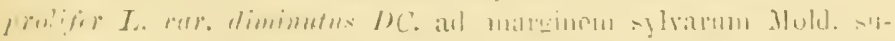

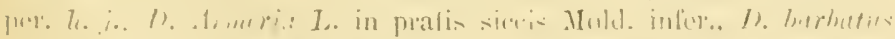

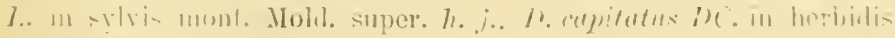

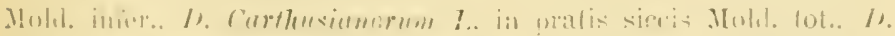

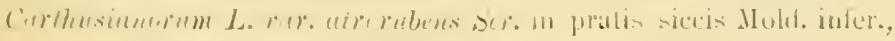




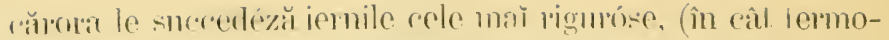

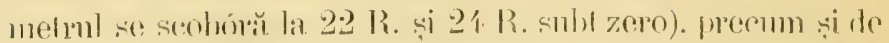

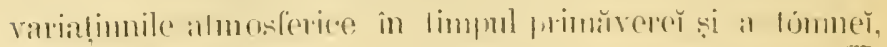

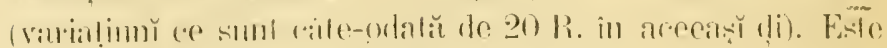

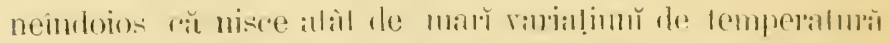

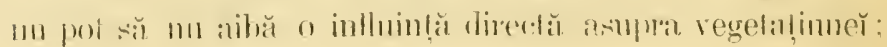

I). gigantens D'Lre in sylvis Mold. infer., I). nitidus Kit. in mout. MoId. super. h.j., D. matmsis Birb. in pratis humidis Ziganesci. D. deltoides $I_{\text {. }}$ ad marginem agrorum Mold. super. $h . j .$, D. plumarius 1 . in pratis Mold. super. $h$. j., D). seretinus Kit. in mont. Mold. super. $h$. j., D. urenurius $I$. in aren. mobil. ad torr. Mold.

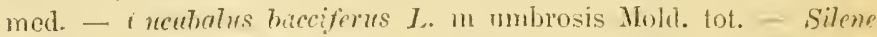
imflute $I$. in sylvis liold. Lot., S. Behen L. in sylvis Scinteia, S. Otites Pers. in sylvis scînteia. S. parvifora Pers. in sylvis mont. Mold. super. h.j. S. multiflora Pcrs. in pratis mont. Mold. super. h. j., S. dichotoma Ehrh. in arris Mold. infer., S. quedridentatr

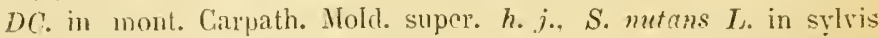
Mold. tot. S. chlmantlu Willd. in sylvis Pekia. S. catholica Oth. in campis areunsis Mold. super. h. j., S. noctifinra h. in syivis Zitanesci, S. mollissimn J'ers. in syivis mont. Mold. super. h. j., s. Ameriu I. in sytvis monl. Mold. super. h. j. - Iyychnis Viseurial I. in sylvic Mold. tot., I. Tisearia L. var. nana in mont. Mold. super.. J. Flns-theuli $I$. in pratis hunidis Mold. nod.. I.

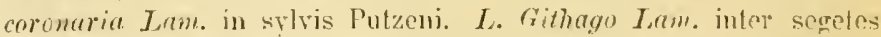
HoJel. tot. - Mremingia mesesss L. in mont. Mtold. super. - IIoTosteum umbellutum $L$. in arvis et rineis. ILold. Lol. - ISperyntu modosn J. in muris vetust. Holel. sirper. h. j. - Stellarir nemo-

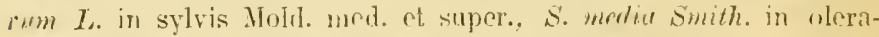

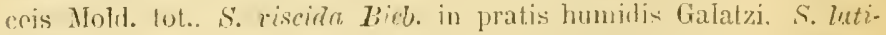
yolir Pen:se in pratis hunidis Galatzi S.lnolostea $I$. in sylvis Mold. tot. s. grominee $L$. in oleraceis Dlangina. s. muralis $L$, ink. in vineis Calat\%i. $\therefore$ pentagina Guud. al foss sals. (ialatzi. - Arcuoria sulinu sor ad fossis sals. Galatzi, A. saxtilis $L$. in saxosis Carpain. h. j., A. serpyllifolia 1. in arvis Nold. tot., A, trinervin 3. in sylvis Mold. Lot. - Cerastium tauricum spm. in palud. sals. Kisko, C. miyatum 2. in arvis Mold. super., ๔. andresancum sor. in aren. ad flum. Sereth, C. Urachypetume hesp. in styis Putzeni. C. oratum Monpe in pal. sals. Kisko, C. riternse 1. in arr. Jold.' sup. Linew. - Linnm hirsutum I. in sylvis Mold. infer. et med.. $I$. nerrosum hit. in arenosin Nloli. med. t. nis tatissimum 1. cult. 


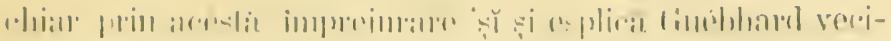

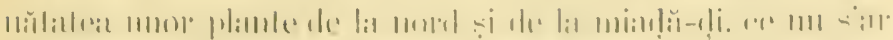

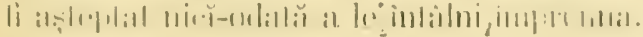

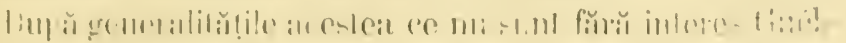

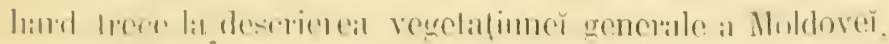

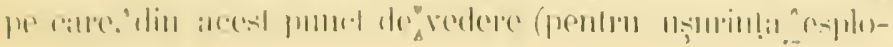

nd us. domest. L. anstriurum L. in rollibus Mold. infir.. T. mon-

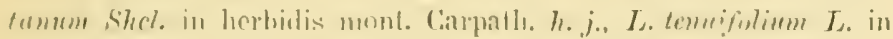

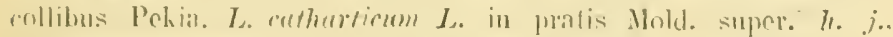

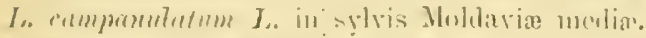

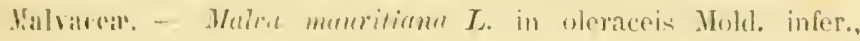

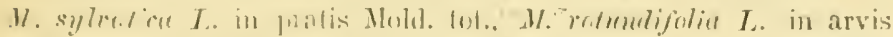

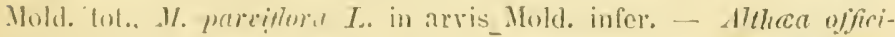

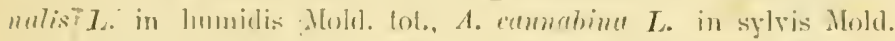
lot.e A. pulliele Kï. in arvis Mols. infer. - Lavatere psemdo-olbia

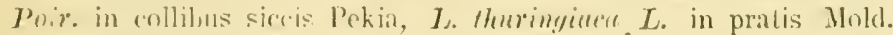
infer. L. cretim L. in collibus siecis Pekia. - Hibisens escul'n-

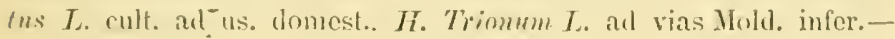
sidte Abutilon L. in vincis fialatzi.

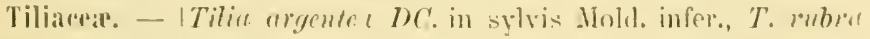
7) in sylvis Moldavial inferiora.

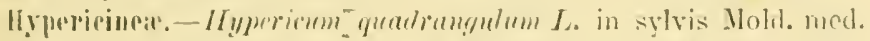

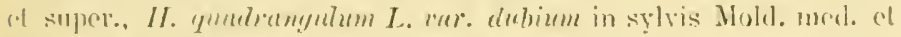

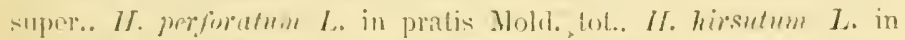

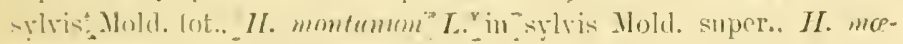
siurum spm. in rollibus Galatzi.

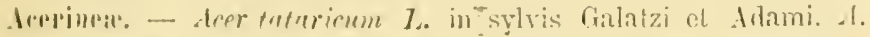
Psmulo-Plutunus I. in sylvis Mold. super. h. j.. A. rampestre I.. in sylivin Molld. tot.. A. eampestre T. ear. anstrinea Trutt. in sylvis Adami. A. platamoides I. in sylvis Molet. tot. A. phetamnides J. eur. lariniatum hit. in sylvis Mold. Lot.

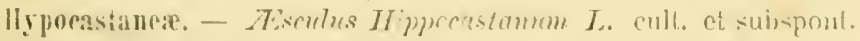

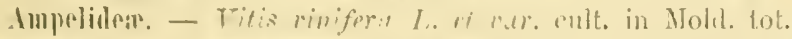

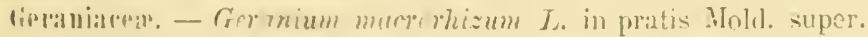
h.j., G. tuberosum I. in pratis AInld. supre. h.j., G. pratense I. in pratis Mold. super. h.j.. G. pheoum Iam. in sylvis Mold. tot., G. pulustre I. in pratis humidis Mangina, G. molle L. in pratis Mold. tot., G. pusilhum $L$. in pratis Mold." super. h.i., G. rolundifolinum $L$. in pratis Nold. Int.. Fr. columbinum I. in coll. Mold. Int.. F. Johomicum

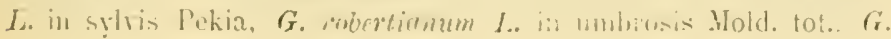




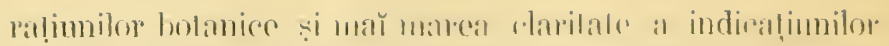

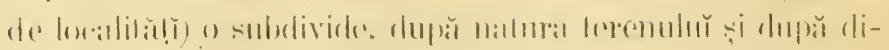

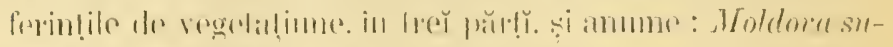

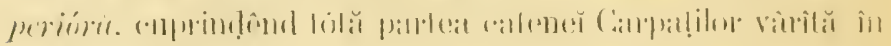

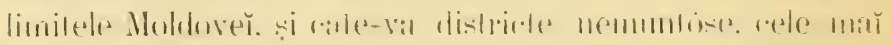

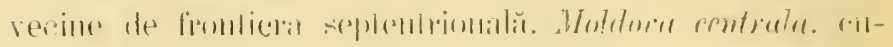

'amguinam I. in sỵtris Mold. tot. - Frodium ricutarinm T'Herit. in pralis Mold. tot., $E$. serntimem Stee. in mont. Ciahlan h. $j$.

Balsamincal.- Impations noli-tangere $I$.. in syl. hum. Mol. sup. h.j. Oxalidea. - Orulis arefosplla J. in sylv. Hold. super. et med. Kygophyllear. - Tribulus terrestris $T$. and vias Mold. infer:

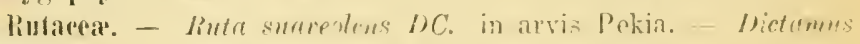

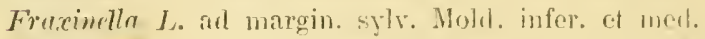

Celastrimeat. - Stephyle pimute J. in sylys Monast. Adami. - Eronymus enroperes L. in sỵtris Mold. Int., E. latifolius Srip. in sylvis Mold. Lot., E. ecrrarosus Scop, in sylvis Mold. super.

Rammes. - Rhammus enthurticus J. in sep. Miloll. tot., Rh. "?pims L. in sylvis mont. Mold. super. h. j., Kih. Frethunter J. in sylyis mont. Moldavia superiore h.j.

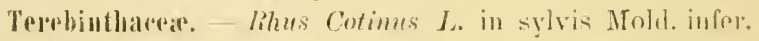

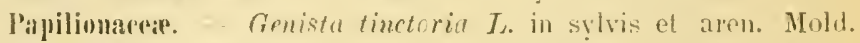
med. - Cytisus Imburnum I. mult. el sulspont., (". nigrircus I.. in mont. Mold. snpes. h. j.. C. Ifuchunthus Kit. in șyis mont. Mold. super. h. i., C. anstriucus J., in arvis Mold. tot., C. suprimes Jure. in cull. mont. Nols. super. h. j., c. hirwutus L. in asperis Mold. infer. - Onr.nis spimose Muhlr. in pratis humidis Mold. tot. O. altissima Iam. in pratis Mold. super. h. j. -

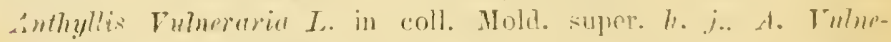
ruriu J. rat. ulpestris Kit. in rmp. mont. Carpath. he. j.. Medicayo satira I. cull. ad us. domest. Mr. Inpmlina J. in arvis Molu. 101.. M. faloata 3 . in pratio Hold. tot., M. minima Lam. in are-

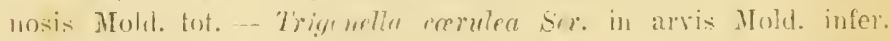

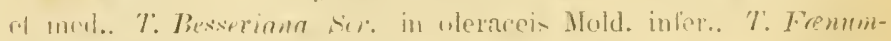

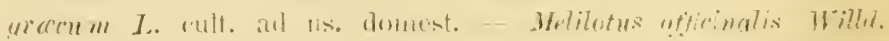

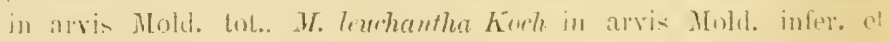

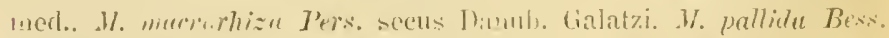

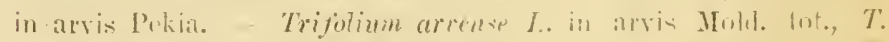

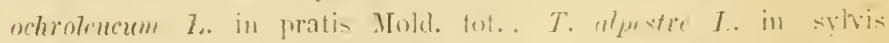

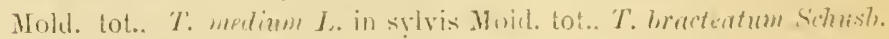
in humidis arnosis al $\mathrm{H}$. sieretl. T. pratense J. in pratis Mold. 


\section{SXXIII}

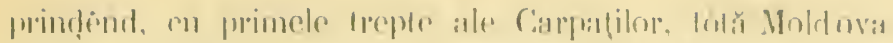

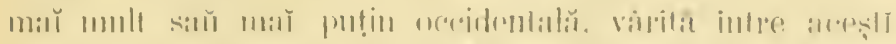

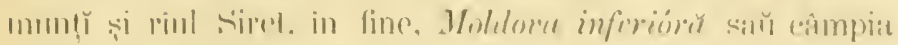

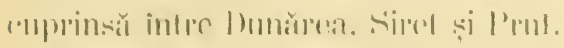

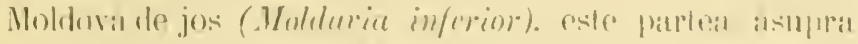

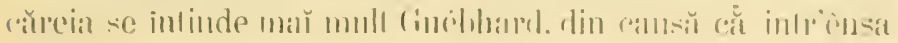

Int.. T. glubosum $I_{\text {. }}$ in oleracris Pekia, T. rubens $J$. in sylvis Mold. Int. T. repens 1. in pratis Molll. Lot., T. alegans Sori in lumuidis P'utzeni, T. montanum 7. in coll. Nold. tol., T. suteranum I. in pratis Molll, supper. h. j., T. smumosum L. in pratis Mold. super. h. i.. T. resupinatum Kil. in pratis Mold. super. h. j., T. spaticeum I. in pratis Mold. smper.h.,., T. frargifrmm $L$. in lommilis Molel. tot., T. mocumbens L. in sylvis Mold. tol., T'. filiforme 1. in arvis Mold. tot. - Doryenium herbucenm Fill. in sỵlvis alen. Molıl. tot. - Lotus remiculatues L. ju pratis Mold. Int.. I. comiculatus 7 . ear. arensis in arvis Putzeni; $L$. corniculutus I. rar. alpinus in pascuis $\mathbf{A l}$ old. super. h. j., $J$. comniculutus I. rar. temuifolins in pratis Mold. super. h. j. - Crly"yrthiza ahinata L. in humidis Molr. infer. - Galega officinalis L. in hunidis Mold. tol. - Rohinie Pspulacucin L. cult. et suls.sponl. in Molil. 1ot. - Coluten arbonescens l, in pomariis Jassy h.j. - Ihuera alpine Jarq. in pase. edit. Carpath. h.j., Ph. astruguline Dr. in pase. cdit. Carpath. h.j. Oxytropis uralensis DC. in pasc. edit. Carpath. h. j., O. pilosa IHC, in arvis Pehia. - Astra-

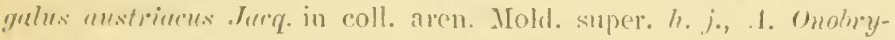
rhis L. in prat. Mold. med. et infer., A. Onelnychis I. ror moldarinus in pral. Mold. med. et infer., A. glycyphyllos $L$. in syly. Mols. tot., A. cire 2. in pratis Mold. tol.. A. asper Jueq. in pratis Pekia, 1. yulegiformis $L_{\text {. }}$ in pratis moul. Nold. super. h. j.. a ponticus l'all. in inll. sicc. Mold. infer., A. cxscenmes $l$. in coll. sicc. Mold. infer.. . t. monspessulanus $I$. in prat. mont. Mold. super. h.j.. A. "roputens l'is. in coll. aren. P'ekia. - Cormilla winimu L. in roll. siec. Molit. supl. h. j., C. corouretu L. in coll. sice. Mold. super. h.j., C. rertirn I. in sylvis Monast. Adami, C. rrin L. in pratis Mold. Int. - Onobrychis ronfertu Dese. in pratis (1kna, O. requidentatr I' ' $\mathrm{r}$. in coll. Mold. infer. - ricer arietimum $L$. cult. and us. domest. - Fraba rnlgaris Mench. cult. ad us. domest. - Virin pisiformis L. in sylvis Mold. infer., $r$. dumetorem $L_{\text {o }}$ in sylvis Mold. med. et infer., Ir. sylratica $L$. in sylvis Mrold. super., I'. araced $L$. ad sepes Mold. Int. I polyphylle Desf. arl sepese Uold. Int. $r$. 


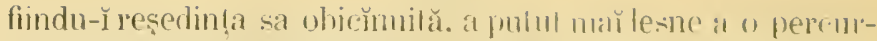

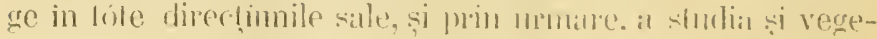

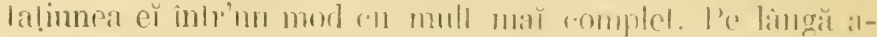

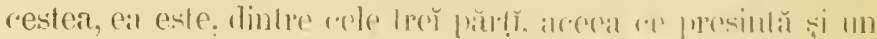

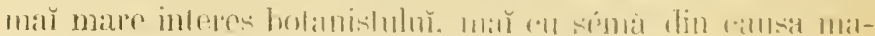

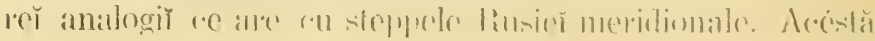

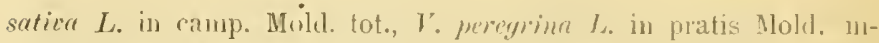

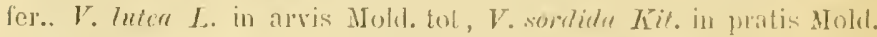

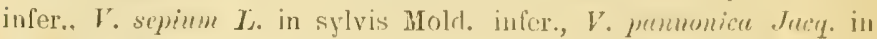
oleraceis Mold. tot. - Firmm Lens L. cult. all us. domest.. E. hirsutum L. in sylvis Molı. infer.. E. momunthos L. in sylvis ad Monast. Adami, E. tetraspermum L. in arvis Putzeni. - P'istm sertirum $L$. et rar. cult. ad us. domest. - Lathynes latifotius $L$. in vineis Pekia, L. pratensis $L$. in pratis humidis Moll. tot.. $L$. tuberosus L. in arv. hunid. Mold. tot., L. palustivis L. in paluul. Mold. med., L. Nissolia I. in sylvis MLonast. Adanni, I, suticus I.. inter segetes Mold. tot., $L$. hirsutus $h_{\text {. }}$ in sylvis Mlold. super h. j.Orobus remus $L$. in sylvis Mold. med. et super, O. ricioides IX. in mont. Mold. med., O. sylnaticus $L$. in sylv, Mold super. $h . j$. $O$. niger $L$. in sylv. Mold. tot. O. tuberosus $L$. in sylv. Mold tot., O. varius Soland. in coll, aren. Mold. infer., O. ulbus L. in sylv. Mold. infer. - Phaseolus rulyaris Savi et rai. cult ad us domest., P. multiflorus Willel. cult. - Lallab mlyaris seari cult.

Rosacere. - Amyctulus nenu I. in arvis Mold. fot.. A. communis L. cult, in Mold. infer. - Pessice rulguris Mill. L. cult. in Mold. med. et super. - Anneniner rulyaris Lum. cult. in Mold

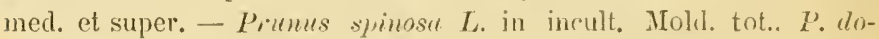
mesticn $L$. et ral. cult. in Molel. tol. - Cevesus urium Manch. in sep. et sylv. Mold. tot., C. Juliane $D C$. cult. in Mold. med. et super., C. capronian.e J)C. cult. in Mold. meal et super., C. Mtehaleb Mill, in sepibus Cralatzi, C. Padus L. in sylvis Miold. sirper. - Spi-

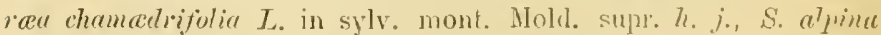

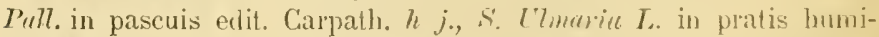
dis Mold. super. 7 j.. S. Filipendul" L. in sylvis Mold. tot - Mryas

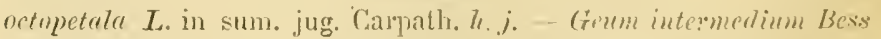
in umbrosis Mold. super. h. j., Gr. wbanmm L. in sylvis Meold. tot. G. rivale L. in rivul. Mold, super. h.j.-Wreirlstrinia gevides Willd. in sylvis Mold. super. h.j. - Rubus ideus I. in syivis Molu. meil. et super.. R. cresins $L$. in sylv. Mold. tot. R. casins $L$. nur. arensis

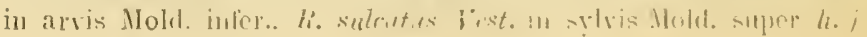




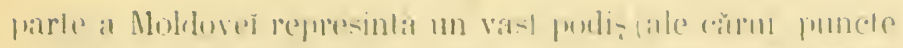

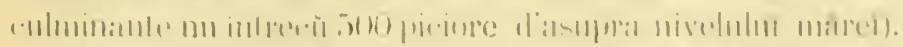

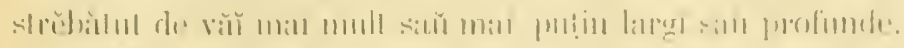

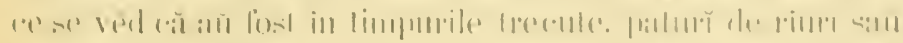

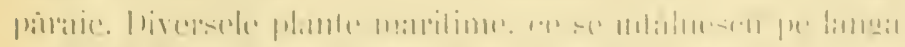

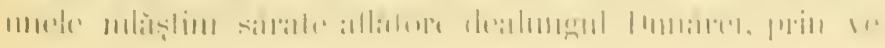

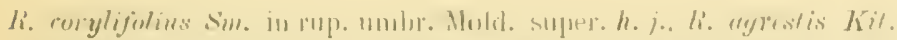

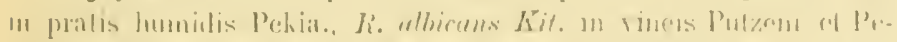

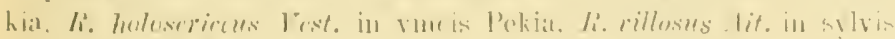

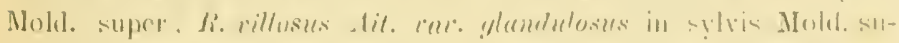

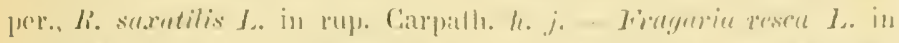

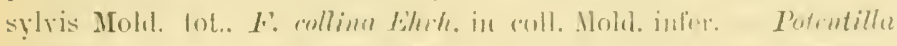

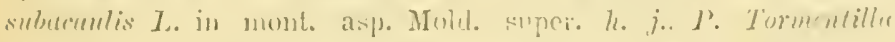

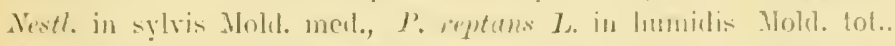

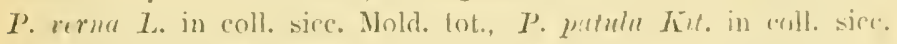
Mold. infer., P. aryented J. in pralis Mold. 10t., P. murer $L_{\text {. }}$ in pasc. edit. Carpatlı. h. j., l'. hiva $l$. in siecis MLold. mel. et infer., $P$. rectu $I$. in vincis Nikoresci, I'. supina $I$. in humilis Gra-

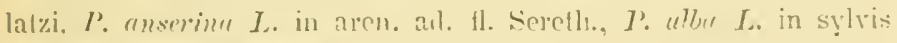
Jonast. Adauri, $P$. nitilu L. in sum. jug. Carpatl. h. j., I'. Fraga-

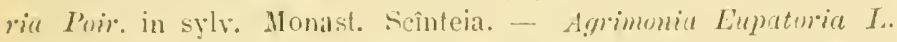
in aridis Mold. Lot. - Sanguisorln officinalis $L$. in pratis Molu. super. h. j. - Totcrium Sanyuisorbu $L$. in pratis Mold. super. h. j., P. rillosum sibth. in coll. aren. Muld. infer. - Resa aremsis Huds. in arvis Mnld. tot.. R. sempervirens $I$. in coll. Putzeni, R. gullien I. var. officinalis cult. ad. us. lomest.. Ii. pimpinellifolia $I$. in sy.lv. Mold. tot. Le. pugmea Bieh. in prat. et sply. Mold. infer.. R. caniua $L$. in sep. Mols\}. tot. R. canina I. we. collina Ser. in coll.

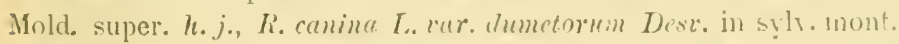
Molil. super. h. j., R. mbiginnse $L$. in sylv. mont. Hold. super. h.j. - Cratagnes Oxyurantha L. in sỵly. et sep. Mold. tol., C. Oryucrentha L. var. monostylu in sylv. at sep. Mold. sminer. h. j.--Cotoneraster vulyaris Limll. in rup. inont. Mold. super. h. j. - Mespilus gemanica $L$. in sylr. Jassy h. j. - Pyens communis $L$. in sylvis Mold. tot. P. communis $I$. rem. sutive cult. ad. us, domest.. $P$. Malus L. ef rar. in sylr. Mlolil. tot. ct cult., P. torminalis EHrh. in sy.lv. Adami. P. aucuparia Geo\% n in sylv. Mold. med. et super.-Cydonia vulgaris Pcrs. et war. cult. et subspont. in sylv. Mold. infer.

Onasrarier. - Epilobium spicatum $t$. in sỵlr. Mold. super.. E. rosmerinifolium Hanter in alen, ad torr. Pulna $E$. aljomum $I$. in 


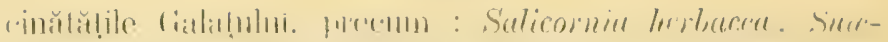

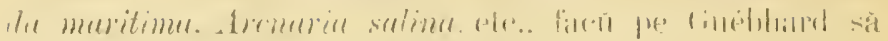

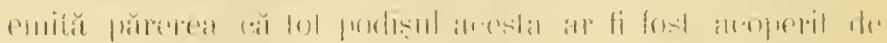

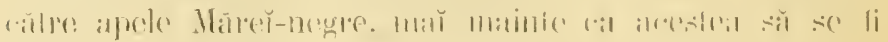

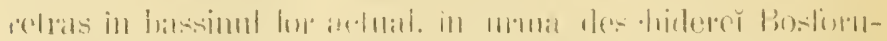

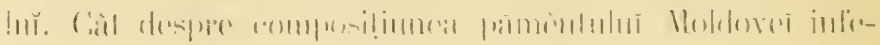

pase. erit. (arpath. he, j, E. rosinm 7)

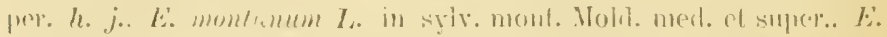

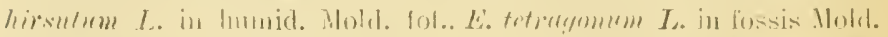

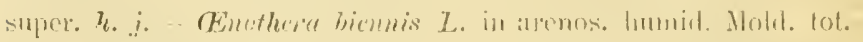

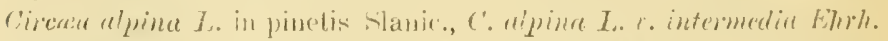

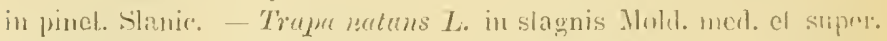

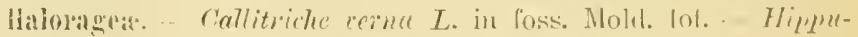
ris enlyuris $L$. in fosmis Holdavix superiore $h . j$.

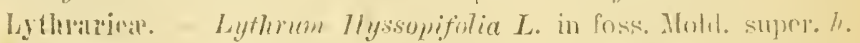

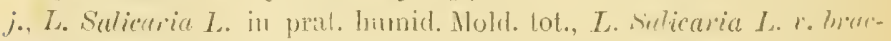
Lessum in humid. al Dammbium, L. virgatum L. in prat. Fanrei.

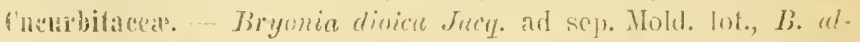

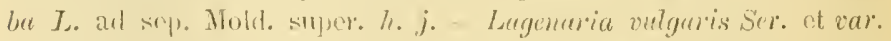

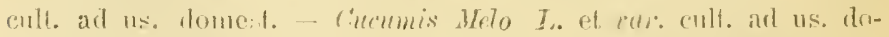
mento, C. satims L. culf, at us. domest., C. Citrullus Sre cult. art us. domest. Cururbitu Pepo $I$. cult. art us. domest. ('. remurowa

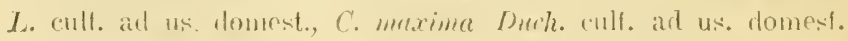

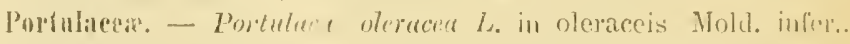

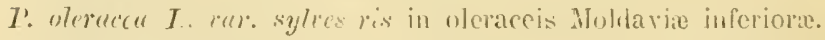

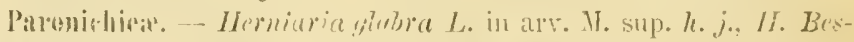

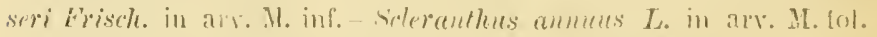

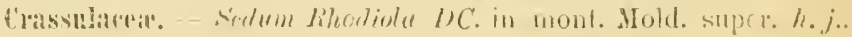
S. latifolimm Bert. in mont. Nohl silp. he i.. S. Thephime L. in'aren. Mold. tot., S. slcllalum L. in monl. Nold. sup).. s. arve J. in glar.

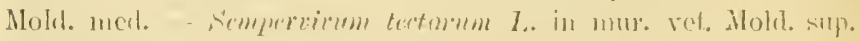

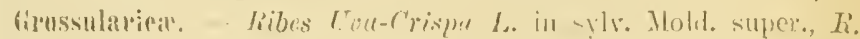

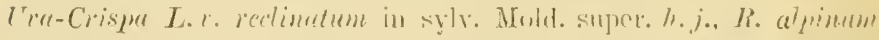
I. in sylv. Miold. sup. h. i., R. rubrum I. in sylv. Molıl. sly. h.j.

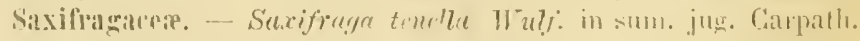

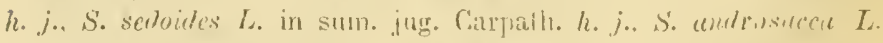
in sum. jug. Carpath. h.j., S. Bursolune $L$. in sum. jug. Carpath. h. j., S. musrovides Wulf. in sum, jug. Carpath. h. j., i. musicoides Wulf, in sunt. jug. Carpath h. j., S. musisoides Wulf. $r$. musclueter in

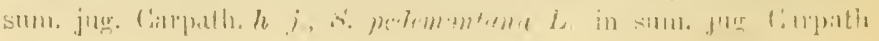




\section{YYYII}

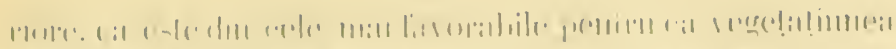

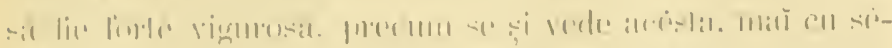

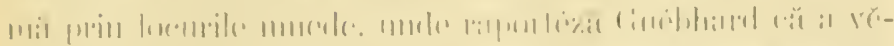

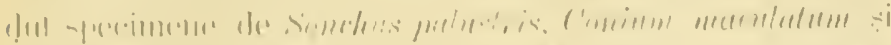

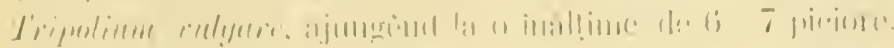

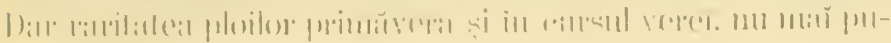

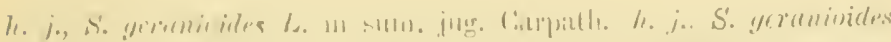

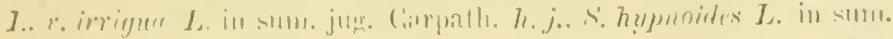

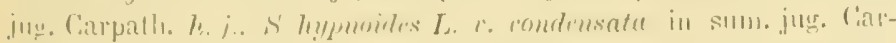

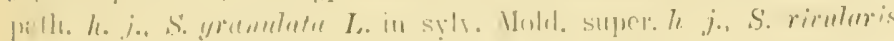

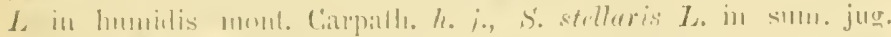

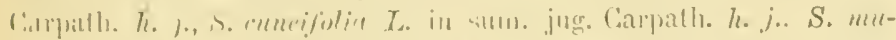

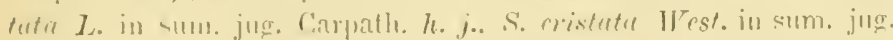

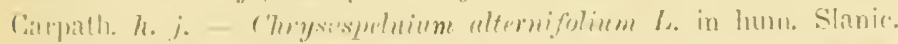

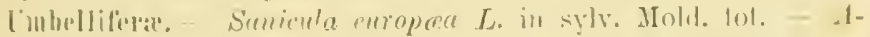

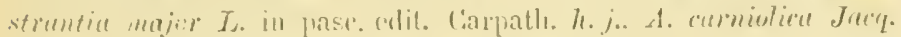

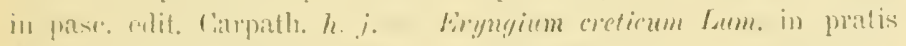

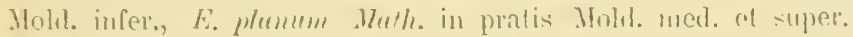

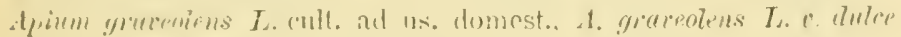

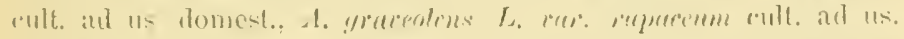

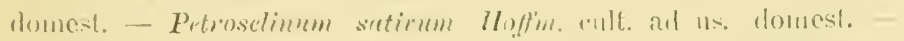

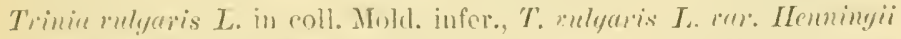
in enll. Mold. infer", Falceriu Rivini 2. in arvis Mold. tot. -

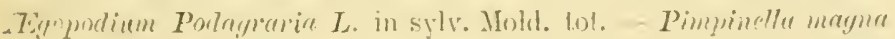
I. in pratis Mold. Lot. - Siem lencitolium Birb. in palud. Molıl.

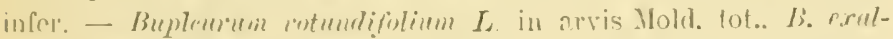
tutum Birb. in sylv. Pekia et Putzeni, B. tuleatum L. ad marg. syly. Molul. super. h. j. - Gsuanthe pencelenifolie Lull, in sỵls. Faurei. - Ethusu cynapivides Bieb. in ruder. Mold. infer. - Ferni-

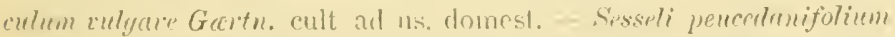
Bess. in pratis Iold. ined. et infer.. S. meleratum Ehrh. in arvis

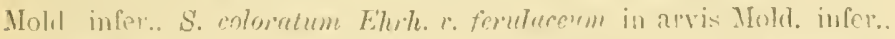

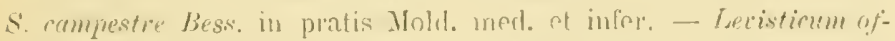
firinale howh. cult aul us. domest. - Fevele sylewtira Bess. in syly.

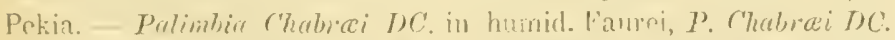

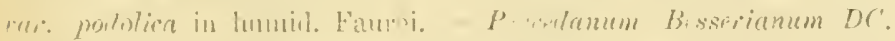

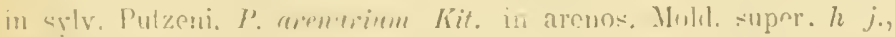

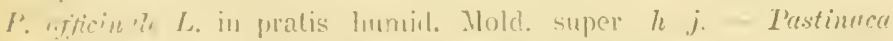

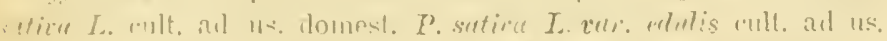

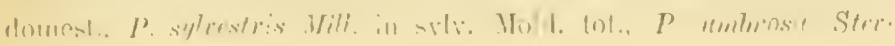




\section{XXXVLII}

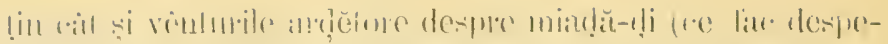

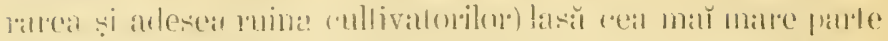

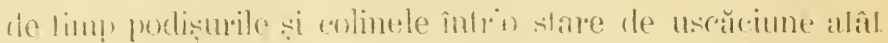

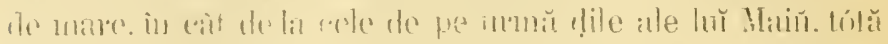

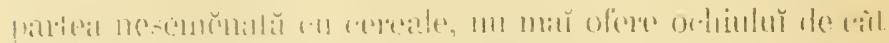

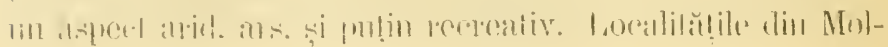

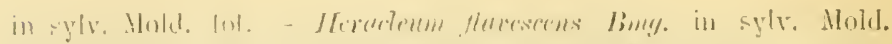

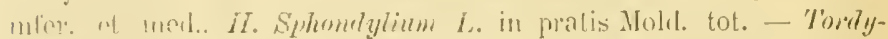

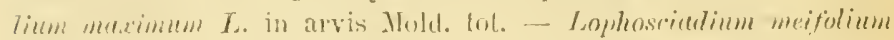

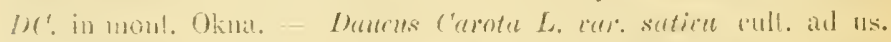

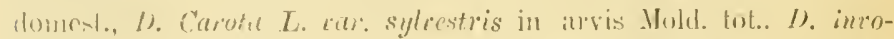
lurvetus sibth. in arvis Fanrei. - Concelis dnuroiles $T$. in arvis

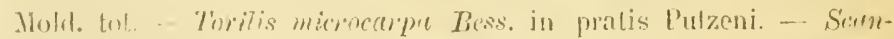

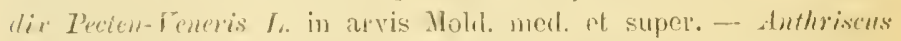

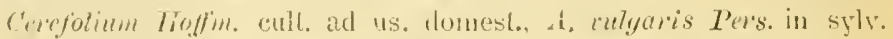
Mold. tot. - Cherophullum bulbosum $J_{\text {. }}$ in sylv. Mold. tot., C. temulum $L$. in sylv. Mold. tot. - Conium maculutum L. in rader. Mold. tot. Corindrem sutimm $L$, in arvis Mold. super. el cult. Araliaerar. - Hedera Melix $T$. in sylvis Moldaria totius.

f'opluer. - Cormes mess $I_{\text {. }}$ in sylvis Moldavie Lotius. C. sanminere 7. in sylvis Mloldavia totius.

Lopunthesers. - Viscum album L. paras. in ard. Mold. med. el sip.

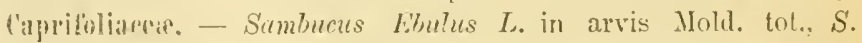
nigre l. in scp. Mold. tot. - Viburmum Latentane L. in syls. Mold.

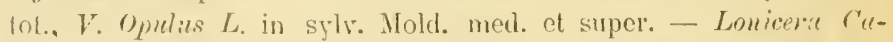
prifolium $I$. in sylv. Mold. super. $h . j ., L$. Periclymenum $L$. in sylv. Molit. super. $h j$., L, nigra $L$. in sylv. mont. Mold. super. h. $j$.

Buhinecre- Gulum leve Thuill. in pral. Hold. super. h. j., (r. alpestir Gand, in prat. Mold. super. h. j.. G. Bucemi All. in steril. Mold. supcr. h.j., G. pumilum Lrem. in prat. mont. Carp. h. j. G. Monlluyo L. in vin. Mold. infer., G. Molluyn L. $t$ secubum in vin. Mold. infer.,

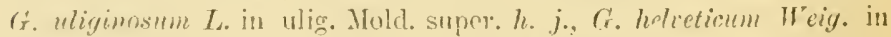
mat. mont Mold. super. h. j. G. mbioides L. in syly. Mold. med. ef sup., G. eerum $L$ in prat. Mold tot., $G$. ero-mollugo Waller. in aprie. Mold. inf. G. cemum Scop. in sylv. Fausci, Gr retrorsum DC. in mont. Gkna, (r. Cruciatn Scop). in sylv. Molu. med. et sup., G. apricum Sibth. in coll. Putzeni. G'. Aparine L. ad sep. Hold Lot.

Valevianese. - Vuleriunelle costutu $D C$. in vincis Idoldavio infe-

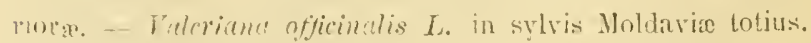

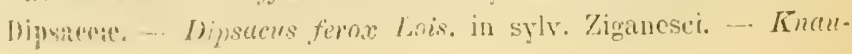




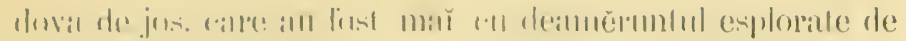

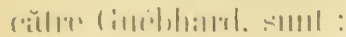

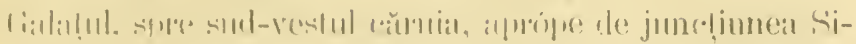

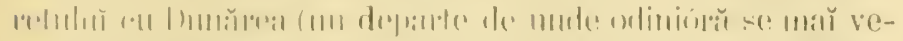

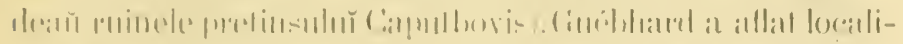

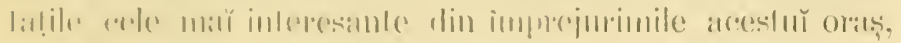

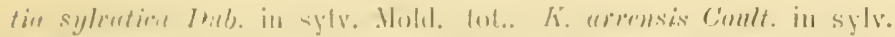

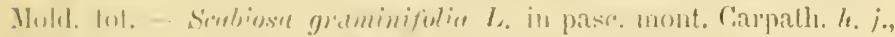

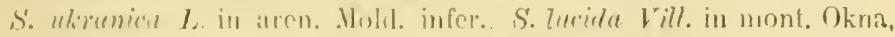

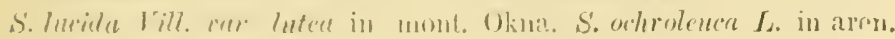

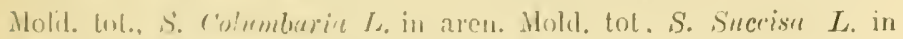
pratis lumid. Moldinvia superiore $h . j$.

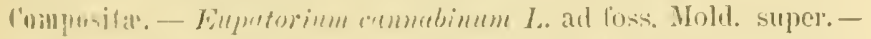

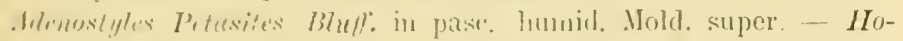

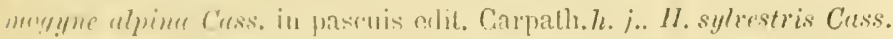

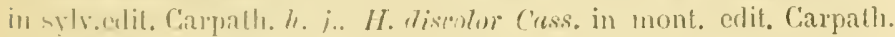

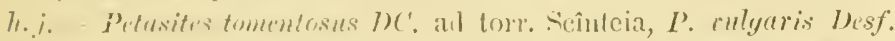
in lummil. Mold super. h. j.. I'. ruly eris Des. retr. subfemineus in lumid. Molsl. s!per: h. j., I. ulbus Gererth. in mont. Molı. super. h.

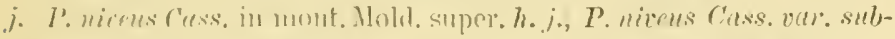

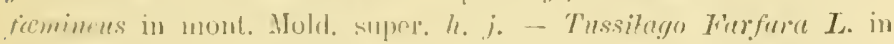
argil Mold. 1ol. - Aster alpinus 1., in prat, edil. Carpath. h. j., d. Amrllus $L$ in arvis et sylvis Mold. tol. - Tripolinu vulgare Nees. in prat. humil. Mold. tot., T. relyure Nees. rer. pamnnicum in humil. Mangina, T. mulyore Nees. rer. dlifusum in foss. sals. Galatzi, -

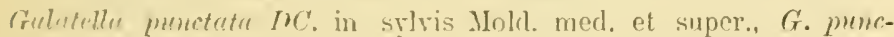
fute DC. rear. insculnta in sylv. Faurei. G. dracunculniles DC. in strly. Ziganesci. -- Erigeron conulensis $L$. in arvis et sylvis Mold. (1)t.. E. reme I. in sy-tr. mont. Hold. super.-Bellis perenuis L. in pratis Molel. super. h.j. - Soliblagn Virye-durea $L$. in prat. et syls. Mulk tot. - Linosyris rillosn $D C$. in coll. aren. Mfold. infer., $L$.

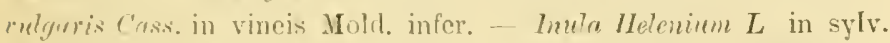
MEslil. tot., I. ensifolia $L$. in coll. aren. Mold. infer., I. germanica $L$. in arvis Mold. tot, I. hirte $L$. in prat. mont. Hold. super. h. $j$., I. Conlus-Christi L. in arv. el svlv. Mold. infer., I. Oculus-Christi L. ror. compestris in arv. ec syly. Molld. infer.. I. salicina $L$. in syly. Molel. tot., I. salicina L. var. latifolia in sylv. Faurei, I. grandiftora Will, in sylv. Mold. infer., l. sprircifnlia $L$. in sylv. Pekia. - Pulicarin rulguris Gertu, in prat. humil. MIold. tot., P. dysentericn Gertn. in prat. MIold, tot. - Buphthatmuem sulirifolium DC. ad rad, mont. 
II.

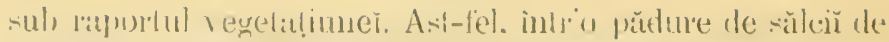

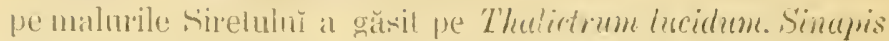

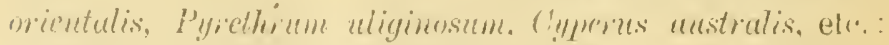

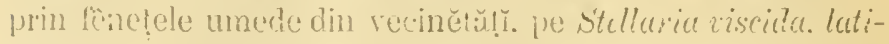
folier, Pesedu mediteruneu; in line. intro o mică porlgorie sllălăială de pădur de pe o colina rerină, pe Túununeulus polyun-

Ciappath. h.j. - Teleliu corelifulin Kit. in val nonl. Carpath. h. j.Xenthium strumarium L. ad vias Mold. toh., I. spinosum I. in incult. Mold. Lot. - Melianthus anmus L. cult. ad us. domest.. II. tuberosus I. cult. ail us. domest. - Bidens tripurtitu $I_{\text {. }}$ in hu-

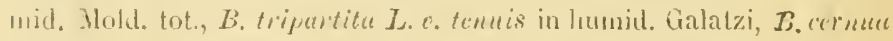
W'ille. in humid. Mangina, B. cermu Willd. rer. rudiute in tumuil. Mangina, Anthemis tinctoria $L$. in arv. Moht. tol., A. aremsis $I$. in arv. Mold. tot. A. azsstriaren Jueq in arv. Mold tot - Achillea Millefolium $I_{\text {. }}$ in arenosis Molel. tot., A. lanatu Spreng. in pral. Nold. infer., A. compactu Wrille. in coll. Galatzi, A. stucese Kit. in inont. Mold. super. h. j.. A. tomentoset J. in apric. Carpath. h. i., A. prectinata Wille. in syls: alren. Pekia, A. Gerbesi Bicl. in sylv. et prat. Mold. infer., A. magna Wille in glareos. Mold, super. h.j - Ptarmior Clutena DC. in pase. edit Carpath $h j$. -

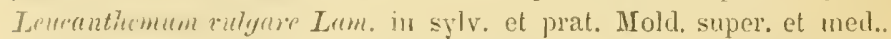
I. rotremlifolium DC: in pinctis Mold. super, h. j., I. montumum DC. in saxosis Carpatis. $h . j$. Hatricuriu Chamomilla $L$. in arvis Mold. tos. - P'yrethrum corymbosum Willd. in sylv. Mlold. tot., P. achillecefotiom Bie's. in eoll. aren. Nold. infer., P. uliginosum $I$, in palud ad Sereth of Dambium. - Aitemisir Alsinthium L. in incull. Mold. tot.. A. Dracencules: $L$. rar. sative cult ad us. domest. A. scoporin Kit. in olerac. Mold. inter., A. sulina Wille. iu palud. sals. Mangiua, A. Beschniukium DC in palud. Ziganesci, A. Abrotanum $L$. cult. ad us. domest., A. pontica $L$. in apric. Mold. tot, A. anstrinere Jiecz in prat. Mold. tot., A. vulgaris $L$. in pratis Mold. tol., A. spiertet Wulfy. in sum. jug. Carpath. h. i.Tinacetem cutyare L. in humid. MIold. tot., T. boveule Fisch. in humicl. Galatzi. - Gurpluchium lutou-ulbum L. in sylv. IIold, super. G. uliginosum L. in ulig. MIola. infer. - Helichrysum arenarium DC'. in coll. aren Wold. tot. - Ondetheca supine DC. in uligin. mont. Carpath. h.j. - Filago germanica Wille. in arvis Mold, super. h.j., F. corensis L. in arvis Molıl, tot - Antenavie clpive Gertn. in ruont. Carpath. h. j., A. dioiece Geren. in monl. Hold med. et sllper. - Lerontoyndiuin cilpinum Cuss, in sum. jug. Carpath. $h . j$. 


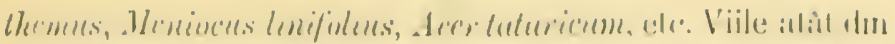

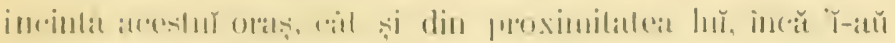

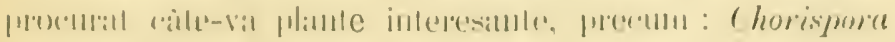

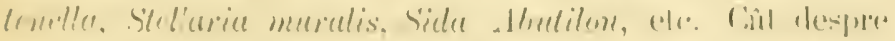

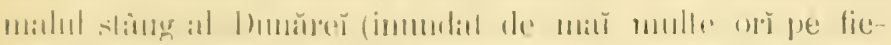

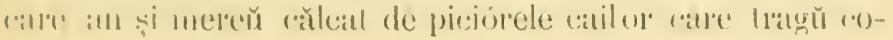

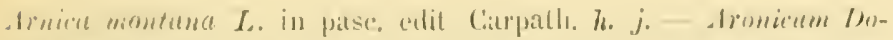

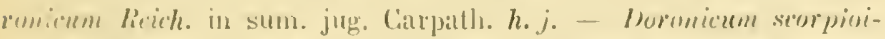

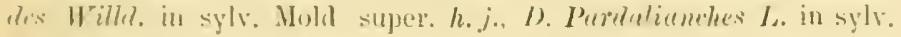
Mlold, super, h. i. Seneen culguris I. in uletile. Mold. tot., S. riscusius I. in sylt. Mold. super. h. j., S. sylueticus $L$. in sylv. Mold. super. h. j.. S. irrualis Kit. in arvis Mlold. infer'., S. Jacobau $L$. in pral. Mold. super. h. j., S. concrejolius Huls. in arvis Mold. infer.. S. puluelosus L. in lumid. Galatzi, S. Fiuchsii Gimel. in sylv. Molil. super, S. antrentians IJC. in pasce edil. Carpath. h. j. likhops bunmtians hochel in coll. aren. Mold. infer., E. spharecephalus L. in sylv. Muld. Lot., E. spherocephutus L. c. paniculatus in s.y. Muld. super. h, j. - Verenthemum rentutum Lum. in arvis Molı. tot., X. cylindraceum Sibth. in arvis Faurei. - (arlinu subaculis I) ' . in pasc, mont. Carpath. $h$ j., C. rucemosu $L$. in syli. Molu. tol. - Crupinu vulyuris Cass. in areu. Mold. infer. - Lentrophyllum lenatum I) . in arvis Ilolil. tot. - Certhemus finctsrius 1. cull. ad us. domest. Onopordon scanthinm L. in ruler. Mold. Lot. - C'ymura Seolymus I. cult. all us. domest., C. Curelunculus $L$. ault. ad us. domest. - C'areluus nutuns $I$. in l'uler. Mols, super. h. j., C. ucunthosides in ruller. Mlold. super. h. j., C. Persimutr Jucq. in syly. Mold. super., C. sminutus Biel, in moll. Molıl. intor., C. hemulosus Ekrh. in incult. Mlold. tot., C. het-

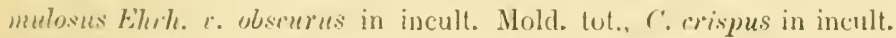
Mold tot. - Lenum tomentosu Lam. in ruder. Molel. super. $h$. j., L. mujur Girptn. in ruder. Mold. infor.-Cirsinm lunceolutum Scop. in sylv. Hold. infer., C. ferox DC. in syly. IIold. super. h. $j . . C$. mioplenrum Scop. in prat. Ilold. tot., C. areense L. in prat. Mold. 1ot., C. canum Bieb, in sỵlv. Pekia, C. palustre Siops. in prat. humial. Mold. tot. C. glatinosum Lame in nenor. Jumid. IIold. super. h. j.. C. tricaceplealoiles DC. secus rivul. mont. Carpath. $h$. j., C. heterophyllum DC. in prat. mont. Hold. super. h. j. - Serratulu tinctorin $L$. in sylv. Mold med., S. tinetoria $r_{\text {. }} v$. indirisa in sylv. Mold. mesl., s. coremutu J. in prat humid. Faurei. - Jurinea mullis $D C$ '. in prat. Nesld. Lot. - Centanen tricocephala IVilld. 


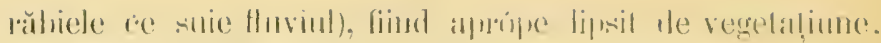

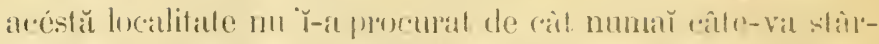

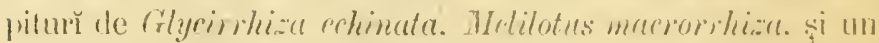

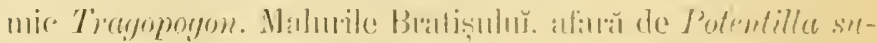

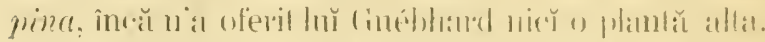

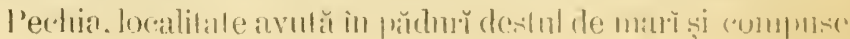

in sylv. Adami et Faurei, C. Mensedialliana symeng in coll, aren. Prekia, C. Cygmes I. in alvis Mold med. et super., C. deprestra Biels.

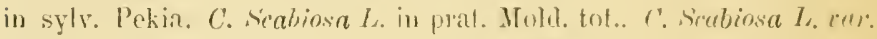
rlbe in sylv. Faurei. C. Jarea I, in prat. Mold. tot. C. . Juerel L. rat.

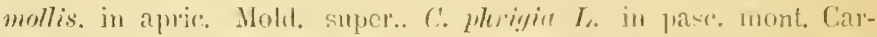
path. h. j.. 6. trinervice steph. in aprir. Moshl. super. h. j., C. mentana L. in pase. monl. Carpall. h. j.. C. nigre L. sin pralis Mrold.

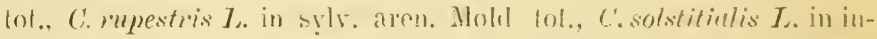

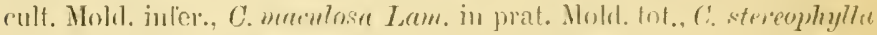

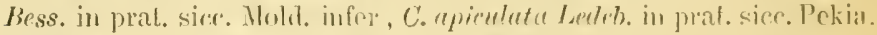
- Irmpsana communis 2. in olerar. Mold. med. et super., L, inter-

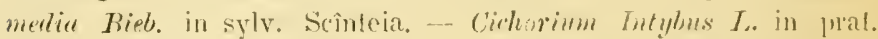

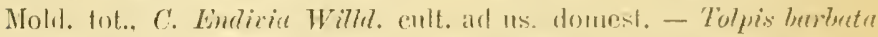

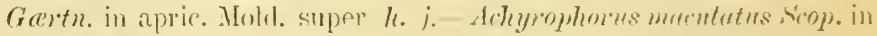
sylv. Mold. tot., A. hetreticus somp. in prat. edit. ('arpath. he j

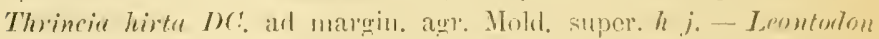

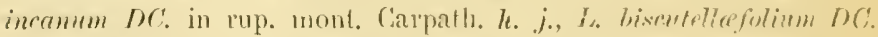
in prat. Putzeni, I. dulsium Roth. in monl. Okna, L. hastile I. in prat. Lumicl. Mold. super. $h$ j., L. respremen kit in aran. ad torr. Putna L. hispirtum $L$ in coll. Mold. infer. - Pondospermm osturgutare Loth. in palusl. Mold. tot., I. Iaciniatum Dr. in prat Mohl. tot, $I$. intermedium Giuss. in prat. Mold. sup?r. - Trugopogon majus .Jaeq. in arenosis Mold tot., T. porrifolium L. in prat. Mold. infer., T. undulatum Jaeq. in prat Putzeni, T matnese L. in prat. Mold, tot., T. minus Fries. al litl. Dannl, Galatzi, T, centupestipe Bese. in syly. Faurei, T. lirescens Thess, in prat. sals. Galalzi. scorzonera mollis Bieb. in coll. arell. Holel. infor.. S. Janugincsn Burg. in sylv, aren. Mold infer, s. rosere Kit. in prat. mon!. Muld. super. h. j., S. hemilis $L$ in prat humid. MIsll. super. h. j. S S. hispenter L. in prat. humicl. Molls. super el cult. - Picris hieracioiles L. arl marg. agr. Mold. tol., P. Sipmengeriane Lom. in syly. Putzeni - Lachere virosa $L$ in aggeribus MIold. infer.. I. Sca-

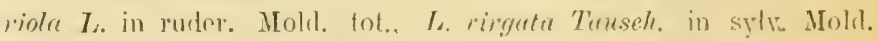

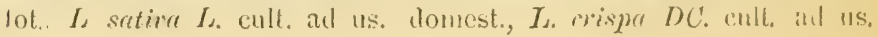




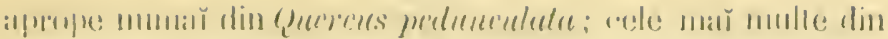

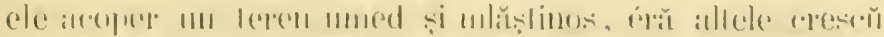

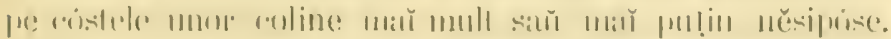

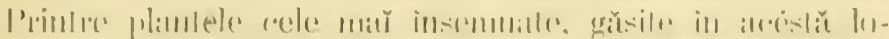

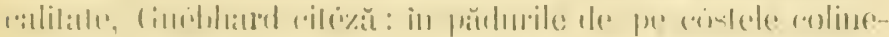

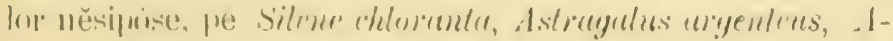

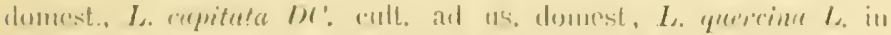

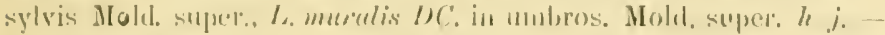

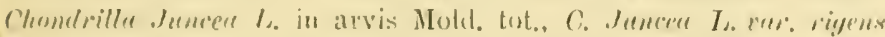
in arenosis Pekia, r'. prenenthoieles V'ill. in pral. lumnicl. Ziganesci. - Tarorucum Dens-leonis Dess. in prat. Mrold tot.. 'T' se-

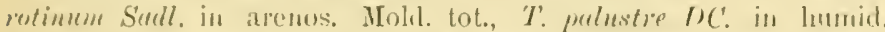
Pulzeni, T. corniculutum DC. in aren. Mold. super. h. j. - Crepis

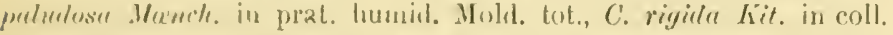
l'ekia, C. "gyestis Kit. in arvis Pekia, C. tectormm I. in sylvis Inold. tot. C. tretorne I. rerr. segetulis, in arvis Mold. Lot., C. teeforum I. reer. grecilis in sylv. Mold. infer., C. corymbose Ten. in

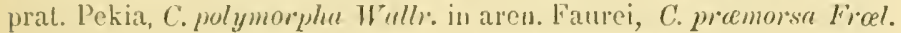
in herb. mont. Carpath, h. j. - Barlhausier fatila DC. in humil. Putzeni, B. faraxucifolia IDC. in arenosis Mold Lot,, I3. setosa I)C. in aspr. Motel, super. h.j - sonchus palustris $L_{\text {. }}$ in prat humid. Mold. tot., s. fullax Wullr. in olerar. Mold. tot., s'. tenerrimus $L$. in olerac. Mold. infer. - I'rmunthes pupuree $L$. in sylv. Mold. merl. et super. - Hieracium rilloselle $L$. in coll. MIold. tot., $H$. Bunhimi Bess. in sylv. monast. Scînteia, If sumentosum Frœl. in coll. aren. Pekia, 11 . flayclare Wills, in prat. Mold. tot, $H$. brachiratum Berlol. in coll. Iold. infer., 11 . pratense T'ausch. in prat. mont. Mold. med., II. prealtum Gochn. in prat. mont. Mold. med., II. prealtum Gochn. v. abscurum Frel. in sylv. mont. Mol. med., II. collimum Gochn. in coll. Mold. super. h. j, H. umbellatum L. al margin. sylv. Mold. med. h. j., II. Sabandum All. in sylv. Mold. merl. h. j., H. prellescens Kit. in pasc. edit. Carpath. h. j., H. spherocephutum Kit. in sum. jug. Carpath. h. j., H echioides Lumn. in șylv. Mold. infer.. $H$ auruntiacum $L$. in prat. hunrid. Slanik, $H$. cymosum Vill. in sỵlv. Mold. infer.. H. prenanthoidcs Vill. in prat. Molvl. infer., H. sylvaticum Smith in sylv. Arlami, H. sylrestre Trussh. in syly. Mold, infer., H. rirosum Pull. in sylv. Mold, infer.. 11 remosum Willd. in sylv. Adami. H. gracile Frol. in sylv. Itold. merl. - Mulyedium alpinum Less, in prat edit. Carpath. $h . j$. l'ampanulacear. - I'hytemme conescens Kit. in syly. Mold. med. 


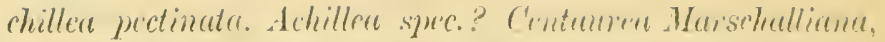
(j. depressa, Cirsium ectum, Thesium atgens. Iris sipua-

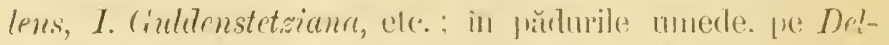

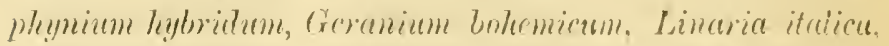

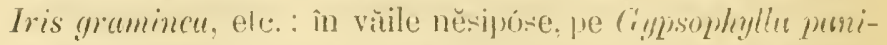
culate, Lavatera psendo-oblia, I. sreticu, C'empanula mul-

et infer. I'. puctuglorum h. in prat. edit Carpath. h. j. - Cumpuralu Merlium L. in syly. Moldl. super. hi j., C. direryens IVilld. in sylr. Monast. Scînteia, C. alpinu .Jer. in pasce. edit. Carpatlı. h. j., C. siltivicu I. in prat. aren. Mold. infer., C. ylomeratu L. in syls. Mold. med. et super., C. multiflor' Kit. in prat. Pekia, C. thyprsorides I. in pasc. eclit. Carpath. h. j., C. lutipolin L. in sylv. Mold. Lol.. C. repunculociles $L$. in syly. Mold. tot., C. Romonirnsis L. in sylv. Mol. infer., C. Bononensis I. r. ruthenicu in syly. l'ekia. C. linifoliu I. in prat. Mold. merl. et super., C. persicafolirs L. in sylv. Mold. tot., C'.

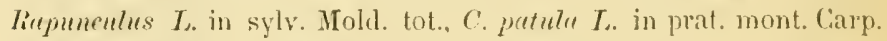
h. j., C. spetulatu siluth. in prat. mont. Carpath. h. j., C. collinu

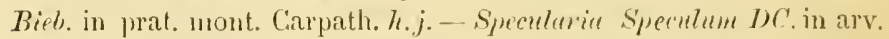
Mold. super. h. j., S. hybridie DC. in arv. AFold. super. h. j.

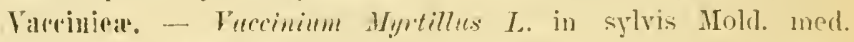
el super., V. uliginosum L. in uligin. Molı. super. H. j., Ir. Titisilece $L$. in sylvis Moldavix superiore.

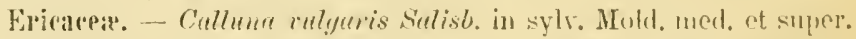

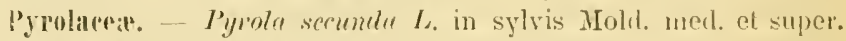

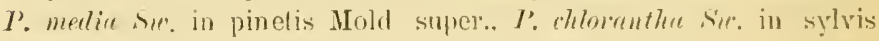
Mold. med., $P$. intumlifolin $L$, in sylvis Moll. super. M. j. - Moneses greudiflore Sulist. in sylvis mont. Carpath. h. $j$.

Lentibularieat. - Ctriculurie rulgaris L, in stagn. Mold. super.

Primulacear. - Primele officinatis Jucq. in sylvis Mold. tot.., P. elatior Jacq. in sylvis Mold. super. h. j., P. minima $L$. in sum. jug. Carpath. h. j., P. furinosu L. in uligin. Carpath. h. j. - Ciregorie Vitaliune Dub in sunn. jug. Ciarpath. h. j. - Antlossece vil-

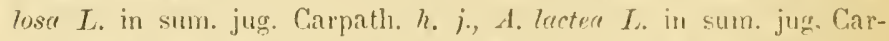
path. h. j., A. elongate $L$. in vineis Mold. infere, A. maximu $L$. in vineis Mold. infer. - Cortusa Muthioli $L$. in mont. Cirpath. $h . j$. - Soldanelle alpina $L$. in turfosis mont. Carpath. h. i. Lysi-

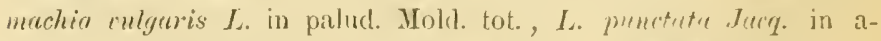
ren. Mold. med. et super., L. mumulurie $I_{\text {. }}$ in hmu. MIoll. lot., $L$. nemonum L. in sylv. Mold. super. h. j.--Aungallis urensise L. in

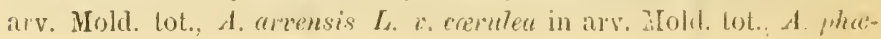




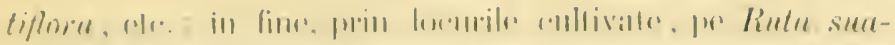

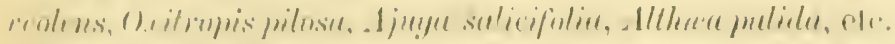

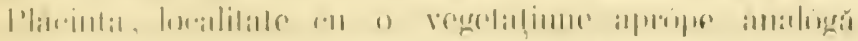
•ll

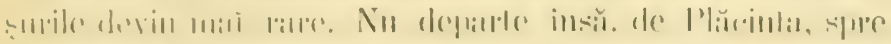

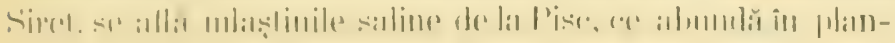

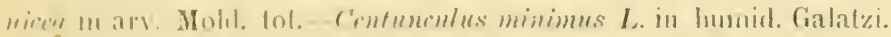

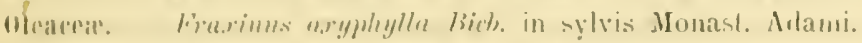

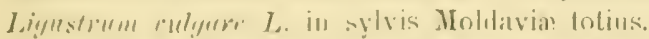

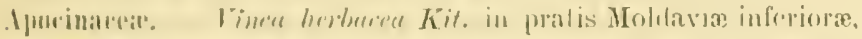
1. mimn h. in silvis Muldavie superion: he j.

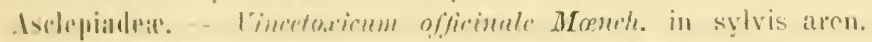
Molal. tol. - ("ynumehum acutum I. in oleraersis Mold. infer.

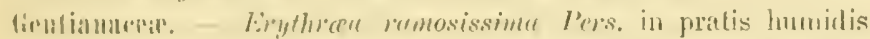

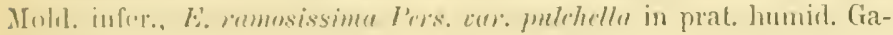

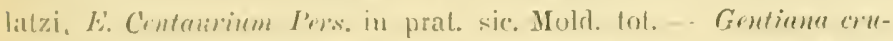
rivele $L$. in prat. Inmuil. Monld. tot., G. Amerelle $L$. in pratis Mold.

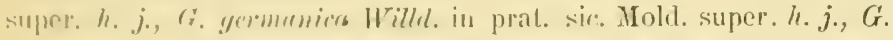

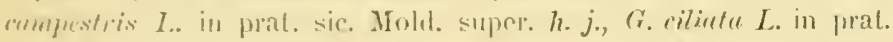

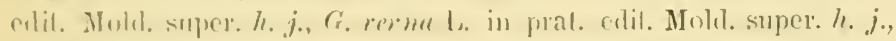

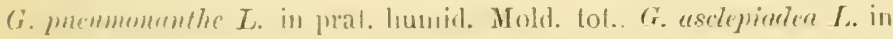

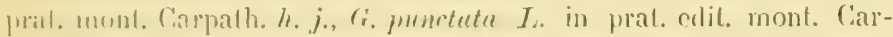
fallh. h. i., Limmanthemum nymuloides Link. in fossis Galatzi.

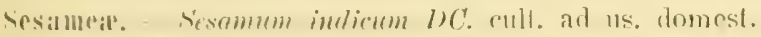

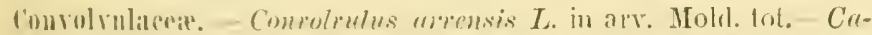

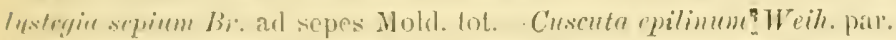

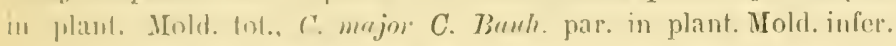

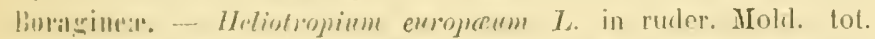

Cerintle mojor Is, in arvis Molil. super. It. j, C. aspora lioth. in arvis Molld. super. h. j., C. minor l. in arvis Molde tot. - behium

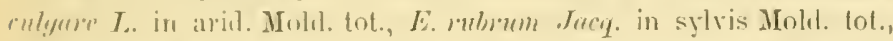
li. seritemm ITahl. in arcuos. Pekia. - Lithospermum arense $L$.

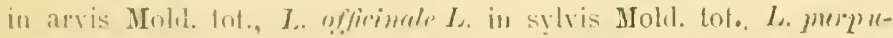

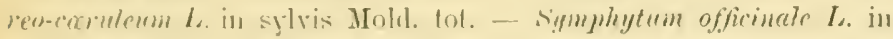
lumid. MIold. Int., s'. cordatum Kit. in humid. Nold. super. h. j., S. bullutum Jacy. in syly. Monast. Arlami. - Lyropsis arrensis L. in arv. Mold. tot.. L. putln Lam. in arenos. Mold. med. ef infer. - Onosmere echioides $L$. in prat. Moldo infer. - Pulmonaria officinalis $I$. in sylvis Mold. tol., I'. angnestifolia $L$. in sylvis Mold, int..

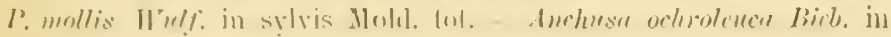


te rare şi curiose, dintre care, Guebhard a cules. pe Ramunculus pedatus, Lepidium crassifolium. Corastium tauricum, C\% oratum, Sium luncifolium, Barburea tauricu, elr.

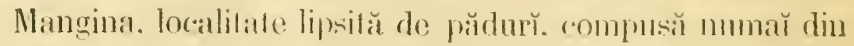

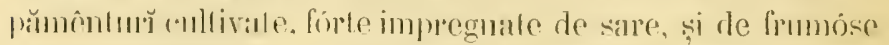

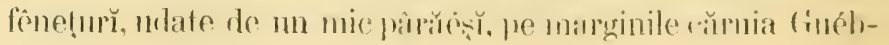

aren. Mold. Lot., A. officinulis $L$. in prat. Mold. tot., A. anyustifolir L. in prat. Mold. tot., A. tinctoria $W$. in sylv. Mold. super. h. j., A. undulutu $L$. in syls. Mold. tol. - Asperugo procumbens $I$. in ruder. Mold. tot. - Lchinospermum Lappula Ithm. in arvis Mold. tot., E. deflexum Lelom. in aren. Mold. infer. - Myosotis collina Ehrh. in coll. Mold. tot., M. arensis Sibth. in arv. Mold. super. h. j., M. palustris With, in aquos. Hold. Lot., M. spursiftore Mik. in sylv. Adami, M. sylvatica Elurh. in sylv. Mold. med. et super., M. cespitosa Schultz. in prat. Mold. med., M. alpestris Schmid. in pasc. mont. Carpath. h. j.. Erithrichium nanum. Schrud. in pasc. inont. Carpath. h.,. - Cynoglossum officinale $L$. in ruder. Mold. tot., C. sylvaticum Sm. in sylv. Mol. tot., C. umbellatum Ǩit. in aren. Tecuci.

Stanacese. - Lycium europaum L. ad sepes Mold. tot. - Car)sicum anmum $L$. cult. ad us. domest. - Solanum Melongena $L$. et var. cult. ad us. domest., S. tuberosum $L$. cult. ad us. domest., S. villosum Lam. in arvis Mold. super. S. ochroleucum Bost. in arvis Mold. infer., S. nigrum $W$. in arvis Mold. tot., S. Dulcomara L. in humid. Mold. tot. - Iycopersicum esculentum Mill. cult. at us. domest. - Physalis Alliekengi $L$. in sylvis Mold. tot., Atropa Belladona $L$. in sylv. Mold. med. et super. - Datura Stramonium L. in olerac. Ifold. tot., D. levis L. in olerar. Nicoresci. - Nicotiana Tabacum L. cult.-Hyosciamus niger $L$. in olerac Mold. tot.

Serophulariacear. - Terbeseum Thropsus I. in arvis Mold. tot., $V$. Blattaria L. in humirl, Mold. tot., V. I'haniceum $L$. in prat. Mold. infer. et med., I'. lychnitis L. in prat. Mold. inler., V. compactum $L$. in sylvis Mold. infer.. V. peniceum Schr. in prat. Mold. infer, V.gallicum $W$. in arvis MLold. super. h. j.. V. pyramidatum Bieb. in arvis Mold. super. h. j. - Linaria minor Dest. in arvis Mold. super. h. j., L. spuria Vill. in arenosis Faurei, L. alpina DC. in glareos. mont. Garpath. $h$. j., L. vulgaris Mench. in arv. et vineis Mold. tot., L. genistifolic Mill. in arenos. Galatzi, I. dalmn. tica Mill. in arvis Mold. tot., 1.. italica Trev. in sylv. Pekia. Srrophularia nodosa $L$. in humid. Mold. tol., S. aquatica $L$, ad torr. Mold. super.. S. glanduloser Kit. in umbrosis Faurei, S. Iaciniota 


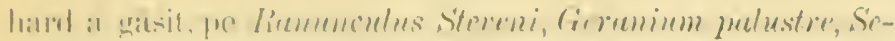

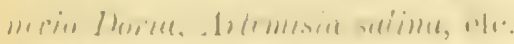

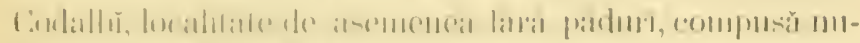

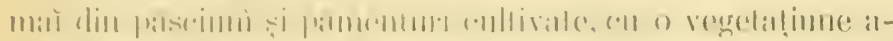

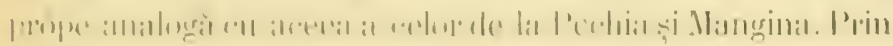

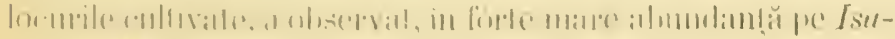

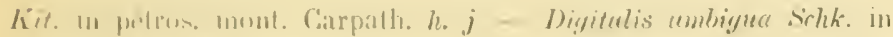

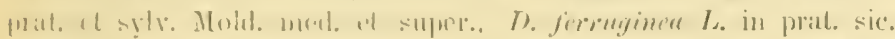

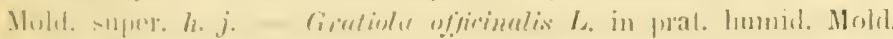

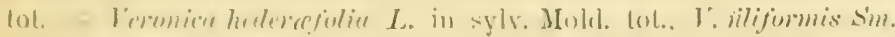

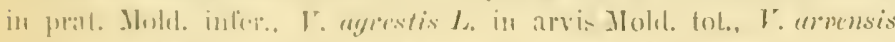
1. in arvis Mohl. Wol., H. triphyllos L. in arvis Mold. tot., r. pere-

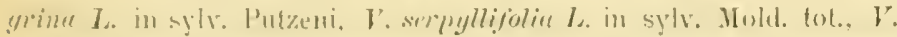

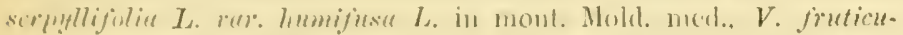

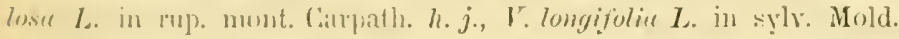

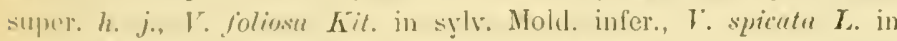
sylv. Mold. neel. of super., I: nulecte l'uhl. in coll. arid Pekia,

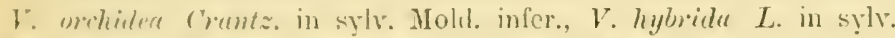
Mold. super. h. j, T. officinalis I. in syly. Mold. med. et super., I. Cleumatrys 2. in sy. Mold. tot., V. lutifoliu L. in syiv. Hold. meal. el super, $I^{\circ}$ Tenerium $L$. in prat. sic. Mold. tot., $V$. seutel-

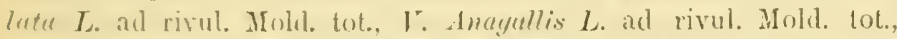
V. Becerebunga L. in humil. arl fl. Sereth, $V$. anstriuca $L$. in prat. inolil. tol., I. orientulis dit. is coll. Putzoni, - Melempyrum arense 1. in arvis Moli. tot., 1\%. cristutum L. in prat. Mold. tot., I.

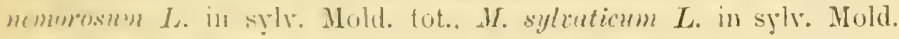
super. - l'sticuluris foliase $L$. in prat. Mold. met. et super., $P$. juluwhis $L$. in prat. lumid. Mold. super. h. j., I. revticillatu $L$. in pasce vdil. Carpath. $h . j$, , $P$. rostrata $L$. in past. edit. Carpath. $h . j$. - likinunthes yluber Lam. in prat. Molel. tot., R. glaber Lam. rar. minor in prat. mont. Carpath. h. j., li. hirsutus Lem. in sviv. Mold. fot. - Gdentites rubre bing. in arvis Mold. super. h. j. - Euphersive oficinotis $L$. in prat. Mold. meal. et :uper. k. $j$.

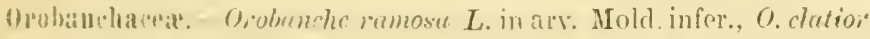

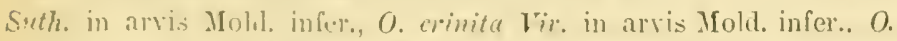

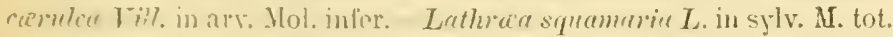

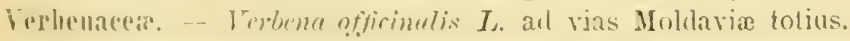

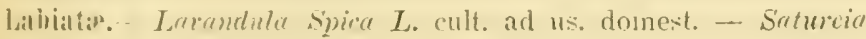
hometensis L. cull. ad us. domest. - Wentha pipirita $Z$. cult. ad us.

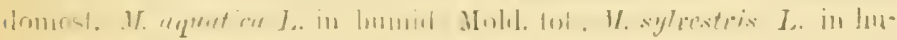


tis macox : éră de prin păsciunĭ, a reroltat în 1843, pe Sisym-

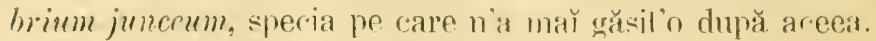

P’uțenı̆, localitate constituilă de ioline, ree forméd̦ă punctul culminanl al podișulŭ Moldovĕ de jos anve de acolo se plécă

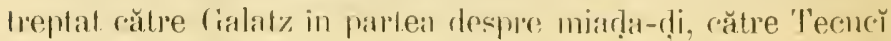
in partea despre nord. I'lanlole rulese de cimóbhard in aréstă

mid. Mold. tot., M. viridis $I$. in sylv. Mold. Lot., M. arrensis 1 . in arvis Mold. tot., $M$. Pelegim $L$. in humid. Mold. tot., Me cervina

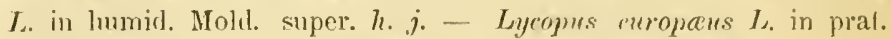
bumid. Mold. tot., L. exaltatus L. in prat. humicl. Mold. Lot. -Sulvin sylestris $I_{\text {. }}$ in arvis et pratis Molll. fol., S. sylrestris L. A. culba in arvis et prat. Mold. tot., S. sylrestris L. fl. rumo rar. minor in arvis Pekia, $S$. Ethiopis $L$. in prat. Mold. infer., $S$. austriaca $L$. in prat. Mold. infer., S. officinalis $L$. cult. ad us. domest., S. revticillata $L$. in vineis Mold. infer., S. pretensis $L$. in prat. Mold. med. et super., S. Sclarea L. in umlır. Mold. super.-. Origanum vulyure $L$. in camp. Mold. super. h. $j$, O. heractioticum $L$. in camp. Mold. infer., O. Hajorane $L$. cult. ad us. domest. Ocimum Busilicum L. cult. ad us. domest. - Thymus Marchulliumes $W$. in prat. Mold. infer., T. Serpyllum L. in prat. sic. Mold. super. h. j., T. citriodorus Bing. in syly. M[old. super. h. j., T', hirsutu..

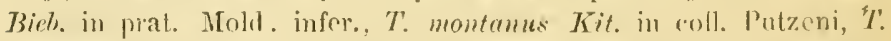
grareolens Bifl. in monl Okna. T. lemuginosis Srhk. in prat. Mold. super. h. j., T. Aciuns $L$. in arvis Mold. tot. - Melissu officiuntis 1. in syly. Mold. int. - Clinoportinem relyure L. in syly. Molil. Iot.

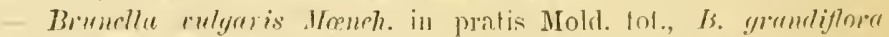

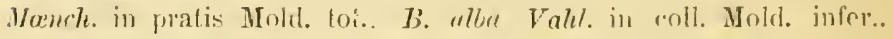

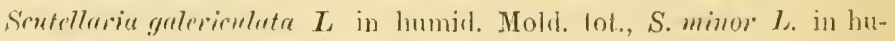
mid. Mold. super. $h$. j., S. peregrina $L$. in sylv. Mfold. Int. - Nepeta Cutaria $I$. arl vias Mold. tol., N. pmonomiar $Z$, in sylv. Mold. med.

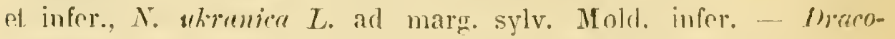
rephalum moldavica L. cult. ad us. domest., D. austrierum L. in coll. calcar. Mold. super. h. j. Melittis melissophyllum $L$. in sylv.

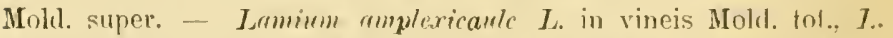
pu'purem L. in olerar. Mold. tot., L. levigatum L. in syly. Mold. tot., L. maculutum I. in pomar. Mold. super. h. j., L. album L. in pomar. Molsl. super. h.j., L. incisum Willd. in vineis Mold. infer., L. ruggosum dit. in svlv. Molrl. infer. - Ironurus Cardiaca $I$ in humid Mold. Int., L. villosus Desf. in pral. Moll1. infer. - Gle-

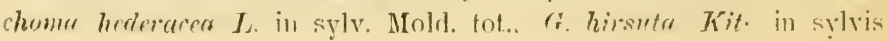




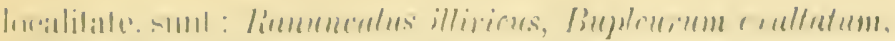

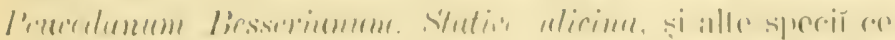

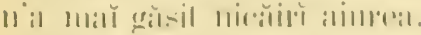

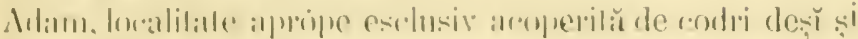

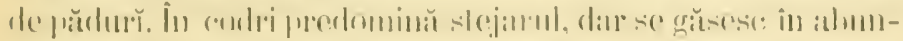

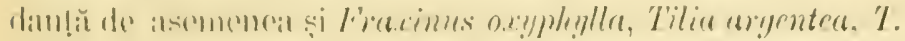

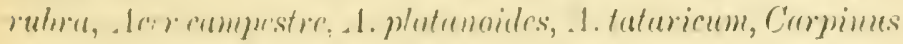

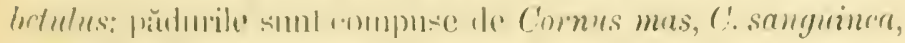

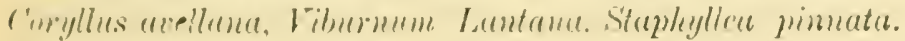

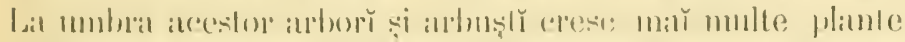
insemmate, precum : Corydulis Morschulliona, Lathyrus

Molul. infor. - Gulenbenton 7outeum Huts. in syly. Hohl. tot. -

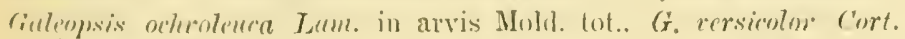
in sy. Arold. meil, et super., G. Imelumm $L$. in arvis Mold. super.h.,., G. Timmlit L. in olerac. Mold. super. h. j. - Stachys germenire $L$. in arvis Molıl, tot., S. pulustris $L$. in prat. humid. Inld. fot., sta arensis $L$. in arvis Mold. tot., S. syleatica $L$. in s.j. Mold tot., s. anmun $I$. in arvis Mold. tol., S. hirta $L$. in itrvis Mold. infer. - Betonica officinalis L. in syls. Mold. tot. sinteritis montuna $L$, in arv. Mold. infer. - M/armbinm rulgare $I$. in incult. Mold. Lot., M. peregrinum $L$. in arv. Mold. infer. - Ballotu nigru .. in olerac. Mold. tot. - Mhlomis herbo-tenti L. in alvis Molel. med, et infer., Ith. tuberose $L$. in prat. humic. Mold. infer. - Tencrimu Laxmanni Murr. ad marg. sylv. Mold. infer. T. Sermdium 1. in humid. Mold. tot. h. j.. T. Botry." I. in sylv.

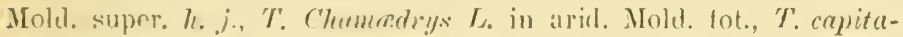

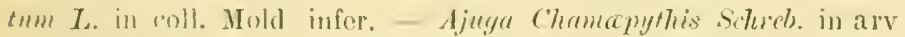
Mold. sıper. h. j., A. Chia Srherh. in arvis Molel. infer., A. salici-

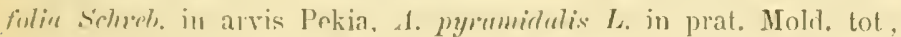
A. repturs L. in syly. Mold tot.. A. Generusis I. in pratis Moldavire superiore h. i., .1. alpriur $I_{2}$, in pase edit. Carpatlı. H. j.

Plumbaginear. - Stutier Tuturien $I_{\text {. }}$ in arenosis Molelaria infe-

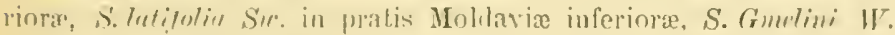
in paluel. sals. Ziganesci. S'. ulicinu Th. in collibus Putzeni.

l'lantaginacerp. I"trnterye major $J_{\lrcorner}$. in prat hmmid. Mold. Int.

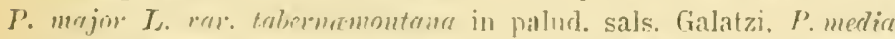
J. in prat. Mold. tof., I'. lasenenteifor I. in prat. Mold tot., P. Corunti fomern, in palud. sals. Pisen, P. arenarin Kit. in arenosis

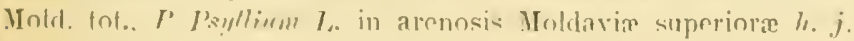




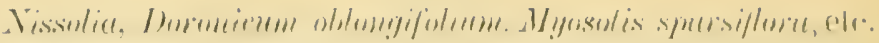

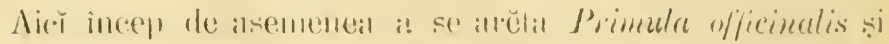

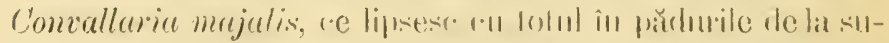

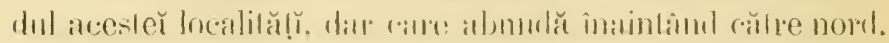

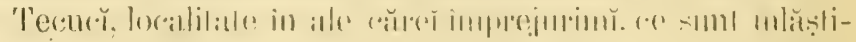

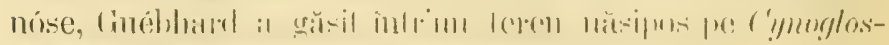
sum umbellatum si slinm are merium.

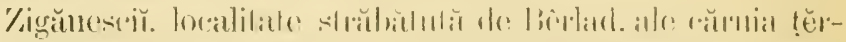

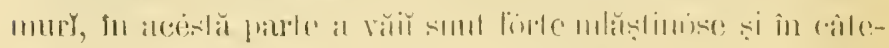

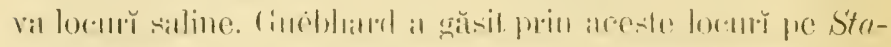

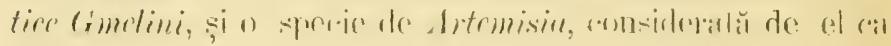

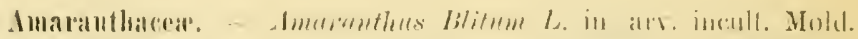

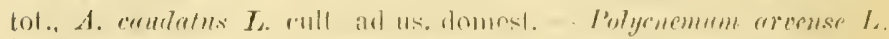
in arvis Mold. Lot., I'. jumiperimm Birh. in inoll. aren. Cialatzi.

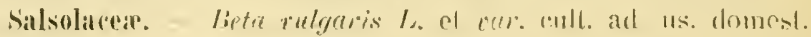

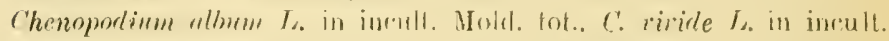

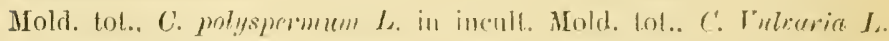

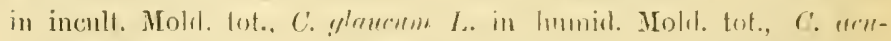

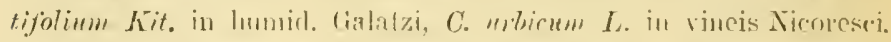

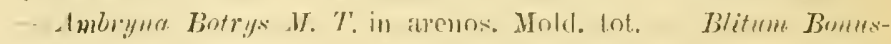

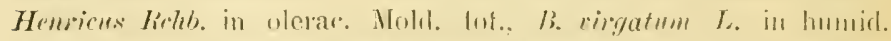
Mold. med. et super., li. conpitatum $L$ in lumbid. Mold. med. of

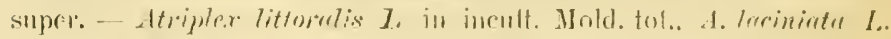

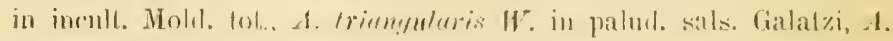
hortensis 2. in ulecar. P'ulzeni, A. Jesmenii, . J'. in olerar. P'e-

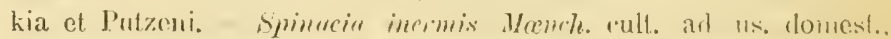

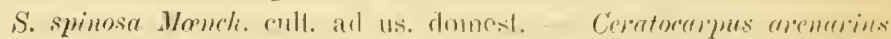
L. in arvis Mold. inler. - Kochin scropation .t. T. in olerac. Molst.

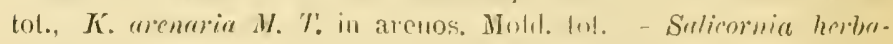

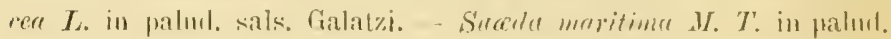
sals. Galatzi. - Sulsole Köli $L$. in arvis Moldavie inforiorme

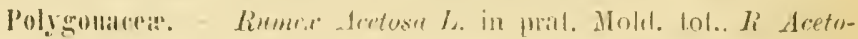

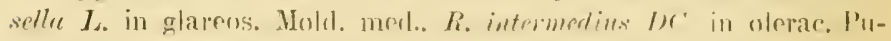

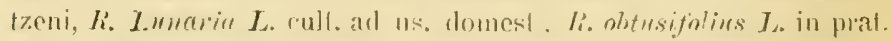

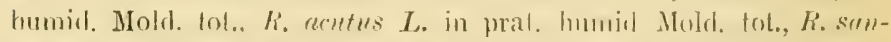

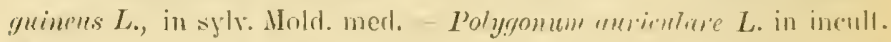
Mold. tot, I'. Bellareli All. in syly. Pelia. P. Alestellore Jicitol in

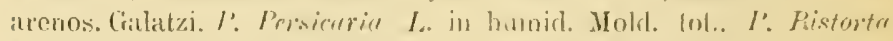

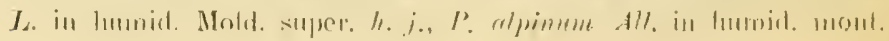




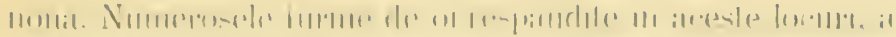

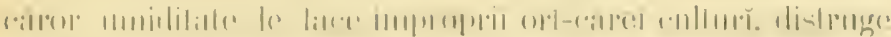

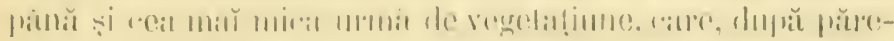

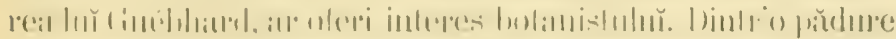

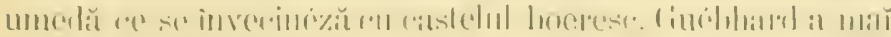

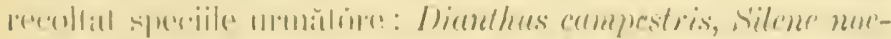

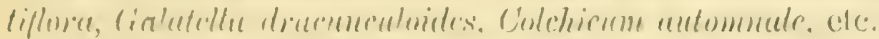

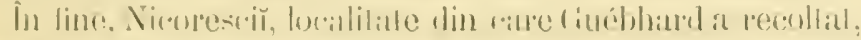

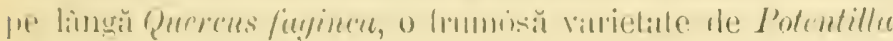

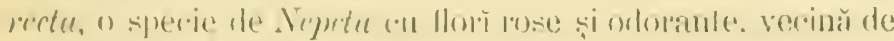

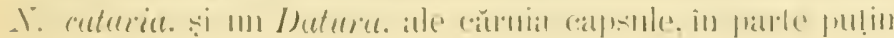

Carpath. h. j.. I'. riripurem I. in hmmid Mold. supere. h. j., I'. M!!-

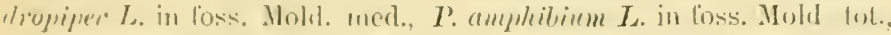

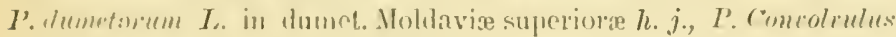

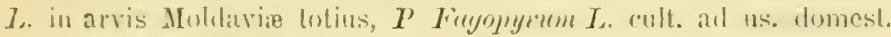

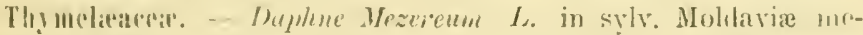
dies ef stperiore, 1 ). alpina $L$. in lapirl. mont. Carpath. $h . j$.

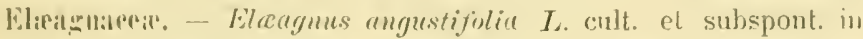
Molil. tul. - Miprophaë themmoides $I$. ad torr. Mold. Int.

Silltalarear. - Thesinm ebrecteatum IFay. in prat. Mold. super. h. j., T. u!finum I. in pasc. clit. Garpath. h. j., T. remosum Haq. in prat. Molt. snper. H. j., T. elegun. Rochel art marg. sylv. Pekia. T' humier rethe in collibus arid. MIoldarie inferiorx.

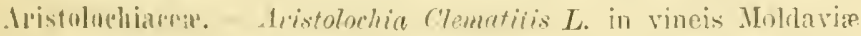
lutius. Asurem meropam $L$. in srlvis . Ifonast. Adani.

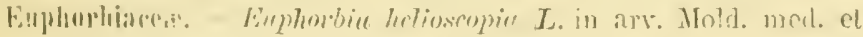

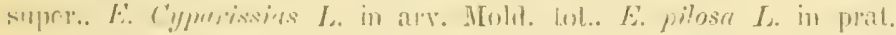

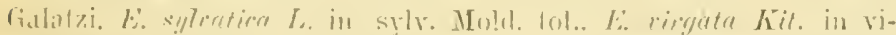

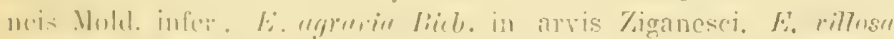
kit. in prat. Mold. super. he, j., F. duleis L. in prat Molil. super. h.

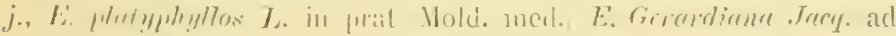

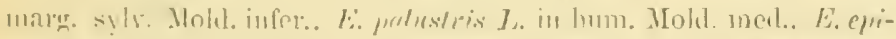

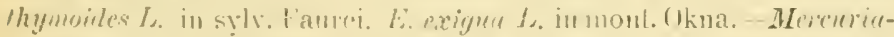

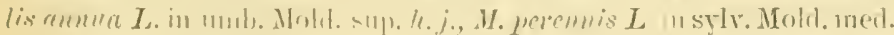

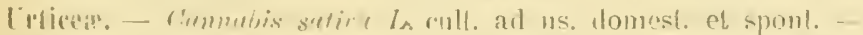

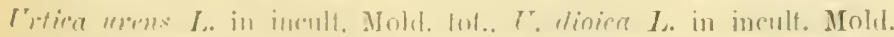

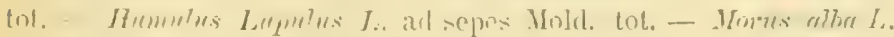

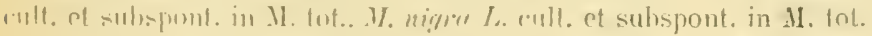

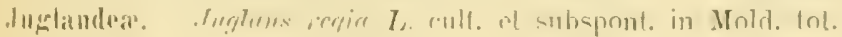




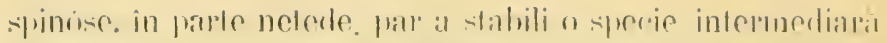

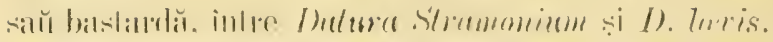

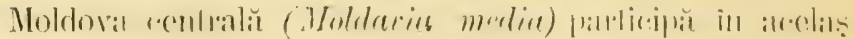

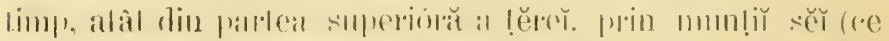

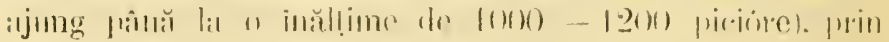

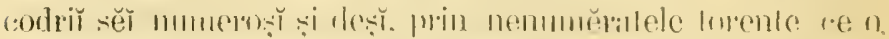

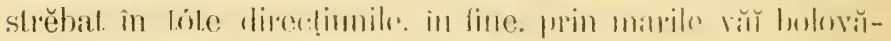

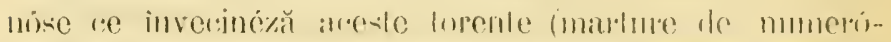

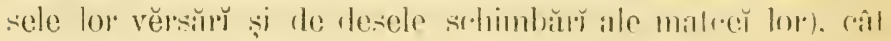

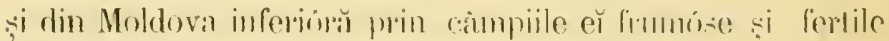

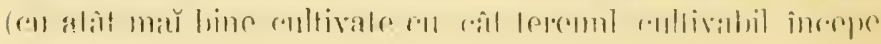

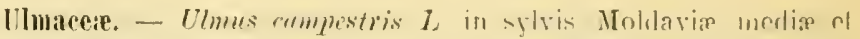

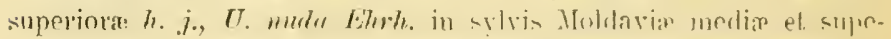

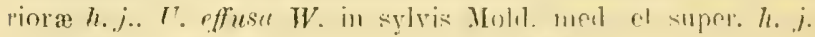

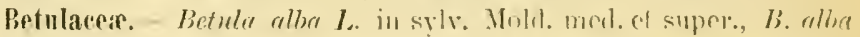

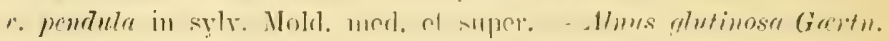

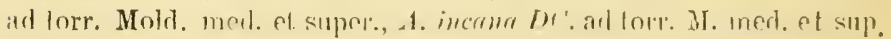

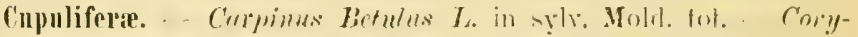

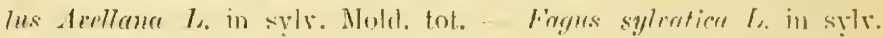

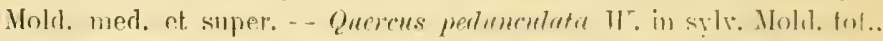

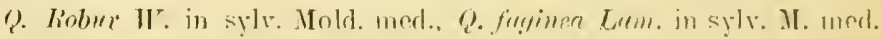

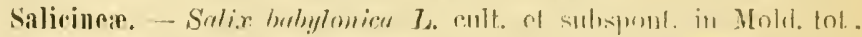

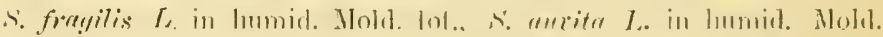

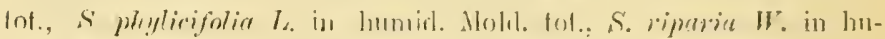

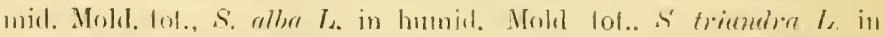

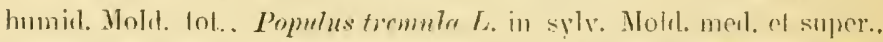

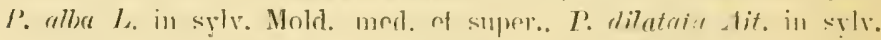

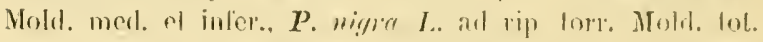

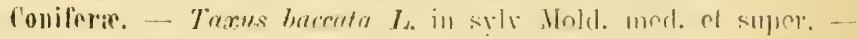

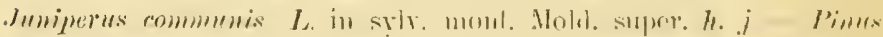

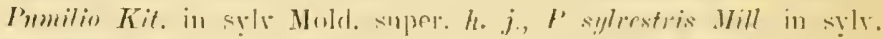

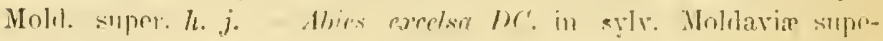

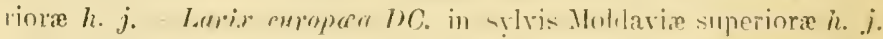

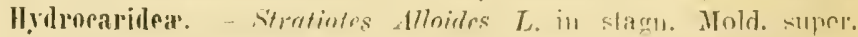
h. i. - Itydrochuris Ionsus-reno. L. in staren. MIold. super.

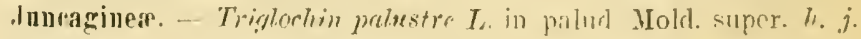

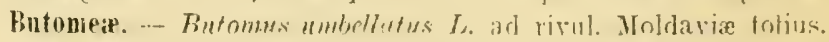

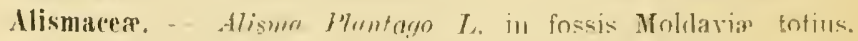

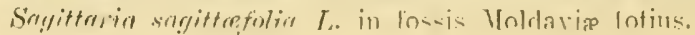




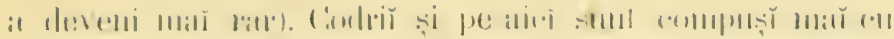

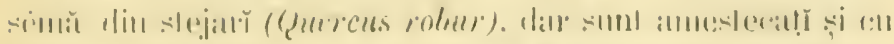

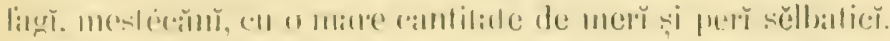

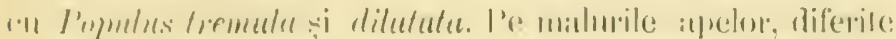

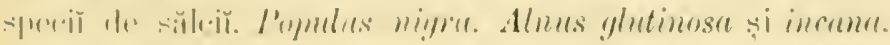
di(1)

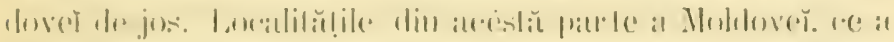

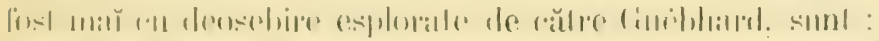

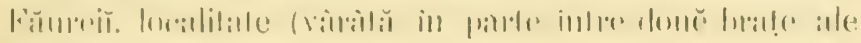

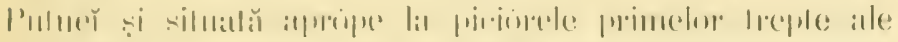

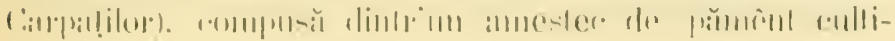

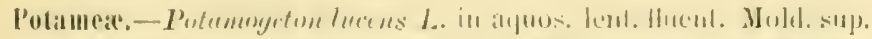
h. i., P. crispum L. in aquos. Ient. Huent. Mold. sup. h. j.. I'. setuerum

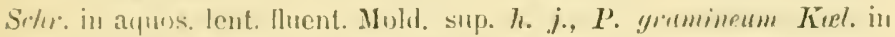

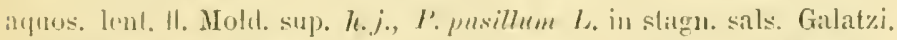

Mrehideid. Orehis ulbide All. in prat. Immirl. mont. Molıl. supel. h. j.. (). odurutissimu L. in prat. humid. mont. Mold. super.

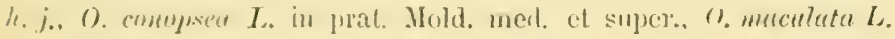
in prat. Mold. med. el super., O. lutifolin l. in prat. MIold. meal. "t super., ") musculin L. in prat. Mold. med. ol super., O. sambutcina $I_{\text {. }}$ in prat. mont. Mold. super. h. j., O. pretustris Jecq. in palusl. mont. Molkl. super. h. i., O. Morin $I$, in syly. Mold. infer., O. "erriegute Lrem. in sylv. Molel. tol.. O. militeris L. in prai. Molel. super., O. coriophora $L$. in pral. Inld. super., O. ustuluta $L$. in prat. Mold. super. h. $j$, () glolense $I$, in prat. Molel. super. $h$. j.. (). pyjominlulis I. in prat. Mold. -mper. h. j., (). bifolia L. in splv. Iolel. tot., O. angnstifolie Lois. in prat. Mold. super. h. i., O) inrervate L. in prat. Mold. super. h. $j$., (). Monoreh is L. in syvis

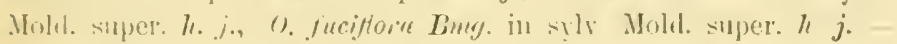

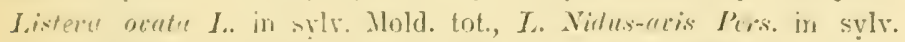

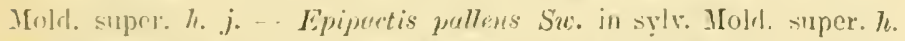

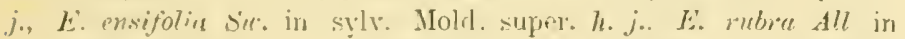
sylv. Mold. supes. h. j., E. latifolia .lll, in syly. Mold. super. h. j.,

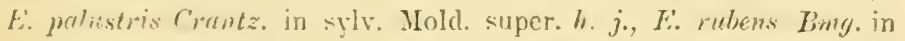
s.ly. Molll. super. h. j-Corallorhiza Hallori Rich. in pal. mont. Ilold. super. h.j. . C'ypriperdiun C'aleolus L. in umbr. Molil. super.

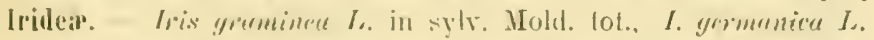
lipepuentis, cull., I. Guldensterltzirna Lap. in coll. P'okia, I. squalens.

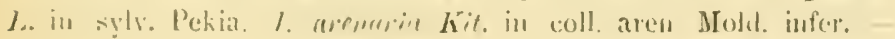




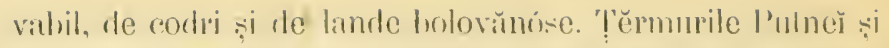
numerosele er insule aroplerile de liorberis enlyuris, Tumu-

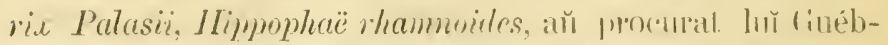

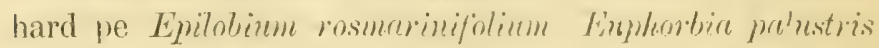

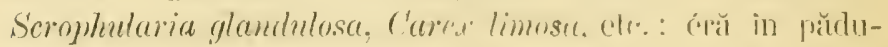

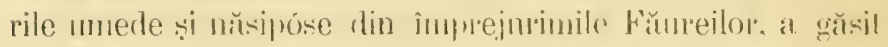
pe clemutis inteyrifutia. Althren anmahime. Limum complanatum, nereosnm, Lythram virgatum, Seranthemam cilindrucemm, S'escli pencelanifolium, Serutula coronutu si câte-vil alte planle. mă fuḷin insemulale. daur pe rale mu le-ă̌ intâlnil în Moldovat de jos.

Glueliolus imbricatus $L$. in pratis humidis Ioldatiae superiore $h$. j. - Crocus minimus Red. in collibus Moldavin inferiors.

Amaryllideat. - Lencoinm estivum $I_{\text {. }}$ in pratis Galatzi. Gulanthus niculis 1 . in pom Noldavia superiors $h . j$.

Smilacear. - Aspreragnes afficinulis $L$. in sylv. Mold. tot., A. temeifolius Lam. in silr. Molte. infor., A. revticillutus $L$. in sylvis Mold. super. h. j. ... Streptomes amplexijolius DC: in sylv. M[ol]. super. h. . . - Paris quadrigolie $L$ in sylv. Mold. super. h. j. --

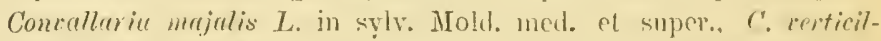
late $L$. in sylv. Mold. med. et super. - I'oluynuatum rulyare ${ }^{\prime}$. in sylv. Mold. tot., P. multiplomem G), in sy]s. Mosld. tol., l'. polyan-

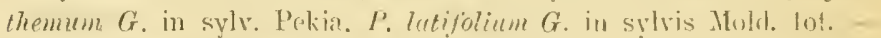
Mreanthemem bifalinu $D r^{\prime}$. in sylvis Moldavis intius.

biliaced. - Tulipe syllestris L. in sylv. Mrold. super. - Frititlaria Meleagris $L$ in sylv. MIold. snper. F. Iutea Bifl, in splvis

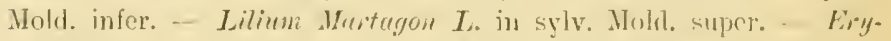
thromium Dens Cunis $I$. in sytv. Mold. super. - I'nalumpium Irrmosum Lam. in arenos. Wold. inler. - Antherirum serotinum L. in pasr. edit. Carpath. h.j. - Scrille bifolia $I$. in sy.lr. Mold. tot Musceri meemosum Mill. in roll. Mold. tot., M. pallens Bess. in arenos. Pekia, If, comoszm . Vill in sylv. Molul. Int. Cruye: pusilla $I_{\text {. }}$ in aren. Mold. infer., G. villose Duth. in vineis Mold. infer.,

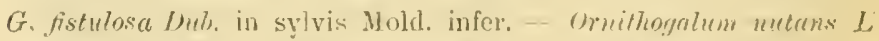
in umbios. Mold: tot., O. refiastem W. in vimeis Mold. infer.

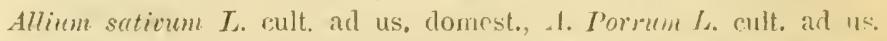

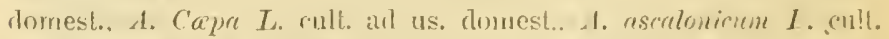

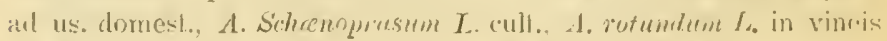

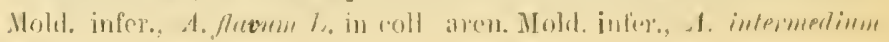




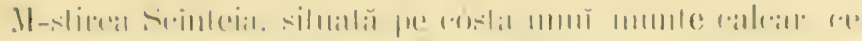

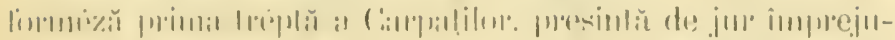
|

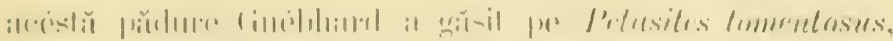

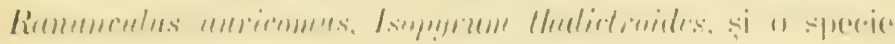

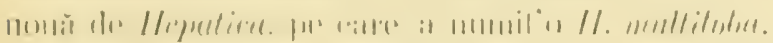

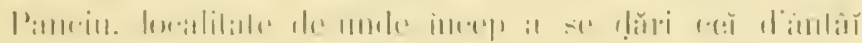

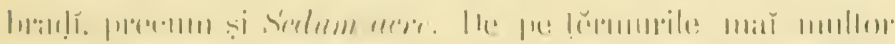

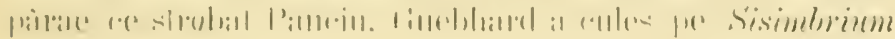
strietisstmillm).

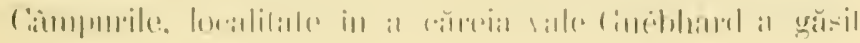

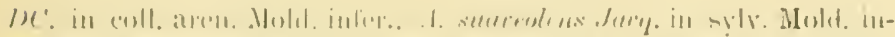

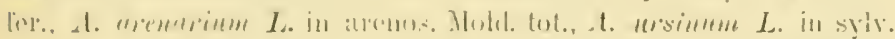

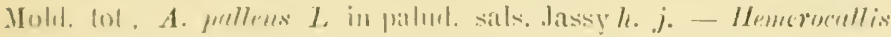

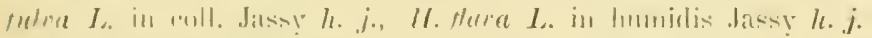

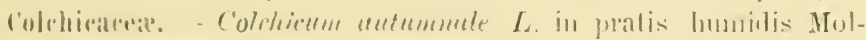

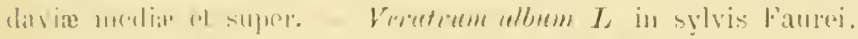

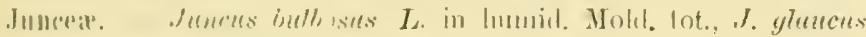

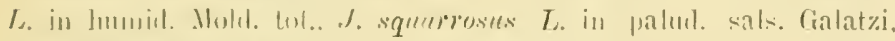

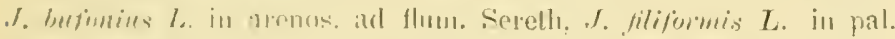

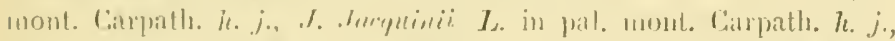

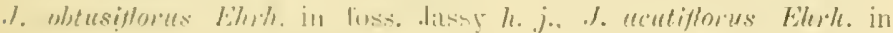

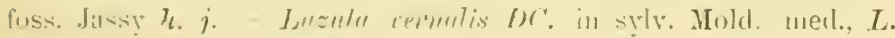

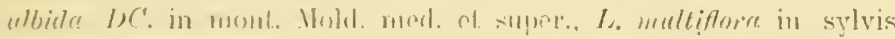

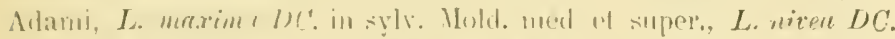

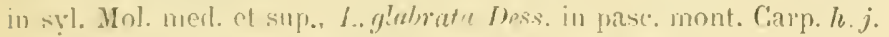

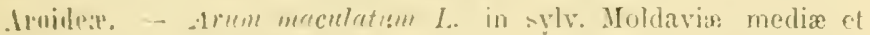

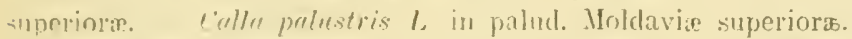

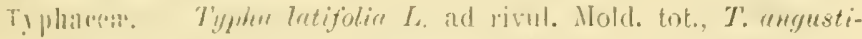

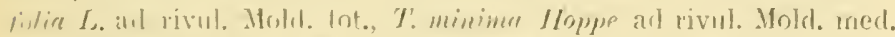

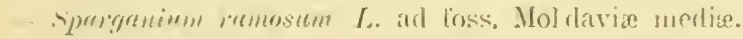

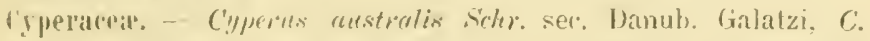
fiscus $L$. in arenos. sec. flum. Sereth. -- Schenues mecromates $L$. in humid. l'nl\%eni. - Siripus larustris $I$. in stagn Mold. tot, S'. tripupler L. in humid. Mold tol.. S. pahestris L. in prat. humid.

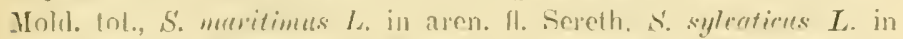

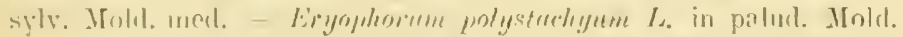

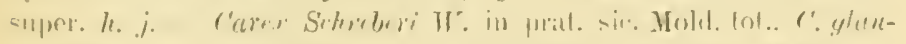

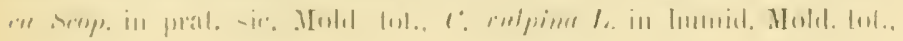


re Campanula linifolia, Sinnpis tanrica, Myricaria germanica, Rumes: acetoscllı ior. multifitus, și câte-va finmóse umbelifere.

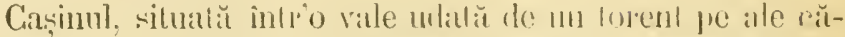

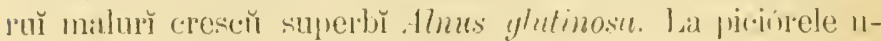

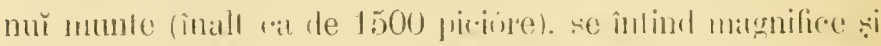

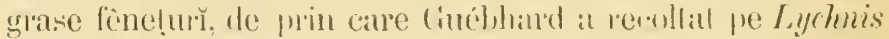

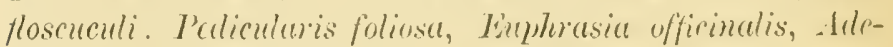

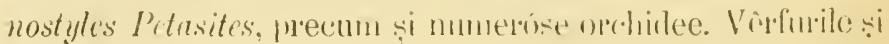

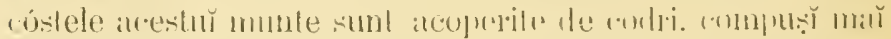

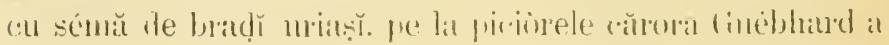

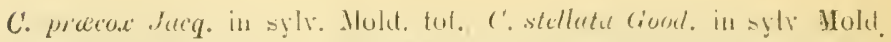
lut. C'. oectis Good. in arvis Mold. tot.. ('. limosit I. in prat. lutmid. Mold. ned., C. hirtn L. in sylv. Mold. tot. C. humilis Leys. in mont. Mold. mal., C. priluse Serp. in syly. Molıl. med., C. sylreatica Hats. in sylv. Mold. tot.. C. petula scop. in sylvis Mold. med., C. brizodiles I. in sylv. Mold. ned., C. divien L. in pralis Mold. super. h. j., C. ulba $L_{\text {. }}$ in prat. MLold. super. h. j.. C!. teretinscule Good. in sylv. Mold. super. h. j., C. strieta Gooul. in sỵlt. Molrl. super. h. j.. C. viculuris W. aul rivul. Molil. super. h. j., C. nemenosa Lumn. in sylv. Mold. super. h. j., C. clundestina Good. in sytr. Mols. super. h. j., C. cupillaris L. in prat. Mold. super. h. j., C. umbiosit Huds, in sỵv Mold. super. h. j., C. paniceu 1. . in Mold. super. h. j., C. atrute L. in pase, edit. Carpath. h. j., C. digitata L. in prat. sic. Mold super. h. j., C. Pstulo-Cyperus L. in humid. Mold. sup. h. j.. ('. ripueria Good. in hum. Mold. super. $h$. j.

Graminere - Mitium londigerem Sched. in arvis Mold. infer.. 1\%. Tolriforme Sue in arvis Mold. tot. - Panicum miliacenm L. cult. ad us, romest. - Digitariu sanguinalis P'ers. in vinejs Mold. infer. - Setarice tividis $I$. B. in prat. Mold tot., S. resticillata $I$. B. in incult. Mold. tot., S. glanca $P$. B. in arenos. Faurei, S. itcalice I: B. in arv. Mold. infer. - Echinochlor Crus Galli Roth. in incult. Mold. tot. - Tragus racemosus Desf. in arenos. Mold. tot. - Andropogon Ischermum L. in arenos. Mold. infer. - Holcus Surghum L. cult, ad us. domest. - May.s Zer Giertu. cult. ad us. doinest. - Crypsis schenoides Lum. in pal. sals. Galatzi, C. ulogecurnides Sch. in aren. Mold. infer. - Hopecuras pratensis L. in prot. Molel.

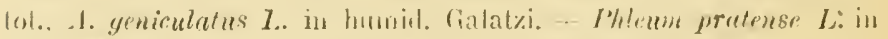
prat. Mold. tor.. I'. undosem L.. in jurat. Jould. Lot. - Calomentro- 


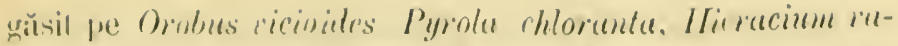

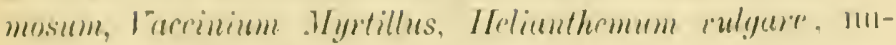

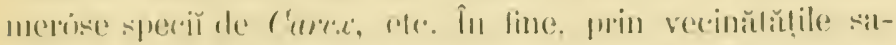

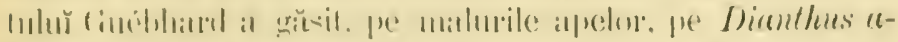

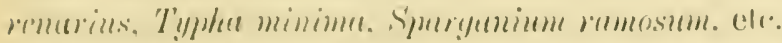

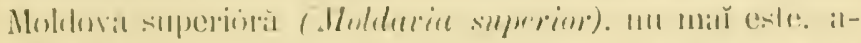

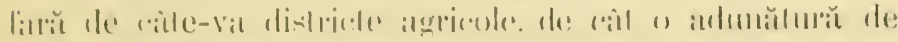

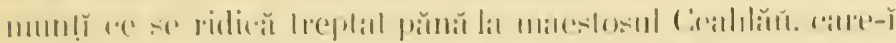

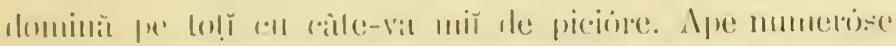

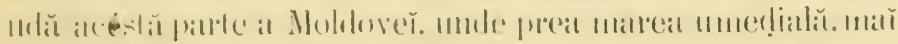

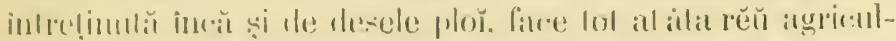

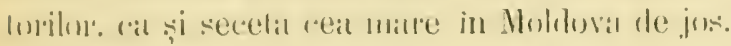

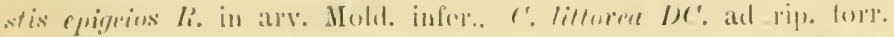

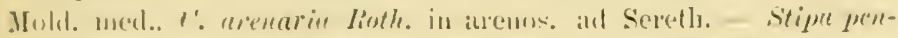

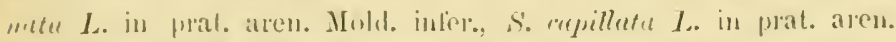
Nolds. infer. - Cynenton Inectylon Pers. in incult. Mtold. tot. - A-

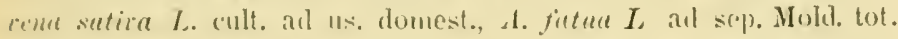

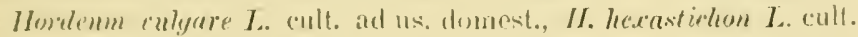
ad us. dounest., II. distichon 1. atd us. domest. II. secellinum schet, in prat. Mold. tot., II. murinem L. in iscoult. Mold. tot. - Jolium

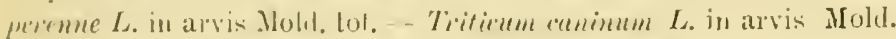
tot., T. repens $I$. in alrvis Mold. tot., T. rigitum sicheb. in arenos. Mold. infer., T'. saticum Lann. cull. all us. clomest., T. compositum L. cull. all n1., donnest., T. durum loesf. cult. ad us, domest. -

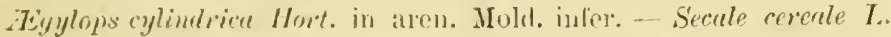

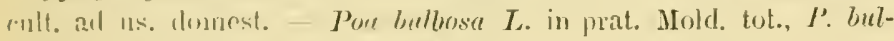

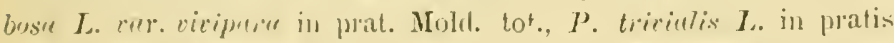

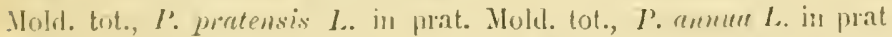

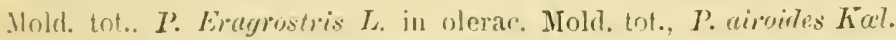
in hunicl. Molil. tot, P. decumbens Sihr. in pral. sals Mangina.

liviza media $L$. in svlv. Mold. tot., B. minor $Z$. in svlv. Mold. silner. - Melice ciliata $L$. in sy.lv. Molr. super. et infer., M. mutans

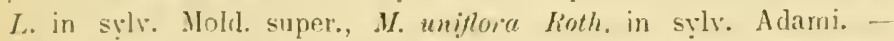
Kalerie cristatu Perw. in prat. Mold. tot. - Dactylis glomerate I. in prat. Mold. tot. - Festuce ovina $L$. in arid. Mold. tot. - Arundo Phrectgmites L. in stagn. MIold. tot - Bromus squarrosus $L$. in prat. Nols. tot.. B. tectorum $L_{\text {. }}$ in prat. Mold. tot. B. rubens $L$. in prat. Molil tol., B. mollis $L$. in prat. Hold, tot., $B$ racemosits $L$. in prat.

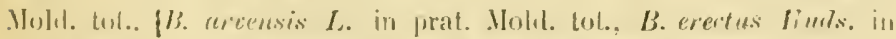

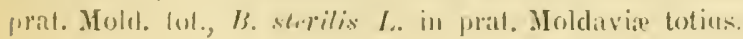




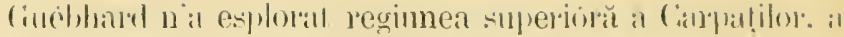
răriar vegelaḷume n’o romósep de câl diu ileial generală

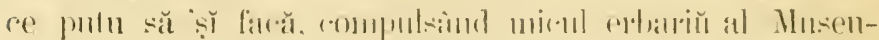

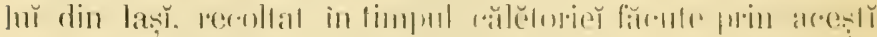

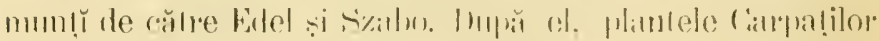

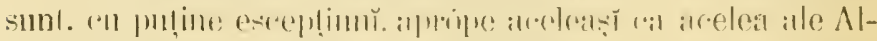

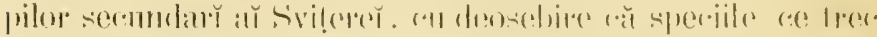

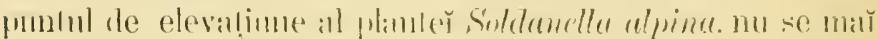

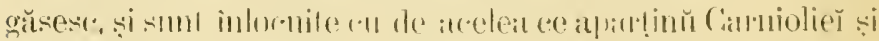

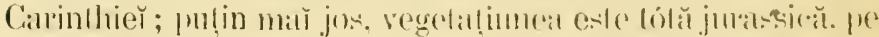

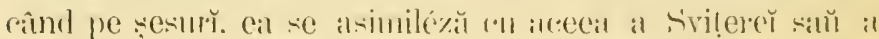

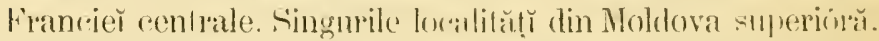

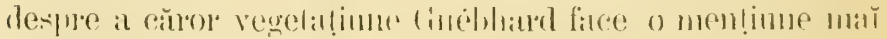

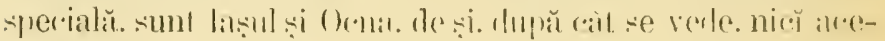

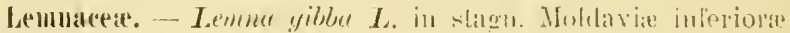

Equisctacers. - Equisetum urense 1. in glareos. Mold. tot. E.

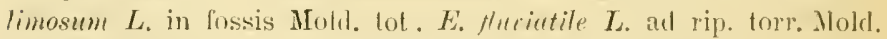
tot., E. palustre L. in humid. Mold. tol. E. sylraticum L. in sy.lv. humil. Mold. super. h. j, E. hiemule L. in sylx. hum. Molıl. sup. h.j.

Piliess - Botrychimem Lumeriu $L$ in pral. edit Carpatls. h.j.

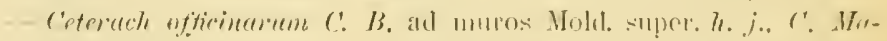

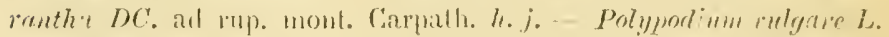

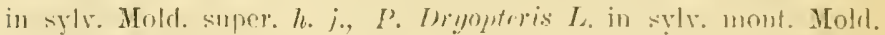

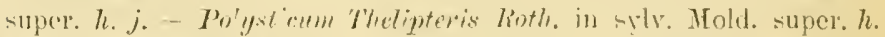

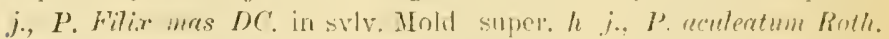
in sylv. Mold. super. 7. j., I. Lom litis Roth. in syly. IIolsl, super.

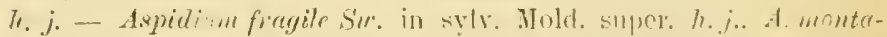

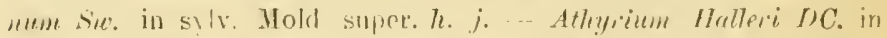
sylv. Mold. suj, भ. h. i., A. Fïlix feminn Roth. in syly. Mold. super.

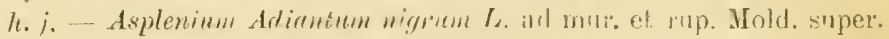
h. $j$, A. Ruta muraria L. algmur. u rup. Molrl. super. h. j.. A. riride

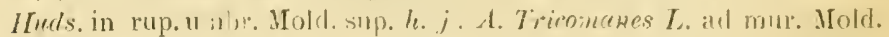
super. h.j.- Sicolopendrium officumle Sir. in hmmid, el mmbros. Mold. super h.j. Birchum spiciut Sir. in prat. Mold. med et super. 7t.j. Pteris aquilina I. ad marg. s:lr. Motd. merl, el super.-Arlautum Conpillus Veneris L. ad font. Molsl. super. h.,j. - Woort-

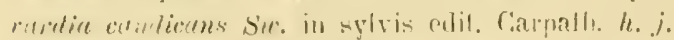

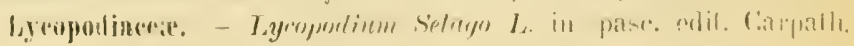

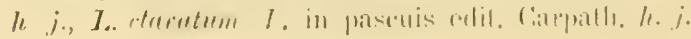


steal 11 :

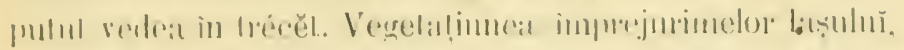

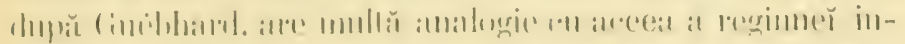

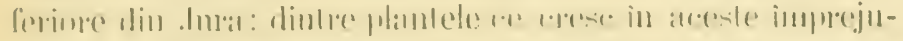

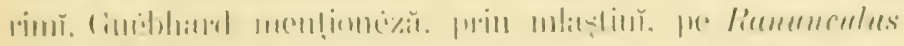

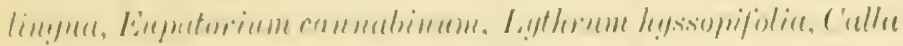

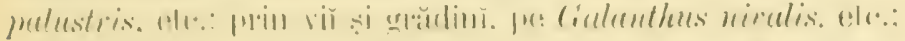

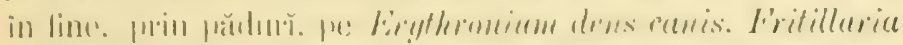

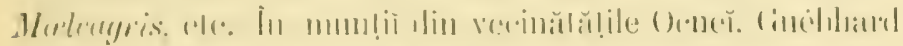

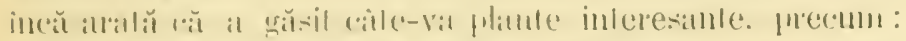

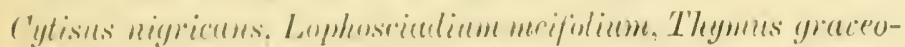

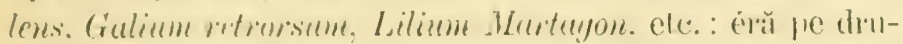

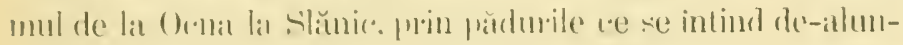

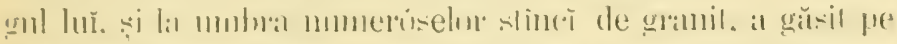

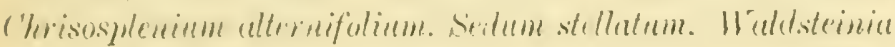

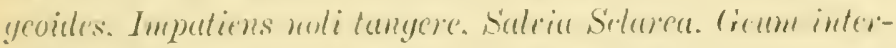

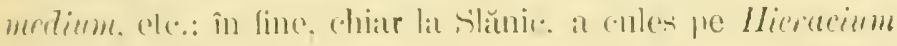

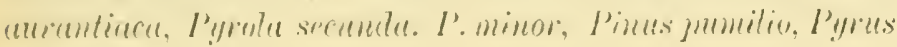
Aucuparia, elr.

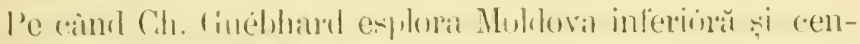

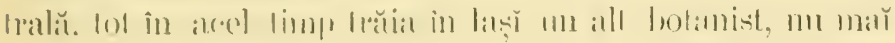

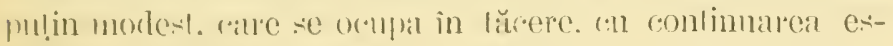

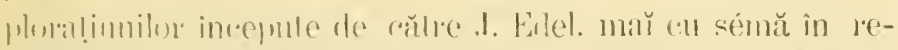

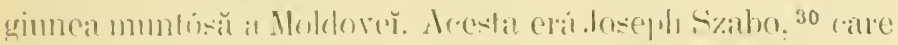

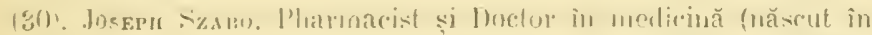

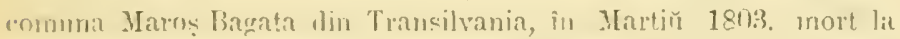

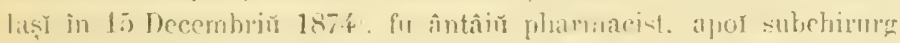
la Ospitalul militar din Iaș, după accena modir servunclariú la Ospitalul contral al sit spirilom, éri lo la $185^{\circ}$ \%, medir arministratol

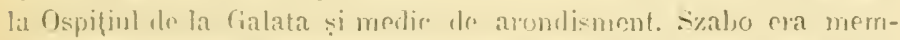

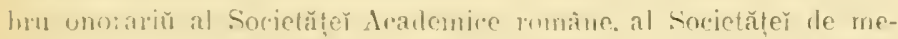

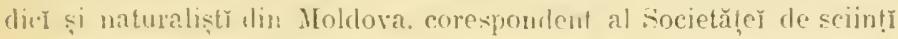
naturale din Hanburg, din Virna. ctr.. și se afla in dese corespon-

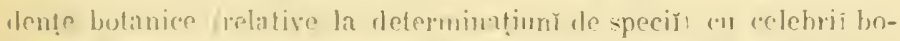

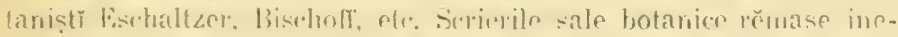

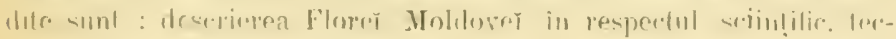

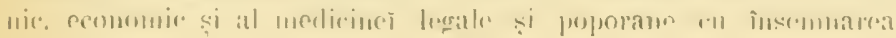




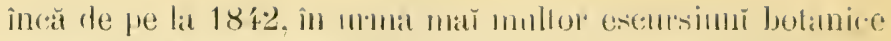

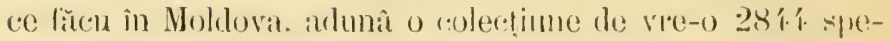

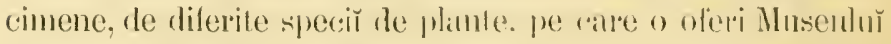

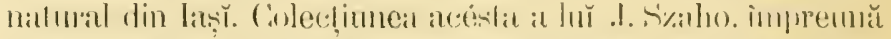

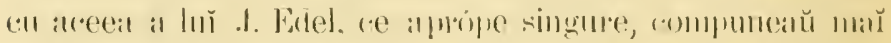

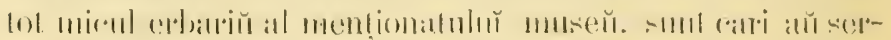

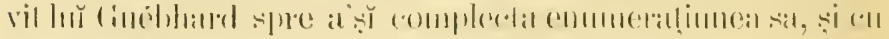

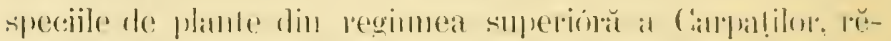

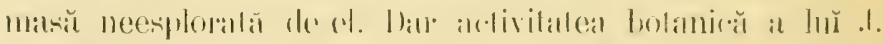

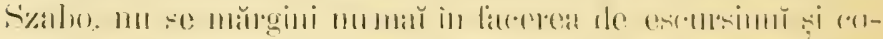

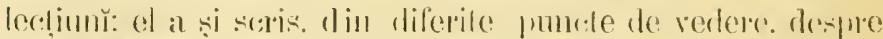

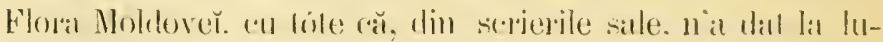

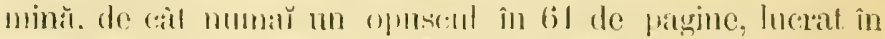

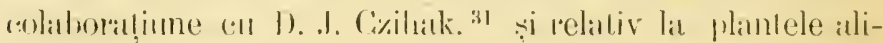
monlate, linclordiste, medicinale, eir.. infledumbalc de că-

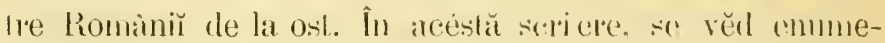

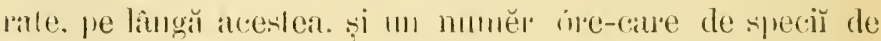

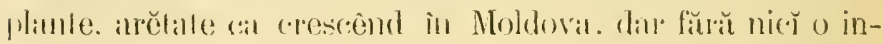

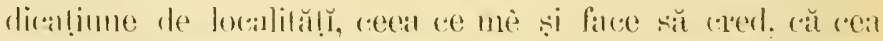

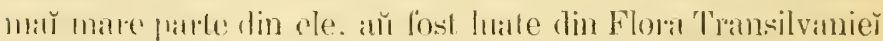
le .l. Bammgarlen. ${ }^{32}$ Considetalimile acestea fac: cal indicat-

geografiĕ plantelor, a localităter și a prŭurutulü ce lo convine mă bine; " disertaf̣un relativă la preumblările sale botanice; Flora judę̧uluĭ Taș̆, ordinată. descrisă și esplicată după sistema

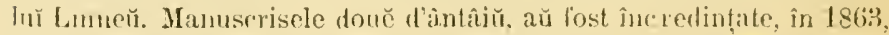
directoruluĩ de $p$ atuncî al serviciulır sanilar; al treitea a frost trinis in 1873, Sorictătec Acadenice române veḍi Anul socict. Acrtd. rom., ton. V1 1871). Manuscrisul din urmă, singurul pe carc l'an věrlıt, este, in c a maí mare parte, o traducere a Flon'oy Transilvanier de Baumganten; cu tote arestea, tol ar jutca fi de órecare folos, raca antomul ar fi posedal mă bine linba română, pe cànd ast-fel cum l'a lăsat, este lipsit de interes. (Datcle biografice co preced, sunt estrase din discursul funcluru rostil la înmormênarea !n̆ J. Szabo de către D. Dr. A. Fetu. ce alı huna-vointa a mi-l comuricas.

(3) ). Da. J. (Zzriak und 1)

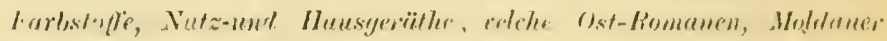

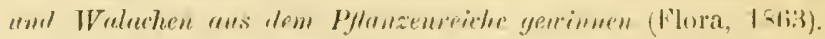

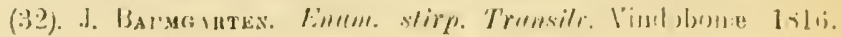


lmmild

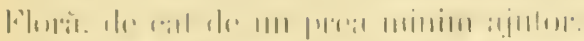

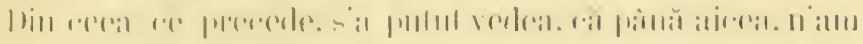

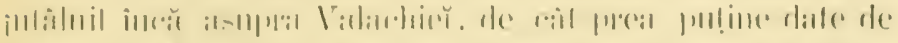

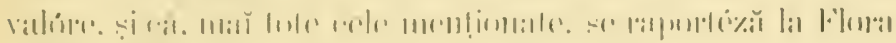

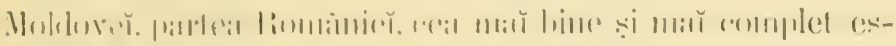

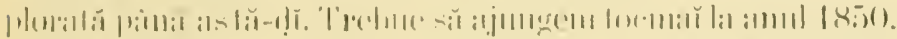

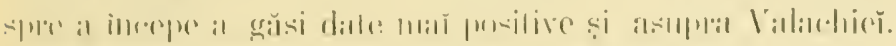
La1 :

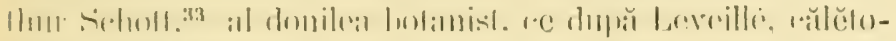

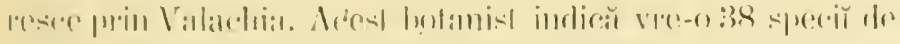

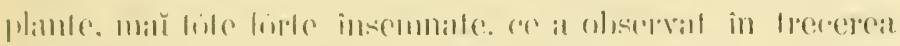

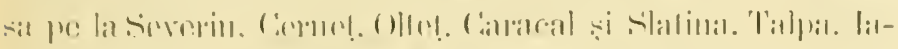

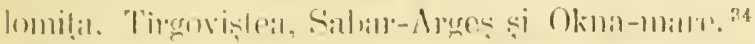

(ail resper mm

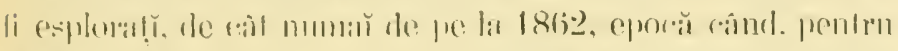

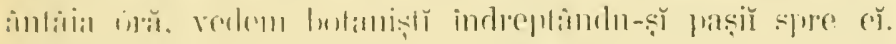

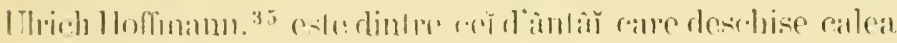

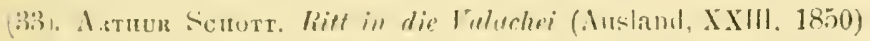

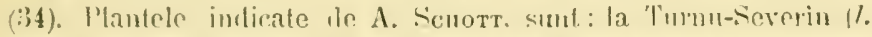

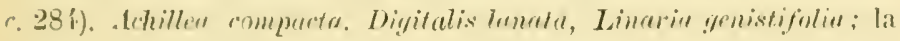

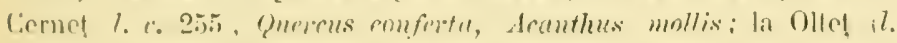

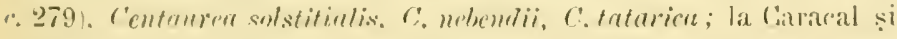

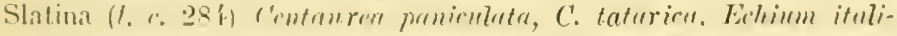

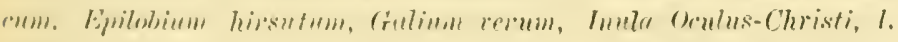

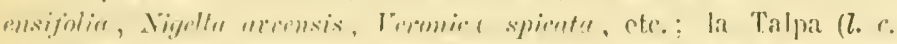

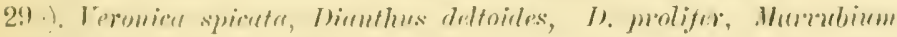

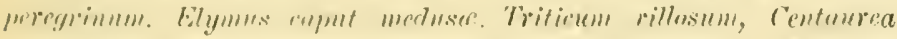

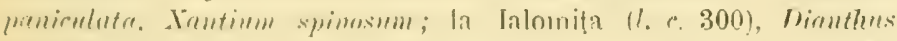

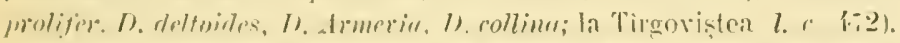

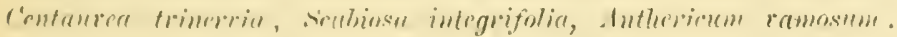

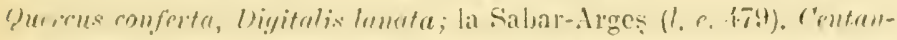

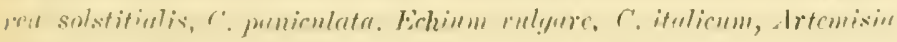

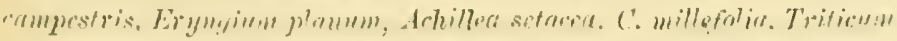

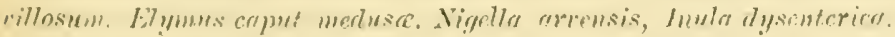

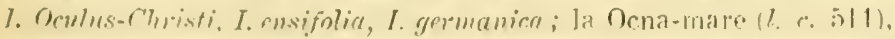

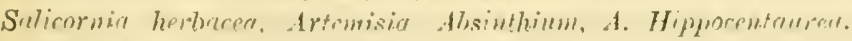

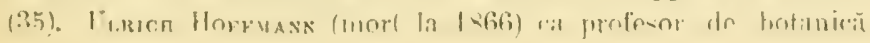




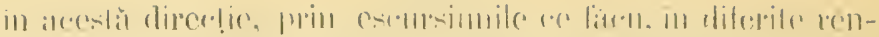

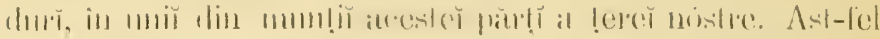

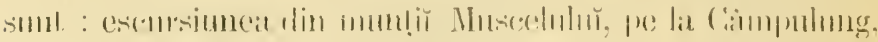

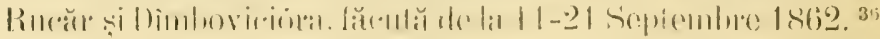

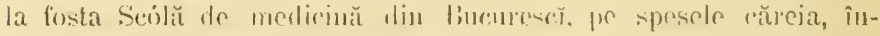

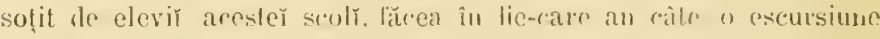

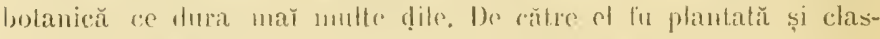
sată fosta mrădină botanică de la Colrmermi, al răreia director a și

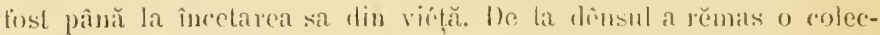
liune de peste 2000 specio de plante, rare, după cail spune D. Dr. Fětu (I. (: 79), ar fi fost tóte rulese din țéra mistră. La 1867, colectimea acésla s'a cumperal de la rĕduva lu Hoffuann, de Eforia spilatelor civile đlin Bucuresč, ce o dlĭłu Asilulŭ Elena-Dónma. Cu tóte ră s’an arut încă ocasiunea de a verlea acéstă colecțiune, totuși pot afirma, după escursimile botanice făcute de U. Hoffmam, că din plantele acester colecținŭ, trelne să fie maí muli de jumăLate, eare provin din speciile cultivate în Grădina botanică de la Cotrocenĭ, atlată sub direcținnea sa

(36). Speciile de plante culese de U. Hoffmaun (Honit. med. al

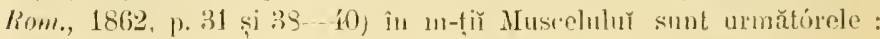

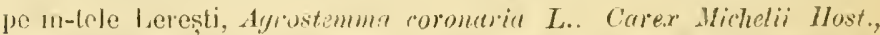

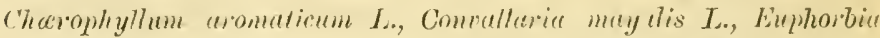
syleatira L., Gentiana Ascle pradea L.. Geranium phaen L.. Salria

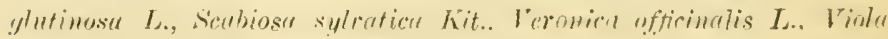

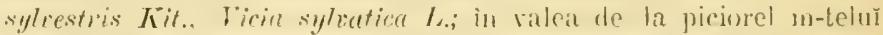

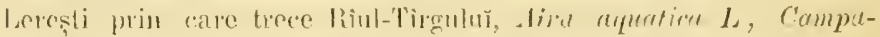

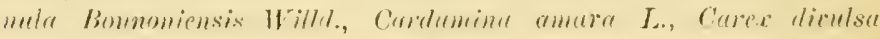

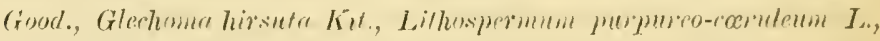

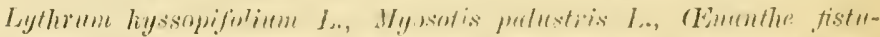

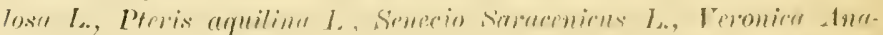

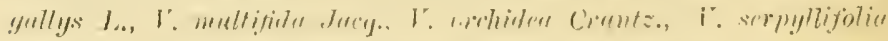

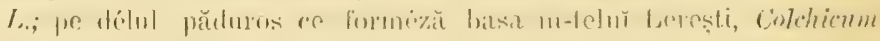

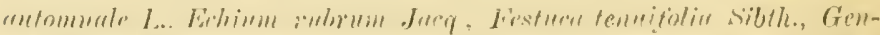

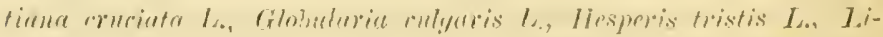

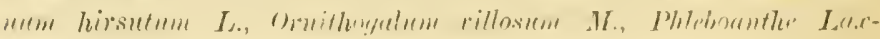

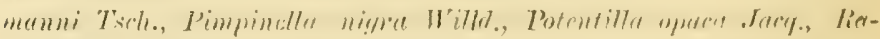

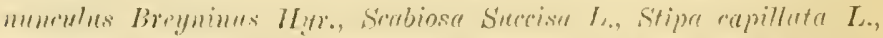

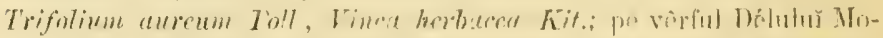

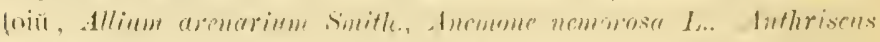

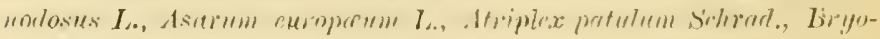

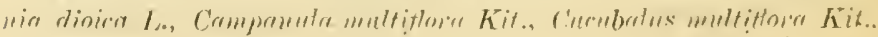




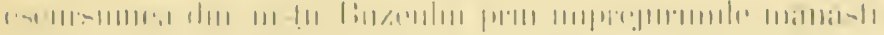

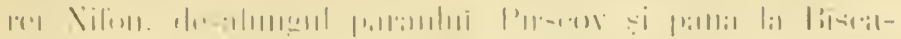

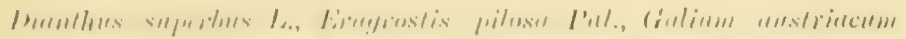

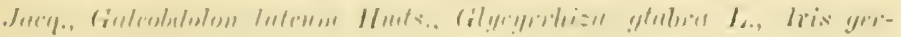

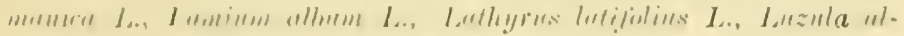

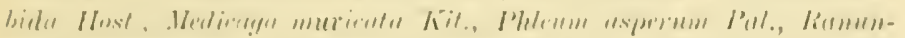

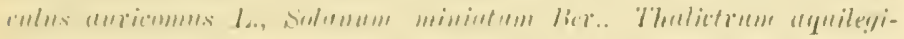

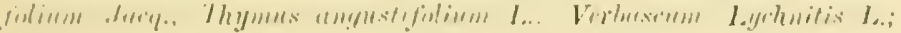

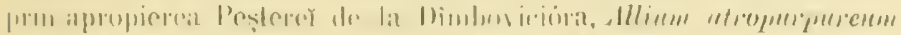

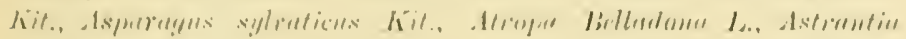

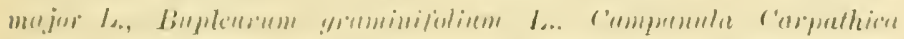

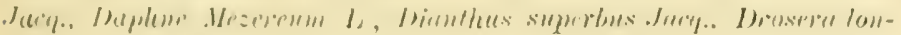

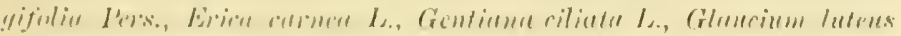

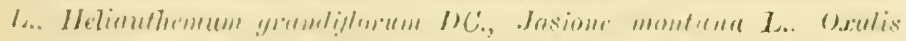

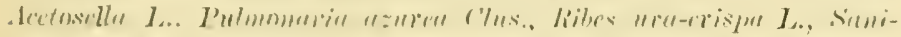

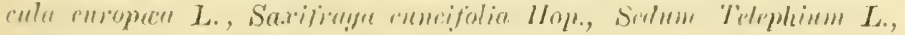

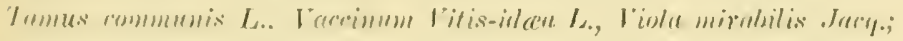

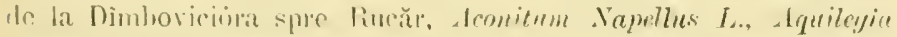

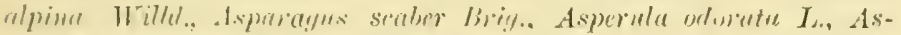

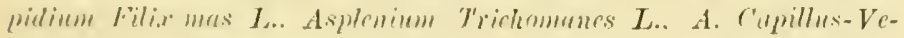

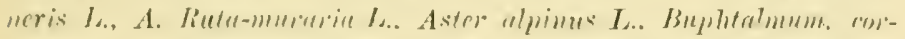

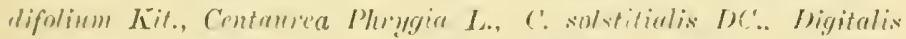

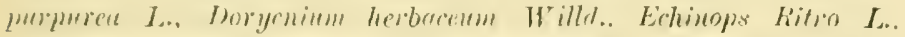

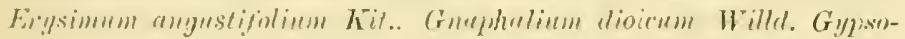

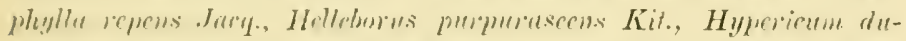

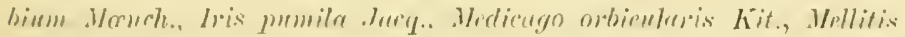
Mrlisophyllum .Jurq., Orolues repums L.. Phlomis tuberosa $L$, Poly-

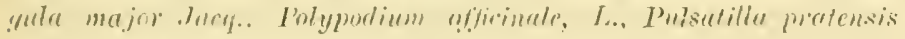

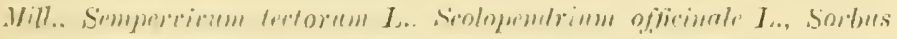

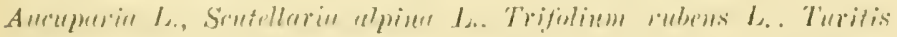

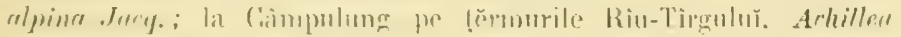

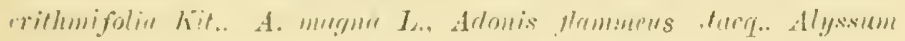

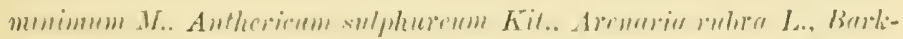

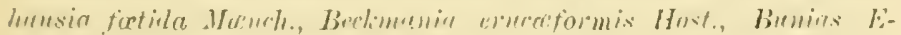

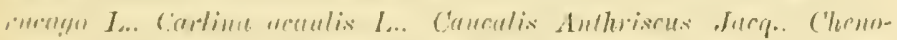

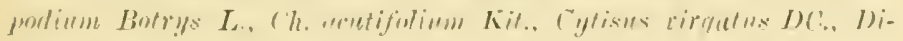

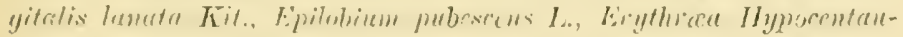

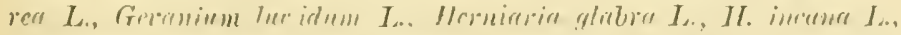

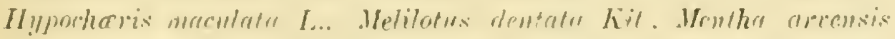

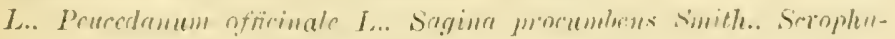

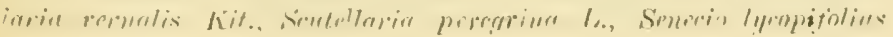




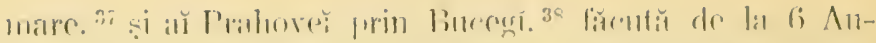

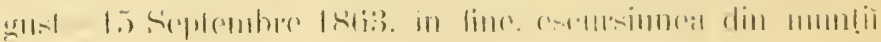

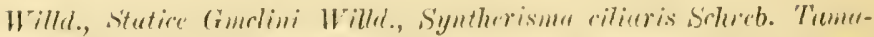

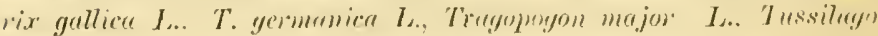

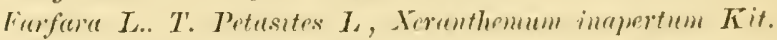

(37. Speciile de plante culese de U. Hoffuram (Monit. med. al Lom., 1864, p. 117-112). ì m-țĭ Buzeuluĭ. sunl : de-alungul pînâlnì Pî̀-

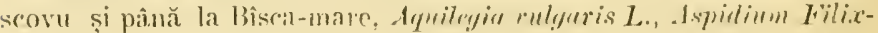

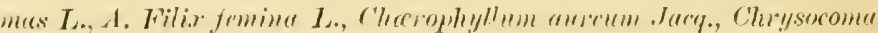

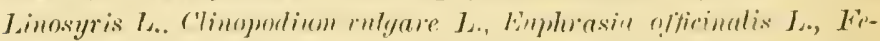

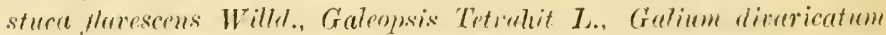

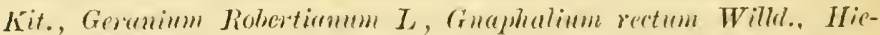

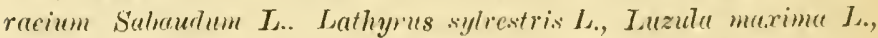

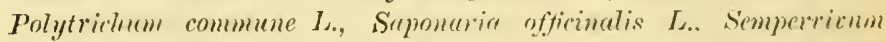
tertorum 1..., Thutictrum aquilegifolinem. Joeq. Tormentille reptans 1 .

13\%). Speciile de plante culese in U. Hoffmann (1. r. 118-120) in m-tir „Prahover, sunt următórele : de-alıngul Telëjenuluí sprrc Valea-largx, Holloborns odoratus Kit., Iris fortidissima L., Myosatis palustris L., Parmassin palustris I., Salix aquaticu Willul. Stachys palustris I., Tama rix germaniea $L$.. Thrssilayo hybrida La.; în vecinătăţile N-stirer Cheia, Arev Pseutu-l'utanus L., Brumella laciniritu L., Bryum undulatum Roth., Carese alba Host, Contaurea.

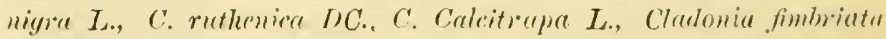

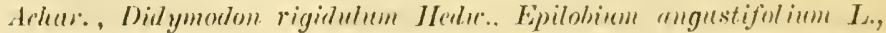

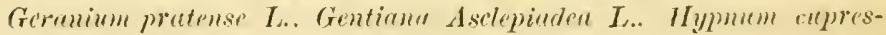

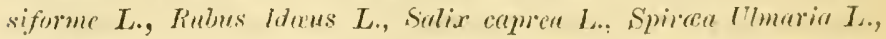

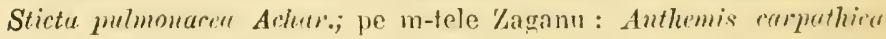

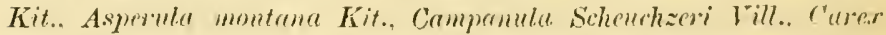

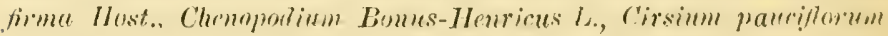

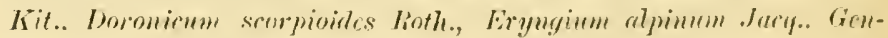

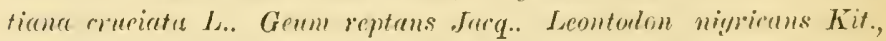
loppirlum alpinum .Jaeq., Phlomis alpina Z., Potentilla patula Kit.,

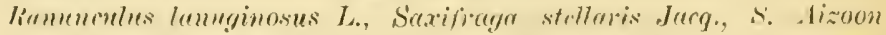

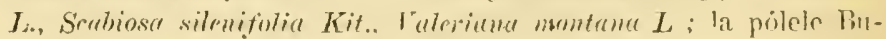

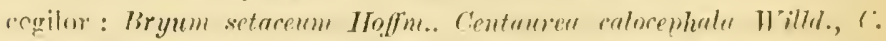

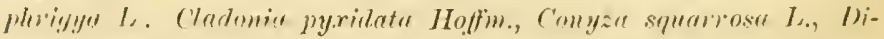

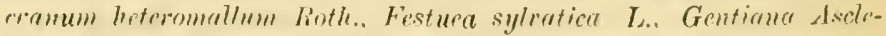
pialea L., Gexanium marmorhizon Jerq., Glechome hirsuta Kit., Hy-

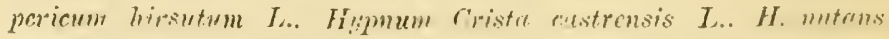

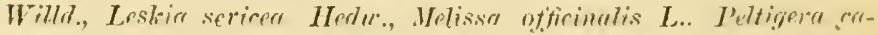

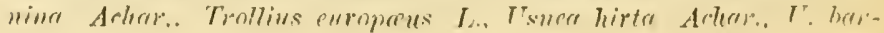




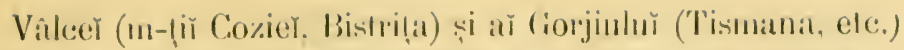
făcule in 1864. " Mălile de sémă despre resultatul escur-

bata Ilofl); pe vêrful Bucegilor: Achillea lanatu Spreny., Ajuga alpinu Jace. Alchemilla montame Willal. Allium Schormoprasum L.,

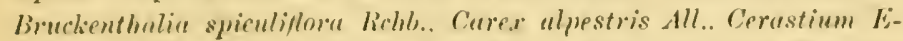

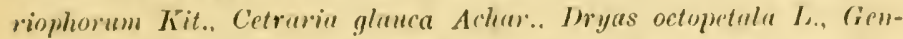
tiume carpathica lite. Geranium pyrenaicum Cav.. Guaphalium supinum DC., Hieracium aurantiacum .Jucq., funiperess ammunis $L$. var. Hana, I.ycopodinm selaginoides h., Pamelia tartarea Achar., Pedicularis asplenifolia Sturm., Poa supina Schrad., Potentilla "cullis With.. Irrimula minima .Jaeq., Pyrethrum alpinum Hop., Rhododendron forrugineum L., Rubus corylifolines Kit., Sulix hituibeliana Roch., Saxipraga uloide's Wulf., S. rupestris Willd., Scorzonera rosea Kit., Scutellaria alpina L., Silene acaulis L., Tussilago alpina Jacq., Jiola alpina Jaeq., Wuldsteinia geoides W'illd. ; prin înprejurimile Obîrșier lalomiţer : Aconitum Cammarum .Jacq., Achillea magna L., Ajuga alpina L., Alyssum saxatile L., Arabis alpina L., Asplcnium Trichomanes L., Campanula carpathica Jacq., Curex saxatillis Kit., Cephalaria transsileanicu Bmy., Cheiranthus cuspidatus Kit., Delphinim alpinum Kit.. Dianthus petraus Kit., D. alpinus L., Geranium pyrenaicum Cav., Geum montamm Jacq., Hirracium montanum All., H. carpathicum Bess., Holcus lanutus I., I.ycopodinu complanatum L., Moltringia muscosa Jaeq., Pellicularis asplenifolia Sturm., Potentilla rupestris Jacq., Saxifragu cuneifolia Kit., S. casia L., Scabiosa Incidu V'ill., Scrophularia vernalis $L_{\text {., }}$ Sentellaria alpina L., Senecio rupestris Kit., Thymus alpinus L., Trifulium auream Pol., riola declinata Kit.

(39). Darea de sémă făcută de U. Hoffmann despre escursiunea din munţir Vàlcer (Cozia, Bistrița) și ar Gorjiuluĭ (Tismana, etc.). se mărginesce numay la un simplu catalog de plantele culese în acéstă escursiune, catalog rěmas inedit, și pe care l'am estras din Dosurul te eșive al actelor scólei de molicina din Bucuresci (An. 186't. Parter II).-Speciile de plante culese de U. Hoffmann în aceștr munţY și cuprinse în catalogul menționat, sunt următórele: Aster comus hit., A. bessarabicus Bess., Atamanthu Libanotis L., Anthyllis Vulncvoria L., Astragalus glycyphyllos L., Agrostis alba L., A. Spicaventi L.. A. diffusa Host., Althare cennubina L., Avtemisia pontica L., A. Abrotunm L., A. compestris L., Asperula lavigata DC., Aspillum Filix femina L., Asplenim Trichomanes L., A. obtusum Kit., A. Ceterach L., Brunella grandiflora L., Betonica hirusta L.. Bryum nutums I.. B. cespititiun I.., B. glancum L., B. sericeum 
siunilor luı̆ U. Hoffmann, de și firte scurte și reduse numă̌ la nisce simple enumeraṭunı̆ ale speciilor găsite în diferitele

L., Buphthalmum cordifolium Kït., Bupleurnm fulcutum L., Culamintha officinalis DC., Companula glomereta L., C. patula L., C. rapunculoides L., Carduus pannonicns L., C. crispus L., Carlina vulgaris $L_{\text {., }}$ Carthamus lanatus $L_{\text {., }}$ Castunea vesu. I.. Centunrea coriacea Kit., C. Cruprina L., C. nigra L., C. plerygin L., C. $w^{*} a$ tensis Thuill., C. solstitialis L., Cetraria glancu Achar., Clicerophyllum aromatieum L., Chenopodium Botrys L., Ch. crysomelanospermum., Ball., Chrysochomu Linosyris L., Cireau Lutetiana L., Cirsium ucranicum Bess:. C. Hrysithales Seop., C. tuberosum All., Clatomin cornuta Hoff., C. pyxidata Hoff., Clematis Vitalba L., Conyzat squarrosa L.. Cynanchum Vincetoximm L., Cytisns niyricans L., Dianthus collinus Kit., D. Armeria I., Dipsacus pilosus L.. Echinops Ritro L., E. splucrocephalus L., Epilobium gr'andiflorum L., F, roseum L., Equisetum hiemale L., E. pulustre L., Erythrou Centuurium Pers., Eupatorium cannabinum L., Euplurusia luteu L., Eronymus

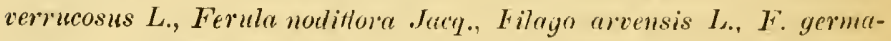
nice L., Gutirm Tinifolium I)C., G. syleaticum L.. Galengsis T'etrithit I., Genista tinctoria L., Gentiana Pnenmonanthe L.. Cnidium alsacaticum DC., Gypsophilu muralis L., Halera Helix L., Heracleum sphondylium L., Hievacium sabaudum L., Holcus lamutus L., Hypnum cupressifcrme L., II. punctutum W.. H. serpyllifolium Hrilli.. H. abietinum L., H. complumutum, Imputiens nolitungere L., Inula Helenium L., Juniperus communis L., Juneus acutiftorus Ehrh., Laserpitium latifolium L., Luzula ulbidu L., Lestitu sericea Hed". Láthyrus syliestris L., Lacatera thuringiaca L., Leonurus Cardiaca L., Lobaria fraxinea Hoff., L. pranastri Holf., Lycopus enropaus L., Lysimachia punctutu L., Harchantia polymorphu L., Marrubium peregrinum L., M. vulgure L., Melampyrum nemorosum L., Mentha incuna Sol., M. Pulegium L., M. sutiva Sol., M. sylvestris L. var, angustifolia, Micromeriu rupestris Benth.. Mnium cristatum L., M. cirrhatum L., Moehringia muscosu L.. Moliniu carulea. Mœnch., Nepeta eitriodora .Juer., N. undu Jucq., N. Junonica L., Ononis arvensis Jacy., Origumum vulyure L.. Purietaria officinalis L., I'armelia pulmonaria Achur., Peucedanum Cervariu L., P. Iongifolium Kit., Plileum prutense L.. I'olygalu major Jacq., I'olygomum Bellarlii hit., P. minus Ait.. P. Nemolapathum L., Polypodium

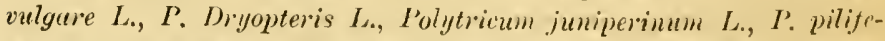
rum L., Polystichum cristutum Roth, J'renunthes muralis L., I'teris aquilina L.. I'nlierria migaris L., I'yrethrum matrophyllum I)C., 


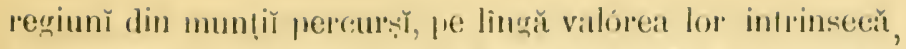
aй și meriful, ce este jusl a li’l recunósee, de a fi primele

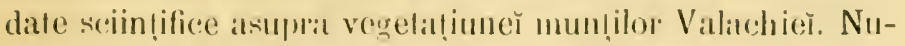
merul tolal al Mauntelor colese de U. Hoffuann in cursul atcestor escursiun, se snie lit vre-o 4:30 de speciü, printre care 1 u se vede s̆̆ fi descoperil nicĭ una nouă.

Fŭră de a maǐ vorbi de ore-care erborisal lunı̆ de un interes maı̆ mediocru, еe s'ă mă fücul in unele păr!̣i ale Romăniĕ +1, cam atceslea eră cunoscintele nóslre atsupra

Quercus rolun L., Rose sprinosissima L., Rubus casius L., Salix

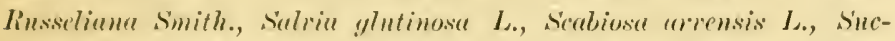

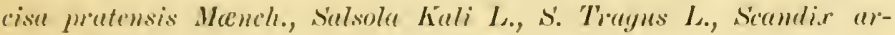
rensis L., Scolopendrium officinarmm L., birophularia laciniata Kit., Senecio Jacobar L., silene rupestris Kit., s. petroen hit., Selinum carrifolium L., Sesceli gracile Kit., Seratula tinctoria $L_{\text {.., Solilayo }}$

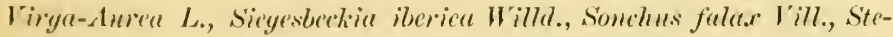
renceulum peschele deher., Thymus montumes L., Terucrium ChamaArys L., Trifolimm anrenm I'oll., T. filiforme Sar., T'. punnonicum Kit., T. parriflorum Kit., T. resupinutum Kit., Ieslusenm lenutum Schrad., V. nigrum L., V. orientule Schrod., I'eronicu paniculutu DC., I. orchidea Crentz, I. meticafolia L., Vicia polyphylla L., Viscum album $L$.

(40) Precum sunt erborisaţiunile, în numĕr de douě, făcute de D-1 DR. D. Grecescu, una la m-stirea Sinaia, alta la $m$-stirile Agapia, Varatic și Némţu. Spre a face învederată valórea ce trebue să se acorde datelor provenite din acest isvor, voiŭ presenta aicea o analisă despre ambelc aceste erborisaţiuñ. Întîia s'a făcut pe spesele ScóleI de inedicină din Bucurescĩ, de la :3-1o August 1868, după cum ni-o arată autorul în relaţiunea ce face despre ea și care se află publicată în Nr. 50 al Monitoruluĭ oficiul din 1869. Acéstă relaţiune, Inăcar că nu ofere vre-un interes maI deosebit, autorul eĭ a crediıt necesar a o republica încă o dată la 1876 (veḍi Revista contimpor(unx, 1876, pag. 334-3337), fără îusă de a menţiona că ea mă fusese altă dată publicată, ci presentîud'o ca o lucrare cu totul nouă sub titlul Excursiun botunice pe Buceyi, de și la finele acesteĭ dări de sémă arată. că crborisaţiunea sa n'a fost făcută pe Bucey̆y, ci la poblcle acelor munț (loc. cit. pag. 3’t1). Dar nicř că era de lipsă a o mar spune, de vreme ce acésta se vede în deajuns, din lista ce dă de plantele in nuněr de 150 specir, ce a cules̆r saŭ observat în cursul acestel erborisațiunI, și printre carri, afară de vre.o $2-3$ spe- 
Florě Romăniě̆, cînd, în luna Februariŭ 1876. comunicăiŭ Societiạteĭ geografice romtune (Bul. 1876, Nr. 7 și 8. jaig. $60-$

rir (Rhododemdron alprinum IIoffr., ete.) ce 'T-aŭ fost aduse de pe Vêrfu cu-Doru, de către DD. Berıath, Letzınamn și Braustätter (ved̦i Mon. ofic. I. c.) și un Vurcininum Myrtillus ce 'Y-a fost dat de un cioban (ibidem), nu figuréză numele a nicì uncia din interesantele specir alpine, ce împodobese cu profusiuıe avutele piscurĭ ale acestor munți. Cı tóte acestea, măcar că crborisaţunea D-lŭ Gr. s'a mărginit nuแa împrejurul m-stirir sinaia, și că relațiunea sa nu cu. prinde. nicr chiar dintre plantele ce crese pe la pólele Bucegilor, de cût numar pe cele vulgare și mar comnu cunoscite, totŭ arŭ presenta óre-care interesŭ, dacă autorul eı̆ nu ne-arŭ arătia clŭ însușĭ, puţinul temeiŭ ce trebue să puncm pe indicaţiunile ce ne dă; căcr altmintrelea, cum ne-am puté explica numerósele contraḍicerị și inconsecințe ce întâlnim în aceeași dare de sémà publicată în rîudurĭ diferite, și pe care nicăerĭ, nu sună că nu le justifică, dar nicř măcar nu le relevéză, după cum ar cere regulelc sinonimier, condiţume indispensabilă spre a'și putea pune cine-va în acord crorile comise în determinațiunile și arătările anterióre, cu îndreptările pe carĭ lc-ar crede necesare maĭ târḑin̆? Ast-fel comparând relaţiunea publicată în 1869 , cu acceași rełațiune republicată îu 1876 . aflăm indicate: la Poinna-Ţapulŭ̆, în intăia, pe Digitulis lunatu și Lycopodium Selago, specir carY în a dona devinŭ Digitulis grendifora și Lyeopodinam claratum; în fundul văir pîrâulư̆ l'iatra-A1'să, în întăia pe Myosotis lancifolit Giver., specic consideratã ca nonă. dar care în a doua să transfómă în vechia și vulgara specie linneană Myosolis palustris L.; în Vałea-Cășŭrier̆, în îtîia, pe C'ampamula, când mưor Giver, când mugniflor G Grec, specie considerată și acésta ca nouă, dar care în a doua devine cunoscuta și veclia specie Cempamula petule $L$.; în fundul păturiĭ. ce îıvecinéză calea ce duce la F.rmit, în întăia, pe Thymms: Chemedlys L., Erigeron comulense. L., Doronicum tussilugifolia Grer. și Lipuris reme Gree, ultime douě considerate ca specir nouĕ, dar carř în a doua devin Teucrium Chamadrys L., Lrigeron?, Dononirum austriacum L., și Huluxis pulutest Suctutz; pe Vêrfu-cu-Doru, în înătia, pe Rluododendron Chumacistus L., specie, care, în a doua, devine Rhodmdindron alpimm IIoffi., de și-fie dis în trécět-nu este nicr unul, nicr altul ci Rhododendion myrtifolitum sirhott Kotschy; etc. De altă parte, cu tóte că 1)-1 Gir. afirmă, atât în relaţiunea publicată în 1869. cât și

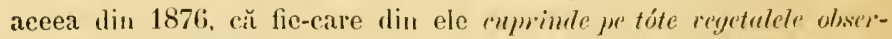

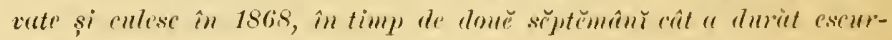
siunea la pólele Buccogilor. nor̆ vedem că, î̀ relaţiunea de la 1869 


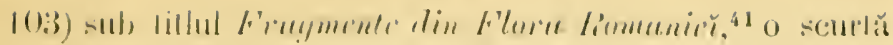

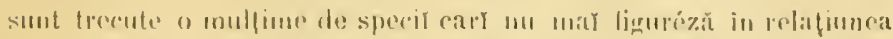

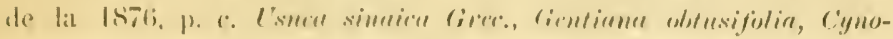

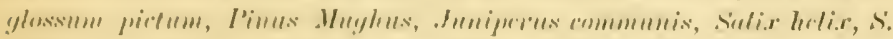

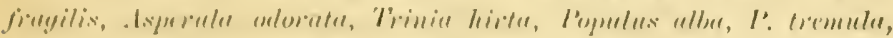

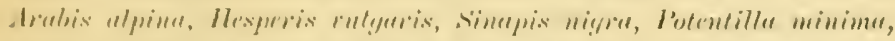

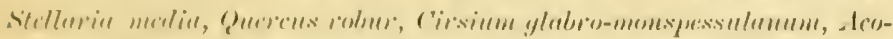

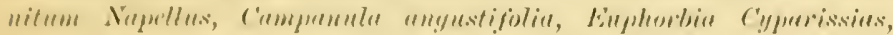

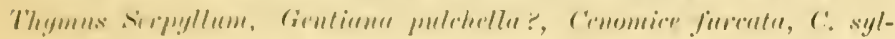

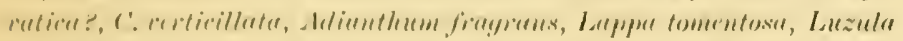

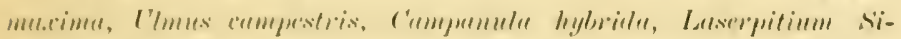

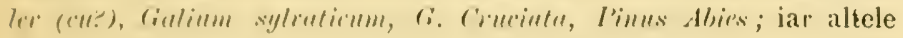

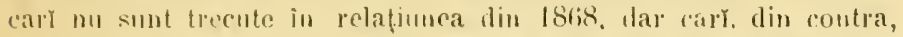

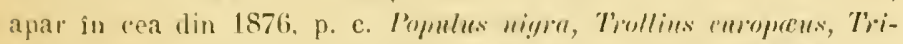

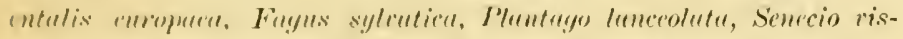

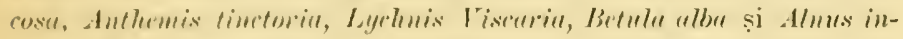

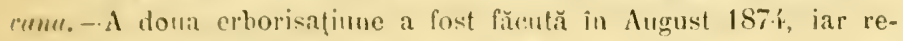
laţiunea re ıe dă tespre ea. impreună cu calalogul plantelor ou-

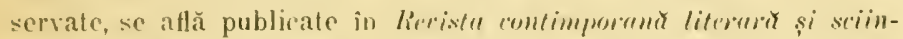
tiffict (1876. Nr. 8, parr. 117-1333). Din cele rre-o 260 specit, ce se găsese enuměrate, nicr una nu este care sn ofere vre-un interes mal deosebit, ca caractere, raritate saŭ stațiune. san̆ care să nu se fi indicat, tot prin aceleaşr regiuny de către alții cu mult may înainte. afală munar de acelea, pe carr delerminaținnea lor cronată le face să sară in ochr̆. Ca specimenc vou cita pe : Pinus M/uyhus I. (1. c. 1:20) indicat îu muntî le la sihla (munți ale căror pusste culminate u trec inălținca de 1000 metri), ce mu póte fi d.. cît resultatul meì det runațiun greșitr, de vreme ce un cunóscem nicy un loc in Carpați. unde P'mus Muyhus (conifern̆ ce caracleriséză reginea alpină inferióră, și care nu îcepe a se arăta He cait mumill (1. pe la inălțimea de 1500 și 1800 metri) se des.

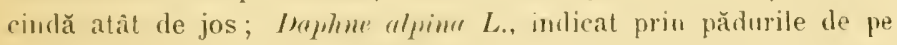
inălţimile de la sihla (l.c. I22), este de sigur altă erore, pe care nu ni o putem explica alt-fel, de cât prin imprejurarea eă autorul

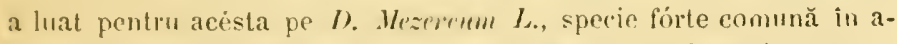
rea localıtate, și despre care, cu lite acestra mu să face nicr o mentimne; Digntulis merlin $L$, indirată în păturea te la vale de Aga-

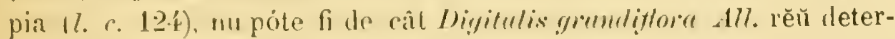
minată; Erynumem umethystimum L, imlieat pe campia de la vale

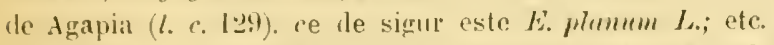

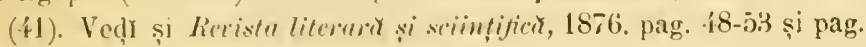
$1+1-178$. 
enumerațiune, cuprinḍend vre-o 700 speciī de plante recoltate de mine în cursul anilor 1874-1875, din districtele Iaș̆, Bacăй, Bêrlad, Ilfov, Arges și Muscel.42

De atuncí incóce, avuiŭ ocasiunea de a revisita multe din aceste localităț̆ și a afla mă multe alte speciŭ, eare mĭ sč̆pase în escursimnile anterióre. Tot-o-dată am dat o estensiune cu mult miı̆ mare câmpulŭ̌ meŭ de investigațiune, esplorând o muḷ̨ime de loealităț̆ nouĕ, și acordând o deosebită atenṭiune mă ales vegetaținer̆ munților celor mă inalı̣̆ aı̌ Ronănieŭ. ${ }^{43}$ Ast-fel am esplorat : în Iuliŭ 1876,

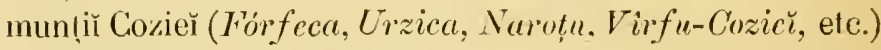
și munții din vecinătăḷile Salinelor Oenele-marı̆ și a Băilor de la Olănescĕ ; în August 1877, muntele Céhlăŭ şi alțĭ munț̆ din împrejurimile sale ; în Iuniŭ 1878, m-tị̆ Bucegĭ (Furnica, Vêrfu-cu-Doru, Pescera de la Obirşia Ialomițĕ, Jep̆, Babele, P'étra-arsă) și alț̆ mun(̣̆ din împrejurimile Sinaier̆ (Piscu-căneluц, etc.); în Iuliŭ acelaș an, m-țiu Comănescilor de la Palanea (Ciudomiru, Tărhauşu, Tărhäușclu), munțiñ

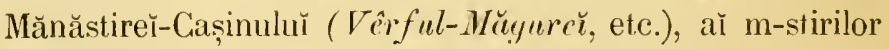
Némţu (Pleșu), Procov, Sĕcu, Sŭhăstria, Sihla, Agapia și alțĭ munțĭ din acéstă regiune; în fine, în Juliŭ 1879 , m-tele Penteleŭ și alț̆ munț̆ din disıriclul Buzĕŭ, și de prin împrejurimile salinelor de la T'îrgul-Ocně̌. ${ }^{44}$ Din tóte aceste localități am făcut abundante și interesante recolte.

(42). Profit cu plăcere de acéstă ocasinne spre a aminti că amabilităţi̛ amiculuř și colegulur meŭ D. profesor Gregoriŭ Stefănescu. datoresc câte-va specir de plante interesante (Aspidium Lonchitis Sio., Teucrium montamu L., etc.), culese de el cu ocasiunea escursiunilor sale geologice prin m-țiù Muscelulur.

(43). Înălţimea fie-căruia din ınunțir esplorațí, precum și altitudinea fie-cărel specir, aŭ fost luate cu ajıtorul Barometrulư Aneroid.

(4千). Despre unele din erborisațimnile mele în care aın fost însoțit și de elevir facultăţey̆ nóstre le sriințí. s'aŭ făcut scurte dărí de sémă (ved̦i Ree. seciint., 1877, pag. 116, 189. 19\%), de către unul din vechiř meì elevĭ, D. Lycherłopulo, naturalist laborios și modest. căruia, sub pseudonimul de Cher. O. Lupodly, retitorir Reristĕ sciintifice 'r datoress. mar multe articole importante. 


\section{MPEIMGE L.I INTROIICTIUNE}

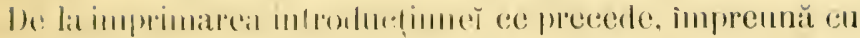

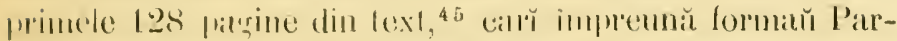

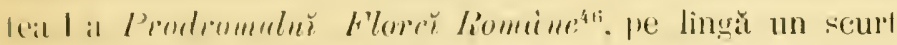

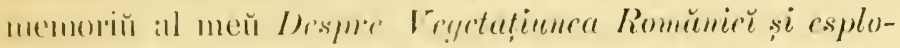

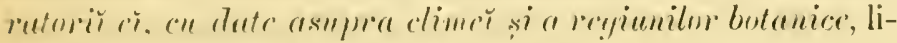

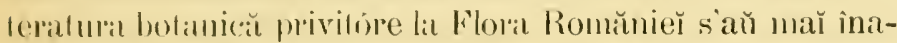

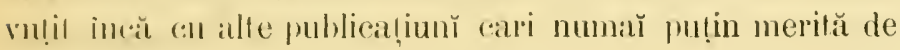
it fi men!ionale.

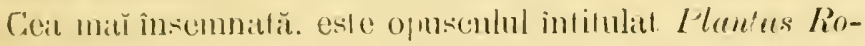
maniur huc 'squer comnitas de D)-l Angust Kanil\% profesor de

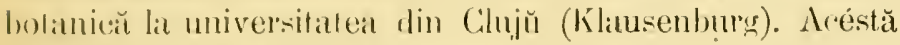
lusare, renllal al unor latboriose si forte consciintiose eercetăr biliostalfice. este resumatul fidel al maĭ huluror datelor hotanice mă mult orĭ maı̆ pu!̣ esacte. datorite diferi-

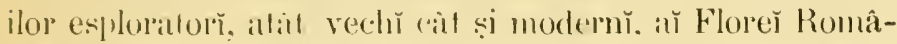

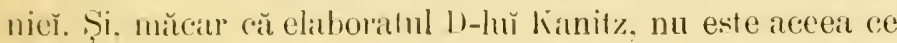
sar pufea nun o lucralle critică. lipsai erbariilor explorato-

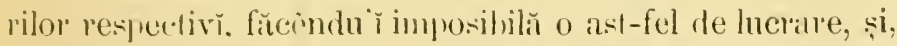

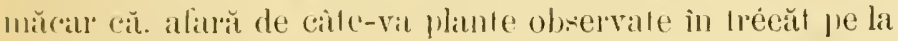

(ii) Sitrecurêmlu-se mał multe crorr în paginele log-les din Parlea I. pagrincle acesten s'aŭ imprimatŭ din noŭ.

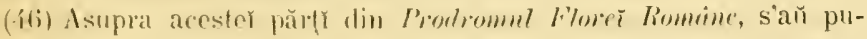

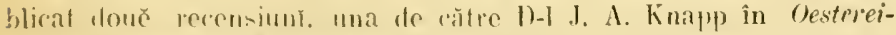

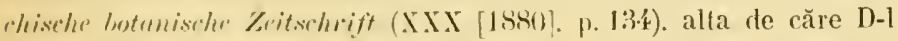

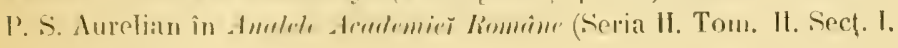
pag. 35 is-3is 8 ). 
Virciorova, el nu cuprinde alte observațunı̆ projmiĭ autorelŭ, nu este pentru acésta o scriere mă̌ puḷin interesanfă și chiar prețiósă pentru nol̆, mă cu sémı̆ din causă că autorul ě̌ ne atrage alen!̣iunea asupra mă multor dale botanice imporlante ce se referă la unele localitățĭ din districtele Banatuluı̆ și ale 'Transsilvanieř învecinate eu truntariile lĕreı̆ nostre, precum sunt acelea ale IDD. A. C. Justus, J. F. Frein, Fr. Fr. Fronius, Schur, Kolschy şi M. Winkler, asupra unor localităṭi din muntiǔ Buceğ ; ale DD. V. de .lanka, Borbás și Simkovics, relative la Vîrciorova și la Porțile-de-ferŭ; ale luĭ Kolschy relative Ia Pétra-Craiuluĭ şi lat Vîrful-Baciuluı̌: în fine, a le D-luı̆ V. de .Janka ${ }^{47}$ relalive la Céhlăŭ şi la îmırejurimile Ploescilor. Deosebit de aceste din urmă date, pentru care noŭ ǐ rĕmânem cu tolul recunoscĕtor̆, în opusculul D-Jı̌ Kanitz, se maĭ află enumerate un óre-care numĕr de speciĭ de plante, cari aŭ fost recoltate de pe lingă Galaț̆ şi din Dobrogea de către frațî̀ I. și Max. Sintenis, ${ }^{4 s}$ de D-1 J. Schaarschmidt de la Sinaia și Constanţa, de D-1 Dr. D. Grecescu din Ilfov, Prahova, Buzĕŭ, etc., de D-1 A. P. Alessi ${ }^{49}$ de la Ploesč̆,

(47) D. V. DE JaNKA aŭ visitat Céhlăul în anul 1868 August în 4 (st. n.) ; iar pe lîngă Ploescy aŭ erborisat în vara anulǔ 1873.

(48) Catalogul plantelor recoltate de fraţii Sintenis aŭ fost comunicat D-luı̆ Kanitz de către D-I R. de Uechtritz din Breslaŭ, botanist de către care aŭ fost determinată acéstă colecțiunc.

(49) Plantele în numěr de 90 specir, recoltate în lunele Iuliŭ și August ale anulur 1880 de către I)-l $\Lambda$. P. Alessi, profesor la gimnasiul superior din Năseud. aŭ fost determinate de către DD. F. Porcius și V. de Janka. Pe plantele aquatice din mica colecțiune a D-lur Alessi, D-I J. Schaarschınidt, june algolog din Clujŭ și vechiŭ elev al D-lur Kanitz, află și delemină maĭ multe specir de Alge, despre esistența cărora în colecțiune nič prin minte nu-r trecuse colectorulur, după cum lesne se și póte înțelege. Dar acésta nu împedică pe D-l $\Lambda$ lessi ca, într'o scriere recentă, de o valóre botanică de puţină însemnătate. întitulată O escursiune botanica in Romănia și Dobrogea, în care autorul ne dă și descripțiunea plantelor recoltate de el, se'şı revendice paternitatea descoperirer Algelor aflate și determinate de D-1 J. Schaarschmidt. 


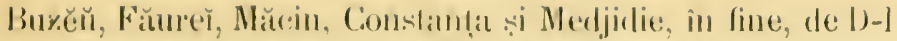
(i. Vutskils, elev al J)-Jur Kanil\%, de pe lingă lașī.

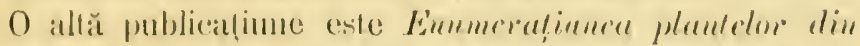

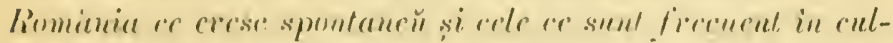

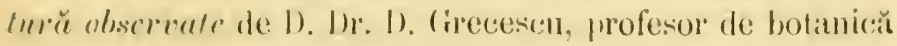
la fatullatea de medicină din Bucurescĕ. În acesslă luckare se atlit enumerate, pe lingă plantele publicate în M/onitorul oficial din 1869 și in lívista contimpmină din $1876^{50}$, आă multe alte speciĭ observale de aulor de atuncì incóce în districlele Bač̆̆ı̆, Buzen̆, Prahova, Ilfov, Bîmboviṭa, Muscel, Vlaşca și Mehedințí. immpremua cu căte-va plante recollate de D-I Phammacist Chania de prin vecinălățile mănăstireì Nèmṭulŭ.

In fine, D-l C. F. Nyman, botanisl din Stockoln, in Conspretus Florae ruropece, citéz̆ multe din plantele colectiuner̆ lur Guébhard, cu numerile lor respective şi cu corecțiunile delerminațiunilor Guébhardiane, de câte orì acestea șắ intâmplal să fie eronate ${ }^{5 ?}$.

Pe lanğ̌ aceste nouě fântànı̆, de aluneì încóce mi s’ă̌ mă sporit și materialele mele sciințifice, atât prin escursiunile nowĕ ce an maĭ făcut in diverse părțĩ ale tẹ̆rě̌, cât și prin unele prețiose colecținn de planle ce mi-aŭ fost puse la disposițiune.

P'rintre acestea, trebue să mentionez man̆ întâĭ Érbariul lü L’trich Hoffmam, mullă vreme considerat ca pierdut,

(50) Veḍ Introdluctiuner pag. LXVII, nota 40.

(5) Cât despre cele lalte specir de plante pe care D-l Nyman, în fasc. III și IV (pag. \{93-846) ale opuluY seŭ, apărute posterior publicațiuner opuscululuy D-lıY Kanitz, le atribue Florer Romănier, nu după exsic'catele luy Guébhard, cele mar multe din acestea nu trebue acceptate de cât cu multă reservă, ca unele ce sunt ritate după lucrarea D-lur Kanitz. in care datele, cele mar de multe ory eronate, sunt inșirate așia precum aŭ fost aflate prin diferiţir autory, și în general, afară de rare escepțiunı̆, fără de a fi mar fost supuse la vre-un control, ceea ce ar fi reclamat și colecţiunile autorilor pe ale căror date le menționéză. 
dar catre fu in fine allat intrunul din podurile Asilului Elenta

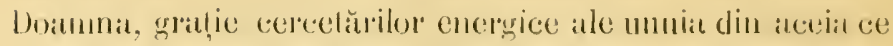

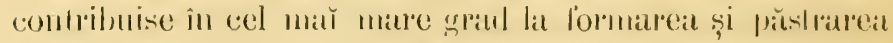

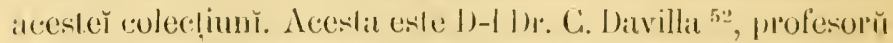
de chinnie medieală la fiuculbatea de medicină din Bucureseì.

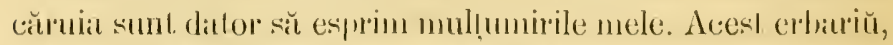
ce atshă-ḍi face parle din colectimuea musenlur din Bucu-

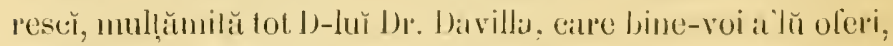

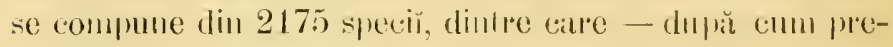

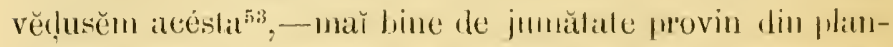

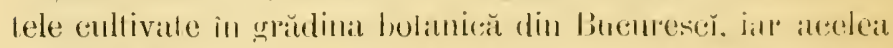

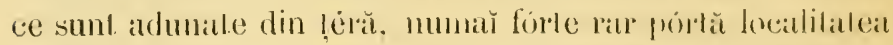
de unde aй fost culese, ceea ce fatee cai acéslă coler:lime, in mare parte destrusă de vermĭ, să pérdă fórte muit din valorea è̆ sciinlıifică.

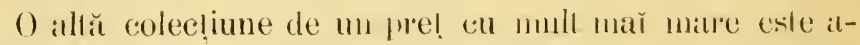

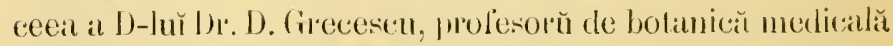

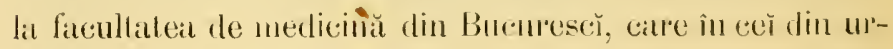
mă treй anı̆ a reincepul escursiunile bolanice cu un \%ol çi o pasiune ce-lŭ onoră, și calle in curand vor lace din el u-

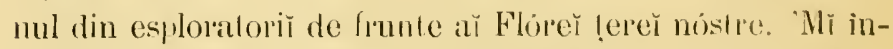
deplinesc o plăculă dalorie exprimand via mea recunoscinț̆ inniculuĭ și colegulŭ men̆ b-J br. (rrecescu, pentru des-

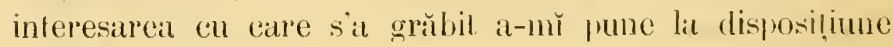
frunósal sil colecṭiune.

(52) Pentru istoria desvoltăleI sciinţer în țéra nóstră este bine să sc ('unóscă, că D-l Dr. C. DAvilla, in calitate de director al vecheĩ șeole de

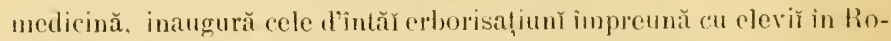
mânia de dincréce de Mlilcov. Tot acestur distins bărbat 'ù revine și

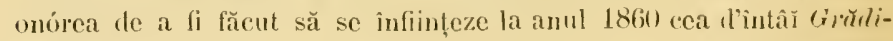
nu botunicr̆ în acéstă parte a țěrer. în urma แnu fórte însemmat raport ce presentă încă de pe la anul 1855), Domnitoruluĭ de atunci Știrbeiñ-Vorkă. raport ce din títe punctele de vedere face onóre a-

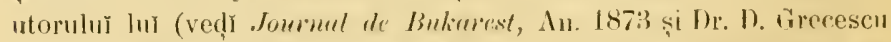
Catalogul plantelor cultirate in Grestlina botanică din Bucuressic in russul rmilor 1s\%1-1875, pag. 15-17).

(5:3) Veḍ̆ Introslucținué p. LXI. nota 35. 


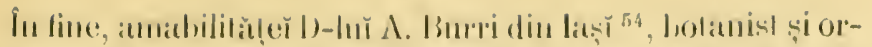

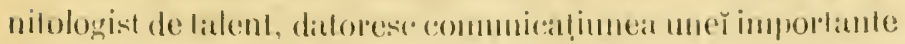
colecęimn de peste 600 speciö de planle, recollale de elŭ in

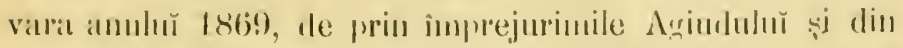

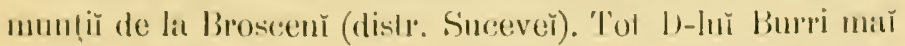

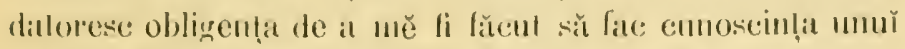

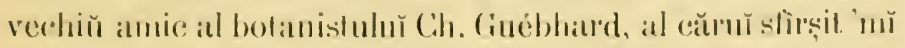

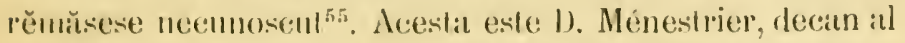
coloniè francese din lașĩ, venerabil și forrte simpralie hălrìn

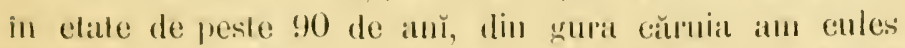
date preliose, eare completėă biografiat atesstur athil de merilos bolinist.

(5.4) D. Alkxıs Burr, compatriot al luy Clı. Guébhard, este nativ din Lausanne, de unde aŭ venit în Moldova la vârsta de 20 ant, în anul 1850), în calitate de institutor, ceea ce rěmase până astă-ị̂.

(55) Veḍl Introulucțiuneu p. XXIV, nota 27.

(56) Iată mișcătórea narațiune ce ne făeu D. Ménestrier despre botanistul Ch. Guébhard:

C'était en 18\{2. j'habitais Galatz. Un jour que j'assistais au déharquement des passagers du bateau à vapeur, je remarçuai un voyageur qui paraissait fort mécontent; il maugréait tout en se promenant sur le pont du navire déjà presque résert. C'était un homme d'une cinquantaine d'années, de taille moyenne, blond, haut en couleur, d'un extérieur avenant, bien que fort négligé de sa personne. Comme il parlait français, je m'informai de la cause de son mécontentement. Il riapprit qu'aux Portes-dle-Fer, dans le transbordement on avait oublié sa malle et qu'il se trouvait sans linges, sans vêtements. Je l'engageai à venir chez moi et mis mes nippes à sa disposition en attendant qu'il retrouvait ses effets. C'est ainsi que je fis la connaisance de Ch. Guébhard, depuis ce jour notre liaison devint intime et ne fut rompue que par sa mort. Il n’apprit qu'il était envoyé par le naturaliste Delessert. au prince Moruzi, pour diriger ses serres.

Voilà donc Guébhard installé à Pekia, partageant son temps entre la direction des serres du prince et les herborisations du roisinage. Il avait été stipulé qu'il aurait toute liberté à cet égard et il en usait largement car il faisait souvent des absences de deux on trois jours. C'était un homme infatigable : muni d'un fusil que je lui avais prêté, de sa boîte de fer blanc et d'un morceau 
Colecṭ̂nı̆ mič̆ de plante, din diverse localităț̆. mi să̆

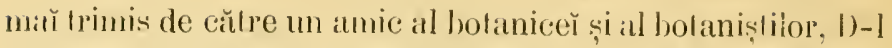
N. Ioneseu, ilustrul profesor de istorie de lit mniversitalea din Tas̆̆̆, de eălre D. Stefan St. Sihlénu. doctor in sciinlı̆ naturale, de către fratele meй Alexandru Brandzat. mofesor de istorie la liceul din Tașĭ, de cütre D. Nircea Ganca, în fine de călre uniř din vechiǒ meř discipulí, precum 1)l). Sabba Stefăneseu, Anton Colorẻnu și N. Alhanatsescu. 'Joḷi aceștia să ıriméscă nullı̆mmirile mele.

de pain, il s'en allait tout seul, à travers champs, sans savoir un mot de la langue du pays. A. te Candolle de Genève recueillait le fruit de ses recherches.

Je voyais souvent Guélhhard. son commerce était des ptus agréables; c'était un homme fort instruit. parłant plusieurs langues, plein d'ésprit, poëte à ses heures. témoin cette chanson que je n'ai point oublicee, malgré mes 90 ans. 11 s'agit d'un jeune Suisse engagé dans l'armée française :

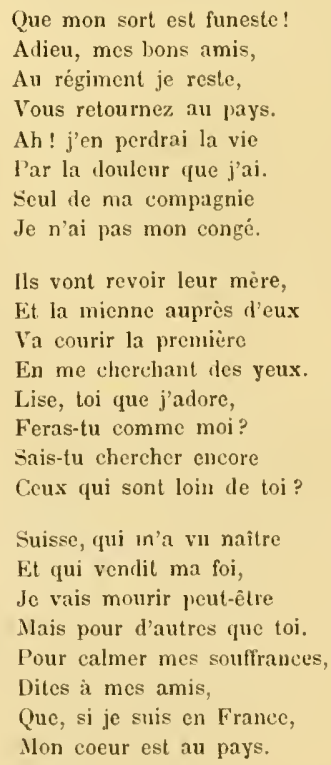

Mon ami m'a raconté quelques épisodes de sa vie quui a été passablement accidentée. Il était originaire de Neufchâtel cu Suisse. 


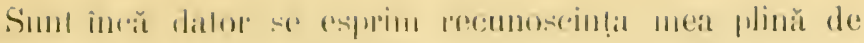

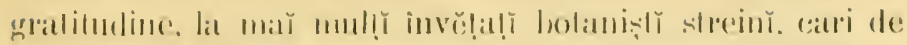

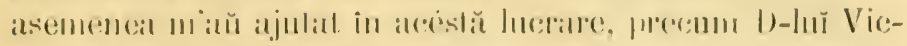

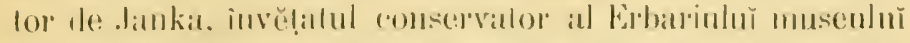

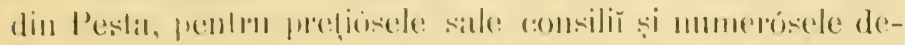

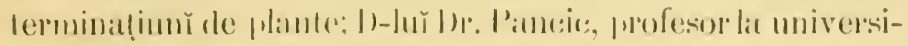

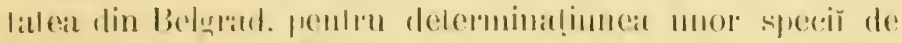

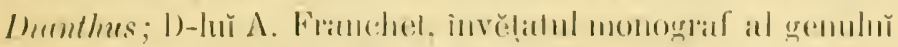

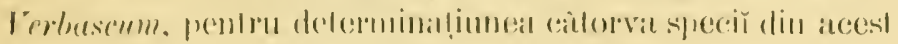

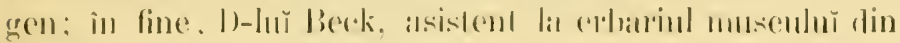
Vienal, pentru determinalimea citlorvit speciö de Orobumeler.

Il paraît qu'au débul il ful employé dans le commerce à Paris. Plus tard nous le trourons it Livourne en qualite de consul du roi de Wurtemberg. Un jour fu'il faisait at pied le royage de Livourne a florence, il ful saisi par des brigands qui le relatshaient apres une assez longue délention, ayant enfin reconn son insolvabilite. Dans les grands jours il purlatit encore en Moldavie la deromit yuil reçut alors du roi de Wurtemberg.

Reprenons le lil de nolre rieit. Toul alla bien i Pekia du vivant du vienx prince Morızi mais il sa mort, ses héritiers négligerent le jardin el le botanisle an point de le laisser manquer de pain, lai ol une pauve jenne fille, virlime des passions brutales d'un des scignenus de l'eudroil. C'est dans celle triste situation vers la fun du printemps de lsin, que Gueblatal ful alteinl du cho-

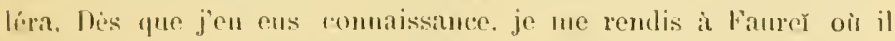
se trouvait alors. Hiblas! j'arrivais trop tard; il chait mort. Hes bolémiens l'avaient enveloppé daus des nalles ot jeté dans une fosse à la lisière de la forêt. On s'élait hîté de jeter aussi sur le funier ce qui restat te ses précieuses collections. C'est en vain que sa femme érivil de la suisse pour revamer re qui restail de son mari. II ne restail absolument rien. 


\title{
CONSPECTUL LITERATUREI
}

\author{
ȘI \\ ESPLICAT⿱ IUNEA A B REVIAT⿱ IUNILOR
}

\section{Lucrărì publieate :}

A. Amlrae Curolus Justus. Der Butschetsch bei Kronstalt und Skit Jalomicza. Eine Alpenwanderung in Siebenbürgen (Aus der Leipziger illustrirten 7eitung Band XXIl, Nr. 5633 vom 15 April 1854). Verhandlungen und Mittheilungen des siebenburgischen Vereins für Naturwissenschaften zu Hermannstalt VI. Jahrg. (185̃)).

A. Bot. Zeit. - A. C. Justus. Beiträge zur Kenntniss der Flora des südlichen Banates, der banater Militärgrenze und Siebenbürgens Botanische Zeitung von Schlechteruluhl und Mohl XI (18533), XIII (1855), XIV (1856) Jahrg.

Al. - Alessi A. P. in Kanitz Pl. Rom.

Alexi A. P. 0 escursiune botanică în Romănia și Dobrogea. Sibiť, 1883, in-8 108 pag.

Aurel. - Aurelium P. S. Terra nostra schițe economice asupra Romănieł. Erliț, a doua. Bucurescř, 1880, in-40. XXV1 și 3.14 pag.

Bmg. En. - Baumyarten Johannes Christianus Gottlob. Enumeratio stirpium Magno Transsilvaniae principatıi praeprimis indigenarmm, in usum nostrarum botanophilorum conscripta inque ortinem sexuali-naturalem concinnata. Vol. 1-3 V'indobonae, 1816, Vol. '1 Cibinii, 18.46, in-80.

Benkert in Gris. et Sch. It. 355.

Boiss, Fl. or. - Boissier Fdmomm. Flora orientalis sive Enumeratio plantarum in Oriente a Graecia et Aegypto ad Indiae fines hucusque olssrrvatarum. Vol. I-IV. Brtsilirre, 1867-1875, in-8 . 


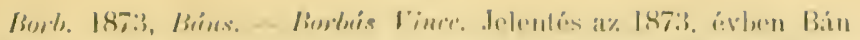

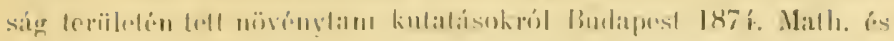

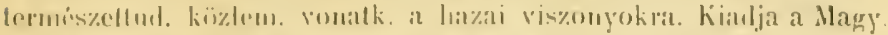

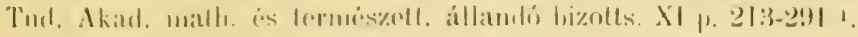

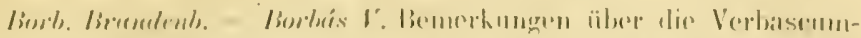

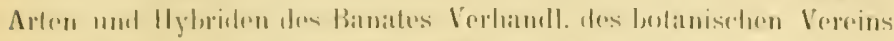

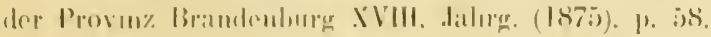

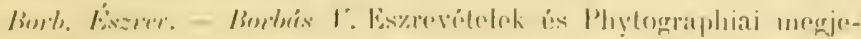

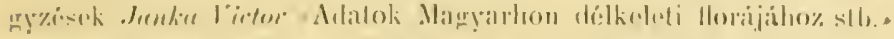

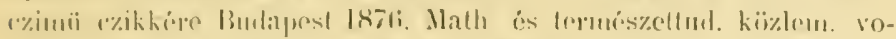

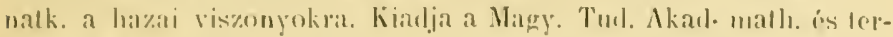
mészelt. illt. hizotts. Xlll. p. 2.).

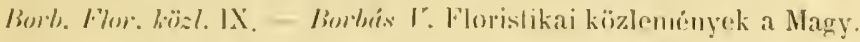
Tul. Akadómia illtal timogatolt lolanikai kulatísamból. Bulapest

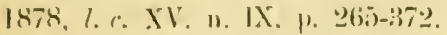

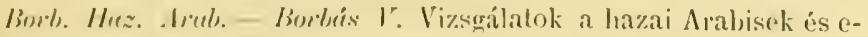

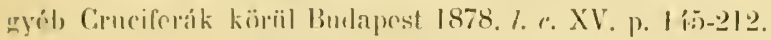

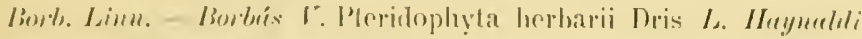
ILmgariea. Linnica XLII (187!)). p. 2003.

Borb. Lor: - Burbris I. Floristikai arlatok kïlönös tckintettel a Roripaikra. Ertekezések a tomószeltulominyok körébö̈l kiarlja a Magy.

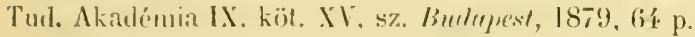

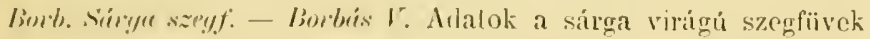
és rokonok systematicai ismeretóhez Burlapest 187i. Math. és termíszettur. kïzlem. ronalk, a lazai viszonyokra. Kiarlja a Magy. Tuıl. Mkad, math. és természelt. állandé bizotts. XIII. kït. p. Ibন-216.

Borb. Sigub. pter. - Borbes: I'. Symbolae at pleridographiam of Characeas Hungariae praceipue lanatıs Verhandl. der k. k. zool. bot. Gesellsch. Wien Jalıg. XXY (187i)), p. 781.

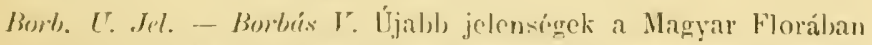
Budapest 1875. Malh. és termeszettud. kïzl. vonatk. a hazai vis\%onyokra. Kiadja a Magy. Tud. Akad. math is termószelt. allantó bizolts. XII. küt. p. 7.̈-88.

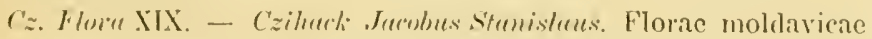
species ac genera hucuseme exrursionibus explotata ac secundum

(1) cf. Horb. in Oest. Hont. 7.eit. XXY (1.575), p. 207 ef in Bol. Jahreshericht III 1875), p. i1s. 


\section{LXXX}

Limucei systema ordinata Mns. Maji 1836 «Floras hot. Zeitung Jahrg. XIX (18:36), Bd. 2. Beiblätter p. 58-74.

\section{Czih. - Ved̦r Cz. Flor XIX.}

Cz. et Sz.-Czihack Dr. J. und Szubo Dr. J. Heil-und Nahrungsmittel, Farbstoffe, Nutz-und Hausgeräthe, welche die Ost-Romanen, Moldauer und Walachen aus dem Pflanzenreiche gewinnen, Flora XLVI (186:3), imprimată și separat.

I). Br. Fraym. - D. Bramlzu. Fragmente din Flora Romănier cuprinḍênd considerațir generale asupra vegetaţier Românier și enumerația cîtor-va din plantele ce crese spontaneŭ în România, cı arătarea localităților unde se găsesc. Comunicațiune făcută în sesiunea din Februarie 1876. Butetinul Societățer geografice Române. Anul 1. No. 7-8, Bucuresčr, 1 Iulie -1 August 1876, pag. $4\{-10 \%$.

D. Br. in Rev. lites:-sc. - D. Brondzu. și B. P. Hasteŭ. Revista literară și sciințifică. 1876, pag. 48-53 și pag. 141-178.

D. Br.-D. Brundza. Despre vegetațiunea Romănier și exploratorir ě. cu date asupra climě̃ și a regiunilor botanice. Analele Acalemier Romîne, Seria II, Tom. II, Secț. II. p. 303-380, imprimat şi separat.

D. Br. Amul. Acad. Rom. - D. Brandza. Plante nouě. Analele Academier Române, Seria II. Secț. 11 (1881). p. 537-5338.

DC. Prod. - De Candolle Auy. Pyjramo it fil. Prodromus systematis naturalis regni vegetabilis. Puris, 1824-1864, 16 vol. in-8!.

Démid. Voy. - Démidoff Amutole. Voyage dans la Rusie méridionale et la Crimée. II Tome, Puris, 18.33.

Ellel.-Edel Julius. Bemerkungen iiber die Vegetation der Moldain. Nach eigenen, im Jahre 1835 gemachten Beobachtungen entworfen. Verhandl. des zool.-bot. Vereins in Wien III (185:3), p. 27-42.

Fotu Ir: Anast. Încercările făcute pentru desvoltarea sciinților nalurale 'în Romănia. Analole Soc. Acal. Rom. Seria I, Tom. V. Sect, 11, 1873, pag. 11-33 și 7ł-1-80, imprimat și separat.

Fuss Fl. Truns, - Fuss M. Flora Transsilvaniae excursoria. Cibinii, $18666, x$ și 864 p. in-80.

Fr. - Freyn Josephus F. Az 1871-1873, éven Magyarország keeti részeihen gyiujtött növenyek jegyzéke. Freyn . Jizsef vasúti mérnök. némel kézírata utín kïzli dr. Borbés V. Budapest 1876. Math. es természettud. Kïzlem. vonatkozólang a hazai viszonyokra. Kialja a Magyar Tud. Akarl. Xill. kïl. p. (65)-1:30. 


\section{IXXYL}

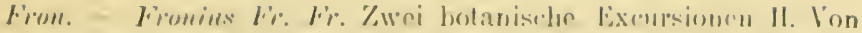

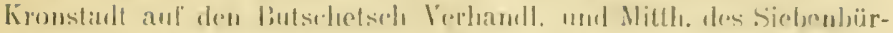

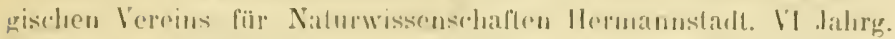
$(18.5 .5)$. 1. $199(3-2)(1)$.

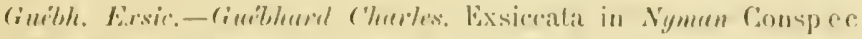
lus Florie liuropacar.

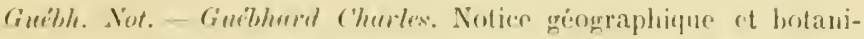
que sur la Molelavie pour servir d'intreduction a la llore de re pays (lire de la Bihliohthene universelle de Geneve. Fivrier lsig).

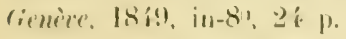

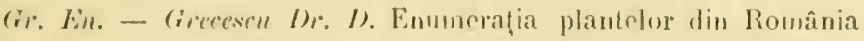
ce erese spontaneŭ și reele e.e sunt frecuent in eultură observate.

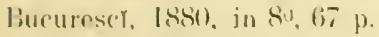

Gr. Libor: - Grecesen $\mathrm{H}$. 0 erborisaţune pe la monăstirile Agalpia. Varaticul și Némțul. Revisla contimporană literară și sciințifică. Anul $\mathrm{V}, \mathrm{Nr}$. \& din 1 August 1876 , Bucuresc'r.

Gir. Excurs. - Greresen In: Exeursiun bolanice po Bucegr. Revista contimporant. Anul N. Nr. 4 din 1 Aprilic 1876. Bucurescr.

Gr. Monit. ofic: - Greresen 1). Excursiunea scinnifică de la Buregiŭ. Monitorul oficial. Anul 1869, Nr. 50, pag. 311-312,

Gris. It. hung. - Veḍ Gris. ot Schenk It.

Gris. et Schenk. It. - A. Grieseluch et A. Schenk. Iter Hungaricum a. 1852, susceptum. Beiträge zur Systematik der Ungarischen Flora. Wiegmann's Archiv für Naturgeschichte XVIll (1852), p. 291.

Hucq. Lícise. - Hucquet IB. Neneste physikalisch-politische Reisen durch die Dacischen und Sarmatisehen oder Nördlichen Karpathen. Nïrnbery. 1790-1796, \& vol. in-8".

Haynald. - Haynald Latoricus in Lianitz Pl. Rom.

Heruff. En. - Ileuffel Joceme. Enumeratio plantarum in Banatu Temensiensi sponte erescentium et frequentius cultarum. Findoboware, 1858, in-8". Aus den Verhandlungen der $k \mathrm{k}$. \%oologisch-botanischen Gesellschaft in Wirn (Jahrgang 1858, p. 39-2.40) besonders abgedruckt.

Hoelzl. - Hoelal Carl. Ucher die von IIacquet wïhrend seiner karpathenreisen gemachten botanischen Verhandl. der $k . k$ zool.hot. Ges, in Wien XI (1861), p. 433-416, imprimat și separat.

Hoff. Excurs. 1862. - Hoffmam Ulrich. Excursiune botanică in 


\section{I.XXXII}

distrietul Muscel de la 11-21 Septembre 1862. Monitorul medieal al Româniel. Anul 1862, Nr. 4 și 5, pag. 31 și pag. 38-40.

Hoff. Excous. 1863. - Ioffmann Ulvich. Excursiunea lotanică și inineralogică din anul 1863. Monitorul medical. Anul 186.t, Nr. 15, pag. 171-120.

Jenkia. - Jenka rictor de in Kanitz Pl. Rom.

Junket Al. - Junku Victor de. Adatok Magyarhon délkeleti florájahoz tekintettel Dr. Borbas $V$. jelentésére \& Az 1873 évben a Bánság területén tett növénytani kutatásokról.» Bưlapest 1876. Math. és természett. közl. vonatk. a hazai viszonyokra, Kiarja a Magy. Tud. Akarl. Xll. köt. p. 151-187.

Jenkice Limn. - Jankil Victor de. Adnotationes in plantas dacicas nonnullasque alias europaeas Linnaca tom. XXX. fasc. 5. (1860), I) ianthes puinosies ex Del. sem. b. bot. Vindob. a. 1858 ibid. tom. $\mathrm{XXX}(186(0))$, fasc. $6, \mathrm{p} .748$.

Jankif Oest. bot. Zeit. - Janka Victor de. Oesterreichisehe botanische Zeitschrift VIIl (1858), p. 199. - XVT (1866), p. 366. - Correspondenz aus Bukarest XXIII (1873), p. 322, etc.

Jonla Term. fïz. - Janka I'ictor de in Természctrajzi füzetek.

Janka Zool.bot. Ver. - Janka Victor a. Verhandlungen des zool.-lıot. Vereines in Wien VIl (1857) Verh. p. 123.

Kanitz Il. Rom. - Kanitz Augustus. Planlas Romaniae hucusque cognitas enunerat. Clumtiopoli, MDCCCLXXIX-MIDCCCLXXXI, in-80 XXII și 268 pp.

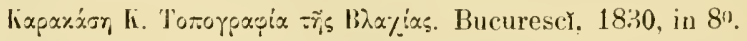

Kurpp. .J. A. Oester. bot. Zeit. - Knapp. J. A. Oesterreichische botanische Zeitschrift XXVII (1877), p. 362.

Ky. - Veḍi kotschy.

Kotschy.-Lotschy Theorlorus. Beiträge zur lienntniss des Alpenlandes in Siebenburgen Verhandl. des zool.-bot. Ver. in Wien 111 (1853).

Lére. - Léveillé Jean in Démidoff Anutol. Voyage dans la Russie méridionale et la Crimée. It Tonne, I'tris, $18\{3$.

Nym. Consp. - Nyman Carolus Frill. Conspectus Florae Europaeae. Orebro, 1878-1882, in-80.

Odobesco A. et Aureliano I'. S. Notice sur la Roumanie. Puris, 1867, in-80.

Reissek: Dr. S. Ueber die Wanderungen des Xantium spinosum. 


\section{I.XXXIII}

Aus den Verbamblungen der $k$. $k$. \%oologrisch-botanischen Gesell-

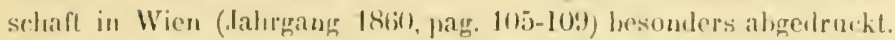

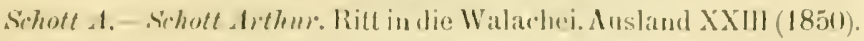

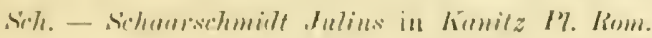

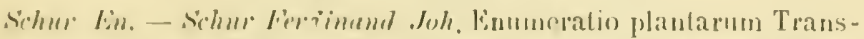
silvaniar exhibens: stirjes Phaneromanas sponte crescentes aleue

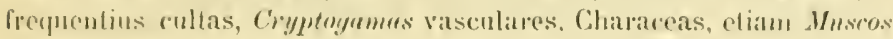

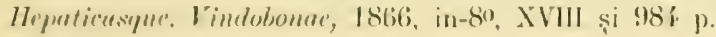

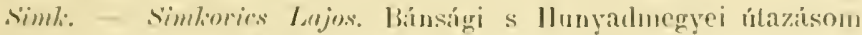
187-1-hen. Bulapest 1878. Math. és természett. kö\%lem. vonathozólag a hazai viszonyokra. Kiztlja a Magy. Tud. Akad. math. és teruészett.

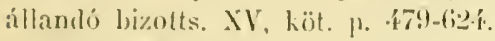

Sutzu N. Notitir statistice asupra Moldover. Lrlit. T. Codrescu

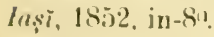

lechtr. it sint. - Lechtitz li. r. et Fratres Sintenis in hanitz P. hom.

1. - Vutshits Gcoryius in komitz M. liom.

Tirnar Constoutin. - Rudimentum physiographiae Moldaviae. Burtae, 1835, VI și ti2 p. in-80.

Wink\% - Winler Moritz in Kanitz I\%. Rom.

Winkl. - Winkler Moritz. Reise nach dem siidöstlichen Ungarn ınd Siebenbürgen. Oesterreichische botanische Zeitschrift XVI (1866).

\section{Manuscripte :}

Gurbh. Not. monuse. - Gubhum Chures. Notice géographique et botanipue sur la Moldavie, pour servir d'introduction à la Flore de ce paỵs.

Guebh. manusc. - Guchlum C. Enumeratio plautarum quas per aunos 18 t: ad 18 in in Moldavia collegil et observavit.

Hoff: manusc. - Hoffmann Ulrich. Catalog de tóte plantele culese cu elevir din șcóla de medicină în timpul escursiuner din anul $186 x$ făcută în regiunea Carpaților (un-ţi Cozič̃, Bistrița și Tismana, ete.).

Sz. menusce. - szabo Joseph. Flora districtulur lași. ordinată după sistema luI l.inneŭ, descrisă și esplicată după J. Ch. G. Baumgarten (autorul Florel Transsilvanieł). Iușĭ, 1873. 


\section{LXXXIV}

\section{Colecțiuni de plante (Exsiccutt) :}

Buri A. - Plante de la Agiud și Broscenr.

Chuniu. - Plante din districtul Némţ (vĕdiute în Erbariul D. Dr. Grecescu).

Lidel, Szabo si Czihack. - Plantele lu1 J. Eilel din Erbariul museutur din lașr.

Hoffmann $U$. - Plante din districtele Buzĕŭ. Prahova, Muscel Vîlcea, Gorjiŭ, etc.

Grecescu Dr. D. - Plante din distrietele Buzĕŭ, Ilfov, Prahora. Vlașca, Argeș, Vîlcea și Mehedințir.

Literile $h, j$. înaintea numelur lur Guébhard, indică că specia de plantă pe care o menționéză a fost věḍută de el în Erljariul museulư din lașĭ.

Vulg. - Numire vulgară.

! - După nume de autor, indică că planta a fostŭ vĕḑută saŭ recoltată de acel autor în localitatea menționată. După numele unuĭ colector citat după un alt autor, indică č̆ acel autor a věd̦ut planta recoltată de acel colector. După o localitate indică că planta a fost recoltată și de către mine din acea localitate. După Exsiccatı vre-unur colector saŭ autor, indică că'eŭ an vĕdiut specimenul original al acelur colector saй autor.

Notu.-Planta a fost recoltată saŭ observată de mine în tóte localitățile ce nu sunt urmate de niç un nume de autor saŭ colector. 


\section{PROMROMIJI. \\ FLOREI ROMÂNE}

\section{DIVISIUNEA I}

\section{DICOTYIEDONE}

I'lante a pine formale in general dintrun sistem eotdicall distincl, sii dintron sistem lemnos co shatur concentrice. încungiurând () medulă centrală.

\section{SUB-DIYISIUNEA 1 .}

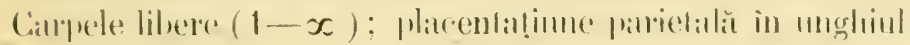
inlern.

\section{RANITGULACEE.}

Florĭ ermafrodite. regulate s. neregulale. - lieceplacul

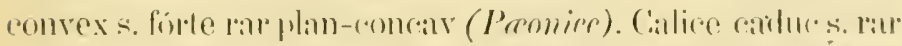

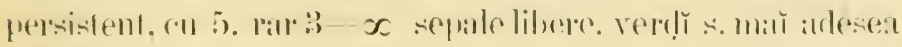

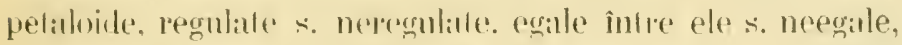
imbricate, valvale s. indnplicate. Corilă nulă s. poḷ̣petală, 


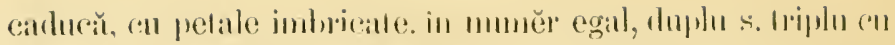

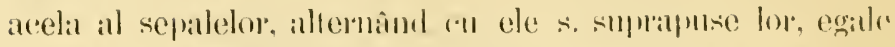

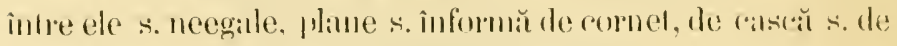

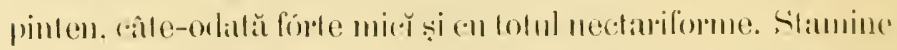

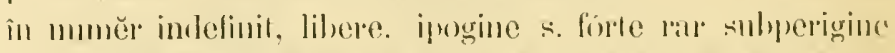
(P'romiec), inserate spiral s. in verticile; antere hasifixe. 2-lo(mlite, introlse extrome s. laterale, deiscente longitmlinal.

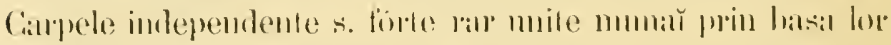

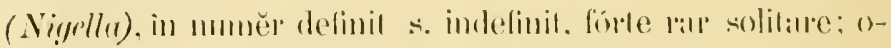

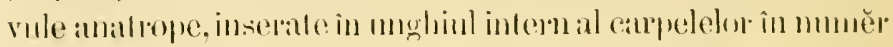
mai mult s. mai pmḅn mane pedonĕ rôndur verlicalle, s. so-

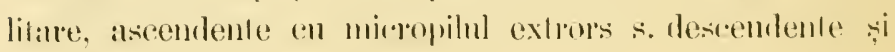

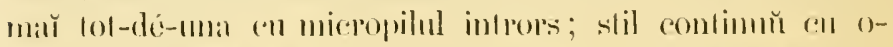
vilrul, de ordinal bateral și fórte sour, cu extremilalea stigmatică simplă, aulesea persistent, rontinuand râle-odată a

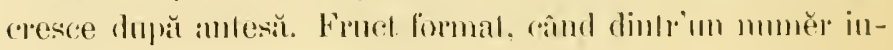
definil de arbene mulice s. coronile de slibnl persistent si

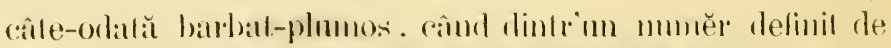
folicule verticilate, polysperme si deiscente prin moghinl in-

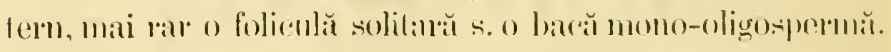
Seminte solilare, ascendenfe s. pendente. s. mumenóse si 2-seriale orizonlal de a lumgnl mughiuluĭ inlern: allumen voluminos, cămos s. cornos: embrion lïrle mic, dreph, bit-

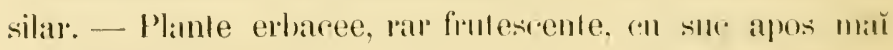

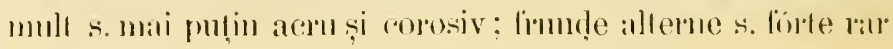

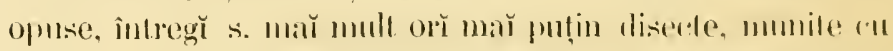
peţiol de ordinar dilalal lat baš̆ lipsile de alevěralle slipule; florř solitare terminale s. axilare, orř grupale in diverse modıIเั.

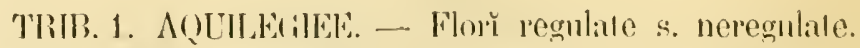

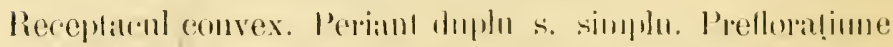

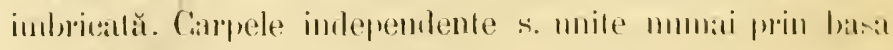

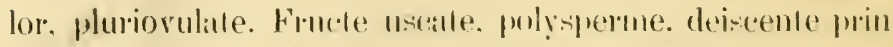
unghinl intern. - Plante erbacee, perene s. anmale. Frundie alterne. 


\section{A. Florĭ reegulate. \\ 11. Prefule givetrumets.}

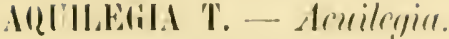

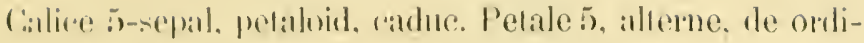

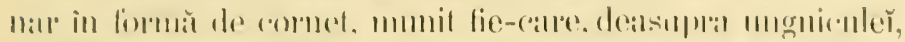

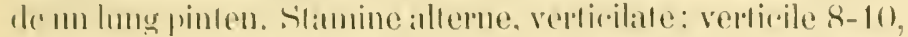

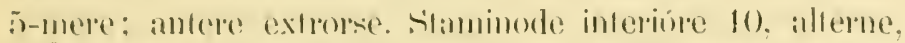

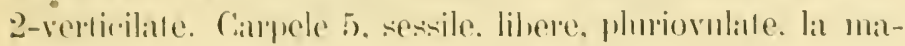

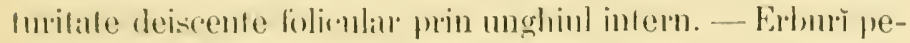

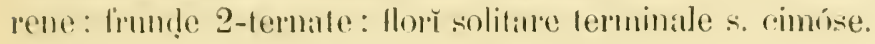

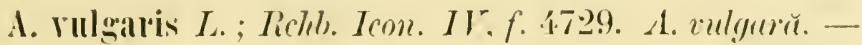

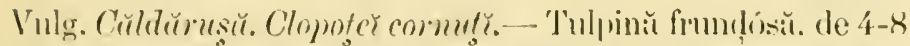
decim.. plurilloră. simplă s. rammsă călle vêrf puḷin pubescentă. Frumle radicale 2-lernate, long peḷiolale, on divisimnile de antaiml ordin forte lung petiolnlate. 'n segmente

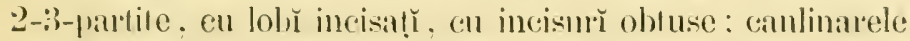
1-3, sulsessile: flomble 3-secte, cu segmente de ordinat

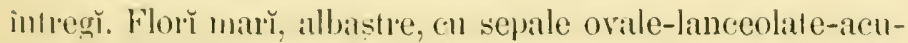
minate. erecte. pubescente in afară. Pelale hunchiate la vôrf,

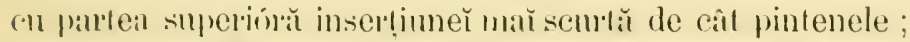

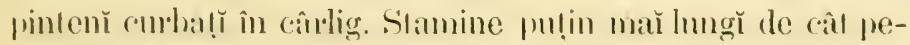
lalele. Silanninode obluse. - of Immiü-Aumust.

Abit. și staț. - Pădurite munţilor. - M-ţir Buzeulur (culeu de lu ph-

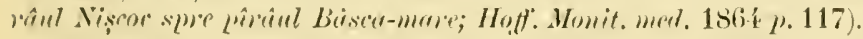

1. alpina L.; Rele. Icon. IV. f. T.736. A. atpinu.-- T'ul-

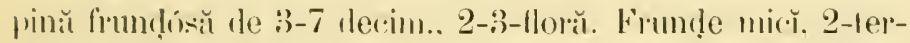

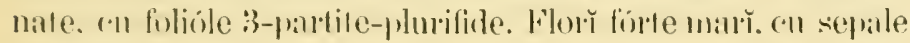
ovale-alcuminale. lórte patente. Pelale trumchiale la vêrf. cu

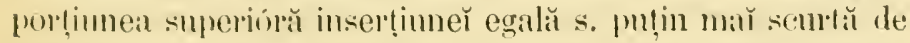

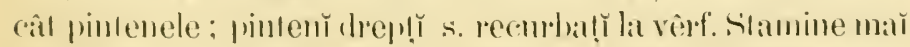
sinrte de wil petalele. Staminode acmminate. - of ImminAlugnest.

Abit. și staț. - Stîncele umbrite din regiunca alpină. - Vêrful 


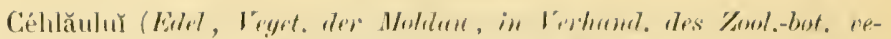

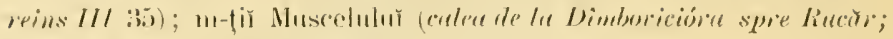
Hoff: Honit. metl. 1862, 1. :39\%).

\section{b. Petulemepintemate.}

\section{NIGELLA T. - Nigrlu.}

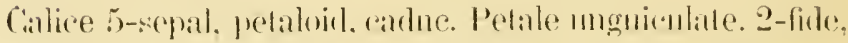

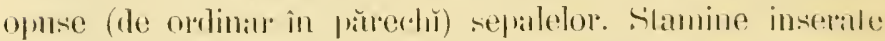

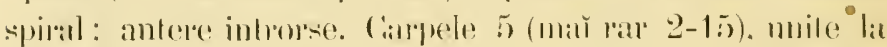

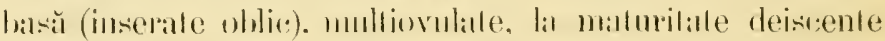

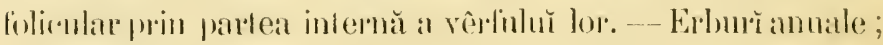
limmle disecte: Hor lemminale, mmile côle-odată ro un inrolurem.

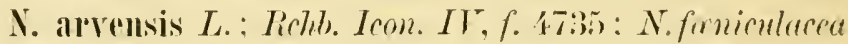
Gurbhard. manuse. (non D)C.). N. de rûmp). - Vulg. Nigrhürü,

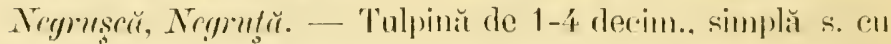

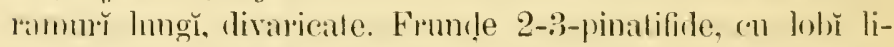

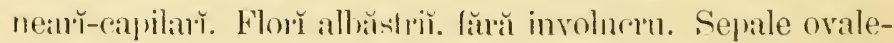
suborliculare. acuminate, lung unguiculale, col vênișire verẹ̆. Pefale 8 (6 smprapuse in părechĭ sepalelor anteriore și celŭ fosterior, ér̆ 2 solilare in fitta sepalelor laterale), munite deasupra ungniculeŭ de o foveolă profundŭ, acoperilă printrin sol\% lung aristat, indoite în drephul foreolě, terminate

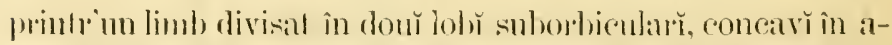

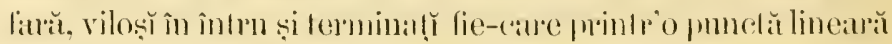

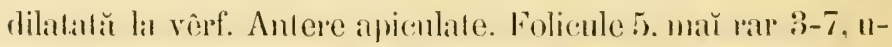

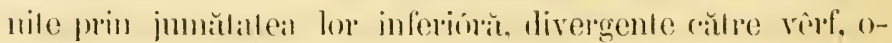
blonge ingusle. puṭin atenuale la basă, munile pe spinare de trĕ nersure, și terminat printr"um rostru stilat de lunginea

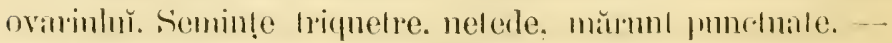
$\odot$ Inniä-Septemlure.

Abit. și staț. - J'rintre semănŭturile de şrâŭ și agrii din terenu-

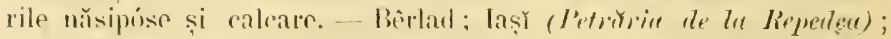

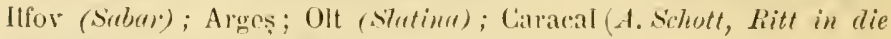
Waluchei, in Ausland XXIII, p. 284-479); etc. 


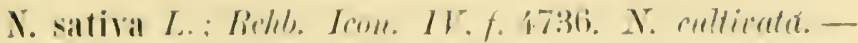

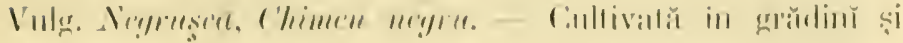

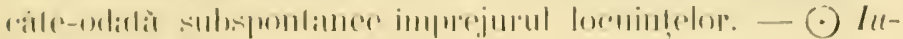
liet-.lingerst.

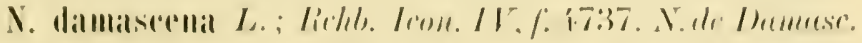

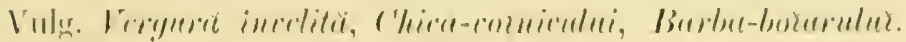

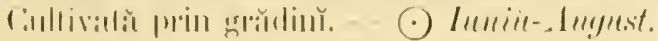

\section{HELLEBORIS'T. - Vildm.}

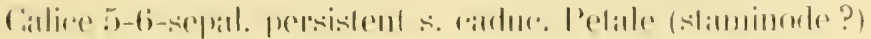

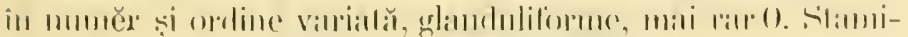

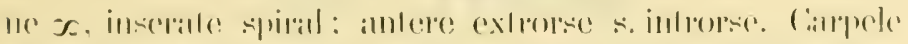

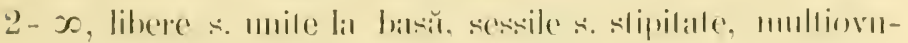

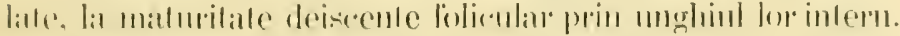

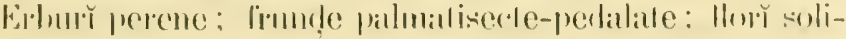

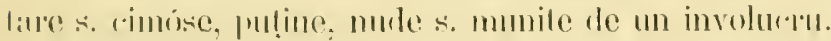

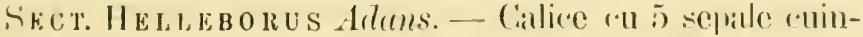
(m) iale. ('illpele sersile.

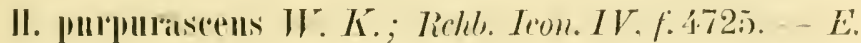

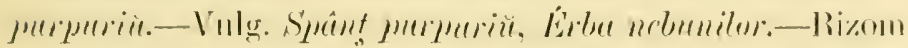
negrir.ios. gros, lamms, r.ll fibre radicale numerise, lumgh si finte pulernice. Thupine ammale de 2-:3 derim.. orente. pur-

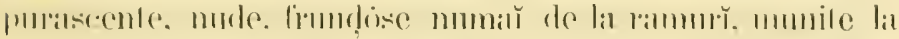

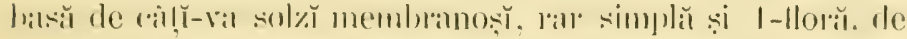

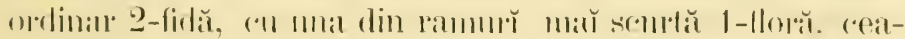

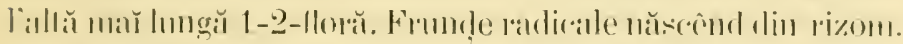

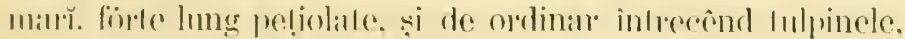

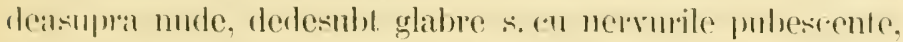

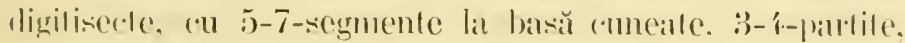

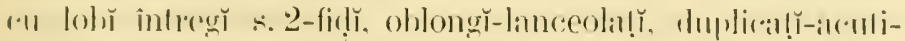

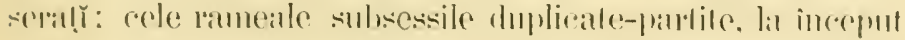

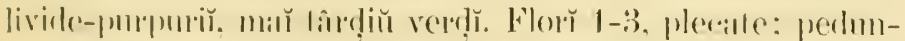

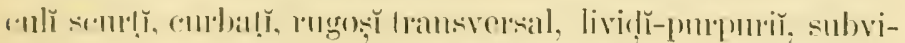

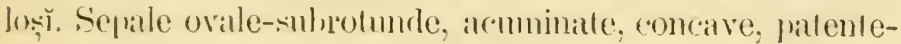




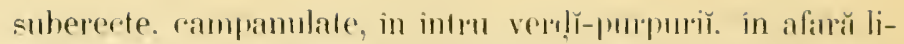

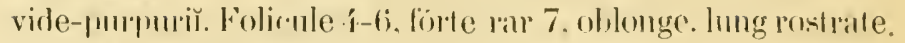
- 2t Merticir-durile.

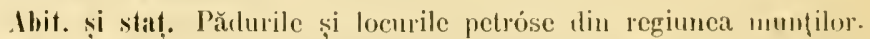

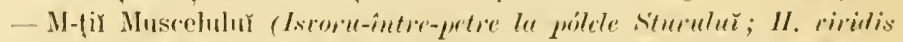

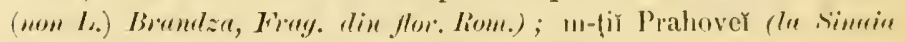

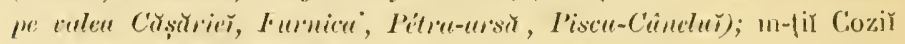
(Urzicu, Vôfu ('ezii).

II. odorus Kit.; Richb. Icon. IV, f: 4.721. E. odtorent. -

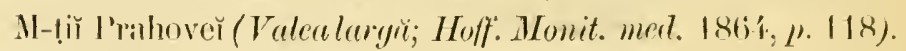
- 9 Fedrutiv-Martiu.

\section{ISOPYRUII L. - Isopir.}

Calice i-(i-sepal, pelaloid, cadue. Petale (slaminode?) în numĕr varialibl, glandıliforme, s. mă rar 0 . Stamine $\infty$. inserale spiral, cîlc-odată puţine; antere snblaterale. Carrpele 2 - $\infty$. libere, sessile $1-\infty$-ovulate, la maturitate deiscente folicular.- Erburř amuale s. perene; frundie allerne s. subropsite, ternate-deseompuse.

I. thalictroides $L$. Richb. Icon. IV, f. 4728. I. Rutişorncutcvěrut. - Plantă glabră. Rizom orizontal elongat. sulbție, cn fibre radicale elongate, mụin cărnóse-grumóse, dispuse in fascicule sjatiate. Tulpină de 15-25 centim., erectă, suptire, simplă s. aprópe simplă, plırifloră. Frmnḍe suptịr̆, mŏ, verd̦ĭ-glanceseente, 1-2-ternate; radicalele lung petiolate, cu 3 segmente lung pețiolnlate 3 -secte, on lobr̆ obo-

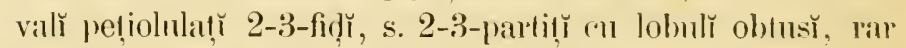
intregĭ caulinarele 3-secte, culobı̆ 3-partị̣ı̆, 3-fic̣̆ s. intregr ; bractealele subsessile, adesea indivise; stipule ovilesuborbiculare, membranóse. Flor ř mụin mumeróse (2-6), micr̆, albe. Sepale ollonge, patente, forte allı. Petale foirte mic.̆̆, glandnliforme, în formă rle cornele contractate lil haš̆. a mult mă scoule de cat sepalele. Folicule 1-3, olınge-0vale, puțin atenuale la baš̆, ra rostru cu mult man̆ scurt de cat folicula. - 2 Aprile-Nüuё. 


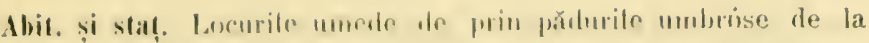

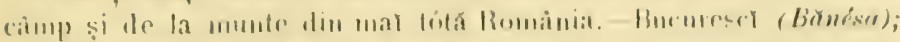

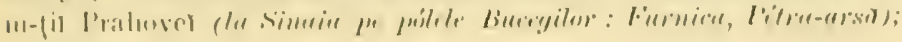
laș (Nitrlen); cte.

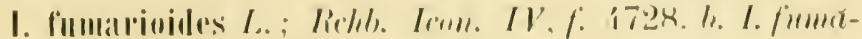

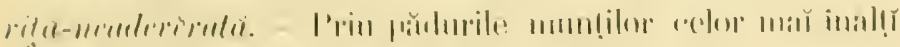

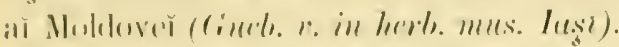

\section{tromballis 1. - Troliir.}

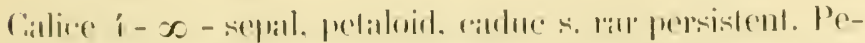

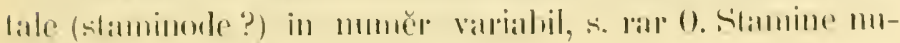

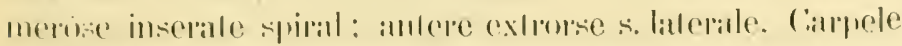

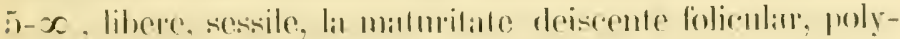

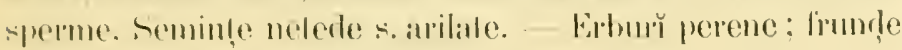

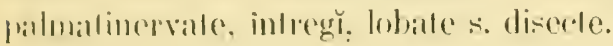

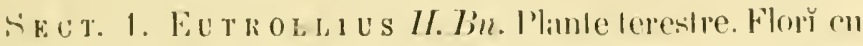

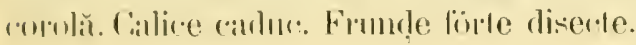

T. enropieus $L_{\text {. }}$; lichl. Icon. IV.f. 1.713. T. rnopin.-

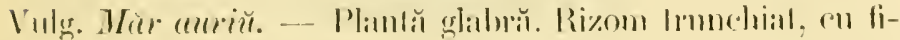

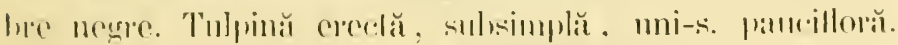

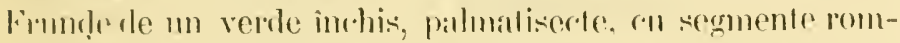

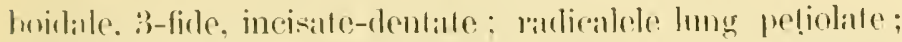

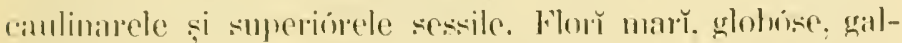

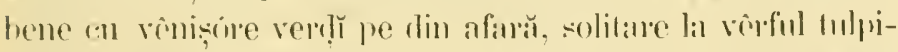

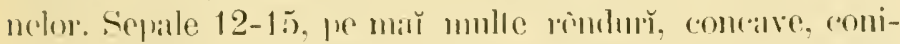

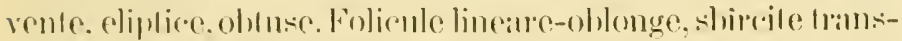

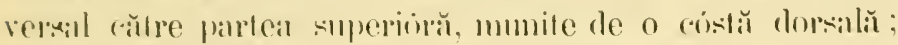

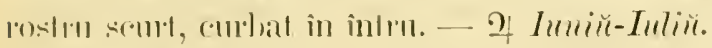

Ihit. si staṭ. Păsciunile diu regiumile alpestre. - M-ṭir Bucegr

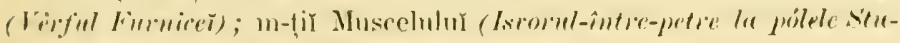
rului); In-ți Bacăıluั (Prulanca); ele.

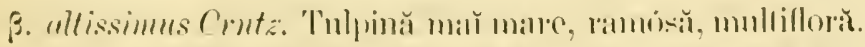

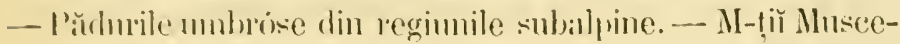
lulı̆ (I’ullina-C'ncii). 
SEct. 2. Cal tha $L$. Plante armatice. Florì apretale.

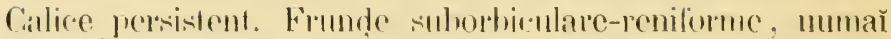
aremile s. dentale.

T. palustris Bromelace herb. flor. Liome; Culthe pulustris I. ; Richl. Icon. IV. f: 4712. T. de balteì. - Vulg. Culcret-

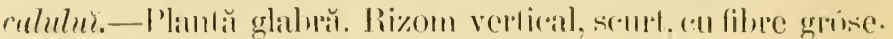

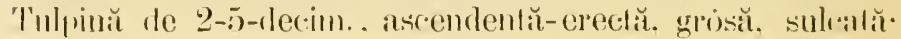

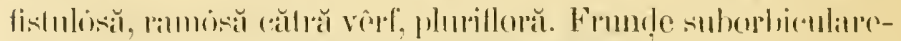

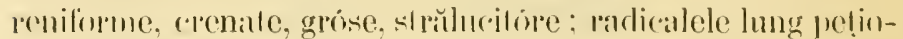
lale; superiorele sessile s. subsessile; lote la basă dililate

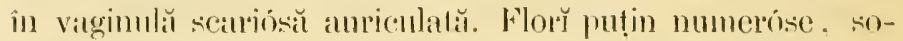

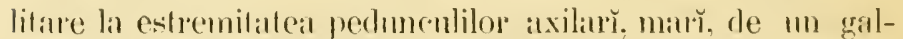

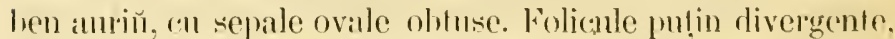
nhlomge, romprimate, shitrite transversal, r.u 3 nervure dorsile; rostru rerembat.- 2 Amile-Mraiu.

Abit. și staț. Bălțy, mlăștin̆. marginea pîraclor. prin prejurul isvórelor. - Bucurescĭ (ne mulul Colentiner, lu Bŭnésus); m-țĭ Bureğ

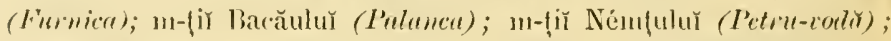
Galațĭ (brutiş); etc.

\section{B. Flor neregulate.}

\section{DELPHINIUM T. - Delfin.}

Calice 5-sepal, petaloid, neregulal, (×ll sepalul posteriop mă mult s. maй puḷin galeat (A'onitum) s. ralcaulat (I) lphi-

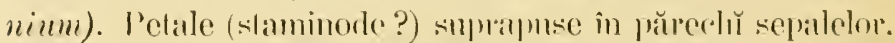
neegale; posteriórele în numerr de 2 , liole rlesvollale, libere s. naй mult оॅ̆ maй pulin unile între cle, smul s. sessile și

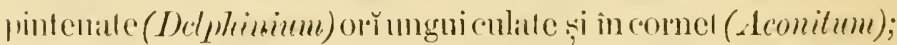

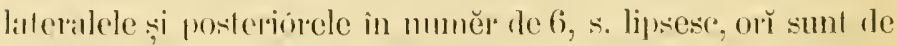
formă villiă̆, râte-odală redıse la lamele mič. Slamine $x$. inserale spinal: antere introme. (anpele 1-5), sessile. libere.

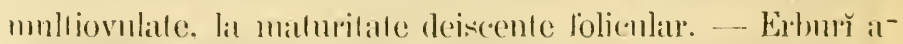

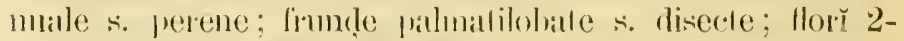
bracteolille, in raceme. 


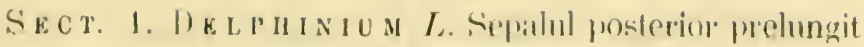

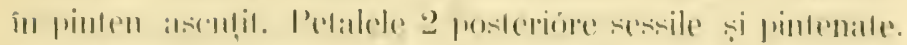
Ciaprele 1-5.

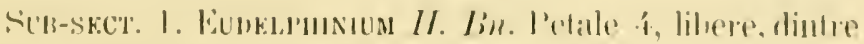
(“110.2 :

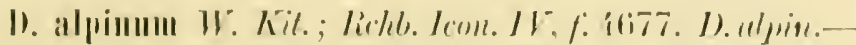

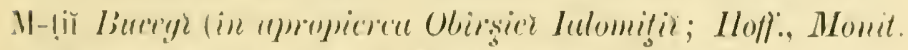

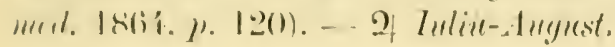

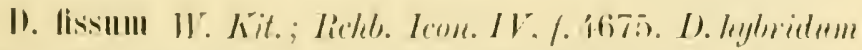

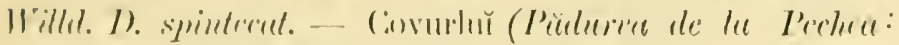
(ilub. l. с.)... of Inviü-ingyust.

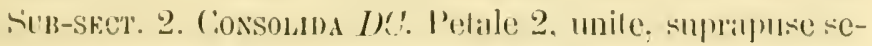

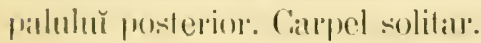

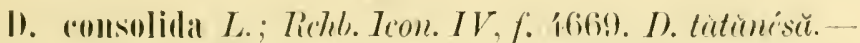

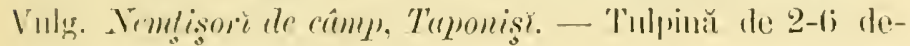

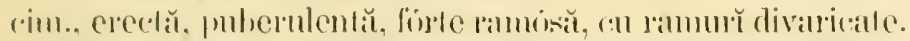

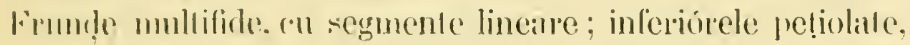

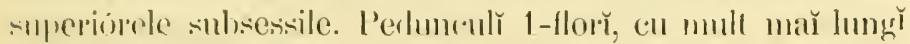

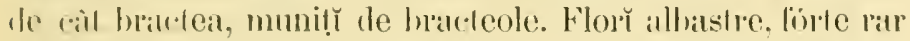
illue, in rareme scoule, laxe, pancillore, divaricate. Sicpale

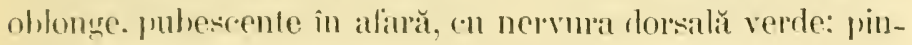

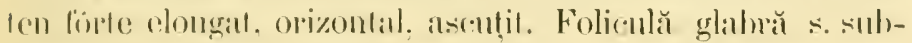

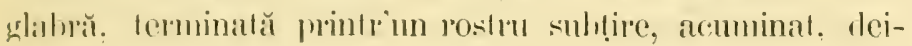

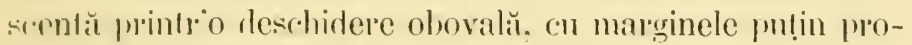
rminente. Seminte neğº. rugoke, r.u shircilur membranose divisille in loımă de sol\%̆. - - P Iuniü-Auryust.

Ibit. ṣi staṭ. Fừte comun prin semăıăturile de grâŭ.- llfov(Cio-

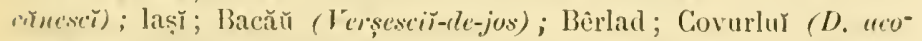
nili (non L.) (iull). l. c.); Prahova; ete.

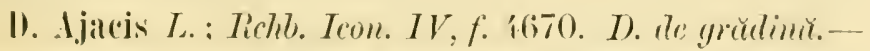

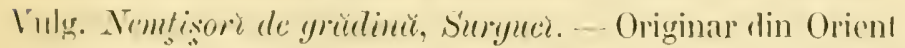

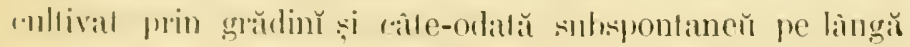
loconintri. - $\odot$ Ituriü-_tuyust. 
SECT. 2. A C 0 N 1 T U $I$. ; Seplalul posterior în cască de formă variabŭ. Pelalele 2 posteriore lung unguimulate, la vêf in lopmă de romel. (aupele $3-5-7$. Fomble palmalisirle.

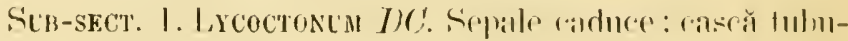

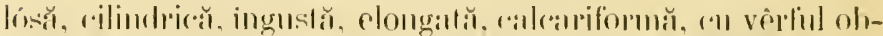

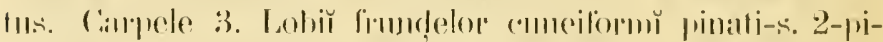

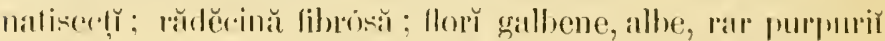
$\therefore$ villegille.

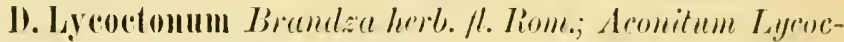

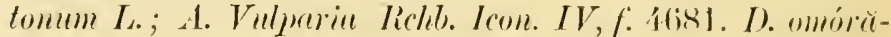

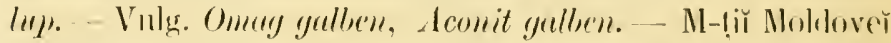

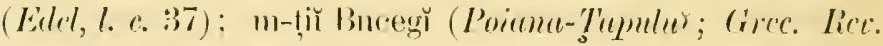

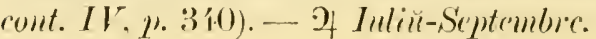

D. pyrenaicum Bremera lect. flor. Tion.; Aconitum Jy-

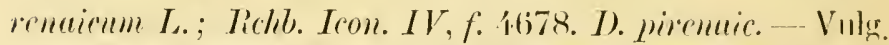

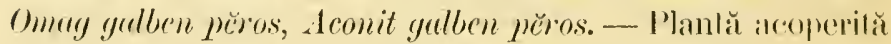

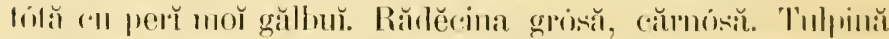

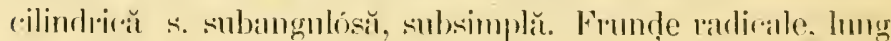

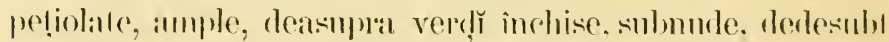

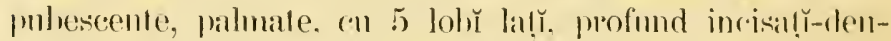

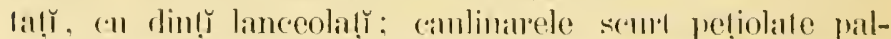

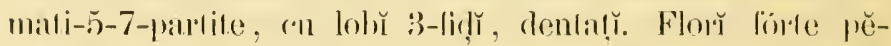
rise. Have-ordnolence, in raceme terminale, inguste. elon-

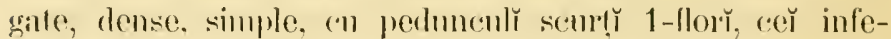

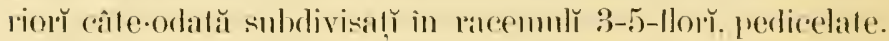
Sepale lingle pĕrose, cel posterior erect, prelungil in ful, en verfiul oblus, strimbal la mijloc, dilatal la deschidere, atenuil in rosirn inainte. Pelalele 2 posteriore erecte, ('n pinten

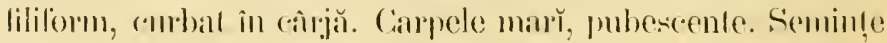
shircile pe tote felele. - If Intiü-Augnst.

.hit. și staț. Păsciunile muede și marginea pădurilor umlurise din regiunile alpestre. - M-țiī Musceluluĭ (pólcle Sturulur dexpre Iscor $(1-i n t r(-p)(\hat{e})$. 


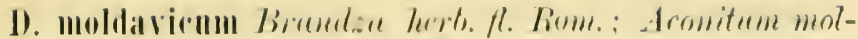

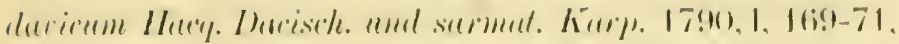

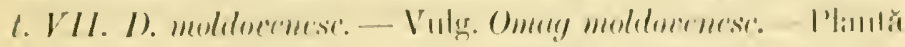

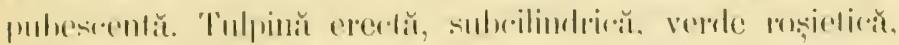

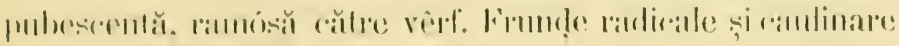

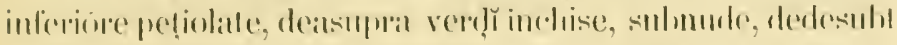

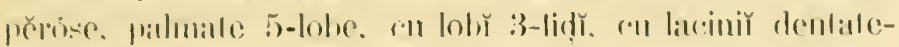

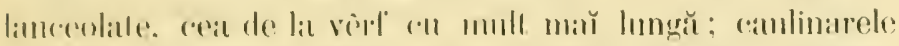

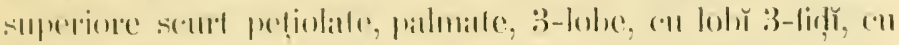

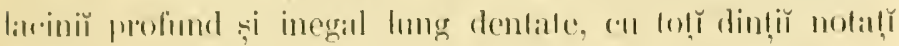

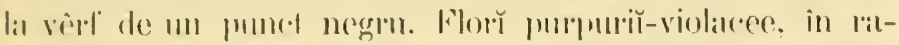
rence forminale s. axilare, firle lunğ, laxe, ("I pedicele ererte-pilcule. 1-flore: batcteole 2, lineare. Sepale in intru perre-hanbale: rel posterior erect, prolmgit in mh elon-

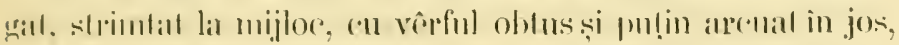
lat gurĭ dilatal și atemal in rostru. Pelatele 2 posterine erecte, en pinten filiform surbat in cil rjă. Folicule 3, divari-

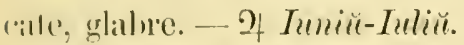

.Mit. și stitț. Pe lìnğă stîncile unbrite şi pe marginea păduritor subalpine și infralpine. - M-țir Muscelulur̆ (Dimboricióno).

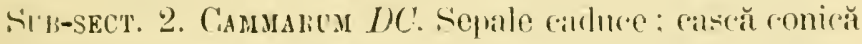

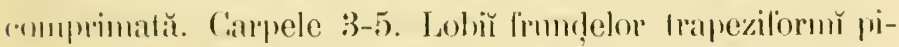

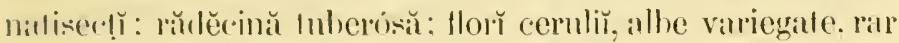
(aillice.

I). C'anmmarum Brandzu herd. fl. Rom.; A conitum C'emmetrem . Jeery.; Tichl. Icon. IV, f. 4689'. D. Cimmmeron. - Vulg. Omug. - Prin pădurile mmbróse ale munților. - Buregi

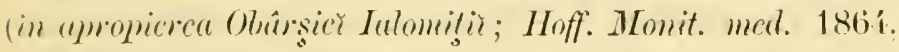
11. 12(1). - 2f Inlin̈-Srytrmbire.

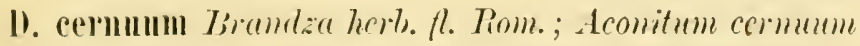

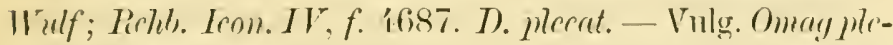

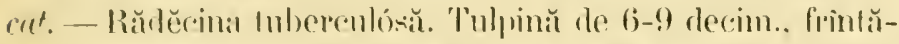

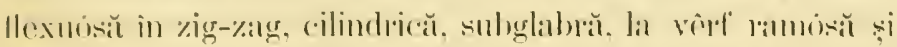

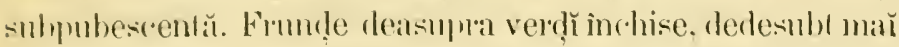
palide, glabre pe ameindoute fetele, palmati-n-partite, cu 
segmente la basă cunciforme. late-romboidale, 2-3-fide, cu

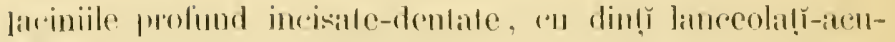

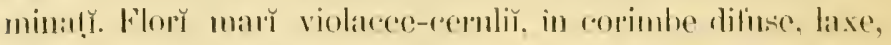

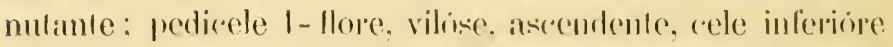

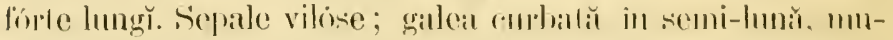

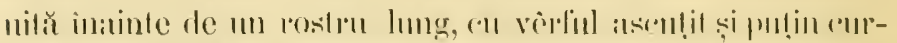

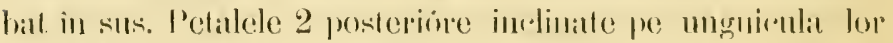

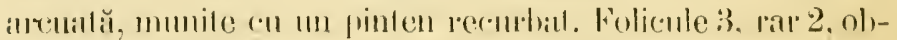
longe, vilise. divanicalle. - of deuyust-beptrmbie.

Mbit. și staț. Pădurile subalpine. - Reginuea inferiơră a Cièlău-

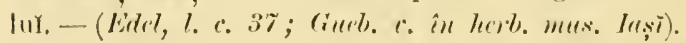

I). paniculatum Rinudea herl. /l. Rome; Aconitum puniculatum Lam. ; Iichb. Icon. $1 \mathrm{~V}$, /. i.686. D. pneniculat. - Vulg.

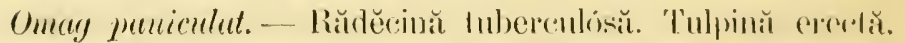

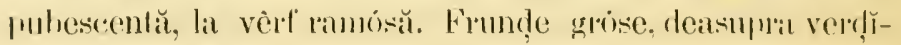

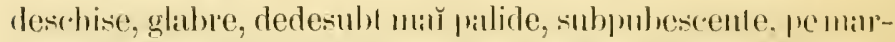

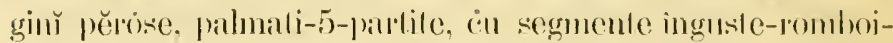
dale 2-3-fide. coi laciniile ingusle. profund incisile-demale. Florř violacee-cermliŭ, in racene paniculale. mullillome, ra-

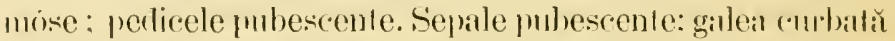

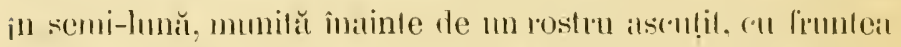
simnată. l'elalele 2 posterióre inclinate pe ungniculit lor curhală, munile de un pinten resubat. Folicule 3. pubescente, divalricalle. - 2 Inliü-Sentembre.

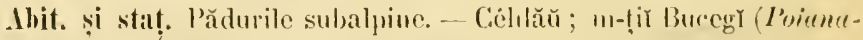

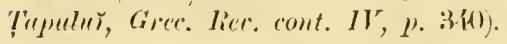

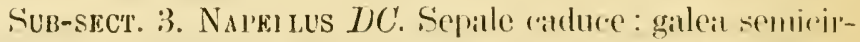

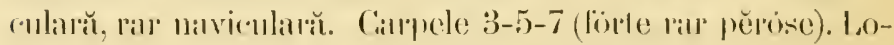

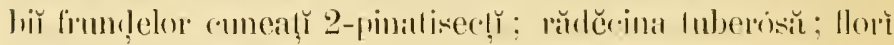
maı̆ ålesea remulĭ.

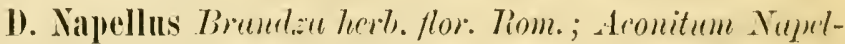

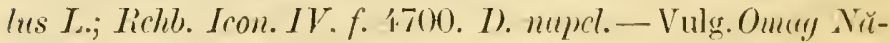

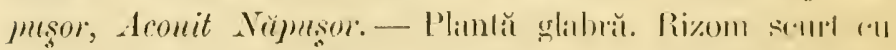

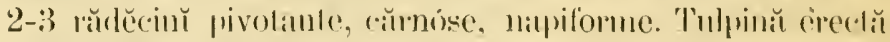

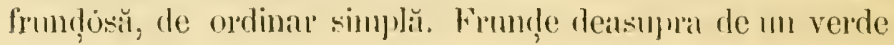




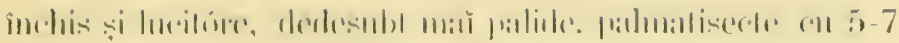

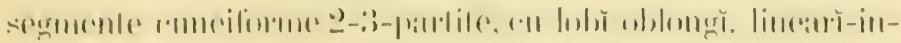

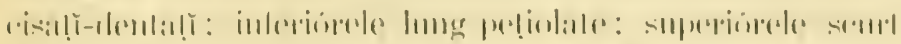

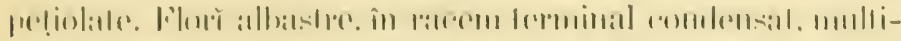

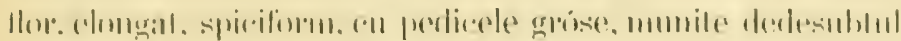

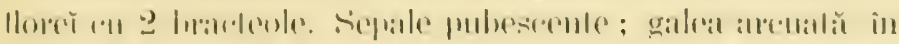

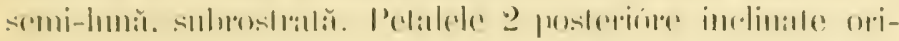

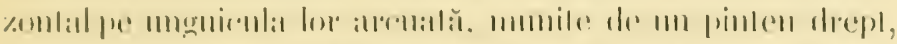

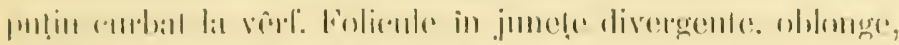

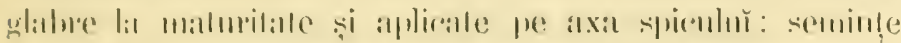

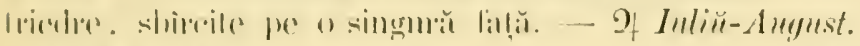

Abit. și stal. Proserunile de prin pădurile subalpine - Vềful (iilılüulur.

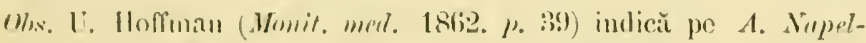

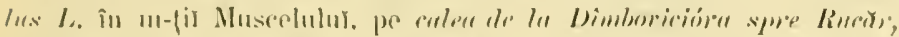
foralitate umele ĕ "

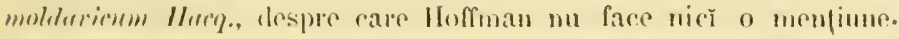
Arestă implejurare mĕ face să presupun, pînă la probe contrarie,

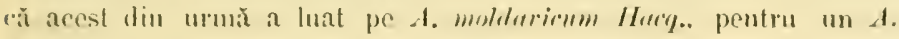
Nitpelllus L.

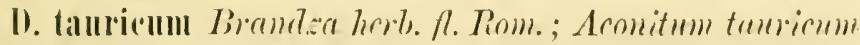
Wulf; Reth. Irom. II. f. 4.709. 7). tamrir. - Vulg. Omag

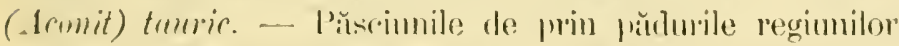

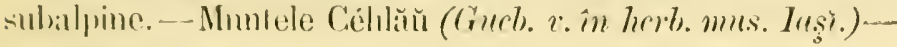
2) Auyust.

1). strietum Rramlact hert. fl. Rom.; A. Nayellus L. x. mumum Bimy:; Aronitum stristum Brrmh,; Tehh. Ison. II; f.

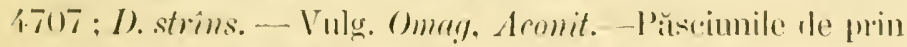

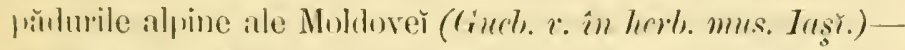
9. Inliü-Auyust.

I). Neubergense Promba herb. fl. Reom; Aconitum Nru-

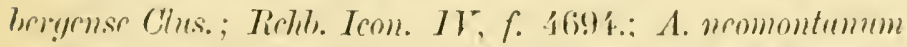
Wulf. I). Nomberyens. - Vulg. Omangel muntilor. Aconit. -

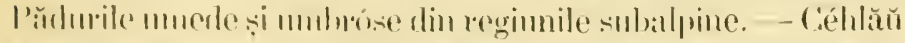
(A. Meomontumum Eilel 7. c. 37 ; Gueb. $\imath$. in herb. mus. Iaģt. -2 August. 
TRIB. 2. RANUNCULER. Flon regulate. Receptacul con-

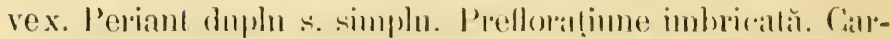
pele independente și in momĕr indefinil. 1-ovolile de la in-

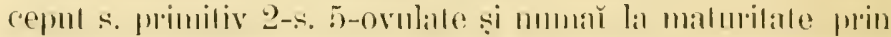
abortatre devenind 1-ovulate. Orul descendent coll mirropil introls-superior, s. extror's-superiol', or assendent cu micropil extrors-superior. Foncte uscale, monosperme, indeiscule.

- Plante erbirce anuale s. perene. fromde alteme.

\section{RANUTCLUJ' Hall. - Remmment.}

Calice 5-3-sepal, erbacen̆, de ordinar caduc. Pelale 3-20,

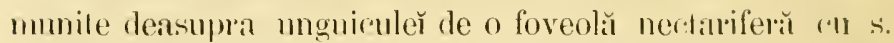
făıӑ sol\%, și dispuse în rorolă simplă s. dmplăt. Slamine $x$, spirile: antere laterale s. extrorse, Canpole os. 1-ovmlite; ovil ascendent ru micropil extrors-inferior; Achene so. rit-

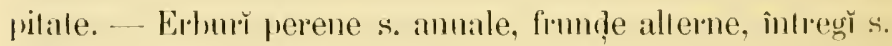
disecte: flor solitare s. cimose, psendo-corimbóse or umbelile.

Sirct. 1. Rinuncutus C. Banh. Florĭ 5-mere. Corolă simplă. Carpele agregale în cappiln globos s. oblong. negi-

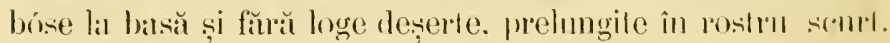

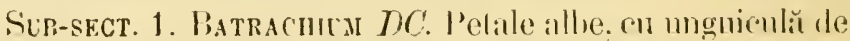
ordinal gallhenă și cu foveolă nectarileră făı̆ sol\%. Carppele shồcile lransversal. - Hanle arualice. submergenle s.plulilire.

R. anuatilis $L . ; R c h$. Iron. III. f. 4576. R. acuatir.-

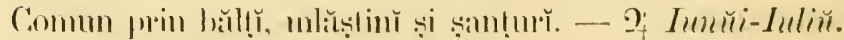

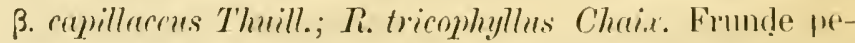
biolate, lobte sulmèrgente și de aceeași lommă, mullilide, r’u

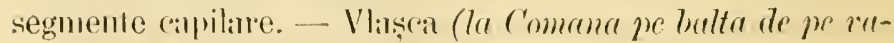

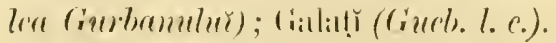

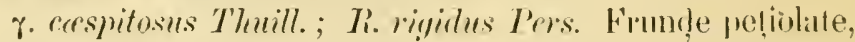
tóte emergente și de aceeaș̆ lommă. multifide, cu segmente 


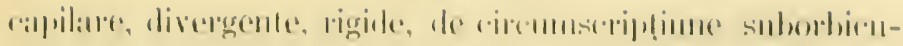

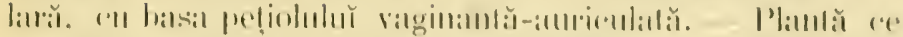

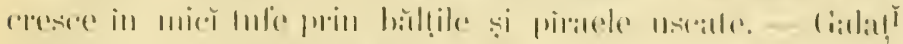

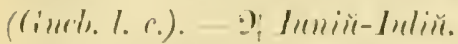

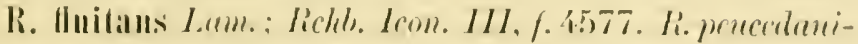

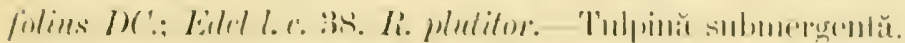

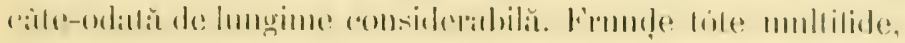

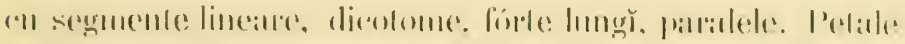

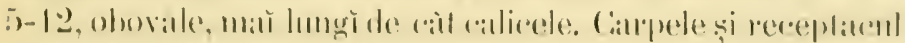

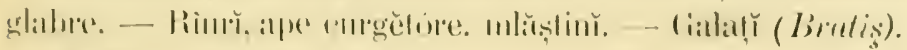

of Mnim-dumpust.

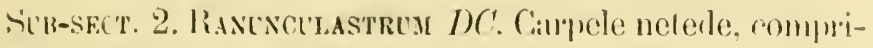

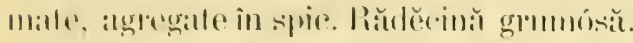

R. pedatus IV. K.; Lichl. Iron. III, f. 4591. R. pedut.--

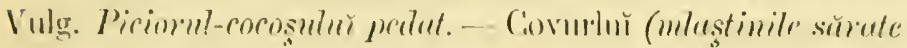

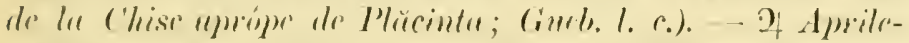
Muiri.

R. illyricus L.; Rehl. Irom. III, f. 4587.--R. de Iliriu.-

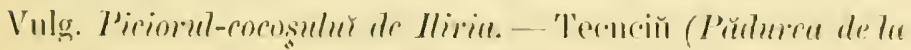

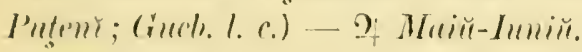

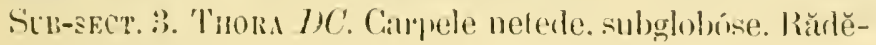

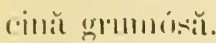

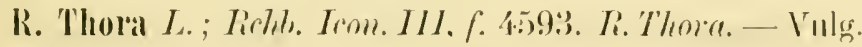

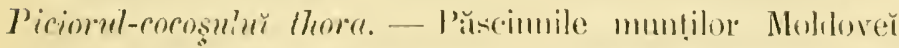

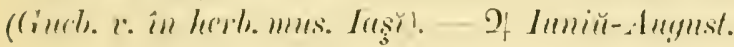

Sirb-sert. 4. Hecatonia I.C. Canpele nelede ovile-sulpo-

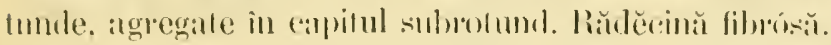

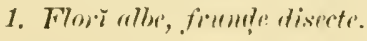

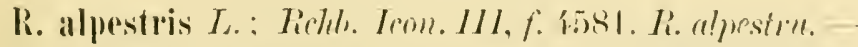

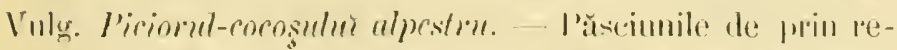

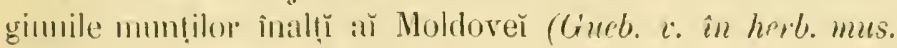
I(usit). - Intiu. 
R. aconitifolius L.; Rech. Icon. III, f. 4585. Ri. cu frun-

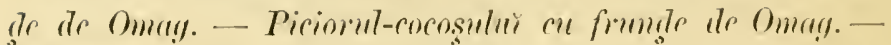

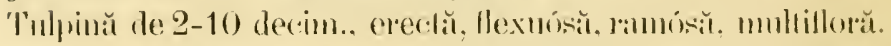
Frunde palmali-3-7-paldite. al segmente ovale-lamcolale, aldminalle, incisille-dentale. Bractee inferióre lanceolate, dentite, neacuminate. Flori albe, scml subcorimbóre. (') peduncule vilóse. Seprile pubescente. Pelale obovale cu fovenla nechlıiferă munilă de un sol\%. Stamine de lungimea oviarelor. Cimpele (i-15). ohovale, umblate-subcomprimate lateral, nervale. glabre; rostm erect, recmball la rôf ; receptacul vilos.

B. platanifolius; R. platanifolius L. Tulpină rigislĭ. Frınde mắ marı̆, eи segmente mă înguste, lanceolate. lungacuminate : cele radicale cu divisimn 3-fide. înguste. acuminate, incisate-dentate, pubescente dedesubt, jrecum si vitginulat pețiolelor' flor̆ mă mař̆, lung subcorimbóse cor pe-

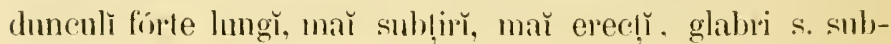
pubescenți bractee inferióre mă ingusle, lanceolate-lineare, întreğ s. subîntreğ. acuminate: slamine o dată mal̆ lungì de calt orarele. - 2 Iuniŭ-Iuliut.

Alit. și staţ. Pădurile umede și umbróse de prin locurile stîn-

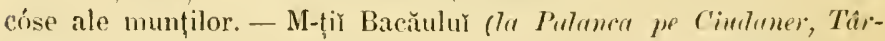
hăuşel).

\section{Hor galbene; fromde nedicisate}

R. Lingua L.; Rethb. Icon. IJI. f. 4595. R. Limlur.Pe marginea hălţilor, a șanturilor și a rîurilor. - lum-

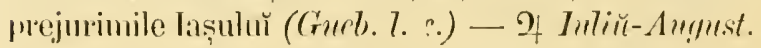

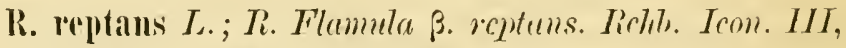
f. 4595 rer. B. - Moldova (EAd 7. c. 40).

3. F7or gă galbene; finude disecte.

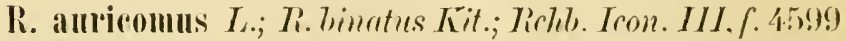

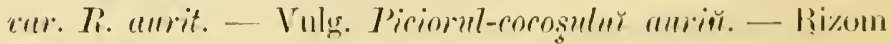
scurt, nodoros, en fiture radicile mumerise, verticilinte la basa 


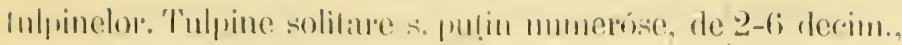

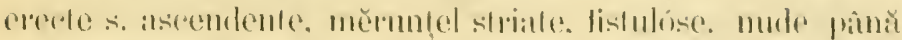

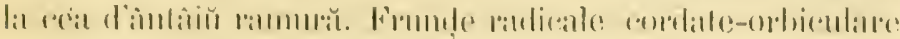

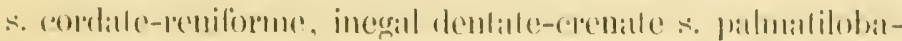

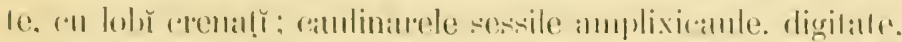

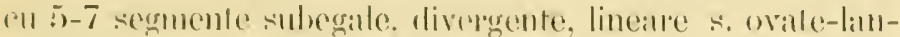

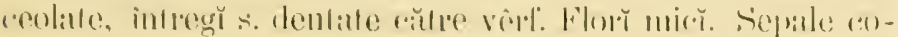

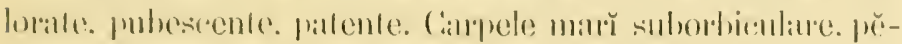

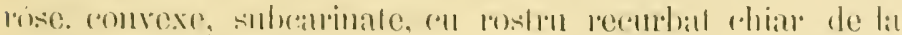

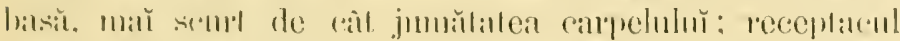
glituru. - Q Mrevtiu-sprile.

Abit. și staț. Püulurile umbróse. - Bucurescr (Antonader, Cirgh-

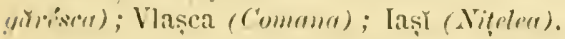

R. Cassubius L.; Relu. Ienm. III,f: 4601. R. Cussubir. - Vulg. Picionul-cosoşului Casubic. — Frumde subroriare!. subvilise. malicalele l'orle mařr, rordate-reniforme. denlale s.:3-lobale. (amblimarele digitate. an segmente late, rombohite-lanreolate, suhegal serati-denlale. Flor măr. Carprele

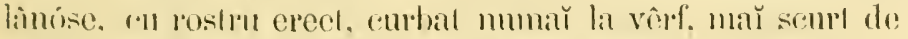

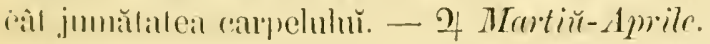

Anit. ș slaț. Pădurile umbróse. - Vlașca (Comonno); Васӑй (C'rmpeni).

li. sceleratus L. Ficht). Icon. III, f. 1.)98. IR.serlerat. -

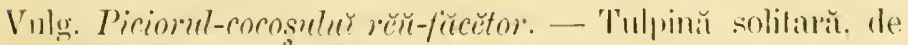

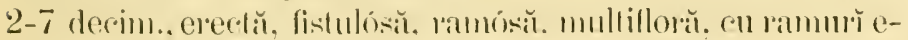
recte. sublicolome. subpubesente s.gladre. Frmole glabre

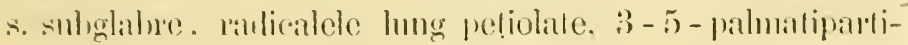

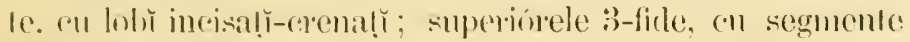

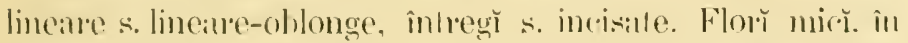

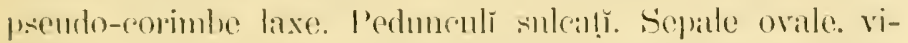
lise, rellexe. Pelale maı̆ somles. de lumgimeal calicelıĭ. lip-

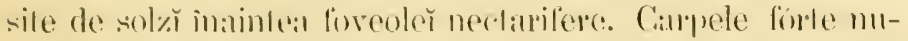

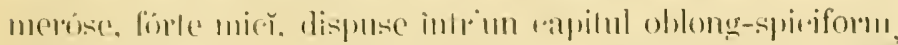

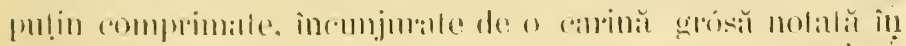

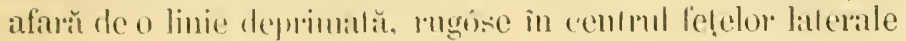


cu rostru fórte scurt s. submul; receptacul puliu vilos. $\odot$ Maiй-Srptrmlire.

Abit. și staț. lorurile umede, marginea lacurilor, a iazurilor. -

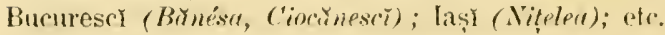

R. montanus Willd.; Rehb. Ienn. III, f. 4603. R. de munte. - Vulg. Pirioribl-rocogulur de munte. - 'T'ulpină de (j-15) centim., erectă, rigiclă, de ordinar 1-floră, călre vêrf pubescentă. Frunde radicale glatbe. ral pmbescente, lnng petiolate, palmatipatite, an :3 semmente obovate, 3-fide,

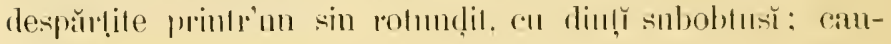
linarele sessile, 3-5́-partile. ro segmente lineare-ohlonge. divergente, obtuse. Pedunculĭ nesuluaț. Seprale pubescenle, patente. Pelale on solzul loveolè nertarilere firte scurl s. sulinul. Carpele carmale, on letele subconvexe, glabre, cu rostru recurbat, c'n mult mă scult de câl ovariul : receptacul pĕros. - 2 Mniй-Iumiй.

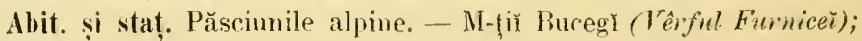
Vêrfıl Céhlăulıł; etr.

R. acris L.; Ruhb. Jcom. III, f. 460ti, R. reru. - Vulg. Piciorm-rocoşlut ueru. - Rizom simplu. oblic s. appópe orizontal. premors, munit in lólă longimen sil de libre latdi-

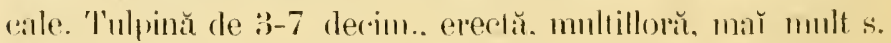

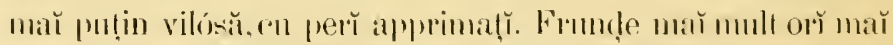
puțin vilóse, rarlicalele lumg petiolate. palmalipurtile, cu

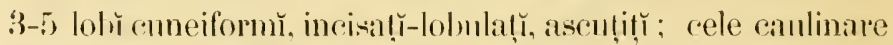

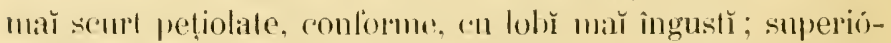
rele subessile, de ordinall pilmatisecte al $3-5$ segmente

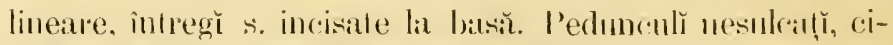

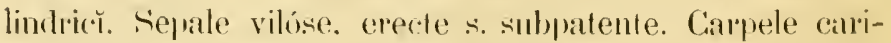

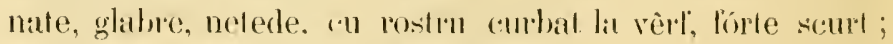

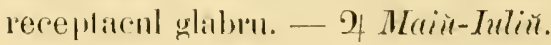

Abit. şi staţ. Fêneţele, pătlurile şi locurile umetle de la eâmp și

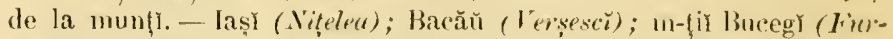

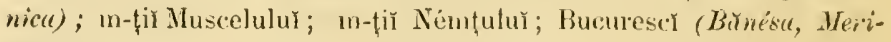
nani); etc. 


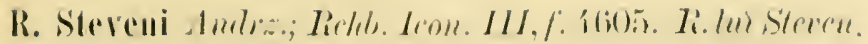

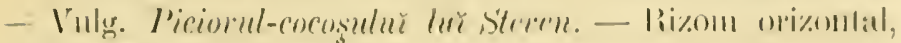

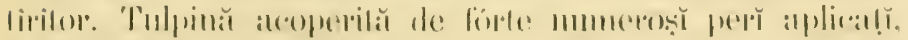

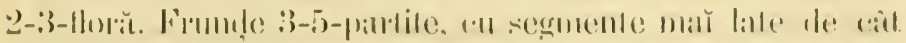

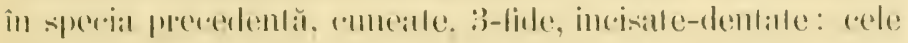

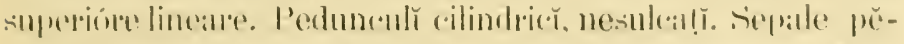

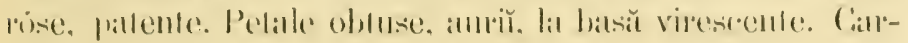

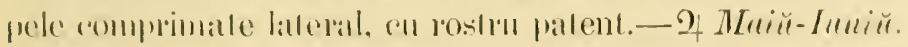

dhit. și slaṭ. Locurile umede, pe malul pâractor. - Covmrlur (limjina ; (int). 1. r.).

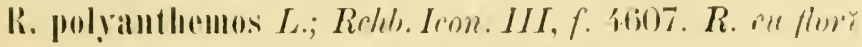
multe. - Piriorul-encoşnluy su flor multe. - Planlă pĕ-

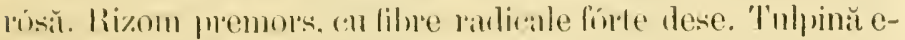

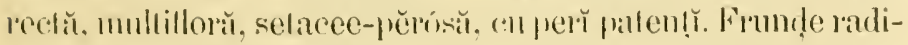
"ale. orale-orthiculale. :3-5-palmaliserte, con segmente incisit-

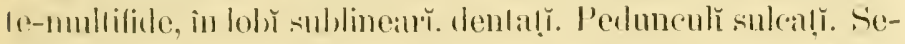
pale vilise. pillente. Pelale reluse. Campele an carinat :3-co-

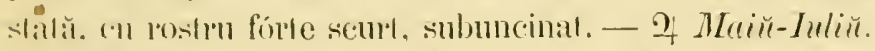

Aloit. și staṭ̂. Prin pădury̆. - M-ţir Bacăulur (Apele minerede de la strmic); Galaţi (Fostesete reche; (rueb. 1. c.).

R. nemorosis IDC.; R. syleaticus Thuill.; R. numens śrhlrieh.; Relhb. Icon.III. f. 4608. R. de müdure. - Vulg. Piciomel-cocosulur de püdure. - Rizom serurl. gros. verlinal. cu

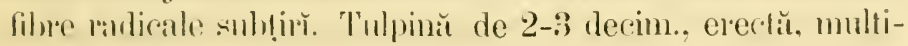

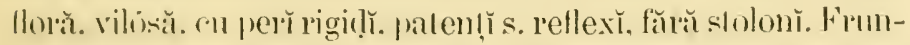

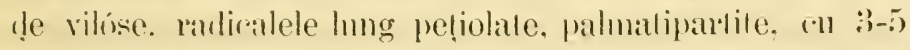
segmente kale. cumeiforme-romboidale. 3-fide. c." lobulĭ călre vîf aculi-dentaḷ: smperinrele subsessile, de ordinar palmalisecte. (") 3-5) segmente lineane, intregi s. incisale-den-

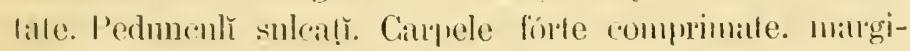

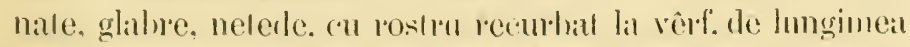

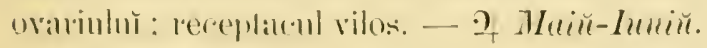

Alit. și vtaṭ. Pădurile umbróse din regiunile muntisse. - Ml-fir bu-

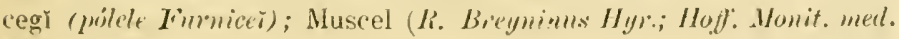
$1862 \mu .38)$. 
R. lannginosus L.; Rehb. Icon. III, f. 4609). R. liknos. -

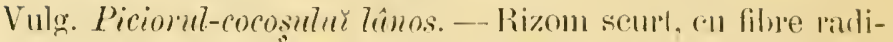

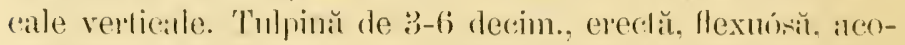

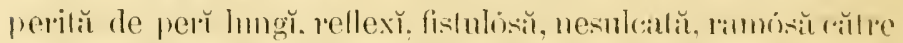

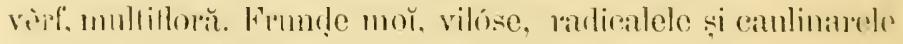

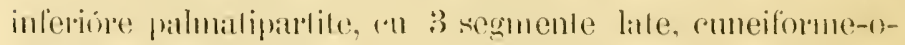

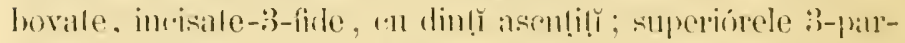

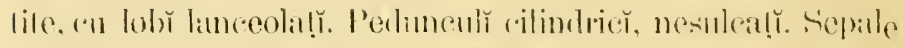
vilise, inlinse. Carpele lat-matrinale. emmorintate-lenticol-

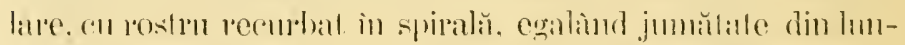

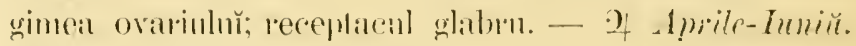

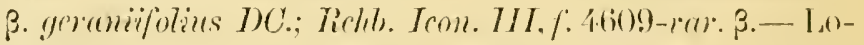

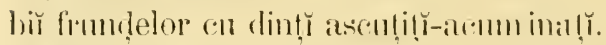

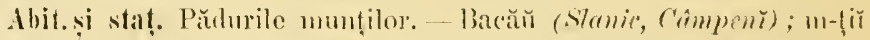
Prahorer (Zйgemu; Hoff. ahonit. met. 1864 p. 118).

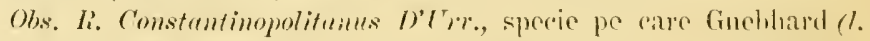
c.) o indică en crescênd prin lecurile unubróse de la P'eche (corur-

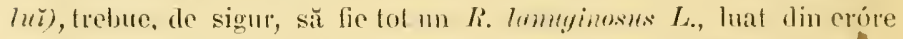

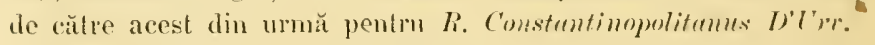

R. carpathieus Willd.; R. Lerechenfeldianus Schur. R.

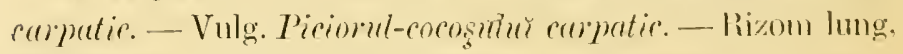

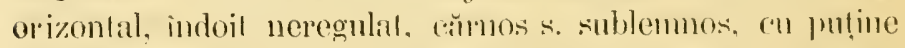
fibre ratdicale. 'l'ulpine solitare s. maĭ multe, de 4-6 decim..

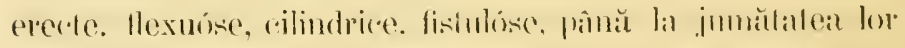

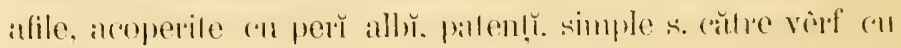

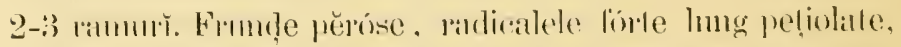

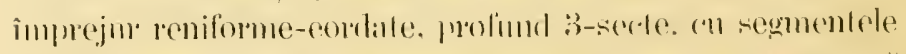

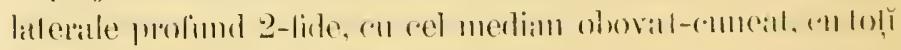

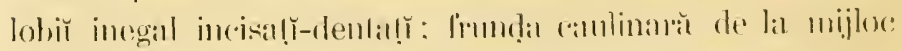

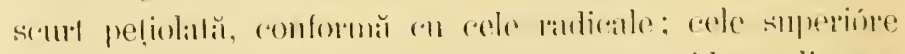

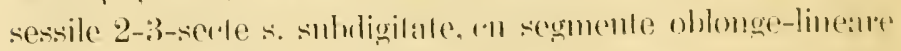

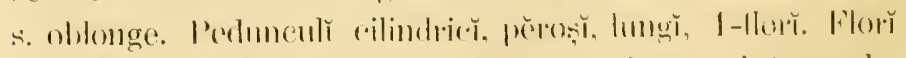

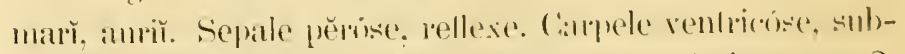
lenticulare, carinale, cu rostru forte sempl circinat. - - 2 Iluirit-Inniu.

Abit. și stat, Pĭdurile subatpine. - M-țir Bucegr (nólele Furnicei). 


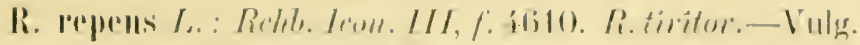

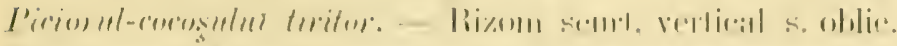

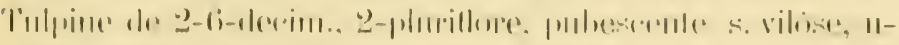

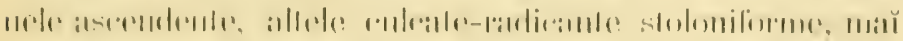

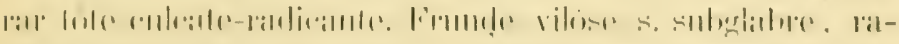

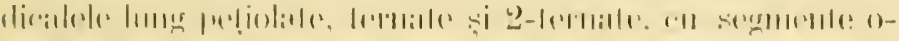

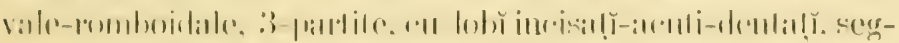

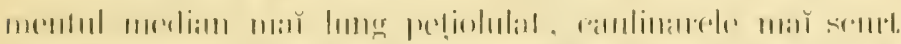

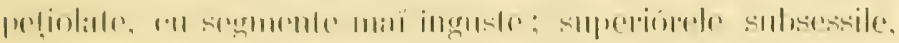

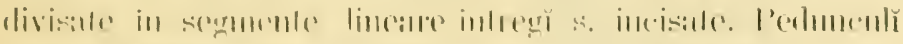

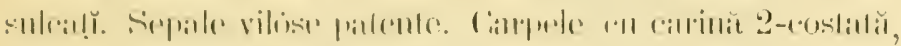

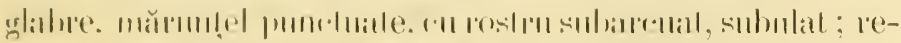

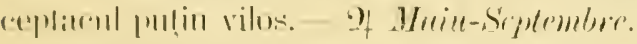

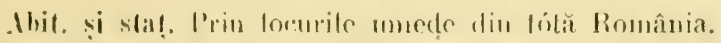

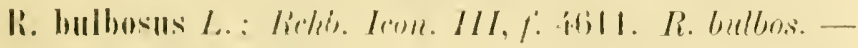

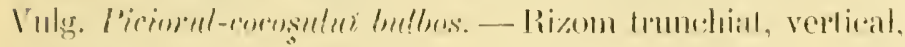

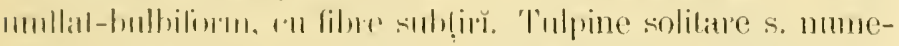

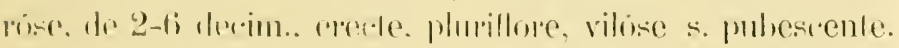

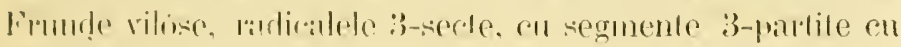

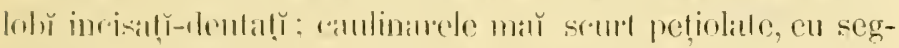

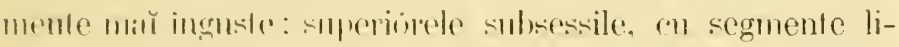

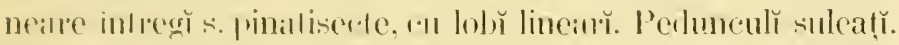

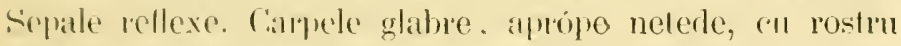

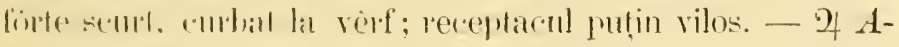
prile-Inume.

Mlit. și staṭ. Păsciunilo și pădurile din tótă Romània.

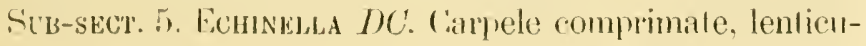

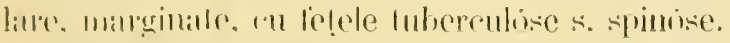

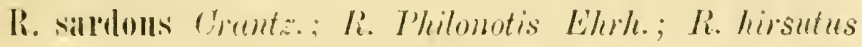

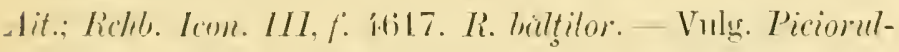

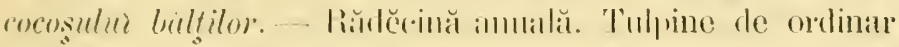

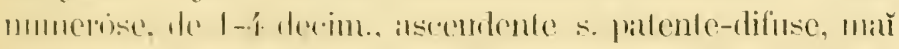

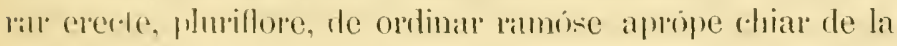
basit, pubescente $\therefore$ vilose. Frunţe vilose s. pubescente, 
radicalele si cole inferiore destul rolung petiobate, 3-partite s. 3-secle, ('ll segmenle incisille-dentale, r.ll segmenlul

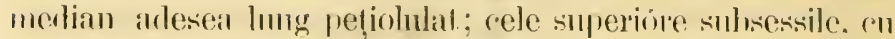
segmente lanceolate-linenre, intreğ s. incisitle. Perlunralli sulcaț. Sepale vilose, reflexe. Carpele forple romprimate. glalme, lenticulare, incmnjurale fur o costă subtire, mroeminenlă, verlastră, cu lę̣ele plane, munile rălre margine de mua s. mal̆ multe rêndury de lıbereule, re lipsesc rille-odală. ru rostru lal, scmit, drepl s. de-abia rurbat: receplacul viJos. - Mriü-Auyust.

Ihit. și staț. Vir, marginea bălţilor, locurile năsipóse și inunlate. - Rîmnicu-Vâlcir (pe culea Oltulŭ si " Lotrulur lu Golotréni); Jași (Niţeleri); Bêrlad, ete.

R. arvensis L.; Richt. Icon. HI, f. 461'. I. de cimm). -

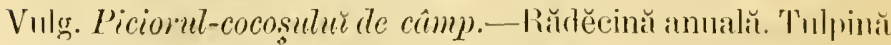

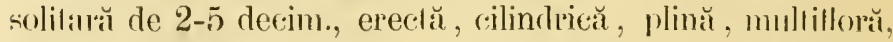
adlesea ranósă aprópe chiar de la hasă, palidă, muescentă $\therefore$ subglabıӑ. Frund, glabre $\therefore$ pubescente, radicalele inmg petiolate, :3-patlite s. 3-secte, cu segmente r.meiforme elongale, neregulat 2-3-fide: caulinarcle 3-secte, cu segmente

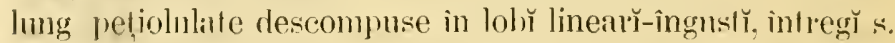
incisați : smperiórele subsessile, conlorme. Pedmuncul̆ nesinl-

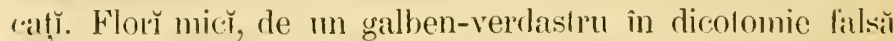
$\therefore$ lalerale opuse frumdelor. Sepale vilose, snbualente. Callpele $3-8$, forte marı̆, ohovale, comprimate. încmunute de o róslă grós̆ă, ar felele laterale amate de proeminen!e spimóse dreple si de tuberentĭ, a rostpu drept, linear. subulat. mă lıng de àl jumălatea carpelılıú ; receplacıl vilos. - Maйї-Iипій.

Ihit. și staț. Śmĕnăturile și locurıle cultivate din tótă Romània.

R. muricatus L.; lichl. Icon. III, t. tilñ. R. spuinos.Vulg. Piciomul-cocosulur spinos. - '́lulpină de 1-3 rlecim..

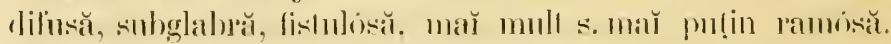
Frunde glabre, eordale-subrolumde. renate s. 3-firle: rele superióre obovale, runeilorme la biš̆. P'edunculĭ sulcaț̆, 


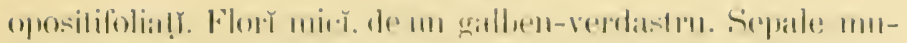

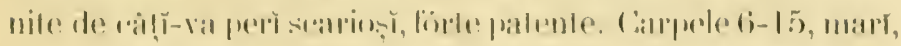

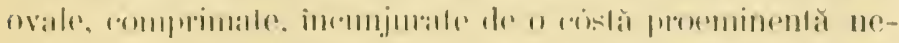

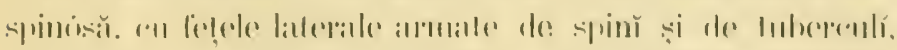

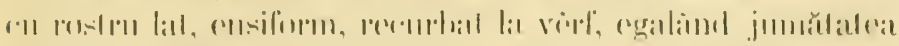

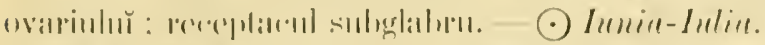

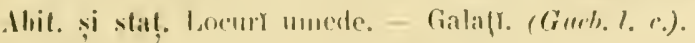

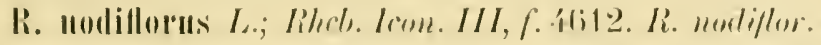

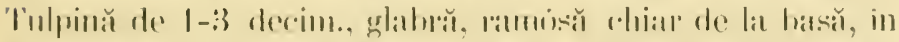

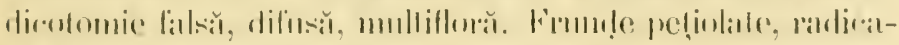

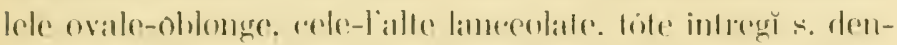

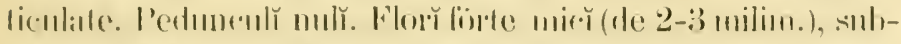

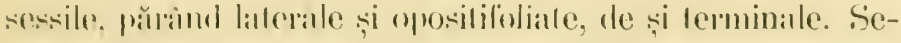

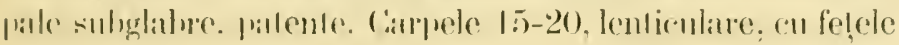

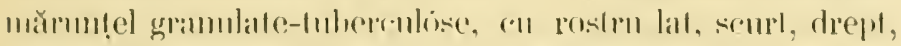

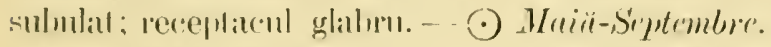

Mhit. si stal. Bălifie uscate - Burureser (chilili).

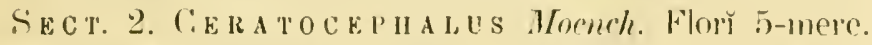

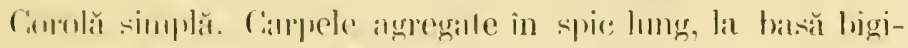

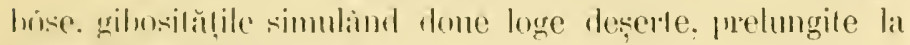
vivt in rostrul lumg.

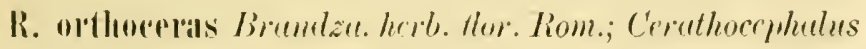

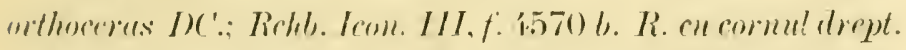

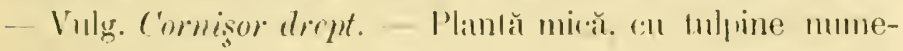
rose, sranilorme. 1-llore, de :3-10 renlim., lamose-tomen-

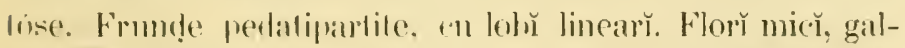

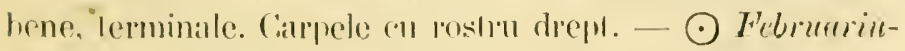
Ajri!r.

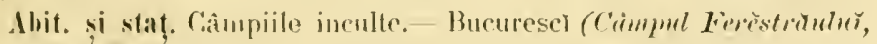
Triĭ); lași. etr.

OHs. Erlel (I. r. R0) inctică a fi vẹdut in simpiile Moldover pe $R$. fulcotus L., sperie re cŭ n’an îutâlut incă. și pe care nu o แuenlione\% de rit cu mare înfoială, tiind ‘n putință ca, printro erơre de determinațiune, Edel să fi luat pe $h$, orthocerss pentru $h$. fulculles $L$. 


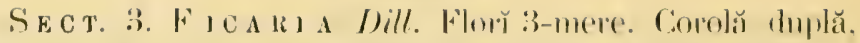

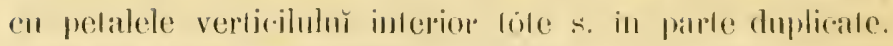

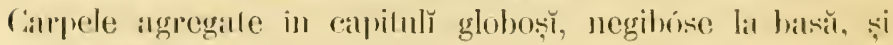
neprelungite in rosiru.

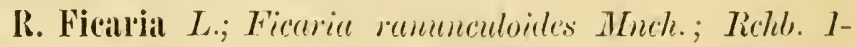
con. III, f. \$572. R. Ficuriu. - Vulg. Grämsor, Untisor.

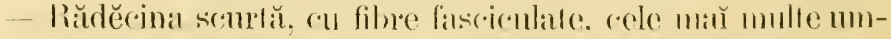

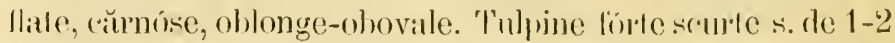

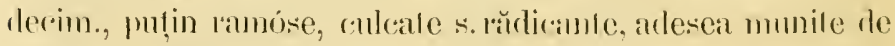
lumbile la subsuóna firumdelor. Frunde peliolate, cordale, gróse, lucitore, de un verde inchis, inlreğ s. simuate-crenale, ("॥

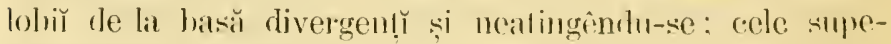

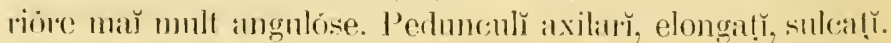

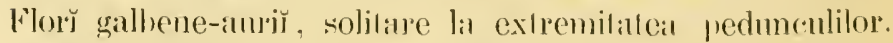

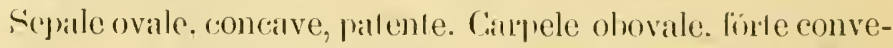

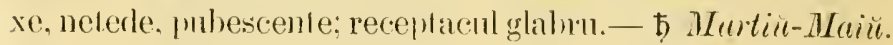

Abit. şi staț. Pădurile umede din tótă România.

\section{MYOSURUS Dill. - Myosur.}

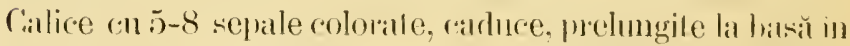

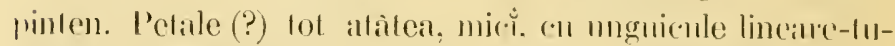
bulose, nectarilere s. 0 . Slaunine 5-20; anlele hisifixe. cxtrouse. fanpele en, imbricale spiral în spice, pe nu receplacoll linle elongat, ramiform : ovul solilirl. pendent, cu micropil inlrors-superior. Arhene so, triquelre, spicale. - Elbur anmale; frunḑc întreğ ; floř pedumrnale, solitare, terminale.

M. minimus L.; Relit). Icon. III, f. 1569. M. pitic.-

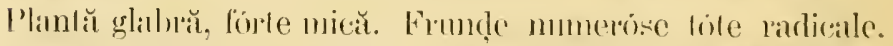
lineate, ingusle, subohtuse, wecte. P'erluncoulĭ radicalli, de

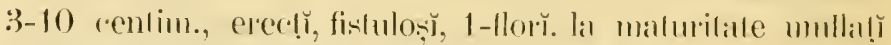

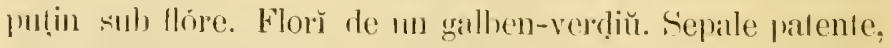

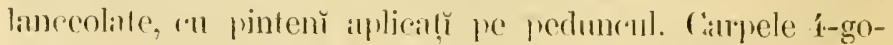

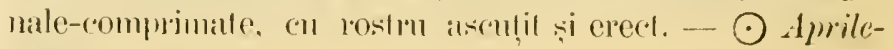
Maili. 


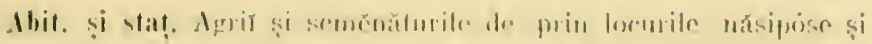

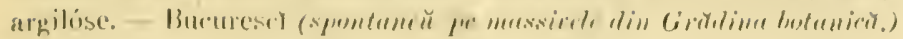

\section{MEMONE Hall. - Anemonut.}

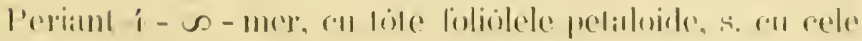

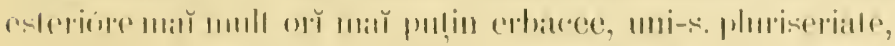

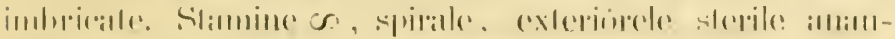

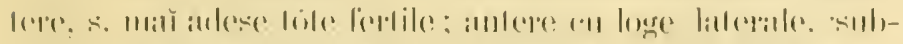

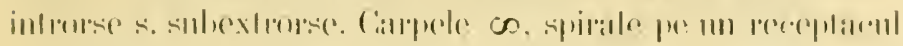

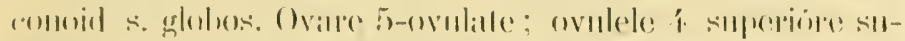

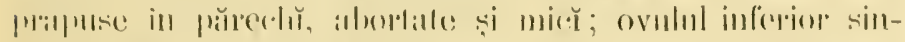

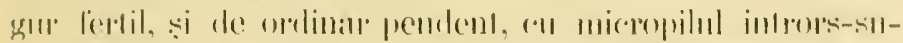

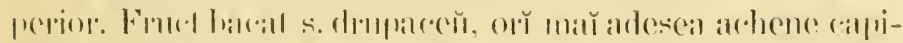
lille. 10) (o)

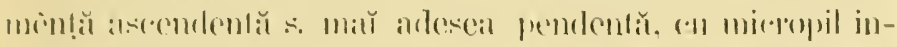

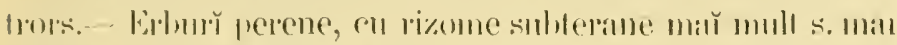

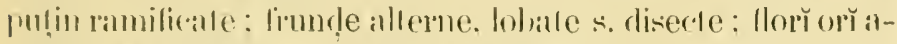
xilare, s. mă arlesca lerminale, solilare s. cimóse, sqm

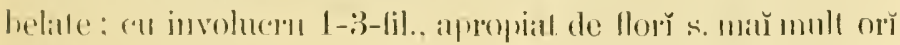

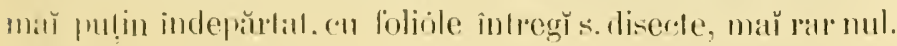

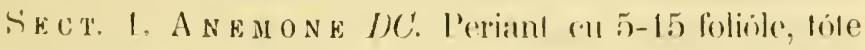

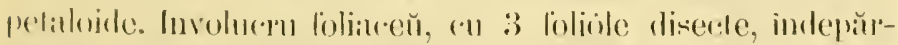

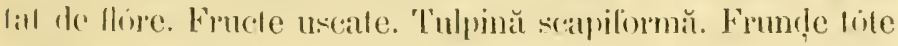
rarliciale, petiolisle.

Sim-sec t. 1. Pousatula Tournef'. Cimpele juelumgile la vèl

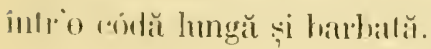

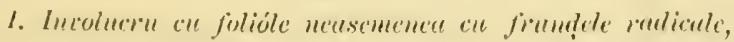

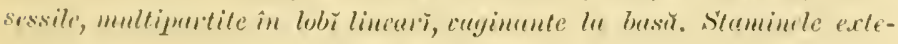
riove celuretute.

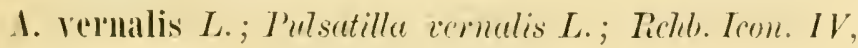

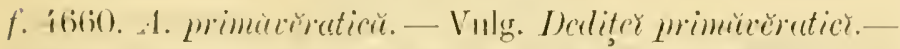

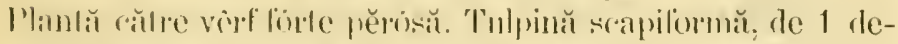
cim. ․ mă mulı, I-floră. Frunde pubescente, infinse in ro- 
setă, pinale cu 1-2 părecbŭ de foliole latle, ovale-romboidale,

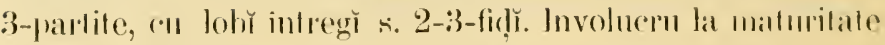
mu mull depărtal de flore, föpte vilos. Flóre suberestă : pedum+ul nelıngindu-se mult la maturilate. Perianl ammanulal, de ordinar cal 6 sepale eliptice, erecle, vilise pe din afirră, interiorele 3 albe, cele-l'alte violacee. Carpele ohlonge, vilose. - 2 Mnсій-Lитіи.

Abit. și staț. Păsciunile alpiue. - M-țir BucegY.

A. Pulsatilla L.; Pulsetille vulyeris Mill.; Redel. Ierme. IV, f. 4657. A. Pulsutilic. - Vulg. Dediter, I'ulsutilit. -

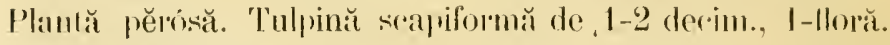
Frunḑe perróse, 2-pinatisecte, cu divisinnile cele d'intaiĭ sul)pețiolılate, cu lob̆ linearı̆-acmminaț̆, intregi s. 2-3-fic̣̆. Involucru fórte depărlat de flóre, lörte vilos. Flóre de un all nasiliu-

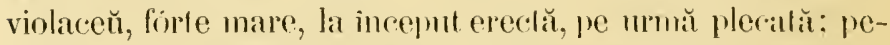
duncul lungindu-se förte mult și îndreptandu-se la maturilate. Periant campanulal, cu ti sepale eliphice, asculite, vilise ne din al'ară. Carpele oblonge, vilóse. - Of Mutic-dywile.

Abit. și staṭ. Câumpiile de pe lângă pădữ și colincle uscate. Împrejurimile Iașuluŕ; etc.

1. pratensis L.; Pulsatilla nigricuns Bima.; Pulsutilla pretensis Mill.; Richb. Icon. IV, f: 465̃. A. liededor. Vulg. Dediter de licede. - Planlă pĕrósă. Tulpină seapiformă, 1-floră. Frmnd̦e 2-pinatisecte, ru lohĭ linear̆, fóple

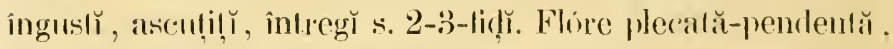

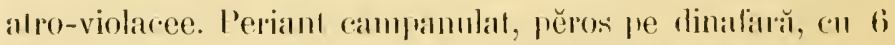

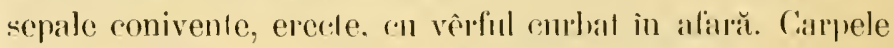
oblonge, vilóse. - 2f Aprile-Muiru.

Ahit. și staț. Poenile de prin pădurile inuntóse.--M-tir Mluscelulur̆

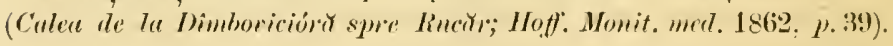

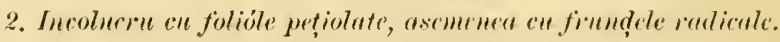
Stamine tóte fertile.

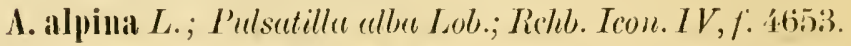
- A. Alpilor. - Dediteir Alpilor. - P'lantă polimorlă, li in- 


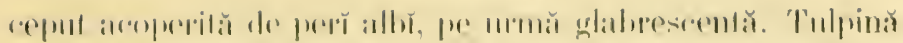

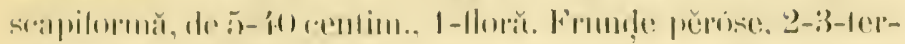

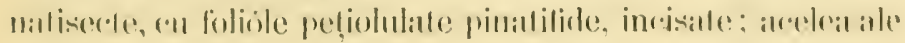

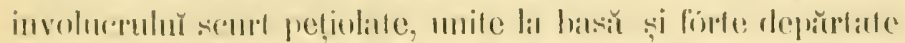

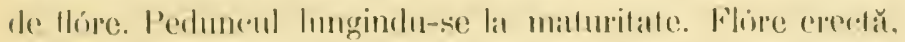

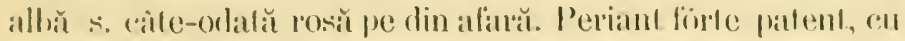

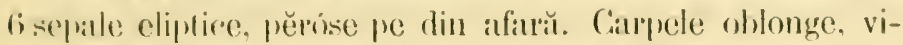
lise. - If Iumiè-síntembre.

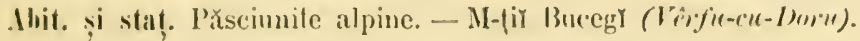

Sub-secr. 2. Aneanantrus Eindl. Cianpele necodale, terminale pringlo puncelă lörle semotă, nebarbală.

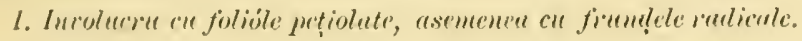

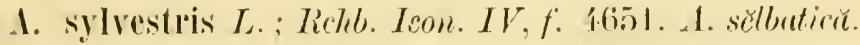

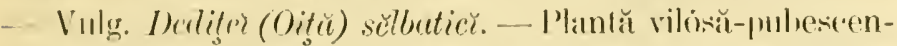

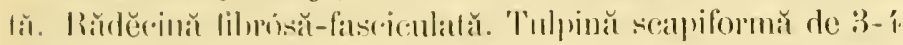

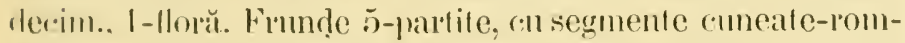
lobidile. 2-3-firle, inegal incisate-dentate. l'edinenl ereet. Flive male. albă. Periant patent, (:แ 5)-7 sepale, ovale-obfusc. pubescente in afară. Carpele forle numerose, mič̆, vilose-fomentrise, agregale în capritul oblong.-2f Amile-Marix.

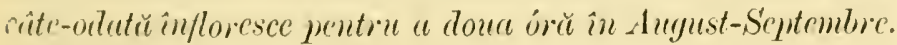

Ibit. și staț. P'oenile de prin pădurile. lived̦ile și viile din tótă

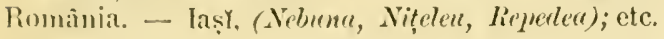

1. nemorosa $L_{\text {.; }}$ Rethl. Icon. IV. f. 46.1. A. purturilor. - Ri\%on orizonlal, fiote lung, subtice, ranos. Tulpină

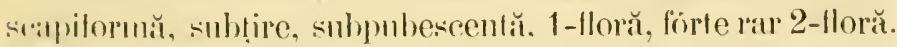

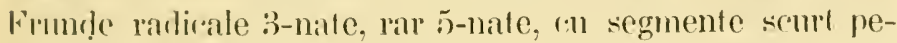
linlulate lanceolate. incisite-rlentate, cel din mijloc :3-fid. rele lafcrale 2-fide. nătscond departe de scap și după înflorire. P'edmuroul la malmritale curbal la rồf. Flóre albă s. Iosĭ. I'erianl patent cu 6-9 sepale ovale, glabre. Ciarpele 1()-25, puhesente. - of Murtiü-Aprile.

Alit. și staṭ. Pădurite și tufărişurile umbróse din părţile câmpene și muntúse dị tótă România. - Bucurescy (Cemica); m-țiY Prahovel (sinceice). 
A. ranumculoides L.; Lerhe. Icon. IV. f. 4tisis. A. cu flor.

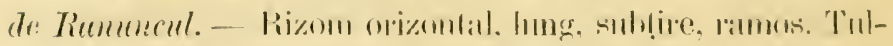

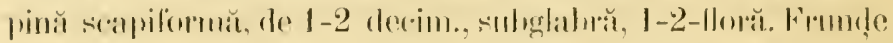

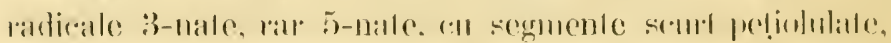

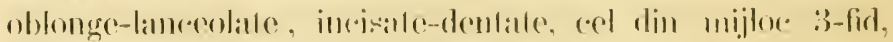

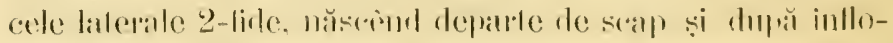

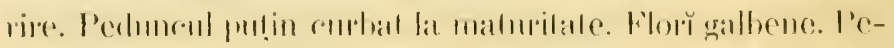

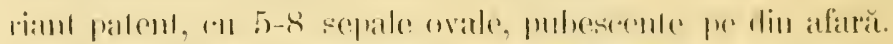

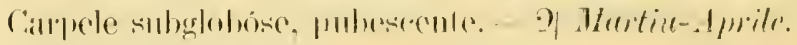

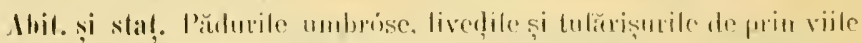

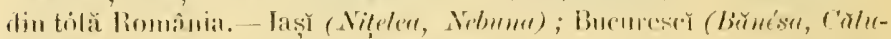

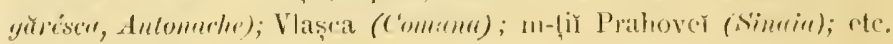

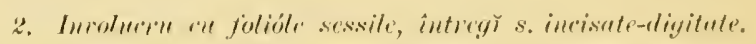

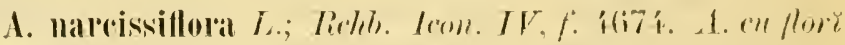

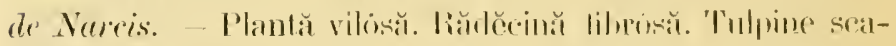
pilorme, solilate s. mat mulle, de 1 -3 decom., finde vilise. 1-6-flore. Frumde radicale lung petiolale, maluati-3-5)-par-

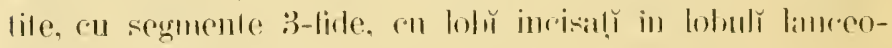

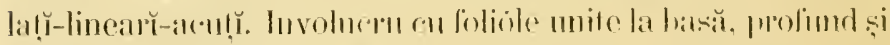
egal divisate in segmenlo lancoolale, la vèt incisale-dlentate.

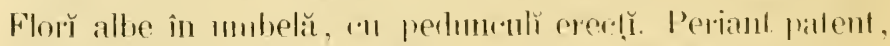

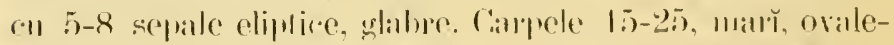

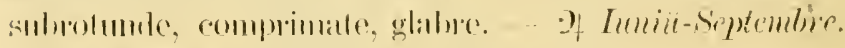

Mhil. și stat. Piscoumite alpine de prin locurile stincóse și cal-

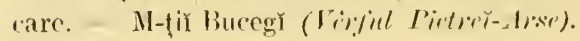

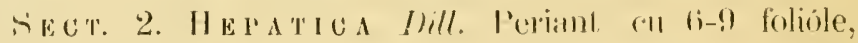

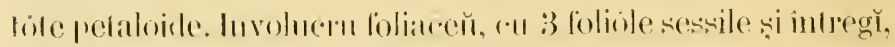

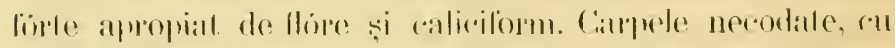

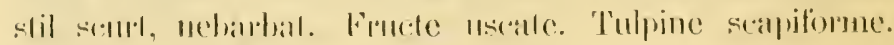
Finume role radicale.

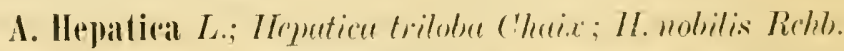

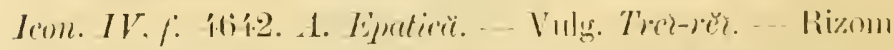
oblic: s. verlical, goros, coll libe malicale numerose. Tulpune

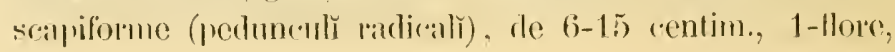




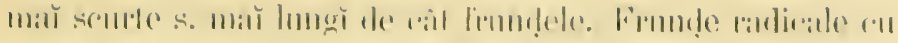

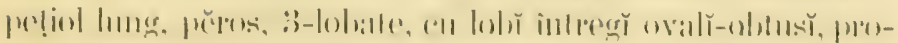

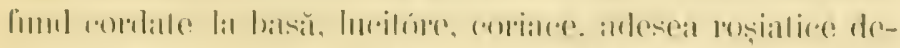

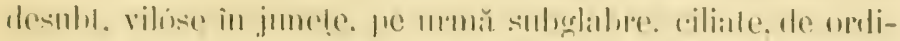

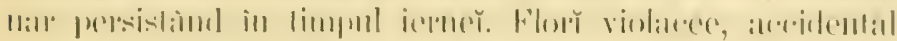

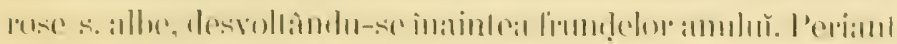

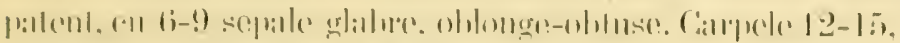

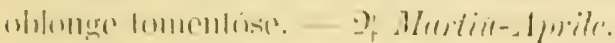

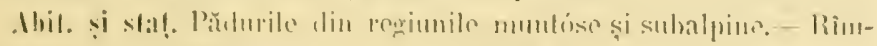

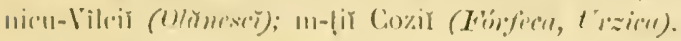

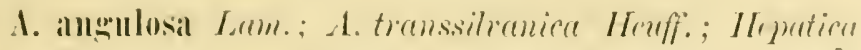

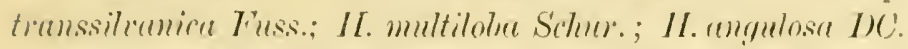

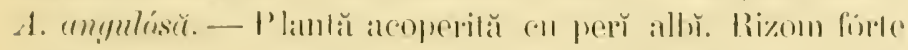
lums. orizonlal. en fibre radicale, forle muncrise. caprilatreși

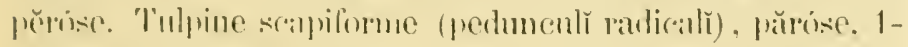

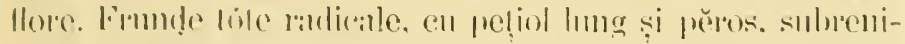
lome-romlate, :3-lobale, ('n segmenle firle lale. comeallesulnulunde, crenale-lobale, cu segmentele laterale incisile lolatle. cu segmenlul din mijloe :3-5)-lolmlal. loble moncronate.

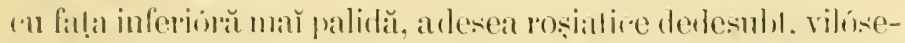
tomenlise în junete. pe urmă subglabre. riliale. Folinilele in-

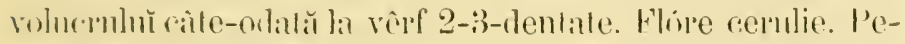

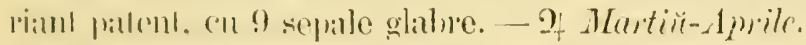

Abit. ș staț. Pădurile nunbróse din reginnea muntrisă. - Ba-

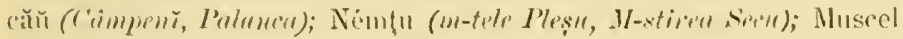
(mitele stumu); cle.

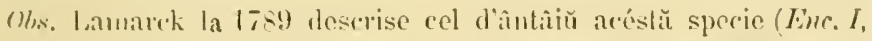
16!!) după un specimen cultivat in Giverdinn Almothectrilon. din l'r-

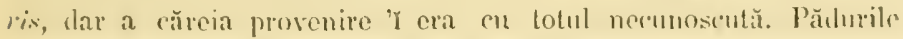

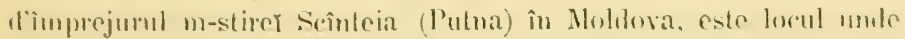

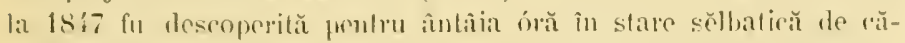

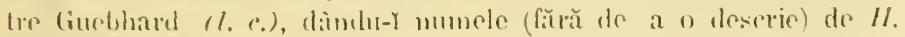
multilobu, mesciind, se vede, ră ca fusese descrisă c" mult maì înainte de către Lannarck; mannserisul hŭ Guebhard liiml nepubli-

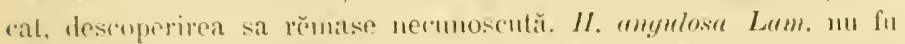

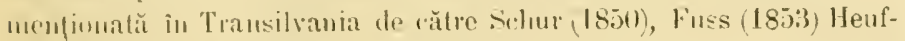
$f_{\text {cl }}(1858)$ de cail riłfi-rat an după areea. 


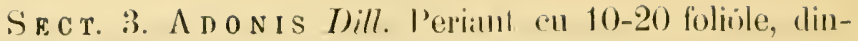
tre care cele 5 exteriore erbacee, simuland un calice 5-sepal, rele-lialte interióre pelaloide simulând o copolĭ. lnvor-

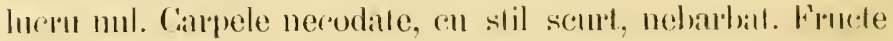

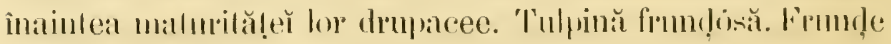
radicale și calulinare. pinalipartile, cu lob̆ multilic̣ĭ.

Sub-secr. 1. Adona DC. Cample en stil dreph, asiendent. Rằlĕcină amıalĭ.

A. autommalis Bramiza hert. fl. Rom.; Adonis automnalis L.; Rehb. Icon. III. f. 4621. A. tomatica. - Vulg. Rutsenţü (Cocoşel) tomnutic. - Plantă subglilbră. 'Tulpină erectă, sulcală, simplă s. ramósă la vêrf. Peduncul senrı, 1 Hor. Sepale patente, glabre. Petale puḷin maı̆ nič de cail sepalele, obovale, patente, concave-conirente, pmp!rĭ, pălatle cu negru la bašĭ. Carpele în spric: stràns, oval-oblong; manginea superióră a cappelelor gibósă (ătre mijlocul el̆, fără

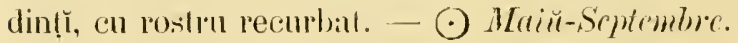

Abit. și staț. Semĕıăturile și locurile inculte din tótă Romûuia.

A. aestivalis Bramlza herb. fl. Rom.; Adonis restiralis L.; Reht). Icon. III, f. 4ti19. A. virratică. - Vulg. Ruscentü (Cocoşel) vărutic. — l'lanlă glibră. 'Tulpină erectă. sulcată, simplă s. ramós̆. P'eduncul 1-flor. Sepale glabre. Petale 5-8, oblonge-obtuse, de done orr maŭ lunğ de cit sepa-

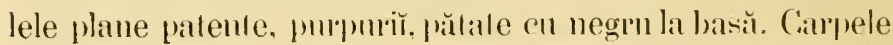
in spie strîn, oval-oblong, cu marginea superinis al carpe-

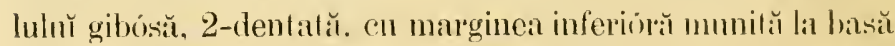
de un dinte, eu o mic̆̆ créstă transversalĭ ce conturméză a-

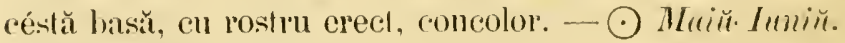

Abit. și staț. Semĕnăturile si locurile inculte din tótă România.Bucureser̃ (Mogosiniri); elc.

A. Alammea Brandza herb. A. Rom.; Allonis flammea Jacy.; Relus. Icon. III, f. 4620). A. colórre focului. - l'ulg. Ruscuţă (Cocosel) colórea foculuĕ. - Tulpină erectă, suleală, ramósă. Pedunculĭ 1-florı̆, mă̌ lungì de cât în speciile pre- 


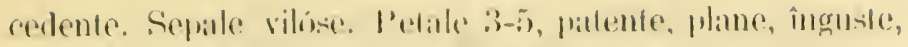

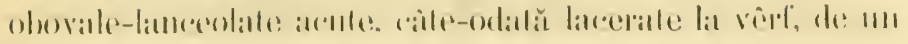

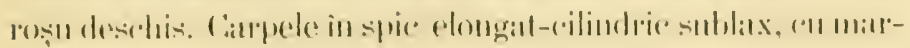

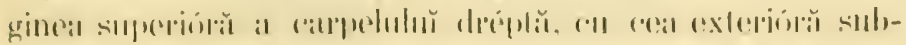

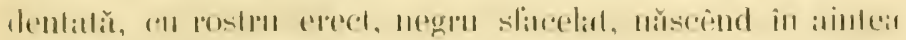

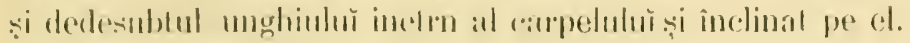
- Immin- Inymst.

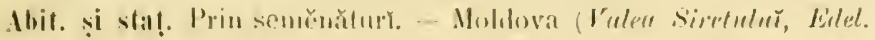

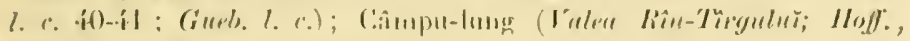
Monit. mol. 1'. - (1)).

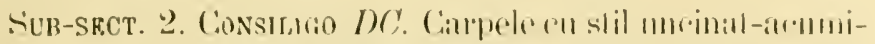

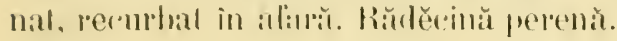

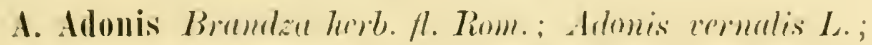

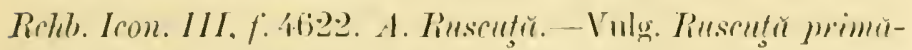

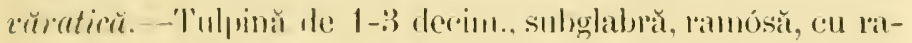
mm 1-Horr, cole mail multe sterile. Fimude inferióre scuamiforme sulwalginanle: rele-lalte sessile, coll divisimni cappilare.

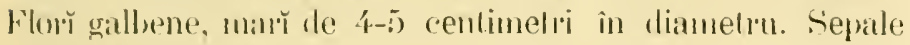
pubescente. Pelate 10-15, oblonge-lanreolate, dentieulate

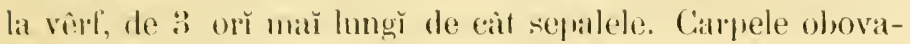

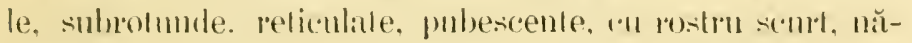

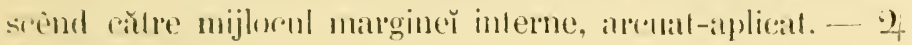
Am)ile-Muiri.

Abit. și stạt. Colinele. seměnăturile și păsciunile useate din tútă Romitnia. - Tașt; șěsul Prutulur (Fdel I. r. 40)-1.l); etc.

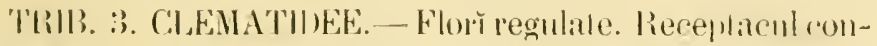

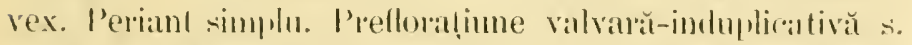

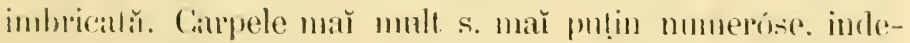

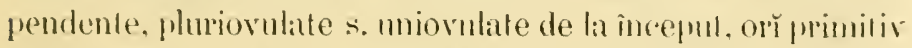

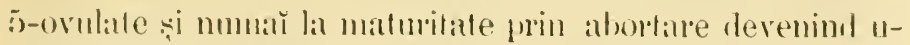
niovalate. Orul descendent, cu micopil intrors-snperior. Fructe nscalle monosperme și indeiscente s. polssperme si deisrente prin unghiul intern. orř hareiforme și indeiscente. - Hanle firutescentes. erbacee perene. 


\section{A. Calice vulvat-induplicat; fronḑe opuse.}

\section{(LEMATIS I)C. - Clematita.}

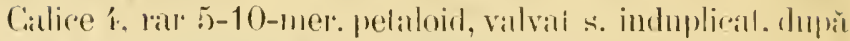
anles̆̆ câle-orlală imbrieat. Corolă 0 . Slaminode exteriore pelaloide $\infty$, s. mă adesea 0. Stamine ferlile $\infty$, spirale: an-

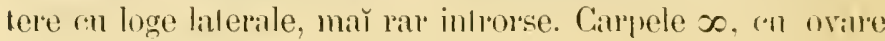
5)-ovnlale: ovilele 4 superiore supnajuse în părechr̆, abollale și mič̆ ovulul inferior singur lerlil, pendent, ("u micr)pilul intrors-smperior. Achene eapilale, coronale en $11 n$ slil scurt s. codal, nud s. barbat. Sĕmênță pendenlă. - l'lunte lemınose. de ordinar scandentc, lar subfrutescente s. erbacee; frmd̨e opıse, simple s. mă adesea ternate s. pinale, ('n peliolul volubils. tratnsformat în câtreiŭ. Florĭ cimóse-racencise mă rar solitare, mole s. 2-loracteolale.

Sinct. 1. Cin a a to L. Slaminole exlerviore pelatloide 0 .

\section{Tulpine erbaces si ereete.}

C. lecta $L . ; C$. crecta All.; Rehl. Icom. II, f. A.titi. (

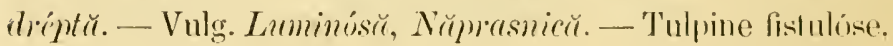
de fi-12 decim., smbpmbercente s. glahre. Fronde pinalicom-

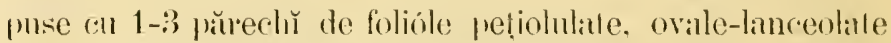

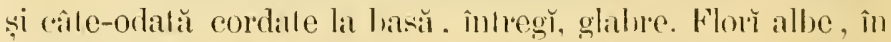
umbele de cime conbalale, remile ìn racente cur lamilieatimŭ opmse. Sepale 4-5̆), obovale, fomenlóse pe mangin̆. Cimpele glabrescente, comprimate, ferminate printropme-

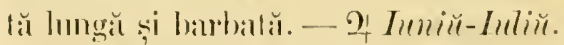

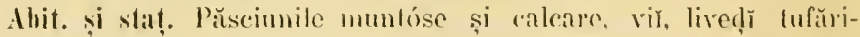

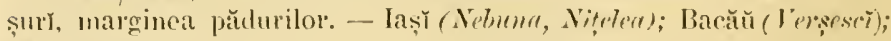
Muserl; ete.

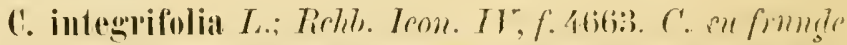

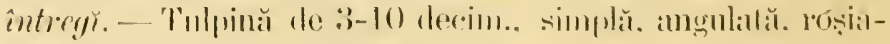
tică, jubescenlă, 1-llöй. Frunde simple, sessile, ovale-lan- 


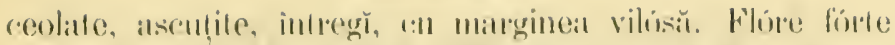

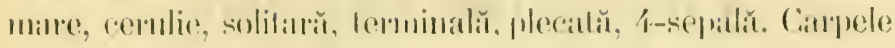

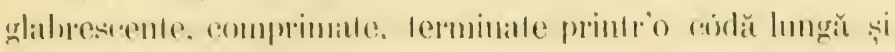

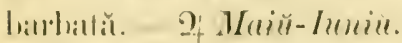

Abit. si sta! Păsciunile umede și năsipise de pe margineat pă-

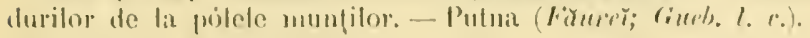

\section{Tulprine fintescente si somdente.}

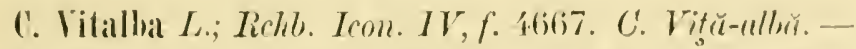

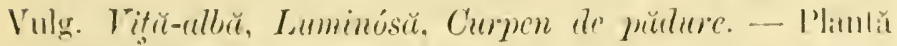
subpubescenlit. Tulpine silmenlóse, atcălĭlóre, de lungi-

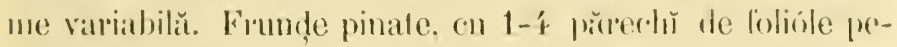

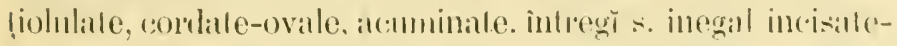

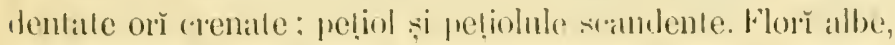
in cime remnite in racene cor ranifical imn opmse. Seprale de ordinall í, oblonge, gróse, tomenlóse pre amendoně fetele. climnine allse. Ciarpele orale-ilscultite, vilóse, lerminate prin-

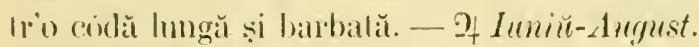

Alit. și staț. Pădurr. tufărişurŭ șanţurile și gardurile viilor. fórte comună ì tótă România.

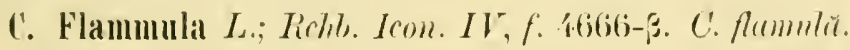

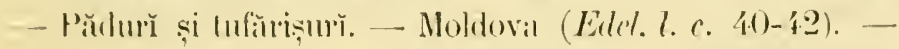
t) Imniñ-Alugust.

Sict. 2. A TRAGENE $I$. S Staminode exterióre petaloide ss, simmlînd o corolĭ.

C. Alpina MLill.; Atragene alpina L.; Releb. Icom. II,

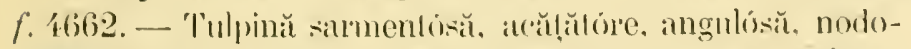

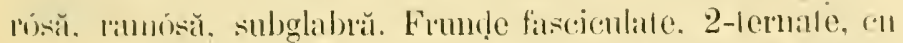
foliale ovale-lanceolale. ar-muninale, aconli-selate. Florǐ violacee, marr, solitare, axilare, plecale. cor peduncul mă̆ lumg de câl lrundia. Seprale 4. subrilise pe din aliarĭ. Staminode

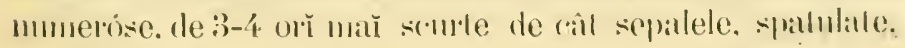

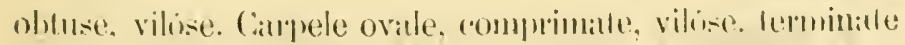

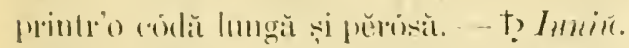

Abit. si stalt. Locurile stincóse din pădurifo subalpine. Bacătŭ

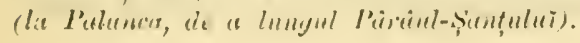




\section{B. Calice imbricat; frumle alterne.}

a. Carpole 1-oinlate; firect 1-sperm şi deiscent.

\section{THALICTRUII T. - Trilitu.}

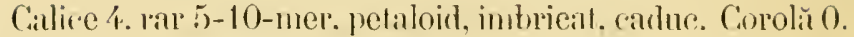
Stamine $\propto$, lóle ferlile s. mă rar cele exterióre slerile petaloide: antere cu loge sublaterale. Ciapele mụin nmmerise. Ovare 1-ovulate; ovul pendent, cu mieropil intrors-superior. Arhene sessile s. slipilate triquelre s. membranose îmllate. - Erburi perene: frund̦e ternale descompmse câte-ordată stipelate; llorı̆ racemóse s. racemóse-cimóse.

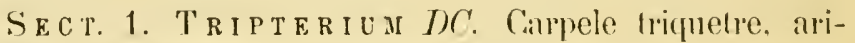
pate. stipilale, făı̆ cósle longitndinale.

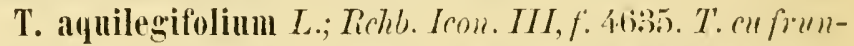

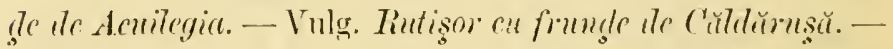

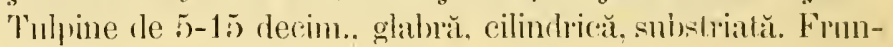
de B-ternate, slipelite, cu foliole obovile. cmeiforme, obus denlate-lobate. Flor rose. purpmiř s. albe, in cor'inbe de cime nunliflore. - I Maій-Intir.

Albit. și staț. Păscimile umbróse de prin pădurile de la pólele munţilor și locurile rěcoróse din regiunea subalpină. - M-ţi Bucegr (Pestera); m-țir Musceluluĭ (Isrom-intreptetre la púlele sturmlui);

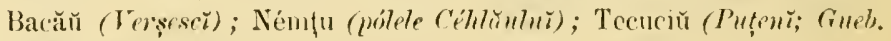
l. c.); etc.

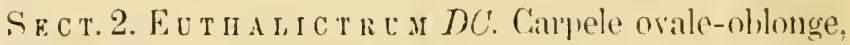
munite de cóste longiturinale. sissile s. substipilate.

T. alpinum L.; Rrh. Iron. III.f. f6.25. T. Ilpin.- V'ulg. Rutigor alprin. - Vêrful Céhlăılı̆ (EAlel, 7. c. 336). - 2 Iuliu-August.

T. fotidum I.; Rehb. Irom. III, f. 4626. T. frtirl.-Vulg. Riutişor puturos. - Pantă glandulo: felidă. Rizom fără stolone, enițênd un fascieul de rădĕ- 


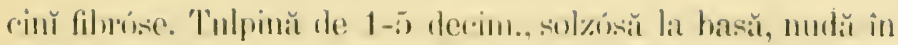

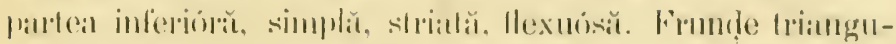

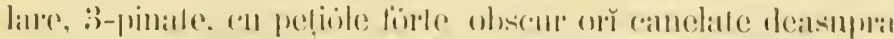

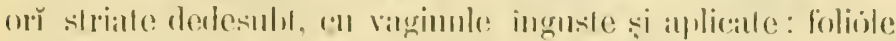

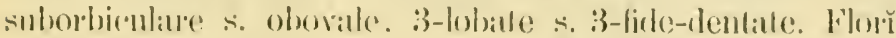

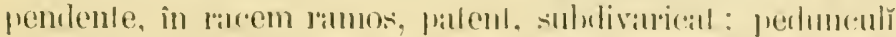

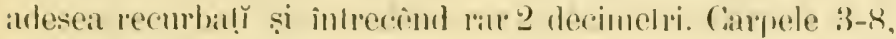
sessile, scomte. ovile-oblongre. romprimale, all riste finte

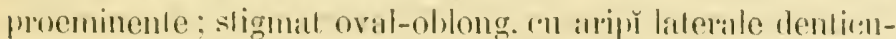

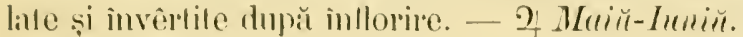

Aluir. și staț. Stinıcile calcare din regiunea alpină. - M-țir Musiclulur (Dimboricioina).

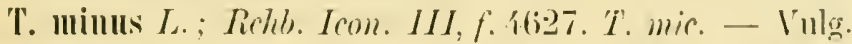

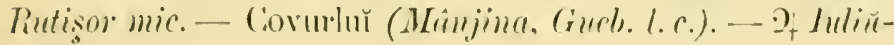
August.

Obs. Guebhard (l. c.) pretinde a fi ğšit prin viile de la P'eche (Cortului) pe T. saratile Schleith. specic proprie stincilor calcare din regrunile alpine și subalpine. Localitatea ce intlič̆ acestei specir, este o mrob̆ evident $\breve{~ d e s p r e ~ e r i r e a ~ d e ~ d e t e r m i n a t ̦ i u n e ~ r e ~ a ~}$ treluuit să comitŭ Guebhard, luând, cine scie ee specie de Thalirtrume, pentru un T. scarcatile.

T. majus Jacy.; Reld. Icon. IIJ, f. 1629. T. mare. - Bu-

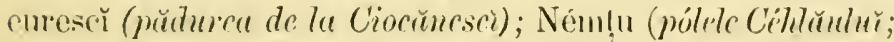

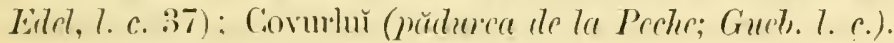
- 9y Iuniĭ-Iuliu.

T. elatum IIurr.; Relll. Iron. III, f. 4638. T. malt. -

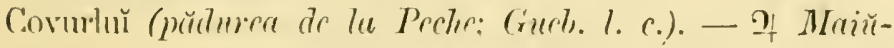
Itunik.

T. medium Murr, Rehl. Iron. III. f. 4632. T. mijlocin. - Vulg. Rutisor mijlosir. - Pădurile monede de la prilele

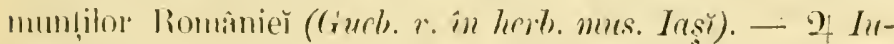
niri-Inlix.

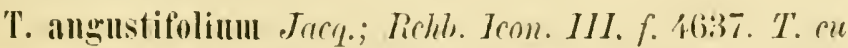

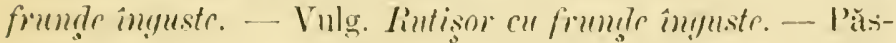

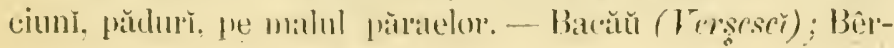


lad (pădurea de la Slobozia); Némțu (pólele Cétlüulur; Eidrl, 1. с. 37). - 2 Inиiи-Iuliü.

T. Bauhini Crtž.; Rich». Icon. III, f. 4636-c. T. luð̆ Bauhiu. - Vulg. Rutişoru lù Bauhin. - Putna (Funcer; Gurb. l. c.). - I Mапіи-Iuniü.

T. lucidum L.; Rell. Icon. III, f: 4636-b. T. Tucitor. Vulg. Rutişor lucitor. - I'rin locurile muede. - (ialațĭ (intro püdure de sülcir pe malul Siretului ; Gucls. l. e.). - S) Iипій-Iиliй.

T. flavum L.; Rehb. Icon. III, f. 46339. T'. yulben. - Vulg. Rutişor galben. -- Némṭu (pólele Céhlŭulur; Eddel, l. c.37). 2 Iuliü-August.

b. Carpele $\infty$-ovulate; fruet polysperm.

\section{ACTAA I. - Acten.}

Calice 4-6-mer, petaloid, imbrical, caduc. Corolă 0. Stanine $\infty$, tóte fertile s. maň um cele exterióre sterile și petaloide; antere introrse $s$. extrorse. Carpele $1-\infty$, nultiovulate, lat maluritate bacate s. uscate și deiscente folicular. Slamine 2 -seriate, netede s. sol\%óse. - Erburr perene; frmonde simple s. mă adesea ternali-compuse și descompuse; flor in ratceme mar̆ lot-dé-ma terminale, simple s. compuse.

Sect. 1. Cin ristophoriana Tournef. Carpel soliLar, lit matmritate baccilorm și indeiseent.

A. spicata $L . ;$ Rehb. Icon. 1 V, f. 4739. A. spieatü. Vulg. Christof orru, Erba-Sintulur Clerist of or, Erba-tâlharulur. - Plantă subglabră. Rizom gros, en fibre radicale lunğ, pulenice. 'T’ulpină erectă. geniculală, sublire, simplă, nudă în patlea inferiónă, purtand către pantea superióră 2-3 firund̦e. Frunḍe petiolate, 2-3-ternalisecte, cu segmente ovale-alcuminale, incisilte-duplirale-serale, sessile s. pețiolnlale, cel terminal 2-folsal. Florñ albe, mič̆, dispnse de ordinar în doně 
rareme perdumonlate ovale, dese dintre rate unul este opus

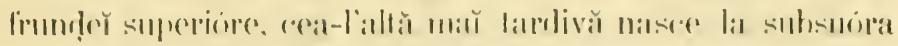

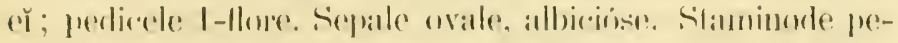

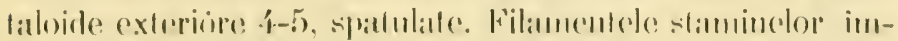

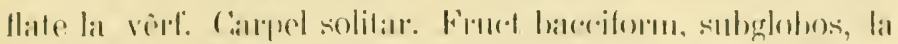

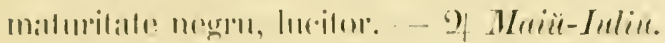

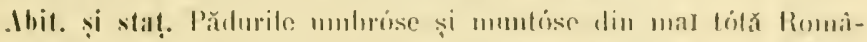

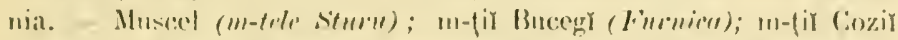

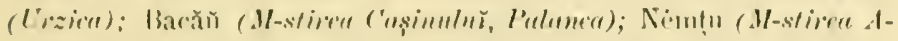

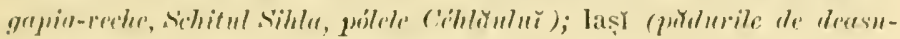

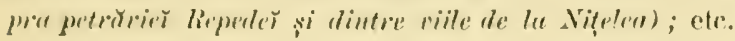

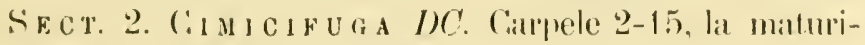
tate usate si deiseonte foliculan.

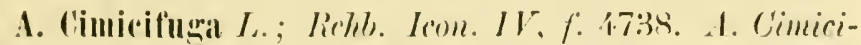

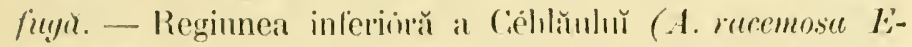

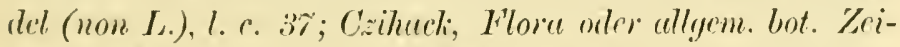
tung, 1836, II, p. 58-7'; ( Gueb. v. in lect. mus. Iasit). 2 Iuliü-August.

TRHB. 4. PBONIEE. - Florĭ regulale. Receplacul planenuæav. 'eriant duplu. Prefloratime imbricată. Carpele putin mumerise, independente, mulliovalate. Frucle nscate, folyserme, deiscente prin unghiul intern. - Plante prene, erhacee s. lemmóse. Frundic allerne.

\section{PHONIA T. - Peomiu.}

Calice 5-6-mer, simplu s. rluplu, erhacen̆, imbrical, persistent. Pelale 5-10, constiluind o corolă simplă s. (hplă, neforeolate, imbricale, caduce. Stamine $\infty$, sulperigine; antere introrse. Disc perigin inlerior androceulŭ, mic și glanduliform s. maй yal cı mult mă desvoltat, saceiform, petaloid, invělind ovarele. Carpele 2-6, multiovulate, la mafurilate deis('ente folicular. - Erburĭ prerene, maŭ rar arbust s. subarhuscull̆ ; limnde pinati-disecte s. descompuse; florĭ terminale. 


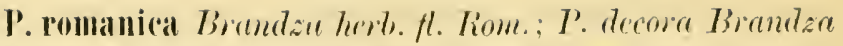
(non - luders.) fray. flor. liom. in Bul. soc. geoyr. rom. 1876. 1. 77: R'. officinalis Rets. var. lecterophylle, in herb. mus. Viudob. I’. romănéscü. - Vulg. Bujor romŭnesc. Ri\%om col fibre radicale, fasciculate și teminale cu luberrule oblonge-eliplice s. moniliforme, cărnose. 'Tulpine erecte, de $7-8$ decinn., subcilindrice, subsulcate, glabre. Frundle forte hung petiolate. glahre pe amêndonĕ fețele, verḍ̆-inrhise deasupra, palide-subglancescenle dedesubt, 2-ternate, cus segmentele laterale scmt peliolnlate, col cel terminal cu

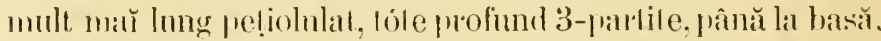

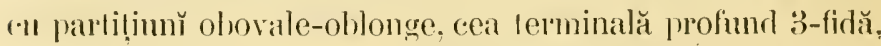
lal eralele 2-3-ficle. lóle cul lolı̆ ovalı̆-lanceolaṭ̆, inlreğ s. in-

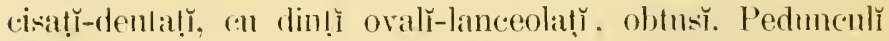
glabri. Florř marr̆, de colórea săngelur. Sepale 5-6, inegale subfoliacee. P'etale 8-11, obovale-cuneiforme, concave, suberecte, lungr̆ de 5- 7 cenlimelri. Stamine glabre, mă lunğ de ail carpelele: antere mă scurte de cait jumălalea filamentulur. Campele 2vergente-subarenale la malmrilale: stignat lumg, roz s. purmmin̆. lameliform, förte recurbal in formă de cîrjă. - 9 Maiit-Inenir.

1bit. și staț. Poenĭ și marginea pădurilor. - Vlașca (föorte commu

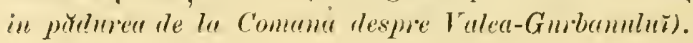

(bis. Guebharl (l. c.). Ellel (l. c. 40), Czilı. și Szab). (I. c. 31), indieă pe I'. officiumlis lietz., ca fiind lórte conmuă în împrejurimile Tecuciulur (Pechr) și a Galațulur. De și n'am av'ut încă ocasimea de a recolta însu-mŭ acéstă plantă din aceste đìn ummă localitățr. totıși m 'nı̆ este necunoscută, fiind-că am rĕḑut un specimen din ea in Erhariul 1). Alf. De Candolle din Geneva, ce 'i fusese trimis la 1847 de către Gucbhard și chiar din uma din localităţle indicate maY sıs; ast-fol în cât. sunt în posițiume de a putea afimna. că planta din împrejurinile Tecuciuluĩ și a (ialaţulư este tot acerașr ce cresce prin pădurea de la Comana, adecă specia nunită de noI I'. romuniro, iar un alleverata $P$. officinulis hetz., si de care noua specie se deosibesce mă cu sémă prin frumdele sale cu mult mă Jaciniate. 


\section{ROSALEE.}

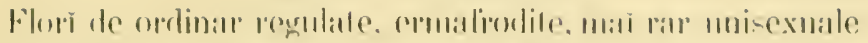

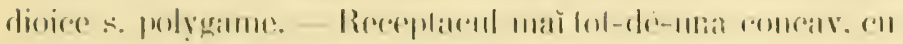

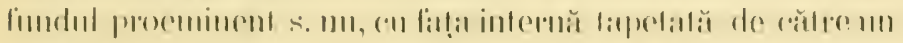

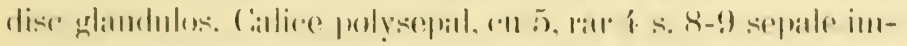

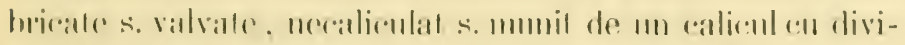

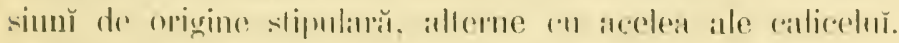

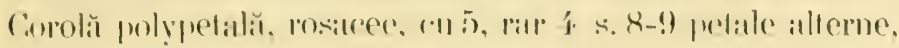

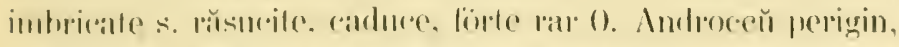

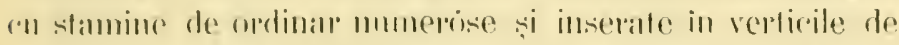
ralle

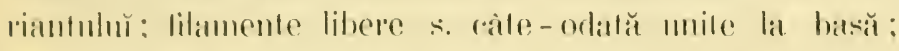

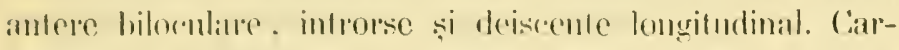
pele $x, \leq 1-5$, de ordinar independente mnele de altele și

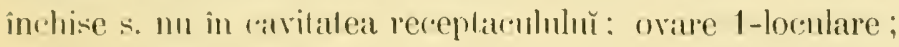

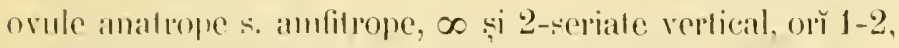
ascendente s. descendente și cu micropil exlrors-inferior $\therefore$ extrors-superior; slil rar terminal. mă adesea lateral s.

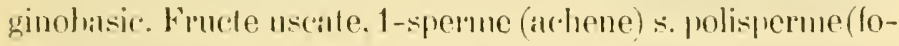
licule), orı̆ cămóse (druparee s: pomacee), simple s. mulliple, şi tol-de-una induviale, adecă purlate s. imvelile de rătre re-

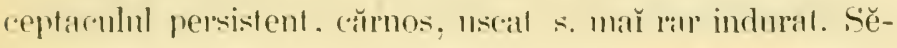
mèntă de ordinall fără allımen: roḷ̣ledóne căłnóse, planronvexe. foliacee liı germinațune: radiculă ascendentă $\therefore$.

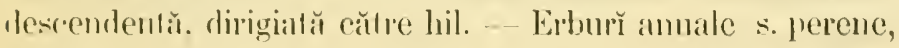

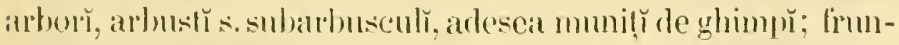
de de ordinar alterne, simple s. rompuse, allesea insoţite de slipmle: Hor in inflorescente variate.

TRIB. 1. ROSEE. - Reeepticnl lörte coneav. rol fumblul neproeminenl. Calicul 0. Ovare infere s. inchise în cavilaleat

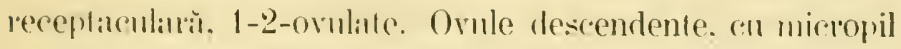
extrors-superiol. Frucle uscalle, inchise in inleriorul recep- 


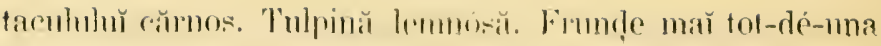
pinali-(с)mіныse.

$$
\text { ROSA T. - Rosa. }
$$

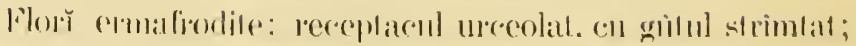

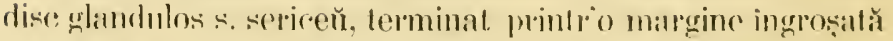

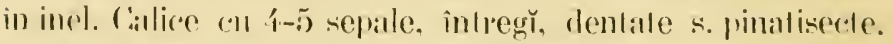
ralure $\therefore$. peristente. Pelale $4-\tilde{5}$, scurl unguiculate, de ordi-

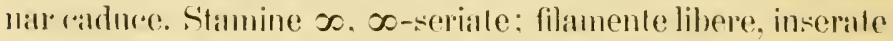

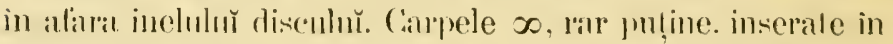
fmolul receplacouluhur, sessile s. stipitate: stile subterminale s. lalerale, exserle, cn extremitatea sligmalică capilată, lihere s. lipule cŏtre vêf. Frllet mulliplı: achẹne $\infty$. glabres.

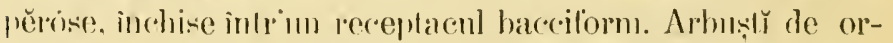
dinar mmniț̆ de ghimp); fronde impariprinalle, cu folicile de ordinar serale; slipule petiolare; Hor solitare s. cimósesuhcrorimbóse.

R. Intra Mill. li. gulbenü. - Vulg. Tramiafiv gulben. l'rin huciur. pe làngă îngrădinı gle grădinilor (Eldel, l. c. 1.2). - †) Iимій-Inliй.

R. pimpinellifolia $L$. TR. cu fimde de Pimpronclio. Vulg. Trandafir cu finmele de P'impinelü. - Prin păramile din lótü Rombania (Gueb. l. c.; Czih. l.c.)- †) Inmin̆-Inliu.

R. spinosissima I. Ri. fórte spinósă. - Vulg. Trandafir forte sprims. - Kegiumea m-lilor Coziě̀. Bistrita și 'lismama (IIoff. mumusc.). - †? Iuniй-Iulin.

R. alpina I. R. alpimai. - Vulg. Trandafir alpin.-Be-

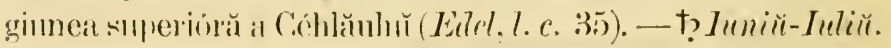

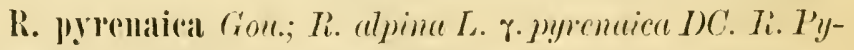

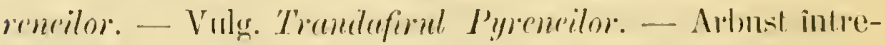

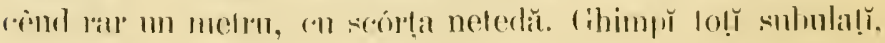

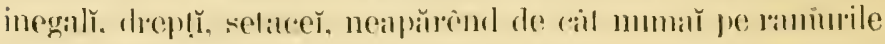

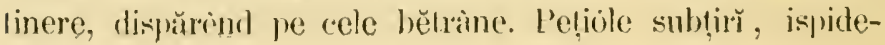




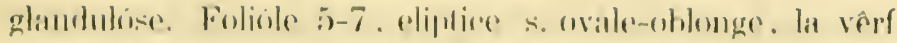

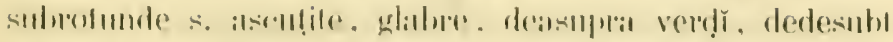

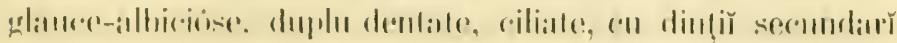

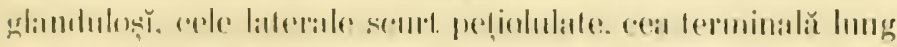

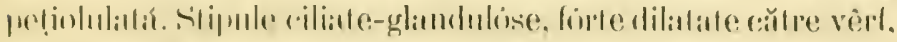

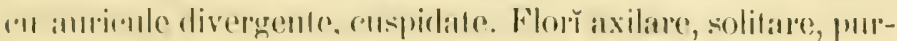

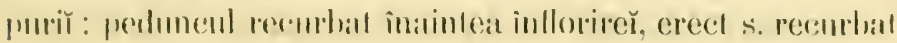

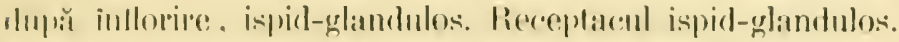

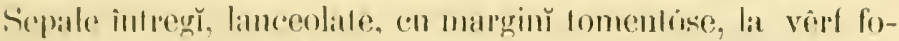

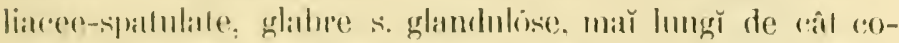

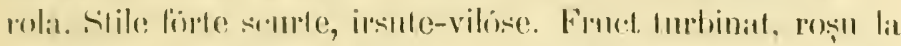

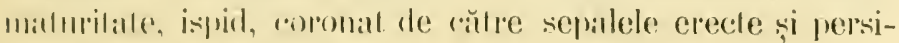
sente. - t? Mreiri-Luliui.

lhit. și stat. Pădurite umbrose și musde din regiunca munfilor.

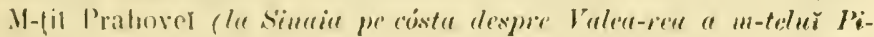

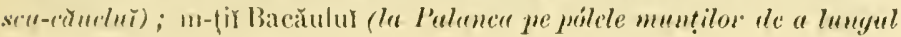
l'iriul-ș'(m)!ului); cte.

R. sulphurea Ait. li. sulfuric.-Vulg. Trendafir sulfurin. - I'rin prindurile Moldover inferione (Gucb.l. c.), - t? Luniü.

R. ruligginosa L. R. meginitü. - Priu pădurile şi huciurile Mullover (Eilel,I. c. 37-42. Gueb. e. in herb. mus. Iaşi). to Insiü-Iuliut.

R. collina Jucy. Ri. de dél. - Colinele Moldover superiore (Eild, I. c. 5.2); R. cuminu L. ver. collinu (Giucb. v. in

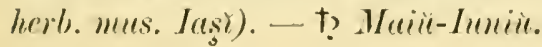

R. Inmetorum Thuill. R. huciurilor.-- Prin hucintile sii

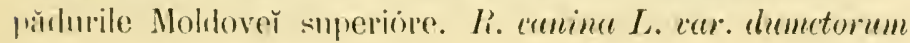
(liuel). $e$. in hert. mus. Iaşy).

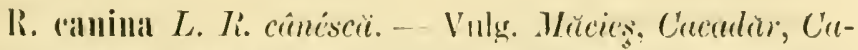

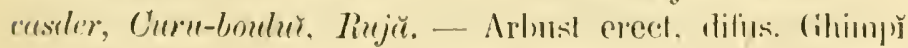

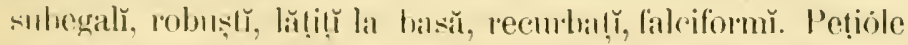

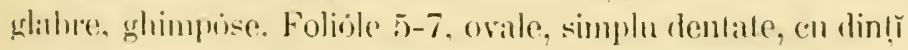

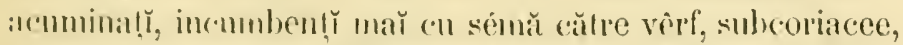
glabre, dedesubt glance. Stipule litte către vềf, asculite. Flor 
mirositore. solitare s. in corimh 2-5-flor : pedınculĭ glabri.

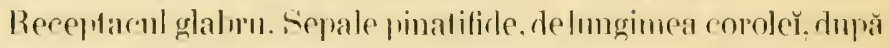

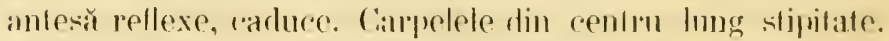
slile sompe. libere. Fruet ovoid, glabm, neflevenind mile de

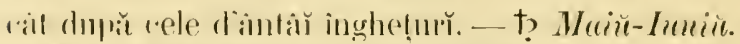

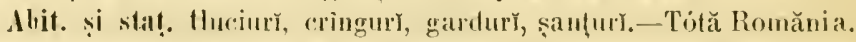

R. alba L. li. albai. - Vulg. Trandafiv alb. - Huciumí, pringur. - Moldova (czih.l.c.). - †. Iuniui.

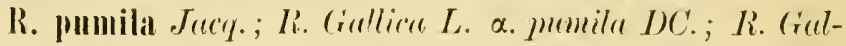

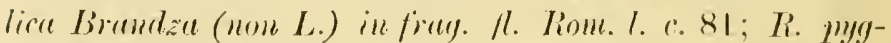
mere W. Birb. R. piticu. - Vulg. Trandafir yitic, Rasur). - Arbmsl forle mice infrerend bar 2-3 decim. (ihimpla a-

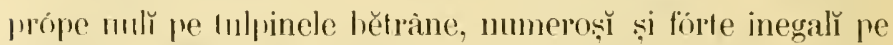
rammile lincre, unĭ selarĕ și adesea glanduloṣ̆, alțĭ mă maı̌ sุi subfalciform. l'etiole inegal ghimpose-glandulise. Foliole 5-7, ovale-subrolunde, subduplicate-dentate, (^u dinț̆ laț̆, glanduloș̆, deasmpła verḍĭ inchise. dedesubl mă palide, pubescente, coriaree. Slipule lörte inguste, la verl

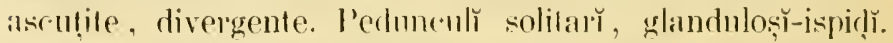

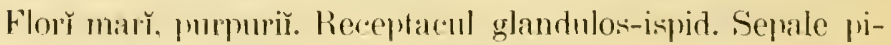
natifirle, lat vêl' dilatate, acomminate, rellexe la matmilale. firucl piriform s. suluglohos, glandulos-ispid. — †) MaiuInilix.

Abit. și staṭ. Păsciunile espuse sórelur, marginea locurilor eulti-

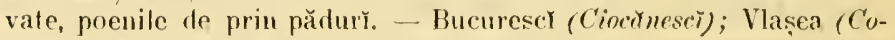
m(t)(1); Васӑй (Verşescŭ); ete.

R. centifolia $R$. cu o suta de fot. - Vulg. Trundufir de dulecuţ̌. - Cultival prin mar̆ toite grădinile. — †? MaiuIuriti.

R. damascenta Mill. R. de I) Mmeesc. - Vulg. Trandafir de lună. - Cullivalt prin grădinı̆. - †? Primä-vara, vara şi tómuna.

R. arvensis Huds. R. dre rêmp). - Vulg. Trandafir de e(ump). - Arbust en ranurĭ clongate, llexibile, flageliforme, cı ghimpr inegalĭ, falciformŭ. Petióle pulsescente, glandulóse, 


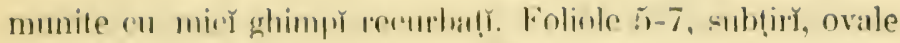

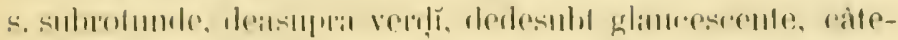

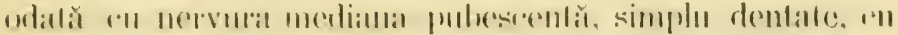

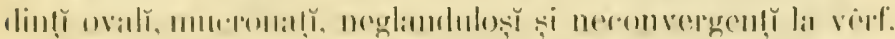

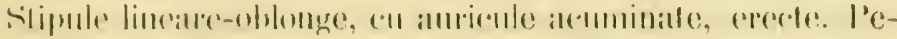

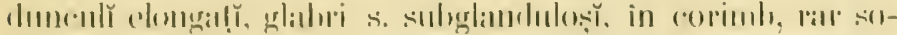

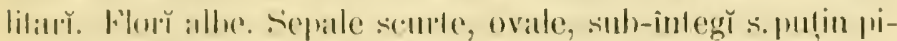

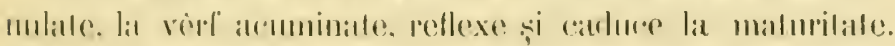

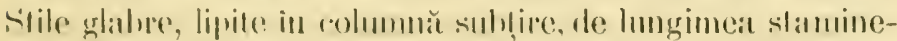

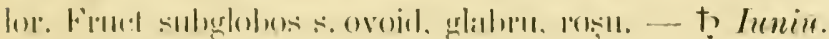

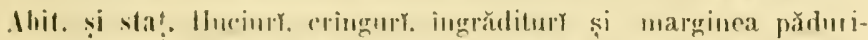
for diu reginnea caimpénă și paină in cea subalpină din tötă Rominia.

R. sempervirems L. Ii. merurese-verele. -..- Vulg. Tran-

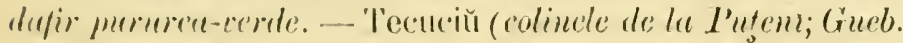
1. r.). 一 t. lenin.

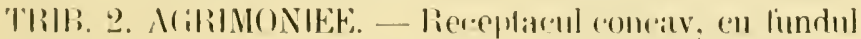

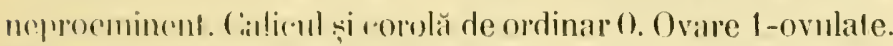

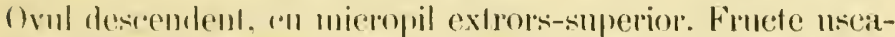
le, inchise in interiorul mun receptacul de ordinar uscat. l’upină erbacee s. lemnós̆.

\section{AGRINONIA T. - Agrimonic.}

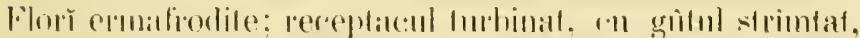

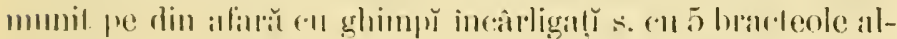

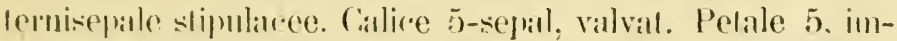
bicale. Stamine 5, alternipelale, $s, \infty$ si dispuse in 5 fialange allernipetale. libere. inselate imprejurnl ineluluĭ glan-

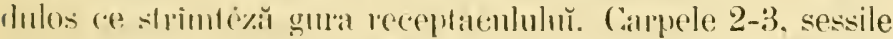

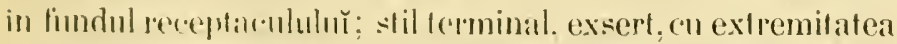

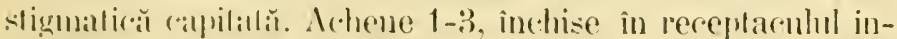
durat și ade-ea aculeat-lapacen̆. - E.tbur perene: frunde alterne, intremple imparipinale, cu slipule petiolare; flor 
in raceme spiciforme, terminale si axilare: pedicele bracteolate.

A. Eupatoria L. A. Inmbremic. - Vulg. Turituitmare. -. Plantă fï̀le pĕrósă. T'ılpină de :3-8 decinı. angılósă, erectă, simplă s. puṭin lamós̆ către vêpf. Frunḍe muru, deasuplat vilise, dedesubt cennșin̆-tomenlise, cu segmente firte

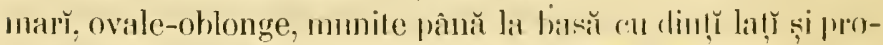
find̦ĭ, amestecate cu segmente forle mič̆, dentate s. intregr ; stipule marr, invaginante, forte incisale-dentale. Florı̆ galbene, nmmerose in lumgr raceme spiciforme; pedicele scurte. erecle, lia vôff irticulate, munite la basă de o braclce :3fidn̆. si la anticulatimea sa de 2 bracteole opmse. Sepale oville-ascuṭite. 3-nerviale, dıpă antes̆ persistente și conivente. P'elate ovale, patente. Achenă solitară inchisă in interior'ul unn reereptacul uscat, cu smprafața exterióră sulcată şi mmnil̆̆ in sus de ghimpr incârligaț̆, suberecṭ̆, reflex pe pedicel. Seminte albe, ovale, deprimate către vêrf, netede. - 2 Iuniii-itugust.

Alit. și staț. Huciurř, erîngury. Lufărișurr, pădurY, atât din regiunea câupénă cât și cea muntósă, dìn tótă România. - lași ( $N^{\prime}$ i-

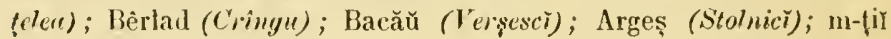
Coziey (Forfecu); etc.

\section{ALCHEMILLA T. - Alchemilı.}

Florĭ ermalirodite, apelale: receptacul urceolat, strîmtat la gît. Caliee 4-5-sepal, valvalt, umunit de un calicul format din tot atâtea folioble alterme, mă miç. Stamine 1-5, alternisepale, lihere, inceate imprejurul marginer̆ îngroşate şi glandulose a disculun receptacoululŭ ; filamente sub vêrf articulate; antere terminale. Carpele 1-'́, sessile s. stipitate; stil hasilar s. ventral, cu extremitatea sligmatică capitată. Achene 1-4, inchise întrin receptacul membranos. - Erburi perene s. annale; frund,e alterne, lobate, digitate s.palmatipartite; stipule peţiolare; flor förte mič, de ordinar agregate in cime corimbóse, axilire s. terminale. 
A. vulgaris $L_{\text {. }}$ A. commun - Vulg. Crentisouer - Plantă

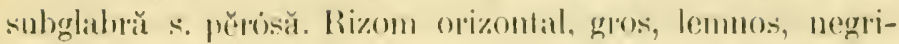

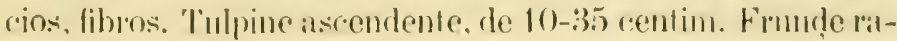
dicale lung petiolate. reniforme. incrẹ̣te de la basă spre periferie. divisatto in 7-9 lob̆ semi-orbicuları̆, dentaḷ̆ de jur

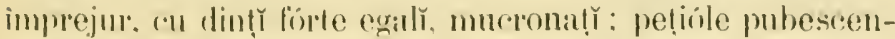
te: stipule conivente-lubulóse. Flor unič, de un verde-găl-

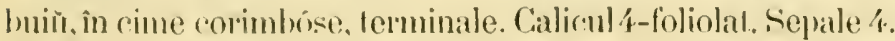
Stamine f. Campel solituriŭ : stil basilan. - 2 Maiй-August.

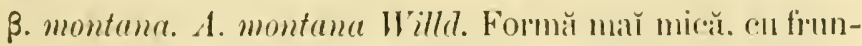
de pĕrise-sulssericee.

Alit. și stuṭ. Păsciunile de pe róstele tutulor munţilor. - M-ţi

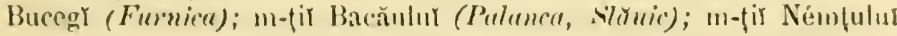

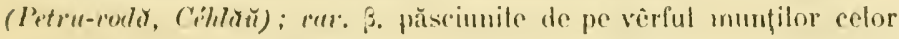
mar inalţ (c'éhlǐn̆, Buergi).

\section{SANGtisoRBA I. - Sanguisomba.}

Florǐ polygame s. emafrodite, apetale; receptacul turbinat, strûntat la gût. Calice 4-sepal, maì mult s. maŭ puṭin pehaloid, decusat-imbricat. Stamine 4 , opositisepale, s. $\infty$, inserate imprejurul nurginer ingroșate și glandulóse a disculur recephacululur̆ ; filamente libere, seurle și drepte, s. elongate, capilare, Ilexure și pendente; antere didime. Carpele 1-4, inchise în receptacul ; stil terminal, r"n extremitatea stignaŁič̆ peniciliată-atspergiliformă. Achene mă adesea solitare, inchise intrin receptacul indurat, f-gonat, neted s. rugos, murieat s. f-pter. - Erbur de ordinar perene: frunde alterne, imparipinate : stipte pețiolare: Ilorǐ 2 -bracteolate, in spice teminale, globrise s. oblonge; perlunculĭ lunğ, solitarl s. cimoș.

Sect. 1. SA NGU ISORBA L. Florl elmafrodite; stamine 4 , scurte şi drepte: carpel solitar.

S. officinalis L. S. ofirmală. - Vulg. Simlorstre - Hizon gros, lemnos. 'Tulpină erectă, inalıă, de 5-12 deeim., sub- 


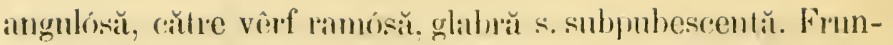
d̦e glabre, dedesubl glance, cu 7 -1:3 folióle corlacee, cordaleovitle-oblonge, regulat aculi-denlate pețolulate şi adesea munite lat basă de donĕ stipele oviale-dentale. Flory în spic

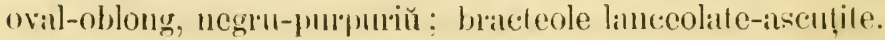
de lungimea florilor. Sepale eliptice, negre-pmpmiй, c:むduce. Stamine de lunginea sepalelor. Receplacul fructifer 1-gonal, cu unghinri subaripate, en fețe rugóse. - of IuliŭAngust.

Alit. și staț. Păsciunile și fènețile din locurile unede și turfóse de la pólele munţilor. - Nénųu (W-stirea Némțtulna prin fềuṭ̂le umede de pe maryinea soseler ce duce la monastive).

Sect. 2. Pot e R I U y $L$. Florĭ unisexuale s. poligame; stamine $x$, elongate și flexuóse ; (a)pele 2-3.

S. Poterium II. Bu.; Poterium Sanynisnrba I. S. Potivir. - Vulg. Cóbarea. - Păscimile și fènețele din locmile umede. - Ném!̣ (Czih. şi Szab. l. c. 31): Gupl. v. in hert. mus. Iaş̌. - 2) Iuniŭ-August.

3. villosa. Colinele arenacec a Moldover inferióre. (S. villosa (ruel). (nou Silth.) I. c.).

S. polygama II. Bn.; P'oterinm polygremum WK. S. polygamŭ. - Colinele nscalle de pe langă Bêrlad (Czih. şi Szah. I. c. 31).

THIB. 3. FHAGARIEF. - Receptacul concav, cu fundul proennent și conic. Calice con s. fără callicoll. Ovane libere. neînchise în receptacul, maì tol-dé-rma 1-ovulate. Ovule atscendente s. descendente, m micropil extrols. Fructe supere. - Tulpină erbacee s. frutescentă.

\section{FRAGARIA T. - Fragariu.}

Flor ermafrorlites.poligane; receplacul lat pateriform, en fundul proeninent ; i conic: Calice 5-sepal, valvat, persi- 
stent ; adicul (2n 5) divisum exterine, altemisepale, persi-

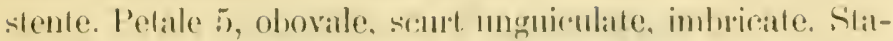
mine 20 - $\infty$, perigine; filancute litere sulprersistente. Caurpele $\infty$, inserate pe vîful proeminent şi conic al fumdulŭ receptacululŭ ; ovitre 1-ovulate : ovul semi-inatrop, descendent, an miropil extrors-superior; stil subbasilar. Achene $\therefore$ drmple so, mulate pe partea proeminentă persistenlă, cătrnós̆ și sucolentă, ovoirlă s. globósă a receptacululur, îm-

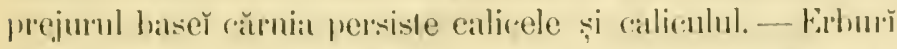
prerene. stolonifere, pĕrise s. sericee: tulpină subterană (simpodiü); linnde alterne, 3-foliolate, mă 1"u pinate; stipule peṭolare, membranose; flor lerminale s. opositifoliate, solilare orĭ mă adesea cimóse la vêrful unuй seap) ('omm.

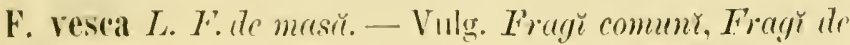
pridure. - Stolone munite de un soly în fie-care din intervalele re sepilră tufele de frunde. Thupine scapiforme de 1-33 decim.. rar intreeênd puṭin fimnd̦ele. nude s. cu o singuri frunḑă florală. Folióle orale-oblonge, dedesubl pubescente-

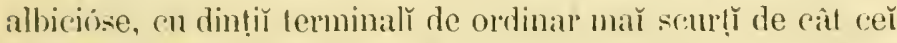
lateralĩ : pețiol cu perĭ patențĭ. l'edicele en perīaplicalı̆. Catlice patent s. reflex la maturitatea fructuhŭ. Fruct roṣı, rar alb, ơoid-sulgglobos. purtînd earpele pinnă la baši. — Aprilo-Iuniü.

Abit. și staḷ. Poenile pădurilor și colincle din tótă România.

F. collina Ehrl. F. colinctor. - Vulg. Crümsun. - Stolóne lịssite de sol\%ŭ în intervilele ce separă mfele de frunḍe, afuriı de cel din urma. Tulpine scapiforme de 1-2 decim.. intrecônd

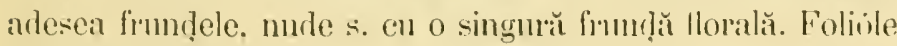
oblonge-orale. dedesubt pubescente-albicióse și cîte-odată

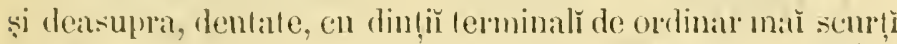

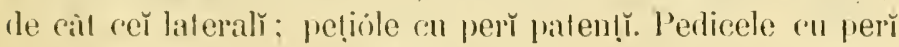

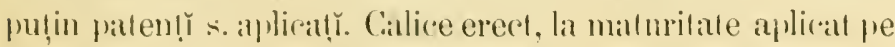
foucl. Fruct rosil. subglobos-ovod, ou basa ingustală și necarpeliferĭ. - 4 stuin-Iunir.

Abit. și stat. Poonile pădurilor și colinele aride din tóte părţile Romănier. 


\section{P0TENTILLA T. - Potentila.}

Florı̆ 4-5-mere. Slamine mă adesea 20 - $\infty$, mă ıа 10 s. 5, opositisepale s. opositipetale. Compele $\infty$, maй rar puṭine: stil cu bitsa câte-odată articulată, terminal s. ventral. Achene inserate pe un receptacul la maturitate pĕros, nscat s. spongios. Cele-lalte curactere ca la Frugaria. - Plante erbacee s. subfirutescente; frunde alterne, digitale s.pinate; stipule pețiolare: flor solitare s. cimóse-corimbóse, terminale s. axilarè.

Sect. 1. Potentridastrux Ser. - Flory̆ 万-mere; receptacul la maturitate uscat. Stamine $20-\infty$, rar mal̆ puține. Carpele $\infty$.

1. Flor ulbe.

1. Frunde trifolintr.

P. Fragariastrum Ehrh.; P. Fragaria Sm. P. Fragariuneadererat. - Vulg. Frăgurel neroditor. - Pntna (püdureu de lu m-stirea Sctunteiu; (rueb. l. c.) - of Aprile-Muir.

P. nitida L. P. strchlueitóre. - Vèrfurile calcatre ale mun-

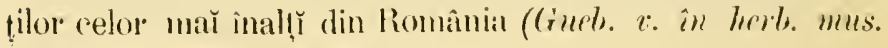
Iaş̌r). — I Iuliť-Srptrmline.

b. Drunge palmalisecte cu i-i fulinile.

P. alba L. P. albŭ. - Thutova (pouturéa de ia m-stirea Adam; Gurb. l. c.). - I Maiu-Septemlure.

c. Finute pinatisecte.

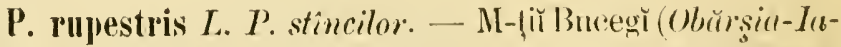

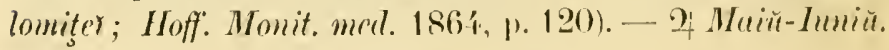

2. Flori gallene.

a. Frumde ternate.

P. subacaulis L. P. atpópe farre tulpima. - M-tio Mol-

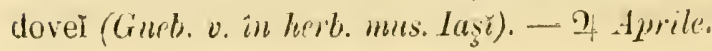


1. Frmule palmatiseste, ru is-ĩ folioble

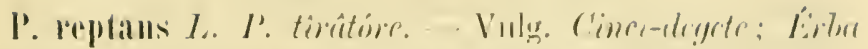

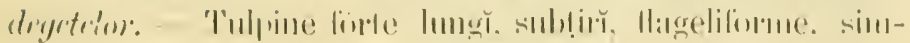

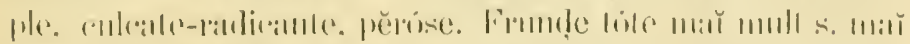

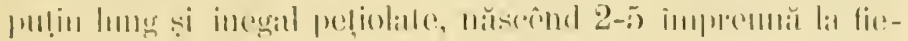

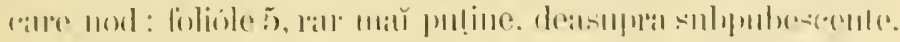

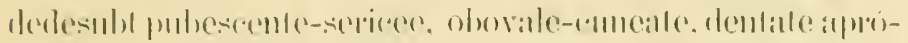

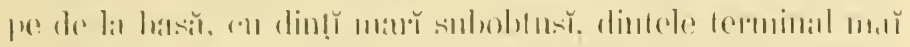
İlor

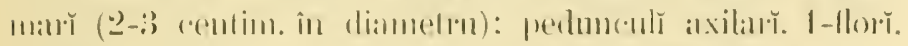

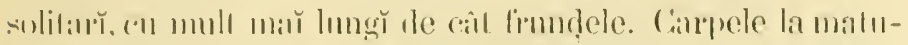

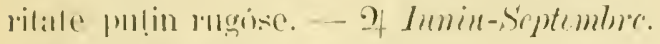

Abit. și staṭ. Margino drumurilor și a șanţurilor. păscimnile ॥-

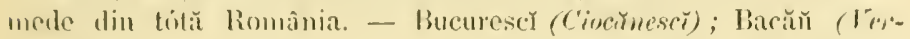

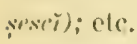

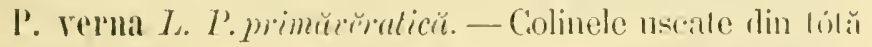

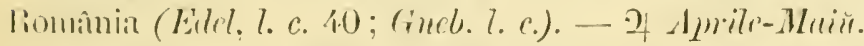

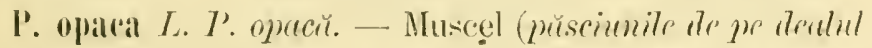

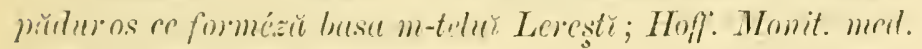

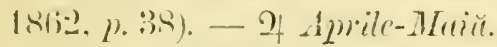

P. patula WK. P. intinsü. - M-ṭĭ Prahovĕ̌ (Zăgamn:

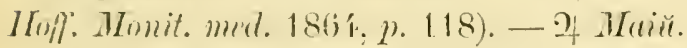

I'. heptaphỵlla Mill.; 1'. intermedie Nestl. (non L.). I'.

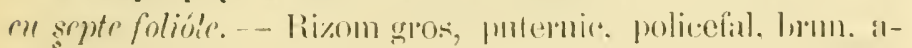

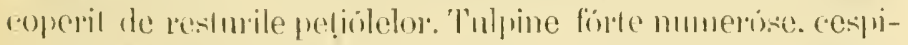

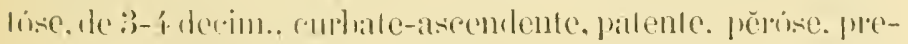

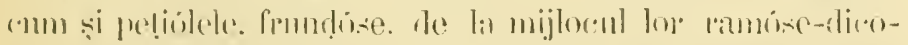

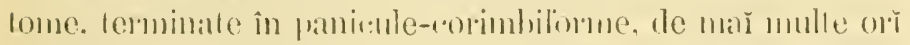

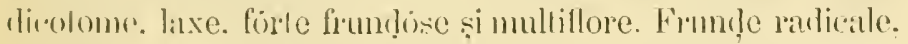

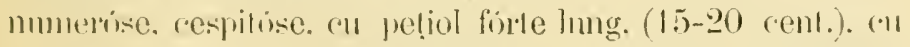
7. rar :)-9 folisile obovale-cunciforme. s. ohlongr-cuneiforme.

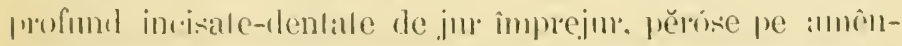

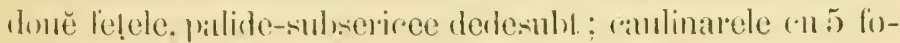

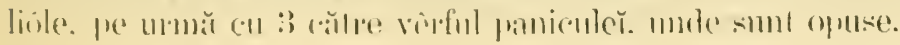


precum și rammile; stipule ovile-lanceolate, inlreğ. Flor

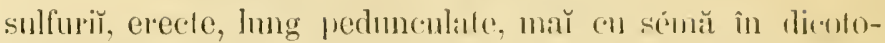

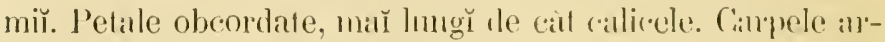
cuate-rugíse. - 9 Maĭ-Iutiŭ.

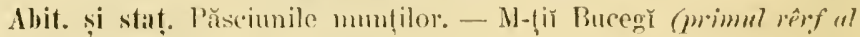
Funieri); m-tir Cozier (Fórforeu); ete.

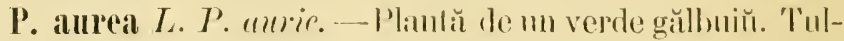
pine ascentente s. suberecte, smbtirĭ, pancillore, ('n perı̆ aplieaț. Frunde radicale lung peliolulale, (•и :3 folioble obo-

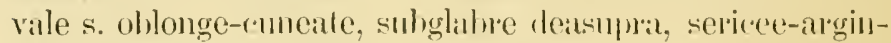

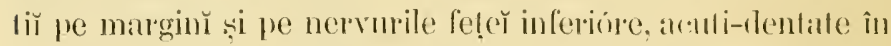

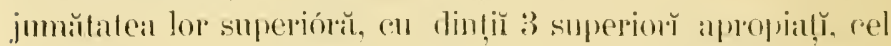
median mă̌ mie; (aulina lreğ; stipule ovale-lanceolate, ascuḷite, întreğ s. suldrleulale.

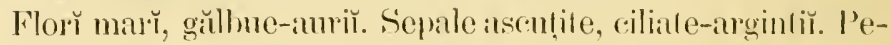
lale late-olucordate, de donĕ oř̀ mă lunğ de câl calicele. Carprele shinceite. - 2 Imiru-Aumzst.

Abit. și staț. Păsciunile din regimile subalpine. - Vêrful Cóhlăı-

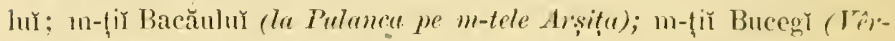
ful Furnicer); etc.

P. argentea L. P. argintie. - Vulg. Serintitóre. - Tulpine numeróse, de 1-5) decim., întinsc pe pămènt, ascendente s. suberecte, tomenlise-albiciose, ferminale in corimblax. Frunde inferiore peliolate, cele superiore sessile, (n 5 fo-

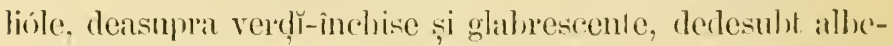
tomentóse, lung-cmmeiforme, förte ingnslate sii întreğ în jumătatea lor inferoinŭ, profund incisale s. pinatificle în ju-

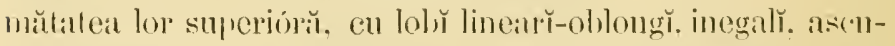
liți, cu marginile subrevolute; petiol tomentos-albicios; slipule întreğ, lineare-acmunime, s. 2-3-ficle. H']or în cime terminale, fimmdose, phri-multillore. Cinpele la malurilale

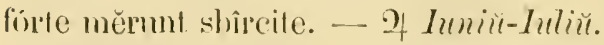

Ahit. și stat. Cóstele aride și pelróse, poenile de prin pădurt. -

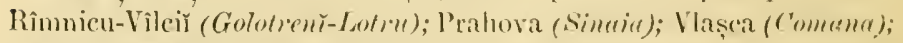

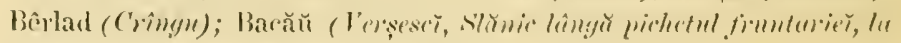
Puluner pe rềiul Alşițer); che. 


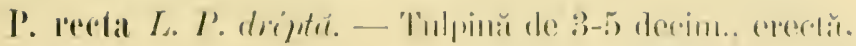

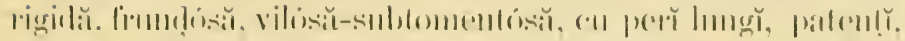

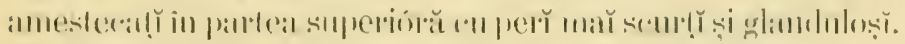

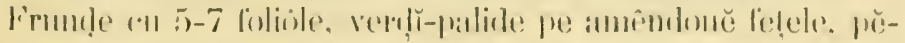

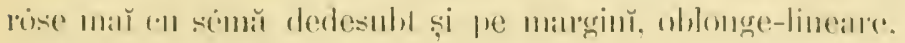

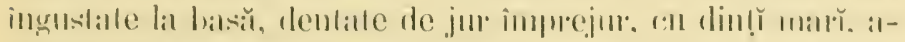

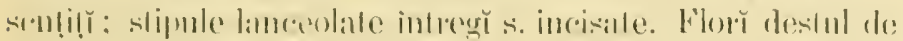

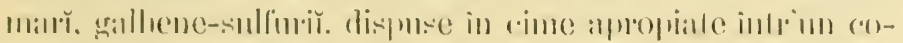

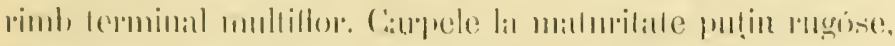

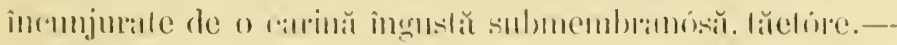
of Muiri-Inliu.

Alit. și stal. Ponnile de prin pădnry. - Buenreser (Merinomi);

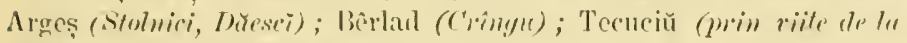

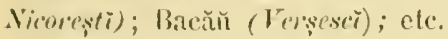

P. hirta L. P. prósčs. - l'rin locmrile aride și uscate din

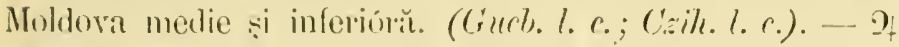
Muiй-Jипіи.

$$
\text { c. Fimmle pinatiscete. }
$$

P. supina L. P. culcate. - T'rin locmile monerte si are-

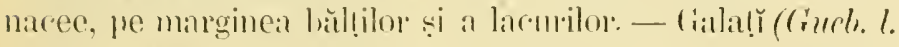
r.). - Mnim-Septrmlire.

P. Anserina L. P. Anscrinč. - Vulg. Srrintitóre - Tu-

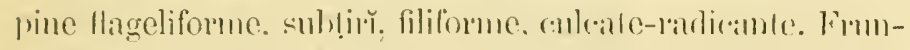

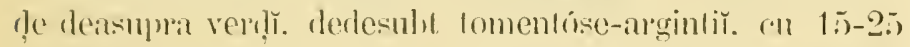
folicile oblonge. mofund armuli-dentate de jur împrejur: al-

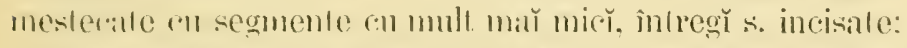

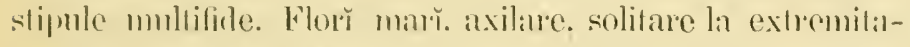

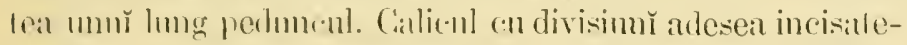

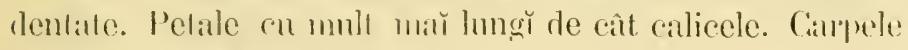
nelowle. - of Menim-Srptember.

Abit. și slaṭ. NHsia și malurile arenace a rîmilor și a gîrletor,

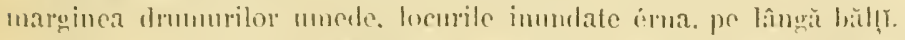

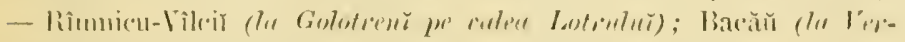

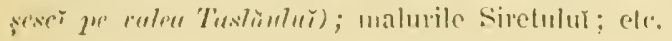




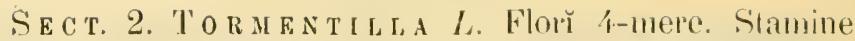
$20-\infty$. Carpele numerose.

P. Tormentilla Nesll.; Tosmentilla serete T. T'. Tormentila. - Vulg. Srlizet. - Tulprine numeroise de 1-i decim.. patente-ascendente. subḷı̆, mă mult s. mă puțin ramóse,

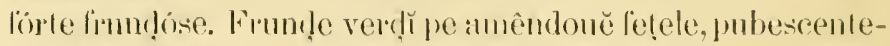
ciliate; radionalele peliolate, distruse in momentul inlloriger ; ranlinarele lole sessile, an :) loliole oblonge-raneifornne,

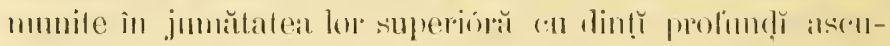

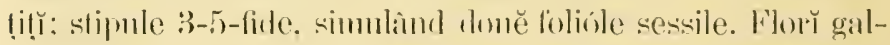

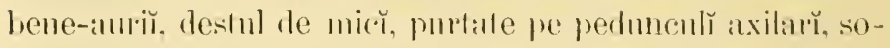

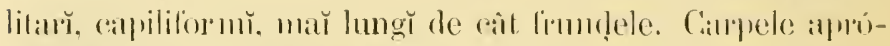
pe nelede. - of Imini-lutiu.

Ahit. și staț. Păsciunile umede și uscaté de prin pădurile mmm-

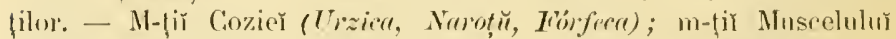

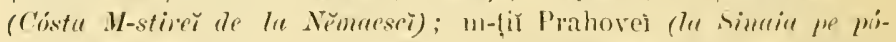

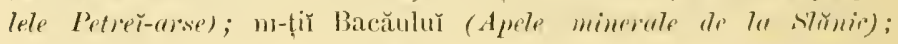

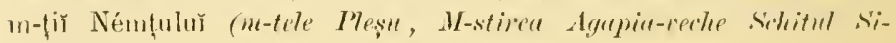
lala) ; ete.

I. procumbens Sibthomp. ; Tormentilla reptams L. T. cul-

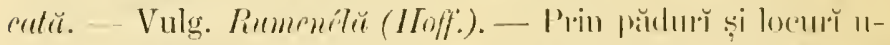

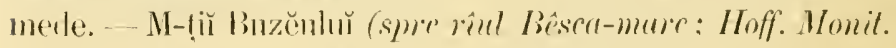
med. 186я, p. 117); Mohlovil (Czih. l. с.).

\section{RITBTS L. - RMy.}

Florı̌ ermafrorlite s. polỵgame : alice necalirulat. imbri-

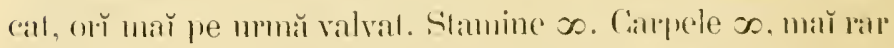
putine: ovire 2-ovulate; ovule colaterale, descendente. ("u micropil extrors-smperior : stil sublerminal. 1)1mpe os. 1-sper-

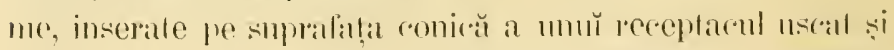
spumgios. Cele-lialte caractere ca la 7'otentilla. - Arbmsă

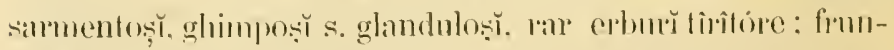
ḑe alterne, simple și lobale. s. rompuse, palmate or impar-

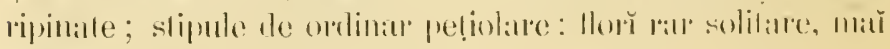
adesea dispmse in rime romimbiforms. axilane s. terminale. 


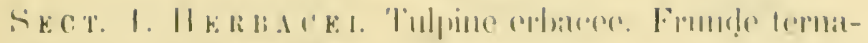
le. Slipmlo libere, rallimille.

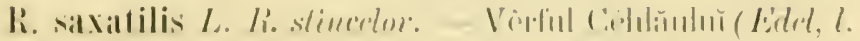

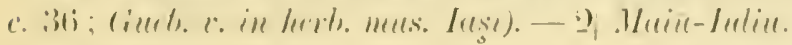

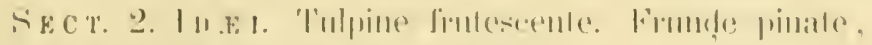
ell $5 \therefore$ : : loliole. Silipule peeliolane.

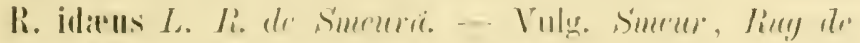

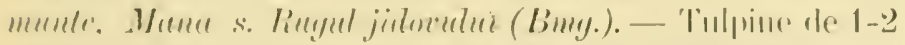

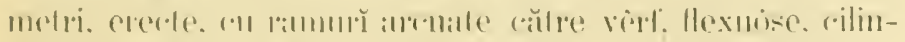

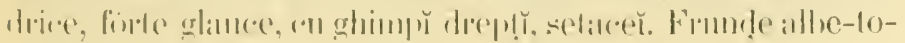

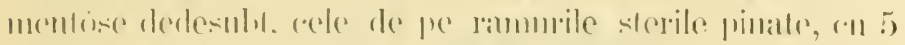

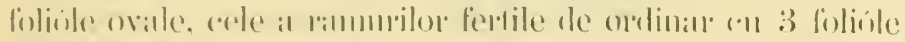

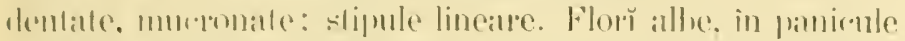

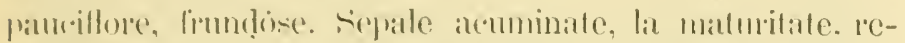

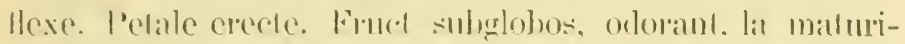

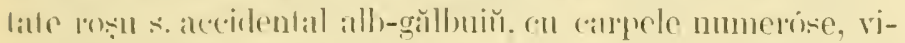

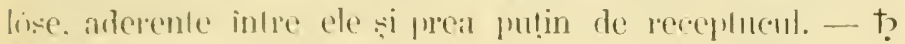
Mrint-Inniu.

Alit. si staḷ. Pădurile umede din reginnea muntósă din tótă Romània. - Cultivată și prin grădint.

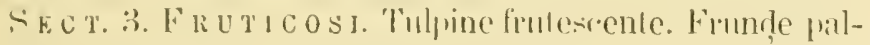
mate. 11 : 8 is lolicile. stipule peliolatre.

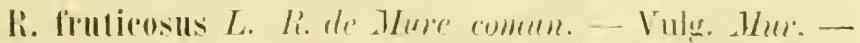

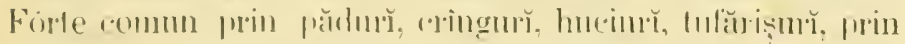

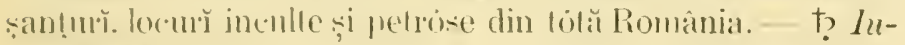
nili-liliu.

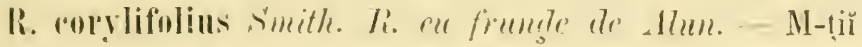

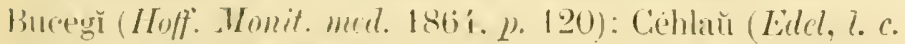
3i). - t? Iuliel-1uyust.

R. agerestis ШК. R. ale cêmp). - Covmrhiŭ (püscimnile

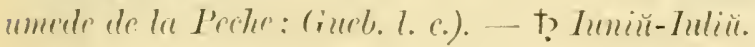

R. memorosus Mayne. Ti. de padure. - Pădurile din mă

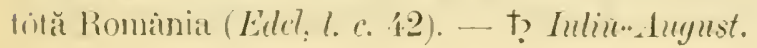


R. ciesius L. R. albastru. - Hucinde si pădurile din q memusc.). — to Iuliü-Sentembre.

ж. areensis Wullr. I'pu locurite cultivale ale Moldover inlericile (ciurb. l. c.).

Obs. Guehhard (l. c.) indieă în diferite localitățri încă eâte-va spe(ciĭ de Ruluts, sub niss:e denumirř, insě, ce prohéză o determinatiune do o esactitate intoelnieră. și a căror sinonimie, în lipsă de specimene, este cu nepulință de stabilit. Din ummĕrul acestora

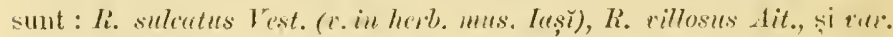

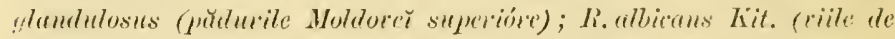

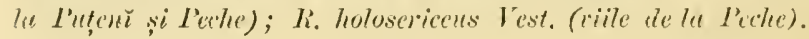

\section{GEUII H. Bı. - Gen.}

Calice de ordinar calliculat. Carpele so, mă rar puḷe subdelinile, inserate pe un receplacul semt s. claval, intreg s. plurifid ovul solitar, subbasilar-atscendent, cu micropil exhors-inlerior; stil teminal s. subleminal, la bas̆ râle-o-

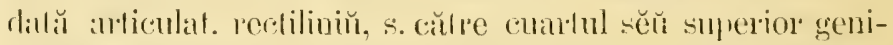
rulit-inticulat, mut s. batrbal-phumos. Achene $1-\infty$, lermimate ru cicatricea stiluhur s.cu stilul persisient. dreft s. geniculat-anticulal, cu articuhul superior cartuc. - Cele-lialte "alaclere ca la Potentillu. - Exhurĭ cu lizone perene, adtesca liratore s.stolonifere: frunde radicale imparipinaticectc. r.ll segmente loild inegale, lobales. incisale-dentate, lateralele frime mič̆, terminalele forte amule, adesea ronlluente inllonnl singur ; (aulinarele 3-foliolate, 3-lohate. s. luacteiforme: slipule pelioline, forte ample, subfoliace ; Horr de ordinar puline, solitare la extremitalea lulpiner̆ și a ramurilor.

SECT. 1. EU E U Jois. Carpele $\propto$. Stil geniculil-articulat, persistent, glabus s. cu anticulul terminal vilos.

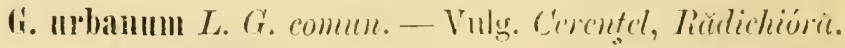

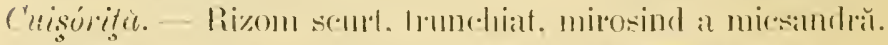

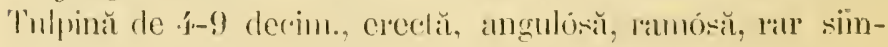
plă. Flor erecte, galbene. Cálice verde, pubescent, cu se- 


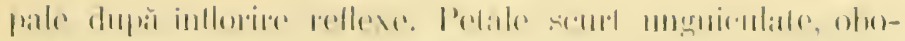

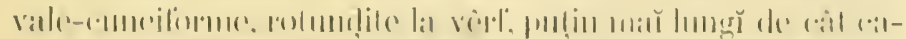

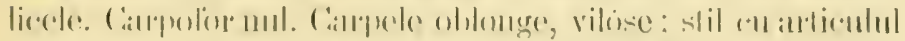

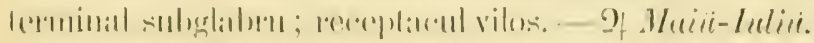

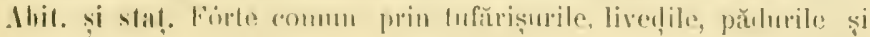

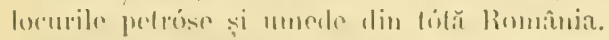

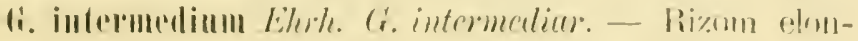

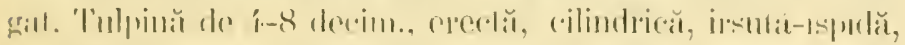

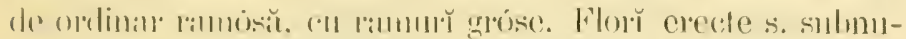

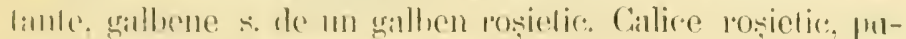

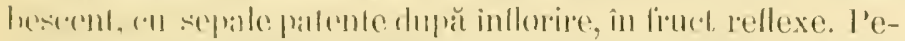

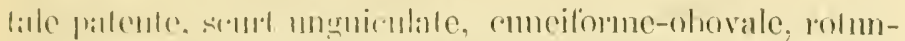

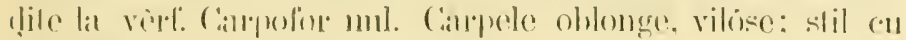

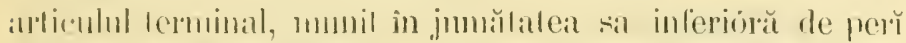
lungr. _- In Inim-Iulie.

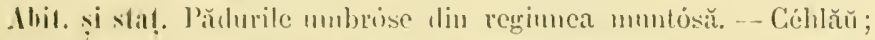

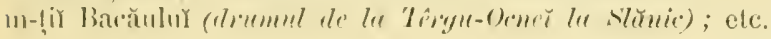

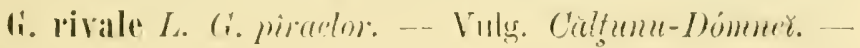

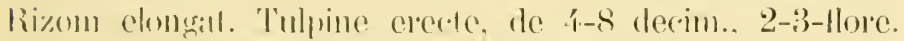

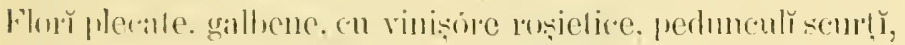

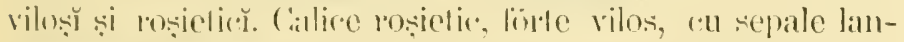

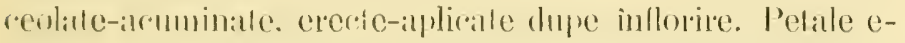

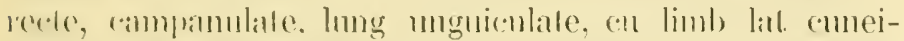

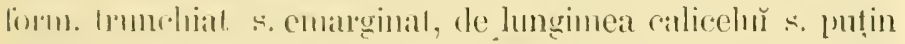
mali somte. Campolon de lungimea ralicelnt. Campele ovale,

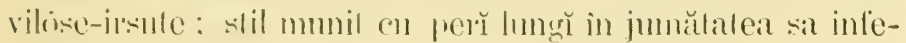

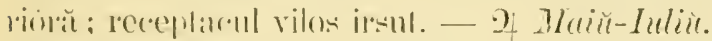

llit. și satt. Loemrile umbrose și umede, maroginea piraelor și a isvorelor de prin pădurile din recrinnile muntóse. - Ml-pii Buceğ

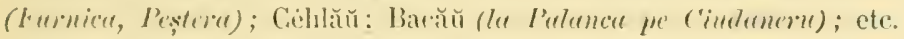

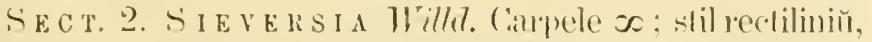

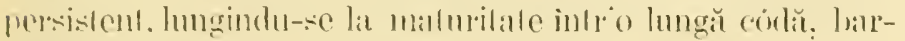

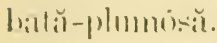

A. montanmแ I. Cr. muntilor. - Rizom fără slolóne. Tulpunesolilates. mă multe. erecte. de 5-35 comlim., 1-flore. 


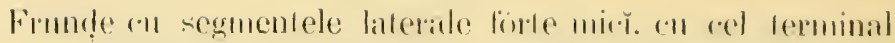

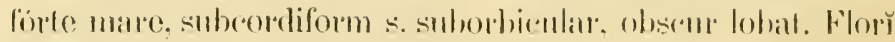

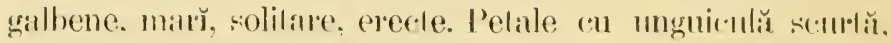
mir lınğ de cât calicele. Carpele ovale, vilose, temninance printrin lung stil butbat-phmos: receptarnal puberulent.2. Muric-Luniü.

Alit. și slaț. Prăscimile alpine de pe vèrful nunụilor celor mẵ

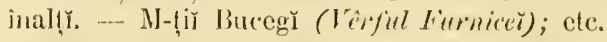

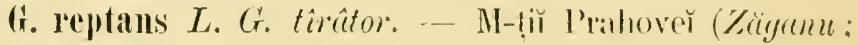
Hoff. Monit. mad. 1868, 2. 118). - - Iunii--Lugust.

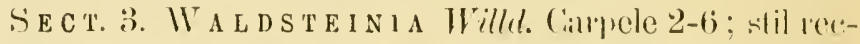
liliniŭ. la baš̆ ardiculal, caclue la malmilate.

A. Waldsteinia H. Bn.; Wuldsteinie geoides Willd. (i. Waldstrinier. - Vêrful Bucegilor (IIoff. Monit. med. 186i.

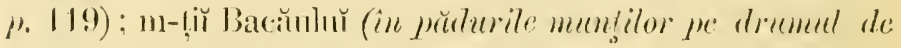

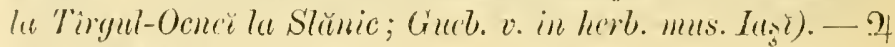
Itortiu-sluiu.

\section{DRYAS L. - Driacla.}

Filorì exmafrorlite. 8-9-mere: calice necaliculal. Arhene ferminate cu un lung stil persistent si hillbal-plumos. - Cele-

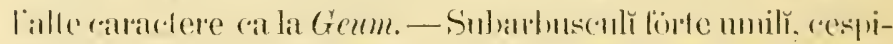
|o:̧̆ : |m|pină griš̆, scourtă; frund̨e simple, alterne: slipule prẹtolare; florĭ solitare, terminale, perhmenlate.

I). octopetala $L$. D. cu opt ptale. - 'Tulpine subfinle-

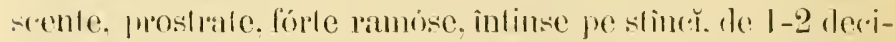

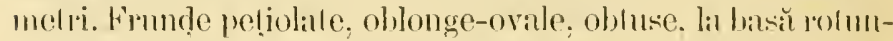

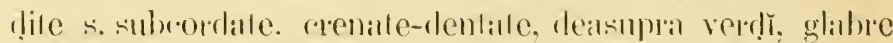

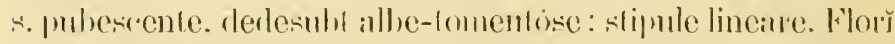

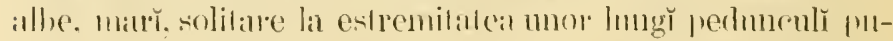

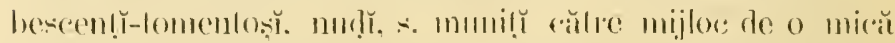
bracteolă Jineară-ascutiliă. Callice pubescent. I'elale de donĕ or̆ mă lınğ de câl sepalele; receplacul fórle vilos. Carrpele 


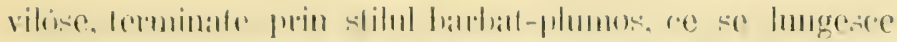

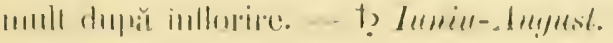

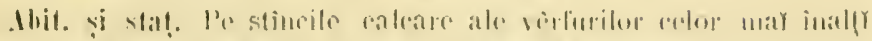

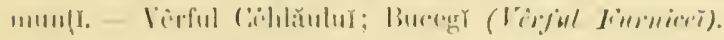

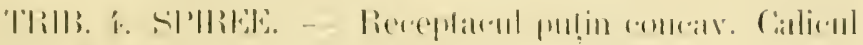

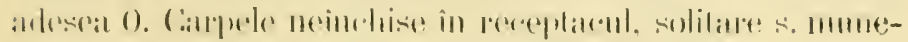

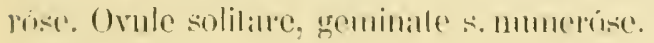

\section{SPIREL T. - Sprivere.}

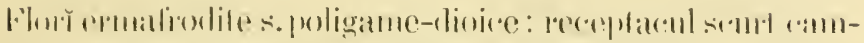

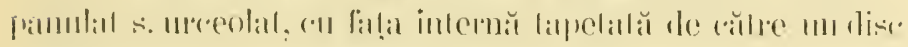

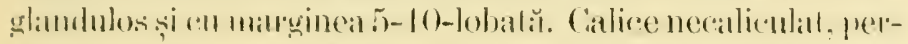

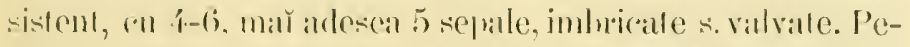

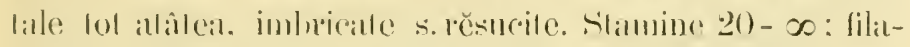

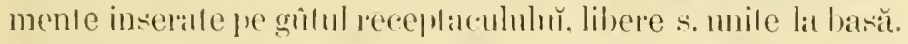
(impele mal̆ adesea 5), opositipelale, s. maŭ mar allernipelale.

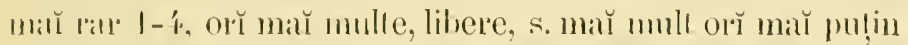
sus unile, inserale in lundul receptaculului ; stile lerminale s. subterminale, drepte s. geniculate. cu estremitatea

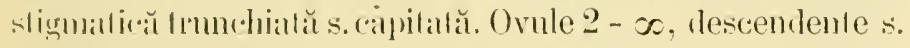
mă rar ascendente. or 2-seriale lansversal in unghü in-

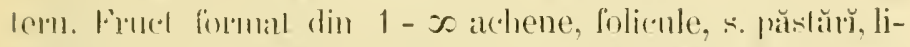
leve orĭ unile, direple s. mă rar conlumbile. Seminte $1-\infty$.

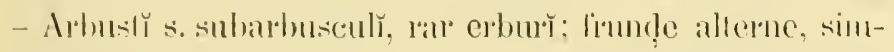
fle, digilale, pinale, s. descompuse: slipule lallerale liberes. pe!̣olare: Hor in latceme, spice, s. corimbe, simple s. compuse. orı̆ in raceme de cime unipare s. plupipare, axilare

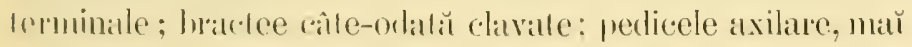
mulı s. maй puḷu sus inscralle.

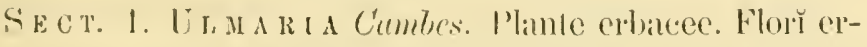

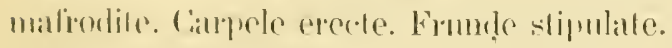

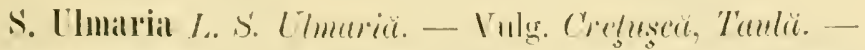
kizon gros, lemnos, anmos, cu libre radicale forte nume- 


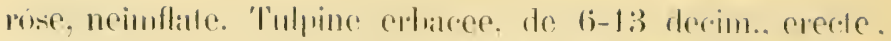

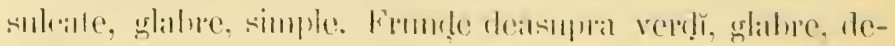
desilht fomenlose-anginliü, inlremple pinalisecte, cu n-?)

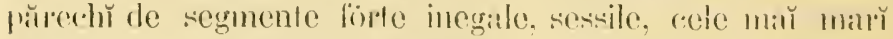

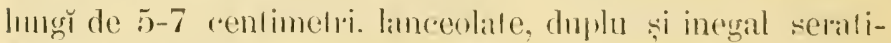
dentale. ferminalele ronlhuenle întrun segment en mull

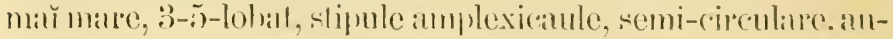
rirnlale, serali-dentale. Florì athe, in rime rorimbose probi-

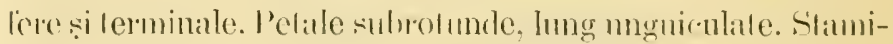

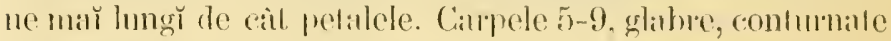

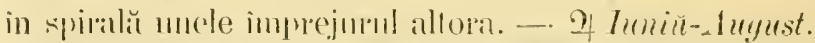

Abit. și staț. Malul aprelor. păscomile și fêneţile umede din :c-

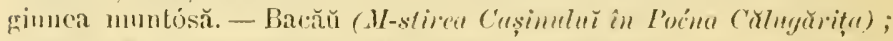

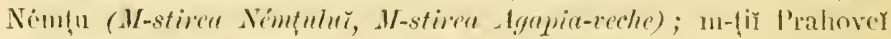
(m-stiver Cheie); etc.

S. Filipendula L. s. Filipendulï. - Vulg. Alglicrĕ, Oylier, Trisgor, Fervige albe. - Rimom an fibre ridicale imflale apripe de estremilălile lor cu luberenle oroide. 'Vulpine erharee, de 3-8 da:mo, erecte, simple. pmin frmolise. Frm-

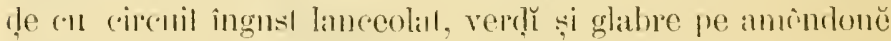

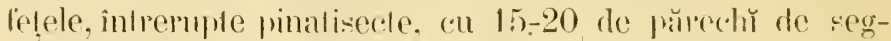

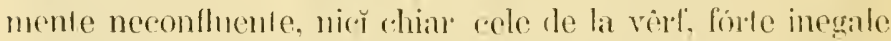
(de ${ }^{2}{ }_{2-1}$ enlim.), sessile, lineare-lanceolile, inegal incisile-

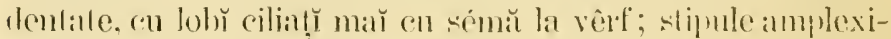

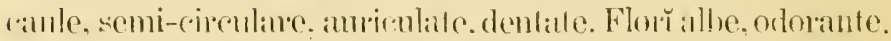
in rime copimbose prolifere si lemminale. Pelale obovile.

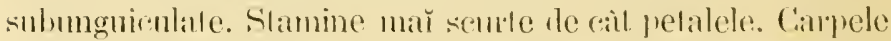

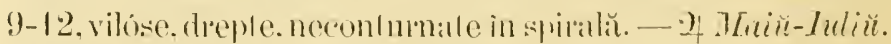

Lhit. si stal, Păscimile useate și poenile de prin pădurile din

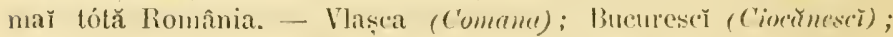

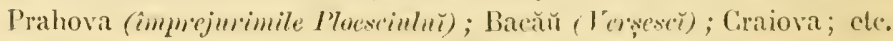

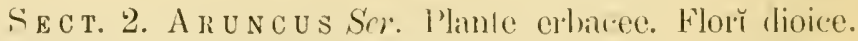
farpole pendente. Fimde fără slipmle.

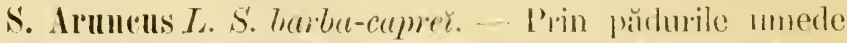
sim 1 mbrose din regimea subalpina a m-lilor Moldover (EAdel,

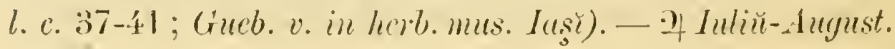




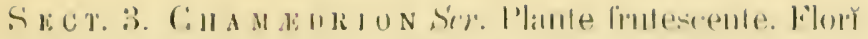

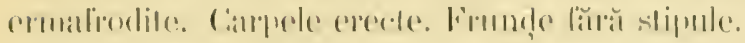

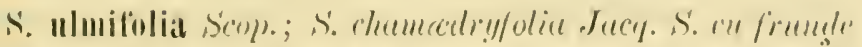

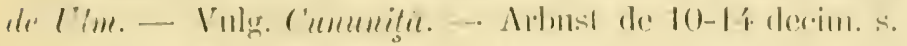

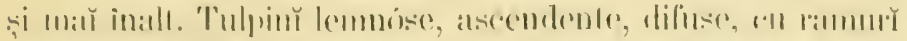

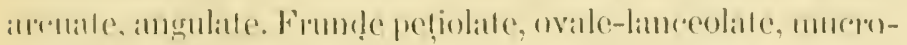

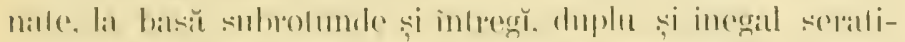

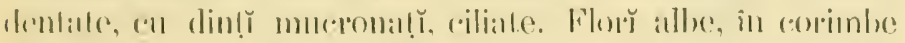

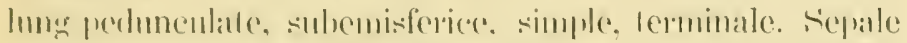

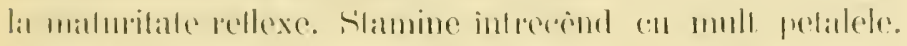

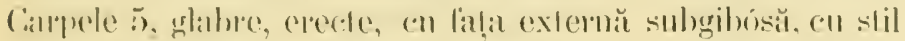
sulereer, aprical. - t) Iuniit-Iuliu.

llit. și staṭ. Pe lîngh̆ stîncile umbrite de prin pădurile din régrimea subalpină. - M-ţir Muscelulur (S'turu); m-țir Prahover flu

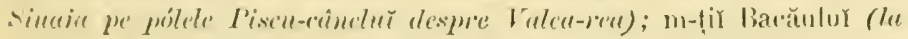

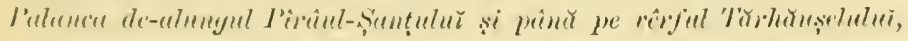

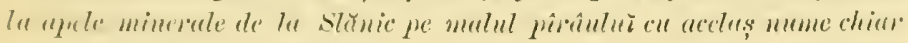
in juf! iscoimlui No. i); etc.

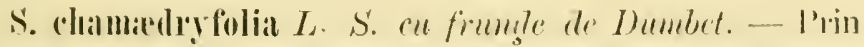

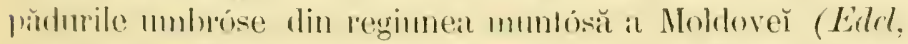

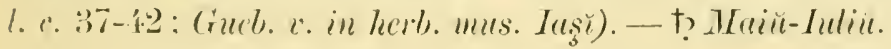

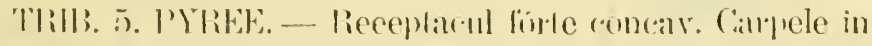

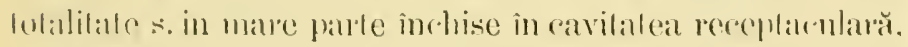

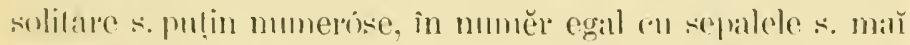
multe. Ovare mal̆ lol-dé-ına 2-ovulate. Orulo rolaterale. ascendente, ru micrnpil exlrors-inferior. F'urel pomaleen̆. de ordinan' roronal de resturile calicelur s. de cicatricele sale. 'Tulpină lemnos:ă.

\section{PYRLS T. - Tér.}

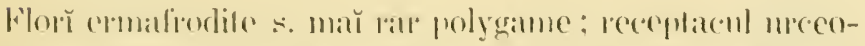

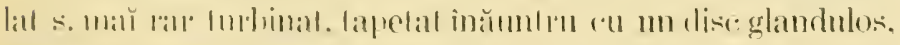

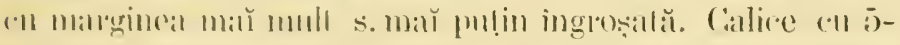
cejale imbricale, persistente s. cadure. l'etale 5, suborbicu- 


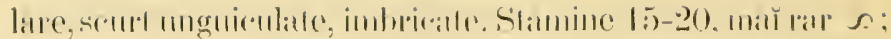

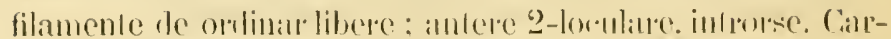
pele, orı̌ 5 allemipetale, or 2-1. (Sorlus): ovare inserale

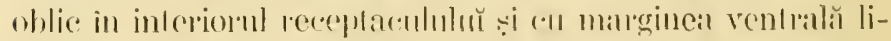

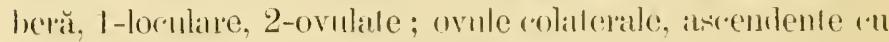
micropil extrors-smerior, aderen obmale: stile terminale, orı̆ ('॥ tolul libere (P’yrus), or

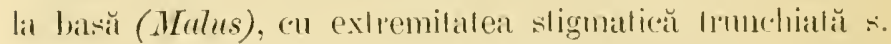

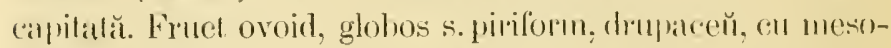
(ar) (receptacul) de ordinar cărnos; cndocarl) 1-5-locular, rristalcen̆-fiagil s. eorlatecu-carlilaginos. Seminte 1-2 in tie(a) loge, erecte, cu tesla mall adesea cardiliginos. pe din it-

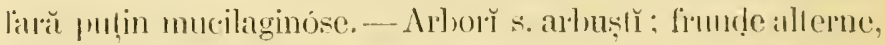
simple s. pinali-compuse, rarlure; slipule laticrale, radure: florì in colimbe simple, sompuse din cime, alleseal preroce, eșind din mugur gros̆, intainlea firmndelor.

SECT. 1. PY R O I I 0 R U M $I)($. Slite 5 , libere. Find lubinal s. subglobos, neunbilical la baš̆. cone ndocall) corliacertrartilaginos, an 5 loge. Flor cor combóse, cu perlicele simple. F'runḑe simple.

P. communis L. I'. commu. - Vulg. P'ér selbutio - Ar-

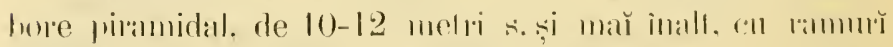

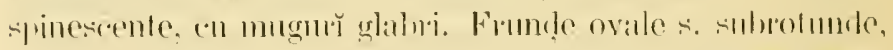

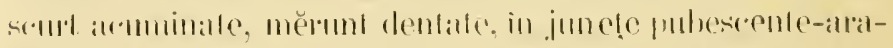

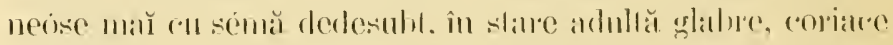

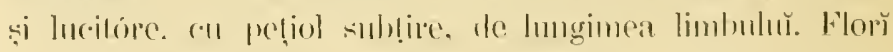

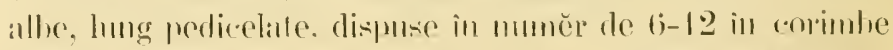

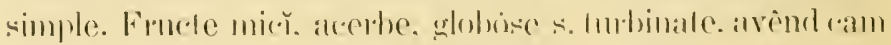

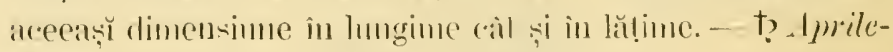
ILair.

Ibit. și stiț. Spontanen̆ și förte comm prin tóte pădurite din România.

Obs. Pěrnt sîtbutic, este specia ce se cousideră ră ar li produs

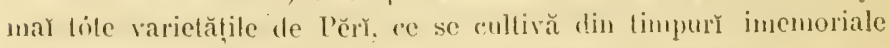
prin grădinı̆. vir și liveç̣̆, 


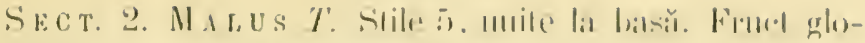

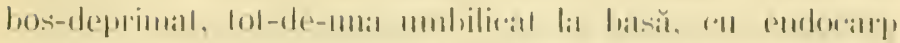

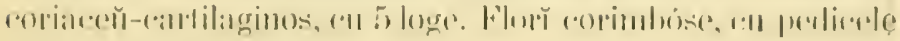
simple. Fimmle simple.

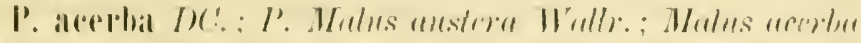

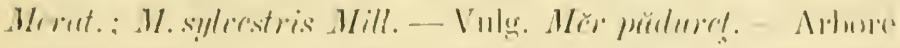

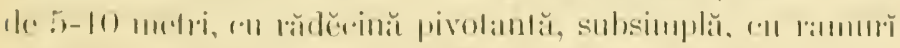

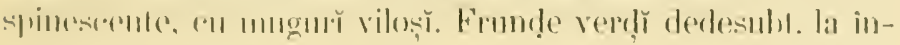

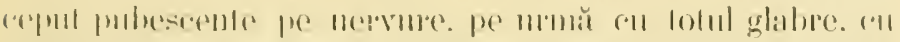

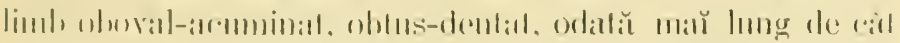

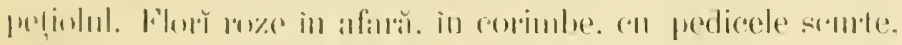

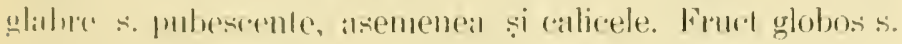

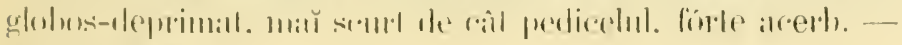

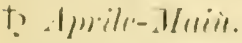

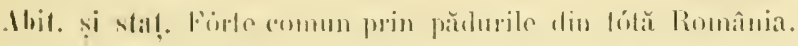

I'. Malus L. I'. Mulus mitis IIralle. : Malues domestira

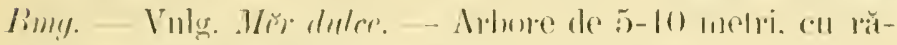

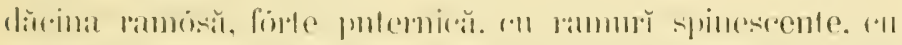

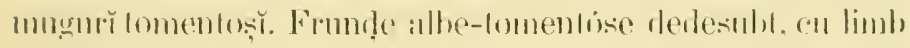

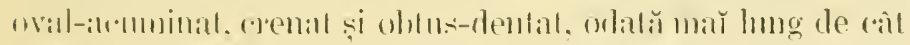

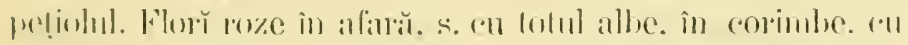

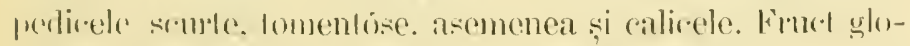
lus $\therefore$ sholous-rleprimal, dulce. 一 t) Amile- Main.

Abit. si state. Cultivat prin tóle viile și lived̦ile din fiomânia.

(J). La acéstă specic se rapórtă tüle varielăţile de Merĭ, ce se

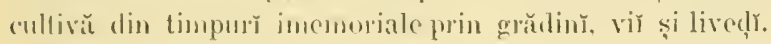

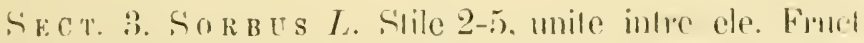

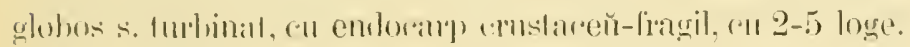

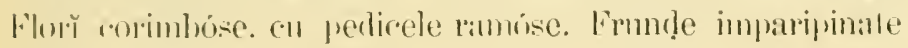
$\therefore$ piniliserele.

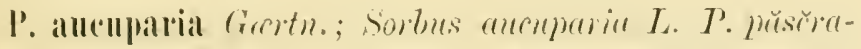

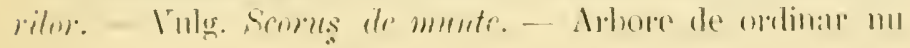

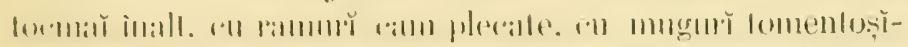

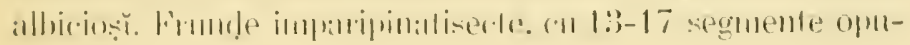


se, sessile, subegate, oblonge-lineare, asculite, serali-rlentate,

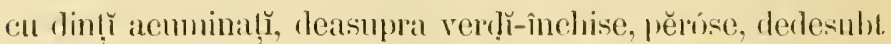
mă palide și mă̌ mult s. mă̌ pụin fomentóse, mă cu sénă

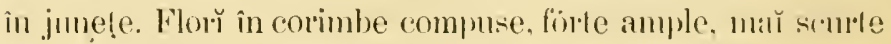
de cill frmdele, pubermle. Sequle crecte, după inllorire inIlexe in:̆ы

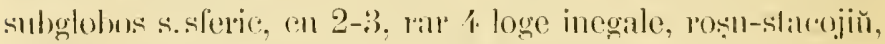

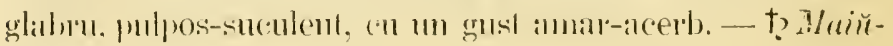
Inniir.

Abit. și staț. Pe stîncile diı pădurile muntóse, mă̌ cu sémă din regiunile subalpine și alpine. - M-țir Cozier (Förfeete, Urzior, Nor-

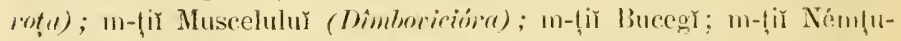

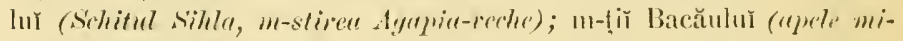
nerale de la starnic); ete.

P. Sorlous Gertu. ; P. domestica Sm.; Somluns domestiru I.

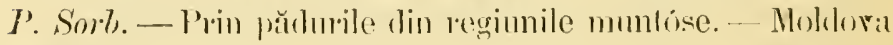
(Eilel, 1. c. 42).

Sect. 亿. TOR

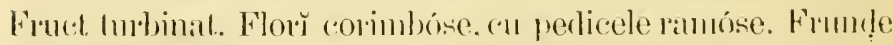
simple, lobale-ingulose.

P. torminalis Ehrh.; S. torminatis Crantaz.; Crataynes torminatis I. P. torminal.-Vulg. Sorb. - Arbore de 10-15)

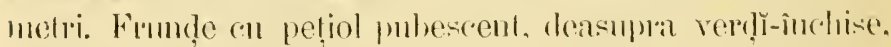

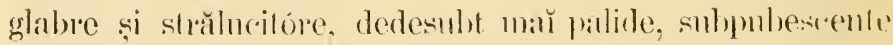
s. glabre, pinalinervale, all nervare fórle putin numeróse

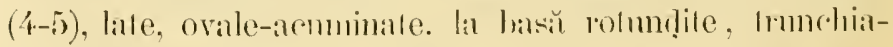

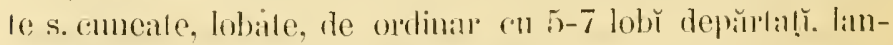

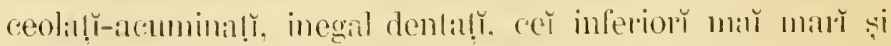

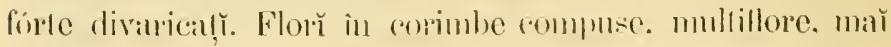

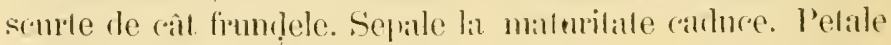

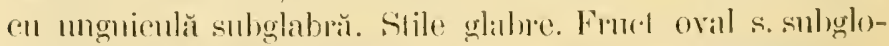

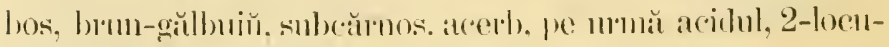
la11. — † Maĭ-Iимій.

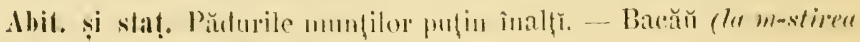
Cuşimulur pe Piscul-stimer); elc. 


\section{('TONA T'. - (intuim.}

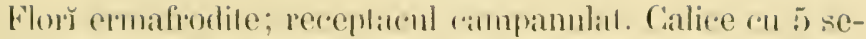

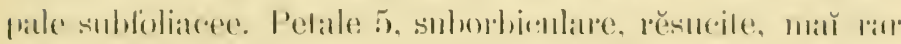

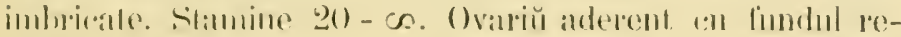

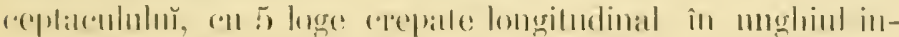
Irro, so-ovulate: ovule 2-seriale vertical, iscendente; sti-

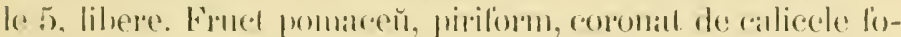

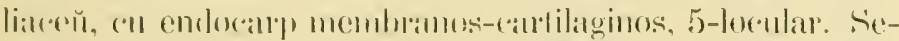
minte ss in lie-cale loge, rll testa pe din afară murilaginos.

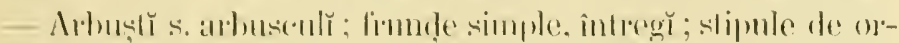

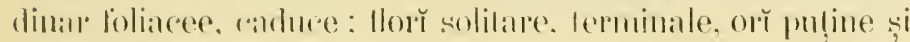
(corimlurse.

1'. vulgaris Pers.; Pyrus Cydonia L. Gr. romm. - Vulg.

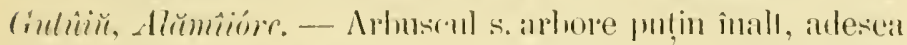
ramos chiar de la bas̆ĭ, ('и mumile linere fomenlóse. Funde sourt petiolate, ovale s. ovale-oblonge, obluse s. asculite.

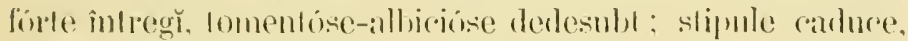
subfoliacee, ovale-ianceolale, înguslale la lats̆, mĕrunt den-

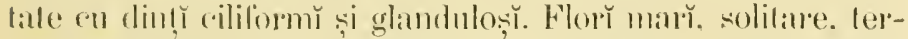
minale, sulseswile. Rereptacul ovoid. Sepale exu marginĭ glandulóse. Pelale alle s. allo-roșiclice. eliptice. emarginate, de

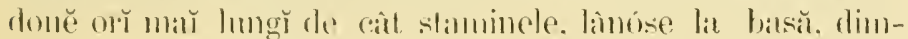

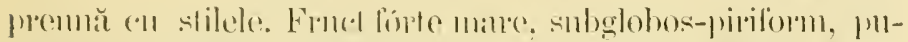
besent-tomentos, gallon. finte solomt. - to dprile-Muir.

Ahit. si stat. Cultivat prin liveḍ și vì din timpur imemoriale, și ('âte-oulatŭ subspontaneŭ prin tufărișurile și pe lângă ingrăditurile d'împrejurul boeninţelor.

\section{CRATAbits T. - Püducel.}

Flory̆ ermafrodile: receplatul ureeolal s. campanulat. Se-

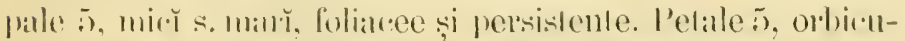

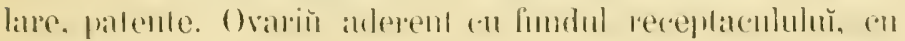

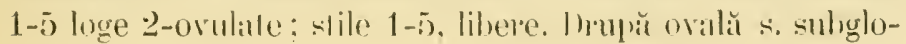


hris̆, roronalĭ de calicele persislent: prene 1-5). osóse. 1-

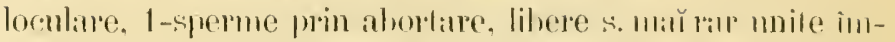

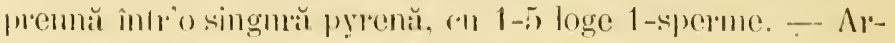

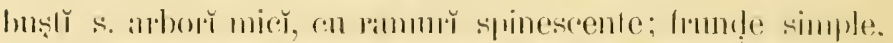

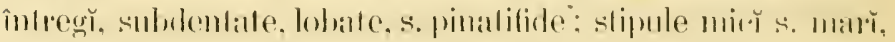

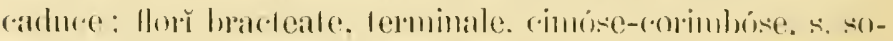
lilane.

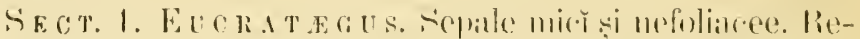

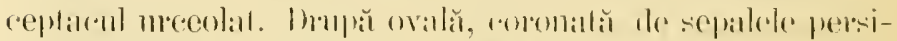

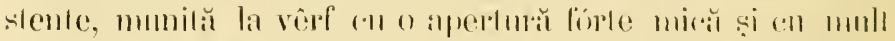

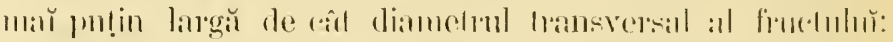

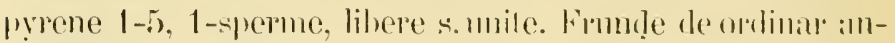
gulate-lobale. Flotř în corimbe lerminale.

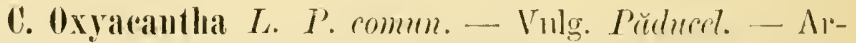

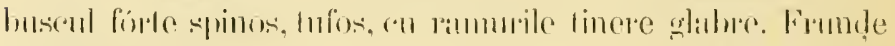

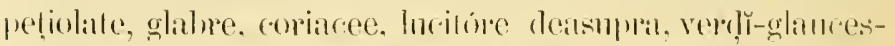
rente derlesubl. olovile-romeiforme. pinalibolnte $\therefore$ pinali-

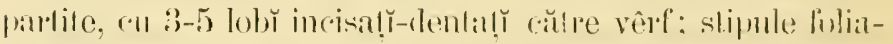

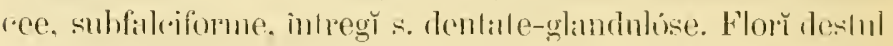
de mič̆, con milos de migrlale amlille, allse s. losielice, in co-

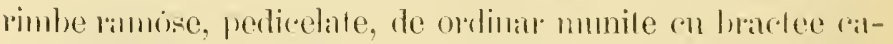
dure; perlicele glahre. Sepale glabse, ovale-acmmimale, linde

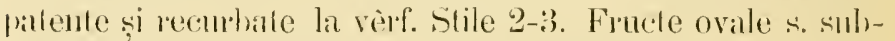

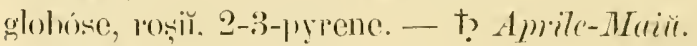

Abit. și staḷ. Marginea pădurilor, tufărișurŭ și crîngur̆, at:ît din reginnea rîmpénă. cît și din cea muntósă. - Tótă Romînia.

6. monogyna Jueq. P. monogym. - bifere de speria prexe-

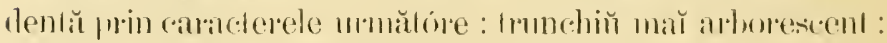

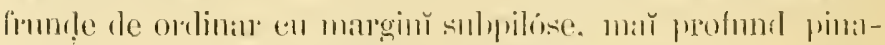

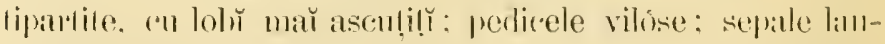

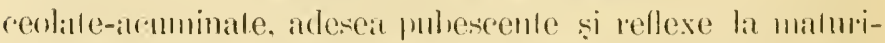

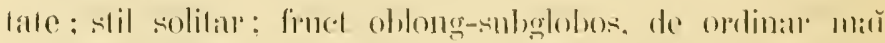

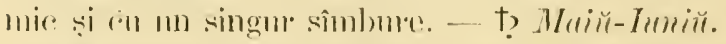

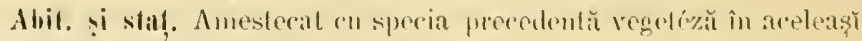
staţiunt. dar cu mult maí commun. 


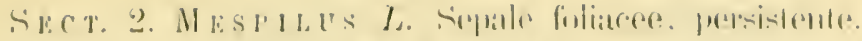

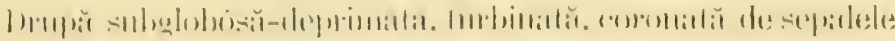

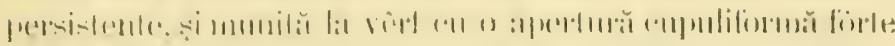

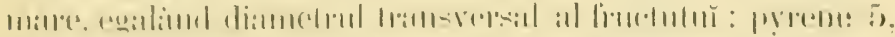

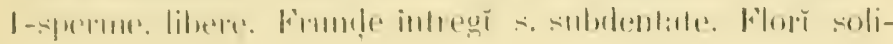
lille.

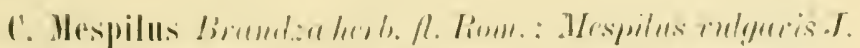

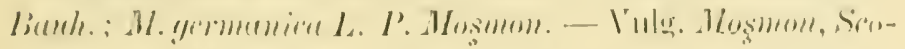

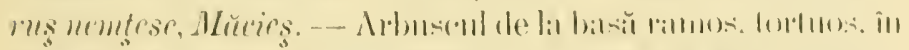

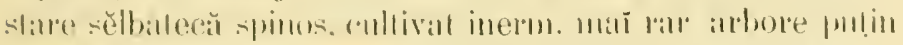

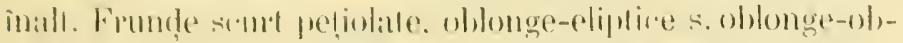

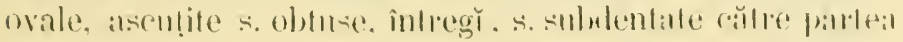

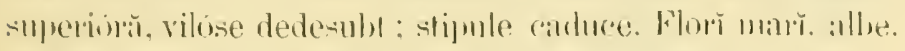

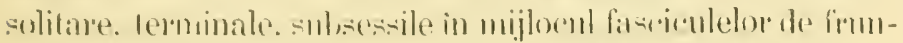

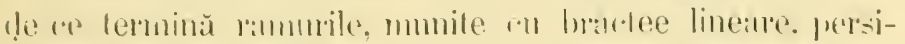

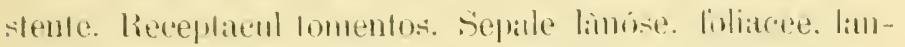

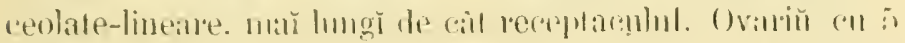

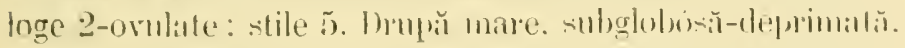

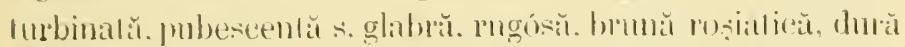

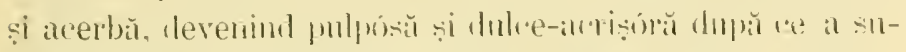

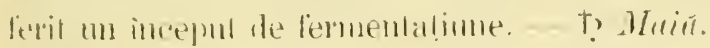

dhit. si vaṭ. Pădurile și turăriṣurile din reginnea muntósă a-

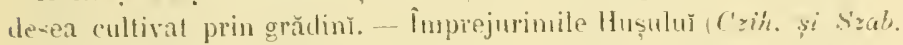
l. c. 26 : Eulpl, l. c. f.: : Fueb. l. c.)

\section{COTOSEANTER Medir. - infomensinen.}

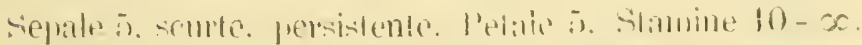

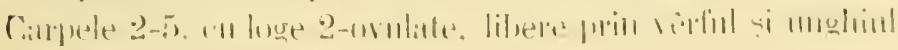

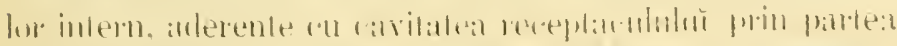

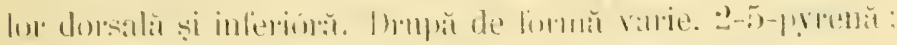

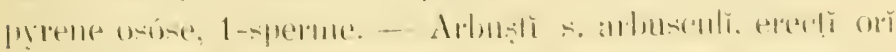

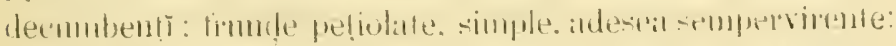

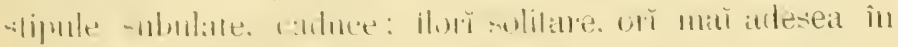

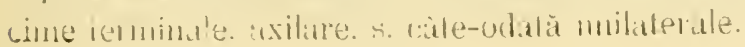


1. vulgaris Lindl.; Irspuilus Cotonenstor I. C.. comnen.--

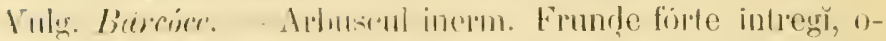

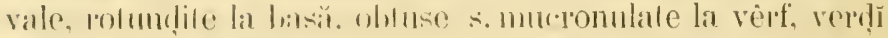

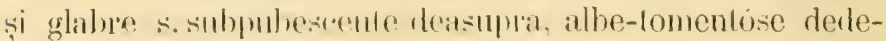
suld, forte somll petiolate. Flor allhe-rosiatice, axilare, solilare, geminate s. ma rar lemate, somt pedicelate, la incepul

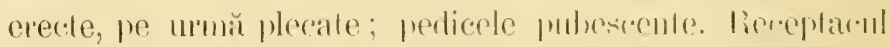

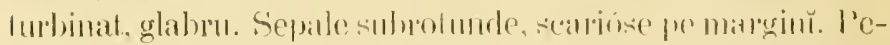

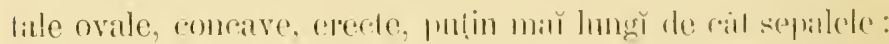

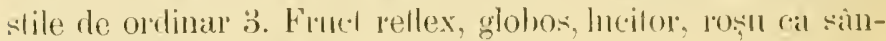
sele, glabru. - t? Muin-Inиiu.

dbit. și staț. L'e stincile de prin pădurile muntóse din regimen

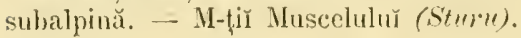

\section{MIELANCHER Medic. - Ametundien.}

Receptacul campanulat s. ureeolat. Callice (en 5) sepale dentiforme. Petale 5, lineare-linceolate. Stamine $\infty$. Ovariŭ mil̆ mult s.mă puṭin adhat cu receptaculul, cu 2-5-loge 2-ovolate, incomplet subdivisate prin despăr!̣inr false in logete 1-ovulate. Fruct sulgglobos, coronal de către dințĭ ea-

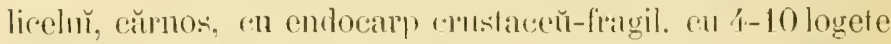

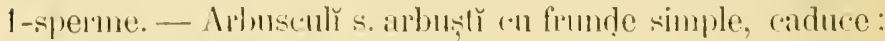
stipule elongale-subulate, s. mič̆, mă̆ zar 0 ; flor'̌ lacemóse $\therefore$ cinóse-raremóse, lirateate.

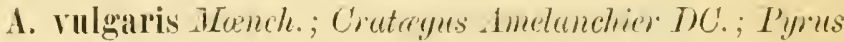

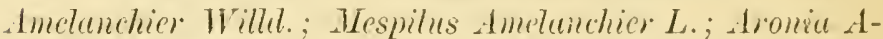
melanchier Tishb. -- Prin crepăturile stincilor din pădurile

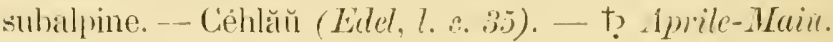

TRIB. 6. PRIUNEE. - Receptacul pulin concav. Carpel maì tol-dé-una solitar, liber', neînchis. Stil inseral pe vêrful ovariulı̆. Ovariŭ 2-ovulal. Ovule colaterale, descendente

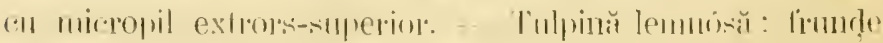
simple. 


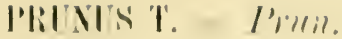

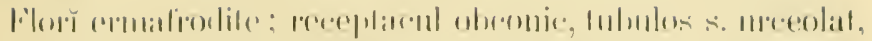

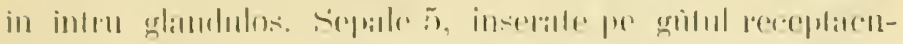

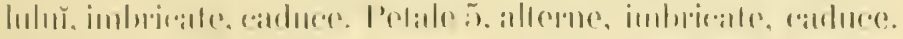

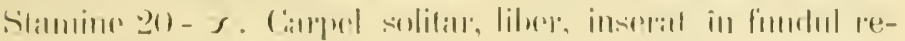

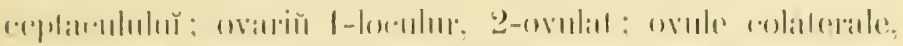

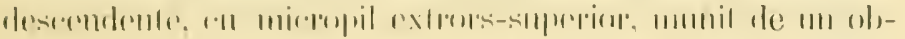

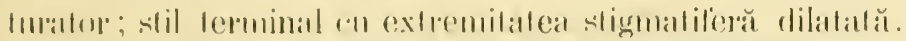

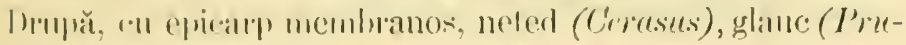

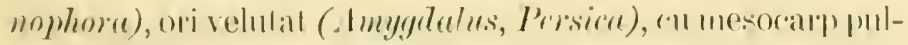
jos $\therefore$ dur (. Im!yyduless) : simbure neled, s. lugos foraminulos

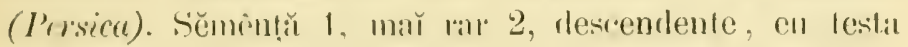

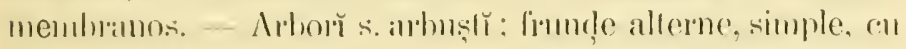

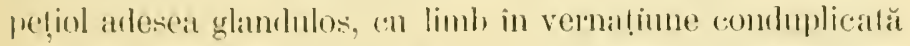
$\therefore$ convolutiltă : slipmle laterale : florı̆ solilare, orı mă adesea (orimbrise s. racemose. născônd inainles. in acelaṣ fimp cu firminele.

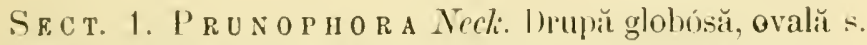
olılongă. glabră, acoperilă cu o ellorescenț̆ cerosă, glancă-

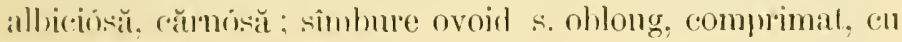

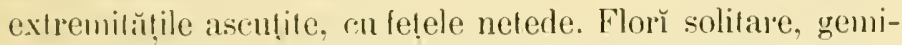
nate, s. umbelate-fasciculate, esind de orlinar din interiorul umı mugure solzos, inainte s. in acelaș̆ limp cu fimmdele: frunde in vernaliune convolulată.

P. domestica L. I'. domestic. - Vulg. l'erj. - Original din Cinncas, se cullivă din timpurí imemoriale prin lived̦ile din lob̆ă România. - t? Aprile.

P. insititia L. I'. altoit. - Vulg. Coolden. - Originar

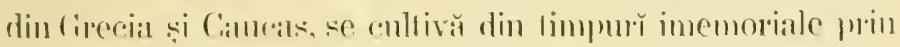

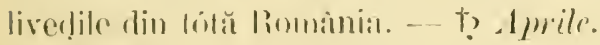

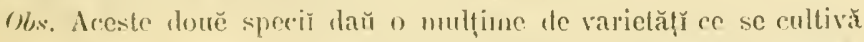

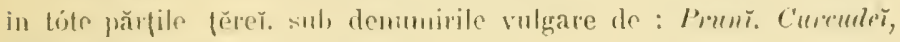

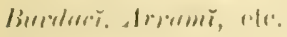




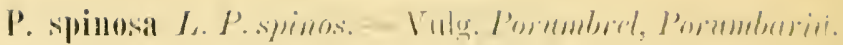

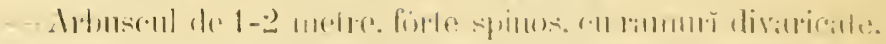

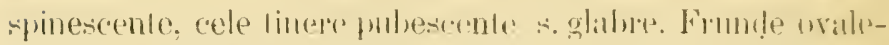

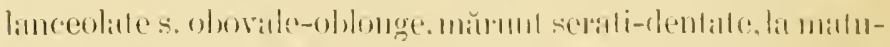

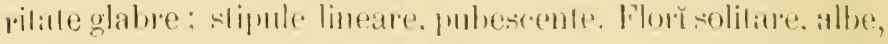

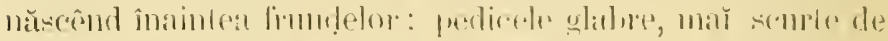

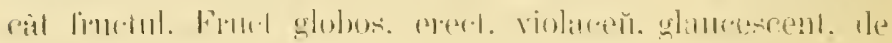

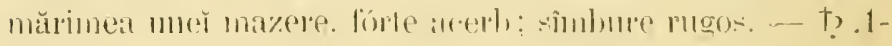
milt.

Alit. și saṭ. Prin lorurile inculte din totă România.

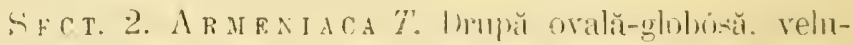
lată. mulpos̆: simbure oval-globos. comprimal. neled. cu marginile sulcate longitudinal. Flor solilane s. puline. sub-

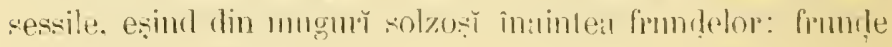
în vernalimute ronvolulalĭ.

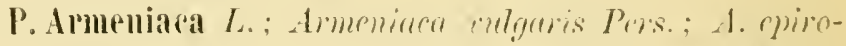

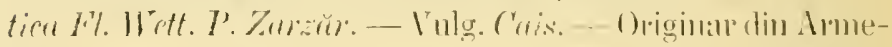

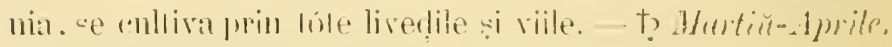

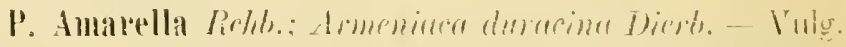

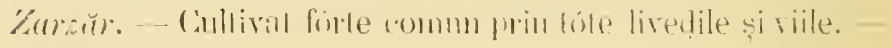

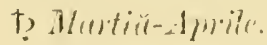

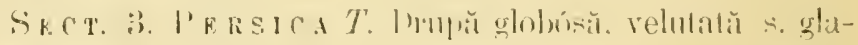

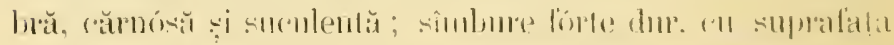

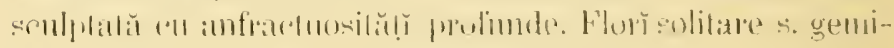

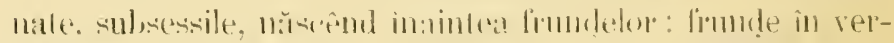
nalimme romelmplicaltat.

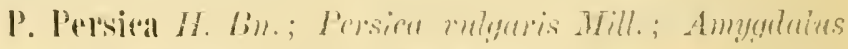

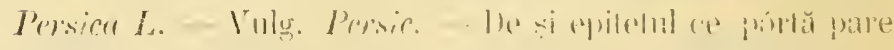

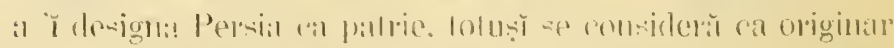

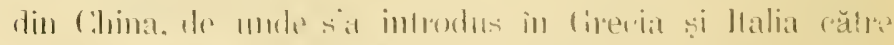

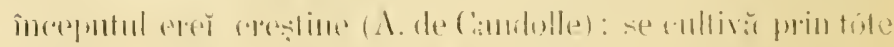

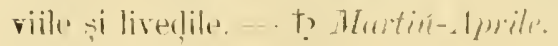

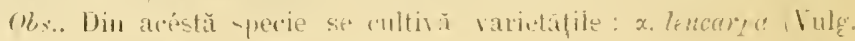

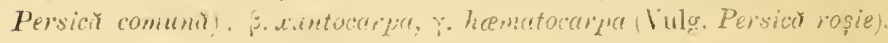

o. lacis (Vuig. Persicr̆ Golaş̆). 


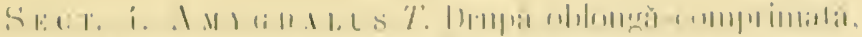

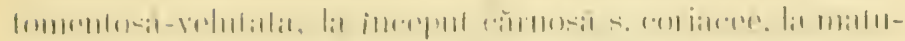

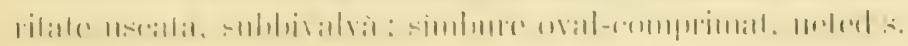

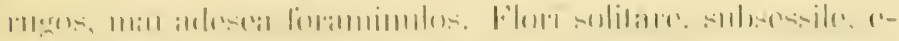

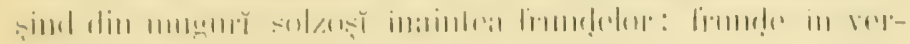

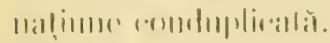

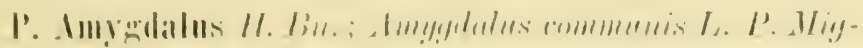

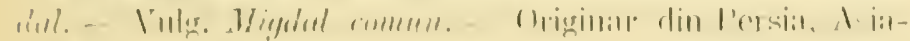

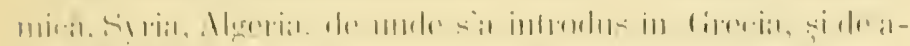

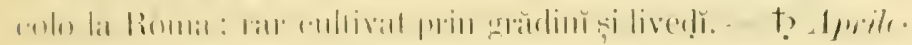

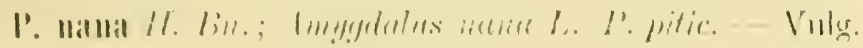

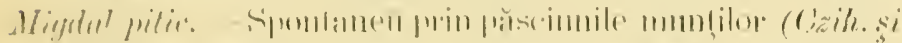

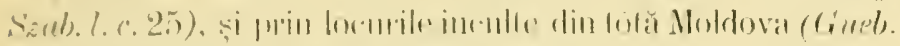

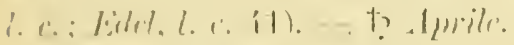

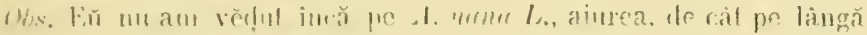

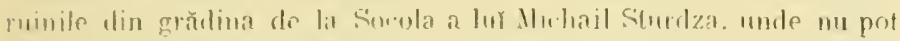

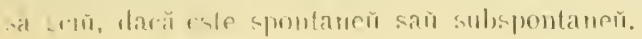

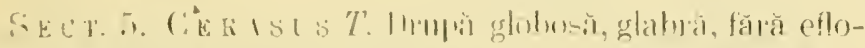

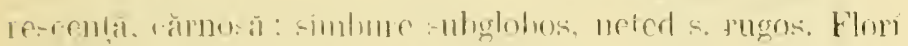

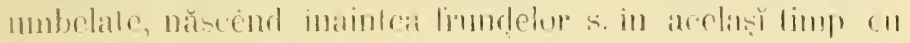

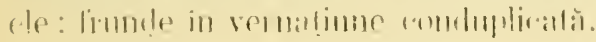

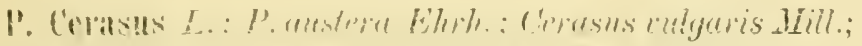

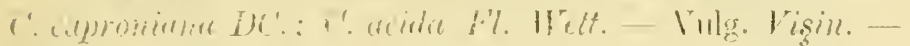

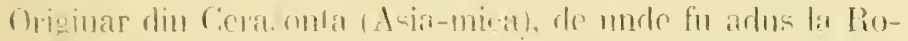

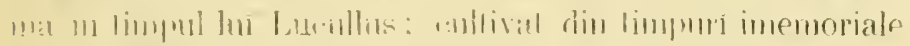

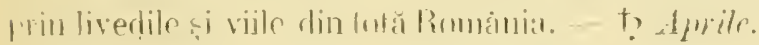

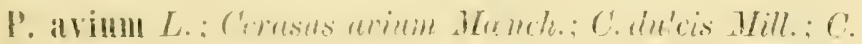

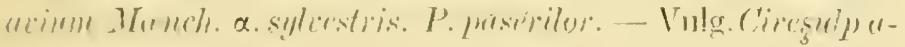

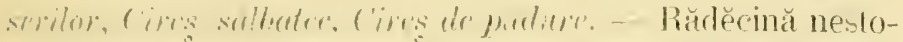

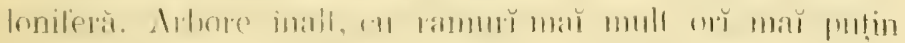

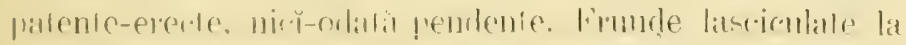

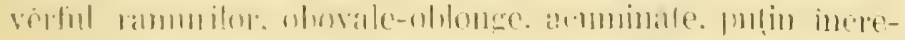

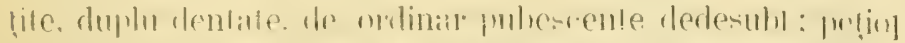

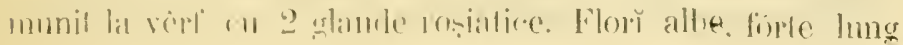




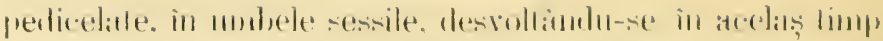

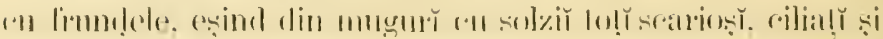

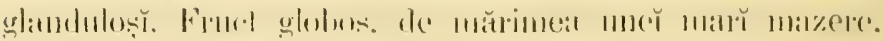

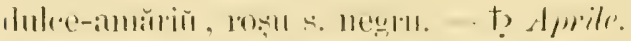

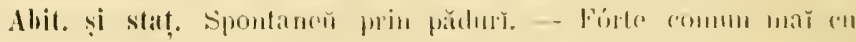

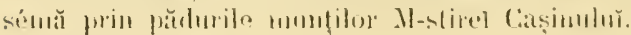

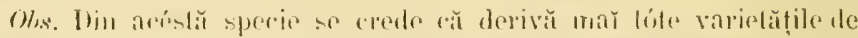

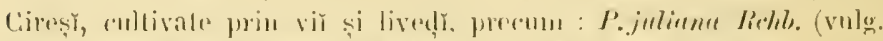

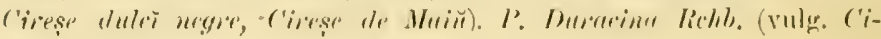
rese-Drotymate): ate.

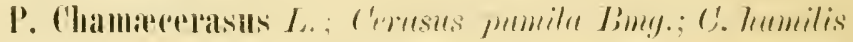

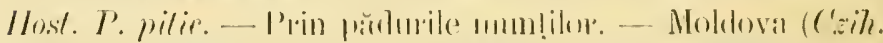
si s.aub., I. r. 2(i). - t? Ipritr-Inir.

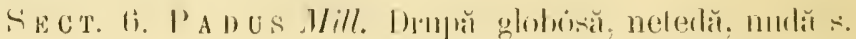

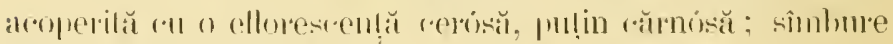

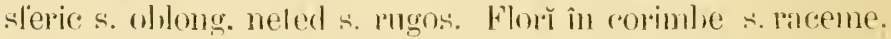

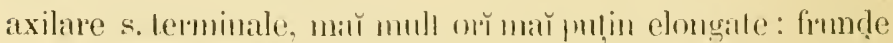

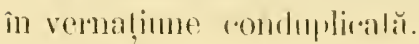

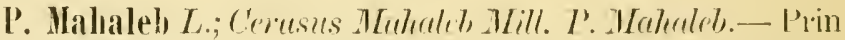
pădmile de prin lormile pelrose. - Baia : Nem!n; Apele mi-

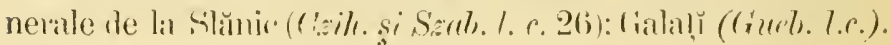
- t? Amilr.

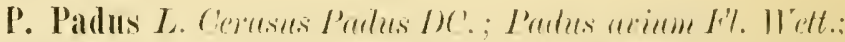
P. enlyuris Ilost. I'. cu strugur. - Vulg. Mulin. - Albore

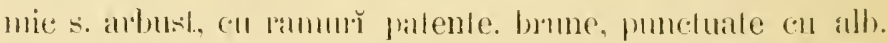
Frunde glalıe, oblonge-ohovale, acominate, mĕrunl denlale,

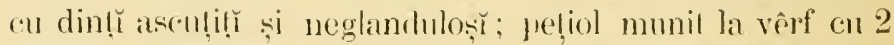
glande. Flor allı . mirosilore, născônol in acelaș̆ timpl cu frund̦ele, in lınğ rareme lalerale, cilindrice, vendente. munile la basă con caile-va fmunde : pedicele. cole mă mulie. persistenle după înflorive. Sepale rolmolite si ciliale-glandulose. Frucl negrı, glohos, de mărimea mner mazere, amall și föle acerb. - †, Maili.

Abit. și staţ. Pădurile umede din reģimea muntós̆. Cultisat adesea prin parcurı și grădiñ. 


\section{PAPIIONACEL}

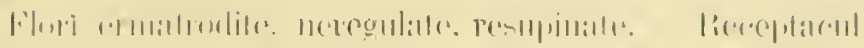

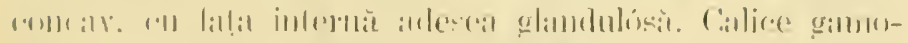

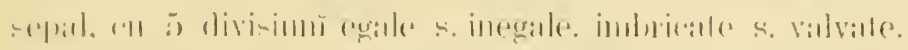

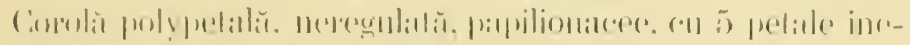

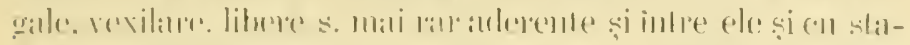

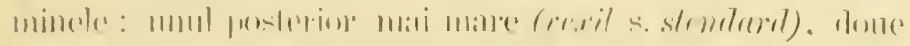

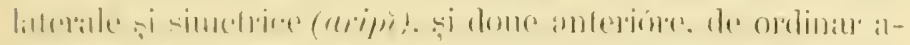

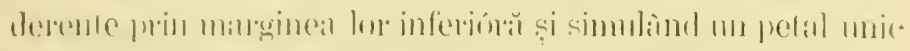

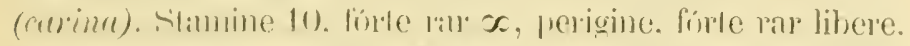

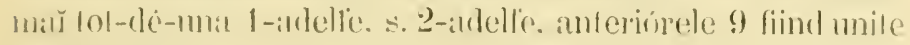

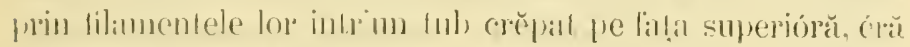

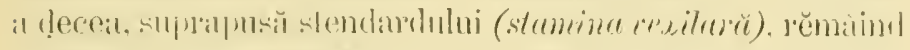

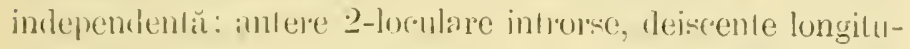

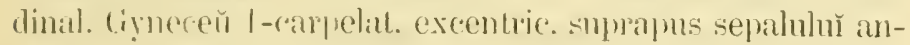
terior: ovaliŭ liber. I-locular, cu platcenla parietal suprapus

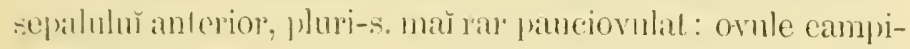

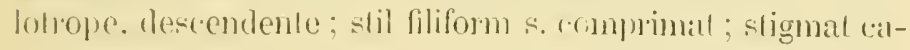

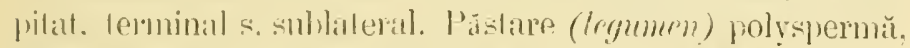

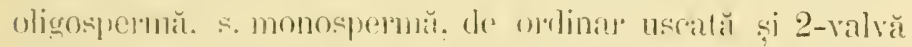
la malurilate fơle râ indeiscentă şi subcărnosă. càle-odată lomenlacee, și divisală prin gùluitur lransversale în may̆ multe logetr. re se seprură la maturitale in arliculi 1-spelmŭ

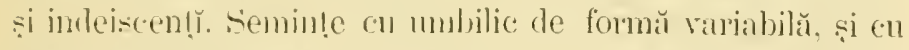

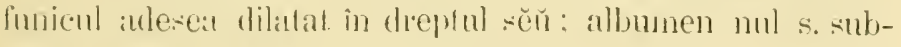
mul: embrion embat. cu radicula fórte rar reclilinie, mă lut-

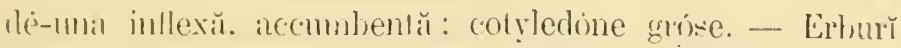

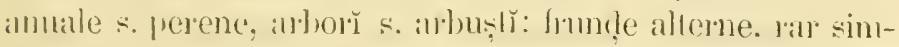

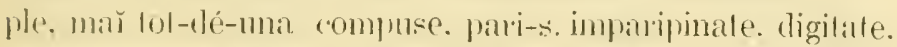

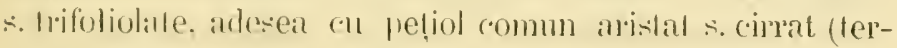

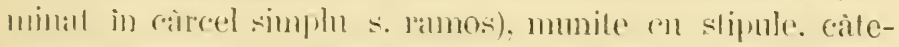
ullalĭ și roll slipele: flor lomminale, axilalle. s. Jillerale. rar

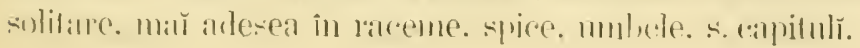




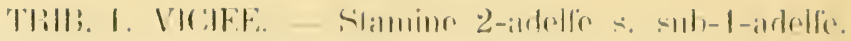

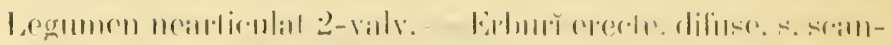

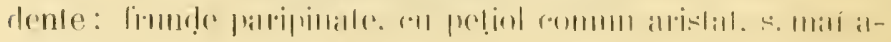

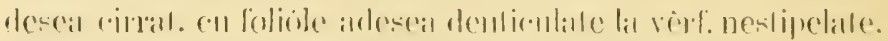

\section{VII'le T. Tirin.}

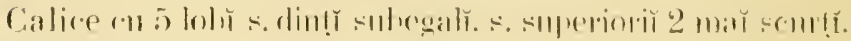

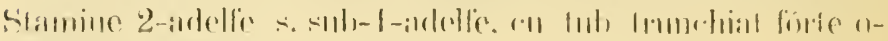

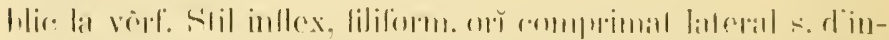

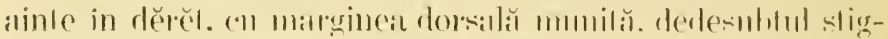

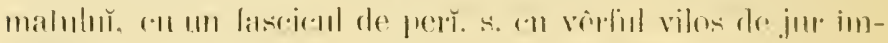

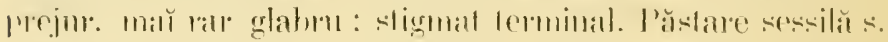

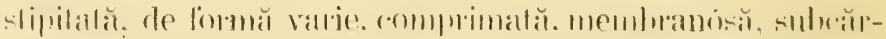

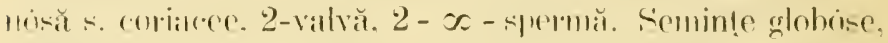

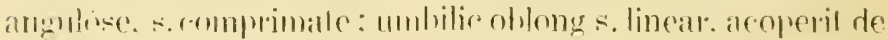

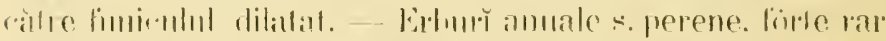

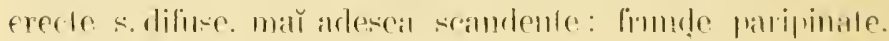

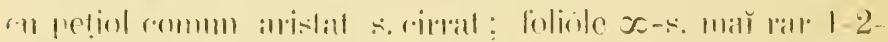

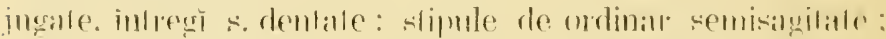

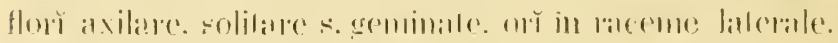

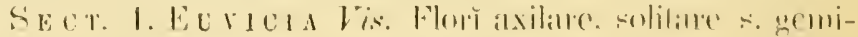

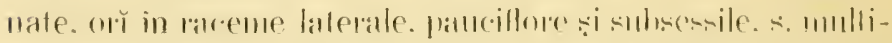

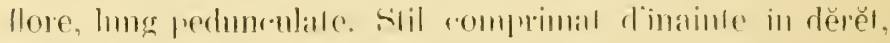

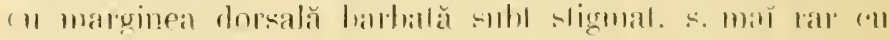

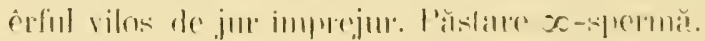

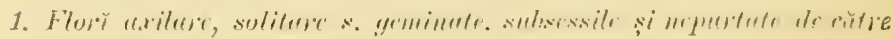

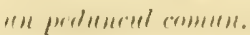

" I'üslare sessilü: caliet regulat.

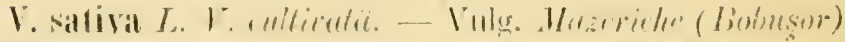

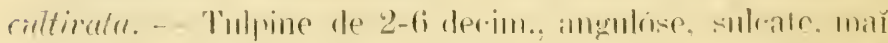

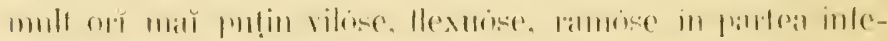

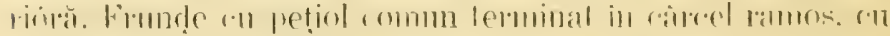

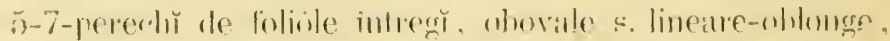

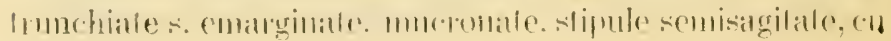




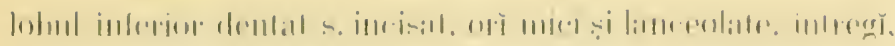

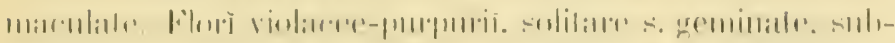

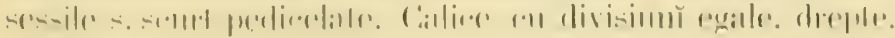

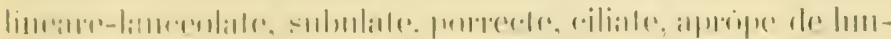

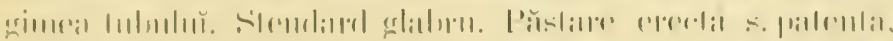

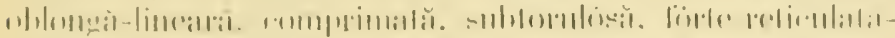

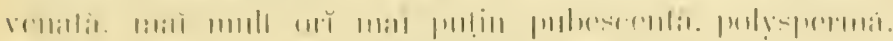

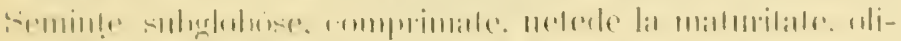

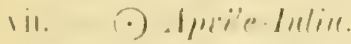

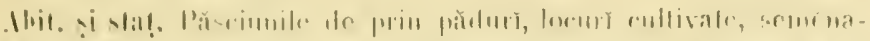

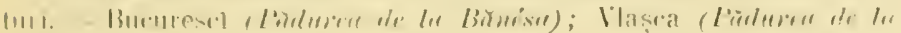

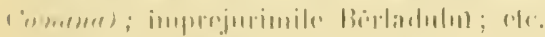

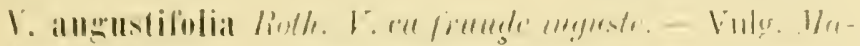

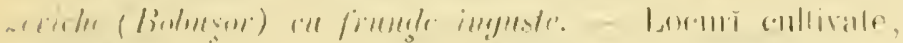

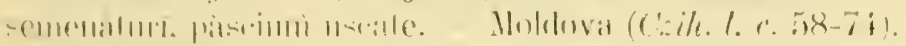
- (•) Ifriig-Iulite

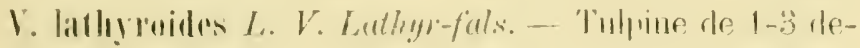

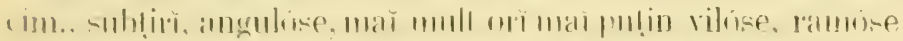

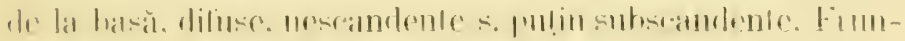

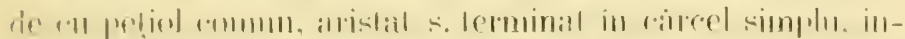

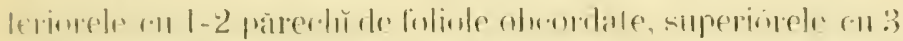

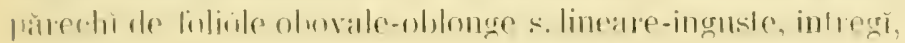

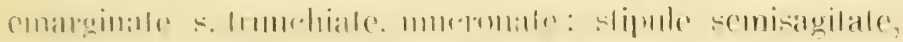

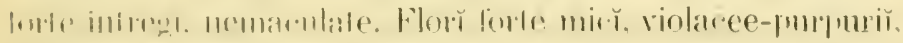

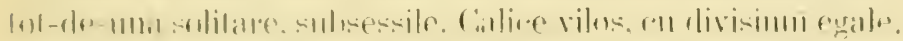

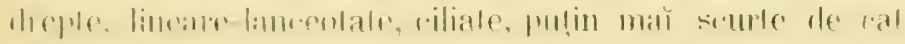

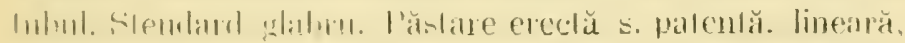

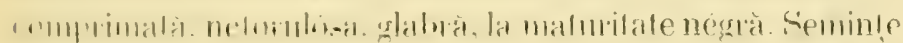

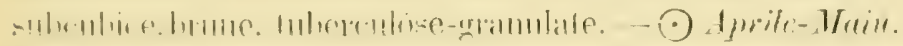

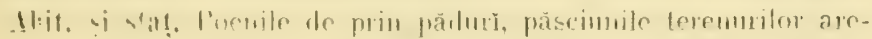

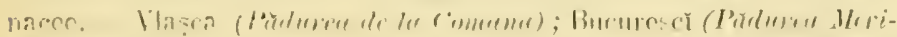
(16)1): $r(x)$

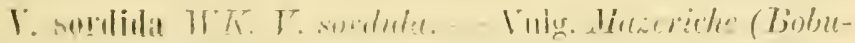

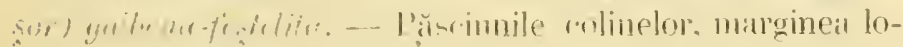

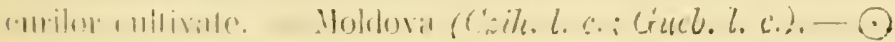
H.Iin-toliti. 


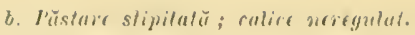

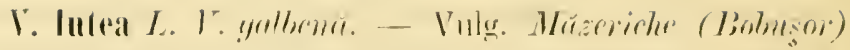
yullume. - P'rin loxmrile collivale și pre marginea semĕnă-

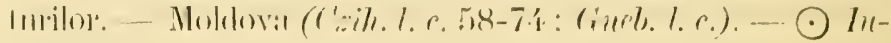
miir-Julir.

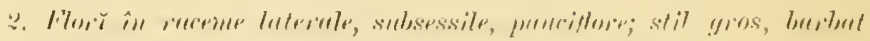
sullit sligymul.

1. Pristllite sessiliu

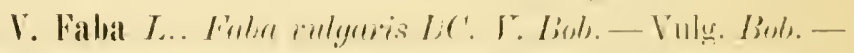
Finte comm coltival in ritmp ș prin grădinede de legume.(.) Inniй-גugmst.

1. Pisture stipilutü.

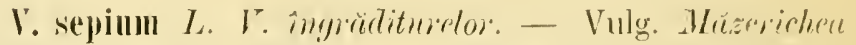
(Bobnegor) ingruditurelor. - Rizom ramos, cu stolóne filiforme, roșietice. Tulpine de:3-9 decim., scandente, flexmóse. angulose-sulcale, puțin pubescente s. subglabre. Frundie en petiol comm terminat in cârcel ramos, cu 5-8 părechĭ de folióle decrescente de la basă la vêrff, alterne s. suboposite. sulppețolulate, ovale-ohlonge. trunchiatc orĭ emarginate, s. ovale-lanceolate si suhasculite, mucronate. ciliate: stipule remisagilale. alcutidentale, adesea maculate. Florĭ sordideviolacee, cu viniçore purpmir. palente orizontal, in racem 2-5)flor. c'll peduncul commu förte scurt, şi cu mutt maĭ scurt de 'ât frund̦a. Calire perros, cu dinţĭ. cu mult mă scurṭ̆ de cât

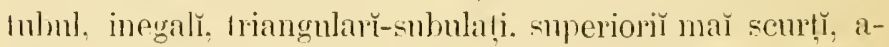
scendenț̆-convergen!̣̆. Stendard glabru. Păstare erectă \&. reflexă. oblongă, comprimată, glal, r̆. nelenh̆. négră la maInritate: umbilic linear, egalund donč treimu din circumfelințit sinnint ĕ. - St Maĭ-Lmin.

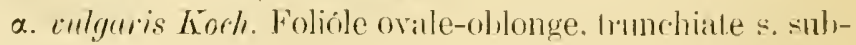
emarginate.

P. montance Loch. Folicile ovale-lanceolate. subasculile.

Abit. și staţ. Pădurite crbóse, lufărişurr. îngrăditurǐ. - Var $x$. Bu-

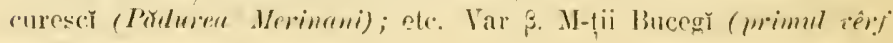
al Funicei); etr. 


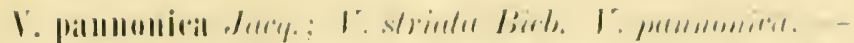

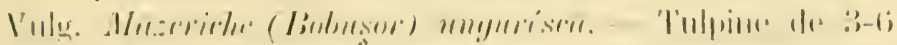

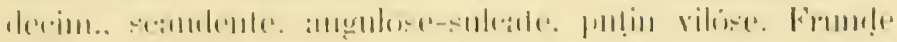

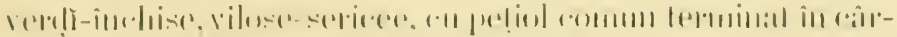

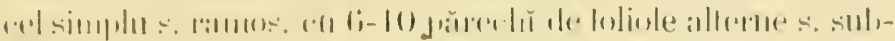

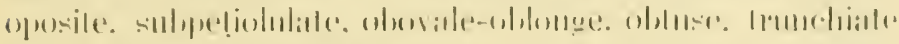

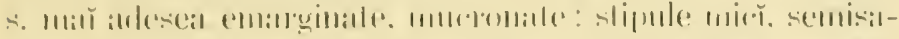

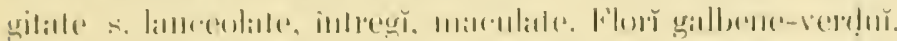

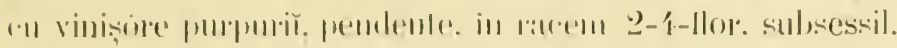

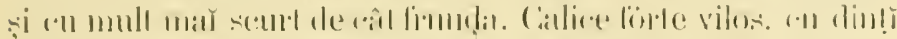

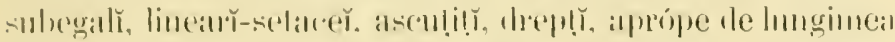

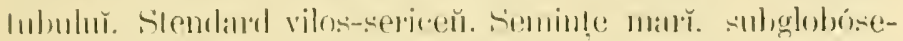

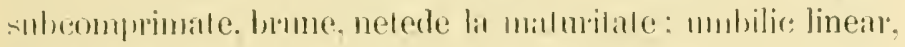

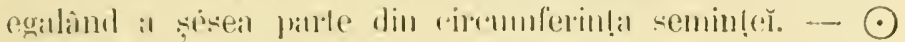
Illin-Iulin.

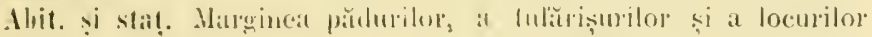

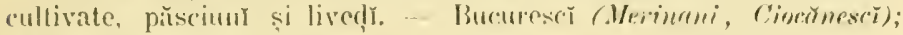
Vlașea (Comururu); Bêrlad; ele.

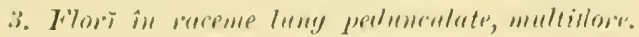
1. Stit yros, brevbint subt stigmul.

V.dumetormm L. V. tufurisurilor. - Vulg. Masericheu (Bobusun) tufurvisuvilor. - 'Tulpină scandentă. de 10-15 recim. lonte angulós̆ă, sulnalală, glabă. Frund̦e terminale

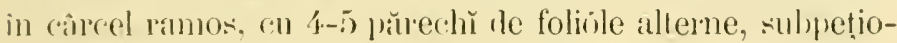
lulate, ovale-lanceolate. ohuse, mucronate. reticulate-venaเe. mĕrunt ciliate pe marginǔ : slijule semilunare inciratemullidentale, aplicale. Florĭ purpurĭ. pe mmă gallbene-sordide. patente. in raceme laxe, 3-7-flore, ererte-patente, cu peduncul de lungimea frunțer̆ s. mă lung. Calice coll dinț

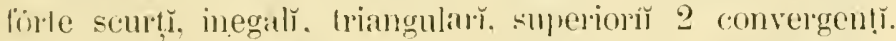
silendard glabru. Păsıre comprimală. oblongă. mĕrunt leli'nlată-venată. glabŭ. Seminte globŕse, negriciose: umbilic linear, egalinnd donĕ treimŭ din circunferința seminṭĕ. - Immin-Lulin.

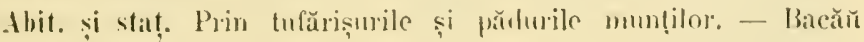
(Iongescir-de-jos); ete. 


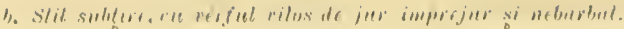

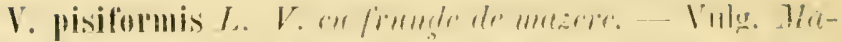

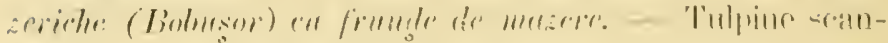

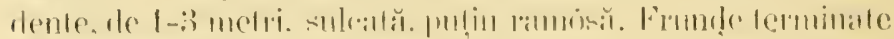

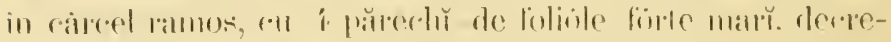

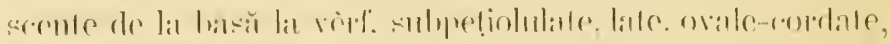

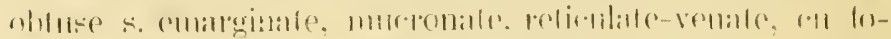

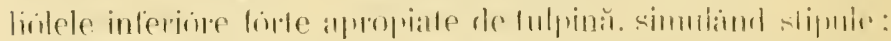

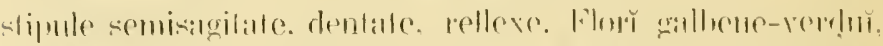

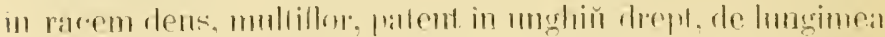

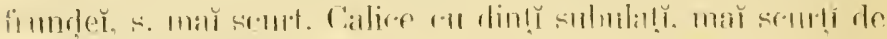

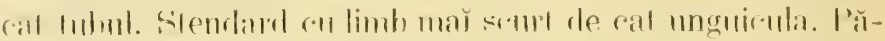

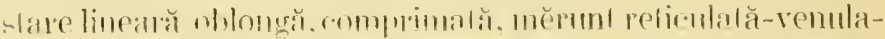

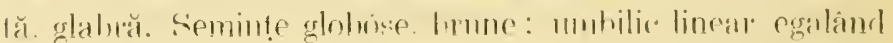

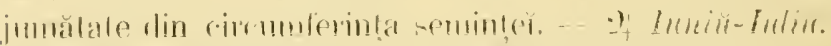

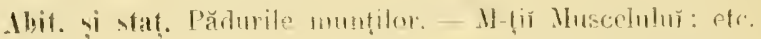

V. sylvatiea L. 1. di pature -- ling. Wrewirhe (Bo-

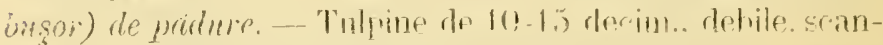

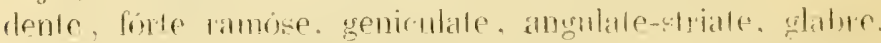

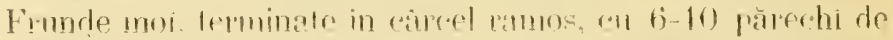

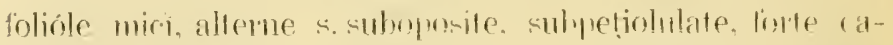

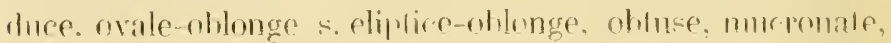

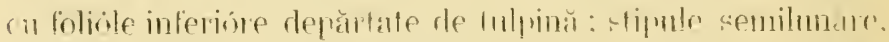

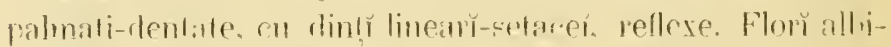

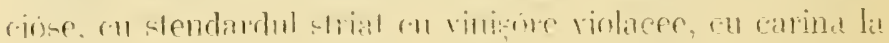

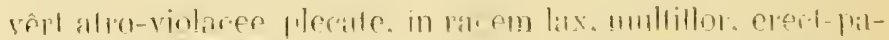

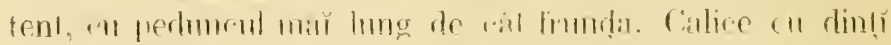

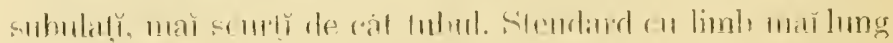

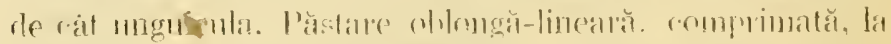

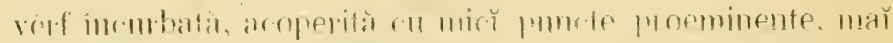
lat pubescente in jurctĭ incgrindu-se la mafuritate. Se-

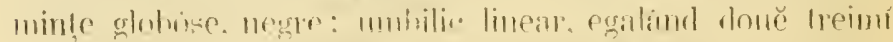

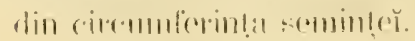

9) Jurniar-Lelize.

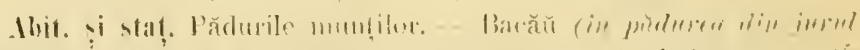

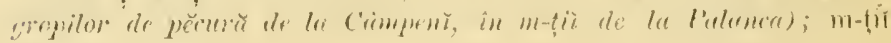
Muscolubur: fle. 


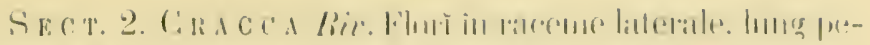

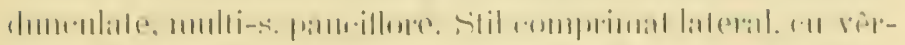

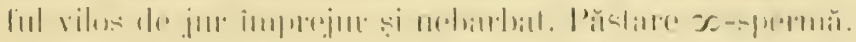

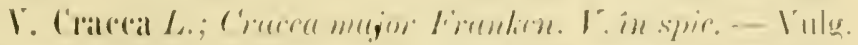

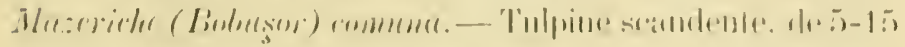

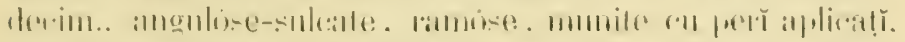

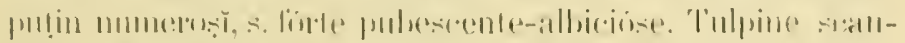

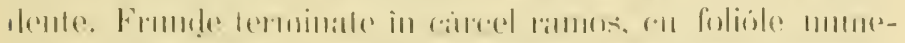

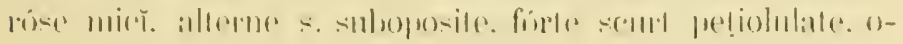

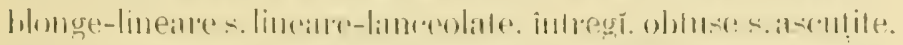

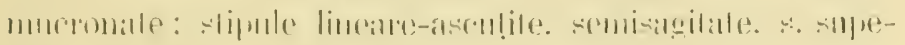

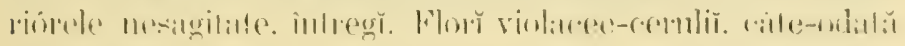

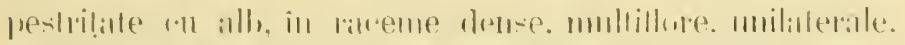

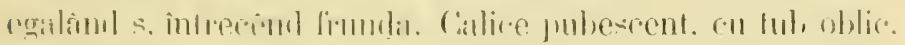

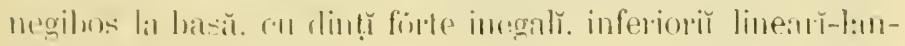

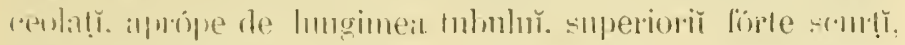

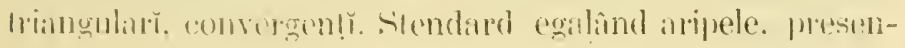

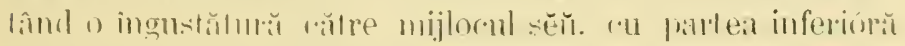

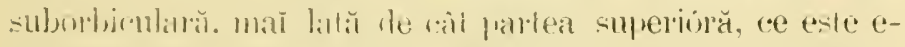

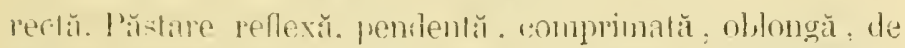

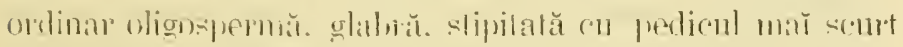
de rat ubul aliremi. Seminle glohise. negre. nelede lis ma-

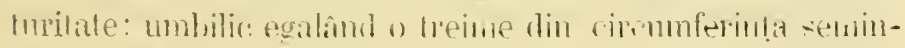

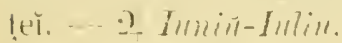

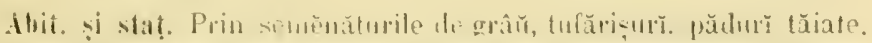

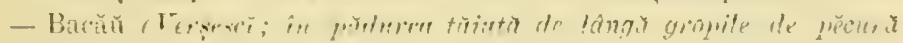

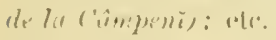

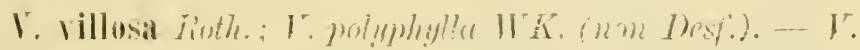

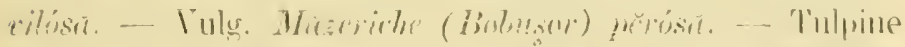

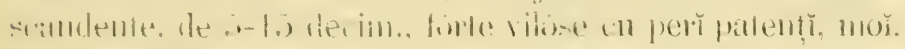

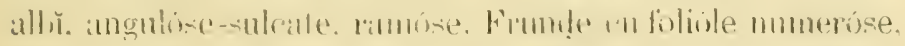
mir

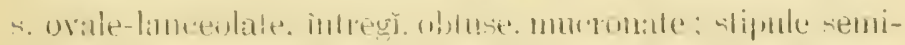
agitate, orile-lancenlate. asulle, nervale, intrewi. Flor violacee-ceruliĭ. ru aripile alhe. în rareme multiflot'e. uni- 


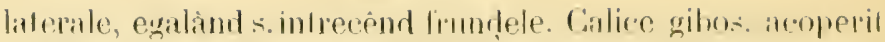

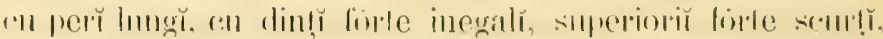

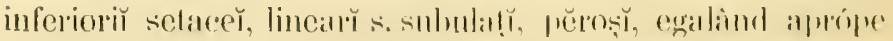

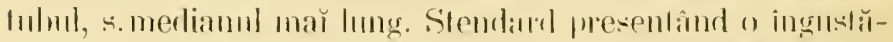

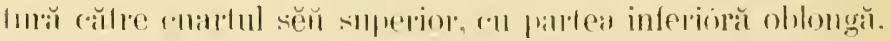

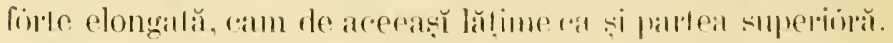

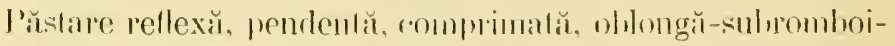

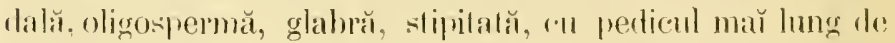
rit mbul raliceluu. Seminle subglobrise, brune, glislue, ncterle la malmila!e; mmbilic egaland a opla parte din ril-

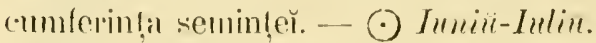

Alit. și staṭ. Semĕnăturŭ de grâŭ, păsciunr mutóse. - Kacăı̆ (Verseser); ete.

Ols. Cizihak (I. I. 58-7-1.). Guebhard (I. c.) și U. Hoffinamm (momusce.), indică in România. primul, pe $\mathbf{V}$. pollyphylla fără nume de

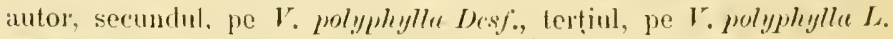

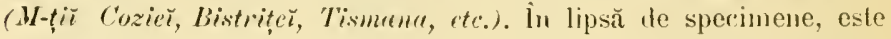
cu neputință de a se putea spuse, dacă planta autorilor acestora

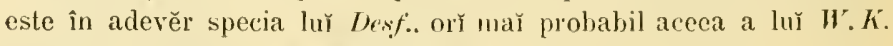
ce este sinonimă cu $r$. vilosa Roth.

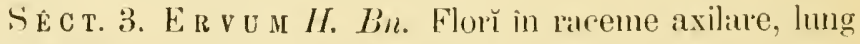
pedunculale, pauciflore, dâte-odală reduse numal̆ la 1-2 Horr. Stil subţire. pmṭin comprrinal d'inainte în dĕrět. cu vêrfiıl pubescent de jü imprejur, și nebarlıat. Păstare 2-6ispermiă.

V. tetrasperma Hench.; Errum tetraspermum I. V. cu patru seminte. - Vuls. Măspriche (Bobusor) en patrll seminte. - Tulpine de :3-8 decim., cespritise, sublirr. muhescente s. subglalme, scandente, rumse. Frunde lemmale

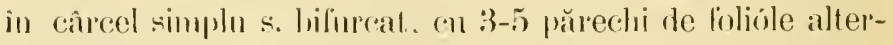
ne s.suboposile, subpeliolulale, linearc-olulonge, obluse, mueronale, sericee; stijule semisigilale, ascuḷile, intreğ. lilor

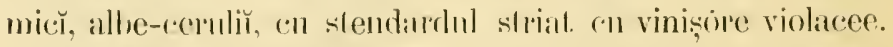

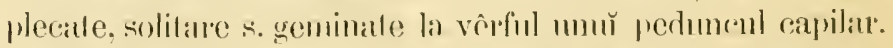

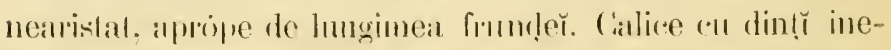

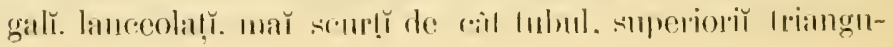




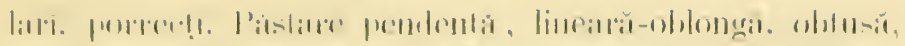

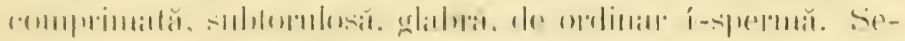

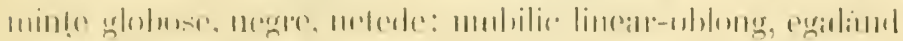

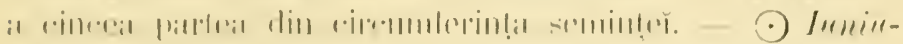
Inlill.

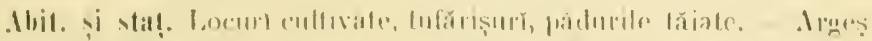

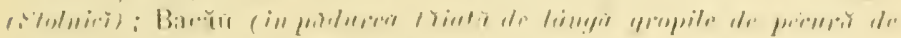

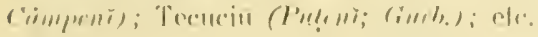

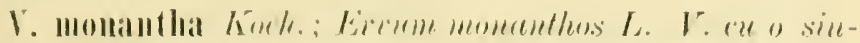

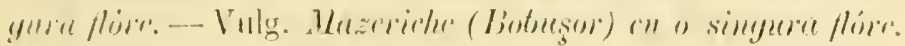

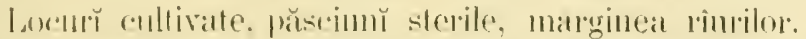

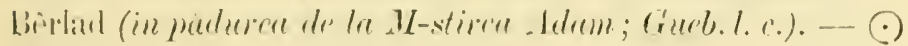
Inin-Iulin.

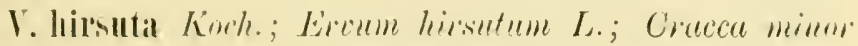

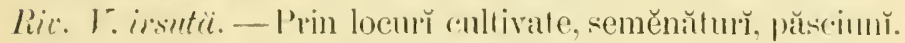

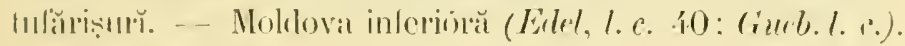
- Print-Inlin.

\section{LENS T. - Linte.}

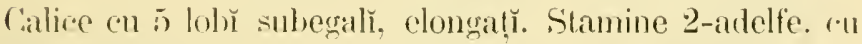
tubul trum hiat lórte ofslic la vêrf. Stil subtire. inflex. comuflimat d'inainte în děrĕf, munit pe lața josterióră c.u o linie longitudinală de perı̆, glabı pe fața anterióră: stigmal. telminal. Păstale stipitată s. subsessilă. comprimată. scurlă. 1-2-spermă. 2-valvă. Seminte lenticulare, comprimale : umbilic oval s. oblong, acoperil. de călpe funiculul dilatat. Elbur erecte s. subscandente : frunde paripinate, cu peḷiolnt comun aristat s. cirlal: stipule membramo-ce, semisagitate. ascuṭite la basă flor solilares. în raceme pancillore spmrin̆ axilare.

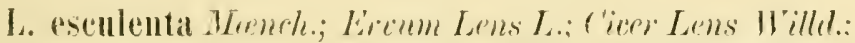

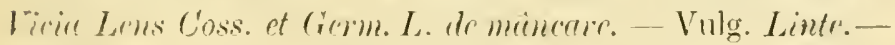

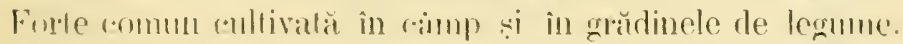

- Innin-Inlin. 


\section{LATHYRIS T. Lathys.}

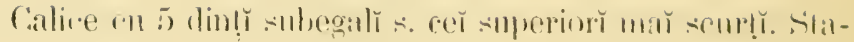

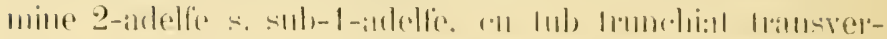

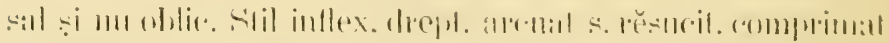

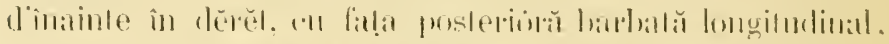

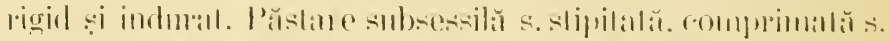

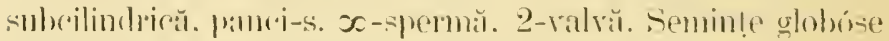

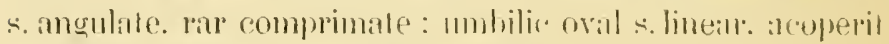

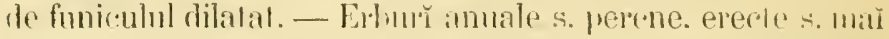

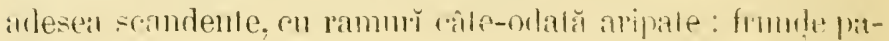
ripinale, 2 - sc-jugate, ru lob folinlete foliacee ((),olurs). s. cu cele superine cirriforme; peliol romm angulat. s. m:14 1:11" dilatat-filorlinal: stipule foliacee, savitales. semiangilale. 1"ill

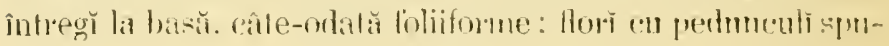
เiŭ axiları̌. $1-x-$ flor , :

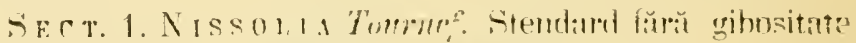

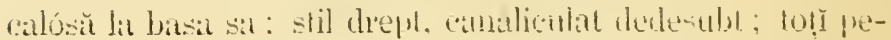

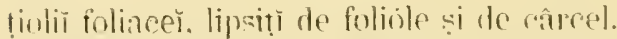

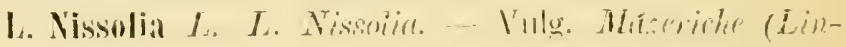

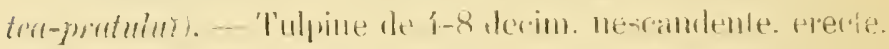

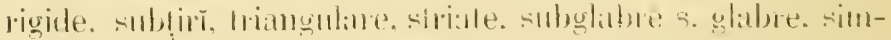

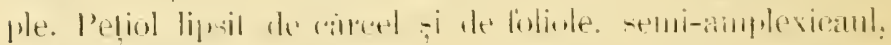

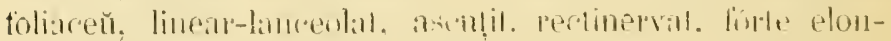

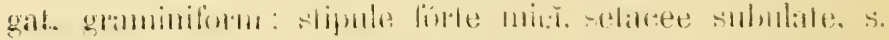
sul,

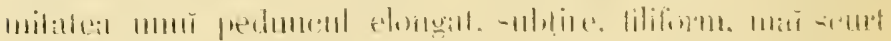

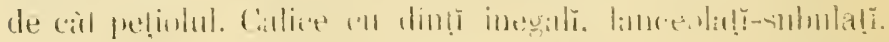

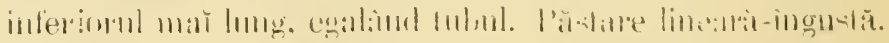

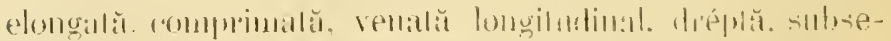

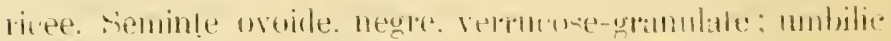

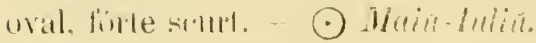

thit. si staț. Seménătury. locurr cullisate pienile de prin -păduri ci prin pădmile tăiate. - Viaces (1mana); Arges (Stolizici); Bacăŭ (Campenti); ctu. 


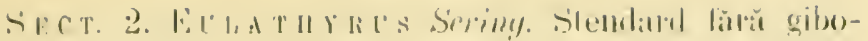

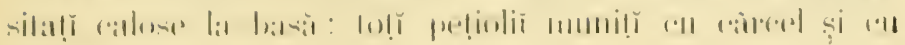
linliislu.

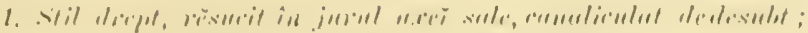

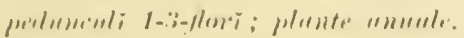

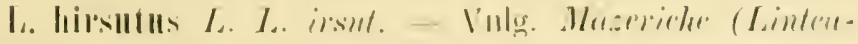

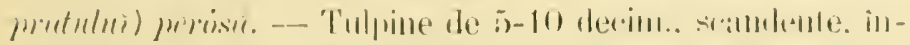

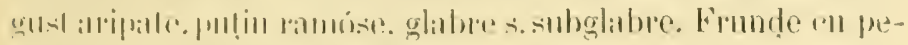

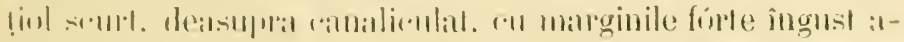

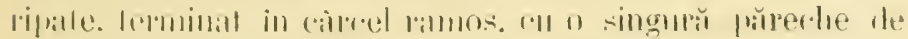

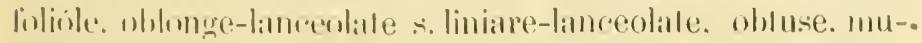

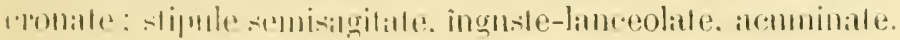

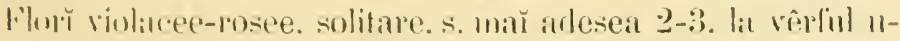
mui pedumrul forre elongat. elect-patent. de 2-:3 orĭ maı̆ lımg

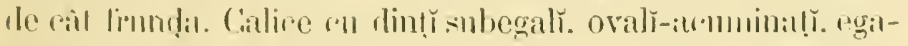

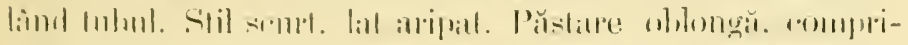

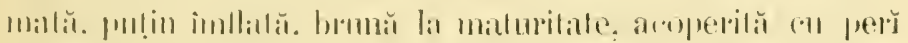

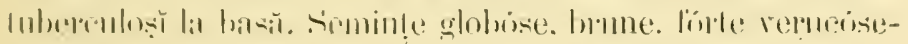

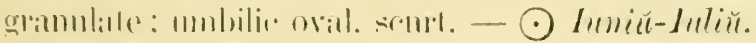

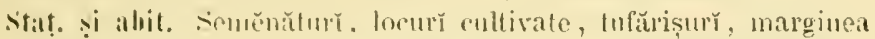

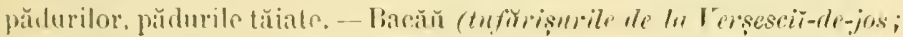

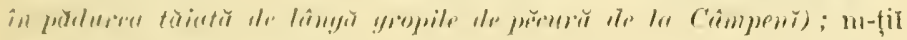
Musceluluĭ: elı.

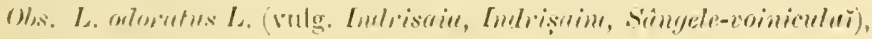

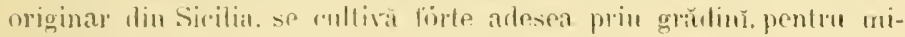
rnsul florilor sale.

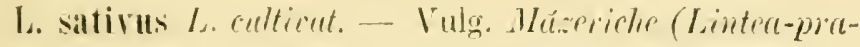

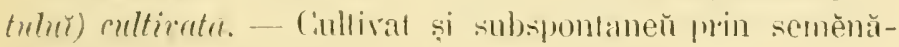

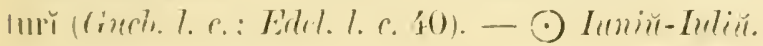

2. Stil arent-rascudent, ressucit in jurvel ares sale, tubulos lu imiilor: pertuneuli multiflori; plente perene.

L. sylvestris $L$. L. de pridure - Vulg. Mrăariche (I.intra-pmatulur) st pridure. - Tulpine de 1-2 metri. scandente. lat aripate. glabre. Frmote rol peliol lal aripal. lemminale in cûrcel ramos; cu v singură păreche de folicile elongate, 
ingmsle-lanceolate, obtuse, mmeronale. B-nervale : stipmle somisagitale. linearc-lamreolate. r.n ambicule lineare. elon-

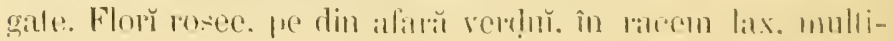

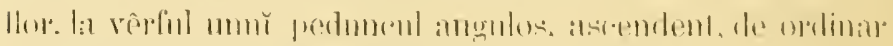

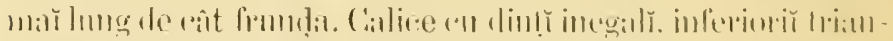

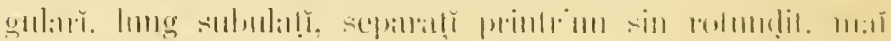

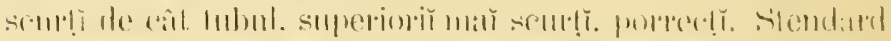

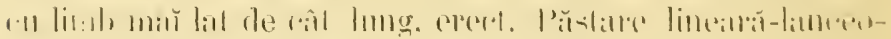

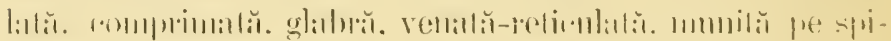

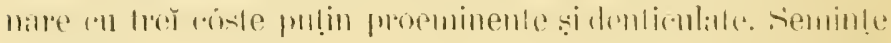

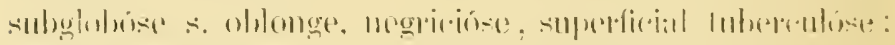

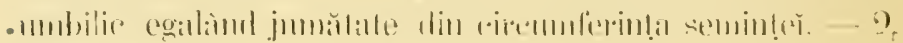
Imniri-Iuliu.

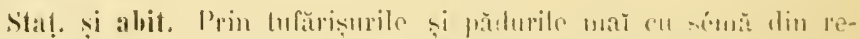

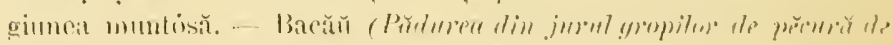

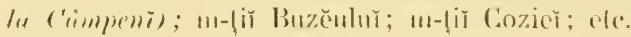

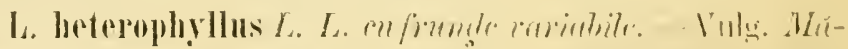

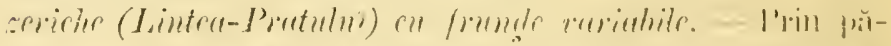

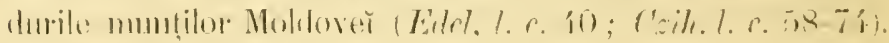
$\therefore$ Immiit-Inliir.

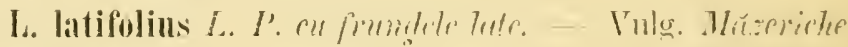

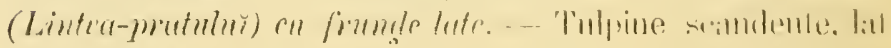

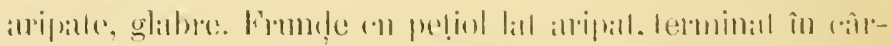

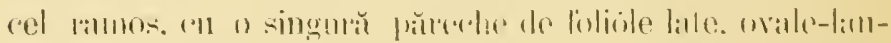

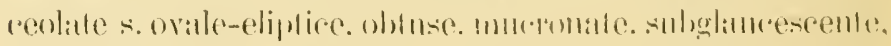

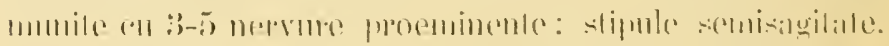

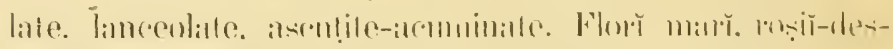

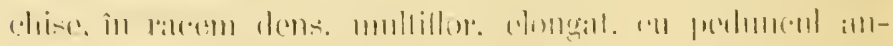

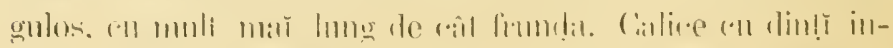

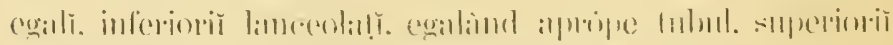

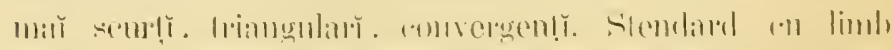

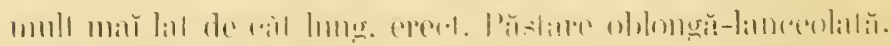

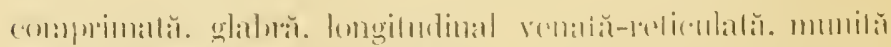

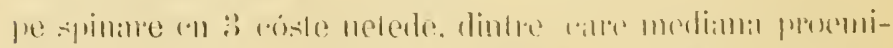

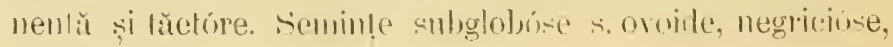




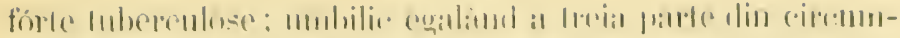

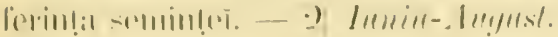

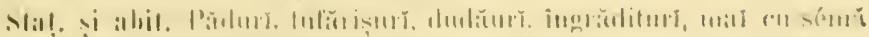

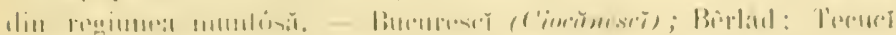

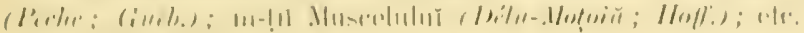

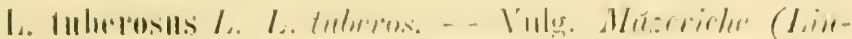

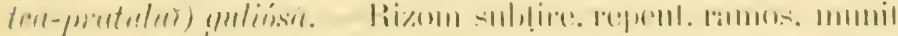

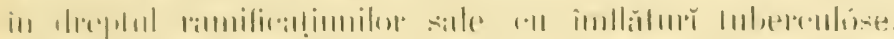

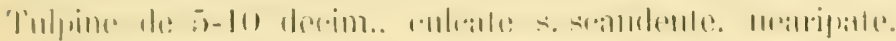

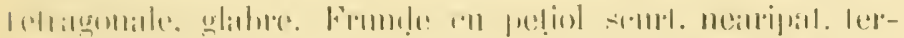

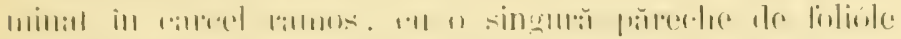

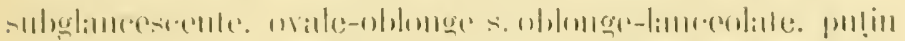

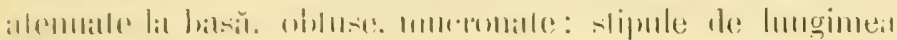

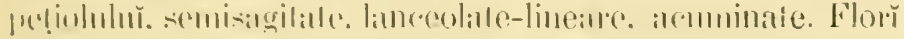

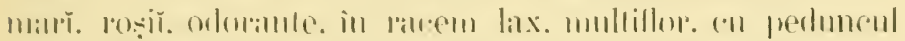

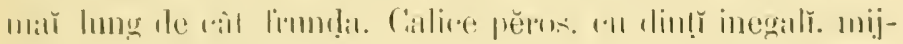

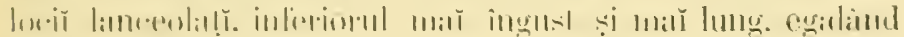

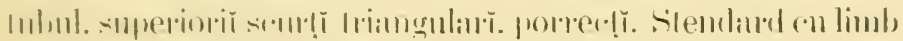

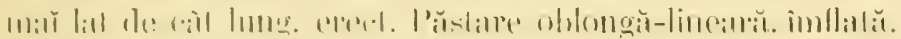
Iel

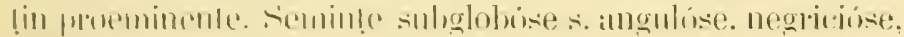

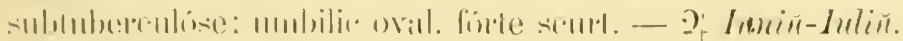

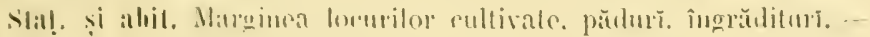

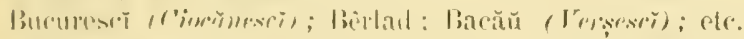

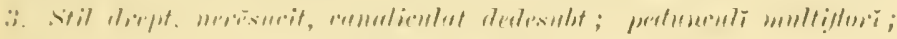
plonte perewing.

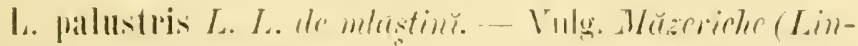

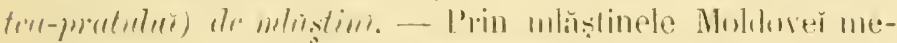

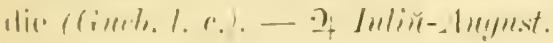

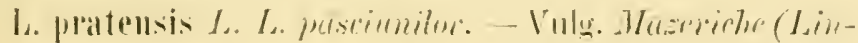

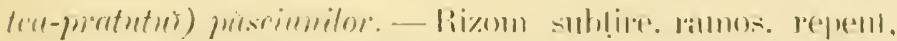

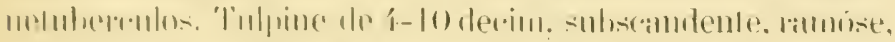

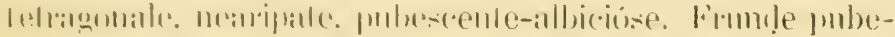

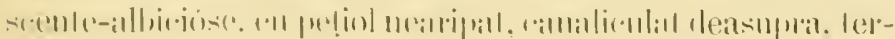

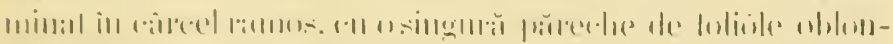

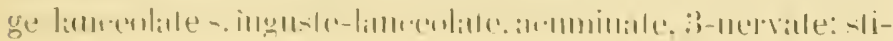




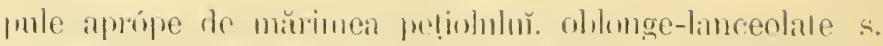

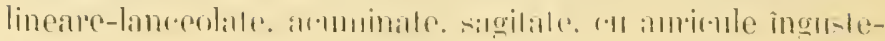

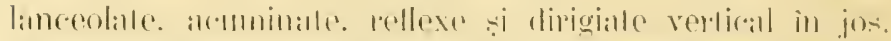

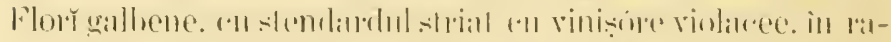

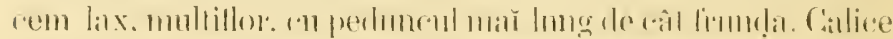

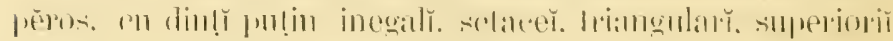

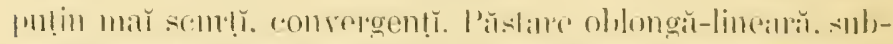

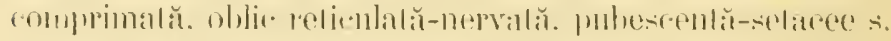

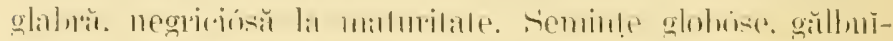

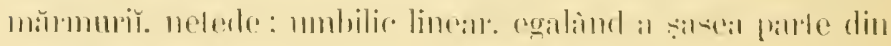

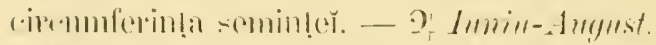

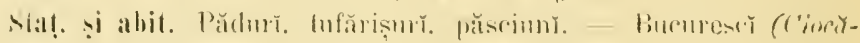

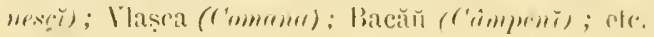

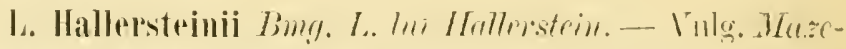

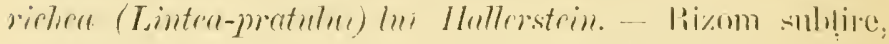

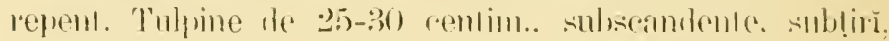

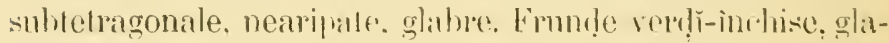

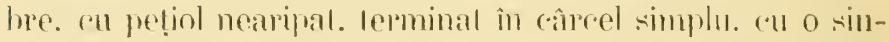

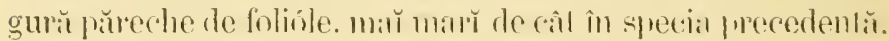
oblonge-lanreolile s. oville-limreolate. muromulate phurinervale; stipmle de măıinea lobiolelor. late. ovale-lanceolalu, acmminale. sagilale. r.11 aminlervide-lanceolate acmminale. dirigiale orizonlal. si nu rellexe. Flor gallsene, ru slendard strial cu vinișore violicee. în racen lax. 1-5̆-for, col pedmu-

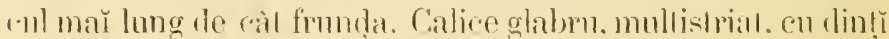

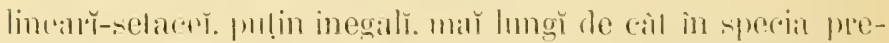

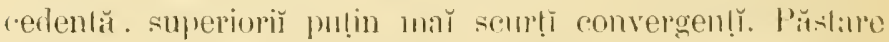

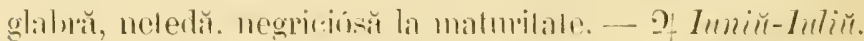

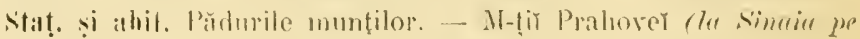

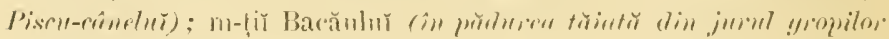

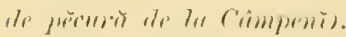

(1)s, sie distinge de suecia precedentă prin raracterele urmălíre

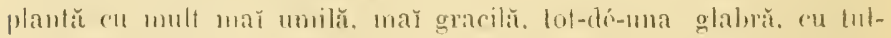

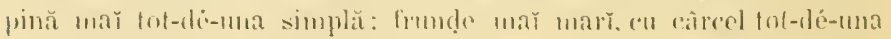
simplu: stipule c"n mult mai mar. lale. orale-lancenlate. "u anriculd late, ovale-lanceolute, acuminate. patente orizontale: racem tot-dí-una pauciflor: calice gla\},ru, cu dinți linearj-setaceí. aprópe de 2 or mă lunğ̌. 


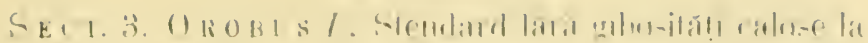

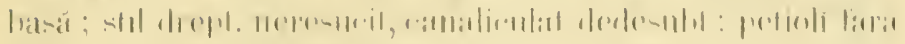

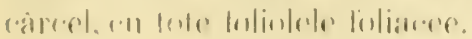

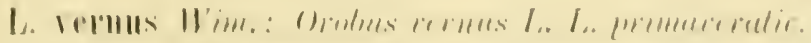

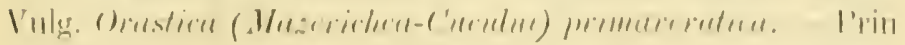

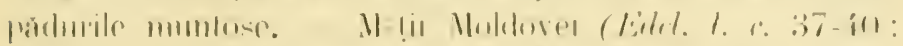

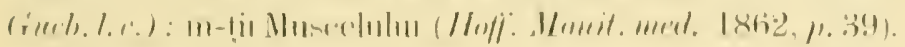

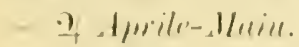

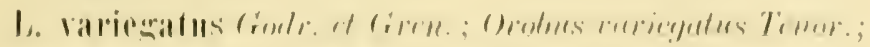

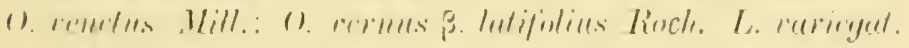

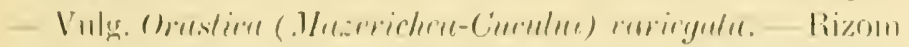

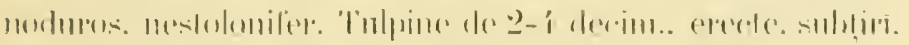

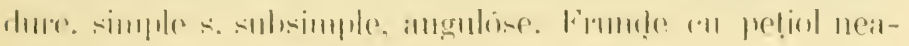

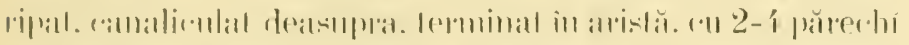

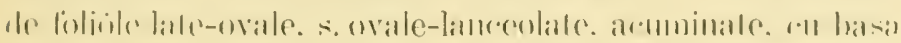

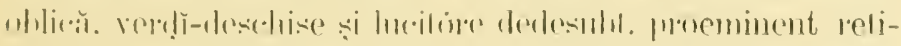

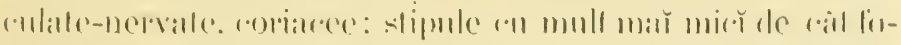

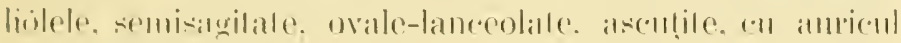

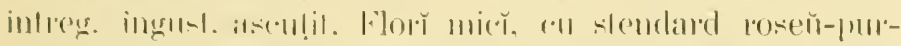

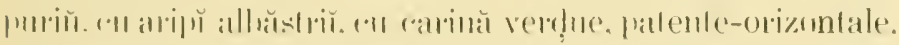

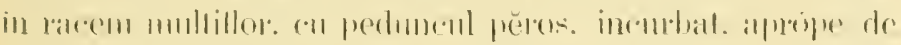

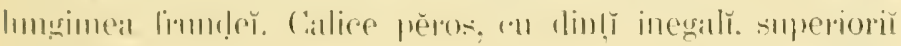

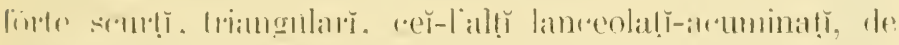

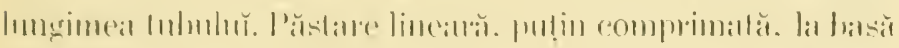

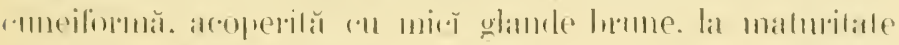

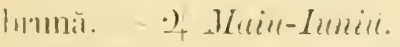

Mlit. și abir. Pădurile umbróse din reginuca muntilor. - drges.

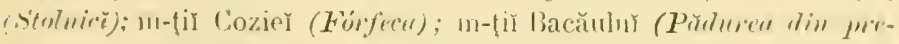

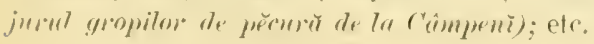

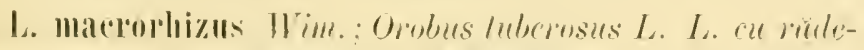

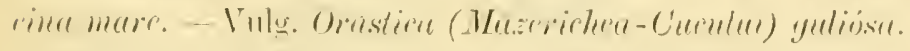

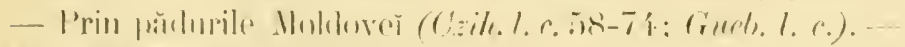
-) Trrin-lumin.

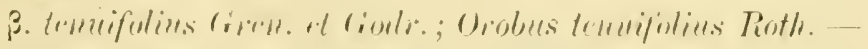

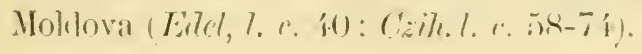


L. niger Wim.: Orobns niger L. L. nergrt. - Volg. O-

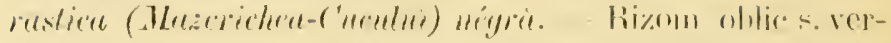

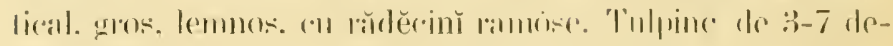

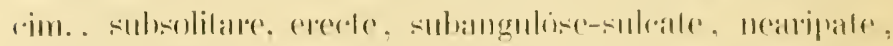

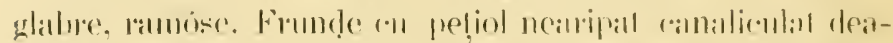

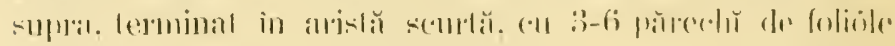

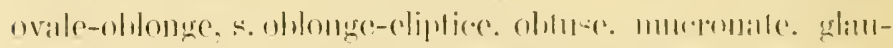

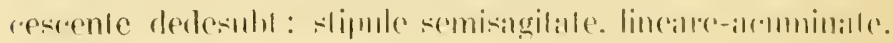

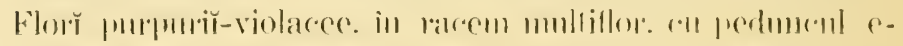

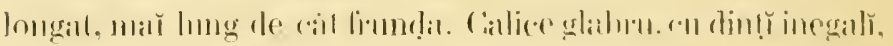

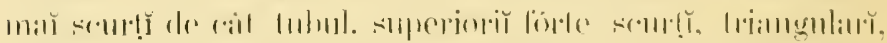

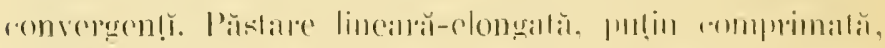

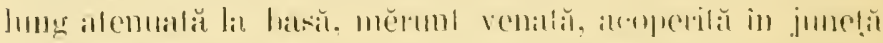

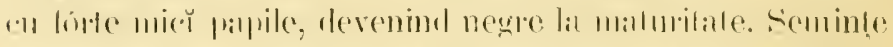

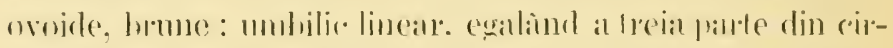

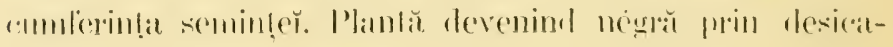

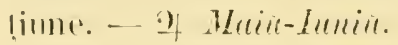

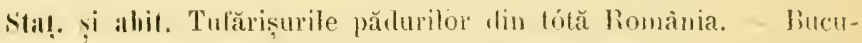

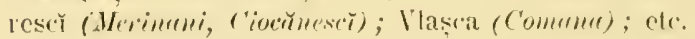

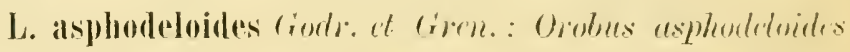

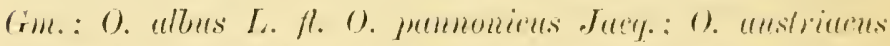

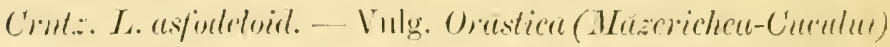

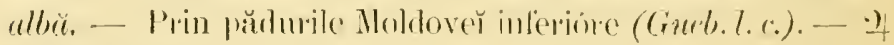
Mreiet-Inniir.

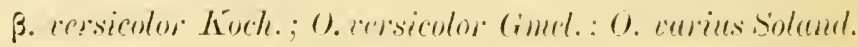
liegimea muntrisă al Moldover (Eder. 1. c. 37 ; Caih. 1. r.: (int) l. e.).

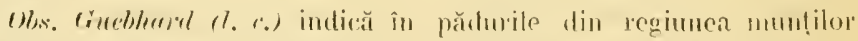

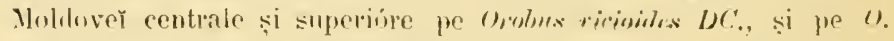

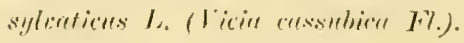

PISLII T. - 1/Grer.

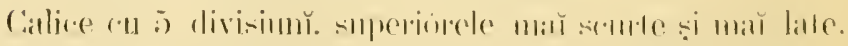

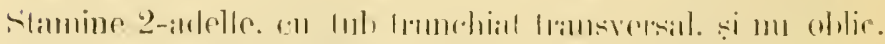

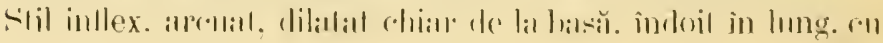




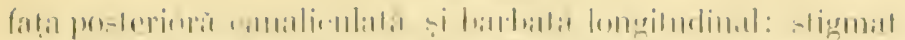

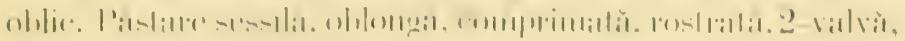

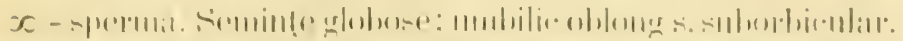

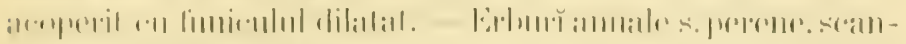

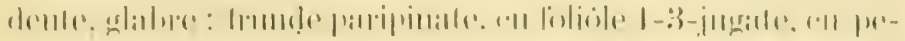

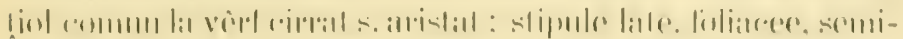

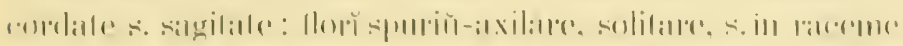

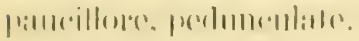

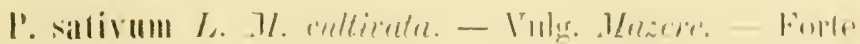

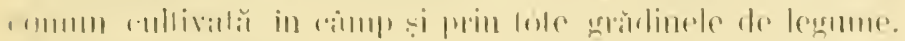

(•) Iminilinlin.

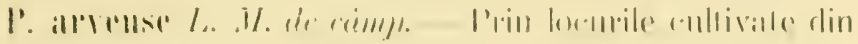

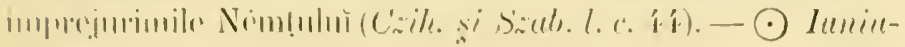
Ilingllitit.

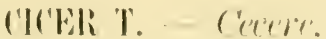

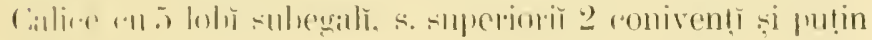

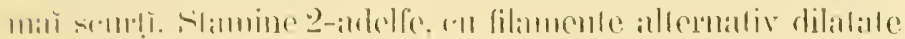

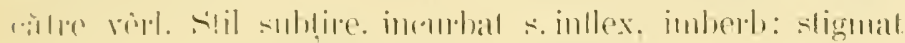

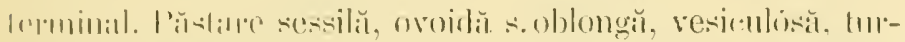

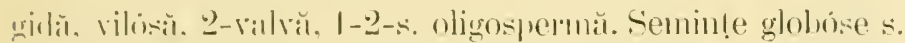

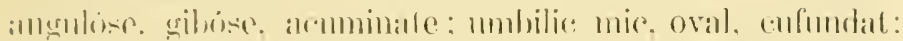

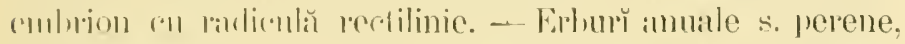

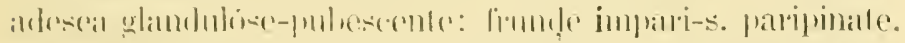

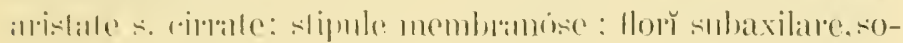
lilile s. puliur, pedmmonlale.

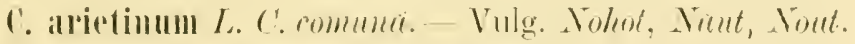

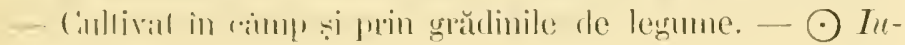
nill-Iulie.

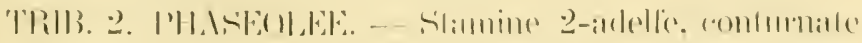

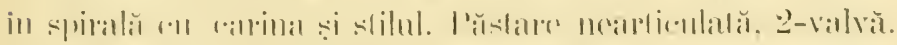

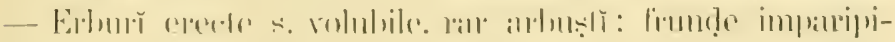

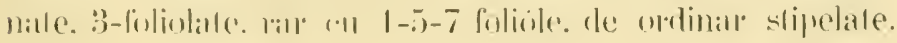




\section{PHASEOLIS \%. F Firolu.}

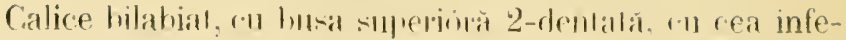

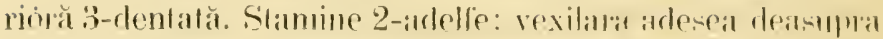

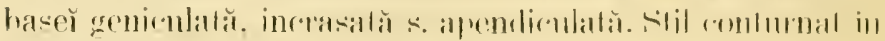

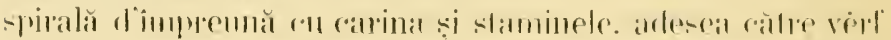

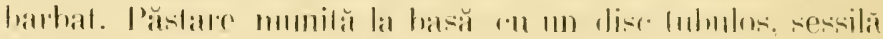

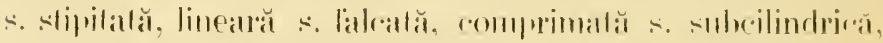

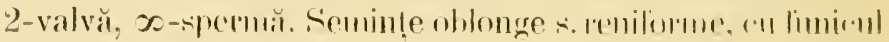

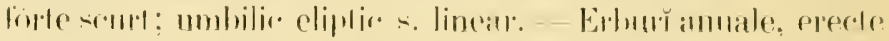

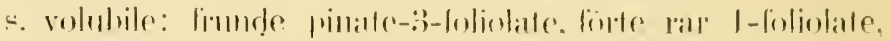

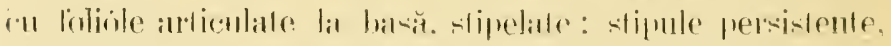

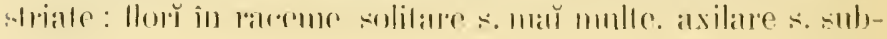
axilare.

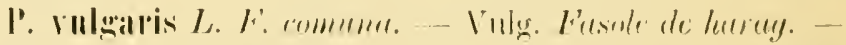

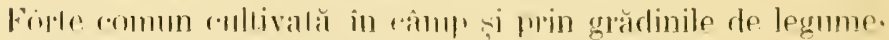
sub mă mulie varietăḷ̆. - - Inniı-Juliu.

Ohs. Se mal cultivă de asemenea: P. munus $L$. (volg. Fusolo ológy), 1'. multiflorites Willel.

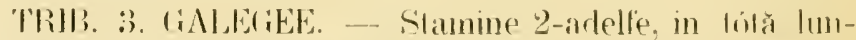

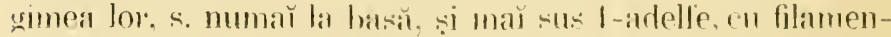

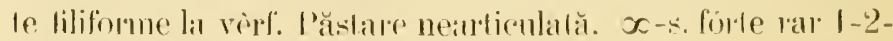

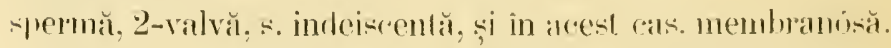

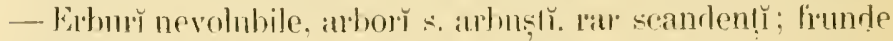
imprapinatle, rar 1-3-folioble. ch petiol comm nerirral la vîf: si ru folinle de ordinall întreğ.

\section{GALEGI T. -- Galeya.}

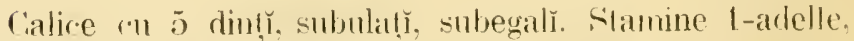
in porțunea lor inferiorŭ en tuh, compled. Stil subulal. in-

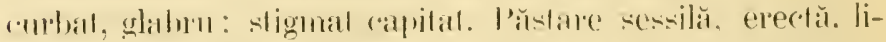

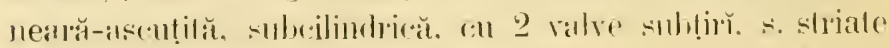
oh]ic. $x$-spermă. śemin!e transversil-ohlonge. - Erhur 


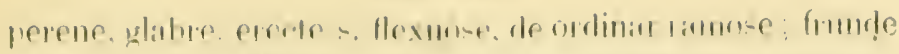

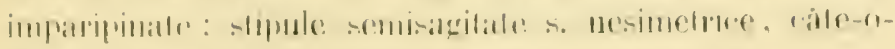

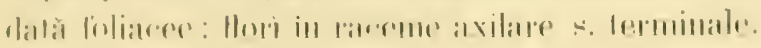

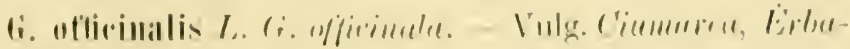

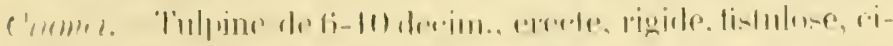

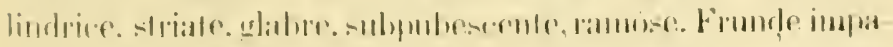

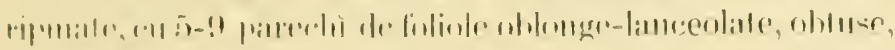

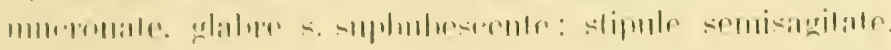

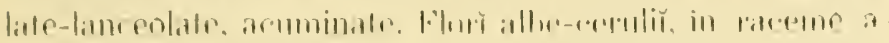

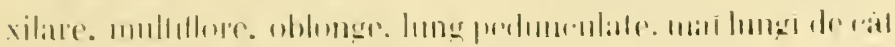

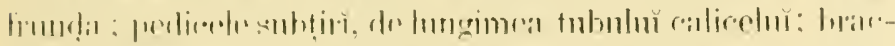

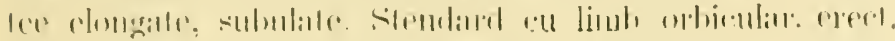

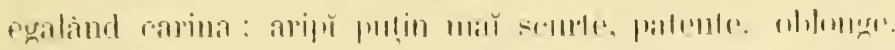

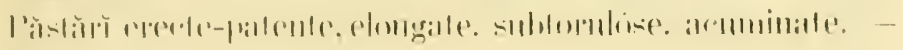

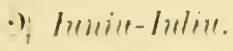

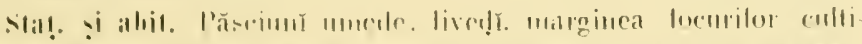

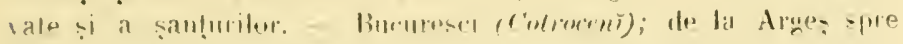

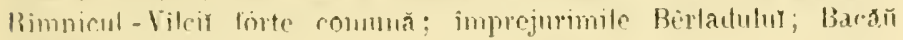
(limesciti-tle-jos); ete.

\section{ROBINLI I. - Rubiniu.}

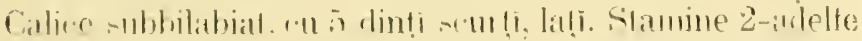

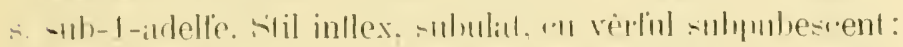

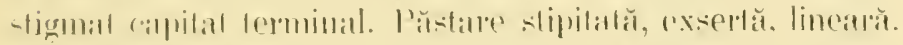

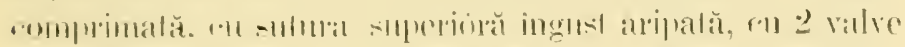

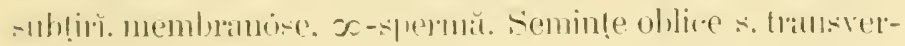

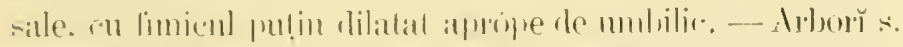

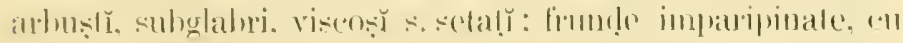
lolicle $x$. rle orlinar stiprelate: slipmle mič. selacee s. spinexcente: Ilor în l'areme axilave.

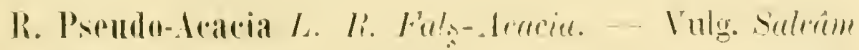

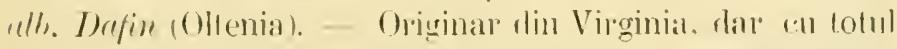

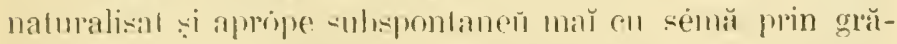

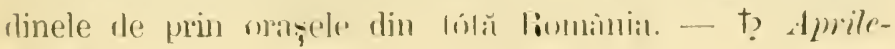
Wuiu. 


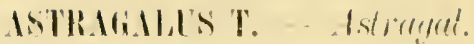

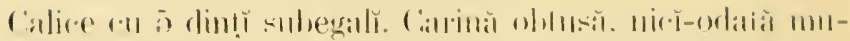

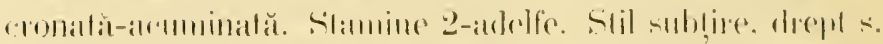

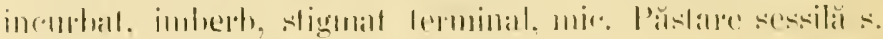

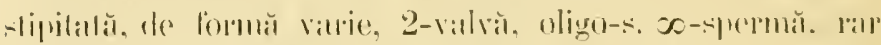

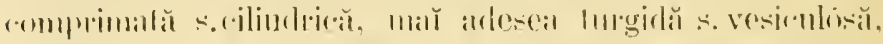

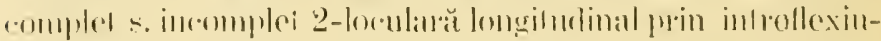

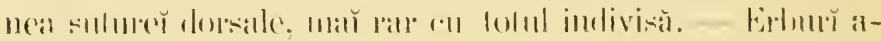

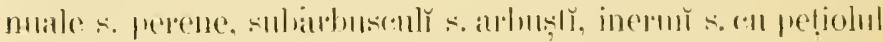

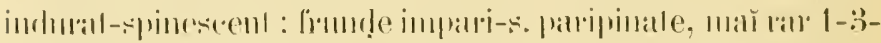

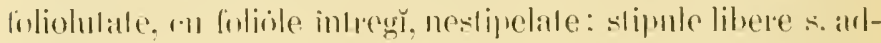

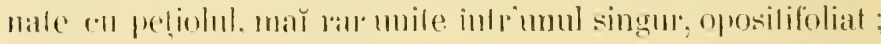

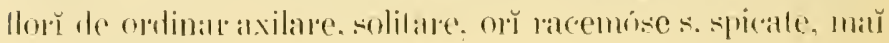
ral $11 m b$ belile.

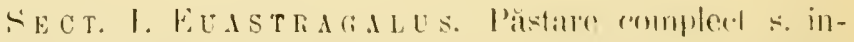

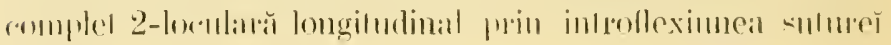
dortiale.

- 1. Hoblorychis L. A. Syererte.- Rizon gros: lemmos.

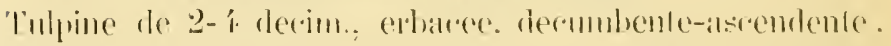

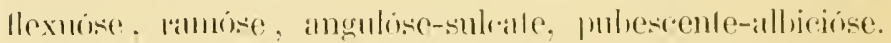

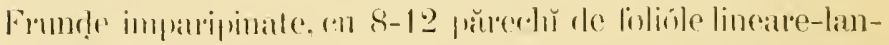

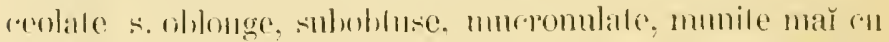

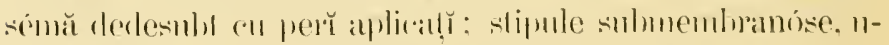

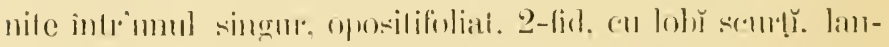

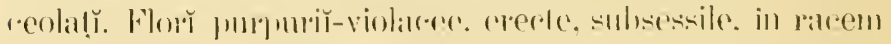

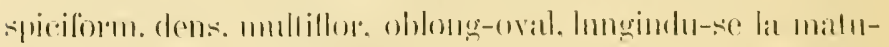

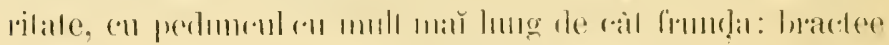
:

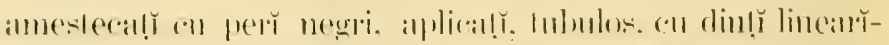

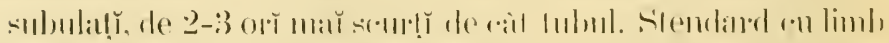

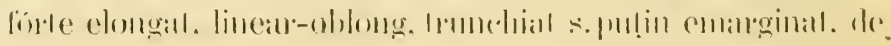

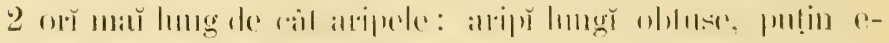

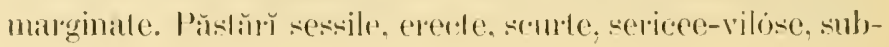




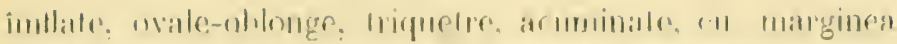

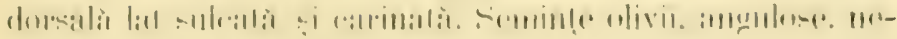

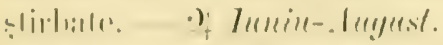

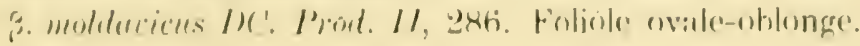
frlilue : sine waile:

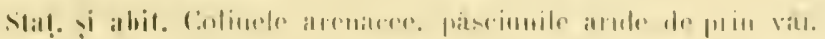

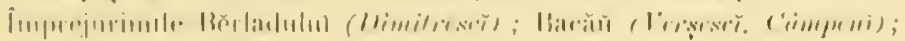

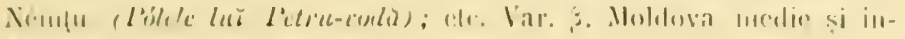

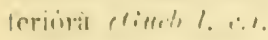

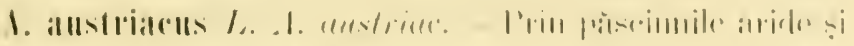
allendere

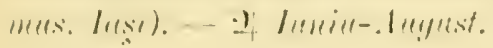

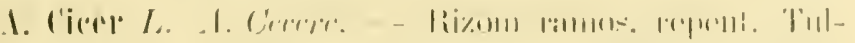

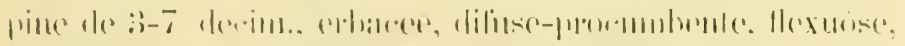

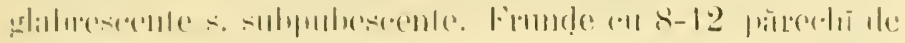

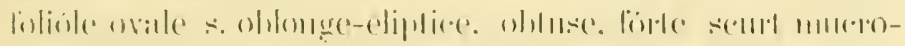
nalle. Imm

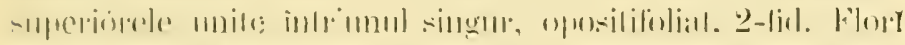

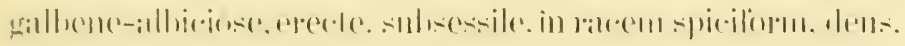

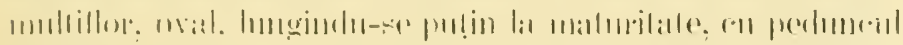

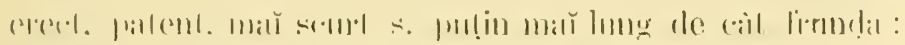

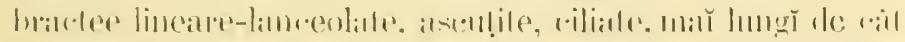

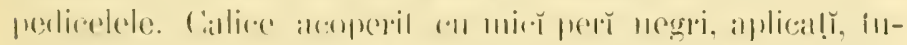

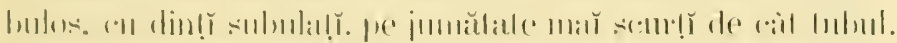

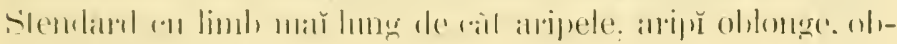

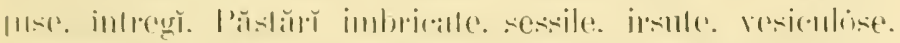

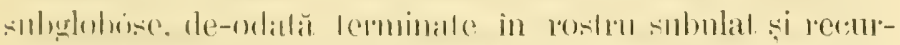

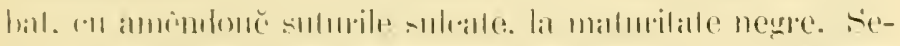

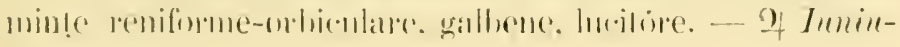
Aluyust.

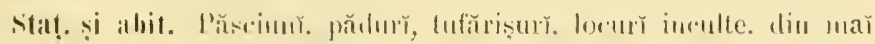

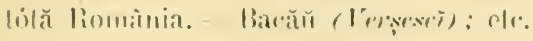

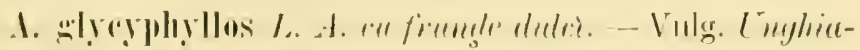

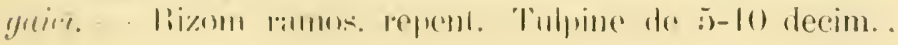


erbacee, procumbente, flexumec. subglabre, angulate-sulcate.

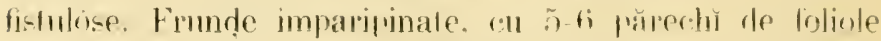

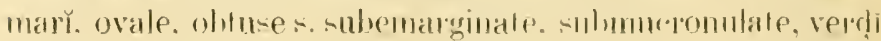

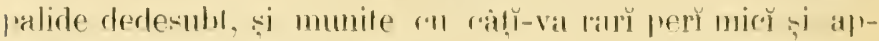
primatr: slipule, alată de role inleriore, grale-lanceolate, armminate. Forr gallone-verdur. crevde-palente, in rarem dens, mulliflor. oval-ohlong, longindu-se puttin la maturitate,

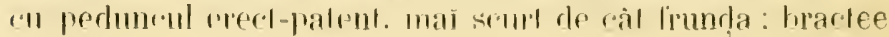
lineare-lanrenlale, acuminale-subulale mă lunğ de càl peri-

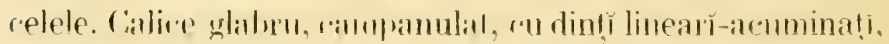

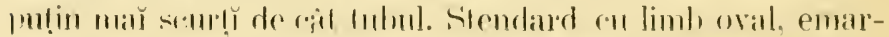

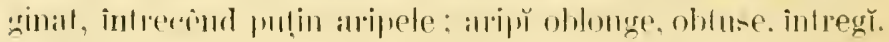

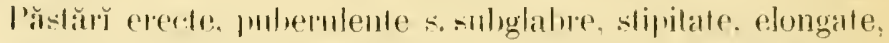

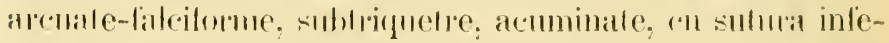

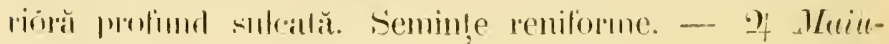
leliii.

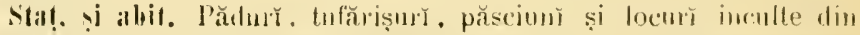

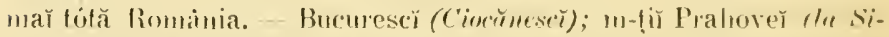

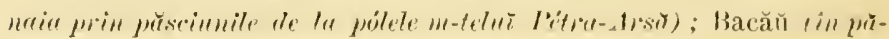

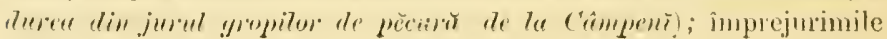
Bêrladuluĩ : etc.

1. asper Jary.; 1. dhomentus I'all. A. usymu. - Thilpine.

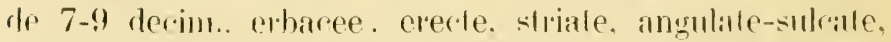

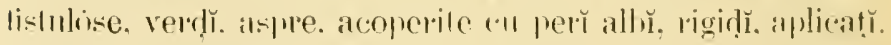

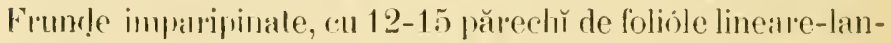
ceobile s oblonge-lineare, ascuțite, munile pe amendouĕ letele r." perı̆ allı̆, aplimaț: stipule libere. lanceolate. Florŭ galbene-verd̦h, erecte, stricte. subsessile, rarem spriform. föle

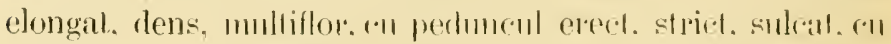
mull mă lung de cit fomcla: Inaclee lanceolate-subulate, mă lungh de cât pedicelele. Calice acoperil coll perĭ negri, aplicaṭ̆. Imbulos-subeampamulat. membanos. on dinț subula!̣̆

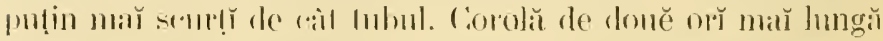
de rill alicele. Păstăli imbuate-spicate. erecte. lineare-

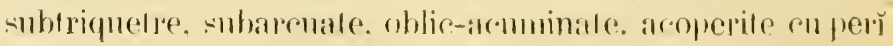




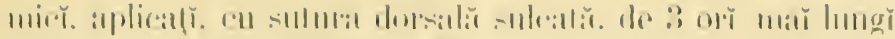

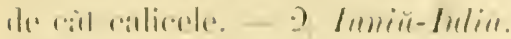

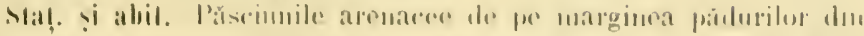

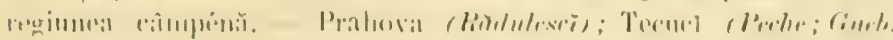
1. 19:14.

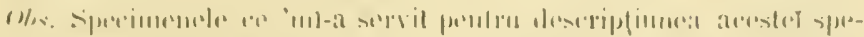

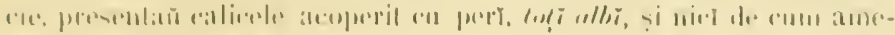

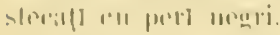

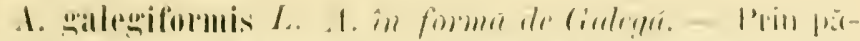

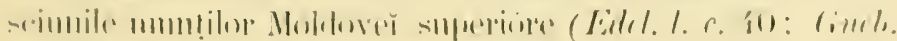

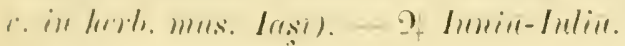

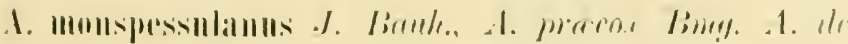

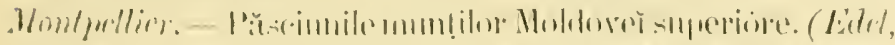

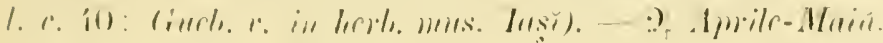

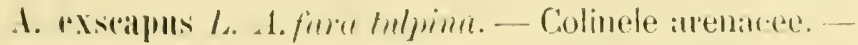

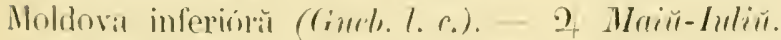

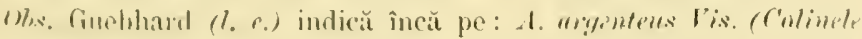

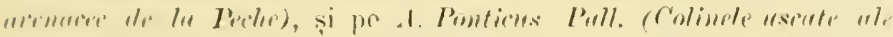
Brolureri inferioners.

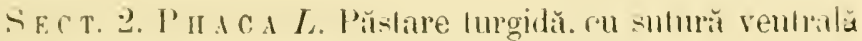

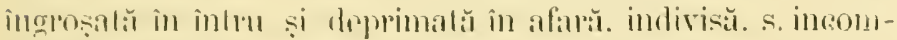

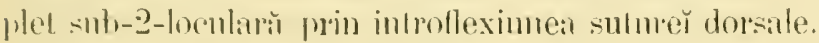

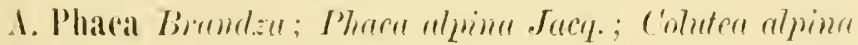

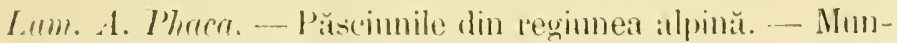

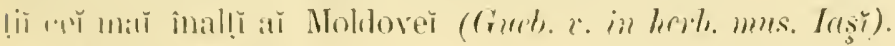

Of Iulin-Augmest.

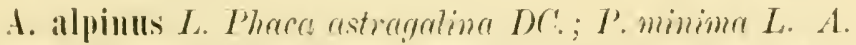

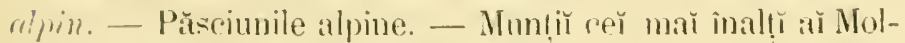
dover. (Gimel. r. in horb. mus. Iasis).

\section{OXYTROPIS HC. - Orytrop.}

Cambint munconală-armminală. slil drepl s. incurball; stig-

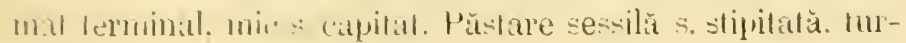




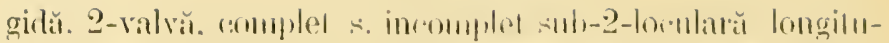

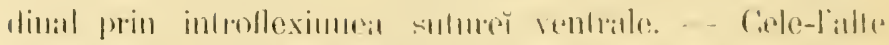

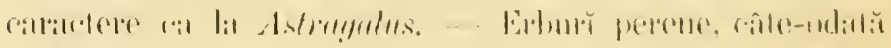

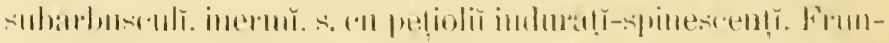

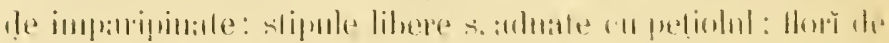

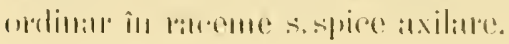

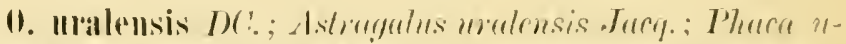

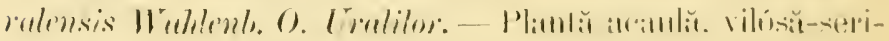

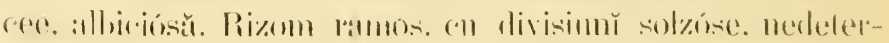

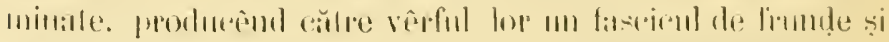

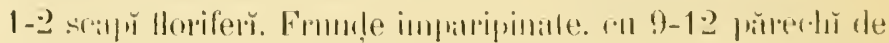

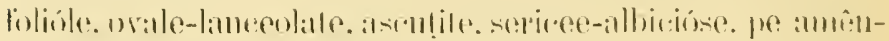

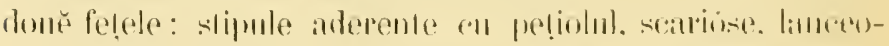

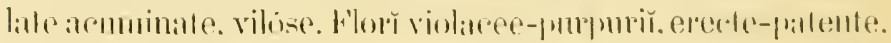

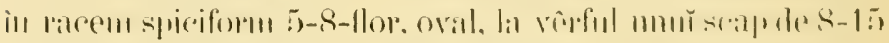

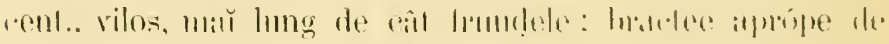

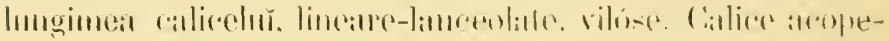

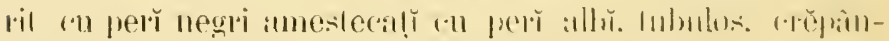

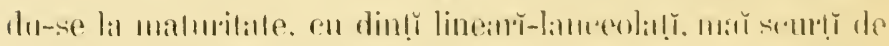

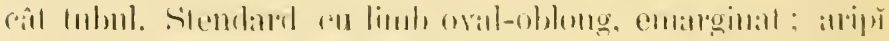

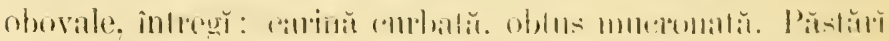

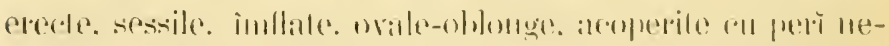

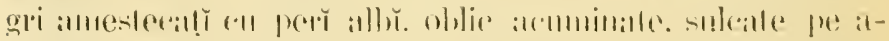

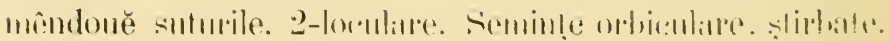
- 2. Inliv- luepest.

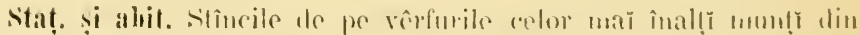

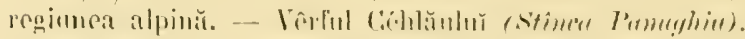

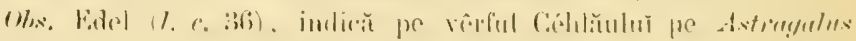

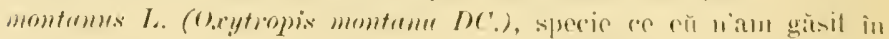

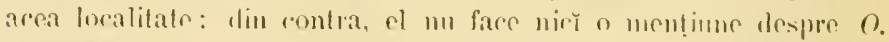

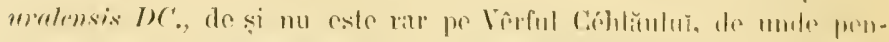

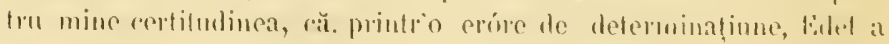

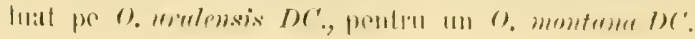

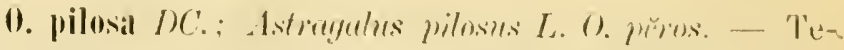

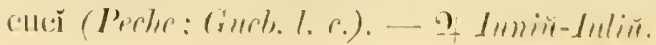




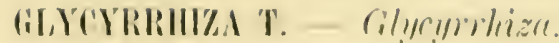

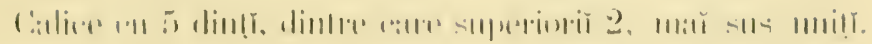

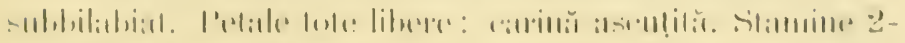

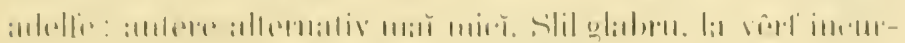

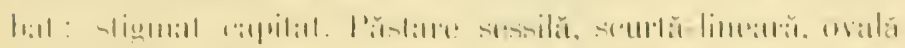

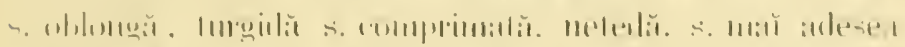

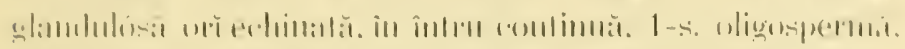

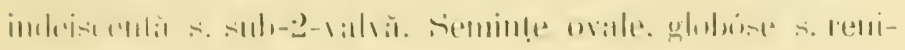

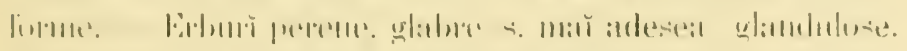

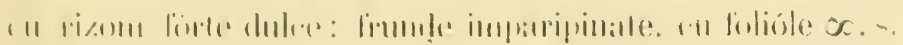

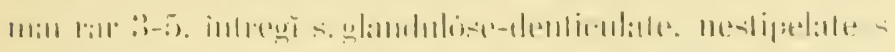

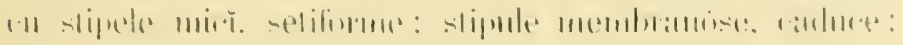

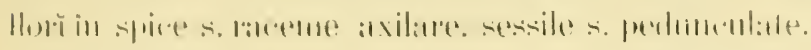

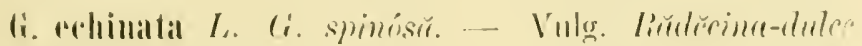

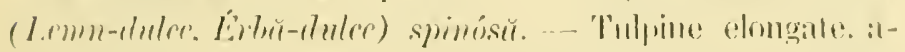

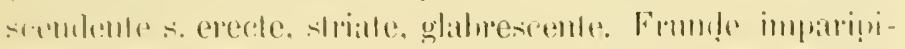

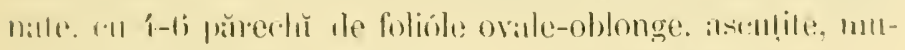

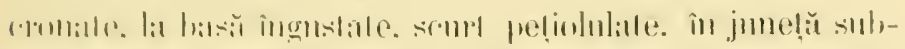

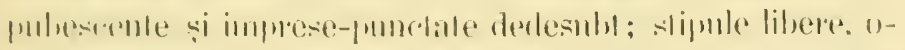

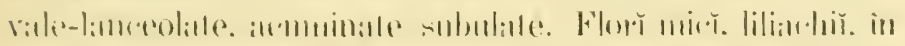

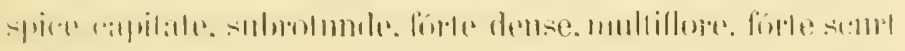

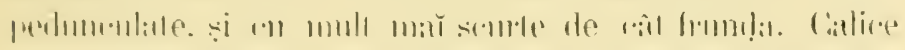

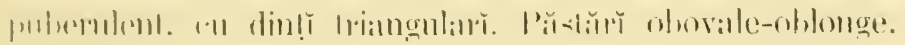

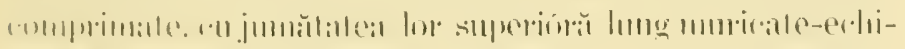

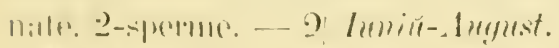

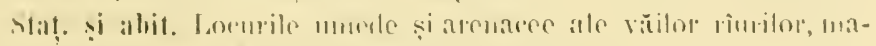

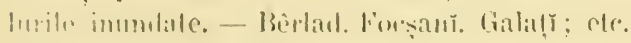

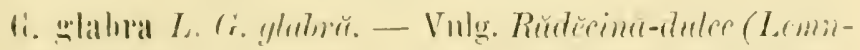

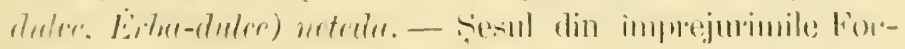

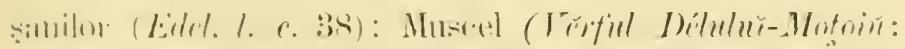

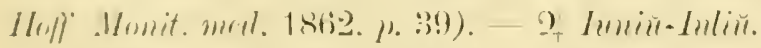

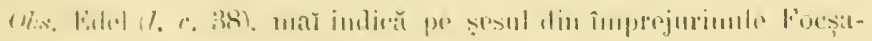
nilor pere gistiele text. 
TRIB. 1. 1.OTEE. - Stamine 1-s. 2-ardelfe. 5 dindre ele.

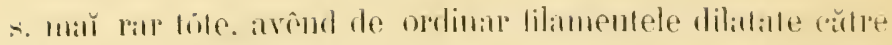

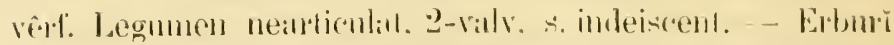

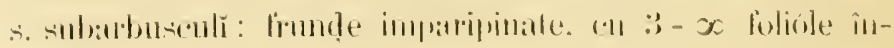
lregi.

\section{L.0TIS L. - Lot.}

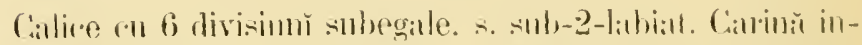

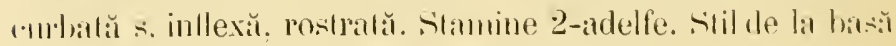

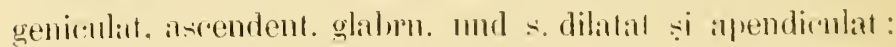

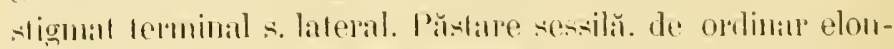

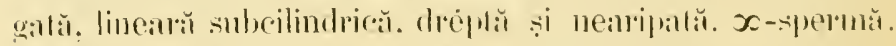

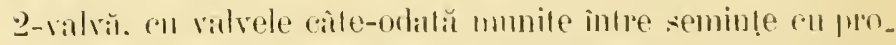
lomginente colnlose hanmersile. subsepliforme. si andese:1

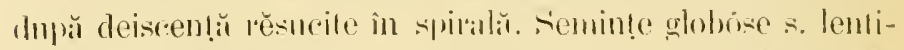

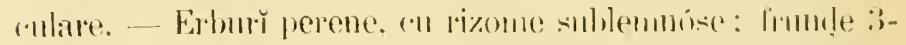
loliolale: slipmle libere. folioliforme: Hor in mulsele-lithe. 1.2-s. mullillore. pedumatiate.

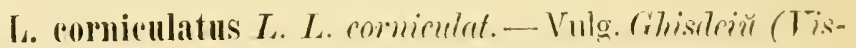

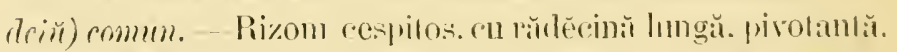
Tulpine de $2-6$ decim.. prostrite s. ascendente-difice. ru ramurı̆ crecte, angulóse. glabrescente. pubescente, s. vilóse. Frunde verdĭglaurescente dedesubt. (') foliole obovale-enneilorne, mucronate s. subemarginate, mă rar lineare-asmtite. glabrescente s. pĕrose ; stipule neregulat orale-lanceolate, mă lınğ pe râl pe!̣iolul. Florĭ galbene, cu stendard și aripĭ adeseal purpuriì. în umbele-fitce capituliforme. de or-

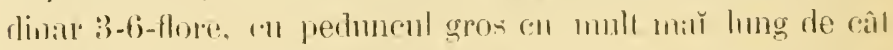
frund̦a. Calice ru divisimŭ la bas̆ă late-triangutare, pe urmă de-odată lineare-filiforme. subulate, te lunginea lubulur. pĕ-

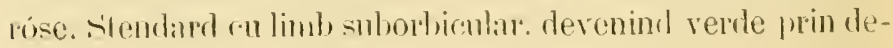
siıațme: aripr late-obovate. r.ll marginea inferioră forle curbată: (alrină curbală în unghin̆ drept. Pŭstărĭ patente, subcilindrice, dreple. glabre. brone lit maturitate cu valve rĕsucite in spirală. - ? Main-Sóntemlin'c. 


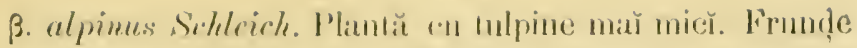
subsessile, en foliole naı̆ nič̆. Ihinţĭ calicelıŭ adesea mă scenț̣̆ și miı̆ lațĭ.

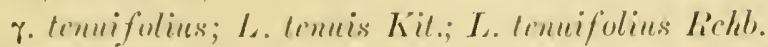

Stal și alhit. Păsciunile uscate şi fênetele din reginnea câmpénă

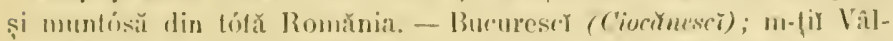

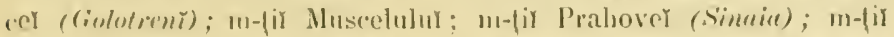

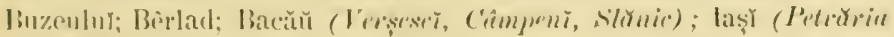

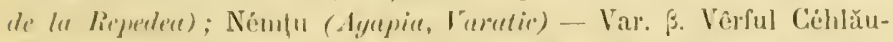

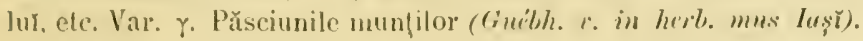

\section{DORYCNIIM T. - Dorycniu.}

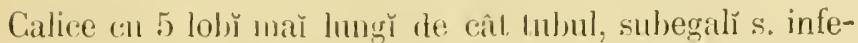
rioriĭ maı̆ lunğ. Citrina obhuš̆. Stamnine 2-aldelfe. Stil incurbal, glab)ru; stignat cajufat. Păstare oblongă, cilindrică s. lumgid̆ $1-\infty$-spernŭ, între semințe subseptată s. pulpóši, 2-vilvă. Seminte globóses. comprimate, nearilate. Ethurĭ s. subarbusculĭ, frunde sessile, 3-foliolate; stipule lihere, folioliforme, ceea ce lace cat frund̦ele să jură digritate 5-foliolate, llor'ı spurin̆-capitates. unbelate.

D. herbaceun Tilld. D. crbacru. - Vulg. Trifoiu-Caprelor, Sulițírŭ. Tulpine numeróse, sub-erbacee, difuseascendente, către vồ ranóse; ranurǐ erecte, pĕróse. Folióle si stipule oblonge-obovale, atenuite la basă; mucronulate, pěróse. Florĭ albe-violacee, numeróse, în capituľ mič̆, pedunculiț̣i: pedunculĭ patențĭ, nự̆ s. munițĭ către vêrf cu o foliolĭ solitară; pedicele de lungimea tubulŭ ealicinal. Callice pĕros, cu dințĭ triangularǐ ascuṭiț̆ĭ, o dală malı scurțĭ de cail Inbul. Stendard cu limb obtus, neapiculat, necontractat deasupra unguiculě̆; aripı̆ puţin mă scurte și ma puḷin late de cât stendardul, acoperind cu totul carina, ce este violacee. Pŭstare ovoidă, subaculă, cu suturǐ osóse, puțin carinate, de ordinas monos]ermă. — † Iuniŭ-Iuliu.

Staț și abit. Pe costișele, corlhanete și pe malurile aride și are-

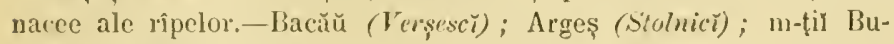
zěulur̆ (Bisca) ; etc. 
ANTHYIJIS L. - Anthylidť.

Calice persistent, tubulos s. îmflat, cu co dinṭ̆ subegilĭ. s. superioriŭ 2 mă̌ marĭ s. mă̌ mult orı̌ mă puțin unị̣. Petale lung unguieulate. Carină de formă varie, incurbată, de ambe laturile gibósă. Stamine de ordinar 1-ardelfe. Stil glabru; stiginat terminal. Păstare subsessilă s. stipitată, ovoidă s. scurt lineară, dréptă, arcuat ă s. falcată, inclusă, indeiscentă s. maŭ târd̦iŭ 2-valvă, 1 - $\infty$ - spermă, înăuntru continuă s. transversal septată; semințe nearilate. - Erluurı̆ s. subarbuseulĭ; frund̦e pinnate s. 1-foliolate; stipule mič s. O; flor inegal capitate s. seurt racemóse, maĭ rar solitare.

A. Vulneraria L. A. Vulnerarie.-Prin păsciunile și fènețele de la pólele munților - În m-ịì Prahovĕ la m-stirea Sinaia; în m-țiǔ Museeluluĭ pe stîneă m-stirer̆ de la Nĕmăescĭ; în m-țiŭ Némțuluŭ la pólele luı̆ Petru-Vodă; etc. - 2 JuniǔAugust.

3. alpestris.-Pe stînca Panaghia de pe vîrful Céhlăuluı̆.

Obs. J. Edel (l. c. 36) indică pe vêrful Céhlăulur pe A. montanu, specie ce eŭ n'am găsit în acéstă localitate. De altă parte, el nu face nicr o mențiune de A. Irtheretria L. var. alpestris, de și acéstă varietate nu este rară în localitatea menționată. De aič̃ pentru mine bănuiala, confirmală și de Ch. Guébhard, care a ved̦ut specimenul lữ Edel, că acest din urmă, printr'o eróre de determinaţiune, a luat pentru $A$. montana pe A. Yulneraria $L_{\text {. }}$ rar. alpestiris

TRIB. 5. T'RIFOLIEE. - Stamine 1-s. 2-adelfe; filamente adesea dilatate la vêrf. Legumen nearticnlat, 2-valv, rar indeiscent. - Erburŭ, rar subarbuseulĭ; frund̦e imparipinate rar digitate, 3 -foliolate s. simple; folióle adesea denticulate.

\section{TRIFOLIUM T. - Trifoiu.}

Calice cu 5 divisiunı̌ subegale s. inegale; superiórele 2 mă mult orĭ mă̌ pụ̣in unite; inferiórele 3 s. 1 mă̌ lıngĩ. Corolŭ mă adesea marcescenlı̆, cu petalele, tótes. în parte, unite la basă într'un tub seurt; carină olıtusă. Stamine 2- 


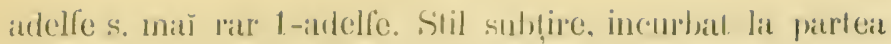
smperiorĭ, cu vôrful uncinal inflex; sligmal terminal, calpitat

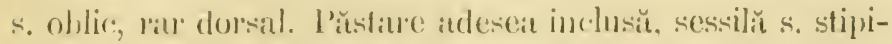

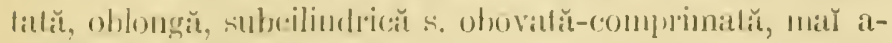

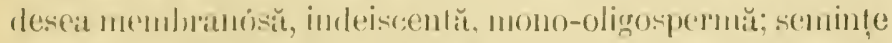
nearilale. - Embur ; frunde 3-foliolate; stipule lipile cu peliolul: llori capilale s. spuicalte, mă rar subumbelate s. solititre.

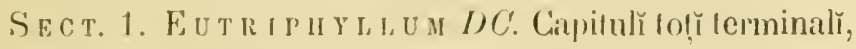
cu lóle tlorile ferlile; calire nevesiculos, en 10 s. 20 de nervure; păstitre ovoidă, inclus̆̆, 1-spermă, 1-valvă, s.desehil̦èndu-se mintr"un opercul.

T. pamnonicum Jacq. T. de Ĺngaria.- Prin fênețele și pŭscimnile de jurin poenile și marginea pădurilor de la câmp și din regŭunea muntilor.-Prin îmı̣rejurimile Bucurescilor la Ciocŭnescĭ ; prin împrejurimile Argeşului în pădurea Pi-

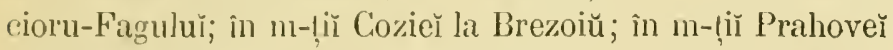
la Sinaia; in m-(ị̌ Buzĕulur̆ la Gura-milě̆; li pólele Céhlăuluй; etc. - 9 Iиniй-Iuliŭ.

T.ochrolencumı Jarq. T. gŭlbiu. - Prin fênețele de prin pŭdurile cimmene și din regiunea munților. - Prin împrejurinile Bêrladulŭ ; în m-țiǔ Bacăulư̆ la Slănic; etc. 2 Inniй-Iuliü.

Ob: Din eróre am indicat prin împrejurimile Bêrladulur pe $T$. incarnatum L. (fraym. flor. Rom. loc. cit. p. 15́x), luând pentru acéstă specie tot un Tr. acholeucum Jac'q.

T. alpestre Jacq. T. alpestr.. - Prin fênețele de prin pocnile și marginea pridurilor de la ctimp şi de la pólele munților.- Prin împrejurimile Bucurescilor la Ciucănesč ;

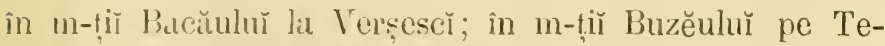
git; cte. - 2) Iuriü-August.

T. pratense $L$. T. de f́êucţc.-Fórte comun prin fênețele şi păsciunile âtât din regiunca câmpénă cât și din cea mun-

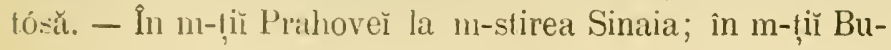




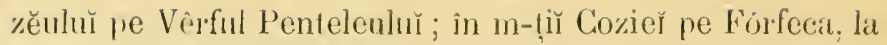
Golotrenĭ; în m-țiǔ Bacč̆uluǐ la Verșescĭ, Comănescĭ; în m-țiŭ Némțuluŭ ; etc. - - I L mniй-Octombre.

T. Pubens Jaer. T. rosiatic. - P'rin pădurile din lólă Moldova (Guéb/. l. c.); în m-liĭ Muscelnlŭ de la Dîmboviciora spre lincăr (IIoff. Monit. med. 1862, prag. 39). - 2 Iıniй-August.

T. medium L. T. intermediariv. - P'rin jădurile din tólă Moldova (Guébh. l. e.). - 2 InniŭtSeptembre.

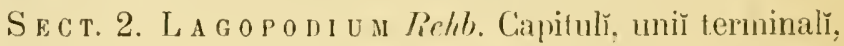
alțǐ axilař, cu tóte florile fertile; cillice nevesiculos, an 10 nervure; păstare ovoidă, inclusăh, 1-spermă, membranósă, deschid̦êndu-se neregulat.

T. arvense L. T. de tarint.-Vulg. Papanaš̌. - Förte commn prin tarinele, viile și păscinnile de prin locurile nĕsipóse și sterile. -- In Vlașca la P'rund ; în m-țiù Vîlceř pe malul Oltuluì la podul de la froran, fórte abundant; la Bêrlad în prŭdurea Crîngu; în m-ṭĭ Bacăuluŭ la Verşescĭ; la Iașĭ prin viile de la Nițelea; etc. - $\odot$ Inniu-_hugust.

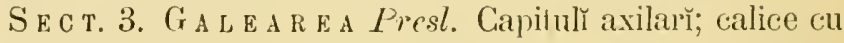
2 buse; inferióra erbacee, 3 -dentată; superióra membranósă, inflândı-se în beșică; stendard cu vêrful porrect; păstare ovoidă, nestipitată, inclusă, 2-valvă, nerostrată, 12 -spermă.

T. fragiferum $L$. 'T'. fragifer.-Prin păsciunile umede mă̌ cu sémă de pe tẹrmurile něsipóse ale rîurilor, pe marginea drumurilor. - În n-ṭiĭ Buzĕuluĭ pe malurile Bâscer̆; in m-țiĭ Bacŭulŭ la Verșescĕ pe malurile T'aslăulur̆; etc. 2. Timiü-Octombre.

T. resupinatum T. L. rèsturnat.-Prin fênetele uscate din regiunea muntós̆̌t. - În m-țĭ Moldoveř (Ldel l. c. 40 ;

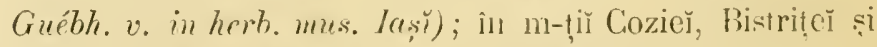
Tismaneĭ (Hoff. mamuse.).- - Iulin̆-Iugrest. 


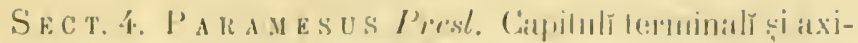

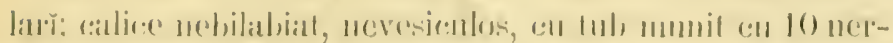

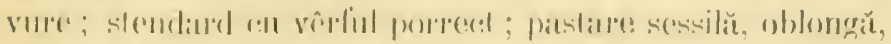

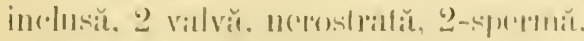

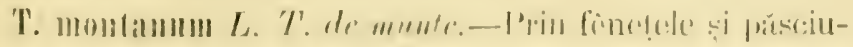

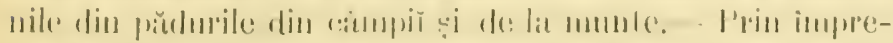

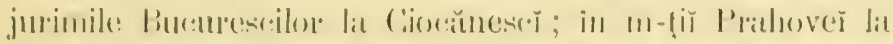

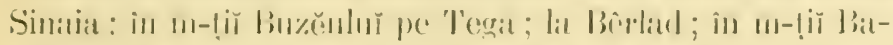

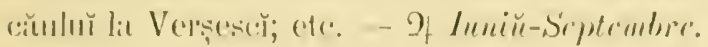

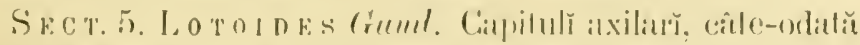

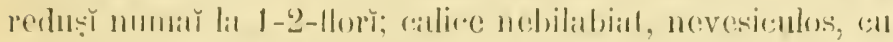

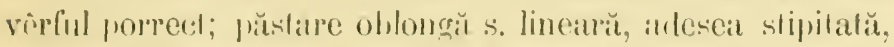
exserlĭ, 2-valvĭ. nerosilralĭ, 2-(i)-spermă.

T'. repens L. T'. tiritor. - P'rin phosciunile și fònețele de prin locurile mnede și něsiprose din cûnpiile şi munțĭ din

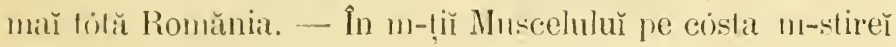
de la Nĕmăescr̆; in m-tĭ P'rahover la Sinitia; elc. - 2 Irair-Octombre.

T. hybridum L. 'T. ibrid. - Prin fènețele și păsciunile umede. - În m-tị̆ Bacăuluĭ la Verșescĭ; în m-ṭĭ Vâlcẹ̆ la (rolotreni pe malul Lotruluй; ele. - Iuniй-Octombre.

Obs: Este aprópe cert pentru mine. că. T. cleyons Sari, indicat de Guébbard (l. c.) prin locurile umede de la Puțent, nu este de cât $T$. hybrirlum $L$., luat din eróre de determinațiune pentru $T$. eleguns sarti.

T. parvillorum Kït. T. cı floř mič. - In mn-țĭ Coziě̆ Bistrițer și a Tismaně (Hoff. manusc.).-- of Maій-Iuniŭ.

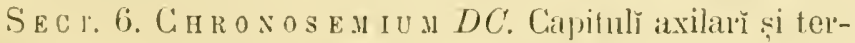
uninalï; calice nebilabiat, nevesiculos, forte deschis la gn̂t, cu lub munit cu 5 nervure; stendard cu vèrful incurbat; păstare ovoidă. tol-deauna stipitală, exsertă, 2-valvă. 1-sjlermă.

T. filiforme L.T. filiform.-Prin păsciunile de prin locurile nĕsiporse din tólü Moldova (Curbl. l.c. i; in m-tị̆ Coziĕ.

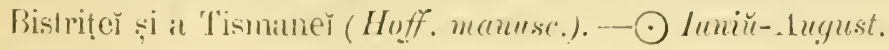


T. procumbens L.; T. campestre Schreb. T. culcat.-Prin pădurile din tótă Noldova (Ėlhl l. e. 40; (inéhlı. l. c.). - $\odot$ Iииій-дияльs/.

T. agrarium L.; T. aurcem P’oll. T'. agrariǔ.-Prin locurile cultivate, păsciunile şi pŭdnıile din càmpi și de la ınunț. - Prin împrejurimile laṣnluĭ la Nițelea: în m-ḷŭ Bacăulı̆ la Slănic; in ın-țĭ Muscelulŭ la m-stirea de la Nĕmăescĭ; în m-tiĭ Cozieı̌ pe Förfeca; elc. -- $\odot$ Juniü-dugnust.

Obs. Guébhard (l. c.) indică prin fêncţele Moldoveĭ superióre pe T. spadiceum L., după un specimen vĕd̨ut în erbariul Musculư din Iași. Cât despre T. globosum L., T. bracteutum Schousb., și T. spumosum $I_{\text {. }}$, specir pe care Guébhard (l. c.) le indică în diferite localitățĭ din Moldova, 'mI este témă, să nu fie resultatul vre-unor determinațiuny eronate. de vreme ce este puțină probabilitate ca să se întâlnéscă prin regiunea Floreč nưstre.

\section{MEDICAG0 L. - Luzernŭ.}

Calice cu 5) divisiunı subegale. Petale libere, caduce, carină obtusă. Stamine 2-adelfe. Stil ıă̌ mult s. mă puṭin dilatat, la vêrf subulat. glabru; stigmat subcapitat, oblic. Păstare sessilă s. scurt stipitată, exsertă, elongată s. renifơmă, falciformă s. conturnată în spirală, cu marginile spiraleı̆ netede și inerme s. spinóse, subleiscent spermă: semințe neitrilatc. -- Erbuṛ̆, latr arbusculr̆; frund̦e pinate 3 -foliolate; stipule lipite eu peţiolul; florǐ solitare puține saŭ mă adesea numeróse, racemóse s. scurt capitate.

S E C T. 1. LU PULINa Gr. et Godr. Păstare indeiscentă, convexă pe fețe, reniformă, curbată în spirală la vêrf, nestirbată, lipsită despiniñsi de nervură concentrică estramarginală.

D. Iupulina L. L. lupulinĕ.-Vulg. Culbecésă hemeiósŭ. - Prin păsciunile uscate din locurile aride și nĕsipóse din câmpiile și munții din maĭ tólă Romănia. - La Bèrlad; în m-ṭĭ Bacăuhŭ la Slănic; în m-țĭ Némţulur̆ în m-țiĭ Ciozieĭ la Golotrenr̆; etc. - $\odot$ Inniǔ-luliŭ. 


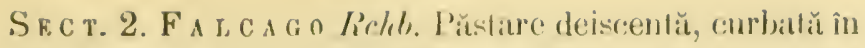
secere s. in elice perforal in cenlru. lipsilă de spint și de ncrvură concentrieă estramalrginalit.

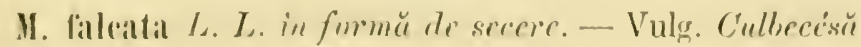

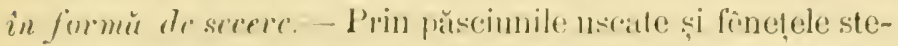
rile, pe malurile alride ale rînelor și ale mâneătm elor de alje

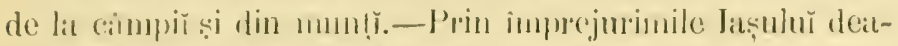

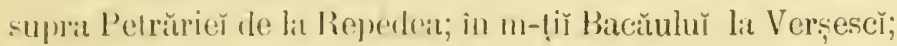
la Bêrlad; prin imprejurinile Bucurescilor la Ciocănescř ; în

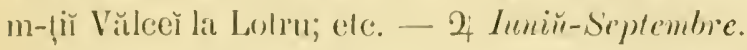

II. saltiva L. L. collivalü. - Vulg. Cullsccésü cullivalü.Förte comm cultivitĭ și subsiontanee prin imprejurimile Bucurescilor la Cíocănescī, Clnitila; etc. — 2 Inniй-Aregust.

II. Inedia Br's. L. inermediară. - Vulg. Culbecésă mijlocir. - Prin ph̆sciunile sterile din Moldova (Edel, l. c. 38). - 2) lutiu-srplembre.

S Fст. 3. SPIR OCA R P S $D C$. Păstare indeiscentă, orbiculară, curbată în elice neperforat în centru, munită de o nervură concentricĭ estramarginală și de ghimpı̆ s. luberculĭ ce nasc prin douě vădĕcinı̆.

I. minima Lam. L. micŭ. - Vulg. Culbecésă micŭ. Prin câmpiile sterile și něsipóse. - În împrejurinile Bucurescilor la Merinani; in Vlaşca la Comana; în tótă Mloldova (Eılcl, l. c.; Ginćbh.l. c.); etc. - $\odot$ Maій-Luniŭ.

Ols. U. Hoffman (Konit. med. 1862, p. 40) indică la Câmpulung. pe těrmurile Rîu-Têrguluĭ, pe Melicuyo orbicularis Kit. și M. muricato Kit.

\section{MELILOTUS T. - Sulfină.}

Callice fiersistent, cu 5 dinți subegalĩ. Petale libere de androcen̆, caduce; carină obtusă. Stamine 2-adelfe. Stil filiform, către vêrf incurbat, glabru; stigmat terminal, capitat s. oblic. Păslatre sessilă s. stipitată, scurtă, subsfobósă s. o- 
voidă, rectilinie, exsertă, indeisceută s. sub-2-valvă, nonooligo-spermă ; seminte nearilate. - Erburı̆ anuale s. bisanuale; frundie pinate, 3 -foliolate; stipule lipite cu pețolul; florı̌ în raceme axilare s. subaxilàce.

II. dentata W. Kit.s'.dentatŭ.-Vulg. Sulcinĕ (Molotru) dințath. - Prin fènelele unede din regionea muntósă. La Cîmmulıng le termurile Rî̀-Tîrguluı̆ (Iroff. Monit. med. 1862, p. 40) ; in munții Moldoveì (Edd, l. c. 37). o Iıliü-Septembre.

II. macrorrliza Pers.; H. officinalis Willd. S. cu rădèciň̆ mař. - Vulg. Sulcinŭ (Nolotru) cu rădécin mař̀.Prin locurile uncde, pe malurile rìjelor și a rîurilor. - La

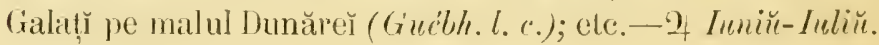

II. alba Lam.; M. leuchanthe Koch. S. cellă.-Dulg. Sulcinŭ (Molotru) albŭ. - Pe malurile rîurilor din regimea cenIrală și superióră a Româniě̌. - În nn-țiu Bacăulıŭ la Verșesč pe malurile Taslüuluĭ; în m-lîi Vâlcề pe malurile Oltulŭ la Cẳimănescĭ, Căciulata; și pe malurile Lotruluŭ li Gololenı̆, etc. o' Luniü-Iuliǔ.

II. arvensis Wallr.; M. Petitpierreana Rehb.: M. of $i^{-}$ cinalis Lam.; M. pallida Bes. S. de țariň.--Vulg. Siulcinä (Holotru) de țariň. - Printre scmĕnăturile, fênețele și locurile cultivate din mă̌ tótă Romănia. - or luniǔ-Iuliŭ.

II. corrulea Lam.; Trigonclla corrulé Ser. S. albastră. Vulg. Sulcină (Molotrn) allus tră. - P'rin locurile arenacee cultivate și inculte.-Fópte alındantă la Comana pe malul Cülnișteř chiar lingă podul drumulı̆ de fer ; în Moldova inferióră și centrală (Guébl. l. c.). - $\odot$ Мaій-Iиniŭ.

M. procmmbens Bess.; Trigonella Besseriana DC. S. culcatŭ. - Vulg. Sulcină (Molotru) culcut. - T'uljină ascen-

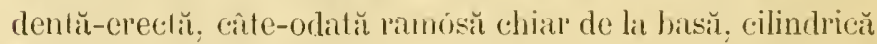
Frunde lung petiolate; inferiórele eliptice-oblonge. superiórele înguste lanceolate, argule-dentate; stipule membranóse, 


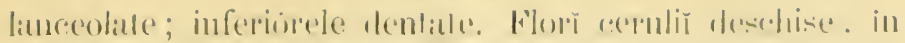

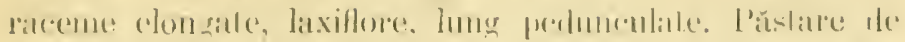

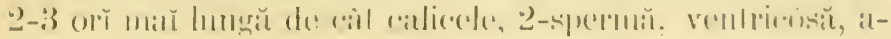

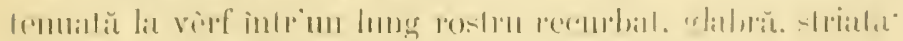

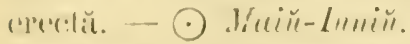

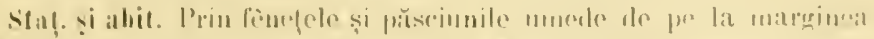

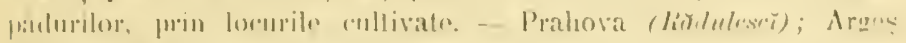

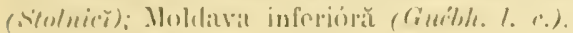

\section{oxOSIS L. - Onomidlu.}

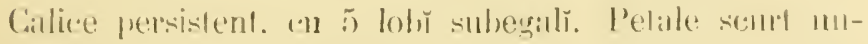

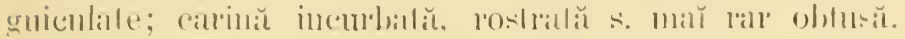

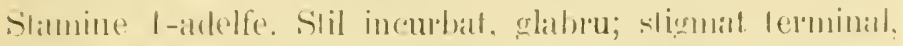

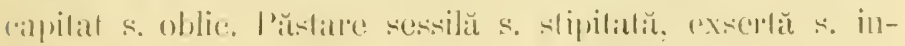

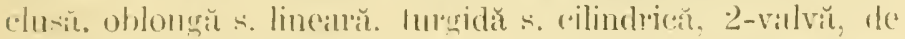

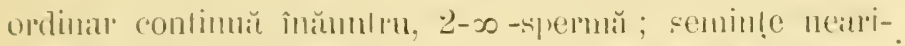

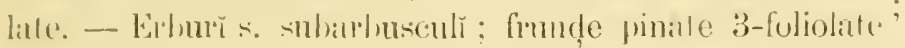
stipme liphife en peliolnd; flor solitare $\leq .2$. 3, racemose.

0. spinosil L.; O. arvensis ear. F. Sum.; O. campesteis

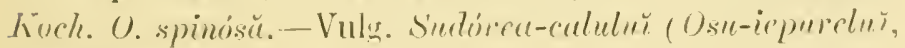

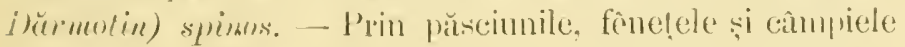

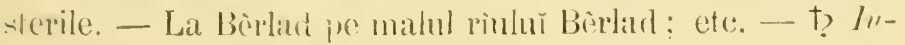
niri-sugust.

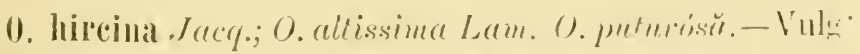

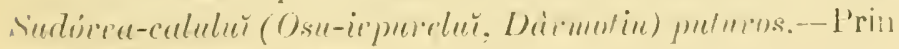

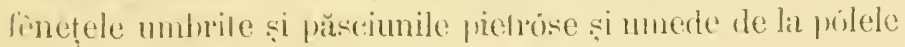
num lilor. - Prin împrejurimele Tașulŭ in livelile viilor de

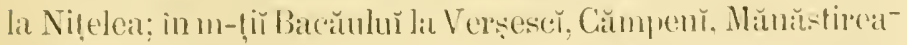

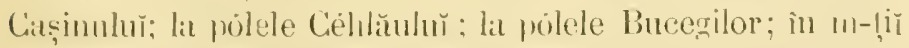
Vílcê̆ la ciolotrenu prin loemile pietrose de pe malnd Lotrulur; elc. - t) Iuniŭ-_lugust.

TRIB. 6. HEHSSAREE. - Sinne libere, I-idelfe, ori ¡n 2-adelfic, inegală s. esgală. 5) din ele atrind lilimenlele (ălle vêrf dilatate s. nu. Leğunen arliculal, ru unul s. mă 
mnlți aulix:nli l-spermin si indeiscen!̣̌. - Platnte crbatee. par frulescente; frumle simple s. imparijunale, panci-s. plurifoliolate, rar 1-3-foliolale: foliole înlreğ. fătră stipele.

\section{ONOBRYCHIS GARTN. - S'purcetŭ.}

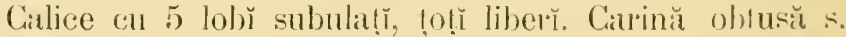
frunchială. Stamine 2-atdelfe. Stil filiform. subereel $\therefore$ inflex; stigmat mic terminal. Păstale exsellă, soxsilă s. slipi-

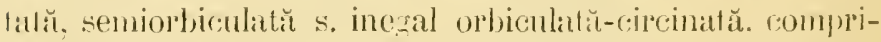
matlă. 1-intienlală, muricată. aripată s. mă ratr netedă, p’ugósă s. reticulală, indeiscenlă, 1-2-spermă: semințe reni-

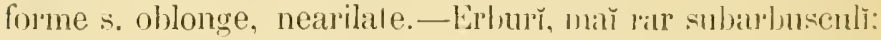
frunde imparipinate; stipule scarióse: flor în laceme s. spice axilitre, lung pedunculate.

0. sativa $L$. S. cultivatü.--Prin păsciunile sterile de pe colinele arenacee, prin finețele de jrin fufirisurile de pe dé luri și corhane, pe malurile rîpelor. - In m-lị Bacŭıluĭ pe délıurile aride de la Verṣesč̃ pe marginea pătdurilor de pe naalul Prahover̆ la Rŭdılescr̆; în m-tị̆ Muscelılıŭ; elc. - D lumin--1urfust.

0. Inantaua $D C$. S. te munte. - Prin păsciunile petróse din regriunea alpină. - Pe Vìful Bucegilor; pe vêrful Cié-

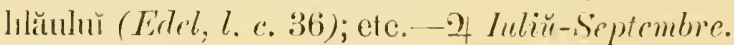

Ob.. Gnébhard (l.c.) indică pe O. conferta Desr., prin fênețele de la Ocna, și pe O. orquidentata D'U $\%$, pe colinele Moldover̆ inlerióre.

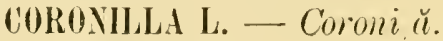

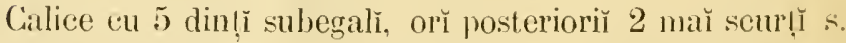
ună̌ sus uniț. Petale lıng unguiculate; carină ineubatĭ, rostrată. Stamine 2-adelfe. Slil inflex, subulat, glabru; stigınal mic, tapitat. Păstare sessilă, cilindrică, tetragonală . s. subcomprimată, dréptă s. arcuată, cu articulĭ oblonğ̌s. elongratị. $\infty$-spermă; sem inte transversal oblonge, nearilate. -- 


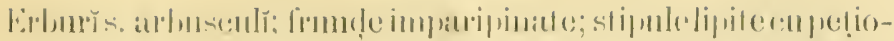

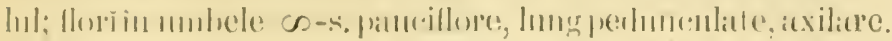

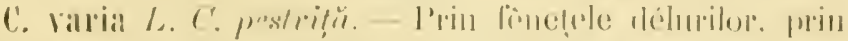

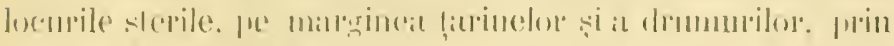

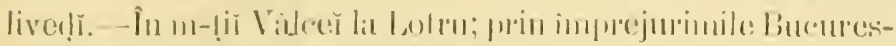

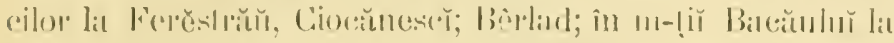

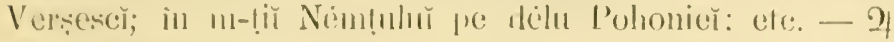
Inпій- | пилимt.

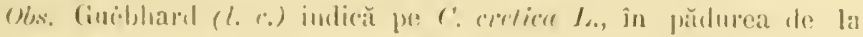

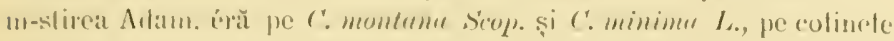

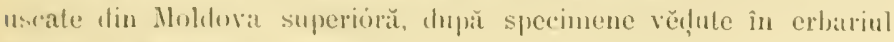
MlusculuY diı laș.

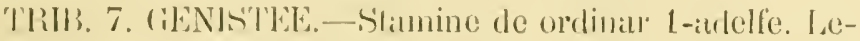
„umen neirliculat, rall indeiscent. - Vildur s. arbustr; frumcle simple. 3-foliolale s. digilate; folicile intregr.

\section{MENIST.I T. - Genistu.}

Cutlice persistent, 2-labiat; busa superiólă profund 2-loballă. cea superiólă 3-dentittă. Citrină snberectăs. incur-

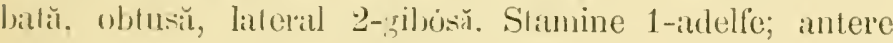
glabre, inegale. Stil incurbat, inflex s. mă rar circinal: stignal capifat s. oblic. Păstare exserlĭ, sessilă, de ordinar

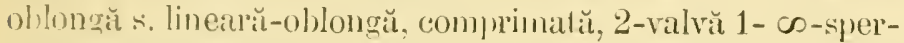
mĭ́; seminte nearilate. - Arlunștĭ s. subarbusculĭ eu s. fară spinŭ frunḍe allesea l-foliolate; slipule inič s. 0; florĭ în rareme s. splice, câle-odată capituliforme, simples. compuse.

(i. tinctoria L. G. boiangiilor.-Vulg. Drobitu (Drobusor, Inistrn, Ginistru) boiangirlor.-I'lin păsciunile și fènetele de prin pădurile campiilor și a muntilor. - La Bèrlad în pădırea Crîngu, în ı-ḷĭ Baccŭulŭ la Verșescĭ, Cân-

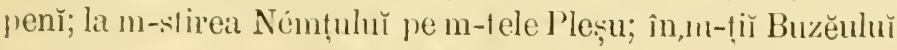

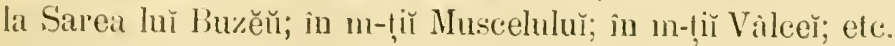
- ћ Inviü-August.

ß.pubescens Lang.-Comună în regiunea tuturor nunților. 


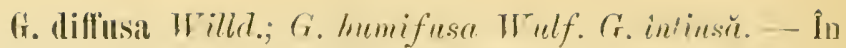
m-tị̂ Bucen̆ pe milurile rîpelor și a mâncălurilor sle ape de pe Vîrful Furnicě̃. - †? Ieniü.

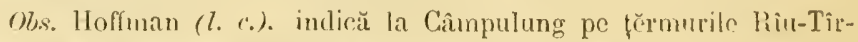
gulur pe G. riryute DC. (C'ytisus rirgatus IIofl.).

\section{CYTISISS L. - Cytis.}

Calice persistent, sub-2-labial; busa superioră Imonchiată s. 2-dentată; inferióra 3-dentală. Pelale libere s. си busa lipilă puḷ cu lubul staninelor; carină dréplă s. incubatit. oblusă s. snbacuminată. Stamine 1-adelle; antere inegale, whabre. Stil incurbal, glalmu; stigmat terminal, capital s. oblic. Pissiare exsertă, sessilă s. seurt stipitată, ollongă s. lineară, comprimală, 2-valvă, $\infty$-spermă ; seminte arilate -Arbușlŭ s. arborr̆ mič̆; frund̦e digilate 3-foliolate, mă rar 1-foliolate: stipule mic̆̆, setacees. 0 ; flor in recence elongates. scurte și pauciflore.

A. anstriacus Jarq. C. anstriue.-Vulg. Drob anstriar. -Pe marginea pădurilor, pe lingă luferiçurile de pe colinele aride-Prin imprejurimile Bucurescilor lat Merinani, Rădnlesç; in Vlașca la Comana, Prundu ; la Bèrlad in pădurea

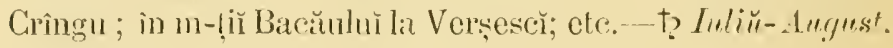

C. luirsutus L. C. pierns. - Vulg. Drob de mun'e. - Pe slincele munților. - În m-țî̀ Coziě̀ pe Fórfeca, Ur\%ica ; în

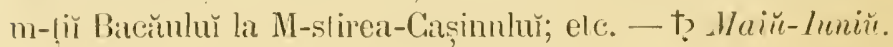

C. nigridans L. C. nẹpirios. - Pe cóstcle pietrose şi pe stîncile de prin pădurile munţilor. - In m-țĭ Vâlcê̌ là

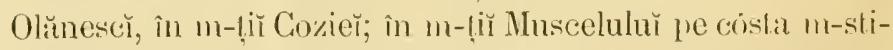
rě̆ de la Nĕmăescĭ; în m-ḷĭ Buzĕuluř la Bissca pe muntele de la spatele statbilimentulur ; în m-țĭ Bacŭulŭ la M-stirea - Cașinuluı̆. - †? Iuniй- tuegust.

Ols. Guébhard (7. c.) indică prin pădurile și pe colinele Moldover superióre, după specinnene vĕdute in erbariul Museulur din IașT. pe C. Icuchanthus Kil. și C. supinus I. (E.tel, l. r. 42 ). 


\section{ELALGNACEE.}

\section{IIIPOPPHÄ̈ L. - Ipofue.}

II. Ihatumoides 1. I. rhamunidă. - Vulg. Cătină-allsŭ. - Pe matcia riurilor de la pólele muntilor. - În Moldova (C:z. Florn XIX, 61 et Exsic.!) tólŭ (Guebh. menusc.); la Agiud, Foçälu (Huc\%. Lisise I, 80; Hoelzl l. c. 442), Odobesč, și pălnă ne milurile Sereluluĭ (Jidel l. e. 37 et lixsic..!): la Făurĕ̌ pe matca Putneŏ (Guehh. Not. manusc.); pe unatea Bistritere, a T'aslăulur și a 'T'rotuşuluı̆; in distr. Buzě̆ pe délul Sibiciuluı̆ ; în Prahova (Gr. En. 51 et Exsic.!) pe lìngŭ P'loesč (.Janka Oest. bot. Zcit. XXIII [1873], 322) pe matci 'Teléjenuluı̆ și a Doftaneǐ; la Tîrgoviștea pe matca Ialomițě́; etc. 一 t? Apriliŭ-Main.

Obs.-Elitaguns angustifolius $L$. (Cz. Flora XIX, 62 et Exsic.'; Sz. manusc.; D. Br. Jragm. l. c. 80; Gr. En. 51) vulg. Răchitică, Salcemirositóre, Maslin-sèlbatec, nu cresce de căt cultivat prin grădinY.

\section{THYHEL \&ACEE.}

\section{STELLER: I, - Stclerc̆.}

S. Passerina L.; Passerina amma Wickstr. S. Pasevinŭ. - Vulg. Limba-vrăbič. - Prin locurile aride. - Lat Tìrgul-frumos (Sz. manusc.).- $\odot$ Iuniй-Iuliǔ.

\section{DAPHNE L. - Dafne.}

I). Mezereum L. D. Mezoreй. - Vulg. Tulichinŭ, Tilickin. Tulcina, Tulpin, Chiperiŭ-lıpulü̆, Lsmu-ềnesc, Cleiție. - Prin pădurile din régiunea montană și subalpină. - În Moldova (Cz. Flora XIX, 64 ct Exsic.!) superiơră (Gucbh. manusc.); în distr. laș̆ la Hadîmb, Mironésă 
și Voinescĭ (Sz. manusc.); pe Cẻhlăŭ (Edel l.c. 35) și la 111-stirile Sihla! (D. alpina Gir. Erlor. l. c. 122 [non L.] et Eirsic.!; Ln. 50), Sĕcu, Sĕhăstria si Agapia-veche; la Mănăstirea-Cașinulŭ, Slănic și Palinca; la Predẻl; în Muscel la Hîmbovicióra (D. Br. Fragm. l. a 79); in Argeṣ pe m-tele Urḑica ; etc. — † Martiŭ-A priliu.

D. alpina $L$. D. alpin. - Pe stincile din regiunea alpină. - În m-ṭĭ Moldově̆ (Cz. et Sz. l. c. 20 et Exssic.!; h. j. Gueble manusc.). — † Maĭ̌-Iuliŭ.

0lıs.- Se mař citéză : D. Laureola L. în Moldova (Cz. et Sz. l. c. 20).

\section{CERATOPHYLLEE.}

\section{CERATOPHYLLIII L. - Ceratofil.}

C. demersum L. C. imecat. - Vulg. Cosor. - In apele stagnante și lin curgĕtóre. - În Moldova (Sz. manusc.); în Vlașca (Gr. Ëu. 25) la Comana. - 2 Iuniǔ-Iuliǔ.

C. submersmm $L$. C. cufumlat. - Ape stagnante și lin curgětóre.-În Moldova (Cz. Flora XIX. 66?; Sz. mamuse.).

\section{URTICACEE.}

\section{URTICA Tompuef. - Uritică.}

V. IIrens L. U. ardétóre. - Vulg. Lidică-mică, Crdiča-crăiéscĕ, Oirşé. - Prin locurr̆ cultivate și inculte, dĕ-

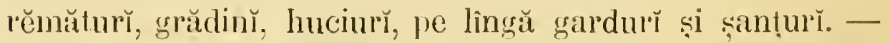
In tótă Romănia! (Cz. Flora XIX. 61 ot Exsic.!; Edtel l. c. 39; Gueble. manuse.; Cz. et Sz. l. c. 5; Sz. manusc.; Gr. Erhor. l. c. 121 it En. 52), - ○ Julin-Septembre.

U. dioica L. U. dioică - Vuls. Urdică-mare. - Prin pădurĭ, locurř inculte, pe lìngă locuințĭ, gardurĭ și șanturur. - În tótă Romănia! (Cz. Frlora XIX, 61; Edrl l. c. 39; 
Guebh. mumusc,; Cz. et Siz. l. c. 5) S'z. mumusc.; Gir. Eirbor. l. c. 121 it En. 52). - 2t Iuliü-Sirptemlier.

\section{PARIETARIA Tommet. - Jarieturie.}

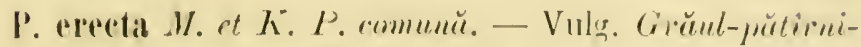
cher, Parucherniţă. - P'rin locurĭ unbrose și umede, pe lîngă zidurř și prin ruine. - În Moldova meridionalá ( $\%$.

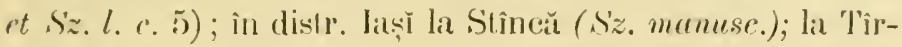
govișlea prin ruinile de la Chindie; la Rimnicu-Vîlceĭ (Hoff. manusc. ef Escsic.!) 'în '/ăvoiŭ; la 'T'urnu-Severin pe ruinele T'urnulǔ! (Gr. Ein. 52). - 2 Iuliŭ-August.

\section{RUTACEE.}

\section{HAPLOPHYLLUM Juss. - Aplofil.}

II. Biehersteinii Spach; Ruta Biehersteinii Veilr. R. linifolia 11. Bieh. A. Lǔ Bieberstein. - Prin stepe şi pe coline aride. - In Moldova (Nym. Consp. 142) inferióră lit Pechea (Ruta suaveolens DC. /p. p.7 et Esssic. ". 330 sec. Nym. Consp. 142). - 2 Iипій-Iиеliй.

0lss. - Se cultivă : Ruta graveolens L. (Cz. et Sz.l.c. 22 et Ersic. !; Sz. manusc.; Gr. En. 17) vulg. Rutr, Virnantiu.

\section{DICTAMUS L. - Dictam.}

D. allus L.; D. Fraxinella P'ers. D. alb.-Vulg. Frăssinel. - In Moldova (Értel l. c. 39 et Exsic.!) inferióră și centralŭ (Guebh. manusc.); de la Huṣ̆ pănă la Galaț̣ și cu deosebire fórte frequent la Pechea (S'z. manusc.), TTigănescĭ și Plăcinta (Cz. et Sz.l. c. 22 et Exsic.!); între Ploescí (Janka!) și Filipescì (Gr. En. 17 et Exsic.!); in Vlasca la Comana; la Visciorova către Porțle-de-fer pe m-tele St.-Petru; etc. - of Maiй-Iniй. 


\section{TRIBULUS Tomrnef. -- Tribul.}

T. terrestris L. S. terestru.-Vulg. Päducherniță, P̌ăduchile-elefantulur, P̌̈uduchele-caliculur, Colț-baber. Prin locurĭ sterile și aride, pe lîngă drumurĭ. - În Moldova (Édel l.c. 39) inferióră (Guebh. manuse.); la Galațĭ (Sz. Lxsic.!) și Têrgu-frumos (Sz. manusc.); între Poiana, Calafat

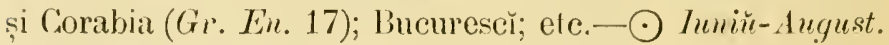

014.- Ailanthus glaudulosa Desf. cultivat în grădinì! (Gr En. 18).

\section{CRASSULACEE.}

\section{SEDUII Tominef. - Secl.}

S. Rhodiola DC. S. Rhodiolă. - Vulg. Rosăcicŭ, Ruşŭ, Rinjă. - Prin locurile stincóse din reginnea alpină. - Pe Céhlăŭ (Rhodiola rosea L. Cz. Flora XIX, 64 et Exsic.!; h.j. Guebh. manusc.; Edcl l. c. 35); în m-țǐ Bucegĭ la Strungă $(F r .110)$ și la Pirăul-Babelor. - - I Iuliŭ-_lugust.

S. IIaximum Suter.; S. Tclephium ß. ochroleucum Neilr. s. förte mare. - Vulg. Iarbă-grasă, larbü-de-urechĭ. Prin pădurĭ, tuferișurĭ, locurĭ stincóse și calcare. - În tótă Moldova (S. Telephium Cz. Flora XIX, 65 et Exsic.!; Guebh. manusc.; Cz. et Sz. l. c. 23; Sz. mamsc.; S. latifolium Bertol.h.j. Guebh. manusc.); pe Céhlăŭ (S. Telephimu Edel l. c. 36); pe lîngă Iașĭ la Repedea de-asupra Petrărieř; la Ciaraclăŭ pe délul Straja; la Ciocănescĭ $(G r$. En. 36 et Exsic.!); în Vlașca la Prund; etc. - 2 Auguest-Sept.

S. purpuraseens Koch.; S. Telephium 3. perpurenm L. s. purpuriǔ. - Prin locurile calcare, petróse și stîncóse din munțĭ.-în Moldova (S. purpurenem, Tausch. Cz. Flora XIX, 65 ; $C z$. et $S z$. l. c. 23); în distr. Iași la códa IazuluǐChiriteĭ către Şĕpte-ómen (Sz. mamusc.)?; la Mănăstirea- 


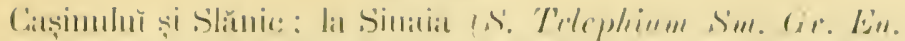

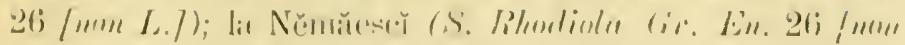

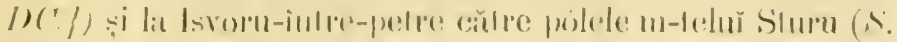

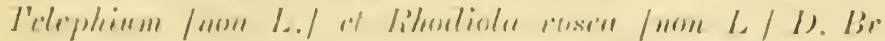

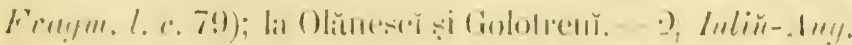

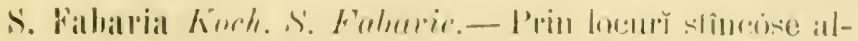

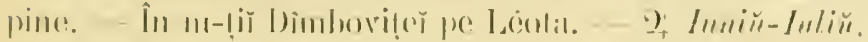

S. I'epatal L.; S. spullu'retum II. Kit. S. spalulul.

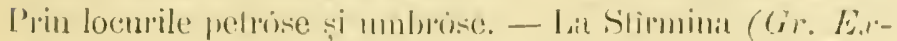

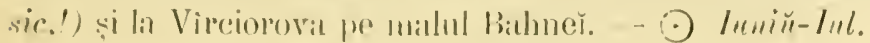

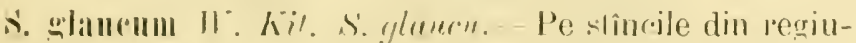

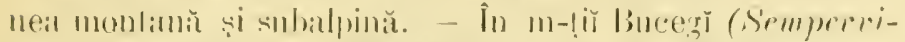

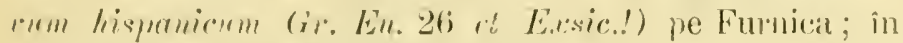

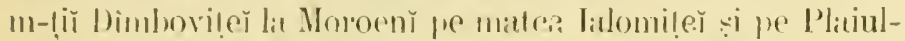

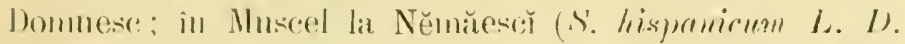

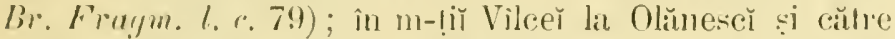
Loflu pe Furfecat si Naro! : la V'ônciorora călre Portile-de-

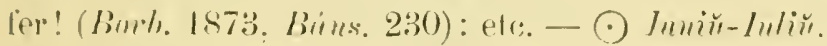

S. atlatutu L. S. urgricius. - Prin pășmnile petróse din regimnea alpină. - În m-lii Buceğ pe Omu (1.5̃ : Frou. 200) si pe Furnica. - O Inlin̆- Luyns.

S. ammum L. S'. nmunl. - Prin locurile perrose pe

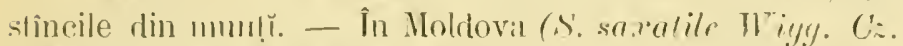

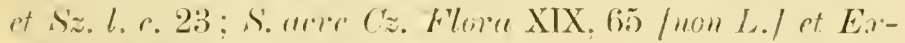

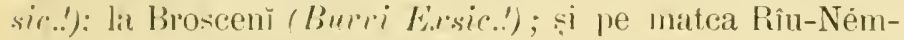

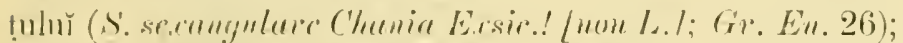
la Sinalia (Gr. Eu. 26 ri E.ı̀c..!); re vîlul Penteleulı̆ : în

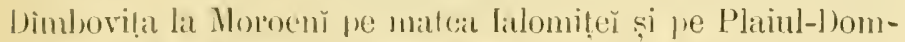

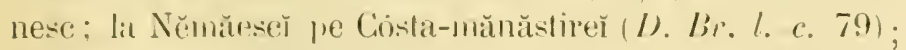

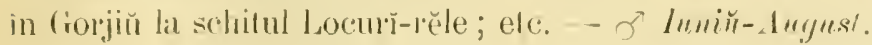

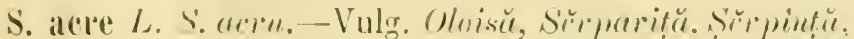

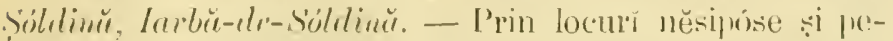

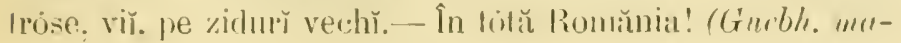


muse.; Edel l. c. 37; Cz. ct Sz. l. c. 23; Sz. manuse.; D. Br. Fragm. l. с. 79; Gir. En. 26). - 24 Iипій-Inliŭ.

S. Sartorianum Boiss. S. Sartorian.-Prin locuř něsipóse și pelróse. - In Mehedințî intre Şchelea-Cladover și Porțile-de-fer. - 2) Iıтій-Inliй.

0)ৎ. - Se maǐ citéză în Moldova : S. villosum $L$. (Cz. et Sz. l. c. 23). -S. dasyphyllım L. (Cz. et Sz. l. c. 23). -S. stellatum L. (Guebh. manusc.).-S. allum L. (Cz. et Sz. 23). - S. reflexum L. (Cz. et Sz. 23). - S. seximugulpr L. (Cz. et Sz. 23). - S. rupestre Lej. (Cz. et Sz. 23).

\section{SEMPERVIVUII L. -- Semperviǔ.}

S. tectorum L. S. ale acoperisurè. - Vulg. Lrechichnițŭ. Erecheriță, Lirechiusă, Jarbŭ-de-urechic, Iarba-ureshě, Iarba-ciulč, larba-tunului, Fardă-de-síucă. -- Pe stîneile calcare din muntì. - In Moldova (Edcl l. c. 40; $C z$. rt Sz. l. c. 24) superióră (Guchlı. manusc.); în m-tĭ Buzĕulǔ la ml-stirea Nifon (Hoff. Excurs. 1863, l. c. 117); în Muscel (Hoff. Excurs. 1862, l. c. 39); și la Bucurescì (Fr. En. 26) transplantat pe acoperișurile rechĭ ale caselor: eic. - 2 Inliŭ-Angisst.

S. blandım Schott. S. blûud. - Pe Pétra-Graiuluĭ la Vîrfu-Baciuluĭ (Kotschy 65).

S. Ileuffelii Schott.; S. patens Griscb. S. lǔ Henffel.Pe slincile calcare din munț̆. - Pe vîrful Céhlăulıı̆ la Panaghie: în Argeș pe vîrful Coziel și pe Urd̦ica; în Vîlcea către Lotru pe Fórfeca; în Gorjiŭ intre Chenia și schitul Locur'r-rĕle; etc. - of Iuliŭ- August.

S. liìtum L. S. pèros. - P’e stîncile calcare din muntĭ.În m-lị̂ Moldover (Cz. ct Sz.l. c. 24; S. globiferum Cz. Flura XIX, 65 /now L. nec Bmy./ et Exsic.!; Cz. et Sz. l. r. 24). - 2 Iuliü-August.

Obs. - Se mar citéză în Moldova : S. montaumu (Cz. et S'z.l.c. 24). - S. aruchnoileum L. (h.j. Guebh. manusc.?; Cz. et Sz. T. c. 24). 


\section{BERBERIDACEE.}

\section{BERBERIS L. - Drarila.}

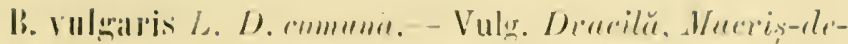

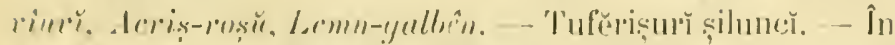

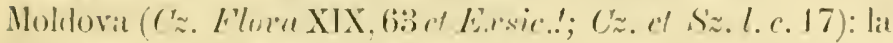

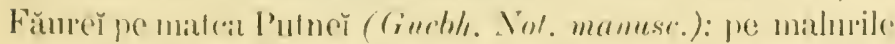

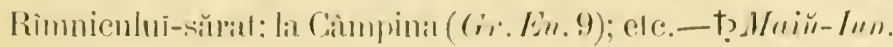

\section{SCB-D!YISIUNEA II}

Ovariŭ unilocular ; placentatịne parietalĭ.

\section{NIUPH EACEE.}

\section{NYMPHLA L. - Nimfă.}

N. alha L. N. allǔ̆. - Vulg. Ninfăr-alb. Plutŭ, Plumirrü-albü. Plumună-allı̆, Titra-ds-apü. - Prin apele stagnante și lin curgĕtóre. - În Moldova ( $C z$. Flora XIX, 66 ot Errsic.!) centrală (Cruebh. mauresc.); de la lacul Brates (Edel l. c. 38) pănă ve lingă Iașy (Cz. et Sz. l. c. 31); la Cristescĕ în Vladnic (Sz. manusc.); in rìul Bêrliıd; în Cülniscea

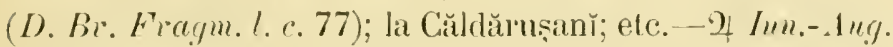

\section{NUPHIR Sim. - Nufür.}

N. Iuteum Sim. N. galbên. - Prin apele stagnante și lin curgètóre. - In Moldova (Nymphea lietca Cz. Flora XIX. 66) centrală (Gucbh. mamusc.) și septentrională pe linği 
lașǐ (Cz. ct. S'z. l. c. 31) de lat Larga în sus, jal în jos de laș̆ nu se scobóră (s'z. manusci.); re lingă lacul Brates (Edel 1. r. 38); ît riul Bêrlatd: la Comana în Cătniscea (I). Br. Frogm. l. c, 77): pe lingă Bucurescì la Cernica! (Gr.

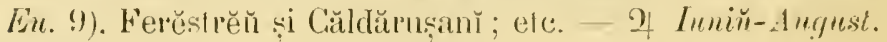

Obs. - Se mat cith\%̆ : l. pumilum Sm. în Moldova (Nym. Consp. 2:3).

\section{PAPAVERACEE.}

\section{PAPAVER Tom'Ief. - Mac.}

P. Rharas L. M. comm. - Vulg. Mac-rosu, Nac-iepuinsc, Paparună. Paparóne. - Locuř̌ něsiposse cultivate ç̣ ruderale.-In tólă Romănia! (Gucbh. mamusc.; Edcl l. c. 40; (z. r' Sz.l.c. 30; Sz. mamusc.; D. Br. l. c. 78 ; Gr. Erhor. l. c. 132 ol En. 9; Kanitzl. c. 173).-○ Mciй-Juliŭ.

P. Inbium $i$. M. dubiǔ. - Prin locurr̆ nĕsipóse cultivate și inculte. - In Moldova (Cz. F'lora XIX, 66 ct Eit-

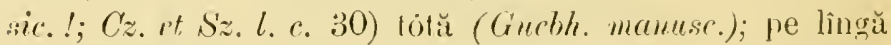
Iaș̆ către Șĕple-Önent̆ (Sz. munusc.); la Bucurescŭ (D. Br. Fra.gm. l. c. 77); la Vîrciorova către Por!̣ile-de-fer! (Borb.

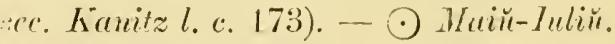

ß. glabrum Koch. - Lat Bucuresč̆.

P. hybridum L. M. ibrid. - Printre sĕmĕnăturı̆. - În Moldova (Cz. et Sz. l’ e 30); pe lingă Iașĩ la Balcin și Miroslavit (S'z. manusc.). - $\odot$ Maій-Luliŭ.

P. alpinum L. M. alpin. - Prin locurile calcare din re-

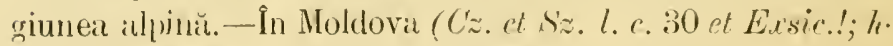
j. (ruebh. manusc.) pe Cèhlăŭ (Janke! sec. Kanitz l. c. 173): in u-lii Buceš (.1.51; F̂. 114; I. pyrenuicum Kotschy 135) pe Omu! (Fron. 149). - 2 Luliŭ-1ugust.

0)h. - :e maĭ citéză : P'. Arugeinone L. in Moldova $(C z$. et Sz. l. с. 30). - lar P. sumuifer'um L. numaY cultivat! (C'z. Hor XIX, 66 ef

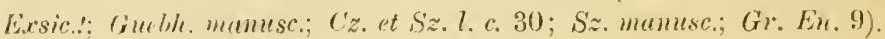




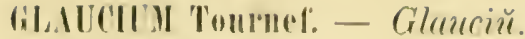

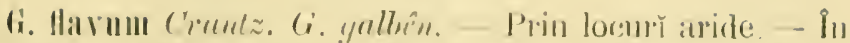

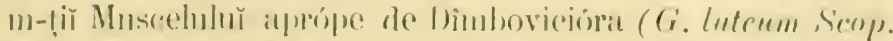

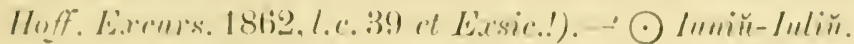

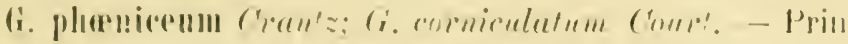

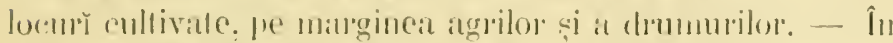

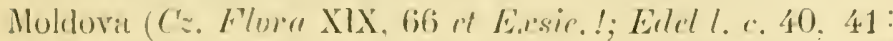

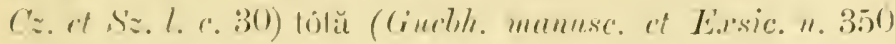

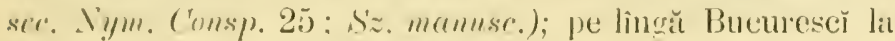

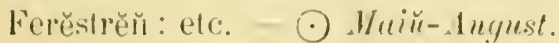

\section{(HELIDOSIIII Tom1'nel'. - Chelidoniŭ.}

C. majus L. C. merer - Vulg. Riostopască, Rostopaste. Iarba-sandanelri. Negelarită. - Prin locurile umbróse de

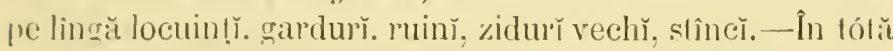
Romănia! (Cz. Flor a XIX, 66 el Exasir.!; Cinebh. meannse: Cz. ot s'z. l. c. 30; sz. manuse.: D. Br. Fraum. l. \&. 77; (i). Eibor. l. c. 132 et E.rsic.!; En. 10).-2 M(aĭ-Sept.

\section{CORYDAJIS DC. - Coridatidü.}

C. Manschalliana Pers. C. lù J/arsehul. - Prin pădurile umbróse de la m-stirea Adam (Guebh. mamusc.). - 9 Martiй-1/aiй.

C. cara Sehu. et Konert. C. exectuat. - Vulg. Brébüu. Brelıenc\%. - Prin pădurile umbróse, pănă în regiunea subalpină. -- În Noldova (Edel l. c. 40; C. bulbosa var. Szalumis $C z$ of $S_{z}$. l. e. 43 ; Fumaria cava vill. Cz. Flor. XIX, 69) ot Evsic.!; Cz. ot Sz. l. e. 43; Sz. mamuse.); lil m-stirea Adim (C. bulbosa Pers. (inebh. manusc.); pe lingü laṣ̆ la Niṭelea ; pe lingă Bucurescè la Bănésa (Gr. Ėu. 10 : 
C. tuberosa DC. D. Br. Fragm. l. c. 78); la Sinaia pe la pólele Furnicě̌ ; etc. - 7 Martiй-Maiй.

P. albiftora Kit. - Tot în aceléṣ̌ locurŏ.

r. solida Sm.; C. digitala Pers. C. solidă. - În pădurile umbróse. - In Noldova (Édel l. c. 40; Fumaria solida L. Cz. Flore XIX, 69 et Eirsic.!, Cz. et s'z.l. e. 43) tótă (C. Hulleri Hay. Giuebh. memusc.): pe lingă laș̆ la Hadìnb, Mironésa, Mogoşĕscĭ (Sz. mamusc.) şi Nitelea ; în Ilfov (Gr. En. 10) pe lingă Bucnrescĭ la Bănésa (C. fabacea D. Br. Fragm. I. c. 78 /uon L'ers.7; Cir. En. 10 et Exsic.!), Antonachi și Cŭlugărésca; Comana ; etc. - - ) Martiŭ-Laiŭ.

C. decipiens Sch. Nym. Ky. C. inspélatóre.-În regimea alpină.-Pe Pétra-Cirainluĭ (Kotschy sece. Schur Ë. 37).

0bs. - Se mar citéză : C. (alpnoides Wrhllbg. ìn Mold. (Cz. et $S z$. 43).

\section{FIMARIA Tournef. - Fumarie.}

F. officillalis L. F. oficinală. - Vulg. Săftevera. Fumă-

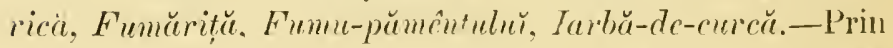
locurř něsipóse cultivate și inculte. - In Moldova (Gucbh. manusc.); la Virciorova către Porțile-de-fer (Borb. 1873. Bäls. 276). - $\odot$ Maій-Sepicmbre.

ß. srandcus lichb. - La Virciorova către Porțile-de-fer frequentă (Simli, 520).

F. prehensilis Kit. F. preensilă. - La Virciorova către Porțile-de-ter (F. calycina Borb. 1873, Bius. 276).

F. anlatolica Bois. F. anatulicŭ. - La Vîrciorova către Porțile-de-fer (Simk, 520).

F. Vaillantii Lois. F. lǔ Vaillant. - Prin locurǐ cal(are cultivate și inculte. - În Moldova ( $F$. parviftora $C^{\prime}$ z. ct S. l. c. 43 [nou Lam.]?) inferióră (Gucbh. mamusc.); pe lingă Iaşi la Tubana, Renedea ' $F$ ' parcittora S'z. mamusc.?). și Nițelea; la Agiud (Burri Exsic.!), pe lingă Bucurescĭ la 
Bănésa (F. pmeviflora I). Br. l. a. 78 [nom Lam./), Cotro-

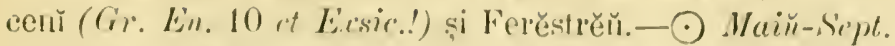

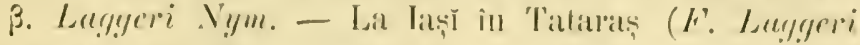
Jord. V.! sece. Kunitzl. c. 174).

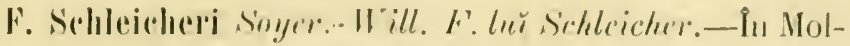
dovil (F'. officimelis $C_{z}^{2}$. Flora XIX, 69) / mom L./ at Essir..';

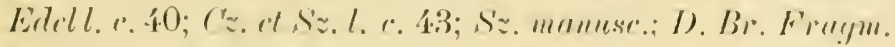
l. c. 78); in P'rahovat și llfor (F'. officiualis (ir. Lin. 10 / nom

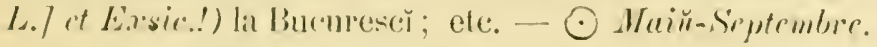

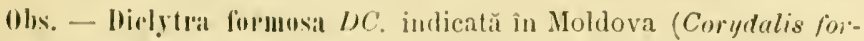
mosu Audr. Eilel l. c. ‘0). mu cresce de-căt cultivată prin grădinT.

\section{CRUCIFERE.}

\section{N.ISTURTIIII R. Br. - Nasturtiǔ.}

N. officinale R. Br. N. officinal. - Vulg. Yasturel.

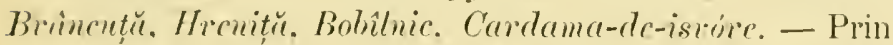
pîrăie. isvóre și mlastinı̆. - În Noldova superiobră (Grueble. munuse.); la pólele Céhlăuluĭ (Sisymbrinm Nasturtium Edel l. с. 36); pe lingă Bucuresč (Gr. En. 11 et Ersic.!) la Fi-

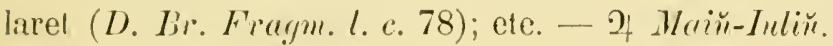

N. allstriacun Cromtr.; Roripa austriaca Bess. N. austriac. - Prin locurĭ umede și mlastinóse, bălțĭ, pe malurile apelor. - In distr. lac̣̆ pe malul Prufuluú (Comelina austriaca Pers. S'z. manusc.); în distr. Bacăŭ la Veršesě̌ ; la Falați (Cechtr. ct Sint. sce. Kanitz l.c. 175); pe lingă Bucurescĭ la Bănésa ṣi Ciocănescĭ (D. Br. Fragm. l. c. 78; Gr En. 11 ct Exsic.!); la Comana ; între Schelea-Cladoveǐ și Gura-văieì pe malul Dunărě̀; etc. - If Maiŭ-Lulin̆.

X. amphiliumm $R$. Br. N. amfibiŭ. - Prin bălı̣̆, ape stagnante, pe malurile riurilor. - In Moldova (Sisımbrium (mpllitriem L. et S. aquaticum Poll. Cz. Flora XIX, 68 et Exrsic.!; Sz. manusc.; S. terrestre Cz. et Sz. l. c. 40 [non 
alior.] st E.rsir.!; Sz. manusc.): la Galatĭ (Gucbh manusc.) la Câmpina (Roripu amplibliu Bess. (ir. Eu. 12 et Exssir.!): la Ferěstrěn̆ și Chitilat ele. - Maiü- Lugust.

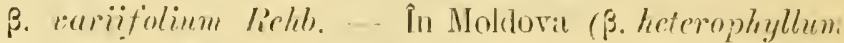
Bung. Cz. ei siz. l. '. 40; Sisymbrimm pimmatifidum Cz.

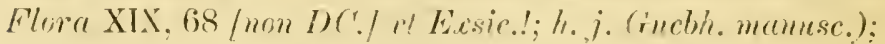
in Ilfov înlre Colentinat și Fundenı̆ (rro. Exsic.!).

X. alrmoracioides Tumsrh. Y. armoracioid. - La frumfaria Romănicĭ (lespre Orşova (Jiuli. XVI, 16).

N. sylvestre R. Rio: Roripa syliesstris bess. I. de püdure. - Prin locurǐ unede, pe lînğ pîrăie. bălți și rîữ. - In Moldova (Sisymbrium sylecsire L. Cz. ct Sz. l. c. 40; Sz. manuse.; Lepidium sationm Cz. Flora XIX. 68 fnon

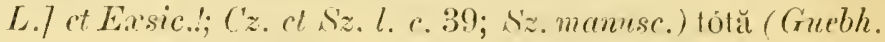
mamusc.); pe lingă laṣ̆ (V.! ser. $K$ (n)iizl. r. 9) la Nitelea și Repedea; la Bucuresci, Bănésa (D. Br. T. r. 78; Gr. En. 11

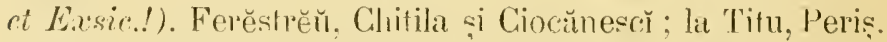
Buftea, Grivina si Sinaia (N. limpizense Gr. Fu. 11 /non

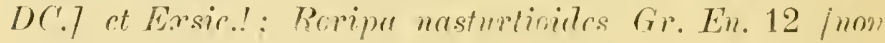

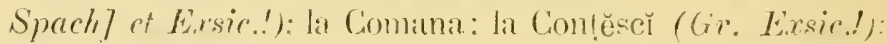

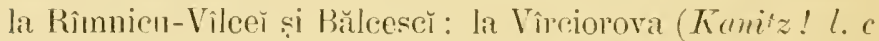

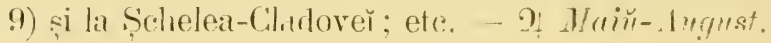

X. barbanpoides Tausih. P. marrostylum. Y. barbarenirl. Prin locurile mmerte de la Comana. - of Thär-Immiั.

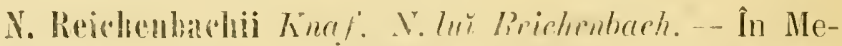
herlinț la fruntaria diutre Romănia su Lugaria (Roripo

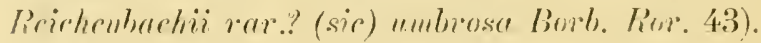

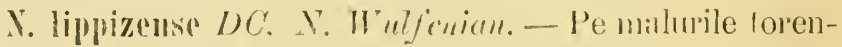
telop din Moldovat smperionă (Gucble. mamusc).

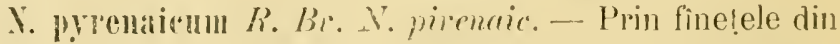
văile muntilor. - În Molrlovil (sis?ymbrim pymenaicum L.

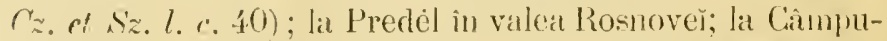

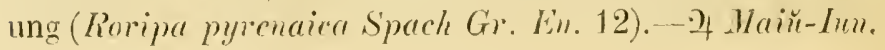




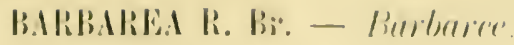

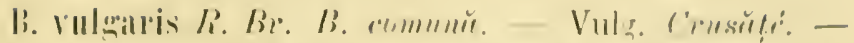

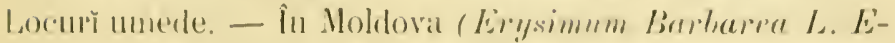

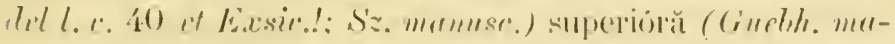

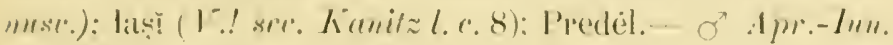

b. archata lichlo. B. armutir. - P'rin locurile unede de

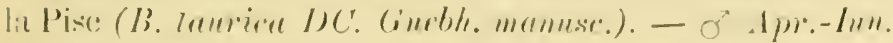

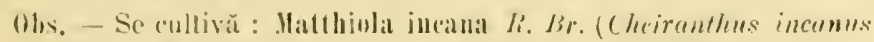

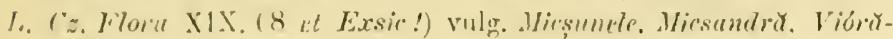

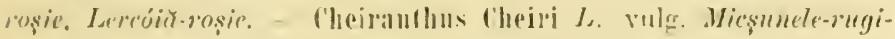

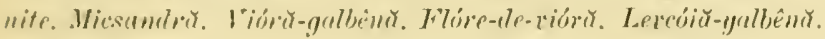

\section{TURRITIS L. - Turitǔ.}

T. glahra L. T. qulabrü. - Vulg. Turnusplĭ, Twricelü. Timmititu. Ploin finele sterile și pe coline uscate. locuri petróse și nĕsiprise. -- In Holdova (Cz. Flora XIX. 68 ei L.rsic.!; Edtel I. f. 40 ; Sz. mamse.; Erysimum austria-

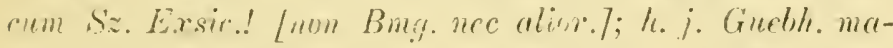
unsc.) totă (roulde. manuse.); La Bucurescì (Arabis perfo-

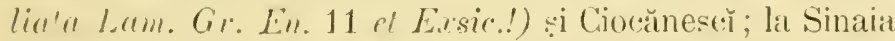

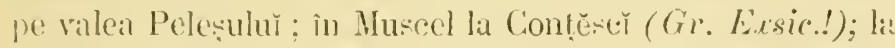

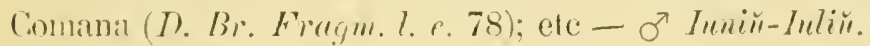

\section{AR.IBIS I. - Arabirlă.}

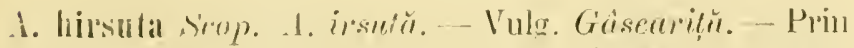
locurile aride rle pe coline și din munți.-- În Holdova (Tur-

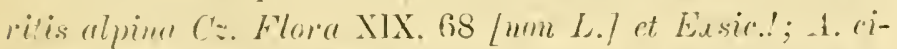
liata h.j. Gurblh. manuse. (uon R. Br. nee alior./) centralü (Gucbh. manus.s.); in distr. Taš̆ cĕtre Ş̌pte-Omenı. Aroneni

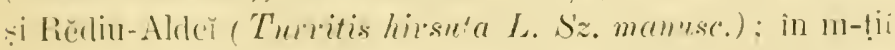
Buceor si la Predel: la Cimpulung pe valea hin-T'irgului 
A. muralis Cre. En. 11 /mon Bertol.] et Exsic.l; la Virciorova călpe Portile-de-fer! (Br,rb. Haz. Arab. 167) și pe

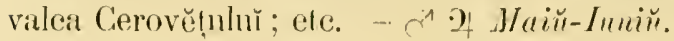

1. sagitlata DC. 1. somitu'te. - La Sinatia pe matcil

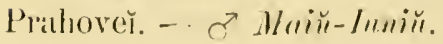

A. alpestris Schloich. 1. alpcstră. - Prin ciěpăturile: stîncilor și prin locurile petróse din regiunca subalpină și alpină.-- Intre Dînbovicióra și Rucăr (A. riliata auct. [non R. Br.] Hoff. Excurs. 1862, l. c. 39). -- o Itniü-Luliǔ.

A. serpyllifolia Vill. 1. en for de serpren. - Prin locurile stincóse și calcare din regiunea subalpină și alpină. - În m-ḷi Buceğ pe lìngă schilul Pescera de la Ialomị̦a (Schur En. 43). - C Inniŭ-August.

A. siricta Huds. 1. strinsŭ. - Pe stîncile din regimea alpină.- În m-tị̆ Bucegĭ (Schter En. 43). - 2 M Maĭ̌-Auq.

A. anriculata Lam. A. anviculată. - Coline aride și locurř calcare și muntóse.-În Moldova (A. stricta Sz. Exsic.!

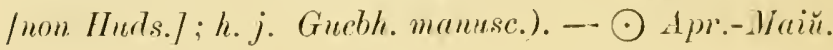

A. alpiıa L. A. alpinŭ. - Prin crĕpăturile stincilor și prin locurile petróse și umede din regiunea alpină și snbalpină. - In Moldova (Cz. Flora XIX, 68 et Exsic.!; h. , . Gruebh. mamesc.; 1. pumila Sz. Exsic.! [non Jacq.7: h. ;. (rucbh. manusc.) pe Céhlăŭ; la Sinaia în valea Cășŭrieì ( $G$ r. En. 11); în m-ṭi Bucogi în valea Ialamị el ( $F r .114)$ și a Colțĕĭ aprópe de schitul Pescera, pe Obirșia; etc.-2) Jun.-Aur;.

A. procurrens W. Kił. A. abundantă. - Prin locurile petróse şi umbróse din regiunea subalpină. - La Pasul T'urnu-roșŭ frequent (Schur En. 43). - 2 Maiй-Lıniu.

A. bellidifolia L. L. cu for de belinlă. - Prin păşınile umede și stîncóse din regiunea alpină și subalpină. În m-tịi Moldoveř (Edel l. c. 37 et Exsic.!; h.j. Ciucbl. manusc.). - 2 Iuniǔ-August. 


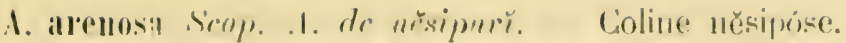

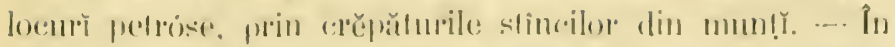

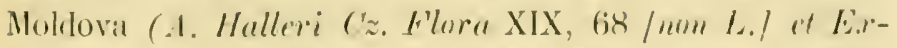

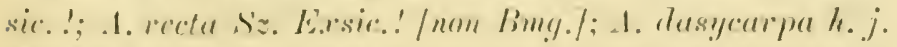

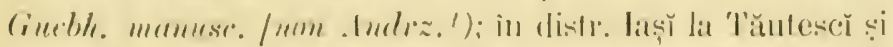

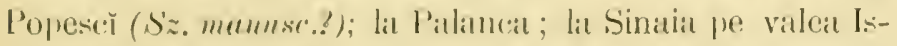
vorul (.1. Malleri (ir. Lin. 11 / m " L. / of E.rsie.!) și at

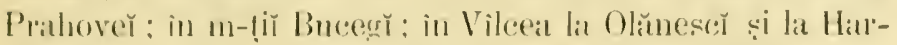

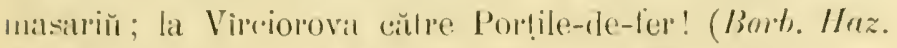

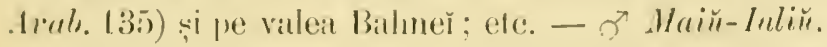

A. Thaliana L.; Comringine Thalime Rerhb.; Sisymlrium

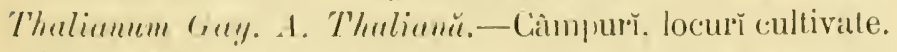

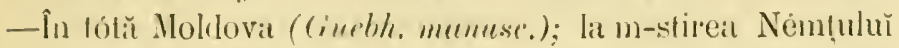

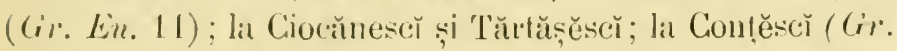

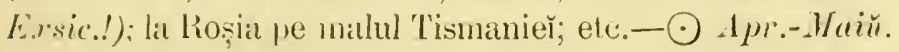

\section{CARDMIINE L. - Cardamină.}

C. pritlensis L. C. de finete. - Prin finețe si poeni u-

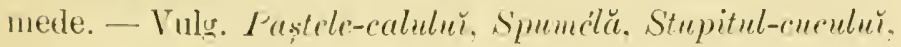
Scriputul-cuculur. - In Moldova (Cz. Flora XIX, 68; Edel l. c. 40); in distr. Iaç̌ către Hordea (Sz. mamusc.); lat

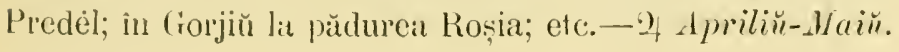

C. rivularis Schur. C. de pîrüie. - Pe lîngă pîrăile și isvórele din regiunea subalpină și alpină. - In m-țî̀ Buceeš pe Funnica, in valea Colțĕ, pe Obîrçia, Pétra-arsŭ, la Pirrŭu-Babelor ; la Predél; etc. - 9. lıniŭ-August.

C. amara L. C. anarŭ. - Prin isvơre şi locurŏ umbróse din munț̆. - In Moldova (Ërlel l. c. 40 et E.rsic.! ; Sisymhrim Nasturium Cz. Flswa XIX, 68 / non L./ et Exsic.!; ('z. el Sz. l. c. 39): la Campina (Gr. En. 11 et Exsic.!) și Predèl; la Rimnicu-Vîlcề în Zăroin̆; etc. - 2 .lpr.-Maĭ̌.

C. Impatiens L. C'. Jmpacientă.-Vulg. Rijnică.-Prin locurile petróse și umbróse, pe lingă isvorele și torentele 
mă̌ cu sémă din reginnea montană și subalpină. - In Moldovar (Edel 1. r. 40) centrală ('ruelht. mamese); la Sinaia

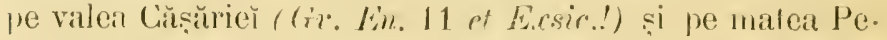
lesului și a Prahově : in Mnseed la isvorul de la Mateiaṣ. în Pescera de la Dìnboviciora (Vasturtimm pulus'op I). Br.

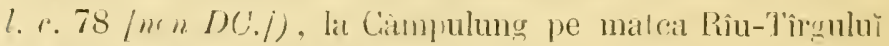
(Sisymbrinm pinmetifidum Gr. En. 11 [non DC.] st Eitsic.!) și la Conțěscr̆ ; în Vileea pe valea Bistriṭeř ; în Melıedinți la Dumbrăvi!a (Gì. Exsic.!); ete. - or Main-Inliu.

C. sylvatica Link. C. de pürture. - Prin pădurile din

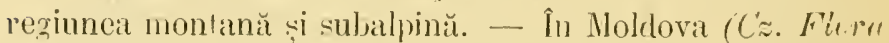
IIX, 68 ct Exsic.!): la Sinaia pe valea Peleșulnù (Gr. En. II e! Exsic.!) și la Predél; în Muscel la Conṭesser ; în Mchedințĭ la Dumbrăvila (Gr. E.rsis.!); etc.- $\odot$ Apriliŭ-Iunix.

C. Lirsuta L. C. irsutŭ. - Prin locurile umede și unbróse din pădurile montane. - La Càmpulung pe matcal

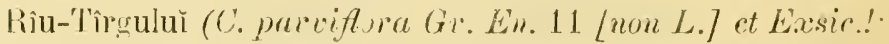
Sisymbrinm supimum Gr. En. 11/non L./ et Exsic.!) si la Con!̣̆sč̀ (G). Eusic.!); liı Vìrciorova cŭtre Por!̣le-de-fer" (Burb. Haz. Lrah. 167); etc. - $\odot$.1priliй-Inпій.

C. parviflora L. C. parvifurŭ. - Prin locur unede și umbróse.-- La Roșia pe mahıl T'ismaneŭ.-- $\odot$.lpr.-Tuliŭ.

C. Iongirostris Janka. C. Iongivostiă. - La Vîreiorova

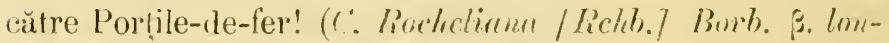
firostris [.Janlinl) Bor\%. Haz. Arab. 169).

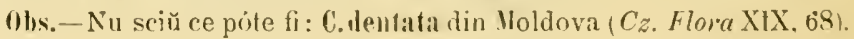

\section{IDETARIA I. ... Dentarie.}

1). bulbifera L. D. bulbiferă. - Vulg. Coltisor. - Prin pădurile umede și umbrose, pînă în reginnea subalpină.

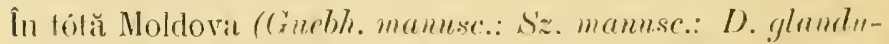
losa $C z$. Flma XIX, 69 [mon II. Kit.] et Exsic.!); pe Cè- 


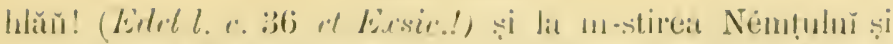

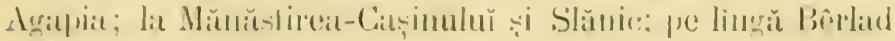

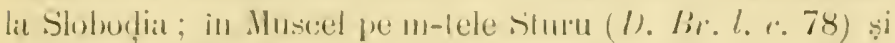

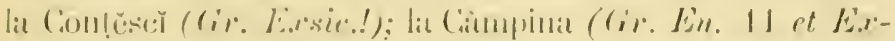

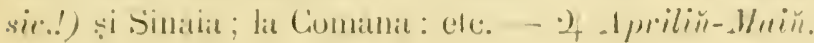

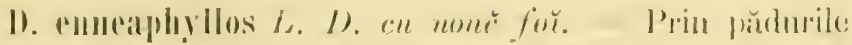

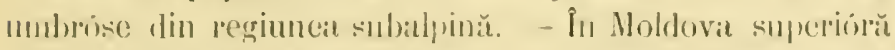

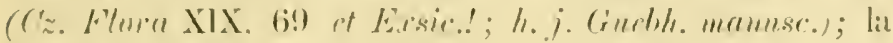

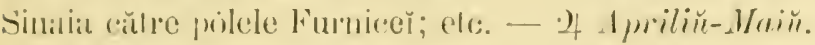

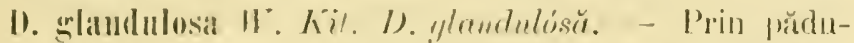
rile umbrise din regiuncit monnană ș subalpină. - In Mol-

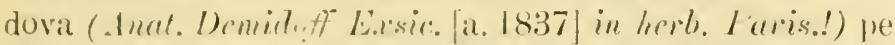

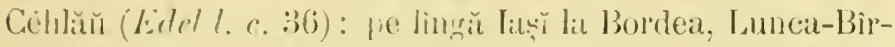

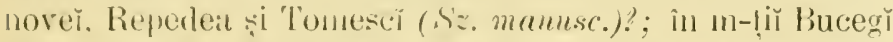

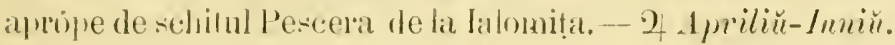

\section{SISYUBRIIM L. .... Sisimbriu.}

S. Alliaria ścop. S. Alinrir. - Vuly. Csturoitu. Alin-

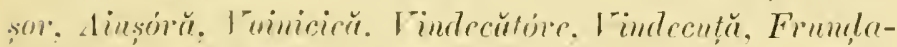

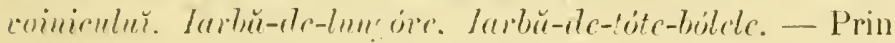
locurile unbrose din pădurĭ, tuferișuř̆. huciurŭ, crînguri și

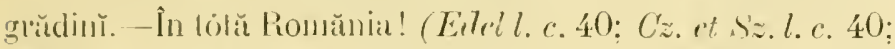
Sz. manuse.; Allinia of ficinalis Andrz. Guebh. manusse; D. Br. Frumm. l. c. 78; Cir. En. 11 el Eirsic..; Erysimum

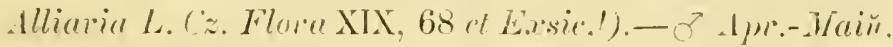

S. strictissimum L. s. föme sirims. - Prin locurile ॥-

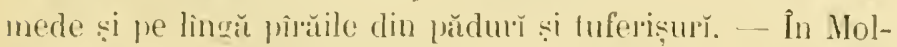

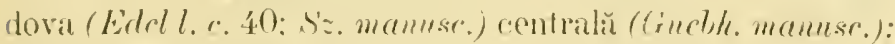

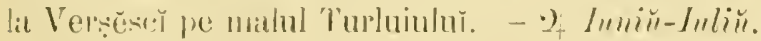

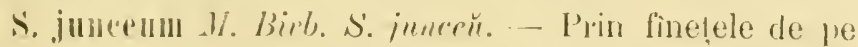
coline si prin locurile sirrale. - În Moldovat (Eirysimum juncrum II. Kir. Cz. Flore XIX. 68 et Ex.sxic.!); la Cordalloi

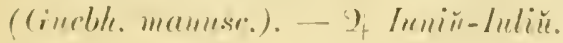


S. Sophia L. S'. ințélepciune. - Prin locurì nĕsipóse cultivate și inculte. pe lìngă drumuri. ziduri și dărĕmăturí. - În tótă Moldova (Cz. Flora XIX. 68 et Esssic.!; Gruebh. manu.sc.; Cz. p! Sz. !. c. 40 ; Sz. mumusr.); pe lingă Iaş̆ la Repedea si Nitelea (D. Br. l. c. 78); pe lin_ă Bucurescĭ ('ir. Lu. 11 et Exsic.!); etc. - $\odot$ Apriliŭ-S'sptcmbre.

S. pannoniam Jacy. S. myzrir. - Locurì inculte, pe lìnğ drumurì și pe marsinea agrilor. - In Holdova (' et. Áz. l. c. 40) inferióră (Gucbh. memuse.'; la Cürnicenť și Proboda (S'z. manesc.); la Bucuresč́; la Virciorova! (Kanitz! l. c. 10) călre Porţile-de-fer ; etc. - ऽ Maiй-Iun.

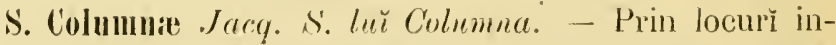
culte și ruderale. - In lótă Moldovia (Eidel l.c. 40 ; Gruclih. mamse.; Cz. et Sz.l.e. 40 ; Sz. manuse.); in Ilfor (Gr. Eit.

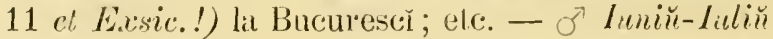

3. iemaisiliqua. - In tólă Moldova (Guebh. mamesc.).

S. Latselii L. S. Lm. Lassel. - Prin dărĕmăturř. locurı̆ inculte. pe lînçŭ drumurĭ zidurĭ, pe coline aride. - In tótă Moldova (Cz. Flora XIX, 68 et Firsic.!; Guebh. manuse.; Cz. et Sz. l. c. 40 ; S'z. mannse; Errece clogata Cz. Flora XIX, 65 [non Bimg./ et Exsic.!); prin viile de la laş̆ (Г.! sec. Lanitz l. c. 176); in Ilfor (S. Iri') Gr. Eu. 11 [non 1.) et Eissic.!) la Cotrocenr (ri. En. 11 et Exsic.!) și Bucurescī; la Rìmnicu-Vîlceĭ ; la Vîrciorova (Kanitz! l.c. 10) către Portile-cle-fer; etc. - or In

S. officinale Scopn. s'. aficinal.-Vulg. Broncuță, Frunda-voiniculı̌. - Pe càmpiile și colinele sterile, prin dărěmăturı̆, pe lingă drumurı̆. - În Moldova (Eilcl l. c. 40 ; Sz. mamusc.) centrală (Guebh. monusc.); la Verșěscĭ; la Sinaia; la Bucuresč̀! (Gr. En. 11 et Exsir.!); la Rimnicu-Vìlcě̃ ; la Vîrciorova!! (Kanitz! l. c. 11); etc. - $\odot$ Iuniŭ-lugush.

0 bs. - Se maĭ citéză : S. Irio L. in Moldova (Cz. et Sz. l.c. 40 ; Sz. manuse.). - lar s. montanum ce se indica in Moldora $(C z$. Flor $\mathrm{XIX}$ 68), иu scin̆ ce poite fi. 


\section{ERYSIMUII L. - Erisim.}

E. repandum L. E. respriudit. - Prin locurile sărate

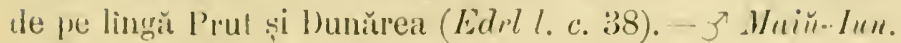

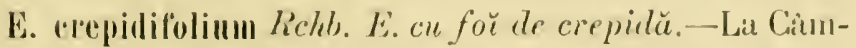

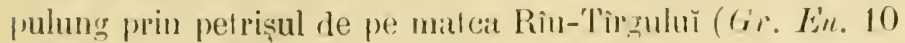
of Escsic. sec. Kaniz l. c. 176). - o l/ain̆-Junin.

E. Cheimanthus P'ers. É. C'hriraut. - Locurť stincóse subalpine și alpine.--în Moldova (Edel l.r.40): la Broscenı̆ (Burri Èrsic.!); în Bucegì (Schur Lin. 56). - 2) Jaiй-Jun.

E. odoratum Ekrh.; E. curniolicum Doll. E. odorant.P'rin locurile slincóse și calcare din muṇ̣̂. - În Moldova (Cz. Flore XIX, 68 it Lisie.!: E. repandum Cz. Flora XIX, 68 /nmu L./ ct E.esic.!; h.j. (inebh. manusc.: E. lieracifolium Cz. Flora XIX. 68 [non L./ et Exsic.!; h.j. (ruebh. manusc.; E. alpinum Sz. Exsic.! fum Roth]; h.j. (iuebh. manuse.); pe Céhlăŭ (Edel l. r. 36); la Caraclăŭ pe Babaghicea; la Sinaia (E. crepirlifoliem Gr. En. 10 [non Rchb.7 ot Ersic.!) pe malul Prahoveĭ și in m-țĭ Bucegǐ pe Furnica şi la schitul Pescera Jalomitẹ̆! (E. Czetzianmm Schur En. 57; E. Cheiranthus Gr. En. 10 /non Pers.7 et E.rsic.!); pe vî̀fu Cozieñ ; in Vîlcea pe valea Bistrițeĭ (Grr. Exsic.!); în Gorjiŭ la schitul Locurǐ-rĕle.- ơ Inuiй-Inliŭ.

E. canescens Roth. E. albicios. - Prin locurĭ aride și stîncóse. pe zidurı̌ vechĭ. - In Moldova (E. diffusum Elerh. Cz. Flora XIX, 68 et Exsic.!; h.j. Giuebh. manuse.; R. anyestifolium Cz. Flora XIX, 68 [nom. Elwh.] ot Exsir.!); in distr. Iiıșì la Erbicenı̀ și Popescì (Sz. manusc.); pe lingă Bêrlad : la Becenı̆. Văleň. Bucuresčs! (Gr. En. 10 of Exsic..'), Bănésa (E. odrixatum et E. chcirantoides (ir. En. 10); Ferěstrěŭ și Chitila; la Comana; in Argeṣ pe m-tele Urdica;

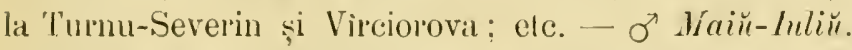

E. cheiranthoides L. E. cheirantoid. - In Moldova (Edel l. c. 40). - $\odot$ I lenir-Septembre. 


\section{CONRIVGIA Reblb. - Comringie.}

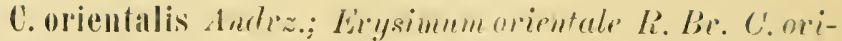
enlulă.-P̂n Moldova (Bras. orientalis L. Cz. et S. z. l. r. 40).

C. anstriala Rellb.; Brassica austriaca Jacy. C. anstriacă. - Lal Vîrciorova către Porțle-de-fer! (Barl). Has.

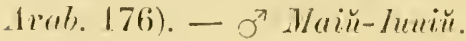

\section{SYRENIA Andr. - Sirenie.}

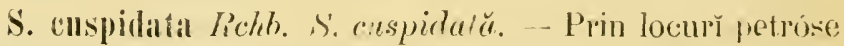
și aride. - In Noldova (Nym. Consp. 42 ; Erysimnu cuspidalum DC. Prodr. I. 197) lat Puḷ̆nı̆ (E. cusppidatum Gucblu. manusc.); pe lingă laçi la l'etrăria-Repedeí; în m-țĭ Bucesch ve lingă obîrșia Ialomițĕ (Cheirauthus cuspidalus Wr. Kit. Woff. Excurs. 1863, I. c. 120 ?); la Comana; la Turnu-Severin și la Vîrciorova către Por!̣le-de-fer?

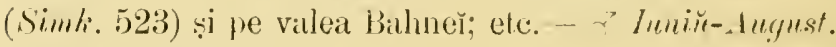

S. allgastifolia Relib. S. c'n for inguste. - Prin locuri něsipóse. - In tólă Moldova (Erysimmu angmsifolinm

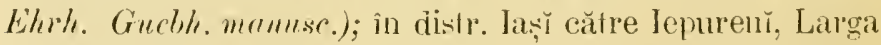
și Perienı̆ (Sz. menusc.): intre Rucăr și IJimbovicióra (Hộf.

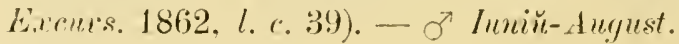

\section{IIESPERIS Tommef. - Esperidu.}

II. tristis $L$. E. trisfă. Prin locnr inculte, finele și

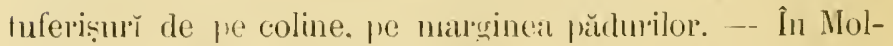

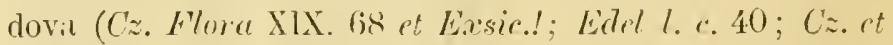
Sz. l. c. 40) inferioră (Cinch) manuse, of Exssic. n. $74.1 \mathrm{sec}$. Nym. Cousp. 38); pe lîngă Jiṣ̌̆ la Aronénu din dosul sit-

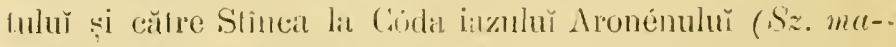

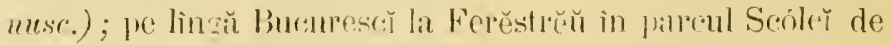




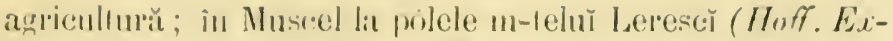
curs. 1862, l. 1.38 rt Essic.!). - o 1 priliu-1/niu.

II. Matronalis I.; H. inotera L. L. matrónelor. -

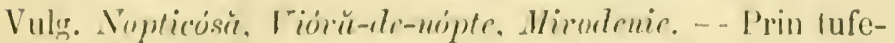

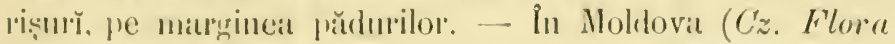
XIX. 69 st lissic.!; Cz. et Sz. l. c. 40): la Galiaț (Ciuchh. munuse.): la Rüdulesció-Filitis (I). Br. Frragm. l. c. 78); se

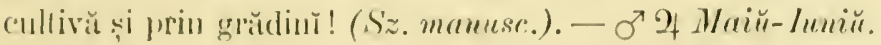

II. nivea Binq. E. albŭ._- P'rin locurile unede și umbróse din pădnrile subilpine. - Pe Céhllău și in Lilpoș (C'z. st S'z. l. ค. 40); la Sinaia pe valea Pelesuluĭ, și in m-tiĭ Bucegr̆ pe valea Ialomiter in sus de schitul Pescera.- $\sigma^{2}$ ' hun.- L lug.

II. runcinala W. Kit. E. runcinată. - Pe marginea pĭdurilor și prin luferișurile de pe coline. - In Moldova (H. inodora Cz. Flura XIX, 68 [non L.] ct Exsic.! ; h.j. (ruebh. manusc.: Eilcl l. c. 40; Cz. ct Sz. l. c. 40); în distr. laș̆ cĭtre Glodosa, Neteda și Budescĭ (H. inodora S'z. mamusc. ?) ; în Vlaşca la Comana cătse Valea-Gurbanuluĭ; în Mehedinț pe délul Stimnina (Gr. Exsic.!) și la Virciorova către Por!ile-de-fer'; elc. - o Maiй-Inniŭ.

\section{BR.ISSIGA Tournef. - Brasică.}

B. Laаpa Koch. B. Rapă. - Vulg. Rapiț̆ăsthatică. Locurì cullivate. - In Moldova (B. campestris L. Cz. ct Sz. l. c. 40; Sz. mamusc.); la Fănreй (B. campestris Guebh. mannse.); Bucurescı̌ (Gr. Ë. 10). - $\odot$ э Maiй-Luliŭ.

0ls. - Se cultivă : R. Rapa ß. oleifera DC. (Guebh. manusc.) vulg. Rupiț. - B. olpracea L. (Guebh. mamusc.; Cz. ot Sz. l. c. 40) vulg.

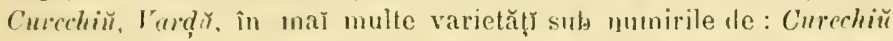

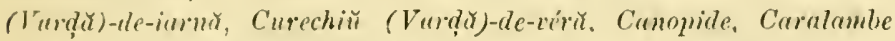
(Calarube, Cararabe). - B. Yapus L. ア. esculenta (Guebh. manuse.

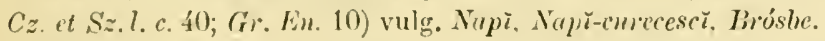

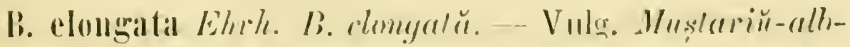
sithutere - Prin loc:ur něsipose, pe coline aride. - In Mol- 


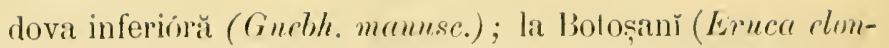
!jata Bm.j. Cz. et Sz. l. c. 40); in distr. laç̧ către Stînč̆,

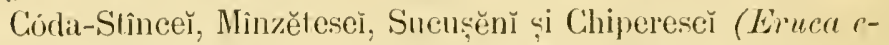
longata Sz. manusc.). - ơ Iuniй-S'plcmbre.

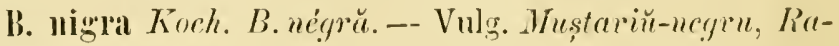
pit̆̌-de-muștariu. - Locurĭ cultivate și ruderale, semĕnăturr, pe marginea agrilor și a drumurilor. - În Moldova (Sinapis nigra L. Guebh. mamese; Cz. et Sz. l. c. 40 ; s'z. mannsc.); Bucuresch! (Gr. En. 10 et Exsic.!).-○Iun.-Iul.

B. Simapis Vis. B. Sinapistrmm Boiss. B. Mustarin̆.-

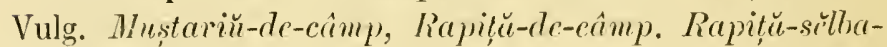
tecă.- Printre sěměnăturı̆, pe inarginea agrilor. - In Moldova (Sinapis arvensis L. Gucbh. manusc.; Edsl l. c. 40 et Exsic.! ; Cz. et Sz. l. c. 40 ; Sz.manusc.; S. orimtalis Cz. Flor a XIX, 68 /non L.] el Exsic.!) centrală (S. taurica DC. (inebh. manuse. [non M. Bicb.7?); în distr. Bacă̆ la Caraclăŭ în Ilfov (S. arvensis Gr. En. 10 et Exsie.!) lat Bucurescì!, Cotrocenı̆ (Sisymbrinm strictissimum Gr. En. 11 Inou L.' et Exsic.!) și Ferĕstrě̆̆; etc.- $\odot$ Inniŭ-luliŭ. ß. oricntalis (Boiss.). - In Moldova (Sinapis orimtalis Murr. Cz. et Sz.l.c. 40 ; Sz. manuse.) la Galaț̆ pe malul Seretulur̆ (Guebh. Not. 15 et maniesc.).

B. alba Boiss. B. albä. - Vulg. Mus'ariŭ-alb, Rapiț̆albă. - Printre sĕmĕnăturĭ. - În Moldova (Sinapis alba Cz. Flora XIX, 68 et Exsic.!; Gucbh. menusc.; Sz. manusc.); în Ilfov și Prahlıova (Gr. En. 10?). - $\odot$ Iuniŭ-Iuliü.

B. dissectu Boiss. B. disrctă. - P'rin sĕmĕnăturile de inŭ. - În Moldova inferióră (Sincpis dissec'a Lag. Guebh. manusc.). - $\odot$ A priliй-Maiй.

B. Pollichii Jess.; Erneastrum Pollichii Schp. et Sp. Diplotaxis bracteata Greu. et Godr. B. bracteată. Prin locurı̌ nĕsipóse, dărěmăturr̆, zidurĭ. - Pe malurile Seretuluĭ, a Trotuşulu (E)nca Erucastrum Giertn. Cz. ot Sz. 


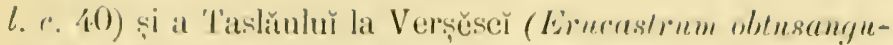
lum I). Br. Fragm. l. c. 79 /mun Rechl.J); în Ilfov (E. oltuscminlum Gr. Lin. 10 ?). - of Muiй-Luliü.

B. Aenuifolia Boiss. B. č for mérunte. - - Prin locurı̌ aride și petróse, pe zidurĭ vechĭ, pe lînğ drumur̆. - In Moldova (Sisymlnivem temuifolimm L. ('z. ot S'z. l. c. 40;

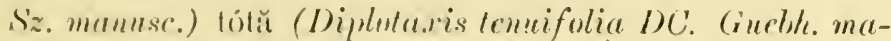
munusc.) ; pe linğ̆ Jaș̆ la Repedea de-asupra Petrăriĕ ; la

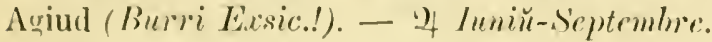

B. Inuralis Boiss. B. de ziduř. - P'rin locurǐ aride și petróse, pe zidurĭ vech.̌ - In Moldova (S'isymbrium muvale L. Cz. ct Sz. l. c. 40 ; Sz. manusc.); în distr. Buzeŭ pe valea Slüniculur (Diplotaxis muralis DC. Gr. Én. 10 et E.rsic.!; D. Lemifulia [non DC.] et D. viminea [non DC.] Gr. En. 10 et Exsic.!) eătre Virciorova; ete.-○Maĭ̌-Sept.

B. viminea Boiss. B. vinjós̆̌.-Pe colinele nĕsipóse din Moldova inferióră (Diplotaxis viminea DC. Guebh. mamusr.); la 'Tîrgu-Ocneı̌ (D. saxatilis Guebh. manusc.o.).

\section{RAPHANUS Tournef. - Râdiche.}

R. Raplanistrum L. R. Rafanistru. - Vulg. Rüdichesélluticŭ. Ruchiţŭ-dc-ogóre. - Prin locurı̌ cultivate, agri, printre sĕmĕnăturı̆. -- In Noldova (Edel l. c. 40; Raphanistrum segetum Bme. Cz. Flora XIX, 69 et Exsic.!; Cz. cl Sz.l.c. 40; Sz. manuse.) superióră (h.j. Gucbh. mamusc.). - $\odot$ Iипій-Iuliй.

Obs. - R. sativis $L$. vulg. Rîdiche, Râdiche-de-grădină, se cultivă în mar multe varietăţr (Cz. Flor XIX, 69 et Exsic.!; Fdel l.c. 40 Guebh. manusc.; Cz. et Sz. l.c. 40; Sz. manusc.; Gr. En. 10 \%.

\section{CIIORISPORA DC. - Chorisporě.}

C. tenclla $D C$ C. C. giuryaš̆. - Prin locur cultivate și ruderale. - In Moldova (Sisyml,rium arcnosum Cz. et siz. 
l. c. 40 /non L.J et Easic.!; Arahis aronosa h. j. Guebh. manuse. (non Scop.J) inferiórĭ și centrală (Gnehh. mannse.); prin viile de la Galațĭ (Guebh. Nol. 16 et E.rsice $n .740 \mathrm{sec}$. Nym. Consp. 28); pe lîngă Odobesč̆; pe linñă Bucuresč̆ la Ferěstrěŭ către gara Tramwaiumilor. - $\odot$ ilmr.-L/ciй.

\section{RAPISTRUM Barl. - Rapistru.}

R. perente Berger. R. perenal. - Prin agri, pirloge, pe lingă drumurř. - In Moldova inleriorĭ (Gucb). mamese. rt Exsic. n. $155 \mathrm{scc}$. Nym. (onsp. 29); în distr. Iaș̆ la Rĕdiŭ-Alder̆ (Cakile perennis L'Herit. S'z. manusc.); pe lìnğ Bêrlad (R. ruegosnm D. Br. Froegm. l. c. 79 /non Berger. nec All.7). - 2 Innin̆-Juliu.

R. rugosum Berger. R. rngus.- Prin agrile din tótă Moldova (Cakile rengosa L'Herit. Sz. mannse.). - $\odot$ Inn.-Inl.

\section{CRAMPE Tournef. - Crambé.}

G. tataria Jacq. C tartaricŭ.-Vulı. Tằtan, Hodolón. -Prin finetele de pe colinele aride.-In Moldova (C.tar:arica IIilld. Cz. Flora XIX, 68 rt Exasie.!: Eildel l. c. 40) inferiôri și centrală (Gurbh. mamusc. et Exsic. 154 sece. Nym. Comsp. 30); către Prut frequent (Cz. et Sz.l. c. 38;

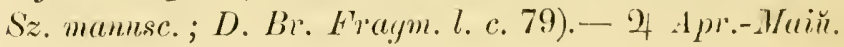

\section{ISATIS Tommef. - Iscutidŭ.}

I. tinctoria L. I. tinchurarilor.-Vulg. Drolusmp, Drebisor, Cardama, Cardaman. -- Locurĭ aride și pelróse.In m-(ị̆ Noldoveř (Ėdel l. c. 37); la Bèrlad, T'ecuciŭ, Focşan̆, Bacŭŭ, Roman, Folticen̆, Pélrà și Ném! (Cz. ot szz.

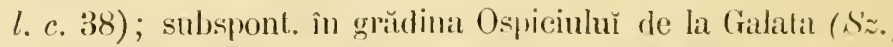

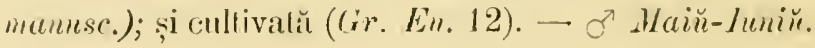




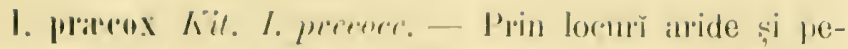

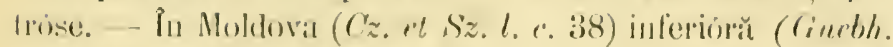
manusc.). - or 1/аій-lıniй.

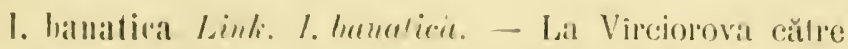

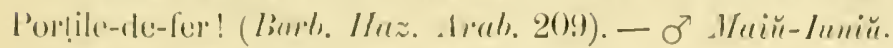

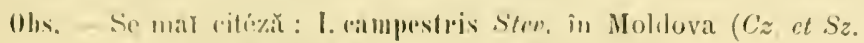
l. c. 38). - 1. orientilis in Molduva (Cz. at Sz. l. c. 38).

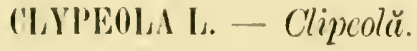

C. Jonthlaspi L. C. Jomthlasprilt. -- In Moldova ( $S z$. bisic.!); pe colinele nĕsiprose de prin vecinulătile fidatilor

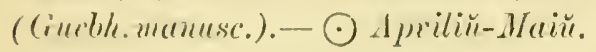

\section{PELTARIA L. - Peltarie.}

I. allialcea .Ju'\%. P'. aliacer. - P'rin loeurĭ stîneóse și unede. Lai V'îreiorova către Porlile-de-fer.-2 Maiǔ-Lun.

\section{MYAGRUMI L. - Miagru.}

II. perfoliatum L. M. profulial. - În Moldova (Calivile profoliula L'Ilevit. Sz. menuse.). - o Maiǔ-Iuniŭ.

\section{NESLIA Desv. -- Neslie.}

S. Palliculata Desv. I. paniculatŭ. - Vulg. Drob. Printre sěmĕnăturĭ și prin pîrlóge. - In Moldova (Bunias

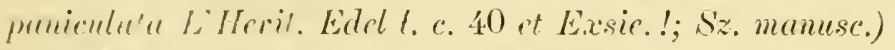
tótă (Cruerbl. mamusc.). - ơ Inniй-Luliŭ.

\section{ELCLIDIIM R. Br. - Euclidiŭ.}

E. syliacum R. Br. E. siviac - Prin locurř aride și ruderale. - In Moldova (I)C. Prod. I, 184; Lyycopsis ar- 
vensis Cz. Flora XIX, 61 /non L.] et Exsic.!) inferioră și centrală (Guebh. manusc et Exsic. n. $739 \mathrm{sec}$. Nym. Consp. $68)$; în distr. Iași către \%ahorna, Larga, Văiluṭa și Iepurenı̆ (Bunias syriaca Gaertu. Sz. manusc.); în Ilfov între Trărtășěscĭ și Guliea (Gr. Exsic.!); etc. - $\odot$ Мaiй-Juniü.

\section{BUNIAS R. Br. - Buniadă.}

B. Erucago L. B. Erucayină. -. Vulg. Hróniță. - La Câtmpulung pe țěrmurile Rîu-T'îrguluĭ (Iloff. Excurs. 1862, l. c. 40 et Exsic.!). - Р Маій-Iипіи.

B. orientalis $L$. B. orientalŭ. - Prin fîneṭe uscate, pîrlóge, pe coline aride, pe marginea agrilor, prin locurǐ ruderale. - In Moldova (Sz. mamsc.) superióră (Guebh. manusc.); la Agiud (Burri Exsir.!); la Bucurescì!, Bănésa! (Gr. En. 12 et Exsic.!) şi Mogoşóia (B. Erucrego D. Br. Fragm.l.c. 79 (non L.7); pe lîngă Slatina eătre Olt; în Mehedinți pe délul Iorgulova (Gr. Exsic.!); etc.--or Mlaiŭ-Inniй.

\section{LUNARIA Tournef. - Lunarie.}

L. rediviva Lin. L. reânviatŭ.-Vulg. Lopățć.-Pădurĭ umbróse și umede din regiunea montană și subalpină.-In Moldova (Cz. Flora XIX. 68 et Exsic.!: h. j. Guebh. manusc.; Edcl l. c. 37); la Sinaia pe valea Pelcçuluŭ (Gr. En. 11 st Exsic.!) și la pólele Furniceř. - 2 Maiй-Lипiй.

I. annua Lin.; L. biennis Manch. L. anualü.-Pădurı̆ umbróse și stincóse din regiunea montană. - In Moldovi (EAlel l. c. 40 et Exsic.!): la Vîrciorova către Portile-de-fer !

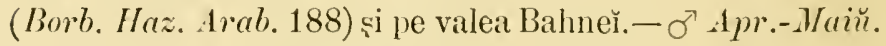

\section{ALYSSTM I. - Alison.}

A. gemonense L. A. de Gemona. - Prin locurı̆ aride și petróse, - La Putẹnĭ (Guebh. manusc.): la Virrciorova 


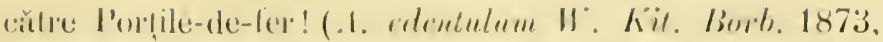

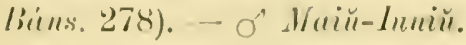

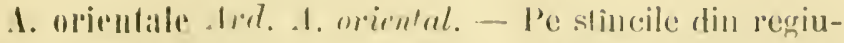

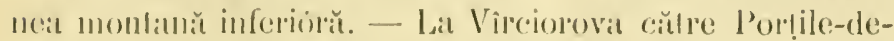

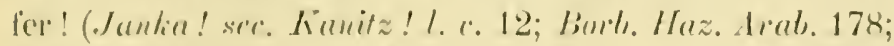

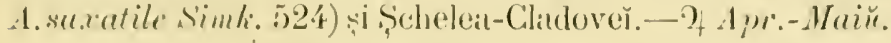

1. saxatile L. . 1. de stimč - Pe slîncile calcare din

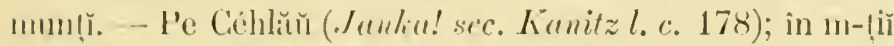

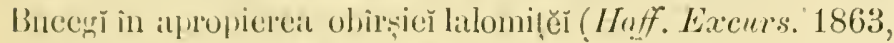
l. c. 120). - 2 . miliu-Inniй.

A. repens bmg. A. reprut. - Prin phasunile stîncóse din reginnea alpină. - Pe Céhlăı̆! (Jankian! Ad. 184; A. alpestre Edel l. c. 36 /uon V'ulf. nee. L.7 et Exsic.!; Cz. Flum XIX, 68 it Exrsic.!); în m-tị̂ Bncegı̀ (1.51) în valea İlomițeř (Fr. 115). lit Strunga (W'inlil.! [sub. nom. A. Wulfrniuni| ser. hanitz l. c. 12), la schitul Pescera, pe Furnica, Obirșia și la Pìrŭul-Babelor. - 2 Inniŭ-Augnst.

A. Mnontanum L. A. montan. - Prin crĕpăturile stincilor. - În m-!̣ĭ Moldover (Sz. Exsic.!). - 7 Maiй-Iuniй.

ß. angustifolium Hruff. - Intre S,chelea-Cladoveř și Gura-văieı̆ çi călre Porṭile-de-fer.

A. rostratum Stev. L. rostrat. - Prin locurĭ aride, pe coline pelrúse și calcare. pe marginea drumurilor. - În Moldova (Sz. Exsie.! /nom A. gemenense/); la Virciorova către Portile-de-fer. - $\odot$ Maй-Iимій.

1. Wicrzbickii Henff. 1. Lǔ W'icrzliek. - Prin locur aride, pe coline petróse și calcare, pe marginea drumurilor.

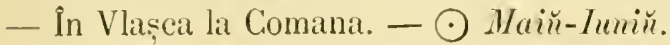

A. campestre L. A. de cômp. - Câmpiī şi coline aride. -În Moldova superiórĭ (Gnebh. mannsc.).-○ Маій-Mm.

A. hil'sutum M. Bicb. A. irsut.-Loeurı̌ aride.-În Moldova (Sz. Exssic.! [nom. A, micropetalum]).-○Apr.-1/aiй. 


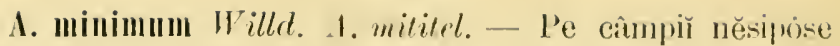
si pe coline aride. - In Moldova (Adyscton minimum Eidst l. c. 40 st Exsic.!; Leppidium Ihrris Cz. Flora XIX, 68 /mun L.7 et Exsic.! ; Cz. ct Sz. l. c. 39) inferión̆ (Gucbh. manusc.); la Agriud (Burri Exsic.!); la Câmpulung pe tĕrnu-

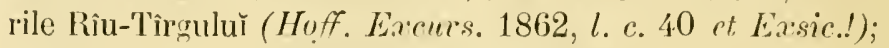
la Craiova în Lunca-Jîulǔ; ete. - $\odot$ Maiй-Inпiй.

A. argenteum Vitm. A. argintiǔ. - Prin locurile petróse și stîncóse din munțĭ. - La Tîrgul-Oeneř (Gurbh. mannsc.); pe Cozia și Urḍica : în m-liî Vîlcě̆ la Harmasariŭ ; pe lingă Turnu-Severin (1\%. Winkiler in herb. Uschtr. scc. Kanitz l. c. 178), la Vîrciorova! (Borb. 1873, Báns. 278; Kanitz! l. c. 13), Portile-de-fer; etc.- 4 Maiй-Lun.

A. calycinum L. A. calicinal. - Vulg. Albiță, Disculet, Ciucusóre. - Câmpiĭ sterile, coline aride, locurǐ petróse.În Moldova (Adyseton calycinum Scop. C'z. Flora XIX, 68 ot Exsic.!; A. campestre (z. F'lore XIX, 68 /non Bniy.] ct Erssic.! ; A. murale Cz. Flora XIX, 68 [non Hr. Kï.] et Exsic.!; h.j. Guebh. manusc.) : la Puțĕnı̆ (crucbh. mamesc.); în distr. Jaṣĭ la Stincă, Códa-Stinceŏ și la Rusĕnŭ (Sz. mamusc.): la Agiud (Burri Exssic!!); pe lingă Bucurescĭ la Cotrocenř! (A. campestrc Gr. En. 11 / mon L./ et Exsic.!), Ferěstrĕŭ și Periş; la Moroenř pe matca Ialomiḷer̆; pe lingă Slatina către Olt; în Gorjiŭ la Roșia ; între Şchelea-Cladoveř și Gura-văiě̆; ete. - $\odot 1$ priliŭ-lıniǔ.

A. incanmII $J$. A. albicios.- Prin locurř nĕsipóse și petrose, pe coline aride, pe lîngă drumurř. - In tôlă Romănia! (Cz. Flara XIX, 68 ct Exsic.!; Letel l. c. 40; s'z. munesse. Bertroa incana D: Gucbh. manuse,; D. Br. Fragm.l. ı. 79 ; V.! sec. Kanitz l. c. 11 ; Burri Exsic.! ; (ir. Lin. 11 st Exsic.!). - o Imiñ-Septembre.

1. linifolium Strph. I cи for de iий. - Pe coline nĕsiprose și aride. - Pe lin tră Galaṭi către juncțiunea Seretnlŭ cu Dunărea (Meniceus linifolius DC. Gucbh. mamusci.). 
IIRIRI L. - Mrubü.

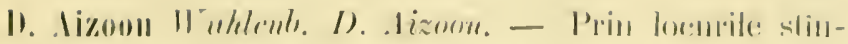

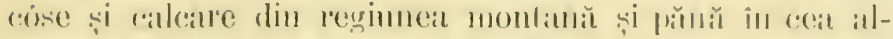

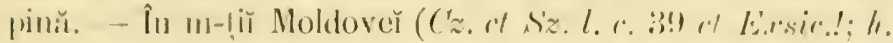

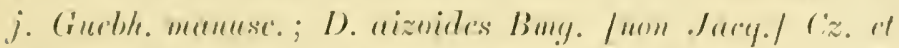

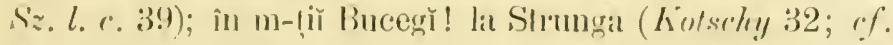

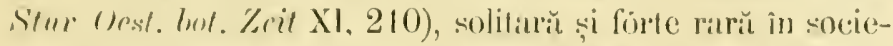
late en D. Mreynaldi, D. Kotschyi. Banffya peteren. Asperrulu cupitalu, Trollius, etc. (Janlea .1d. 185); pe Pétrat-

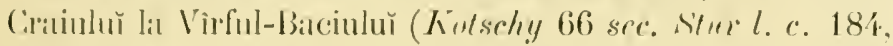
210); în Mehedinți la Vîreiorova de la Porṭile-de-fer și jănă lis fruntaria Ungatră (D). lasiocarpa lioch. Borb. Haz. Arab. 882). - 2 Маій-Іитіи.

I). compacta Sch. Nym. Ky. D. compactă. - Prin lo(mrile slincrise și umede din regiuneil alpină. - In m-țiĭ

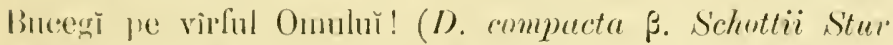
()ext. loul. Zrit. 186), vîrful P'ustiulŭ̌ (D. aizoide's F'ron.

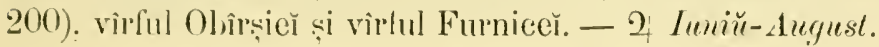

I). Ilậualdi s'tur. D). Lur Haynald.—Prin locurile stin-

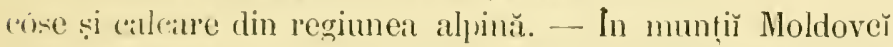
(I). ciliuris Bmy. Cz.et Sz. l. c. 39); in umuttiu Buceğ la Strungal! (Juklia .Ul. 185; Wiulil.'sec. Kuni'zl. c. 12); ete. - of Leniй-ilugust.

I. (ariuthiaca Hoppe: D. Johamis Host. D. cervinthari. - Prin locmrile stincúse din regiunca alpint. - În

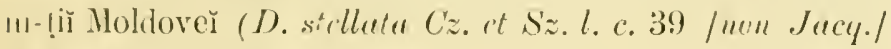

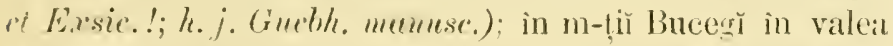
lalomiṭen! (Fr. 16), pe vîrful Furnicě, la Pirăunl-Babelor, către Omu; etc. - 2 lumiü-.lugust.

1). Kotschyi Stur. D. Lǔ Kotschy. - Prin locurile stincose din resimeat alpină. - In Moldova (I). amblosucéa

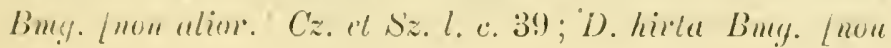




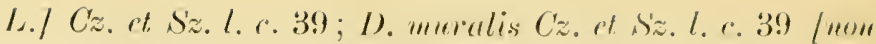

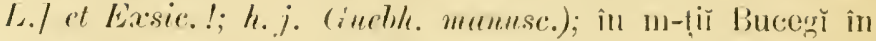
valca Ialomịte (Fr. 16) și la Sirumgal! (.Jantia .1d. 185; Fr. 116). - 2 Inniir-Auciust.

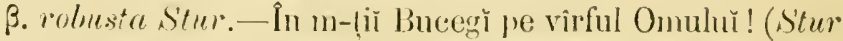
l. c. 190$)$ si fe Pétra-Crainulu la Vìfu-lsalcinlŭ (Kotschy sec. Stur l. c. 190).

I). nemorosia L. I). de pădure. - Pe coline nĕsijóse și

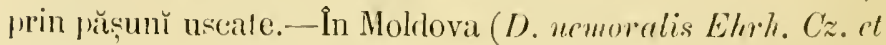
Sz. l. c. 39) tótă (Gurbh. mumesc); lal Arrind (Burri Exsic.!). - $\odot$ Ipriliŭ-Naiŭ.

I). verna $L$. I). de mimăvéră. - Pe cînpurì uscale și friu locuř nĕsipóse, alât cultivate cât și inculte.-în Mloldova (Cz. Flora XIX, 68 et Easic.!; Edtel l.c. 40; Cz. et Sz. l. c. 38 ; ડz. manuse.) tótă (Evophila vulyaris DC. Guchh. manusc.); la Agiud (Burri Exsic.!); la Campina (Gr. En. 11 et Eixsic.'); pe lingă Bucurescĭ la Bŭnésa, Ferěstrĕŭ și Periş; în Gorjiŭ la Roșia; etc. - $\odot$ Mariй-A miliŭ.

0bs.-Se inar ciléză : D. pyrenaica L. în Moldova (Cz. et Sz. l. c. 38).

\section{COCIILEARIA L. - Cochlearie.}

C. Almolacia L. C. Armoracie. - Vuls. Hién, Hirén, Büurlecinü-sölbatecă, Usturoiü. - Prin locurì argilóse și umede. - In Moldova (Armoracia resticana Fl. Wett. Cz. Flore XIX, 68 el Exsic.!; Cz. et Sz. l. c. 39; Sz. manusc.) tótă (Gucbh. manuse.); pe lìngă Brateș (1. vulgaris Edel l. c. 38); lar eullivat in tótă Romănia (Gruebh. manusc.; $D$. Br. Fragm. l. с. 79; Gr. En. 12). - 9 Luniй-Juliŭ.

C. macrocarpa W. Kit. C. macrocarpă. - Prin locurile umede din lótă Moldova (Guebh. manusc.). - 2 Iın.-Inliŭ.

U. Saxatilis Lam. C. de stinč̆. - Pe stîneile calcare din muntiŭ de la fruntaria Moldover (Kernera saxatilis Rehb. Fuss Fl. Trans. 71). - 2 Imiй-Iuliŭ. 


\section{CAMELIS.I Crant\%. - C'umetimì.}

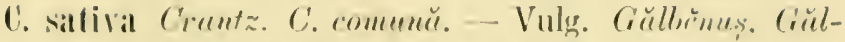

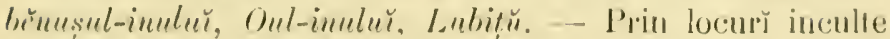
něsipose şi atride. In Moldovi (C'z. Flora XIX, 188 ef li-

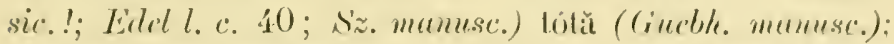
pe linğ̈ Bucurescê la Ferěstrěŭ; la Vîrciorova căltre Por|ịlede-lee! (Burb. 1873, Jiáss. 278); etc. - $\odot$ Inniй-Iuliü.

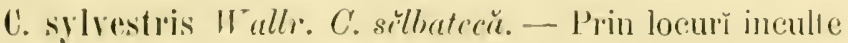
něsipóse și potróse. - In Moldova ( $C$. austriaca $C z$. F'lora

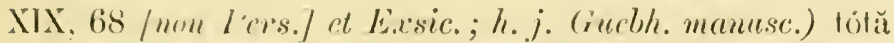
(C. sutira P. pilesen I)C. Gueleh. menuse.); la Agiud (Burri E.rsie.!); lat Buflea (Gr. Lasic.!) și Bucuresç; la Comana; pe lîngă Slallina către Ol1; ; la Vîrciorova (Simk. 525) către Por!̣le-de-fer! (Burl. Haz. Arab. 201); etc.-○ Innin̆-Inl.

C. Nentala ícrs. C. dentatŭ. - Printre sĕmĕnăturile de inŭ. - În tótă Moldova (Guchı. mamusc.); în distr. Iatșy̆ către Larga și Perieni (Sz. manısc.). - $\odot$ Inniй-Luliŭ.

\section{THLASPI Dillen. - Tlaspide.}

T. arvense L. T. de cimmp. - Vulg. Tüssculită. P’ungu-

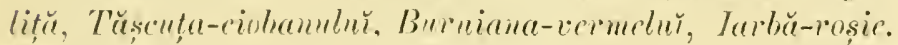

Prin locurí cultivate, inculte și ruderale, pe linğ di’umurı̆. - In Moldova (Cz. Flora XIX, 68 et Exsic.!; Edel l. с. 39, 40; ('z. et Sz. l. c. 39) tótă (Giusbh. mamesc.); la

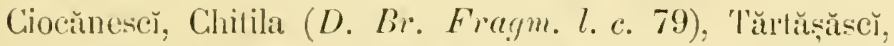
Bucurescĭ (Gr. En. 12 et Exsic.!), Bănésa și Ferěstrěŭ; etc. -- -) Maiй-Septemlire.

T. alliacemm L. T. aliacch. - Prin locurĭ cultivate și inculte. - In Moldova (Cz. Flore XIX, 68 et Exsic.!: h. i. ciucble manusc.; Edal l. c. 40; Cz. ct Sz. l. c. 39 ; Sz. manusc.; Cuhile perfoliuta Cz. Flora XIX, 68 non L'Herit.] 


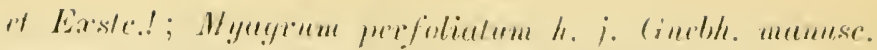
/mun L./): lir I'redèl; elc. - - Mriü.

T. perfoliafum L. T. prefoliul. - Prin lor'ul' cullivale si inculle. - În Moldova (('z. el א'z. I. г. 39); T. preenex

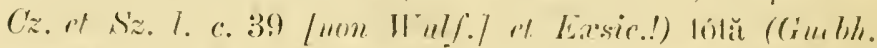

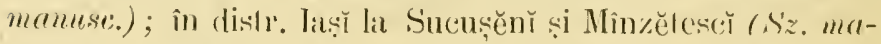

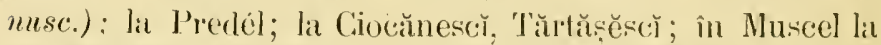

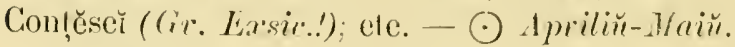

T. alpestre L. $T$ alpostru. - Prin locmeile stincose din

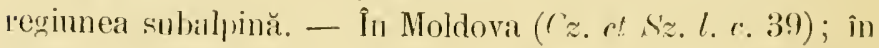

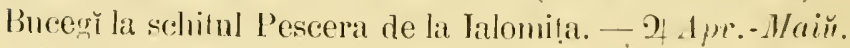

0hs. l. - Se mar citéză: T. montammu $L$. in Moldova (Édel l. $c$. 40; Cz et Sz. l. c. 39; Sz. menusc.). - T. alpinum L. in Moldova (Cz. et Sz. l, c. 39). - T. rotundifolinu Gaut. în Moldova (Lepidinm rotundifolinem All. Cz. et Sz. l.c. 39).

Ols. 2. - Iberis anmara $L$. indicată în Moldıva superióră (Sz. Exsic..; h. j. Guebh. munusc.), nu cresce de cât cultivat prin grrădinY.

\section{IIUTCIINSIA R. Br. - Ihtchinsie.}

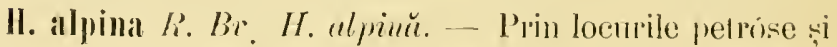
umede din reginneá alpinăt. - In m-liŭ Moldoveř (Lepialium alpimum L. Sz. Esasic.!; h.j. (inchh. mamese.; Diabu al-

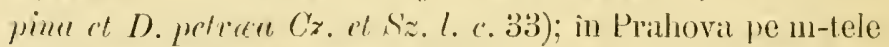
Kăganu (Lepitium alpimum Muff. Esacuss. 1863.l. c. 118),

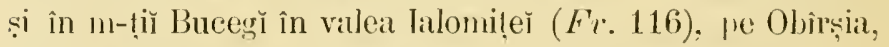

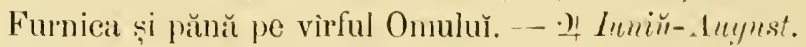

\section{BISGUTELA:A I. - Biscutelø.}

B. Lavigata L. B. netedă. -. Vulgs. Ochilar. Uchilatvitü, Chelürel.-.. Prin păsmmile mmede și petróse din regiunea alpină. - Pe Célılăı̆! (B. sarutilis Édel l. ค. 36: Cz. Flora XIX, 68 et. E.resic.!: h.j. (Gueld. manuse.); in m-tị̆

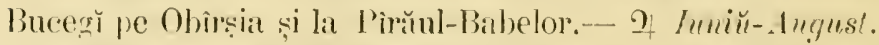

3. glubru Cramel.: B. luciula DC. - În Buceğ̀ pe Fumiea. 


\section{LEPIIIUM L. - Lepriliit.}

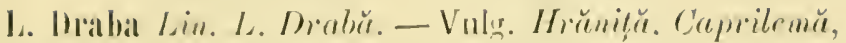

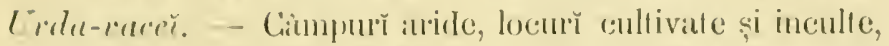

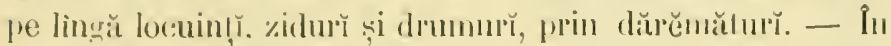
Moldoval (cimblh. mamuse.: Cz. et s'z. l. e. 39; Cochllcaria

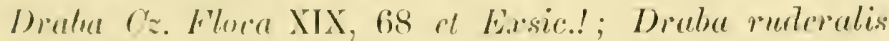
Bimy. Sz. memusc.); la Iiț̣ ; în Illov (Gr. Lin. 12 el Exsir.!) pe lingă Bucurencĕ la Cotrocenı̆, Bănésat și Ferěstrěŭ i in

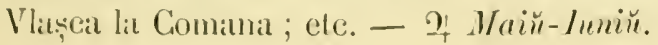

I. (anmpestre R. Br. L. de càmp. - Prin locurì in-

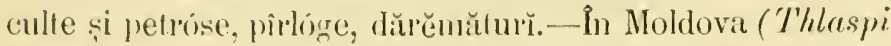
comprstre L. Cz. Flora XIX. 68 et E.rsic.! ; Edtel l. c. 40; Cz. ct S'z. l. c. 39) ; Sz. mannse.) tótă (Guclıh. manusc.) lia Sintilat pe malca l'rahově́ în Muscel (Gr. En. 12 rt E.r-

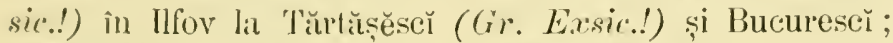
in Vlescar la Comana; etc. - o Mairu-Juliü.

L. perfoliatım Lin. L. perfoliat. - Prin locurĭ ruderale, pe marginea agrilor și a (trumurilor. - În Noldova (Cz. Flora XIX, 68 et Exsic.!; Eidcl l.c. 40 ; ('z. ct Sz. l. c. 39) inferióră (Grucble mamesc.); la 'T'îrgu-frumos și Erbicenı̌ (Sz. manusc.): în Iltov la T'ălăș̆scĭ (Gr. Exxsic.!) și Bucurescí ; ete. - $\odot$ A priliй-Lимiй.

l. ruderale Lin. L. ruderal. - Prin locuri ruderale ruiň̆, pe zidurı̆, pe lingă locninț̆ și drumurı̆. - În Noldovi (Cz. Flora XIX, 68 et E.rsic.!; Eitcl l. c. 4.0; Cz. ct. Sz. l. c. 39 ; Sz. manusc.; L. graminifolinem Cz. Flora XIX, 68

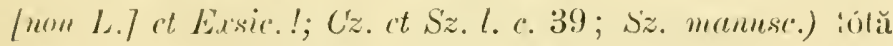
(curbli. mamusc.); în Bucurescĕ ; la Vîrciorova! (Kanitzl. c. 14); ete. - o Iuniü-Lugust.

I. latifolium Lin. L. cu fir lule. - Prin locuro umede. bălțĭ și mlașlinĭ nscille. - In Moldova inferióră (crusble.

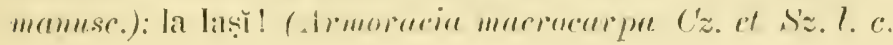


39 / non Bmg./ et Eixsic.!) pe malıl 'Ṭicăuluĭ, a Bahluiulı̆, și călre Unghenı̆ pe lingă calea ferată (V.! scc. Kanitzl. c. 14); pe lîngă Craiova; elc. - 9 Iuniŭ-Luliŭ.

L. crassifoliom W. Kit. L. cu fou grase. - Prin mlastinile sŭrate. - In Moldova (Cz. et Sz. l. c. 39) inferióră la Pisc (Gücbh. manusc.). - 2 Maiй-Inliŭ.

0lss. - Se maI citéză : I. hirtuı Sm. în Moldova (Thluspi hirtum L. Cz. Floru XIX, 68; Cz. et Sz.l. c. 39) la Luncant (sz. manusc.).-I. spinosum în Moldova (cz. et Sz.l.c. 39). - I. satıvuแ L. în Moldova (Guebh. manusc.). - Cele doue d'intăi sunt de sigur resultatul unor erory de determinaţiune; iar a treia, nu cresce de-cât cultivată.

\section{CAPSELLA Mrench. - Capselă.}

C. Bursa pastoris Mench. C. Prunga-popě. - Vulg. Punga-poper̆, Traista-ciobanulur, Straiț-poper, P'ungulit,a-

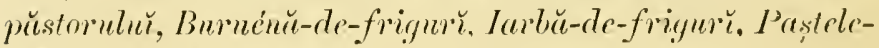
calulux.-CGrădinǐ, vī̄, locurř ineulte și eultivate, dărĕmăturĭ, pe lîngă drumurı̌.- În tótă Romănia! ( $C z$. Flora XIX, 68 ct Exsic.!; Guebh. manusc.; Cz. et Sz. l.c. 39; Sz. mannse.; D. Br. l. c. 79; Thluspi Bursa pastoris L. Edel l. c. 40; Gr. En. 12 et Exsic.!). - $\odot$ Martiŭ-Novembre.

\section{CoR0NopUs Hall. - Coronop.}

C. procumbens Gil.; Sencliera Coronopus I'orir. C. mocumbent. - Prin locuř̌ ruderale s,i unnede. - În Moldova (C. depressus Moench. Sz. manusc.). --. $\odot$ Iuliŭ-duynst.

\section{ATHIONEMIA R. Br. - Ethionemă.}

A. Saxatile $R$. Br. E. de sînč̀. - Pe stincile calcare din regiunea alpină. - Pe vìful Célılăuluı̆ (Thlaspi saxatile L. Cz. ot Sz. l. e. 39 ot Exsic.!; h.j. Gurbh. mumuss.). - 2 Inmin- ilugnest. 


\section{RESEII ACEE.}

\section{RESEIIA L. - Rusetŭ.}

R. inodura Rrhd. R. innderă. - Prin finete nẹsipose.

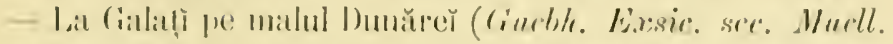

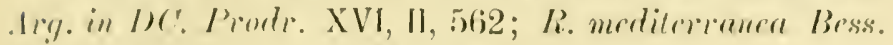
(imelh. Not. 17). - $\odot$ Hain-.luegust.

R. Intea L. R. yullinnir. - Pe colinele aride şi petróse, prin locurř cultivale și ruderale, viŏ, pe lingă zidurî și drumurY. - In tită Noldova (Cz. Flone XIX, 65 rt Easic.!; Eilicl l. o. 39; Gurbh. munusc.: Cz. ct Sz. l. c. 24; R. Lutrola Cz. Filora XIX, 65 /mom L.7 at Exsic.!; h.j. Guebh. mamese.); pe lìngă lașĭ la Balein (Sz. manusc.), Repedea,

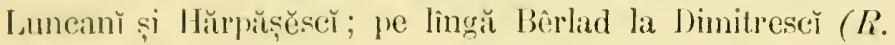
allue D. Br. Fragm. l. e. 79 / $/ \mathrm{mm}$ L./); la Onesei pe malul Trotuṣulŭ ; in distr. Buzĕŭ pe valea Slăniculur spre Becenı̆ (Cir. En. 13 at Exsir.!); în Prahova spre Sinaia și la Cî̀npina spre Telega, Brebu (R. alba (ir. Lu. 13 [non L.] ot

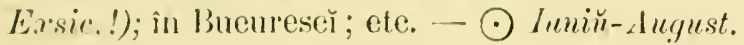

R. Luteola L. R. Lutcolă. - Pe cîmpuř aride și petróse, pe malurile nĕsipóse ale rîurilor, prin locurǐ ruderale, pe lingă drumurĭ. - In Moldova (Edcl l. c. 39; Cz.

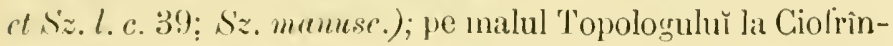
genĭ ; pe malul Oltulur la Rimmicul-Víleer și la Cŭlimênesč́ ; intre Turnu-Severin și Schelea-Clatdover. - or liun.-dueg.

(16). - R. pintulta (C $z$. Flor XIX, 65), nu sciŭ ce póte fi.--Tar R. 0-

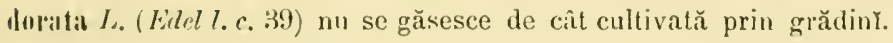

\section{VIOLACEE.}

\section{Violid L. - Violă.}

V. elatior Fries; V. persinfolia Schlenter. 1. inüllutü. - Prin fineḷe, Iuferiṣurı și păduri unnede. - În llfov la Buftear (Cir. Eresir..); etc. - If Main-lmiir. 
V. persicatelia Rolh; V. matensis VI. et $K$. V. de fiuı c. - Prin finnele umede. - In Moldova (Cz. et Sz. l. c. 11) inferióră și centrală (Gush). manusc.); în distr. Iașĭ că-

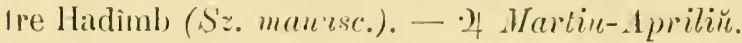

V. milabilis L. IT. mirabilŭ. - Prin pădurı̆ unbrose. -În Moldova (Cz. et Sz. l. r. 11); pe lingă Jași cŭtre Repedea (S'z. manuse.); în Muscel prin ilpropierea Bimboviciorer (IIn 4. Excurs. 1862, l. c. 39 et Exsie..'); la Comana; pe

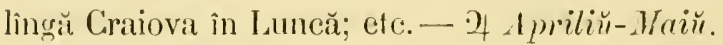

V. sylvatica Fries. V. de pădure. - Prin pădurĭ și tuferișurr̆. - Pe lingă Jaș̆ la Poenŭ și Bî̀nova ; la Agapia și Varatic (Gr. Erbor. l. c. 132 et Ersic.!): in Muscel pe mrele Lerescĭ (V.sylecstris Lam. Lp.p.] Hoff. Exemrs. 1862 , l.c. 31 et Exsic.!) și la Conțěsci (Gr. Exsic.!); la Olănescí (D. Br. Fragm. l. c. 89); etc. - 2 A priliŭ-Maіü.

V. arenaria $D C . V$. de ňsipuř. - Prin locurĭ něsipóse și aride. - La Sinaia pe Valea-Cășăriě̆. - 2 A pr.-Naiŭ.

V. canina $L, V$. củnćscă. - Prin locurı̌ nĕsipóse, poenı̆. pădurì și tuferișurı̆.-În tótă Moldova (Edel l. c. 39; Guebl\%. manusc.; Cz. it Sz. l. c. 11; Sz. manusc.; V. montana Bmy. Cz. ct $S z$ l. c. 11); in distr. Iaș̆ către Cerbulésă ( $V$. montana $S z$. manusc.); pe lînğ Bucuresč la Buftea (D. Br. Fra!ym.l. c. 89); Câmpina (V.palustris Gr. En. 12 /non L./ et Exsic.!); și la Predél; pe lingă Craiova în Luncă ; in Gorjiŭ la Roșia; etc. - 4 Маій-Lипiй.

B. lucorrum Relhb. - În Muscel la Conțĕscĭ (Gr. Exsic.!).

V. odorata L. V mirositóre:-Vulg. Toporaši, Nicsu-

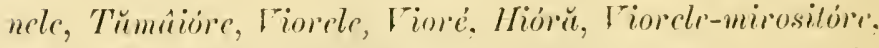
F'lor-ménnnticle, Garáfe. - P'e marginea pădurilor, prin Inferișurı̌, lived̦i, printre vĭ. - In Moldova (Cz. Flora XIX. 62 at Exsic.!; Edtel l.c. 39; Cz. et Sz.l. e. 11; Sz.munusc.; Gr. Lin. 12; Г. umbigmu (z. Flma XIX, 62 [mm IV. Kï./

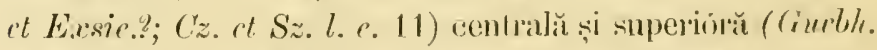

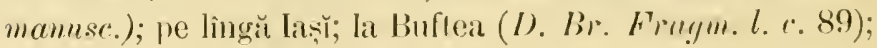




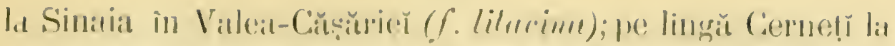

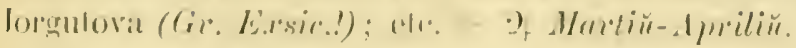

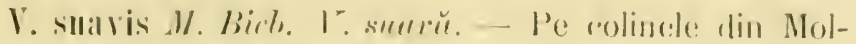

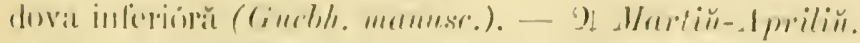

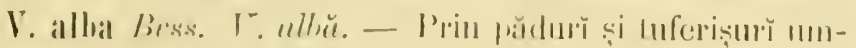

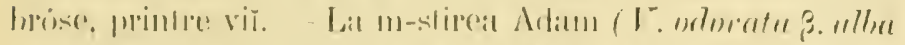

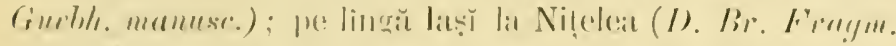

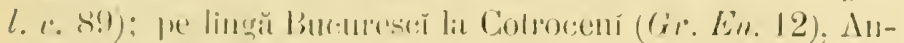

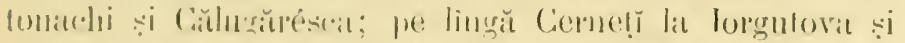

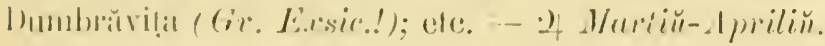

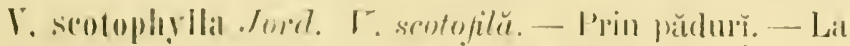

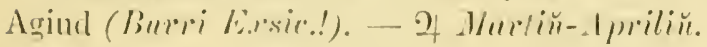

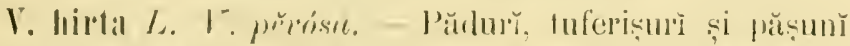

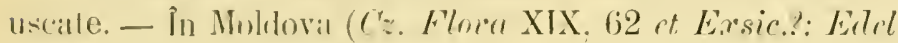

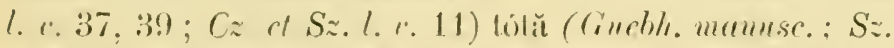

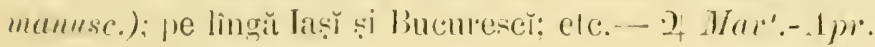

V. collina bess. 15. de coliur. - - Pe coline aride. - La Vireiorova cŭtre Por!̣ile-te-fer (Kanitz! l, r. 16) și la Cerneḷ (Gr. Ërsic.!). — - Martiй-1 priliй.

V. ambigna IV hit. V. ambiquŭ. - Pe coline nĕsiprose - Ta Cimmpina (1. syluatica Gr. Eur. 12 [non Frics.]

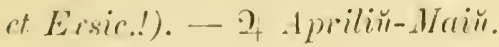

V. Jooi Janlia. F. Lň Joon. - Prin locurile petrose şi calcare din mun!̣. - În m-liĭ Moldoveĩ suluerióre ( $V$. uliginosa Sz. Errsir.\%: h.j. íurbl. manusc.; Cz. st Sz. l. c. 11): la fruntaria despre apele minerale de la liorszék, fóle frequentă (.Iantia Ar. 185). - 2 Apriliŭ.

V. billora L. Y. hifluĕ. - Prin locurile umede şi unbrise de pe linğ̌ slincile din regimea supalpină și alpină. - În Moldoral (Cz. H'lura XIX, 62 et Lasic.!; h. j. Guebh.

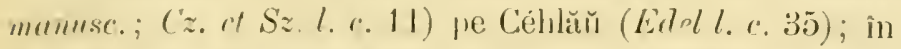

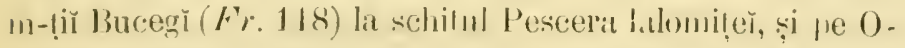

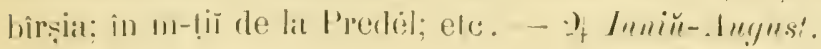


V. declinata W. Kit. V. derlinutü. - Vulg. Cinghiapaserě. - Prin păsunile din reginnea snbalpină și alpină. - In m-tir Moldover $(C z$. rt Sz.l. r. 11): pe P'enteleñ; în

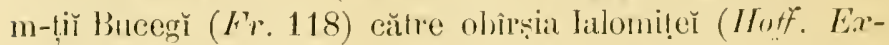
curs. 1863, l. c. 120), pe vialea Colțer̆ aproppe de schitul l'escera, re Furnica, și în m-lii de la P'redél; în m-tiĭ Dìmboviḷeı̆ pe Pripor ș Ordea; etc. - 2 Inniй-lugust.

V. tricolor L. V. tricoloră. - Vulg. Trer-frat,̌-pataț̆, Barba-imperatulur. - P'rin agriǔ, pî̀loge pe cânpurĭ sterile. - În tólă Romănia (1 z. Flom XIX, 62 et Exxsic.!; Edel l. c. 39; Giuebh. mamuse.; Cz. et Sz. l. ค. 11: Sz. mamanuse.; D. Br. Frugm. l. c. 89; (ir. En. 12 ot E.rsic.!). - $\odot$ Maiй-Septembloe.

ß.banatica Koch; I.banulica Kit.--În m-tiĭ de la Predél.

V. arvensis Lherr. I. agrestă. - Prin agriŭ și pirlóge. - În Moldova (T. bicolor Bmg. ('z. Flora XIX, 62 ot Ersic.!; Edcl l. c. 39; Cz. st Sz. l. c. 11; Sz. manusc.) centrală (Y. tricolor var. arvensis DC. Guebh. mamuse.); în Vîlcea la m-stirea Нorez (Gr. Exsic.!); ete. - $\odot$ M(ій-Tuliй.

3. hirsutior Stev. - Între Vîreiorova și Gura-văieř (Simk. 529) către Porțile-de-fer! ( I- mucedurica Burb. L. jel. 287 sec. Simk. [non Boiss.]).

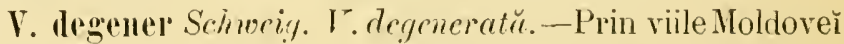

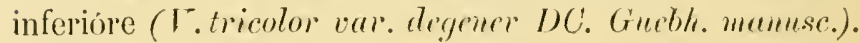

V. Kitaibeliana R. et S.; r. purviftora Kit. I. Kituibclianu. - Pe lingă Craiova la Bucovět pe malul diuluı̆; la Vîreiorova către Portile-ale-fer ( $T$. tricolor var. lïaibeliana Borl. 1873. Bäns. 279). - -) Aprilin.

Y. Intea Sin. Y. gallénŭ. - Prin locurile stincóse din regiunea subalpină și alpină. - În m-!̣ĭ Buceğ la schilul Pescera de la Ialomilạ; în Jîmbovița între Sturḍenñ și Ce-

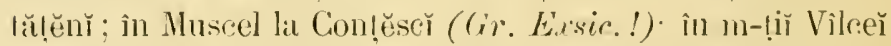
la Golotrenì pe Furfeca și pe valea Bistrițer ; în Gorjin̆ la

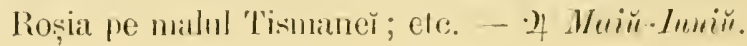




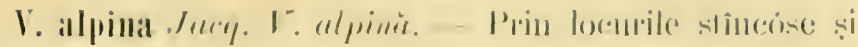

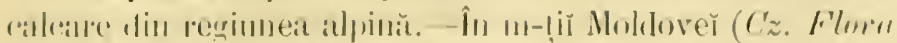

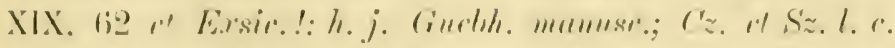

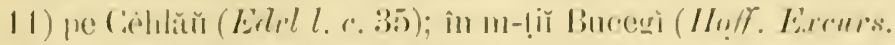

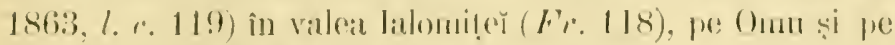

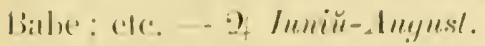

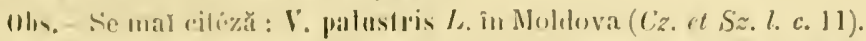

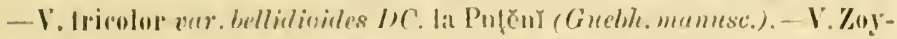
sii Wrulf. in Moldova (Cz. Sz. 1. c. 11) și in Bucegr la Strunga (Kiy 132).

\section{IOROSERACEE.}

\section{IROSERA L. - Droseru.}

11. Iongifolia L, D. an fă lmmğ. - Prin locurile nlginóse - În m-ḷi Muscelulı prin ałroprierea Dîmbovicióreì

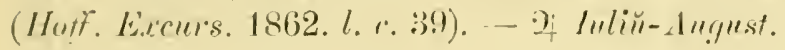

\section{SAXIFRAGAGEE.}

\section{SAXIlikdGid Tomenel. - Saxifragă.}

S. dizoon . Jacy. S. Lizon. - Pe stincile calcare din regimneiı subilpină și alpină. - În m-lị̆ Moldover (Cz. Flor XIX, 64 et Exisic.!; S. arustata C'z. Flora XIX. 64 /non Trest.] it E.rsic.!' h. j. (iueble manuse.) pe Céhllăŭ (S. crustala Ertel l. c. 35); la Brosceni (Burri Exssic.!); pe Pentelen̆: în Nuscel pe m-lele Sturu (D. Br.l.c.83); pe m-tele Kŭganu (Hoff. Liccurs. 1863. l. c. 119) și în m-tiĭ Bucegĭ (Fron. 199; Fr. 110; Gr. En. 26 et Ersic.!) pe Omu! (A.51). Vîrfu-cu-Doru! (Gr. Éxurs. l. c. 340), Pétra-ars̆t. in valea Cioltẹ̆ și a Ialonițer la schitul Pescera; pe m-tele Cozia ; în m-lị̆ Vilcê̌ pe Narọ ; ele. - - of lumin̆- luggust.

S. cochlearis Redh. S. cochlowru. - În reginnea alpină.

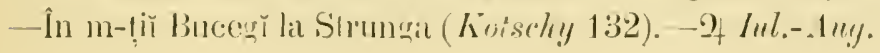


S. transsilvanica Fruss; S. demissed Seleott et Kotschy. S. transsilvenicŭ. - Prin locmile nmede și sîncrise din regiunea subalpină çi alpină.- În m-țī Buceğ in valea Ialomiței (Fr. 110) aprópe de schitul Pescera.-- - If Inliü-Aury.

S. Inteo-viridis Schott et Kutschy. S. gulbènü-verde. Pe stîncile calcare și unede din regiunea alpină.- În n-ṭi Moldoveĭ (S. mutata Cz. Flora XIX, 64 / uon L./ ot Lirsic.!; 11.j. (rueble manusc.); pe Céhlăı̆! (Janlia sse. Kaniz l. e. 203); in m-liĭ Bucegi $(F r .110)$ pe Furnica și pe Pétra-arsă aprópe de l'îrăul-Bahelor. - of hипiй- Lugust.

S. cesia $L$. S. albastiǒ. - Pe slîncile calcare din regiunea alpină. - Pe Céhlăŭ (Edsl l. c. 35) ; în m-tiĭ Bucerğ aprópe de obîrçia Ialomiter (Hoff. Ercms. 18ti3. L. r. 120). - 2 Iuliŭ-August.

S. Burseriana L. S. Burserianú. - Pe stincile calcare din regiunea alpină. - În m-tii Noldově̀ (Cz. Flora XIX, 64 et Ersic.!; h.j. Guebh. manusc.). - of Iuliü-August.

S. aizoides L. S. aizoidŭ. - Prin locurile stîncose nmede și unbróse, și pe lingă lorentele din regiunea subalpină și alphină. - Pe vî̀ful Céhlăuluĭ ; în m-țiù Buceğ (Gr. En. 26 ct Exsic!!) către Onu! (1.51), la schitul Pescera, la Pirŭul-Babelor, pe Obîrșial, Babe; elc. - ? Inliŭ-Aurgust.

ß. autumnatis (L). - În Buceğ. pretutindenea (Fr. 110).

S. Banmegrtenii Schott; S. ictusa Bmq. S. Lur Baumgarten.-- Pe stincile calcare din regiunea alpină.-- In Moldova (S. sedoides Cz. Flora XIX, (j4 inon L.7 el Exsic.!; h.j. Guebh. manusc.); pe Céhlăŭ (S. retusa Janlia! 4 Aug. 1868 scc. Ketuitz l. r. 203) la Stînca-Panaghia; în m-liị Buceğ pe Vîrfu-cu-Doru și pe vîrful Onulŭ. - - If Inik̆-Iuliŭ.

S. oppositifolia L. S. cn fou opuse. - Pe stincile din regiunea alpină.-Pe Céhlăŭ (Jankia sec. Kanitz l. c. 203);

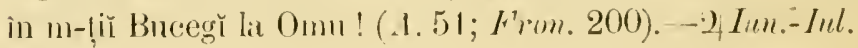




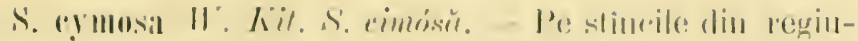

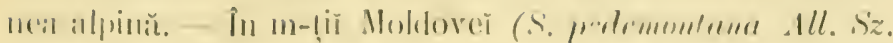

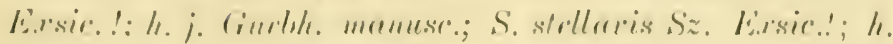

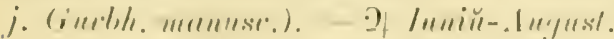

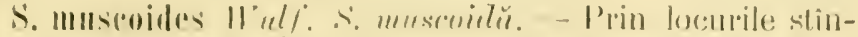

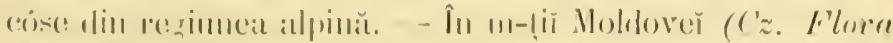

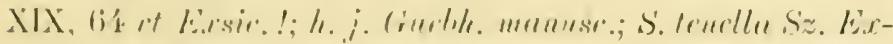

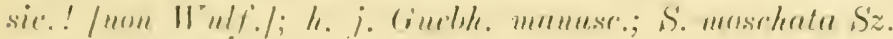

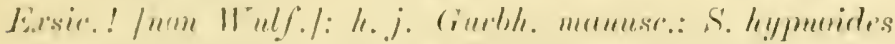

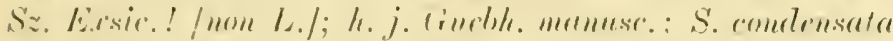

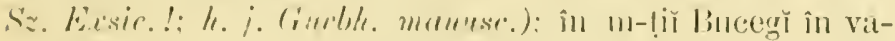

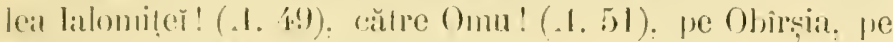
Balle; ete. - 2) Inniü-lugust.

S. alldrosidea L. S. androstere. - Prin locurile slin-

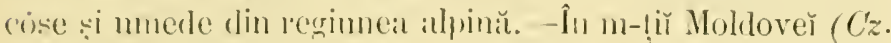

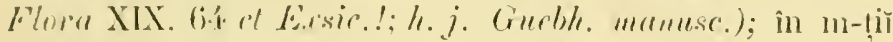

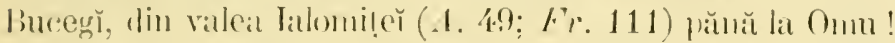
$(1 \% r m .200)$. la Strunga (Cir. En. 26 ot Exisic.!). la selitul Percera, pe Camaiman; ele. - y luniü-durgest.

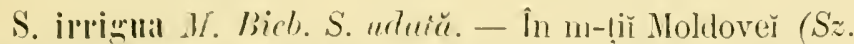

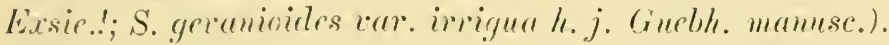

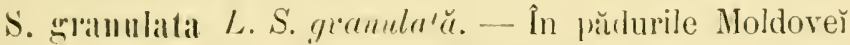
smperiore (Sz. Eisisc.!; h. j. Crucbh. mamusc.); pe Cẻhlăŭ

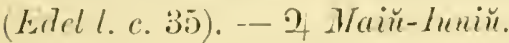

S. curpathica Rrhh. S. carpathică. - Pe stincile mmede

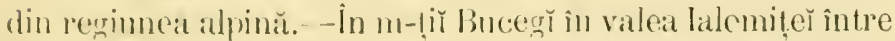
Obirsia și toonmele ( $\because$ rormua Janka Ad. 184; Fr. 111) şi pe Obirsia (1\%. Wintiler, Engl. Saxif. 10'x).--2 Iuliü-Lug.

S. pontroversit Strmb.; S. adscendens L. S. dispmetatü.l'rin locurile stimcrise, petróse și unede din regiunea subal-

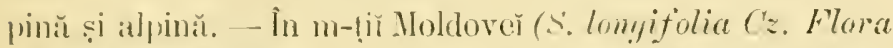

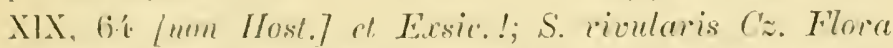
XIX, (is /non L. nec alior.] et Eisic..'; h.j. Guebh. manusc.; 
S. Allionii Cz. Flora XIX, 64 fron Bmy.] at Exsic.!) pe

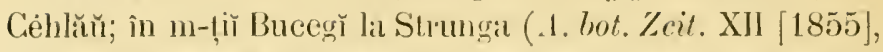
473: S. romosissima Schur Fr. 111), ve valea Colṭen la Burlacu și pe Obirșia; pe Pétra-Ciraiulŭ la Vîrful-Baciuluĭ (Kotscly 65). - $\odot$ Iuniŭ-August.

S. bryoiles L. S. brinitŭ. - Prin locurile petróse din regiunea alpină. - În m-lị̆ Buceğ pe Omu (.1.51; From. 200; Fr. 110). - 2f Iuliü-Alugust.

S. stellaris L. S. stelarĕ. - Prin locurile umede şi pe lîngă pîrăile din regiunea subalpină și alpină. - În in-lịi Buceğ̀ în valea Ialomițeĭ (Fr. 111). - D luliü-lugust.

S. cmeifolia $L$. S. cn foù cumeiforme. - Pe lîngă stîncile umede și umbróse din regiunea subalpină și alpină. În m-ṭĭ Moldoveì (Sz. Exssic.!; h.j. (iucblh. manusc.); în m-țĭ Bucegĭ în valca Ialomițer̆ (Hołf. Excurs. 1863, l. c. 120 ct Fissic.'; Gr. En. 26) puṭin mă sus de schitul Pescera, și pe Furnica; în Museel pe lingă Dimbovicióra (Hoff. Excurss. 1862, l. c. 39); în m-țiù Vîlceŭ la Olănesč́ ; în Gorjiŭ la schitul Locurĭ-rĕle. - 2 IKaǐ̆-1ugust.

S. rotundifolia L. S. cи fŏ rolunde. - Prin locurile u. mede din regiunea subalpină și alpină.--În Buceğ în valea Jalomitẹ̌ (Schur En. 240); la Olănescŭ și la Lotru pe Fớrfeea; la Vîrciorova pe valea Bilhner. - If Imniǔ-_uqust.

ß. repanda Koch. - În n-țiŭ Bucegi la schitul Pescera Ialomițer̆ (S. reppande Willd. Schur En. 240).

S. heucherifolia Grisel, et Sch. S. cn for de heucheria.Pe lîngă slîncile umede și isvórele din regiunea alpină. În m-lị Bucegì (Fr. 111; Wrintil.! Eugl. Saxifraga 116) în valea Ialoniḷer (Schur En. 250) pe lingă schilul Pescel"a

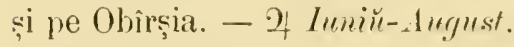

S. Inetiana Boiss. S. Huctionŭ. -- Pe lingă stîncile nmede și pe malurile torentelor din regimnea subalpină. În m-liĭ Noldover (Clerysosplenium opposotifolium Cz. Flora 


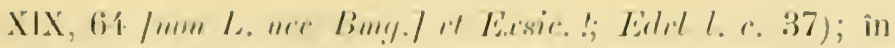

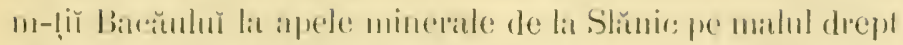

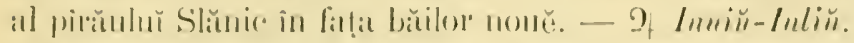

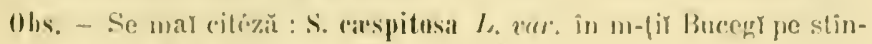
cile mubrise de la Strumga (Kotschy 1:32).

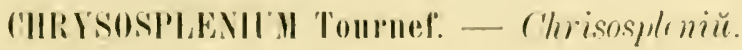

C. alteruifolimm L. C. "'n fur alterm.- Prin locurile umede și mulnrose și pe linğ pirrăile din pădurile montime şi

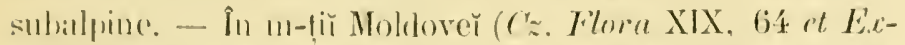

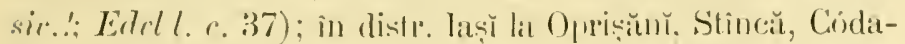

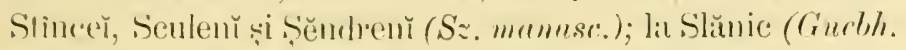

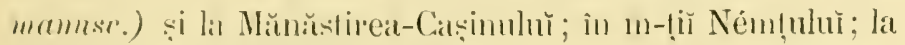

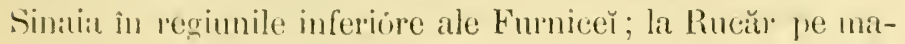

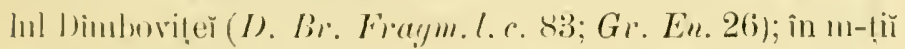

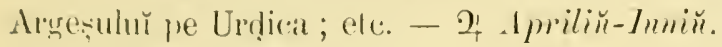

\section{PIRXISSII Tomrmel. - Pernasie.}

P. palustris L. L. de mlastini. - Vulg. Suppirlaitŭ-albŭ. - Prin păṣnile mlăstinóse pe milurile torentelor din regimnea montană și subilpină. - In m-!̣i Moldoveŏ (Cz. Florn XIX, 63 et Exsic. '; h. j. Gucbh. mamsc.) la pólele Céblăuluĩ (Edel l. r. 36). schilul Durăŭ, Sihlit, m-stirea

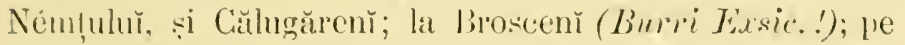

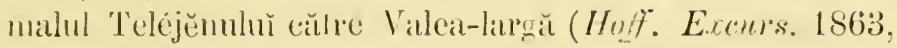
l. 1. 118), la Sinaia pe vilea Pelesulŭ (G). Ixmers. 1863, 1. ('. 338 et Exssic.'; Lin. 13) și la schitul P'escera Ialomiţer̆;

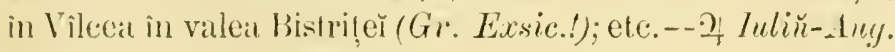

\section{RIBES L. - Ribe.}

R. Girosisularia L.; R. Cirossularia a. glandulose-setosnm Led. Re. Grossnlarie. - Vulg. Agrij, Iyrişă. Acrişă, 


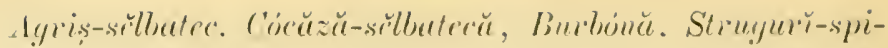

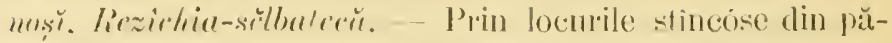
durile subalpine. - În m-lii Molduveř (Cz. Flera XIX. 62;

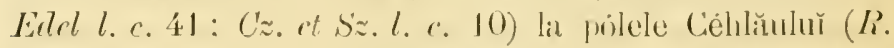

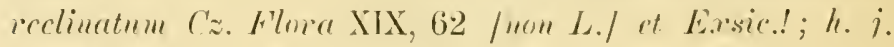
Guebh. menuse.; Eidel l. e. 36; (z. it sz.l. c. 10); la m-stirea Sěcus și la schitul Silıla: în m-fiù Bacŭulŭ la Palanca;

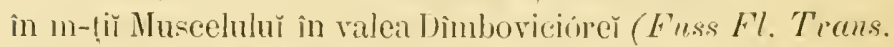
233 ; R. Lea crispa Iloff. Exames. 1862, l. с. 39 [um L.] ct Exsic.!) și pe m-tele Sturu (li. reipathicum D. Br.

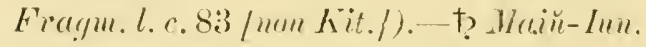

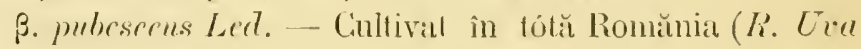
crispa L. Edsll. c.41; Ginelh. manusc.; Cz. st Sz. l. c. 10; R. Grossularia (ir. En. 26).

\%. glabrum Koch. - Cultivat în lơt̆ Romănia (R. reclinatum L. Sz. manuss.).

R. niggrmm L. R. negrn.-Vulg. Struguř-negri.-Prin pădurile montane și subalpine. - În m-!̣̆ Băcăuluĭ la Ocnă, Comănesč, etc. $(C z$. , t Sz.l. c. 10) și cultivat prin grădinı̆ (Sz. manusc.; Gr. En. 26). - †? I priliŭ-_laiй.

R. rubrimı L. R. roșu. - Vulg. Pomușórŭ. Cócăzŭ, Strugnrč̆, Strugurĕ̌-roşĭ. - Prin locurile stincóse din pădurile subalpine. - Spontaneŭ in m-țĭ Némţuluĭ la schitul Silhla!; iar cultivat în tólă Romănia (Cz, st Sz. l. c. 10 et Exsic.!; h.j. Guebh. munuse.; Sz. manusc.; Gr. En. 26). - t? Apriliŭ-Maiu.

R. petraeum IVulf. R. de stinč. - Vulg. Fültior. Prin locurile stîncóse și umede din pădurile umbróse ale regiuneŭ subalpine. - În Moldova (Ėdel l. c. 41) pe Céhlǔŭ (Edcl l. c. 35) și pe m-tị̆ le la Saru-Lorna (Cz. ct Sz. l.

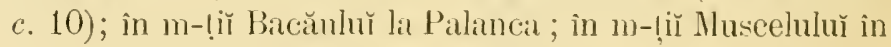
valea Dimboviciórer (Fuss l. c. 234). - †? Apriliŭ-Iuniu.

R. alpinum L. R. alpin. - Prin pădurile stincóse din regiunea subalpină. - În m-tiŭ Moldoveř (Sz. Eissic.!; h. j. 


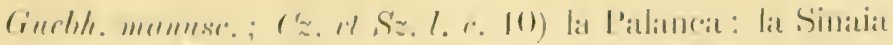

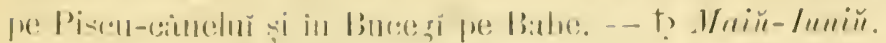

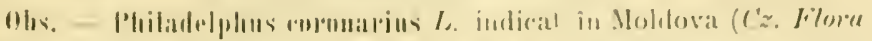

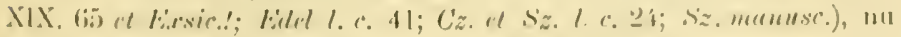
s.' găsesce de citl cultivat prin griùlıur.

\section{MRISTOIOOC'IIICEE.}

\section{ARISTOIOCHII I. - Aristolochir.}

1. Clemaltitis L. A. Clematită. - Vulg. Mterul-lupulur.

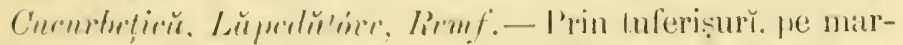

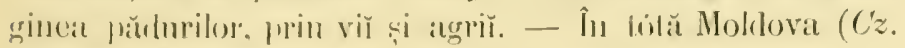

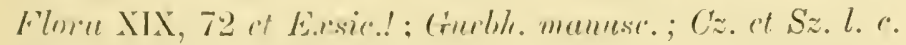

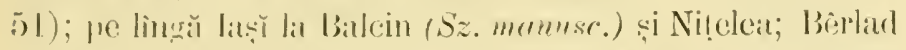

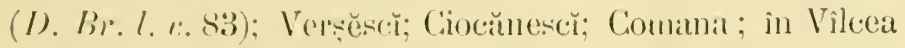

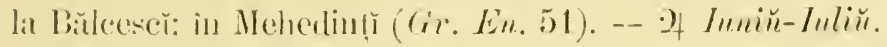

1. pallidal Ir. Kit. A. prelială - Prin Iuferișurı̆. - În Moldova (.1. rohlenda Bmy. Cz. et Sz. l. c. 51 / mon L.7) către 'Ṭbana, Borěccĭ, Mironésa și Ciocaloca (Sz. muunsc.). - 9 Aprilin-1/ain.

(obs. - Se maĩ citéză : 1. Imıra L. în Motdova (Cz. et Sz. l. c. 51).

\section{AS.IRUII L. - Asar.}

A. europiatum L. A. suropean. - Vulg. Pocherinic, P'opirnic. Popilnir. Piprrinl-lupulur. Pipremss̆y. - Prin pădurile mnede şi umbróse. - In Moldova ( $C z$. Flora XIX.

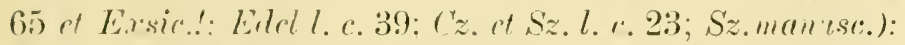

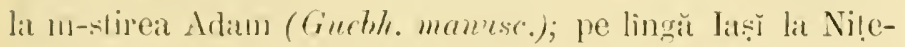

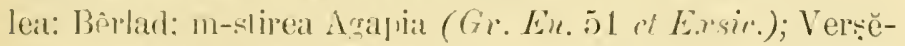

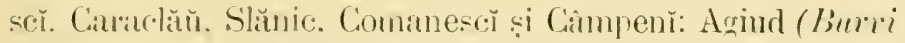
Easie..'); pe lingra Bucurecer la Merinani (D. Br. Fragm.

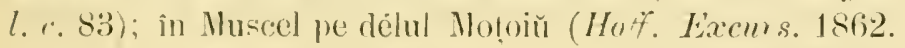

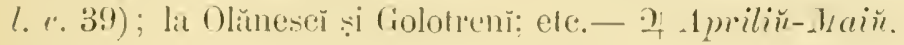




\section{CLCURBTTLEE.}

\section{BRYONLA L. - Brimie.}

B. dioica Jacq. B. dicirŭ. - Vulg. Mută'ôre. Hutätórecu-pómr-roșǐ. - Pe gardurile viilor și a grăddinilor !ẹ̆ră-

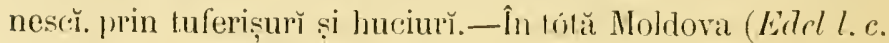
40 st Ex.xsie.!; Guel,h. mamuse.; Cz. rl. Sz. l. (. 42): Ial Agind (Burri E.rsic.!); in Muscel (D. Br. Freegm.l. c. 4.2); pe rîrful déluluı̆ Moṭoin̆ (Hoff.Excur's. 1862, l. ค. 399) : etc. of Iuliü-lugnest.

B. allaa L. B. alluă. - Vulg. Mutătore. Mutắbire-cu-

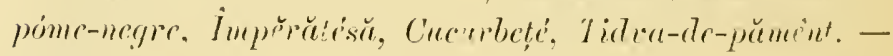
Pe gitrdurile vilor și a grădinilor țerănesč̆, prin luferişuri şi huciurı̆. - In Holdova (Cz. Flora XIX, 69 et Exrsic.!; h.j.

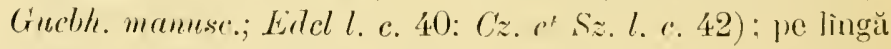

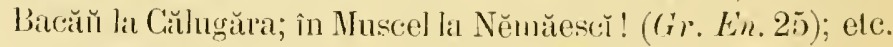
- I) Inliü- lugust.

(0)s. 1. - Se cultivă îu tólă Romănia : Fucuuis sativus $L .1 C z$. Flore XIX, 89) et E.rsic..'; Guebh. manusc.; Cz. et s'z. l. c. 41 ; Sz. manusc.; Gr. En. 55) vulg. Pepene, Crestarete. - C. Melo $L$. et icur. (Gucbh. munusc; Sz. manusc. et Exsic!; Gr. En. 25)] vulg. Zĕmos, Pepene, Pepene-gulbên. - C. Citrullus Ser. (Gruch. mumu.c; Cucurbita Citrulles I. C'z. FHor XIX, 69 et Ex'sic.!; Cz. et Sz. l.c. 41; Sz. memusc.; Citrullus vulyuris Schrul. Gr. En. 25) vulg. ['epene-verle, Harbuz, Lubenițy, Lebentẹt.

Olıs. 2. - Se cultivă în tótă Romănia speciile uruătóre : C'ueurbita Helopepo L. vulg. Cucurbètă, Bostan-ulb. - S. Pepo L. ct ea). (Cz. Flore XIX. 69 et Exsic.,'; Guebh. munusc,; Cz. et Sz. l. c. 11; Sz. ma-

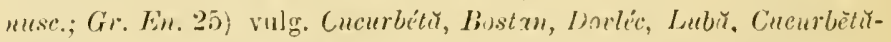
poscéscr̆. - C. verrurosa $L$. (Guebh. manusc.) vulg. Docléc. - C.

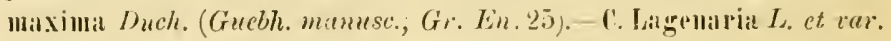
(Layenariu vulgaris Ser.Guebl, menusc,; Gr. Eu, 25) vulg. Tülu, Cu-

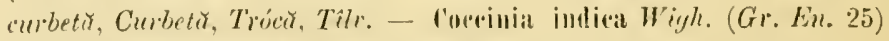
vulg. T"eturet, Trirtücuţŭ. 


\section{CISTACEE.}

\section{HELANTHEMIII Tournet. - Eiliuntem.}

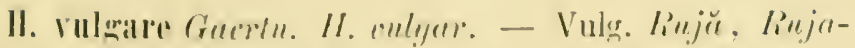

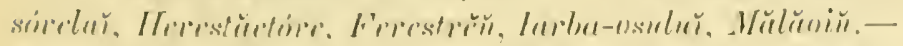
Pe coline itride. prin prộnnile uscale din munț̆. - În Nol-

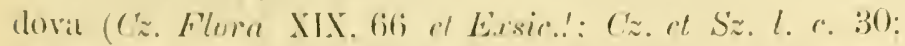

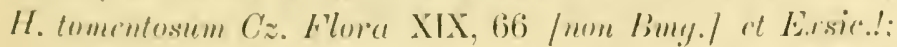

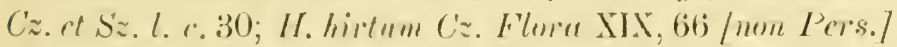

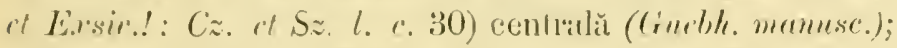
min mun!̣ (Edel l. c. 37) : lat Brosceñ (Burri E.rwic.!); in

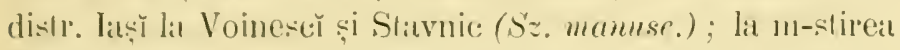

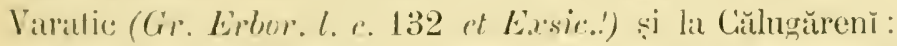

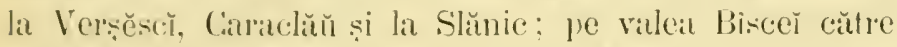

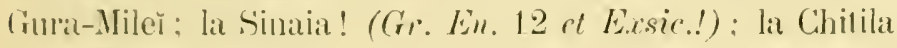

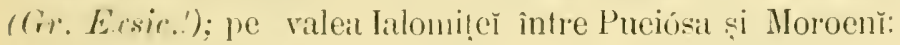

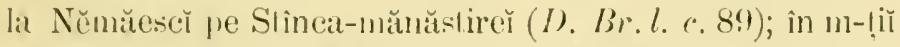

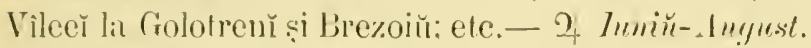

3. Lmmentosum Kuch. - La Sinatia și în m-ṭĭ Bucegř pe

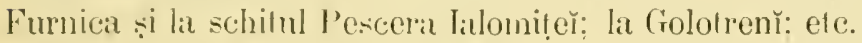

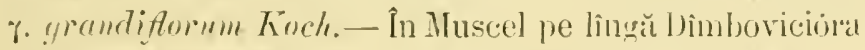
(II. grautifturum I) C. Hoff. Excurs. 1862, l. c. 39).

II. Alandicum Rehb.; H. welendienm o. glabrum Toch; H. glabellem Schur. E. elautie. - Prin păşunile stîncóse subalpine și alpine. - Pe Céhlăй (H. sormyllifolium

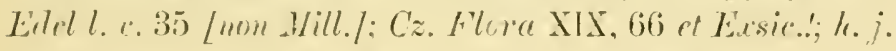

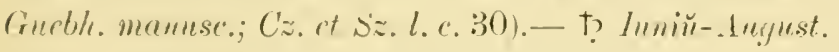

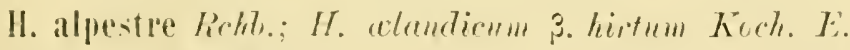
alpestru. - Plin păçuile petrose din regimea subalpină

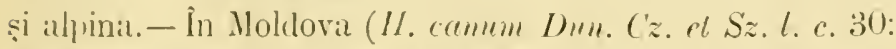
H. merifolium ('z. Flore XIX, 66 /min DC. ure alior./ it

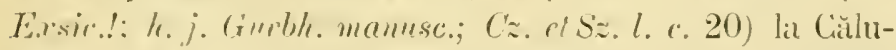

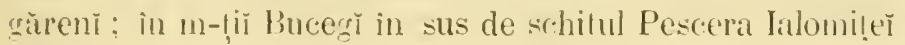




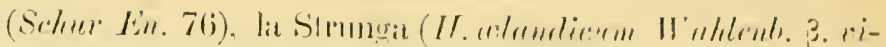

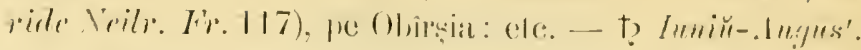

H. prosumbens I) in. E. prormulesut. - J'e coline něsipóse și uscate. - În Moldovia (II. Fumana Eitel 1. r. 40)

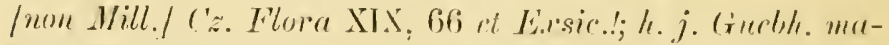

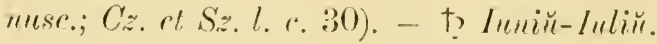

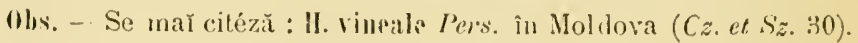

\section{HYPERICACEE.}

\section{IIYPERICIII $\Lambda_{0}-$ Iperi:}

II. Amansilvanicum Crlatinestit. H. macrelatum Fuss. I. irunssilmanic. - Prin finelele alpestre. - In Moldova la

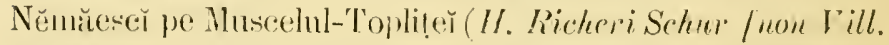

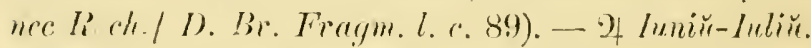

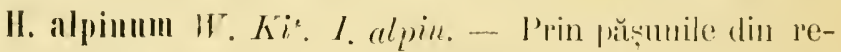
gimnea alpină. - İn reginuile inferiore ale Céhlaulu (EAdel

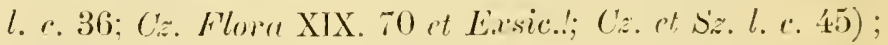

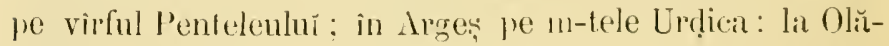

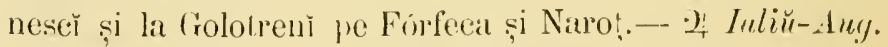

II. montimum L. I. montan.-Prin pădırile montane.În Moldova $(C z, c t S z . l, c .45)$ superioria ((iucbh, manusr.); la Ciurdea și Cerbulésă (Sz.manusc.). - Of Inniŭ-Angust.

II. hirsutum L. I. irsut. - Prin pădurile umbróse. În tohă Noldova (Cz. Flora XIX, 70 et Eirsic..! Guethli. ma-

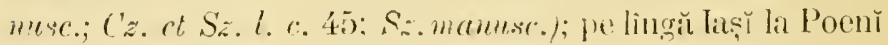

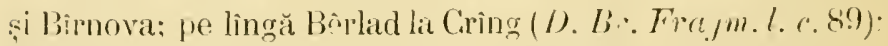

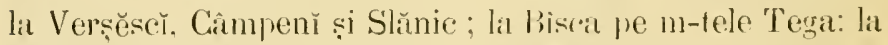
poilele Buceutor (Hoff. Eireur.s. 18633. l. e. 119 ot Exsir..)

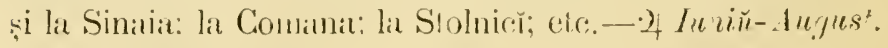

II. Megans sicphe. I. elegani. - Pe coline aride. - În Moldovar (H. Kohlianum sijr. ('z. ct Sz. l. c. 45); pe lingă 


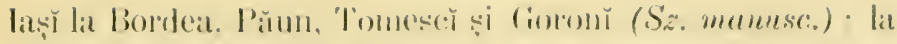

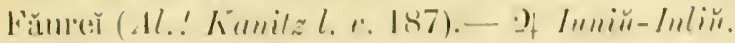

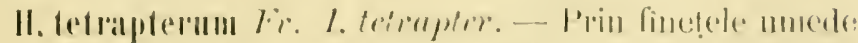

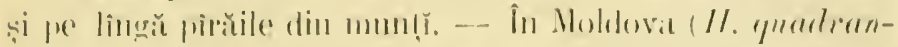

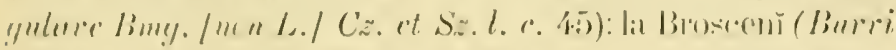

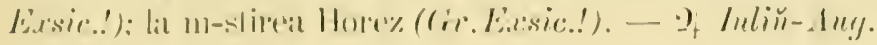

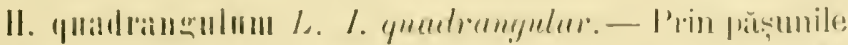

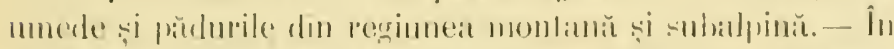

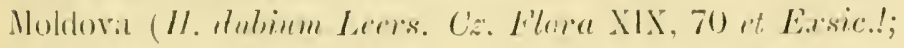

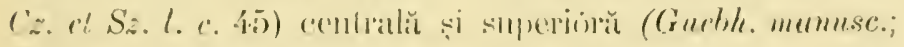

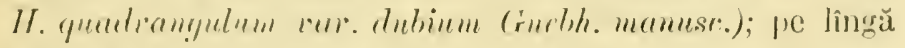

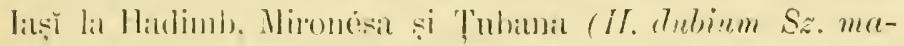
nuss.) : in reginnile inferiore ale Céhlăuluĭ: la bêrlad (I).

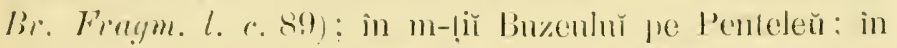

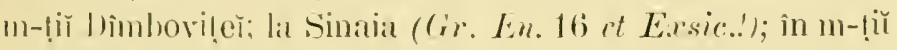

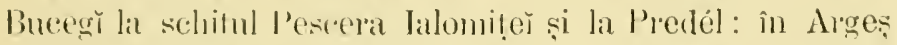
pe Lrḍica: in Vilceal pe m-tele Nitrol.-2 Immin̈-Angust.

II. prerioratula L. I. perforat. - Vulg. Pojurrițu, Su-

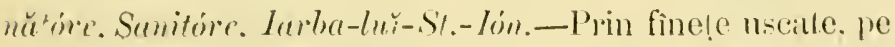

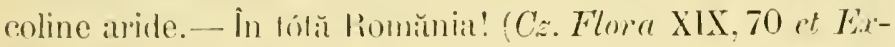

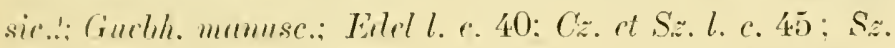
menuse.; D. Br. Fragm. I. c. 89: Gr En. 16 ; H. microphyllum Gr. En. 16 [mm .Jord.] et Exsic.!).-2 Lum.-1ug.

Obs. - Se mař citéză : H. Rỉcheri Vill. în Moldova (Cz. et Sz.l.c. 45). - II. pulrhlrum L. în Moldova (Cz. et $S z$. l.c. 45 ; $S z$. munusc.).

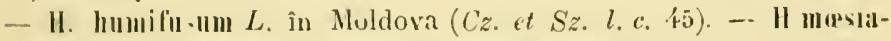
('um $5 p)$. pe colinele de la Galați (Guebh. mamusc).

\section{GENTIANACEE.}

\section{GENTIANA L. - Gentianŭ.}

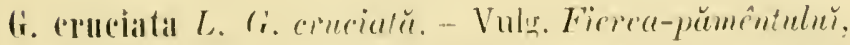

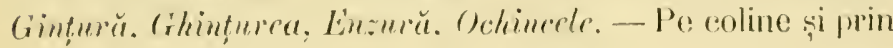


poenile din pădurı̆. - În tilă Moldova (Erlel l.e. 37 et E.r-

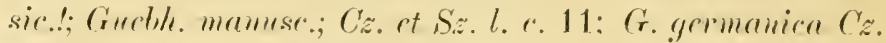

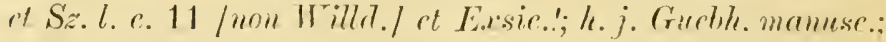
(i. campestris C. Flora XIX. 62 [nom L.] at E.rsie..' le.j. (inchh. manusc.); la Bioscenı̆ (Burri Exssic..'); pe lîngă Iaș̆ la Valea-adîncă. Repredea (Sz. mamusc.) si Nitelea; la mstirea Némṭulıu pe f’leșu și la Agapia-reché la Caraclăŭ pe Babaghicea, la Mănăstirea-Ciạ̣innhŭ și la Palanca; pe m-tele

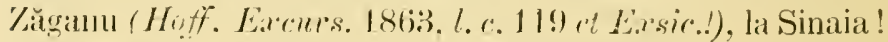

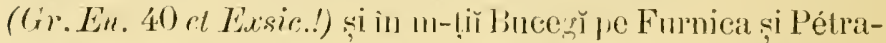
arsă ; în Dîmhovița între P'etrocita și Ţị̂a și je n-tele Prinoru; in Mluscel pe m-tele Lerescr (Hoff. Excurs. 1862. $l$. c. 38 et Exsic..'); la Comana pe valea Gurbanuluü; în Arges la Dăescŭ : la Virciorova pe Plaiul-scurt; in frorjiŭ la schitul Locurĭ-rĕle: etc. - 2, Muliŭ-A lugnest.

(i. phlogifolia Schoth ot holschy. G. Atogifnlia. - În m-tiĭ de lit fruntaria Moldoveř (Fuss in (rrisel). et Sch. It. 330, 331). - 2 Juliŭ- luguest.

(t. Intea L. ('. galbènă. - Prin pășunile đin regiunea

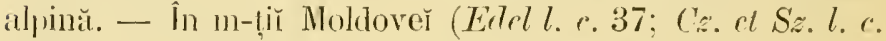
11; D. Br. Fragm. l. с.90). - 2 hediu- ingust.

(i. pannoniơ Scop. G. ungaricŭ. - Přșun alpine. -

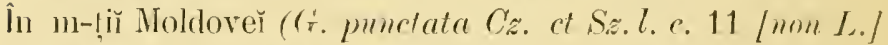
et Exsic.!: h.j. (incbh. manusc.). - of Inlin- lugust.

G. acaulis L. G. acaulă. - Prin pĭșunile din regiunea

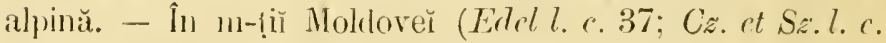
11). - 2 luniй-. Iugust.

A. excisa Presl. Cr. excisatŭ. - Vulg. Ucincéter. Cupe. - Prin pășunile din reginnea alpină. - În m-tiī Bucegĩ pe Furnied, Pélra-arsă: efc. - of Inniü-Juliu.

4. frigilla Hacuker. G. frigurósă. - Prin pășunile din regiunea alpină. - În m-lị̆ Buceğ $(F r .97)$ pănă pe virfufile de înaintea Oımhur (1, 51). - 2 theliu-1ugust. 


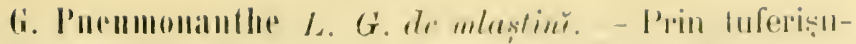

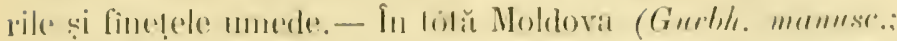

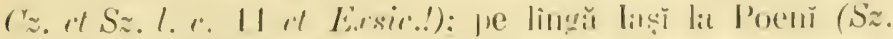

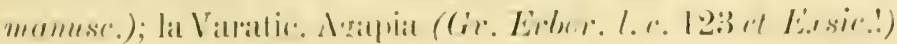

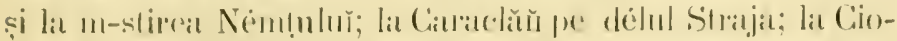

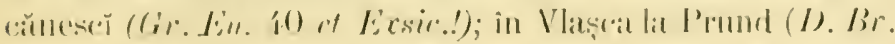

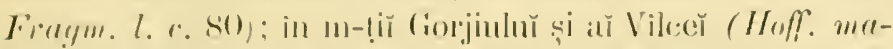

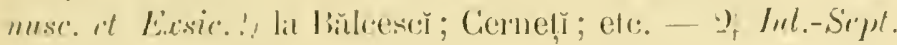

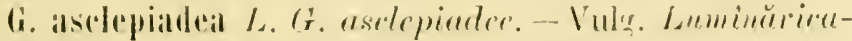
jümintulnu. - P'pin pădurile unbróse si monede din regin-

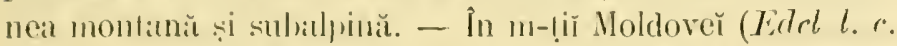

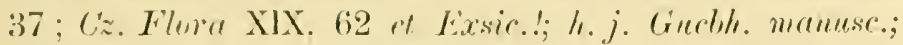
$C_{z}$.rl $S_{z}$. l. c. 11); in m-liĭ Nèmtnhŭ pe Petru-Vodă, la m-stirea Ném!̨ulu pe m-tele Pleṣ, lit schitul Procor, Silhliı, Agâjia-veche și Durăŭ; la T'îrgu-()cneì c̦i liı Slăuic: la m-stirea Chéia și la pólele Bucesilor (Hoif. Lacurs. 1863. l. c. 119 of Exsic.') - lit Cimpulung (Gr. Ein. 40) pe m-tele Le-

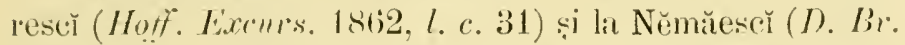
1. 1. 90): în Arges pe m-lele Urdica; elc.-2 duy.-Sopt.

(i. utriculosi L. G. utrirulessŭ. - Prin pășnnile unede din regrinnea sulaljpină și alpină. - În m-țiù Buceğ la Strunga

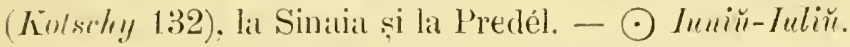

f. niralis L. (i. aivalü. - Prin locurile petrose din re-

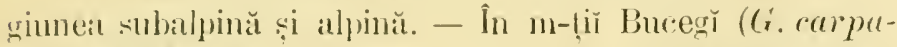
liche Hr. Kit. Wott. Fixcurs. 1863. l. e. 11.9) pe Furnical și pe valea Colțeř la Burlacu. $-\odot$ Iulin̈-August.

(i. aestiva R. et Schult.: G. angulosa M. Bicb.; G. ermu 3. aluta Grisst. K. de véră. - Prin păşunile petróse din regiunea subalpină și alpiuă. - In m-lị̆ Bucegĭ pe vìful Furniceӗ. - 9 Luniй-Angust.

G. verıa L. G. de primătérŭ. - Prin pășunile petrose din regiunca alpină. - Pp Célulăŭ (Edel l. c. 35); Cz. Flore

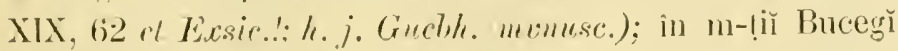

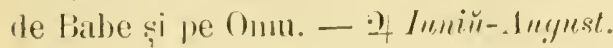


(i. ciliata L. G.cilinith.-Prin locurile mmede și petróse

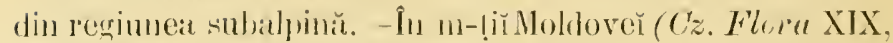

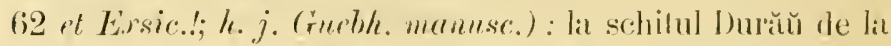

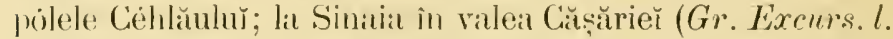

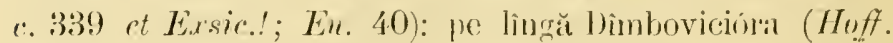
Excurs. 1862, l. r. 39). - $\odot$ Anyust-Septembre.

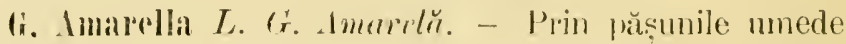
din reginneit subsalpină. - În regimile inferiose ale Célılăulù ! (Edel l. c. 36; Cz. Flora XIX, 62 st Exsic.l; h. j. Gueble. manusc.; $C z$. ci $S z$. l. c. 11): în m-liĭ Bucegẹ la Strungat (flore albo Ko'schy 132). - - Anguest-Septembire.

G obtusifolia Hilld. G. spainde'ť. Prin prășunile subalpine și allpine. - În m-ljĭ Buceğ și la Predèl. - $\odot$ lı!

(i. germanica Willd. Gr. germaniĕ̌. - P'pin păsunile din resiunea montană și subbupină. -- La Broscenı̆ (Burri Ersic.!); pe Céhlăŭ, la schitul Sihla și la m-stirea Némı̣u-

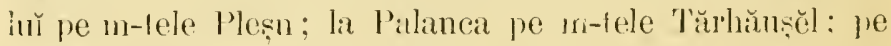
Penteleñ; la pólele Bucegilor (Gr. En. 40 at Exsir.!) și la Sinaia ; ele. $-\odot$ Angust-Septembre.

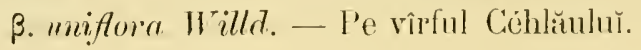

\section{ERYTHRAA Rich. - Eritre.}

F. Centanrium Pers. E. Centanrăt-mich̆. - Vulg. Potrócŭ. Fisren-pămêntulur. Tintaură. Frigon. - Prin finețe

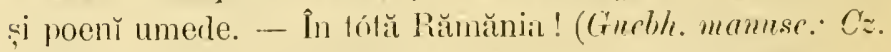
rt Sz. l. c. 9: Sz. manuse.; D. Pr. Fragm. 7. r.90: Gr. En. 40 et Ersic.!; Kanitz 1. c. 226: E. Hyppocentanrea IHoff. Excurs. 1862, l. c. 40 rt Exsic.!; E. ramosissima

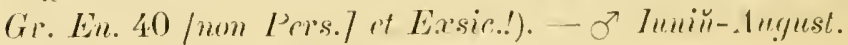

E. pulchella Fries. E. finmosich. - Prin finele ninede.

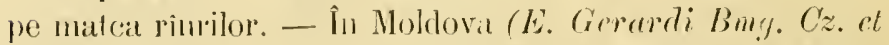

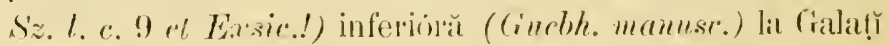

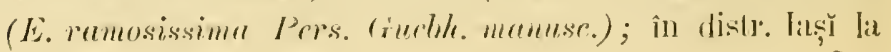




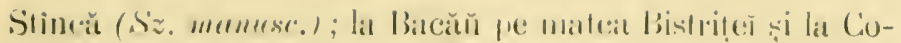

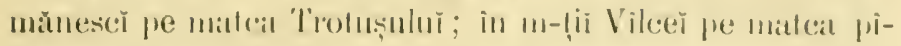

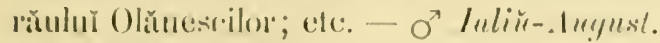

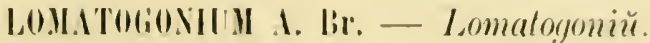

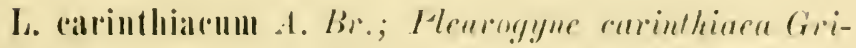

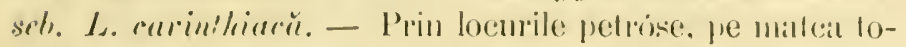

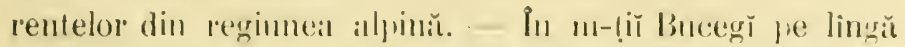

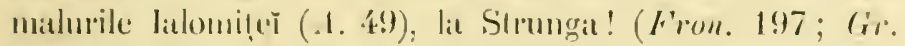

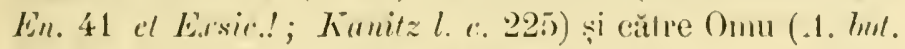

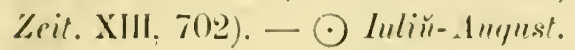

\section{MENYANTIES 1. - Meniant.}

II. trifoliata L. M. Irifoliul. - Vulg. Triforsie. Tri-

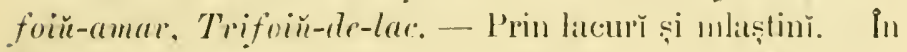
Romania (Curaca; l. c. 116; D. Br. l. r. 90); la Bucurescĭ (Gr. Ein. 41 et Exasic..') in suburbia Brostenĭ sub cimitirul Şerban-Vodă. - It Apriliü-M/aiu.

\section{LMNANTILEIIII Gimel. - Simmantem.}

L. IImphoides Link.; L. pellutum (imel.; Willarsia nymphoides Ve'nl. L. nimforil. - Plutitor pe supratata apelor stagnante și lin curgèlore. - Pe lingă (ialați (fimlbh. manusc.); pe lingă Bucuresscĭ li Ferěstrěŭ (I). Br'.l.r. 90);

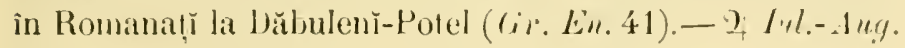

\section{OROBANCHEE.}

OROBANCHE I. - Orobanche.

0. exulenta Berı. () incruntulă. - Parasilă pe rădĕcinile luĭ Lotus, Cytisus și Cienista. - Pe lîngă Cómeṭ̂̆ lat 
lorgutova (Gr. Errsic.!) și la Vîrciorova către Porṭile-defer. - If Inniir-Iuliii.

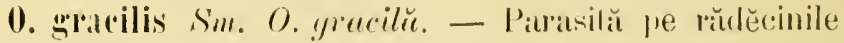
lu Cylišsus și Gruista. -- La Vìrciorova cătro Porṭile-rle-

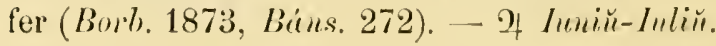

0. Gallii Duby; O. vulgaris DC. O. vulgark. - Vulg. Terigel, Verițel. Crăliciur. Iarbu-untulur, Flórea-untulur.

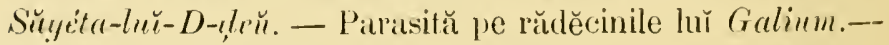
În Moldova (O. caryoplyyllacea Sm. Cz. Flora XIX, 68 et Exsic.?; (z. et s'z. l. c. 38) pe lingă Jaşı̆ la Balcin în ViatVîrnav (O. caryoplıyl. Sz. manusc.?); în regiunile inferióre ale Céhllăului (O. caryophıjl. Edsl l. c. 36) și la m-stirea Némḷulı̆ pe m-lele Pleșu; etc. - 2 lıniй-Juliŭ.

0. Epithymum DC. O. Epithim. - Parasilă pe rădĕci-

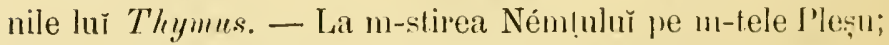
la Agind (Burri Exsic.!); în m-țǐ Bucešr la schilul Pesceral

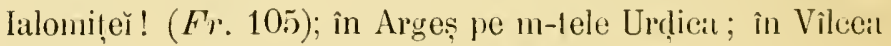
pe m-tele Fórfeca; etc. - 2 Iипій-Iuliŭ.

O. flava Alart. O. galbênŭ. -- Parasilă pe rădĕcinile lı̆ P'etasites. - În m-tiĭ Bacŭıluı̆ pe valea Slăniculı̆ către fruntarie. - 9 Iuliŭ- luegust.

Obs. - Se mar citéză: 0. Mlatiol Bug. în Moldova (Cz. et $S z$. l. c. З२; Sz. mamusc.) inferióră (Guelh. mamusc.) și în regiunile inferiòre ale Céhlăulur (Edel l. c. 36). - (). tuteil Bmg. în Moldova ( $\Gamma z$. Flor XIX, 68; Cz. et $S z$. l. c. 38; Sz. manuse.) la pólele Cỉhlăului ( $H$ (lel l. c, 36).--0. crinita Viv. în Moldova inferióră (Guebih. mumusr.).

\section{PIIELIPEA Iesf. - Felipee.}

P. corrulea C. A. Mley. F. allüstrie. - Parasilă pe rădĕcinile de Lehillea. - În Moldova (Opoluanche corrulea L. Cz. et s'z. l. c. 38) inferior:̆ (cuebh. manuse.) ; in dis-

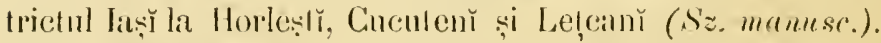
- 2f Lипій-Inliи. 


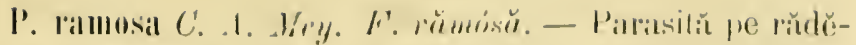

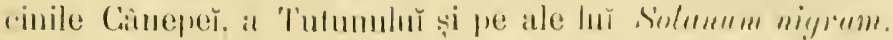

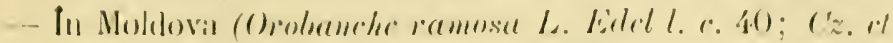

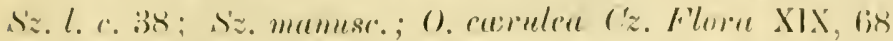

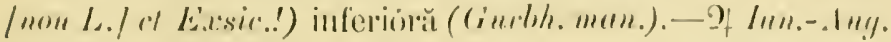

\section{B.ATHREA I. - Latice.}

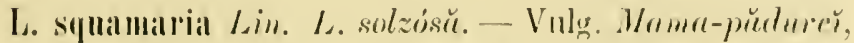

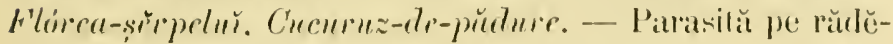
cina arborilor din pădurile unede și umbróse. - In Mol-

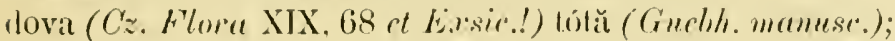

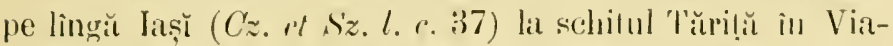
Veisal (Sz. mamusc.) și la Nitelea (D. Br. Frorgm.l. a. 90); pe lingă Bucureseí la Cernical: la Comana; în Muscel la Con!̣ěscì (cir. Eisir..!); pe lingŭ Cratiova ; în Mehedin!̣̆ pe

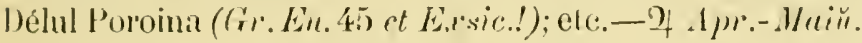

\section{XXIY. TAUARISCINEE.}

\section{MYRICARIA Dest. - Mirisurie.}

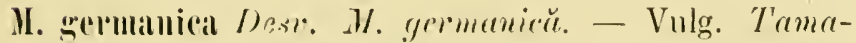
riscrŭ. Cütinŭtmič̆. - Pe malurile si pe matca torentelor și a rìurilor de la pólele muntilor. - În Noldova ('Tamarix yermanica L. Cz. Flor" XIX, 63 et Exrsic.!) centralĭ (Gincbh. mamesce) de lit pólele Céhlăuluı̆ și pănă aprópe de Odobescĭ (T. yermanica Litel 1. (. 36. 37); pe milurile

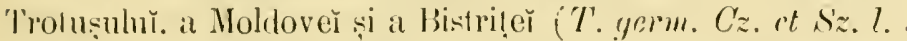

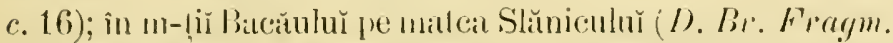
l. c. 90); lit Agiud (Buer. Érsic.!); pe malca 'T'elejĕnulŭ și

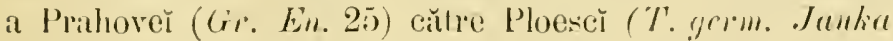
Opst. hot. Zeit. XXIII [18733], 322) și la Sinaia : la Cîtmpu-

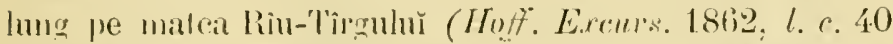

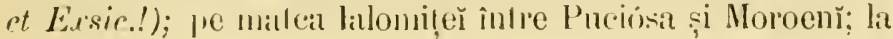


Rîmnien-Vîlcè̌ pe malul Olnulŭ́ pe malca pîrăulur̆ Olănescilor; cte. - †? Imnirt-Inliü.

\section{TAMARIX L. - Tumariscĕ.}

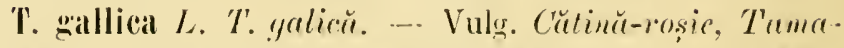
riscă. - Pe malurile și pe matca lîurilor. - Pe lingă Bărboşı (Uechtr. et sint. see. Kunitz 1.c. 186); pe matea Prahover̆ căıre Ploesĕ împreună cu Myricaria germanica, cu specia următóne și cu Hippophä̈ phammoides, fórle frequentă (Jankia Oest. bot. Zeit. XXIII [1873] 322); la Cîm-

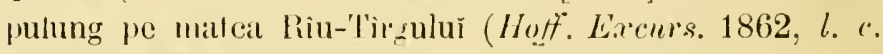
40). - †? Maiй-Luliü.

T. Pallasii Desv. T'. Lŭ P'allas. - Pe malurile și pe matea rîurilor. - In Moldova inferiórĭ pe malurile Seretulùn! (Guebh. manusc. et Exxsic. ". 776 sec. Nym Consp. 253; Boiss. Fl. or. I, 773; T. gallica Cz. Flore XIX, 63 / $\mathrm{mm}$ L.] et Exsic.! ; Edlel l. c. 38; (́z. et S'z. l. c. 16) pănă la Foeșanı̆ (T'. gallica Edel l. e. 37 et E.rsie.!; CZ. et Siz.l. c. 16); pe matea Putneĭ la Fĭureĭ ((ineb). Not. manusc.) și Agind (Burri Exsic.!); de la Huṣ̆ î jos ('T'. gallica Sz. manusc.); pe malul Tasliŭulŭ eătre Sloboḍia; în distr. Buzeŭ la Sarea-lŭ-Buzĕŭ; pe matca Prahoveř către Ploesč̆ (Janka Uest. bot. Zeit. XXIII [1873|322) şi Câmpina; pe

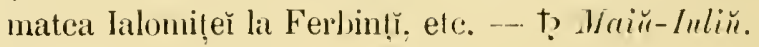

\section{XXY. SALICACEE.}

\section{SALIX Touruef. --- Salce.}

S. pentandra $L$. S. pentandrŏ.-Pe malurile rîurilor.- -

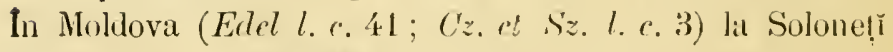
(S': manusc.). - †? Maiu.

S. fragilis L. S. fragidăt. - Vuls. Riachitu. - Pe mallurile rîurilor și prin locurile monerle. - In tólă Romănia! 


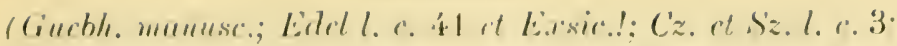

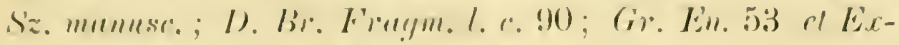
sir.!). — t?. 1, miliii-s/aiii.

3. deriprens Kurh. - lu Muldova (s. deriprems Hoffm.

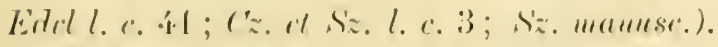

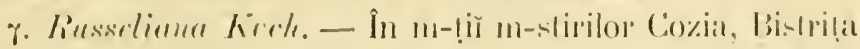

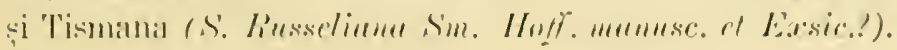

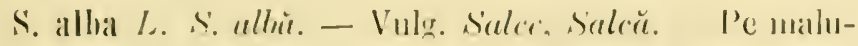

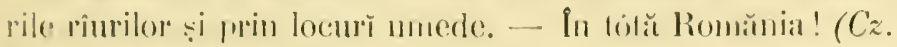

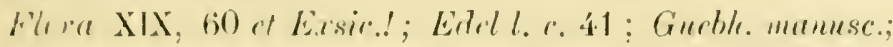

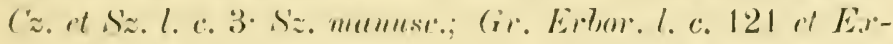

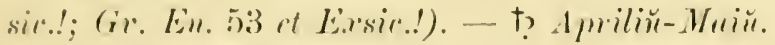

ß. vitellima kinch. - Vulg. Lasie. - In Moldova (s. vitollima 1. Edel l. c. 41; Cz. rt siz. I. c. 3).

S. triand»a L. S. triamhrŭ. - Pe malurile apelor şi prin locurì măı̆tinôse. - In tôtă Romănia! (Vurbh. mamese.: Cz. ot Sz. I. e. 3; Sz. manusce). - t? Apr.- Maiй.

P. diseulor. - In Moldova (S. cmyggdalina L. ('z. et Sz. l. с. $3 ;$ Siz. mamuse.).

S. purpurea L. S. purpurie. Vulg. Rüchită-rosie.l'e malưile apelor și frrin locur mlăștinose. - In Moldova

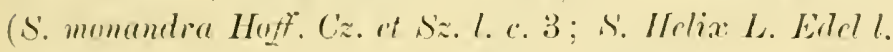
c. \$1) pe malıl Prutuluй (Sz. mamusc.); la Nẻm! (S. Melix

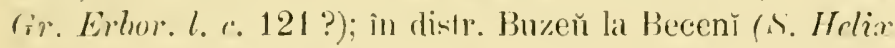
(i). En. 53 et Érsir.?); la Predél; la Cerneṭ̆ pe mahul 'Topolnițel ( (ir. Ë. 53 ?). - †) Wartin̆-Apriliŭ.

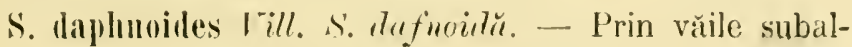
pine. - In m-liŭ Vìlceŭ la pasul 'Turnu-roșin (Schur En. 618). - t? Martĭ̈-Ipriliü.

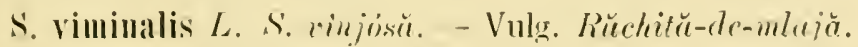
- Pe malurile rìupilor. - In Molrlova (Edel l. c. 41: Cz. rí

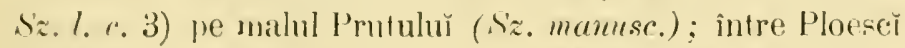
și Vălenì ((ir. En. 53 ?); elc. — †? Mariiu-Apriliü. 
S. incana síchrant. S. albicirisŭ. - Prin văile umede din munț̌. - In Moldova (Anders. in DC. Prod. XVI, II, 302) tôtă (s. riparia Willd. Gucbh. manensc.); în Vîlcea la Călimăneseĭ (Gr. Exsic.!). - †? I priliñ-1Maiu.

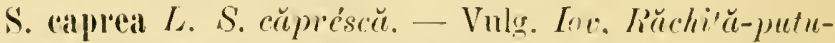
rissŭ. Răchitŭ-móle. - Prin pădurile unede, cu deosebire din regimnea montană. - In Moldova (Edel l. c. 41; Cz.ct Sz.l.c. 3 ; Sz. mamusc.); pe lînği Jișŭ la Niṭelea și Repedear (I). Br. Frarm. l. c. 90); în distr. Bacăn̆ la Cânupení; călıe Vashluĭ la Valea-Mloṣnégulur̆ (Gr. Erhor. l.c. 121); la m-stirea Cheia (Hoff. Excurs. 1863, l. c. 118), la Câmpina (Gr. En. 53); etc. - † .Martiü-.1 priliŭ.

S. anrita $L$. S. aurită. - Pe lingă pîrăie, prin pridurĭ umede. - In lótá Moldova (Gurbh. manuse.); în Ilfov la Chitila (Gr. Exsic.!). - †? A miliй-Naiй.

S. silesiaca Willd. S. silesiucă. - Pe lîngă stîncile umerle și pe lìnğ torentele din pădurile subalpine. - In Moldova $(C z$. ct $ง z, l$. c. 3) la Palanca pe lingă Pîrăul-ṣan-

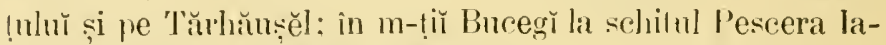

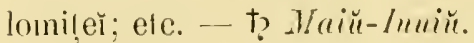

S. cinerea $i$. S. comsic. - Pe lîngă ape, prin locurř umede. - În Moldova (Edel l. c. 4; (z. et Sz. l. c. 3); pe malul Prutuhŭ la Slîncă (S'z. mamusc.); la Títu, Therganı̆ (Gr. En. 53 et Ersir.!). Peris și Buftea; la Predél; etc. - †े Martiй-A milin.

ß. aquatica. - In m-ṭī Buzenluì către Valea-largă ( $S$. aquatica Sm. Hoff. Excurs. 1863. l. c. 118 et Exsic.!).

S. myminites L. S. an for de mirt. - Prin locurile stincoise și umerle din regimea alpină. -- In m-lii Moldover (Cz. Flora XIX, 60 it Exsic.!; S. aphusenda Cz. Flora XIX,

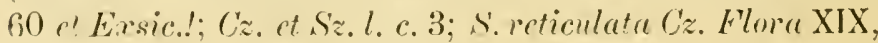
60 [non L.] et Exssir.! : Cz. ot Sz. l. r. 3); in n-!̣ĭ Buceğ in valea Ialomi!̣ $(F r .82)$. - ț Inniй-Iuliur. 
S. retusa L. S. monsĭ. - Prin locurile petróse din re-

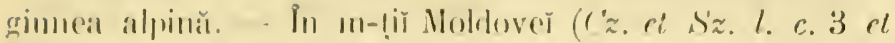

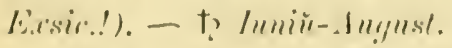

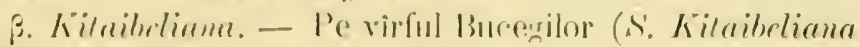

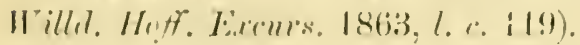

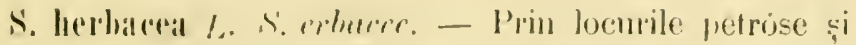

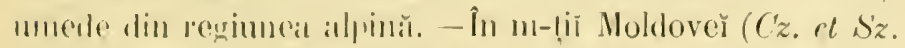

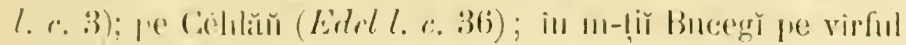

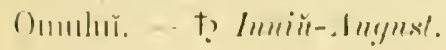

S. reticulata L. s' reticululŭ. -- P'rin locurile slîncóse

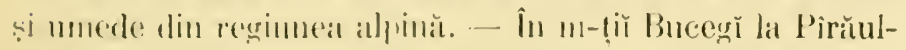

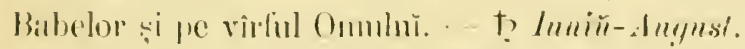

(bhs. 1.- Se mar citeză : S. rubla Huds. la Ghergañ și Titu (Gr. En, 53??), - S. armuluata Sm. în Moldova (Cz. et Siz. l. c. 3) şi la Titu și Ghergany (Gr. Ln. 53?). - S. hastata L. în Moldowa (Cz. et

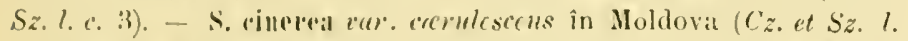
c. 3).- S. fagifulia in Moldova (Cz. ct Sz. l. c. 3).-- s. silesian Willd. verr. sphucetutu în Moldova (Cz. et Sz. l.c. 3). - S. mỵlilluides $L$. in Moldova $(C z$. ct S Sz. l. c. 3). - S. pluylicifolia $L$ în tótă Moldova (Guebh. manusc.; Cz. ct $S z$. I. c. 3). - S. incubicea I. in Moldova

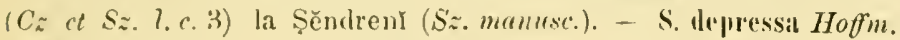
in Moldova (Cz. et Sz. l. c. 3) - - S. Posmarinifolia L. in Noldova (Cz. et $S z$. l. c. 3). - s. limosa Whlbg. în Moldova (Cz. FYlora XIX. 60; Cz. et Sz. l. c. 3). - S. Jatepuinii Host. in Moldova (Cz. Flora XIX, b0; ( $z$. ct $S z, 7, c, 3)$.

()bs. 2. - S. babiloni(a L. vulg. Sulic-pletóstr. indicată în Bucurescy (Gr. Ẻ. 533 et E.rsic..!) nu se găsesce de cît cultivată prin grădiny și cimitire! (Guebh. manusc.).

\section{Poplias Touruef: - Plop.}

I'. allha L. L'alh, - V'ulg. I'lulă. - Prin luncì çi \%ă-

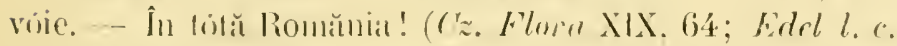

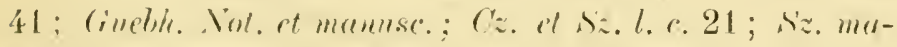
musc.; (ir. Lither. l. r. 121 ot Ein. 53: Kintilz! l. c. 115). -

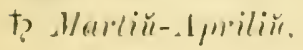


P. canescens s'm. P. albicios.- Prin lnncì și zăvóie.-În Moldova ( $P$. alba $\beta$. caueserns $C z$. et Sz. l. c. $21 ; S z$. manusc.); la Verșĕscĭ in Iunca Tazlăulur̆; la Slatina în lunca Oltuluĭ; etc. - t? Hartiü-stmiliu.

P. tremula L. P. tremurătoriü. - Vulg. Hop-dsmunte. - Prin pădurĭ. - In Moldova (Edel l. c 41 et E.xsic.! ; Cz. ot Sz. l. c. 21 ; S'z. manuse.; Betula nama Cz. et Sz. ct Exsic.! (non L.J) centrală și superióră (Guebl. Not. 17 et manusc.); la Stefănescĭ ; pe lingă Jaš̆ la Nițelea; la Câmpina; pe lingă Bucurescĩ la P'auleleimon (Gr. En. 53 ct E.rsic.!); etc. - †? Martin-Apriliü.

P. nigra $L$. $P$. necgru. - Prin luncì și zăvóie. - În 1ótâ Romănia! (Guebh. Not. 17 el manusc.; Edel l. c. 41 ct Exsic.! ; Cz. ot Sz. l. c. 21 ; Sz. manusc. ; (ir. En. 53). t? Marlin-Apriliü.

Olıs. - Se inaì citéză : P. repanda Bmg. in Moldova (Cz. ct Sz. l. c. 21). -- Iar, P'. Mylan idalis Ros, indicat în Moldova (Sz. manusc.; Gr. lirbor. l. c. 121) centrală și iuferióră (P. dilatutu Ait. Gucbh. Not 17 ct manusc.) și in Lunca Oltulư spre Islaz (Gr. En 53', nu se găsesce de cât numar cultivat.

\section{SUB-IIVISIUNEA III.}

Ovariŭ plurilocular; placentațiune axilă.

\section{IIALVACEE.}

\section{MALVA Tournef. - Nalbă.}

II. sylvestlis L. N. de pätulere - Vulg. Nalbä. - Prin locurile ruderale din oraṣe și sitle, pe lingă gardurĭ. locuințĭ si drumurĭ. - În tôtă Romănia (Cz. Fìno XIX, 69 st Ex- 


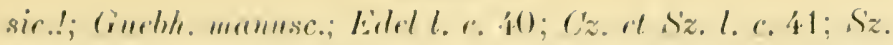

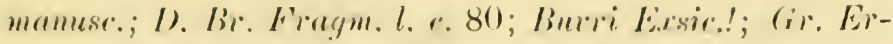

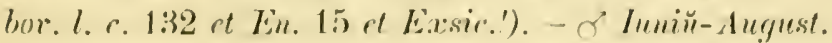

3. cilubra. - - Prin locurile cullivale din Moldova inferionă

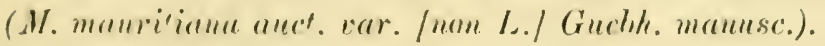

II. rofundifolia L.; A. vulyaris Fries. . . cu for ro-

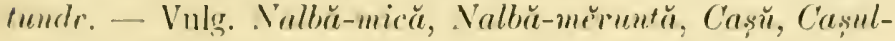
mupry. - P’rin locurì cultivate și ruderale, pe lingă drunurŭ și locuinți. - In tilă Romănia (Cz. Flore XIX, 6!) $\mathrm{ct}$ Exsic..; Gucbh. mamuse; C'z. of Sz. I. r. 41; sz. mannsc.; D. Br. Fragm.l. : 89; Gr. Erbor. l. c. 132 rt En. 15).- Imnin̆-Septrmbier.

M. borealis H’allm. N. borcală. - Prin locurǐ cultivate

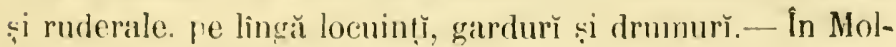
dova inferiólă ( M. parviflora. Huds. Fnon L.] Gurbh. mamusc.); la 'lìrgoviștea; ete. - $\odot$ Iuniŭ-Septembre.

0hs. - Se maĭ citéză : M. Alcea $I$. în Moldova (Sz. manusc.). II. muschata $L$. în Moldova (din eróre M. montana Cz. et Sz.l. c. 41). - M. (rispa L. in Moldova (Sz.mrnusc.).

\section{ALTHAA I. - Altee.}

A. officinalis L. A. oficinalŭ. - Vulg. N'albă-mare, Nalbia-albă. - Prin locurì umede, pe malurile rîurilor. În tólă Moldova (Cz. Flora XIX, 69 et Exsic.!; Guebh. manusc.; C'z. et Sz. l. c. 41; Sz. mamusc.); către Galați (Edel l. c. 32,41$)$; la Bèrlad (D). Br. Frragm. l. c. 89); pe lìngă in-stirea Vitratic (Gr. Erbro. l. c. 132); la Versẹ̌sč̀ pe malul Taslăului şi la Caraclăŭ; la Aggiud (Burri Érsic.!); pe lingă Craiova; etc. - 2 Iuliŭ- Angust.

1. cammaliuna L. A. cun for de crincpă. - Ye marginea pădurilor și prin mferișurĭ. - În Moldova (Cz. Flora XIX, 69 ot Exsic.!; (C. ol Sz. l. r. \&1) tótă (Gucbh. mamesc.); în distr. Jași la Balcin în Via-Vîrnav și la Rědĭu-Aldeĭ (Sz.ma- 
mese.); la Comana (D. Br Frogm. l. c. 89); in m-!̣i m-stirilor Cozia, Bistriḷa și Tismana (Ihoff. manusce of Exsic.!); in Mehedințĭ (Gr. En. 15) la Vîréorova (Kunitz! l. ‘. 25) către Portile-de-fer; etc. - 2) Iulin-August.

A. hirsuta L. A. irsutŭ. - Pe mareinea agrilor. - In

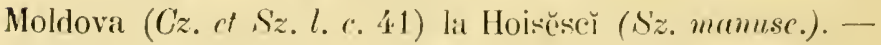
$\odot$ Iuliŭ-Augnest.

A. pallida W. Kit.; Alcon pallida biss. A. palintŭ. P'rin finete sterile. pe coline aride. - În Moldovil (Cz. ot Sz. l. c. 41 ot Exsic.! ; Laco'ror alpiun Cz. Flora XIX, 69?) inferiơră (Guslı. menuse. et E.rsie. n. 306 ser. Nym. Consp. 127); in distr. laș̆ la Şipote, Liırga, T'îrgn-frumos si Erbicenù (Sz. mamusc.); la Comana; la Virciorova către Portile-de-fer. - or Inniü- lugust.

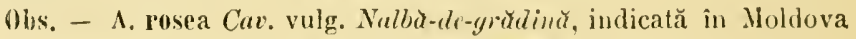
(Cz. et Sz.l.c. 41; Sz. manusc.), nu se găsesce de cât cultivată prin grădinI și eâte-o-dată subspontanee.

\section{LAVATERA L. - Lavaterč.}

L. thuringiaca Lin. L. turingiacŭ. - Prin finele, poenı̆, fuferişuř, pe marginea agrilor și prin semĕnăturı̆. În Moldova (Cz. Flore XIX, 69 et Eiresic..'; Edel l. e. 40, 41; Sz. manuse.) inferióră (Gucbh. manuse.); la Jiș̣̌ (V..! sec. Kanitz l. c. 25) și Hărpăš̌scč ; în distr. Bacĕŭ lat Versĕscě ; pe lingă Berlad; în Rimmicu-š̆rat la Caaata ; în Ilfov (Gr. En. 15 et Exsic.!; Althea of ficinalis Gr. En. 15 Inon L.] et Exsic.!) la Ciocănescŏ (D. Br. Fregmo.l.c. 89); in Argeș la Stolnič̆; pe lîngă Craiova; în m-!ị̆ m-stirilor Cozia, Bistrita si Tismanil (Hoff. mamse. ot Liesic.!); elc. - 2) Imniu-. lugust.

Obs. - Se mar citẻză speciile următóre : I. coretica $L$. la Pechea (Guebh. munusc.).- L. Mlhia L. în Molrlova (Eilel l. c. fí) de la Bêrlad in jos la Şosin și Pucitóia (Sz. munusc.). - L. Psendu-0lbia Poir. la Pechea (Guebh. mamusc.). 
HIBISCIS L. - Jlise.

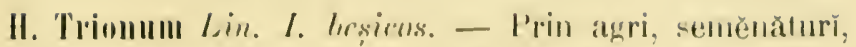

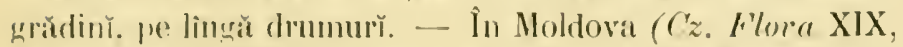

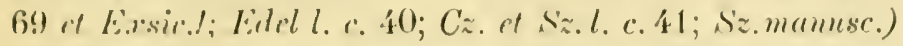

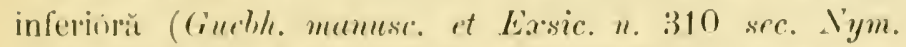

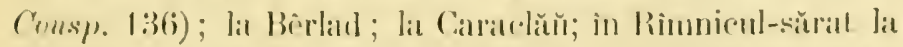

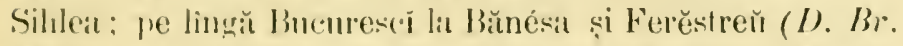

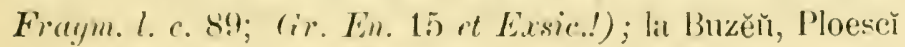
çi Viurgin (Al.! sec. Kinnitz l. r. 187); în Vileea la Băl-

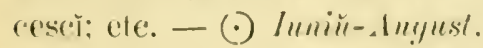

Obs. - Se cultivă : II. esculentus Lovulg. Bame. Bumbe (Cz. Flora XIX, 69 st Ersic.!; Cz. et Sz. l. c. 41 ; Sz. mamusc.: Gr. E). 16).

\section{ABUTILON Giertı. - Abutilon.}

A. Avicemma Grevth. F. lǔ Avicenna. - Prin locurì cullivate, pădurì și viĭ. - Pe lìngă lașĩ și Cralațĭ (Sida Abutilem L. Guebh. Not. 16 et manusc.; Malva tomentosa s'z. Exsic.!); la Bucurescĩ; in Vilcea la lbălcescǐ; in Mehedinți la Cerneți (Cir. Lin. 16); elc. - $\odot$ Iuliŭ-August.

\section{TIJIACEE.}

\section{TILIA Lin. - Teiй.}

T. argentea Desf. T. arqintiŭ. - Prin pădurŭ. - In Moldova (T. Comentosa Bmg. Eilel l. c. 42 ; Cz. et Sz. l. r. 30; T. enroparu ('z. Flora XIX, 66 [non L./ et E.rsic.!) inferioră (Guwhh. manuse. et E.rsir. n. 312 sec. Nym. Consp. 130); la Verşẹcič : in distr. Buzĕŭ la Becenì (T. alba W'. Kit. Gr. Én. 15); in Mehedinți la Stirmina (T. parvifulia Gr. En. 15 / hon Elrhl./ et E.csic..') și călre Virciorova; etc. 
T. platyphyllos ścop. T. cи for mar. - P’rin pădurĭ. - În Noldova (T. grandifolia Eklik. Edel l. c. 42 : 'T. grandifora Cz. rt Sz. l. c. 30 ; Sz. manuse.); in Ilfov (Gr. È. 15?). - †? Jипій-Iuliŭ.

T. rulira DC. T. roşin. - In pădurile din Moldova inferióră (Guchh. manusc.). - †? lulin̆.

T. parvifolia Elerh. T. " for mir. -.- Prin păduri. În Moldova (Cz. Flowa XIX. 66 et Eirsic..! ; Eild l. c. 42 ; T. parviftora $C z$. of $\$ z . l . c .30 ; \$ z$. manusc.); pe lingă Iașì la Nį̣elea (T. plaighphyllos D. Br. F'ragm. l. c. 89

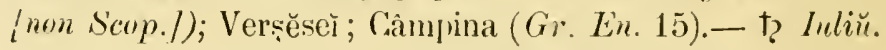

\section{THEREBINTHACEE.}

\section{RIIIS I. - Rus.}

R. Cotims L. R. Cotiu.-- Vulg. Sccumpie.-- Pe coline aride și petrose. - În Moldova (Cz. Flora XIX, 63 et Easic.!; Edel l. c 41) inferióră (Guebh. manusc.); pe Prut de

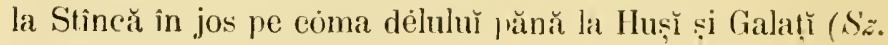
Exsir.!), de unde apol se întinde peste tótă lẹra de jos ( $S z$. manusc.). și către Bêrlad, Teenciŭ și Focșanì ( $C z$. et S Sz.l. c. 16); in Ilfov la Peris: în Vlascea la L'rund; de la Severin

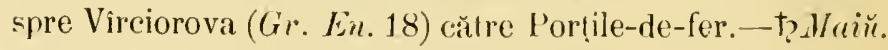

0bs. - Se cultivă prin grădinr: R. typhina $L$. (Cza et Sz.l.c. 16; Sz. manusc.; Gr. En. 18) vulg. Oțetariur.

\section{EUPHORBIACEE.}

\section{EUPHORBLA L. - Euforlite.}

E. palustris L. E. do mlastini. - Pe malurile apelor, prin locurı̌ inlăștinóse. - În Noldova (Cz. Flıa XIX. 65 et Exsic..; Cz. et Sz. l. c. 24; Sz.munusc.) centrală la Făn- 


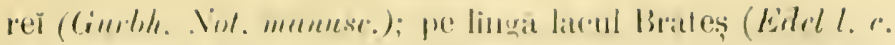

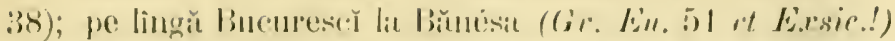

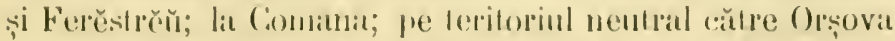

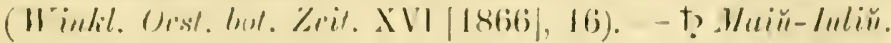

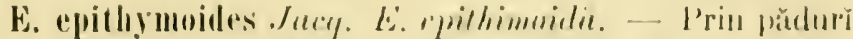

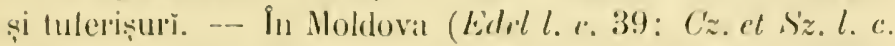

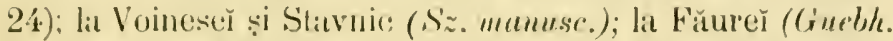
manusc.); la Agiud (Burri Exsic.!); lat Vălenĭ (É.frugi-

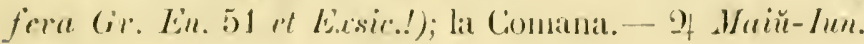

E. lingrulata Mruft. E. limgulatú. - Prin locurř petróse și umbróse. - Là Vîrciorovil către Porṭle-de-fer $(B o r l)$.

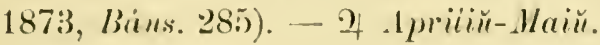

E. anğulata Jury. E. angulatu. - P'rin locurile umbróse din pădurile subalpine - hn Moldova $(C z$. et Sz. l. с. 24) ; lat Predel pe u-tele Susaiŭ. - 9 Mriй-Inniй.

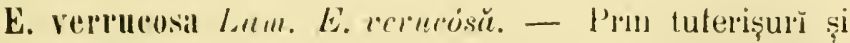
pădurı̌. - In Moldovil (Cz. IFlona XIX, 65) et Eissic.! ; $C z$.

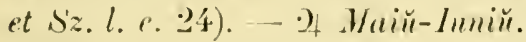

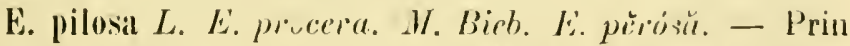
pădurile umbrose si unede. - In Moldova (k. rillosa $W^{7}$. kit. Cz. F'luru XIX, 6i) at E.rsic.! ; h.j. Ginebh. manuse.; Cz. ct S'z.l.c. 24; S'z. mamuse, E. sylvatica Cz. Flora XIX,

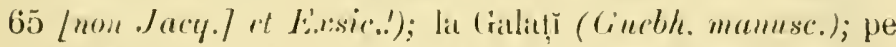
lingă Biplatd la Caring; la Chitila și Ciocănescó ; la Comana; etc. - 9 Inniü-Iuliu.

E. plathyphylla L. E. plutifilü. - Vulg. Lap'elt-cânelni, Buruianü-de-negp̌. - P'rin locurř cultivite, inculte și petróse, pe lingă drumurĭ, printre petrele de pe matcat

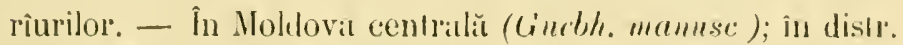

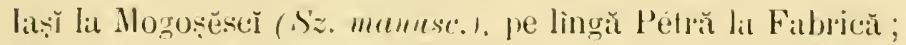

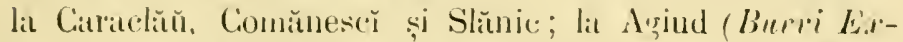

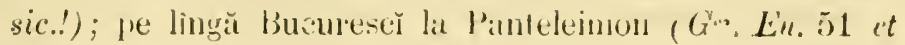


Exsie.! ; E. strieta (ir. Ein. jot luom L./ et Exssic.!) si in Dudescǐ ; la Craiova ; la Bălcesč și la Crolotrenì intre Șchelea-Cladover̆ și fimra-văieř; ete. - $\odot$ Imnĭ-Septembre.

E. Ielioscopia L. E. elioscopre. - Vulg. Avior, Alior, Aior, Laptolr-crinelnu, Laptels-cuculŭ, Buruiună-de-friguř. - Prin locurǐ cultivate, printre senı̌năturĭ, pe marginea agrilor. - In Moldova (Cz. Flora XIX, $6 \tilde{\text { et }}$ et Lxsic.!; Edel l. c. 39 ; Cz. el Sz. l. ค. 24 ; Sz. manusc.; D. Br. Fragm.l. c. 89) centrală și superióră (Guebh. manusc.); în distr. Bacăı̆ la Caraclăŭ : în Prahova la Brebu; în Muscel la Conț̌̌sč̆ (Gr. Exsic.!); etc. - $\odot$ Maiй-August.

E. allygdaloides L. E. amigdıloidŭ. - Prin pădurile umbróse. - In tótă Moldova (Edel l. e. $39 ; C z$. et Sz. l. e. 24 ; E. sylvatica Jacq. Guebh. manusc.; Cz. et Sz.l.c. 24; Sz. manusc.; E. I'eplus Cz. Flora XIX, 65 [non L./ st Exsic.! ; Edlel l. c. 39 ?; Cz. ct Sz.l. c. 24; Sz. manusc.); la Comănescì și Câmpenĩ; la Agiud (Burri Exsic.!) ; la Sinaia către pólele Furnicê̌ şi la Predél ; în Muscel pe ı-tele Lerescì (E. sylv. Hoff. Excurs. 1863, l. c. 31); la Comana; la Bucovăț pe malul Jiuluř; în Gorjiŭ la Roșia; la Vîrciorova

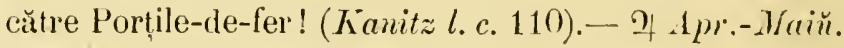

E. lucida $W$. Kï. E. lncidă. - Prin lunč și lînețe umede. - În Moldova (E. niccensis Cz. Flora XIX, 65 [non All.] et Exsic.l; Cz. et Sz. l. c. 24); in distr. Jașŭ la Zahor-

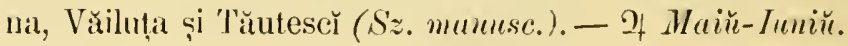

E. salicifolia Host. É. cu for de salce. - Prin finete . tnferişurı̆, pe lîngă drunurı̌. - În Moldova (Cz. ct S'z. l. c. 24; S'z. manuse.); pe lingă Slatina cĭlre Olt.-2f Maiŭ-Jun.

E. virgata $U^{r}$. Kit. Li. víngrisŭ. - Prin fìnețe, tuferișurĭ, pe lingă drunurı̆. - În Moldovil (Cz. Florea XIX, 65) et Exssir.! [uom. E. segptalis et E. ('yparissias/) inferioră (Cruchlh. mumusc, et Exsic. n. 10, 17 sic. Nym. Consp.652); in distr. laṣ̆ la Moinescŏ și Ciprelescĕ (Sz. maunsr.); pe lîngă 


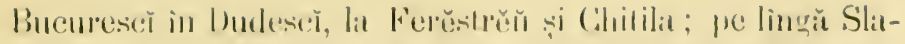

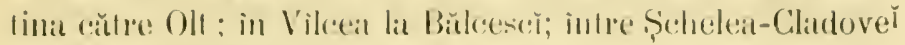

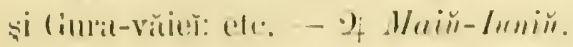

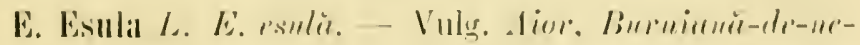

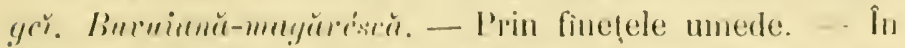
Moldova (C. Flore XIX, 65 al Es.sir.! / mom. E. viryala/;

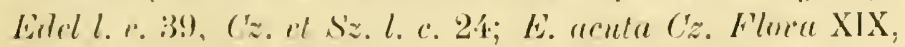

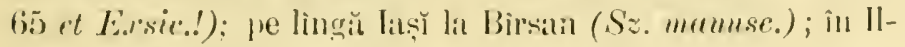

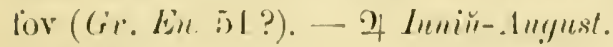

E. Cyparissiats L. Le mir-chiparos. - Pe coline arde,

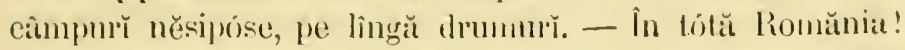

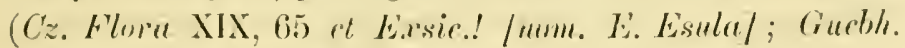

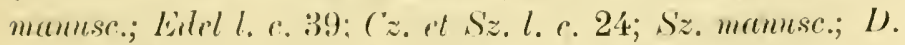
Bi. Fraym l. r. 89; Buri Exsic.!; Kanitz l. c. 111; Gr.

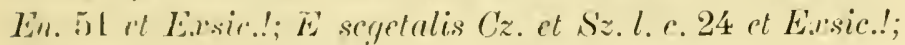

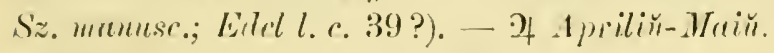

E. Gerardiana Juey. E. Gerartiana - Coline și câmpuř něsipose. - În Noldova (Cz. Flora XIX, 65) et Exssic.!; Cz. et Sz. l. r. 24) inferióră (Ginehh. mamıse.); în dis. Buzen̆

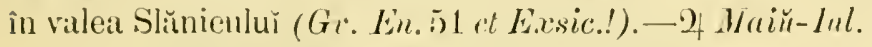

E. nlareosa , H. Bih. E. de petris. -Prin locurĭ sterile și inculle, coline něsipóse și jetróse.-... In Moldova (E. dulcis

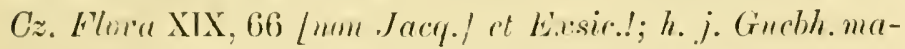
mese.; (z. ct Sz. I. c. 24; E. falcula (Iz. Flora XIX 65)

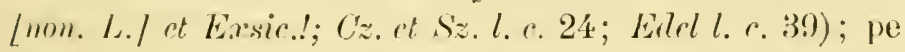

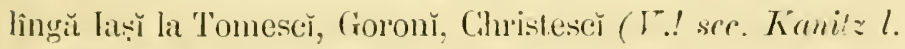
c. 242 ; E. nircernsis s'z. (uon All./) și la Repedea de-atsupra Pefrăriě̃: la Agiul (Burri kissir.!); pe lingă lincuresci

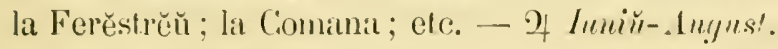

E. agraria .T. Birh. E. agrarie. - Pe coline și cimpurı̌ aride. - lı Moldova (F. plo'yphyllos C'z. ct s's. l. c.

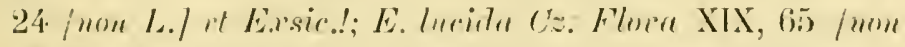

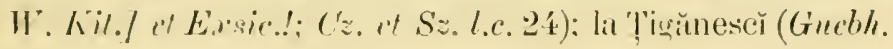


(mamusc, el Lisice. $11.11 \mathrm{sec}$. Nym. Consp. 65:3); Iltov (Cir.

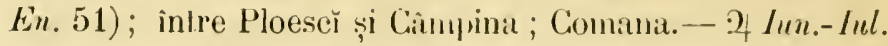

E. Ialmaticat Vis. E. dalmatica-Lat Virciorova (Simli. 595; E. tuurinensis Borb. U;.jel. 84).

E. falcata L. E. fulculú - Prin locurile aride. - Intre Șchelea-Cladoveř și Gura-văič̃. - $\odot$ Iuniŭ-Septembre.

E. exigua L. L. militică.-- Prin agr’i și locurù cultivate. - In Moldova (Cz. ct Sz. l. c. 24); prin viile de la Socola (Szz. man.); la 'Tìrgu-Oeneì ( Ginebh. man.). - $\odot$ lun-Śept.

ß. retusa koth. - Sculenĭ, Ş̌ndrent, Solonețĭ (S'z.man.).

\%. tricuspidala Koch. - În Moldova (E. diffusa Jacq. Cz. et Sz. l. e. 24) la Brătulenĭ și Cuculenì (Sz. manusc.).

E. Latlıyris L. LE. Latiridă. - Prin locurĭ cultivate.In Moldovil (Edel l. c. 39; Cz. ct Sz. l. c. 24; Sz. manusc.; D. Br. Fragm. l. c. 89); în T'eleorman la Măgurele-Flă-

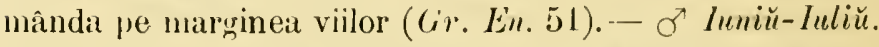

Obs. - Se maí citéză : E. Chamiexyee $L$. în Moldova (Cz. et Sz. l. c. 24). - F. "aruiolic'd Jucq. in Moldova (Cz. et Sz.l. c. 24). - E. saxutilis Jacq. în Moldova $(C z$. t $S z$. l. c. 2't).

\section{MERCURTIISS L. - Mercuralit.}

M. perennis L. M. perenală. - Vulg. Trépădălóre, Brîa, Brciü, Slıbonov, Burniunü-ciuéseй. - Prin pădurile umbróse din regiunea montană. - În Moldova ( $C_{z}$. Flora XIX, 65 et Exsic.!; Cz. c! S'z. l. c. 22) centrală (Gueb/. manusc.) la pólele Céhlăuhŭ (Edel l. c. 36) și lu m-stirea Agajua-veche; pe lingă Ia ;i la Şorogarí ( $S z$. ma-

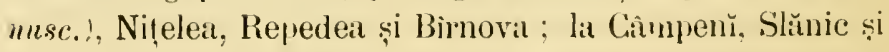
Palanca; la Sinaia ( $G r$. En. 51) cătpe pólele Bucegilor și la Predél; elc. - - Apriliŭ-s/aĭ̌.

M. ovata Sternb. et Hoppe. M. cu for orale. - Prin tuferișurı̌. - La Gralaṭ̆ (M. livida Buyg. Cz. ct s'z. l: r. 22); la Comana pe Valea-Combanulŭ. - of Ipriliŭ-dMaĭ. 


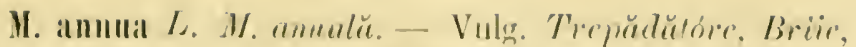

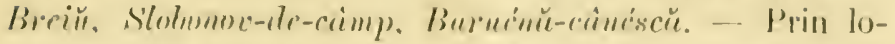
curi cultivate si ruderale. - In Moldovia $(C z$. Flora XIX,

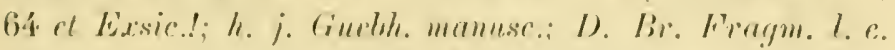
88); la Chiperesce și pe malul Prululŭ (Sz. mumuser.); la liat-

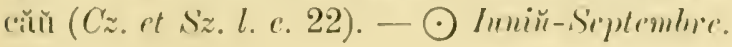

\section{GALLTRICHE L. - Calitriche.}

C. platycarpa Külz. C. platicarpă. - Prin ape starsnante si lin curgětore. - In Noldova (C. intermedia Bm!. S'z. mumesc.); la Mănăstirea-Cașinulŭ ; la gara 'Tilu în ała Suța (Gr. En. 25 et Exsic.!). - 2 Maiu-Septemlne.

C. verina Kü̈z. C. de mimŭvéră. - Vulg. Diente. Prin mlaștinř și bălțĭ. - In tỏtă Noldova (Guebh. meenusc.; $S z$. mamuse.): la Palanca; în Mehedinți la Dumbrăvį̣a ( $G r$. Exsic.!). - 2 Apriliü-Septembre.

C. Lamulata Küıtz. C. incêrligatč. - Prin ape stagnante și lin curgětóre. - La gara Titu în apa Suṭa ( $G r$. En. 25 et Exsic.?). - 2 Mаій-Septembre.

C. autummalis L. C. de tómnă. — Prin mlașlinŭ și bălţĭ. - In roł Mŏ Moldova (Sz. manusc.). - 4 Anuyust-Seplembire.

\section{GERANiaceE.}

\section{GERANIUM I. - Geraniǔ.}

(i. macrorrhizon L. G. cu rüdécinŭ mare. - La pólele Bucegilor către Sincia (Hoff. Exemrs. 1863, l. c. 119).

f. sanğninem L. G. sângeriŭ. - P'rin pădurile și lulerișurile din locurile aride. - In Moldovi (Eild l. c. 40; Sz. mannse.; G. prostrulum Cz. Flora XIX. 69 al E.rsir.!;

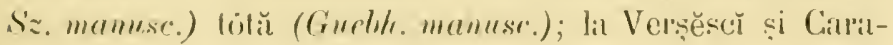


clăŭ; la Bêrlad în Ciring; la Ciocănescŭ ; Câmpina (Gr. En. 16 ct Lixsic.!); Comana (D. Br. l. c. 86). - 2 Iun.-Sept.

G. paltestre L. G. de mlastinu. - Prin finețe umede și umbróse, pe lîngă pîrăie. - In Moldova (Edcl l. c. 40; Sz. manusc.); la Mangina (Gruebh. mamusc.); la Broscenı̆ (Burvi Exsic.!) ; la Némț (Gr. En. 16) și m-stirea Némṭulǔ̆; la Verşěscĭ și Caraclǔŭ ; la Sinaia (G. nodosum Gr. Excurs. l. c. 339 [non L.] et Exsic.!; Gr. En. 16); etc. - 2 Lun.-Aug.

G. sylvaticum L. G. de pădure. - Prin pădurile și fìnețele umede din munț. - In Moldova (Edel l. c. 40;G. sanguineum $C z$. Flor a XIX, 60 [non L.] et Exsic.!) superióră (G. tuberosum h. j. Giucbh. manusc. [non L.]); pe Céhlăŭ (G. macrorrhizon Edel l. c. 36 /non L.7; Cz. Flora XIX, 69 et Exsic.!; h. j. Guebh. manusc.); în distr. Iaşŭ la RĕdiŭAlder și Voinescǐ ( $S z$. manusc.); la Palanca pe lîngă Pìrăulşanțuluı̆ ; la Sinaia (Gr. En. 16 et Exsic.!) şi în m-țiĭ Buceğ la schitul Pescera-Ialomițer̆; etc.-2 Iuniŭ-Augnst.

G. alpestre Schur. G. alpestru.-Pe lîngă pîrăile din regiunea subalpină și alpină. - La Palanca pe lîngă Pîrăulșanțuluǐ ; în m-țiù Buceğ la Pîrăul-Babelor. - Y Iul.-Aug.

G. pratense L. G. de finețe. - Vulg. Pliscul-cucórě, Ciocul-barzeй, Greghetin. - Prin finețele umede și unbróse, cu deosebire din munț̆. - In Moldova (Cz. F'lor'c XIX, 69 ct Exssic.!; h.j. Gucbh. manusc.; Edel l. c. 40; Sz. mannsc.); la Broscenı̆ (Burri Exsic.!); la Verş̌sč̌ ; în distr. Buzĕŭ în valea Slăniculuŭ $(G r . E n .15)$; la m-stirea Cheia (Hoff. Excurs. 1863, l. c. 118 et Exsic.!); în Muscel la Isvorul-între-petre (D. Br. l. c. 89). - 7 Jun.-Ang.

G. phaum $L$. G. negricios. - Prin finetele umede din pădurile umbróse, pănă în regiunea subalpină. — În tótă Moldova (Guebh. mamısc.; Sz. manuse.); la pólele Céhlŭuluŭ (E Iel l.c. 36 et Exsic.!); la Palanea; la Agiud (Burri Exsic.!); la Slănic călre pólele Furnicě̌; la Predél; în un-țī 
Dimboviter̆ pe Platul-J)onnesc; in Muscel pe m-tele Lerescì

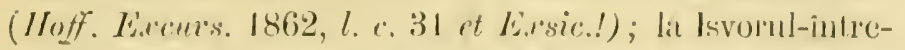

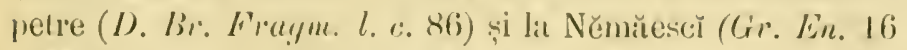

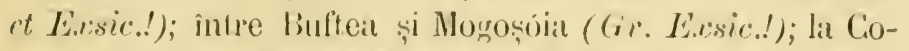
manat; in Vilcea in valea Bistrițer̆; la Vireiorova călıe Porṭilede-fer pe III-lele St-Pelsu; etc. - 2+ Maiй-Inniй.

G. Pỵtenaicun $L$. G. pirenaic. - Pe Buceğ là obîsșia Ialomį̣er (Hoff. L̇acurs. 1863, l. c. 119, 120): la Vîrcioroval către Porṭile-de-fer (Borb. 1873, Búns. 286).-Z Iul.-Auy.

(i. columbinum L. G. parumbic. - Prin tuferişurı̌, agri, locurı̆ aride și ruderale, printre vĭ, pe coline stcrile. - In Moldova (Edel l. c. 40; Sz. manuesc.) tótă (Ciucbh. mamusc.): pe lingă laṣ̆ la Nị̣elea; în Argeș la Vlascuţa (I). Bir. l. c. 86); la Periş; la Conțĕscr (Gr. Exsic.!); la Comanat; pe malul Dunŭren̆ la Şchelea-Cladovcř; tetc. - $\odot$ Maiй-lul.

G. dissectım L. G. discct. - Printre sĕıĕnăturı̆, min locurĭ cnltivate și ruderale, pe lingă drunurı̆ și gardur.̌ In Noldova (Edel l. c. 40; Sz. manusc.); în Ilfov (Gr. En. 16 ct Exsic.!) la Periş şi în Dudesč̆ ; etc. - $\odot$ Maiŭ-Luliŭ.

G. divaricatıu Ehrh. G. divaricat. - Prin finețele din pădurĭ și tuferișurı̆, printre vĭ̌, pe coline. - La Pechea (G. Bohermicum Guebh. manusc. /non L./ et Exsic. n. 324 sec. Nym. Consp. 135); pe lingă Iaș̆ la Mironésă ( $G$. boliemicum Sz. mamusc.); pe lingă Bucuresĕ la Bănésa și Periş (D. Br. Fragm. l. c. 86; Grr. Ln. 16 et Érsic.!); în Vlạ̣ca la Comana ; la Vîrciorova eătre Portile-de-fer! (Borb. 1873, Báns. 286); efe. - $\odot$ Jипій-August.

(i. molle L. G. móle. - Prin locurř puderale, pe lingă gardurǐ și drumurı̌. - În Moldova (Edel l. c. 40) tótĭ (Guebh. manusc.). -- $\odot$ Maiй-Angust.

G. rotundifolium L. G. cu for rotunde. - P'rin locurile petróse din pŭdurile muntose. - La Vîreiorova către valea Balınè. - $\odot$ Inniй-sieptemlne. 
G. pusillım L. G. mititel. - Prin locurĭ cultivate și ruderale, grăddiň̆, pe lîngă drumurǐ și gardurǐ. - In tótă Moldova (Cz. Flora XIX, 69 et Essic.!; h. j. Gucbh. manusc.; Edel l. c. 40; G. rotundifolinm Cz. Flora XIX, 69 [non L.] et Exsic.!; Gucbh. manusc.; Sz. manusc.; G. palustrc Cz. Flora XIX, 69 [non L.] et Exsic.!); la laș̆ (G. moll D. Br. Hragm.l.c. 86 (non L.7); la Agiud (Burri Exsic.!); in distr. Buzěŭ la Becenı̌ (Gr. En. 16 et Exsic.!); in Ilfov (C. molle Gr. En. 16 [non L./ et Exsic.!) la Bucuresĕ̌, Bănést, Buftea; etc. - $\odot$ Inniu-Septembre.

f. Incidum L. G. lucitoriŭ. - Prin pădurile petróse și pe lîngă stîncile umbróse din regiunea montană.-- La Cî̀npulung pe tĕrmurile Rîu-Tìrgulŭ (Hoff. Ercors. 1862, $l$. c. 40); la Virciorova către Bahna. - $\odot$ Maiŭ-August.

G. Robertianım L. G. Robertian. - Vulg. Năprasnicŭ. - Prin locurile umbróse din pădurĭ și de pe lîngă ștîncĭ și ruine. - În tótă Romănia! (Cz. Flora XIX, 69 et Exssic.!; Edel l. c. 40; Guebh. manusc.; Sz. manusc.; Hoff. Excurs. 1863, l.c. 117; D. Br. l. c. 86; Burri Exsic.!; Gr. En 16 et Eessic.!; Borb. U. jcl. 84; Erodium charophyllum Cz. Flora XIX, 69 [non Cav.] et Exsic.!). - $\odot$ Inn.-siept.

(i. purpurenu Vill. G. purpuriŭ. - La Vîrciorova către Portile-de-fer (Borb. U.jcl. 84).

G. per'rugosum Borb. G. sbircit. - La Vìrciorova către Porțile-de-fer (G. catarractarum Simk. 538).

\section{ER0DIUM L'Ilerit. - Erodiǔ.}

E. cicntaninm LiHerit. E. cicutariü. - Vulg. Pliscnlcucórĕ. - Prin locurǐ něsipóse cultivate şi inculte, grădinı̆, càmpurı̆, pe iinz̧̆ drumurĭ. - In tótă Romănia! (Cz. F'lora XIX, 69 et Exxsic.!; Edel l. c. 40; Guebh. manusc.; Sz. manus.; D. Br. Eragm. l. c. 86; Grr. Lin. 16 et Exsic.'; E. 


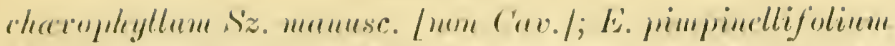

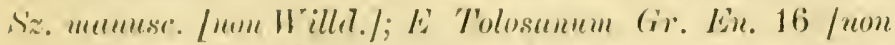

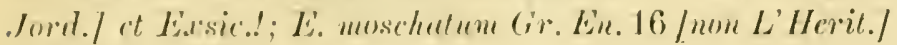

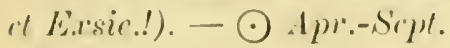

E. serotimum Stev. E. Lirdiă. - In regiuneal subalpină. - P'e Céhlăı̆ (S'z. Éxsic.!; h.j. Guebh. manuse.).

Ohs. - Se mar citéză : E. hirr un Willd. în Nold, infer. (Guebh. man.).

\section{IIIPATIENS I. - Impacientŭ.}

I. moli tangere I. I. commenü. - Vulg. Slübümog, Slobonon, Brir. - L'rin pădurile umede și umbróse din regiunea monlană și subilpină. - În Moldova (Cz. Flora XIX, 62 "l k.xsic..') centrală și superióră (Gucbh. manusc.); la Broscenı̆ (Burri Exssic.!); lì pólele Céhlăuluň! (Edel l. c. 36), la Pétrĭ çi la Agapia (Gr. Erbor. l. c. 133 et Exsic.!); la Batcŭı̆, Conrŭnesč (Cz.ct Sz.l.c.11), Palanca, Mănăstirea(aı̣inuluı̆ și Slănic (D. Br. Fragm. l.c. 87); la Bîsca la Sinatia către pólele Furnicě́; în Muscel (D. Br.l. c. 87); pe l'riıĕt, la Rucăr și Dìmbovicióra (Gr. En. 17); la Pitescŭ în lınciı de pe Rìn-Dómneř; în m-țiŭ Vîleě̌ și ă Gorjiulul̆ (IIu!f. manusc. et Exsic.!); etc. - $\odot$ Iuliŭ-August.

\section{XALIS L. - Oxalidă.}

0. Acetosella L. O. Macrisor. - - Vulg. Macrisul-iepuvelǔ, Macris-iepurese, Macriş-trifoios, Macriş-păsăresc. - Prin pădurile unede și umbróse din regiunea montană și subalpină.- În tólă Romĭnia! (Cz. Flora XJX, 65 et Exsic.!; Cz. ct Sz. l. c. 23; Guebh. manusc.; Ėdel l. c 35); Hoff. Excurs. 1862, l. c. 39; D. Br. Fragm.l.c. 87; Gr. En. 17 ct Exsic.!; O. corniculate Gr. Monit. offic. l. c. et En. 17 [non L.7). - 2 A priliu-Maiu.

$0 b s$. - Se mar citéză : 0 . stricta $L$. în Moldova $(C z$. et $S z$. l. c. 23). 


\section{IINACEE.}

\section{IINUM L. - Inй.}

L. flavum L. I. gallên. - Pe coline aride, prin finețe uscate și prin poenile din pŭdurı̌. - In Moldova (Cz. Flora XIX, 63 et Exsic.! ; Fdel l. c. 39, 41; Cz. ct Sz.l. c. 17 ; Sz. mamese.) centrală (1. complanatım Gucbh. manusc. (non L./); la Hărpășĕseĭ ; la Verșěscĭ și Caraclăŭ; la Agiud (Burri Exsic.!); pe lîngă Bêrlad la Crîng și Slobod̦ia; la Rădulescī̌-Filitis și la Periș; la Comana ; la Němăescĭ pe Stînca-mănăstirě̆ (D. Br. Fragm. l. c. 87). - 2 Jun.-Aug.

L. lirsutum L. 1. pèros. - Prin finețele uscate, prin poenile și pe marginea pădurilor.- In Moldova $(C z$. et $S z$. l. c. 17; Sz. manusc.; L. perenne Cz. Flora XIX, 63 [non L.7 ct Exsic.!) inferióră și centrală (Guebh. manusc. et E.esic. n. 294 sec. Nym. Consp. 124); la Jașŭ (V.! sec. Kanitz l. c. 188) și Hărpŭșĕsccí; pe lîngă Bêrlad la Slobod̦ia; la Agind (Burri Exssic.!) ; pe lingă Bucurescı̆ la Ferĕstrěŭ (L. viscosum Gr. En. 15 /non L.] ct Exsic.!), Bănésa, Merinani, Peris, Chitila și Ciocŭnesč̆ (D. Br. Froumm.l. c. 87); în Vlaşca la Comana și Prund; in Muscel la pólele mtelŭ Lerescĭ (Hoff. Excurs. 1862, l. c. 38 et Exsic.!). 2) Iuniü.August.

L. nervosum $W$. Kit. I. nerros. - Pe coline uscate, prin fîneṭe nĕsipóse. - În Moldova $(C z$. et S'z.l. c. 17) centrialŭ (Gucbh. manusc.): către Văiluța, Zahorna și RădiuAlder (Sz. manusc.); la Comana; etc. - 2 Iuniü-August.

L. austriacmm L. I. austriac. - Vulg. Inéțu. - Prịn finețe nĕsipóse, pe coline aride. - În Moldova ( $C z$. ct S'z. l.c. 17) inferióră (Gucbh. mamesc.); la Popricani (Sz. manusc.); pe lingă Bucurescĭ (D. Br. l. c. 87) la Buftéa, Cioeănescĭ și Titu (Gr. En. 15 ?); etc.- 2 Iıniй-Iuliŭ. 


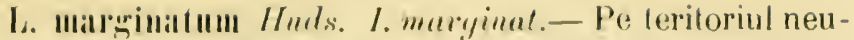
träl linğ Orșova (Winkl. Oest. bot. Zeit. XVI [1866], 16).

I. perentue $L$. I. permal. - Pe coline andide, prin lìnẹ̦e și poenŭ něsipóse. - In Moldova (E)del l. c. 29 it Exsic.!; Cz. it Sz. L. c. 17 ; Sz. manusc.; L. usitutissinum Cz. Fllmer XIX, 63 /nom l.] et Exsic.!; L. austriacum. Cz. et S'z.l.c. 17 [non L.] et Exssic.!); lat Verșęscĭ (L. austriacum I). Br. Fragm. l. c. 87 [non L.]); in Vilcea la Bă!cescĕ, n-stirea Cozia și la Golotrenĭ; etc. - 2 Inniǔ-Iuli,

I. alpinum L. I. alpin. - Prin pășunile din regiunca

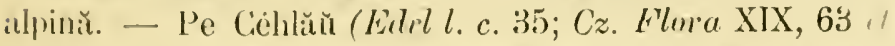
L.usic.!: Cz. ot sz. l. c. 17; L. montanum h.j. Ginebh. mu-

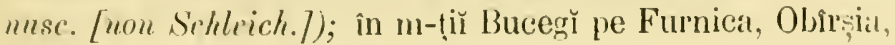
l'étra-alšĭ; etc.-2 Iиniй-Iиliй.

I. tenuifolium L. I. cu fŏ měnunte. - Pe coline aride, petróse și calcare. - În Moldova (Cz. ct Sz. l. c. 17); lil Pechea (Gucbh. mamusc.); la Iepurenı̌ și Lețcanĭ ( $S z$. mamusc.); la Vîrciorova către Bahna pe nt-tele Curchia. of Iипій-Luliŭ.

L. catharticum L. I. purgativ. - Prin finețe și pășunı̆ umede, pe matca rîurilor. - În m-tịi Moldoveì $(C z$. Flor X XIX, 63 et Exsic.!: h. j. Gucbh. mamusc.; Edel l.c. $37 ; C_{z}$. ct $S_{z}$. l. c. 17); în distr. Jași către Cucóra (Sz. maunsc.); la Car'aclăŭ; la Comarnic pe matca Prahover̆; la Sinaia! (Rutiola linoides Gr. En. 15 /non Gmel.] et Exsic.!) și in m-liĭ Buceğ̌ pe Furnica; ete. - $\odot$ Iuniй-Mliŭ.

L. Radiola L.; Radiola linoides Gmel. I. Radiolà. P'rin locurĭ nĕsipóse și umede. - In distr. Iaș̆ la Țubana (Sz. mamusc.).

0bs. 1. - Se maY citéză : L. narbonense $L$. în Moldova $(C z$. et $S z . l$. c. 17) la IașY și ErbicenY (Sz. manusc.).

Obs. 2. - L. usitatissimum $L$, vulg. Inŭ. cultivat și subspontaneũ ! (Edel l.c. 39; Guebh. manusc.; Cz. et Sz. l.c. 17; Sz. man.; Gr. En. 15). 


\section{CARYOPHYLLACEE.}

Agrostemin L. - Agostemă.

A. Githago L.; Githago segetum Desf. A. Gitaginŭ.Vulg. Neghină, Zizanie. - Prin grăie. - In tótă Romănia! (Cz. Flora XIX, 65 et Exsic.!; Edel l. c. 39; Cz. et Sz. l. c. 23; Sz. mamusc.; D. Br, Fragm. l. c. 87; Gr. Excurs. l. ¿. 339 et Erbor. l. c. 131; En. 13; Lychnis Githaigo Lam. Guebl. manusc.). - $\odot$ Iипій-Iuliŭ.

\section{LYCHNIS Tournef. - Lichnidŭ.}

I. Viscaria Lin.; Viscaria vulgaris Rehl. L. Viscarie. - Vulg. Lipiciósă. - Prin finetele, pășunile și pădurile de la cûmpiř și din munțĭ. - În Moldova $(C z$. Flor a XIX, 66 et Exsic.!) tótă (Guebh. mumusc.); în distr. Iaș̣̆ la Voinesch̆, Cucutenı̆ și Stavnic (Sz. manusc.); la pólele Céhlăuluı̆ (Edsl l. c. 36); în m-țiŭ Bacŭulŭ la Slănic; pe Penteleŭ la Ciașărie ; în m-țiì Bucegĭ pe Furnica; în Dîmbovița la Petroșanǐ; la Chitila și Bănésa; la Comana (D. Br. Fragm. l. c. 87); la Conțĕscȟ și Stîlpenĭ (Viscaria purpurea Wimm. Gr. Lu. 13 et Exsic.!); la Olănesč̆; etc. - of Maiǔ-Inniŭ.

L. Flos cuculi Lin. L. Flórea-cucului.-Prin pădurile și fînețele umede de la câmpiĭ și din munțĭ. - În Moldova (Cz. Flor'a XIX. 65 et Exsic.!) centrală (Gucbh. manusc.); către Slobod̦ia-Voinescilor (Sz. manusc.) și la Nițelea; la pólele Céhlăuluĭ (Edel $l$. c. 36) : la Sinaia pe valea Peleşulur și la Predél; pe lingă Bucurescì la Bănésa și Merinani $(D$. Br. Fragm. l. c. 87); lı Cŭmpulung și Stîlpenĭ (Gr. En. 13 et Exsic.!); la Comana ; în Mehedinți la Iorgutova ( $G r$. Exsic.!); la Crolotrenı̌ pe m-tele Naroṭ; etc. - 2 Maiй-Iun.

L. Coronaria Lam. L. Coronarie. - Vulg. Curcubeŭ. Barba-impèratulue, Flórea-cunune , Flocoşĕle. - Prin pă- 
durile de pe colincle aride și din muntiu petroș̆. - In Mol-

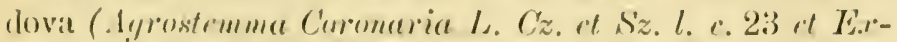
sir.!); liı Repedea (.1. Curmariu L. S'z. munuse.); la P’ı-

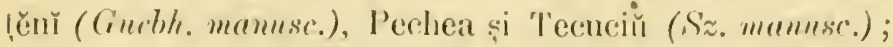

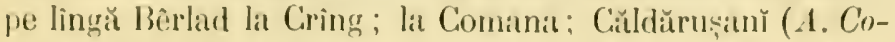
rmuria L. D. Br. Fragm. l. c. 87); în Muscel (A. Curmariu L. Gr. Ln. 13) pe m-tele Leresŭ (IIoff. Excurs. 1862, l. c. 31); la Stolnicĭ; la Slatina către Olt; la Vîrciorova către Porṭile-de-fer; la Golotrenĭ pe m-tele Fórfeca.-o lun.-Iul.

I. respertiua Sihth.; L. dinica $\beta$. Lin.; Mslamtrium pratense Riehl. L. vespertină. - Vulg. Opaiță, Opalitęl. - Prin tuferișurŭ, pe marginea pădurilor și a agrilor, pe lingŭ gardurı̌. - In Moldova (L. arvensis Sehk. Cz. Flora XIX. 65 et Exssic.!; Sz. mamuse.; L. quadridentata Sz. Exsic.! [non Bmg.]; Silene quadridentata h. j. Guebh. mamusc. Fnon DC.7) totă (L. allo Wrill. Guebh. manese.); lat Jașŭ! (Milundrinm album Garclie J..! sec. Kanitz l. c. 17); lat Bèrlad (1/. syluestie I). Br. l. c. 87 [non Riwhl.]); Buzeй (Al.! scc. Kanitz l. c. 182); la Râdulescĭ-Filitis (M. album Garcke D. Br. Rev. lit.-sc. [1876], 161), Gherganı̆ (Silene noctiflora Gr. Eit. 13 [non L.] et Exsic.!), Titu, Cioch̆nesč̆, Bucuresč̆! (S. pratensis Gren. ct Godr. Gr. Eı. 13 et Exsic.!). Bănésa! (S. diuma Gr. En. 13 ; [non Gron. et Godr.] et Exsic.!; S. untans Gr. En. 13 [non L.] et Exsic.!), Ferěstrěŭ, Mogoșoia, Chitila, Dudesč́ ; la Comana : în Vîlcea la Bŭlcescı̆ și la folotrenı̆.- o Inu.-A hug.

ß. macrocarpa (Boiss.). - Pe lingŭ Bucuresç̀ la Bănésa (1. sylvestec D. Br. Fragm.l. c. 87 [non Refhl.]).

I. diurna Sibth.; L. dioica a. Lin.; Mrlandrium sylvestre liwhl. L. diumă. - Prin pădurile umede și umbróse din regiunea subalpină. - În m-tị̆ Noldover (L. sylvestris Ioppe Cz. Flora XIX, 65 ct Exsic.!; Edel l. c. 37); la Palanca către pólele Puturosulur̆; elc. - 2 J Iun.-Aug.

I. nemoralis Henff.; Melandrium nemorale A. Br. L. de codri. - Prin pădurile umbróse din regiunea montană 
şi subahpinar. - La Sinatia pe valea Peleşnlur; în Melıedinț

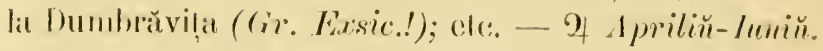

Ohs. - L. clialeedoniea $L$. vulg. Arşinic, selbătěcită la m-stirea Gafton (Sz. meanusc.) și cultivală prin grădiñ.

\section{COCUBALUS liı. - cucubal.}

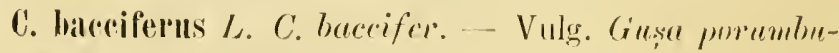
lni. I'rin lunc:̆, tuferișurŭ umede și umbròse, pe gardurĭ. - In Moldova (Cz. F'lora XIX, 64 et Exxsic.!) liotă (C'uslih. munusc.); pe lingă lașĭ la Valea-addincă (Sz. mumusc.) și la Nį̣elea (I). Br. l. c. 87); în muṇ̣̆ (Érlel l. c. 37) la Baceăŭ, Tìrgul-Ocneй (G'r. Erbur. l. c. 131 ct Exsic.!; En. 13); Ver-

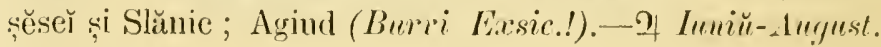

\section{SILENE I. - Silenc̆.}

S. inflata Smith. S. infatur. - Prin poenĭ, fìnete, tuferișurư și locurĭ petrơse.- În Moldova (Viscagu Brhen Bme. Cz. Flora XIX, 64 el Exsic.!; S'z. manuse.) tólă (Guebh. memusc.); la Agapia (Gr. Libror. l. c. 131), la Sinalia in Valea-Gŭ̌şărier ; pe lìngă Bucuresč la Văcŭresč̆, Bănèsa, Ferěslrěŭ și Merinani (D. Br. l. c. 87); Němăesĕ (Cir. Lin. 13); la Vîrcioroval către Porṭile-de-fer. - 2 1/aiŭ-Luliŭ.

3. alpina Schur. - Prin pășunile alpine. - In m-tị Buceğ̌ la schitul Pescera Ialomițĕ și la P'ìrăul-Babelor.

S. Zawadzkii ILerbich. S'. lui Zawadzlii. - Prin pășınile stîncóse și calcare din regiunea alyină. - La Broscenı̆ (Burri Eissic.!); pe vîrful Céhlüulŭ! (S. alpestris Eidel l. c. 35 [unn.Jacq.7?; Melaudrium Zavadzkii A. Br. Janka! iu litt. Rohlob. Linu. XXXVI, 237; Lychis alpina Cz. Flora XIX. 65 [non L.] et Exsic.!). - 24 huniй-Iuliü.

S. Armeria L. S. Armerie. - Prin locurile stincóse și něsipóse din regiunea montană. - În m-țiĭ Moldover̆ $(C z$. Flora XIX, 64 et Exsic.!; h.j. Guebh. manusc.; Edel l. c. 


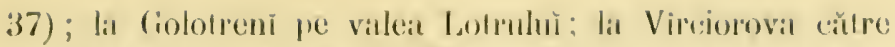
I'or!̣le-de-fer! (Kunitz l. c. 18); els. - $\odot$ lumiü-dugust.

S. flavescens W. Kit. I. gullic. - Pe stincile calcare

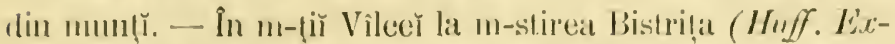

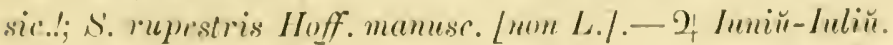

S. ilalica l'ms. S. italicŭ. - P'rin locurile petróse de pe coline și din pădurile munților. - În Romănia (S. pilusel Iloff. Exsic.!); în m-tiĭ Bneeğ la sohitul Pescera Ialomițe (From. 202); în Muscel pe délul Moṭoin̆ (Cucrubaluss multiflorus Hoff. E.rems. 1862 l. (. 39 /non Willd./?); in Melsedinlị pe dẻlul Poroina (Grr. En. 13). - 2 Iиniŭ-Iuliü.

S. nemoralis U. Kit. S. de codri. - Vulg. Lipiciesŭ. - Prin locurile stincóse din pădurile munṭilor. - In Moldova (I'iscayo multifora Cz. Frlona XIX, 64 /mon Bimg.] it Eisic.!; h. j. Guebh. mamesc.): la Popricanı̌ (V. meltif. Sz. man.?). Larga și Erbicenì (Sz. man.); la Vîrciorova căIre Por!ile-de-fer! (Borl. 1873, Bans. 283).-2 Iun.-Jul.

S. untans L. S. mutuntŭ. - Pe marginea pădurilor, prin fincțe și păşunĭ uscate, locurĭ stîneóse din munț̆, pănă în regiunea alpinǔl. - În Moldova (Sz. manusc.; Viscago glutinosa Cz. Flora XIX, 64 [non Bmg.] et Lisisic.!; Edel l. c. 37; V. mollissima Cz. Flora XIX, 64 [non B3mg.] et Exsic.!; h.j. Guebh. munusc.); în distr. Iaș̆ la Rusĕnı̆ şi CódaStinceŭ ( I. mollissima Sz. mannesc.?) tótă (Guebh. manusc.); pe Penteleŭ la Cü̆șărie; la Sinaia (Gr. En. 13 et Exsic.!; S. tatarica Gr. Excurs. 1863, l. c. 339 [non I'ers.7) pe Furniea și Vîrfu-cu-Doru (S. velutina cir. En. 13 /non Pmurr.] el Easic.!); în m-țĭ Dìmboviḷer pe Plaiul-Jomnese; la Nemăescĭ pe Stìnca-mănăstireř (S. livida $D . B 1$. l. c. 87 [non Hilld.]; la Golotrenǐ; efc. - 2 heniǔ-Iuliŭ.

S. livida Willd. S. lividü. - Prin pădurile montane.La Slîncă și Rĕdiu-Aldeĭ ( $S z$. mamusc. ?)) la Vîrciorova către Portile-de-fer (Bmb. 1873, Báns. 283). - q lun.-Iul. 
S. transsilvanica Schur; S. Aubin Herbich. S. Manssilvanicŭ.-Prin locurr stincose subalpine și alpine.-Pe Cé-

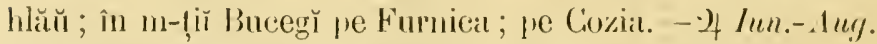

S. viridiflora L. S. viridiflorŭ.-Prin pridurile unbróse. - Lai Cemana; la Iorgutova (Gr. Exsic.!). - 2 Inn.-Inl.

S. longiflora Ekterh. S. lomgiftoră. - Prin tuferișurile de pe colinele aride. - In Moldova inferióră (Guebh. manusc. et Exsic. n. 807 sce. Nym. Consp. 91). - 2f Iuliŭ-August.

S. chlorantha Ehrh. S. chlorcentü. - Prin pădurile de pe coline. - La Pechea (Gucbh. manusc.). - 2 lul.-Aug.

S. densiflora D'Urv. S. exaltatu F'riv. S. densiforŭ.-Pe câmpir něsipóse, pe coline aride și petróse. - În Moldova (Viscago parviflora $C z$. Flora XIX, 64 / non Bum.) et Exsic.!; h.j. Guebh. manuse.); la Zahorna (V.parviftora S'z. mamuse.): la Caraclăŭ pe Babaghicea; pe linğ̆ Bucurescĭ la Ferĕstrĕŭ ; la Vîreiorova cĭtre Por!lile-de-fer! (Borl). 1873, Báns. 283) și la Gura-văiě̆; ele. - 2 Maĭ̌-Iuliŭ.

S. Otites Smith. S. Otites. - Pe càmpurř nesipóse, pe coline aride. - In Moldova (Tiscago Otites Bmy. Edel l.c. 37 ; S. catholica Sz. Exsic.! [non dit.]; h. j. Guebh. mamusc.) lotă (Guebh. manusc.); pe lîngă Bêrlad (S. volgensis D. Br. Fragm. l. c. 87 [non Spm.]); la Cáaclăŭ ; la Agiud (Burri Exsic.!); pe lîngă Bucurescŭ la Ferěstrěŭ ; la Co-

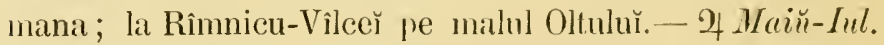

S. petrata W. Kit. S. de petriș. - Pe stîncile calcare din munț̆. - - În m-tị̆ Vîlcê̌ și ă̌ Gorjiulŭ (Hoff. manusc. st Exsic.!) la schitul Locurı̌-rĕle. -- 2 Iиniй-Inliü.

S. puadrifida L.; Heliosperma quadrifidum Reht. S. quatrifidü. - Prin loeurile stîncóse și umede din reginnea subalpină și alpină. - In m-lị̆ Bucegí $(F r .120)$ pe valea

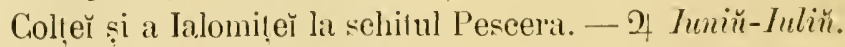


S. alcunlis /. S. acrulì. - Loxuri slincóse si mmede din

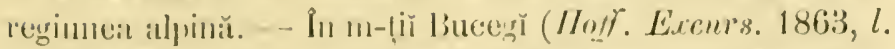
c. 120 ; From. 198) pe Furnica, Biabe, Omu.-2f Jun.-1ug.

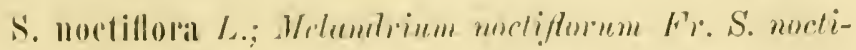

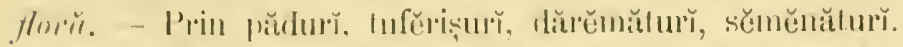

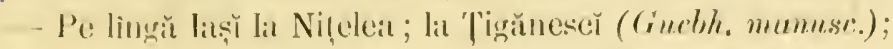

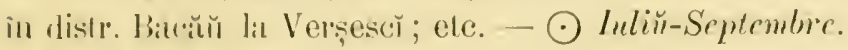

S. dichotomat Ehrh. S. dicotomŭ. - Prin finețe, pe matroinea bŭdurilor, a åfilor şi a drmmurilor. - In Mol-

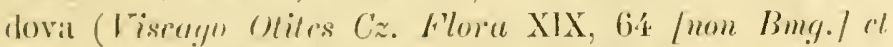

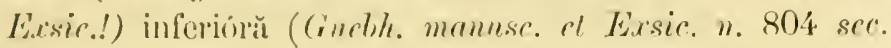
Nym. Consp. 93); pe lingü Bèrlat (D. Br. Fragm.l. c. 87);

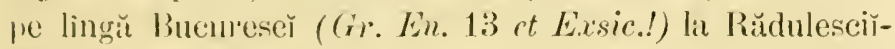
Filitis, Periṣ, Ferěstrĕı̆ și in Dudesč ; in Vlișçca la Connana și P'rund; ete. - ơ Maiü-Inliŭ.

S. conica L. S. conič̆t. - Prin locurile nĕsipóse de pe malurile rîurilor. - În Moldova (Sz. manusc. ?); pe malul

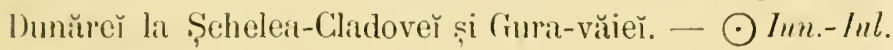

0lss. - S. Lerchenleldiana Bung. din Moldova (Cz. Flore XIX.

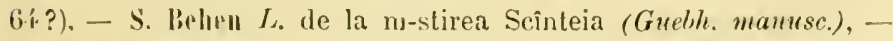
S. poly plıylla Bmg. de la Erbicenı̌ și DelenǏ (Sz. mumusc.), sunt căte trele resultatul unor determinaţiun greșite.

\section{SAP0XARIA L. -- Saponarie.}

S. Vacearia L. S. Tacarie. - Vulg. Fllírea-cŭlugürnlй, Păсйricŭ. - Printre semĕnăturı̌, pe marginea agrilor. - În Moldova (Edel l. c. 39 ; Taccaria pyramidala Fl. Witt. Cz. Flora XIX. 64 et Exsic.!; (z. et sz.l.c. 23) 1ólĭ (Gruchlh. manusc.); pe linğă Iaș̆ la Hlineca (Sz. maunsc.); la Bîrladr; lat Caraclăŭ către Babaghieea; la Agiud

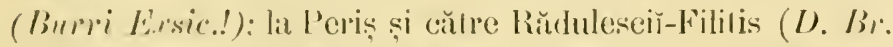

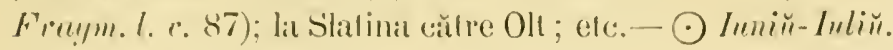


S. offleinalis L. S. oficinalŭ. - Vulg. Soponel, Süponel. Soponul-calului, Odogaciü. - P'e inatca rîurilor, prin luncĭ, tutĕrișurĭ, pe lingă gardırǐ și drumır̆. - În tótă Romănia! (C'z. Flora XIX, 64 et Exsic.!; Edlel l. c. 37, 41; Gucble. mamusc.; Cz et Sz.l. c. 22; Sz. menu.sc; IIoff. Excurs. 1863, l.c. 118 et Exsic.!; Hoff. manusc.; I). Br. l. c. 87; Gr. Lirbor. l. e. 131; En. 14 et Exsic.!; Kanitz!l. c. 19).-2! Zul.-Auy.

S. glutinosa M. Bieb. S. clciós̆. - Prin locurile petróse și calcare din pădurile muntose. - La Virciorova către Porlile-de-fer (Simk. 532) pe St.-Petru.-24 Maĭ̌-Iul.

\section{GYPSOPHLA L. - Gipsofilu.}

G. repens L. G. repertŭ. - În Moldova (Cz. Flora XIX, 64.?); între Rucăr și Hîmbovicióră (Hoff. Lxxenss. 1862, 39).

G. paniculata L. G. paniculatŭ. - Vulg. Gipsarit,u, Ipsoniță, Iperige, Ipcărige. - Pe coline și locurĭ nĕsipóse.La Pechea (Guebh. manusc. et Lixsic. n. 789 scc. Nym. Consp. 99); pe lingă Bêrlad (D. Br. F'ragm. l. c. 88) și între Bêrlad și Tecuciŭ, fórte frequentă; etc. - Y Inliü.

G. fastigiata L. G. fastigialŭ. - in Moldova (G. arenarin W. Kit. Edel l. c. 39) către P'rut (Sz. mannesc.).

G. transsilvanica Spreng.: G. petraea Rehb. G. transsilvanică. - Pe stîncile calcare din regiunea alpină și subalpină. - Pe vîrful Céhlăulŭ (Banffya petraca Bimg. Eddel l. c. 35; (z. Flora XIX, 64 et Exssic.!; Jankia Oest. bot. Zrit. XVI [18666], 366; Scabiosa graminifolia Sz. Exxsic.! /non L../; /.j. ('iucbh. manusc.) la 'Tócă; în Bucegĭ la Omu! (Frm.199) și la Sinaia în vale de mănăstire.-2f Inn.-Ang.

d. miuralis L. G. muralü. - Prin locurı̌ nesipóse și petrose. coline și câmpurı sterile. - In Moldova ( $G$. Saxi-

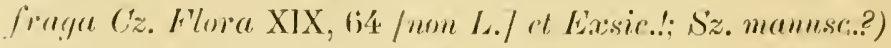
smperionă si inferioră (cimebh. mannse.); la Costuleni și la Balcin în Via-Vîrnat (Sz. mamusse) : la Slănie: la Ag̣ind 


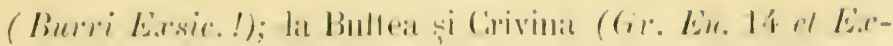

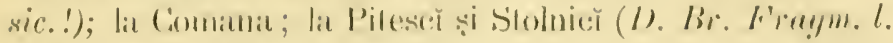

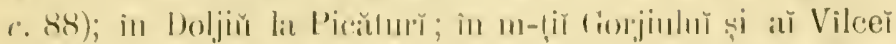

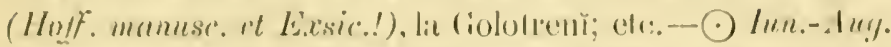

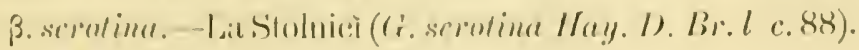

TIXIs šop. - Tunicü.

T. illưrica Boiss. 'T. iliviră. - Pe costele petróse și

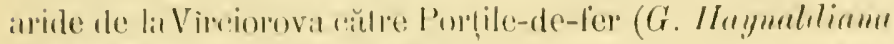
Junka kixs. a. 1870 at . .1. 165).

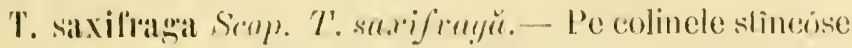
și peetrise. - Lai Vireiorovil rălle Porṭile-de-fer! (Kanilz!

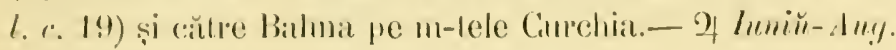

\section{DINTHISS I. - Diant.}

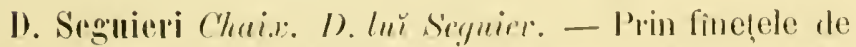

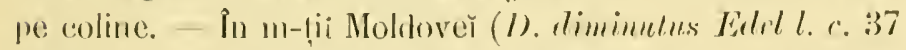

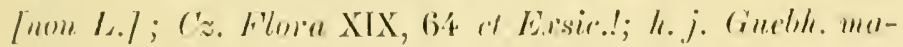

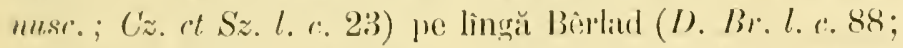

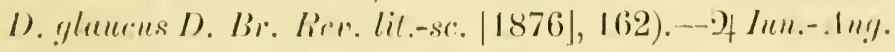

I). rolliuns II'. Kii. D. de colime.-P'rin fine!̣ele și poe-

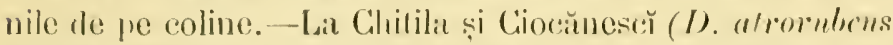

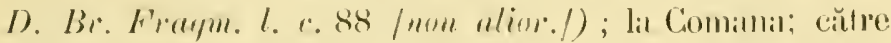

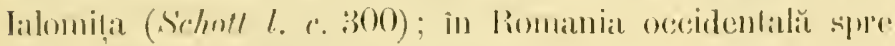

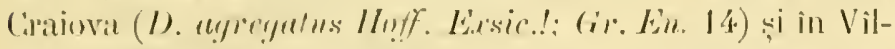

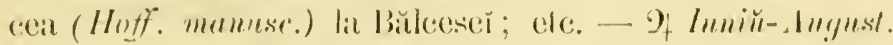

II. guttatus .V. Birh. I). patal. - P'tin finnelete monede.

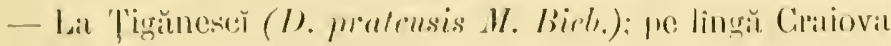
in Lanneй. - of luniй- lnyus/.

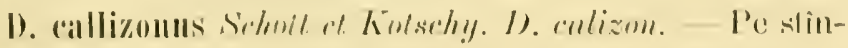

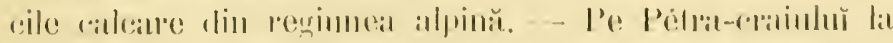

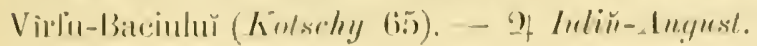


I). cesius Smith. D. verdiü. - Pe stincile calcare din regimea alpină. - Pe Céhllăŭ (Édcl l. c. 36).

I). deltoides $L$. D. deltoid. - Prin finel̨ele și poenile uscate. - La m-slirea Agapia (Gr. En. 14)?; în Vlașca la Talpa (Schott l. c. 296) şi către Ialomiḷa (Schott l. c. $\$ 300)$.

D). gelidus Schott, Nym. Ky. D. imghețat. - Prin jăsunile calcare din regiunea alpină. - In Moldova (D. alpinus Cz. ot Sz.l. c. 23 /non L. nec alior.J); pe virful Bucegilor (F). 120; D. glacialis A. 51 [non Hacnke]; Fr. 120) la Strunga (D). glacialis Fron. 198), către obîrșia Ialomitẹ (I). alpinus Hoff. Excurs. 1863, l. c. 120), pe Obîrșia, la Pîrău-Babelor, pe Furnica, Vîrfu-cu-J)oru; etc.-2 I I n.-Aug.

I. Armeria L. D. Armerie. - Prin locuř sterile şi něsipóse, finețe. tufĕrișuř̆, poen și pe marginea pădurilor.In Moldova (Cz. et Sz. l. c. 23 et Exsic.!) interióră (Guebh. manusc.); la Hadînb, Mironésa, Repedea (Sz. manusc.) și Niţelea; la Verșescĭ și cŭtre Slănic; je lîngă Bêrlad la Sloboḍia (D. Br. Fragm. l. c. 88); în Ilfov (Gr. En. 14 et Ẻs:sic.!) pe lîngă Bucuresĕ ; la Comana; către Ialomiţa (Schott l. c. 300) ; la Stolnicĭ, Vlăscuṭa și Curtea-de-Argeș; pe lingă Craiova la Lémna; în m-tiĭ Gorjiuluĭ și al̆ Vîleẹ̆ (IIoff. mamusc. ct Exsic.!) la Crolotrenĭ ; la Cerneți și Iorgulova (Gr. Exsic.!); etc. - or Inniŭ-Augnest.

D. compactus W. Kit.; D. barbatus L. $\beta$. alpinus Neils. D. compact. - Pạsunı̆ alpine și subalpine. - La Broscenı̆ (Burri Exsic.!); în m-ţiı̆ Buceğ̌ pe Furnica.- -2 Inn.-Ang.

Obs. - D. barbatıs L. indicat în Moldova (Sz. manusc.) la Agapia-veche (Gr. Erbor. l. c. 131) și Varatic (Gr. En. 14), nu cresce de-cît numal cultivat prin grădinY.

I). trifasciculatus Kit. D. trifasciculat. - Prin locurile slîncóse din regiunea monlană și subalpină.-- In dosul

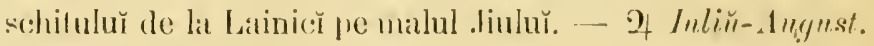

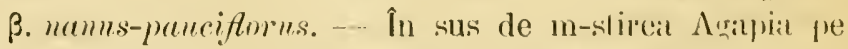

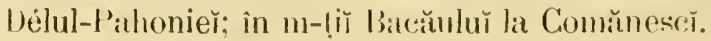




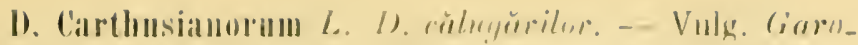

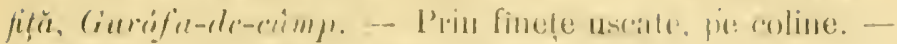

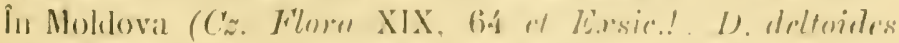

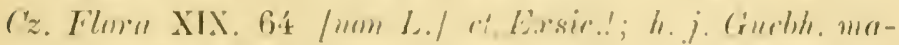

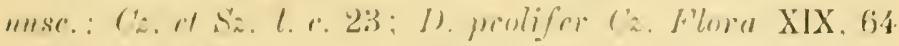

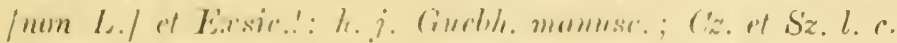

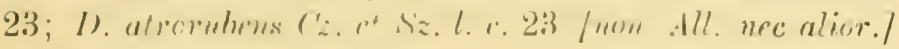

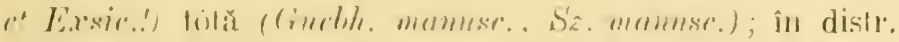

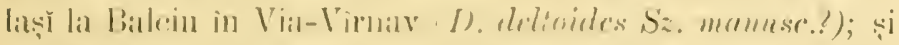

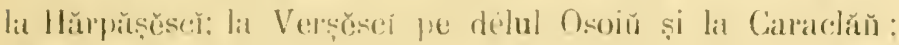

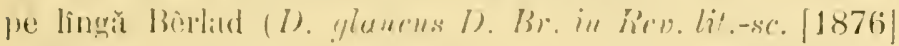

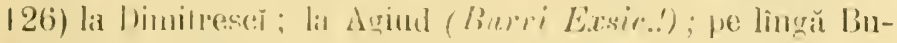

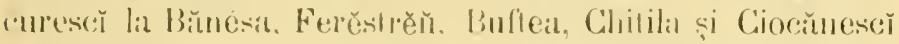

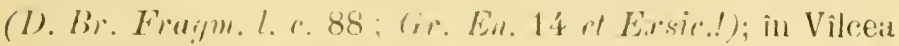

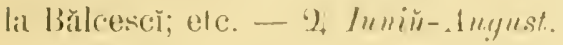

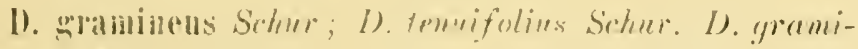
пей. - Prin păşnile petrice și pe stincile calcare din regiunea subalpină și alpină. - In Moldova (I). nilidus $\left(c_{\alpha}\right.$.

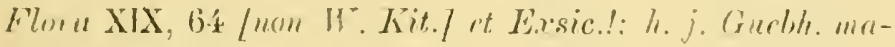
nusc.; ( $z$. rt Sz.l. c. 23) urin regiunile infericire ale Ci-

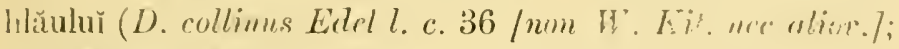

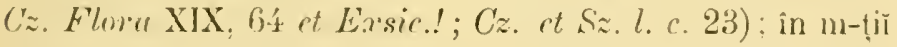
Buzĕulur pe vîrful Penteleulŭ: in m-tiĭ Buceğ pe linğ̆ Strunga (D. carthusianomum var. Iomifolius Schur Fr.120), la schitul Pescera Talonițě!! (Fron. 202). ne Furnica și la Sinaia! (D. congestus Gr. Eit. 1't /nom Gron. et Gudr. I ot Exsic.') etc.- ? Iuniü-Augus/.

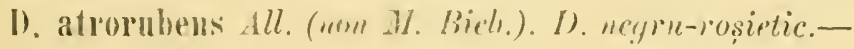
Prin finețele uscate, pe stincile din regiunea monland. -

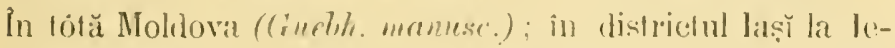

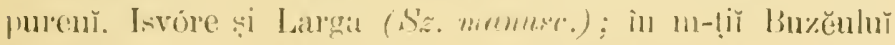

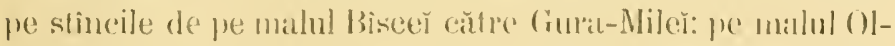

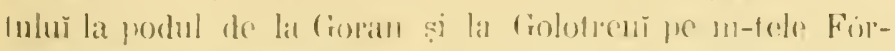

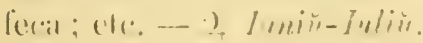




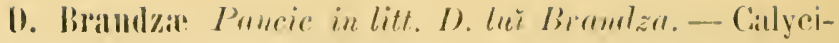
bus brevissimis, squamis latissimis, oblusis, lotis eoriateeis. Stalluar ale foliis el floribus valde similis D), brachyantu. Sed gregis Citlthusianorum. - ') lul.

Slaṭ. și abit. - Pe stîncile calcare diu pădurile subalpine. - Îu

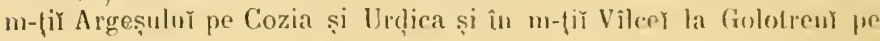

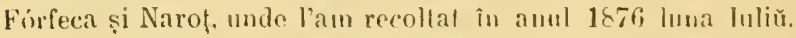

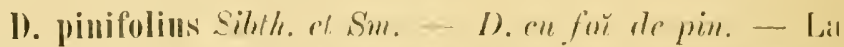
Vîreiorovil pe slincile calcare de lat P'ortile-de-fer! (Janka! Oest. but. Zeit. XX [1870], 250; 117. 165). - 9f lun.-Iul.

I). Capitatus DC.; D. alvombrens W. Bisb. D. capital. - Prin finețele uscate de pe coline, prin poenile din tufe-

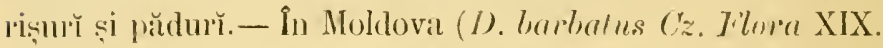

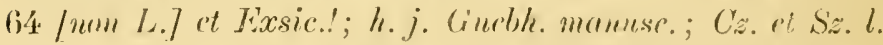
c. 23) inferionă (Guch. manusce et Exsic. n. $792 \mathrm{in} \mathrm{herl.}$

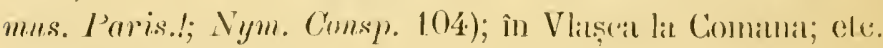
- 9 Inпій-Iuliu.

1). giganteas d' Ure. 1). giganide. - P'e coline nesiprose și pelróse, locurĭ slincose și callatre, prin linete nseille din

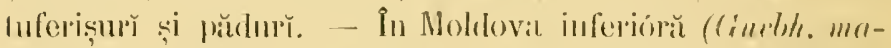
nusce. Ex Exir. "79:3 in herh. mus. I'turis.!); pe malul Bu-

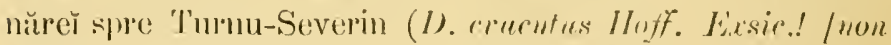
Griscb./; Gr. En. 14); la Vîrciorovil călle P'orṭle-de-fer!

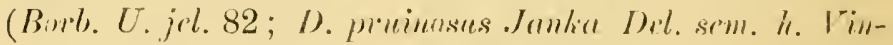
(tob. 1858; reinpr. in Linn. XXX [1860). 749); D). Lanaticus Hentf. in (tris. It. hueny. 1. 301 ; simle. 530; rf. Vrile. Nuchtr. 264) şi cuittre Balhna pe P'lainul-seurl și pe m-lele

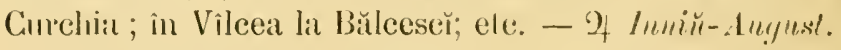

I). giganteiformis Barh. I). gigunteiform. - Lat Vilrciorovil călre P'urlile-de-l'er' (Burh. U. jol. 83; D). lumulicus Burb. 1873; Biins 282 (mun I/enff./).

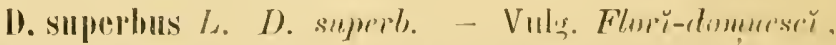

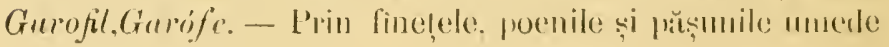




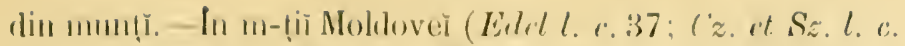

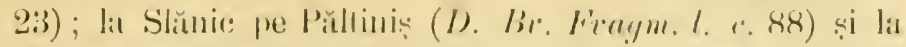

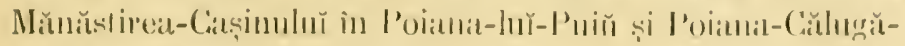

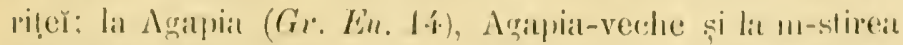

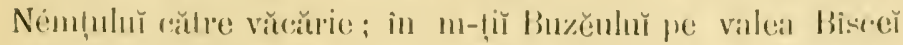

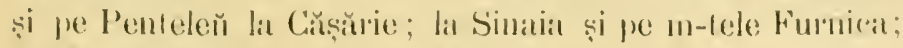

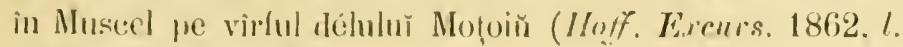
(․ 39); cte. - 9, luliur-.luqust.

D. plumarius L. D. plumeriü. - Vulg. Barber-nuegurulur. - Y'e stincile callante din reginnea subalpină și alpină. - In Moldova (c'z. ot Sz. l. e. 23: lı.j. Crueluh. manusc.?); în Muscel pe lingă Imobovicioma (D). serutimus l).

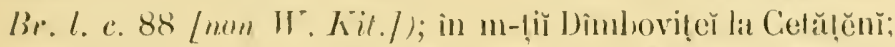

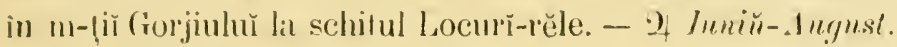

D. pethens H. Kit, D. de stinč̀, - Pe stinncile calcare din regimea subalpină și alpină. - In Moldoval $(C z$. ct $S z$.

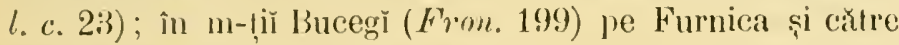
obirşia Jalonitẹ (Hoff Eicurs. 1863, l. c. 130) lat sehitul P'escera! (Winkl.! sec. Kanitz l. c. 21).- 2 Inmiü-Lugust.

I). prolifer L. D. prolifer. - Prin finete sterile, pe

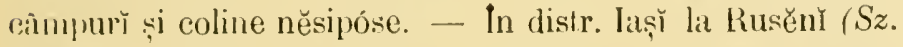
mamusc.?); în Argeș la Stolnicì și Vlăscuṭa (D). Br. Fruegm. 1. c. 88); la Rîmnicu-Vìlcê̌ pe malul Oltuluŭ ; în Mehedințĭ li Schelea-Cladoveĭ, Gura-văiě̆ ete. - $\odot$ Iипій-Iuliŭ.

0lss. 1. - Se mal citéză : 1). Balbisii Ser. pe délurile petróse de la Becenir (D. collinus Bulb. [non W. Kit.] Gr. En. 14). - 1). al'rnarius $L$. prin něsipul de pe unatca torentelor Moldover centrale (Guebh. murusc). - 1), sytvestris Wulf. in Moldova (Cz. et Sz. l.c. 23) la Agapia (Gr. Erbor, l. c. 131; L̀ 14?) și pe lingă Dimbovicióta (Hcfl. Exours. 1862, l. c. 39). - D. virenillens Jacq. in Moldova (c z. et Sz. l. c. 23). - I) seprntinns W. Lït in distr. IașY la Balcin în Via. Vîruav (Sz. memuse.).

0bs. 2. - Se cultivă prin grădinĩ : I). (auyoullyllıs L. vulg. Gu-

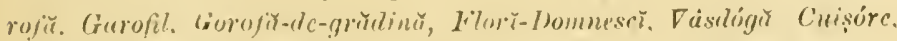

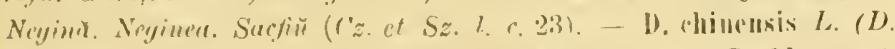

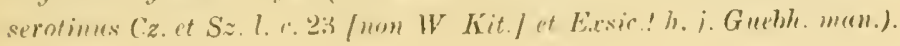




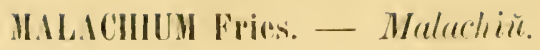

M. aqualicam Frirs. M, aquatie. - Prin locurǐ umede

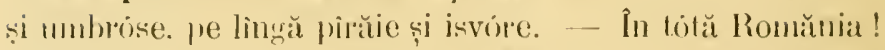
(1). Br. l. r. 88; Gr. Ër. 15 al Exsie.!; Corostinm nquat-

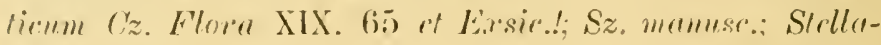

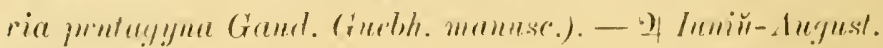

\section{CERASTHIY I. - Cerestiŭ.}

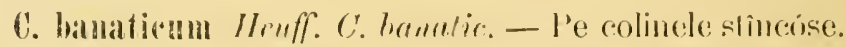
- Lat Vîreiorovir eătre Por!̣ile-rle-fer! (Burl). 187:3, Bians.

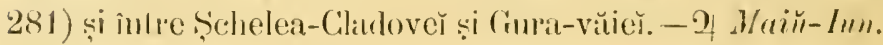

C. arvense L.; C. strichm Iarnlir. C. de camp. - Prin ph̆șmile unnede și locurile petrose și calcatre din regimnea

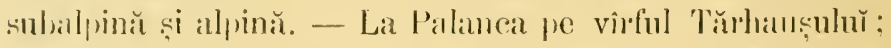

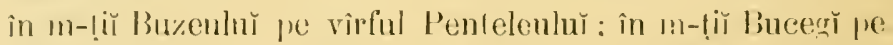

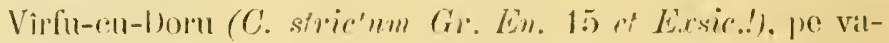

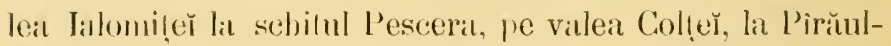

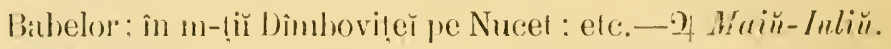

C. alpinum L. C. olpin. - L'e stincile calcare și jăṣunile petrose și umede din regimen alpină. - L’e vîrful Cé-

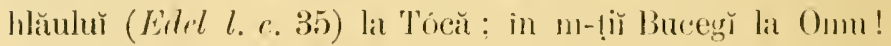
(Fron. 200). - of Main-dugust.

3. Lnualum Kord. - - He stincile calcare şi prin păsunile pelrơse din regiunea alpină. - Pe vîrful Céhlăulù! ( $C$. vilLosmm Bmy. Eidel l. c. 35 et Exsic.!; Androsace villosa Cz. Flora XIX, 61 [wom L.J of Exsic.!: h.j. (inchh. mamusc.);

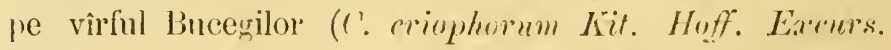
1863, l. c. 120), la Onu! (c. villosum livm. 200), Virfu-cuborn! (C. Lanalum Lam. (Hr. Lin. 14 at Ersic..'), Furnicat.

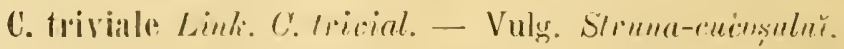

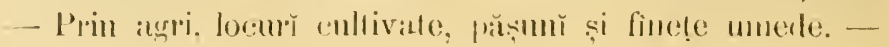




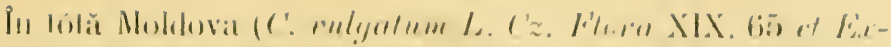

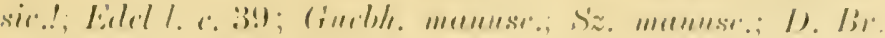

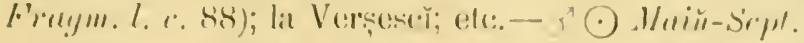

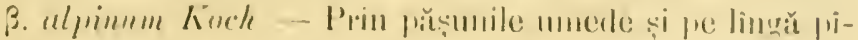

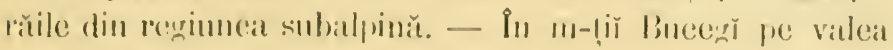

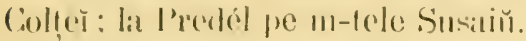

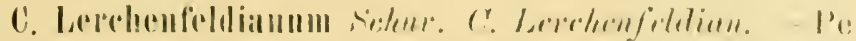

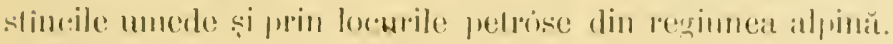

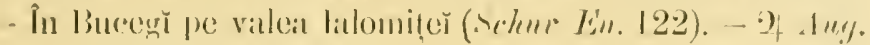

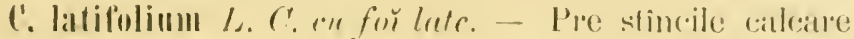

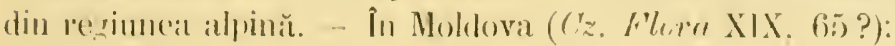

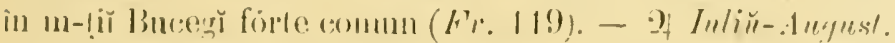

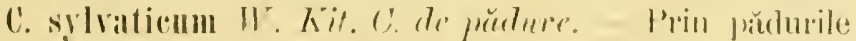

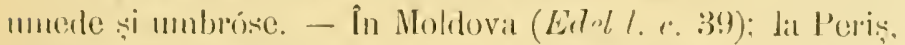

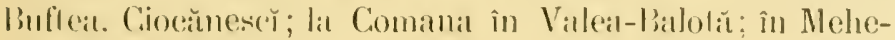

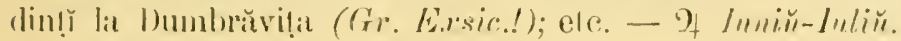

6. slomeratum T\%uill. Cr. glomerut. - Prin igeri. Io-

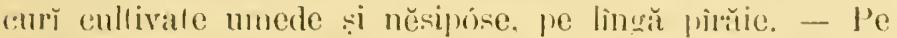

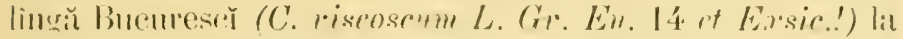

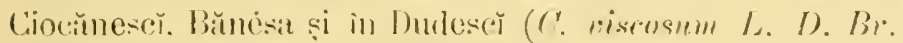

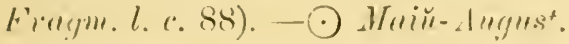

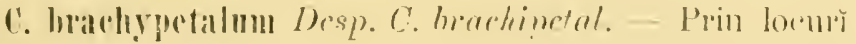

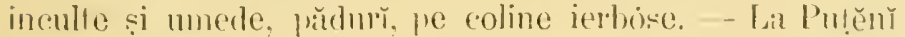

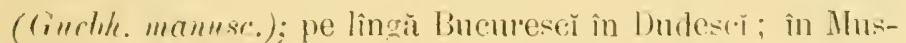

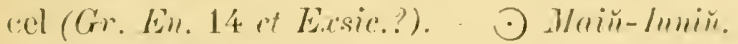

3. ylandulosmm Schmr. - Prin mlastinile săralle de lis l'isce (C. tauricum Sm" Guebl. mammse.).

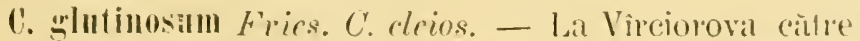

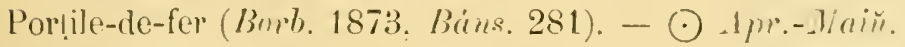

C. semidecamblum L. C. semidecendi"n. - In totă Moldova (Sz. me(tullsc.). 
C. Higynum Vill.; Stellaria cerustrites L.: Dichorton "erastoides Rchh. C. trigin. - Prin pășunile stinncóse și umede și pe lìngă pîrăile din regimnea alpină. - In Buceğ re vilea Ialoniter en Scleranthus neglectus, Arenaria ciliuta, Cineraria capitata, ete. (Fr. 119). - Y Jul.-dug.

C. anomalum W. Kï. C. anmual. - Prin locurĭ cultivate, le câmpmri şi păşunĭ nĕsipóse și umede. - In Moldova (C. arvense Cz. Flope XIX, 65 /non L.7 et Exsic.!; Edel l. c. 39; Guebh. manuse.); la Unghenĭ, Moroeni și Prisěcanı̀ (Sz, mamısc.); la Galațĭ (Stellaria viscida $Y$. Bieh.

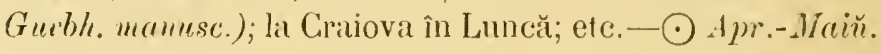

Obs. - Se mar citéză : C. ovatum Hoppe prin mlaștiuile sărate de la Pisc (Guebh. manusc.). - C. illyricum And. priu locurile něsipóse de pe matca SeretuIur (C. androsucenm Ser. Guebh. munusc.).

\section{IIENCIIIA Ehr's. - Moenchie.}

M. erecta Fl. Wett. M. erectŭ. - Prin mlaştinile sŭtrite de la Pisc (Sagina srecta $i$. Gublh. manusc.).

\section{STELLARIA L. - Stelarie.}

S. nemorum L. S. de pürdure. - Vulg. S'seluță. Sléüfitcr. - Prin pădurř umbróse și umede. - În Moldova Cz. Flora XIX: 64 ct Exsic.!; Sz. manusc.; Constimn fontrmum (z. Flora XIX, 65 (non Bug.] rt Eissie.!) centrală ș superióră (Guebh. mamusc.); la Palanca pe m-tele 'l'ărhăușĕlı; la Sinaia către pólele Furniceer; la Predél; la Němă-

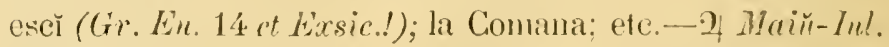

S. media Fill. S. intermediară. - Vulg. Rocovinŭ. Ro-

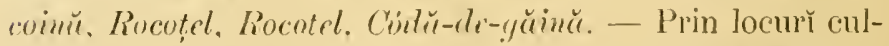

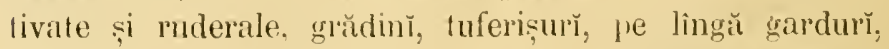
drumurì și pirăie. - În létă Romănia! (Gruebh. mamusc.; 


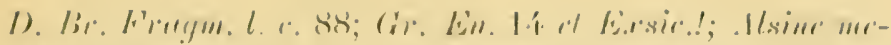

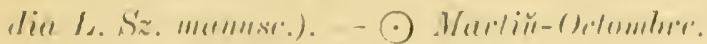

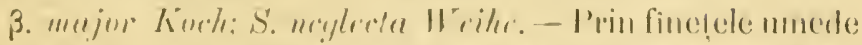

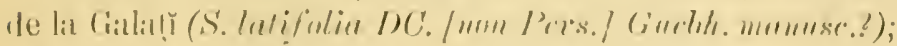

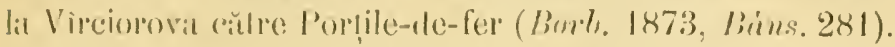

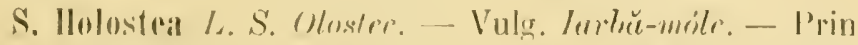

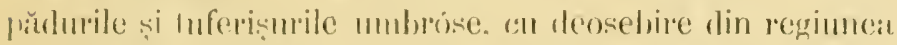

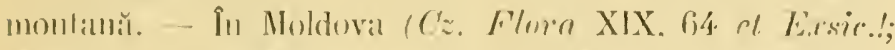

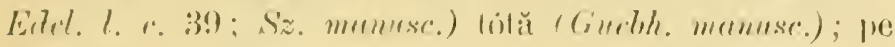

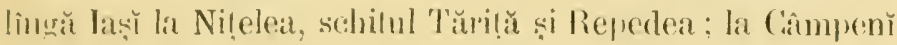
și Slănic; la Agind (Burri E.rsic.!); la Sinaia călre pólele

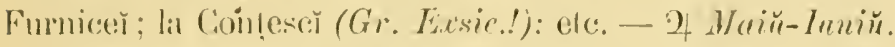

S. pilustris Ehrh. S. palustrŭ. - Prin finele mlaștinise. pe lingă iazur. - In Moldova (S. fomfana Cz. Flora

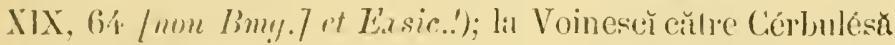
(s). glanea Hith. Sz. manuse.). - 2 Inniй-Inliu.

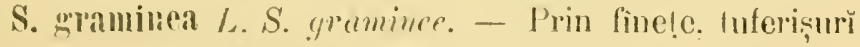

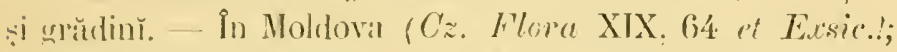
Lidel l. e. 39; Sz. meumse.); la Mangina (Guebh. menuse.);

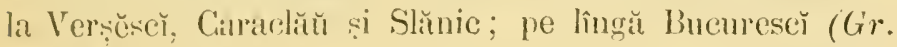
En. 14́ it Eessic.!) la Chilita și Ciocănescì (S. graminifolia 1). Br. Fraym. l. r. 88); in Dimhovi(̨a ne m-tele Priporu; la Virciorova călre Bahna; ete. - 2 M Maiй-Luliu.

S. uliginosa Murr. S. uligimósü. - Pe lingă isvore și pirăie, finețe mlăstincise. - În tótă Moldova (Sz. mumuse.).

3. fontuna bimg. -- În regiunea subalpină la Negrulésă, P'risecenŭ, Valeat-didanulŭ și Valea-Bicazulŭ (\$z. manusc.).

\section{H(1LOSTEIU $\varkappa_{\circ}-$ Olostrŭ.}

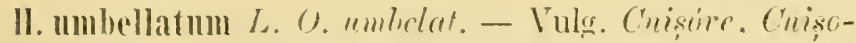
riți. Rocolel. - Prin locurì cullivale, pe câmpurĭ. - In Moldova (Edel l. c. 39) tótă (Guebh. manuse.); la Agind 


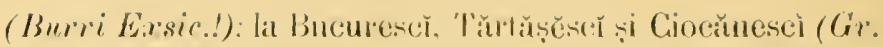

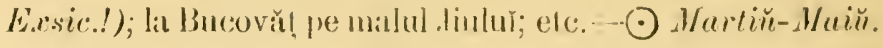

\section{MEIIRINGIA L. - Meringie.}

M. trinervia (lairv. M. trinevială. - Prin pădurile unede şi unbróse. - În tôtă Moldovil (Gnebh. manusc.); lit Măuăstirea-Caș̣inuluĭ şi Slănic; pe P'entelen̆; la Comana; lit Virciorova către Bahna; efc. - $\odot$ Mспй-lıиiй.

II. muscosa L. M. muscúsŭ. - - Pe sfîncile calcare și unede din pădurile umbróse subalpine. - În Moldova superióră (Guebh. mannsc.); lat Sinaia pe valea Peleșuluŭ! (Grr. Eu. 14 el Exsic.!) , în n-tii Bucegì către obîrșia Ialomilẹ̆ (Hoff. Excurs. 1863, l. c. 120 el E.r.sic..') și la pólele Furnicě ; la Nĕmăeseì (D. Br. l. c. 88); în m-tị̆ m-slirilor Coziat. Bistrila și Tismana (Hoff. mannsc.).-2) Mlain̆-Inl.

\section{ARENARIA 1. - Arenarie.}

A. rigida 17. Birb. A. rigiză. -- Stepe și locurĩ aride. În Moldova (Gueblh. Eissic. ". 567 sece. Nym. Cousp. 113).

A. biflora L. 1. biftem ǔ. - Prin locurile stincóse și umede din regiunea alpină. - l'e vìrful Bucegilor ( 1,51$)$ la Onu! (Fron. 200). - 2 inniй- Lugnest.

1. ciliata $L$. A. ciliatŭ. - Prin locurile stincóse din regiunea alpină. - In m-tị̆ Bucegì pe valea lılomị̣ě̆! (Fr. 119). - 9 luniŭ-dugust.

A. serpylifolia L. A. cen for de sérpun. - Prin locurì aride, něsipóse și petróse, câmpurĭ, agri, grădinĭ, pe lingă drumuri. - În tútă Romănia! (Guebh. manusc.; Sz. muunsc,; D. Br. Frerym.l. a. 88; Burri Lixsic.!; Alsine media ('z. Flom XIX, 63 luon L./ e' Eesie.!' Edel l. C. 39 : (zz. el sंz. l. c. 16). - $\odot$ Inuiri-luliu. 


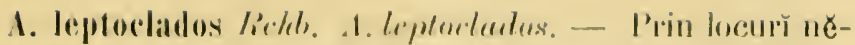

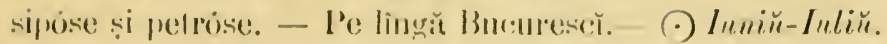

Ohs. - Se mar citéză : A. gratrenlons Schreth. prin viile unede de la Galafr (Stclluria murulis Link. Gueldr. Not. 16 et munusc.).

\section{ALsINE Waluleuh. - Alsină.}

A. Cherleri Fenzl. A. lu. Cherler. - Pe slîncile unede și pășunile calcare din regiunea alpină. - $\hat{l}_{11}$ m-tị̆ Bnceğ

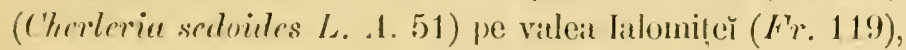
la Omu! (From. 200), pe Babe: elc. - Of lunir̆-August.

1. austriaca M. K. A. aıstriucŭ. - In reginnea alpină. - P'e Pétra-Craiulır̆ la Virfu-Baıciulur (Arenaria austriaca .Jacq. Kotschy 65). - 2 Inniй-Anegust.

A. falcata Groiseb. A. falcatĕ. - Prin luferișurile stîncóse şi calcare de pe colinele munlóse. - La Vîrciorova călre Porlile-de-fer (Arenaria frutescens Kit. Siml. 534) pe in-tele St.-Petru. - 2 Maiй-Iıniй.

1. catarractarum Janke. 1. cataractelor. - La Vîrciorova pe stîncile de la Porțile-de-fer (Janka Ad. 165).

1. slomerata Fenzl.; Arenaria glomerafa N. Bieh. A. ylomerată. - Prin stepe și loculř nĕsipóse și petróse, pe stîncĭ calcare.-In Moldova (Aren. fasciculata Ertel l. c. 38 [nou .Jacq.] et Exsie..'); pe lingă (ralațî la Vadul-unguruluĭ (Aren. fasciculala Sz. mamse.).- Р) Iипій-Iuliŭ.

A. recurva Wahleub. A. recurbală. - Pe stincile calcare din reginnea alpină. - În m-tị̌ Bucegì pretutindenea (1. 51: Kotschy 134). - 2 Iuniй-August.

A. verma Bartl. 1. exrnală. - Prin locurile stîncóse din regiunea mon:ană. subalpină. și pănă prin pășunile petróse din regiunea alpină. - Pe Cèhlăŭ (Aremaria saxatilis Edel l. c. 35 /non L.J et Ersic.!: h. j. Guebh. mumusc. 


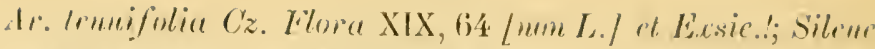

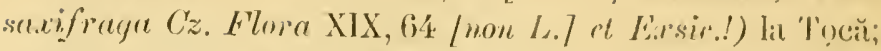
în m-lịi Buceğ (1. Villarsii Gr. En. 14 /nom M. K./) în valea Ialomitec la schitul Pescera ; la Predél; la Virciorovi

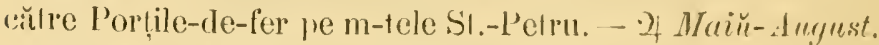

B. alpina Koch. - Prin păsunile calcare și mmede din reginnea alpină. - In m-lị̆ Bucegì (.1. alpina .1.50) pe Vîrfu-cu-1)or'u (Gr. En. 14 et Exsic..'); ele.

\section{SAGINA I. - Saginŭ.}

S. nodlosa Fenzl. S. nodtoróšr. - Prin locurř umede și nĕsipóse. - Pe malul Prutulur̆ la Soloneṭ̆, lijvolarr̆, pe malul Stavniculuŭ la Voinescĭ (Spergula nodosa L. Sz. manuse.).

S. Linnai Presl.; Spergella sagimnides Rechb. S. Lni limneй.-- In Buceğ pe valea Ialomi!̣e (Fr. 118). - 9; Inliŭ.

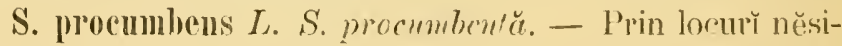
póse și umede, pe matea rîurilor, pănă îı regiunea alpină. - In Moldova (Aren. ciliata Cz. Flora XIX, 64 [nom L.] et Exsic.!; Spergula nodosa Sz. Exsic.! lmon L.]; h. j. Gucbh. manusc.); în distr. Iaș̆ la Minzètescì (Sz. manusc.); pe Penteleŭ la Cășărie ; la Càmpulıug pe malca Rîu-Tîrơnluй (IIoff. Excurs. 1862, l. c. 40 at Eitsir.!; Speryella glabra Gr. En. 14 [uon Rechl.] et E.rsic.I); la Sinaia (S. apetala Gr. En. 14 fmon L.7 et Exxsic.!) si in m-tĭ Bucegi pe Babe; la Golotrenı̆ si la 111-stirea Horez; elc. - 2f Huin-Scpt.

\section{SIERGIIA L. - Sprergulă.}

S. arvensis $L$. S. de cimp. - Vulg. Hrana-racě. -

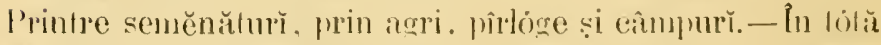
Moldova (Sz. manusc.); către m-stirea Varalic (Gr. Erlor. l. с. 132?). - $\odot$ Iипій-Luliŭ. 


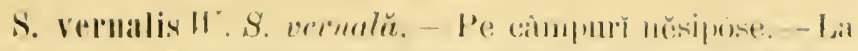

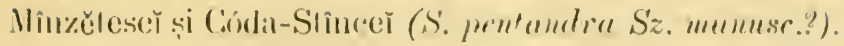

\section{SPERgitadRA Pers. - Spergularie.}

S. Saliua Pre'sl.; Leprigomum mediem Hahlemb. Inon Fr.] S. salinu. - Prin locury unede și sărate, pe lingr̆ saline și isvóre minerale. - In Moldova (Aromarin ruhra Cz. Flora XIX, 64 [non Roth] et Exsic.!); prin mlastinile sarate de pe lingă Galați (Ar. salina Ser. Gurbh. Vot. 18 et manusc.) şi la Vadı-Ungurulŭ (Atr. rebro Sz. manuesc.); la salina de la T'ìrgul-Oeneì! (S. nureina Harlal l. c. 445 ; Ar. rubra $\beta$. marina L. Hacq. Reise II, 149), la apele ninerale de la Slănic şi la Caraclăŭ pe délul Slatina; la Sarealŭ̌-Buzě̆ ; etc. - $\odot$ If hnĭ̌-August.

S. rubra Prìs. S. rosie. - Prin locurù nĕsipose și peIróse. - La Pilescĭ (S. rubra ß. pinquis Gr. En. 15 fnon Frnzl] et Exsic.)! ; la Câmpulung pe matca Rîu-Tírguhŭ (Arenarice rubra Roth Hoff. Excurs. 1862, l. c. 40 et Exsic.!) și la Němăescĭ pe matca pîrŭuluŭ Němăescì (Lepigonеми rubrum Wahlenh. D. Br. l. с. 88). - I Maiй-Srpt.

\section{PORTULACACEE.}

\section{P0TULACA I. -- Portulacd.}

P. oleracea $L$. P’. vulyară. - Vulg. Iavbü-grasŭ. Por.. rinŭ. - Prin locurı̌ nĕsipóse, cultivate și ruderale, curțĭ. glădinǐ, vǐ̆, pe lîngă zidurị și drumurì. - In lótă Romănia (Guebh. mamusc. et Exsic.n. 772 sec. Nym. Consp. 253; Edcl l. c. 39 ; Cz. ct Sz. l. c. 24 ; Gr. En. 25 ; P. olera"ra 3. sylerstris (ruebh. manusc.).

0)s.-Dintre Etatinee (XXXIV) se citeză : Eatine Hydropiper $L$. prin bălţile inundate de la Olteniţa $(G r . E n .15)$. 


\section{PARONYCHIACEE.}

\section{P.LONYGIIA L. - I'aroniclie.}

P. cephalotes M. Bieb. I'. cefalotü. - P'e stineile de lat

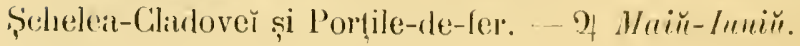

\section{HERNIARIA I. - Emrarie.}

II. goliahra L. E. glabră. - Vulg. Iarba-feciórè, In ba-

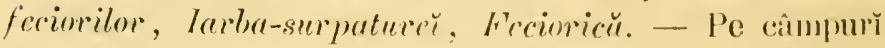
nĕsipóse și sterile, pe coline aride și petróse. - In Moldova pe malurile Bistrițe și a Serehulŭ (Cz. Floxa XIX, 62

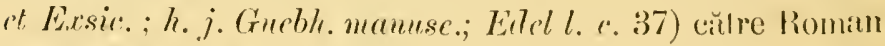
și pe lîngă Bach̆tŭ $(C z$. et $S z$. l. c. 11) la Călugăta pe délul '’’igănescilor; pe lîngŭ Bucuresĕ la Bănésa! (ror. En. 25) et Exsic.!); la Câurpulung pe !ĕrnurile Rîn-'lîrguluŭ (IIoff. Excurs. 1862, l. c. 40 et Exsic.!): ete. - - Iml.-ípp'.

II. incana Lam. E. albiciósŭ. - Prin locurì nesipóse și sierile, pe coline aride și petróse. - Intre Şchelea-Cla-

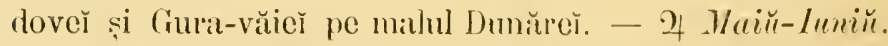

3. angustifolia Ledel, - In Noldova (II. hirsuta Cz. et S'z.l.c. 11 / nou L.] et Exssic..') inferiorĭ (H. Besseri [Fisch.] DC. Guelh. manuse. et Exsic.n. $773 \mathrm{sec}$ Nym. Consp. 256); in distr. Jaş̌ la Chiperescì (H. hirsutu Sz. manusc.); la Sinaia pe valea Isvoru (H. hirsuta Gr. En. 26 [non L.] et Exxsic.!); la Ferĕstrĕŭ (H. incana D. Br. F'ragm. l. c. 88) și lia Bănésa! (H. hirsuta Gr. En. 26 et E.rsic.!); la Comana; ele.

\section{SLLERINTIIIS L. - Sclerant.}

S. perennis L. S. perenal. - Vulg. Sincerier̆. - Prin locurile stîncóse, petróse și nĕsipóse din munț. pe matca 


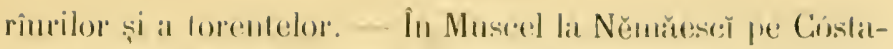

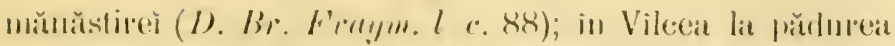

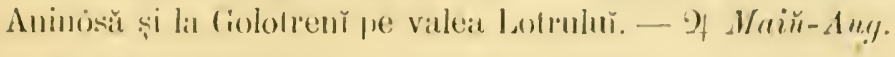

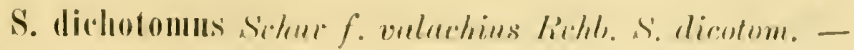
P'rin clěphălưle slincilor. - La Virciorova călre P'ortile-

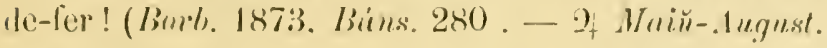

S. nerglectus limch. S. negles. - In reginuea alpină a

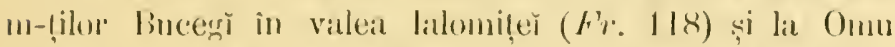

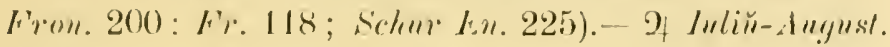

S. Incinatus Srhur. S. uncina'. - P'rin locurile petróse din regimnea montană, smbalpina și alpină. - Lä l'alatueal

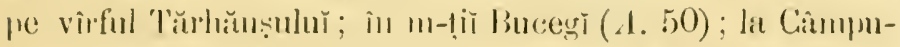

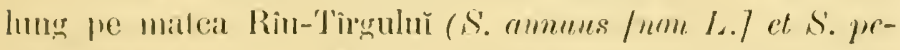

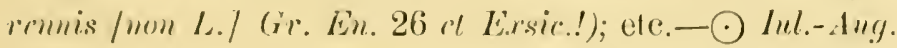

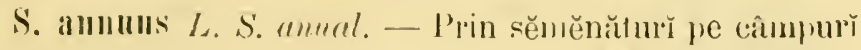
něsiprise, prin locurı̌ petróse. - In töh̆ Noldova (Guelh).

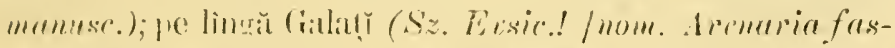

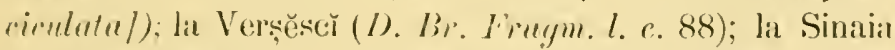

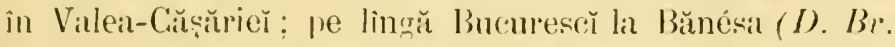
l. c. 88 ; Gr. En. 26 et Exsic.!; S. peremmis 1). Br. l. c. 88 Inon L./); pe lingă Slalina; ele. - $\odot$ Maiñ-1ugnest.

Obs. - Dintre Firvillee se citéză : Hesombiryunthemum sp. prin

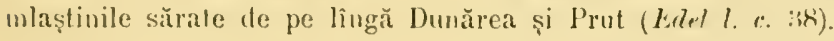

\section{POLYGALACEE.}

\section{POITHALA I. - I'olygaľ̆.}

P. Clamminxus L. P. Chamelmx. -- Prin locurile stincóse din reginnea subalpină și alpină. - Pn vilea Slănicu-

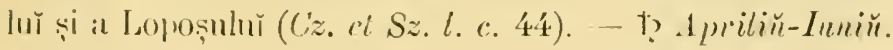

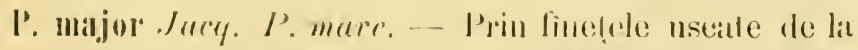

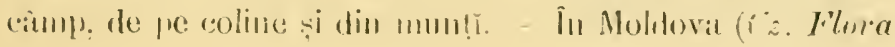


XIX, 69 ot Exsic..; Edel l. c. 39; Cz. ct Sz. l. c. 43) inferióră (Gurbh. mamus'.) ; în distu. Taṣĭ la Repedea, Budescĭ şi Hadlunb ( $S z$. mannsc.); la Cianaclău pe Babaghicea; pe lîngă Ploescĭ (Janku! src. Kunitzl. c. 188); in Vlașca la Comana; între Rucăr şi lièmbovicióra (IToff. Excurs. 1862. l. c. 39 et Exsic.); și la pólele Sturulŭ călre Mateiaș (D. Br. F'vagm. l. c. 86); în m-țī Vîlceê şi aì (rorjiuluĭ (Hoff. manusc.); etc. - 2 M Maĭ̌-Iuliŭ.

ß. alliflora. - Pe lîngă Bucurescì la Periṣ.

P. comosa Schli. P. comósă. - Prin finețe sterile, pe coline nĕsipóse. - In Moldova ( $P^{\prime}$. austriaca $C z$. Flora XIX, 69 [non Crantz] st Exsic.!; h. j. Gusbh. manusc.; Cz. ct Sz. l. c. 43) inferióră (Guchh. manusc.) ; pe lingă Jașĭ la Nițelea; la Câmpina (P. vulgaris Gr. En. 13 /non L./ et Exsic.!), Vălenĭ, Ciocănescĭ! 'Tărtășěscì și Gulia (Gr. En. 13 ct Exsic.!); în Muscel la Conțĕscĭ şi Němăescì ( 1 'v vulyaris D. Br.l. c. 86; Gr. En. 13 et Exsic.!); etc. - 2 Maiü-Iuliǔ.

P. vulgaris L. P. vulgară. - Vulg. Șrerparițĭ, Amărélă. - Prin finețe sterile și prin locuř̌ nĕsipóse de liı câmp, de pe coline și din munț. - În Moldova ( $C z$. Flura XIX, 69 et Exsic.!; Edel l. c. $40 ;$ Cz. ct Sz. l. c. 43 ; Sz. manusc.) tótă (Gucbh. mamusc.); pe lingă Iaș̆ la Niṭelea; in m-ṭi Némṭuluĭ la Călugăreni; la Slănic pe m-tele Pufa; la Sinaia (1'. vuly. B. alpestris /non Koch nec. alior./ et I. anara [non Jacq.] Gr. En. 13 et Exsic.!; Lrcires. I. $\iota$. $340)$; pe lingă Bucurescì la Merinani (D. Br. Frugm. l. c.

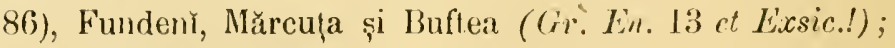
in Dîmbovița către Moroenı̆ pe matca Ialomițeì; in m-lịi Vîlceй la Brezoiŭ.-2/ Nhaiǔ-dugust.

P. amara Jacq. I'. amorŭ.-Prin păsunile din regiunea

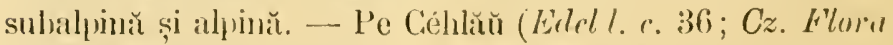

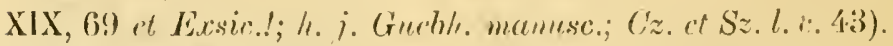
- 2 Inпiй-Aluynst. 


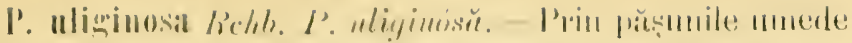

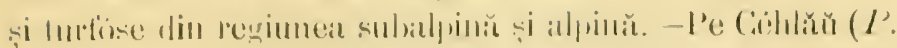

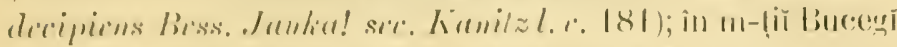

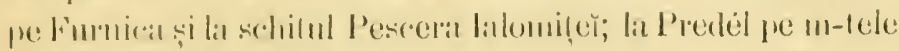

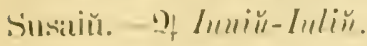

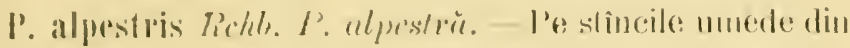

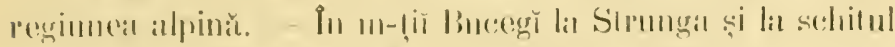

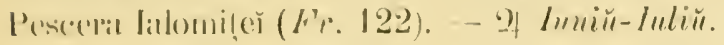

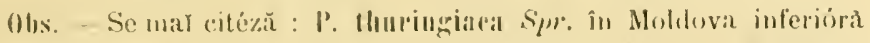
( (rubb). mumse.). -S. orientalis in grădinile din Noldova(sz. mon.).

\section{CELASTRACEE.}

\section{EVONIMUS I. - Evonim.}

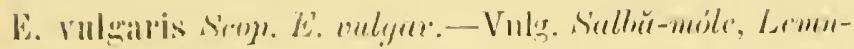

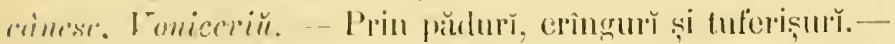

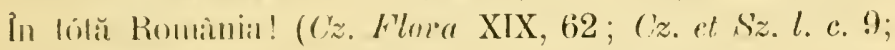

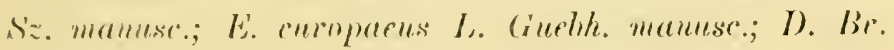

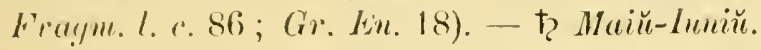

E. latifolius somp. E. cu for latr. - Prin pădurile diu reginnear montanta. - In Moldoval (C'z. Filora XIX, 62 et li. sie.!; Lilel l. e. 41; Cz. et Sz. l. c. 9; Sz. manust.) lotĭ (Gusbh. manuesc.). - †? Maiй-Iuniй.

E. reprurosas Scop. E. veruces. - Vulg. I emu-riins.

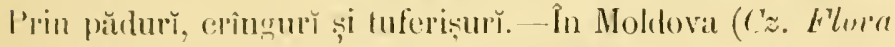

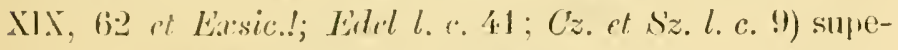

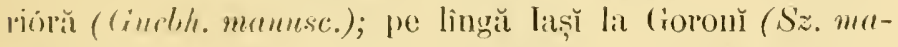
muse.) și la Niṭelea; pe lingŭ Bèrlad (D). Brr. Fragm.l.c.

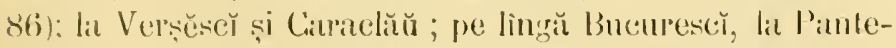

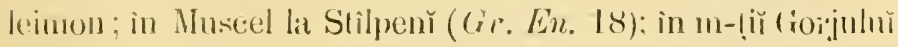

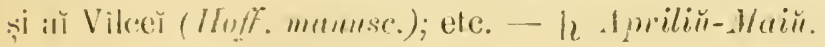

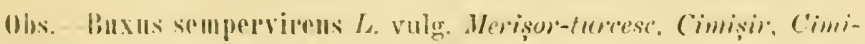

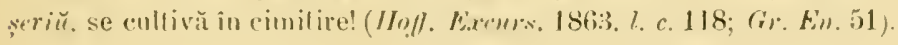




\section{RHAHNACEE.}

\section{RHAMNUS $\mathrm{I}_{2}$ - - Ramn.}

R. Frangula L. R. Frangulă. - Vulg. Crusiun, I'asa-

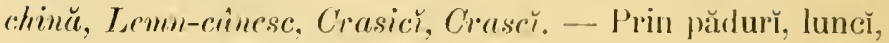
luferişuř̆, prin sĕciurile viilor. - In Moldova (EAlell. c. 41; Cz. et Sz. l. c. 9; R. alpinus Cz. Flora XIX, 62 /nm L./ et Exsic.!: h. j. Gunbh. manuse.; $C z$. et Sz. l. c. 9); pe lingă lași la Nițelea (D. Br. Fraym. l. (. 86) și la Solonețĭ (Sz. mamısc.); Némț și Muscel (Gr. En. 18); la Periss; la Slatina ırrin luncile Oltuluĭ; în Vîlcea la Bălcesč̌. - 2q Maiй-Lın.

R. rapestris Scop. R. lı̌ Wulfeniŭ. - Pe stincile din regriunea subalpină. - In Moldova (Cz. et Sz. l. c. 9).

R. cathartica L. R. purgativ. - Vulg. Verigariü, I'árul-cinter, Spinnl-cerbulnt, Salbă-móle.-Prin tuferrișury și pădurŭ. - In Moldova ( $C z$. Flor a XIX, 62 et Exsic.l: $C z$. et. S'z. l. c. 9; Sz. manusc.) tótă ((iueblı. mamesc.) păıă în regiunile inferióre ale Céhlăulı̆ (Edol l. e. 36): la m-stirea Némḷulŭ (Gr. Ẻn. 18); pe lîngă Jaş̌̆ prin sěciurile viilor de la

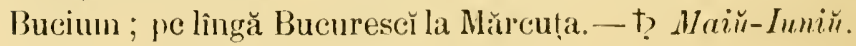

R. saxatilis $L$. Rr. de stinč́. - Pe stincile din pădurile munților. - In Moldova (Edel l. c. 41 ; Cz. et Sz. l. c. 9.).

\section{VITACEE.}

\section{VITIS I. - Vită.}

V. vinifera i.; V. sylvestris Gimsl. V. viniferă. -

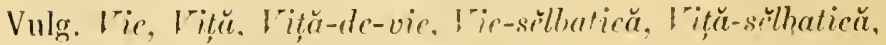

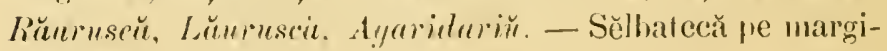

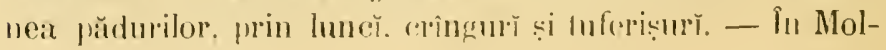


dova (1. Labrusare Seop. Lwon L./ Edel l. c. 39, 40); we

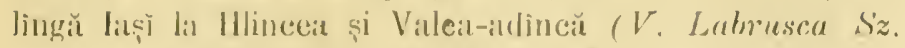

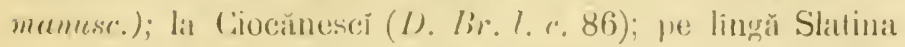

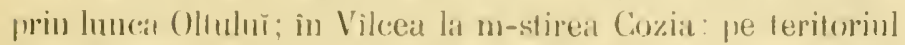

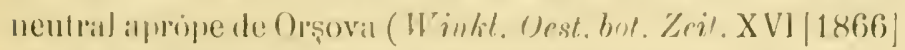
184), la V'ìceiorova, Ballna, (iura-văiel; elc. - Iar culti-

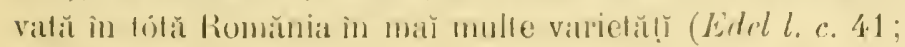

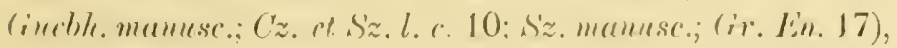

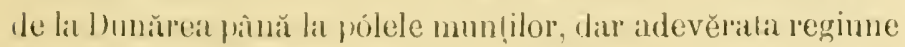
¿ viilor suml rolinele ce incep la Oratvila și se termină la

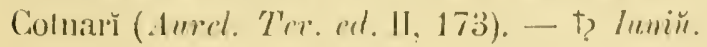

\section{SAPINIDACEE.}

\section{ACER L. - Artariü.}

A. pseudoplatanus L. A. Fals-pla'an -.- Vule. Laltiu. - Prin pădurile din reviunea momlană și subalpină. - În Moldova supuerióră (Cz. I'lora XIX. 64 if Exsir.!; h. i. (incbh. manusc.; $C z$. et $S z$. l. c. 20); pe lîngă Jași la Niṭelea (D. Br. l. c. 86); la Verșĕscı̆ și Mănăsiirea-Cașinulŭ; la un-stirea Sĕcu (Gr. En. 16 et Ersic.!) ; pe valea Bîsceŭ: la m-stirea Cheia (Hoff. Ercurs. 1863, l. c. 118) și la Sinaia; la Predél; la Conțĕscĭ (Gr. Exsic.!); etc. - †? Maiŭ-Iun.

1. platanoides L. A. platanoid. - Vulg. Arțar. - Prin pădurile din regiunea montană. - In Moldova (Cz. Flora

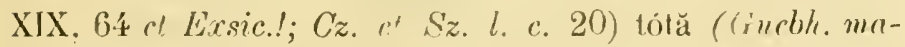
nusc.): la m-stirea Poéna sị la Țubana (Sz. manusc.); călre Aqaunia și m-stirea Némţuluĭ (Érbor. l. c. 133 et Exsic.l: En. 17); în Prahova la Şotrile; în Vîlcea la Călimănesč în pădırea Onufrie (Gr. Exssic.!); ete. - †? 1 pr.-Naiŭ.

3. laciniatum Ait. - În tólă Moldova (Gusbh. manuse.).

1. cimpestre i. 1. eampestru. - Vulg. Crimyastru. -

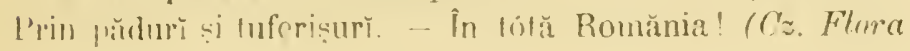


XIX, 64 st Exsic.!; Ciucbh. manusc.; Cz. st Siz. l. 1. 20; S'z. mamusc.; D. Br. Frogm. l. c. 86 ; (iv. Libur. l. c. 133; E. 16 et Exsic.!). - † .1 priliu-Maiu.

B. austriacum Tratt.-M-stirea Adam (Guebh. manuse.).

A. tataricam L. A. tarlaric.-Vulg. Gladis, Verigariu. - Pe marginea pădırilor, prin tufĕriṣurŏ, prin sĕciurile viilor. - In Moldova (A. cordifolium Bmy. Cz. Flora XIX, (j4 st E.rsic..; Cz. rt s'z.l. c. 20 ; S'z. mamuse.); pe lîngă laṣ̆ la Nịclea; re lingă (ridiaṭ̆ çi la m-stirea Adam (Cimb)h. Vot. 16 ; mamese el Eisic. n. 315 sec. Nym. Consp. 135); in Illov (Gir. Én. 17 ot Exsic.!) la 'Tigănesè̆, Perişs și Merinani (I). IBr. Fraym. l. c. 86); la Comana; elc. - †? Maiu.

\section{STAPHYLEA I. - Stafile.}

S. pinsala L. S. penată. -- Vulg. Clocotiss. - Pe marsinea pădurilor, prin crîngurĭ, min sĕciurile viilor. -- In Moldova (Cz. Flora XIX, 63 et Exsic.'; Edel l. c. 41; Cz.

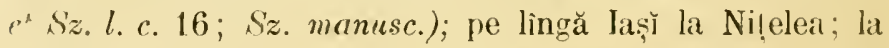
Verşěseř ; lat m-stirea Adam (Gurbh. manusc.); în Ilfov (Gr. fin. 18 ct lixsic.!) pe lingă Bucurescĭ lat Buftea (D. Br.

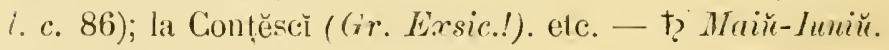

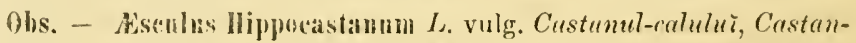
unrcesce, Castun-sèlbatece, indicat în Moldova superiónă (Guelh/, man.), tum cresse de-cât cultivat! (Cz. et Sz. l. c. 20; Sz.muruse.; Gr. En. 17).

\section{ULMACEE.}

\section{LLMIUS i. - $U / m$.}

V. campestris $L$. U. campes/ru. - Vulg. Clm. - Prin

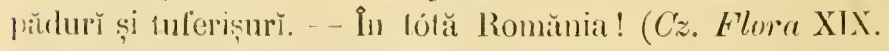
fi2 el Exsic.l; h. j. Ciurbh. mamusr.; Cz. it s'z.l. c: 12; 1). Br. Frogm. l. c. 103; (ir. En. 52 et Exisic.!; L. mula 
Ekhrh. Cz. et Sz. l. c. 12 et E.tsic.!; h.j. Guebh. manusc.; Sz. manusc,; Gr. Erbor. l. c. 122). - †? Martiü-1 priliu.

3. suberosa Koch. - I'rin pădurile și luferișurile din regiunea montană. - In Moldova fînă în regiunile inferióre

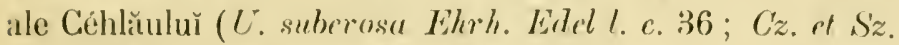
l. c. 12); pe lingă Iaș̆ la Repedea (Śz. mamusc.) și Nițelea ; la Mănăstirea-Cașinuluy̆ și la Coman; etc.

I. eflusa Willd.; $L$. pedunculata Foug. $U$. pedunculat. - Vulg. Velnis. - Prin pădurile montane. - In Moldova (Cz. Flora XIX, 62 et Exsic.!; h.j. Cinshh.mamuse.; Cz. ot

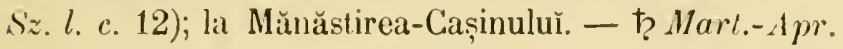

\section{CELTIS L. - Celtide.}

C. australis L. C. austral. - Sĕlbatec prin tufěrișurile diu locurile stincóse și petróse de la Vîrciorova către Portile-de-fer! (Borb. sec. Kanitz l. c. 112) pe lîngă calea ferală. - In cele-l'alte părțĭ ale Romănieĭ numař cultival prin grădinı̆! (Gr. En. 52). 一 † Apriliŭ-Maiŭ.

\section{FICUS L. - Smochin.}

F. carica L. S. comun. - Vulg. Smochin. - Sĕlbatec pe stîncile de la Virciorova către Porțile-de-fer (Janku zool.-bot. Ver. VII [1857], 123). - În cele-l'alte păr!̣̆ ale Romăniě̀ numaì cultivat! (Gr. En. 52). - † Iul.-Aug.

Obs. - Mor'us alhai L. și -- M. nigra $L$. vulg. Agud, Dud, lugod, Jirrgariŭ, Murř. se cultivă (Edel l. c. 41; Guebh. manusc.; Cz. et Sz. l. c. 6; Sz. Manusc.; D. Br. l. c. 103; Gr. Erbor. l. c. 121 et En. 51).

\section{HIMULUS I. - Hemeir.}

II. lıpulus L. H. comun. -.. Vulg. IImmeiŭ, Hamciü.-

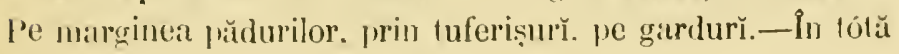


Ronănia! (Cz. F'lora XIX. 62, et Essice! ; Edel l. r. 39) ; Guebli. manuse.; (Zz. o' S'z. l. (. 12; s'z. manuse.; I). Bi.l.

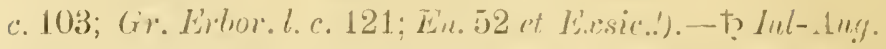

Uis.-('inuhis sutiva L. vulg. C'inepŭ, cultivatĭ și subspontanee in tótă Romănia! (C'z. Florn XIX, 62 et Firsic.!; Fidcl 1. c. 39; Guelih. manusc.; Cz. et Sz. l. c. 12; Sz. manusc.; Gr. Erbor. l. c. 121 et lin. 52).

\section{XUII. GASTANEATEL.}

\section{PAGI'S L. - Iray.}

F. sylvation L. F'. Ae püdure - I'rin pădurile din regiunea montută. - In tólă Romănia! (Cz. F'tora XIX. 67

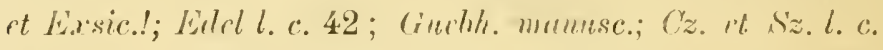
35); Holf. Ereurs. 1863, l. c. 118 ; sz. mamuse: D. By.

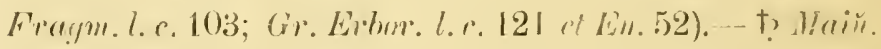

\section{CASTANHA lipertil. - Crastrm.}

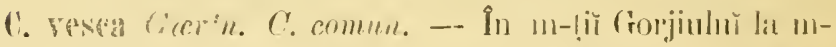

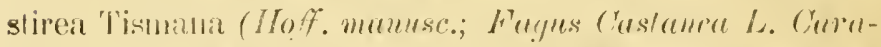

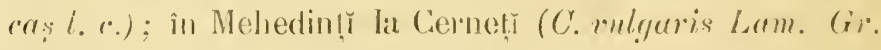

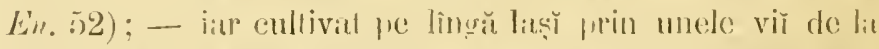

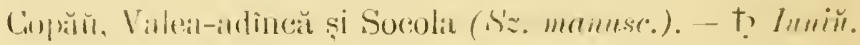

\section{GITRCUS L. - Stejur.}

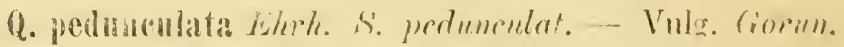

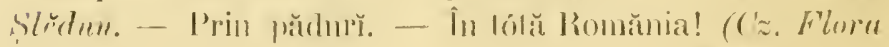

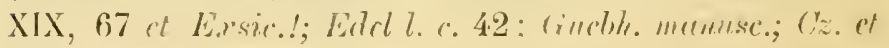

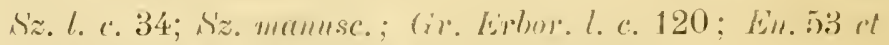

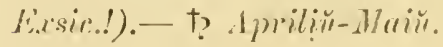

Q. sessiliflora simith. S'. sessilifur. - Prin sŭduri.

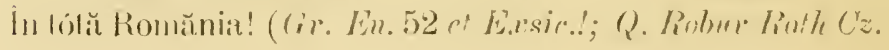




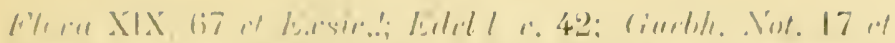

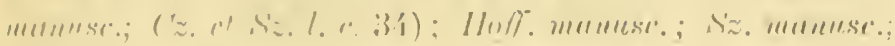

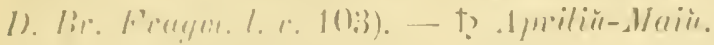

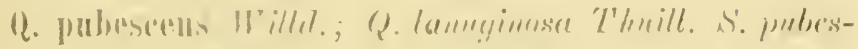

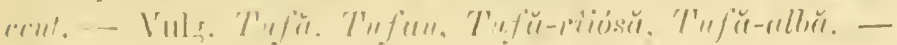

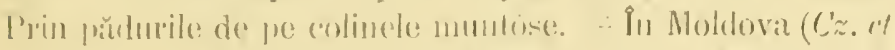

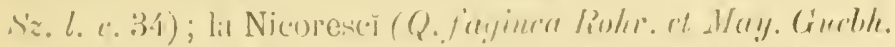

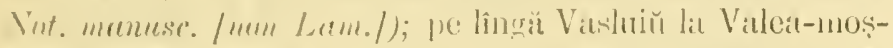

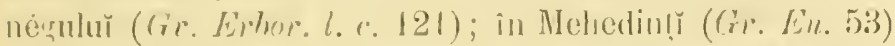

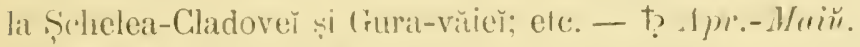

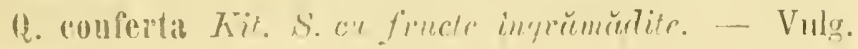

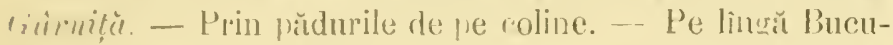

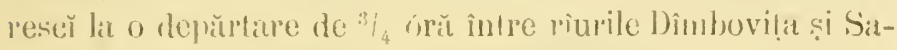

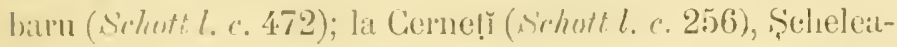

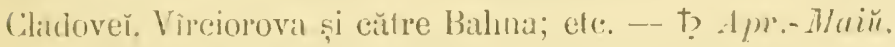

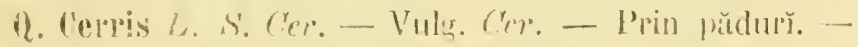

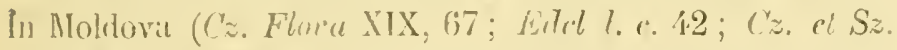

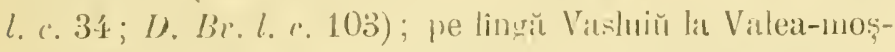

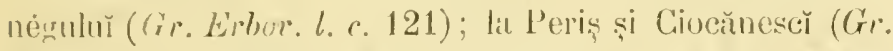
En. 53); la Comana; la Rîmnicul-Vîlcě̀.-- t? .1pr.-Maiŭ.

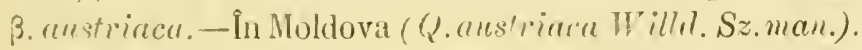

\section{Colithis l. - Alun.}

1!. Colurna L. 1. C'ulurnŭ. - Prin jădurile de pe colinele numlóse. In Romănial (. Tym. Consp. 6933): cătne Vat-

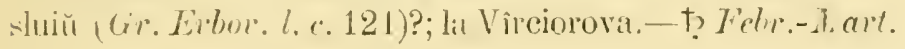

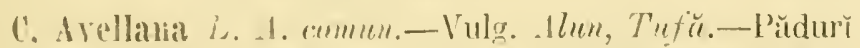

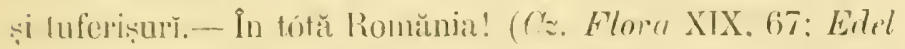

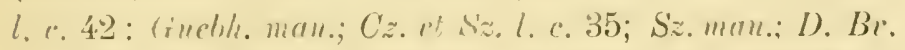

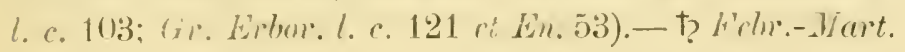

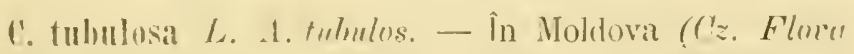

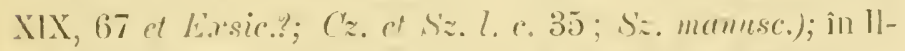

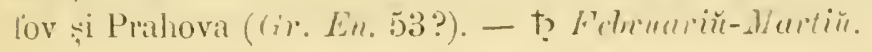




\section{CARPINUS L. - Carpinn.}

C. Betulıs L. C. comun. - Vulg. Carpîn. - P'rin pădurile cu deosebire din regiunea montană. - In tólă RoInănia! (Edel l. c. 42; Guebh. manusc.; Cz. et S'z. l. c. 35; Sz. mannsc.; D. Br. Fragm.l. c. 103; Gr. Erbor. l. c. 121 et En. 53 ; Borb. 1873, Báus. 256). - †े A priliŭ-Maiй.

C. Ininensis Scop. C. de Duin. - Vulg. Cărpiniță. Prin pădurile și tuferișurile montane de la Vîrciorova! mă frequent de cât specia precedentă (Borb. 1873, Báns. 256; Kanitz! l. c. 113). - † Apriliǔ.

\section{BETULA L. - Betulŭ.}

B. verrucosa Ehrhr.; B. alba L. (p. p.) Koch. B. verucósă. - Vulg. Mestécăn. - Prin locurile silicióse din pădurile montane și subalpine. - In tótă Romănia! (B. alba Cz. Fllora XIX, 61 et Exsic.!; Edel l. c. 41; Guebh. manusc.; Cz. ct Sz. l. c. 6; Sz. manusc.; D. Br. Fragm.l. e. 103; Gr. Erbor. l. c. 121; En. 53; B. pendula Roth Edel l.c. 36, 41; Gucbh. manusc.; Cz. ct Sz. l. c. 6).- †? Apr.-Maiu.

B. pubescens Ehrh.; B. odorata Bechst. B. pubescentä. - Vulg. Mestécŭn. - Prin locurile umede și turfóse din

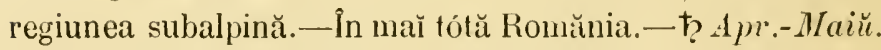

\section{ALNUS L. - Arin.}

A. incana Willd. A. albicios. - Vulg. Arin, Anim, Arin-alb. - Prin luncile și pe malurile torentelor din regiunea montană și subalpină. - In Moldova (Edel l.c. 41) centralĭ și superióră (Guebh. Not. 17 et manusc.); la Mănăstirea-Cașinulŭ, Slănic și Verșěscǐ ; in m-tiî Némịtulun̆ ; la Sinaia și Predél; în m-țiu Muscelului ( 1 . pubescens $D$. 


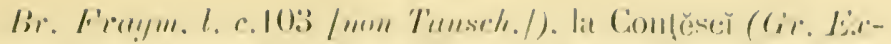

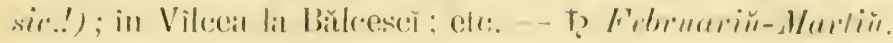

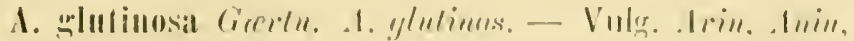

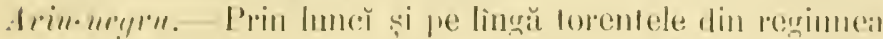

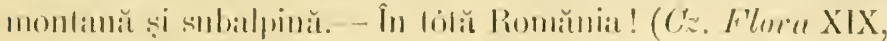

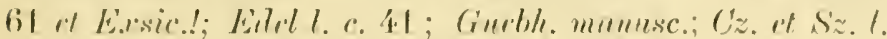

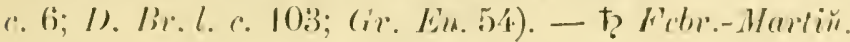

1. viridis I) A. verte. - Vulg. Liliac-rle-mum!r. l'rin păsumile pelróse și mnede din regimea alpină. - I's

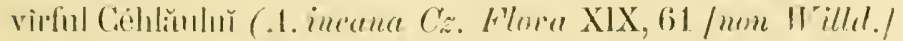

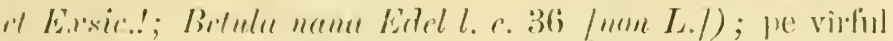

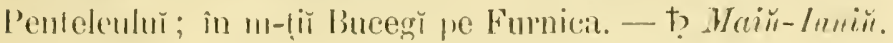

\section{WYTHRACEE.}

\section{LYTHRUM L. - Litru.}

1. Salicaria Lin. L. Salicarie. - Vulg. Rüchitun. -

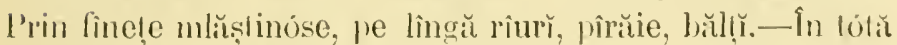
Romănia! (Cz. Flor XIX, 65 et Ex.rsic.!; Edel l. c. 38; Gurbl. mammse.; Cz. et Sz. l. c. 23; Sz. manusc.; D. Br.l.c.

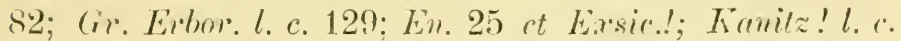

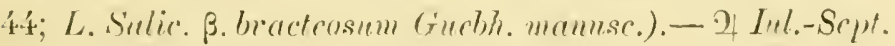

B. camescens Koch. - I La Pitesci și la Crolotrenĭ.

L. virgatum Lin. L. viregus. - Prin finctele mmede.In Moldova (Cz. Flora XIX, 65 et Exsic.! ; Eitel l. c. 39 : Cz. et šz. l. c. 23; L. IIyssopifulia Cz. Flene XIX. 65 /non

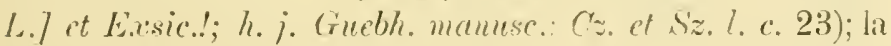
laṣ̂ (L. Mysssop. Crucbh. Vut. 23) pe malul Bahluiulŭ (Sz.

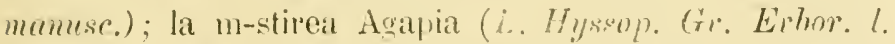
c. 129 ?); pe lingă Bêrlad (D. Br. l. c. 83); la Fŭı ưĕ (Guchh.

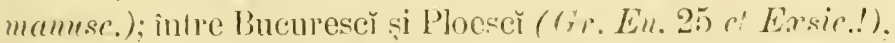
la Buftea, Crivina. Ciocĭnescĭ. (Hherganĩ: în Vlaṣca la Purund (L. Hyssop. D. Br. l. c. 83 [non L.7). - 2] Julin-dugust. 
L. Hyssopifolia Lin. L. ce for de is(m). - Prin locurile nĕsiprose și inundate din luncile de pe malurile rôurilor. -

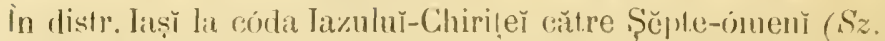

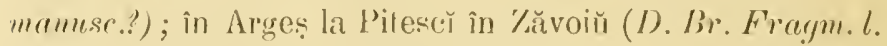
c. 83); în Vîlcea la pădurea Aninisắ; etc. - 2 lul.-Sept.

\section{ONAGRARIACEE.}

\section{EPILOBIUM L. - Epilobiǔ.}

E. alugustifolium L. (non Lam.). E. cu for inguste. Vulg. Sburătóre, Rüuscóge, Iarba-St.-Tón. - P'rin pădurile mă cu sémă tăete din reginnea montană și subaljpină. In Moldova snperióră (L. spricatum Lam. Ciucbhemannsc.);

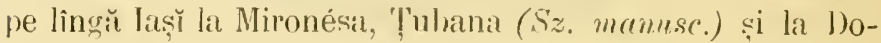
brovĕt ; la pólele Ciéhlăuluĭ isilel l. r. 36; Cz. Flor X' XX. 63 et Exsic.!), m-stirea Agapia (Gr. En. 24), Agapia-veche și la schitul Sihlat; la Palancaı, Slănic şi Càmpenř; la Ag̣ud (Burvi Exsic.!); la m-stirea Cheia (Hoff. Excmes. 1863, $l$. c. 118 et Exsie!) si la Sinaia pe Cumpăl ((ir). Excurs. l.

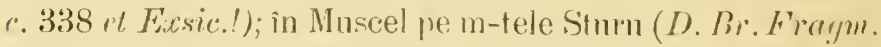

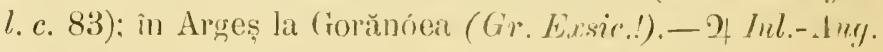

E. rosmarinifolia Haenke; E. Dudence rill. E. cu fur de rosmarin. - Pe malurile rîurilor. - Lat Făureı̆ pe matcal Pulně̀ ((tuelsh. Not. munnse.); la Agind (Burri Exssie.l); la Rîmnicul-Vîlceř pe malurile Oltuluĭ : etc. - O+ Jul.-Aü.

E. lissutum L. E. irsut, - Prin locurile mlăștinóse din

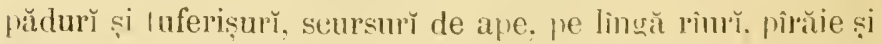
girle. - In Moldova (E. arandiflorum. 1ll. Cz. Flora XIX, 64 ot E.esic.!; Edel l. e. 39; E. tetragomem Cz. Flora XIX. (if /mon L./ et E.rsic.!; le.j. Guebh. mamnse.; E. parviflerum. h. j. (Ynebh. munusc. Fnon Schreb.7) tótă (Guebh. manusc.); pe lìngă Brateș (E. yramtift. Edel l. c. 38); pe lingă Iași la Hlincea, Nicolina ( $E$. gromdif. Sz. mamusc.); și la 


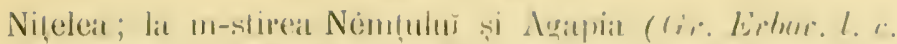

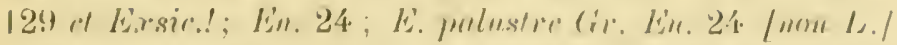

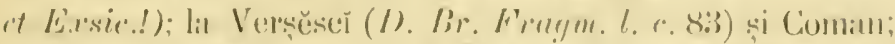

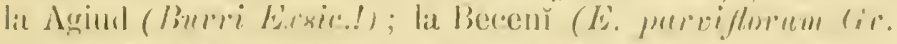

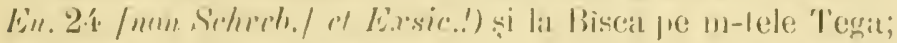

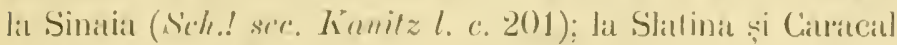

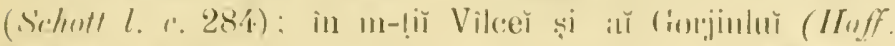

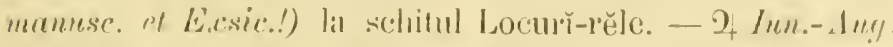

W. purillarum (Schreh.) Rónz. Li. parvifter. - Prin

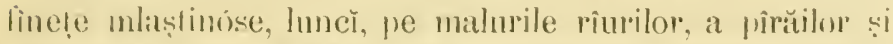
¿ helesteelor. - In Moldova (Sz. manusc.); la Cînnoulıng

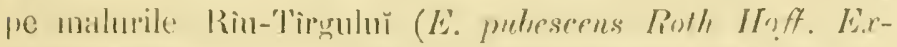

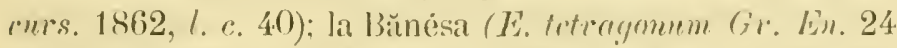
f "ron L./ ot Exsic.!). Mososóia și Cihitilar; pe lingă Cimaiuva

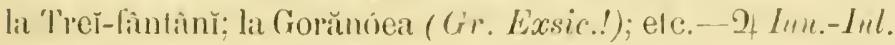

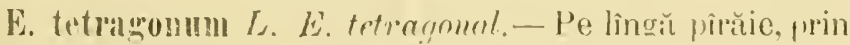

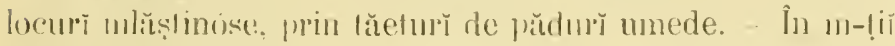

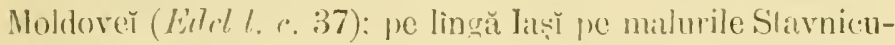

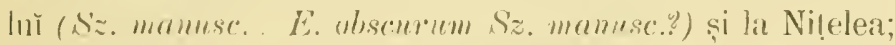

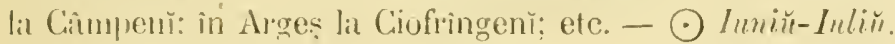

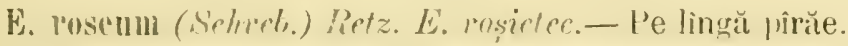

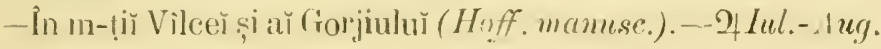

E. montanmm L. L. montan. - Prin locurile umede si mmbrise din pădurile montane şi subilpine. - In Moldovi (C'z. F'luru XIX, 64 et Eirsic.!) centrală și superióră (';urhh.

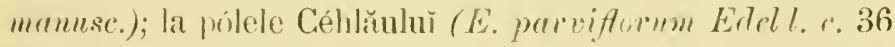

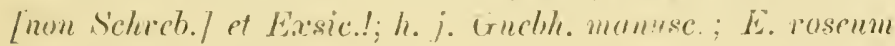

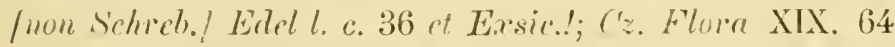
ot Eisie.!; h. j. (rnebh. mannsc.), la Agapia (E. alpinnm (ir. En. 24 /mun L./ pt Exsic.!), m-stirear Ném!̣ulıŭ și Si-

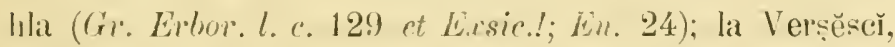

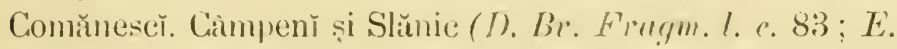
rosenm 1). Br. ibid. /mm Schrel./); la Sinaia! ((Gr. En. 24 
et Exsic.!; E. parviftorum (or. Eirrurs. I. c. 339 /umu

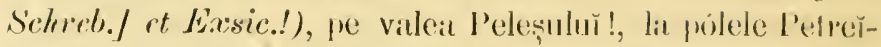

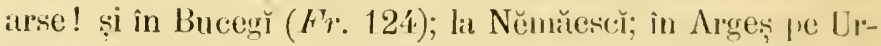

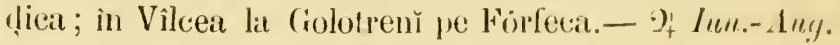

\section{(ENOTIIERA I. - Einoterč.}

0. biennis L. E. bicnalŭ. - Vulg. Lnminițŭ, Liminițanoptẹe. - Prin locuř něsipóse și umede. pe malurile rînrilor, prin șanţurile de lîngă drumưr. - In tólă Moldova (Guebh. manusc.) pănă în munṭ̆ (Ėdel l. c. 37 ct Exssic.!); pe malul Prutulur la Unghenǐ către Gucóra (S'z. manusc.); pe lînğ Teeuciŭ și Bêrlad la Dimitrescr̆ ; la Verșěsề și Slĭnic; la Agiud (Burri Exsic.!); pe malurile Ialomițen̆ la Ferbinți (Gr. En. 24) și Bojdana; pe malurile Prahoveĭ la Rădulescĭ (D. Br. l. c. 83) și la Sinaia (O. muricata Gr. Én. 24 [non L.] et Exsic.!); la Comana; în Vîleea la Bălcesccĭ; la m-stirea Cozia şi Golotrenı̌; în Gorjiŭ la Roșia.-2) Lun.-Au:y.

\section{CIRCAA L. --- Circee.}

C. Intetiana L. C. parisianŭ. - Vulg. Telișcă, Tiliscŭ. Vrăgitóre, Vrotilică. - Prin pădurile umede și umbróse din regiunea montană. - În m-țin Moldoveǐ (Edel l. c. 37; Cz. Flora XIX, 60 et Exsic..); la Agapia (Gr. E». 24. et Exsic.!), Agapia-veche și la Căluğarenı̆ pe m-tele PetruVodă ; la Mănŭstirea-Cașinuluı̆ și la Slănic (D. Br. Fragm. l. c. 83); la Bîsea pe m-tele T'ega; la Pitesč în Zŭroin̆ și pe m-lele Cozia și Urd̦ica; la Rîmnicu-Vîlceř în 'Zŭvoin̆ ; in m-țiù m-stirilor Cozia, Bistrį̣a și Tismana (Hoff. manusre. et Exsic.!); etc. - 2 Luniü-Alugust.

0. intermedia Ehrh. C. intermediară. - Prin lădurile umede şi umbróse din regiunea subalpină. - În m-ḷị bacăuluŭ la Slŭnic (Guebh. manuse.). la schitul Sihla : în Vilcea în valea Bistrițer̆ (Grr. Exsic.!); etc.- $y$ lul.- dury. 
C. alpion L. C\% alpină. - Prin phudurile muede si umhrise din regimea subalpină. - Pe Céhlăı ( Lidrl l. c. 35); C. Flura XIX, 60 et E.esic.!) și lia Sihlia (Gr. Evbrr.l. c.

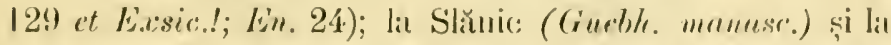

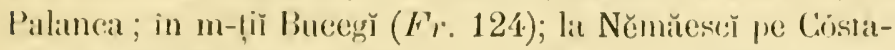
mănăstirè̃ (D. Br. Frraym.l.c. 83); etc. - 9) Inliü-Augues/.

\section{TRAPA I. - Trapă.}

T. Inatans L. T. imotütóre. - Vulg. Ciuline. Castanedr-luc. - Ape slagnante și lin curgẹtore. - In Moldova centr. și super. (Guebh. manusc.), cu deosebire în partea nordică ('T. vulgaris Cz. et Sz. l. c. 5 et Exsic.!); in Romanaț și Teleorman pe lîngă Dunărea $(G r$. En. 24).—○ lın.-lul.

\section{MYRIOPHYLLUM L. - Miriofil.}

II. verticillatum L. M. verticilat. - Vulg. Mfolurubülțř, L'risnel, P’nițĭ. - Prin ape stagnante și lin curgĕlore. - In Moldova (Sz. manusc. rt Exsie.!; h. j. Guebl. manusc.; Ceratophyllum submersum Cz. Flora XIX, 66 ?); la III-stirea Némțulŭ (Chania Exssic.!); în distr. Bacăŭ lit Brătila ; în Colentina (Gr. En. 24?); etc.- 2 Iuliü-August.

M. spicatum L. M. spicat. - Prin ape stagnante și lin curgĕtöre. - In Noldova (Sz. manusc. ct Exsic.! / nom. Potamogeton peetinatus]; h.j. Guebh. mamuse.); la Ciocănescì și la Sinaia (Gr. En. 24 ct Exsic.!); la Comana în Cailniscea (D. Br. Fragm. l. c 83); etc. - 2 lul.-Aug.

\section{HIPPURIS I. - Ipuride.}

H. Vulgaris $L$. 1. comun.-- Prin ape stagnante și lin curgĕtóre. - În Moldova superióră (Sz. Ersie.!; h. j. Guebh. mamusc.); în distr. laș̆ la Cristescè (Sz. mamusc.); în Colentina (Gr. En. 25 et Exsic.!) la Ferěstrěŭ.—2 Iul.-Auy. 
MIY. LIBEHIFERE.

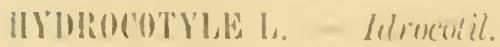

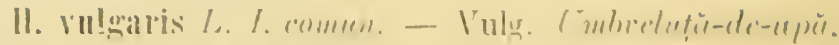

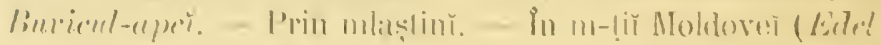

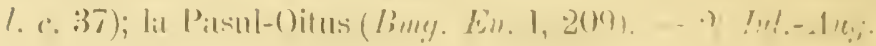

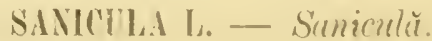

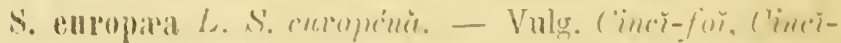

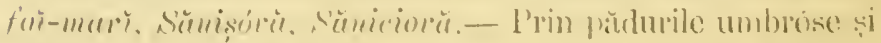

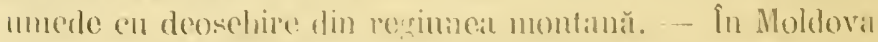

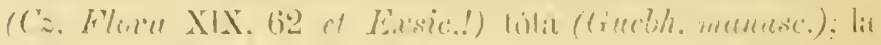

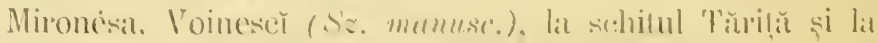

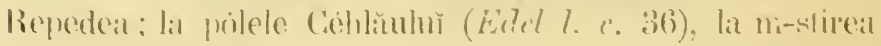

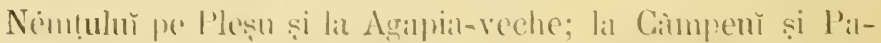

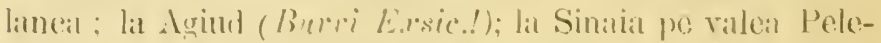

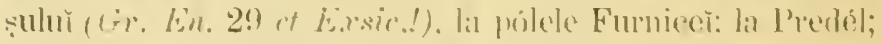

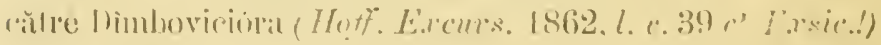

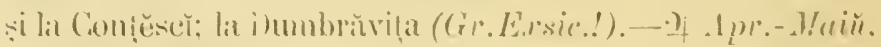

\section{ASTRANTII I. - Astrantie.}

A. major L. A. mare - Prin tìne! ele și păcunile monede

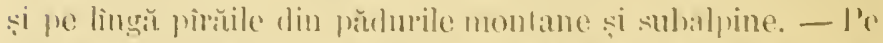

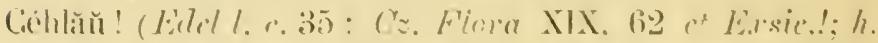

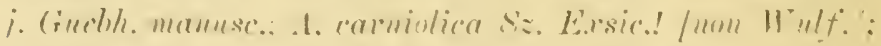

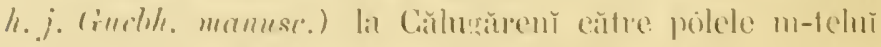

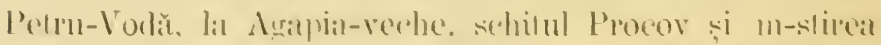

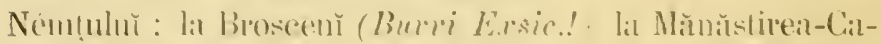

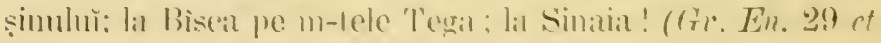

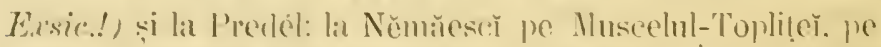

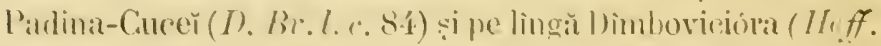

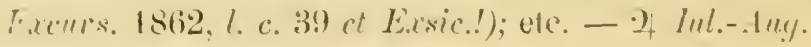




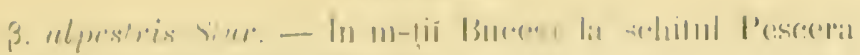

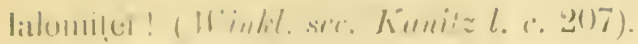

\section{ERTVEIUM L. - Eringin.}

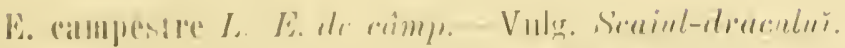

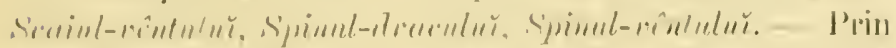

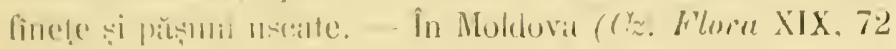

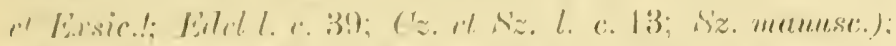

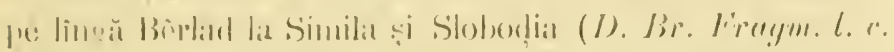

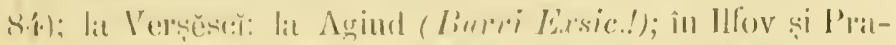

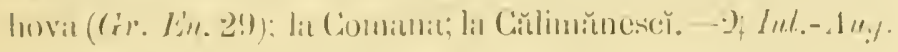

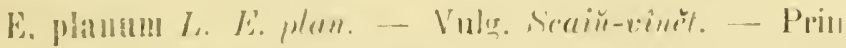

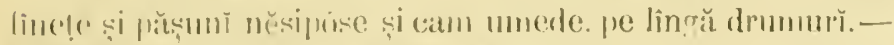

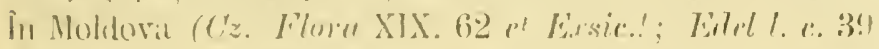

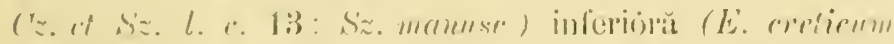

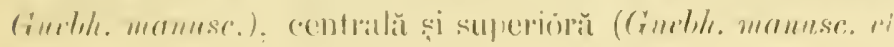

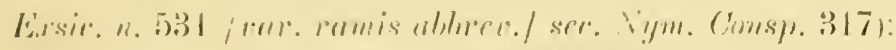

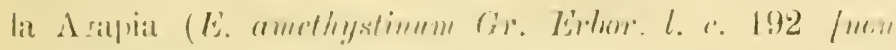

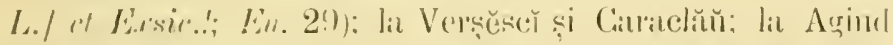

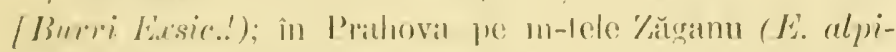

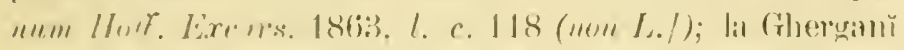

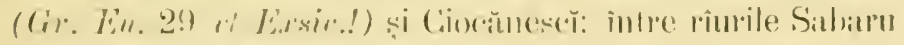

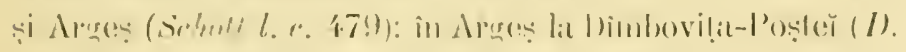

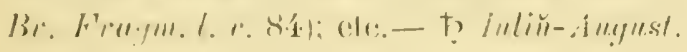

\section{I'I'!T: Һ. - r'irutč.}

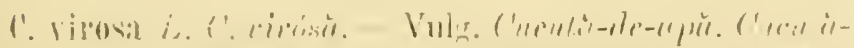

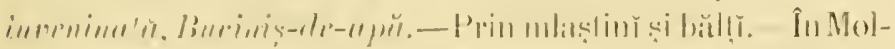

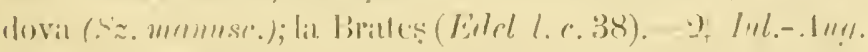

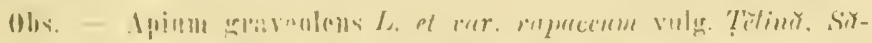

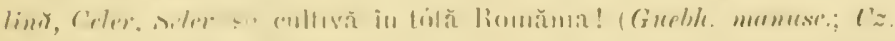

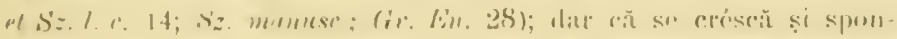

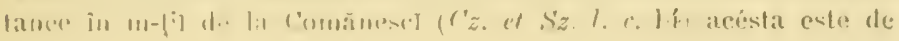


sigur o eróce. - Petroselinuı salivum IIofm. vulg. P'etrinjei, Pètrunjęl, se cultivă in tótă Romănia! (Guebh. manusc.; Apium petroselinum L. Cz. et Sz. l. c. 14; Sz. manusc; Gr. En. 28).

\section{TRINIA Hofim. - Trinie.}

'T. vulgaris $D C$. T. commenă, - Pe coline slerile. - În Moldova (S'elimum Seguieri Cz. Flora XIX, 62 /nou Bmy.7 ot Exsic.!; Cz. et Sz. l. e. 13; Hyppomaratrum pelvifurme Cz. Flora XIX, 62 /non Bmg.] et Exsic.!).- - A pr.-Mlain.

ß. Hemingii Koch. - Pe colinele Moldoveř inferióre ( $T$. Henningii Hoffm. Guebh. manusc.).

T. Kitaibellii M. Bicb. T. lǔ Kitaibel. - Prin finețele sterile, prin păşunile și luferişurile de pe colinele calcare. La Agiud (Burri Exsic.!); la Comana; la Vlascuṭa și Stolnicì (I). Br. Fragm.l.c. 85); pe lîngă Slatina; la Vîrciorova către Porțile-de-fer pe m-tele St.-Petru. - $\sigma^{7}$ Maiŭ-Jun.

\section{FALCARIA Ilost. - Falcarie.}

F. Rivini Host. F. lu气 Rivin. - Vulg. Dornic. - Prin sěměnăturĭ și pîrlóge, pe marginea agrilor. - In tótă Moldova (Guebh. manusc. et Exsic. n. 538 sec. Nym. Consp. 304) pănă în mun!̣̆ (Sium Falcaria L. Edel l. c. 36 ; Sz. mamusc.); la Hărpăşěscǐ și Scobâlțěnı̆ ; la Bêrlad ; la Agiud (Burri Exsic.!); în Rîmnicu-sărat la Caiata; in Ilfov (Gr. En. 28 et Exsic.!) la Buftea, Chitila și Ciocănesč̆ (D. Br. l. c. 85); la Comana și Prund; la Craiova. - o Iul.- Auy.

\section{EG0P0IIUM L. - Eyopodiŭ.}

A. Podagraria L. E. Podugrarie. - Vulg. Picimul-

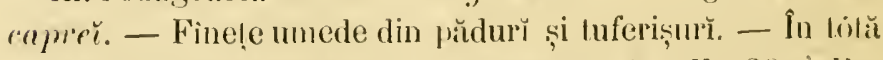

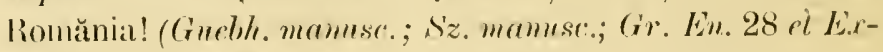
sic.!). - I Maiir-Iulin. 


\section{C.llill L. - Chimion.}

1'. C'ami L. C. commen. - Vulg. Climimu-dr-caimp, Chi-

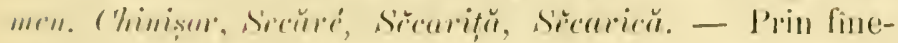
lele și păstunile moulane, subalpine și alpine. - In m-ṭi Moldover (Edel l. a. 37; Cz. Flona XIX, 63 it Lixsic..! Cz.

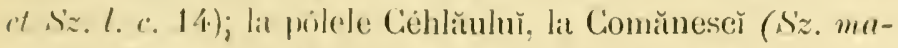

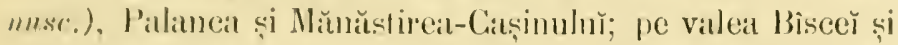
pe. I'entelen̆ la Sěpte-isvóre; în m-lii Bucegì pe Furnicar;

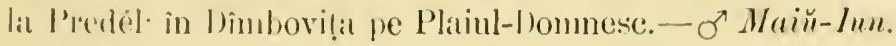

C. Bulhocistamum Koch. C. Bulbocastan. - Vulg. Alu-

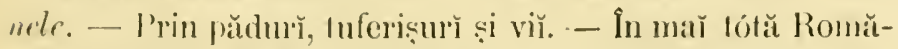
ulia ! (Bunium. Bulbocastanum L. Cz. et Sz.l. c. 14; D. Br. Frn!m. I. '. 85; Gi. En. 28). - 2 Juniй-Iuliй.

\section{PIMPINELLA L. - I'impinclă.}

P. Maglla $L . P$. mare.-Prin finetele umede din regiuncia montană și subalpinăt.-În Moldova $(C z$. ct $S z$.l. c. 14)

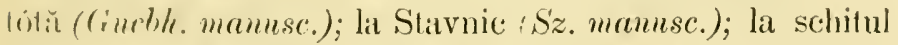
P'reov! (Chania Exsic.!; Gr. En. 28) și la m-stirea Ném!uluř; la Cimmpenĭ; la l’redél. - 2 Maiǔ- Aug.

\%. Lnciniata Koch. - In Moldova (1\% orientalis Gon. (z. et Siz. l. 1. 14).

j. rissscta (Retz.) Kuch.-În Moldova (Cz.et Sz.l.c. 14).

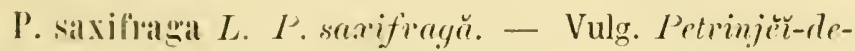
rrimp. - Prin fînețe și phṣunì sterile, pe coline aride, prin locurr̆ pulrose și calcare din munțĭ. pănă în regiunea alpină. - În lotă Romănia! (Cz. Flora XIX. 62 et Exsic.!; Cz. st Sz. I. c. 14; Sz. manusc.; (ar. En. 28 st Exsic.!; D).

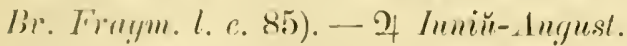

B. dissectifolid Koch. - In Moldova (I'. hiveina Lerers.: ('z. . S : . l. . . 14). 


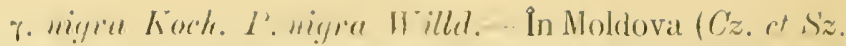
l. c. 64) la Slolodiat-Voinescilor (Sz. memusr.); in Nuscel la pólele m-teluŭ Lereseì (Hôff. Exx'ue's. 1862, l. c. 38).

SIIUI L. -- Sĭ̌̆.

S. latifolium L. S. r:n for late. - Vulg. Cositgrel, Borlernicŭ. - Prin mlaştinı̆, ałe stagnante și lin curgĕtỏre. - În mă în lólă Romănia! (Eidel l. c. 37). - D Inlin-Auyust.

S. lancilolium L. S. cu for lanciforme. - Locurr̆ mlăștinose. - În Noldova inferiöră (Crnelh. manusc.); pe lingă

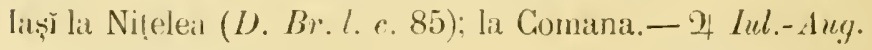

S. angustifolimm L.; Bernle angustifolia Kóch. - H'rin

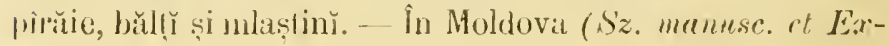
sic.!) in lunca Dolnovẹtuluĭ; în Vlaşca (G'r. En. 28 rt Lir:sic.!) la Comana; la Iorgulova (G'r. Exsic.!). - $2+$ Inl-Sept.

\section{BUPLEURUM L. - Bupleuru.}

B. rotundifolium L. B. cu for sotunde. - Vulg. Ù?'-

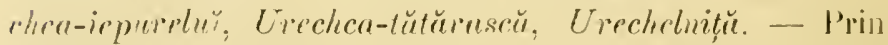
Iıferișur̆, semĕnăturĭ, mirisĕ, pe marginea agrilor. tolă Moldova (Gruebh. mamusc. et E.xsic. n. 538: sec. Nym. Comsp. 311); pe lingră Iaș̆ la Balcin (S'z. manusc.); la VerŞěscì; la Agiud (Burri Exsic..'); la Comana.-○ Inn.-Iul.

B. juнceum L. B. juncos. - Locurr̆ petróse și umbróse.

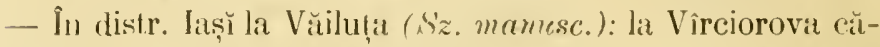
tre Portile-de-fer! (Borb.Flor. kiozl. IX, 272).-O lum.-A uy.

B. lalcatum L. B. falcat. - P'rin locurile aride și peIróse do ve coline și din regiunea monlană. -.. In Moldova

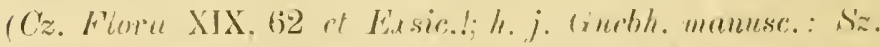

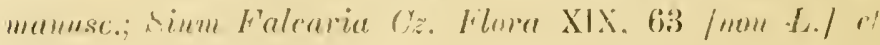

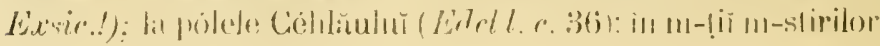




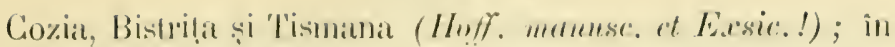

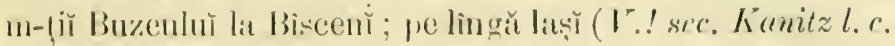
51). - 9 Iulin-Uctomber'

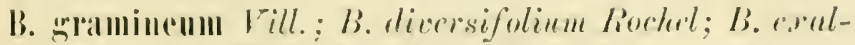
tutum Korch /non 1T. Biel.7; B. buldense Bury. /um ITos1./. B. gremincŭ. - P'rin păşunile stincóse şi caleare din regiuneal subilpină și alpină. - Pe vîrful Céhlüuluĭ către T'óč̆; pe Buceğ ; în Crorjiŭ între Cihenia și Loeurǐrele. - 9 luliit-_lugust.

Obs. - Se maY citéză : H. ي̣raminifolium Wahl. în Muscel pe lîngă Dînbovicióra (Hoff. Excurs. 1862, l. c. 39). - R. exilltattum M. Bicb. în pădurile de la Pechea și PuțĕnY (Guebh. manusc.).

\section{ENANTHE L. - Enante.}

A. media Grisch. E. intermedier. - Prin poeni și finete unede. - In Moldova (GE. perecedanifolia Cz. et Sz.l.C. If [uon Poull.]) în distr. Iași la Hŭruășĕser ; in Ilfov la Cio("inescè! (Gr. En. 29 ct L̇xsic.!) și Merinani; în Vlaṣca la

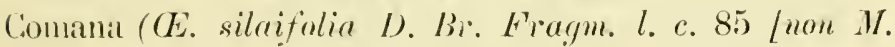

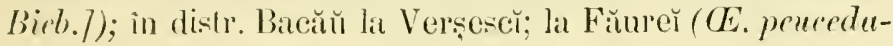
nifolia Guebh. munusc. (uon Proll.J); în Muscel călre m-tele Leresč pe valea Rìn-T'ìrguln (CE. fistulosa Hoff. Excurs. 1862, 1. c. 31 / non L.] ct E.rsic.! [nom. W. silaifol.]); în Mehedinți la Dumbrăvị̣a ((ir. Exssie.!) și pe leriloriul nentral apróple de Orșovia (Winkl. Oest. bot. Zeit. [1866」16).-

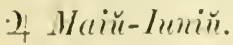

(E. Plellandrium Lam. E. Felandriŭ. - Vug. Mararaš̆. Murariü-bielților. Chimimn-de-upŭ. - Prin mlaștin̆. pîrăie, bălḷĭ, laemrǒ. - În Moldova (Phellandrium aquaticum L. ( ${ }^{2}$. Flora XIX, 62 of Exesie.!; Sz. menuse.) pe lingă Brates (Edel l. r. 38); pe lingă Bucnresci (Ph. uquut. (ir. Én. 28 se Errsic.!) la Bănésat și Ferĕstrěn̆ pe malul Colen-

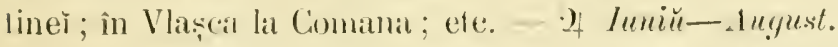

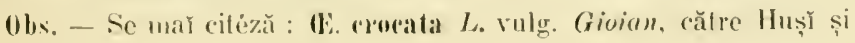




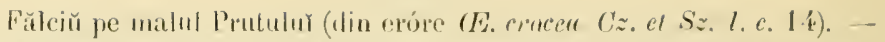

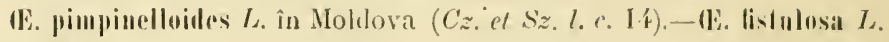
în Moldova $(C z$. et $S z$. $l$ c. 1 té).

\section{ETHLSA L. - Etusŭ.}

A. Cynapium L. E. Cinctpiü. - Vulg. Petrinjele-crüne-

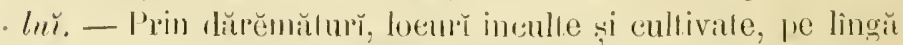
gardur. - - In Molilova (Cz. Fyeru XIX. 62 et lissic. !; Sz.

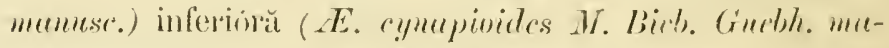
muse.); în llfov ((iv. En. 28 et Exsic.!); în Vîleea la m-stirea

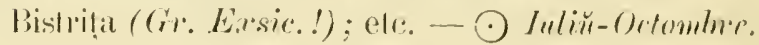

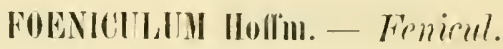

F. officoinale All. F'. oficimul. - Vulg. Molurie. Secrerea-

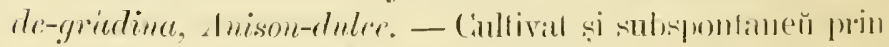

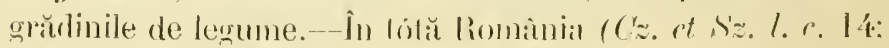

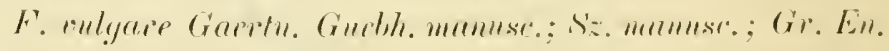

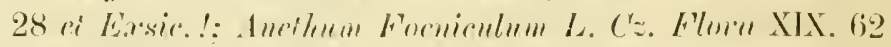
et Exasir.!). - o Inliü- lugurst.

\section{SESEA I I. .- Seselinĭ.}

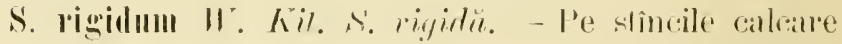

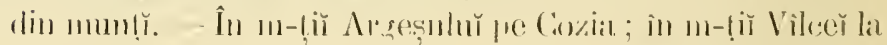

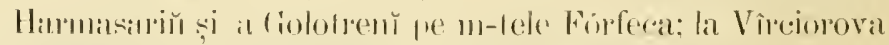
Eălre Porlile-de-lor (liml, fol. Käzl. IX, 280). - 2) Ju"iй- Ingusisi.

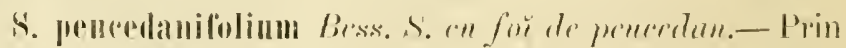

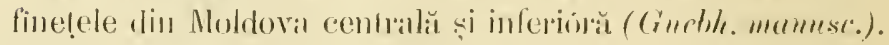

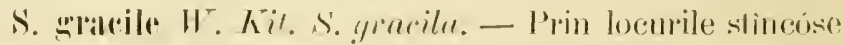

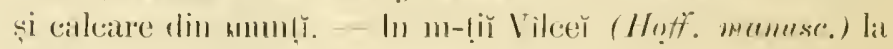
Golobrent. - 2) Inliü- Lingust. 


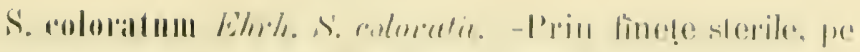

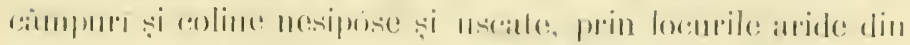

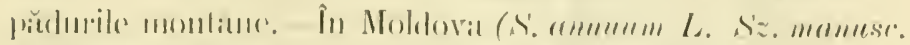

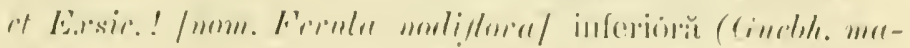

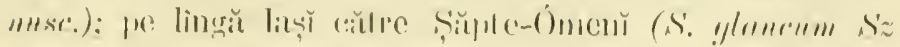

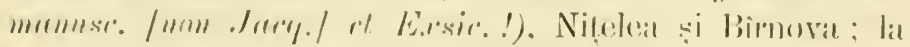

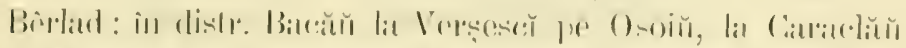

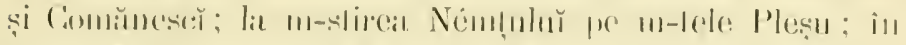

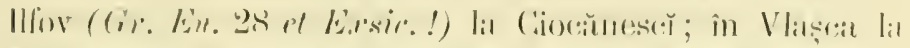

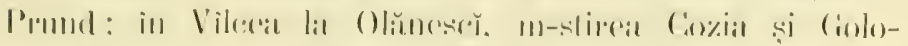

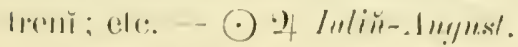

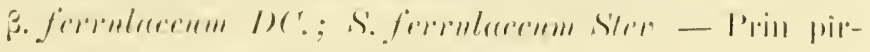

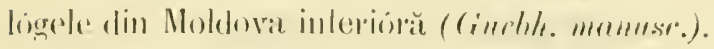

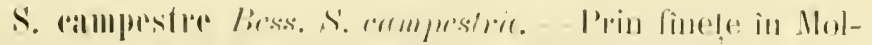

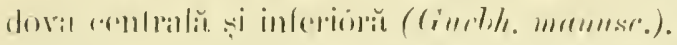

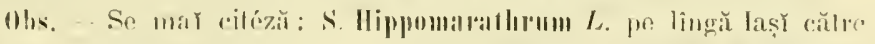
Hollsoca pe costele IazuluT-Chiriţer (Ilimmonathenm petriforme l. Ir. s'z. mumuse.).

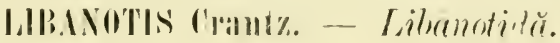

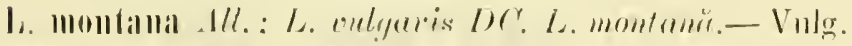

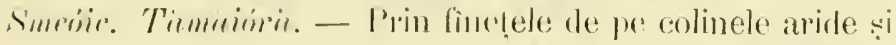

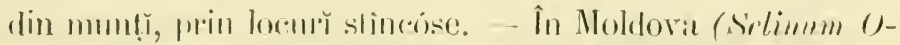

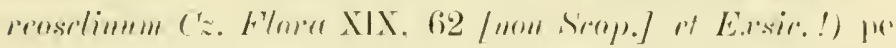

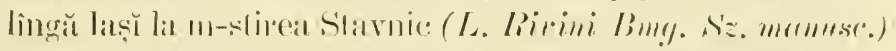

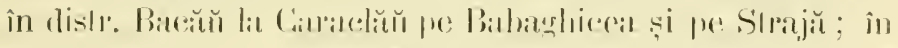

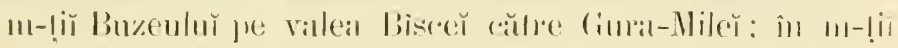

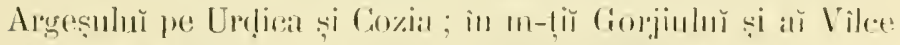

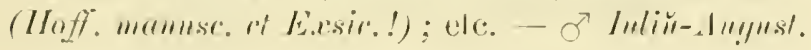

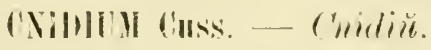

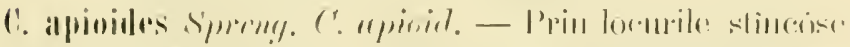

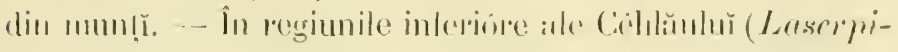


tinm silaifolium .Jac\%. Edel l. e. 36); în m-țiĭ Vîlcẹ̆ la Golotrenı̆. - 2 Imliü-August.

C. renosum Koch. C. vênos. - Prin finețe și pădurǐ umede.-Pe lîngă Bucuresci la Merinani. - 2 Juliŭ-Angust.

\section{ATHADANTIIA Köł. - Atamantŭ.}

A. Matthioli Wulf. A. lui Matthiol. - Prin locurile petróse și prin crĕpăturile stîncilor calcare. - În m-tiì Vîlcě la m-stirea Bistrița (Hoff. Exsic!). - o' Iunin̆-August.

\section{SILAUS Bess. - Silaŭ.}

S. pratensis Bess. S. de fincte.-Prin finetele fertile.În districtul laș̆ către Domnesč (Pencedannm silaus $L$. Sz. manusc.) și la Hàr|răsěsč̌. - 2 luliŭ-dugust.

S. Besseri DC.; S. alpestris Bess. S. luð Besser.-Prin finețele nesipóse. - In districtul T'utova la (ihidigenı̆ aprópe de gară, pe lìngă calea ferată. - 2 Inliŭ-dugust.

\section{IEUII Tonl'nef. - Meй.}

II. Mntellina Ġaerin. M. Mutelină. - Vulg. Briölă, Chiminul-ursulǔ̆. - Prin pășunile din regiunea alpină. Pe Céhlŭh (Edel l. c. 35); în n1-țiì Bucegi (Fr. 108) pe Vîrfu-cu-Dorŭ, Furnica, Babe și Omu. - 2 Inliŭ-Angrustŭ.

\section{LEVISTICU/I Koch. - Leustén.}

L. officinale Koch. L. oficinal. - Vulg. Lenstén. Buru-

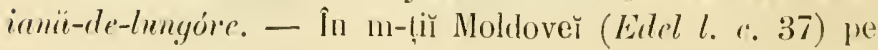
malurile Trotușulŭ̆, a Siretulŭ și a Prululŭ (Ligusticum Levisticum L. Cz. et Sz. l. c. 13); subspontaneŭ ì in-tii Buzĕıluı̆ la Bîsca; cultivat prin grădinile tẹrěnescì din tötă 


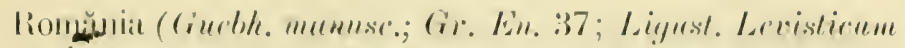

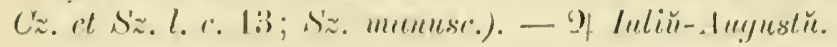

\section{Ślimur t. - Selin.}

S. Carvifolia L. s'. an for de rhimion. - Vulg. Angr-

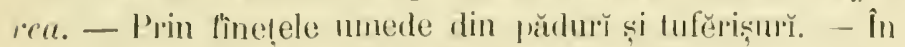

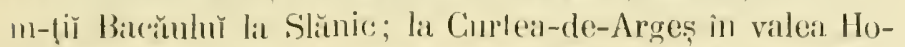

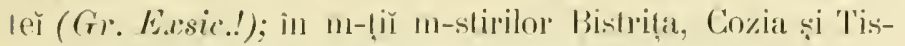

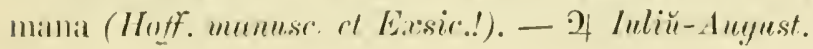

\section{INGELICA Н. - Angelică.}

A. sylvestris L. A. de pürdure - P'rin finctele și locurile umede din fŭ̌dur pe lingă fûrăie umbrơse.- În fótă Moldova (Giub). manusc.); pe lîngă liș̣̆ la Repedea (Imperatoria syluestris DC. S'z. manusc.) si Nitelea (D. Br. Eragm. l. e. 85); la m-stirea Némḷuluọ çi la Agapia; în disır. Bacăŭ la Verșěscŭ și Cial'aclaŭ; în llfov (Gir. En. 27) pe lingă Bucurescĭ (D. Br. Fragm. l. c. 85); în Vlaşca la Comana: etc. - 2 Iuliü-Auqust.

B. clatior IT ahlenh.; A. montana Schleich. - Prin finele şi locurì umede și umbróse din regiunea subalpină. - La Predẻl; in Vìlcea la Olănesci și m-stirea Hore\% (Gr. Exsic.!).

A. Archangelia L.; Archangelica officinalis Hoffm. A. Archangeliciu. - Vulg. Anglielieă, Buciniş. - Pe lìngă rîurile, torentele şi pîrăile din pădurile montane și subalpine. În Moldova (Edcl l. c. 37: Cz. ct Sz.l. c. 13) pe lingă laṣ̆ în lunca Dobrovẹtuluĩ ; în m-ṭị Bucegì în valea lalomițě la schitul Pescera. - 2 Iuliü-1ugust.

\section{FERULAG0 Koch. - Ferulag.}

F. syluatica Rchb. $F$. de pèdure - Prin finnetele uscate din pădurile de la càmpiŭ și din munți. — In Moldova 


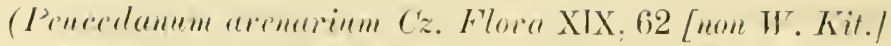

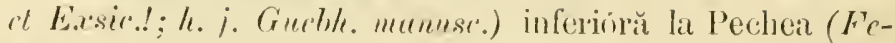

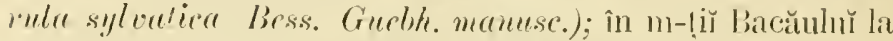
Slănic; în Ilfov între Cihitila și Ciorănescŏ (Ferule syleaticen

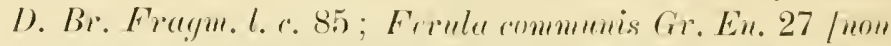
Desf.l et Exsic.!): in Vlaçca la Comana (I). Br. Fragm. l. «. 85); la Virciorova către Por!̣le-rle-fer! (F. sylvatien 3. commutata simli. 55̃3; Borl. Flor. Közl. IX, 291; F. monticala Borl. 1873, Bans. 273 /mun . Ioulia Term. rajzi Füz. III [1879/383]) pe III-tele St.-Pelru; elc. -) Iuniü-Juliü.

F. galbanifora Koch. F. gallouifor. - Prin finelele de pe colincle sterile. - In Moldova (F. sulcuta Ladeb. Gueblh.

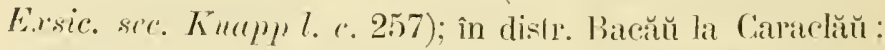
la Ploesčl printre viile de pe coline ( $F$. compestris [Bess.] Janke! Oest. bot. \%rit. XXIII [1873] 322); pe lîngŭ Craiova la Breasta; în ı-!̣i m-slirilorı̆ Cozia, Bistrị̣a și Tis-

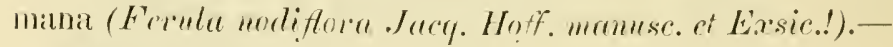
2) Intiü-1 leguest.

F. meoides Boiss. Fr. mend. - Prin finneḷe uscale. - În

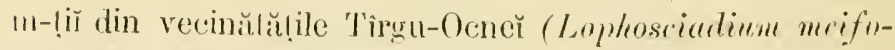

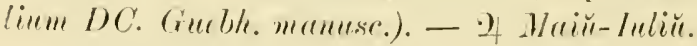

\section{FERILA L. - Firulă.}

F. Ilufelii Grissh. F'. lne Houffel. - L'e stìnci cal-

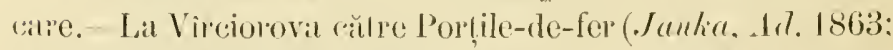

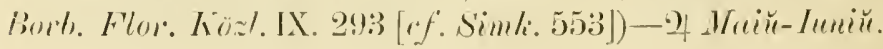

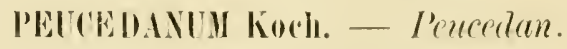

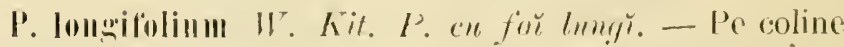

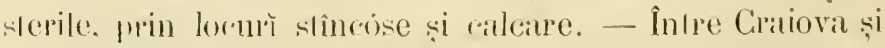

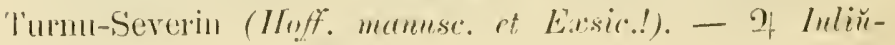
luzjust. 
P. rampestre dentio. P. de rimp. - Prin finelele de

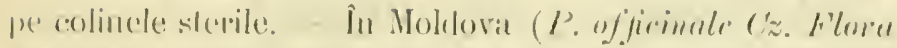

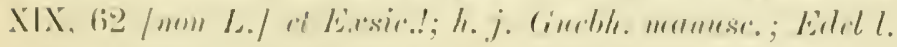

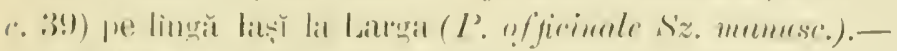
.) Lulin-.lutyust.

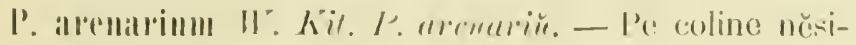

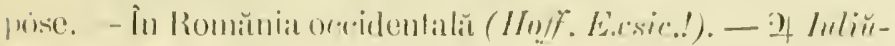
siptembire.

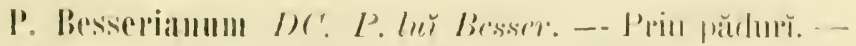

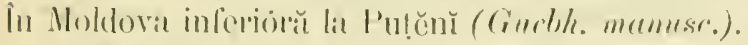

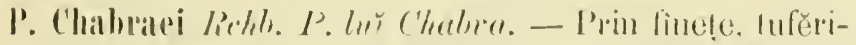

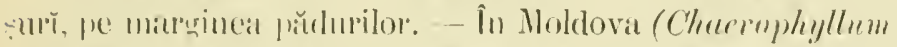

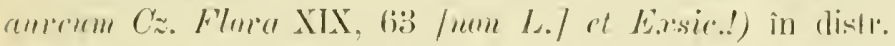

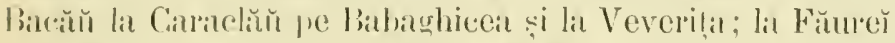

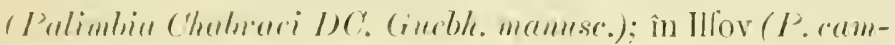

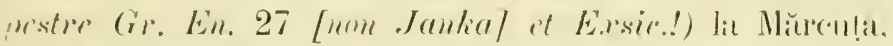

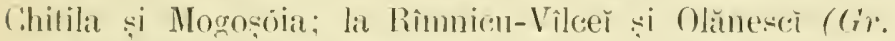

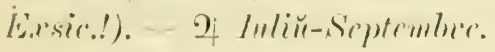

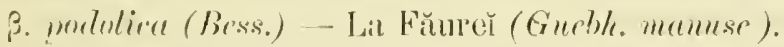

P. Latibolinm JC. P. an for lule. - P'rin fincle și

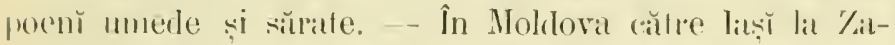
hornat (Cuncalis latifoliu Sz. mamese. ot Estsic.!); in IIfor

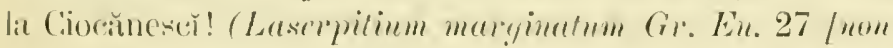

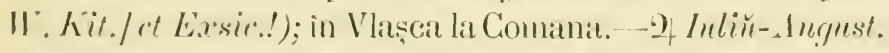

P. Cervalia Lap): Coreuria Rivini Garetn. P. Corrarie. - I'pin finctele sterile te pe coline si din mun! ĭ,

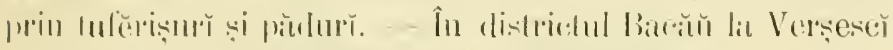

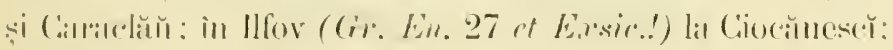

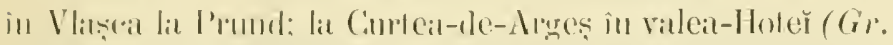

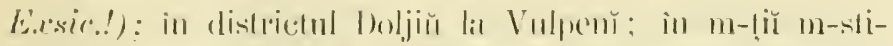

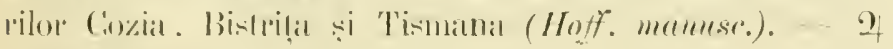

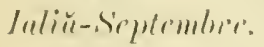

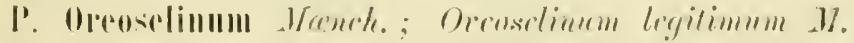
Bich. I'. Mrenselin. - Prin finelele usate de pe colincle 
aride și din pădurile montane. - În Moldova (Scliunm Orensclimum Edel l. e. 39; Cz. et Sz. l. c. 13; s. austriacum Cz. Flona XIX, 62 finon Jacq./ et Exsic.!; Cz. et Sz.l.c. 13; S. Carvifolia Cz. ct Sz. l. c. 13 /non L.] ot Lxsic.; Sz. manusc.) pe lînğ laș̆ la Hadînb (s'z. mamusc.); în m-lị Némḷluı̆; în distr. Bacăŭ la Verșesĕ ; la Curlea-de-Arges, m-stirea Stînișora și la m-stirea Hore\%(Gr. Exsic.!); elc.2 luliй-S'eptembre.

P. alsatioun L.; Solinum alsaliemm Crantz. P. ulsatic. - Prin fincte sterile, fuferişur, pe coline aride, pe marginea pădurilor și at drummulilor. -- În districtul Bateăŭ lia Verşescĭ. Callaclaŭ și la Moșia-Ocně̃; in Ilfov intre Chitila și Ciocănescř! (Gr. Lu. 27 ct E.tsic.!); în districtul Vlaṣca la Prund; in u-tiù m-stipilor Cozia, Bistrị̣a și Tismana (C'nidium alsaticum s'm. Hoff. munuse. ot E.rsie.!); etc. - 2 h heliŭSeptembie.

P. anstrianum Koch. P. anstvian. - Prin tuferiçurile

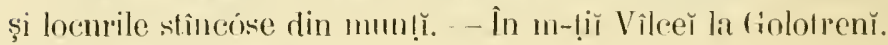
- If huliü-Auegust.

P. palnstre Monch.; Thysselimm palnster Hoffm. P. de mlaștiň. - Prin finețele și unferișurile din locurile mlăstinóse, pe lìngă lacurı̆. - În Moldova (Selinum palustrer L.

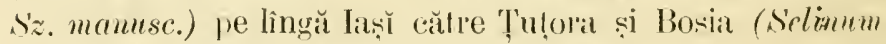
sylvestre Jaeq. Sz. mamusc.). - of Lulin̆-dugust.

Obss. - Se maĩ citéză : P. ofticinale $L$ la Ciùmpulung pe valea RîuTîrgulur (Hoff. Excurs. 1862, l. c. 40).

\section{ANETHUII L. - Marariu}

A. maveolens L. Mr. commen. - Vulg. Marariu. - Cul¿ivat și subspontameŭ prin gumóele grădinilor. - În tótă Romănia (Cz. F'lor"l XIX, 62 al Exsic.! ; Edel l. c. 39; Cz. et Sz.l.c. 13; Sz. mamuse.; I). Br. H'argm.l. c. 85; Gr. lin. 27). - $\odot$ luliü-August. 


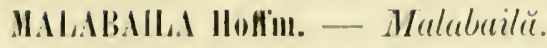

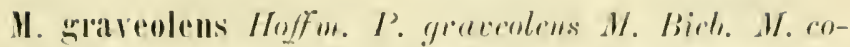

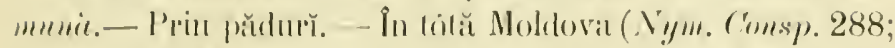

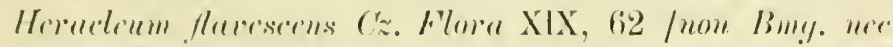

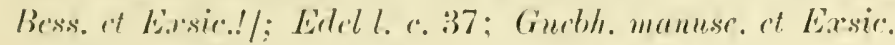
n. 548 sir. Nym. C(ms). 288). - 2 luniй-1 luynst.

\section{PASTINACA L. - T'üstimac.}

P. edulis L.: P. syllesestris Mill. P. commu.-Vulg. Pästimae. Pestirmac. l'estranar. - P'rin finete, cringuri, pădurı̆, locuř umbróse, inculte, aride, pe linğ drumuř̆, pe coline. - In Moldoval (Edel l. c. 39); P. sativa P. sylvestris I)C. Guebh. manuses.) inferiorĭ (I’. numlnose Ster. Guebh. mumusr.): la Huṣ̆ și Fălciŭ pe mahı Prululıŭ (Cz. ot Sz. l. $\therefore 13 ; s_{z}^{2}$. mumuse.): pe lîngŭ laș̣ la Repedea sub stîneile

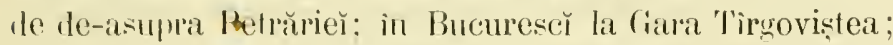
intre Tiu și (iherganı̆ (Gr. Eu. 27 et Easic.!); la RìmnicuVîlcĕ (Gr. Érsic.!); etc. - or Iuliŭ-Septembire.

B. crlulis I)C.; P. sutive Mill. - Cultivată în tótă Romănia (Guebh. munuse.; Gr. Èn. 27).

P. opaca Bernh.; P'. sativa $\beta$. clatior Rochel. P. opacit. - Prin finețele, pășunile și ruferișurile din munṭ̆, pe lingă drunurĭ. - În m-ṭi P'ahoveř între Azuga și Predél (Gr. Exsir.!). - o luliŭ-Septembre.

\section{HERACLEUH L. - Eracleŭ.}

H. Sphondylium L.; H. Branca msina All. E. Brinca-

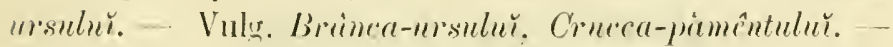
Prin finețe. Iufĕriṣurı̆, poenı și pădurĭ mmede. - În tótă Moldova (Edel l. a. 39; Guebh. mannesc.); in distr. Jaş̣̆ la Solonẹ̣ (Sz. manusc.); în m-ṭî̀ Prahover̆ la Predél; în m-ṭĭ 


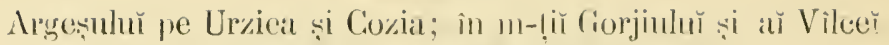

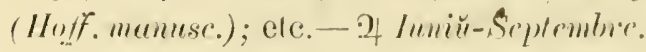

II. sibiricum L. E. sithiric. - Vulg. Brince-nesulur.

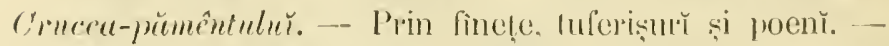

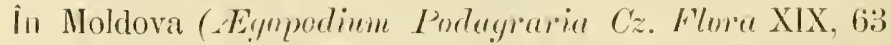

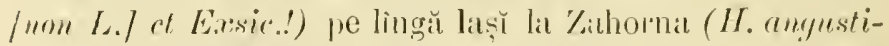
follum Sz. manuser. [non Bmy.J) și Nilelea; Biollad; in distr. liacăı̆ la Catraclĭŭ; în Ilfov (H. spletemed. Gr. En. $27 \mathrm{rt}$ E.rsic.!) pe lingă Bucurescĕ (H. Sphomel. I). Br. Fragm. l.

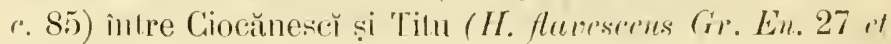
E.ssice!): în Vlaṣca la Comana: in m-lị̂ Vîlecŏ la m-stireal Cozia: etc. - 2 Inniй- lurjust.

\section{TORIOYLUU L.-.. Torditiǔ.}

T. maximum Lin. T. mate - Vulg. Téposicio - Pe coline inculte, min Iuferisurr, pî̀loge, locmrǐ collivate, aride i petróse. - În totă Moldova (Guebh. mamusc.; Crenculis maxima Bing. S'z. menusse); pe lingă Bèrlad (D). Br. F'retgm. 1. е. 8); pe lingă Bucuresec̆ la Ferestrĕŭ; în Vlaṣca liı Comanı: pe lingă Slatina; in Mehedinț la Vìrejorova către Portile-de-fer! (Borh. Flor. Kozl. IX, 296) si la GuraVйіей: ele. - $\odot$ Iuliü-septembre.

\section{S!IER Scop. - Siler.}

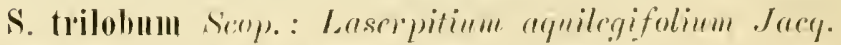

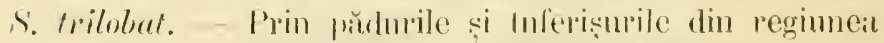
montană. - Lat Virroroval către Porlile-de-fer! (Kanitz! 1. (. 47), - 9 I/air-Inliu.

\section{LASERPITIUII L. - Laserpitiu.}

L. Iatifolium Lin. L. en for late. - I'rin finctele umede, Inferișmile și poenile din reginneat monlanĭ și sub- 


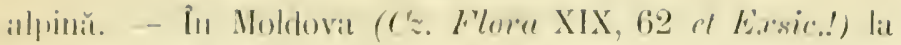

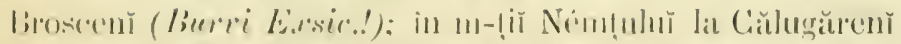

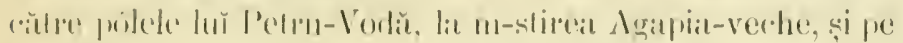

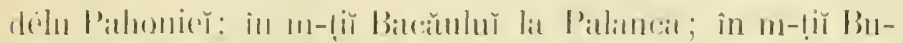

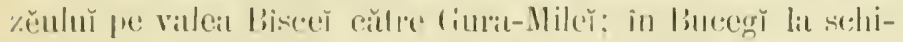

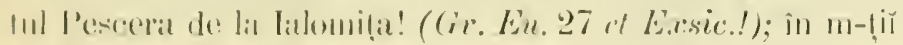

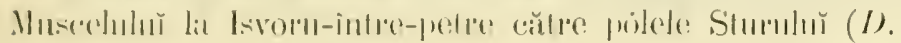

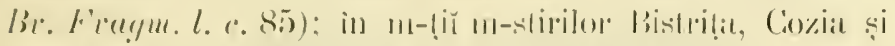

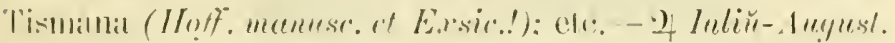

1. pruthenicinu Lin. L. pressian. - Vule. Sommonósa. - Prin lìnele și poeñ̌ umerle din reginnea monlană. - În

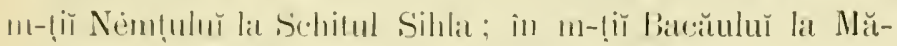

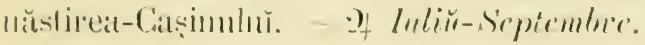

\section{ORLAYA Hoffin. - Orlaie.}

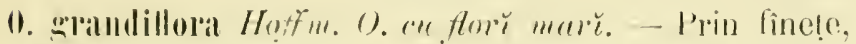

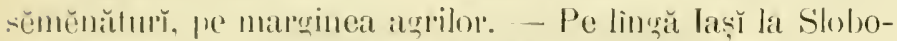
ulia-Voinescilor (Cauralis gramliftura L. Sz. manuse.); in Prahova la Ploescŏ. Băticoŏ și Sinatia; pe lîngă Bucurescŏ la

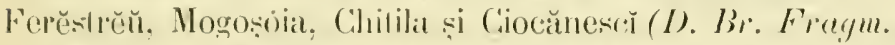

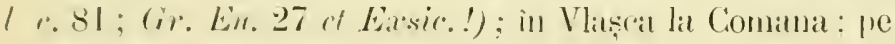
lingă Slatinat ălre Olt; Tumu-Severin, Schelea-Cladově̆, etc. - $\odot$ Iuniü-August.

\section{I).AUCUS L. - Morcov.}

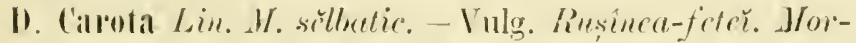

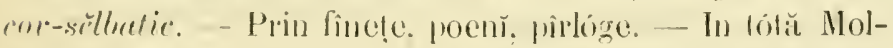
dova (Edtel. l. c. 3!) ; D. syluestris ('s. Flora XIX, 63 ri

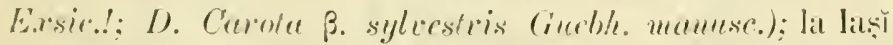

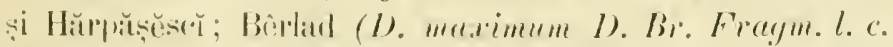

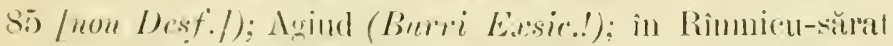
lit Caiala; in Illor (Gir. Ėu. 26 et Exrsic.!) pe lingă Bucu- 


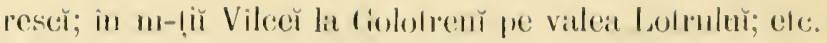

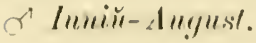

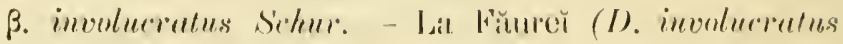
(inchlh. maruese. (mom sibth./).

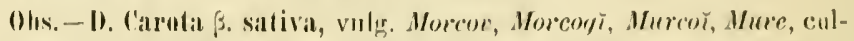
tivat în grădinile de legmme đlin tótă România (Gueble munusc.; Cz. ct Sz.l.c. 15; Sz. mucumse.).

\section{CAUCALIS Ilıfl'm. - Cancalidĕ.}

C. dancoidles L. C. danrovida. - I'rin sŭmĕnădurĭ, pìloge, pe marginea agriilor, locmll inculle si aride. - In

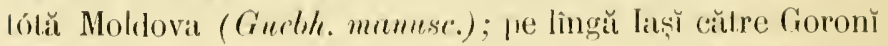

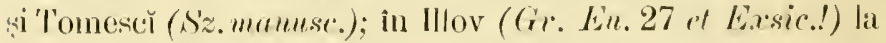

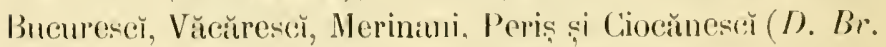
Fragm. l. e. 86); in Vlașea la Comanar pe lingă Slatina lit Ionășĕscĕ; ele. - ò Inniй-Inliŭ.

\section{ToRIIJS Adans. - Torilis.}

T. Antluisens Gmel. 'T'. Lutrisc. - Vulg. Matmaturdiŏ-

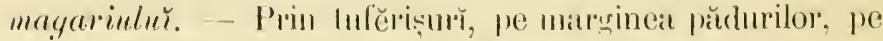

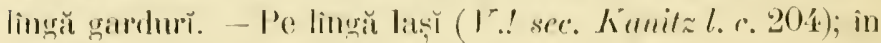

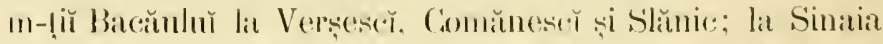
(Gr. En. 27 at Exasice!); pe lingă Bncuresce lat Merinani,

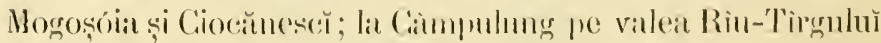

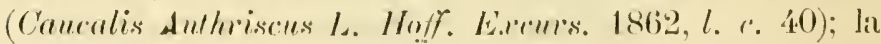

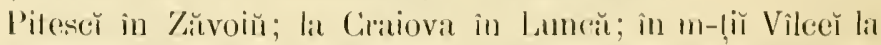

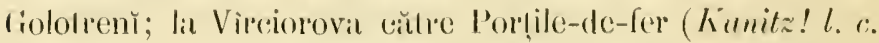
i.7); ele. - o luniй-Lugust.

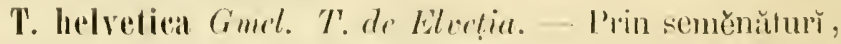

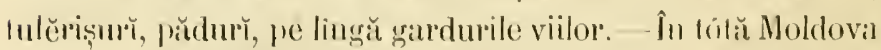
(Cancalis arvensis Huds. Sz. munusse.); pe lingră latş̆ la Ni-

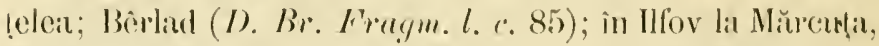

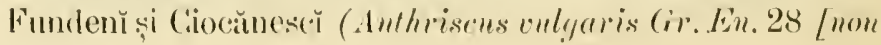




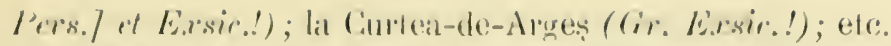
- or lulivic-lueyust.

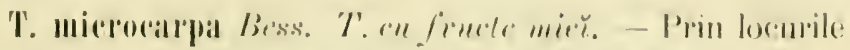

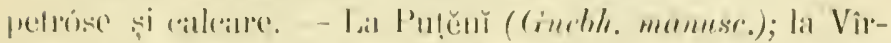
riorovit către Porlile-de-fer! (Simli, 555). - o Imniü-Luliu.

Obs. - Se mal ciloză : T. nodusil Gueren. pe lingă laşy la Zahorna, Vuiluta și Larga (C'nucalis nodosa Scop. Sz. memuse.).

\section{St.INIII 1. - Scandice.}

S. Peden Veneris L. s'. Peptenele-Fineret. - Prin

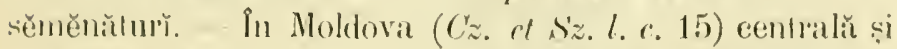

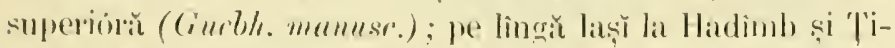

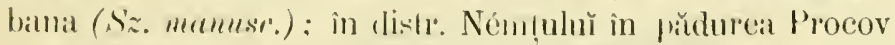

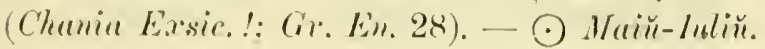

\section{INTHRISGUS Holfm. - Antrise.}

1. sylrestris Hoffur. A. de piulure. - Prin lìnele, tu-

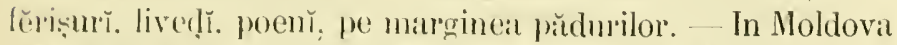

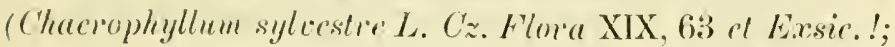

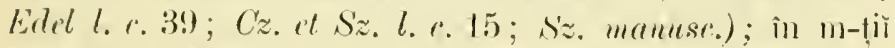

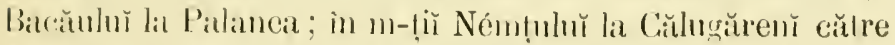
Petru-Vodă: la Virecioroval cătrelPortile-de-fer! (Borl. Flor.

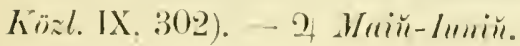

A. alpestris $11 \mathrm{im}$. al cirab.; Cherophyllum mithlum Wuldrmb. A. alprstru. - In pădurile umbróse și mnede

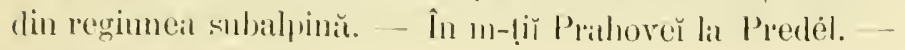
1) luniй-Alu!just.

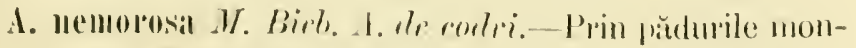

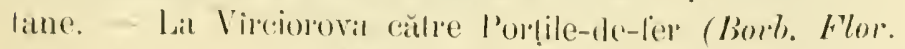

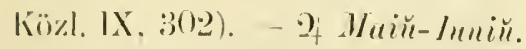

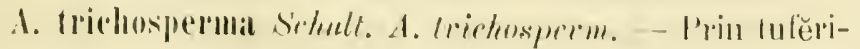

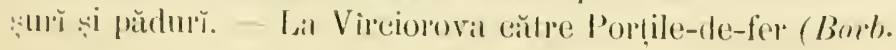

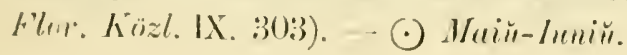


A. Cerefolinm Hoffin.; Sinudix Gerefolium L. A. Cer-

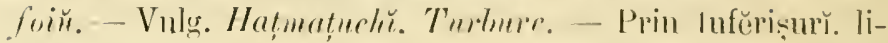
red̦ĭ, gunóile grăddinitor, pe mareinea pŭdurilor și a viilor. pe lingă gardurě. - În Moldovar (Secondix Corefolium L. Cz. Flora XIX, 63 ot Exssic.!; Eilel l. r. 39; Cz. it Sz. l.

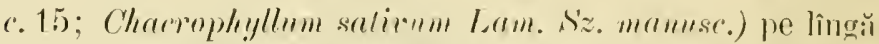

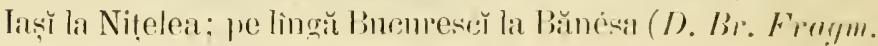

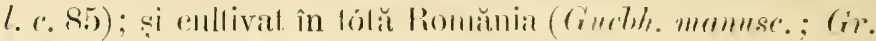

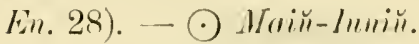

A. Vulgarlis Pers. A. commu. - Prin locurile inculle de

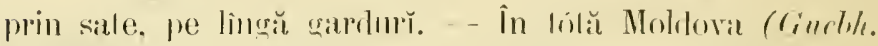
mamuse.). - $\odot$ Mniril-Imnir.

\section{P'IIYSOodULIS Tausch. - Fisocaulus.}

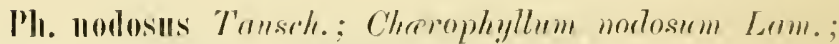
Anthrisens mulnsn L. F. nostos. - Prin lufĕrișurile și pădurile din reginnen montană. - În m-tiı̌ Nıscelılıı̆ pe

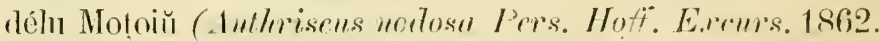
1. с. 39?); lil Virciorova către Porṭile-de-fer! (Borl. F'lor. Köl. IX. 303). - $\odot$ Maiи-lıniй.

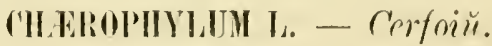

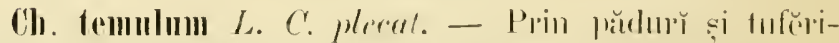

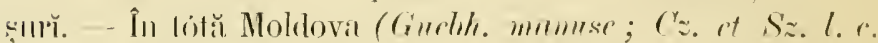

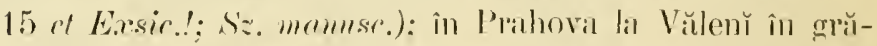

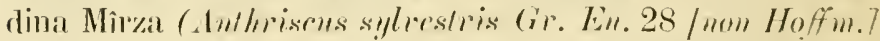

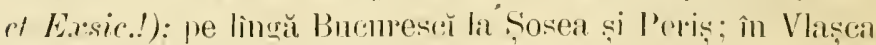
la Comana (I). Br. Freegm. l. r. 84): la Virriorova călle Portịle-de-fer; ete - or Immin-luliin

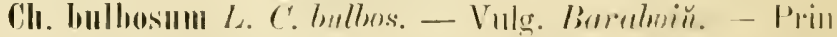

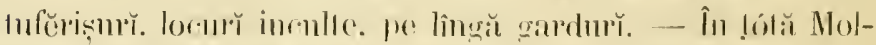

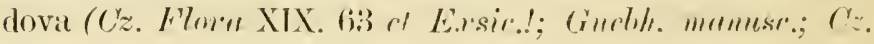




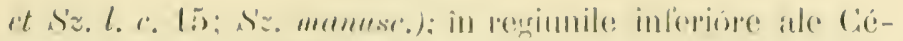

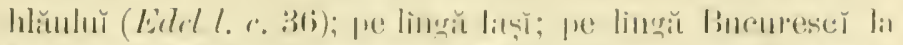

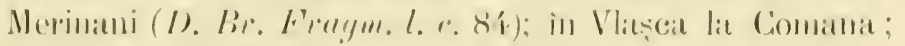

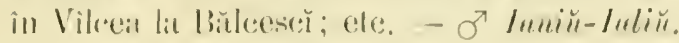

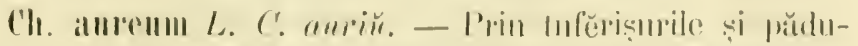

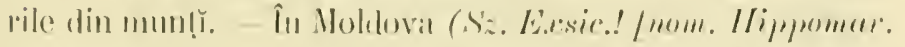

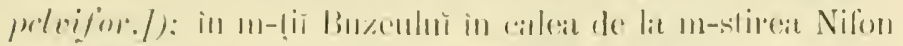

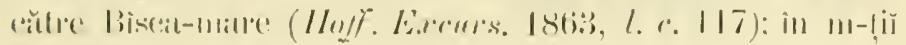

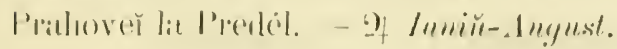

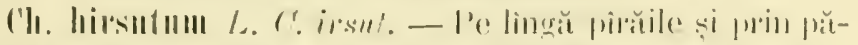

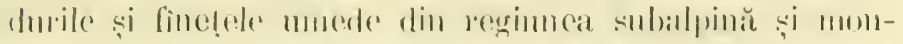

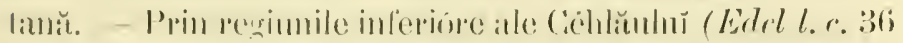

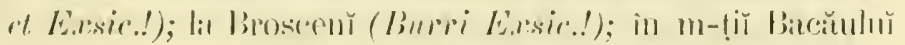

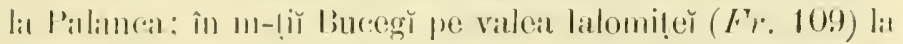
schitul Peseerat de lat latomitat, in pesiumile inferiore ate

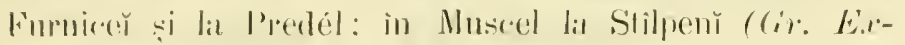
sir.!), cle. of lumiti-.1n!mst.

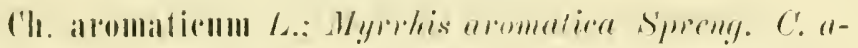
romatix. - l'e lingă pirăile ;i prin lufișurile și poenile umede din pădurile reginnĕ montane. - În m-tĭ Noldovei

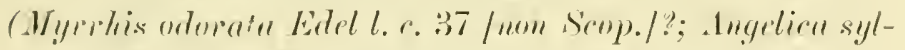

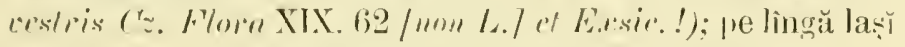

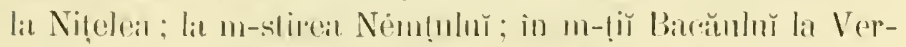

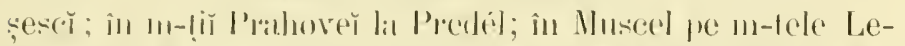

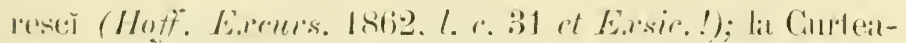

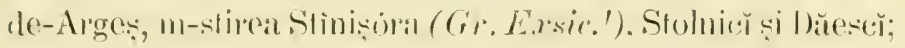

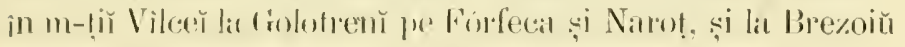

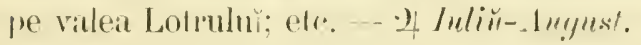

\section{CovIII L. - ruentir.}

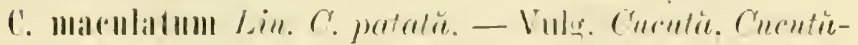

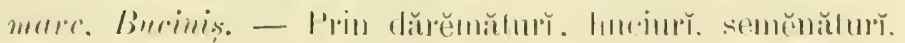

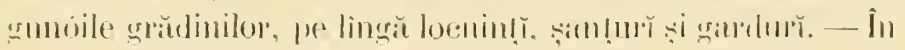


tótă Romănia fóte comună (Hacq. l. c. I, 19; Hoclal l. c. 441 ; Edsl l. c. 36; Cz. Flora XIX, 62 rt Exsic.!; Guelih. Vot. 11 et mumesc.; Cz. et Sz. l. r. 14; D. Br. Frargm. l. c. 85; Gr. En. 29). — - J Iuliй-śeptembre.

Olıs. - Se mar citéză : Plenrospermum anstriatem Hoffm. vulg. Morcoréncă, in Moldova (Ligusticum astriacum L. Cz. et Sz.l. c. 14); la Sinaia pe malul drept al Prahover către Valea - Cășărieł (Gr. Lx curs l. c. 339; et En. 29 ?).

\section{CORIANDRUII I. - Coriandru.}

C. sativum L. C. cultivat. - Prin sĕmĕnăturı̆, locuř cultivate.-In Moldova superióră spontaneŭ (?) și cultival prin grădinile (Guebh. nєamusc.) din mă tótă Romănia (Gr. L̀. 27). - б Iuniй-Iuliŭ.

\section{PRANG0S Lindl. - Prangos.}

P. ferulacea Lindl.; Cachrys alata Hoffm.; Laserpitium ferulaccum L. P. ferulaceŭ. - Prin locurile stincose de pe coline și din munți. - La Vîrciorova către Portile-defer (Janka in Borb. 1873, Bäus. 238 et .1d. 163). - 24.

\section{HEDERI Liı. - Iederŭ.}

II. Helix Lin. I. acritietóre. - Vulg. Iedera, Iederacelor-frumuscle, Jederu-d,inelor. - Prin pădurì umbróse, pe stîncĭ și zidurĭ nmede. - In tótă Moldova (Guebh. mamuse.; Eidcl l. e. 39, 41; Cz. et Sz. l. e. 10; Sz. m(uusc.); pe lîngă Iaș̆ la Nițelea, Repedea și P'oenǐ ; în m-ții Prahově̆ (Gr. Eн. 29 et Exsic.!) la Sinaia pe Furnica ; pe lingă Bucuresč la Bănessi. Merinani (I). Br. Fratgm. l. c.84), Antonachi și Cuălugărésca ; în m-lị̂ m-stirilor Cozia, Bistrị̣a și Tismana (Hoff. manusc. it Essicic.!); ete. - ț SeptemberUctomline. 


\section{XIVI. CORNACEE.}

\section{CORNIS L. - Corn.}

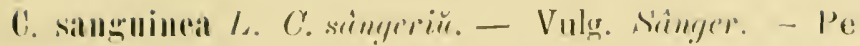

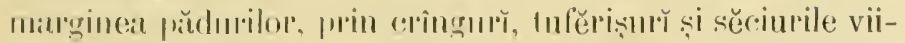

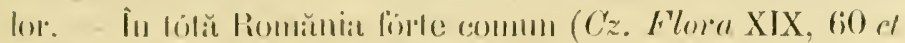

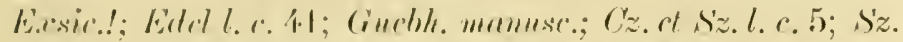

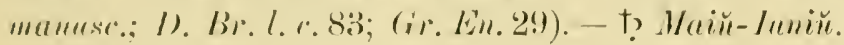

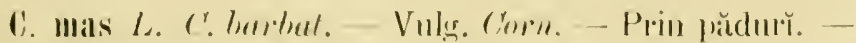
In tiłă Romăn

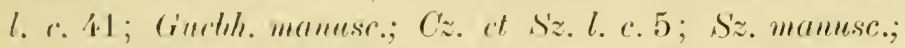

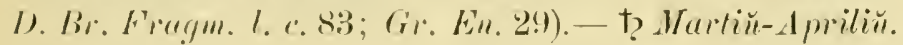

\section{SWII. CARRIOLICEL.}

\section{MWMX.І 广. - Adoxă.}

1. Moschatellina H. A. Moschentellinà - Vulg. Frougueliț. Moscnson. - Prin pădurile unede, pănă în reginnea

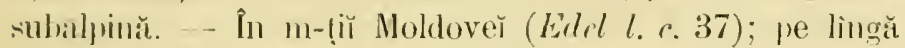

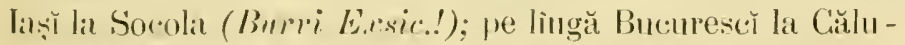

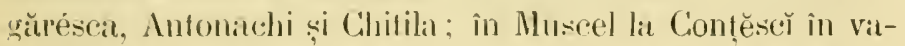
lea Rincăciovu (Gr. Es.sic.!); ete.- - Martiü-1 priliü.

\section{SAHBICUS L. - Soc.}

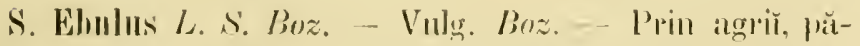

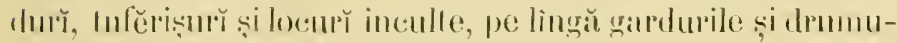
rile de prin silte. - În liotă homănia forle commun (r'z. Frora

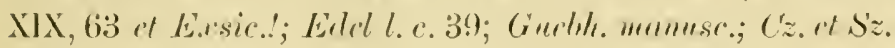


l.c. 16; Sz.manusc.; D. Br. Fragm.l. c. 84; Burri Exsic.!; Gr. Erbor. l. c. 127; En. 29).- 2 Inliŭ-August.

S. nigra L. S. negru. - Vulg. Soc. - Prin pădurĭ, huciurı̆, pe lîngă gardurile de prin sate. - În tótă Romănia, fórte comun (Cz. Flora XIX, 63 et Exsic.!; Edsl l. c. 41 ; Gnebh. manuse.; Cz. et Sz.l. c. 16; Sz. manusc.; D. Br. Fragm. l. c. 84; Gr. Erbor. l. c. 128; En. 29) - † МаійInniu.

S. racenosa L. S. cu struguri.-Vulg. Soc roșu.- Prin ןădurile din regiunea subalpină. - In Moldova $(C z$. Flora XIX, 65 et Exsic.! ; Edel l. c. 41 ; Cz. ct Sz. l. c. 16) prin regiunile inferióre ale Céhlăuluı (Edel l. c. 36), la schiłul Sihla! (Gr. En. 29), Agapia-veche și la m-stirea Némțuluı̆; la Broscenı̆ (Burri Exsic.!); în m-tị̆ Bacăuluĭ la Mănăstirea-Caşinuluĭ; în m-tịi Prahovel̆ la Sinaia pe Piscu-cîneluř şi la Predél. - † Maiŭ-Iuniü.

\section{VIBURNUM L. - Viburn.}

V. Lantalla L. V. Dîrmoz. - Vulg. Dirmoz, Dirmoe. Drimoc, Drimos. Cócciză. - Prin pădurile și tufěrişurile: de pe délurǐ și din regiunea montană. - In tótă Moldovi (Cz. Flora XIX, 63 et Exsic.!; Gurbh. mannsc.; Edel l. c. 84; Cz. et Sz.l.c. 15 ; Sz. manusc.; D. Br. Fragm.l. c. 84); pe lîngă Jaş̣̆ la Nițelea ; în distr. Bacăŭ la Verșesč̆; la Agiud (Burri Exsic.!); pe lingă Slatina către Milcovude-jos; în Mehedinț̆ (Gr. En. 29); elc. — t? Main.

V. Opulus L. V. Călin. - Vulg. Cúlin. - Prin pădurile și tufĕrișurile umede. - In tótă Noldova (Étel l. e. 41 ; Guebh. mamesc.; Opulus glandulose Bug. Cz. Flora XIX. 63 et Lxsic.l; Cz. et $S z$.l. e. 15; S'z. mamusc.); pe lîngă Jașŭ la Niţelea; la Agiud (Burri Exasic.); pe lingă Bucuresè la Măreụa, Fundenì și Colentina; in Musced la Conṭescè ( Grr. 
Lissic.!) : pe linğ Slatina in luncile Olunlǔ ; ele. - t? Мкий-Iпniи.

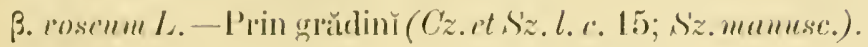

\section{LONICERA I. - Lonicerŭ.}

L. Caprifolium L. Lonicerie Caprifoiŭ. - In Moldova (C'z. Flora XIX, 61 it Esesie.!; h. j. Cuebh. manuse.; Cz. it s'z. I. c. 7 ; s'z. manuse.) și la Bucurescè (Gr. Én. 29),

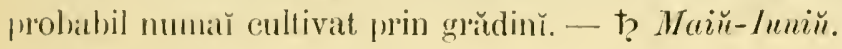

I. Periclymenm L. Lonicerï Periclimen.-Prin tufe-

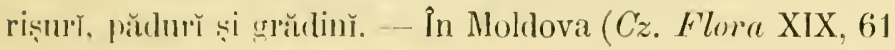

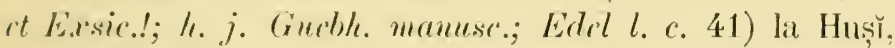

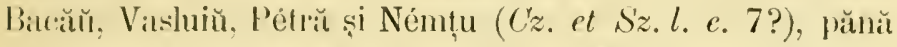
in regiunile inferióre ale Céhlüuluĭ (Edel l. c. 36). t? Inпiй-Iuliu.

I. Xylostem L. Loniceră Xilosteй. - Prin pădurile din regiumea montană și subalpină. - In Moldova (L. alpryena Cz. Flora XIX, 61 [uon L.] et Exsic.!; Edel l. c. 41; $C z$ et $S z . l . c .7$ ) pe lĭngă Iaș̆ la Mironésa și Hadîmbu (Sz. manuse.); în m-țiĭ Prahovel̆ la Sinaia pe Piscu-cânelŭ ; în Muscel pe m-tele Sturu (D. Br. Fragm. in Rev. lit.-se. 158) și la Stìlpenŭ (Gr. En. 30 ct Exssic.!); în m-ţiǔ Vîlcer̆ la Golotrenĭ pe Fơrfeca şi Naroț; in Arges, pe m-tele Urd̦ica. †? Maiй-lıniu.

I. niģra L. Lomiceră négric. - Prin pădurile din regiu-

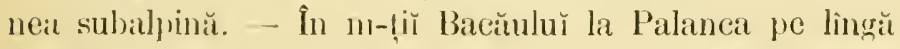

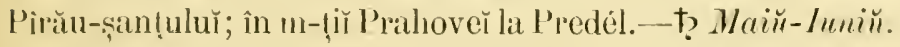

L. alpigena L. Lomicreric alprigencic. - In pădurile din regiuneal subalpină. - În m-țĭ Bacăuluı̆ lal Pasul Oituz. (bm!. Èn. I, 160). - †? Main-Lипій.

()ls. - L. latarica L., indicată din èóre pe marginea pădurilor din Ilfov $(G r \ln .30)$, nu se găsesce de cât cultivată prin grădiuy. 


\section{RUBIACEE.}

\section{SHERARIII I. - Sherardie.}

S. arvensis L. S. de cimp. - P'rin locurr cullivate, fîr-

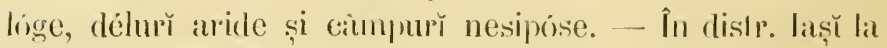

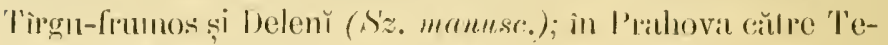

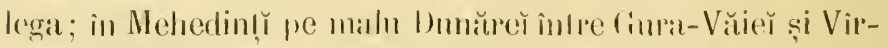

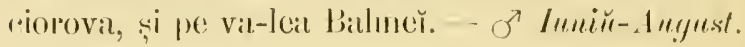

\section{ASPERULA I. - Asperula.}

A. taurina L. A. Lauricŭ. - Prin pridurile umede și

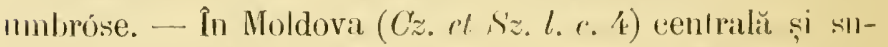
perióră (Guebl. memense.); la Agind (Bmrri E.rsic.!): pe

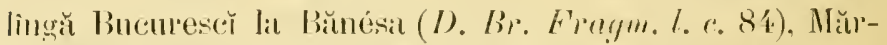
cuḷt și lat Ciocănescĕ; in Vlașca lat Comanta ; in Mnscel lat Contesç (Gr. Ersic!!); pe lingă Craiova in Lunnăi in Me-

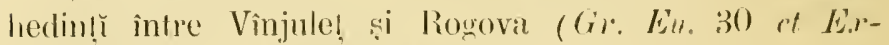
sic.!); ete. - If I milin-Inniu.

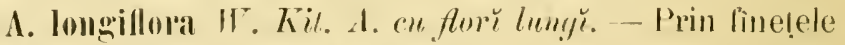
Moldover inferióre (Curbh. munuesc.).

A. finctoria L. A. tineturmilur. - Prin ufĕrișurile de pe colinele anide. - In Moldovil (Cz. rt S'z. l. r. 4); în distr. Bacĕŭ la Canıtctăŭ pe Slatina; în distr. Buzĕŭ la Becen în

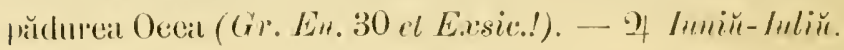

A. cynanchina $L$. A. cincunclicib. - Prin finețele useate, pe colincle aride. - În Moldoval (Cz. ot siz.l. e. 4; (igysoro-

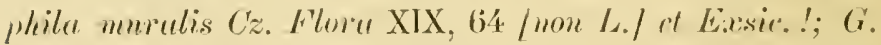

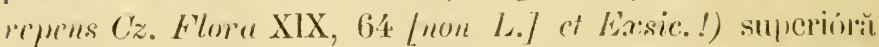

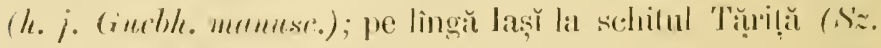

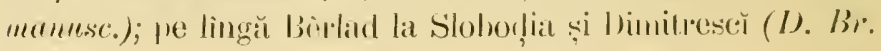
Fraym. l. ґ. 84); în distr. Bacĕu la Verșescè pe délu Oso- 


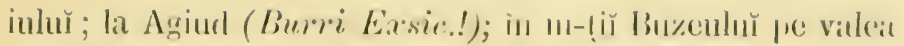

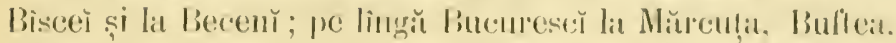

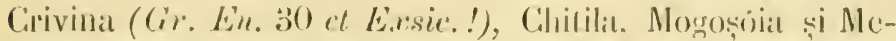
rinani ; la Curfeat-rle-Arges, Slolnič și Vlatscullat; elc. - : Inniü-siptembre.

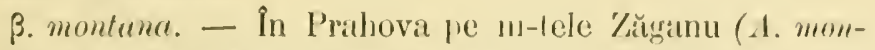
tame $U^{5}$. Kit. Moff. Exrours. 1863, l. ‘. 118); la Vî̀ciorovia cŭlle l'or!̣le-de-fer.

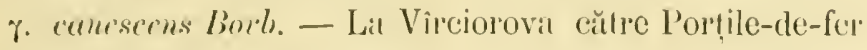
(Bmb. 1873, Báns. 266).

1. Capilata H'. Kit. A. cupitatii. - Pe stîncele din revrimear subalpină inferioră și alpinăt. - In Moldova (1. Allionii Bmg. Cz. et Sz. l. c. 4); în m-liĭ Buceğ în valea latlomiḷ̆ (Fr. 96) la schilul P'escerat. - of Imniŭ-August.

1. odolata L. A. volorantă. - Vulg. Mama-päture i

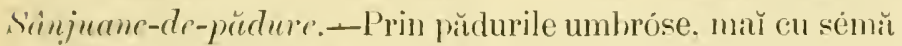
dim regimnea monfană. - In Moldova (Cz. Floru XIX, 60) et Lxsic.!; Cz. et S'z. l. c. 4) centrală și superioră (Gucble. mamse.); în disłr. lași la Hollescĕ, Lunganŭ, Voinesč̆, Slàvnic (Sz. mumuse.). Schitul-Thărịtă si Repedea; în m-tị̌ Ba-

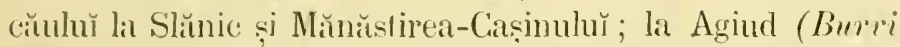
Exsic.!); în P'rahova la Sinatia (Gr. Em. 30) călre pólelc Funniceř și la P’odél; în Vlaṣca la Comana; în Mluscel la

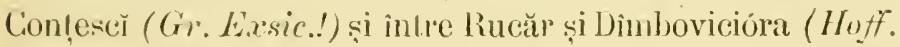
Excus. 1862. l. (. 3!) rt Exsic.l); in Argeş la m-stir(ar Cozia; efc. - 2 M Meiй-Juniй.

1. Iparine Schotı. 1. Aparine. - Pe malurile rîurilor,

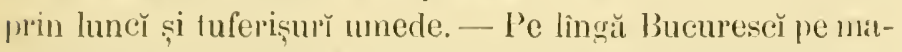
lul Colentiner intre Mogoșóia și Chitila (G». Exsic.!). ) Julin̈-s'rplentore.

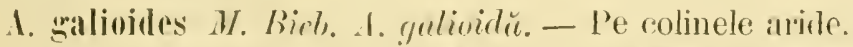

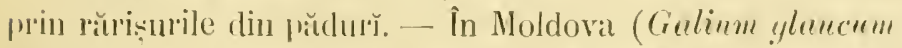
L. Cz. et siz. l. c. 4) inferioră (comhle mamese); lat Agiud (Burri Exsic. !); în Vlassca la Comana (D. Br. Frougm. l. r. 
84); în Mehedinṭ la Vîreiorova călre Porțile-de-fer. ') Iимiй-luliü.

B. Lyraica DC. - În Moldovit (1. Iyraice Bess.s. Cimebh. Exsic. ". $700 \mathrm{ap.} \mathrm{Nym.} \mathrm{Comsp.} \mathrm{332)} \mathrm{pe} \mathrm{lingă} \mathrm{Galați} \mathrm{și} \mathrm{lași}$ A. arvensis Sz. Easic. (nou L.J!).

A. Lumifusa M. Bicb. 1. mmifusie. - Prin locurı̌ sterile si umede, pe coline aride, pe limgi drunmrǐ. - In Moldova (Galinm anstriacum Co. Flara XIX, 60 / $/ \mathrm{mm}$.Jacr.l ot Lxsic.!; Cz. et Sz. l. c. 4) inferióră (Guebl. menusc.); pe linğ̌ Jaş̆ la Ciric (V.! ap. Kunitz. l. c. 20.9), Nițelea și Repedea; în Rimnieu-sătal la Ciiliala; la Buyĕŭ (Al.! ap. Kanitz. l. c. 209) şi Becenı̌; pe lingă Bucurescĭ ître Fundenı̆ și Mărcuța (Galium urhorolcucum Gir. Liı. 30 /non

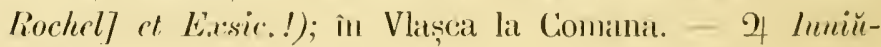
August.

Obs. - Se mal ciféză : ‘. alvensis $L$. în Moldova (Cz.et Sz.l.c. 4) superióră (Guebh. mamusc.) către m-stirea Némțulułu (Gr. Erbor. l. c. 127)?.

\section{RIBIA L. - Rubie.}

R. tinctorum L. R. Aincturnter. - Vulg. Risibii. Ródea, Brociŭ, Rumenele. - Pe lingă (ialițĭ, Bèrlad, Tecuciŭ si Foesanı̆, spontanee? ( $(z$. et s's.l. e. 4); iatr subspontanee și cultivală în tótă Romănia (Guebho manuse.; Carecels; l. r.; durelian l. c.; Gr. En. 30). - of Inliü-Anynst.

\section{(HALIII L. - Galiǔ.}

G. Cructiata sicop. G. cruciat. - Prin finetele de min

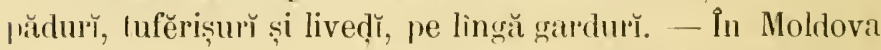
(G. Vaillantia L. Cz. Flara XIX, 60 it Essic.!; Edall.e. $39 ; C z$. et Sz.l.c. 4; Sz. mamuse.) centrală și superión (Gucbh. maunsc.); pe lînğ̌ Iaș̆ la Nịcelea (I). Br. Frogmu.l.c. 84); în m-țĭ Bacăuluĭ la Slănic către fruntarie; la Agind (Burri Exsic.!); în Prahova la Câmpina și Vălent (Gr. 
Lèrac.!); pe lingă Bururescĭ la Bănessil, Merinani (D. Br.

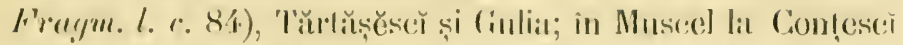
(civ. Lin. 30 at Exsir.!); in Vlașea lat Comana; pe lingit Cratiova în Luntrĭ ; în Gorjiŭ la Roșia ; în Mehedinți liı Cerneţi și lorgutova (Cor. Lxsic.!): ele.- If Main̆-Inniü.

(i. verum Siop.; G. Bantini li. at S. G. de primacéra. - Prin pădurile unede şi umbróse din reginnea monlimă și subalpină, locull' slincờe. În Moldovar (Vaillantiu "lublua 1. Cz. Flora XIX, 60 at Earsic.! ; Edel l. c. 39;

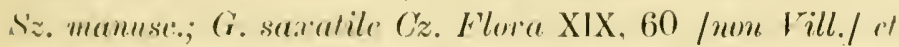

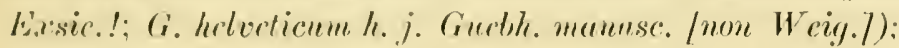

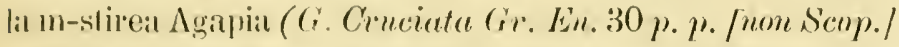

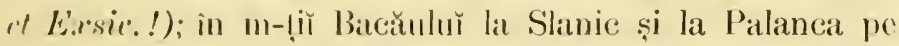
Trŭrhaușĕl ; in P'ulna liı Făureě (Guebh. mamusc.); în Prahovat la Cîmpina, Sinalia (Gr. En. 30 ct Exsic.!), în m-ḷĭ Bueegř pe Furniea și la Schilul Pescera de la Ialomiḷ; lit P’redél; în Muscel lat Nĕmăesč̆ pe Cóstaz-mănăstireŭ (D). Br.

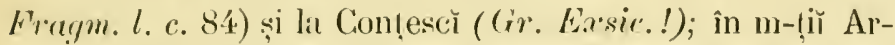
geșulŭ pe Urd̦ica și Cozia; în Vîlcea la Lotru pe Fórfeca; elc. - 2 Маiй-Jемiй.

G. pedemontanum All. G. de Piemont. - Prin locurì nesipóse, coline aride. - In Moldova (Vaillantia pedemomtrum Brll. (z. Flore XIX, 60 rt Exsic.!; Sz. mamesc.); în m-liĭ de pe lingă T'îrgu-Ocnĕ (G. retrorsum DC. Guebh. mumuse.) și de la Slănic; in Vlașca la Comana; în Argeș la Vlĭscuṭa (1). Br. Frutgm. l. ('. 84); în Mahedințĭ la CruraVăiě̆, Schelea-Cladover, Vîrciorova și pe valea Bahnĕ́; etc. - $\odot$ Маій-Iитіи.

G. tricorne "tith. (i. tricom. - Prin locurǐ cultivale argilose. - În Moldova (G. spurium Roth. Cz. ct Sz. l. c. $4 ; s z$. munusr.).

(t. Aparine L. G. Aparine - Vulg. Turiță. Scaĭnmŕrmm. - Prin locuř cullivate, Infĕrișurŭ, păduř̆, pe lîngă garduř. - În tólă Moldova (Édel l. c. 39; Gnebh. manusc.; 
Cz. el Sz. l. c. 4; Sz. manuse.); la Agiud (Burri Exsic.!); pe lîngă Bucurescĭ la Bănésa (D. Br. Fragm. l. c. 84), Ferestrěŭ și Periș (Gr. En. $30 \mathrm{ct}$ Exsic.!); in Vlaṣca la Comana; în Argeș la Dăescĭ ; în Mehedințĭ călre Crura-Văieĭ, Vîrciorova și Bahna; ete. - $\odot$ Luniü-Septembre.

B. Vaillantii Koch. - În Moldova ( $G$. infestum W. Kit. Cz. ct Sz.l. c. 4) în distr. Iaș̆ cŭtre Tăuteser̆ (Sz. manusc.); in Mehedințĭ călre Gura-Văiě̀ pe malul Dunărĕ.

G. palıstre L. G. palustru. - Prin locurĭ mede, mlășlinóse, bălț̆̆, pe malurile |ûrăilor și a lacurilor. - Pe lìngă Bucurescì la Periș, Crivina și Gherganı̆ (Gr. En. 30 p. p. it Exsic.! ; G. uliginosum Gr. En. 30 [non L. nee Herat.] et Exsic.!): în Vlaşea la Comana; etc. - 2 Maiŭ-Luliŭ.

B. clongatum Rehb.; G. clongatum Presl. - În Noldova (G. uliginosum Cz. Flora XIX, 60 [non L.] st Exsic.!; h. j. Guebh. manuse, Edel l. e. 39; Cz. et Sz. l. c. 4; Sz. manusc.); la Agiud (Burri Easic.!); pe lîngă Bucuresch, în Dudescĭ, la Cotrocenı̆, Bănésa și Ferestrěŭ! (G. palustre Gr. Lin. 30 /non L.] at Ex.sic.!) pe malul Colentiner̆; în Vlașca la Contana; etc.

"G. rotundifolium L. G. r'u for rotunde. - Prin pădurile umbróse din regiunea monlană și subalpină. - In Mol(lova (Cz, el Sz. l. c. 4).

G. boreale L. G. borecel. - Prin finetele umede din pădurile unbónse. - In Moldova (Cz. et Sz.l.c. $4 ; G$. palustre (r. Flora XIX. 60 /non L./ et E.xsic.!; Edel l. c. 39) superioră (G. Bocconi h.j. Gueble mamusc. [non DSC.7).2) Inliü-August.

G. Pubioides L. G. rubionil. - Prin finețele din pădurì,

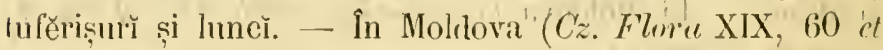
Exsic.l; Eilel l. c. 39 ; Cz. et Sz.l. c. 4) centrală și superiólä, (Guebh. manuss. et kisisic. n. 707 ap. Nym. Comsp).

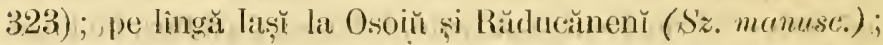

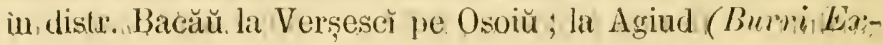




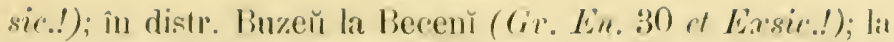

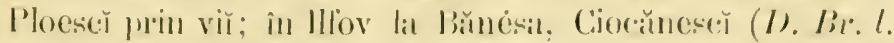

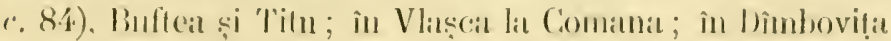

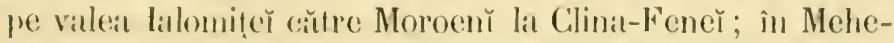
dinṭ̆ pe teriloriul nentral anróne de Orşovil (IViulil. Oest. bot. Zrit. XVI [1866] 16); elc. - 2 Main-lulin.

(i. Bailloni D. Br. Awal. Aceed. rom. sert. II, tom. II. sect. II, 188I, p. 538, Tah. II. G. Lǔ Baillon. - T'ulpină de 15-20 centim., ramóš in dicholonie, ereetü, tetragonalĭ, netedĭ. Frmde qualerne, ovale-lanceolate, acuminate, trinerviate, membranóse, cu fitcia superióră verde-închiš̆, cu cea inferiór:̆ verde palid mĕrunt ispidule, lunğ de 20-30 mill., late de 5-10 mill. P'e-

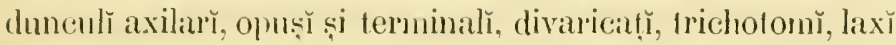
multillorĭ, munị̣̆ la bas̆ cu 2-4. bractee, fórte miě̆, oblonge-lineare. Fructe sessile saŭ subsessile, netede, glabre. - 9 Inпій-. lugust.

Stuț. şi Abit. - Prin pădurile stîncóse din munţr. - În m-ţir Vîlcer la Olănescr, m-stirea Cozia (Asperula laviguta Hoff. manusc. (non L.] et Exsic.! [cum Asperul. taurin mixt.]) și la GolotrenY pe m-tele Fórfeca.

A. rerom L. G. gullečn.-Vulg. Sinziene, Simziene, Sân-

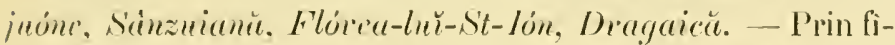
nețe, jĭșmìn, poenile de prin păduř̆. - În tótă Moldova (Cz. Flone XIX, 60 et Exsic.!; Guebh. manusc.; Cz. et Sz. l. (. 4; Sz. manusc.) ; în distr. Botoșanı̆ la Stefŭnescĭ ; Iaș̆ ; T'eenciŭ ; Bêrlad; Bacŭ̌̆ ; Verșeseı̆ și Slănie; Agiud (Burri E..'sic.!): in Rìmnieu-sěrat la Caiata ; în distr. Buzeŭ la Becenı̌ ; in Prahova la Vălenı̆ (Gr. En. 30 et Exsic.! ; G. teunifolium Gr. Ein. 30 [non DC.J it Lixsic,!); pe lingă Bu(“urescĕ la Bünésal (D. Br. Fragm.l. c. 84); Merinani. Buf-

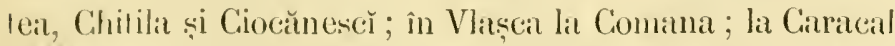
si Slathna (Scholl I. ‘. 284) către Oll; pe lîngă Craliovil in

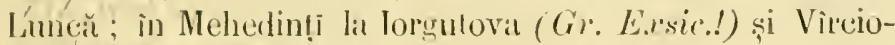
rova! (Kanitz! l. c. 5̌3); elc. - of Itniü-1negust. 
A. purpuresull L. G. purpuriü. - Prin locmer slincose si petrose. -Lai Virciorova călre Porlile-rle-fer ( Burl). 1873. Büns. 228). - 2 Inlin̈-duynst.

G. sylvaticum L. G. de prudure. - Prin tufĕrișutrile și

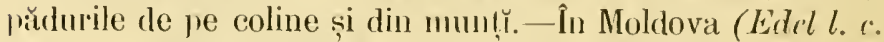
39) ; Cz. et Sz. l. c. 4; Sz. mumuse, A sperula tinctoria $C z$.

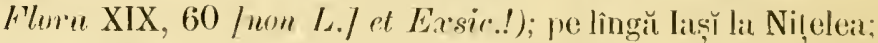

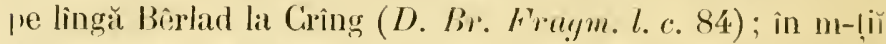

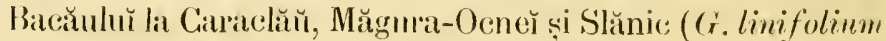
1). Br. Fraym. l. с. 84 [non Lam.7); liı pólele Céhlăuhı̆: in distr. Buzĕŭ la Becenı̆ și în Prahovit către Sinaia (Crr. En. 30 Exsic.!; G. Linifulinm Gr. En. 30 /mon Lum./ \&

- Ésesic.!); în Buceğ și la l'redél; pe lingă Slatina căl.’e Milcovu-de-jos; în m-l,ĭ̌ Gorjiulŭ și ă̌ Vîlcel̆ (Huff. monuse of Exsic.!); în Mehedinț la Dumbrăvilà (Gr. Exsic.!) și îu valea Bahneí; clic. - of luniй-Inliü.

4. aristatum L. G. aristat. - Prin locmmile stincrise si petróse din pădurile munților. - În m-ṭĭ Bucegr mă̌ jos de schitul Pesceral de la Ialomita (Schur Én. 283). - 2 luniŭ- luygust.

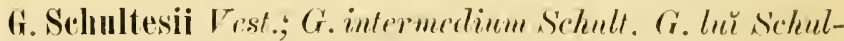
1es. -In distr. Buzĕı̆ la Becenı̆ ( (ir. Erssic.!). - 2 I luliu.

(A. capillipes Rehb. G. capillipes. - Prin pădurile stîncóse și umede din regiunea montană și subalpină. - İı

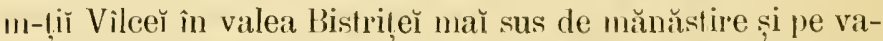
lea Ollulŭ̌ călre m-stirea Cozia! (Cr. linifulinm Muff maunsc. [uon Lam.] ct Exsic. !: Gr. Exssic.!), la Olănesč̆ și la Golotrenĭ pe m-tele Fórfeca. - 2 Inniй-Alugust.

(i. Mollugo L. G. Molluyu. - Prin lufĕrișurĭ și pe mallginea prourilor. - În Moldovit (Edel l. c. 39) et Exsir.!; Cz. rt Sz. l. c. 4; G. Buccomi Cz. Flore XIX, 60 /non DC./ it Exsic.!; Cz. ct. Sz. I. c. 4; G. Aparime Cz. Flora XIX, 60 [non L.] cl Easic.!) inferióră (( 


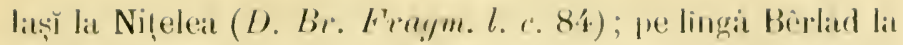

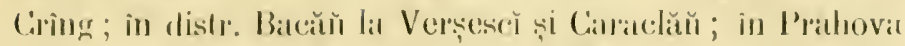

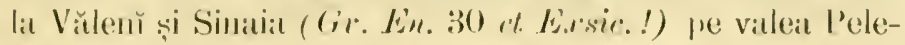

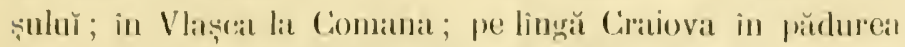
Lénna ; in Mehedinţĭ la Virciorovat călre l'orţile-de-l'er; efc.

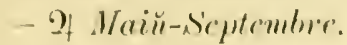

3. pilosmlum stodme. - An Vlascea la Comana ; in Mehe-

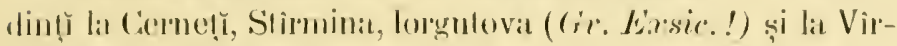
rorovat călle l'or!̣ile-de-fer.

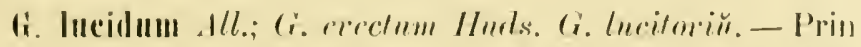

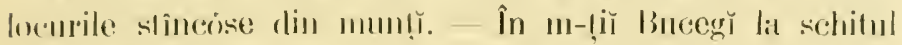

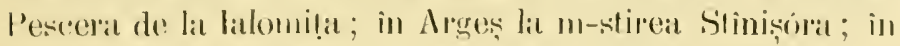

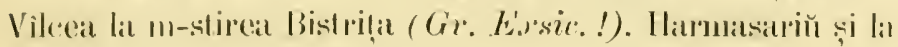

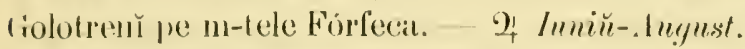

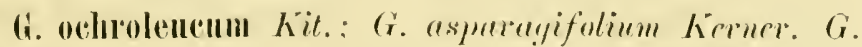
uchrolene. - Prin locurile stîncrise din mun!̣̆. - I a Vircio-

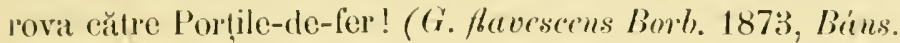
266). - э) Iипій-Iuliü.

G. alsstriacum .Jaeq.; G. sylerster Proll. it pl. aurt. (i. anstriar: - Prin păsunile slîneóse sị calcare din regiunea sulatpină. În Moldova (G. momlanum Cz. Flora XIX,

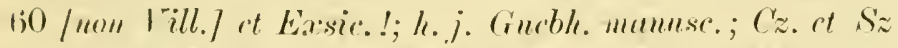
l. r. 4); pe Buceğ (G. pmmilum F'ron. 19!)); in Muscel pe virfu déluluй Moṭoin̆ (Ilıff. Exoners. 1862, l. с. 399). 2) Iuniй-Juliï.

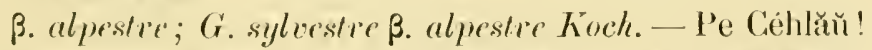
(G. alpestior R. et S. I. i. Courhh. mamusc.; G. pusillum Edel l. с. 35; Cz. Flore XIX, 60 ot E.rsic. !: Cz. rt. Sz. l. r.

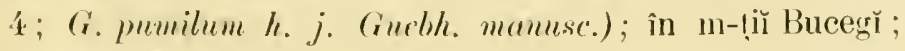
pe vêrfu P'enteleulŭ.

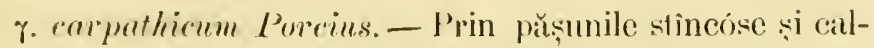
care din regiunea alpină. -- Pe vîrfu Bucegilor.

()ıs. - Se mar citéză : (i. vero-mollıgo Walt. pe colinele aride din Moldova inferióră (Guebh. m(emusc.). - (i. Pubrnum L. în Moldova 
(Cz. et Sz. l. c. 4).- (i. appricum Sibth. at Sin. pe colinele de la Putén\}

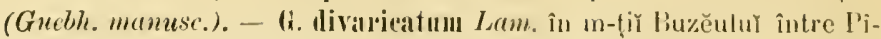
râul Pîrscovu și Bîsca-mare (Hoff. l'xcu'6. 1863 7.c. 118).

\section{VALERIANACEE.}

\section{VALERTANA L。 - Valerianč.}

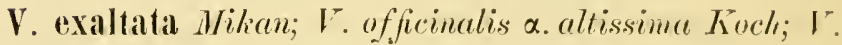
altissima Hornem. V. inaltŭ. - P'rin finețele și pădurile ॥mede din munți.. - În m-țiĭ Vìlcê̌ pe valea Lotrulǔ la Brezoiŭ. - - Iuliŭ-August.

V. officinalis L. V. oficinalǔ. - Vulg. Odolén. Navalnie. Gus:a-porumbulǔ. - Prin finețe umede si pădurı̆ umbróse, pe lîngă pîrăie. - In lólă Moldova ( $C z$. Flora XIX, 60 et Exsic.!; Guebh. manusc.; Edel l. «. 39; Cz. ct sz. l. c. 3; Sz. manusc.) : în distr. Bacăŭ la Verșesč ; la Agind (Burri Exsic.): in m-tị Buzĕuluĭ către Bîsca pe m-tele 'T'ega ; în m-ḷiu Prahover̆ lit Sinaia către pólele Furnicę̆; pe lîngă Bucurescǐ la Cotrocenı̌! ( $G r \cdot E n .30)$, Dudesç̌, Chitila și Ciocănescě ; în Dîmboviṭa la Crhergaň̆, T'itu, Tîrgovistea și Clina-Fencŭ ; în Vlașca la Comana; în Muscel la Isvoruintre-petre (D. Br. Fragm. l. c. 98); în Argeș la Stolnieĩ ; în Gorjiŭ la schitul Locurı̆-rele; în Mehedințŭ la Vîreiorova pe valea Bahně̌; etc. - of Maiй-Lйій.

3. minor Koch.- În m-țî̀ Vîlceè la Golotrenı̌ pe Fórfecii; in Argess pe m-tele Urdica; ; ete.

V. sambucifolia Miken. V. cu for de soc. - Prin pădurile umede și pe lingă torentele din reginnea subalpină. In Moldova (V. cxaltata Cz. Flora XIX. 60 /non Mileen./ et Érsic. !; Cz. et Sz. l. c. 3) min m-lị̂ Bacăuluŭ la Palanca pe lìngă Pîràu-șintululǔ; în m-ṭî̀ Prahoveř la Sinaxia pe malırile Peleșulur̆ lîngă Pavilionul de vînătơre al regeluĭ; èl‘. - 2 lıniй-Alugust. 
V. dioica L. F. dioniru. - Prin finetele unerte din re-

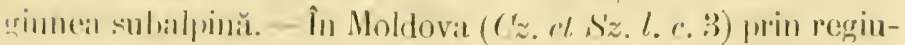

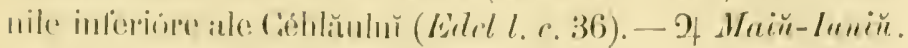

V. Iripharis /. I. triptran. - Prin locurile unede slin-

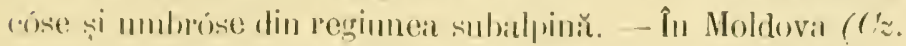

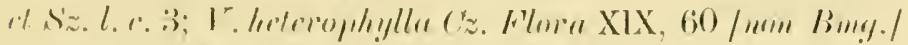

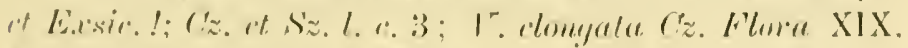

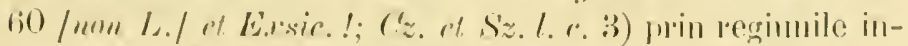

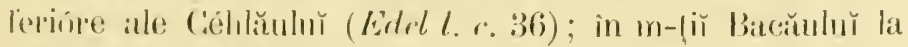

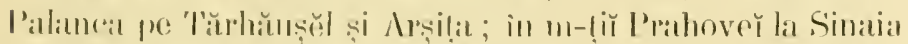

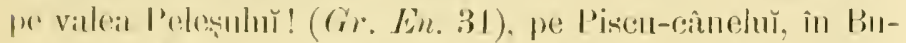

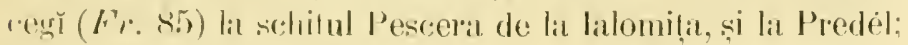

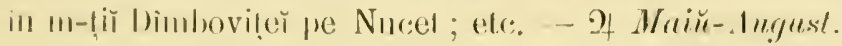

Y. montana L. Y. montomì.-Prin locurile monede, slîn-

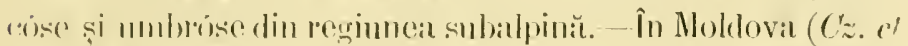

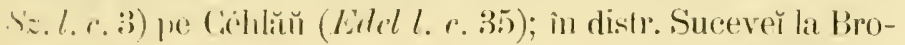

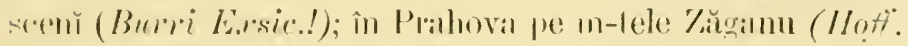

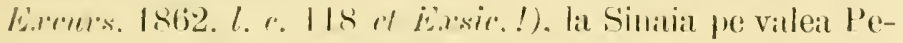

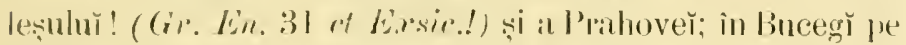
Furnical și la schitul Pescera de lit lalomilą; in Muscel pe m-lele Sturu (D). Br. Froum. l. c. 98). - 4 lemin-August.

V. simplicifolia Kabuth. Y. cu for simple.-Prin loarile ule sii mmbrose de pe lingă torentele din pădurile

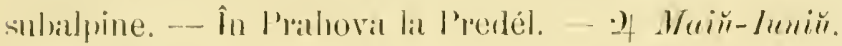

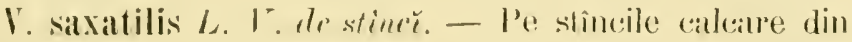

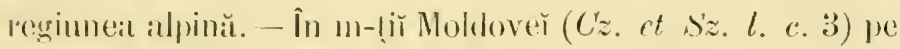
(Céhlǐŭ (Ełlel l. e. 35).

\section{VALERIANELAA Poll. - Talerianelä.}

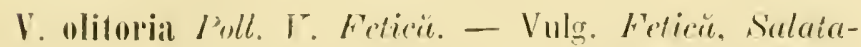

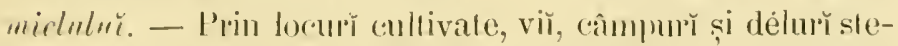
rile. - În Noldova (Fertia olitorin II whe. Cz. Flora XIX.

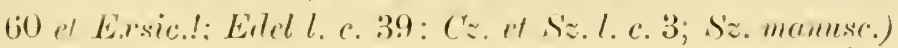


pe lîngă Iaşĭ la Nițelea; pe lîngă Bucurescĭ la Bănésa (I). Br. Fragm. l. c. 98), Mărcuța și Fundenı̆ (Gr. Exsic.!); în Argeş la Stolnicǐ; pe lîngă Craiova pe malul Jiuluŭ la Bucovăț; în Gorjiŭ pe malul 'Tismaneı̆ la Roșia; ete. $-\odot A$ priliǔ-Maiu.

V. Morisoni DC.; V. dentata Poll. V. lǔ Morison. Prin locurı̌ eultivate, sĕmĕnăturŭ, câmpurĭ și coline sterile. - In Moldova (Fedia dentata Edel l. c. 39; Cz. et Siz. l. c. 3; Sz. manusc.). - $\odot$ Apriliǔ-Maiǔ.

ß. Lasiocarpa Koch.; V.pubescens Mérat; Fedia dasycarpa Stev. - Pe lîngă Bucurescĭ la Mogoşóia, Chitila și la Periş în valea Coeioe (Gr. Exsic.!); în Vlașea la Comana.

V. turgida Betcke. V. turgidă. - Prin finețe uscate. locurı̆ aride şi muntóse. - La Vîreiorova către Porṭile-defer! (Borb. C. Jel. 76; Simk. 559). - Р Maiй-Iипiй.

Obs. - Se mal citéză : V. costati $D C$. prin viile din Moldova inferióră (Guebh. manusc.).

\section{DIPSACEE.}

\section{DIPSACUS L. - Dipsac.}

0. sylvestris Mill. D. de pădiere. - Vulg. Varyaciobramulŭ, Varga-pästorinlǔ,, Scaiй-voinicescŭ, Iarbavoinicéscă. - Pe lìngă drumurĭ, șanțurĭ, prin fînețele din pădury și tufĕrişuri, locurì inculte nesipóse şi umede, pe malurile mliștinilor și ale pîrăilor. - In Moldova ( $C z$. Flore XIX, 60 ct Exsic.!; Edel l. c. 39; Cz. et Sz. l. c. 4; Sz. mamusc.); pe lîngă laș̆ la Nebuna, Nį̣elea, Schilul-

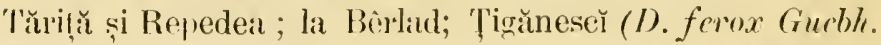
imannse.?) în distr. Bateăŭ la Verșescĕ pe valea 'Taslăulur̆ pe lîngă Bucurescŭ (Gr. Én. 31 et Eassic.!) la Bămésa pe malul Colentineŭ, la T'îı și Crherganı̆; ôn Vlasșca la Cọomana; ete. - $\odot$ Inliü-Septembre. 
3. pimuatifulus Korh. - Tot in aceléşi locmrì cu specia

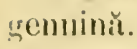

I). lacinialus L. I). lacimiat. - P’rin finę̣e și lulěrișurì umede, pe mirginea prudurilor', pe malurile apelor. - In

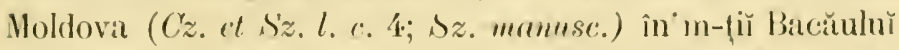
la Cîmpenĭ pe linğ̌ batia de prŏeură; pe lînğ̌ Bucurescŏ (G). L̇n. 30 at Exsic.!) la Bănésa pe malul Colentiner și la Ciocănescĭ; în Vlișea liı Comana; etc.- $\odot$ Inliŭ-A uggust.

1). pilosus $L$. D. peros. - P'e malurile umbróse ale rîurilor, prin phădurı și tuferișurı̆ umede. - In Moldova ( $C z$. F'lor XIX, 60 et E.esic.!; Cz. et Sz.l. c. 4) pe lingă lașì la Hadimb și Mironésa (Sz. manusc.); la m-stirea Agapia; in distr. Bacăı̆ la Verşesel ve malul Turluiulŭ; pe lîngă Bueurescì la Crivina ( $\mathrm{r} r$. Exsic!!); în Arges pe m-tele Ur-

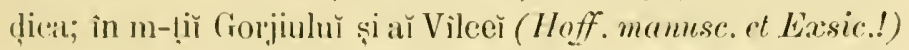
liı Olănesč și către m-stirea Cozia. - o Iuliŭ-dugnst.

\section{CEPHALARII Schrat. - Cefalarie.}

C. Aranssylvanica Sclerad. C.transilvanicü. - Pe margrinea agriilor" și a viilor, pe cimpurŭ și coline aride. - In Moldovil (Edel l. c. 39); h.j. Guebh. mannse.; Cz. et Sz. l. c. 4; Scabiosa lencantla Cz. Flora XIX, 60 lnon L. nec Bmg.l et Exxsic.!) pe lîngă laş̆ la Şăpte-ómenı̆ (Scabiosu transsylranica L. Sz. mamesc.) și la Buciun; la Agiud (Burvi Exsic.!); la Ploesè̃ (1l.! ap. Kanitz l. c. 210) și în

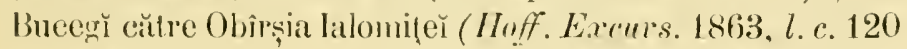
ct. Exrsic.!)? ; pe ling: Bucurescĕ lat Merinani, Mogoşóia și Buflea; in Vlaș̣a la Combna și l’rund ; în Voljiŭ lat pădurea Lémma; ete. - $\odot$ Inliú-séptembre.

C. cormiculata Réem. re Schult. C. corriculatie. - Prin locuř̀ petrosese și sterile, coline arride. - În Moldova (Sece-

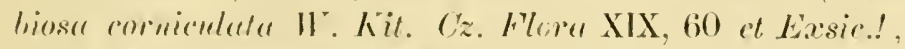
('z. et s'z. l. c. 4; Sz. mannse.); în Covurluin̆ la Pechea 


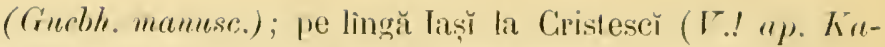
nitz l. c. 210). - 9 Iulin-Sisptemelue.

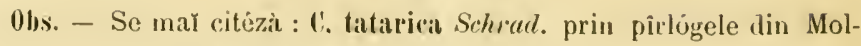
dova inferióră (Guebh. munusc.).

\section{KNAUTIA Conlt. - Knautie.}

K. Iongifolia Kush. K. cu for lungr. - Vulg. M/uscatudroculn. - Prin păınnile stincóse din reginnea subalpină i alpină. - In Moldova (Scabiose lomegifolin 11. Kit. Cz.

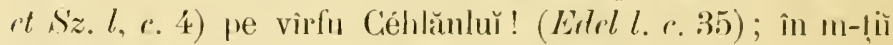
Bucegi la schitul Pescera de la lalonị̣a! (Fr. 89) şi la Predél ; in Argeș pe in-lele Cozia ; in Gorjiŭ la schitul Locurřrele. - 9 Inliü-durgust.

K. sylvatica Duluy. K. de pardure. - Prin pădurile unbróse din munț̆. - In lólă Moldova (Guebh. manuse.); in Muscel pe m-tele Leresč (Hoff. E.trmis. 1862, l. $\bullet .31$ ); la Curtua-de-Arges ((rr. Lrssir.!): ete. - of Inliü-August.

ß. lancifolia Menetf. - Prin pădurjle din reginnea subal-

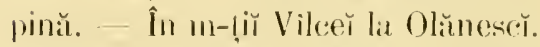

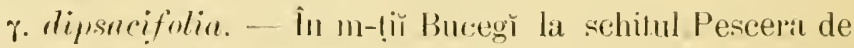
lat lalomila (Scahiosa dipsecifolin Host. Hintil! sec. Krenitzl. 2.211 ).

K. Irymeja II'nff. K. Drymrja.-Prin pŭrbrile de pe coline și din munṭĭ puṭin inalțĭ. - P’e lîngă Cerneți la Ior-

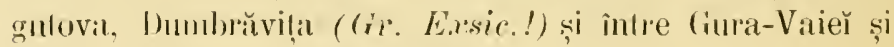
Vìreiorova. - 2 lunin- luegust.

K. arvensis Combl. K. de câmp. - Vulg. Huscatu-dra-

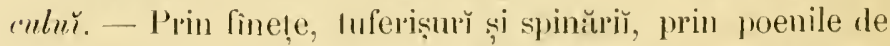
prin prudur şi pe coline. - In lolĭ Moldova (Guebh. ma-

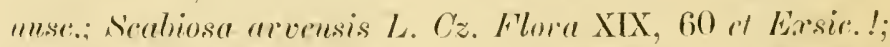

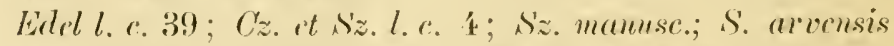

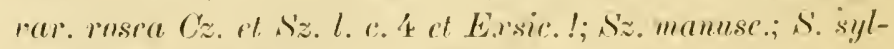
vatica Cz. Flora XIX, 60 /non L.] et Exsir. !: Cz. rt s'z. 


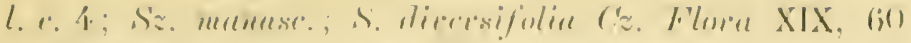

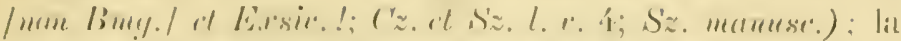

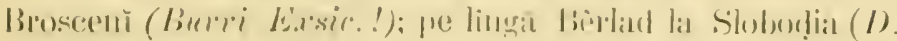

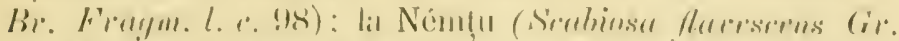

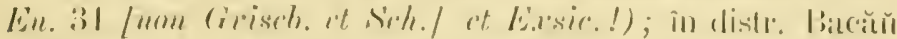

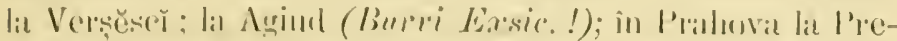

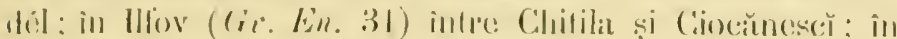

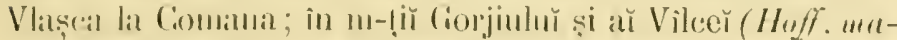

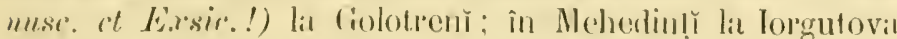
sil lluoval (Cor. Lissie.!); ele. - of luniri-dugust.

3. integrifulin Menff. - Pn Moldova (Sicabiosa surecisen ("z. Flora XIX, 60 / mom L./ it Es.rsic.!; h. j. Guelhe. mamusa.) pe lingŭ lașŭ la Repredea : la m-stirea $\Lambda$ gapuia (K. syl-

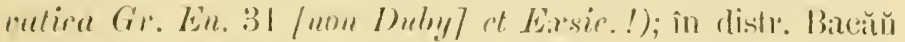

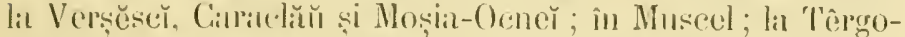

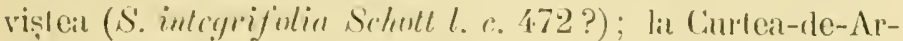

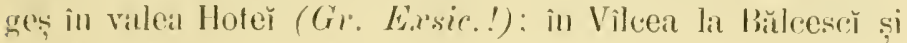
pe valea lootrulŭ la Bre\%oin̆.

K. atrorubens .Janka in litt. ad D. Br. K. négrŏ̌-pmepurir.-Limb calicinal subcilindracen, atenuat-8-atristal, cu ariste aprópe de done or mă lungi de cill limbul; cu sele (sctae) între ariste nule sén̆ förte semrte; cu pedicelul calicinal (stipex:) fórte distinct. - 2 Mairi-Juliur.

Staț. și ahit. - Prin fîneţe useate, tuferișuř și spinerit. - În România (Trichera arrensis var. jurmerea Ho(f. Exsic.!) pe lìngă Bucureser pe marginile Colentineř ( $K$. hybridt Gr. Ën. 31 [non Coult.] et Firsic!: K. hybrida fs. integrifolia Gr. lin. 31 [non Gren. et Godr. nee alior.] et Exsie.!) la Ferestrěŭ, Măreuţa, Chitila, Buftea și Ciocănescy; in Vlasca la Comana.

Olıs. - Fórte afină en K. macerlonicu Griseb, de care totusị difere : prin limbul calieina] sutucilindracrŭ atcmeut-S-uristat (limbus calycinus subcylindracens uttemuatus-s-(r)istatus), éră nu scurt apert campanulat și abrupt-8-aristat; prin aristele "uprópe de doue ori mă lungi de cut limbul (aristar limbo fere duplo longiores), cră nu sle lungituea limbulur; prin sctele dintre ariste nule sítü förte scurte (setae inter a-

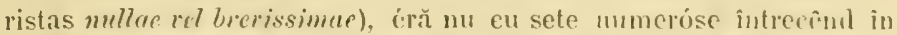
lungime jumătatea aristelor; prin pedicelul calicelur forte distinet (stiper ealycis ıistinctissimus), éră nu de abia distınet. 


\section{SC'ABIOSA L. - Ścubiosŭ.}

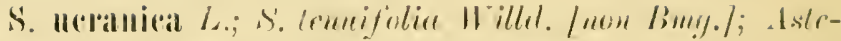

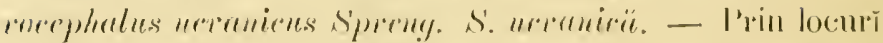
sterile și nesipóse. - In Moldova inferiórăi (Guedble munuse.);

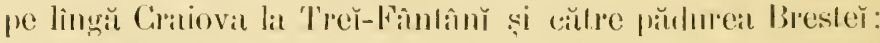

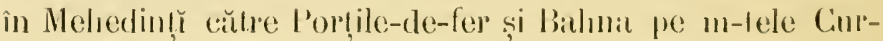
chis. - of luliur-duryust.

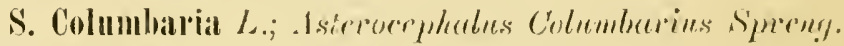

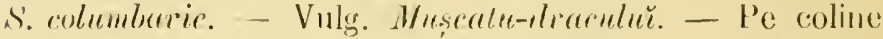
uscate și prin fìneţele slîncóse din munți. - În Moldovi

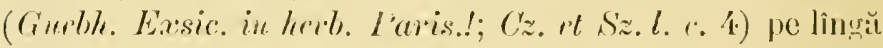

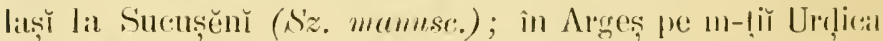

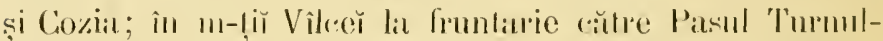
roșu (Fiess frl. Troussile. 301), si la (iolotrent pe m-lele Forfecat. - or of Imuirt-duynst.

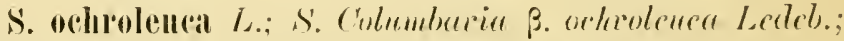

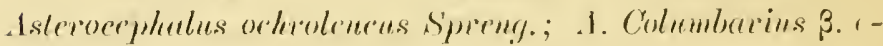

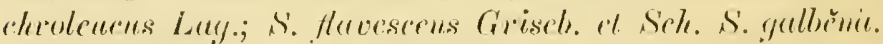
- Vulg. Sipicï. - Prin finel̨e uscite, locurr̆ nĕsipose do

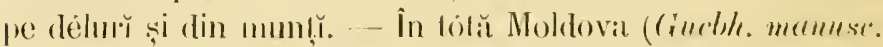

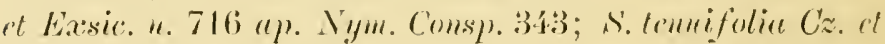

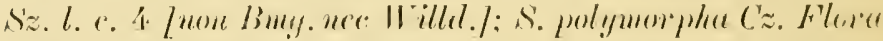

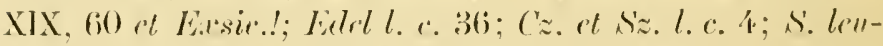

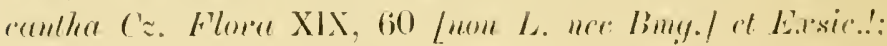

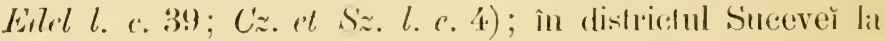

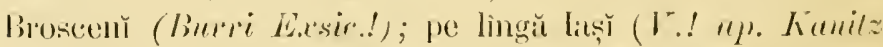

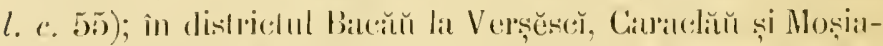

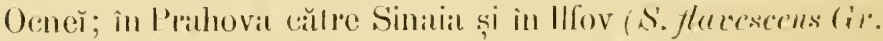

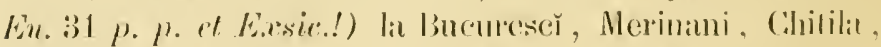

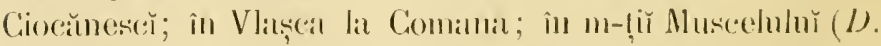

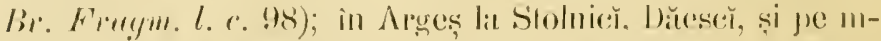

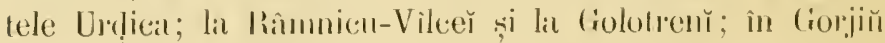




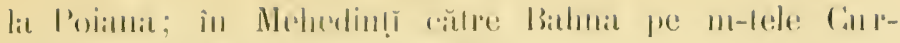

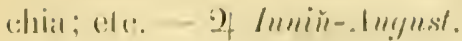

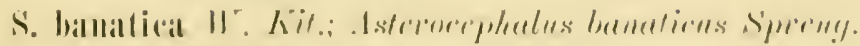

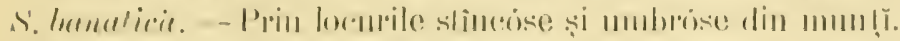

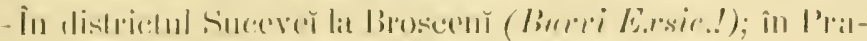

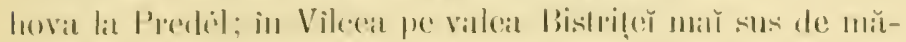

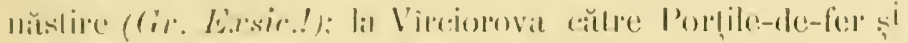

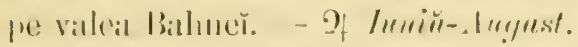

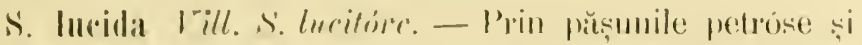

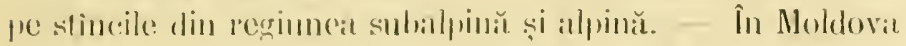

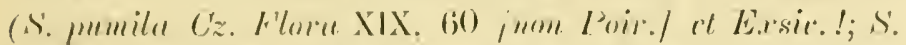

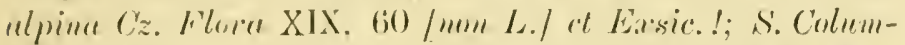

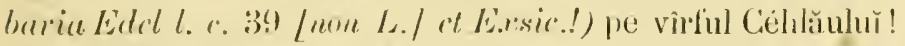
(.Junlin ap). Kunitz l. e. 210); în m-liī de la T'êrgu-Ocnè̆

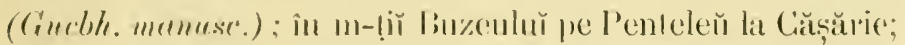

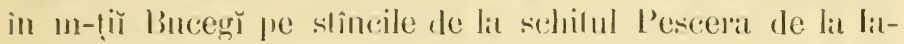

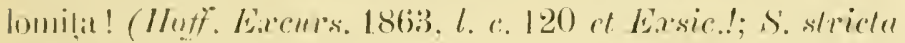
II. Kit. (ir. En. 31 rt Estrite!) si pe valea Babelor; ele. - or Inlin-Angust.

S. Suceisa L.; Succisa pratensis 1/nench. S. Succisï.Vulg. Lünin. - Prin fintetele unnede din pădurile si tuferișurile regiuneŏ montane. - În Noldova (Edcl l. c. 39; ('z.

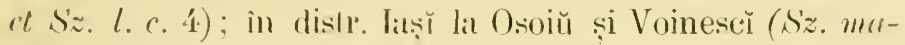
mesc.!); la Agapia (Crr. Em. 31 et E.rsir.!). m-stirea Néntuhŭ și la schiful Sihla: in m-ḷi bacăuluĭ la Moṣia-Oenè: pe dèlul Strajju și lat Măıăstirea-Ciașinulur̆; in Prahoval la

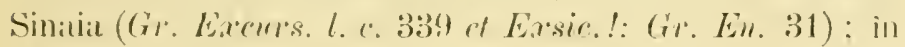

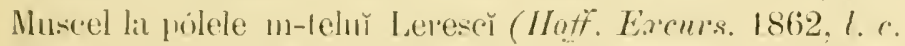

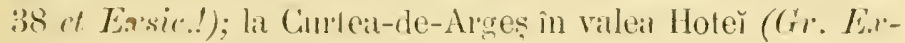

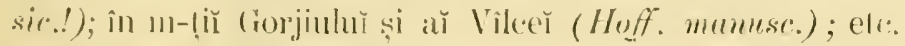
- 2) Inliü-Séplembire.

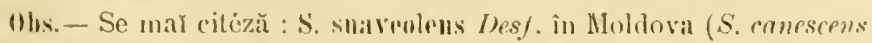
W. Kit. ('z. et Sz. l. c. 4). - S. silmoifotia W. Kit. in Prahova pe

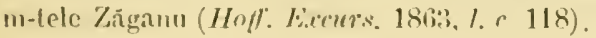




\section{SYNANTIIEREE.}

\section{C.ORYMIBJFERE.}

\section{EIPATORICII L. - Eupalorie.}

E. cammalinum L. E. cu fŏ de cûncpë.-Vulg. Cainipacodruluĕ, Diembravnic, Cânepiơrč̆, Cânepólie. - Prin locurile umede si umbróse, pe lîngă pîrăile din pădurı̌. - Îu Moldova (Cz. Flora XIX, 71 et Exsic.!; Edtel l. c. 41; Sz. manusc.) superióră (Guebh. Not. 23 et mamusc.) pe linğ̌ Iaşı̆ la Nițelea; în m-ḷii Bacăulıŭ la Slănic $(D$. Br. Fraym. l. c. 100), Càmpenı̌ şi Verşěscı̌; la m-stirea Agapia (Gi. Erbor. l. c. 129 et Ersic.!) și pe délu Pahonier ; în m-țì Buzĕuluı̆ la Bîsca pe T'ega; în I)imbovița la T'itu și (Gherganĭ (Gr. En. 31 et Exsic.!; Kanitz l. c. 216); in m-liĭ Gorjiuluı̆ şi aı̌ Vîlceǔ (Hoff. mannsc. et Exsie.!) pe malul Oltuluŭ către m-stirea Cozia ; etc. - 2f Inliu-Anynst.

\section{AderNostries Cass. - Adenostil.}

A. albifrons Rehb.; A. albida Cass. A. cu fot albc.-Vulg. Cincuraș. Flórea-ciumer, Bosací. - Prin pădurile umbróse din regiunea subaljină, pe malurile forentelor și a pîrăilor. - În Moldova (C'acalia albifions L. fil. Cz. Flora XIX, 71 et Exsic.!) superióră (1. Petasites Bl. st Fing. Guebh. manusc.) pe Céhlăn̆ (C. albifrons Edel l. c. 36); în ı-țiǔ Bacăuluŭ la Palanea pe lìngà Pirâu-șanțulŭ ; in m-tii Prahover la Sinaia pe P’iscu-cânelŭ și cŭlre pólele Furniceř şi a Babelor; etc. - 9 lullĭ-dugnst.

A. alpina Bluff. et Fing. A. alpinä. - Prin pădurile subalpine și pășunile alpine, pe malurile pîrăilor. - Îı

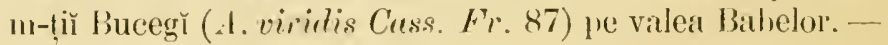
2) Inliй-Auyust. 


\section{Honogise Gass. - Omoginu.}

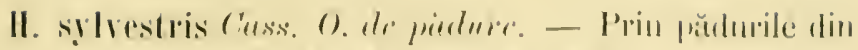

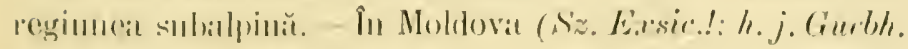

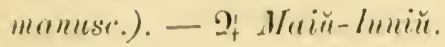

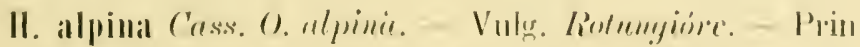

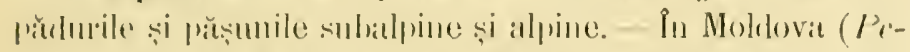

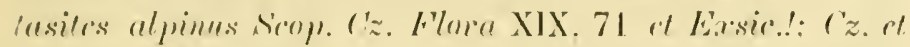
s.z. I. c. 1s) superiorĭ (h. j. Gurblh. manust.; H. discolor

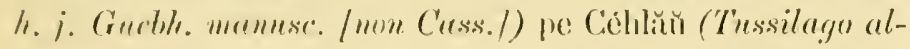

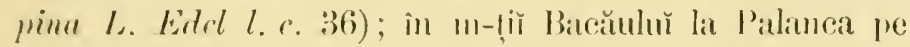

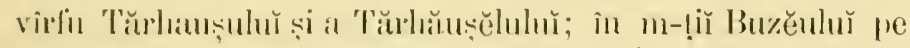
Peuteleă: in m-tị̆ l'rallovè pe Buceğ! (T. alpina Hoff. Excurs. 18633 , l. (. 119) în valeal Ialomilè ! (Fr. 86), Fur-

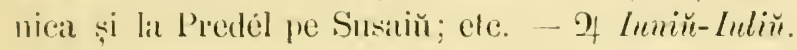

II. discolor Cass. O. discolurie. -- Prin passunile din re-

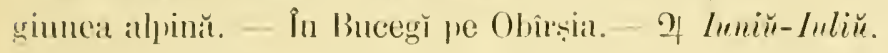

\section{TISSILAG0 1. - Tussilag.}

T. Farliara L. T. commen. - Vulg. Podbul, Porlbil. Prin locurile aldgilóse și mnede, ne linği pîrăie. - In tótă Moldovil (C'z. Floru XIX, 71 at Easic.!; Edel l. c. 37; Gurbh. mamusc.; Cz. ct Sz. l. c. 4.9; Sz. mamusc.); pe lingă

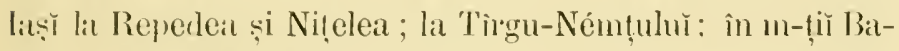
căılŭ la Slïnie: in Prahova la Vălenı̆ $(G r$. En. 31) și Si-

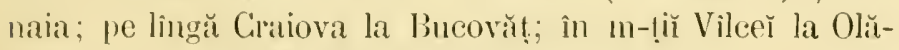
nescř; ete. - of Martiu-Apriliu.

\section{PETASITES Gacrtı. - Petasită.}

P. oflicinalis Mornch. P. uficinalii. - Vulg. Captulan, Cieptalač, Brustur, Brustur-dulce. Riudäcina-ciumě, Cu- 
muruz, Sudóce-laptrlui. - P’e lingă pîrăile din pădurile regiunĕ̀ montane. - In Moldova (Cz. Flora XIX, 71 of

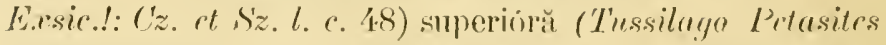
Muff. Edel l. c. 37; I'. vulgaris Desf. I. j. Gumblh. manuse.;

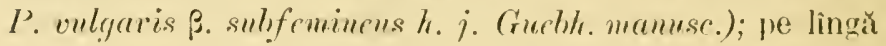
Iiși la Repedea (Sz. mumse.; P'. hybridus s'z. manusc.) și la Niṭelea (I). Br. Frorgm. l. e. 100); la m-stirea Némṭulǔ̆

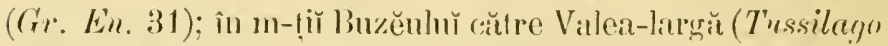
lugbridu Hoff. Excurs. 1863. l. c. 118); în Nuscel la Câmpmlung pe malurile Riu-T'ìrguluř (T. Pelusies Hoff. Exarurs. 1862, l. «. 40) și la Contescì (Gr. Erasic.!); etc. - 2 Harliü-ipriliu.

P. albus Garmern. I'. albie. - Vulg. Cucminz. - Pe malurile torentelor din pădurile subalpine și montane. - In Moldoval superióră (Cz. ct s'z. l. r. 4; h. j. Guelh. manuse; I. ramesus Cz. Flora XIX, 71 it Exsic.!; Cz. it siz.l. c. 1.8; P. mivens (Z. Flmo XIX. 71 / hom Bumg.7 ot Eassic.!;

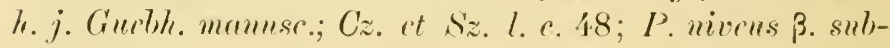

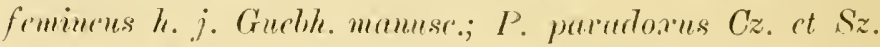

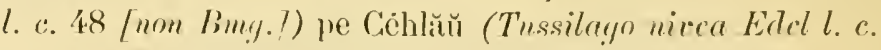

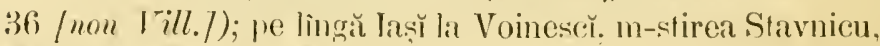
Mironésal și Poenŭ (S'ż. mamuser.); la m-stirea Nému!nlur̆ (P’.

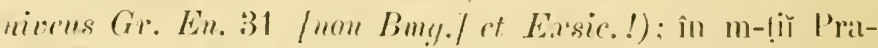
hover la Sinaia $(G r . \operatorname{Lu} .31)$ pe malurile Pelesulur. - of Ipriliu-_laiü.

0hs. - Nu sciú ce pot fi : P. tomentusus DC. indicat la Scinteia (Guebh. manusc.) și Tusssiliagno palustris de pe Céhlăŭ (Élel l. c. 36).

\section{LINOSYRIS DC. - Linosiridŭ.}

1. Vulinalris Cass. L. commonic. - Prin finetele sii mferrişurile de pe colinele atride. - In Moldova (Chrysocoma Li-

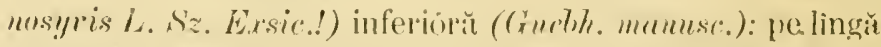

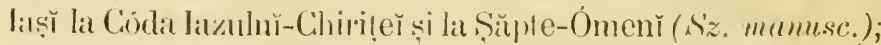
in m-țĭ Bacăılư̆ la Caractăŭ pe Babat-ghicea și pe Moșia- 


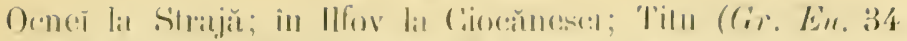

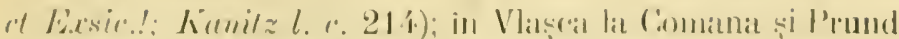

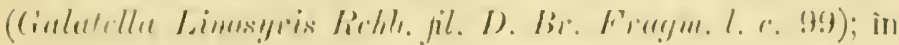

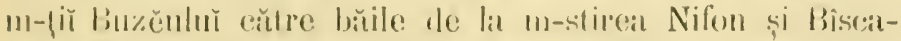

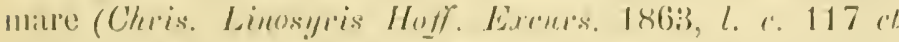

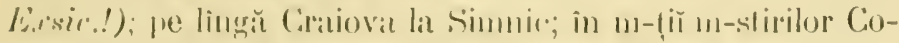

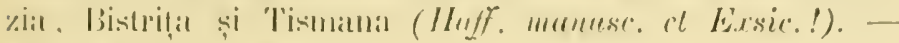

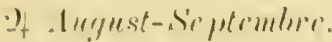

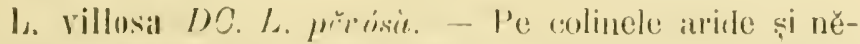

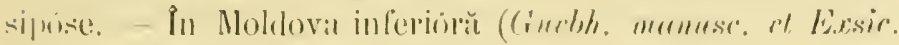

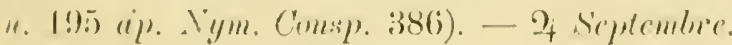

\section{ASTER I. - Astru.}

1. alpinus L. 1. alpin. - Prin pășmile stincóse din reuguneat alpină. - Âl Moldova (1'z. Flone XIX, 71) pe Cé-

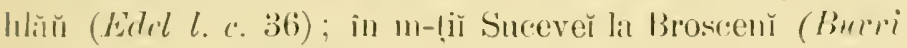

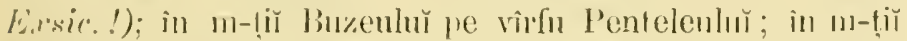

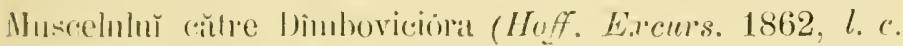
39). - 2 Iuliur- Iunysst.

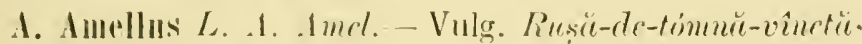

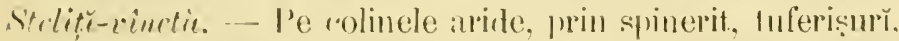
Inin locurile petrose din regimnea montantă - În tolă MolHoval (Cz. Flera XIX, 71 at E.rsic.!: Edel l. e. 41: Guebh. munusc.); în distr. laç̣̆ la Solonẹ̣̆, Trifescŏ, Adamachi

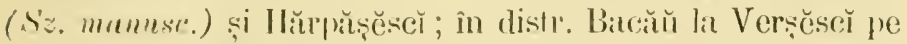

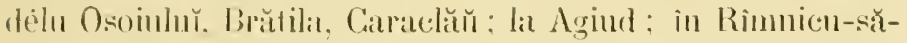

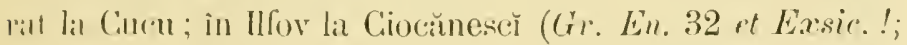
Krnniz l. e. 214); in Vliș̣ca la Comana și Prund (I). Br.

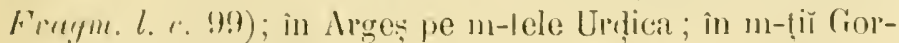

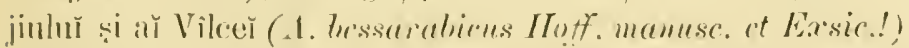

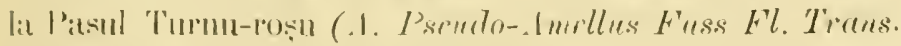

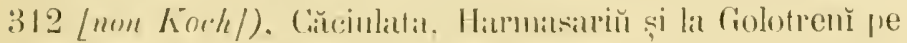

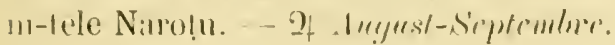


1. T'ripolimm L. A. Tripmliu. - Prin finetele si locurile

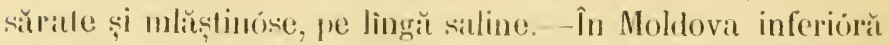
(Tripolinm velyare Ners. Gurlok. Vot. 11 et maruse.) pe

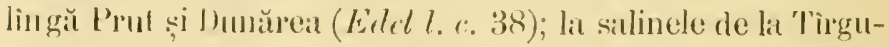

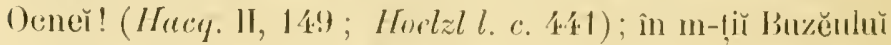
la Sareat-lŭ-Buzĕú în Prahoval la Telega. - 2 AugustSeptembire.

B. pannonicus Blluff. rt Fingerh.; 1. prennonicus Jacq. -Prin finctele mlaștinóse și sŭrate. - In Moldova (1. Tripolium Cz. Flor XIX, 71 / non L./ et Exsic.!) inferióră la

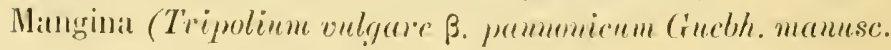

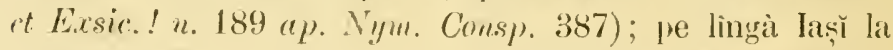
Costulen̆, P'risacinı̆. Ţ'u!̣ora (A. Tripolium Sz. manusc.). Vişan, Cuculenĭ și lat Podul-Ilóič̆.

Ү. diffusum Nées. - Prin mliștinile sărate de la Cralațĭ (Tripolinm vulgare var. diffusem I)C. Guebhe manusc.).

\section{G.ILATELLA Gass. -- Galatelĕ.}

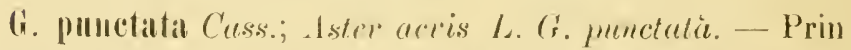
finclele umede şi sărate. - In Mloldova (Astế punctatus W. Kit. Cz. Flor" XIX, 71 it Exsite. [nom. A. canus]!) centrilă şi superiorĭ (Gurbh. manuse.); je malurile Prululŭ și a bunăreĭ (A. muctutus Édel l. c. 38); pe lingă Iaş̆

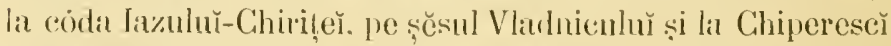

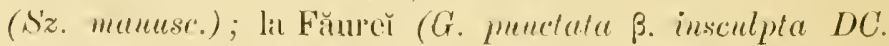

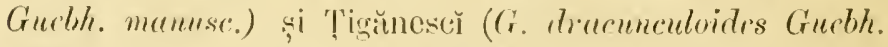
mumuse.); în Vlașca lat Comana către valea Gurbamulur și la Prund (G. insculpta V'ers. (1). Br. Frogmu. l. c. 99); ete.-

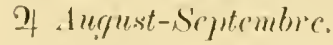

(i. canna Vees. Gr. c'n fŏ allicióse.--Prin finę̧e şi tuferişurı̆. - În Moldova (1ster cemus IT. Kit. Cz. Flora X IX, 71 ; Eslcl l. c. 41) pe linğ liș̣̆ către (ioron̆ (Sz. manusc.); in m-ţĭ Gorjiulun și aŭ Vileeř (Hoff. manusc. ct Exsic.!).2) August-Septembre. 


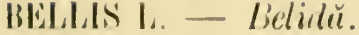

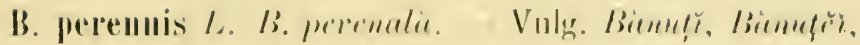

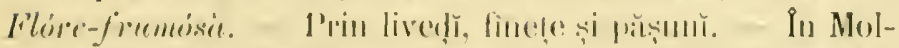

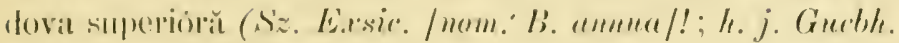

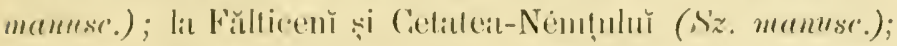

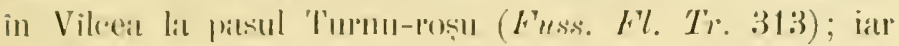

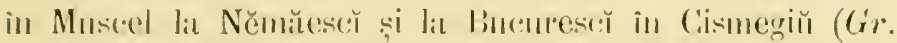

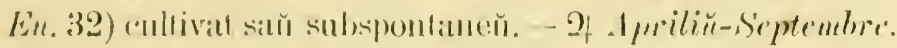

\section{ERlieRON L. - Erigeron.}

E. alladense L. E. de Conade. Vulg. Beetrinis, Spirince. Sorvert, Stelutic. - P'rin locurř cultiville și ineulte.

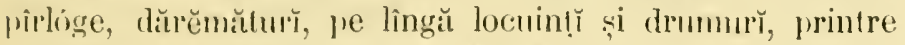
petrele de pe malca rîurilor. - In Moldova (Cz. Florra XIX, 71 it Eisic.!; Sz. manusc.; E. rucemosum Cz. Flora XIX, 71 /non Bung.l et Exsic.!) tólă (Guebh. manusc.); la Iaşı̆! (I.! "1). Lanitz l. c. 63); Bêrlad (D. B). Fragmu. l. c. 99); Agind (Burri Éxsic!!): în distr. Bacăŭ la Cutraclŭŭ; in Ilfov (Gr. Eu. 31 it Exssic.!; Kunitz l. c. 215) pe linğ Bucurescĭ; in Vîlcea la Bălcescè și frololrenĭ în fiorjiŭ la Roșia; etc.$\odot$ luliu-septenture.

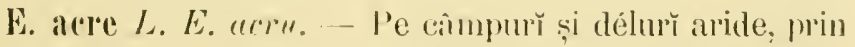
lomury sterile din mun!̣̆. - În Moldova (Cz. Flora XIX, 7 I 't Exssic.! ; Eilel l. c. 41 ; S'z. mamusc.) centrală (Guelsh. memese.): pe lingă Iaș̆ ( I.! ap. Kúnitz l. c. 63) la Nilelea:

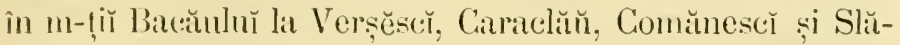
nic (D. Br. Fragm.l.c. 100); la Agind (Burri Exsie.!); in P'rahova la Sinaia (E. carpathicum Gr. En. 32 /nom Gristh.] ot Exsic.!; E. Villarsii Gr. En. 32 [non Bell.] at E.rsic.!). in Bucegì (E. alpimem Gr. En. 32 [non L.] at Exsic.!) și Predél; în Ilfov (Gr. En. 31 et Esssic.!; Kanitz l. c. 215); la Buftea și Crivina; în Muscel (Imula graveor- 


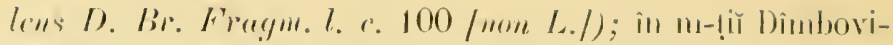
tĕ pe Plaind-Domnese; liı Arges pe m-tele Urḍea și Cozia;

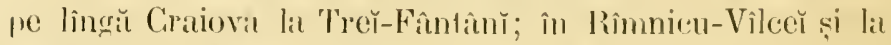

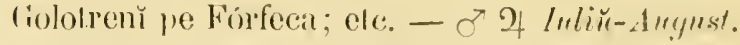

E. alpinum L. E. alpin. - P'rin phsunile petróse din regimea alpină. - In Moldova (Edd l. c. 37) pe vîrfu Cé-

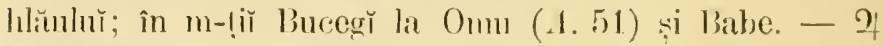
Inlivi-1ugust.

E. "uูiflorum L. E. "niffor. - Prin pŭșnile petróse din

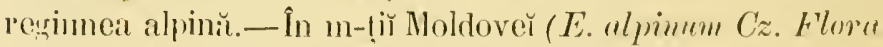
XIX, 71 /nom L.7 of Exsic. /mom. Aster alpimus/!; h.j. (ruchlh. mamuse.) pe vîrful Céhlăulı̆ (.Janka! ap. Kanizl. r. 215); în Buceğ pe Obîrụia și Babe. - 2 lulin- luegust.

\section{SOLIDAG0 L. - Solidaginŭ.}

S. Virga anrea L. S. Vargitede-ame. - Vulg. I'argä-

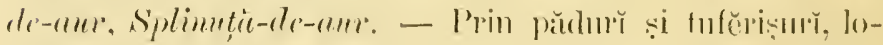

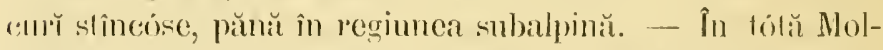
lova (Cz. Flene XIX, 71 et Exsice!; Guchle. memese.); in

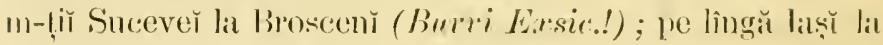

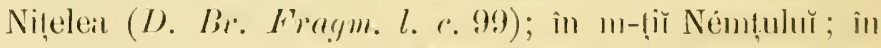

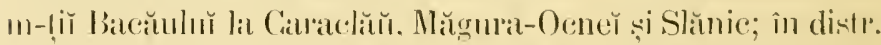

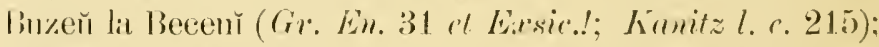

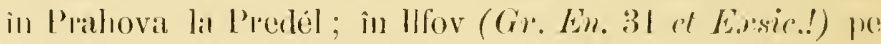
lingă Bucurescĕ; în Vlisçea la Comana și P'rund; la Cuulea-

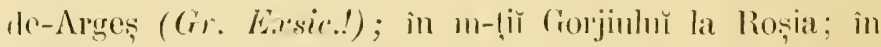

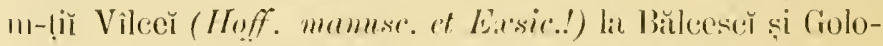

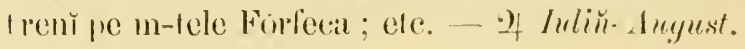

THLLKIA Bm心. - Teletic.

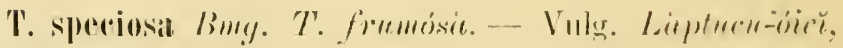

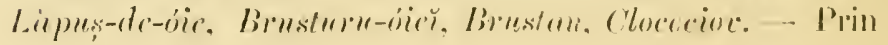




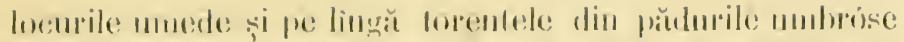

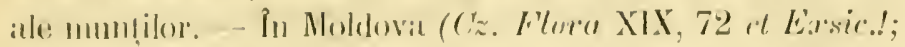

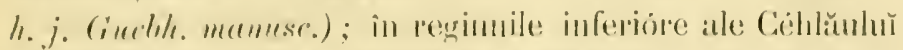

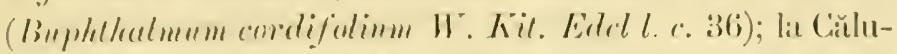

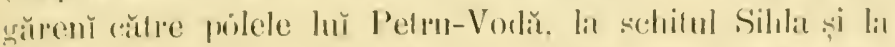

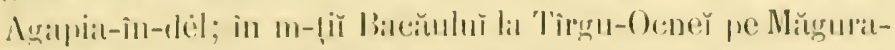

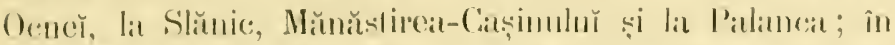

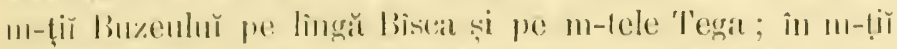

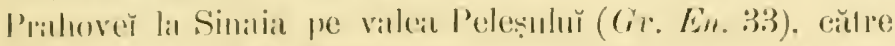

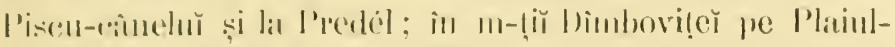

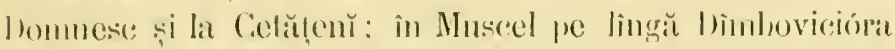

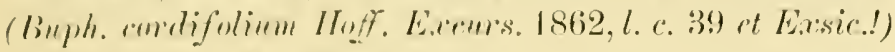
lat Pesceră (D. Br. F'roym.l. c. 100); în Arges către pilele m-tehŭ Cozia la Varallical m-liì m-stirilor Bistrilat, Co-

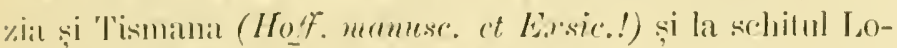

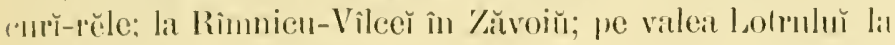
lïе\%оій ; cle. - 2 Inliü-dugust.

(1)ৎ. - Gueblıard (Not. 23) indică, din erore, acéstă plantă și prin imprejurimile Iașulur, dar în acéstă localitate ca nu provine.

\section{INULA Һ.-Inulă.}

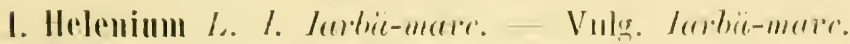

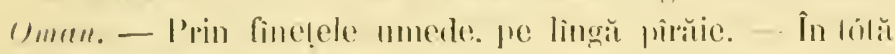

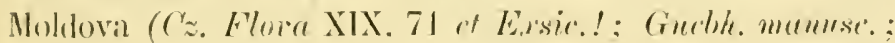
Eild l. c. 37 ; Cz. rl sz. I. c. 4.t; s'z. manuse.); pe lingă Iilș̆ laı Niṭelea (I). Br. Fra!mm.l. c. 100) și Lungamı̆ în

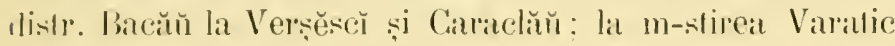

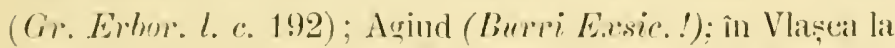

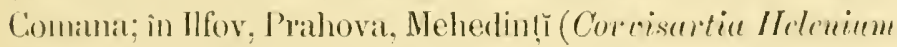

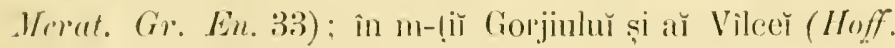

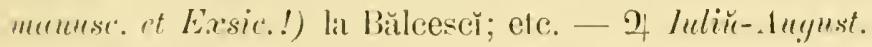

1. g̈ermanica L. I. gremanicä. - Prin finelede nseate

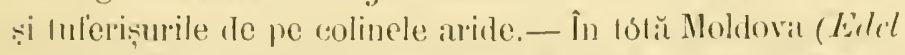

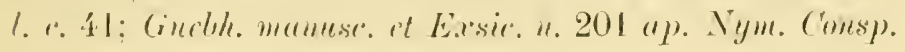


392; Cz. ct sz. 1. c. 49 of Lixsie.!; s'z. menuse.); pe linğ

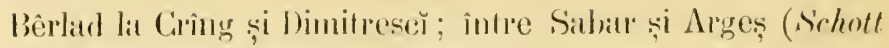

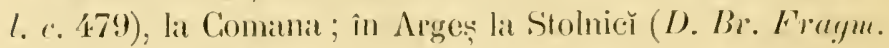
l. с. 100); î Mehedinț̆ intre Sehelea-Ciantover și CimratVăiě̀ ; ele. - 2 lunir-Angyest.

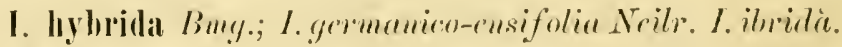
- P'rin locurì aride și ierbose. - In Moldova (Cz. Filora XIX, 7I; Cz. et s'z. I. c. 4; s'z. mumuse.); in Vlașcal la Comand. - of luniü-d leyust.

I. ensifolia L. I. cu foŭ rasifurme. - Pe délurile aride și ierbúse. - În Moldova (Edal l. c. 4.1; Cz. ct Sz. l. c. 49); Aster consifolius Seop. Cz. Flora XIX. 71 et Exsir.!) infe-

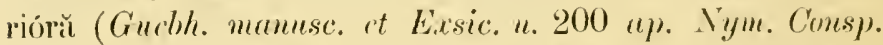
392); pe lîngă laș̆ către Largar (Sz. momesc.); pe lingă Bêrlad (D. Br. Frogm. l. e. 100); în distr. Bacăŭ lat Caraclăú pe Baba-ghiceat; între pîurile Sibar și Arges (Sichott l. ‘. 479); la Comana ; la Caracal și Slatina (Schott l.c. 284).-2) luniŭ-August.

I. salicina L. I. cu for de salcr.-Vulg. Cimonir.-D'rin

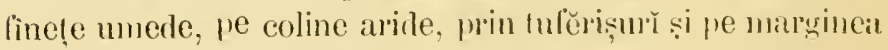
pădurilor. - In lótă Noldova (Gucbh mamesc.; Eidel l. ¿.

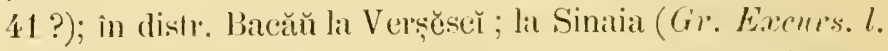
с. 339; Gr. En. 34); in Vlașca la Comana ; în m-lị̆ (rorjiulur la sethitul Loemř-rĕle. - 2 h hin̈-August.

ß. cordata; I. cordatu Boiss.; I. squarrosa Griset. / Inou L.). - In Moldovat (I. salicina B. aspera [Poiret] Guelhle. Exsic. n. 71 ap. Beck Denkschrif. der mathem.-naturu iss. cl. d. k. akad. d. wissen. Xl.IV, 303) la Fŭureŭ (I. saticina 3. Latifulia DC. Crucbh. manuse.); lat m-stirea Agapia (1. germanice Gr. Erbor. l. c. 129 [non 1Fill.nec L.]?; I. squarrusa $G r . E n .33[n o m L$.$] ?); în Ilfov la Ciocănescì (Gr. Exx-$ sic.!); în Vliș̣ea la Comana.

I. synarrosa L. I. squuróš̀. -- Prin fuferișurile si pădurile de pe colinele aride.-In Moldova inferióră la P'echea 


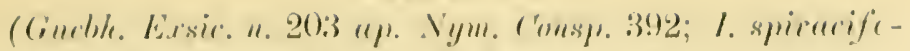

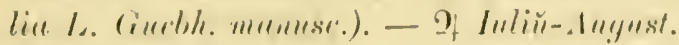

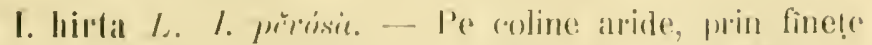

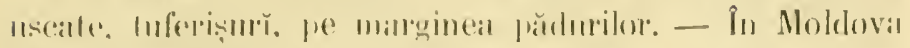

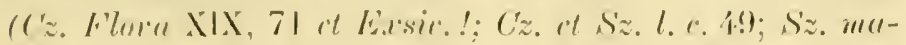

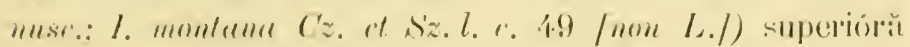

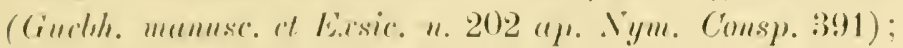

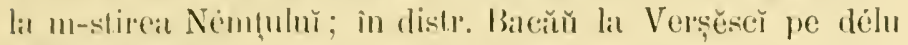

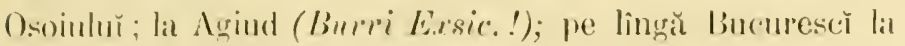

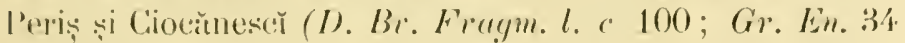

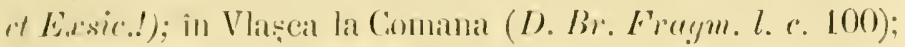

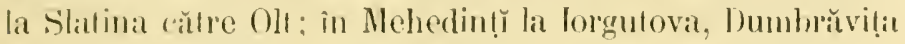

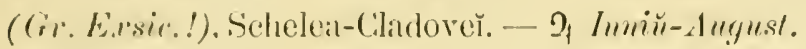

I. Conyza D) I. Conizü. - Vulg. Mórtea-pmicelne.-

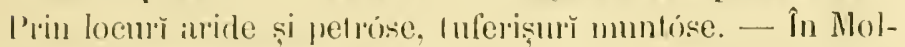

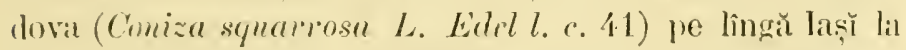
Rusěnĭ, Tonesč. Goron (S'z. munusc.) si la Repedea de-

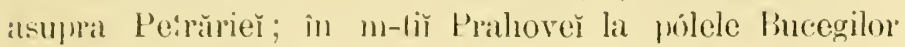
(C. squarrosu Hoff. Excues. 1863, l. c. 119 el Eassic.l); in m-ṭi m-stirilor Cozia, Bistrița și Tismana (Hoff. mamusr.). - o Inliir-Septembre.

1. Oculus Christi L. I. Ochinl-lur-Crist. - Prin locurì aride. finete sterile și pựn hufĕriṣurı̌ - În Moldova infe-

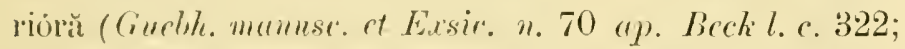

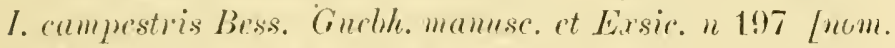
1. Or.-Ch.7 "p. Xym. Consu. 392); intre rîurile Sabar și

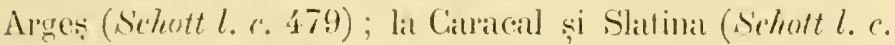
28. - - - Invirir-Inliir.

I. Writanica L. I. Iritumicu. - I'rin locurr și fineṭe nmede. pe lingă pîrŭie și mlastini, pe mauginea pădurilor.--

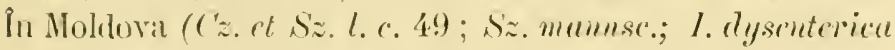
Cz. Flurer XIX, 71 /mon L./ it Exsic.!; Ellel l. c. 41; I.

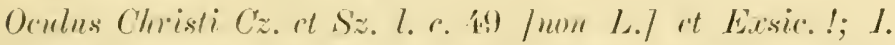

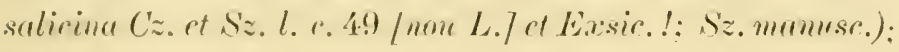




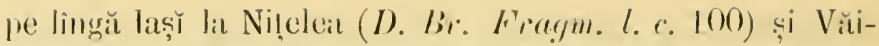

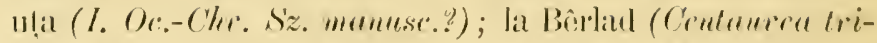

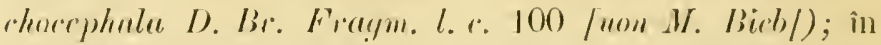

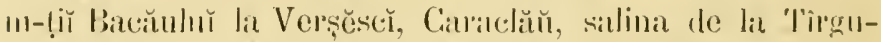

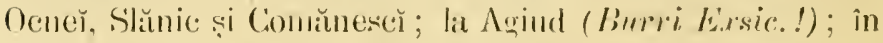

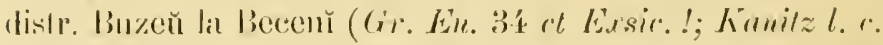
215); la Fŭurĕ și Ploescĕ (.1l.! ap. Kuniz l. c. 215); 10 lingă Bucurescĕ la Merinaıi ; pe lingă Craiova in Lımă ; in

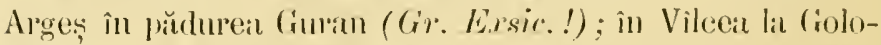

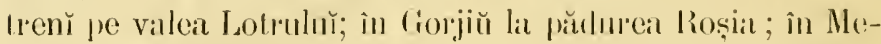

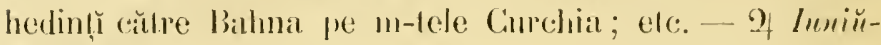
sieplemelore.

I. bifrons Lin.; I. glalura Bess.; Cumyza aluda Bumg.

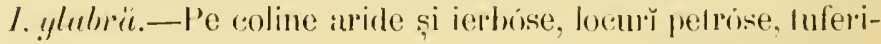

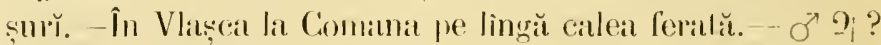
Inlin-.lugust.

Ohs. - Nu sciŭ ce póte fi : I. garandillorà Willt. din pădurile Moldoveř inferióre (Guebh. mamusc.).

\section{PULICARIA GaertI. - Pulicarie.}

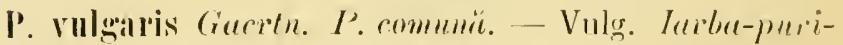

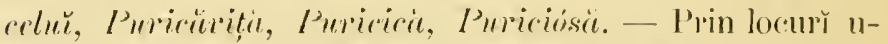
mede, inumdate. hălị̆, pe malca lî̀urilor și a pinrüilor. - În bilă Moldova (C

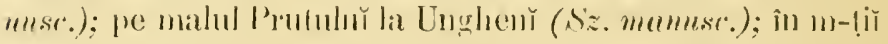

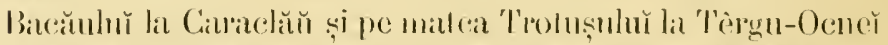

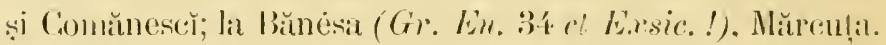

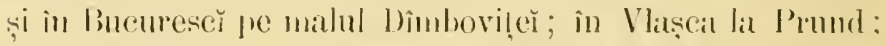
lat 'libu (Gr. Lasie.!; Kanilz l. a. 215): la P'ileset și Ciurleat-

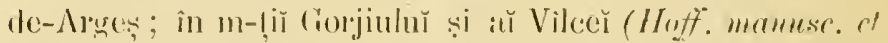

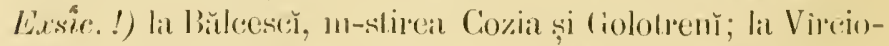

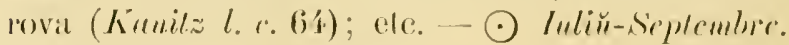

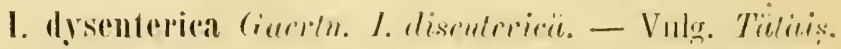

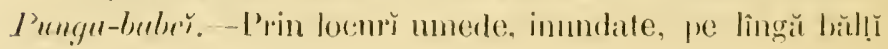




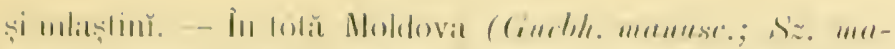

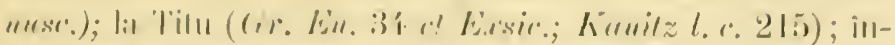

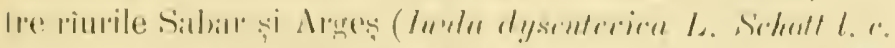

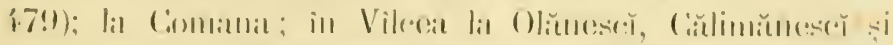

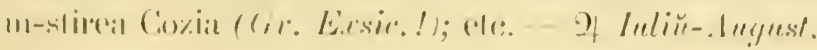

\section{BIIENS I. Bialenl.}

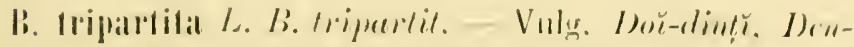

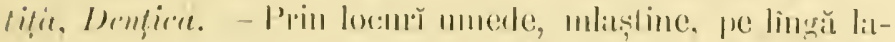

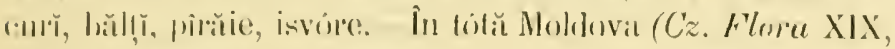

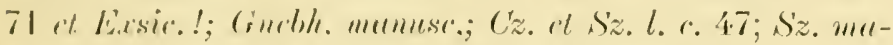

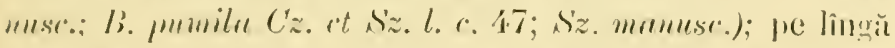

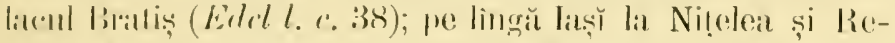

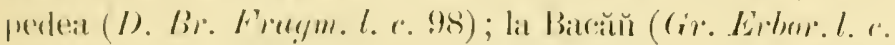

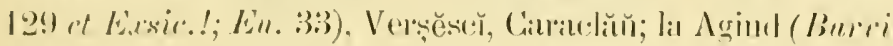

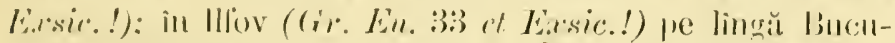

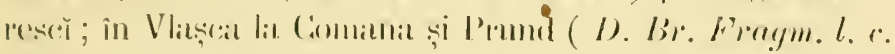

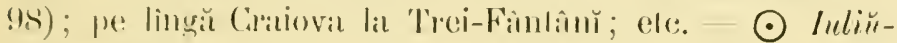
Sieplembirior.

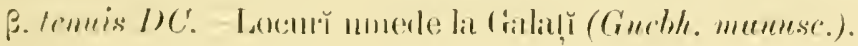

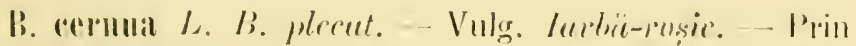

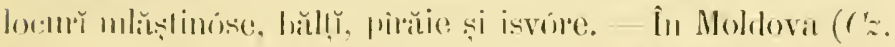

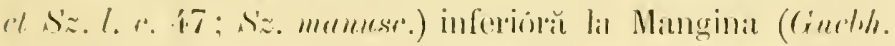

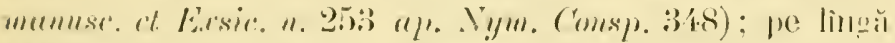

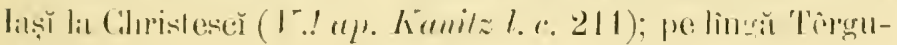

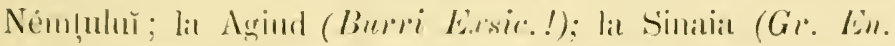

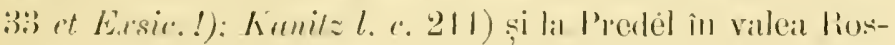

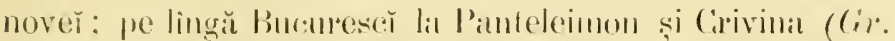

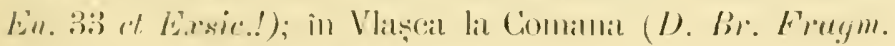

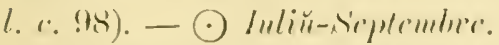

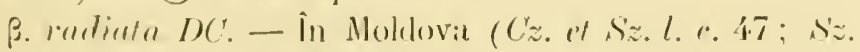

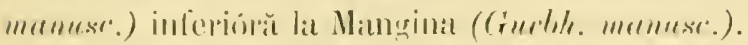

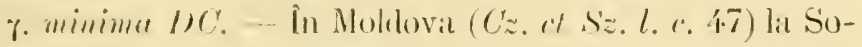

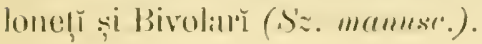


0hs. - Se cultivă : Ilelianthus amuns L. (Cz. Flora XIX, 72 et

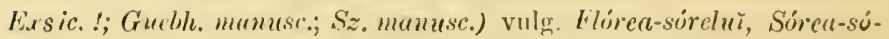

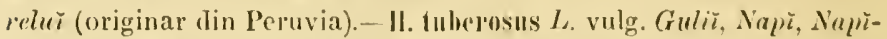

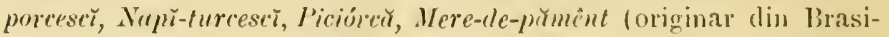

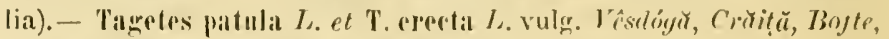
Ocheșele, Buruene-tlommesci, Lerfen-mare, Firrfon.

\section{(ARPESIIII I. - C'arpesiu.}

6. cermunu L. C. plecat. - Prin locurile mnede din pădurile de pe coline și din regiunea monlană. - Pe lìnğ̌ lași la Birnovit și Poeñ̆ in Vlașea la Comana către valea Balolă (Gr. Exxsic..!); pe linğh Graiova la Leamna; în Argeș lia isvorul de la pólele m-Ieluĭ Urdicar. - $\odot$ Inliŭ-duynst.

\section{FILAG0 L. - Filagină.}

F. germanica L. L'. germenierü. - Vulg. Firicicie, Lai-

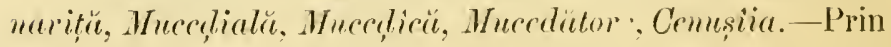
agrĭ̌, pîrlóge, păşunı̌ uscate, coline aride şi petróse. — La m-stirea Varatic în poeana din délul Vărăriĕ (Gı. Erbor. l. c. 128 et Exsic.!; En. 34); la Têrgu-Ocnĕ̀ pe Măgn:atOcně̆; în m-tị m-stirilor Cozia, Bistrița, Tismana (INoff. manusc. ct Exsic.!) si la Horez (Gr. Exsic.!); lit Vîreiorova; ete. - $\odot$ Inliü-Septembre.

F. arvensis $L$. $F^{\top}$. de c(imp. - P'rin agrĭ̌, pî̀loge nĕsipóse, pășun uscale, locur aride şi petróse. - În lolă Mloldóva (Guebh. manuse; Graphulium arecuse L. Cz. Flora XIX, 71 et Exsic.!; ('z. et Sz.l. c. 48; G. gormanirum Cz. Flora XIX, 71 fuon IInels.] it Exsice!; Cz. et Sz. l. c. 48; Edel l. e. 41 ; F. germanice h. j. Guelh. manuse. (non L.J); fe lingă laș̆ la Păun, Repedea (G. areense s'z. manuse.).

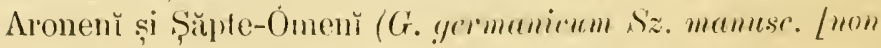

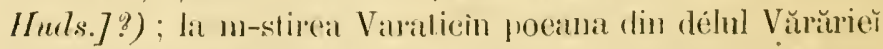

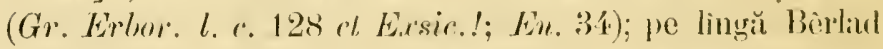

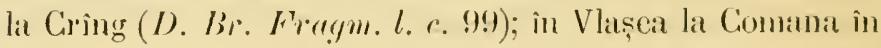




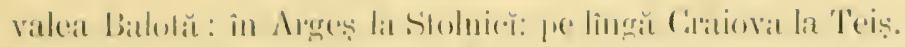

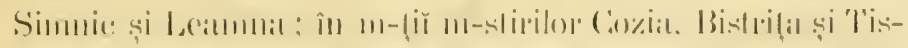

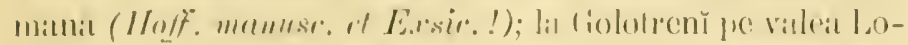

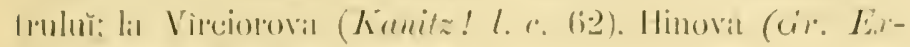

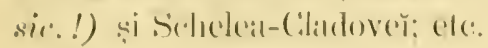

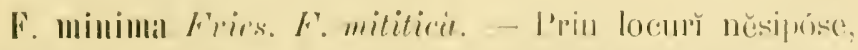

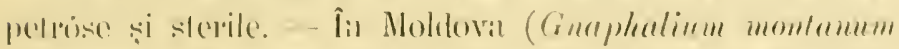
lim!y. (

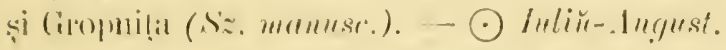

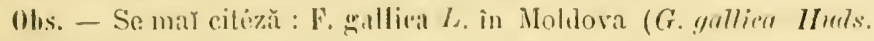

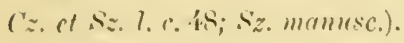

\section{GistIIMIUII 1. - Gnafaliǔ.}

(i. splvaticum L. G. de pürture. - Prin locurile aride din phidurile monlime. - În Moldovar (Sz. mamse.) prin

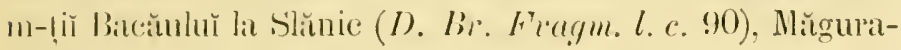
Ocncọ și lil Comănescĭ: la m-stirea Agapia cĕtre Varatic in délul Vŭrüriè (Gr. En. 34; Gr. rétum Gr. Erbor. l. c. 128

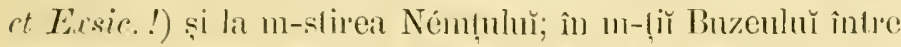
m-stirea Nifon și Bisca-mare (Hoff. Exenrs. 1863, l. c. 118)

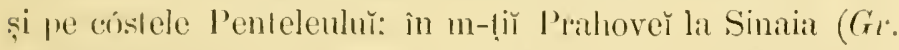
En. 3' at Exsic.!; Kanitz l. c. 214) si la pólele Bucegilor;

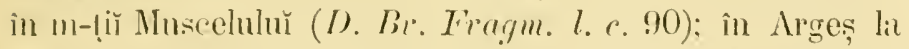
m-stirea Stinișora și în frĭdurea Guran (Gr. Ėssic.!); in

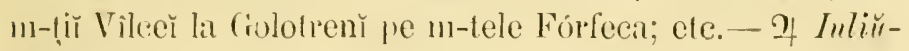
lingust.

G. nopreğiemu Gumn. G. norvegir. - Prin pășunile

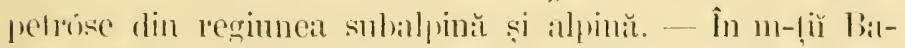

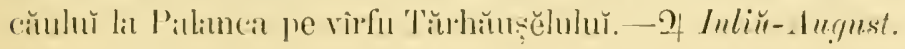

(i. supinum L. C. militel. - P'rin pișunile petróse și irigale din regiunea alpină. - P'e vìfu Buceugilor (I/off.

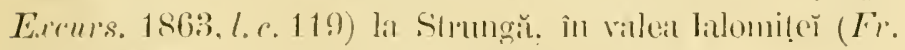
89), pe Bhane si Fumica.- of Inlin-.lurgust. 


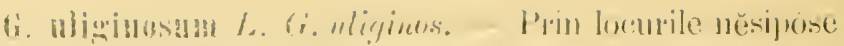

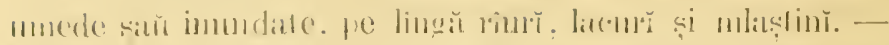

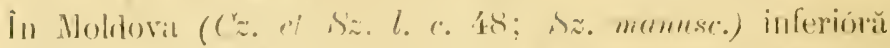

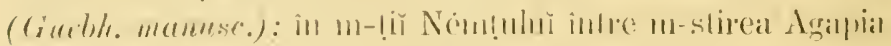

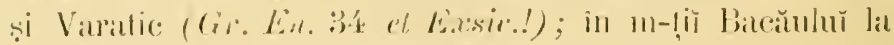

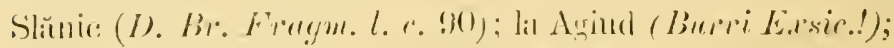

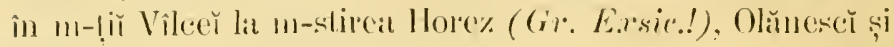

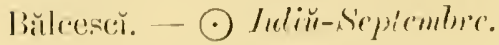

ti. Inteo-alhmu L. (i. galln'u-allicios. - P'rin locurile

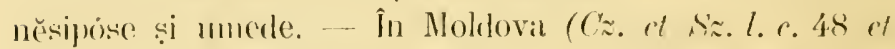

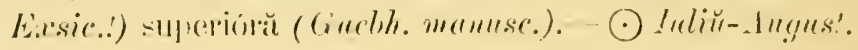

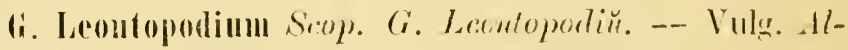
bumćle. - Prin păș̣nile stôncose din regiunca alpinăt.

Lat Broscen̆ (Burri Exase!); pe vìrful Céhlămhŭ! (tedel l.

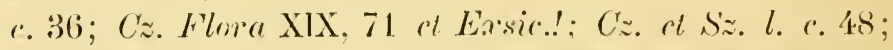

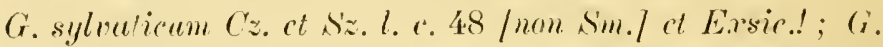
pusillum Cz. \& Sz. l. C. 48 /mon Macnliel; Omalothera sumina sz. Exsic.! /uon Cass.7; h.j. Ginebl. manusc.; Lecintepodium alpinum Cass. h. j. Gucbh. manuse.); în m-lị̆ Bu-

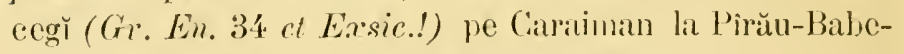
lor! (I). Sturdzu!). - 2 Iuliŭ-Septcmbere.

G.dioiram L. G. rivie.-Vulg. Talpa-mitcr., Parpian.P’rin losurile sievile și prặnnile uscate din munțĭ, pănă in reginnca alpină. - In Molktovia (Edel l. c. 37; Ancmuria di ica cicelu. Cะ. Flora XIX, 71 ct Easic.!: G. rectum. Cz. Flora XIX, 71 / non Sm./ et Exsic.!; Cz. et Sz. l. c. 48;

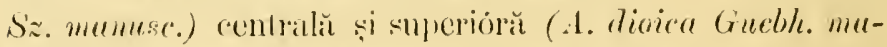

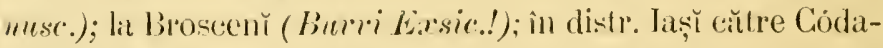

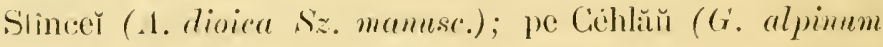

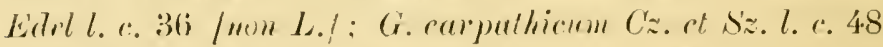

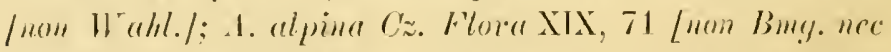

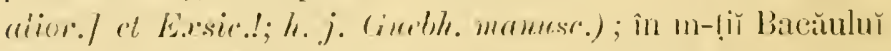

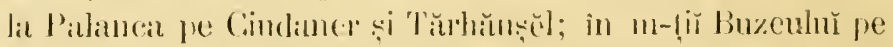

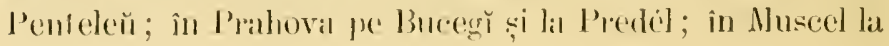




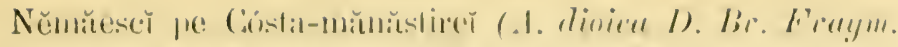

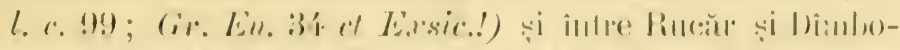

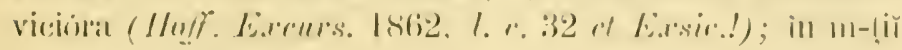

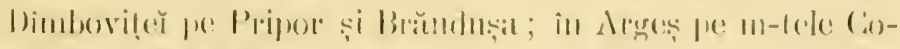

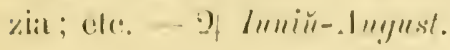

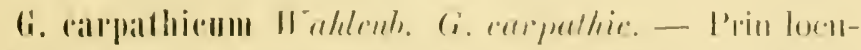

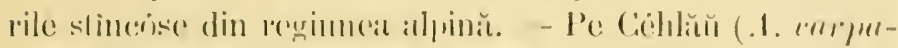

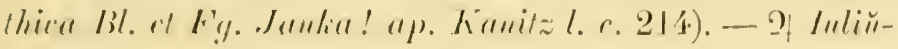
Alughest.

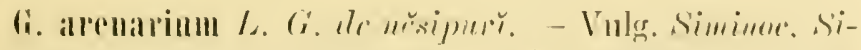

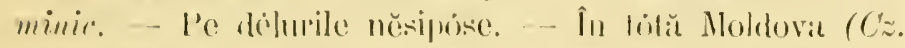

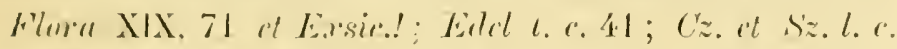
48; Sz. manuse.; Helirhrysum aronurium I)C. Ciuchls. ma-

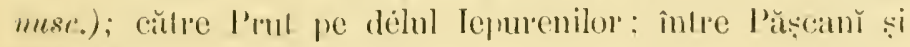

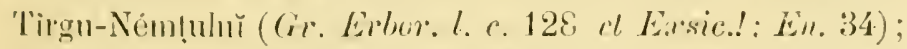
lit Agiud (Burri E.rsic..!); in Nohedinț la Rogova (Gr. Èn. 34). - 2) Inliü- lugusest.

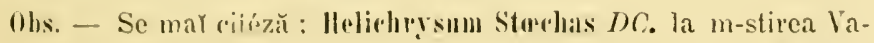

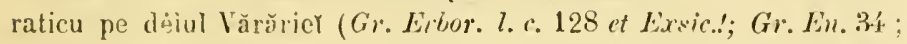

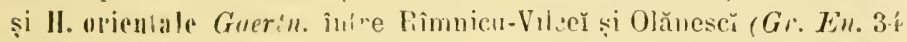

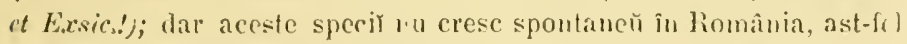
in cât, specinenile mentionale. mu potı̆ proveni de cât din ire('ary grădinto

ARTEMISIA L. - Ahemisie.

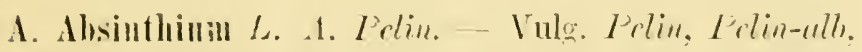

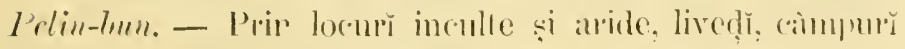

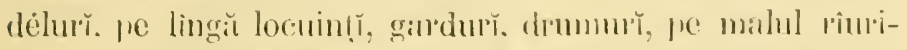

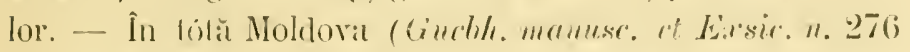

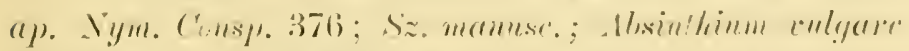

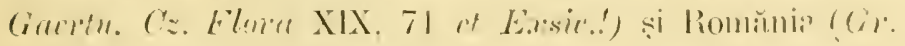

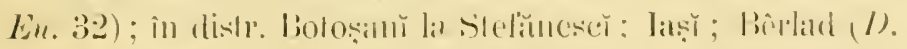

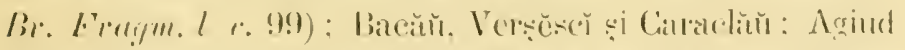

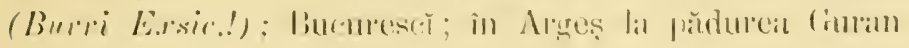




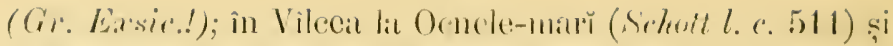

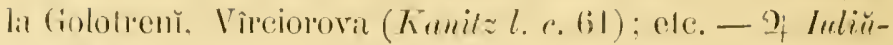
sicrermline.

1. Bammanteni Bess. A. lne Banmgarlen. - Pe slîn-

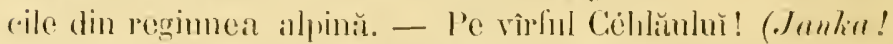
"1p. Kamiz l. e. 214; Alsinllium sprentmm Eidel l. c. 36

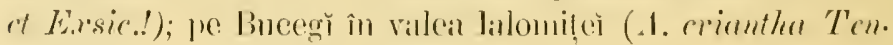
Fr. 88), la (1)m (Fron. 200; Fr. 8s). pe bilbe și pe Péllat-

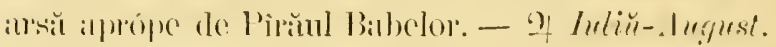

1. pontica L. .1. ponticï. - Vulg. I'elinitit. - Prin fi-

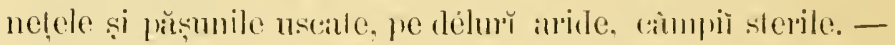

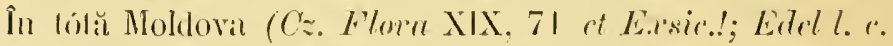

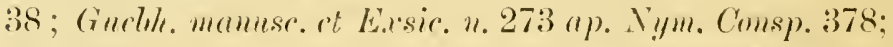

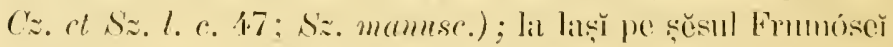

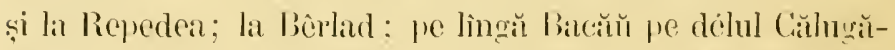

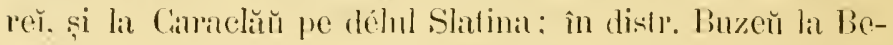
cenı̀ (Gr. En. 33 ct Exssic.! ; Lamitz l. c. 213); în Illor la Chitila și Crivina ; pe lingă Ciraiova în Lamneă ; in n-!̣î Co-

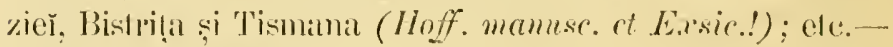
of Juliï-Septembre.

1. austriaca Jacq. 1. austriacit. - Pe dẻlurı̆ și locurř

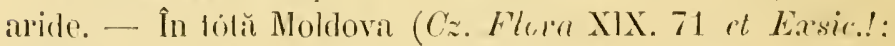
Gurbh. manuse. et E.rsir. n. 278 a). Nym. Cemsp. 378; I). Bl. Fraym. l. c. (9)); in lllor (Gr. En. 32 al Lixsic.!) pe lìngŭ lBucuresĕ ; în distr. Buzcŭ în valea Slĭniculuŭ (Gr. Exsic.!). - 2 Juliü-Septemlne.

A. campestris L. A. de ccimp. - Pe déluri şi cimpurı̆

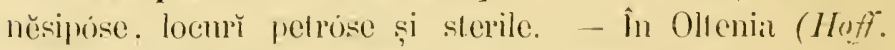
manuss.) si Moldoval (Edel l. c. $41 ; C_{z}$ of sz. l. e. 1.7; Sz. mammse.) pe linği Büuresĕ intre buftea și Crivina (Gr. Eu. 32 et Exsic.!) : intre rîmrile Sahalr și Arges (Sidratt l. c. 479). - 2 Inliu-septembere.

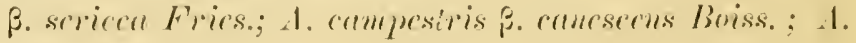

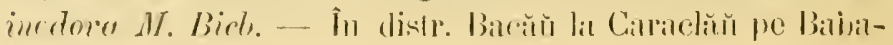




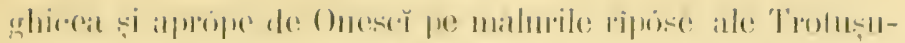

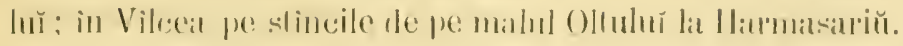

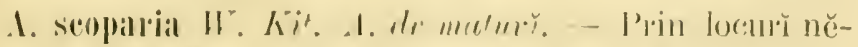

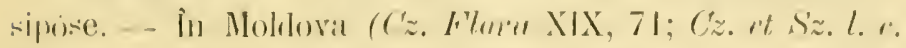

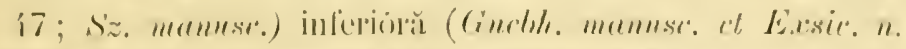

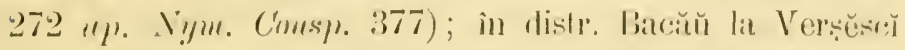
(.l. compustri.s I). Br. Froctgm. l. c. (g) /um! L.J); in

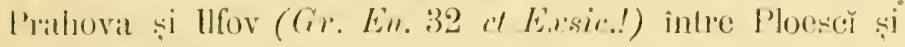

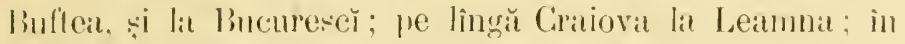

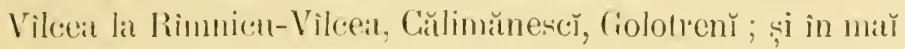

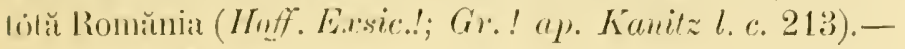
$\odot$. Inyust-isputrmhlue.

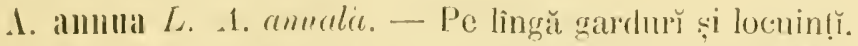

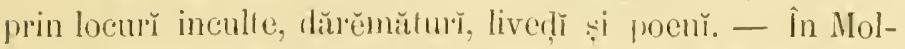
dova (.1. Lanaertifolia Cinchle. E.rsie. 21. 275) / non ill.J (1).

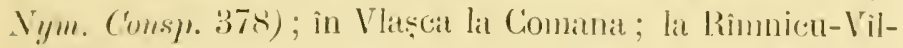

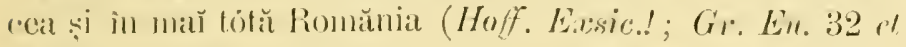
Lersic.!; Kanitz l. r. 213). - $\odot$ Septembire.

1. rulgaris L. A. commäie. - Vulg. Pelinaritu. Prlin-

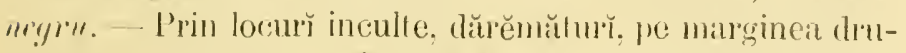

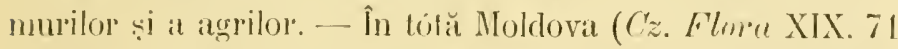

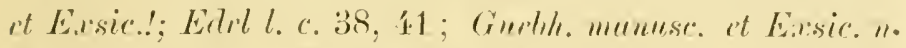

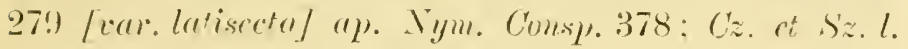

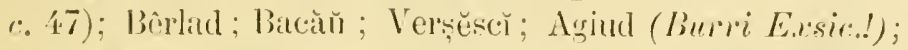
in llfor lă Ciocănesc̆ (I). Brr. Frargm.l. (. 999); în Vilcea

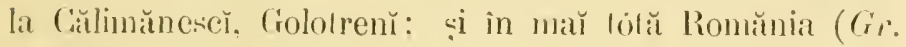
Liı. 32). - 2 linliñ-Septembre.

A. maritima L. 1. maritimŭ. - Prin locurı̆ nĕsipuse

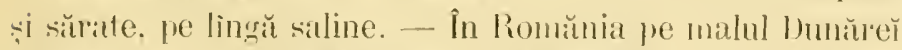

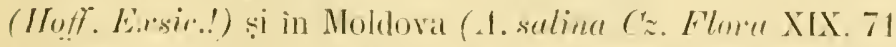

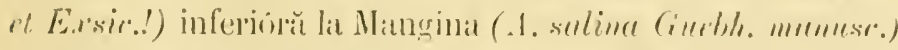

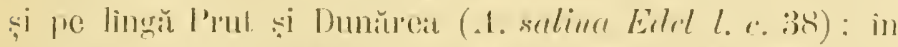

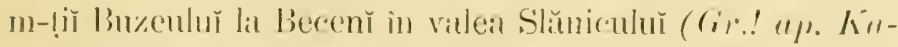

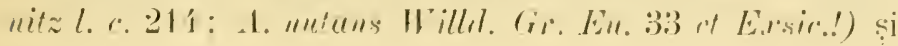




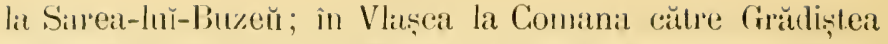

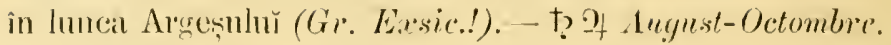

A. frağans ITilld. A. odoruntü. - Prin locurile sărale. - - In distı. Iaș̆ pe lìngă laznl-Chiriter (A. monogyna IV. Kit. Sz. mamusc.?); la 'p̣igănesĕ (.1. Boschnialiuma (rucbh. mumuse.?).

0lss. 1. - A. Ilippocentanrea de la Ocnele-marĩ (Schott l. c. 511), IIu scin ce póte fi.

0!s. 2. - Se cultivă : A. Ahrotamm L. (Guebh. mantesc; Cz.ct Sz. 1. c.47 et Exsic.'; Hooff. matmesc.), vulg. Lemmu-Domumlur, Lemmus. A. dracuneulus L. (Gucbh. munusc.; ('z. et Sz. l. c. 47 et Exsic.!; Gr En. 32!, vulg. Tarhon, Tarahon.

\section{TANACETUII L. - Tanacet.}

T. vilgarle L. T'. commo, - Vulg. Velriec, Iarba-rainln... - P’e marginca agrilor și a viilor, pe lînğ gardurĭ și

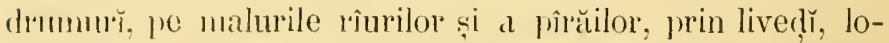
cur inculte și muede. - În lötă Molelova (C'z. Flora XIX,

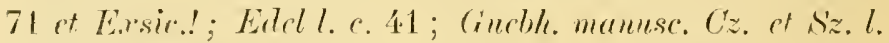

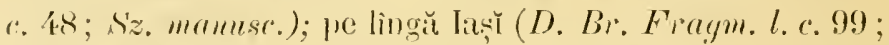

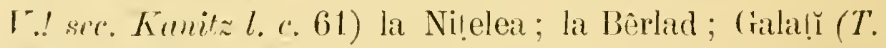

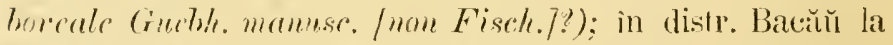

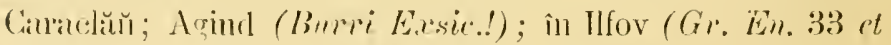
Exasic.!) la Cirivinat în lelıedinți către Bahna pe m-tele Curchiil; etc. - of Inliu-August.

Obs. - Se cullivă: 'T. l'alsamila l. (Cz et Sz. l. c. 4S; Gr. En.

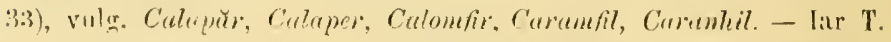

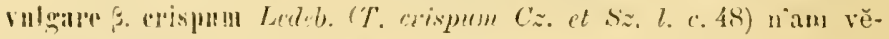
d̦ut nič̃-odală cultivâmßu-ser.

\section{ACIIILESI L. - Achilee.}

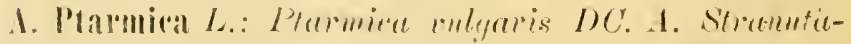

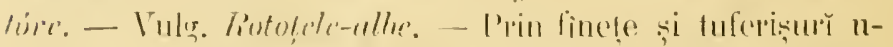

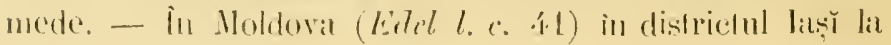




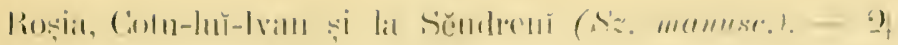
linlint-sipulemline.

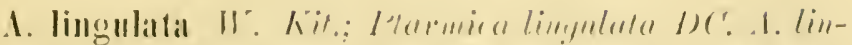

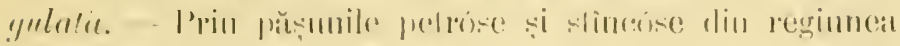

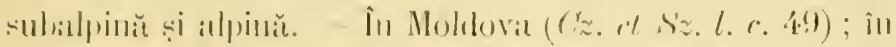

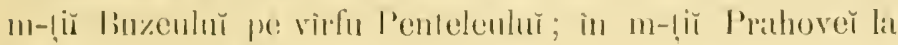
l'redél. - of linlik- leypust.

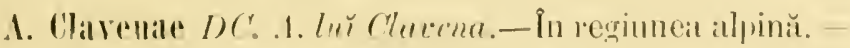

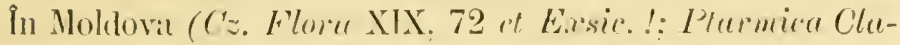

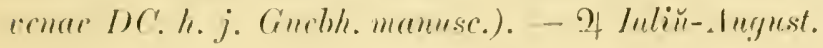

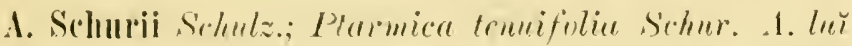
Schur. - Pe lingr̆ slincile uncele, prin locurile nĕsiposec de pe lingă torentele din l'egimea alpină. - In Moldova (Anthemis alpina Bumg. Cz. Fllora XIX, 72 linen L.7; ( $C_{z}$.

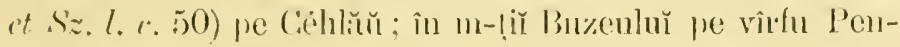

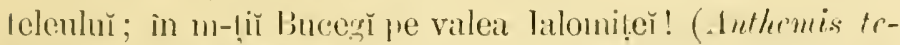
meifulic Seluer Fr. 88), la Omu! (From. 200), la schitu!

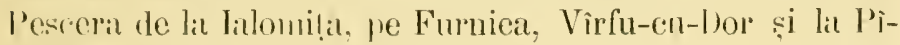
riullbiabelor. - 9 Inliü-1 lugnest.

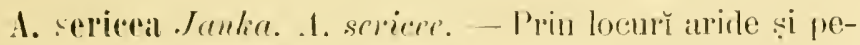

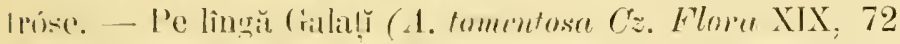

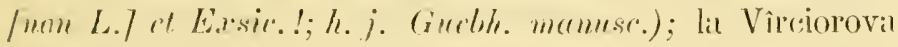

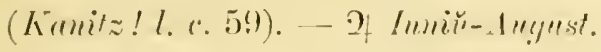

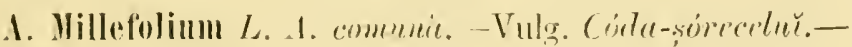

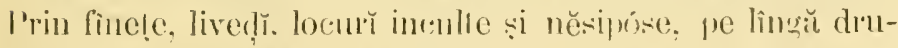

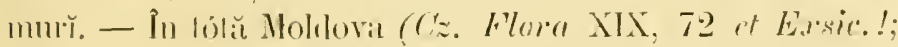

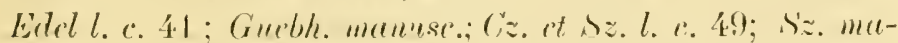

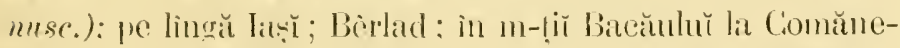

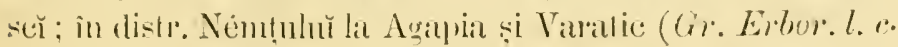
128); in Prahova la Sillatia (Gr. Excers. l. c. ci Exsie.!); și Prelèl ; în Iltov (Gir. Lin. 33 of L.s.sic.!; Kunitzl. c. 212)

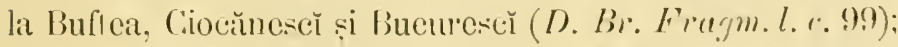

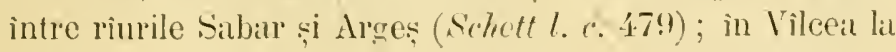


Bălcescĕ și Colotrenŭ; la Cernę̣i (Gr. E.rsic. !) și Virciorova

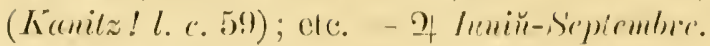

B. alpestris Kork. - Prin păsunile petrose din regimea subalpină. - Pe virfn l'enleleulur ; pe Bucegr in valea litlomițě̀ (.1. Marnkecene T'eusch. F'r. 88) lit schitul Pescera de la Ialomila.

1. setacea W. Kit.; A. Millefoline var. setacere Koch. 1. seluce'e. - Prin finele uscate, pe déluř̆ aride. - In Mloldovil (Cz. st Siz.l. c. 49 at Estric. [nom. 1. Ifillefol.7; h.j. Guebh. menuse.) inferionă (Gucbh. Lixsic. u. 260 /nom. 1. lantalar] sec. Nym. Comsp. 367 ; 1. Lanate Guebh. mamesc.

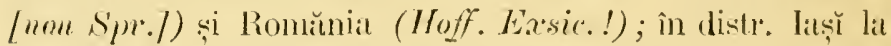
Cerbules̆ (Sz. numuse.); pe lingă Bucurescŏ (Gr. Ëtr. 33 st. Earsic.!) la Ferestrĕŭ şi Ciocănescĕ ; în distr. Vlaşcia la Comana; între rîurile Sahatr și Argeş (S'cholt l. c. 4.79); etc. - 2 Iипій-Luliu.

A. Lanacetifolia All. A. en foŭ de vetrice. - Prin pășnile petrose din regimea montitnă și subalpină. - În m-ḷĭ

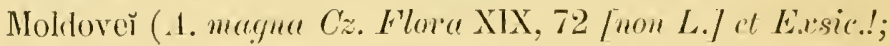
he j. Guchth. manuse.; Edelal. c. 37; Cz. rt Sz. 1. (. 49);

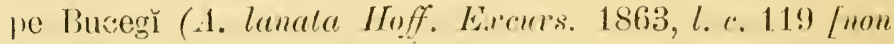

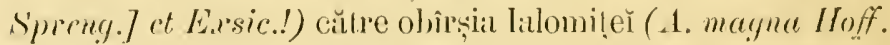
Exenrs. 1863. l. (. 40 et Exsie.!) si la Predél pe m-lele Susitiŭ ; lat Cìmpulıng pe malurile Riu-Tìrgulı̆ (1. magna. IIoff. Excur's. 1862, l. c. 40 rt E.rsic.!); in Arges pe m-tele Cozia; ele.-2 Iuliü-1uyust.

A. dentifera $D C$. A. dentifrerö. - Prin lucurile petróse din regiunea subilpină. - In Moldova (.1. distens Wr. Kit.

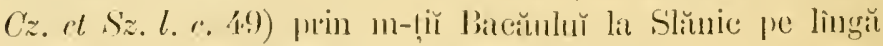
pichelul de lit fruntiule. - of luliü-.lugust.

A. withmilolia W. Kï. A. cu for de crithmu.-Prin locurt petróse montiune. - Lil Cämpulung pe malurile Rîu-T'ìr-

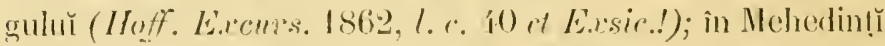
la Vircioroval cathe l'orṭle-de-ler! (Kunitz! l. c. 59), la 


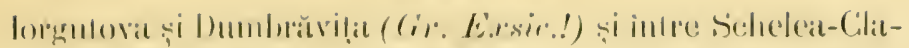

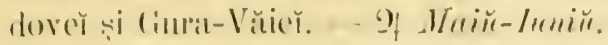

A. Inbilis L. I. mbilie. - I'pin loc:arri immolle si nĕsi-

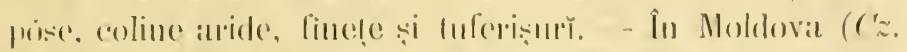

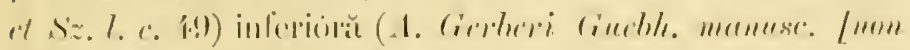

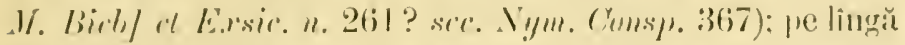

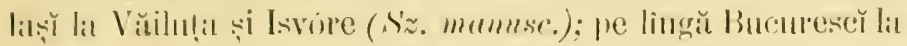

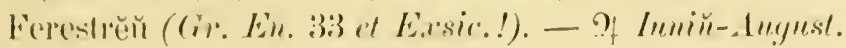

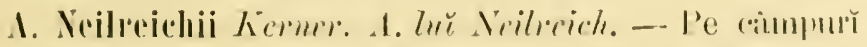
inculle și něsiprose. coline aride, prin finẹ̣e și huferișur.- -

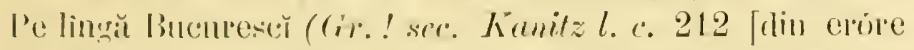
Buceğ) lat Ferestren! (( Cirivina, elc. of Immin-luliu.

A. companda II illd. A. compactic. - Prin locurr petrose,

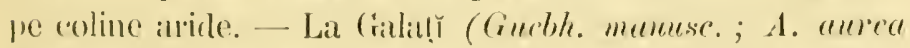

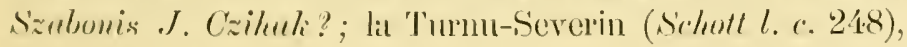

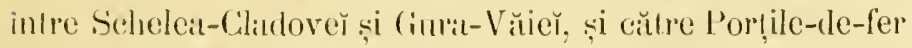
pe m-tele St-Petru la Gruce. - of Inniü-Iuliu.

1. pectinata Willd. A. pectinutä. - Pe délurĭ și prin

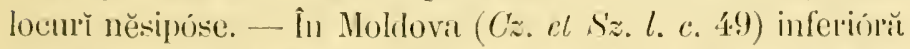

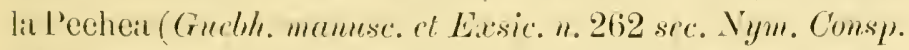
368); in clistr. Iaș̆ la Èbicenı̆ și lepuren (S'z. mamesc.). of luniü-Iuliur.

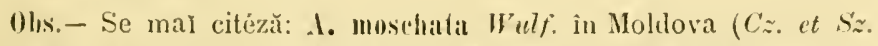

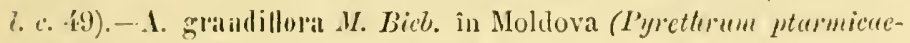
folium Willd. (cz. ct Sz. i. c. \&S)?

\section{INTHEMIS r. - Antemidĭ}

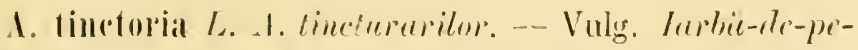

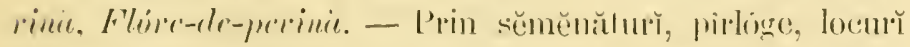

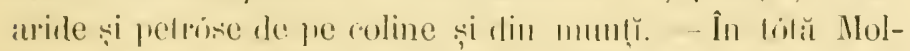

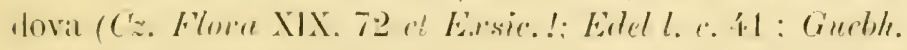

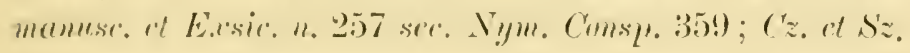




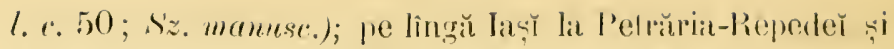

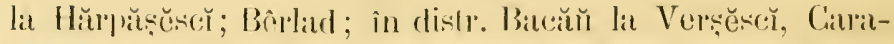
clăt̆, Moșia-Ocně̌; la Agrind (Burri Éssic.!); pe lîngă Bucureser (D. Br. Fragm. l. c. 98; Gr. En. 333 ct Ersiec.!) la Bănésal, Ferestrěŭ. Perị, Crivinit, Chililal și Ciocănesč̆ în Nnscel ; pe lîngă Slatina cŭtre Oll ; în Vîlcea la Bălcescǐ: la Vìreiorova cülre Por!̣le-de-fer! (Kani/z! l. c. 58) și cutíre Bathna pe m-lele Curehia; et.c. - 2! Inlin̆-Auqust.

B. Fussii Grisch et Sch.; 1. chrysenthe Sichur. - Prin locurile stincóse și petróse din regiunea montană și subalpină. - In m-ḷĭ Buceğ la schilul Pescera de la Ialomița! (Fr. 87), la Strunga (1. tinctoria Koschy, 132?) și în valear Babelor; în Arges, la m-stirea Stinisçora și la Fața-Zătvodulıı̆ (Gir. Exsic..!); în Vîlcea la (iolotrenı̌ pe Fórfeca.

A. macraníla Henff. A. cu flor $\breve{\iota}_{\text {mar }}$. - Prin poenile de prin unferişurı și pe marginea pădurilor de pe délırǐ și

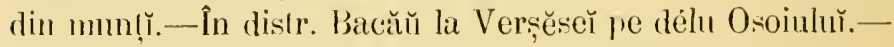
of Inliü- lueguest.

1. altstriaca Jacq. 1. ausfriarı - Printre sĕmĕnăturr̆, prin pî̀lóge něsipóse, lînele uscate, coline aride. - În Mol-

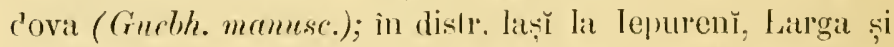
Văilı!̣ı (S'z. manusc.)?; pe lìnğ Bucurescè la Merinani (A. nolilis I). Br. Frecgm. l. c.98 (non L.7). Ferestrěŭ și în Dudescĕ ; in Vlașca la Comana. - $\odot$ Ituin̈- August.

A. ruthenica M. Bìb. A. metruicä. - P’in locurì aride, pe lingă drumurı̆. - În Moldova $(C z$. nt S Sz. l. e. $50 ;.$

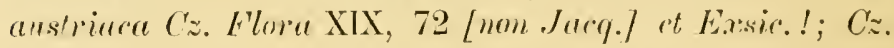

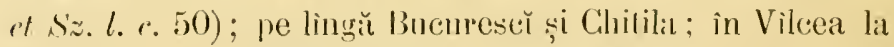

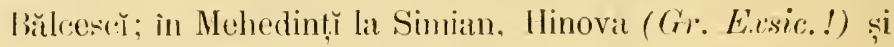

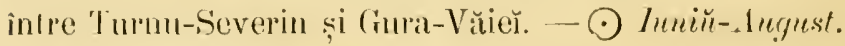

A. alvensis L. A. de ceimp.-Vulg. Romonitien-de-cump. -l'rin locurì nĕsipóse, pîrlóge, finnẹ̣e sterile. - În tótă Moldova (Edtll. c. 41 ; Ginebh. manuse; Cz. ct Sz. l. c. 50; Sz. manusc.); pe lingă Bêrlad la Grìng (A. Cotula D. Br 


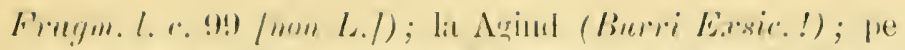

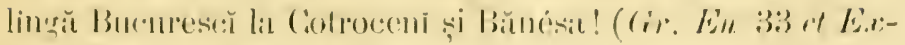

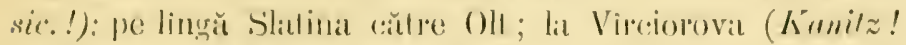

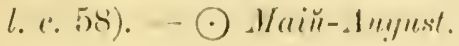

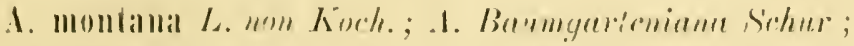

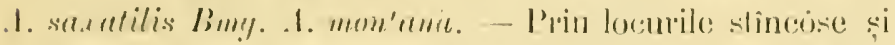

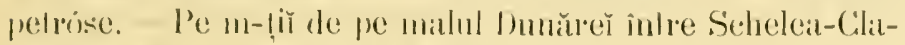

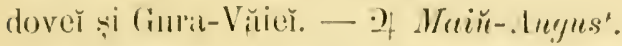

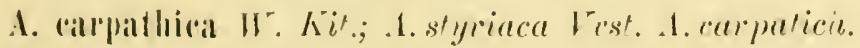
- I'rin locurile petróe și slincose din regiunea alpină. -

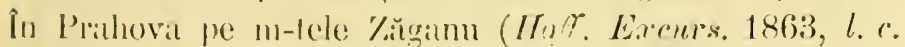
118) și în Buceğ la sechilul P'escera de la Talomila (Fr. 88), in cilleil călre Onu (A. carpathica var. tomontoso-sericen ABZ. XII $\lceil 1855\rceil 308)$, pe Omu! (Fron. 199); A. alpina 1. 51: (Chrysan'hemum alpinmm I). Br. Anal. aced. rom.

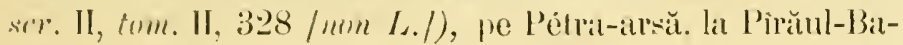
betor. Obirsial. - - f Inlin- lugust.

A. Cotula L.; Mrarueta Cótula DC.; M. firtida Cass. A.

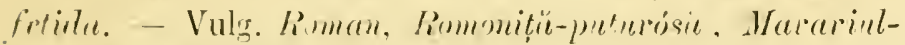

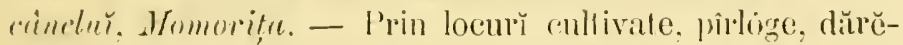

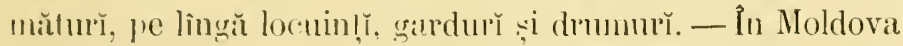

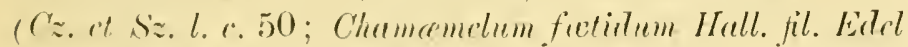

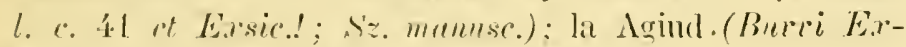

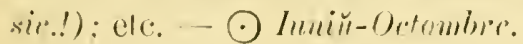

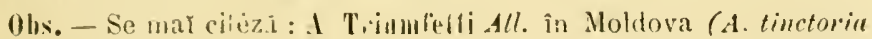

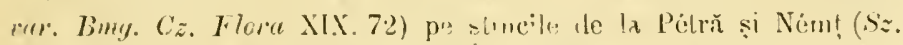

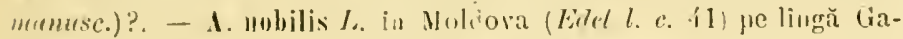
lą̧i către Tịglina și Celatea Genuverilor (Sz: mornesc.).

\section{MATRICARIA I. - Matricarie.}

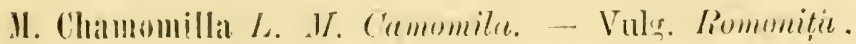

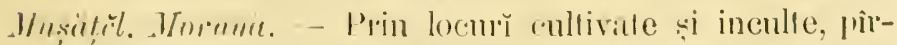

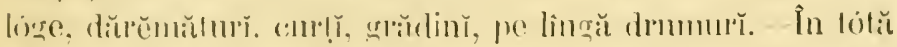

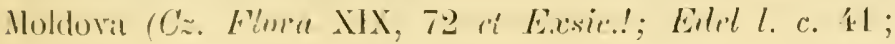




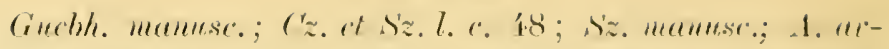
erusis $C_{z}$. Flora XIX, 72 /mon L./ \% Exsic.!) si Romănia (Gr. En. 33 et E.rsic.!) ; laș̆ ; Bòllad; călre m-slirea Agapia

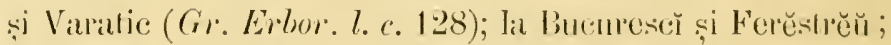

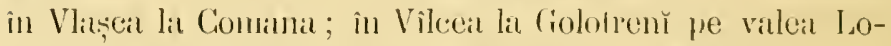
Iruluĭ; la Vîrciorova (Treneectum Chamomillu Kunitz l. c. $60)$; elc. - $\odot$ traiй-Iuliü.

II. inodor'a L.; Chamemelum inodornm I is. M. invdorï.

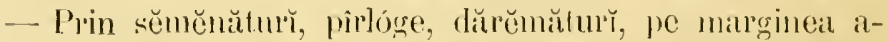
grilor și a drumurilor. - În Moldova (Chrysuntemum inodorum L. Cz. et Sz. l. c. 48; Pypethrum inorlorum Sz. mremuse.) la laş̆, Unghenĭ ( V.! sece. Kanitz l. r. 213) și Sculenĭ (Demid. II, 195); pe lingă Bêrlad (I). Bi. Frecym. l. e.

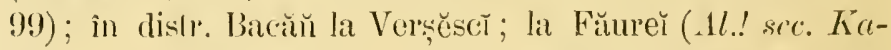
nitz l. c. 213); în Ilfov la Titn și Ciocănescŭ (Gr. En. 33 et E.xsic.!; Kunitz l. (. 213); în Vlaṣca la Comana; la Vîrciorova (T'uncertum inodorum Konilz! l. c. 213); elc. - $\odot$ lumin̈-septembre.

\section{IEUCINTHEMUY Tom'nef. - Leucantem.}

I. vulgarare Lam.; L. comun. - Vulg. Romonițiu-mure,

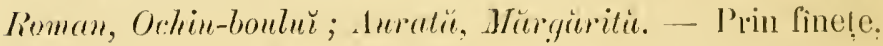
firrloge, prin poenile din pădurĭ. - În Moldova (Gr. Errbon. l. e. 128; Chrysanthenum Lencanthermum L. Cz. Flora XIX. 72 et E.rsic!! Edel l. c. 41 ; Cz. ct Sz. l.c. 48 ; Sz. mamuse; Ch. montumu Cz. Flore XIX, 72 /ron L.J it Exsic..' Cz. ot Sz. l. c. 48; Ch. heterophyllum Cz. et Sz. l. c. 48 [non IVilld./: L. montanum h.j. Gucbh. manusc. (nom DC./) centralĭ și superiòr̆ (Guebh. mamusc.); pe Céhlăŭ! (Ch.

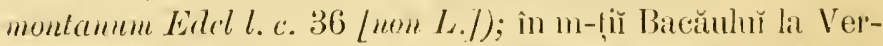

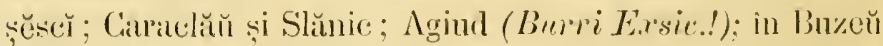

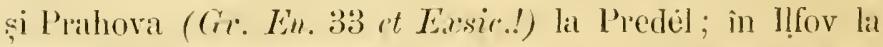

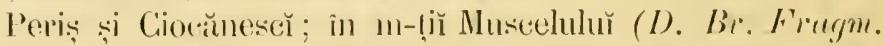
I. (. 99 ; L. pulleus D. Br. Fre(ugm. l. c. 99 (non DC.J); la 


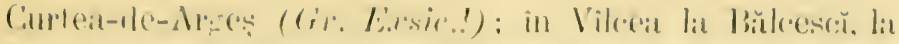

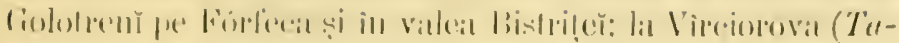

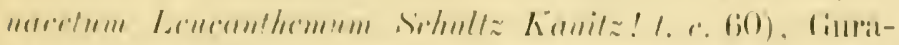

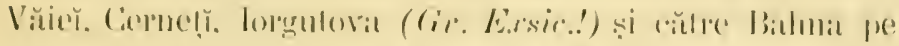

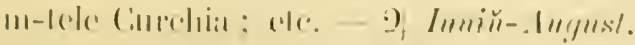

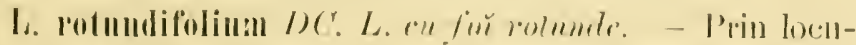

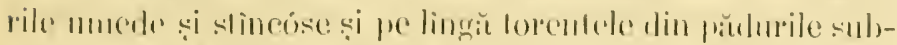

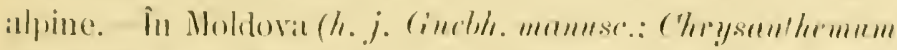

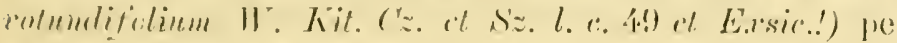

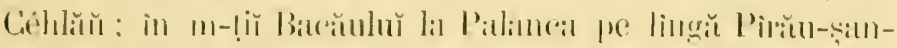

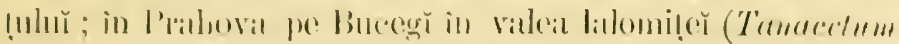

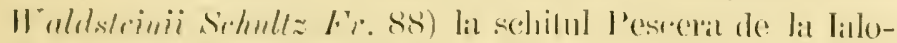

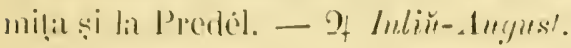

Ohs. - Sce mar citeză : I. alfralum Schue în Moldova (Chrysan-

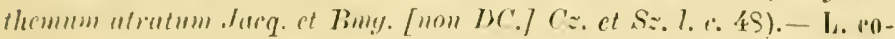

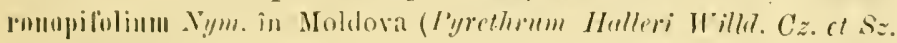
( $\therefore$ 4 4 ) ?

\section{PYRETHRd Ratertu. - Piretru.}

P. corymhositm Wille.; Tunacetumenrymbosum Selunltz. P. corimbos. - Prin püdurı̌. Iuferiṣuro, poent. pe la mitr-

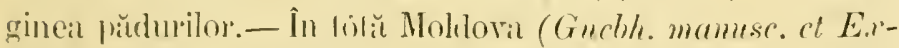
sic. n. 269) ser. Nym. Consp. 372: Chygsenthrm. conymbo-

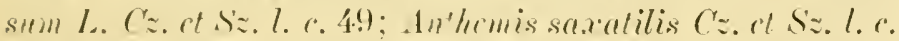

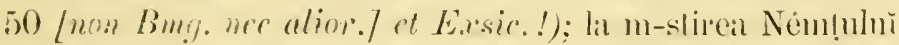
(Lenectuthem. corymlosum Gren. ot Godr. Gr. En. 33) ; pe

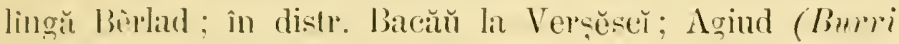

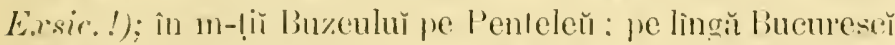

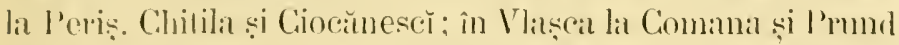

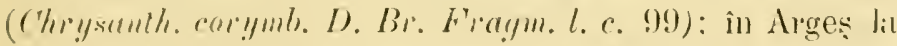

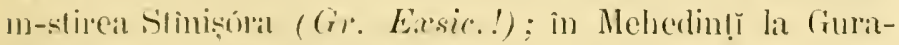

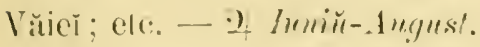

P. Iarthenium Simith,; Tanacrium Parthenium Schnl'z.

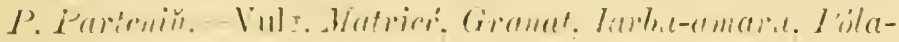


stutĕ-Narĭ, Tarhon. - P'e lingă locuintile și gardurile

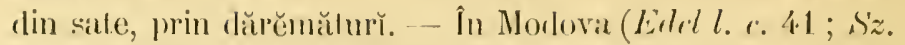

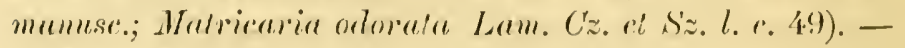
of lnniй-luliu.

P. Mliginosmm Wr. Kil.; T'runarfum serotimum Schultz; Chrysanthemun serolimum L. I'. uligines. - Prin locurile

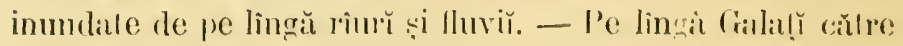
ruinile prelinsulur Cilpul-bovis in luncile de pe malul Sere-

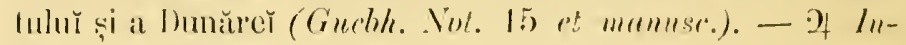
lï̆-sirpismline.

P. alpiumu I'illa. I'. alpin. - În Moldova (I'. mini-

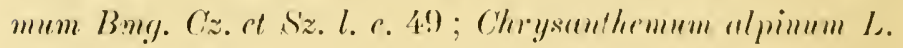
Cz. Flonel XIX, 71; Cz. al s'z.l. r. 4!) / rarel. syn l’. cancasicuml)?; pe virlnl Bucegilor (Hoff. Exars. 18633. I. ค. 119). - I lnliй- luynst.

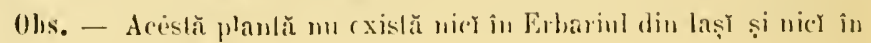
lirhatiul Hoffonannian.

P. macepophllum Willd.; Ciymmecline macrophylla

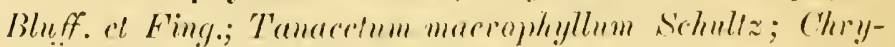
santhemum macrophyllum W. Kit. I’. su for mar. - P'rin locurile calcare din frŭdurile montane și smbalpinc. - ho Mol-

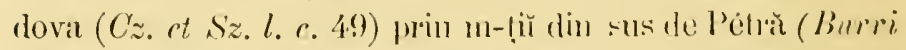

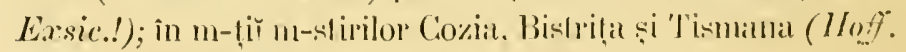
mamnsc. ct Exsice!). - of Imin̆-Iuliu.

P. millefoliatum Willd. P. millefoliat.-- Pe coline nĕsiprose câmpurı̆ aride. - Ân Noldovia (Nym. (rms.p. 373) in-

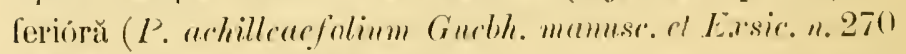

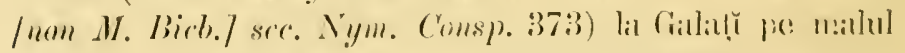

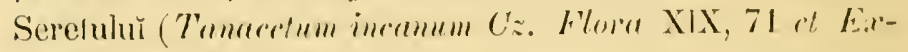

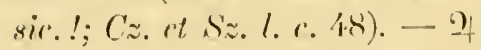

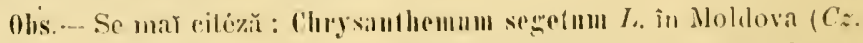

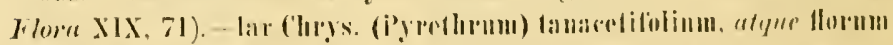

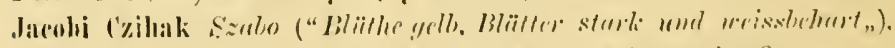

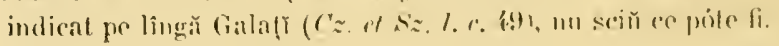




\section{1) (1) IISICIII L. - Doronic.}

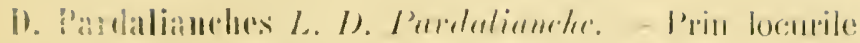

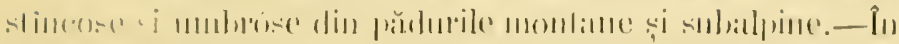

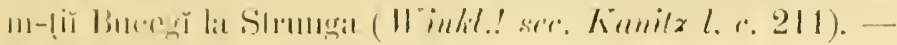
2f linin̈-luliir.

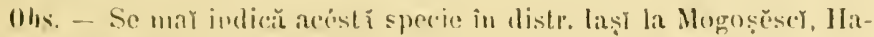

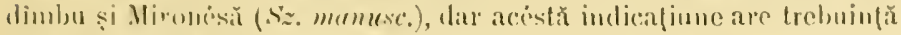
de a li controlatí.

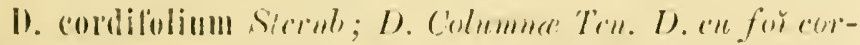

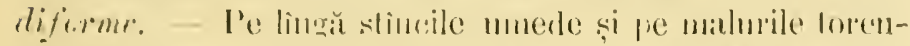
relor din regrimnea subalpină și alpină. - lis Moliovat (D).

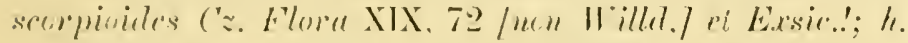

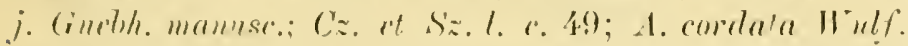

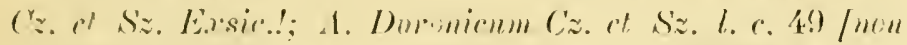

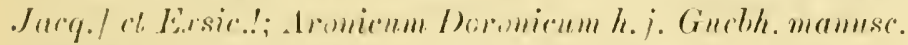

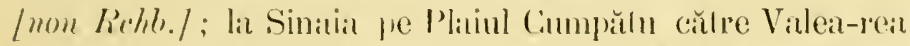

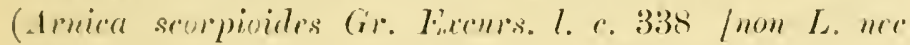

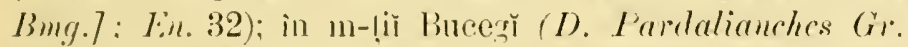

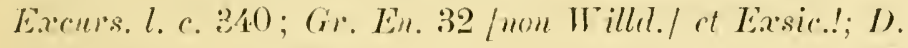
tussilagifolia Gr. Moni'. l.c. D.gi'andiftum Gr. En. 32 Inon Lam.7 et Eassic..') la schitul Pescera de la Ialomilal,

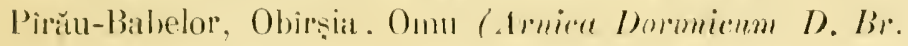

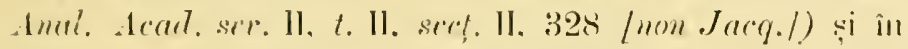
m-tị de la Prodél. - Ot Imnin-Anijnst.

1). austriacum . Jacq. D. austriar. - Vulg. Iarba-cinter.

Prin locurile umede din pădurile montane şi subalpine. In Noldova (Buph'almnm y'andifturnm Cz. Flora XIX. 72 lnon L.] "t E.r.sie.!; B. sulicifolinm h.j. Gueth. mamusc.) in reginuile inferiore (I). I'arelalianches Edel l. c. 36

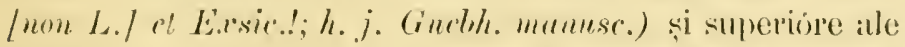

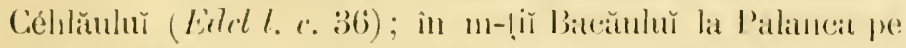

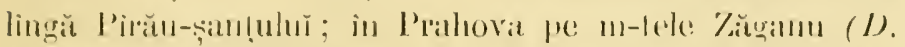

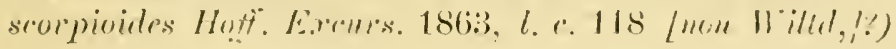


în Buregro pe m-lele Colla alprope de schilul Pescera de la

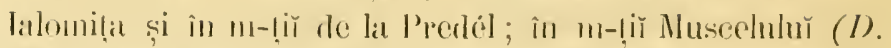

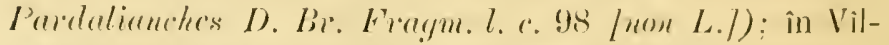
cea pe m-lele Nimoln; cte. - of Iuniü-.1ugusl.

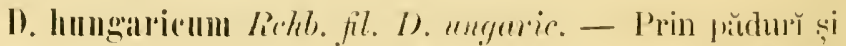
luferișurř de pe coline. - Ân Holdova (I). austriacum $C:$.

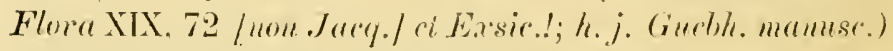

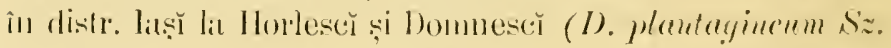
manuse. [non L.J); la m-slirea Adiun (D). oblongifolium

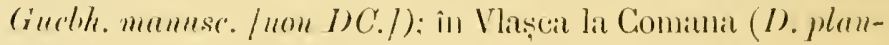

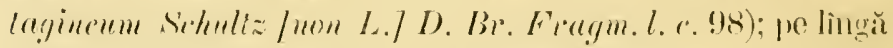

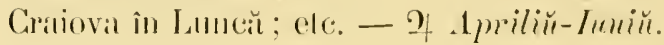

\section{ARNICA L. - Amicic.}

A. Inontana L. 1. monlemic. - Vulg. Poclbel-de-munic. - Prin ph̆șnile și finelele mnede din pătourile montane și subalpine. - În Molhova (Cz. Fllo, XIX, 72 of Exsic.! ;

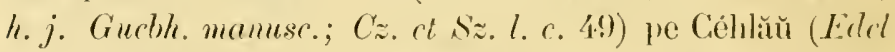
l. с. 36); lit Broscenì (Burri E.resic.!) ; în Prahova lil P'redél; in Muscel la Nĕmăesé̌ pe Cóslit-măuăstireč (I). lir.

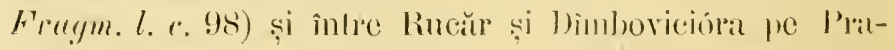

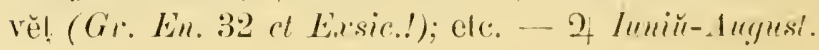

\section{SENECIO L. - Senccion.}

S. Vulgäris L. S. commu. - Vulg. Cruciultita, Pelimbrósa.

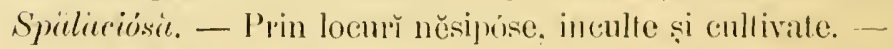

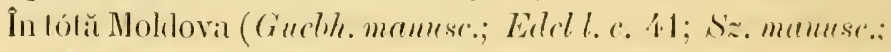
D. Pr. Fragm. l. c. 98); în Prahova la Predél; în Ilfor (Cro.

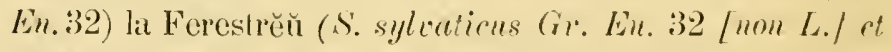
Érsic. !); în Vîleea là Cülimănesĕ (Gr. Exxsic.!); ete. $\odot$ Mariй-Octombire.

S. viseosus L. S. viscos. - Prin locuř̆ nĕsiprose. și pri-

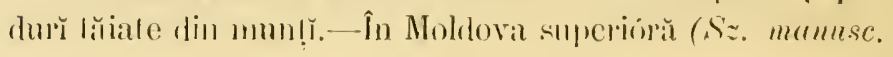




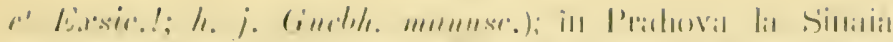

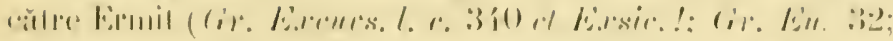

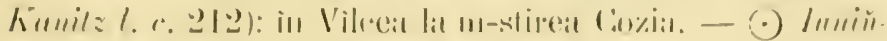
Uill mine?.

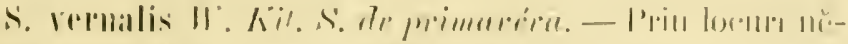

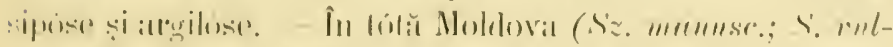

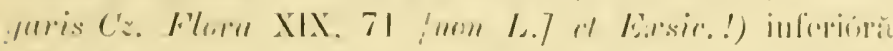

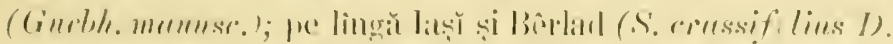

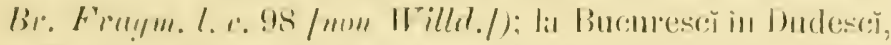

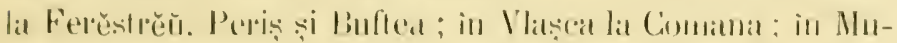

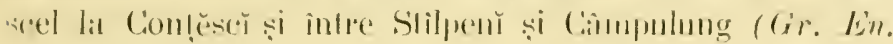

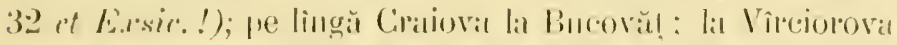
catre Portile-de-ler (Borb. 1873. Brims. 260): elc.- Ipriliir-1/niï.

S. mebrodensis Lin. S. de slinč. - P'rin locurile pelrive

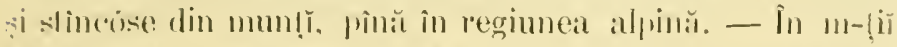
Muldover (s. rupestris W. Kit. Eiled l. c. 337) la Hangu çi

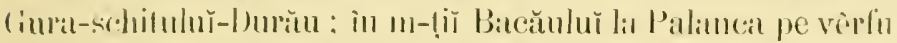

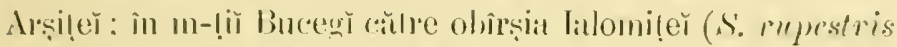
Ihoff. E.rors. 1863. l. r. 120) alprópe de schitul l'esceril pe valea Colḷer la Burlacu; pe vìrfu Furniceř și la Predél pe

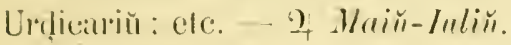

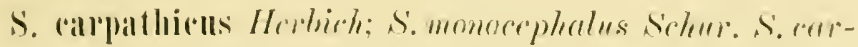

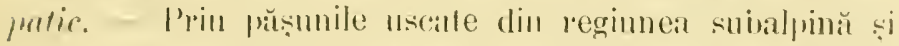

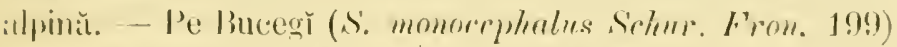

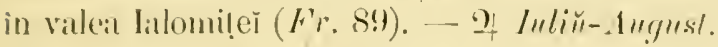

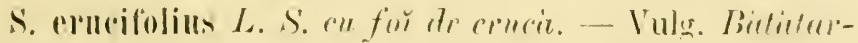

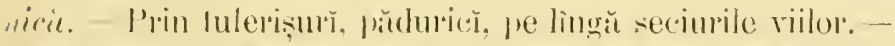
In Moldoval (s. sylealiens C'z. Flopa XIX, il / mon L./ ct

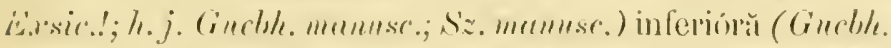

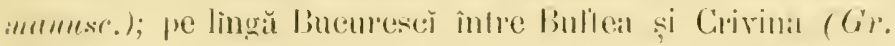

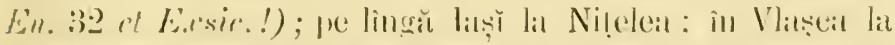

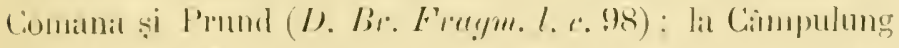
ve malurile Rin-T'irguluí (S. lycopifolius Hoff. Excurs. 


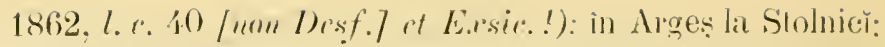

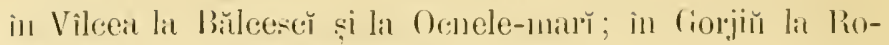
sial ; elc. - 2 lulin̈-duynst.

S. Jatcolnata L. s. incubin. - l'rin fincte. Inferișulı̌ și

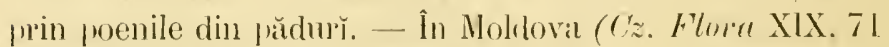

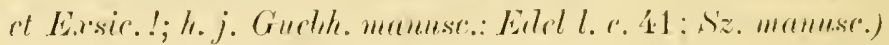

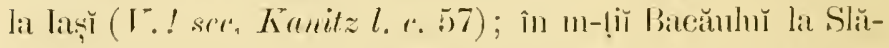

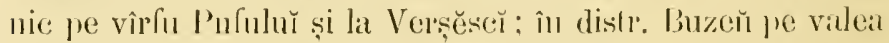
Slăniculnŭ (Gr. Èrsir.!; Kanitz l. r. 211); în Prahoval la l'redél; în Vlaṣca la Commana în Argeses la Gurănöia aprópe de Rîmnic: (Gr. Exs.c.!) : în Gorjiŭ ìn prădurea Roṣiı ; în

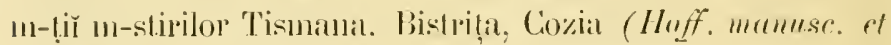

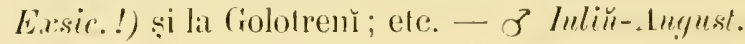

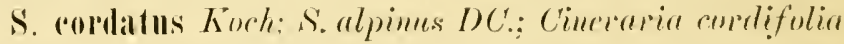
Gonan. s'. cordat. - Prin pășmile mmerle din regiuneal al-

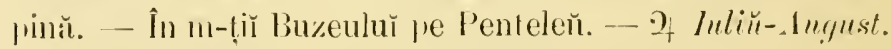

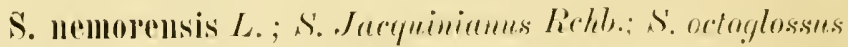
D) C. S. ale collř. - Prin locurile uncale si umbrose din

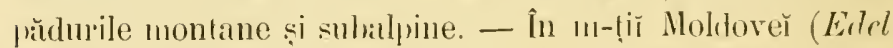

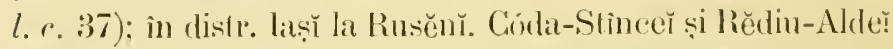

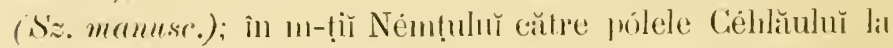

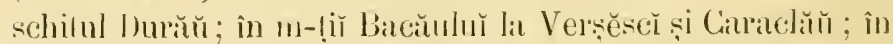

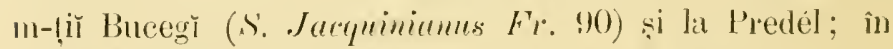

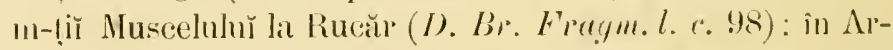
geṣ pe m-tele Urḍiea și Coriar; în Vîl.eal la Grolotrenŭ pe Fórfeca; în Ciorjiŭ la Roşia; ete-2 luliñ-lurgust.

3. Furhaii Buiss.; s. Furhsii Gmel.; s. sumernirns Gr. rt Godr. as parte. - Prin locumile muede si mubrose din pătdurile montane și subalpine. - În Moldovia (s. weatus Cz. Flmu XIX. 71 et Exsir.!) smperioră (S. Fuchsii Crmbl.

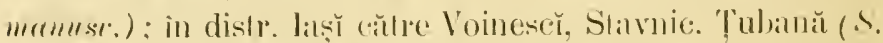

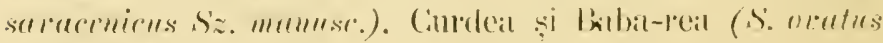

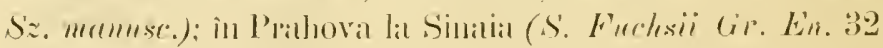
et Exsic.!) tălre pólele m-lelur Pélra-âsă in Muscel pe 


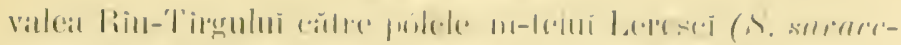

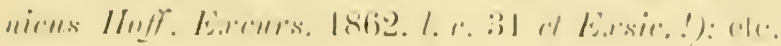

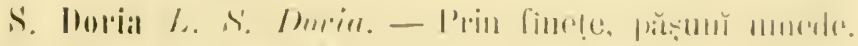

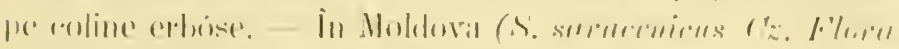

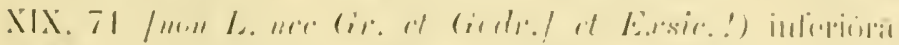

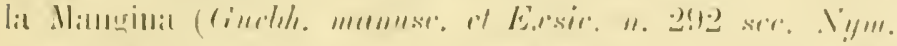

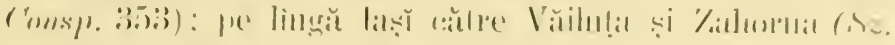

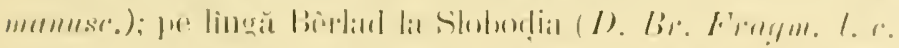

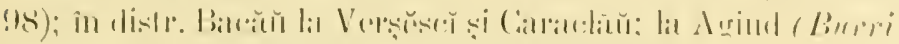

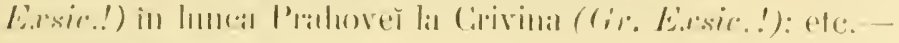
of linlint-.ln!ynst.

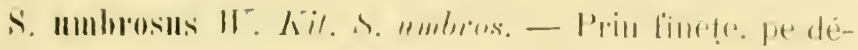

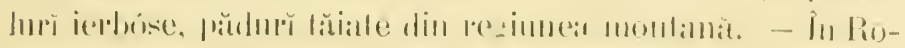

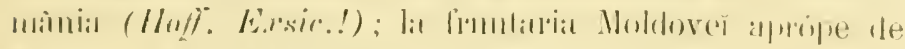

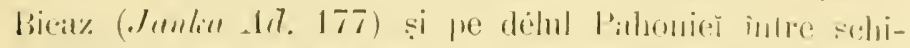

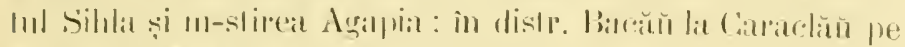

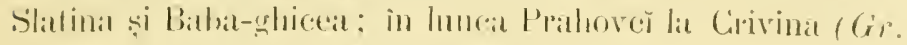

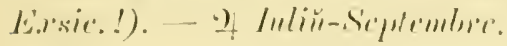

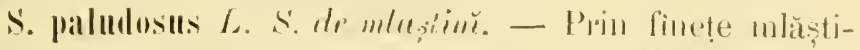
nuse, prin luncile de pe malul rimbilor. - In Moldova (Sz.

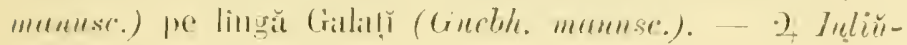
-1uyusi.

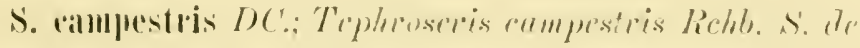
cimp. - I'rin finelele uscalle și pe colinele peltrose. - In

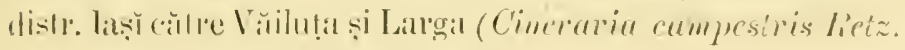

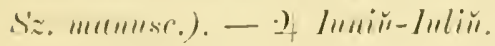

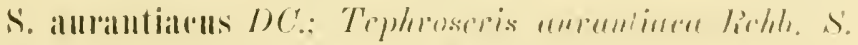

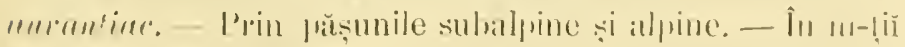

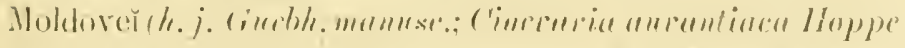

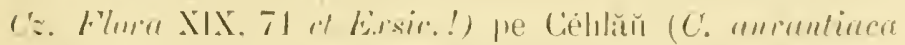

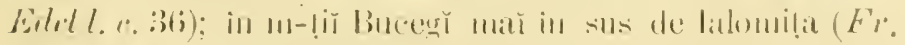

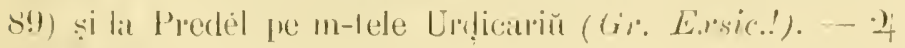
dicuir-luliü. 


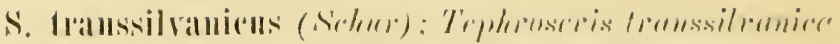

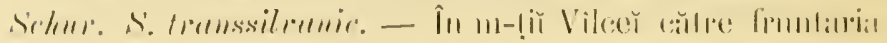

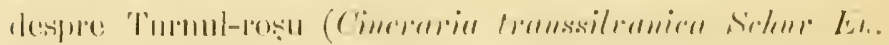

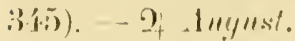

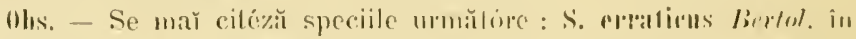

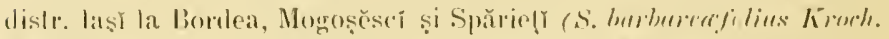

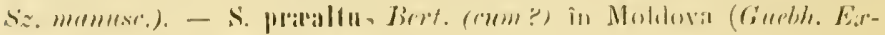
sic. 11.285 ? wer. Nym. ('omsp. 3355

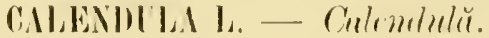

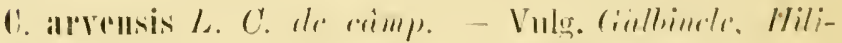

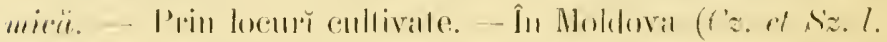

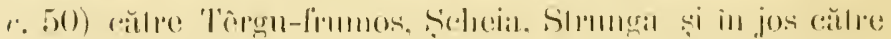

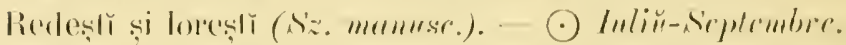

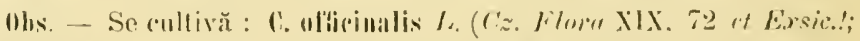

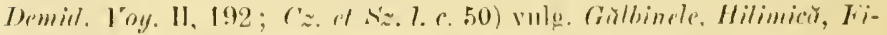

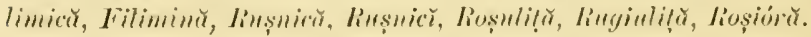

\section{II. (INALOCLPHALEE.}

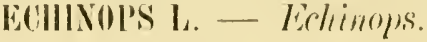

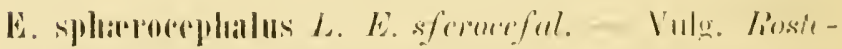

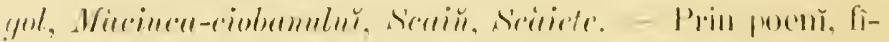

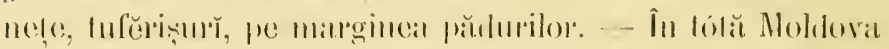

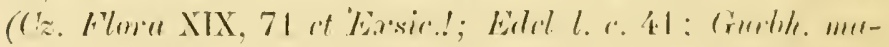

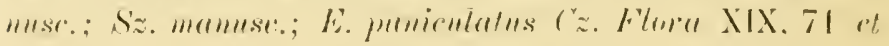

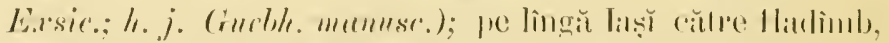

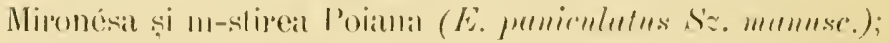

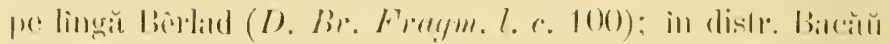

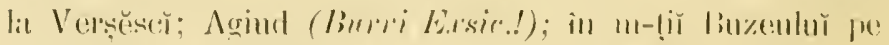

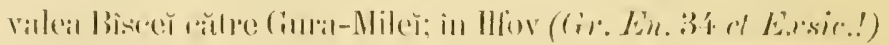

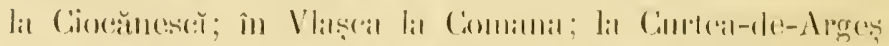

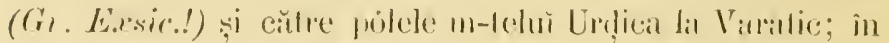

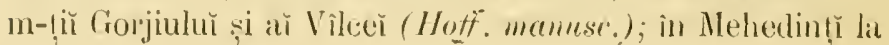




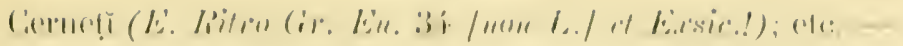

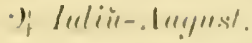

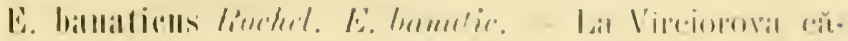

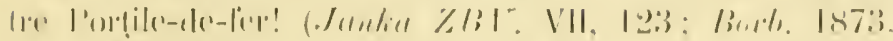

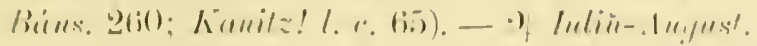

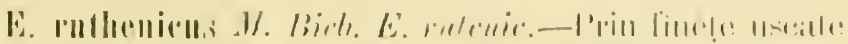

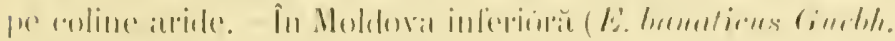

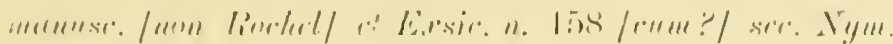

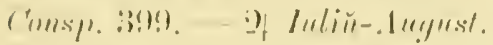

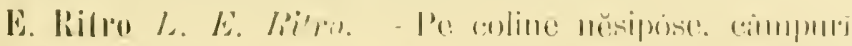

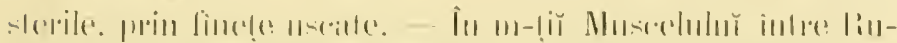

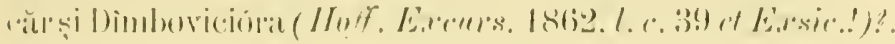

\section{rIRSIUM 'Tommef. - Cirsiü.}

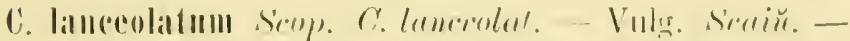

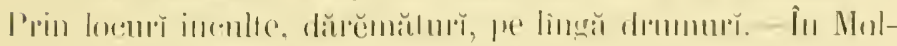

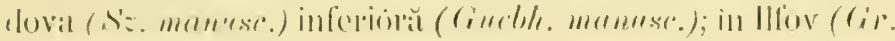

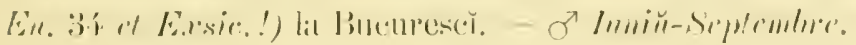

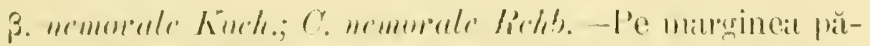

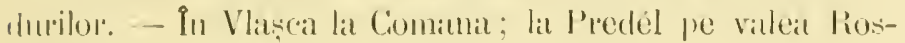

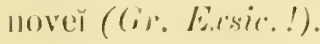

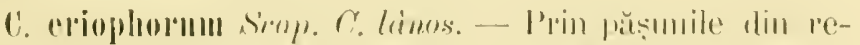

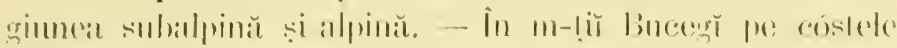

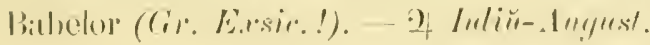

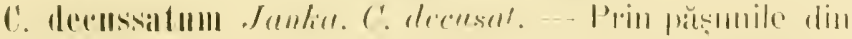

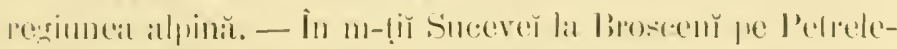

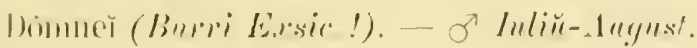

C. odontolepis Buiss. C. odmololepis. I'rin finetcle de pe

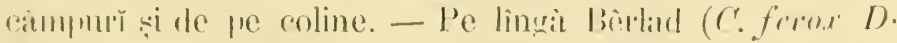

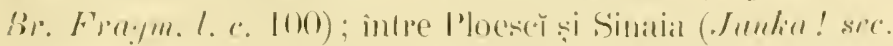

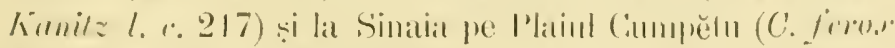

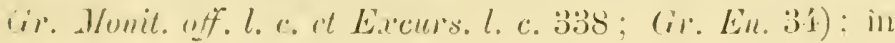




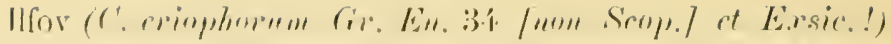

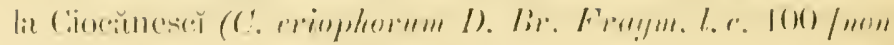

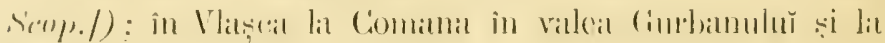

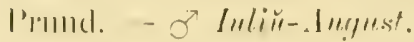

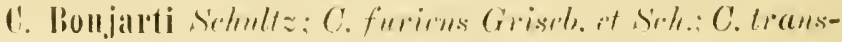

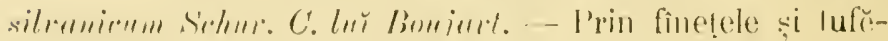

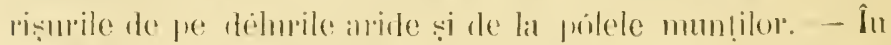

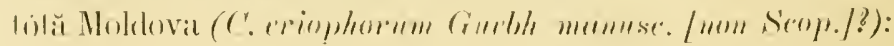

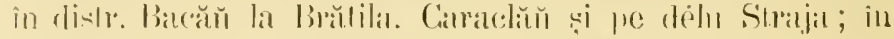

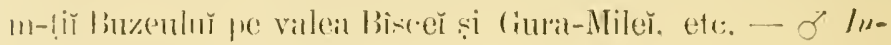
liim-sipermber.

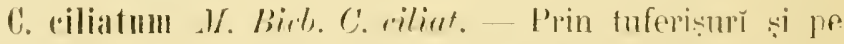

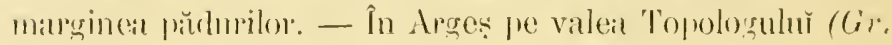
linsir.!). - o luliu-Inynst.

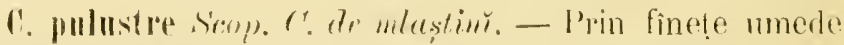

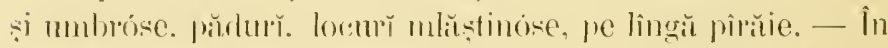

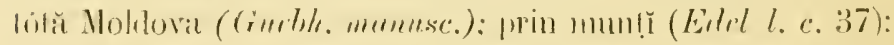

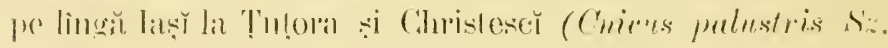

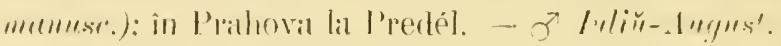

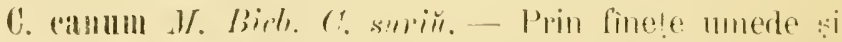

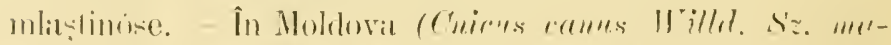

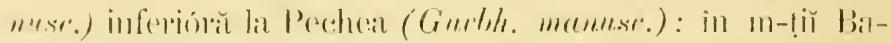

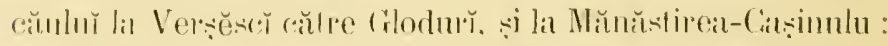

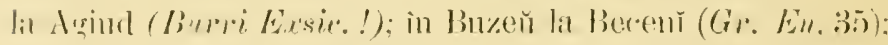

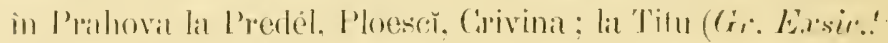

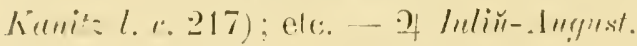

C. Pannonicmm Gand. O. pammic. - Prin finetele 11:-

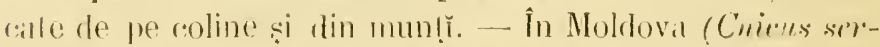

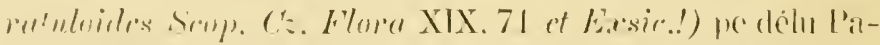

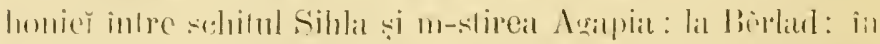

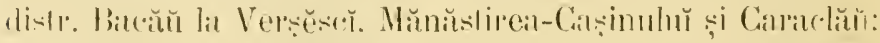

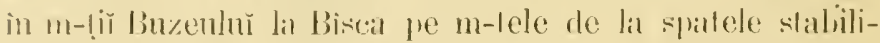

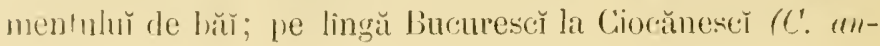




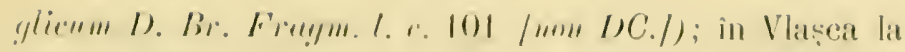

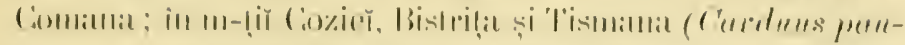

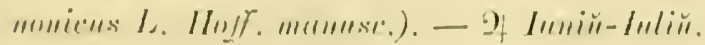

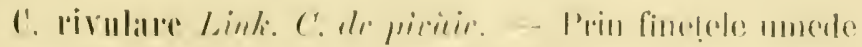

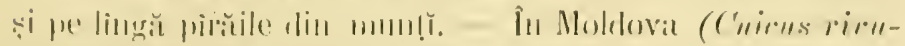

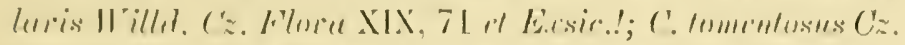

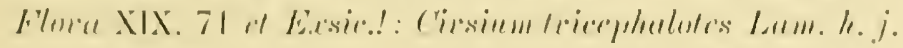

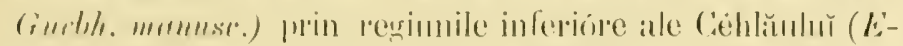

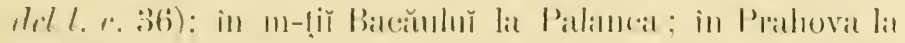

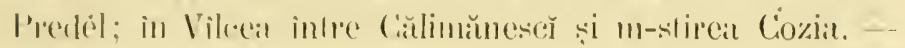
2. Inıiй-.lugyest.

C. Erisilaales somp. C. clrius. - P’rin locurile petróse ị unede din prudurile montane și subalpine. - În Moldova

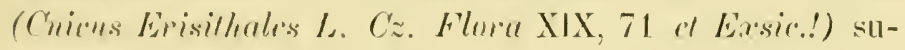

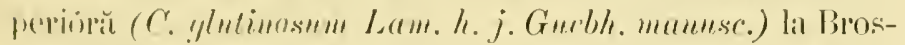

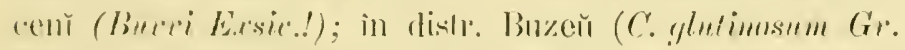

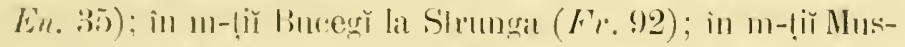

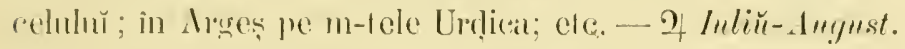

C. paucillorum spmerny. C. puncifler. - I'pin locmile nmele și pe lingŭ pirăile din pădurile unbrose montane și

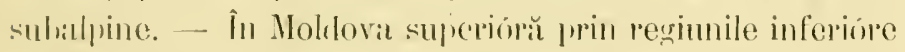

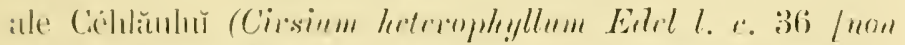

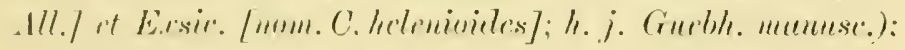

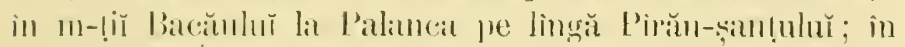

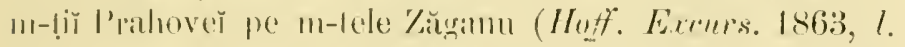

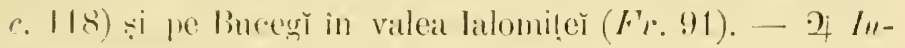
liir-_lu!just.

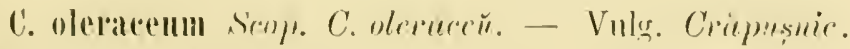

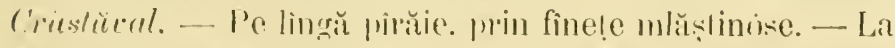

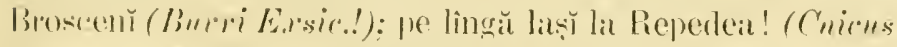

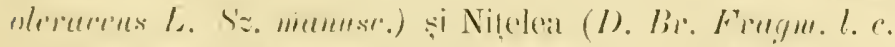

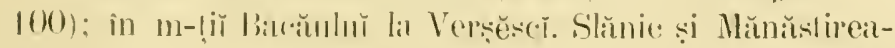

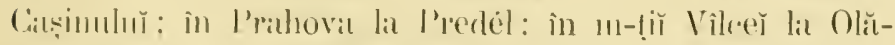
nescì ; ele. - 2 Inliir-_tughest. 


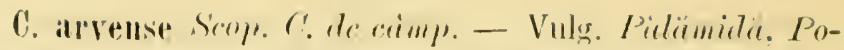

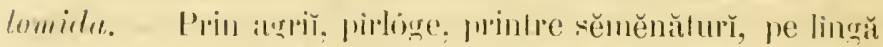

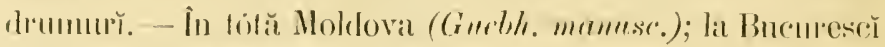
(cir. En. 3is ef Eirsir.!). Buftea, Curvina, ete. - of Iuliudergust.

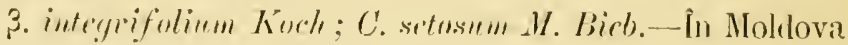

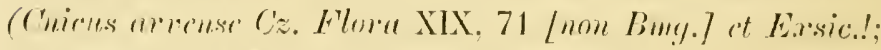

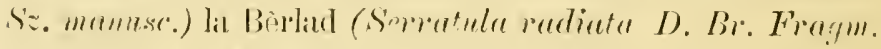

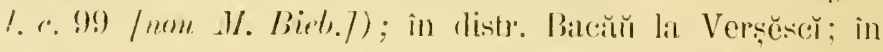

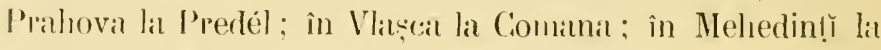
Stirmina (Cor. Exrsic.!): ete.

\%. restitum Kuel. - În Vlașęa la Comana (Gr. Exsic.!).

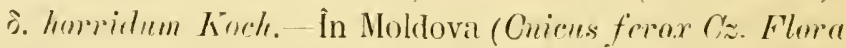

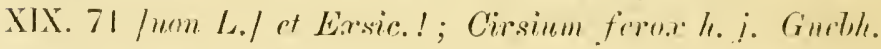

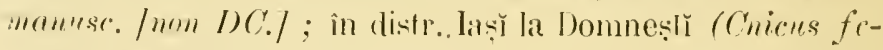
mor. s'z. mumuse.?).

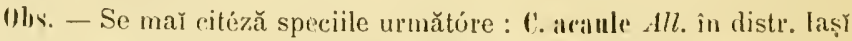
către Sucušcur și Rĕdiñ-Alder (Cnicus ncuntis Irilld. Szz. menunse.). f. serrulatum .1. Bieb. în m-ți m-stirilor Cozia, Bistrița și Tismana

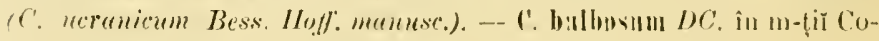
zier, Bistnif̣a și Tismana (Hotr. mumusc.).

\section{G.ARIIJIS 1. - Cardon.}

C. acauthoides L. C. norentwid. - Vules. Simn. Sichin.-

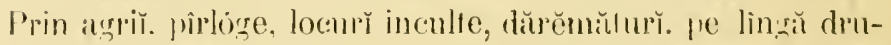

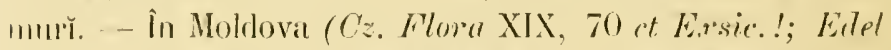

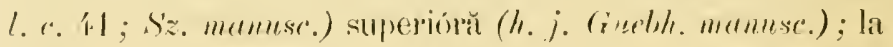

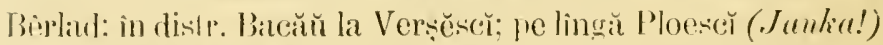

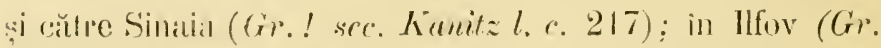
Eu. 35) at E.rsir.!) lat bucurescĕ: in Vlașea la Comanal; in

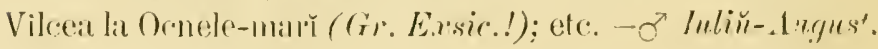

C. alpestris II. Kit. C. alpesten. - Prin pășunile petrose din reginned subalpină și alpină. - In m-lị̆ Bucegì (C. acanthoides Gr. En. 35 fuon L.] et Exsic.!); pe Furnica și la schitul Pescera de la lalomiṭa - of Inliü-_ungust. 


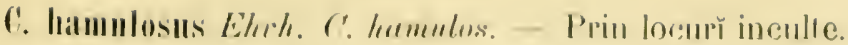

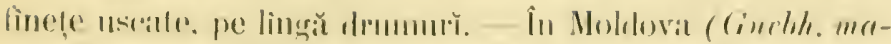

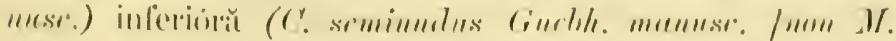
Birl.. !). — o luliir-.lugnest.

3. whermens. - L'rin locurile inculle. - În toilit Moldovil (limellh. menursi.).

C. Mallicaus IV. Kit.; C. allims W. K̈it. C'. alli-

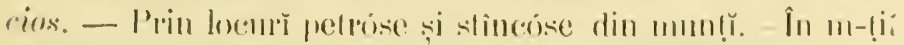

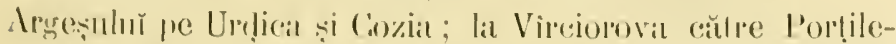
de-fer! (Bur. 1873, Bims. 262) și intre Sihelent-Ciatore:

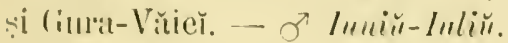

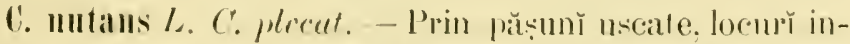

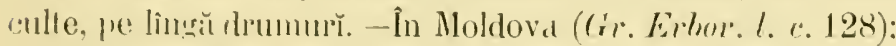

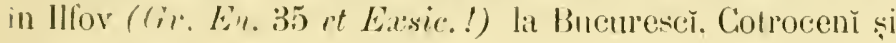

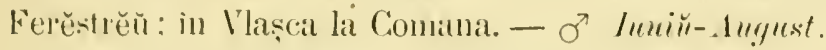

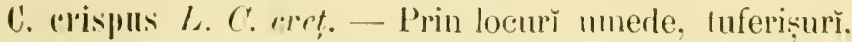

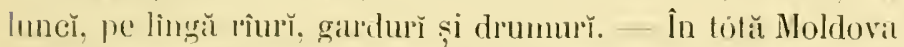

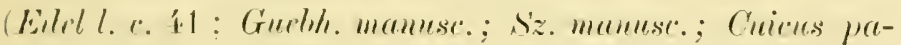
instris Cz. Flan XIX, 71 [am Willd.] of Exsice! D. Br. Frengu. l. I. 100 ; Gr. Erbor. l. c. 128; (ir. Eu. 35); intre Cirivinal și l'loescì (Gr. Exssic.!); la P'itescì in Zavoin̆; in ı-ṭi m-stirilor Tismana, Bistrị̣a și Cozia (Huff. manusc.

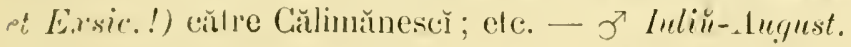

C. Pel'sonlaltat fary. C'. presonat. - the lingă lorentele slin părlurile rériuneı̀ subalpine. - În Moldova (C'z. F'loro XIX, 71 , È, sir.!) superioră (Gurbh. mamest.); în m-!̣i

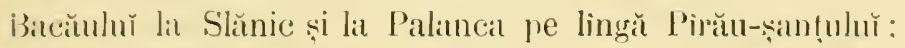

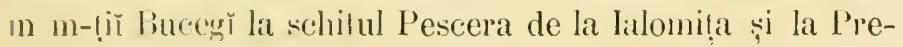
lè] : elc. - 9, Inliü-dugust.

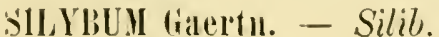

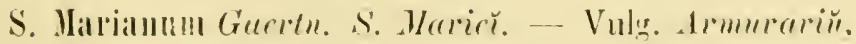

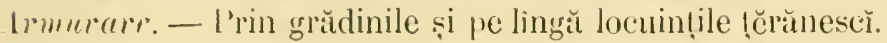


póte numă sulssponlamĕ̆. - Pe limğă laș̆ la Valeat-adincă

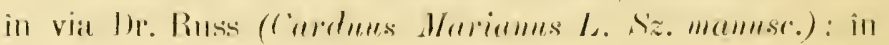

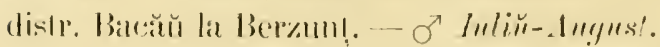

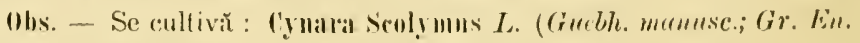

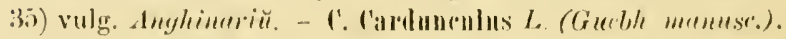

\section{OSOPORDON L. - Onoporion.}

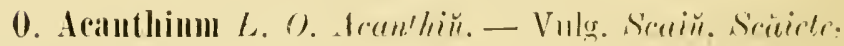

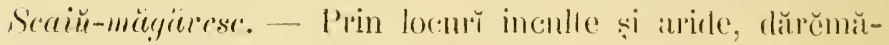

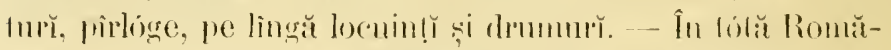

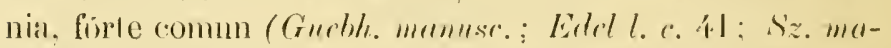

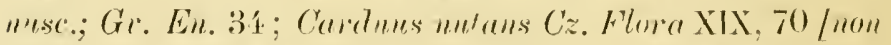

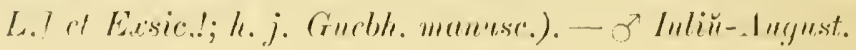

\section{I.LPI'I Touruel. - Binstur.}

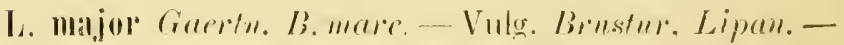

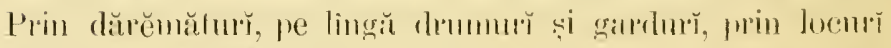
inculle. - in Moldova (Cz. Flona XIX. T(1) Edsire! : F-

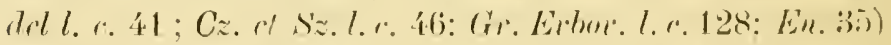

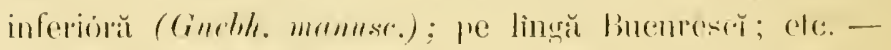
o Inlin̈-siptrmbire.

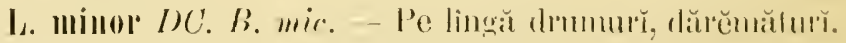

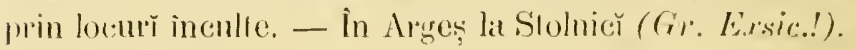

वे Inniй-Alugust.

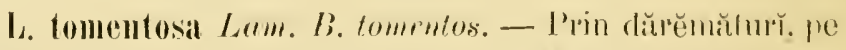

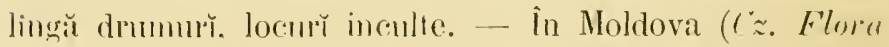

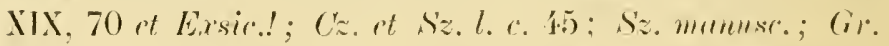

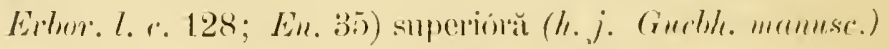
prin resimnile inferiore ale Céhlăuhŭ (Erlel l. r. 36): in

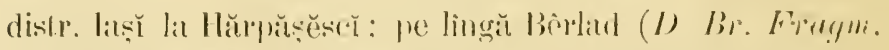
1. c. 181): la Agind (Burri Edser.!) la l'redél: pe lingă Bucurescĕ la Cihilila; etc. - ơ Inlin-śrpembrer. 


\section{C'MRINA L - C'urlimu.}

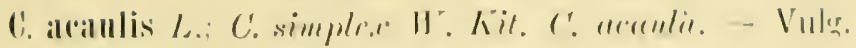

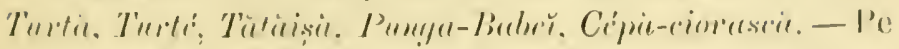

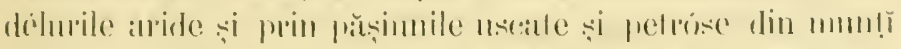

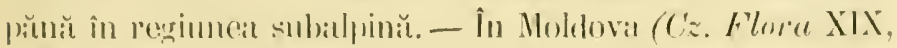

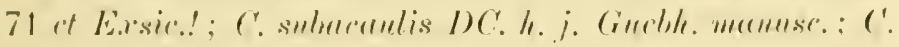

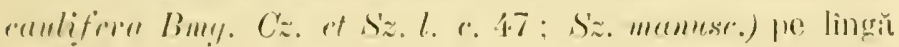

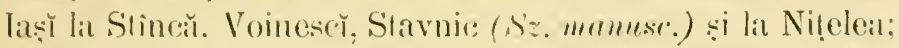
lar P'ètrĭ (Cz. ot Sz. l. e. 46), m-stireat Ném!̣hŭ si pe Cé-

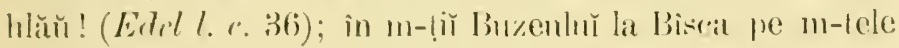

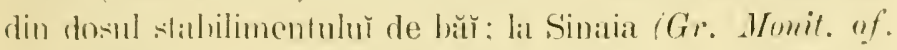

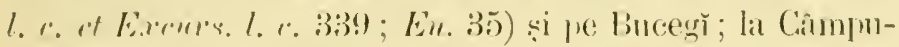

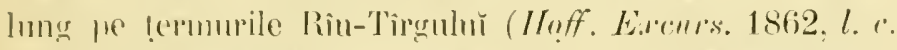

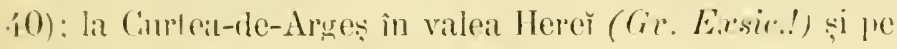
m-lele Cozial : elc. - o Inliñ-.lugyst.

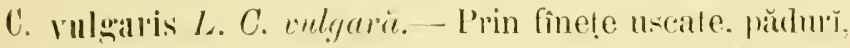

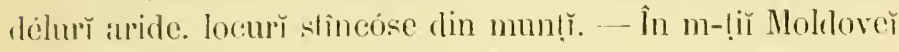

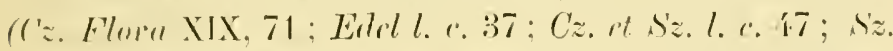

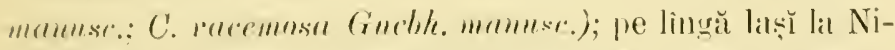

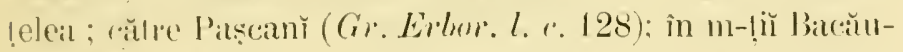

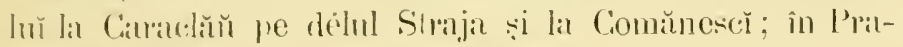

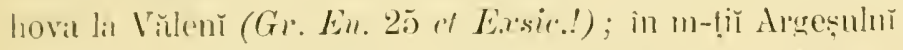

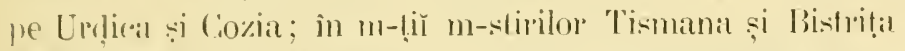

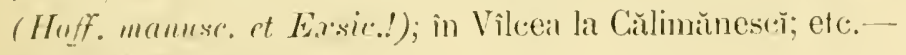

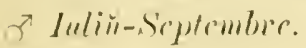

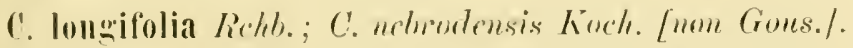

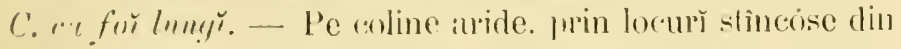

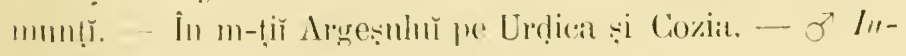
liй-síptemblier.

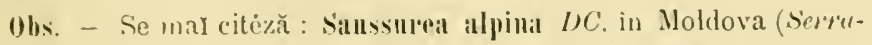

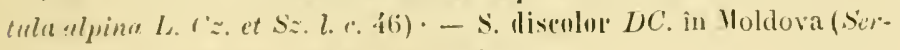
metulu discolor Willd. Cz. et sz. 1. c. qu). 


\section{SERRATULA I - Seruhlii.}

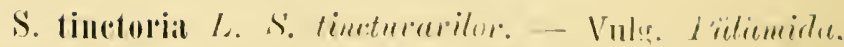

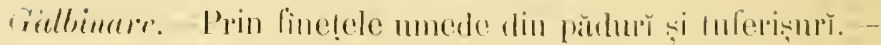

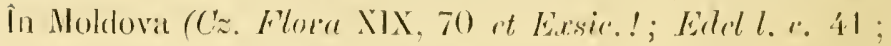

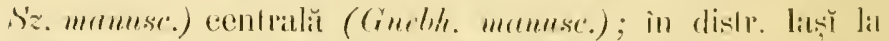

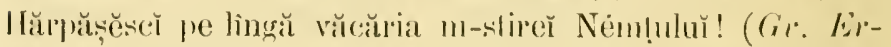
har. l. c. 127) și la m-stlirea Sĕcut; in distr. Batciún la Citrat-

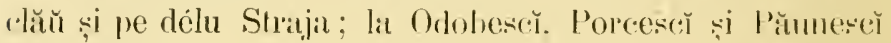

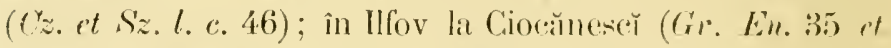

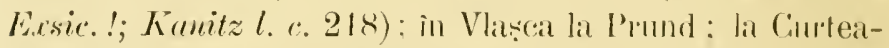
de-Arges și în pădurea Guranulur aproipre de Rimmicu-Vîlcea

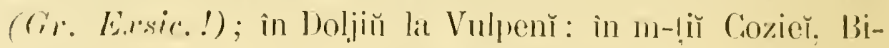

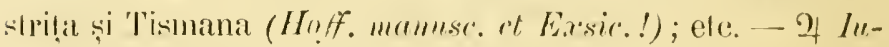
liik-Septembere.

3. imdirisa P'oir.-In Moldoval centrală (Gudbh. manuesce).

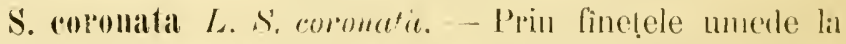

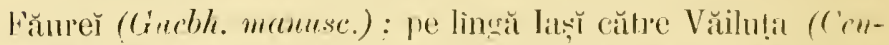
'anrea ruthonica Bme. [uon Lam.] Sz. manusc.?). - I lulin-Alugust.

OHs. - Se maY citéză : S. Palliatit M. Bieb. în Voldova (S. centauroides Bing. [nom L.] (c. et s'z. l. c. f(i).

\section{JIRINEA Gass. - Jarinee.}

J. mollis lickb. J. mólé- Pe coline aride, prin locurì

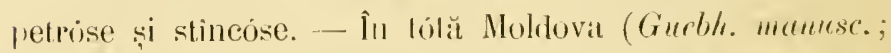
Screratula simplex DC. Cz. et s'z. l. r. 46 ; Cyanus mallis ('z. Floed XIX, 71 it E.esic. !; Cz. st Sz. l. c. 47) superiotri (Contanerer mollis Gueble. mannse. Luon 11. Kit./); lat A-

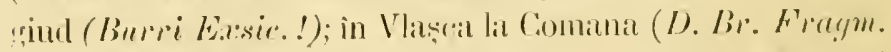

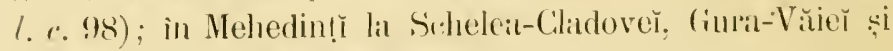

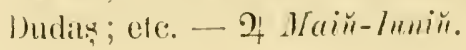




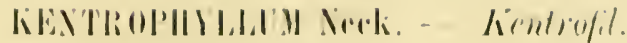

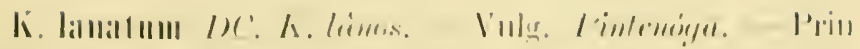

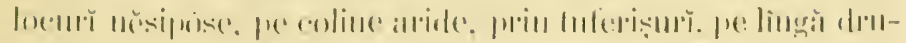

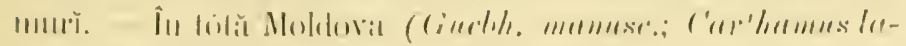

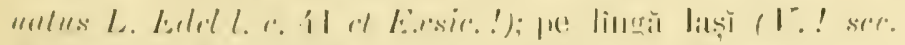

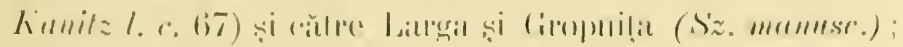

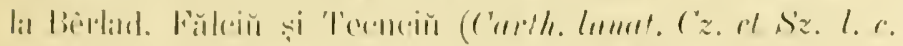

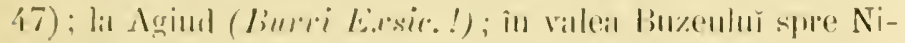

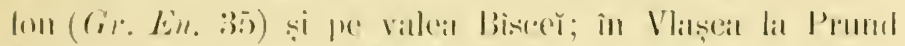

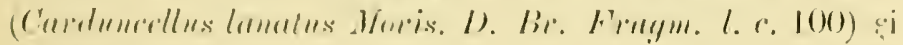

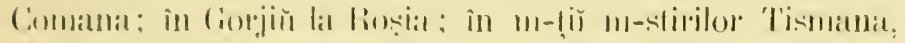

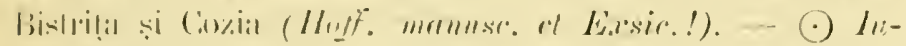
liit-lungus'.

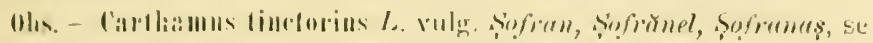

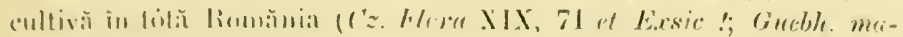

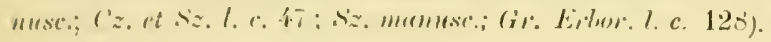

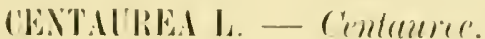

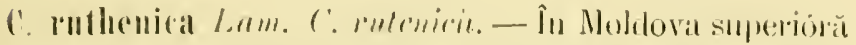

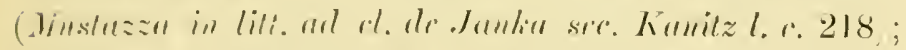

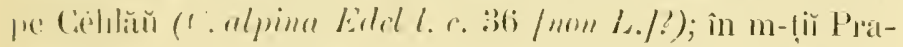

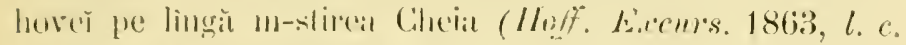
118). - - ) Inliir-.|'m,just.

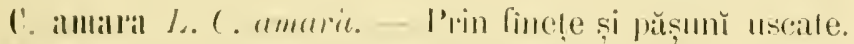

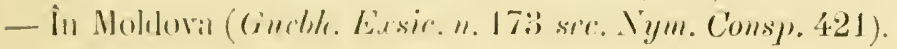
- .) Inlitit-ilugus/.

C. Jalcea L. C'. Jarre- P’rin finetele de prin pădurí și

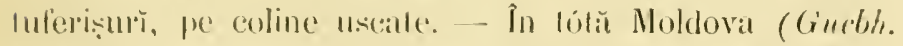

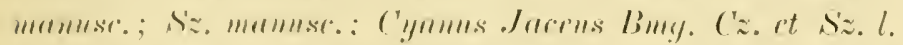

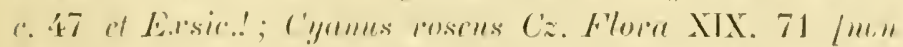

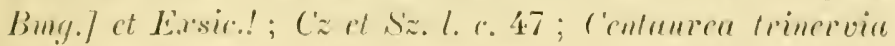
h.j. Giucbh, manuse. (non sitephun.]); ne lingă laș̆ către 


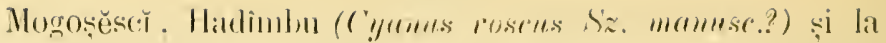

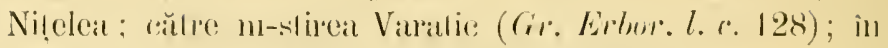
Argess la Stolnič ; ele. - If Juriur-s'septembre.

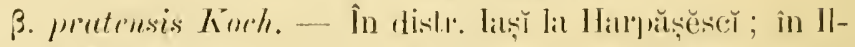

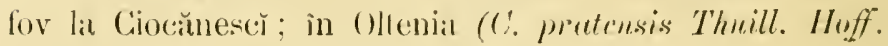
mumusc.).

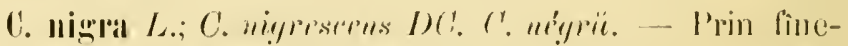
tele și pășmile din mun!̣̆, pămĭ in regimea alpină. - Lal

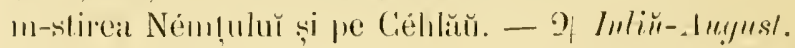

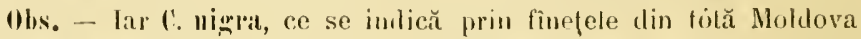
(Gumbh. mumuse.j și pe lîngă lașy la Nebuna și Vișan trebue să lie, de sigur, cu folıl altă plantă de cât C. nigr" $L_{\text {. }}$ - Chiar și C. nigr de

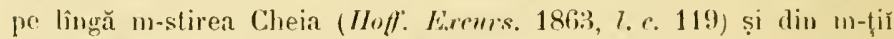
Cozier, Bistrița și Tismana (Họ/f. mumse.), trebue considerată ca o plantă înloiosă, de vreme ce ıı esistă în Erbariul Hoffmannian.

C. plumosa Lam.; C. anstriece Rochel. C. plemeisia. Prin prișnile din reginuea alpinăl. - In Noldova (Cyames

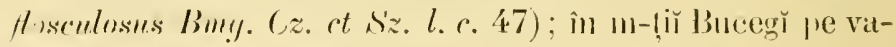

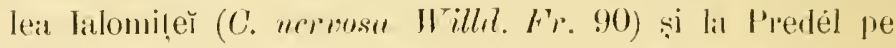

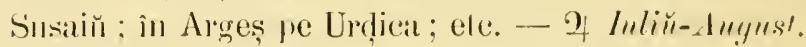

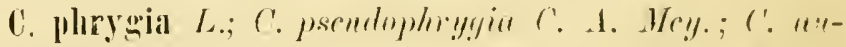

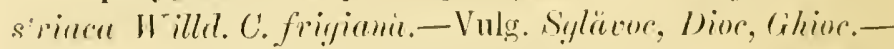
l'rin finețele din reginnea montană și subalpină. - În m-ṭĭ

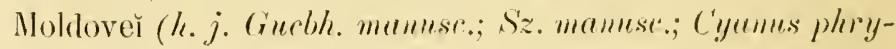
g,ius Bumy. Cz. Flora XIX. 71 al E.rsic.!; Cz. et Sz. l. c.

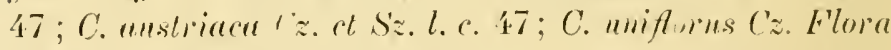
XIX, $7 \mathrm{~L}$ /mm L./) prin reginnile inferiore ale Céhlĭulŭ

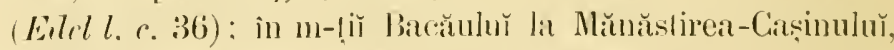

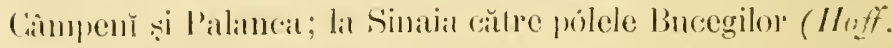

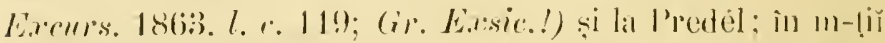

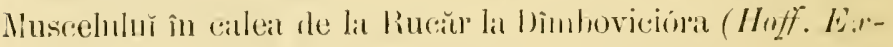

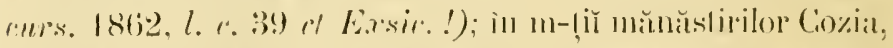

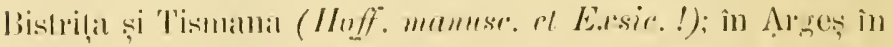

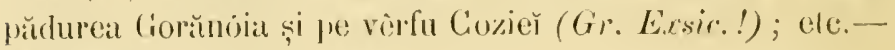
2) luliü-. luegrest. 


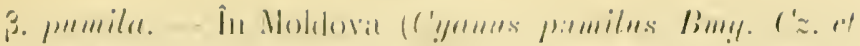
S.

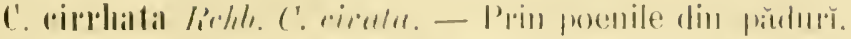

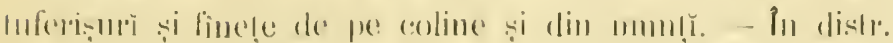

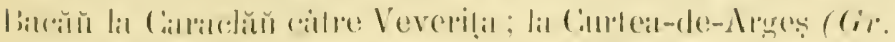

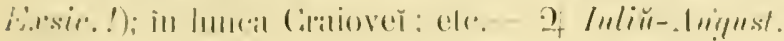

('. stemolopis himene. Costomblepis. - P'rin poenile din

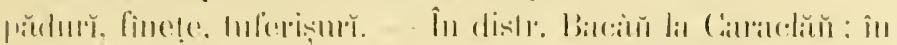

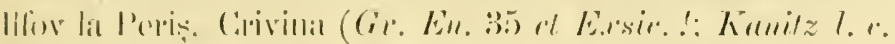

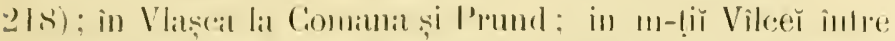

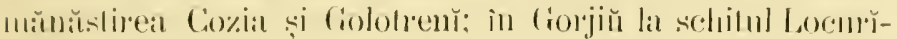
rĕle: ele: - 9 Inlin-.luynst.

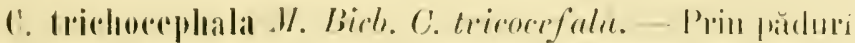

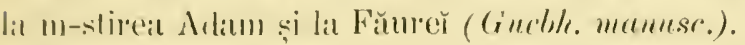

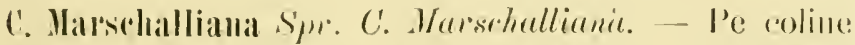
nésiprise. - In Moldova inferionă la l'echeal (cinebh. ma-

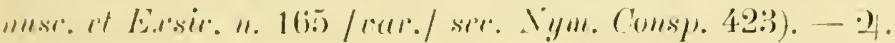

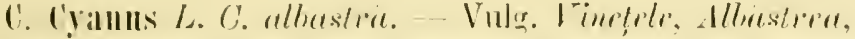

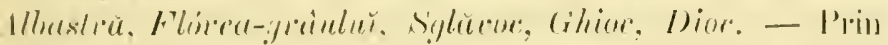

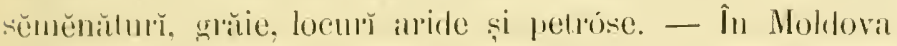

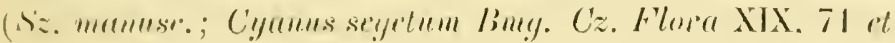

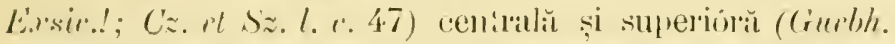

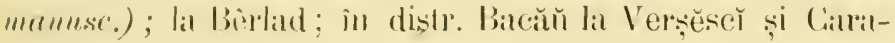

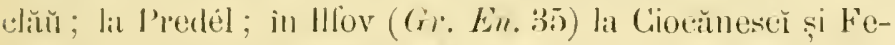

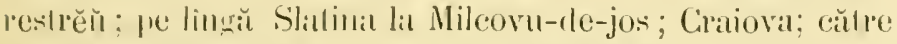

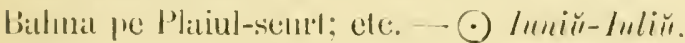

C. Inontima L.; C. monlume- - P'pin pădurile de pe (o)-

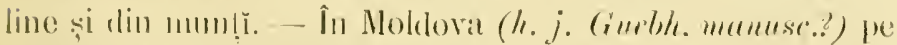

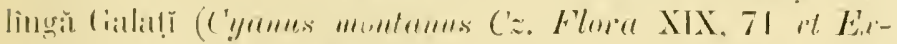

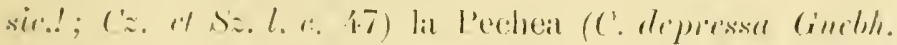

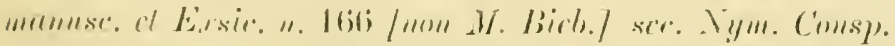

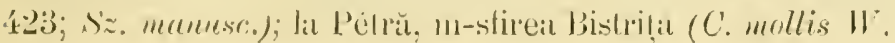




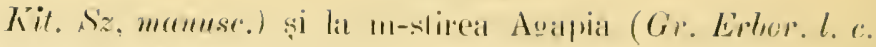

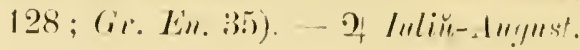

A. axillanis W'illd.; C. stricte U. Kit. O. arilarü. Prin pășnile slincơse din regiunea subalpină și alpină. În m-ịi Moldover (c'yamms memis ('z. Flore XIX. 71 et Ex-

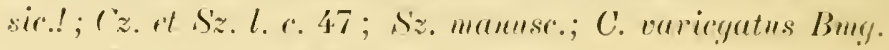

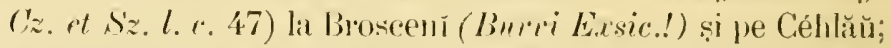
in m-ṭĭ Bucegì lat Strmuga (Kosshy, 132) şi la sehitul Yeccera de la Ialomita. - 2 Lulin̈-August.

C. Hrinervia steph.; Phoopappus trinervius Boiss. C'. trinervialŭ.- Pe colinele ierbóse.- La Tîrgoviștea (Schoti, 4.72). - I luliut-aluguest.

C. Srabiosa $L$. C. Sirabiosä. - Prin tuterișuri și finețe sterile, pe coline aride, pe marginea agrilor si a drumurilor. - În tólă Moldova (Guebh. mumese.; ('yormes Sentriosa Maturh. Cz. Florre XIX. 71 at Esisie.!; Cz. ct Sz. l. c. 47; C'.

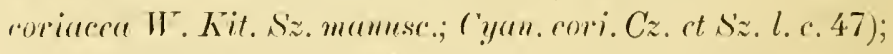

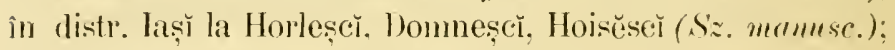

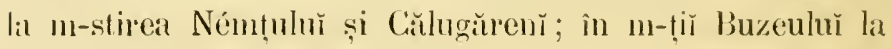

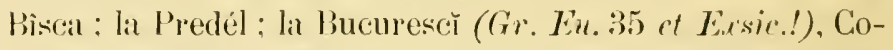
Jentina, Cintitila și Ciocănesč̆, Crivina și Ploesč̆ (C. atromurpurea Gr. En. 35 /un W. Kit.7 et Ersic..!); in Vlașca lil Counana; intre Pitesĕ și Curtea-de-Arges (Gr. Ersir..');

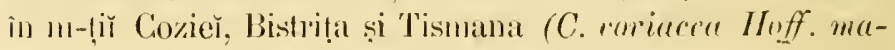
unse. et Exasic.!); cle. - 2f Inliü-.luegest.

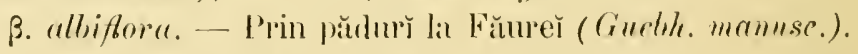

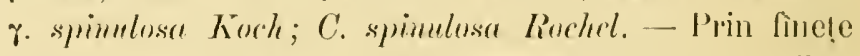
sterile, pe coline aride, pe maromea agrilor și a drumurilor.

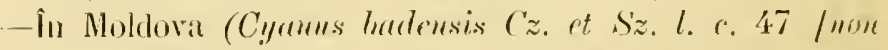

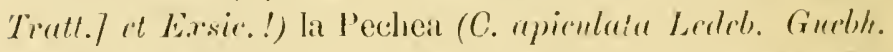

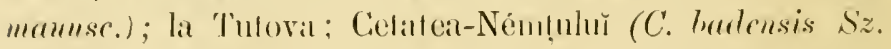

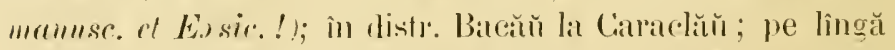
Bucurescí la Chitilal ; la Comana ; in Argess lat Stolnič́; între Rimmicu-Vìlceĭ și Olănescĭ (Gr., Eissic.!): etc. 


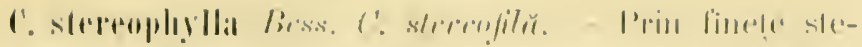

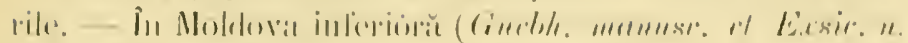

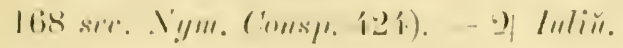

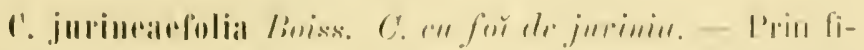

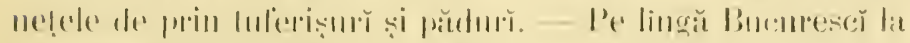

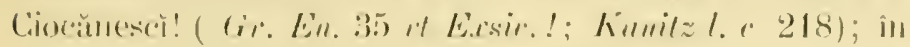

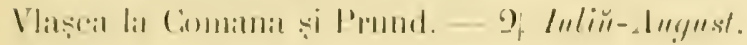

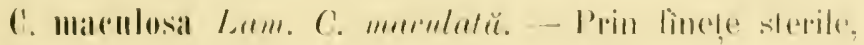

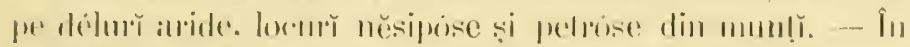

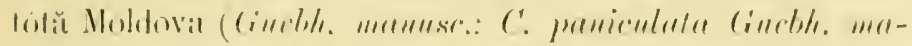

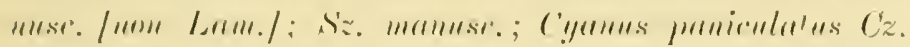

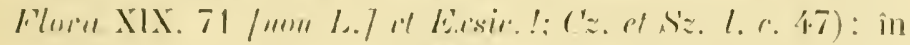

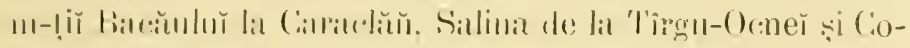

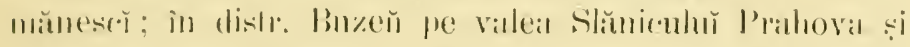

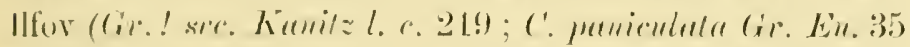

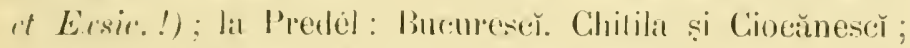

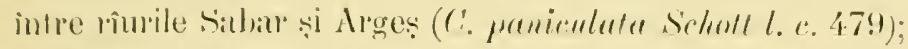

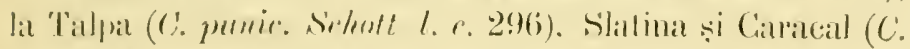

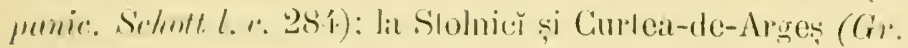

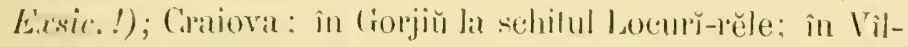
cea la m-stirea Corgia și la Ciolotreñ pe valea Lotrulur ; la

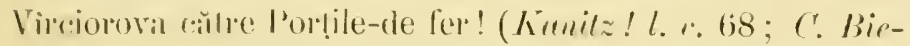

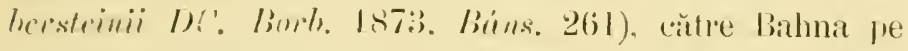
m-lele Curchia și la Turnu-Severin; ele. - o' Inliüsiputemlere.

('. atropmpurea H. Kil. Cotropurpmet. - Prin finetele de pe colinele aride. locurĭ slîncóse mă cu semuă cal-

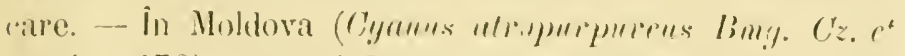

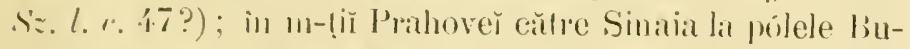

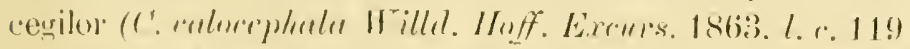

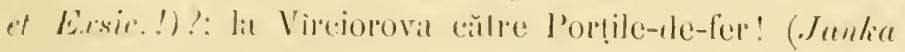
ZBI. V'IT. 12:3: Kienit:! I. a. 68) pe m-tele St-Petru lit

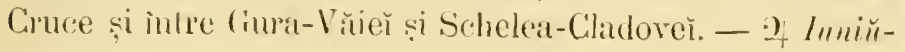
Iuliii. 
C. orientalis L. C. mirutulü. - I'rin finete sterile. In-

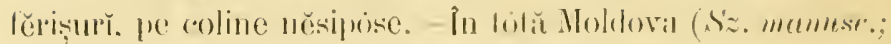

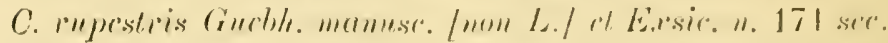

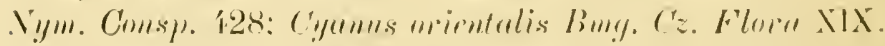

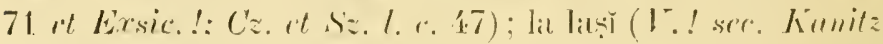

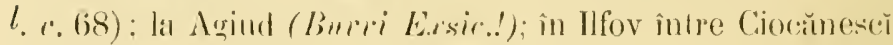

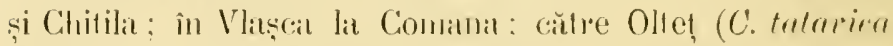

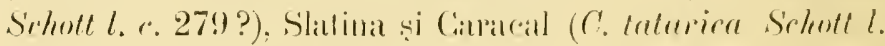

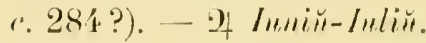

C. solstitialis L. C. solstirinatu. - I'rin locurì sterile, ruderale și incolle, coline aride. pe marginea agrilor și a dru-

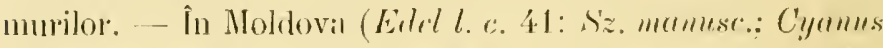

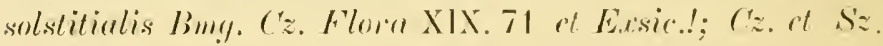

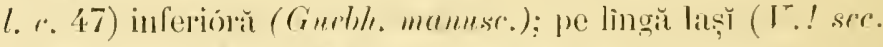
Lamitz l. r. 68) lit Manta-loṣie, Nehmmi si Reperlea: pe

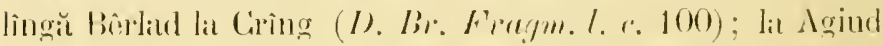

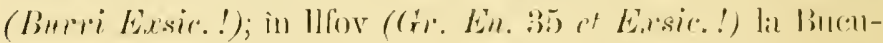

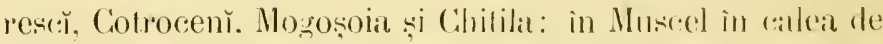

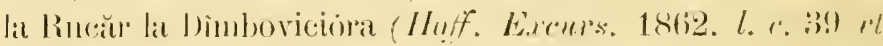

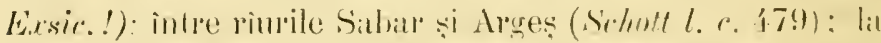
Comalna și Prund; Stohnič : (ălıe Olte! (Solvolt l. c. 27!1); pe limgă Ciratovat la Lémnat; lat Vîreiopoval! (Komilz! l. f.

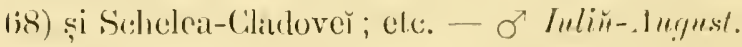

c. Calcitrapa L. C. Caleiliapă. - Pe cimpmrì nĕsi-

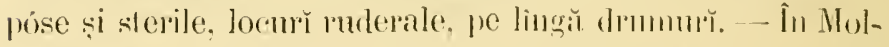

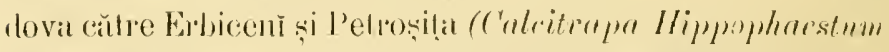

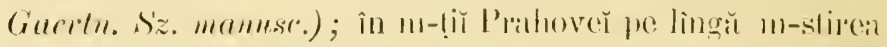

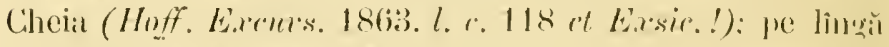

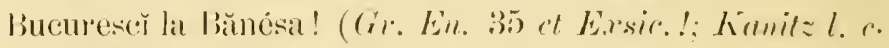

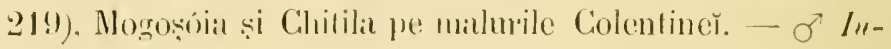
liik-A Ingmst.

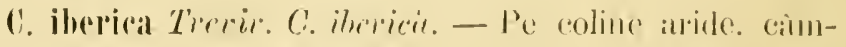

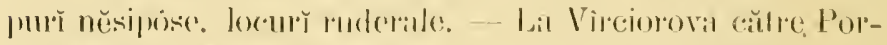
tile-de-fer! (Kanitz! lo e. 68) și lat Turnu-Sererin. or Iulin-inguest. 


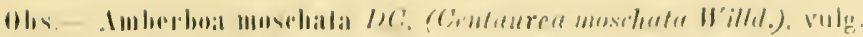

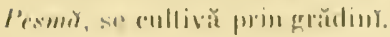

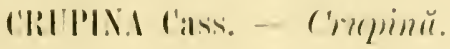

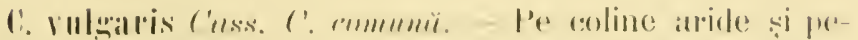

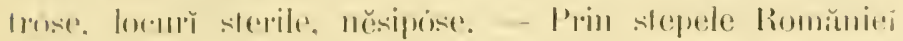

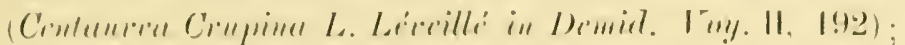

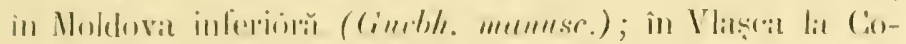

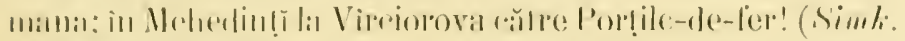

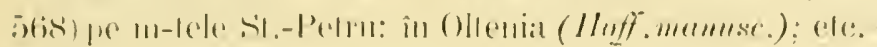
D) lumiin-luliin.

\section{SERATTHEMUII I. - Xeramlem.}

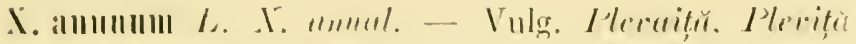

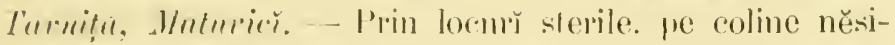

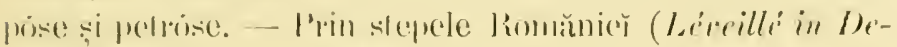
mill. Foy. II. 192): in Molelova (Cz. Flora XIX, 71 it E.r-

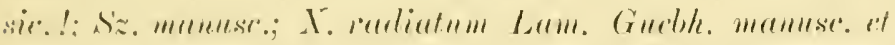

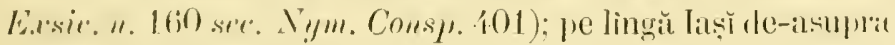

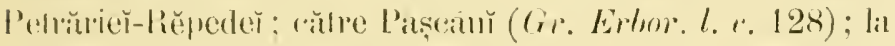

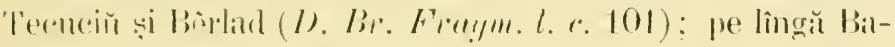

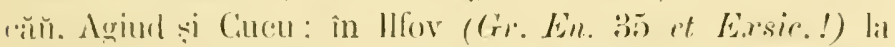

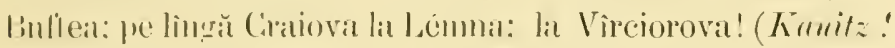

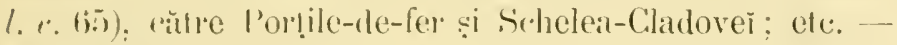
Inlin-.lur!nst.

X. cylindracemm sibth. X. rilindraceñ.-. P'rin locuri - terile. prin finetele de pe colinele nésiprose si petrice. -

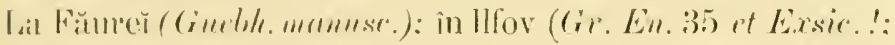

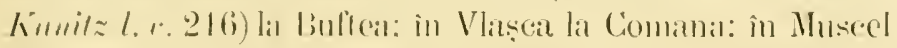

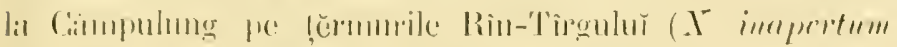

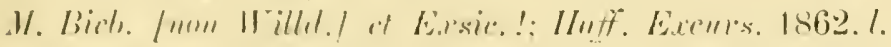

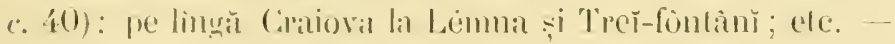
$\bigcirc$ heliir-duynst. 
III. CilcilloliticiE.

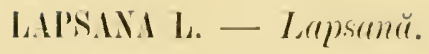

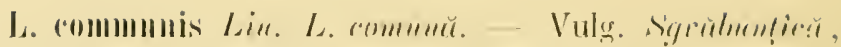

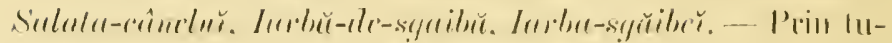

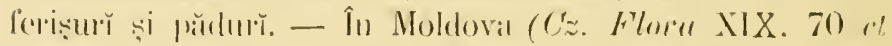

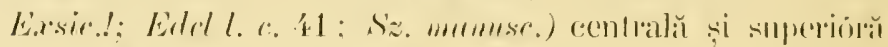

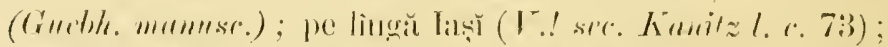

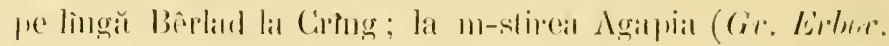

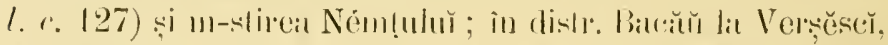

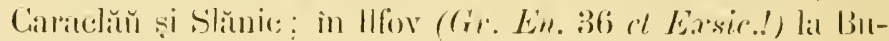

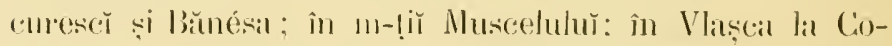

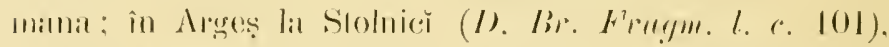

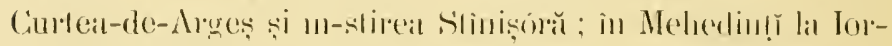

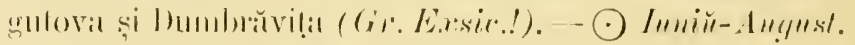

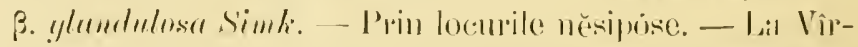

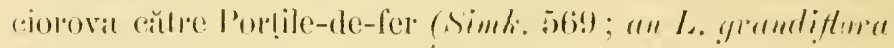

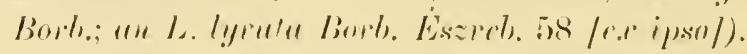

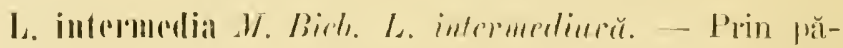
durile munhrose. - La Scinleial (cimbh. mumusr.).

\section{APOSERIS Necker. - Aposerintă.}

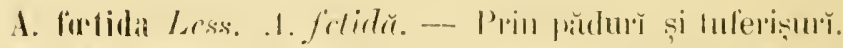

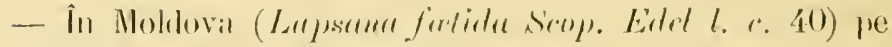

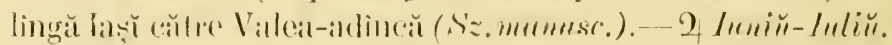

0ls. - Se mař citeză Tulpis barbital Gartn. în Moldova supe-

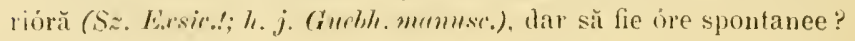

\section{C'ICIIORIIIU L. - Cicoine.}

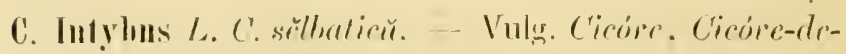
véră. - l'rin l'ị̣̆nı̆ usciale, finețe, locurì inculte, pe miur- 


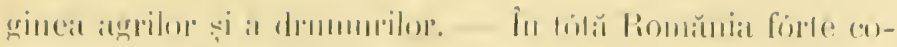

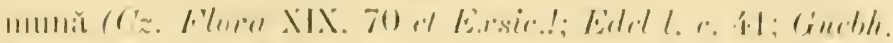

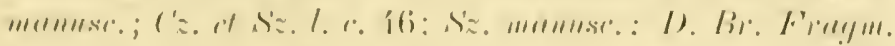

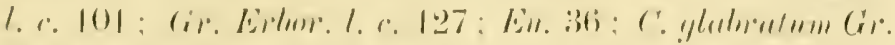

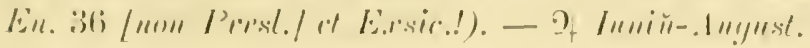

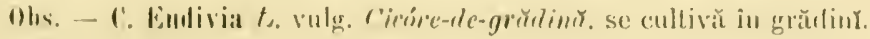

\section{LEONTODOS L. - Lecontodon.}

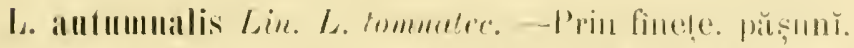

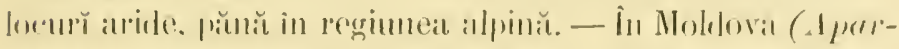

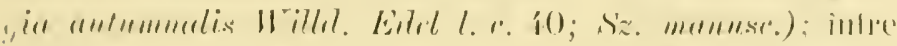

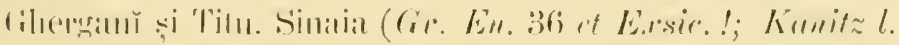

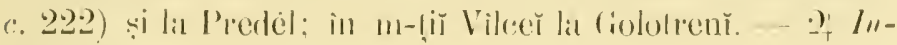
liir-O) (1) mlure.

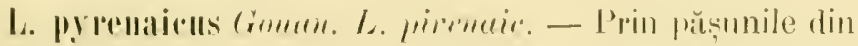

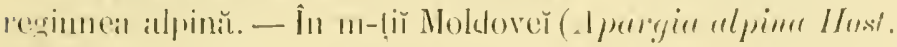
lible(l. (.37). - of lulin-alugnst.

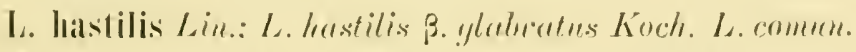

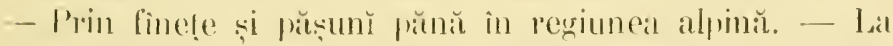

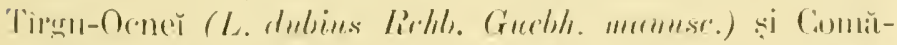

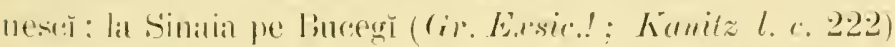

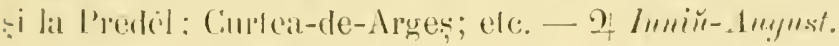

P. hispridus liniss. - Prin tinete și pășmŭ pănă în regin-

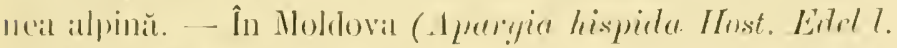

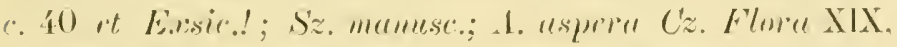

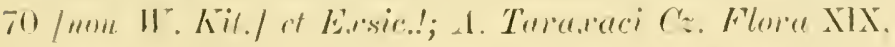

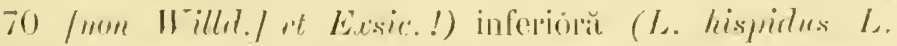

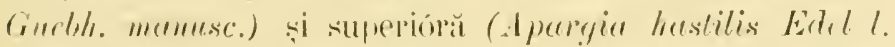

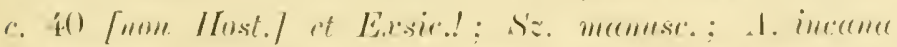

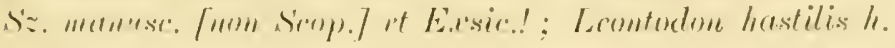

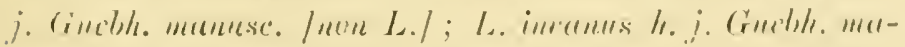

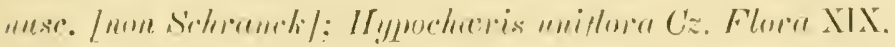

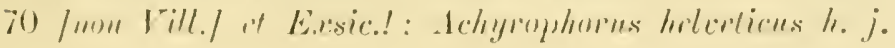




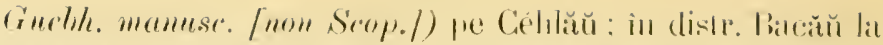

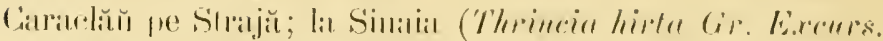

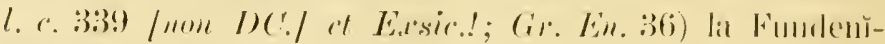

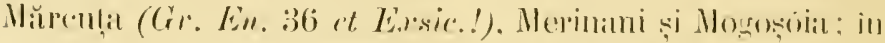

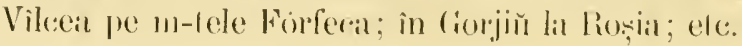

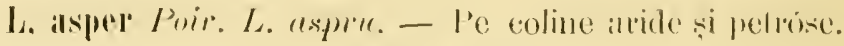

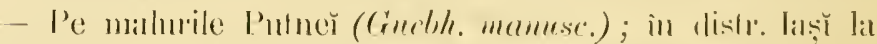

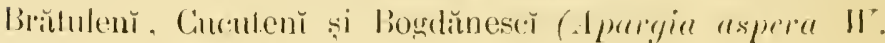
Kit. S'z. meturses?).

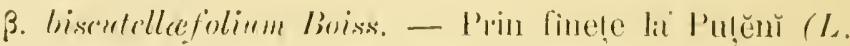

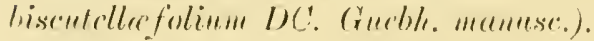

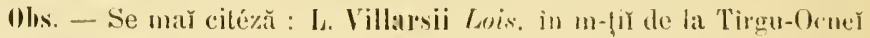
(Gulebh. manuse.).

\section{PICRIS L. - Picridŭ.}

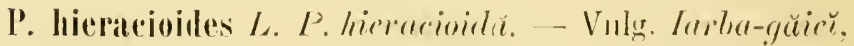

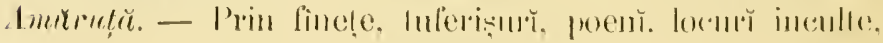

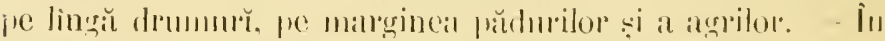

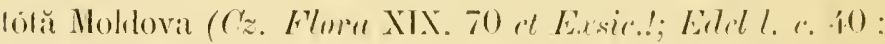

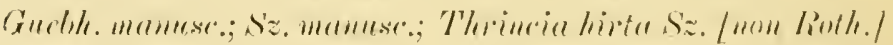

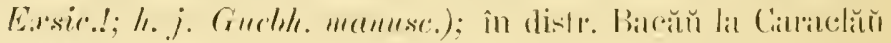

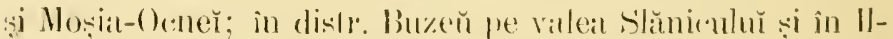

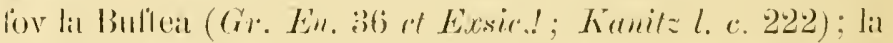

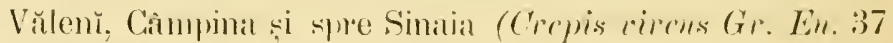

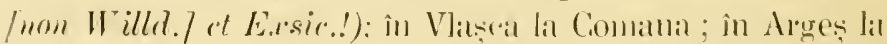

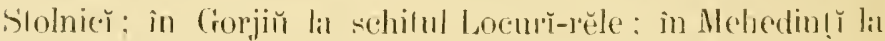

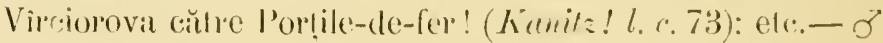
lemiin- leleyust.

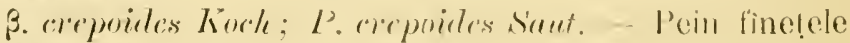

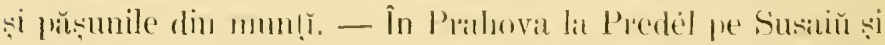

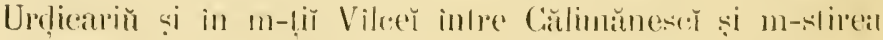
Coriat (Gr. E.rsic.!).

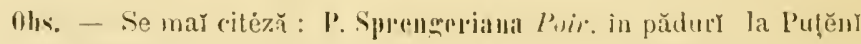
(Guebh. menusc.). 


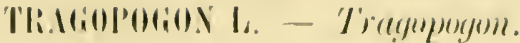

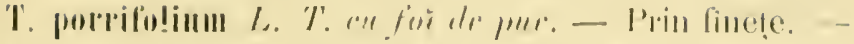

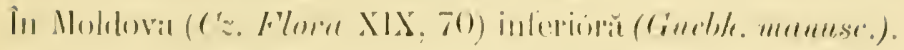

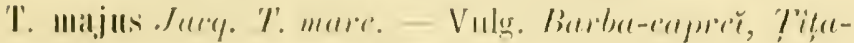

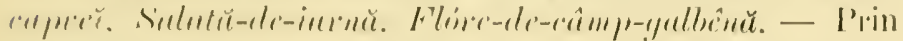
lincle storile. coline aride, něsijuse. - În holă Moldoval

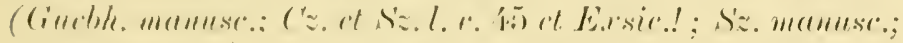

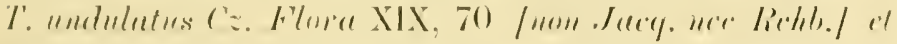

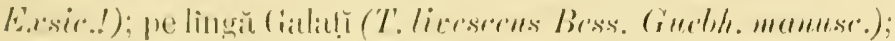

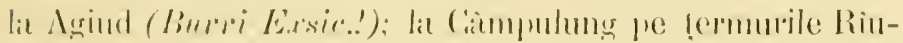

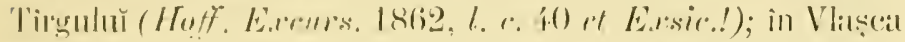
lat Combula : lat Viretorovat rătre Portile-de-fer pe St-PeImu; : vle. - o Inniü-Inliur.

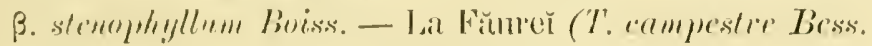

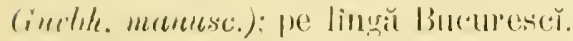

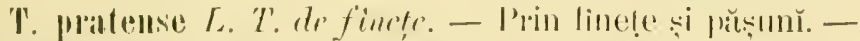

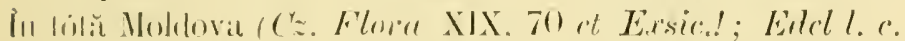

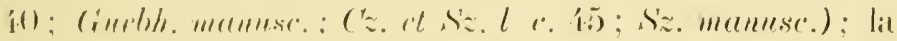

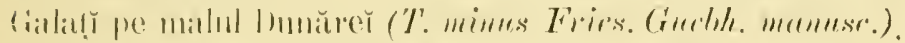

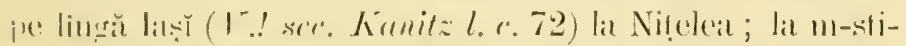

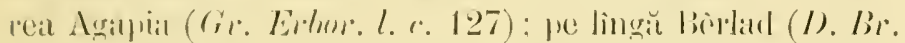

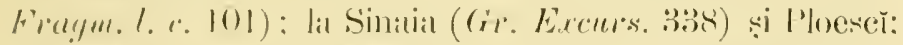

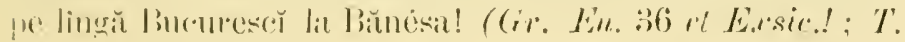

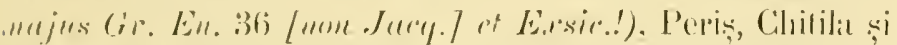

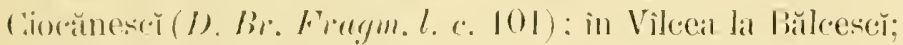

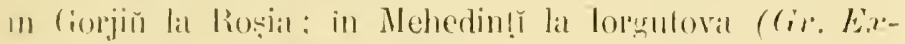
sic.!) : efe - of 1/uin-Iuliur.

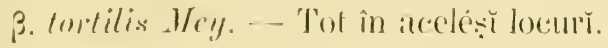

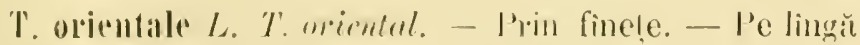

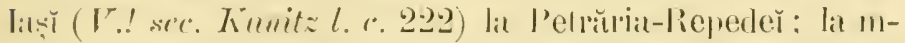

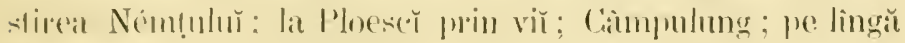

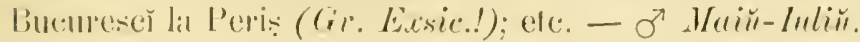




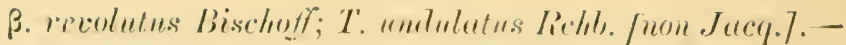

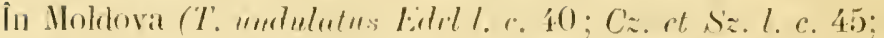

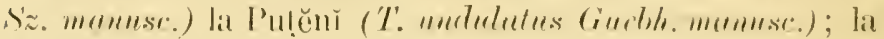

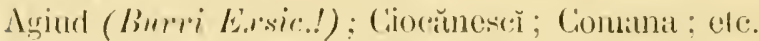

\section{SC'ORZONERA L. - Scorzonerŭ.}

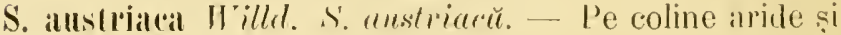

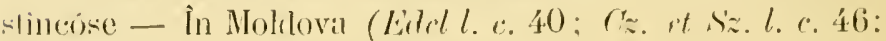

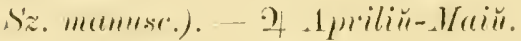

3. Lenunginnsen Bung. - I'rin pădlurile motrose din Mol-

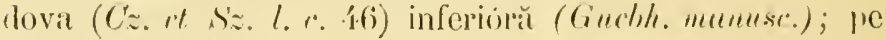

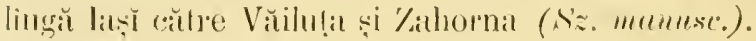

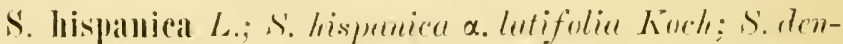

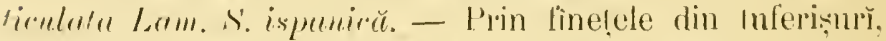

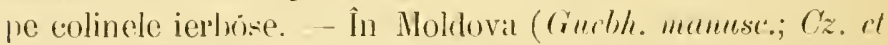

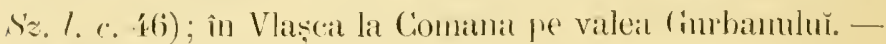
9t Mruir-luniu.

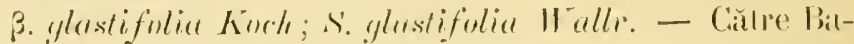

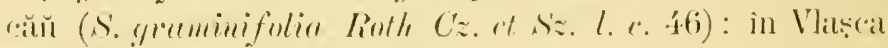
lit Comana pe valeal Gurbamnlur.

S. purpurar L. S'. purpurie. - Pe colinele nĕsipise si - Herile. - In Mloldova (

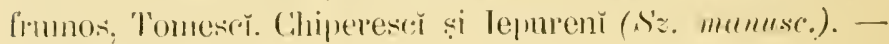
it Inniri-Inliu.

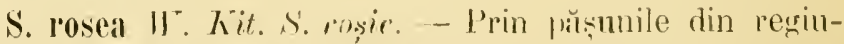

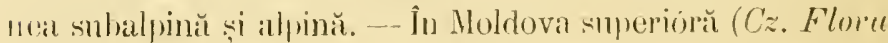

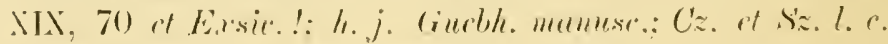

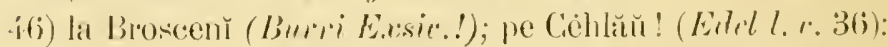

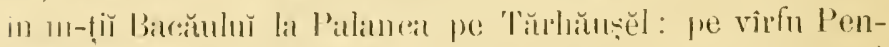

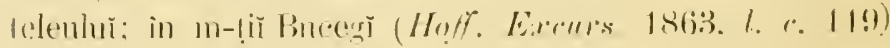
ratre Virfu-ch-boru! (Gr. Eit. 36 at E.rsic.?). pe Furnicil și la Predél pe Susaiŭ: în m-țī Argesculnŭ pe vìrfu Coziē̃ : elc. - 2. Inliü-.lugnst. 


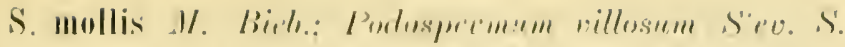

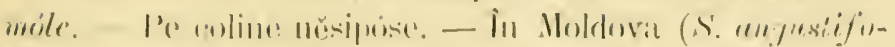

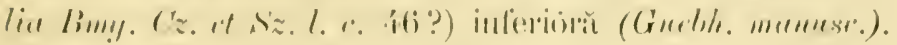

- ? luliin- lingust.

0hs. - Se mal ciliză : S. palrvillora dory. in Moldova (cz. et sz. l.

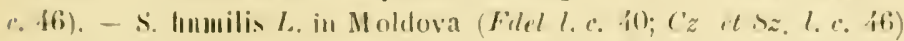

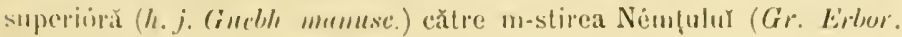
1. e. $1: 27 ?)$.

\section{PoDOSPERMUM IC. - Podosperm.}

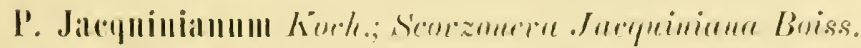

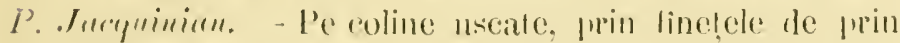

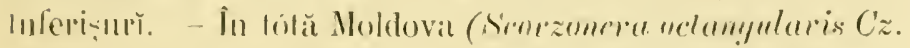

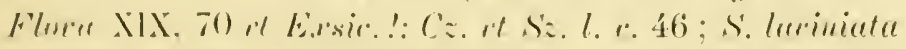

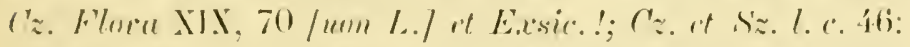

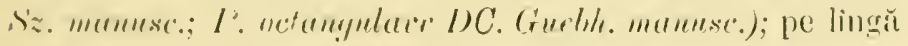

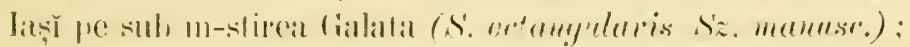

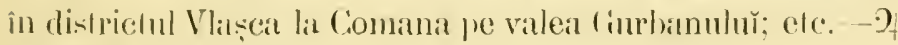
Juniü- tuynst.

P. Iaciniatun I)C.; Sicorzenere laciniata L. P. Inrinial: - Prin fincte. locarro cullivate, pe roline aride. - În totă Moldovat (crmelih. manuse.). - o Mairi-Juliu.

3. intermertimm Gre et Gurle. - P'riu finete in Moldova

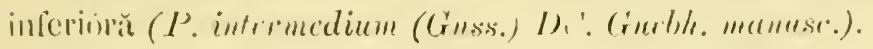

\section{HYHOCHERIS I. - Tpocherialu.}

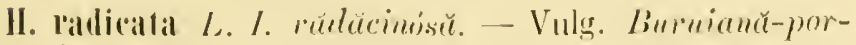

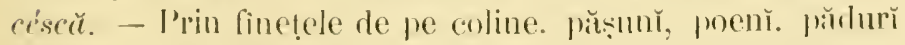

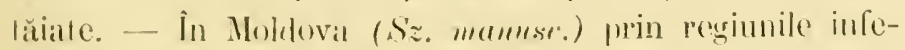

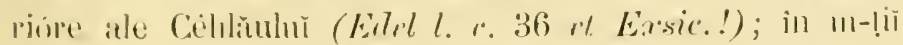

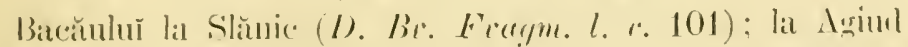

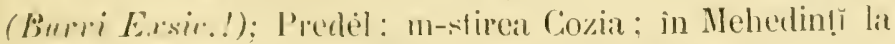

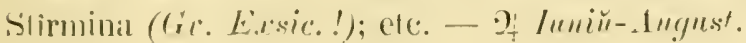


II. M!tatulata L. I. muculalre. - Prin finelele din fufori-

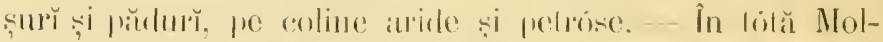

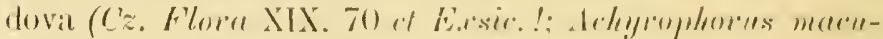

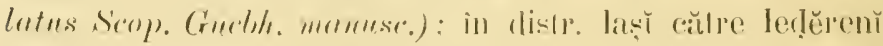

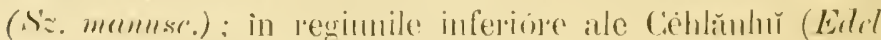

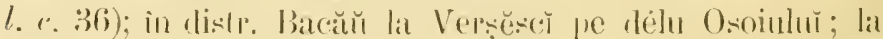

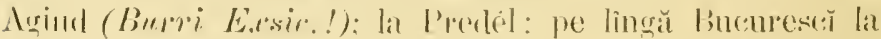

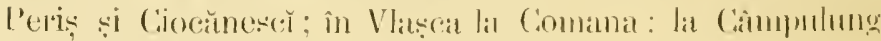

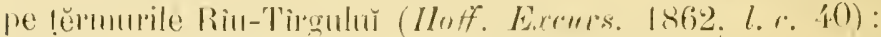

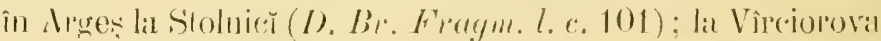

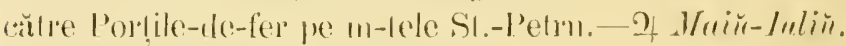

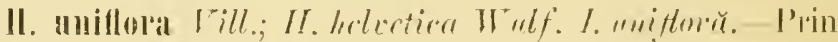

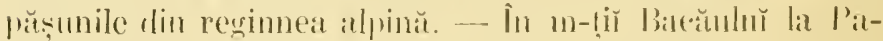

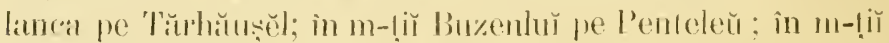
Bucery pe Furnical. - I Inliu-lugust.

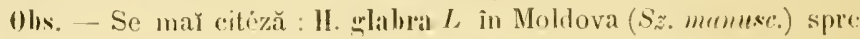
Tirgn-Nómtulur (cir, Erber. 1. (2. 127?).

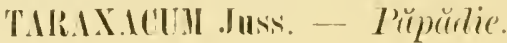

T'. serotinnm I'nir. P. Trirdir. - Pe colinele nseale

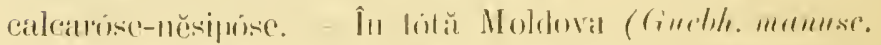

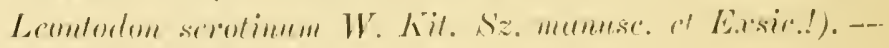
2) Inliur-stoplembliner.

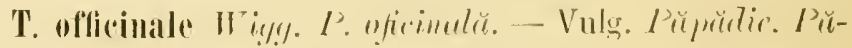

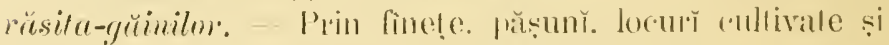

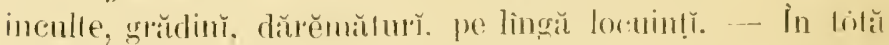

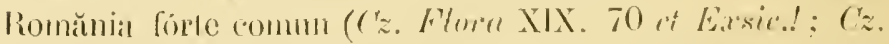

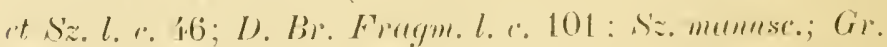

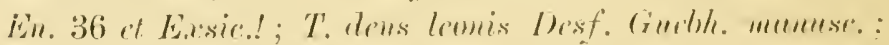

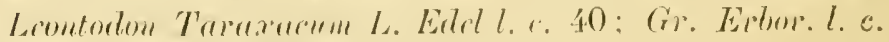

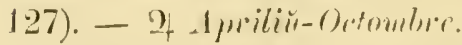

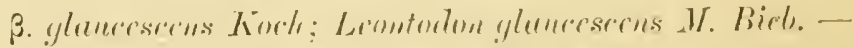

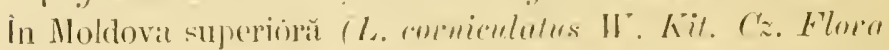

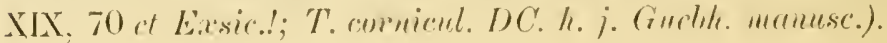




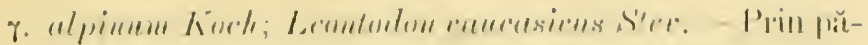

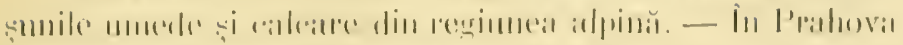

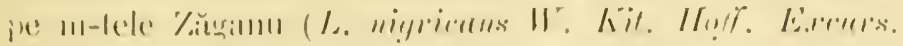

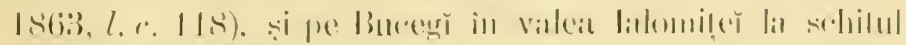

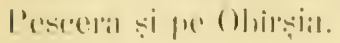

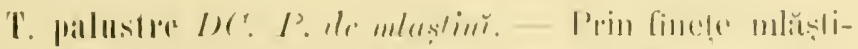

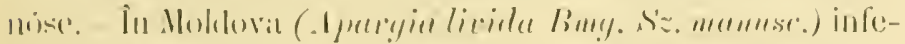

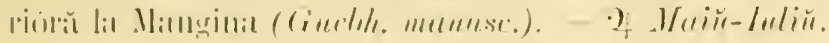

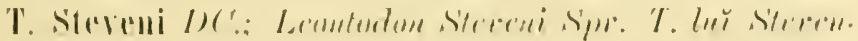

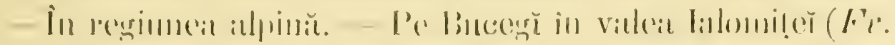

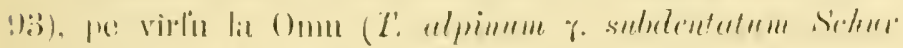
lin. $3(i s)$ - ) . linyust.

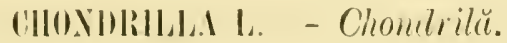

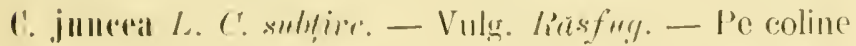

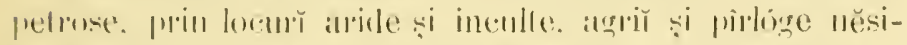

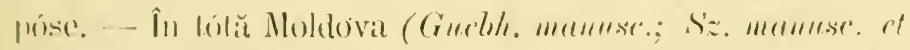

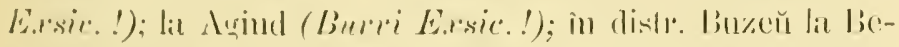

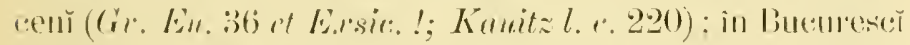

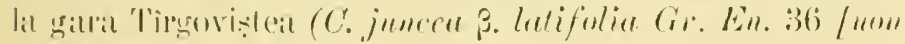

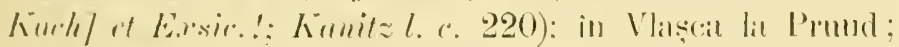

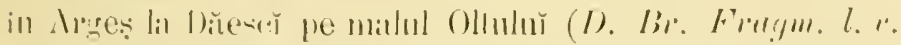

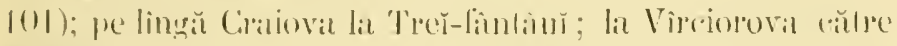
P'orlile-de-fer ; elc. - o' Inlin- Lmynst.

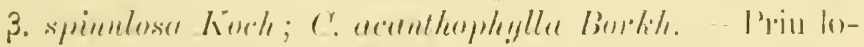

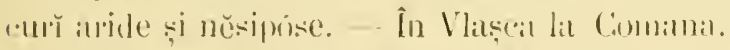

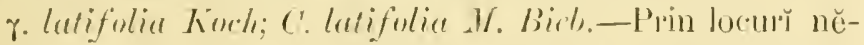

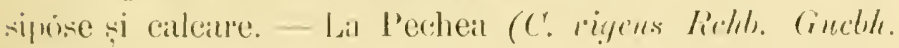
m(1mI1.se'.).

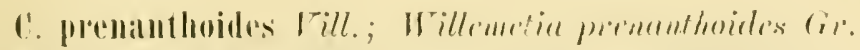

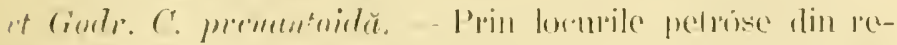

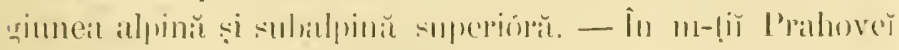
ve bincegri. - ot luliü-_lugust. 
Ohs.-C. prencuthoides din fürtele umele de in Tุigănescr (Guebh. manuse.), "и sciŭ ce prite fi.

\section{PRENINTHES L. - Prenante.}

P. purpurea L. P. purpuriü. - Vulis. Crestruté, Salataiepureln.r. Tulhäré. - P'rin pădurile mulurose din regiunea montană și subalpină. - Ân Moldova rentrală și superióră

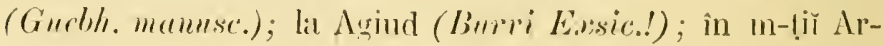
geșului pe Urḍica; in m-liĭ Vilcel pe Firffeca; în (iorjiŭ la schitul Locur'r-rĕle. - 9 Inliü-Inymst.

\section{L.ACTUC: L. - Lăрtucŭ.}

L. virosia lin. L. virósč. - Prin locurì inculte și petróse, pe marrginea agrilor. - În listă Moldova (Eilcl l. c.

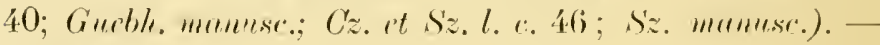
ร’ Inlint-.lugyust.

L. Scarlinla Lin. L. Scuriolă. - P'rin locurī inculte si petróse, coline aride, puine. pe lingă gardurı̆, pe marginea agrilor și a drumurilor. - În tótă Moldova (Guehth. manusc.: L. syluestris Lam. EAld l. 1. 40; Cz. at Sz. l. c. 46; Sz. manesc.; L. virosa Cz. Flora XIX, 70 / mem L.J it E.rsic.!); pe lingă Iașị la Nițeleal (L. virosa D. Br. Frorgm. l. c. 101 [non L.7); la Ném!̣u (L. virosa Gr. Eirhor. l. c. 127 [non L.7 et Exsic. 1); in Prahova la Sinaia (L. viresue Gr. Ex"urs. l. c. 339; (iv. En. 36 et Exesic.!); in Ilfov (L. virosa Gr. En. 36); in Bucuresě (Gr. En. 36 rt Exsir. !) la gara T'ìrgovistea ; în Vilcea la Băleeser̃ ; ete. - of Inliŭ-dugust.

3. angustaure. - In Moldova (L. unyustana All. Cz ct sz. l. c. 46; sz. mommsc.).

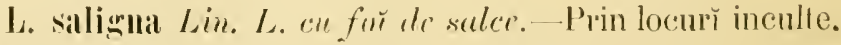

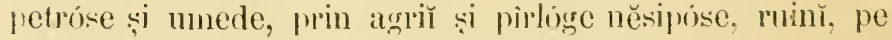
lingă d’umuř̀. - În Moldova (Edel l. 1. 40; Cz. it šz.l.e. 46 ; s̃. munusc.) lia Pétra pe lingă Fabrică ; la Ploesè ( 1 l. 


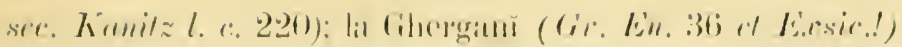

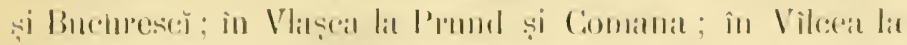

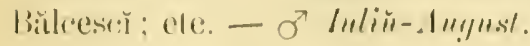

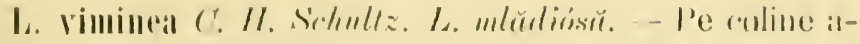

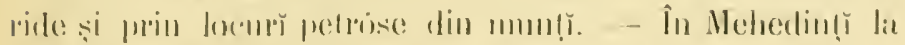

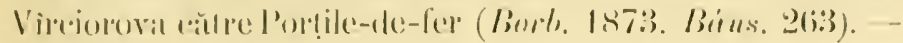

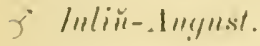

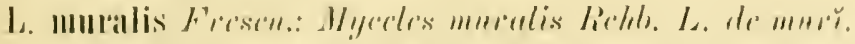

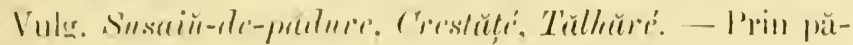
durile umbrove diu regionea montană. - În Moldova (S'm-

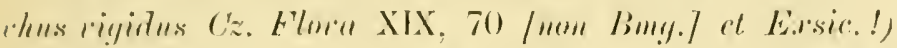

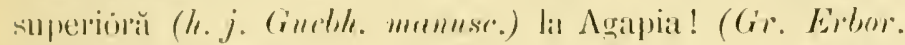

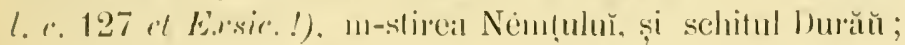

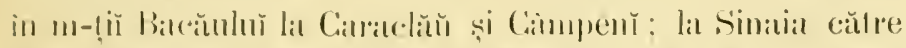

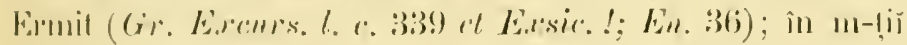
Curiě̀. Bistrila și T'Tsmanal (I'rementhes muralis L. Hoff.

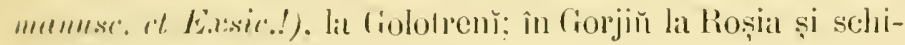
tul Locurĭ-lĕle ; ele. $-\odot$ Inlin̈-Angynst.

L. stricta W. Kït. L. strich. - Prin pădurile de pe coline și din regimea monlimă. - Îl Moldovit superióră

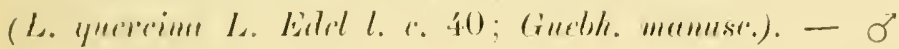
Inliit-. Lu!just.

1. sagillatal IV. Kit. L. e't for srefitate. - Prin pădurì

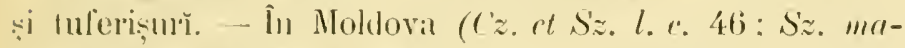

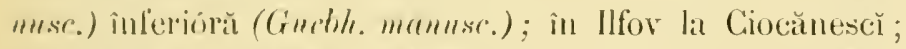

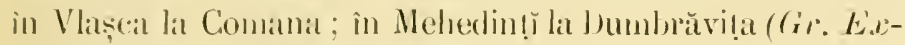
sic.!): ete. - o Inlirit-Anumest.

I. perenuis Lin. L. perintir. - Prin locurĭ petróse, stincrise și calcille. - La Vircioroval către Porṭile-de-fer.

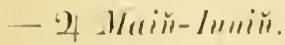

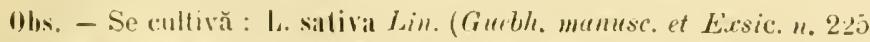

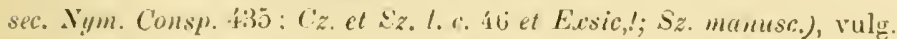

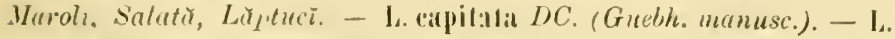
rrispa $D C$ (Guebh, munusc.). 


\section{SONGIIIS 1. - Susuiü.}

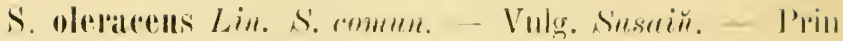

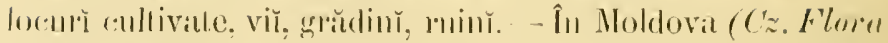

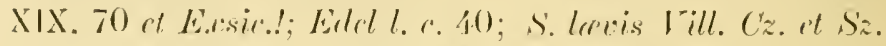

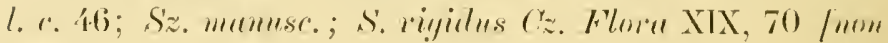

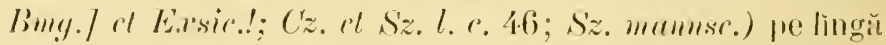
lats̆ lat Nị̣elea (D). Br. Frougm. l. c. 101); la Bucurescĭ (Crr.

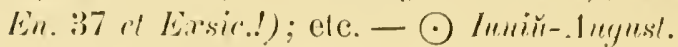

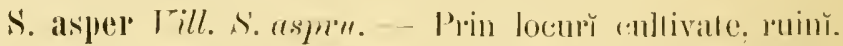

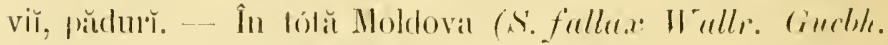

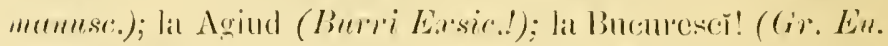

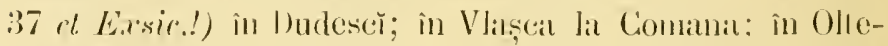

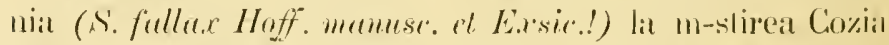

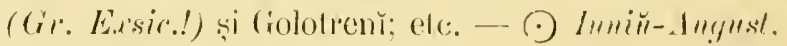

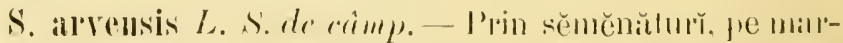

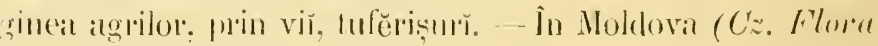

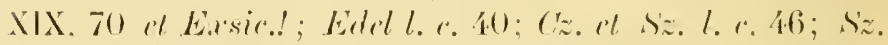

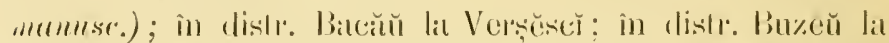

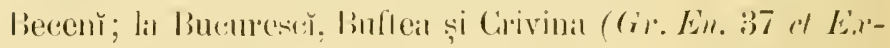

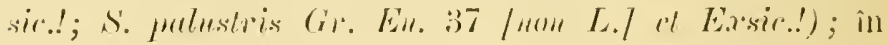

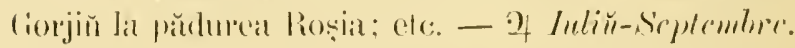

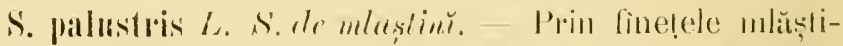
mose. pe malurile rîmilor și al pîrăilor. - l̂ lobă Moldovia

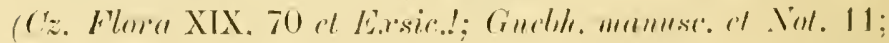

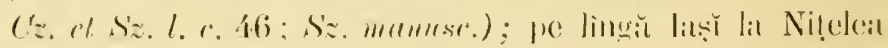

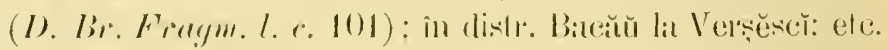
- If lilin- lugyust.

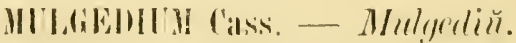

II. alpinnm Less. M. alprin.- P'pin prisunile murde și pe lingă lorentele diı pădurile subatpine. - În Moliloval (h. 


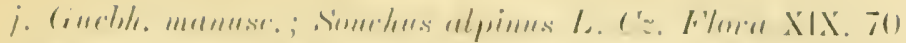

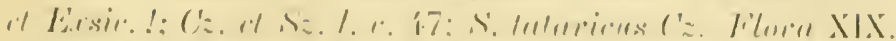

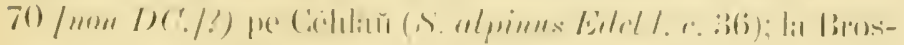

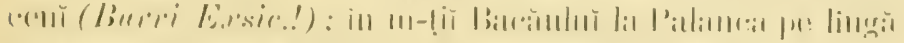

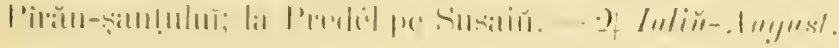

\section{IREl's I. - r'mpielu.}

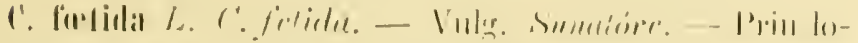

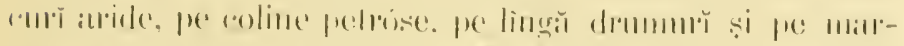

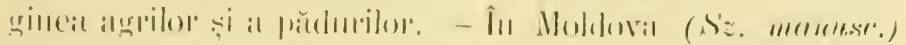

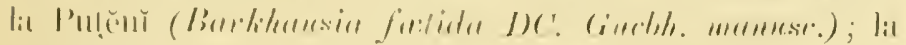

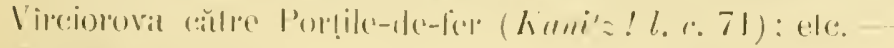

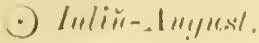

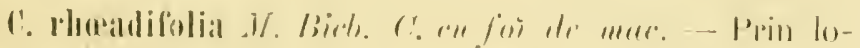

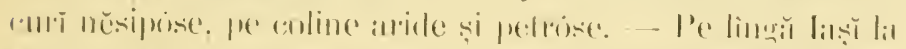

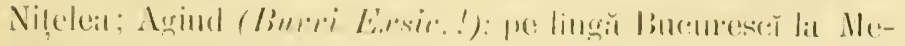

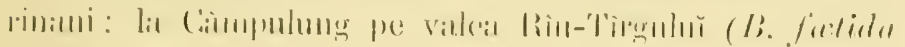

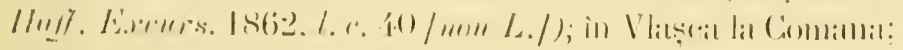

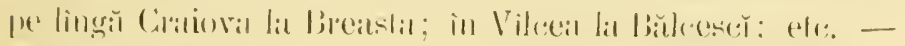
-) Inviir-Inliir.

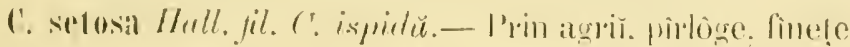

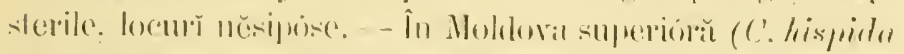

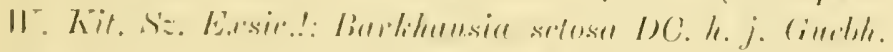

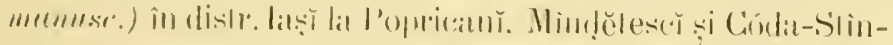

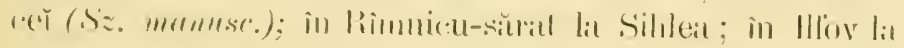

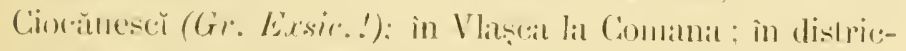

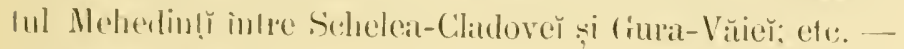
$\odot$ Iniriĭ-Inliir.

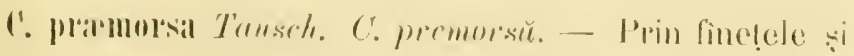

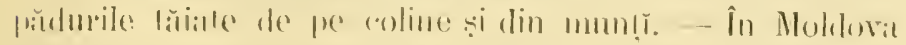

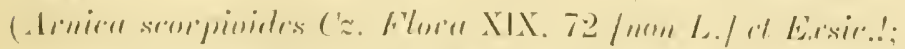

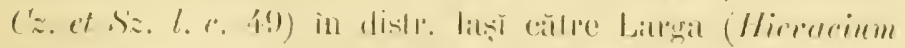

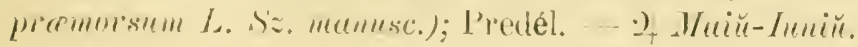




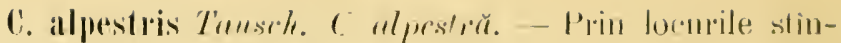
cóse diu regimneal subalpiuă și alpină. - În reginnile infe-

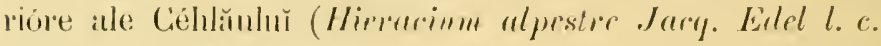
36). - of luliü-ilugust.

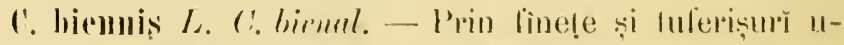
merle, pe marginea pădurilor.--In Moldoval (S'z. mumesc.) pe limgă Berlad (C. Amraxarifolin D. Br. Firreym. l. c. 101

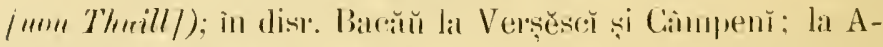

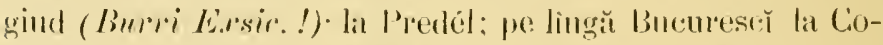

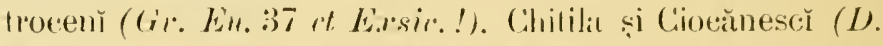
Br. Frougm. l. c. 101): în Vlașca la Comana; etc. - o Irriin-Inliü.

0. nicarensis Bull. C! dr Nizzn. - Prin finele uscate, locolrr aride și petróse. - În m-ṭii Vilceè la Golotreñ̆ elc. or Imnin-Imliu.

C. rigilila Wr. Kil. C. rigirla. -- Pe coline useate.-- In Moldoval (s'z. mamusro) la Pecheil (Guchih. momuse.). - 24 Inliü-Alugust.

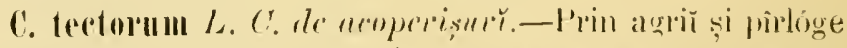

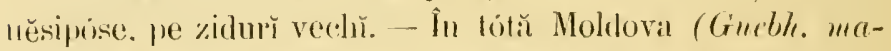

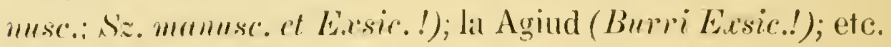
- $\odot$ Mniri-Inliu.

3. seyftulis Ruth. - Prin agriĭ și pînlóge. - În tótă Moldova (Gurluh. munuse; s'z. manusc.).

\%. gracilis. - În pădurile Moldoveì inferiore (Guebh. m(1mus.).

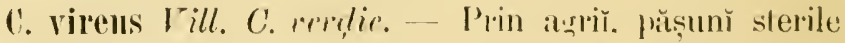

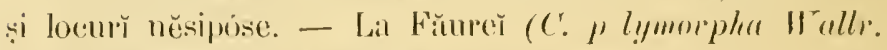

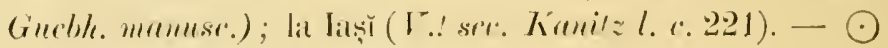
Inniu-sieptembere.

3. aygrestis Kuch. - I'rin fine!̣e sterile și pîrlóge. - In Moldova (C. aypestis II. Kit. Sz. manusc.) la Pechea (Guebh. manusc.); pe lingă Bucu'eser. 
C. Jacquini T'uusch. C. luı Jacquin. - Prin pășunile slîncóse din regiunea alpină. - Pe Céhlăŭ! (Ilierucium chondrilluide's L. Edal l. c. 36). - 9 huliü-August.

C. paludosa shanch. C. de mlastini. - Prin finete mlăștinóse și pădurǐ unede. - In tótă Moldova (Giuebh. manusc.) : în distr. Iașĭ la Voinescĕ (Sz. munusc.). - 2 Inliü-dugust.

Obs. - Se mal citéză : ('. taraxacifolia Thuill, prin locurile něsipóse din tótĭ Moldova (Guebh. menusc.)? - C. sulcisal folia Truusch. la Sinaia pe valea Peleşulut către Ermit $(G r$. Lxcurs. l. c. 3339; Lim. 37?) - ('. blattaroides l'ill. la Sinaia către Valea-rea ( $G r$. Lixcur's. l. c. 388; LM. 37?). - C. montuna Tuusch. în Bucegi către Obîrșia Ialomiter (Hisracium montumum Jacq. Hoff. Excurs. 1863, l.c. 120 ??(. rorgubusa Ten. prin finețe la Pechea (Guebh. munusc.) ?- C. Dioscoridis $L$. in Moldova (Sz. manusc.)?

\section{L.AGOSERIS M. Bieb. - Lagoseridŭ.}

I. Jifida Koch. L. bifidă. - La Vìreiorova către Portile-de-fer! (Simk. 572; Pterothece bifida F'isch. et Vey. Borb. 1873, Büns. 263) - $\odot$ Apriliŭ-Lniǔ.

\section{CEPILLORHYNCHUS Boiss. - Cefalorinc.}

V. hispidus Boiss. C. ispid. - Pe stîncile umbróse. La Vîrciorova către Porțile-de-fer (Lactuca hispida $D C$. Burl. 1873, Bins. 263). - o7.

C. glandulosus Boiss. $\beta$. cutarractarum Simk. C.glandulos.-Prin pădurile dintre Gura-Văiě şi Vîrciorova către Porțile-de-fer (Siml. Term. Füz. I [1877] 169 et 571).- -

\section{HIER.ACIUM I. - Teraciǔ.}

H. Pilosella L. I. Piloselă. - Vulg. Lrechea-șórecului, Culcusu-racě, Tulturicŭ. Hulteniórà, Hultenólü, Iarba- 
Eretrŭ. - Prin pășunı̆ uscale. pe coline și prin munț̆. In bolă Moldova (Cz. Flora XIX, 70 ef E.rsic.!: Gurbh. mamuse.; H. stolonifurnm Cz. Flore XIX. 70 [non H. Kit.] et E.rsic.!; H. Pelcterianum Cz. Flora XIX. 70 Fnm Mrrut.l); în regimile inferióre ale Céhlăulŭ (Ełtol l. c. 36): în n-ṭĭ Bacăulıŭ la Slănic; la Agiud (Burri Érsic.!); la Sinaia; pe lingŭ Bucurescŏ la Bănésa, Ferěstrěŭ, Merinani

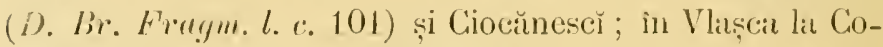
nanla; in Dimboviḷa pe Brănduṣa; in Muscel (Gr. En. 37 ct Exsic.!; hưnitz l. c. 221); în Argeș în pădurea (iuranulŭ̌ și pe m-tele Coriaz (Gr. Exsic!); în Vîlcea la Folotrenı̆ la Vîrciorova către Porțile-de-fer; elc. - 2 Maiŭ-Septembre.

II. bifur'um N. Bieb.; II. prealto-Lilosclla Himm. I. bifurcat.-Pe coline uscate și argilóse, prin fineţe şi poen. - In Moldova (IT. Aagelare Freel. Guebh. menusc.) interióră (H. brachiatum Bertol. Guebh. manusc.); în distr. Batcăŭ la Verșěsč̀. - $q$ Iıniй-Iuliŭ.

II. Auricula L. I. Urechinșr. - Prin finețe, phașunĭ uscate, poenı̆, pe coline și prin munțu. - In Moldova (Ėtel l. c. 40 : Sz. mamusc.) la m-stirea Némtuluř ; la Predél ; în Muscel la Nĕmăescr (Gr. Lut. 37 et Errsic.!; Kanitzl.c. 221): în Vîlcea la m-stirea Horez (Crr. Ersic.!) și la Olănesch; elc. - 2) Inлгй-Septembre.

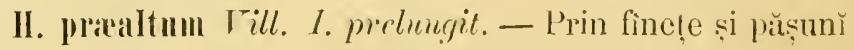
u-cate, pădur̆, locurĭ petróse de pe coline şi din munț̆. În Moldova (IT. cymesum Bing. Oz. Flera XIX. 70 ot Exrsic.! ; H. dulbium Edel l. c. 40 /non Bmg.] ot E.rsic.! ; Sz. manuse,; H. collinum Cz. Flora XIX. 70 /non Bess. nec Gochin et Exsie.!; h.j. Gueble manuse.; H. premorsum Cz. Flora XIX, 70 [non L.] et Exsie.!) centrală (Gucble. maturse.); în Prahova la Filipeser (H. pratense Gr. En. 37 (mon Tunsch./ it E.r.sic.!) și lit pólele Bucegilor ; pe lingă Bucurescĭ la șosea, Bănésa și Merinani; la Virciorova către P'orțile-de-fer; elc. - If Iniñ-Inlin̆. 


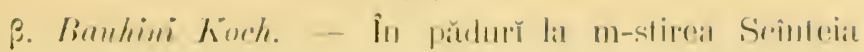

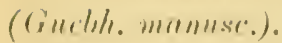

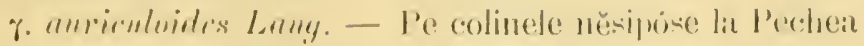

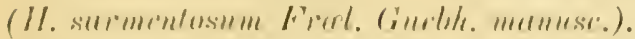

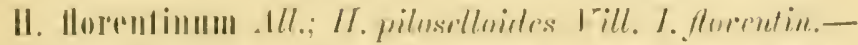

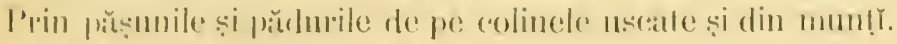

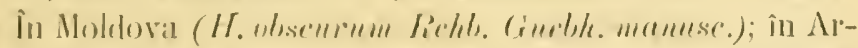

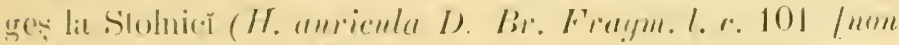
L./). - If Inniü-Juliui.

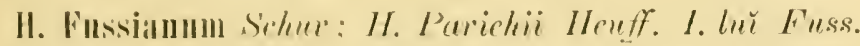
- Prin lon:urile stîncisce si petrise din regiunea montană și sulnalpină. - Î Vilcea la folofreñ.-2 Inliü-August.

II. erhioiles L.ımm. I. rehimil. - P'e colinele nĕsipóse și prin locmile alride din munnț. - In Noldova inferióră (Grueth. mamuse's): la Virciorovia călre Portịle-de-fer (Janka! sec. Kunitz l. '. 221). - 2 Inniй-Inliŭ.

H. cymosimm L. I. cimns. - Prin finetele uscate de pe coline și din munțĭ, prin poenile şi rărișurile pădurilor. In Noldova (II. rehivides Cz. Flera XIX, 70 [non W'. Kit.] st E.r.sic.!) inferióră (Gucbh. manusc.) ; în Tlașea la Comana (II. sebiunm it II. Alerentimum D. Br. Fragm. l. C. 101). - 2 striiи-Iumin.

II. pratense Tauseh. I. de finet, - Prin finețele monlane. - In Moldova centrală (crueblt. menuse.). - 2 Maiir-Iuliur.

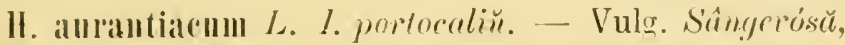

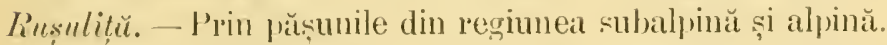
- In Moldovir (Cz. Floru XIX, 70 et Listsic.!) pe Céhlăŭ ! (Eillel l. c. 36); la Broscenŭ (Burri Exxsie.!); în m-lị̂ BaCăuluĭ la Slănic! (Gurbh. momuse.) și Palanca; în m-tii Buжeuluй pe Penteleŭ; în Bueegr (Hotf. Excurs. 1863, l.

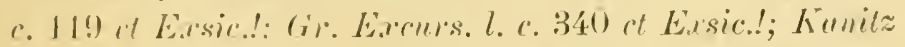
l. a. 221) pe Furnicat si la schitul Pescera de la lalomilą; 
la P'redè ; în m-liŭ Muscehuluı̆ (D. Br. Frragm. l. r. 101) lat Rucăr (Gr. En. 37 rt Exsic.!); în Argeș pe m-tele Coгіa ; et.e. - If Iипій-Inliŭ.

II. statieafolium Irill. I. cu for dle statiere - - P'rin pŭtșunile petróse de pe lingă torentele din văile munților. -

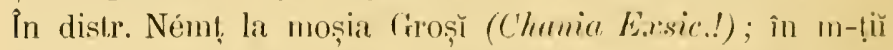
Bucegì pe valea lalomiței (Lerelenfeld ser. Srcher En. 387). - 2 h miй-luliu.

H. villosmu Jacq. I. vilos. - P'rin pășnile pelróse şi pe slîncile din regiunea subalpină și alpină. - Pe Ciéhlăı̆ (Edcl l. c. 36 et Exrsir.!): la pólele Bucegilor către Ermit. (Gr. Excurs. l. c. 339) ; Eu. 37), pe Furnica și la schitul Pescera de la Ialomilia. - 2 Inlin̆-lugust.

H. alpinum L. I. alpim. - Prin păşunile din regiunea subalpină și alpină. - Pe Céhlăŭ (EAlel l. c. 36 et Exsir.); în m-ḷiĭ Bueegì în valea lalomį̣e $(F r .94)$, pe Furnica și Vîrfu-cu-Dor"u. - 2 luliŭ-A legust.

II. vulgatum Fries. I. comun. - Prin pridurile din munțĭ. - Pe lîngă Iașĭ la Hadimb) și Mironésă (II. sylvaticum. Lam. Sz. mamusc.); la m-stirea Adan (H. syle. Guebh. manusc.); la m-slirea Nẻmţulŭ pe m-tele Pleșu (H. sylv. Gr. En. 37 et Exsic.!); în m-(iŭ Bacăulŭ la Slănic; în m-ḷĭ Muscelulŭ (H. murorum. D. Br. Fragm.l.c. 101 /mon L./); in m-țiĭ Buceğ la pólele Furnicę̌; etc. - 2 I Inniй-Tuliu.

H. ramosmm W. Kit. I. rămos. - Prin pădurı̆. 一 În Moldova inferiórĭ (Guchl. manuse.). - - f luniü-dugust.

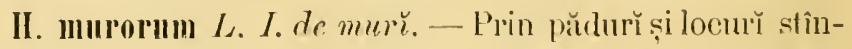
cóse de pe coline și din munțĭ. - În Moldova ( $C z$. Filora XIX, 70 ct Exsic.!; Eddsl l. e. 37; sz. mamuse.) la m-stirea Némțulŭ (Gr. Erbor. l.c. 127 ci Exsic.!) și în regiunile inferióre ale Célılăulur ; în Muscel la Conțěscŏ (Gr. Ex.xsic.!); elc. - of luniй-August. 


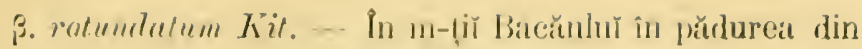

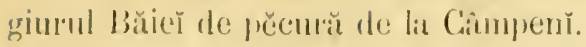

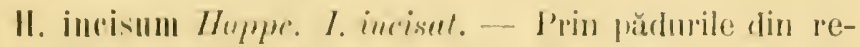

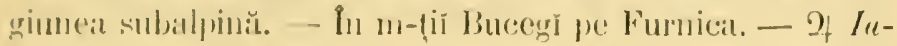
niй-_lugust.

II. pleiophyllum Schur.; II. trunssylvanicum Heuff.; Crepris frussii hove. I. transilvanic. - Prin pădurile din regiunea montană și subalpină. - In regiunile inferióre ale

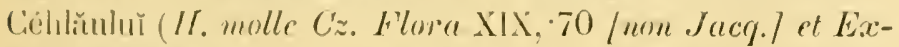
sic.!; Lidel l. r. 336); în m-tiin Bucegi en Cumpanula abietina (F') 98) lat schitul Pescera de la lalomi!a! (Mr. Winkler Enesic. in herh. Uechtr. see. Kanitz l. c. 220 ; H. carpathirum Heff. Exaturs. 1863, l.c. 120 /non Bess.] et Exsic..!); in m-ṭĭ Musceluluŭ! la Conṭěscĭ (Gre. Exssic.!) : în Argeș pe Lræzica și Cozia ; în Vìleca la Golotreň̀; ete. 2) Inniü-Inggest.

H. racemosum H'. Kit. I. racemos. - Prin locurile incnlte, pe narginea pădurilor. - In Vîlcea în valea Oltuluı̆ pe nil-tele Citrlig. - 2 Iuliur-1ugnest.

H. sabaudum L. I. de Savoia. - Prin tuferișurŭ, poenĭ și le murginea pădurilor. - În Moldova superióră (Siz. ma-

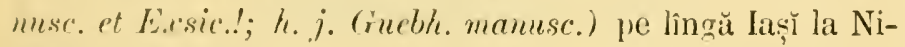
telea și Reperlea (D. Br. Fragm.l. c. 101); in m-tiî Buzeuluĭ cŭtre Bisci-mane (Hoff. Excurs. 1863, l.c. 117 ct Exsir.!) și la becenĭ; in Ilfov liı Ciocŭnescì (Gre.! scc. Kanitz l. c. 220 ; H. boreale Gir. En. 37 /non Fr.7 ot Exsic.!) și Merinani; în Oltenia (Hoff. munusc. et Essic.!); ete. 2) Juliu-Septombre.

H. bortale Fries. I. borral. -- Prin fuferişurĭ, poenĭ și re malrgincal pădurilor. - In Noldova inferiórĭ (H. sylvestre Tausch. Guebh. manusce). - of August-Octombie.

II. Imblellatum L. I. umbelat. - Prin finețe, pășun uscate, tuferişuř și pădurĭ. - In Moldova (II. foliosum Cz. 


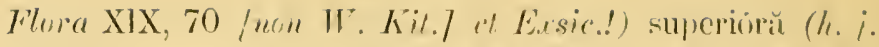

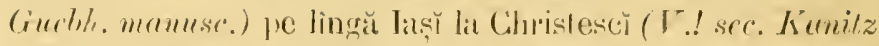

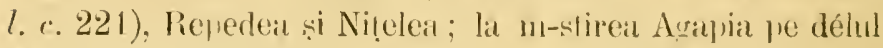

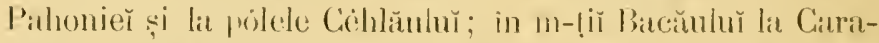

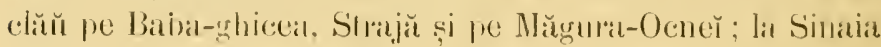

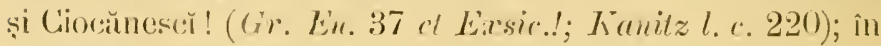

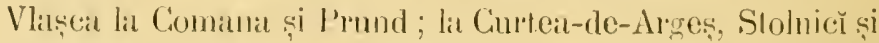
m-stirea Slinișira (Gr. Lirsic.!); în nu-lị̂ Vilueĕ la Olănescĕ și la (iolotreñ pe Narol, etc. - of luliй-Octombre.

H. foliosinm II. Kil. I. foius. - Prin pădurì și printre viĭ. - În Moldova inferióră (ciuebh. manusse; H. virosnm.

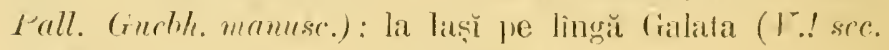

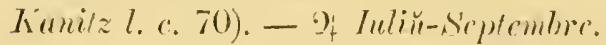

Ols. -. II. spharoceplailun Frol. - II. palleserns W. Kit. - il. gravenlens frol. indicate în Moldova superióră (h.j. Gueblh. mannse.), după specimene vẹdute în Erbariul din lașĭ, un pot fi dé câl resultatıl a tot atâtor erory de determinațiune, de vreme ce ničr una din speciile acestea mu figuržă î erbariul men!̣ionat. - Tot ast-fel trebue să se considere : H. gnrincile Froel. din Moldova centrală (Guebh. manusc.). - - Il. plrentiuthoides V'ill. diu Noldova inferióră (Guebh. mamusce.), ca una ce, fiind plantă alpină. nu este de loc probabil ca ea să se întîtnéscă în regiunea unde o indică Gnebhard.

\section{AMBROSIACEE.}

\section{XANTIIIYH L. - Xanthiu.}

X. strumarium L. X. commu. - Vulg. S'čactele-popei.Prin locmr incnlte și molerale, je lingă gardurı̆, pe margineat atrilor și at drummilor. - Î tólă Romănia forte comun (Cz. Flura XIX. 63 of Lissic.! : Cimeth. manusc.; Sz. menusc.; (ir. Ër. 37). - $\odot$ meliü-Octombre.

X. spinosum L. I. spinos. - Vulg. Holerĕ. Cormulü,

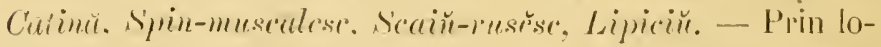

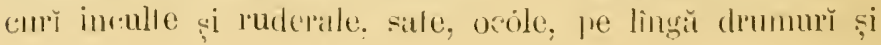




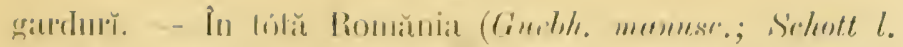

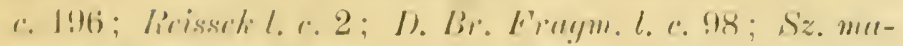

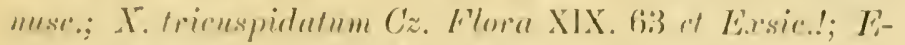
dell. e. 32). - $\odot$ Inlin̈-Septemlere.

\section{CAMPANULAGEE.}

\section{JISIONE 1. - Jasionea.}

I. montana /., . momianŭ. - Prin lor:uri aride pi pe-

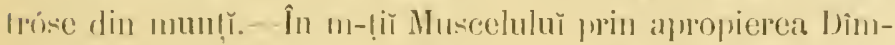

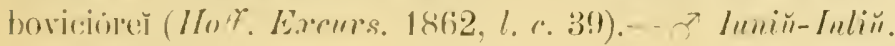

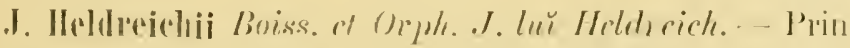
locurile slîncóse. - La Virciorovia călre Porțile-de-fer:

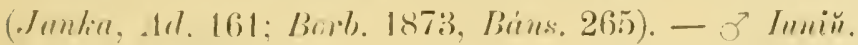

J. Jankir Vrilr. J. Imi . Jumin. - I'rin locurile petróse și slincrise. - La Vîreiorova călre Porṭile-de-fer! (Janha ser. Nym. Cunsp. 486: Simli. see. Kanizzl. c. 76).--o Inuin.

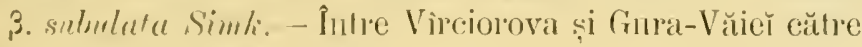
Portile-rle-fer (Simli. 578).

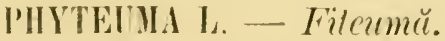

P. orbiculare L. F. orbiculară. - Prin păsunile petrose si ve stincile din regiunea subalpină și alpină. - În Moldovil (P. Lemisparicum C $z$. Flore XIX, 61 /non L./ el Exsic.!: I’ pancifurum Sz. Exsic.! Inon L.7; h. i. Gucblh.

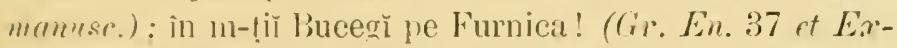
sic.!) i la sìhilul Pescera de la Jalonitịa; în m-ṭĭ Musceluluĭ pe linğ Dînhovicióă (D. Br. Fragm.l. e.97). - 2) Inniü-1numest.

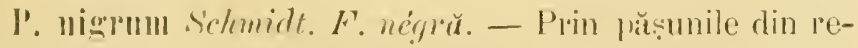

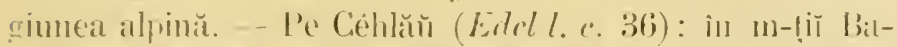

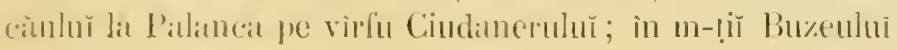


pe vîrfu Penteleuluĭ ; in m-țiǐ Prahoveĭ la Predél; etc. 2) Маій-Iиliй.

P. tetramermm Brassai. F. tctrameră.- Prin pădurı̌ şi fînę̣e stîncóse din munțĭ. - In distr. Sucever la Broscenĭ (Burri Exsic.!); în m-țiı Musceluluı̆ pe lingă Dîmbovicióra (P. spicatum D. Br. Fragm. l. c. 97 [uon L.]). - 2 Maiй-Iuliŭ.

P. canescens W. Kit. F. albiciósă. - Prin păduri și finețe petróse. - In Moldova centrală și inferióră (Guebh. manusc.) la Pechea (Gucbh. Exsic. n. 669 in herb. Paris.!). - 2 hитій-dugust.

\section{CAMPANULA L. - Campanulă.}

C. pusilla Hankic. C. mititică. - Prin pășunile petróse şi stinncóse din regiunea alpină. - In m-tiĭ Bucegı (Fron. 119) în valea Ialomițê̌ și pe lîngă Strunga $(F r .95 ; C$. caespitosa Vill. [non Scop.] Gr. En. 38 et Exsic.!) - 7 Iulǐ̆-August.

C. venusta Schur. C. graciósŭ. - În m-tịi Bucegĩ la schitul Pescera de la Ialomița (Schur En. 442). - 2 A August.

C. rotundifolia L. C. cu for rotunde. - Prin păşunile și locurile stîncóse şi calcare din regiunea subalpină şi alpină. - Pe Penteleŭ. - - I Iuliŭ-A

ß. Baımgarteni Beck. - Prin pășunile stîncóse din regiunea subalpină și alpină. - În m-țĭ Bacŭuluĭ la Slănic pe Pufu ; în m-tii Buzeuluı̌ pe Pentelen̆.

\%. Hostii Bmg.-Prin păşunile petróse din regiunea subalpină și alpină. - Pe Penteleñ ; în m-tiǐ Buceğ (C. rotundifolia Gr. En. 38 [non L.] et Exsic.!) pe Furnica și Vîrfu-cu-Doru.

d. Schenchzeri Vill. C. lǔ Schonchzer. - Prin finețele și păşunile din regiunea subalpină și alpină. - In Mloldova 
centrală (?) și superióră (C. linifolia Guchh. mamusc.) prin

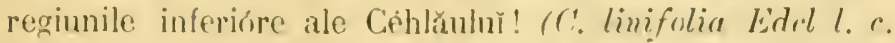
$36)$; in Pralhova pe nu-tele Züganu (Hoff. Lircur's. 1863, l. c. 118) și in un-tiì Buceur spre Virfu-cu-l)oru, Furnical ( $G r$. En. 38 at Ensir.!: C. angustifolia (r). Mromit. ofir. l. c.; C. Linifolin (ir. Monit. nff. I. c.; Erbor. l. c. 338; En. 38) și pe costele Babelor. - 2' Inliü-1ugnst.

C. "arnica Schirde var. Latifolia Schur. C. cernică. P’rin crěpăturile stincilor calcare din reqiunea alpină. - In

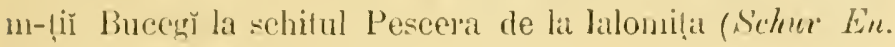
4-2). - 2) Inlin-Lugust.

C. bononiensis L. C. de Bolonia. - Prin fincte uscate, pe coline aride, prin poenile din pădurĭ. I In Moldovi (Cz Flora XIX, 61 et Exsic. !; C'. latifolia Cz. Flora XIX, 61 [non L.] et Exsic. !; Edel l. c. 37 ; C. Cervicaria Cz. Flora XIX, 61 /non L.] ct E.rsic.!) inferióră (Guebh. manusc.) la Pechea (C. vuthenica .1T. Bich. Gucbh. manusc.); pe lingă Jaṣụ la Văiluṭa (Sz. manusc.); pe lîngă Bêrlad (D. Br. Fragm. l.c. 97); la Agiud (Burri Éxsic.!); în Rîmnicu-sărat la Sihlea: în distr. Buzěŭ la Becenu (Gr. En. 38 et Exrsic.!) și la Sirea-lư̌-Buzěŭ ; in Ilfov la Buftea și Ciocŭnesč̆ ; în Vlaṣca la Comana; în Muscel la pólele m-teluı Leresč în valea Riu-Tîrguluú (Hoff. Excurs. 1862, l. c. 31); pe lìngă Craiova la Lémna: în Vilcea la Bălcescĭ.- of Iuliǔ-August.

C. rapunculoides L. C. rapmenculoidă. - In pădurile de pe coline și din munți. - In tótă Moldovar (Guehh. manusc.; Sz. manusc.); pe lînğă Bêrlad lat Slobodia (D. Br. Fragm. l. c. 97); lat m-stirea Aqatpia (Gir. En. 38 ct Exsir.!): în

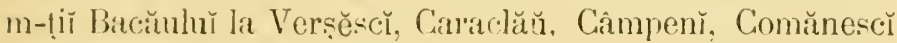
ș Slănic; către pólele Cèhlăuluĭ lat schitul Burăı̆: in Prahovia pe cristele Bucegilor (C. Rapmenelus Gr. En. 38 fnon L.7 st Exsic.!; Kanitz l. (. 22.4); în Ilfov la Ciocănescĭ în Vlaṣca la Comana: in IIuscel la Němăescĩ în Argeș la Pitescî in Zăvoin̆ și pe m-tele Urdica; pe lîngă Ciraiova la 
Lémna ; în Gorjiŭ la Roșia; în m-țiu Vîlceľ (Hoff. mamusc.) lit Golotrenĭ ; în Nehedințŭ între Gura-Vŭien̆ și Vîrciorova, și cŭtre Balnna pe nn-tele Curchia; etc. - 9 luniŭ-dugnust.

C. Trachelium L.; C. urticcefulia schmidt. C. Trachelii.. - Prin jădurọ și luferiṣur. - In Moldova (Cz. Flora XIX. 61 et Exrsic.!; Edel l. c. 39; Sz. manuse.; C. urticafolia Cz. Flora XIX. 61 ct Exsis.!) superióră (h.j. Gucbh. manusc.); pe lìngă Jaș̆ la Voinesci (C. urticcefolia s'z. mamusc.), la Nitelea. Rejedea, Bîrnova, Poenu și Dobrovĕ! ; pe lìngă Bềlad (D). Br. Fragm. l. c. 97); la Agatpia (O. Latifolia Gr. E.bor. l. c. 126 [non L./ et Exsic.!; En. 38), m-stirea Némṭulŭ și la schitul Sihla ; în m-ṭĭ Bacăulŭ lit Verș̌scĭ, Citraclăŭ, Năgnra-Ocně și Palanca; la Agiud (Burri Exsie.!); în Argeș la Pitesč şi pe m-lị Urḍica şi Cozial; în Vilcea la Bülcescǐ. - 2f huniŭ-August.

C. latifolia L. C. cu foĕ late. - Prin pridurŭ si tuferișur umbróse si umede. - În fótă Noldova (Guib). mamusc.). - If Juliǔ-dugust.

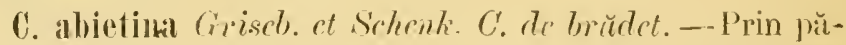
durile din reginnea subaljină. - Pe Céhlăı̆ și către mĭnăstirea Agapial; la Broscenı̆ (Burri Exsic.!); în m-liŭ Bàcăulŭ la Palanea ; pe vîrfu Penteleulŭ ; la Sinaia (Gr. En. 38 et Errsic.!) pe la pólele Furnicer, a Babelor și la Predèl. - 2) Inniü-duegust.

0. patula L. C. résfirată. - P'rin finete și pădurŭ.- În Moldova (Cz. Flona XIX, 61 et Exsic.!; h.j. Gucbh. mamuse.; Edcl l. r. 39 ; Sza manusc.; C. spathulata Sz. Exsic.! [non W. Kit.7; h.j. Gueb.h. mamusc.) la m-stirea Agapia (Gr. En. 38 et Exsic.!); în m-tịi Bacĭuluŭ la Slănic şi Palanca; în Prialıova la Vălenǐ și Sinaia (Gr. En. 38 et Eusir.!; C. ramulosa Gr. Monit. ofic. l. c. [non Jorr.]; En. 67) pe valea Peleșulǔ ; în Dimboviṭa pe m-tele Priporu; în m-țī Musccelulur: la Ciurteit-de-Arges (Gr. Exsic.!); le

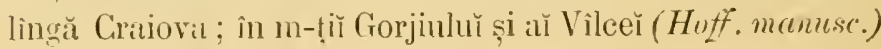




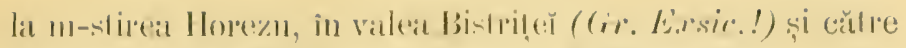

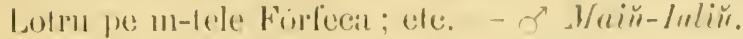

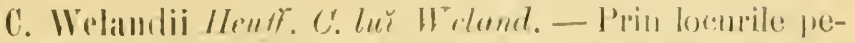
tróse dlin munlĭ. - La Vircioroval wălre Porlile-tle-fer

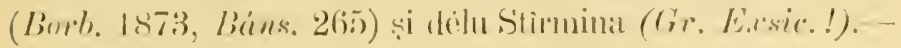
of Maiì-luliu.

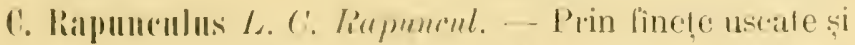

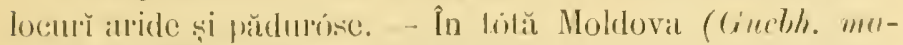

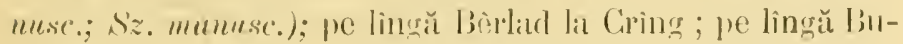

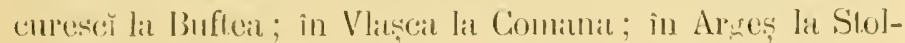
niè (1). Br. Fraym. l. e. 97); in Nehedinlị între Jlinova și

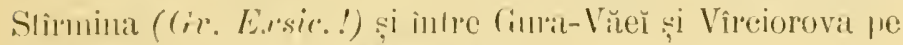
m-lele St-Pelı'ı. - or M/ain-_lugust.

C. persicilolia L. C. re fur de persir. - Prin pădurĭ şi

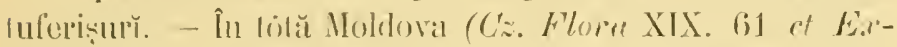

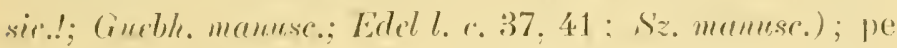

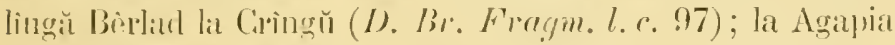

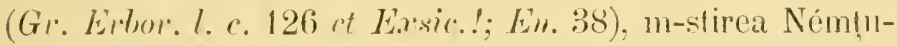

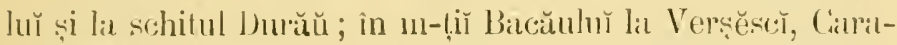

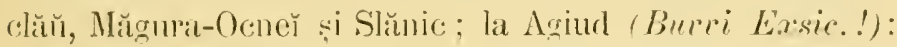
in Plahora la Vŏlenı̆ și Sinaia (cir. En. 38 et Exsic.!)

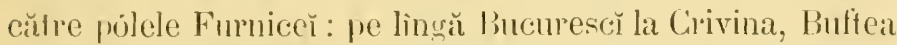
(Gr. En. 38 et Errsir.!) ș Merinani ; în Vlaṣca la Comama; in nl-1̣i Musceluluĭ; in Argeș la Stolnicĭ; în Vîlcea la mănŭstirea Horez. Olănescí li lat Lotru pe m-tele Fórfeca: în Mehedinț̣ la Cerneṭ̆. Iorgutova, Junnlurăvita. Hinova și Stî̀mina (cir. Eissie.!); etc. - I luniü-Iuliu.

3. criocarpa Korl. - La Verěesč ; Stolnič́; la Virciorova pe vallea Cerovĕluluh, inlıe Schelea-Ciladoveř și CiuraVăiel, și către Portile-de-fer.

C. calpathica L. C. carpaticri. - Pe stincile calcare din regiunea subalpină și alpina. - În Noldova (C. rotumdifolin Cz. Flone XIX, 61 /non L.J ot E.rsic.!) in regiunile

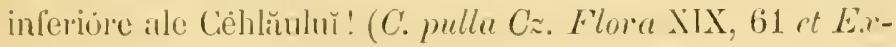


sic.!; Edel l. e. 36); la Broscenı (Burri Exssic.!): în m-ṭi Bucegi (Fron. 202; A. 49; 1. Bot. Zeit. XIII [1855] 328; Fr. 95) aprọpe de Obîrșia Jalonitel (Hoff. Excurs. 1863, l. c. 120) la schilul Pescera de la Jalomița și pe valea Babelor; la Sinaia (Gr. En. 38; C. magnifora Gr. Monit. ofic. l. c. et Errsic.!) și la Valea-Bogdaneĭ lînğ̌ tunelul căiěferate; elc. - 2 Inliŭ-Aurnest.

ß. turbinata S. K. N. - In m-țī Bucegĭ $\left(F^{\prime}, .95\right)$.

C. Cervicaria L. C. Cervicarie. - Prin fìnețele și pădurile monlane. - In m-țĭ Moldover̆ (C. Mcdium Cz. Flera XIX, 61 [non L.] et E.esic.!; Edel l. c. 37) la Broscenı̆ (Burri Exsic.!); în m-țĭ Bacăulŭ la Verșěsch̆, Câmpenì și Slănic; în Ilfov între Buftea și Sŭftica (Gr. Exsic.!); în Vlaṣca la Comana: în m-ṭĭ Muscelulıŭ la Nĕmăeseř pe Muscelu-Topliṭe (D. Br. Frargm. l. c. 97); în Prahova la Sinaia spre Isvor (Gr. En. 38 et Exsic.!); și la Predél; în Mehedinți către Cierneț̆, Iorgutova și Dumbrăvița (Gr. Errsic.!). - 2 Inniй-August.

C. glomerata L. C. glomerată. - Prin fînete, pășun̆, tuferişuř şi pădurı̆. - In Moldova (Cz. Flora XIX, 61 et Exsic.!) centrală şi superióră (Guebh. manuse.); pe Céhlăŭu (Edel l. e. 39), la m-stirile Agapia (Gr. Erbor. l. c. 126 et Exsic.!; Gr. En. 38) şi Ném!̣ pe m-tele Pleșu; la Broseenù (Burri Exsic.!); pe lingă Jaşŭ la Voinesê̆ eătre Cerbulésă (Sz. mamuse.); în m-ṭi Bacăuluĭ la Verşĕsč ( $D$. $B l$. Fragm. l. c. 97), Caraclăŭ, Cìmpent și Palanea; pe lîngă Bueureseì la Peris, Crivina (Gr. En. 38 et Exssic. !) și Herinani; la Sinaia pe Plainl Cumpătul (Gr. Excurs. l. c. 338); în Vlaşça liı Prund; în m-țiĩ Muscelulŭ ; în Argeṣ pe nt-lele Cozia; pe lingă Craiova la Lémna; in m-tị̆ Gorjiuluĭ și aŭ Vîlceı̆ (Hoff. manuse.) la Golotrenı̆; ete. - 2 Maiü-August.

B. speciosa Koch. - În in-tiĭ Buzeuluĭ pe virfu Pentẹlenlŭ ; la Sinaia pe cóstele Bucegilor (C. speciosa Hornem. Gr. En. 38 et Errsic.!), în ralea Babelor și la Predél. 


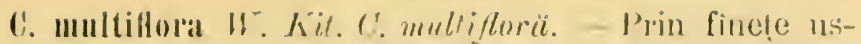

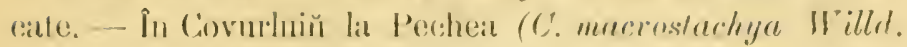

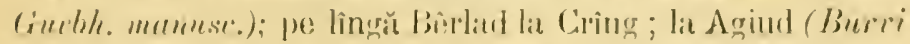

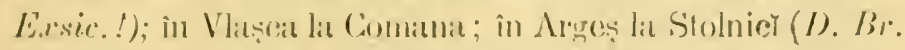

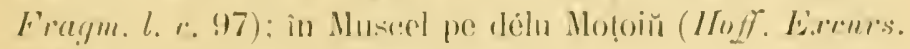

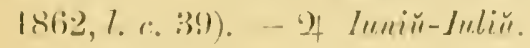

(i. alpina Jnry. C. alphina. - P'rin pășunile petrise din

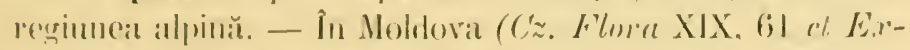

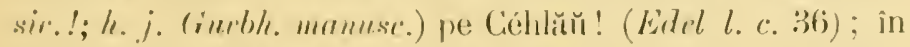

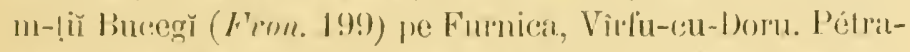

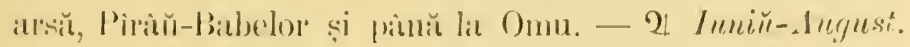

C. harbata L. C. barbala. - Prin păș̣nile din regionea

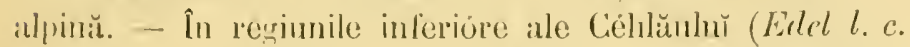

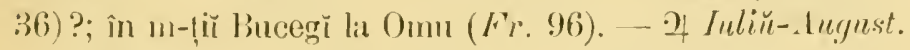

C. sibirica L. C. de Siberia. - Prin fincte useate, pe coline aride și locurı̆ nĕsipóse, pe stinc:̌̆. - În Moldova ( $C$. líepunculus Cz. Flom XIX, 61 [non L.] et Exsic.!; Ertel 1. r. 39 ?) inferióră (Gurlyh. manusc.); în m-ḷĭ Bacăulŭ la Cauratclŭn și cüll’e Palanca la Asăŭ pe lingă soséua de pe

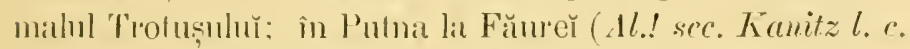
223); în m-lị̂ Buzenhŭ ; în P'rahova pe Bucegĩ pe Vîrvu-cuHoru (C. Alliomii Gr. En. 38 [non Fill.] et E.rsic.!) si între Ciàmpina și Sinatia pe lingă soséua de pe malul Prahı-

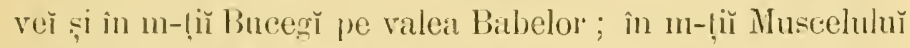
la Dimboviciora (C. spalhulata D). Br. Fragm. l. c. 97 [non W. Kii./), în m-liĭ Vilceĭ la Golotrenı̆ pe malul Lo-

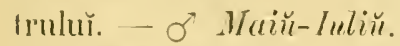

P. divergcus Relhb. - La m-stirea Scîntela (C. divergens Willd. Gucbh. mamusc.); la Vîrciorora călre Porțile-de-fer.

C. Grosselii Heuff. C'. Lǔ Grosselii. - P'rin locurile petróse și pe slincile din munț - Lai Vireiorova călre Por!̣le-de-fer! (Borl. 1873, Bäns. 265; Kanitz! l. e. 74) și pe valea Bahner̆; ìn m-țiī Villecr intre m-stirea Cozia şi Lotsu. - 2 leniü- lügus'. 


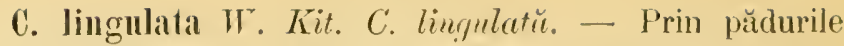
din regiunea montană. - În Mehedinți prin m-tị de la Vîrciorova către l'orțile-de-fer! (Burb. 1873. Bins. 265). - Or Haiй-luniü.

Obs. - Se mar citéză : C. collina $M$, Bieb? în Moldova (S'z. Exsic.!; h. j. Guebh. manusc.). - Iar cât despre C. tlỵrsuidea din Moldova (h. i. Guebh. mamuse.), acéstă indicație este de sigur resultatul uneĭ determinațiun eronate, fiind-că în erbariul din lași. unde arată Guebhard că ar fi vědut acéstă plantă. nu există nimica care să pótă fi luat pentru o asemenea specie.

\section{ADENOPIIORA Fisch. - Atenoforc̆.}

A. suaveolens Meyer; A. litiifolia DC.; Campanula suaveolens Willd.; C. Alpini L. A. odorantă. - Prin finetele çi tuferişurile din pădurile montane. - In Moldova (Companula liliifolia L. Sz. manuss.) la m-stirea Némțulŭ în dumbrava din fuṭa cișmeleŭ de pe șoséua m-stireí, ce conduce la Têrgu-Ném!nluĭ! (Gir. Erbor. l. c. 126 ct Exsic.!; Specularia Speculum Gr. En. 37 Lnon Alf. DC.l et Exsic..!). - - In Inliü-Septembre.

\section{SPECULARLA Heister. - Specularie.}

S. Speculum Alf. DC.; Prismatucarpus Speculum LHerit. S. Oglinda. - Prin secerișurĭ, pîlóge și finețele de prin tuferișuř̀ - În Moldova (C'ampanula Śpeculune L. Edel l. c. 39 et Exesic.!; C. hybriala Cz. Flora XIX, 61 linm L.7 pt Exsic.!) superióră (h. j. Gimebh. maunse.; s'. hybriala h.j. Guebh. manuse. (nom dlf. DC./) pe lingă Iaș̆ călre Slobodia și Slavnie (C. Speculum Sz. mumuse.); la Sinaia călre Buștenı̆ (S. leybrida Gr. En. 37 [iun Alf. DC.] et Exsic.!). - $\odot$ Iniй-Iuliŭ.

(0)\$. - Se maY citéză : S. lỵlırida $A l f$. $D C$. pe lîngă Iașr către Larga şi Isvóre (Cempunula hybrida L. Sz. munuse.). 


\section{IIII. ERTCATLE.}

\section{CIIUNa Silish. - Culună.}

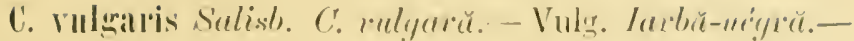

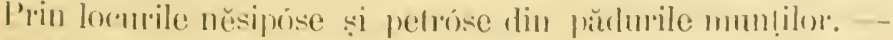

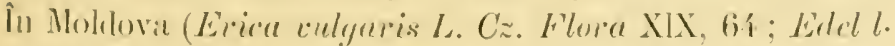

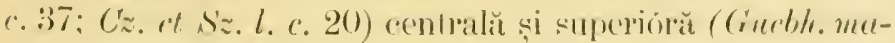

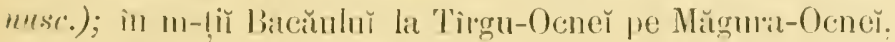
Slănic (D) Br. Fraym. in lisv. lit.-sc. 171), Brătescĭ călte Chicera și la Mlŭnăstireat-Caşinuluĭ ă̌lre Săritórea de la Sointărie; ete. - t? Lulik-sependere.

\section{BRICKENTHALA Robo. - Bruckenthalie.}

B. spiculilolia Relth.; Erira spiculifolia Salish.; E. Breckentalii Spr. B. cu for spiculiforme. - Prin pășnile umede și pelróse din regimnea subalprină și infralpină. In m-tiŭ Moldoveĭ (Menziesia Bruclenthalii Most. Eistel l. c. 37): în m-tiĭ Buzenluĭ pe Penteleй la Că̌s̆ărie: în Pra-

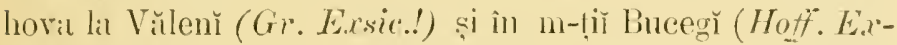
cnrs. 1863, l.c. $119 ; \mathrm{Fr} .106)$ pe Fumica ; in Dimborila pe Pripor și Brănduşa; in m-lî̆ Musceluluı̆ la Nĕmăesč̆ pe Cóslat-mănăstireĕ (D. Br. Fraym. in Reve lit.-sc. 175): in Arges pe rîrful Cozieř. — †? Inniŭ- lugust.

0hs. - Se mắ citéză speciile următóre : E. Tetralix $L$. în Mioldova $(C z$, et $S z$. 1. c. 20). - E. ealruea $L$. în Moldova $(E$. herbecen $L$. Cz. et Sz.l.c. 20) și în m-ţii Musceluluĭ pe lìngă Dîmbovicióra (Hotr: Excurs. 1є62, l. c. 39).

\section{AZALEA I. - Azalee.}

A. procumbens L. A. culcatu. - P'rin locmile petróse din regiunea alpină. - În m-lî̆ Buceğ pe Vìru-cn-l)oru!

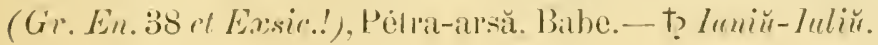




\section{RHOIODENDRON L. - Rododendru.}

R. myrthifolium Schott et Kotschy. R. cu foù de mirt. - Vulg. Cocăzar, Smirdar. Bujor. Trandafir-de-munte.Ṕrin locurile stîncóse și petróse din regiunea alpină. - In m-lị̂ I)înthovițeñ pe Léota aprópe de Paring; în m-tị̌ Buceğ (Fron. 199; Fr. 107; Gr. En. 38 ct Exsic.!; R. ferviegincum Hoff. Lxcurs. 1863. l. c. 120 /non L.]; R. Chamacistus Gr. Nonit of. l. c. [non L.J; R. alpinum Excurs. i. c. 340 ci Exsic.!) pe Furnica, Pétra-arsŭ, Obîrșia și Babe; în m-țĭ Musceluluĭ și pe Pétra-Círaiulŭ la vîrfu Baciuluĭ (Kotschy, 65) ; etc. - †? Iuniü-August.

0lss. - Se maí citéză : Arctostaphylos Uva nrsi sreng. pe Céhlăŭ (Arbutus Ura ursi L. Cz. et Sz. l. c. 22).

\section{VACCINIUII L. - Vacciniǔ.}

V. Myrtillıs L. V. Mirtil. - Vulg. Afin.-- Prin locurile stîncóse și unede din pădurile nontane și subalpine, și prin păşunile petróse din regiunea alpină. - In Moldova (Cz. Fllora XIX, 64 Cz. st Sz. l.c. 20) centrală și superióră (Gruchl. mamusr.); pe Céhlăŭ (Edel l. c. 35) și lia schitul Sihlat! (Gr. Erbor. l. c. 126 et Eisic.!; Gr. En. 38); în 111-tị̆ Bach̆ulŭ la Mănăstirea-Caş̧imulŭ, pe Măgurd-Ocneř și la Slănic; în m-țiĭ Buzeulŭ pe Penteleŭ la Cắçŭrie ; în nn-tị̆ Prahoveı̆ cŭtre Sinaia (G'). Monit. uff.l. c. et Excurs. l. c. 340; Gr. Lin. 38) în un-tị̆ Buceğ pe Furnica; în m-tiù Muscelulŭ la Nĕmăescĭ pe Củsta-mănăstirě̆ (D). Br. Fragm. l. c. 97; Gir. En. 38 ct Exisic.!); şi la Dînbovicióra în

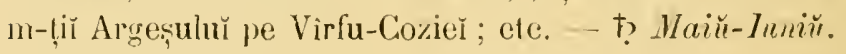

V. uligrimosnm L. V. uliginos. - Prin pasunile umede si petrise din regimnea alpină. - $\hat{n}$ Noldova (Cz. Flora XIX, 64 ci E.rsic. !; h.j. (ineb). manusc.; Cz. st. Sz. l. c. 20) pe Ciéhlăŭ (Ėdel l. c. 35); in m-!̣ĭ Buzeuluĭ pe Penteleŭ la Cŭș̆rie. - †? Maiü-Iuliĭ. 


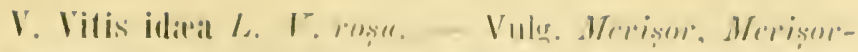

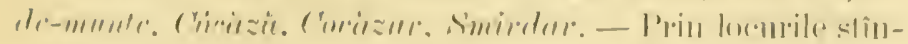

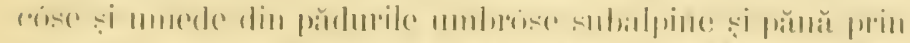

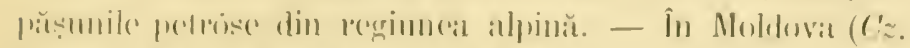

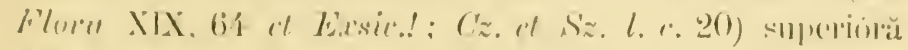

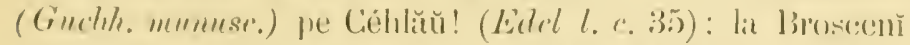

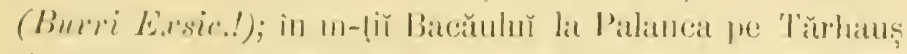

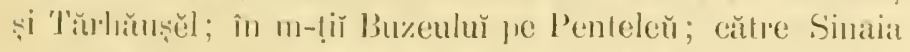

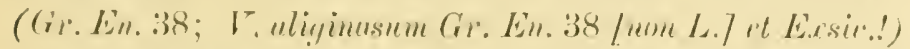

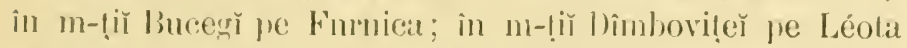

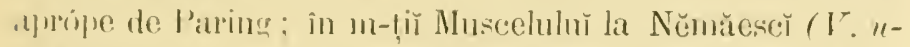

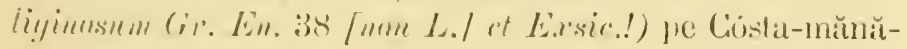

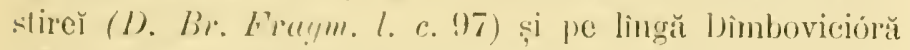

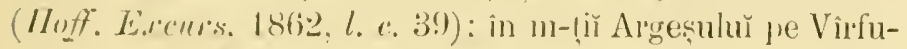

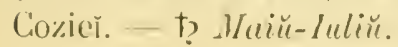

Obs. - Se mar citéză : V. Oxycoco'os L. în m-țir Moldovel (Édel l. c. 37 ).

\section{PYROLA L. - Pyrolü.}

P. rofundifolia L. P. cu for rotunde. - Prin pădurile umbróse și umede din resiunea monlină. - În Noldova (Sz. Exsic.!; h.j. Gueble. mamusc.; Cz. et Sz.l.c. 22) pe

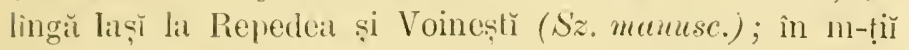

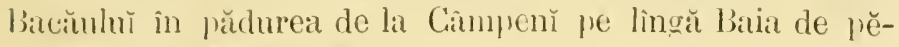
cur̆̌. - 9 Iипій-Luliŭ.

P. clilorantha Sivartz. 1'. gălhis. - Prin pădurile umhróse din reggiunea montană.- În Moldovil centrală (Giucbl. manusc.) lat Mănăslirea-Ciş̦inuluı̆ (Gucbh. Not. nanusc.); la Agiud (Burri Exsic.!). - 9 Inniü-Iuliŭ.

P. minor L. P'. mič̆. - l'rin pădurile umbróse și umedle din regiunea montană și subalpină. - În Moldova

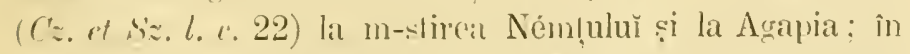

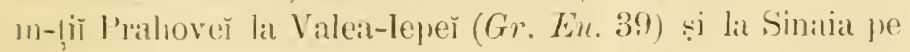




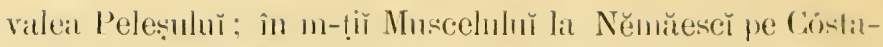

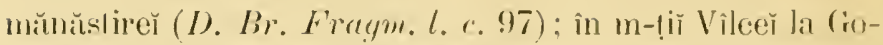
lotrenı̆ pe Föfeca. - 2 Immin-Imliu.

P. secumda L. P. milateralè. - Vulg. Perissor. Merisor. Verdéta-irmer. - Prin pădurile untróse și umede din regiunea montană și subalpină. - În Moldova (C'z. Flor'a XIX. 61. rt Exsie.!; Edel l. e. 37) centrală si superioră

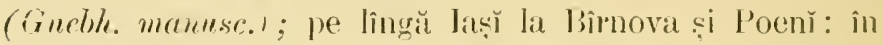

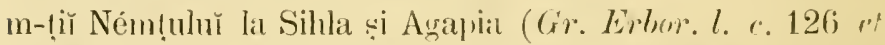
Exsic.!; Cr. En. 39); la Broscenĭ (Burri Exsic !): îl m-ṭi Bacăuluĭ la Slănic și Mănăstirea-Cilṣinulŭ ; în m-ṭĭ Prahovĕ̌ la Sinala pe valea Pelesuluĭ, în Bucegr și lit Predél : in

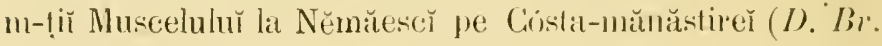

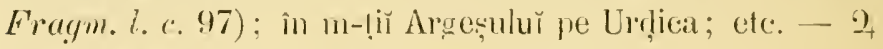
Inniй-Juliu.

P. uniflora L. J. minfloră. - Prin pădurile umbróseṣi umede din regiunea subalpină. - In Moldova (C'z. Flora

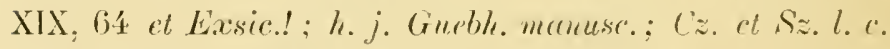
22) pe Céhlăŭ (Edcl l. r. 35) și călse Aqulpia lit schitul Silila (Monesis grondifara Salishl. Gir. Erbur. l. e. $126 \mathrm{rt}$ Exsic.!; Gr. En. 39); la Broscenı̌ (Burri Esrsic.!): în m-tị

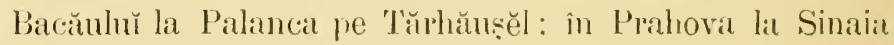
le valea Pelcsulŭ, si în Buceğ la pólele Furnicĕ, in valea

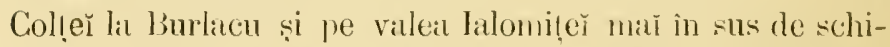
tul Pescela de la Ialomiḷa; în m-țił Jînboviṭel către Nàro! ; etc. - 2 Inпій-Juliŭ.

0is. - Se maĩ citéză : P. Imbellata $L$. în Moldova $(C z$. et $S z . \eta$. c. 22). - P. media Sw pe lîngă laşĭ la Voinești, Horleștĩ și Starnic (Sz. manusc.).

\section{MONOTROPA L. - Monotropü.}

M. Iypopitys L.; M. Hypopitys a. glalura Kuch. M. S'ugc-pin. - Vulg. Śngălóre. - Prin pădurile umbróse din regiunea monlană și subalpină. parasil pe rădăcinile steja- 


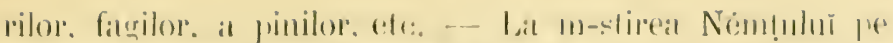

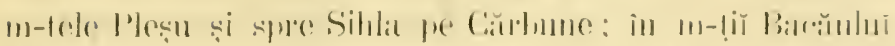

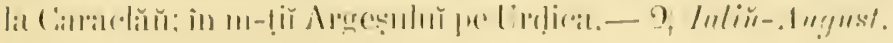

\section{IIY. EMIPETRICEL.}

\section{EMPETRINI L. - Empetru.}

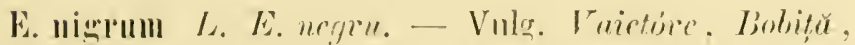

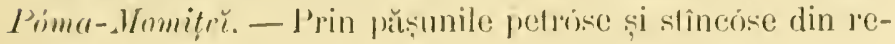
gimnea alpină. - In m-tị̆ Buzeulŭ pe vîfful Pentelenlŭ.-

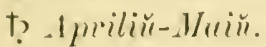

\section{IN. OLELCEE.}

\section{LIGiTSTRIMI L. - Ligustru.}

L. vulgare L. Lig. rommen. - Vulg. Măliniț̆. Lemmucrînelǔ. Lemu-crincsc. Mălin-uegru. - Prin tuferișur’̆. crìn-

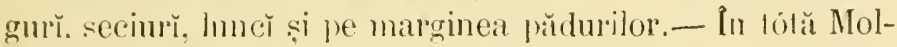

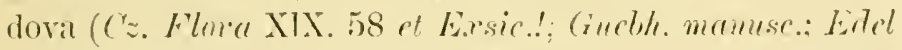
l. e. 41 ; Cz. et Si. l. c. 2 ; Sz. manuse.) și Romănia (Gr.

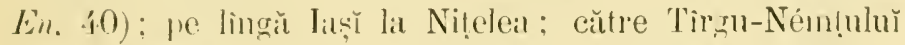
(Gr. Litme l. c. 125); pe lingă Bucureser la Mogosobia: în Dimbovila către Moroenĩ la Cilina-Feneĩ ; in Arges la Stol-

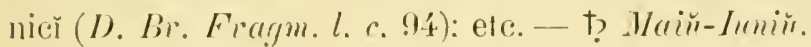

\section{SYRINGA L. - Liline.}

S. vulgaris L. Lil. commen - Vulg. Liliar. Malin-rosu Ioryoun. Sorinte, - Prin pădurile stincóse. - În Mehedinți la Virciorova către Porṭile-de-fer! ( $B$ )rb. sert. Kunitz

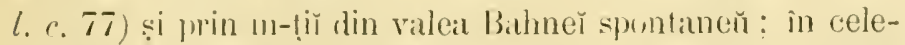

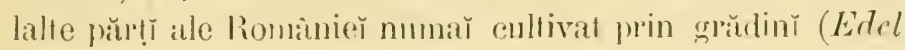




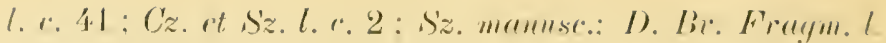

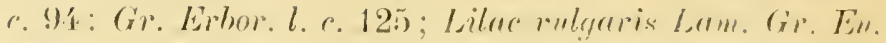
40). - t? Hraiu.

\section{FRAXINUS L. - Frassin.}

F. excelsior L. F. comme - Vulg. Fiassin. - In Noldova (Edel l. c. 41 et Exsie.! Cz. st Sz. l. e. 41 : (zz. ot S'z. l. c. 3; D. Br. Fragm.l. c. 94) pe lingŭ liș̆ la Slincă. Càrlig (S'z. mamusc.), Repedea și Ni!elea: către m-stirca Némțuluĭ (Gr. Erbor l. c. 125); în disır. Bacăŭ la Connan

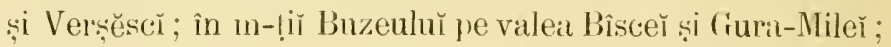
în m-(iî Dînhovil̨ĕ către Moroenı̆ pe Plaiul-1)onnnesc; : în Vlașca la Comana; în Prahova și Mehediṇ̣i (Grr. En. 40); ele. - †? Martiü-А priliü.

F. oxyphylla M. Bieb. F. cul for ascuțite. - Lat in-stirca Adam (Guebh. manusc.). - †? Martiǔ-Aprilin̆.

F. Orins L.; Ornus enropaa Pers. F'. de Manü.-Vulg. Urm. Mojdrén. - Pe coline și prin loenrile slincóse și calcare din pădurile munților. - În Moldova (Édel l. c. 4.1 ; $C z$. ct Sz. l. c. 3) pe lîngă Iaș̆ la Mironésa, Hadìnb și m-słirea Stavnieu (Sz. mumuse.); min viile de pe lingă Ploescĭ ; in Mehedinți la Virciorova călre Porṭile-de-fer pe nn-tele St.-Petru. - †? 1 prilir-1/aiu.

ß. diversifulius Rochel. - În m-tị̆ Vîlceĭ la Olănesccì și liı Crolotrenı̆ ve Fórfeca.

\section{IVI. POLEMONIACEE.}

\section{POLEMOSIIII L. - Polemoniǔ.}

P. Capruleum L. P. albastru. - Vulg. Scara-Dommului.

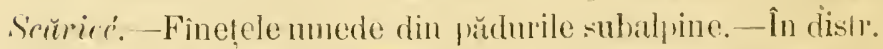
Sucévĕ la Broscenı̆ (Burri E.rsir.!). - †? Imxiй-Juliü. 


\section{WII. S(ILANACEE.}

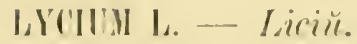

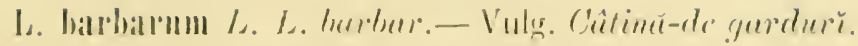

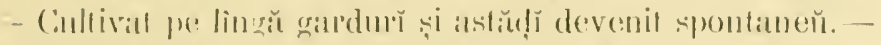

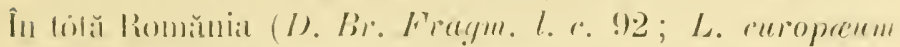

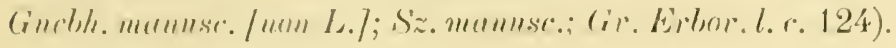
- t) luniin- luegust.

\section{S(OLANIM L. . S Sulun.}

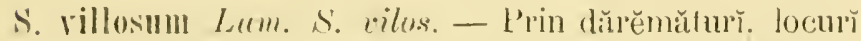

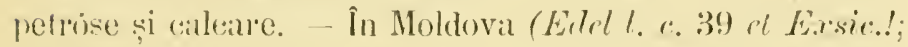
(z. it sz. l. r. s; sz. mumesc.) superiora (Gimelh. munuss.);

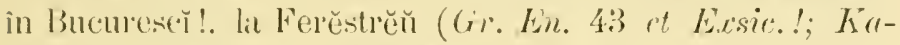
nitzl. c. 22s). - - $\odot$ luliŭ-s'splemlner.

s. miniatnm Beruh. s. cu frncte rosit. - Prin locurì ruderale. - În Muscel pe virfu délulu Moṭoin̆ (Hôff. Lix-

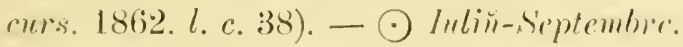

S. nigrum L. S. negru. - Vuls. ITmbra-neptĕ, Zirnĕ. - Prin dărĕmĕturı̆. locurĭ cultivate și inculle, grădinı̆, pe

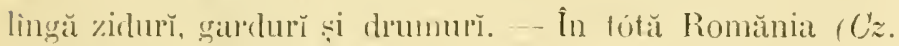
Flum X1X, 62 at Exsic. !; Guebh. manusc.; Cz. et Sz. l. c.

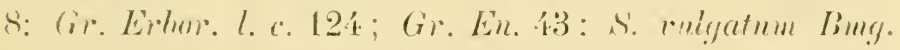

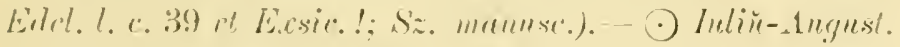

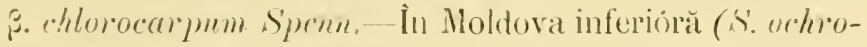
lenerum Bast. (iucbhe, mumuse.).

S. Inlcamilia L. s'. Dulec-amara. - Vulg. Zirnä, Lers-

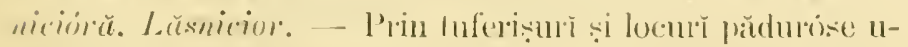

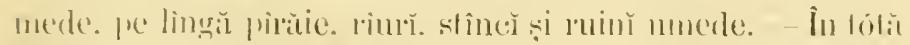

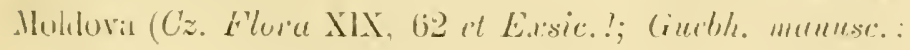




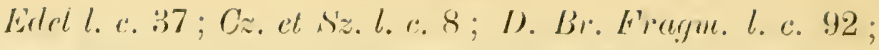
Gr. Lithor.l. c. 124) @i Romănia (Gr. Èu. 43); pe lingă

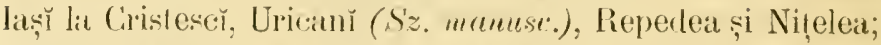

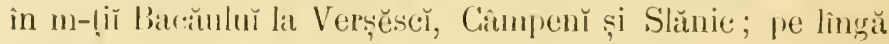
Bèrlatl; pe linñ̆ Ploescŏ la Rădulescĕ ; la 'T'êrgovișteat prin ruinile de lit Chindlia; pe lingă Bucuresě ; pe lîngă Ciraiova în Luncă; cle. - †? Luniü-duegust.

Ohs. - Se cultivă : S. tuberosmun $L$. (Cz. Flora XIX, 62; Guebh. manuse; Cz. tt Sz. I. c. 8; Gr. Lin. 4:3) S. tuberos, vilg. Cartofe, Cartofi, Barabule, Baraboŭ, Bandrabure, Crumpene, Grumcir̆, Crumpiř̆, Nap̌, Bo'oyéne, Hedaburce, Picioicĭ. Picioncì, Mere-de-nămênt, Póme-de-pŭ-

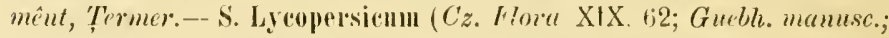
Cz. et Sz. . c. 8; Lycopersicum esculeutum Mill. Gr. En. 4:3) S. Liycoper-

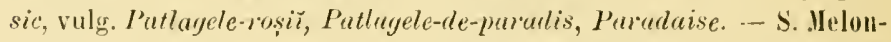
gellit L. (Cz. F?or XIX, 62; Guebh. manusc.; Gr. En. 43; S. esculentum

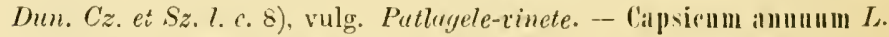
(Cz. Flora XIX, 62 et Exsic.'; Gueth. menusc.; Cz et Sz.l.c. 8; Gr. En.

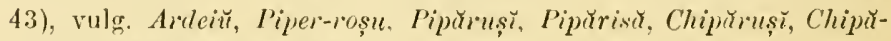
ruşă, l'upricŭ, l'iperiŭ-turcese.

\section{PIIYSALIS L. - Fïsalidŭ.}

P. Alkekengi L. F'. Allielicugge. - Vulg. P'apele, P'apă-

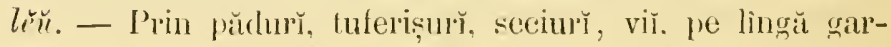
durì și drumuř̆. - În tólă Noldovi (C.z. Flare XIX, 62; Gucbh. mannsc.; Eitel l. ‘. 37, 4.1; Cz. et Sz. l. c. 8) pe lingă laș̆ la Valea-idlincă (siz. manusc.), Nį̣elea și Bîrnova (I). Br. Fragm.l c. 92); la m-stirea Varatic (Gr. Erhor. l. r. 124); în distr. Bacă̆̆ la Caraclăı̆; la Agjud (Burri

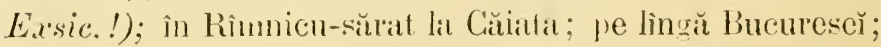
in Vlațcat lit Comana ; în Doljĭn pe malul Jiuluĭ lat Lémna;

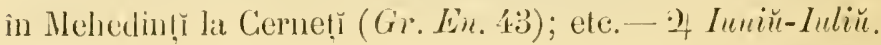

\section{ATROPA L. - Atroper.}

1. Belladonmal L. .1. Bitadona. - Vulg. D/älreggină,

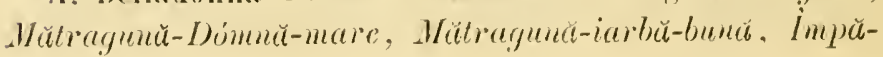




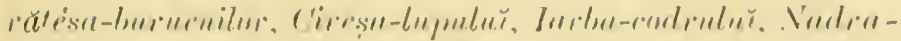

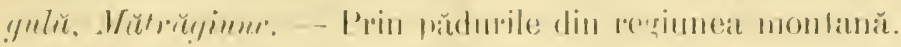

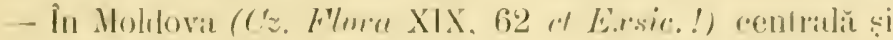

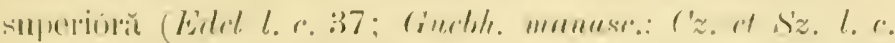

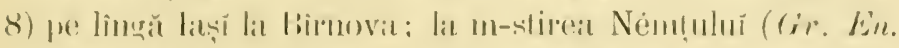

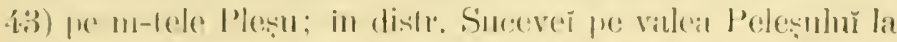

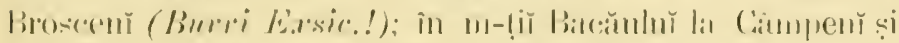

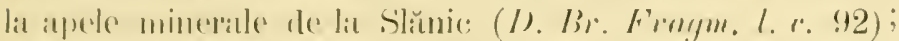

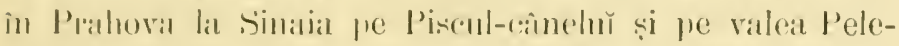

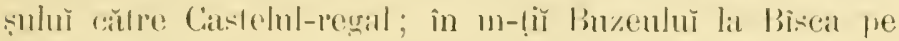

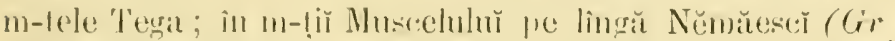

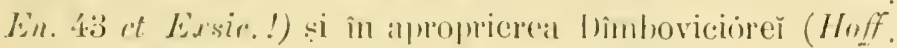

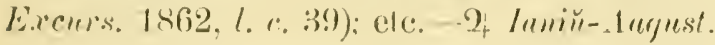

\section{SCOP()LIA Janer.-- Sropolie.}

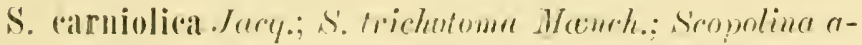

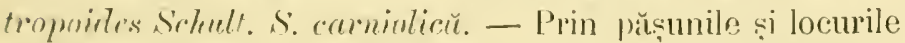
petrose și calcare din pădurile umbróse. - În Moldova (Hyosciumus Scompolia L. Edel l. c. 39); (zz. ot Sz. l. c. 7)

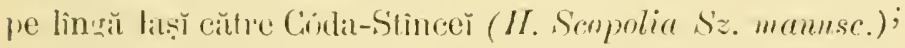

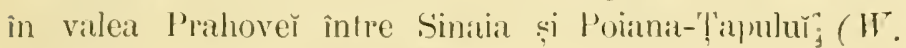
Kuechel!). - If apriliu-1hriur.

\section{IIYOSCIAIIUS L. Masularii.}

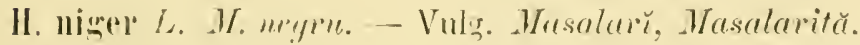

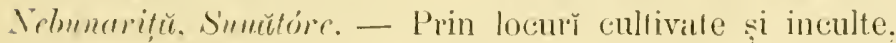

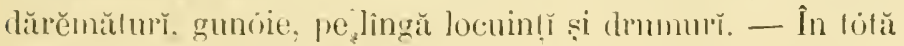
Romănia (Cz. Flora XIX, 62 it Exesie.!; Guebh. mamesc.;

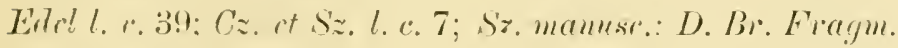

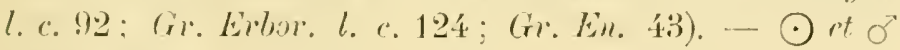
Inмiй-lıliur.

0hs. - Se mar citẻză : II. albus $L$. in Moldova (Edel l. e. 3\$; $C z$. et sं $. l, c .7)$. 


\section{DATURA l. - Datură.}

D. Stramonimm L. I). Stramonie. - Vulg. Cimmăfair, Ciuma-fetè, Laur. slaur. Turbare, Bolandarițĕ. - Prin locurř culte și inculte, dărĕmătur̆, gunóie, pe lìngă gardurĭ și locuinț̆. - In totă Romănia (Cz. Flora XIX. 62 et Exsic.!; Guebh. manuese; Eidel l. c. 39; Cz. et Sz.l. c. 7 ; Sz. manusc.; D. Br. Fragm. l. c. 92 ; Gr. Erbor. l. c. 124; Gr. En. 43). - ○) Inniü-Llngust.

()bs. - Se cultivă : Nicotiana Tabacum L. (Guebh. manusc.: Cz. ct Sz. l. c. 7 et Exssic.!; Gr. Fn. 43), vulg. Tabuc, Tutun. - X. rustica L. (Sz. Exsic.!), vulg. Tutun-turces', Bacon, Baconițx.

\section{SCROPHULARLACEE.}

\section{VERBASCUM L. - Verbase.}

V. phlomoides L. V. commn.-Vulg. Luminărica-I)om-

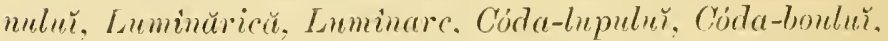
Códa-vacě. Conoratic, P'ur, Lipan. - Pe coline aride și câmpiî něsi|rise, prin pî̀logge și locur inculte, prin văile rîurilor. - In tólă Moldova ( $V$. Theapsus Cz. Flora XIX, 62 [non L.] et Exsic.!: Guebl. mamesc.; Cz. ct Sz. l. c. 7 ; Sz. manuse.; T. thapsiforme et V. cuspidatum Cz. et s'z.l.c. 7 [non Schrar.]); pe lìngă Jaș̆ (V. Thapsus D. Br. Fragm. l. c. 90: 1 . nemorosum S'z. manese. / non S'chrad./ et Exsic.!); in rewiunile inferiore ale Célhlănulu (I. Thapsus Edel l. e. 36 et Eessic.!). la Nómtu și m-stirea Varatic (Crr. En. 43; V. Thapsus Gr. Eroror. l. r. 12': En. 13: $T$.

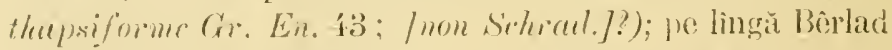

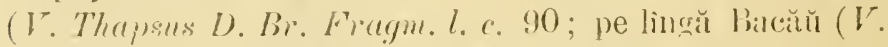
Thapsess Hace. Reise. II. 52; V. thapsiforme Hoelal l. r.

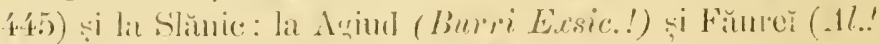

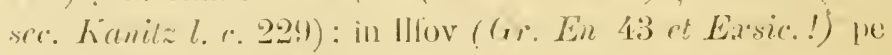




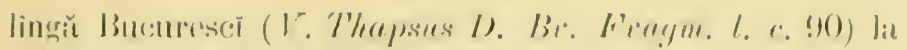

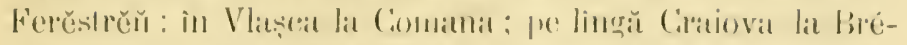

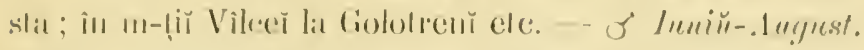

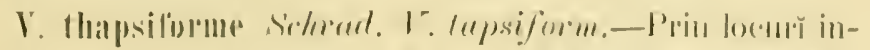

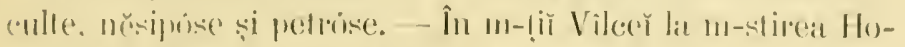

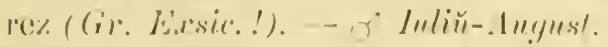

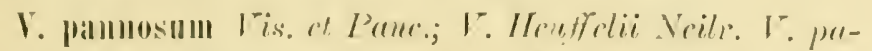
nos. - Lal Vìroioroval călre P'orlile-de-fer! (Borl, Bran-

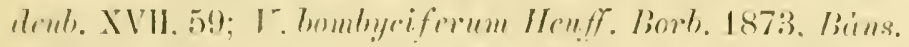

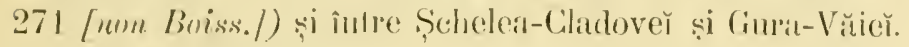
-. बे luniu-Iuliii.

V. Blattaria L, I'. Blalarier. - P’rin Jocuř̀ unede ar-

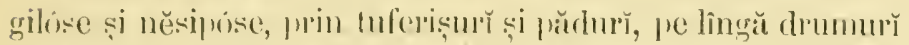
și şințur. - In tótă Moldova (Guebh. manuses.: Cz. et S'z.

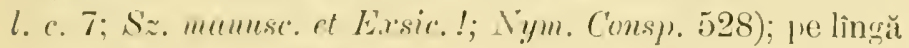
lașĭ lat Niṭelea ; la Bôrlaul: in m-liĭ Batcăulŭ la Slănic; pe

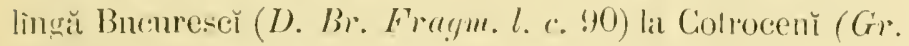
En. 43 et Eissic.!); pe lingă Graiova în Luncă : efc. - જ luпiй-xiplemline.

V. hlattariforme Grisch. Ir. blaturiform. - La Cinteade-Arges (Gr. Jiasir. !); la Vìrciorovil călle Porlile de-fer. - or Juniü-Iuliü.

V. speriosinm siderar. V. firmus. - Prin finclele de pe colinele aride. prin locmile inculte și felrose, min văile rî-

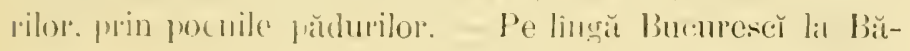

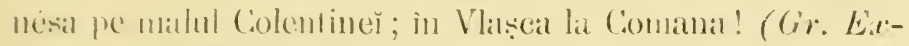

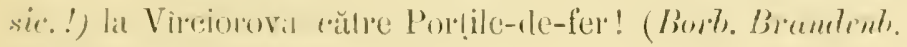
X'll, 5!)1. - or Inniri-Augusí.

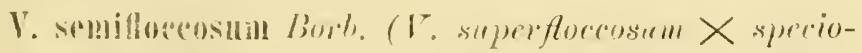
sum). !" stmillmos. - La Virciorova către J'orlile-de-fer (liorh. Huz. Hiah, 2) I2).

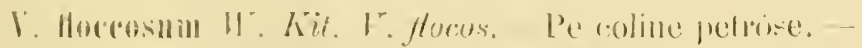

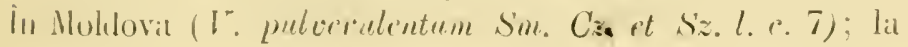


Vircioroval călre Portile-rle-fer! (Burh. 1873. Bions, 271). - 万) Jumiй-Iuliur.

V. Lyedinitis L. T. Lichnit.-P'rin locurile petróse de pee coline și din munț. prin poenile pădurilor, pe naltă rîmi-

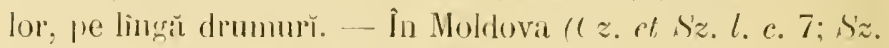
manusc.; Nym. Cemsp). 530; I. nemerosiem (zz. Flora XIX, (i2 / wom sichrarl./ et Lixsir. !: Cz. et Sz. l. c. 7 ; Sz. manusc.; V. album Munch. Cz. ct S'z. l. c. 7 ; V. vigrum Cz.

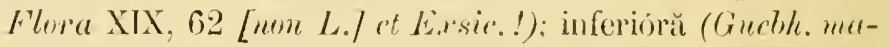

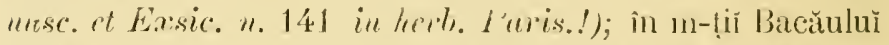
la Slănic; în regiunile inlerinre ale Céhlăulŭ (V. nigrum

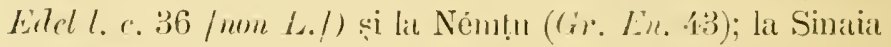
he valeat I'elesulur ; in Jimbovila pe Platul-1)ommese; în m-tiĭ Musceduluĩ pe délul Moḷoin̆ (Hoff. Excurs. 1862, l. $c$.

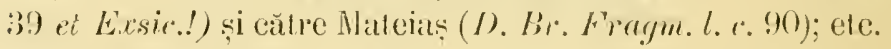

- o luniй-.lugust.

V. nigyum L. IT. neyru. - L'rin linctele de pe colinele siliciose, pe mar.sinea pădurilor. - In Moldora ( $6 z$. of s'z.

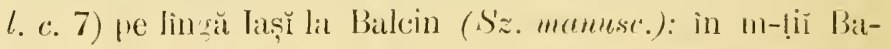

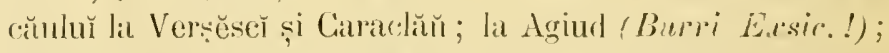
in Ilfor (cir. Lin. 43 et Exsic.!); ne limgă Craiova la Brésla: in Aryes la Cintea-de-Arges ( (ir. Lisie.!) ti la Stolnici; cte. - or Inniú-Iuliur.

V. banaticum Scheal. I. banefir. - P'rin loenrile petróse și stincrise - - La Vîrciorova caítre Porlile-de-fer! (Simli. 584). - o Imniй-Iuliu.

Y. glabialum Friv. I.glabrat. - Prin locurile stincóse s petróse din munț. - Lil Vireiorovil către Porțile-defer! (Nimli. 584); in un-ṭi Vîleề între 111-stirea Cozia și (roJohenı. - or Juinй-dugust.

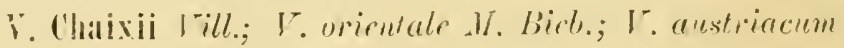

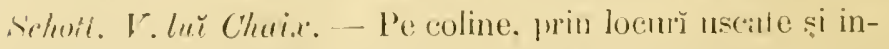

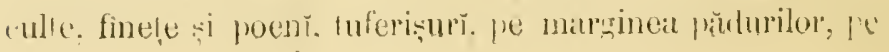




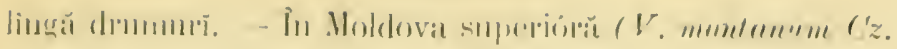

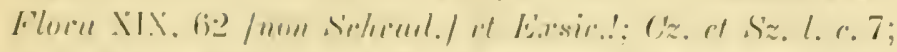

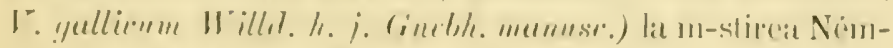

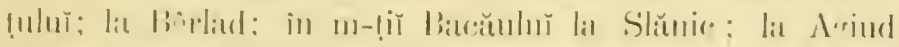

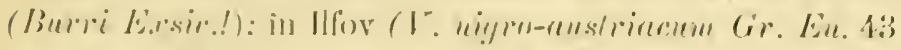

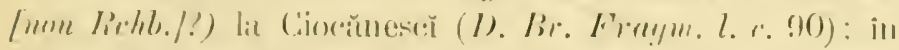

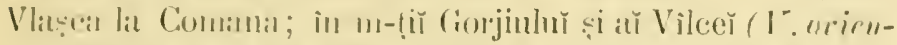

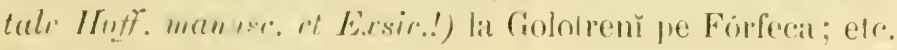

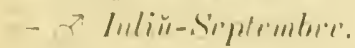

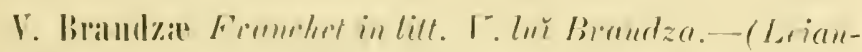
tha). Camlis grateilis, basi parce pubercens, superne glaberrimus, ramosus: folia fere omnia riddicaliat. Iongiter petio-

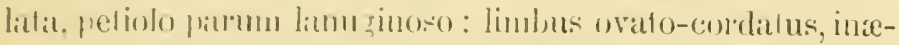
qualiter dupliatu-crentatus, in ficcie superiore glaber, subtus tomento cincreo, brevi, dense vestitus: folia media ef superiona minimat, paltar vel etian subnulla; pedicelli glabri, sub anthesi alpice recurvi, geminati, vel solitarii (ratrus terni), bracteà minutit suffulti, arcublo-patentes. in ramulis munc: alterni. nunc suboppositi, calice sextuplo longiores (15-18 mill. longi); calix glaher: parvus (vix 2 mill.). Pere al bisin usque partifus, lobis ob:usis: corollea lutea (diam. circiter 15 mill.). exfus punclata, glaberrima; filamenta quinupue dense violiceo-hathbtat, intheris ommibus transverse insertis; stignal cilpiatum; caprula ovalo-obfusa. calice subdujlo longior. - $-\sigma$ destute.

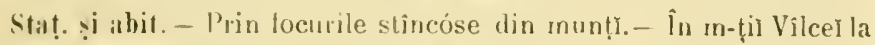
Golortent și pe Fórfeca, unde l'a ru descoperit in anul 1876 luna luliŭ.

0bs. - Ab omnibus Leimthis facile differt foliis profunde cordatis (illis Vert. nigri simillimis) supra glaberrimis, subtus cinereo pannosis. Cun levb. glabruto et alfiniisus. jan inflorescentiae indole minime confundendum.

V. pheniceum L. V. stacosin. - Prin finețe și pădurı̆ - In Moldova (C'z. Flora XIX. 62 et Ex.sir.!; Edel l. c. 41;

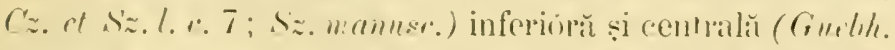

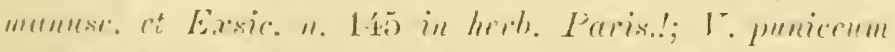

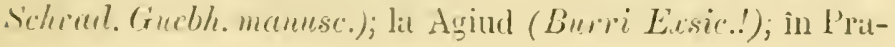




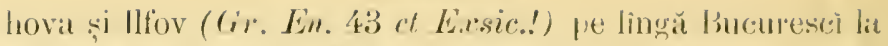
Bămésat, Ferĕstrěŭ și Merinani; în Vlaṣca la Prund; în Ar-

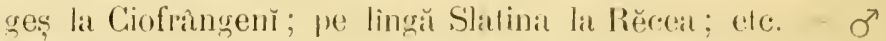
Maій-Inиĭ.

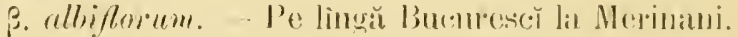

Obs. - Se m I citeză : V. Thapsuides $L$, in regiunile inferióre ale Céhlăulur (Edel 1. c. 36). - - V. counpactum M. Bicb. în Molclova infe-

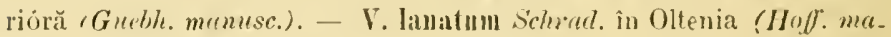
nusc.). - V. Bastardi $R$. S. la Sinnia către lsvor (Gr. En. 43?).-- Cât despre V. pyramidatmm . Mieb. indicat in Moldova superióră th. $j$. Gueb. manusc.) după specimene vèdute în Erbariul din lașĭ. acesta este de sigur resultatul uner eror de determinațiune, find-că 0 astfel de plantă nu există în Erbariul menționat.

\section{SCROPHUTARLA L. - Scrofulurie.}

S. nodosa L. S'. noduriser. - Vuls. Brince-porcului, Bu-

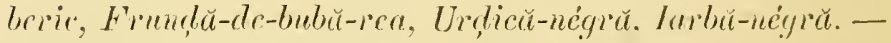
Prin pădurile și tuferișupile mmede, ve lîngă gidrdur. jue malurile rìurilor, bŭlṭilor și a pîrăilor. - În lotă Moldovi (Cz. Flora XIX, 68 et I'xsic.!; Edel 1. c. 37; Cruebh. manusc.; Cz. rt Sz. l. c. 38; Sz. manusc.; S. glamdulusa C'z. Flow XIX. 68 /uon W'. Kit.] rt E.rsir.!; Siz. manuse.); pe

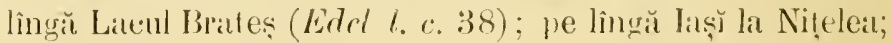

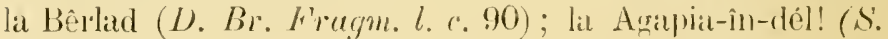
Scopolii Gr. Erbor. l. c. 124 of Exsice!; Gr. Ein. 13 p. p.

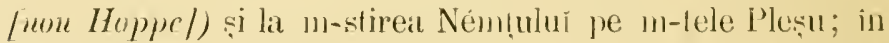

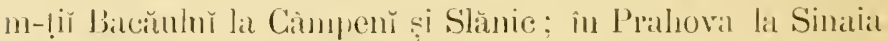
pe valea Peleşulǔ! (S. Scopmlii (ir. Eu. 43\% \% p.; Jonit. of.

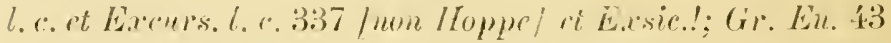

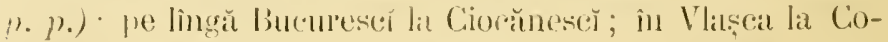
manar; in drges la m-stirea Stinişóra (Gr. Exsic.!); in

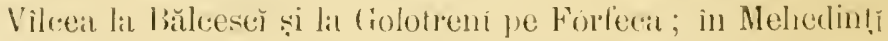
lil llinovar (Cir. Exsir.!); cte. - - of Inniü-Alegrest.

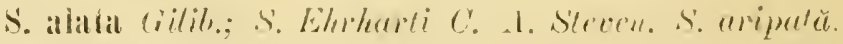
l'e malurile rîurilor si a lorentelor din munṭi, pe lingă 


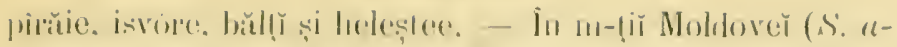

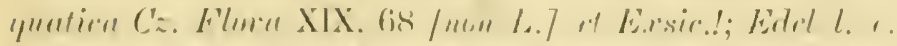

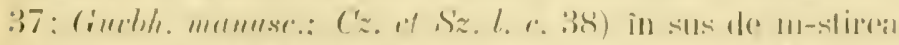

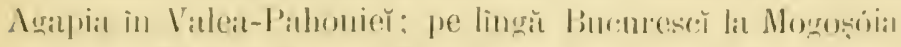

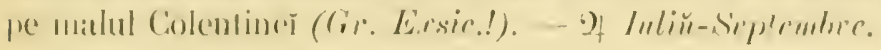

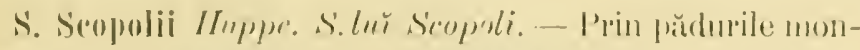

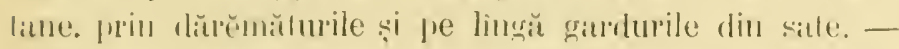

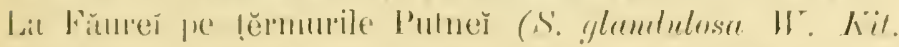

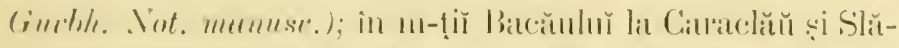

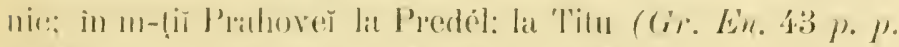

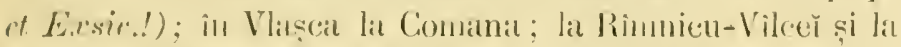
m-slireal Horezu (G). Exsic.!). - o Iuniü-Srptombre.

S. pulverulenta Jantiu. s'. pulecrulentă. - Prin locurile slincrise din mun! İ. - - In Moldova (s'. lacimiatu C'z. Flom XIX, 68 /mon II. Lit.7 et Eessic.!; h. j. Guellh. ma-

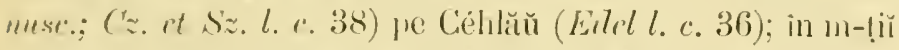
m-stirilor Cozia. 'Tismana și Bistrila (Hoff. manusc.) : in vallea Bistriṭe la m-stirea Bistrita (Gr. Ėsic.!). - 2 Iuliir-.luepust.

S. repralis $L$. S. vernalŭ. - Prin pădurĭ umbróse çi lor.urř uncele. - In Moldova (Cz. et Sz. l. e. 38 it E.rsir..!)

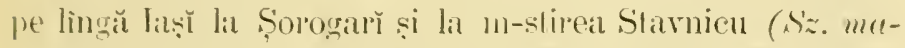

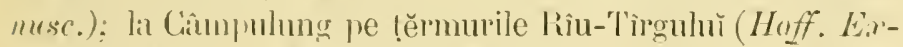

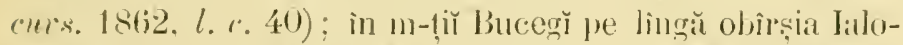

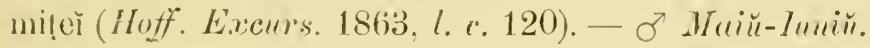

\section{GRATloLa L. - Gratiolă.}

(i. officinalis L. Gr. ofucinalü. - Vulg. Feninaritü. Dhi-

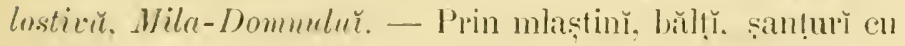
aphĭ. și fincțe mmede, pe malurile apelor. - În túlă Moldova (Cz. Florn XIX. 60 ct Exesic.!; Guchh. mamuse.) : pe

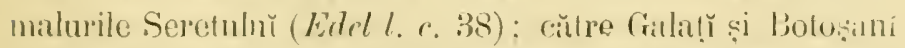

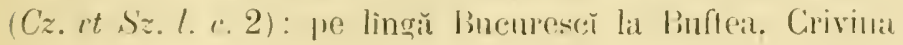




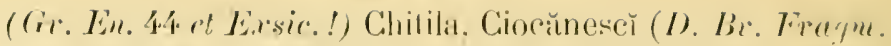

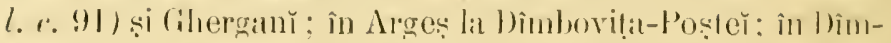
bovita la Heleṣlent-1)omncse: pe Jimgă Slatinat; în ()lı la

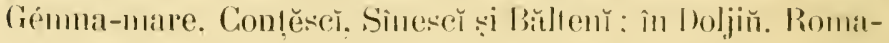

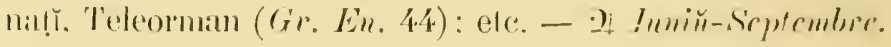

\section{DIGITALIS I. - Digizalu.}

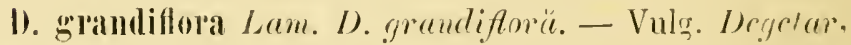
Țitca-rivi. - Prin unferisurile și pădnule de pe coline și din

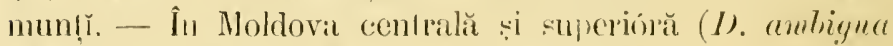
Murr. (z. Flora X]X, 68 et Exsic.!; Ede' l. c. 37. 41; Gurbh. manuse. et Exsic. "1. 139 in herb. I'aris.!: ('z. rt \$z. l. r. 38; Sz. manuse.; D. lu' ca Cz. Flora XJX. 68 Lnom L.] et Exsic.!: Cz. at Sz. l. ค. 38; D. fermgiura Cz. Flora XIX, 68 /non L./ et kiasic.!: lı.j. Guble. mamesc.; Cz. et \$z. l. c. 38; I). lanata Cz. Flora XJX. 68 Lmon

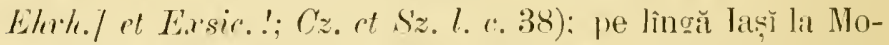
gosĕști. Hadimb și m-stirea Stavnic (D). Lutra Szz manusc. /non L.7) ; ne linği Bôrlar la Crîngu (D). Br. Fragm. l. c. 91) : în l’egiunile inferióre ale Céhlăuluĭ (D). Lufea Eirlel l.

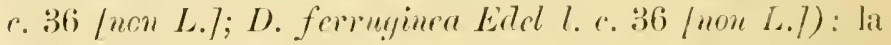
Agapia (I). mortia (ir. Erbor. l. ('. 124 (non Roth7) și lia

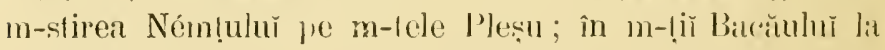
Verșescĭ, Ciuraclăı̆, T'îrgu-Oener. Slănic: și Palanca; la Agind

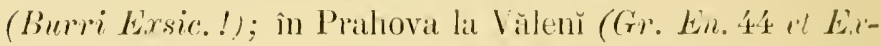
sic.!), călle Telega și la Sinaia; in Muscel pe Padina-Cucĭ̈ în Arges la Stolnič̆; pe lîngă Slatina căıre Olı; în Gorjiŭ lat schilul Locuř̌-rĕle; în Vîlcea la Fiolotrenı̆ pe Fórfeca; în Me-

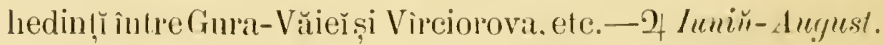

1). lanata EKr\%. D). lanatŭ. - Pe câmpurì nĕsipóse și pe coline aride, min finetele din păduri şi prin tufĕrișur. În Ilfor (Grr. Ér. 44 et Ersic.!) pe lîngă Buncureseì la Me-

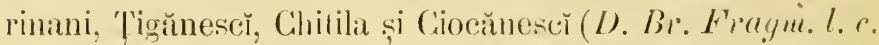
91 ) ; in Jimbovita la Colentina-de-jos! (Scholt l. c. 472) si 


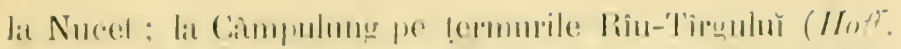

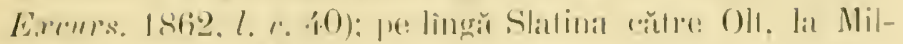

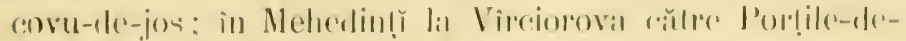

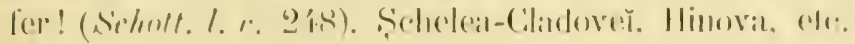

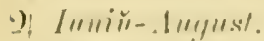

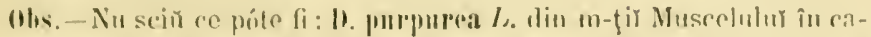

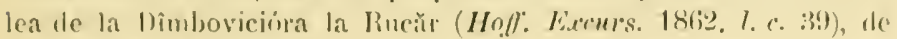
vieme ce acristă specie nแl cresce în România de cît mumał cultivata

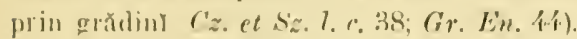

\section{ANTIRLIISUII. - Antirin.}

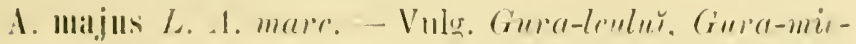
lulur. - Pe vidurile rechŏ. - Lá Têrgoviṣtea pe Cihindia și la m-stirea lélı. pite sponlance: in cele-lalte păr!̣̆ ale

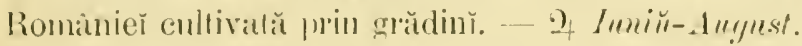

1. Orontimm L. 1. Orontiü - Prin locury cultivale, ne-

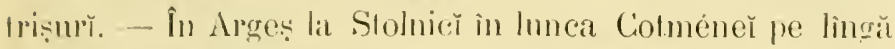

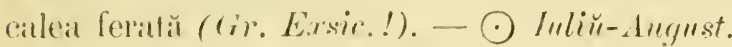

\section{LINIRIA Tomrnef. - Linarip.}

L. Elatine Mill. i. Elatine. - Prin agriì și pîrlóge

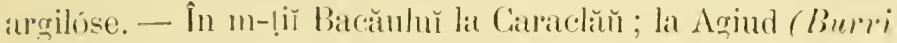

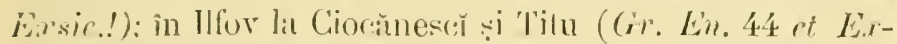
sic.!. Kanitz l. (. 229) : în Vílceal la bŭlresci și la Ocnele-

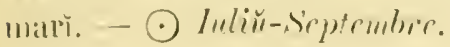

L. spmria Mill. L. spurir. - Prin agrĭ, pìlóge și lo-

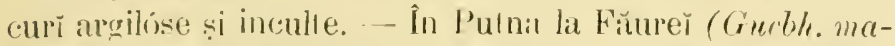
unse.); in Vîlcea iuprópe de Olănesč. - $\odot$ Iuliü-lugust.

I. minor Desf. L. mirŭ. - P'rin petrișurile něsiprise de pe malca torentelor din munți. - - In Mloldovil (c'z. Frtorne XIX, 68 of Eisicic.! Eslel l. a. 40 ; C'z. et S'z. l. c. 38) supe-

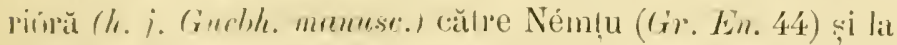

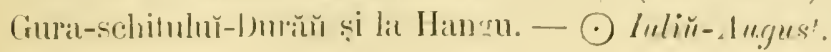


I. alpina L. Limarir alpiur. - Prin locntile pelrose

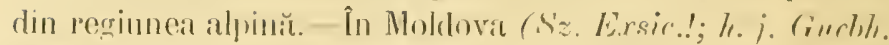

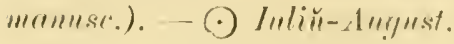

L. alrensis I)esf. L. agrestü. - P'rin agriĭ și p àu-

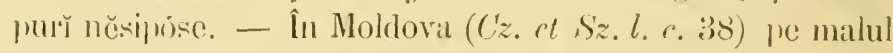

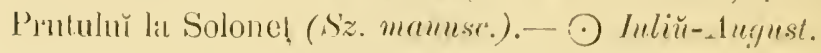

I. genistafolia Mrll. L. en for de genista. - Prin lo-

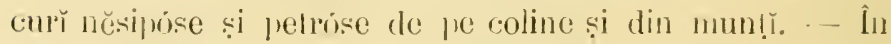
Moldova (Edel l. c. 40; ('z. et S'z. l. ". 38; L. dulmaticu

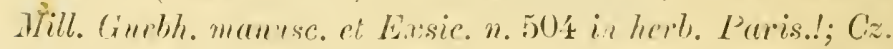
et Sz. l. c. 38) si triă Romănia (L. dalmatica Srhur Ėn.

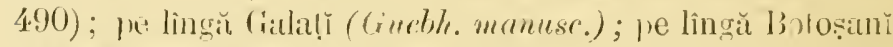
(Antirblimm genistafolinm L. Hacy. Reise. II, 140); Hoctal

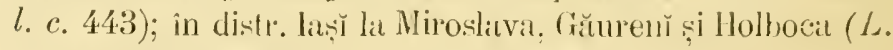

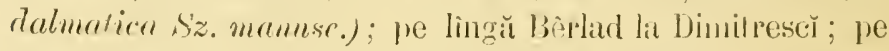

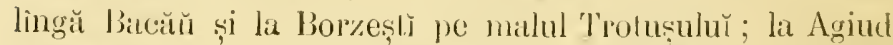
(Burri Exsic.!); in Ilfov (Grr. Lir. 44 et Exsic.!) la Buftea și Cilocămescĕ; în Vlisşcia la Prund (D. Br. F'rugm.l.c. 91); in Argeş pe $111-$ ele Urḍica ; în Vîlcea la Olănesč și la frolotrenı̆ pe Fórfeca și Naro! ; pe lînơ̆ Craiova la Lémma; in Melıedinți la Vìrciorova ciatre Portịle-de-fer! (Śchotí $l$. r. 248; Konitz! l. c. 87) și între Schcleit-Cladoveľ și (ruritV̆̌ier ; etc. -

L. macedonica Griseb. L. macrdonică. - În Noldovit .(Nym. Conss). 538).

1. Italica T'ev. L. de Italia. - I'rin locurr aride şi petróse. - La Pechea (Cruebh. mamesc. et Lxsic. "1. 505 ser. Nym. Consp. 537); la Vaciul (L. linifolia Roch. Schottl. ․ 296); in Argeş la Stolnici (Gr. Exsic.!). - of Muliuseplemblise.

L. vulgaris $t$. Linarie vulyară. - Vulg. Linariță, Insübatic. Bmruinnă-de-in. - Prin locurì aride cultivite și

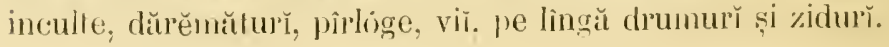




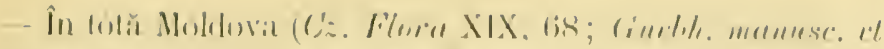

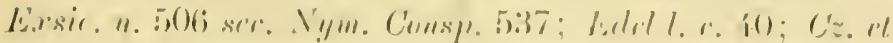

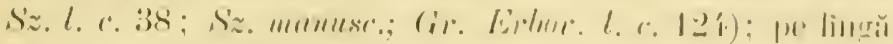

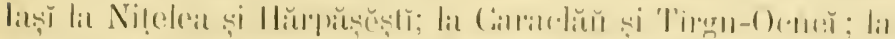

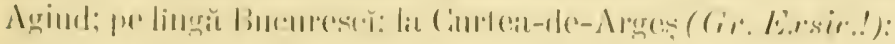

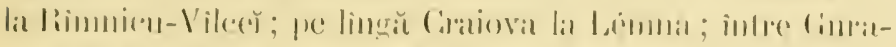

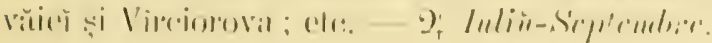

\section{IERosted L. . Tromicŭ.}

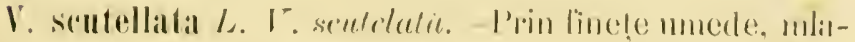

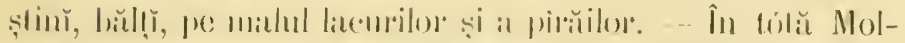

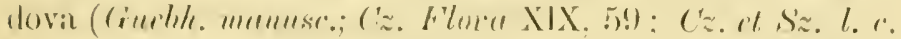

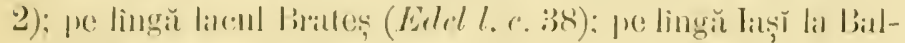

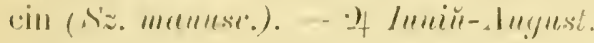

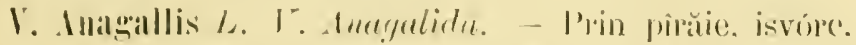

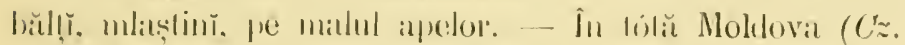

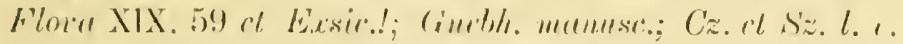

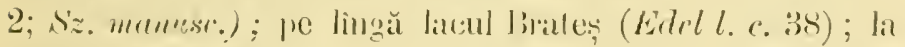

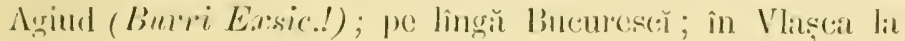

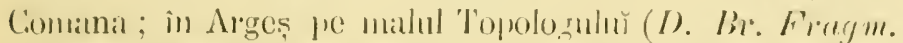
1. 1.91); in Mused in vilea Rin-Tirgului (IToff. Exerurs.

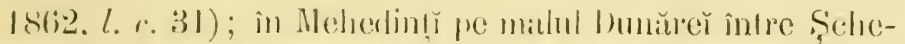

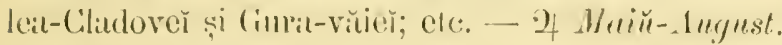

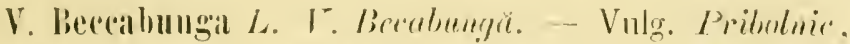

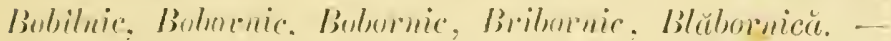

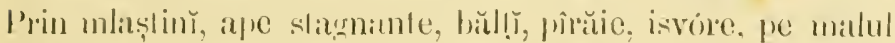

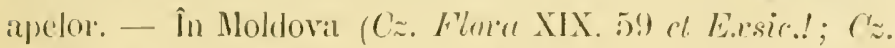
't s'z. l. c. 2; Szz. monuese.) pe lingă fialalı̆ pe malurile Sere-

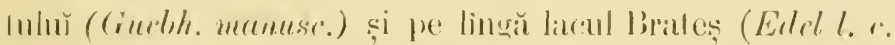

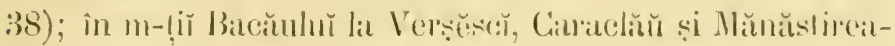

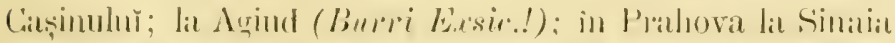

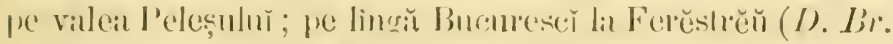

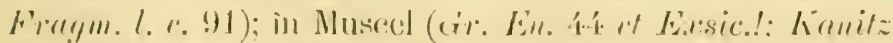

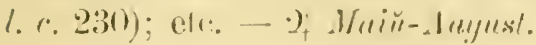


V. IIticafolia Jacq.; V. Latifolia L. ap. Kermer. V. (') for de urdirŭ. - Prin loeurile slineóse şi unede din păduiłle umbróse ale regiuneĭ monlane și subalpine. - În Moldova (Cz. Flura XIX, 59 et Exisic..; Cz. et Sz. l. e. 2) cenrală și superióră (V. Latifolia Guebh. manusr.?); pe lingă Iaș̆ către Reperlea și Mironésa (S'z. mainusc.); în regimnile inferióle ale Céhlăulǔ! (Edcl l. c. 36); la Broscenı̌ (Burri

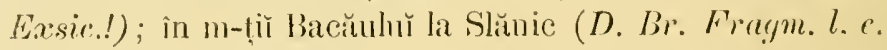
(1)); în Prahova la Sinaia (Gr. Excurs. l. c. 340) pe la pólele Furnicě și la Predél ; în Muscel la Nĕmăescĭ pe Cóstatmănăstireı̀ (D. Br. Fragm. l. c. 91; I. latifulia Gr. Én.

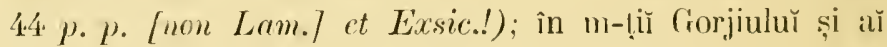
Vîlcê̆ (Hofff. munusc.) la Olănesč̆ pe lingă cascadă, și liı Golotrenı̌ pe Fórfeea. - 2 Maiй-Aurgust.

V. Chamredrys L. I. Strjürel. - Prin finelele uscate, luferișurı̆, poenile de prin pădurı̆, de la cîmpiù și pînă în regiunea subalpină. - În tótă Moldova (Cz. Flora XIX, 59 ot Exsic.!; Edel l. c. 39; Guebh. manusc.; Cz. et s'z. l. c. 2; Sz. mannse.; V. pilosa Cz. Floma XIX, 59 [nom s'chm.]; Cz. ct Sz. l. r. 2 ; S'z. mannse; V. T'encrinm Cz. Florre XIX, 59 /non L./ et Exsic.! ; Cz. et Sz. l.c. 2); pe lingri laş̆ la Petrătria-Repedeŏ și la Niţelea; la ın-slirea Ném!̣!ıluĭ şi pe Céhlăŭ ; în m-țĭ Baten̆uluĭ la Caralelăŭ şi Comănesč̀ ; la Agiud (Burri Eassic.!); în distr. Buzen̆ (Gr. En. 4.4 et Exsic.!) la Bisea pe m-lele Tega ; în Prahova la Sinaia pe l'iscu-cûnehŭ, Pétra-arsă, sehilul P'escera de la litlomila și Predél; pe lingă Bucurescŭ li Ferěstrěŭ (D). Br. Fragm. l. r. 91); ve lingă Graiova in Lumeă : in (iorjị̆ lit Roṣili ; in Argeṣ pe m-tele Urḍica ; în Vîlcea la Golohenì pe

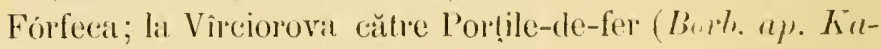

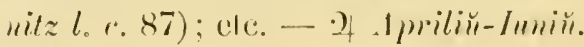

V. montana L. I. montană. - P'rin pădnrile umbrose şi unede din regiuncal monlană și subalpină. - - |̣̂ Mol-

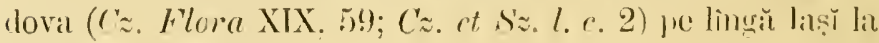




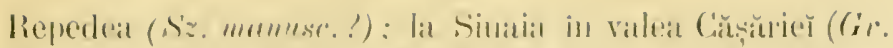

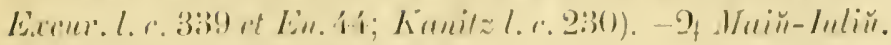

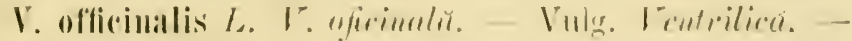

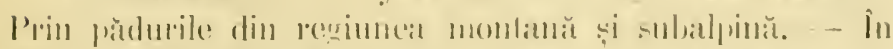

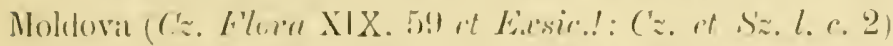

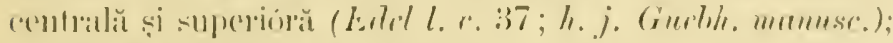

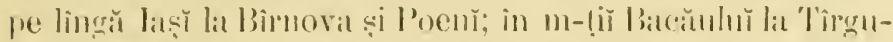

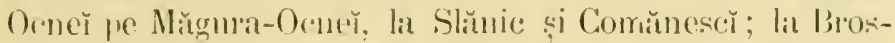

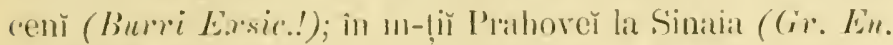

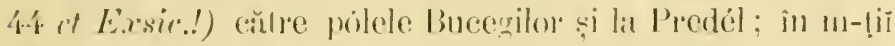

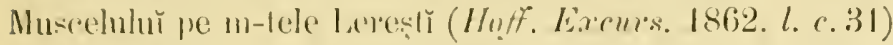

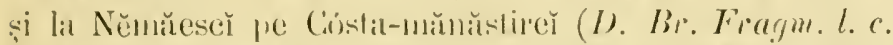

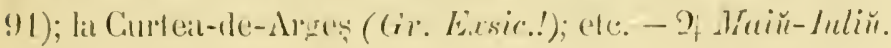

V. aplyylla L. I. afilă. - P'rin locurile stincise din regruncat alpinit. - În Moldora (Cz. ot s'z. I. e. 2 ; I. drpan-

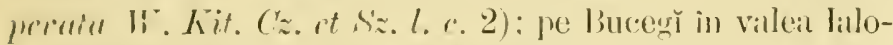

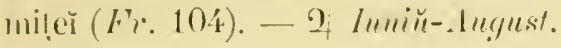

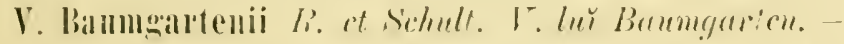
Prin crěpăllurile stincilor din regimnea aljină - În Mol-

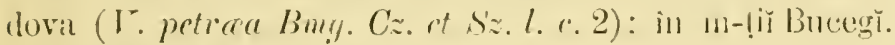
- of luliu-iluyust.

V. prostrata L. T. mostrutir. - Prin finete nĕsipóse

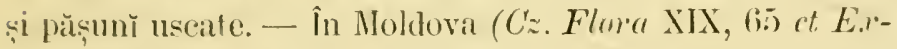

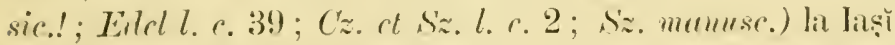

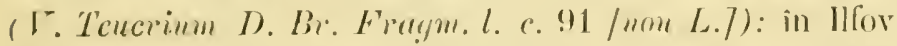
(Gr. En. 44 et Exsir.!) la Bucuresč in Cismegiu și la Bănésa (I. Trucrium rar. minar. I). Br. Fragm, I. c. 91). - 2 Maiй-Tunir.

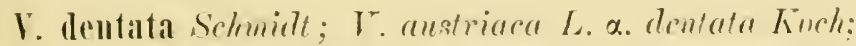

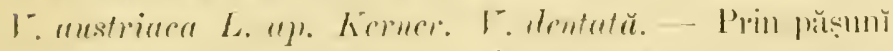

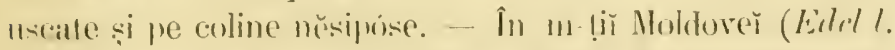

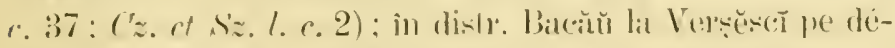

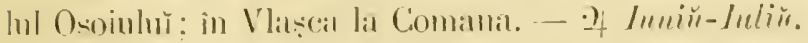


V. orientalis J/ill, V. austriace B. oricutalis C. Koch.

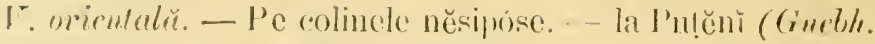
mannse.). - 2 Juniü-Inliur.

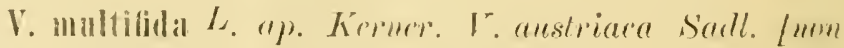
L I.V. multifidŭ. - J'e coline și min fìncțe uscale. - În loblit Noldova (1'. austriace Gueble. mamuse, ot Easic. n. 8 in herh. Paris.!; Nym. C'msp. 545; V. Jacquini $C z$. Flor" XIX, 59 et É.tsic.!) pe lingă laș̆ la lazu-Chiritĕ, Şapte-

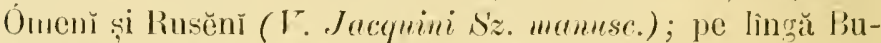
curescĕ la Bănésa (I'. austriare I). Br Fragm. l. c. 9I), Ferěstrěŭ, Cotrocenť și Chitila; la Vălenı̆ (Grr. Érsie.!); in Muscel (Gir. Exsic.!) la pólele n-teluĭ Lerescù pe válea Rìu-'Tìmulnú (Joff. Excurs. 1862, l. c. 31); etc. - 2 Inciin-leniü.

V. Tentrimm L. ap. Kerner ; 1. Pscndochamadrys

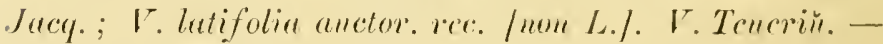
Prin finctele uscate și tuferişurile de je coline și din mun!̣. - Pu Moldova (Edel l. a. 39): s'z. menuse.; V. Intifolien Cz. H'lor XIX. 59 at Exsic.!; Cz. ct szz. l. c. 2 ; r. spuria Cz. Flora XIX, 59 /non L./ et Lixsice!; Cz. et Sz. l. c. 2 ; I. foliose (z. Flore XIX, 59 / $\mathrm{mm}$ WV. Kit./ et Exsic.!;

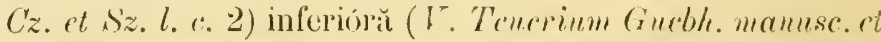

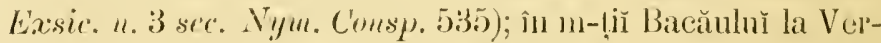

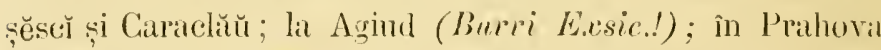

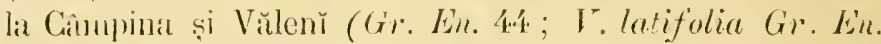

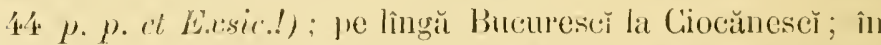
Vlaşea la Contana ; in Argeş; în Mnsceel ( $V$. lntifolia I). Br. Frergm. l. c. 91); je lingă Grajova lat Lémna; in Me-

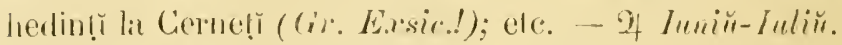

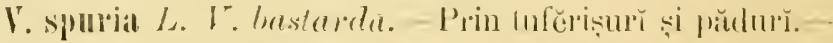

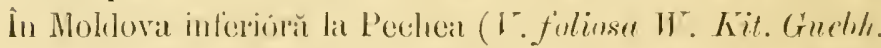

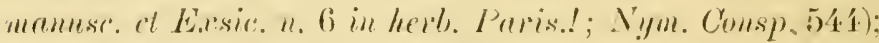

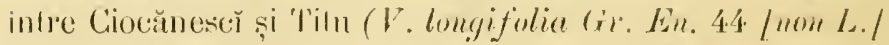

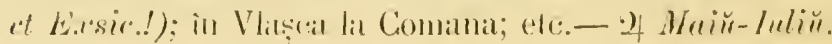




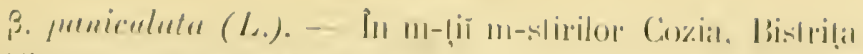

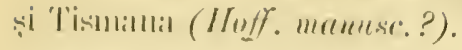

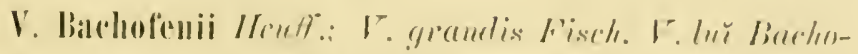
fin. - Prin locurile stincose și petrose din mun!̣̆. - În

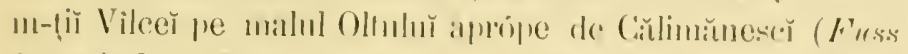

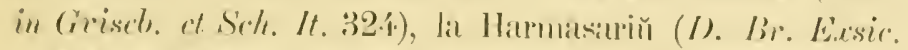
". 922 in Kincep. Ocster. lot. Zeit. XXV'll [1877|, 362) și

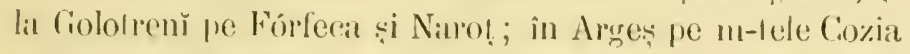
lat m-stirea Stintựira; la Vîreiorova către Porțile-de-fer. - If Juniü-1ugpest.

V. Iongifolia L.; V. maritima L. ap. Kermer. V. cu foi lunğ. - Prin finctele mnede și pe malurile rîurilor. - În Moldova superiorĭ (Cz. Flura XIX, 59 it Exsie.!; h. j. Guebh. mamese.; Edtel 1. 6. 37: Cz. ot s. 1. c. 2; 1. media

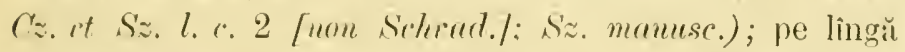
Jaı̣̆ la Socola (S'z. mumusr.) ; la Bî̀lad pe malul rîulŭ Bèrlaul (1. limgifolia B. inciso-serata I). B1. Frargm. l. (. 91); in Vlaṣea lat Prund (V. longifolia $\gamma$. media D. Br. Fragm.

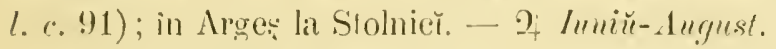

V. spieata L. IT. sppicută.-Prin pășun și finete uscate. - In Moldova (Cz. Flora XIX, 59) et Exsic.!; Cz. et S'z. I. c. 2 : sz. manuse; Nym. Cusp. 544) (entrală și superióră (Gurbh. mamusc.); pe lingă Bêrlad la Dimitrescú ; intre Ca-

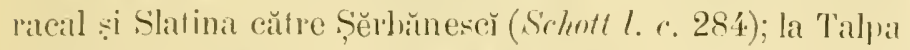

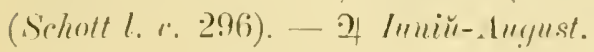

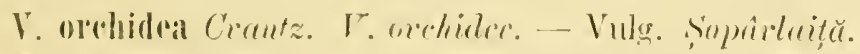

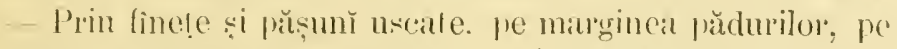

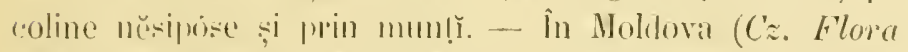

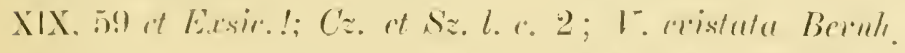

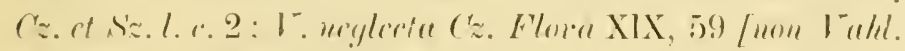

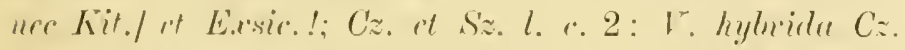

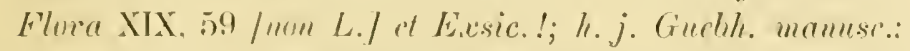
Cz. ot Siz. l. c. 2) inferioră (Guchl, manuse. ct Exsie. 11. 4 .

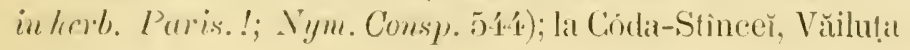


(Sz. mrunesc.), Stîncă, Valea-lupuluй, Isvóre, Iepurenı̆ (V. huylrida Sz. manusc.), Păun, P'icioru-lıpulur, Repedea și Bìrnova (V. meglecta s'z. mannsc.); liı un-stirea Ném!nulŭ pe

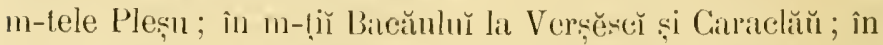

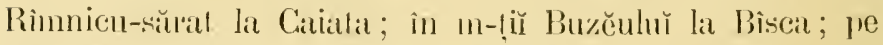
lingă Bucurescĭ la Ciocĭnesč̆ (Gr. En. 44 ct Exssic.!; $V$. spicata Kanitz l. c. 230 /um L.]), Crivina, Buftea (V. spicreta Gr. En. 44 [non L.] et Exsic. !). Chitila, Mogosóia și Merinani; în Vlaşca la Comana; la Curtea-de-Arges, Piciorn-Fağulŭ și la Dînbovila-Por!ẹ ; în Muscel în Valea-

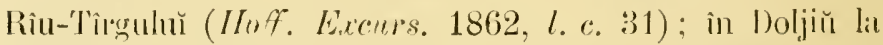

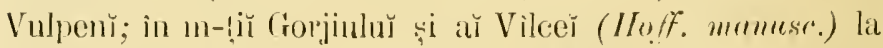

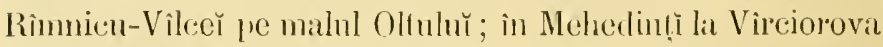

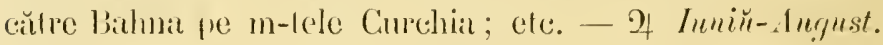

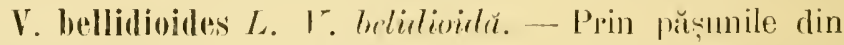
regiunea alpină. - In Moldova (Cz. rt Sz.l. c. 2); în m-tii Bueegr la vama Strungat (Gr. Ein. 44 et Exsico!; Kanila

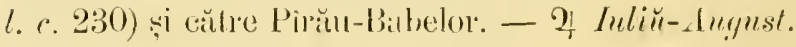

V. fruticulosia L. V. fruiculósŭ. - Prin locurile slîncóve din reginnea alpină. - În m-ḷĭ Moldoveı̌ (Sz. Exxsic.!;

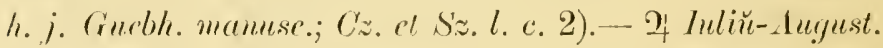

V. alpiıa L. T. alpinŭ. - Prin pășunile petróse din

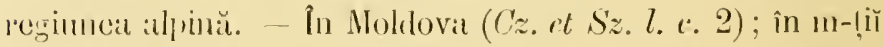

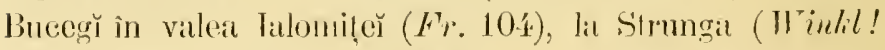
ser. Kani:z l. c. 231) şi pe Babe. - 2 Inviü-Alugust.

3. integrifolia Sedrenti. - În Moldova (Cz. ct Sz.l.c. 2).

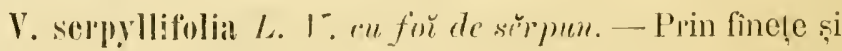

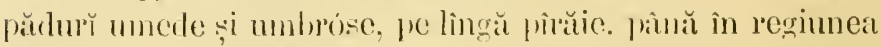
alpină. - In lótă Moldova (Cz. Flore X1X, 59 rt E.rsic.!;

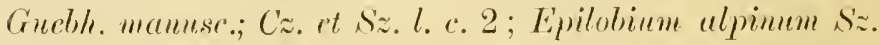

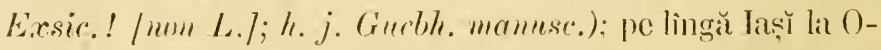
soiŭ și Costulenì (S'z. mamesc.); în m-ṭî Bač̆uluĭ la Palanca re Tărhăuşĕl ; in Illfor la Bucurescĕ în Cismegiu! (Gr. En. 44 et Exsic.!; Kanie l. c. 231) si Ciocătnesch; la Sinaia; in 


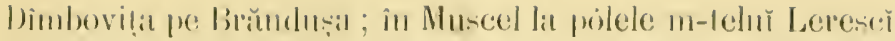

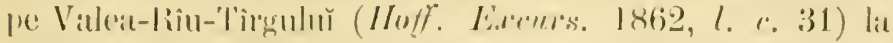

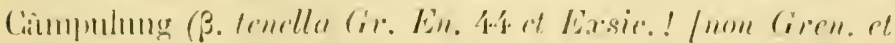

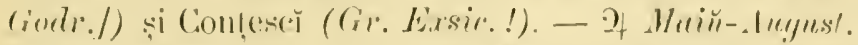

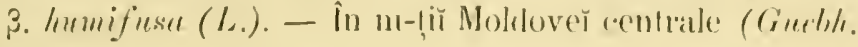
menuser.).

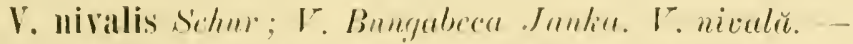
Prin locurile unnede din reginnea subalpină și alpină. - În m-tii de la Predél. - of lminir-d"y,ynst.

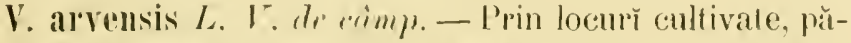

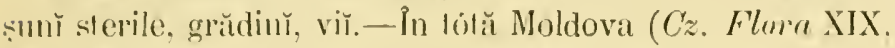

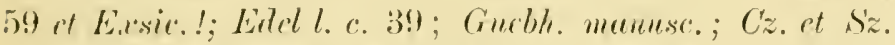

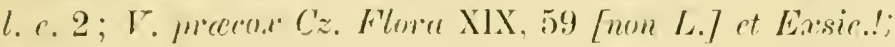

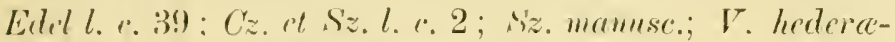
folia r"z. Florea XIX. 59 / Lom L./ et Exsic. !; Edel l. c. 39;

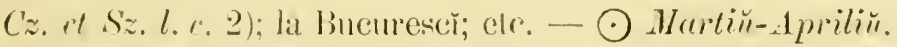

B. romamu (Schmidl). - În Moldova (Cz. el S'z. l. e. 2 ; S'z. mamuse.).

$V$. peregrina $L$. $V$, peregrinc. - Prin locur cullivate. - In Moldova (Cz. ol s'z. l. ‘. 2) inferióră la Puḷĕnu (Crucb)h.

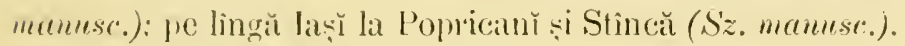
- $\odot$ Iprilin--1/uin.

$V$. verna $L$. $V$. de mimăcéră. - Prin locuř sterile. rimplĭ, roline aride, tuferișurı și |ădur din terenur arenacee. - T̂ Moldova (Edel l. c. 39; Cz. et S'z. l. e. 2: Sz. manuse.). - $\odot$ Aprilin-1/aiй.

V. triphyllos L. I. trifilu. - I'rin locmer cultivale și

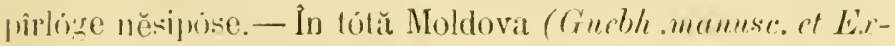
sir. ". 518 ser. Nym. Comsp. 548; Cz. al sะ. l. r. 2; s'z. mu-

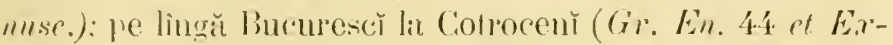
sic. !; Kunilz l. c. 231) și Colentina. - $\odot$ Martin̆-Maĭ.

V. anglestis L. I' ayrestă. - Prin locuri cultivate, vii.

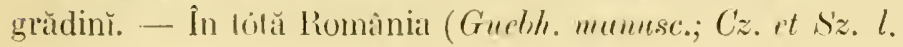




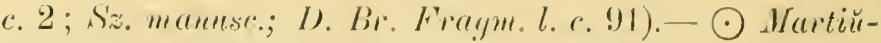
luegust.

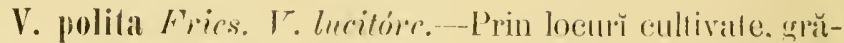
dinı̆. - - In Moldova (I'. auprestis Cz. Floro XIX, 59)/uon

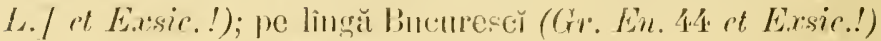
la Cotrocenĭ și la Băıésal (D). Brr. Frorym. l. c.61). - $\odot$ Martiu- lequest.

V. Touruefortii Gmel.; V. persica P'ori. Г. ln Tournefort. - Prin locurǐ cullivate, agriǐ, vĭ̌, grădinŭ. - În Moldova ( $V$. filiformis $D C$. Cz. et S sz. l. c. 2 et Exsie.!) inferiórŭ (V. Burbanmii İ'n. Guelh. manuse. et Exsic. n. 7

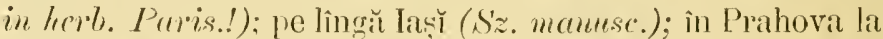
Sinaia (IF. Br.rbanmii Gr. En. 41 et Esesic.!). Vălenì și Cimmina (I". agpestis Gr. En. 44 /uon L./ ot Exsic.!); la Bncırescĭ, Cotrocenı̆; efe. - $\odot$ Martiŭ-November.

V. hederafolia L. I. c" for de isderč. - Prin locur

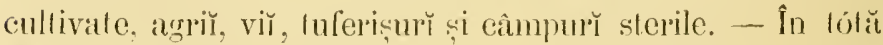
Moldova (Gurbh. maunse.); pe lìngă Jaș̆ la Iedẹrenŭ și Socola (Sz. memusc.); la Agind (Burri Exsic.!); 他 lìngă Bu-

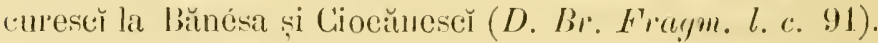
- - A miliü-Maik.

0hs. - Se maĭ citéză : V. Mrglorta Wrahleub. pe colinele aride de la Pechea (Guebh. mannse.). - V. saxatilis Jacy. în Moldova (C'z. et Sz. l. c. 2). - V. acinifolia L. in Moldova (Cz. et Sz. l. (. 2).

\section{T0\%ZLA К. - Tozzie.}

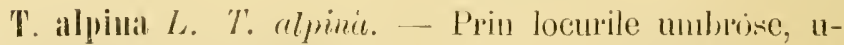
nede şi slineose din resginnea subilprină și alpină. - Lil

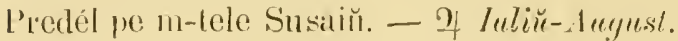

\section{MEIAMI'YRUII H. - Melempir.}

II. clistatum I, Mr. crestat. - Vulg. Grănl-pmepelit,č, Civomoiuy. - L'rin fìneḷele uscate de prin pădurĭ și tuferi- 


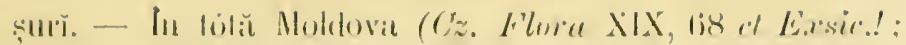

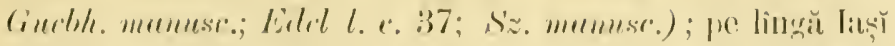

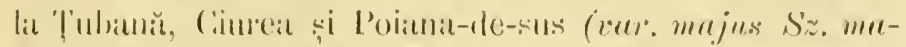

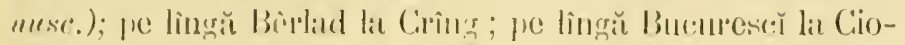

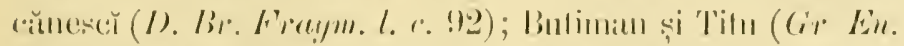

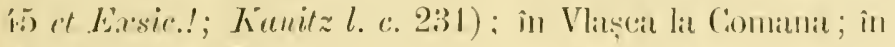
Mehedinṭ̆ la Cernẹ̣ și Iororulota (Gr. Lissic.!); elc. $\odot$ Mniй-Iuliŭ.

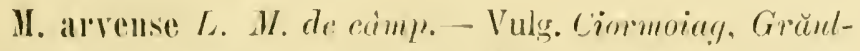

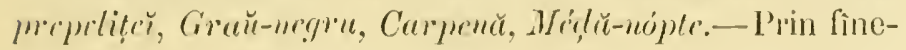

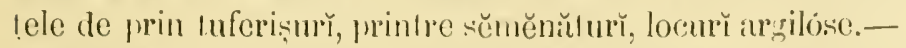

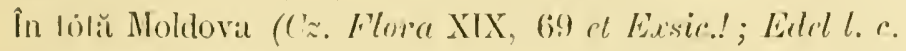

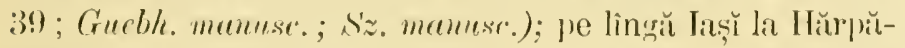

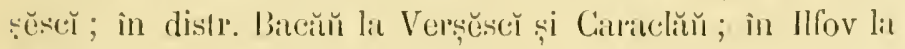
Periş (Gr. Exsic.!); în Vlaçca la Comana; elc. -- of Inniï-Seplemline.

M. barbatum W. Kit. M. bürbess. - P'rintre š̆mĕnă-

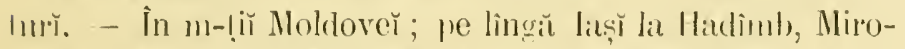

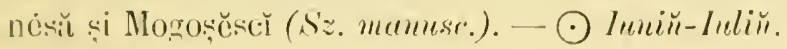

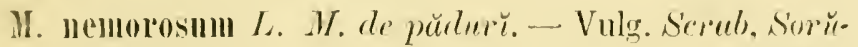

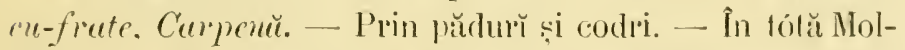
dova (Cz. Flewa XIX, 68 et Exsic.!; Guebh. menusese; Erlel

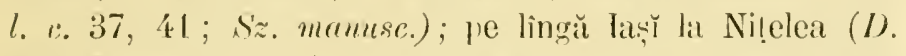
Br. Frarym.l. c. 92); în dumbrava de lia m-stirea Ném!̣-

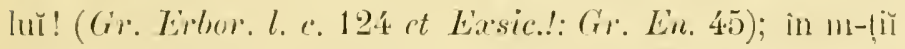

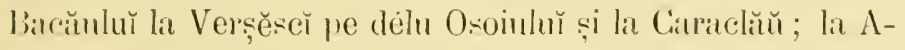
grud (Burri Exsic.!); în distı. Buzen̆ lit Becenı̌ în ph̆durea Ocea (Gr. Eu. 4. et Exsicl; Kanitz l. e. 231); in

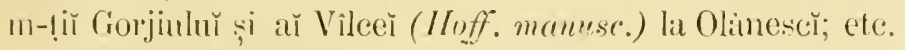

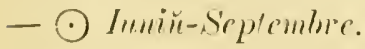

II. pratense $L$. $M$. de fincte - P'rin fineţele de prin băduri și luferișurı̆. - In m-țĭ Moldoveř (Cz. Flora XIX, 68 ; Eitel l. r. 37). - $\odot$ Inиiü-1иegust. 
II. sylvatirum L. M. de codri. - Prin lînețele și pădırile din regiunea subalpină. - - ln Moldova) $C z$. Fora XIX, 68) superioră (ciucbh. manusc.); în m-lị̆ buceğ (Fr. 105). - $\odot$ lenеiй-диeguesl.

I. saxosum Bug. L. de stinč. - Prin locurile slincose și pretróse din regiunca alpină. - Lal fruntaria Mloldover̆ pe Muntele-(iropilor ( $F^{\prime}$ 'ss Fl. 489); pe vîrful Cî̀hlău-

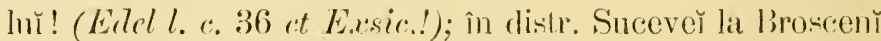
pe vîrfu Barnarulŭ (Burri E.dssic.!); în m-liŭ Buzculıĭ pe vìful Pentelenlŭ. - $\odot$ luliŭ-.lugusst.

\section{PBDICLLARIS L. - Pedicularie.}

P. palustris L. I'. de mlarivint. - P'rin finę̣e mlășinóse. - In Moldova superioră (S'z. Exsic.!; k. j. Cruebh.

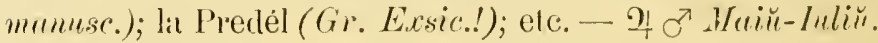

P. comosa L.; P. coronensis Sclur. P. comosă. - Prin lorurile stîncóse și calcare din regianea suhalpină și alpină. - În m-ṭî Buceğ̌ la schitul Pescera de la Jalomiḷı! (Frou. 200 ; Fr. 105); I'. tubrerosa Gr. En. luon L./ st Exsic.!); le vîrful Pentelenlŭ - 2 Inniй-Inliü.

P. (antupestris Giviseb et Sch.; P. pralensis Schur. I'. crempestrŭ. - Prin finețele monlane. - Pe Cétılŭŭ (P. (')mosa Eild l. c. 36 et Exxsir.!); in Museel la Nĕmĕesč̆ (I'. iuberosa Gr. En. 45 / mm L./ ct Exssic.!) si pe Patina-Cin-

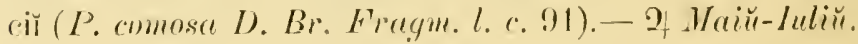

P. exaltata Bess. P. exullulü. - Vulg. Durie. - Prin fimețele din regiunea montană şi subalpină. - In Moldova centrală și superióră la Mănăstirea-Cașinulù! (I) foliosu Gueldh. mamnse. ot Not. manuse. [uem L.7); in m-tị Némtuluй pe Céhlăı̆ (P. foliosa Edel l. e. 36 et Exsic.! ; I’. Secptrum Carolinianum C $C_{z}$. Flora XIX, 68 [nom L.:7 rt Exrsic.!). la schitul Sihla și la m-shlirea Agạpia-în-tél; la

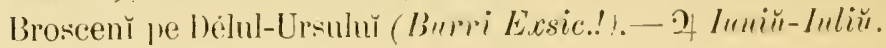




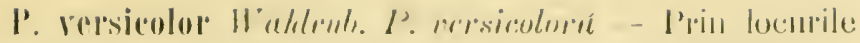

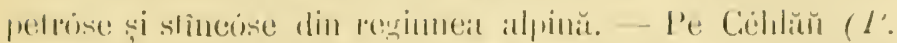

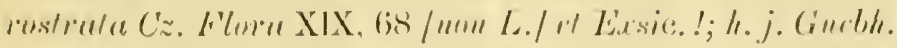

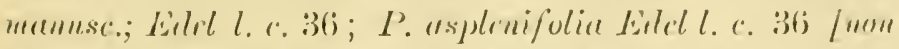

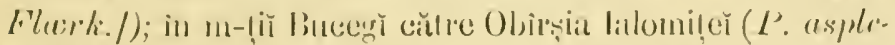

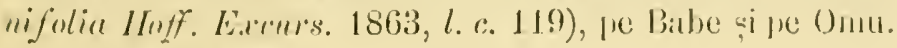
- 2. Inniü-duejust.

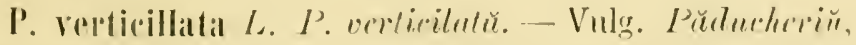

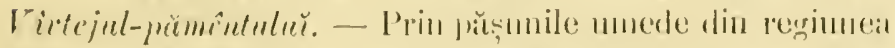
alphint. - În Moldovil (Cz. I.lora XIX, bis et Exsic.!; h.j.

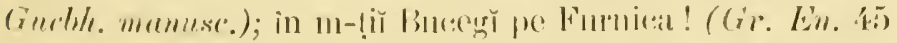

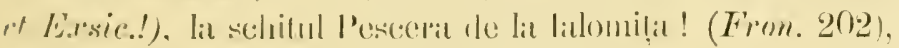

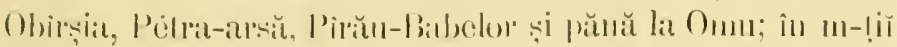

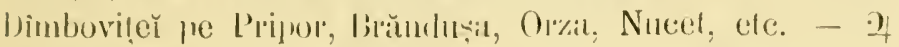
Innik-.luyust.

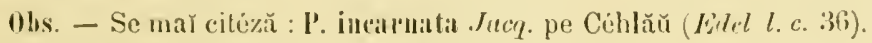
dar acéstio plantă nu exsistă în Firbariul Edelean.

\section{RHINANTHUS L. - Rinunt.}

R. minor Ehrh.; Alectrolophess parviftorus Wallr. R. mic. - Vulg. Clocotič. - Prin finete muntóse. - În Molloval (Cz. Flora XIX, 67 et Exsic.!; R. ylaber B. minom h. j. Guebh. manusc.) in regiunile inferiore ale Célılăuluì! (li. glaber Edtel l. c. 36 it Exsic.!). la Agapia (Gr. En. 4 ert Lasic.!; Kunitz. l. c. 231; R. Crisla galli (rr. Erbor. l. c. 12. și lat m-stirea Nẻm!̣ulı̆ ; pe lingă Jaṣ̆ către Códa-Stîncê̆ și l'oprricanı̆ (Sz. menusc.); în m-lị̆ Bacăulu la Slănic

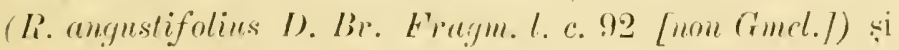

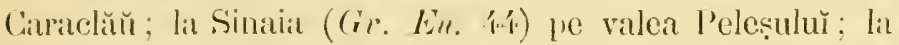

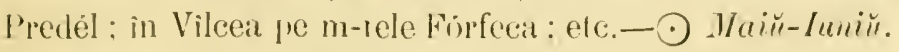

R. Major Elerh.; R. hirsutus Lam.; R. Alectrolophus Poll. - Vulg. Clecutiř̌. - Prin finețe. - În tiŏă Moldova (R. glaber Cz. Flore XIX. 67 et Exsic.!; Guthle manesc.; 
R. hirsules $C z$. Flone XIX, 67 of Exsic. !; Edel l. a. 37 ; (iucble manusc.; R. Crista galli Sz. manusc.): in Prahoval liı Vŭlen (Gr. Ën. 44 ct Exsic.!); in Ilfov la Buftea și Ciocănescĭ ; în Vlaṣca la Comana; în Arges la Stohnič ( $D$. Irr. Froggm. l. c. 92); în Mehedinț̆ Ja Şimnian, Hinova, Cielnelĭ, Jorgntova (Gr. Exsic.!) și între Schelea-Cladover și (iula-văiě̀; elc. - $\odot$ Маій-Imій.

R. alpints Bmy. Re. alpin. - Prin jrạunile din re-

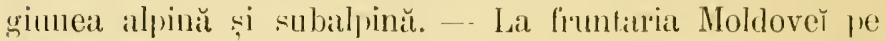

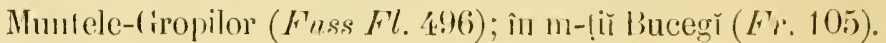
- $\odot$ Inlint-.luglist.

\section{BARTSIA L. - Bertsic.}

B. alpina L. B. alpină. - Vulg. Bursucŭ. - Prin pйșunile şi locurile slineose și mmede din regimnea alpină și subalpină superióră. - Pe Céhlăŭ (Prederota carnléa E-

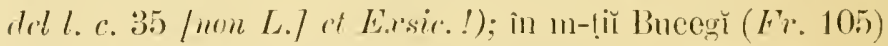

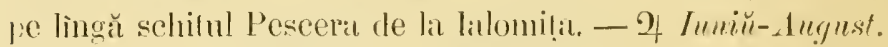

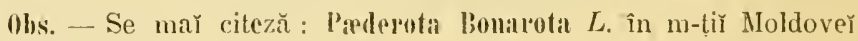
(Sz. Exsic.!)?

\section{EUPIIRASII I. - Eufrasic.}

E. oflicinalis L. E. oficinalü. - Vulg. Burmiță, Burro-

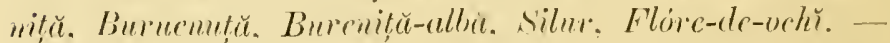

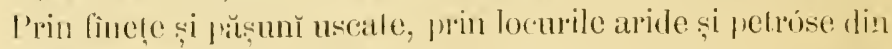
poenile pădurilor și de pe margineat forentelor din munți. fîtuă în reginnea alpină. - In Moldovil (Cz. Flara XIS. 68 et Exsic. !; (z. ct s'z. l. c. 37 ; s'z. mamusc.) (entrată și

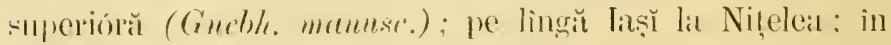
regiunile inferióre ale Cèhlüulur (Edel l. ‘. 36), la Agiıpiiı! și

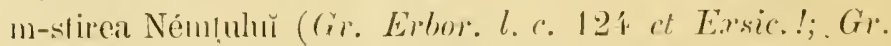

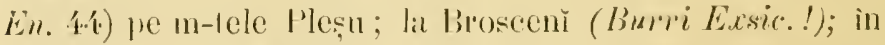

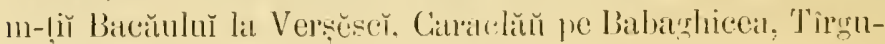




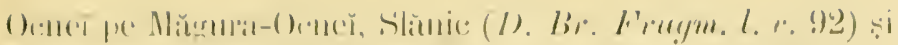

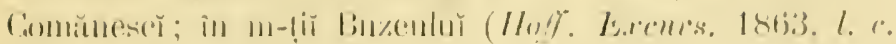

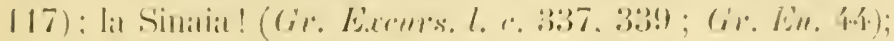

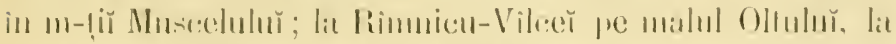

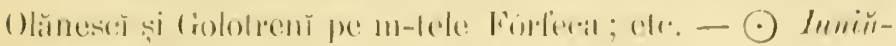
ileyjust.

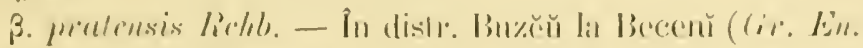

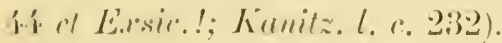

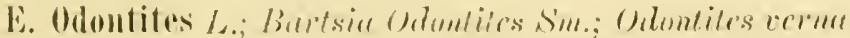

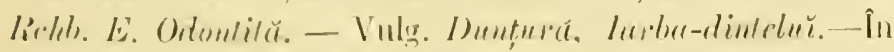

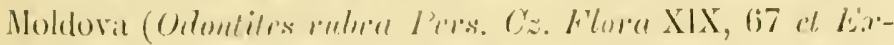

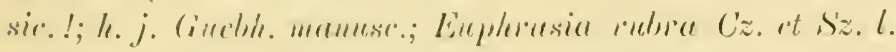

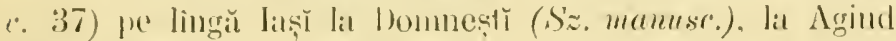

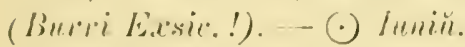

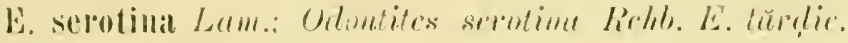

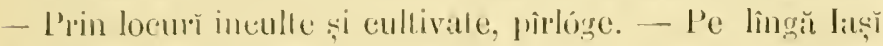

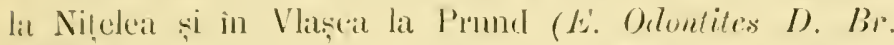

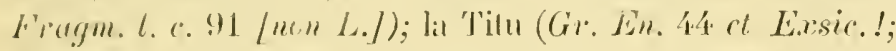
Kuni:z l. ‘. 232); lat Rimmien-Vîlcea şi la m-stireat Horez

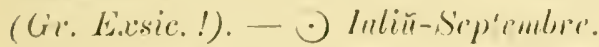

W. Intea L.; Barlsia lutea L. fil. E. galbéntr. - I'rin fi-

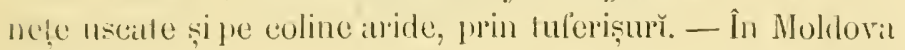

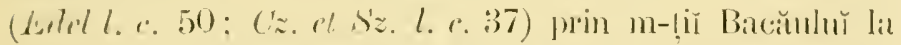

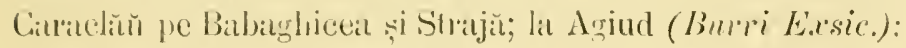

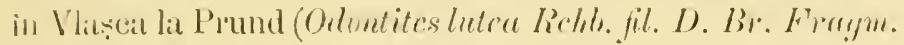

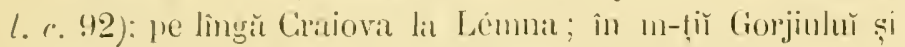

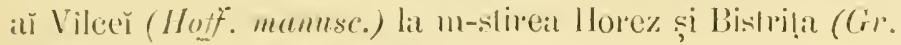
linsir.!). - $\odot$ Juliŭ-Alugust.

\section{MCANTIIACEE.}

\section{ACATHIS I. Acant.}

A. Iougifolius llust. A. cu for lunej. - Vulg. Tulpu-

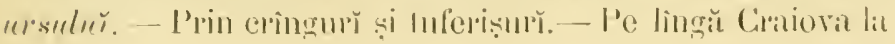


'Teiş; pe lingă T'urmu-Severin la Cerneḷ! (.1. mollis Seleott

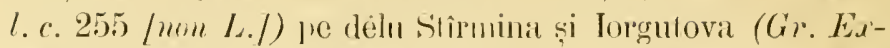
sic.!). și la Vìrciorova călre P’ortile-de-fer! (Janka! sec. Kä-

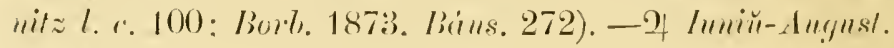

\section{MPOCINACEE.}

\section{VINCI 1. - Vincŭ.}

V. minor L. V.mirä. - Vulg. Cunmit, Merişor, Per-

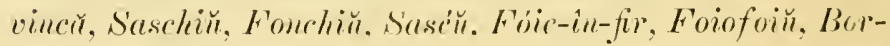

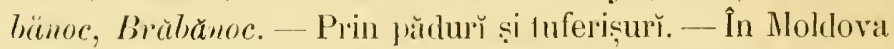
superióră (Cz. Flora XIX, 62 ot E.rsic.!;h.j. Guebh. memusc.; Edtel l. (. 39, 41) pe lìngă laș̆ lit Socola (Sz. mamuse.); pe

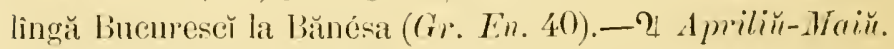

V. Herbarea W. Kit. I. erbaces. - l'e coline aride si

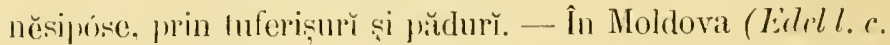
39, 41; Cz. ri s'z. l. с. 9; Sz. manuse.) inferióră (Guch). mannsc. ef Exssic.n. 687 sce. Nym. (omsp. 497); pe lingă Iaș̆ la Niţelea; pe lìnğ Bucurescĕ la Merinani (D. Bre. Hor tym. l. c. 92); în Vlaṣca lia Comana; în Muscel la prilele m-tehı̆ Lereşŭ (Hoff. Excurs. 1862, l. c. 38); în Me-

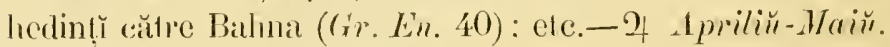

Ohs. - Se mař citéză : V. mutjor L. în Moldova ( $C z$. et Sz. l. c. 9) pe lîngă Jaṣ̆ la m-stirea Stavnic (Sz- momusc.).

\section{IXI. ASCLEPIMUCLE.}

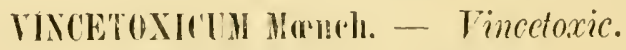

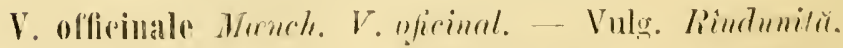

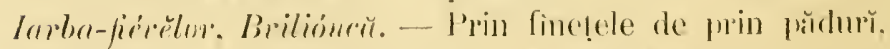

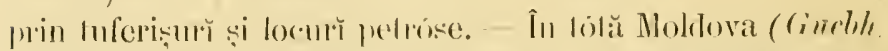

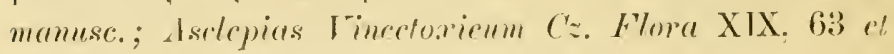




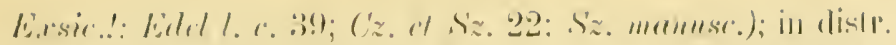

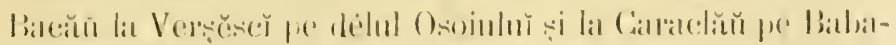

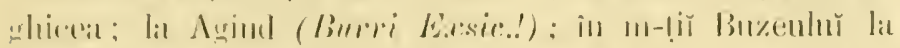

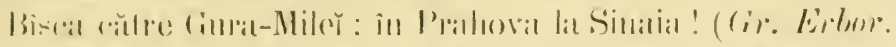

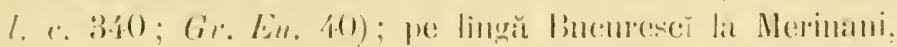

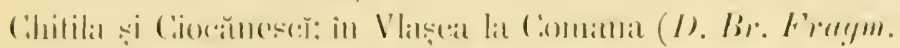

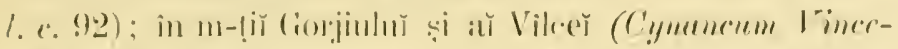

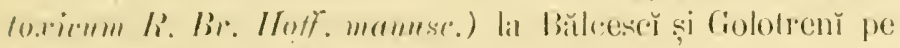
Nalro!: etc. - of shriir-Luliu.

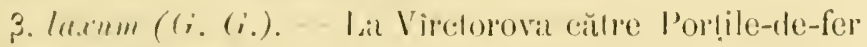
(Bul). sire. Kentitzl. (. 77).

\section{GYINCHUM R. Bir.-- Cinane.}

(i. arutum L. C. asentit. - Prin locmoile něsipose și inculte de pe mallea riurilor. - Î Moldova inferiónă (cimelıh.

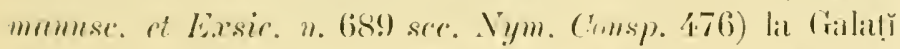

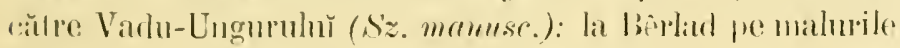

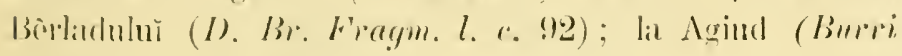
Esisir!!). - o) Inliĭ.

\section{LAI. CONYOLELACEE.}

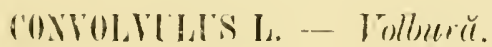

C. sepium L. 1. de garduř̌. - Vulg. C'rpa-iacě. Pe linğ garduř și prin huferișư și pădur umede. - în

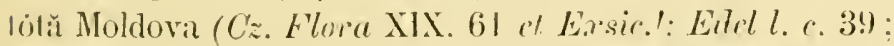

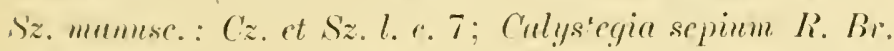
Gurbh. maunsc.): pe lìngă lặ̣ la Nițelea: pe lingă Bêrlad;

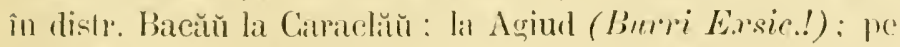

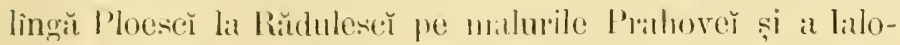

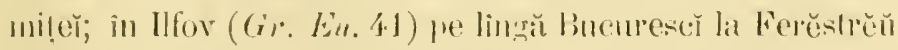

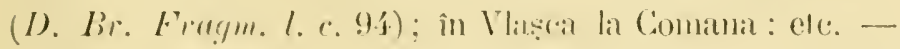
4 Inniü-Seplembie. 


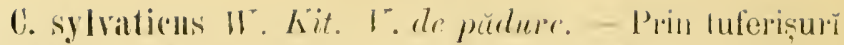
si püdurı̌. - In Moldova (Cz. Flora XIX, 63; Cz. et Sz. l. ¿ 7) pe lingă laș̆ la liěcea (Sz. mamusc.); in Vlașẹ la Co-

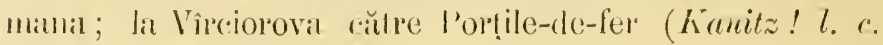

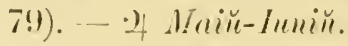

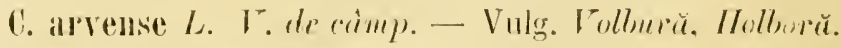

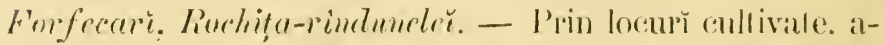

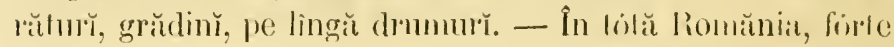

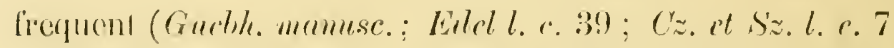
rt Exsic!! Sz. mamusc.; D. Br. Fragm. l. r. 9'; Gr. Erbon. l. c. 123; Gr. En. 41 ; Kanita! l. c. 79). - 9 lıniri-lingusl.

C. cantabrica L. I. de Cautabria. - Prin loemrile petróse şi aride. - La Vircioroval către Porțile-rle-fer" ! Schurt l. 1. 248: Kanitz! l. e. 79) pe m-lele Si-Petro. La Crma-

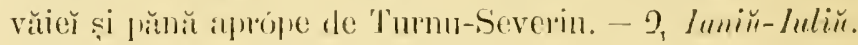

\section{CUSCUTA I. - Cuscută.}

C. europara L. C. de Europra. - Vulg. Torlicl. Turtel.

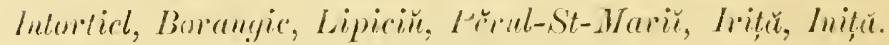

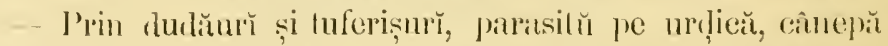
heneiŭ și alte plante. - În tô̆ Romănia (1'z. Floro XIX', 61 et Eirsic.!; EAtel l. r. 3!); Sz. mumese.; (ro. Erbor. l. c. 123; Cr. En. 41 ; C. major D) C. Gurbh. manuse; D. Br. Fragm.l. c. 94). - $\bigcirc$ Inliü-1nyust.

C. Epithymum L.; C'. minor DC: C. mică. - P'pin linetele nsiale din munțĭ, parasilŭ pe thyуm, trifoin̆, genistĭ, erică și alte plante. - În mă lolă Romănia! (Cz. F'lora

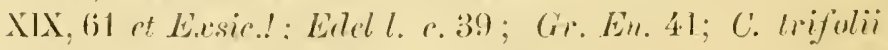
(ir. En. 41 / non Bali.l?). - O Inliü-Augnst.

G. Epilinum Ш ciln. C. imuluĕ. - I'rin sĕměnăhurile de

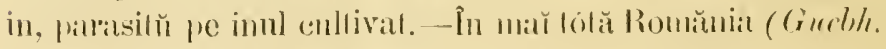
mannsc.). $-\odot$ luliü-luegrest. 


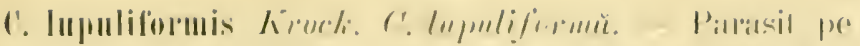

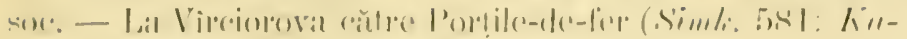

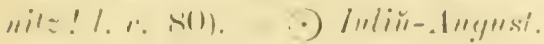

\section{L.XII. BORIGINALER.}

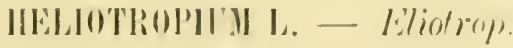

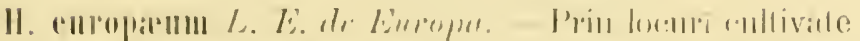

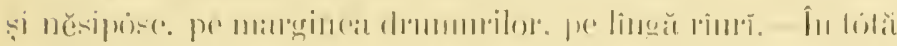

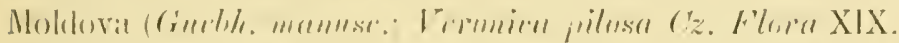

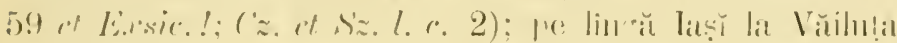

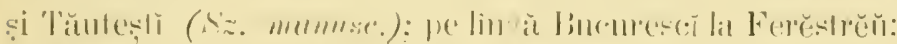

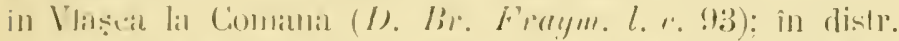

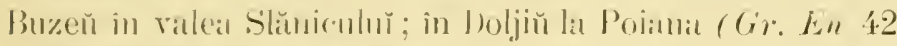

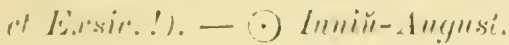

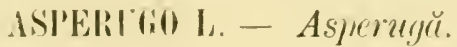

A. produmbens L. .1. procumbentá. - Vulg. Lipiciósč.

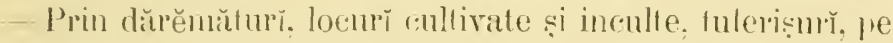

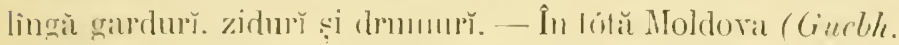

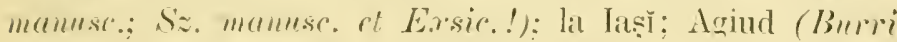
E.rsic.!) : pe lingră Bucurescŭ (Gr. En. 42 r' Exrsic.!) la

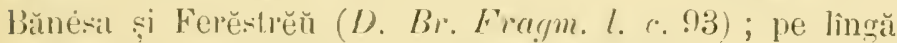
Cratioval lat Moflenī; etc. - $\odot$ Iraiй-Imiй.

\section{ECHINOSPERIIIII SWall. - Echinosperm.}

E. Lappula L. LA. Lapmlĭ. - Prin locurì nĕsipóse și aride. cultivate și inculle. pe liner drunuri si pe coline u-

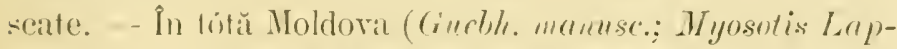

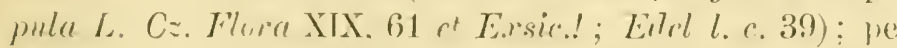

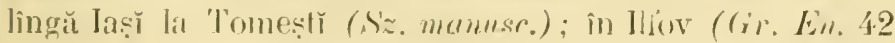


et Exsic.!); re linği Bucurescĭ la Ferěstrěŭ și Ciocănescŏ (D) Br. Fragm. l. r. 94) ; în Vlaṣea liı Comana; la Virreiorova călre Portile-de-fer (Kanitz! l. r. 80) și pe malıl bu-

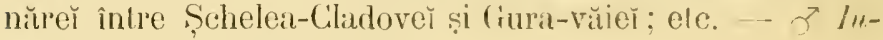
mili-itugust.

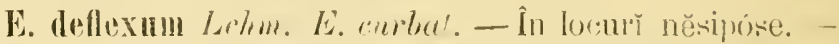

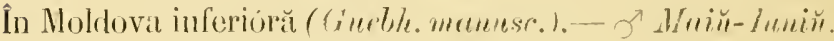

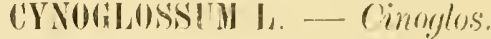

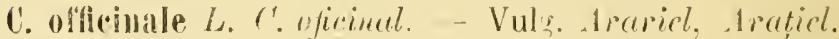
Limbu-cinclur. - Pe coline uscille, prin locurĭ inculle ste-

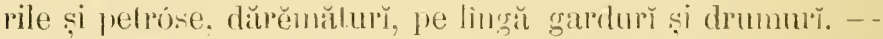

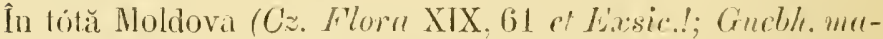
nusc.; Ettel l. с. 39; Sz. mennsc.; C. sigleaticum Cz. Floma XIX. 61 / non Honke/ ot E.rsic.!); lat lașĭ ; Palanca; Agiud (Burri Fase.!); in Prahova la Sinaia ((tr. En. 42 pt kix-

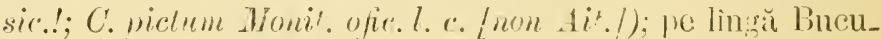
rescĭ la Bănésa și Ferĕstrĕŭ; ìn Vlaṣca la Comanat ; etc. or Main-Luliu.

C. montanum Lam. C. monlan.- Prin pădurile din regiunea montană. - În toltă Molduva (C. sylraticum Sim. Gurbh. manuse.): la Vîrciorova către Por!̣le-re-fer (c.gremanicum Jacq. Burb. 1873, Bïns. 270). - o Maĭt-Iuliü.

\section{MA'TIA Schult. - Mattie.}

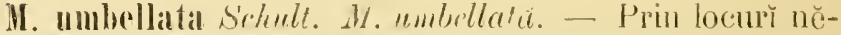
sipóse. - În Moldova (C'ynuglossnm umbellatum II. Kï.

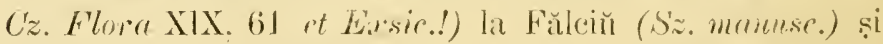

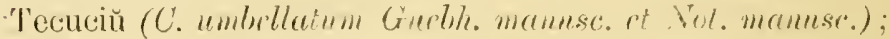
in Mehedinṭi la Vinjule!-Rogoval (Gir. Lin. 42 rt Lissic.!; Kraniz l. c. 227). - M(niĭ-Inieit.

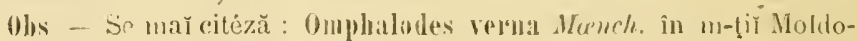
veǐ (C'ynoglossum. Omphulodes L. Ėlé l. r. 37). dar acéstă plantă n'am găsit'o ît Erbariul Edelean. 


\section{AN'IIIS'L I. - Anmust.}

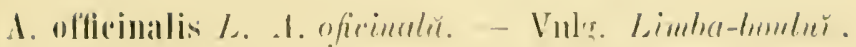

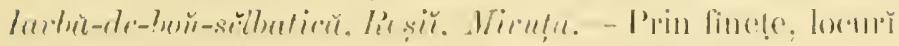

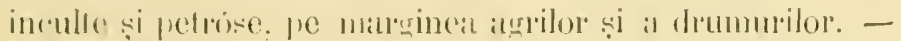

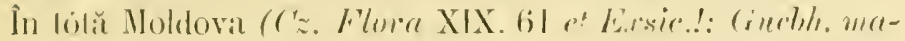

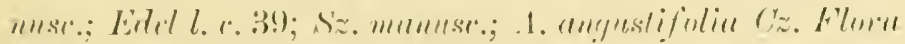

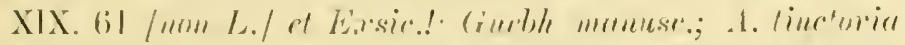

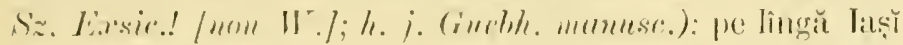

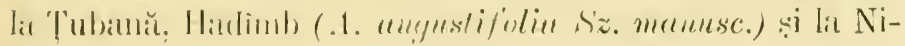

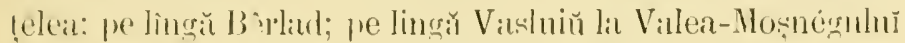

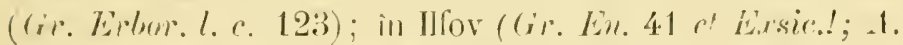

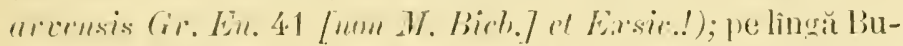

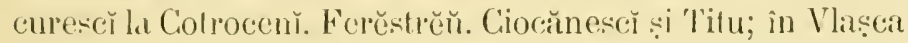
la Comana (I). Br. Frorgm. l. c. 93); în Vỉlcea liı Bălcesè̃

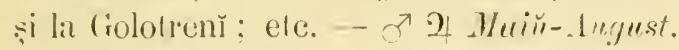

A. ochrolencal M. Biel. .1. galberna. - Prin finețe ste-

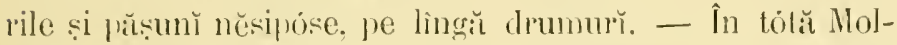
dova (C. Flore XIX, 61 et Exsic.!; Eddel l. c. 39; Gucbh.

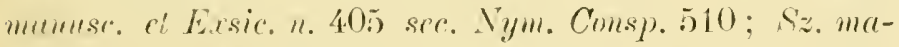
nusc.); pe lingă laș̆ la Busium, Petrăria-Repeder și la Hăr-

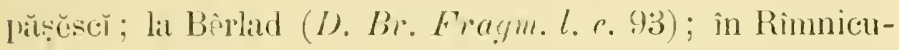

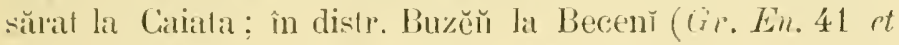
E.rsic.!; Kunitz l. c. 227); pe lîngă Bucurescĭ la Bănésa; în

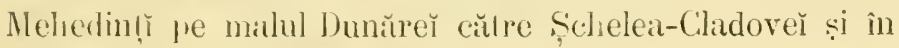
valea Bahneí; efc. - o Marĭ-Alugust.

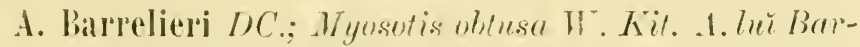
rrlier. - Prin tuferișurile de pe colinele petróse. - În Moldovil (Cz. Floru XIX. 61 et Errsic.! ; Edel l. e. 39;

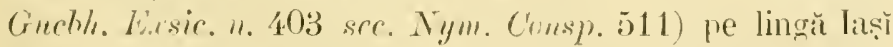

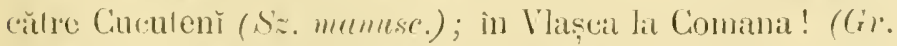
Ersic.!): lil Virciorova călre Portile-tc-fer! (Borl). 1873, Büns. 270). - 2 Inniü-luliur. 


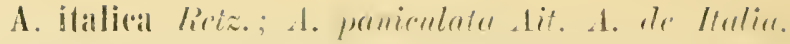

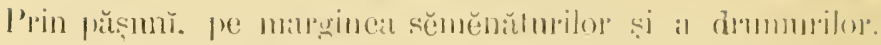

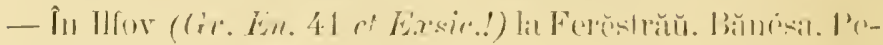

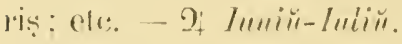

A arvensis .V. Bich. A. de coimp. - Prin locurì calti-

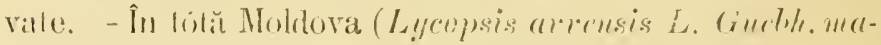

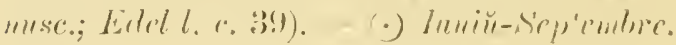

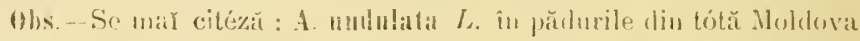

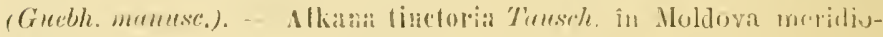

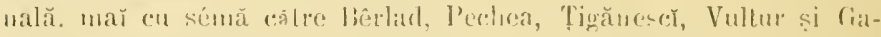

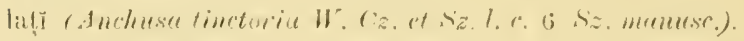

\section{NoNTEL Hedir. - Noner.}

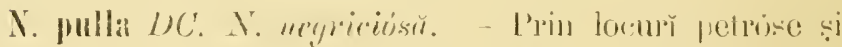

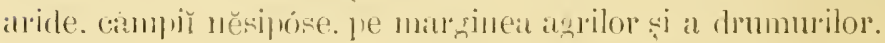
- În Moldovir centrală și smperioră (Gueblh. momuse. ot Exx-

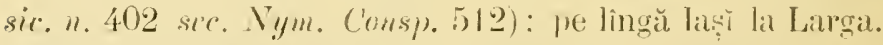

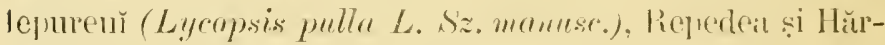

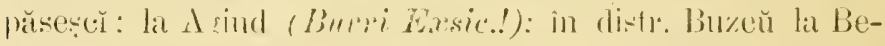

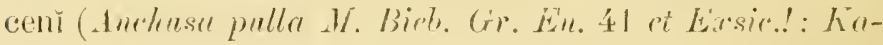

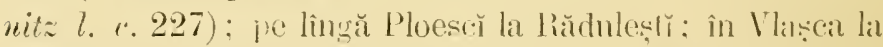

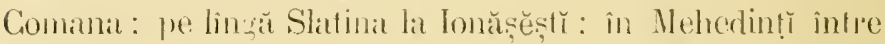

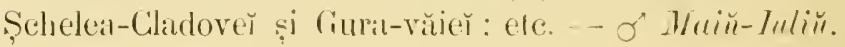

\section{SIMPIYTLIL L. Simfit.}

S. oflicinale L. S'. oficinal. - Vuls. Trétĕuésă. Iarbalui-Tulin. - Prin finetele mnede, ne malurile rimpilor. a pîrăilor și a bătṭilor. - In tótă Romănia! (C'z. Flora

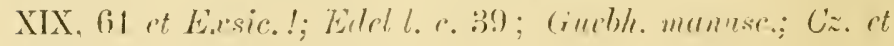

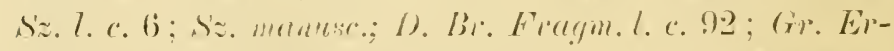

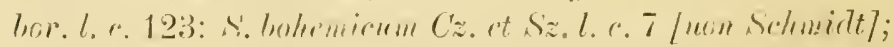

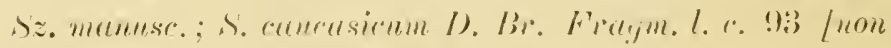

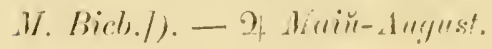




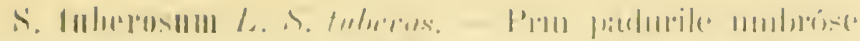

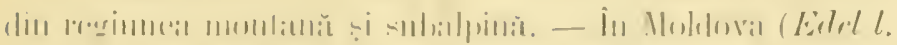

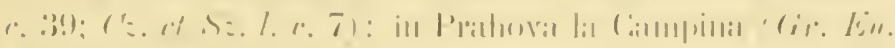

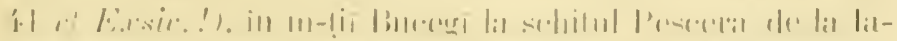

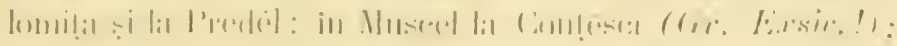

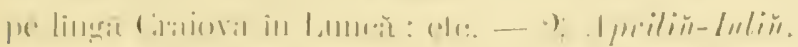

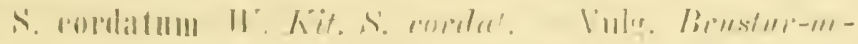

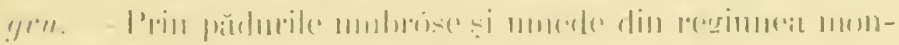
lallit

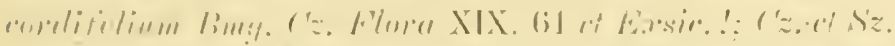

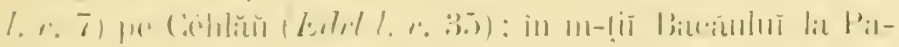

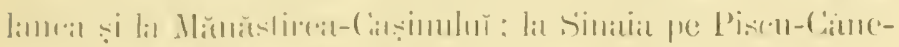

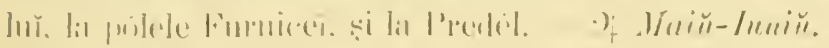

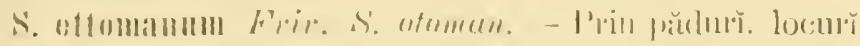

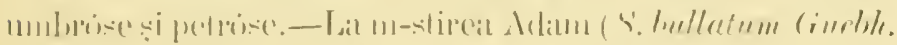

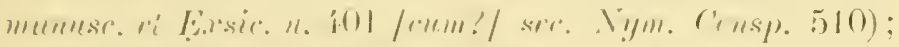

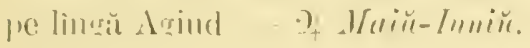

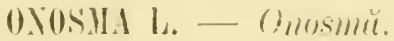

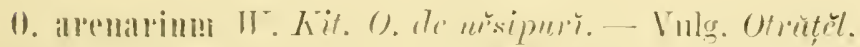
Burunta. - P’rin finelcle și păsunile uriate: pe colinele și

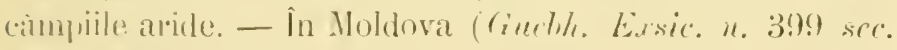

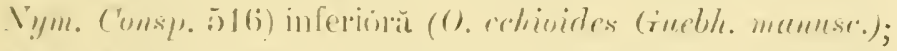

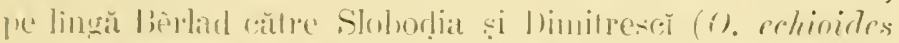

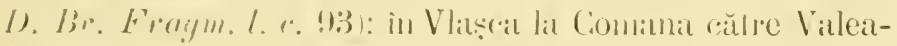
fiumbilmuluí. - o Inniir-Inliü.

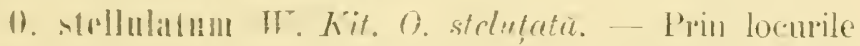

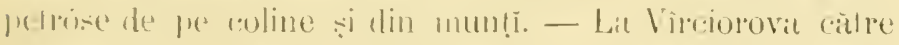

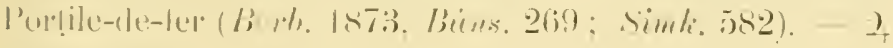
Juniir-Inliii.

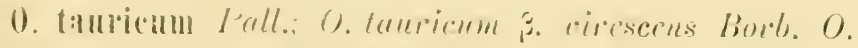

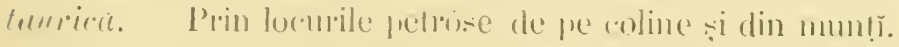

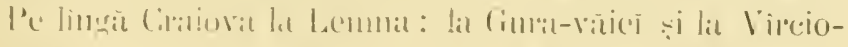

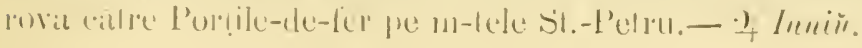


CERINTHE $\mathrm{I}_{.}-$Cerinte.

O. minor L. ('. mirä. - Vulg. P'idosnic, S'ommorisă. Crrtiticu. - Prin fincte, luferișur, pe marginea agrilor ș̣ a drumurilor. - In tótă Moldova (Couebh. manuse.; f'. aspera

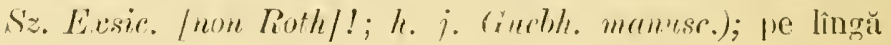

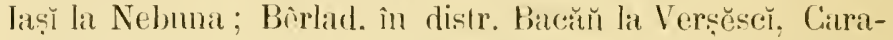

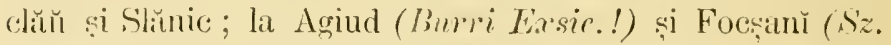
mamsc.): pe lingă Bucuresc: (Gr. En. 41) în Judesč și la Bănésa și Ferĕstrĕŭ pe malul Colentineĭ (D. Br. Frarm.l.

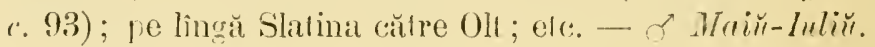

C. aspera hoth. C. asprü. - Prin locuri cultivale și pe narginea agrilor. - In Moldova (Cz. Flora XIX, 61 et E.rsice!; C. mator Sz. Exsic.!; h.j. Gucbh. manuse.; Edel l.

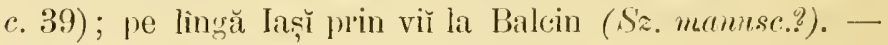
() Imniй-!nlim.

\section{E'IIIIY I. .... Erhiй.}

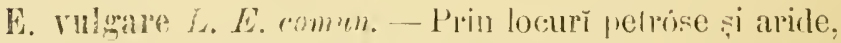
pîrlóge, câmpii, agriŭ, locuř inculte, ve lînğ̆ zidurǐ și dru-

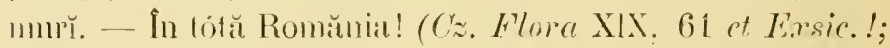

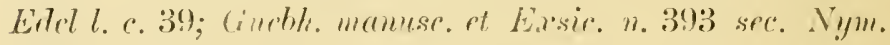

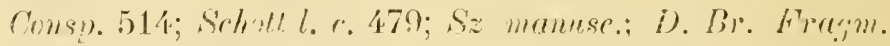

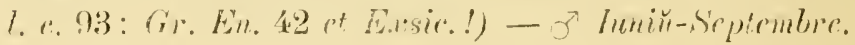

E. rubrum Jucy. E. ros". - Prin finete uscate, pe coline aride i nĕsiprose. -- In tólă Moldova (Cz. Flona XIX, 61

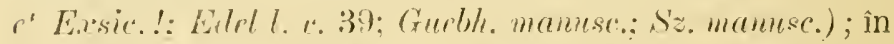

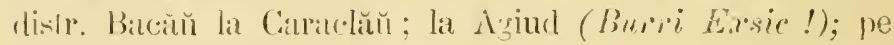

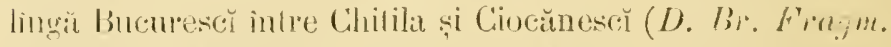

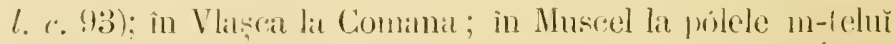

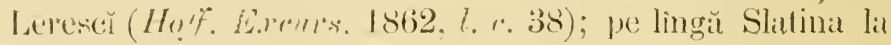

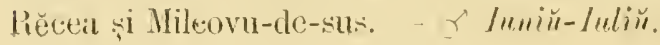


E. altissimmu L.; L. asprerimm H. Birh. (nom Lam.).

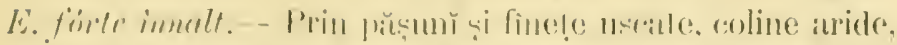

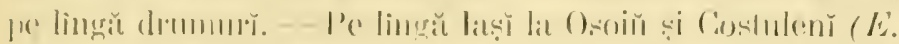

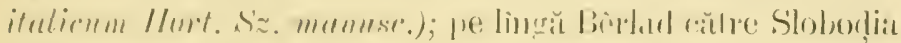

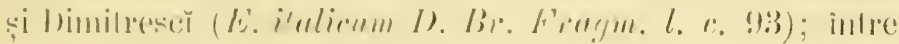

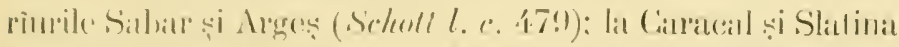

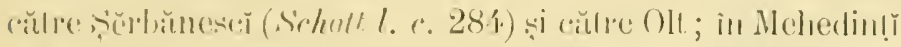

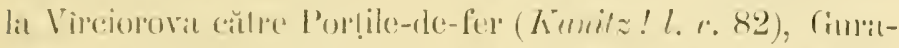

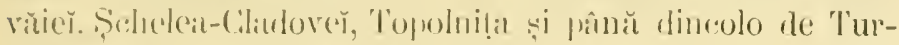
nu-Severin. - ₹ luniü-.lugns'.

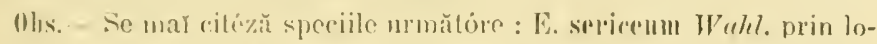

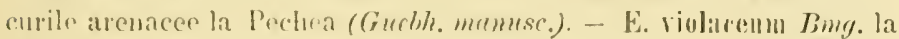
Moinescy și Tipeleștr (Sz. mamuse.).

\section{PULMOSIRIA I. - Pulmonarie.}

P. officinalis L. P. oficinalü. - Vulg. Llmminărieŭ.

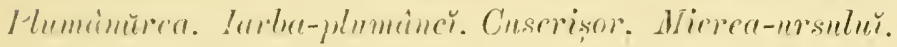
- Prin prufurile mubróse și umede. - In lótă Noldova

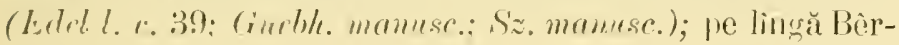
lad lat Crîne (I). Br. Fragm. l. c. 93); in Prahova la

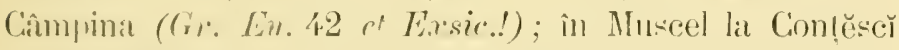

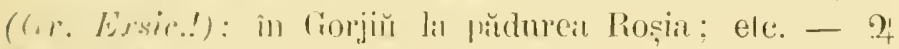
Iarliй-liniй.

I'. mollis Wolff. I'. móle. - Prin gădurile și :uferisupile mulurise. - In litĭ Moldova (Cz. Flona XIX, 61 ot

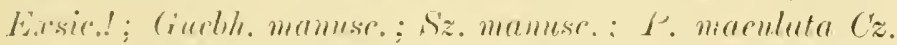

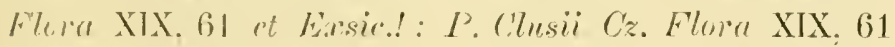

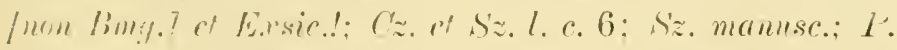

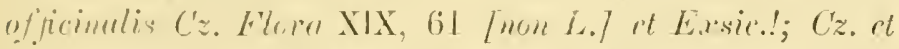

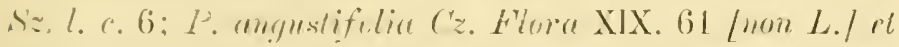

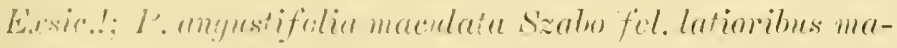

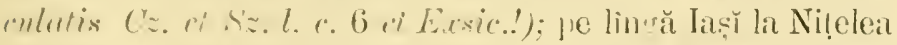

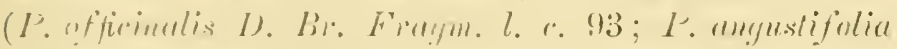
1). Br. Fromm. I. (. 93); la Agiud (Burri Earsic.!); în 


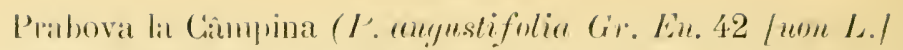

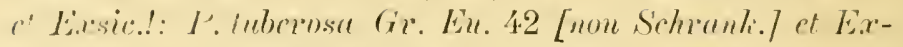

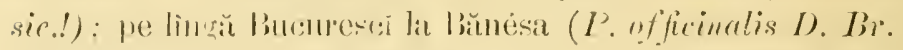

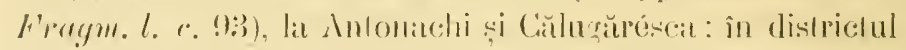

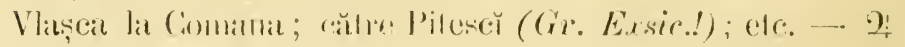
Apriliü-d/ain.

P. rubra scholl. P. rosir. - I'pin lorarile mode si umbrise și pe lîngă torentele din părlurile subalpine. - In

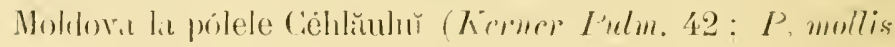

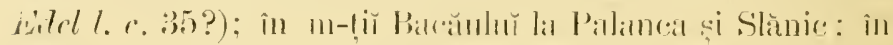
Prahova la Simaia pe villea Polesulur̆ la prilele Furnicer și

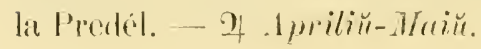

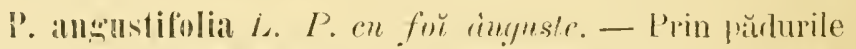

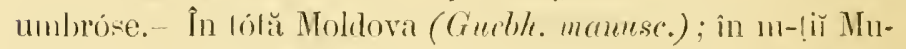

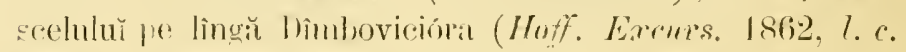

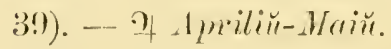

\section{LTHOSPERUIU L. - Litosperm.}

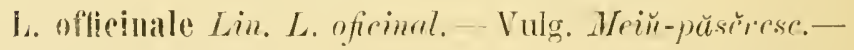
L'rin locurí aride ci pelrise, prin tuferismile rle pe coline.--

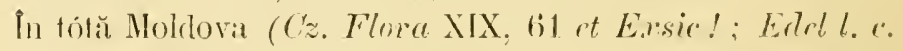

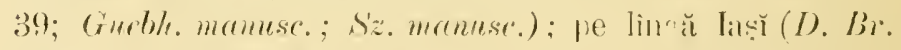

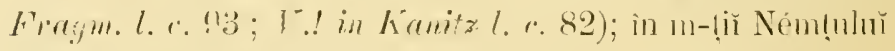
pe linsă Pélră la Fabrič̆ și rătre Hangu la frura-schilnlur

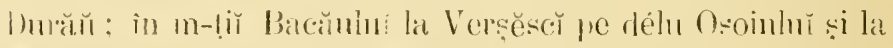

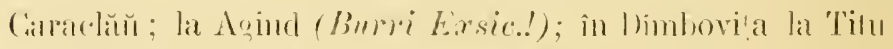
(Gr. Eu. 4 l ot Liesic.!); etc. - - H Haiи-Inliü.

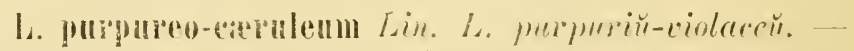

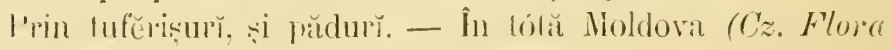

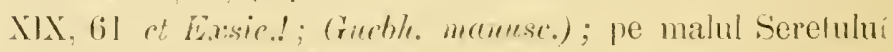

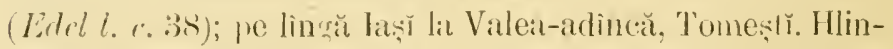

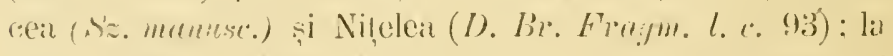

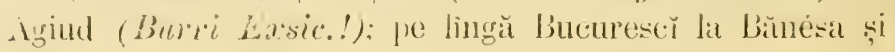




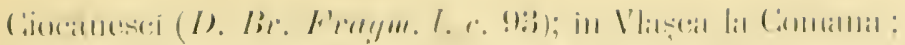

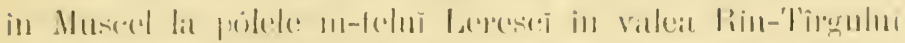

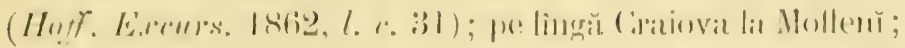

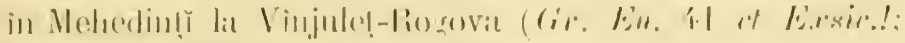

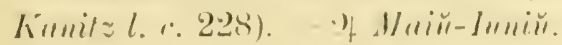

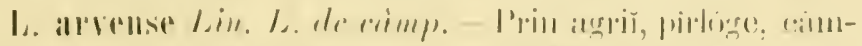

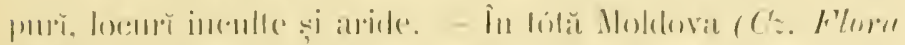

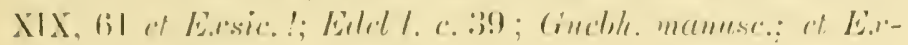

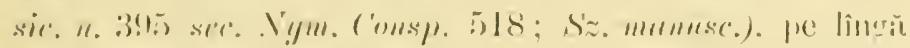

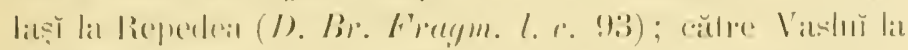

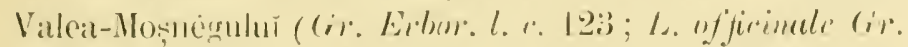

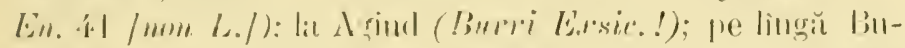

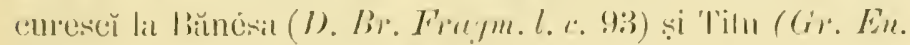

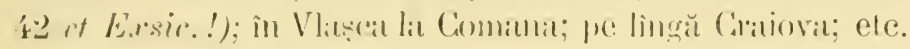

() Ipriliü-Inniu.

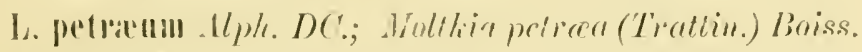

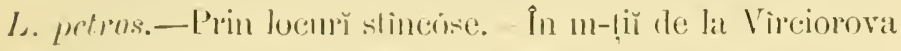

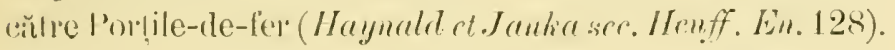

\section{MYosotes L. - Mireti.}

II. palustris Wither. M. de mlesstint. - Vulg. Ochint-

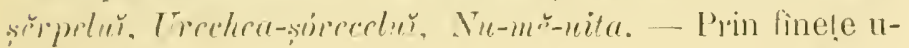

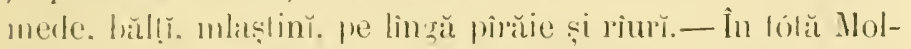

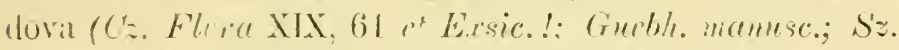

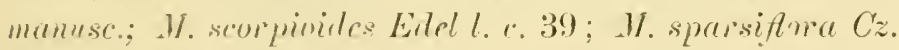

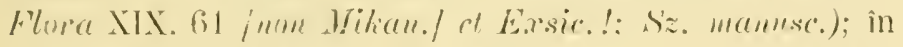

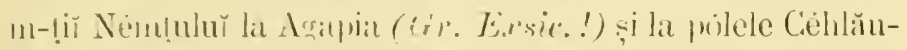

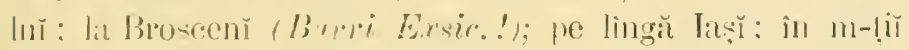

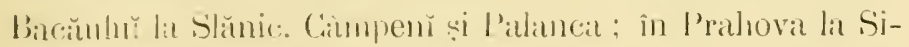

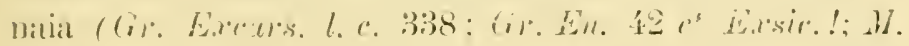

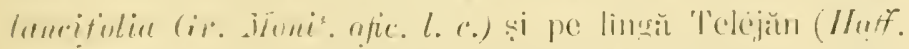

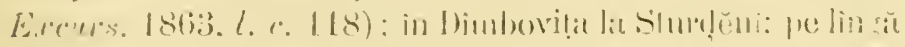

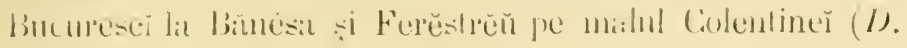




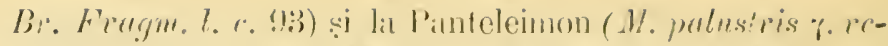

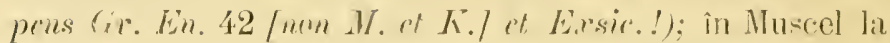

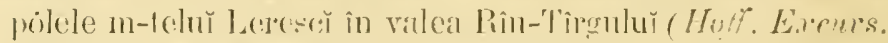

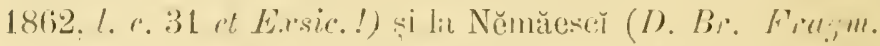

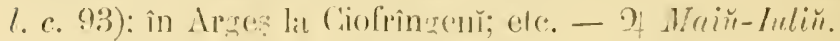

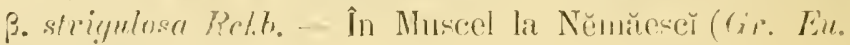

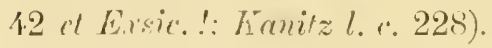

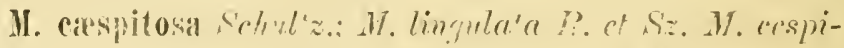

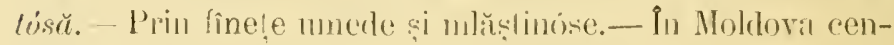

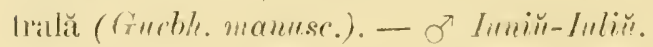

M. sylvatiea $\mid H_{0}, \Phi_{m}$. M. de pridure. - Prin pădunile din regiunea montană si sulalpină. - In Moldova (er. Flower

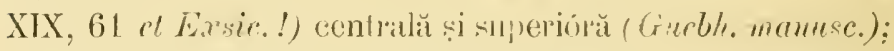
pe lîngă Jaș̆ la Piciorn-Lupulŭ (Sz. menuse.); la Sinaia pe la pólele Furniceř în Inucegı̌ la schilui Pescera de la Jalomiḷ și la Predél pe Susaiŭ. - o Main-Inliur.

3. lartra Bömingh. - În m-lị̂ Bucegĭ pe Furnica.

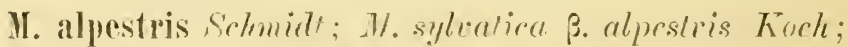

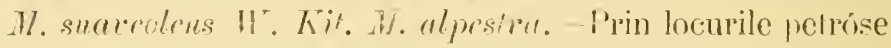

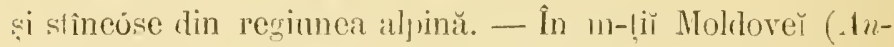

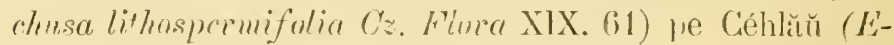

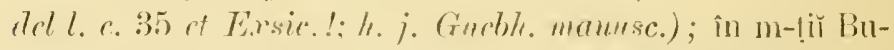

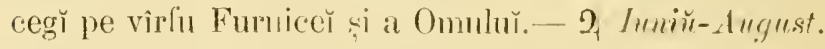

M. intermedia Liuk. M. intermotiur. - Prin păşnı̆,

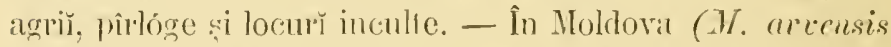
Roth Cz. Flora XIX, 61 ol Errsir.!; Edel l. e. 39; h.j. Gurbh. manuse.; Sz. memuse.) la m-stirea Agaplia și Vara-

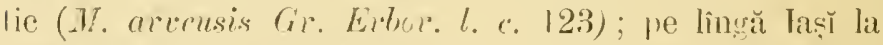

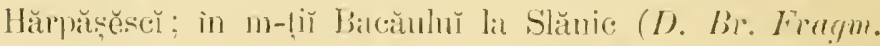
1. c. 93); in dis:11. Buzĕŭ la Becenŭ (.M. sicula Gr. En. 42

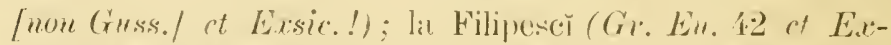

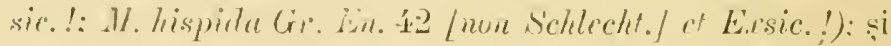

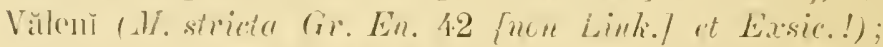

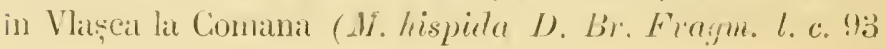




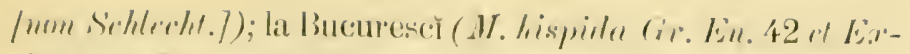

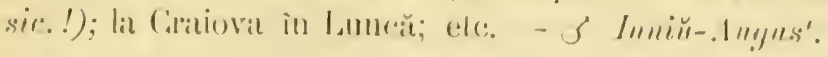

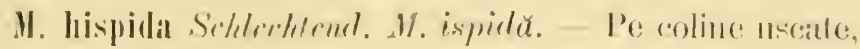

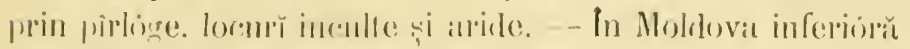

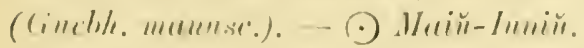

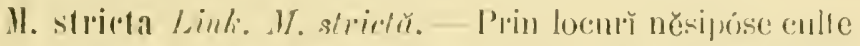

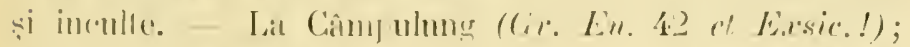

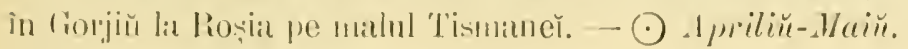

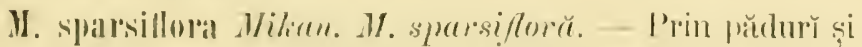
luferișurr unnede. - La m-stireat Adim (Giurbh. manusc.);

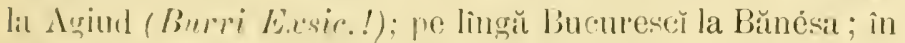

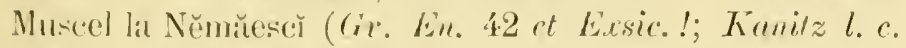

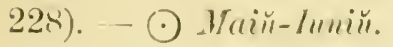

\section{ERITRICIIIM Solard. - Eritrichiu.}

E. villosum Bunge. E. vilos. - Pe stîncile din reginnea

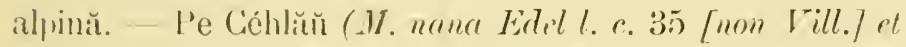

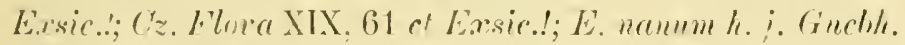

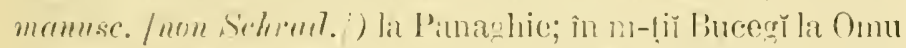

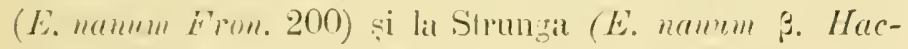

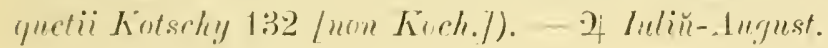

\section{IXIY. VERBENACEE.}

\section{VERBENA L. - Vertină.}

V. officinalis L. T. oficinale. - Vulg. Sporiciü, Spo-

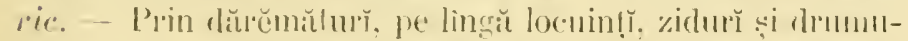

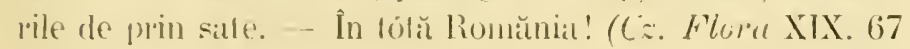

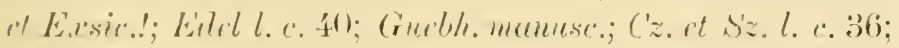

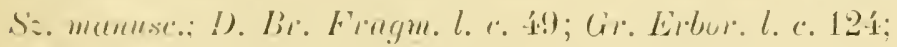

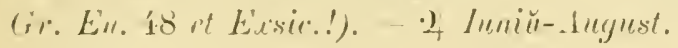




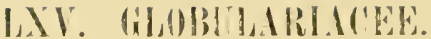

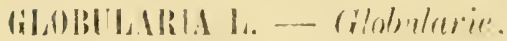

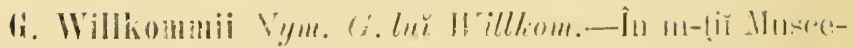

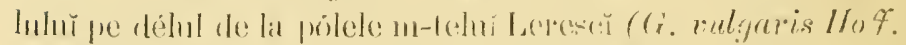

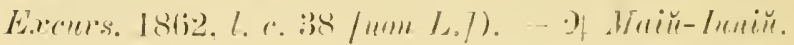

\section{HXT. HIBIIEF.}

\section{IRYT!! ! - Minti.}

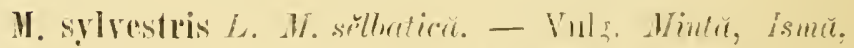

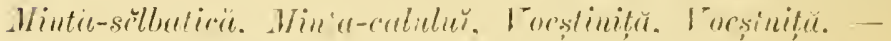

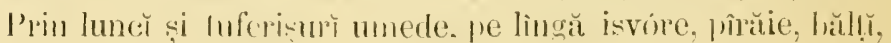
ve malurile rîurilor çi a girlelor. - In tilĭ România forte frequentă (Cz. F'lore XIX, 67 et Exsice!; Eildel l. r. 40;

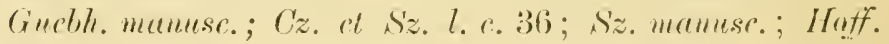
manusc of Eirsic.! ; Lanie l. c. 232; (ir. En. 45) it Exsic.!; Nym. Cimsp. 595; M. nemorosa Cz. Flora XIX, 67 Luon Sclerel). nec Willd.]; ('z. et S'z. l. c. 36; Sz. menusc.;

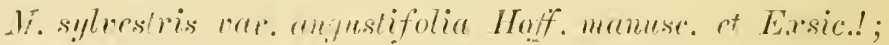

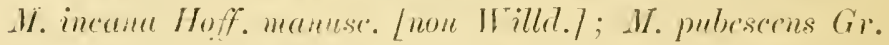

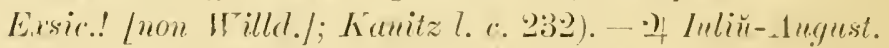

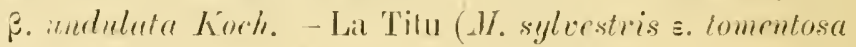
Hoppe Gr. E.rsic.!; Kanilz l. (. 232).

\%.glaber koch: M. viridis luet. germ. - In lótă Nol-

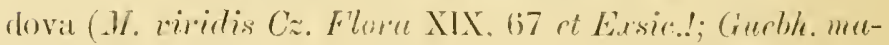

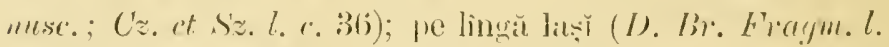

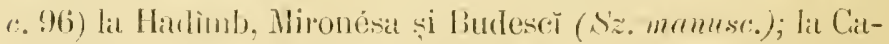
latelŭn: in Vilceat inlre m-stirea bistrila și Horez (Gr. E.rsic.!): elc:

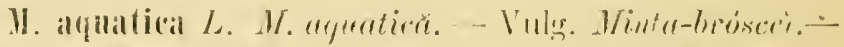

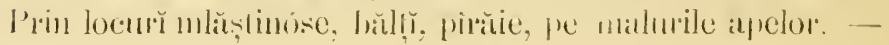




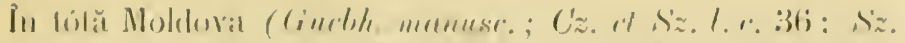

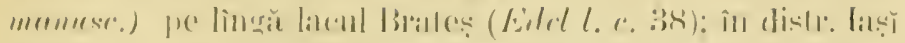

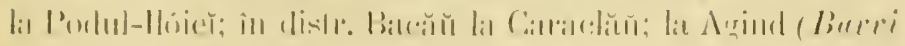

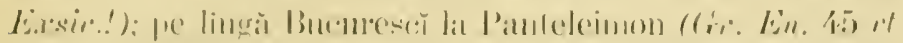

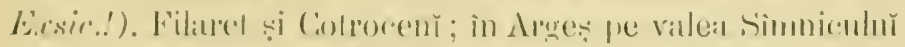

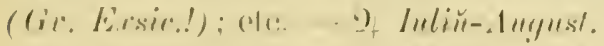

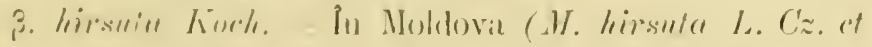

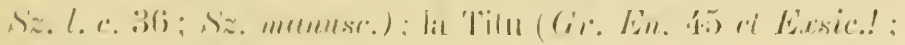

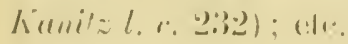

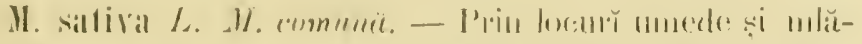

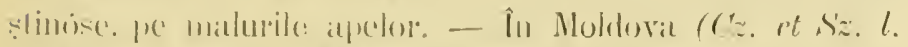

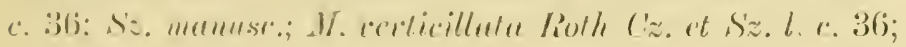

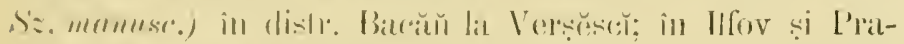

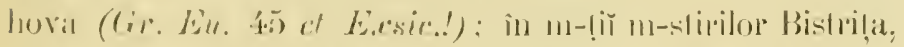

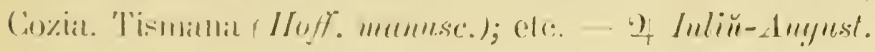

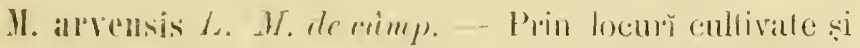

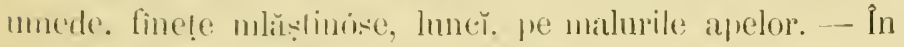

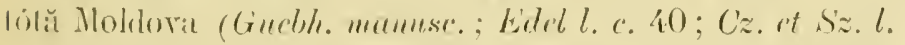

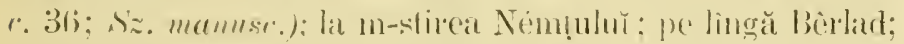

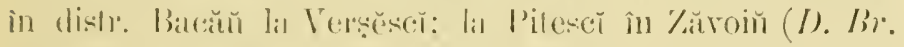

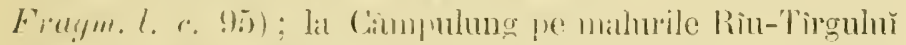

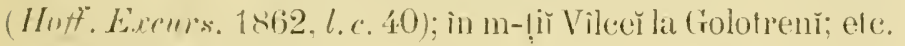
- Inliu- luegusi.

II. Puleginus L.; Pulegium vulyare Mill. M. P'uleriou. - Vulg. Busuincu-cerbilur. - Prin hăbị și locuri mbăı̣i-

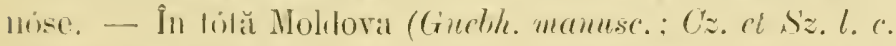

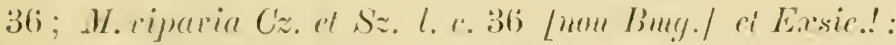

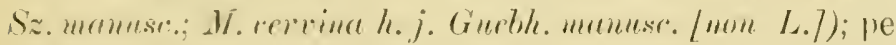

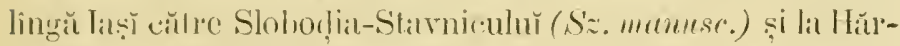

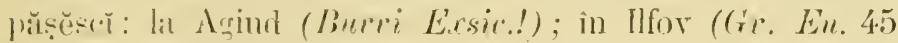
ot E.rsic.!) pe lingă Jüureser la Colrocent și Merinani;

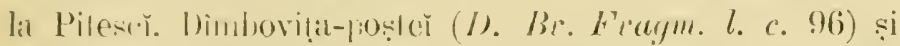

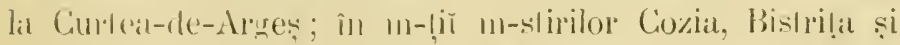

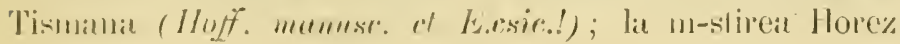




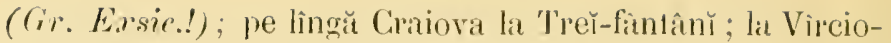
rova către l'on!lile-rle-fer (Kanitz! l. c. 92); elc. - 9 Inlïi-d ligust.

0ßs. 1. - Se maĩ citéză speciile următóre : M. protumlifolia $I$. in Moldova $(C z$. "t $S z$. l. c. 36 ; Sz. munuse) la Agapia (Gr. Erbor. l. c. 125 et Lin. 45?). - H. gratiosima Bing. în Moldora (Cz.

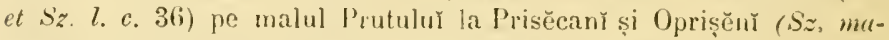
nusc.). - H. serotina Ten. în Oltenia (Holf. menusc.). - M. nigricuns Bmy. in Moldova (Cz. et Sz. l. c. 366). - H. anstrialeit . Jucq. în Noldova (Cz. et Sz. l. c. 3í) pe malul Prutulut (sz. manusc.). 11. gentilis: Eing. in Molılova (Cz. ct Sz. l. c. 36) pe lînğ lași către Starnic și Slobodia (Sz. maniss.).

0hs. 2. - Se cultivă : II. piperita L. (Guebh. manusc. Gis. Ein. 45). - H. crispa L. (Cz. et Siz. l. c. 36). vulg. Mintr̆-créțir.

\section{LYCOPUS L. - Licop.}

L. europaets Lin. L. de Europa. - Vulg. Cervana. Ciorvana. - Prin locurı̌ umede. luncĭ, băl!̣̆. pùrăie, pe malurile gărlelor. - În lólă Noldova (C z. Flora XIX. 60 ct

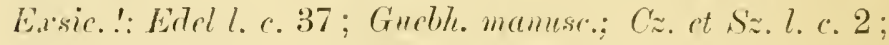

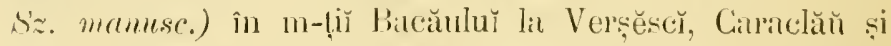
Slănic; la Agiud (Berri Exsic.!); la Sinata (Gr. En. 45 et Exsic.!); la (ihersaň; Pitescr ; Cìmpuhng; în m-liĭ Gor-

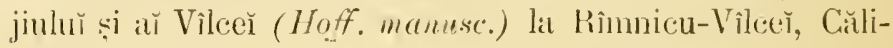

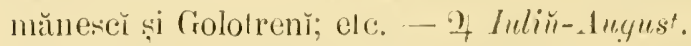

L. exallatus Lin. L. cxaltat. - Prin locurĭ monede, luncì: bălṭ̆. pîrŭie, pe malurile gîrlelor. - In Moldova (c: $\approx$. Fluru XIX. 60 ot livesir.!; ('z. ct Sz. l. c. 2 ; Sz. manusc.) inferióră (Gumbh. manusc.); pe lingă laṣ̆ la Nị̣elea (D). Br.

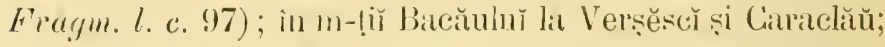

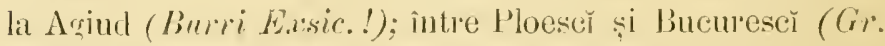

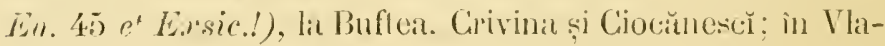
șea la Comant și Prund; în Argeş la Picioru-Faguluŏ; pe lingă Graiova la Bréstal; în Vileea la Büleeseñ : efc. - 2 Inliü-Inegust. 
S.11,11.1 1. s sülic.

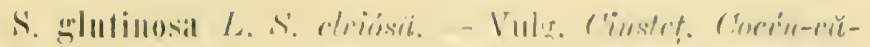

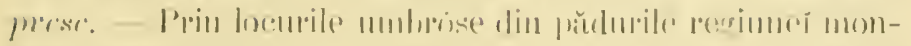

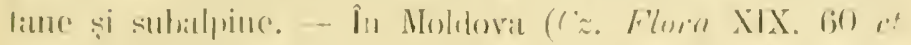

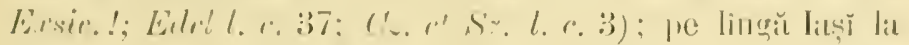

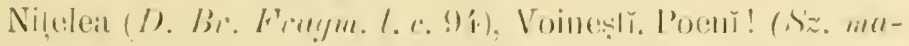

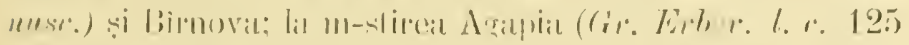

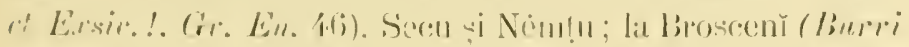

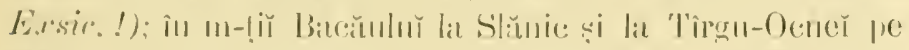

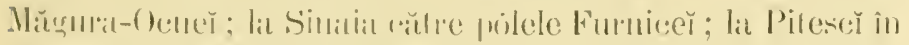

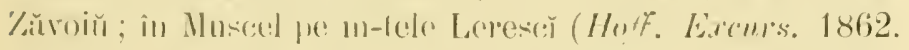

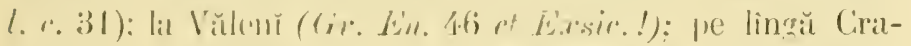

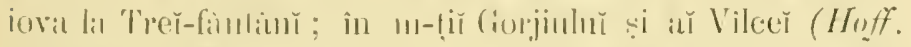

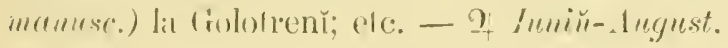

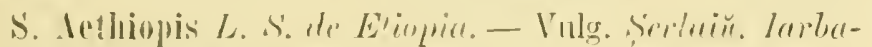

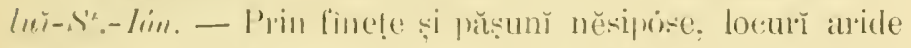

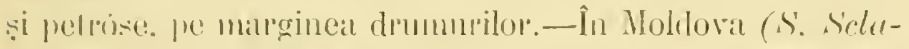

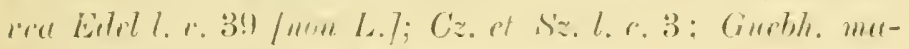

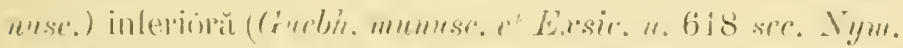

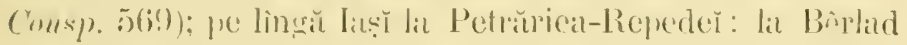
pe déln destre Cring (D. Br. Fragm. I. c. 94): pe lingă

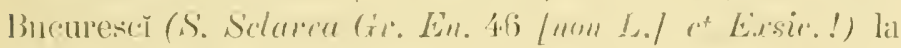

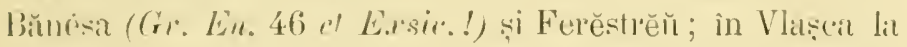

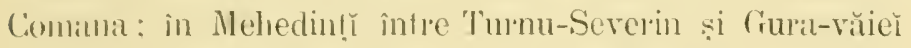

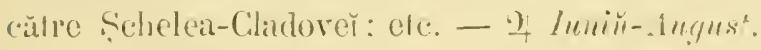

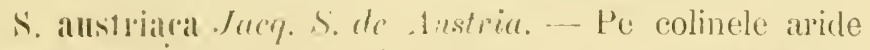
și prin phèsunile uscille. - În Mloldoral (c'z. Flore XIX, 60

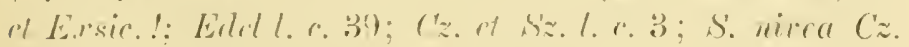

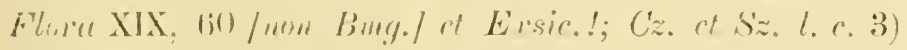

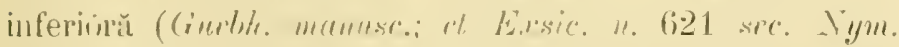

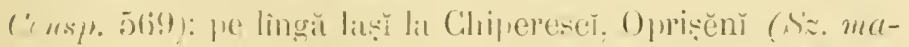

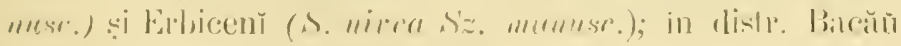

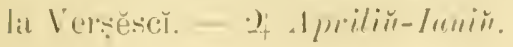


S. pratensis 2 . s. de finete. - Pe coline ande, min

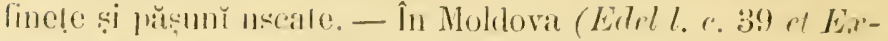

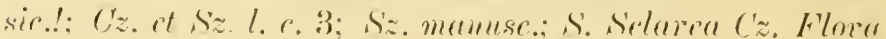

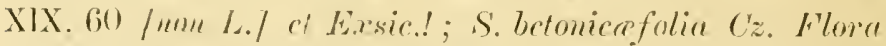

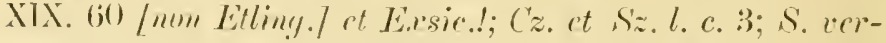
licuarea Cz. rt Sz. l. r. 3 [nom Wahl.] et Lissic.!; S. gram-

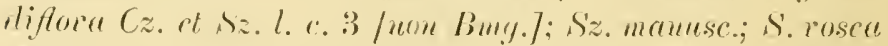
Cz. it Sz. l. e. 3 / hon Bime./; Sz. mamese.; S. pealonsis

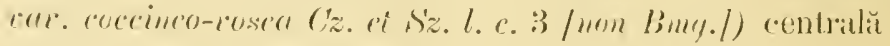

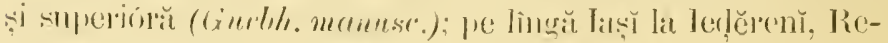

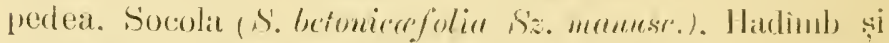

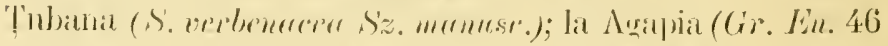

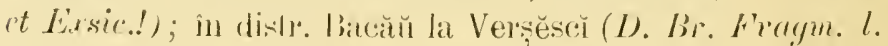

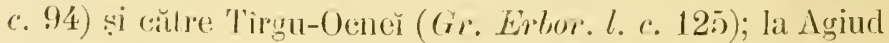
(Burri Larsie.!); pe lingă Bucurescĕ la Bănésa, Merinani çi Ciocănescĭ (I). Br. Fraym. l. c. 94); în Vlașca la Comana; etc. - 2 M Mairu-duynst.

S. sylvestris L. S. de păture. - Vulg. Códa-racer. Prin finele. pe matrginea agrilor șj a drunurilor. - În tótă Moldoral (Gurh, mamuse et Exsic. n. $622 \mathrm{sece}$. Nym. Consp). 570 ; Cz. ot Sz. L. c. 3 et Lirsic.!; Sz. manusc.; S'. Horminum (Z. Flere XIX. 60) (non L.J ci Exsic.!; Edel l. c. 39); pe lìnğ laș̆ (

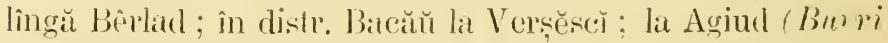

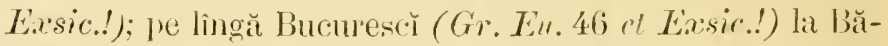
nésa, Ferěstrěŭ, Merinani, Clnitila și Ciocănescí; la Rînnicu-Vîlcer̆ și Bülcescř ; clc. - 2 luniŭ-Lugust.

P. albiftore. - Prin fine!̣e. - In Moldova (Cz. ct Sz. l. $c$. 3) la Verșěsci.

\%. minor. - Prin pîrlóge la Pechea (Guchh. mamese.).

S. mutans L. S. plecatu. - Pe coline aride. - In Moldovat (Cz. Flore XIX, 60 et Érsic.!; Eidel l. r. 39) : Cz. et Sz. l. ค. 3) pe lingă laș̆ către Săpte-Ónenŭ (S'z. manusr.!). - 2f spriliur-Inliur. 
S. amplexifolia Lam. S'. amplerifolialic. - Lat Virciorovil călre P’or!̣ile-de-l'ur (Kunitz ! l. c. 9!3).

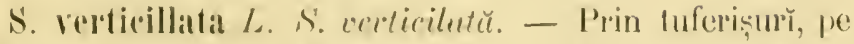

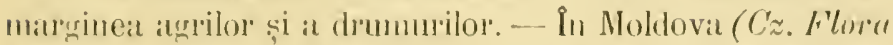

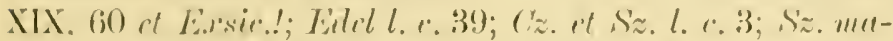

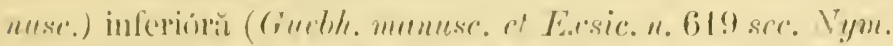

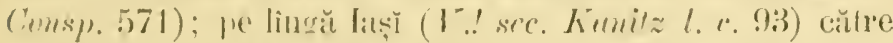

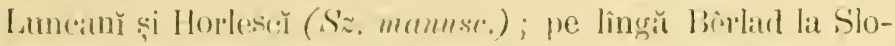

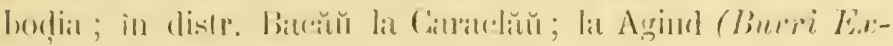

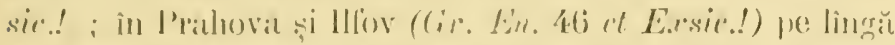

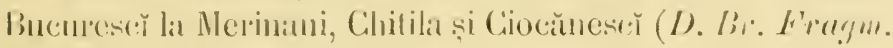

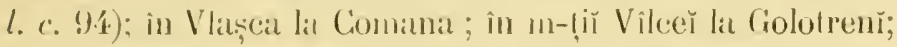

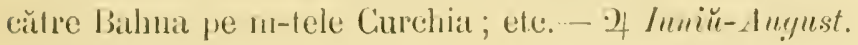

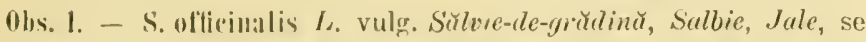
cultivă prin grădinI! (Guebh. munusc.; Cz. et Sz. l. c. 3; Gr. Lin. 46).

Obs. 2. - Se maí citéză : s. nermorosia Bimy. în Moldova (Cz. et $S z$. l. c. 3) pe lîngă IașY către Osoiñ și Goronr (Sz. munusc.). -. S. I'lugusil in Moldova (Czz. Flor" XIX, 60)?

\section{ORIGANGM L. - Origan.}

0. Vulgare L. O. comun. - Vulg. Soviner, Sovovêrv, Solovêrv, Dost, Milot. - Prin finețe, tuferișur, livedĭ, viī, pe marginea pădurilor; pănă în regiunea subalpină. - În Moldova (Cz. Flora XIX, 60 et Exsic.!; Cz. et Sz. l. c. 36; $S z$. manusc.) superioriu (h.j. Guebh. nanusc.); în distr. Bo-

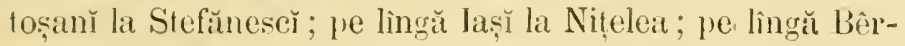
lad (I). Br. Fragm. l. e. 96); pe Ciéhlăŭ ; la Broscenĭ (Burri E.rsic.!); în m-tịi Bacăulư̆ la Ciuraclăŭ, 'Tîrgu-Ocnĕ și Slănie; în Rimnnicu-š̆ıat la Caiata; 'Titu și între Ploescr și Săftica ( $(i r$. Lin. 45 et Érsir.!); pe lingă Bucurescì ; în Arges

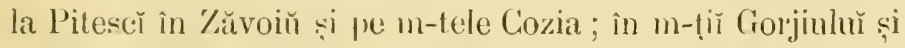

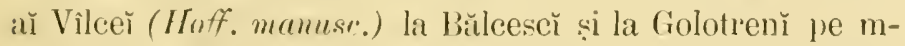
tele Furfeca; pe linği Vîrciorova pe m-tele Curchia cŭtre Bahnat; etc. - 9. Inniü-August. 
3. prismaticum Ǵaud. - Prin finneṭe. - În Moldova in-

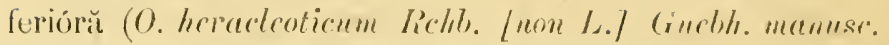
ct Exsic. 1. 624 sec. Nym. ('onsp). 592).

0 ls. - 0. Majjoraua L. vulg. Mĕgherun, se cultivă prin grădinr! (Guebl. manuse.).

\section{THYIISS L. - Thim.}

T. Chambedrys Fries; T. Serpyllmm a. Chamedrys Koch; T. syluestris Scherb. T'. Chemedrys. - Prin pooni și pe marginea pădurilor, pe coline aride. - In tótă Ro. mănia (Nym. C'crsp. 593). - D) luliǔ- Ingust.

T. lannginosmm Schliur. [non Link.]. T. länos. - Pe coline aride și něsipóse. - În Moldova (Cz. Flora XIX. 67 't Exsic.!; lidel l. c. 40; Cz. et s'z. l. c. 37) superióră (h.j. Guebh. manusc.). - 2 Juliü-_ugust.

T. comosus Heuff.; T. transsilvanicus Schur; T. nummularius M. Birb. T. comos. - Vulg. Cimbrișon. Cimbrusor, Sírpun. Sirppunel, Sirpumele, Schinduf, Thimian. - Prin locurile petróse şi pe stincele calcare din munți. -- În Moldova (T. alpines Cz. Flona XIX, 67 /non L.7 et Exsic.l; Cz. ct Sz. l.e. 37) pe Céhlăŭ (T. monianns Cz. Flora XIX. 67 [non W. Kil.l et Ersic..! Edel l. c. 36; Cz. et Sz. l. c. 37); în m-ḷĭ Buzenlŭ către Sibicin̆ pe malurile rîpóse ale soseleř ; în m-4iı̆ Muscelnlnı̆ (T. alpinus D). Br. Fragm. in Rev. lit.-sc. 171 (non L.7) către Câmpulung la Nĕmăesč̆ (T. Chamaedrys Gr. En. 45 /non Fries/ et Eissic.); în

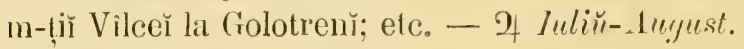

T. montanus Ut. Kit. T. montan. - Prin pășunile şi poenile din munț̆̆, pánă in regiunea alpină. - La m-stirea Ném!uluŭ și la schitul Procov; în m-țî̀ Batuăulu la Slănic

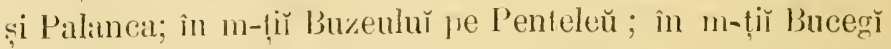
și la Predél; în n11-tiù m-stirilor Cozia, Bistrị̣a și Tismana (Hoff. mannse. et Érsir..!); la Ciololnenì ve m-tele Fórlecat; cte. - - ) lulin-dugust. 
Obs. - Nu pot spune ce póle fi : T. montanus, indicat la Puţeñ

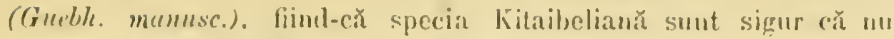
r'esce în aceistă locialilate.

T. Serpyllum (L.) Frvies; T. aneystifulies sichels. T.

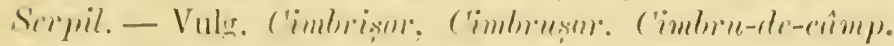

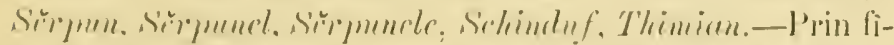

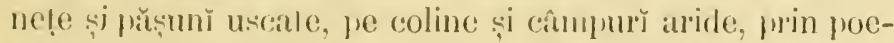

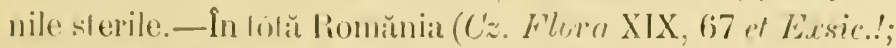

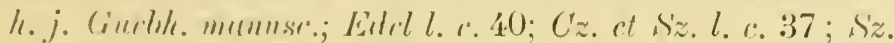
manuss.; I). Brr. Frrugm. l. a. 96; Gr. En. 45; . Vym. Comsp. 594 ; T. sulmuluss Cz. Filore XIX. 67; Cz. ct Sz. l. c. 37; Sz. mamesce; T. angustifulins Hoff. Liseurs. 1862. l. r. 39). - - Inliü-lüjust.

T. pannonicus . Ill. T' panmic.-- I'e coline aride prin fine!̣e sterile. In lită Romănia (Cz. st. Sz. l. c. 37; Nym. C'msp. 594). - 2 Iuliü-1nugust.

a. glabrescens Rrhb. fil.: 'T'. glabrescens Willd. -- La Virciorova căıre Portile-de-fer (Brorb. 1873, Báus. 267).

B. Marsehalliames Reht. fil. - In Moldova (T' citriodorus Cz. Flora XIX. 67 /non Link.] of Exsic.!: le.j. Guebh. manusc.; Cz. ct Sz. l. e. 37 ; Sz. mamusce); la Virreiorova către Por!̣ile-de-fer frequent! (T. I/arschalliamus Willr. Simk. 5!10) și între Şchelea-Cladover și Gura-văieř.

\%."oduratissimns Reld). fil.; T. mloratissimus .1I. Bicb.În Moldova inferionră (T. Marschallianus Grebh. mamuse. [uon Willd.] it Eirsie. n. 627 in herl. P'aris.!).

J. hirsutus Rehb. fil. - În Moldova inferióră (T. hirsutus: 1T. Bish. (iucble, manusc.).

Obs. 1.-T. vulgaris $L$. se cultivă prin grădinI (Gr. Erbor. l. c. 125; Ein. 45 ; et Éxsic!).

Obs. 2. - Satureja hortensis L., vulg. Cimbrne-de-grüdinĕ, Cimbru, se cultivă prin grădinı! (Guebh. munuse. Cz. et Sz. l. c. 35 et Exsic.!; Sz. munuse.).

(1)s. 3. - Se unar citezză : S. rupestres Wutf. în Moldova (Cz. et Sz. l. c. 3i) și în m-țir m-stirilor Cozia, Bistriţa și Tismana (MicroImrria rupestris Benth. Hoff. munusc.). 


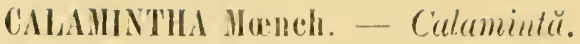

O. Acinos Clairv. C. Arims. - Prin Iocur inculte. pe-

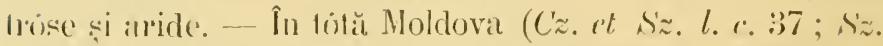

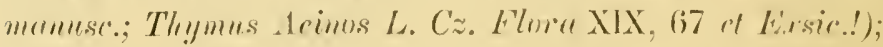

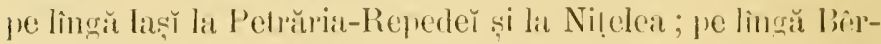

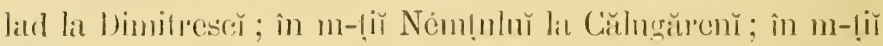

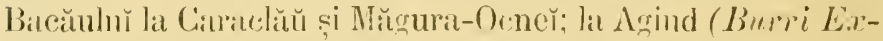

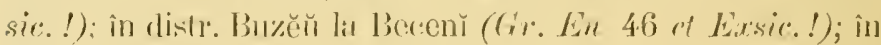

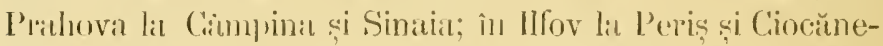

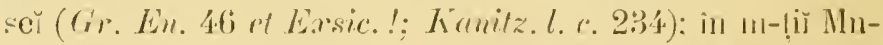

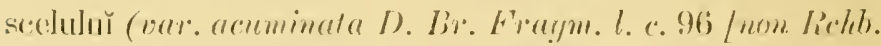

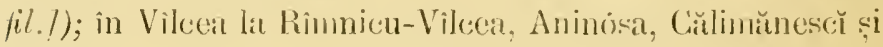
Golotrenı̆; elc. - $\odot$ Innin-_luguss.

C. graveolens Bruth. C. graventencü. - Prin loeurile petróse și montame. - În Mloldovar superiónă prin m-liĭ de

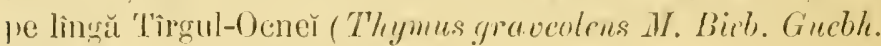
mannesc.). - $\odot$ Inliü-Luegust.

C. suaveolens Boiss.; Thymus suaveolens Sm. C. odorantia. - In Moldova (Thymus graceolens Cz. Fliwa XIX, 67 Fnon Benth.l et Exsic.!; ('z. et S'z. l. e. 37). - $\odot$ Iuliü-Lugnest.

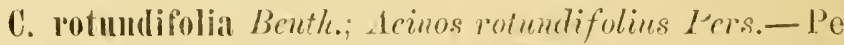
slincile calcare. - În m-tĭ Argeşulur pe Urḑiea și Cozia; in Mehedințĭ la Vìrciorovil către Portile-de-fer! (Burh. 1873 , Bäns. 268) pe m-tele St.-Petru şi între Gura-văieì şi SSchelea-Cladoveř. - 2 Imniй-_lugust.

(. alpina Lam.; Acinos alpioms Nanch. C. alpina. Prin locurile petróse si pe malca lorentelor din reginnea subalpină și alpină superiòr̆. - La Broscenı̌ (Burri Easic.!): în m-ḷĭ Bnceğ ('T. alprinus Hoff. Excurs. 18633. l. c. 120; Gr. En. 4.5 et E.rsir.!) pe Furnical, Virfu-cu-1)oru, 


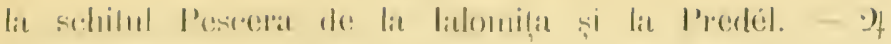

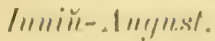

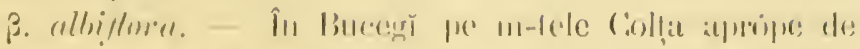

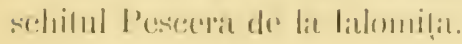

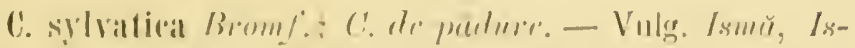

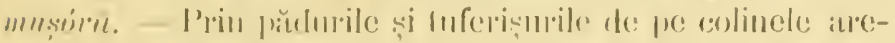

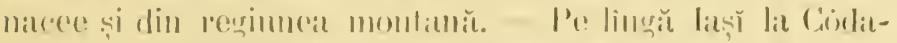

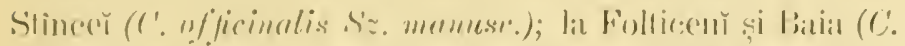

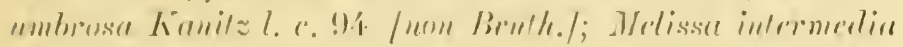

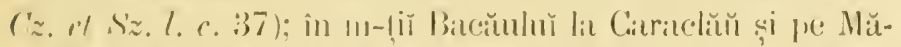

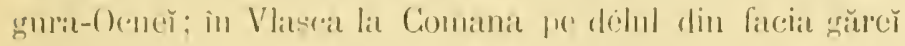

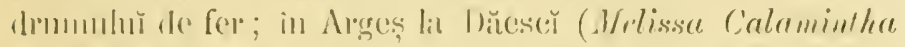

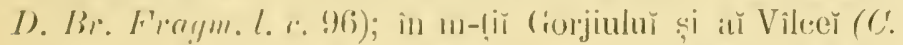

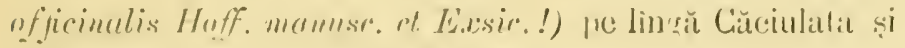
m-slireil Cozia. - in Juliu- I legust.

Ohs. - Nu pot spune ec pite fi: Thyouns Calaumintha, indicat în Moldova superioră $(h . j$. Guebh. m(cmuse.), asemenea plantă neaflân. du-se in crbariul din Iași.

C. Nepetal Clairv. C. Nepetă.-P'rin locurĭ aride și munlóse.-In Moldova (Cz. st Sz. l. c. 37), îl distr. Bu\%c̆ŭ către Becenĩ în valea Slĭniculnŭ (Gr. Ëu. 4.fo et Exsic.!; Kanitz l. c. 234; C. nepetuides Gr. En. 46j /uon Jacy.J et Exisic.!); în P'ralıova la Ciùmpina. - 2 Inliŭ-Aluguest.

\section{CLINOPODHII L. - Clinopodiü.}

C. Vulgăare L. C. commen. - Prin poenile și răriturile de

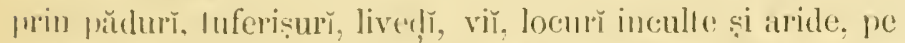

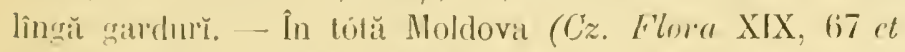

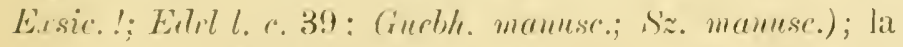

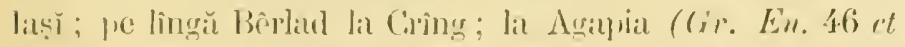

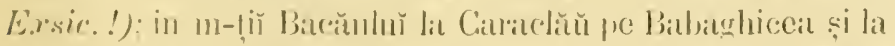

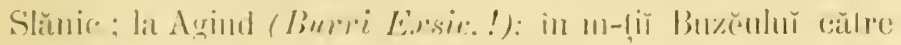

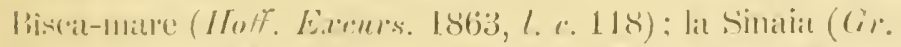
Lircurs. l. c. 126 , Eesic.!; (ir. Ën. 46); pe lingă Bucu- 
reser̆ la Ciocănesě̀ (D. Br. Frarm. l. c. 96); la Ciurtea-deArges; în Vilcca lit Gololrent pe nn-tele Fórfeca; în Mehedințĭ intre Gura-văien̆ și Vîrciorova şi către Bahna pe m-tele Curchia; etc. - If huliй-dugnest.

\section{MELISSA I. - Melisŭ.}

II. officinalis L. M. oficinalü. - Vulg. Rointitu, Iarbastupulnĕ, Hatăciune. - Prin păduř̌. - În tótă Moldova (Grefbh。 memesc.); la Ném!u, Bacăŭ și Foç̧anı̆ (Cz. ct Sz. l. с. 37); la pólele Bucegilor (Hoff. Excurs. 1863, l. c. 119 et Exsic.!). - Se eultivă și prin tóte prisecile (Cz. ct Sz. l. c. 37; D. Br. Fragm. l. e. 96; Gr. En. 46 et Exsic.!). 2) luniü-August.

3. altissima Sibth. et Sim. - La Virciorova către Porțilede-fer! (Kunitz! l. c. 95).

01s. - Iyssoopus ofiicinilis $L$. vulg. Isop, se cultivă prin grădiny (Cz. et Sz. l.c. 35 et Exsic.!; Sz. manusc.; Gr. En. 46).

\section{NEPET L L. - Nepetŭ.}

N. Cataria L. N. Cataric. - Vulg. Cǔtıșnică, Iarbavêntuluĭ, Iarba-mițè, larbŭ-flocósă. — Prin dărĕmăturì locurǐ petróse, pe linğ̌ sate, gardur̆, zidurř și drumurr. In tótă Moldova (C'z. Fllowa XIX, 67 et Exsic..'; Edel l.c. 40; Guebh. manusc.; Cz. ct Sz. l. c. 35 ; N. paimonica Cz. Flor a XIX, 67 / uon Jacq./ pt Exsic. !; Cz. et Sz. l. e. 36); pe lîngă Iaț̣̆ lu Ciurea (S'z. manusc.), Nițelea și schitul Tr̆-

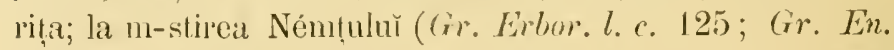

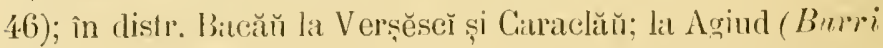
Exsic.!); in distr. Buzĕŭ la Becenı̆ (rr. En. 46 et Exsic.!; Kanitz l. c. 23't); în Arges la Piteser (D. Br. Fragm. l. c.

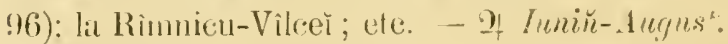

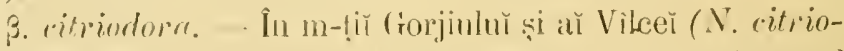

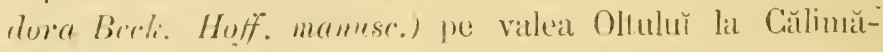
neseì și Cúciulatia. 


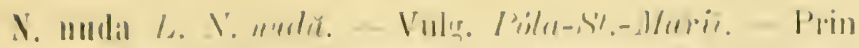

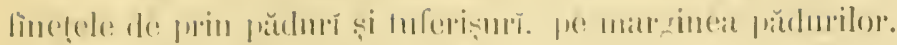

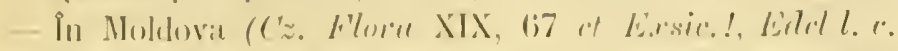

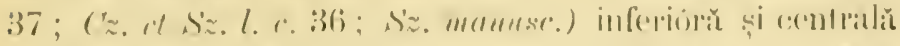

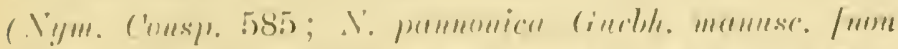

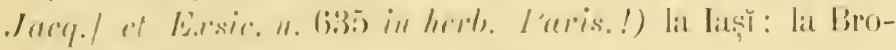

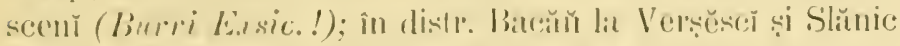

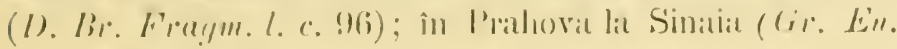

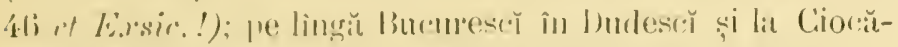

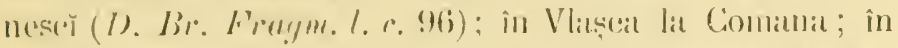

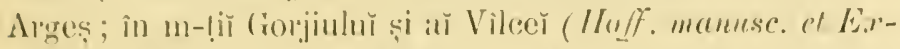

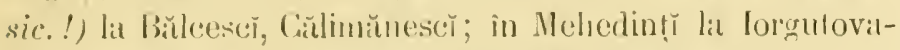

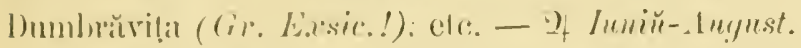

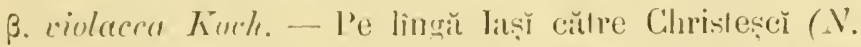

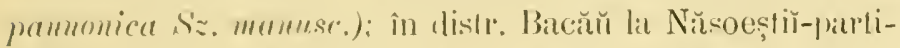

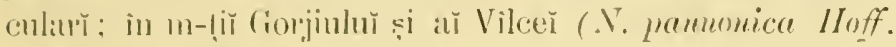
mantse.).

\%. "reranica (1/ Birb.). - Pe marginea pădurilor din Mol-

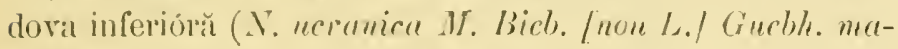
muse. ct Lixsic. "1. $636 \mathrm{sec}$. Nym. Cousp. 585).

\section{GHLE(HOUIA L. - Glechomă.}

di. Lederacea L. G. ederares. - Vulg. Richungiont, Ro-

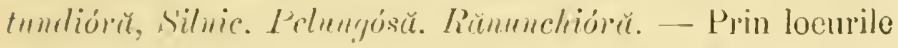
umede de prin pădurı și tufĕrișur. - În tỏ ă Noldova (Cz. Flora XIX, 67 et E.rsic.!: Eidel l. e. 40 ; Cimchlh. manusc. it E.rsic. 11. 643 ser. Nym. Comsp. 587 ; Cz. et sz. l. c. 36; S'z. manuse.): pe lingă Iatși la Nitelea și Repedea; pe lingă Birplad lit Crîng; in Prihova lat Cîmpina (Gir. Ln. 46 ct

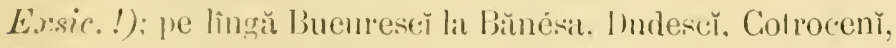

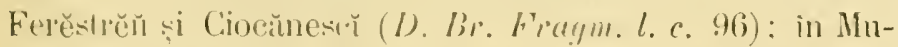

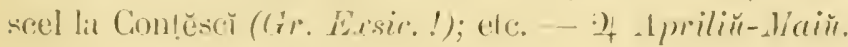

li. hirsuta $\|^{\circ}$. Kï. (i. irsutii. - Prin locmile muede

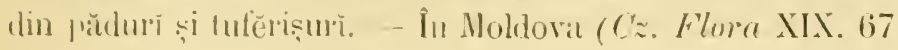




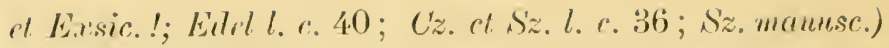

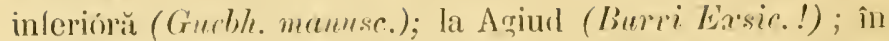

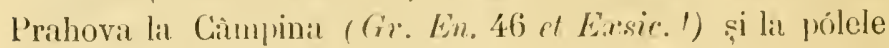
Bucegilor (Ifoff. Excurs. 1863, l. e. 119) pe eostele un-telur Furnica; în Nhecel la pólele m-leh Leresč in valea Riu-

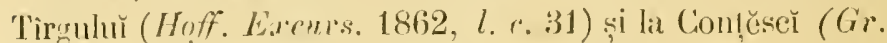
Exsic.!); în Vlascea la Comana (I). Br. Horegm.l. c.96);

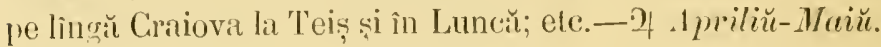

\section{DRACOCEPHALIIH I. - Dracocefal.}

D. Moldaviea L. D. de Moldova. - Vulg. Măluciume, Mătăcină, Mătăciune-moldovenéscă, Mätŭcinm-turcéscă.Prin pădurı̌. - In Noldova (Edel l. c. 39 cl Exsic.!) superióră (D) austriacum ('z. et Sz. l. c. 37 et Exxsir.!' [non L.j; h.j. (incebh. manuse.): de la Taş̆ spre sud pe malul Prutulŭ (Hacy. Rrise, II, 76 ; Hoelzl l. c. 442), pe lingă Hușĩ și Fălciŭ fórte frequentă $(C z$, ct $S z$.l.c. 37). - Se cultivă și prin grădinı̆ (Guebl. mamesc.; Sz. manusc; Gr. En. 46). - $\odot$ Iuliŭ-1urgust.

\section{MELI'TIS L. - Melitĭ.}

II. Melissophyllum L.; M. grandiftira simith. M. Melisofil. - Vulg. Dumbravnic. Dobmanic, Dobronic, Dobrovnicŭ. Ducroonică, Dumbrajnic. - Prin tuferişur și pădury. - In Noldova (C'. Floren XIX, 67 et Exsic.!) superiobĭ (h.j. (rucbh. mamusc.) prin regimile inferióre ale Céhlăului (Eddel l. c. 36); pe lingă Cralul! (f z. of s'z. l. c. 37;

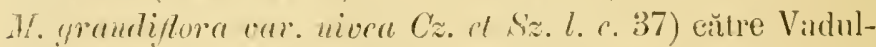

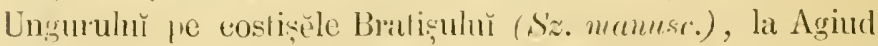
(Burri Esrsic.!); in Jîmbovila la Sturḍ̆ñ̆ ; în Muscel intre Rucăl și Dombrovicióra (IInff. E.reness. 1862, l. c. 39), pe

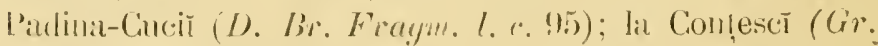

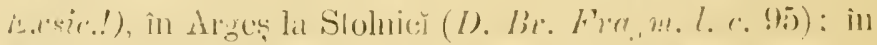

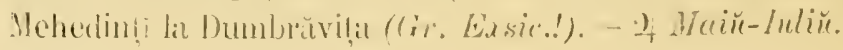




\section{I.I.IIIII L. - I.4min.}

L. amplexisanle Lin. L. amplonifolial. - Prin locur

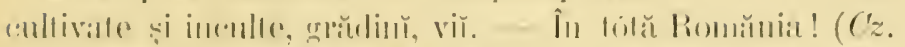

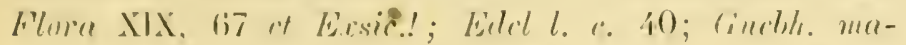

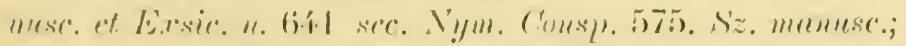

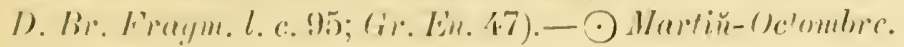

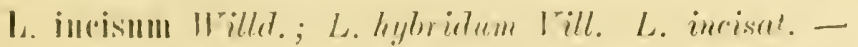

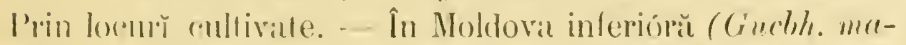

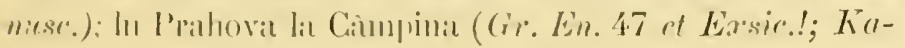

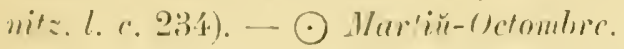

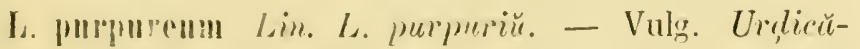

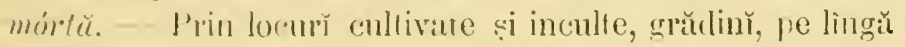

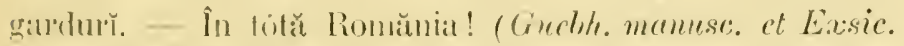
u. 638 sec. Tym. Consp). 575 ; Edel l. c. 40 ; Sz. mannse; D. Br. Fragm. l. c. 95 ; Burb. sec. Kanitz 1. c. 96 ; Gr. En. 47 et Exsic.!). - $\odot$ Marliü-Octomlire.

L. Milculatum Lin. L. macnlat. - Prin locurile umede din pĭdurı̆, tuferiçuri și grŭdinu, pănă în regiunea subalpină. - In Noldova (Cz. Flara XIX, 67 ct Exsic.!; h.j. Ginebh. mamuse.; Edtel l. e. 40 ; D. Br. Fragm. l. c. 95; L. merpuerem Cz. F'lerce XIX. 67 (non L./ è Exsic.!); la Agriud (Buri lésic.!); în I'rahova la Câmpina; pe lingă Bucurescĕ la Bănésa: in Vlaṣca la Contana; în Muscel la Con-

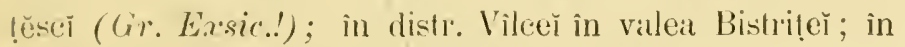
Mtehedinṭ̆ la Vìnjule! (Gr. Eı. 46 et Easic.!); etc. - of Aprilir-Angust.

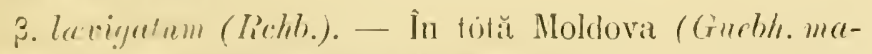

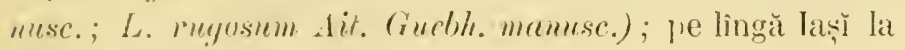
Ṭ̂hana (S'. manisc.).

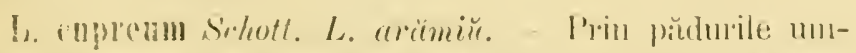

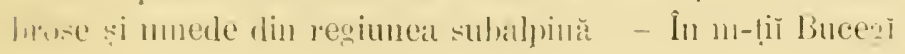




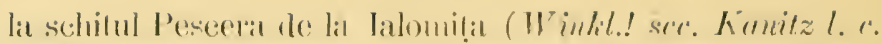

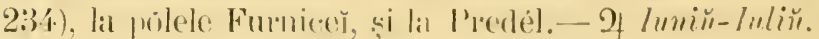

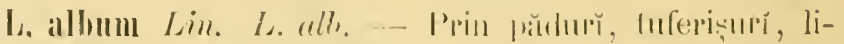

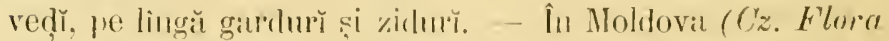

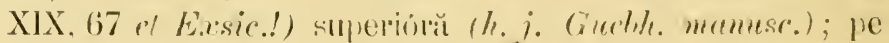

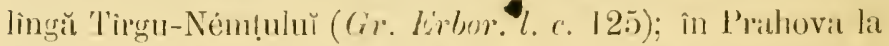
Preclél; în Muscel pe délu Moloin̆ (lloff. Esretes. 1862, l.

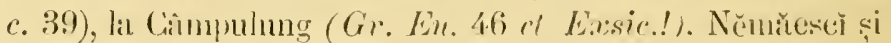
Rucă (D) Br. Fragm. l. c. 95)) : lit Curlcit-de-Arges (Gr.

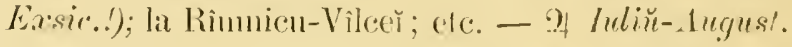

0hs. - Se mar citéză : I. Orvala $L$. la Cucuteny (Sz. mumusc.).

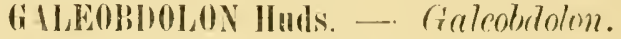

G. Intermm IHuds.; Galcopsis Galeobulalon L. G. yalbên. -Vulg. Gälbiniţă - Prin pădurr umbrose, luferișrì unede. - În tótă Romănia! (Cz. Flora XIX. 67 et Exsic.!; Edel l.

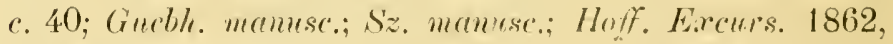
l. c. 39; Burri Exsic.!; D. Br. l. c. 95) L Laminm Cialeob-

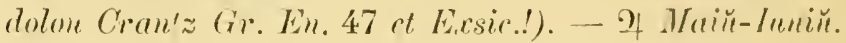

\section{GiLEOPSIS 1. - Galenpisilă.}

(x. Ladanum Rehl.; G. Latifolia Hoffm. G. Ladan. Vulg. Taposnic. Fața-miter, Zélne. - Prin pirlóge și mi-

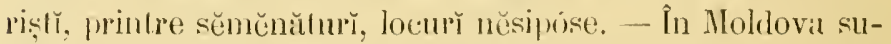
ferieră (Sz. Exsie.!: h. i. Guebh. manusc.) pe lingă laș̆

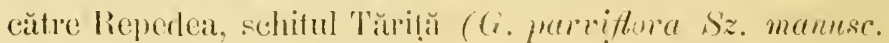
lnon Lam.!) și la Perient̆ și Cünnicenì (Sz. manuse.) ; în

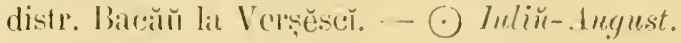

B. angustifolia ITimm. ei Ciroh.: (i. angustifolia Ehrh.

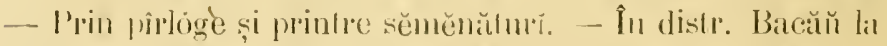

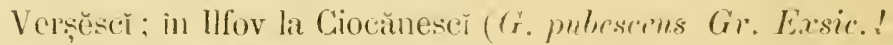

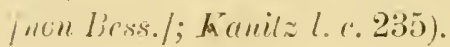




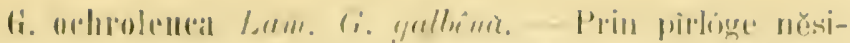

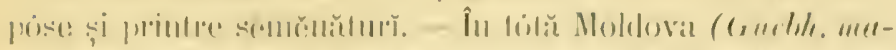

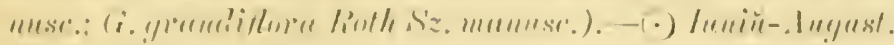

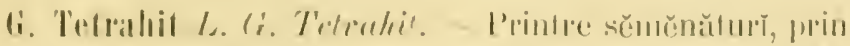

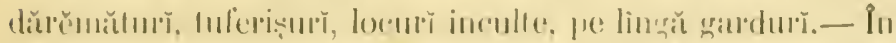

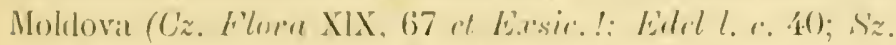

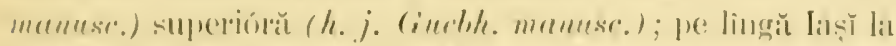

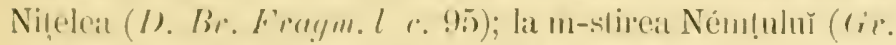

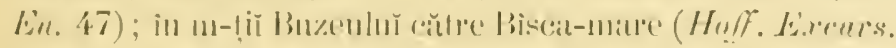

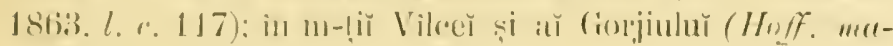
unse.). - O lulin-.luyns/.

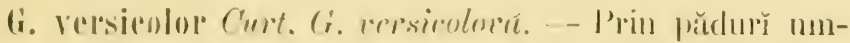

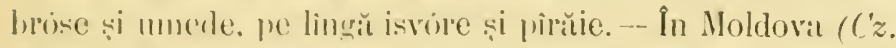

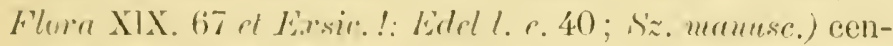

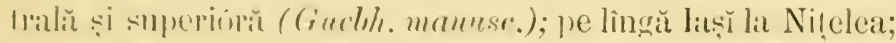

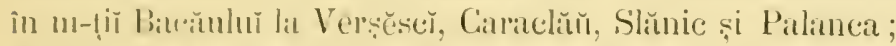

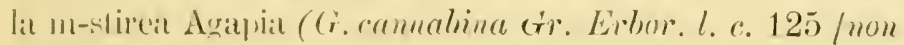
Poll.] et E.rsic. !: Ci. nehrolenea (ir. Eu. 47 [nom Lam.]; la Ciocŭnesč, Tìu si Sinaia (Gr. En. 47 ot Esssic. !; G. ochrolenca Gr. Eu. 47 /non Lam./ et Exsic.!); în Vilcea la

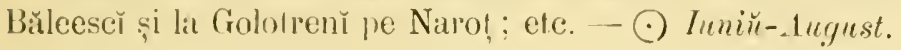

\section{stirins I。 - Stachida.}

S. germanica L. S. grrmanică. - Vulg. Jals, Jale. Prin finete și jăı̣uı̆ uscate, he eoline aride și calcatre. In totit Moldoval (Cz. Flore XIX, fi7 ct Exsic..!; Eitel l. $c$.

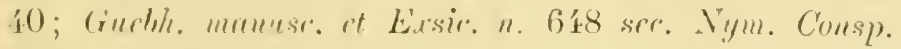

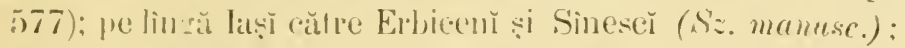
pe lingă Bindad la slohodia ; in distr. Nén! la m-stirea A-

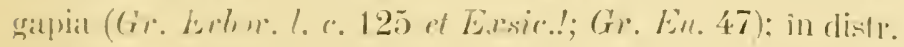

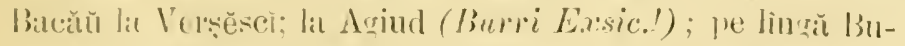

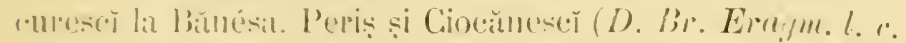

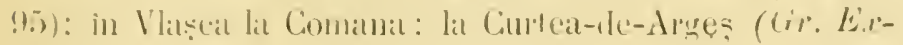




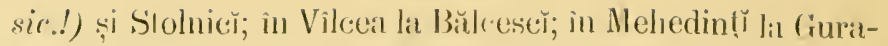
văiè și cŭlre Vîrciorova pe m-tele Cinrchlia aprópe de Bahnit; etc. - or Iuniü-Iugnest.

S. alpina L. S. alpince - Prin pădurile dlin reginnea

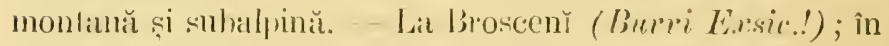

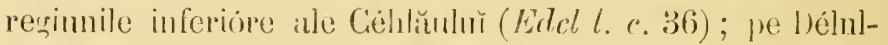
Pahonię̆ intre m-stirea Agrapia și schinul Sihla; in m-liŭ Buzeulur la Bisca pe m-tele 'Tesat; la Predél (Gr. liasic.!); ete. - 2 Iuliü-1 ingust.

S. sylvatica L. S. de pădurc. - Vulg. Bălbisčt. - Prin pădurile umede și mmbróse. - În hib̆ Noldova (Cz. Flora XIX, 67 et Exsie.! ; Erdel l. e. 40; Guelh. mamusc.; Sz.

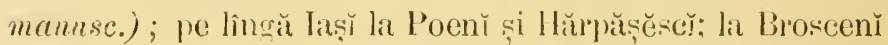

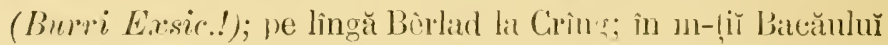
la Tìr Frorm.l. c. 95); în n-tiŭ Bu\%euhŭ la lisisca pe m-tele Tega; în Prahova către 'T'elega și la Sinaria călre pólele Furniceř; la Predél: pe lingă Bucurescĭ la Bănésa! (Gr. En. 47 et Exsic.!; Kunitz l. c. 235); în Vlaṣca la Comana; in m-tị̆

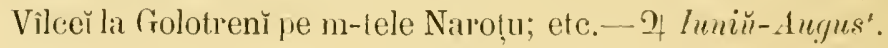

S. palustris L. S. de mlastiň. - Prin finețe mlăștinóse și agriǔ mmede, bălı̣̆, locurı̌ inundate, pe lingă rîuř̆, gî̀le și pîrŭie. - În tôtri Noldova (Cz. F'lora XIX, 67 ot Earsic.l; Ldel l. c. 40 ; (ruebh. manusc.: Sz. mamusc.); in distr. Bacăŭ la Vurș̆ecsi şi Caraclăŭ ; pe lingă Bêrlad; în P'rahova către Valea-larră (Hoff. Earn!ro. 1863, l. c. 118); în Ilfov (Gr. En. 47 et Exsic.!) lit Bucureseì și Cihitila ; în

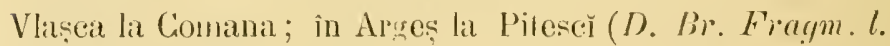

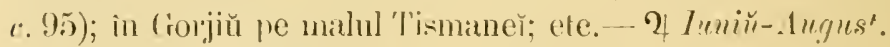

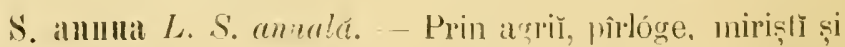
sěmĕnălurĭ. - În tólĭ Moldovi ('́z. Flora XIX, 67 et Exr-

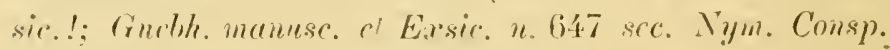

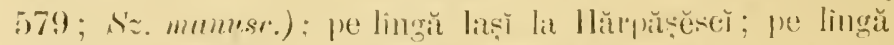

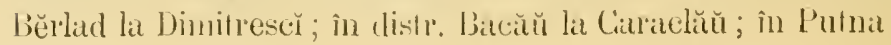




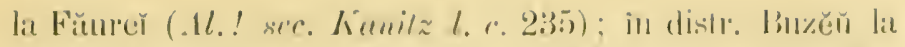

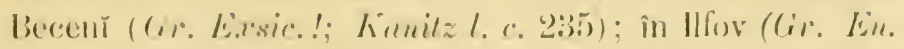

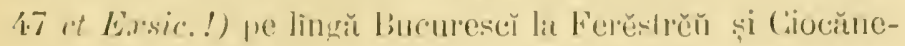

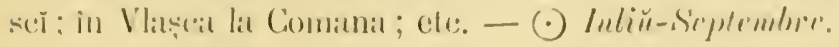

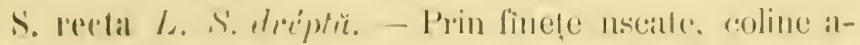

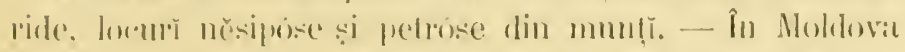

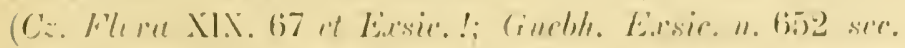

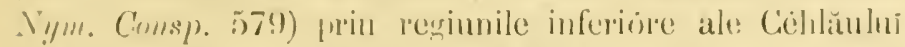

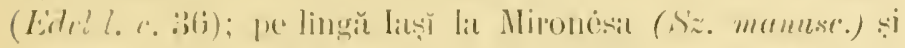

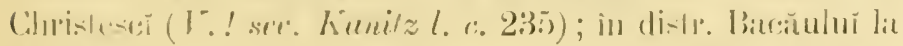

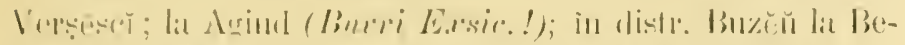

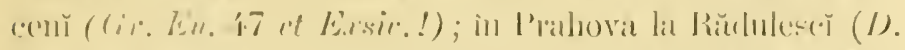

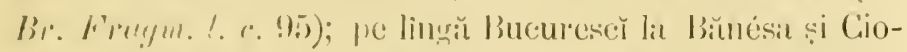

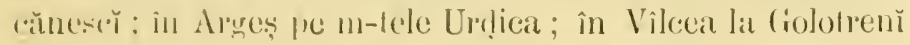

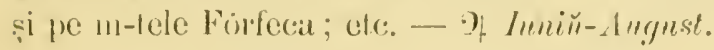

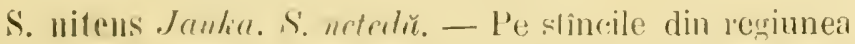

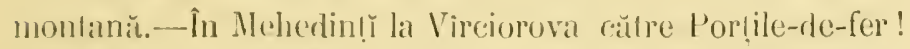
(.Janlea! Limu. XXX. 577: Kaniz' l.c.97; S. remosissima Borb. 1873. Büls. 268; Simk. 591 /sec. Janka non lio-

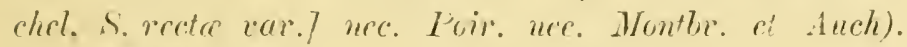
- It Maiu-Iminir.

01), - Se maY citéză: S. arvensis $L$, in tútă Moldova (C'z. Fior XIX.

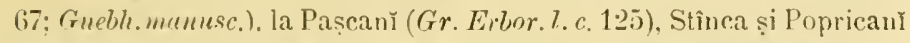
(Sz. mamusc.).--S. hipta $L$. în .Ioldova inferióră (Guelh. manusc.).

\section{BETONICA L. - Betmirŭ.}

B. offorinalis L. B. oficinală. - Vulg. Findecé. Iapbadr-ranc. Jarbatairtuich. - Prin finetele nacate și poenile din pădurı și luferiẹırı̆. - În tótă Moldova (Cz. Flora XIX.

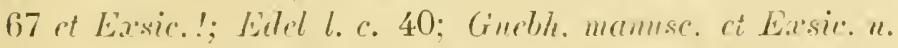
653 sec. Nym. Cousp. 577; (z. et Sz. l. c. 36; Sz. marusc.); la Broscenĭ (Burri E.'sic.!); pe lingă Iaș̆ la Nițelea; pe

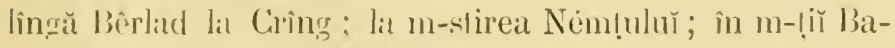

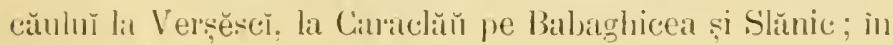




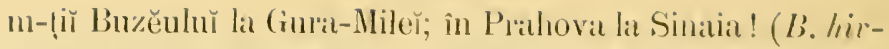

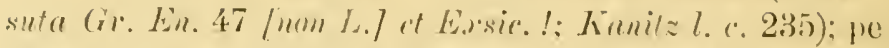

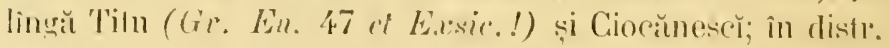

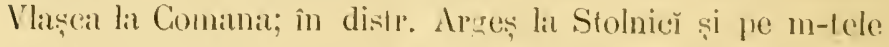

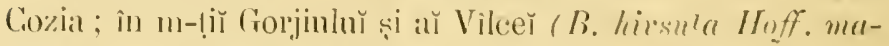
nusce. [non L./ et E.xsic.!) la Golotrenĭ pe Fórfeca ; ele. 2) Inniĭ- Luegust.

Obs. - Ce póte fi : B. orientalis, indicat la Pechea (s'z. monuce.)?

\section{SIIERITIS L. - Sitheritis.}

S. Inontana L. s' montano. - Vuls. Incheictore. Uirechea-sórcculnu. - I'rin pîrlóge și câmpurĭ něsipróse, pe déhuri aride și petróse. - În Noldova (Cz. Flora XIX, 67

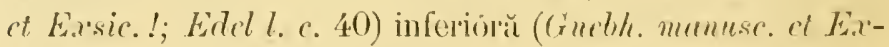
sic. n. 65) sec. Nym. (onsp. 584); pe lingră laṣ̆ la Pelrăria-Repeder̆; pe lingă Bucuresč la Chitila și Buftea : intre

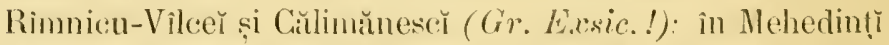
la Virciorova către Porṭile-de-fer! (Borb. sce. Kanitzl. c.97)

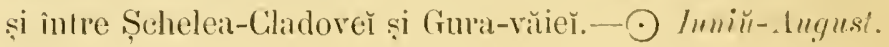

\section{MARRUBIUII L. - Mambiă.}

M. Vulgare L. M. commu. - Vulg. Foronic, Ĺnquras,

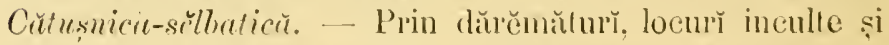
aride, drumurile și gardurile de prin sale. - În lólă Mlol-

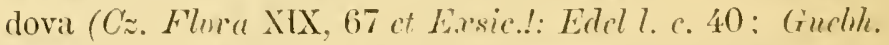
manuse.; $C \approx$ et $S \approx$. l. c. 36; S'z. manusc.): pe lìngă Iașĭ la Repedea și Bìrnovar; la Berlad (D. Br. Fraym. l. c. 96);

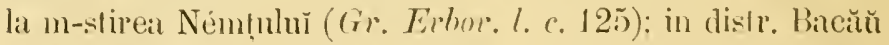

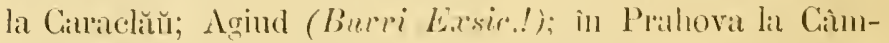

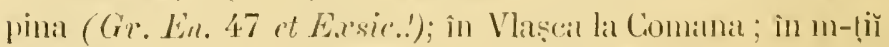

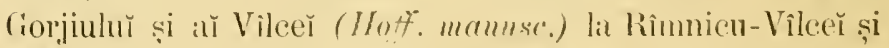

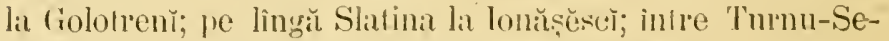
verin și Vîrciorova; ele. - - Itrnik-síplembrer. 


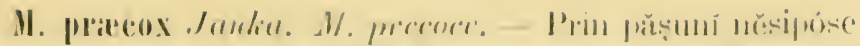

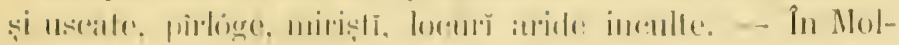

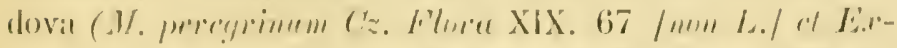

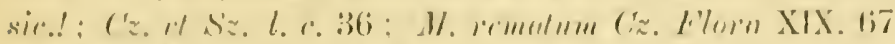

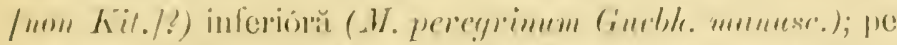

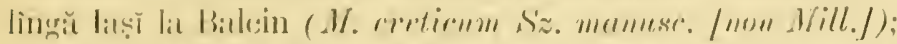

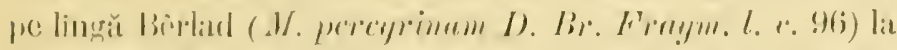

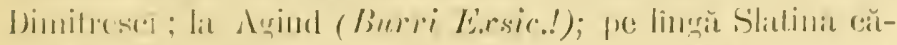

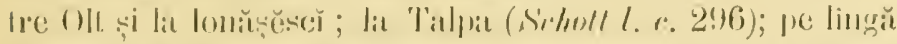

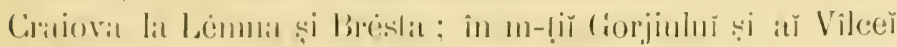

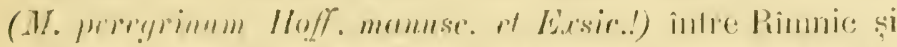

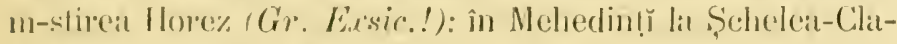

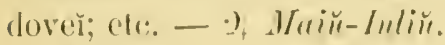

Ohs. - Nu pol spune ce póte fi : M. crispum, indicat îu Ifoldova (Cz. Flora X1X, 67; Cz et Siz. l. c. 36i).

\section{BALLOTA L. - Biclotü.}

B. nigra l. B. migrĕ. - Vulg. I'alus,r.t. - Prin luferi-

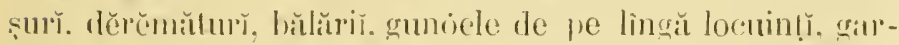

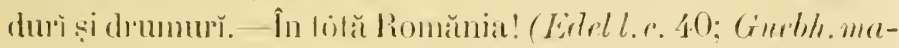

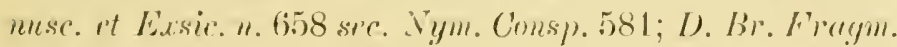

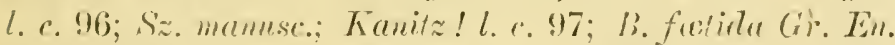

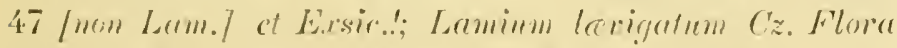

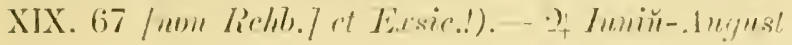

\section{LEONTRIS I. - Lemur.}

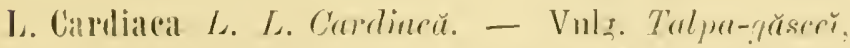

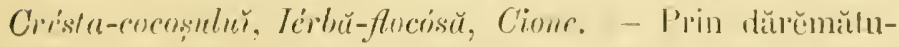
rile și gunóiele de re lingă locuinṭ și gardur.. În lólĭ Ro-

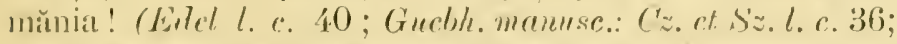

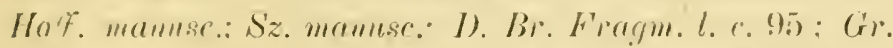

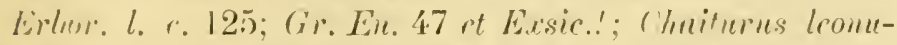

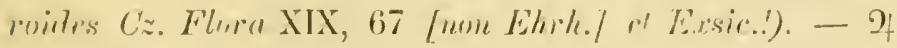
Inlikt-Lingust. 
P. villosus Ledeb.; L. eanescens Dmr\% - Prin fìnẹ̣c. În Moldova inferióră (L. villosus Desf. Guebh. manusc. et Exsic. u. 644 sec. Nym. Consp. 580).

\section{CHAITURUS Host. - Chaitur.}

(.) Marrubiastrum Releb. (. Mapubias'ru. - Vulg.

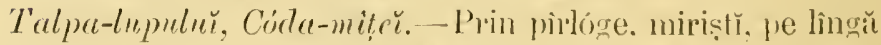

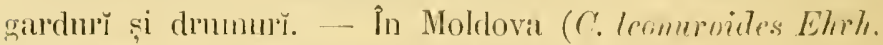

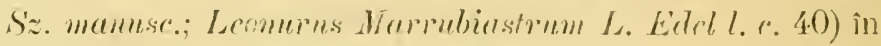

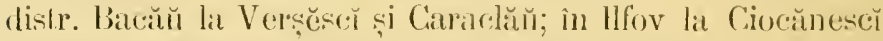

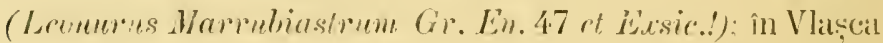
la Prund (I). Br. Fromim. I. c. 96). - of Iuliu-Aumest.

\section{Plll,0IIss L. - Filomilă.}

P. pungens Willd. Fr. impunepetóre. - Vulg. Solovêrvită, Bunduța-vêntulur. - Prin finel̦ele uscate. - Prin stepele Romànier̆ (Levć. in Drmid. Voy. II, 176); în Moldova (Exsic. Guebh. et Franenfeld sec. Knapp. Pfanz. Gatiz. 203) inferioră și centrală (P. herla venti Gueble. mannse. [non $L . /$ ) ; către Botoşanı̆ ( $P$. purpuerea Hacq. Reise, II, 41 ?; P. tuberosa Helzl, l. c. 442 /non L.7?; Kanitz l. c. 98 p. p.?); pe lingă Iaș̆ pe délul de la Manta-roşie; pe linğă Bêrlad la Slobodia (1'. herba venti D. Br. Fragme.l. c. 95); la Agiud (Burri Exsic.!). - 9 Main-luliu.

P. tuberosa $L$. F. iuberósč. - Prin locurì păduróse și aride. - In Moldova (Cz. Flora XIX, 67 of Exsic. !; Edel l. c. 40 ; Sz. manuse.) inferióră (Güerbh. mamusc. et Exsic. и. 659 sec. Nym. Consp. 581); la Aciud (Burri Exsic.!); in m-ṭĭ P'Pahover̆ la Predél ; în m-ṭĭ Muscelılŭ in calea de la Rucăr la Dimhoviciora (Hoff. Excurs. 18(i2, l. c. 39). 2 Mlain-Iuliur.

Obs. - Nu pot spune ce póte fi : P. alpina $I$. indicat în Prahova pe m-tele Zăganı (Hoff. Excurs. 1862, l. c. 119). 


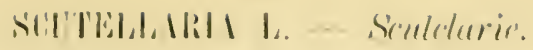

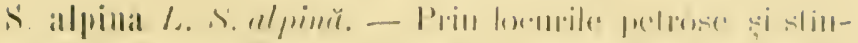

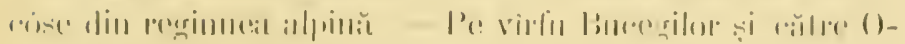

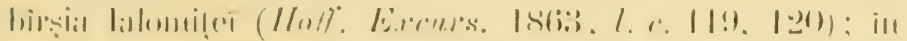

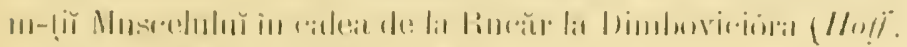

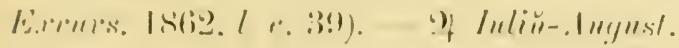

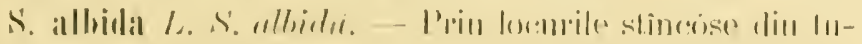

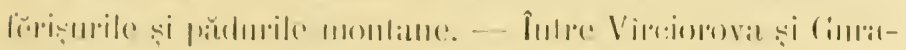

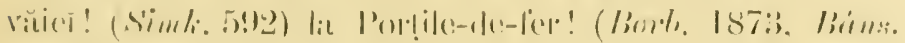

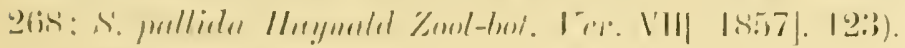
1) dlatiin-lulitit.

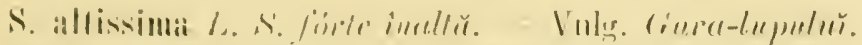

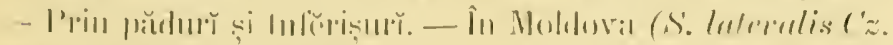

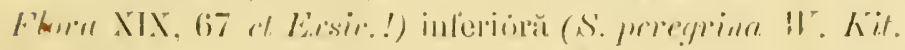

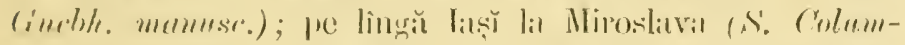

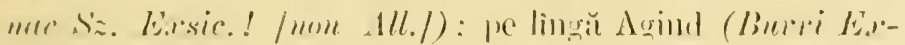

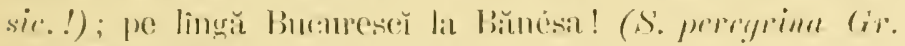

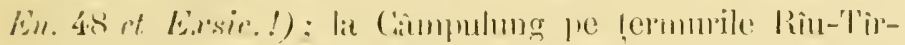

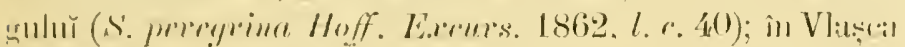

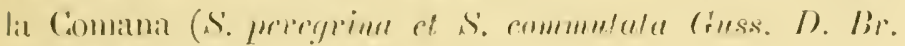

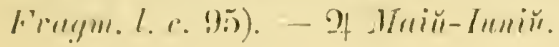

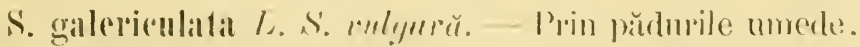

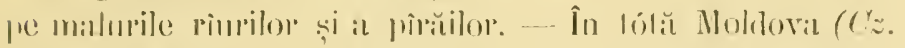

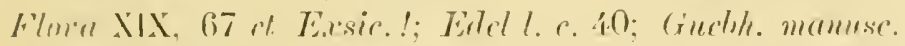

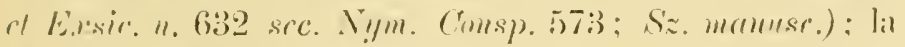

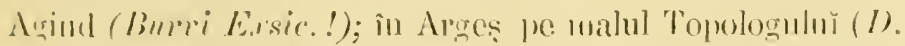

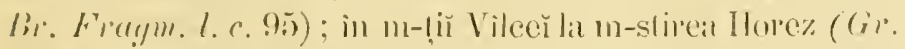

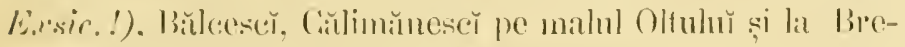

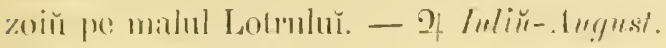

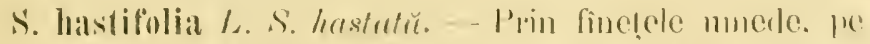

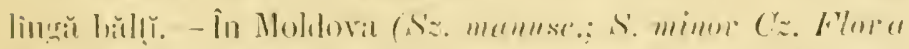

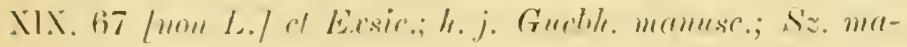




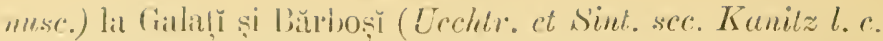
98); ìn distr. Bačŭ la Caraclăŭ ; pe lìngă Asind (Bur. i Exssir.!); in L'rahova la Vălenı̆ (Gr. Exssie.!); pe linnğ Bu-

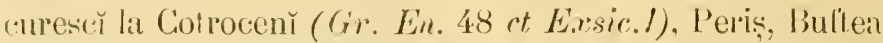
si Cíocănesč̆ i în distr. Vlaṣca la Comana (I). Br. Fragm. 1. с. 95): ete. -2 Inniй-Angnest.

\section{PRINELLA h. - Prunclŭ.}

I'. volgaris L. P. commuă. - Vuls. Soppirlait,ü, Busuinc-de-cümp, Bucnioc-rosn. - P'rin fine!̣e, pășnn, tufĕri-

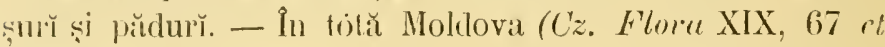
E.rsie.!; Edlel l. c. 40; Gurbh. mamuse,; Cz. ct Sz. l. c. 37;

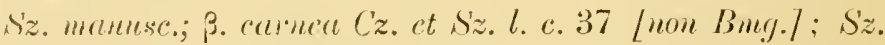
manuse.); la Broscenı̆ (Burri Exsic. !); pe lingă Jaṣ̆ la Hăr-

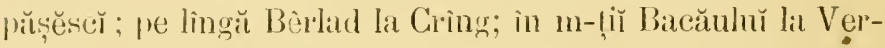
sěseč̆, Caraclăŭ și Slănic (D. Br. Fragm. l. c. 95); la pó-

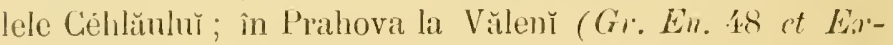
sic.!), Sinatia și Predél; la Bucureser şi Bănésia; în Vlaṣca la Comina ; în Mehedinṭ̆ pe lingă Cerneṭi la Jorgntova (Cir. Exsie.!); elc. - 2 Innin-1ugnest.

3. angustifoliu. - Frunde lineare-lanceolate. - In Arsess

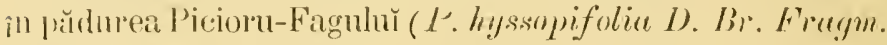
l. c. 95 / $1 \mathrm{um} \mathrm{Lat} . /$ ).

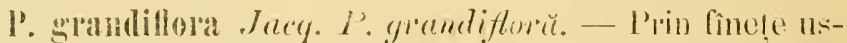
calle, pe coline aride, poenile de prin Inferiṣrŏ. - In lob̆

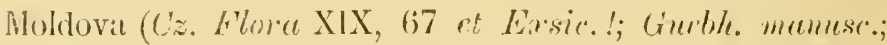

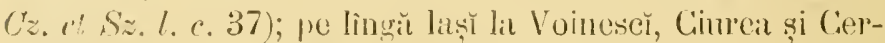

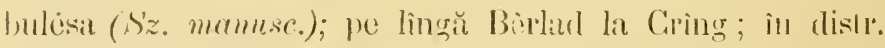

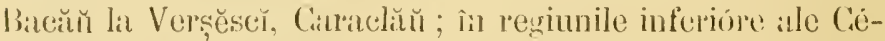

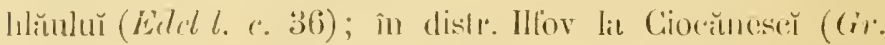

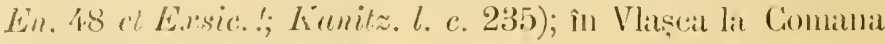

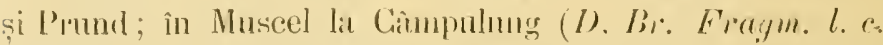

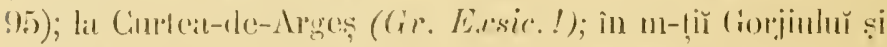

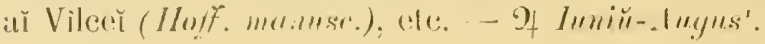




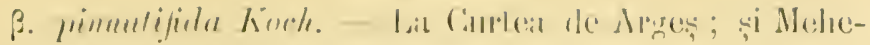

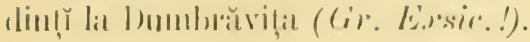

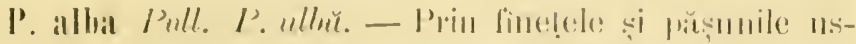

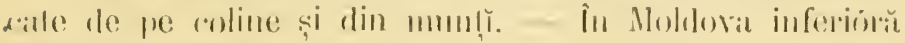

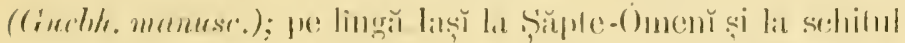

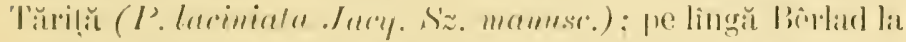

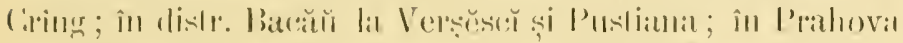

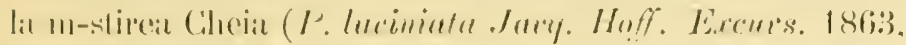

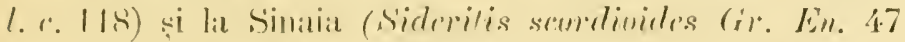

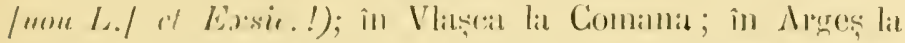

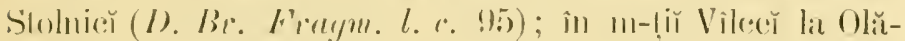

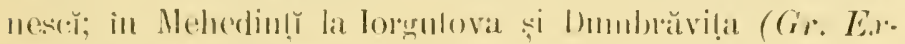

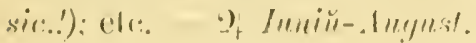

Obs. - Tóte varietăţile acester specir menționate de laummanten în Flora Transilvauiey, sunt indicate și îu Moldova (

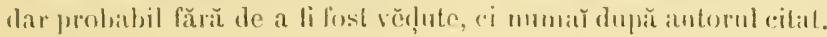

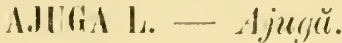

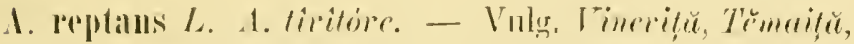

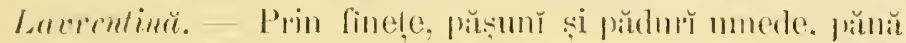

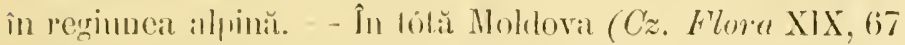

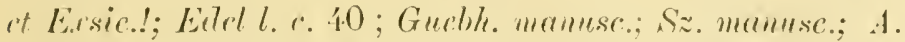
alpina Cz. Flara XIX, 67 /mon Till.7 ot E.rsic..! h. j.

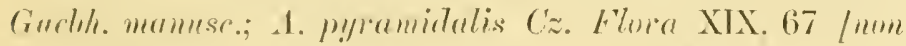

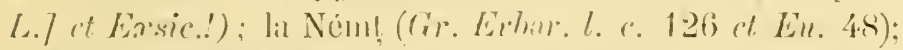

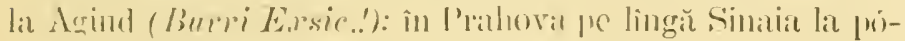

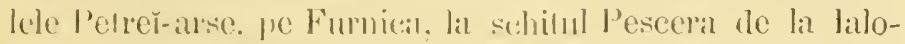

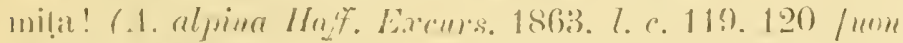

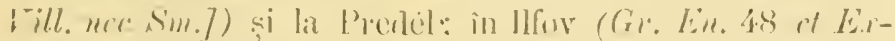

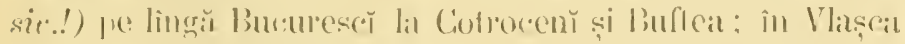

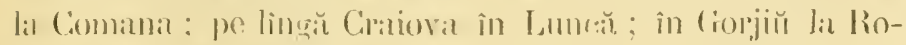

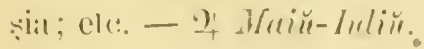

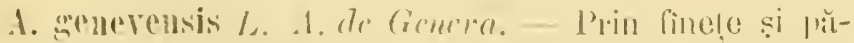

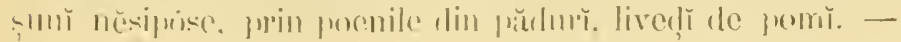




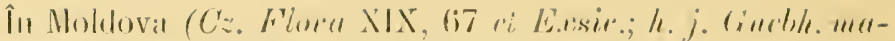

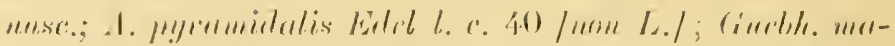

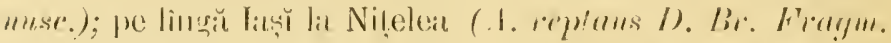

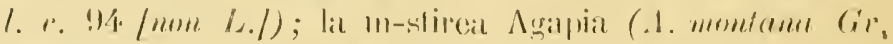

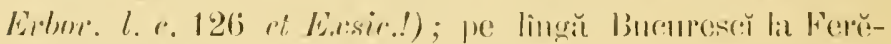

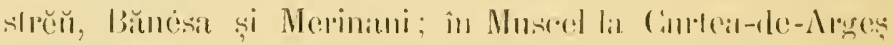
((

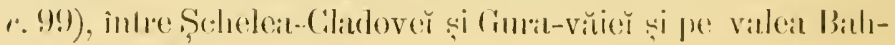
nеу. - of Маій-Inиiи.

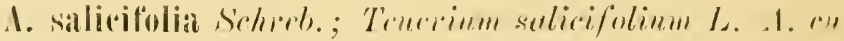

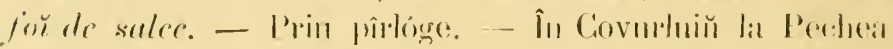

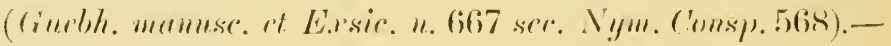
-) Inпій-Inliй.

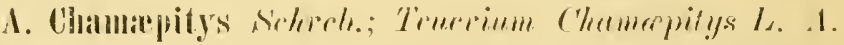

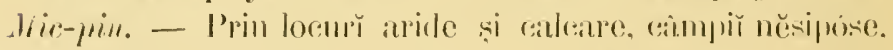

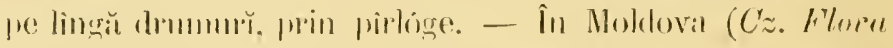

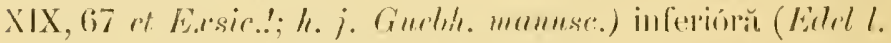

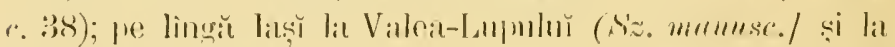

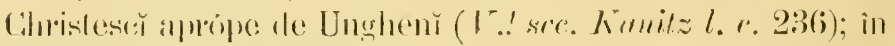

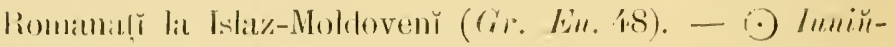
linifust.

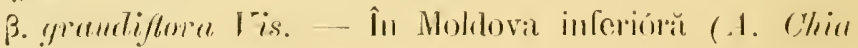

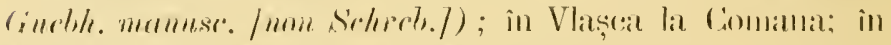

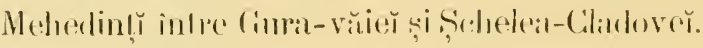

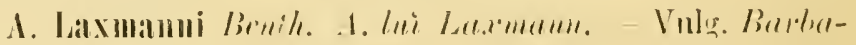

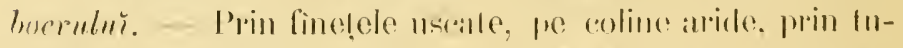

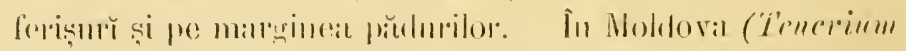
Latrmammi L. (

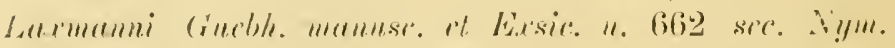

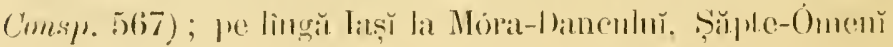

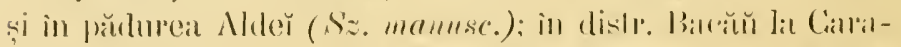

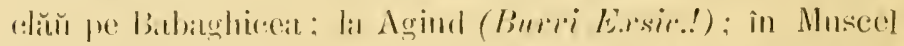

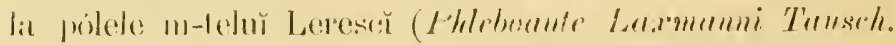

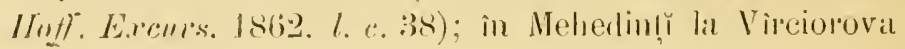




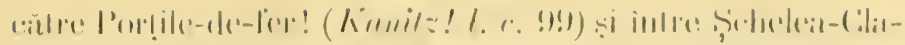

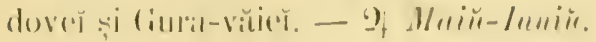

\section{TEI'RIIII L. - Téncriü.}

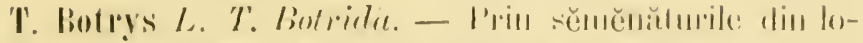

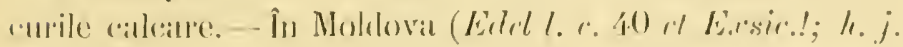

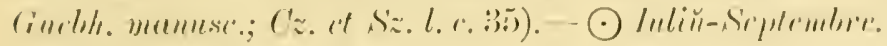

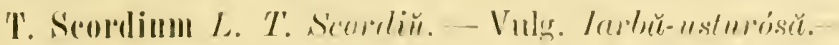

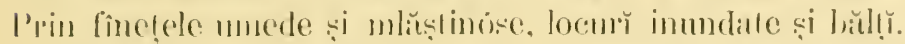

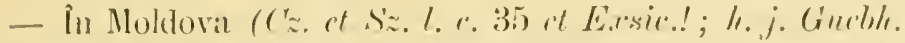

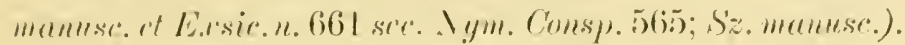
- 9 Julin̈-lu!gust.

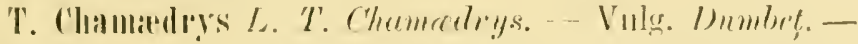

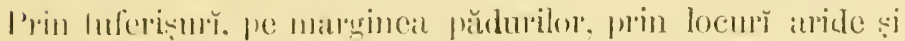

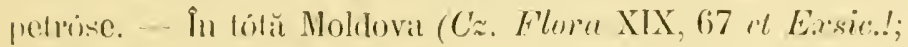

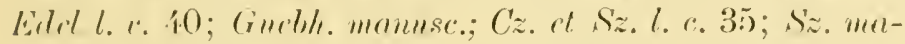

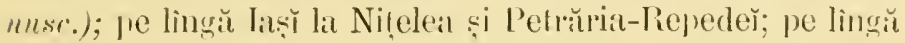
firvlad la Cring (1). Br. Fragm. l. a. 9.1); la m-slirea Aga-

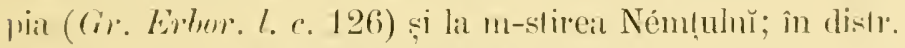

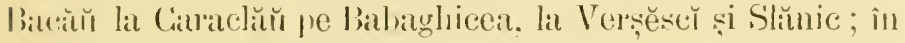

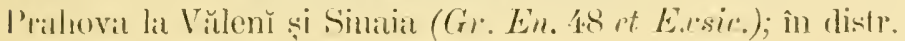

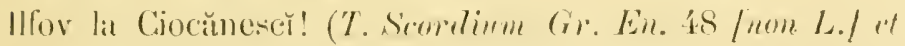

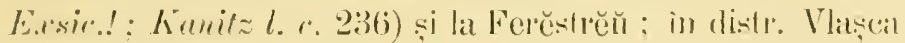
lat Connama; în m-liŭ Muscelılur̆; la Cintea-rle-Arges și la Pi-

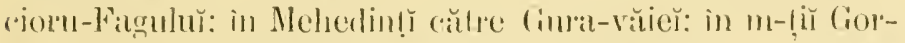

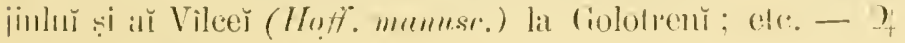
Inniй-1uynst.

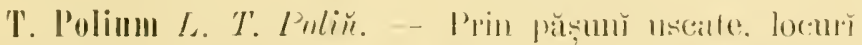

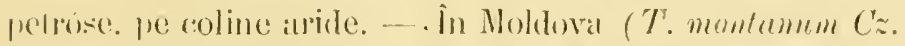

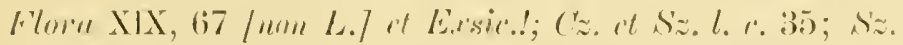

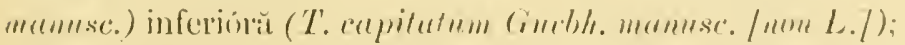

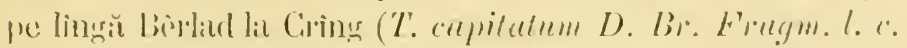

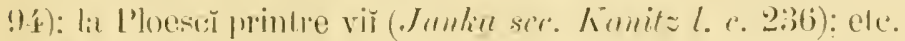

- y Inlin-.luyust. 
T. montanum L. T. mentun. - Prin locmile stincose și

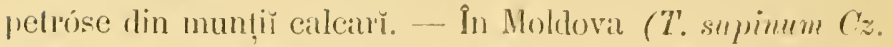

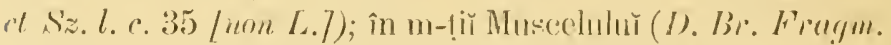

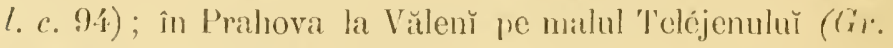
E.rsic.!). - 2 lumiu-1ugust.

3. pannonicum. - In distr. Bač̆̆ lat Citraclăı̆ pe Bahaghicea; la Vîrciorova către Porlile-de-Ler! (T. pannonicum Kem. Simk. 592) și între Gura-văiĕ și S,cheleat-Cliulover̆.

Obs. 1. - Se maY citéză : T. Seorodonia $L$. in Moldova $(C z$. et $S z$. 1. e. 35). - lar T. litifolium din Moldova (Cz. Frlore XIX, 67), nu sciú ce póte fi.

Obs. 2. - Se cultivă : 0ey vandula Spica $L$. (L. vera $D C_{.}^{\prime}$ ), vulg. Lecural, Aspic, Spichinut.

\section{SUB-HIVISIUNEA IV.}

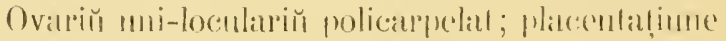
centrallit liberă.

\section{PRIMULACEE.}

\section{TRIENTAls L. - Triontalu.}

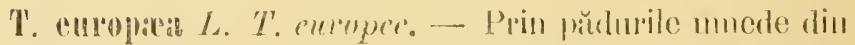

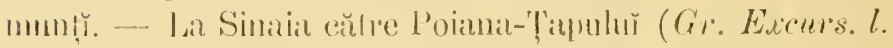

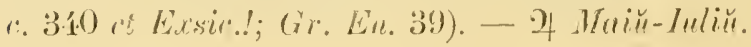

\section{AYSIMAchi L. - Lisimentie.}

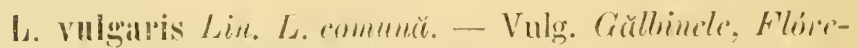

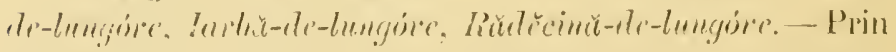

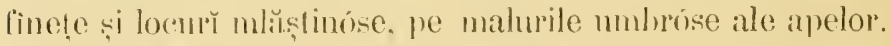
- În lobli Moldova (Gueloh. mamuse.; Eilel l. c. 37; Sz. munuse.; L. thypsiflura Cz. Flora XIX, 61 fuon L.f it Ex- 


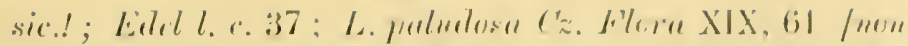

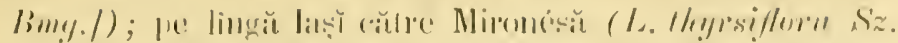
mermuse.)

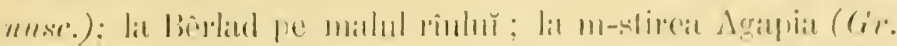

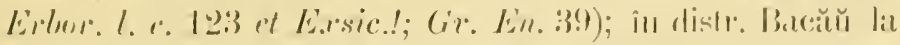

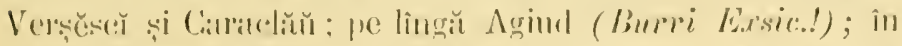

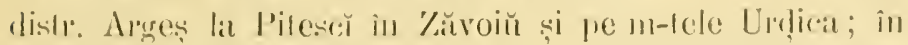

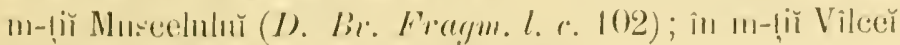

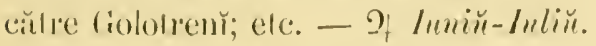

I. Punctata Lin. L. pumelatio. - Prin locamile muneste

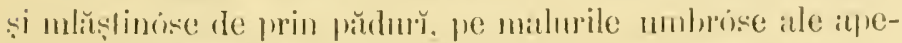
lor. - In Moldovat (C'z. Flora XIX, 61 et Eirsic.!; L. vul-

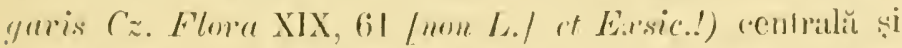

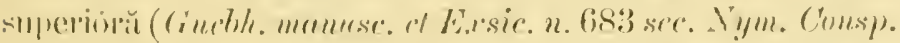

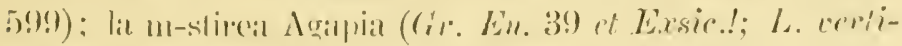

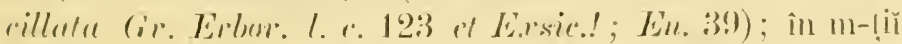

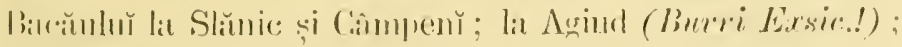

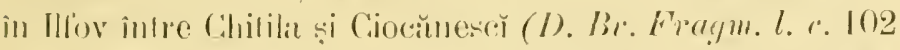

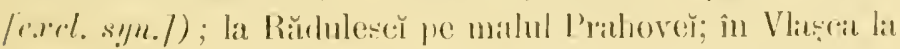

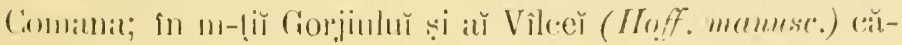

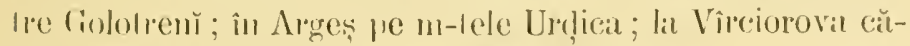

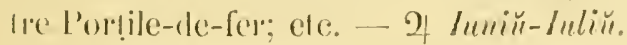

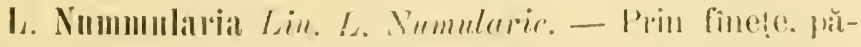

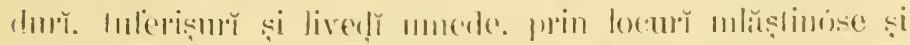

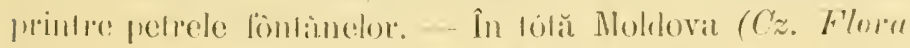

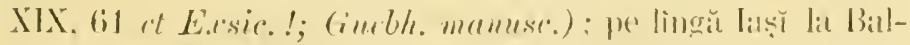

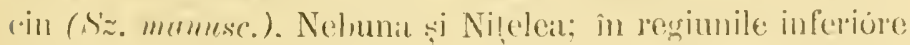

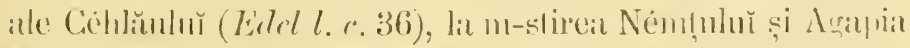

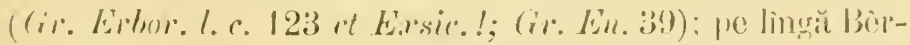

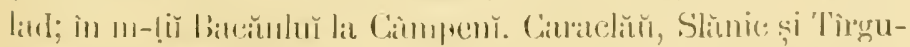

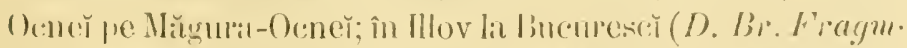

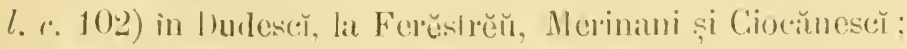

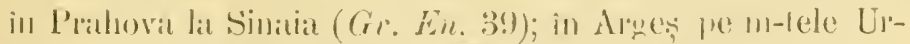

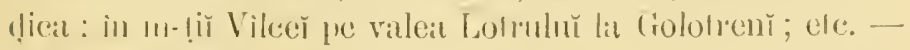
Q. Inniü-Inliü. 


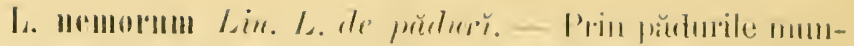

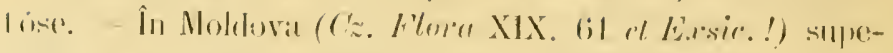

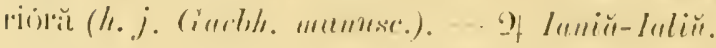

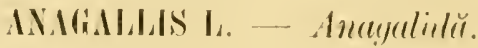

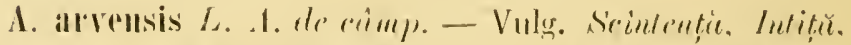

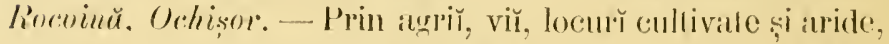

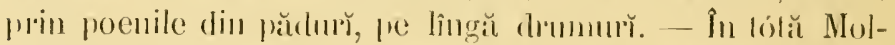
dova (Edell. e. 39); Gr. Eiborr. l. C. 122; .1. pheeniecel Lam.

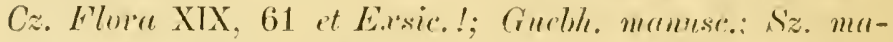
uusc.): la Bôrlad in pădurea Crîngu (1). Br. Fragm. l.c. 102); în distr. Bačŭ la Caraclăn̆; la Ngiud (Burri E.rsic.!);

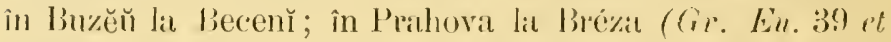

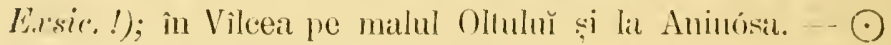
Inniй-s'sptemlere.

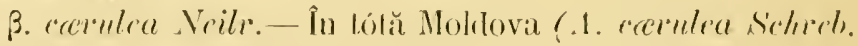

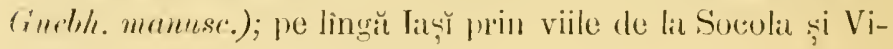
sill (Sz. maunsc.).

\section{CENTTYCLIUS I. - Centancul.}

C. minimus L. C. pilie. - Prin locurile umede și nĕsi-

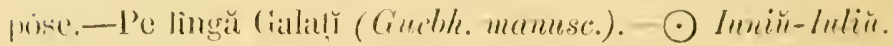

\section{ANGROSICE L. - Androsacé.}

1. villosa L. 1. pérérë. - Pe slincile din regiuncia al-

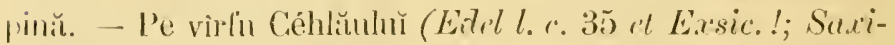

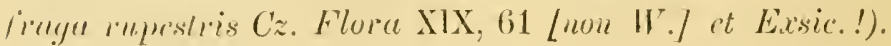
- of Inniй-In!yust.

1. Chathajasme Host. - Vulg. Primulitiu, Laphele-stin-

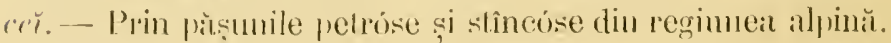
- İn m-liĭ Moldover (.1. septrutrionalis S'z. Exsic. [non 


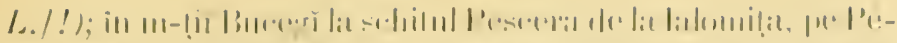

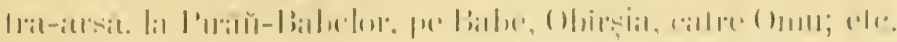

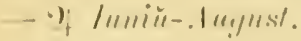

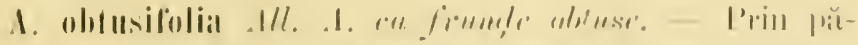

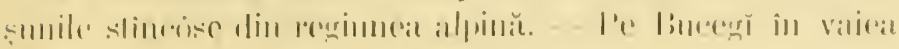

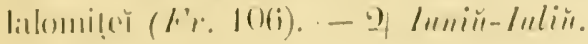

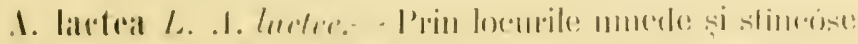

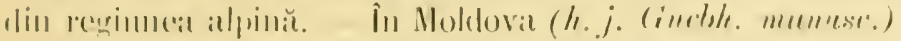

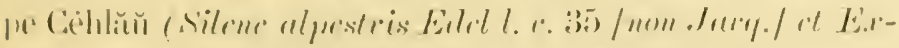

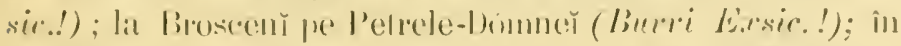

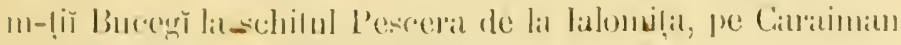
și pe Omu. - - lumin- luygust.

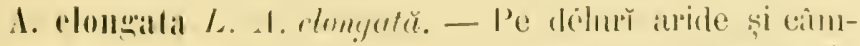
purī něsipuse, min viī și locurř cullivite și inculle. - l̂n

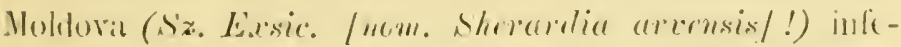

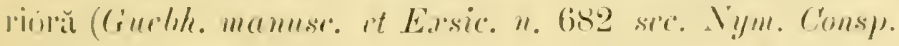

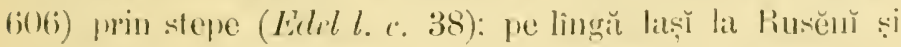

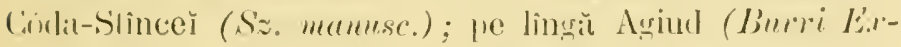

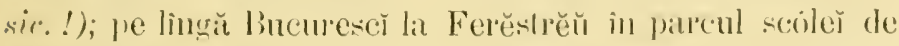

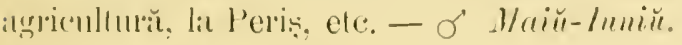

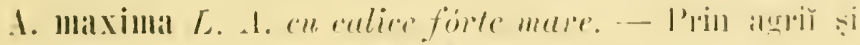

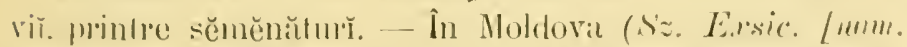

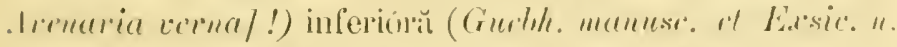

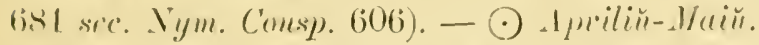

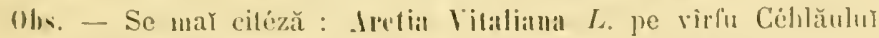

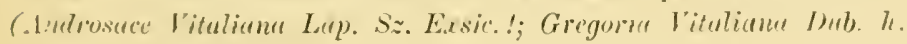
j. Guebh. mumuse.).

\section{HOTTOXIA L. - Otonic.}

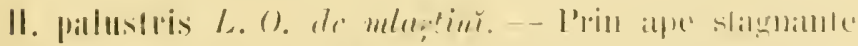

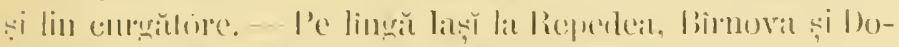

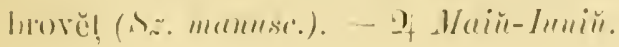




\section{Plimitat L. - Primulă.}

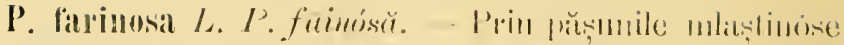

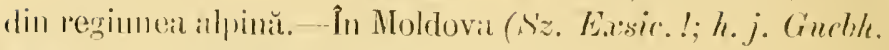
mumusc.). - of Iuliü- lurgust.

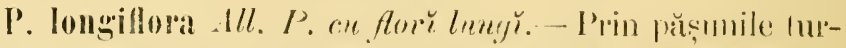
fóse şi muede din regimea alpină. - P'e P'ólra-Ciraindŭ eălre commna Vlüduçal (Kotschy, 64); lat Predél (F'tess,

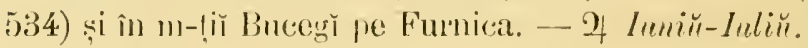

I'. acaulis Jacy.; P. grandiffore Lam.; P. melyaris Huds. P. acaulü.- Prin finc!ele din pădurile subalpine.-

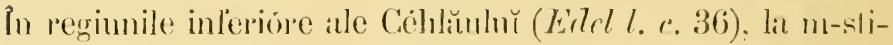

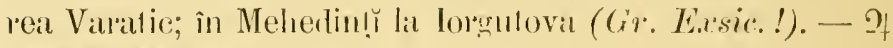
Amiliin-Martiu.

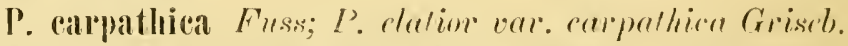

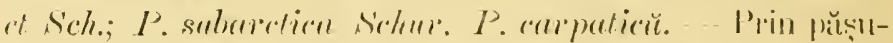
nile slâneóse din reginnea alpină și subalpinat. - l̂ regiunile inferiore ale Céhlăuhŭ (I'. rlution Eeld l. c. 336 [non

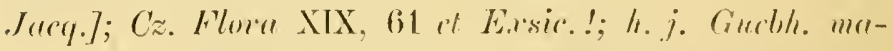

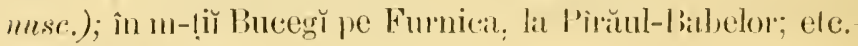
of Inniй-Inliü.

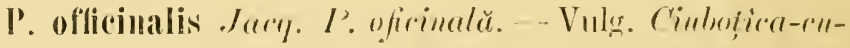

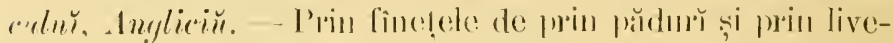

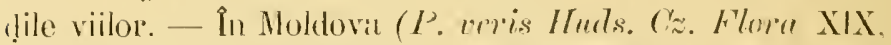
61 et Exsie.!; Cz. rt Sz. l. c. 7 ; S. manuse.) tólĭ (ciuch). manusc.); pe lingă laș̆ eătre Repedea (D. Br. Fraym. l.c. 102); pe lingü Agind (Burri E.rsie.!); lit nu-slireal Ném-

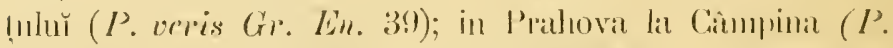

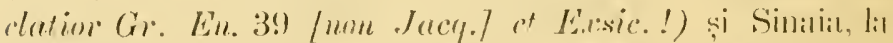

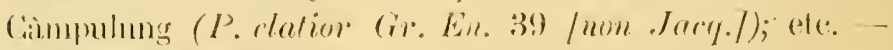
9) Apriliй-1/аiй.

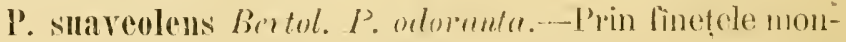
lane și păsunile petróse și unbróse din reginnea subalpină. 


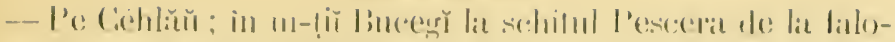

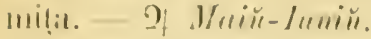

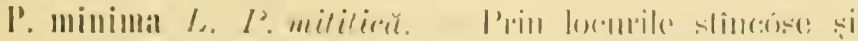

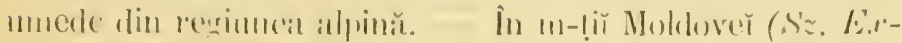

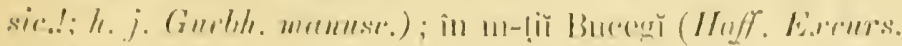
1863.1. 1. 119; Fr. 106i) pe Virfu-cu-1)oru (cir. En. 39!

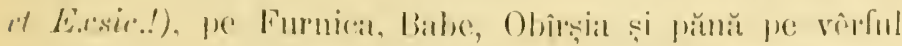

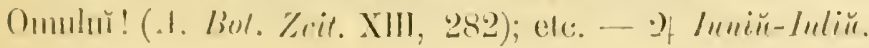

\section{COR'THISA I. - Cortusĕ.}

1. Matllioli L. C. Mne Buthiul. - Vulg. C'inbutica-nersuluc. - Le lingri simeile unede și mubrise și prin locurile petrose de pe lingü torentele din regimea subalpină și

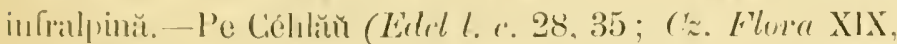
(il it liseir.!: h.j. Gucbhe mamese.); ha Broscent pe Petrele-

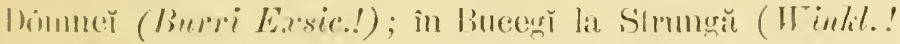
sre. Kunilz l. c. 237), spre liahe (Gir. En. 40), lil sehilul

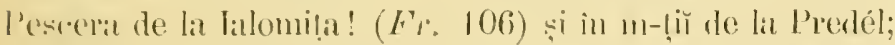

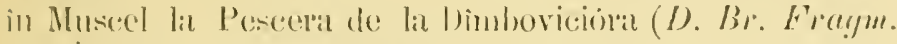
1. с 102). - of Inniü-Iuliü.

C. pubens str. Nym. Ky. C. pubssevele. - P'rin locnrile slineose, umbrise și murede din regimea subalprină și

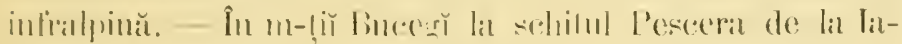

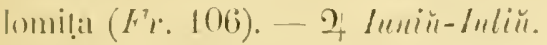

\section{SOLWINELLA L - Soldumeli.}

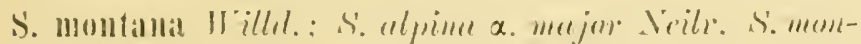

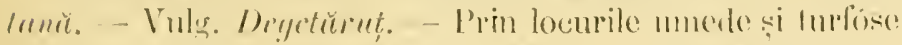

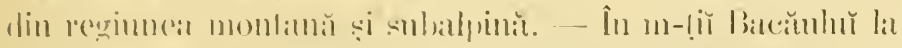

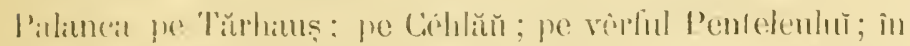
m-lii Buceng ( (

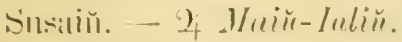




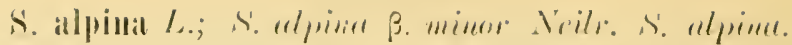

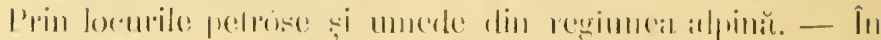

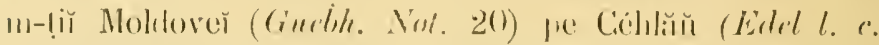

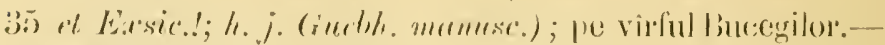
9. Mrair-luliu.

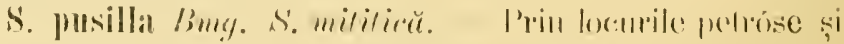

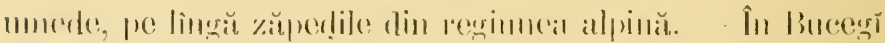

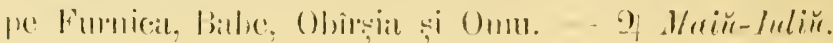

\section{GYCLIVEN L. - ricleme'n.}

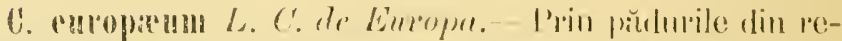

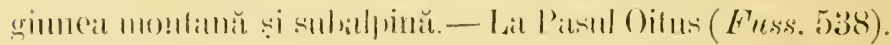

\section{IXVII. LENTIBULLARIACEE.}

\section{PINGutclial L. - Pinguiculă.}

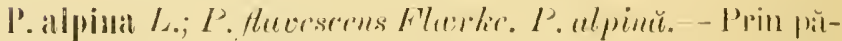
stmile muede și spongiose din regimea subalpină superioră

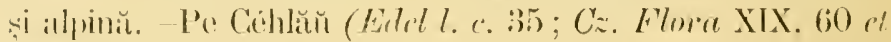

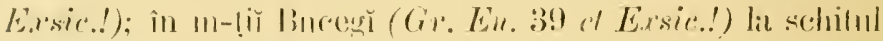

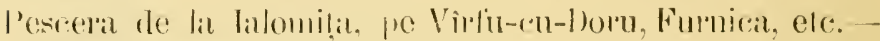
-) Main-Iuliur.

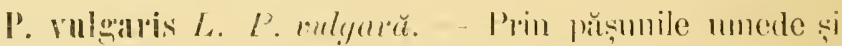

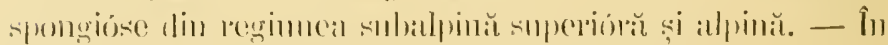

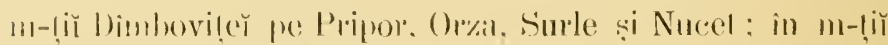

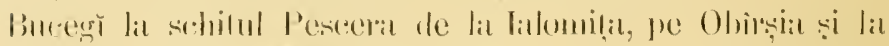

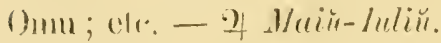

\section{ITRICULARIA L. Etriculurie.}

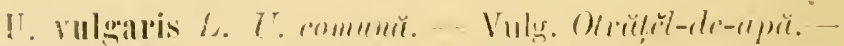

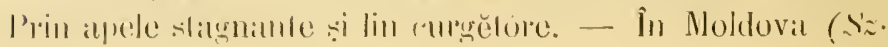




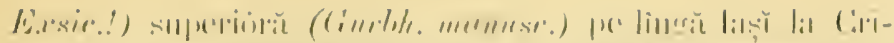

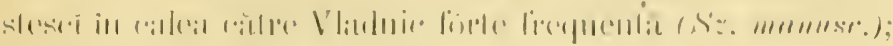

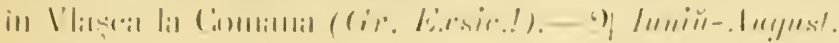

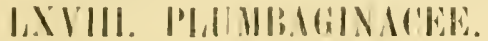

\section{MRILRII Willd. - Armerir.}

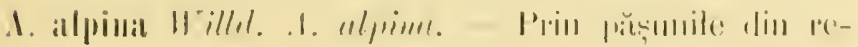

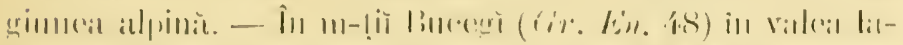

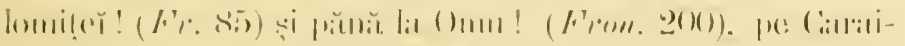

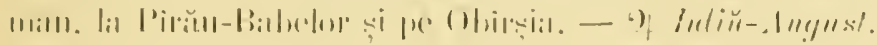

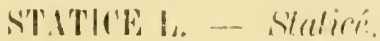

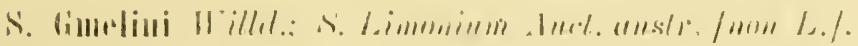

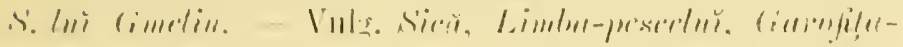

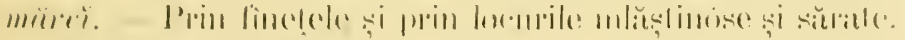

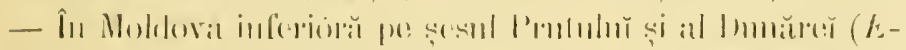

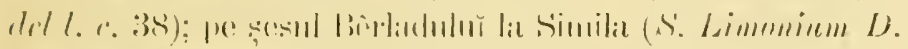

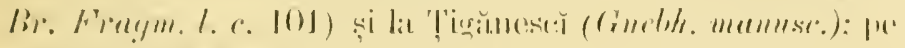

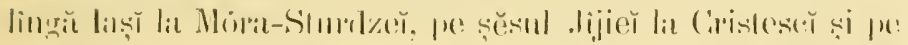

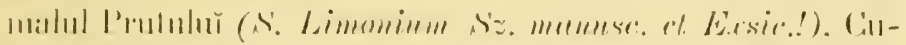

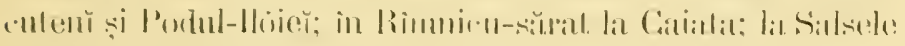

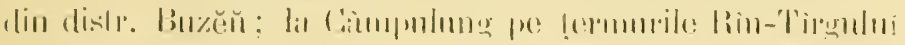

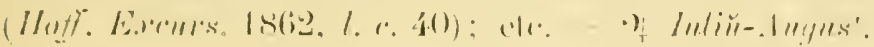

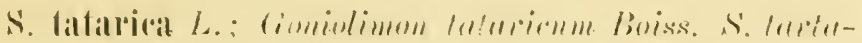

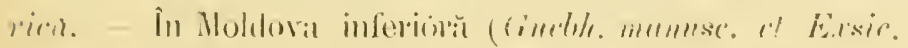

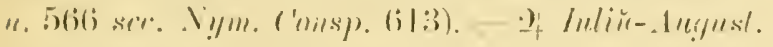

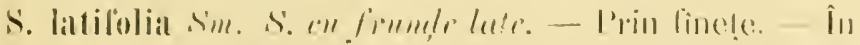

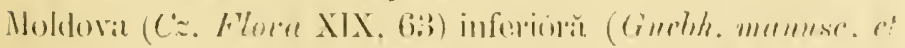

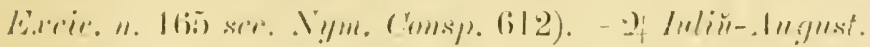

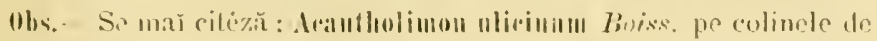

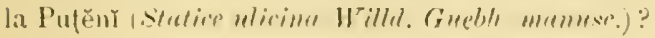




\section{LAIX. PLANTAGINAGEE.}

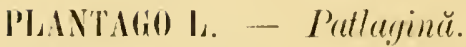

P. major L. I'. mare. - Vulg. Platayinü, Pallayiuer,

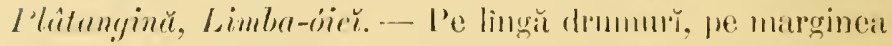
agrilor, prin fincţe monedeși locurr cullivale, phină în resiuncar subalpină. - În lólă Noldovia ( $C_{z}$. Flon'a XIX. 60

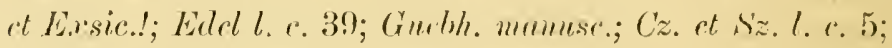
S'z. manuse.; P. major var. maxima Cz. Frlora XIX, 60 |mon Ail./; Sz. manuse.; P. Tubernaemen'ani Cz. Flora

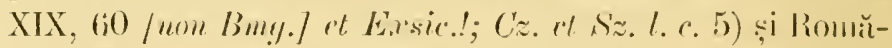

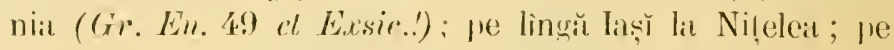
lingă Birrlat la Sloboḍia (I). Br. Frougu. l. (2. 102); in Ar-

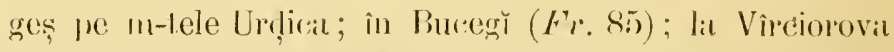
călre Porțile-de-fer (Kamiz! l. e. 102); els. - If luliüSirptembre.

3. minima (I)(\%). - Prin locurile arenacee, petróse și

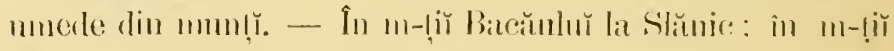
Bureeğ la sechitul Pescerar do lat lalomita.

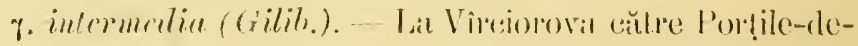
ler (Kunilz! l. c. 102).

P. Cornuti Ganan. P. Lü Tabrincmontana. - Prin lornrile umede și sărate. pe linğă saline. - La Gialalị (Uechlr.

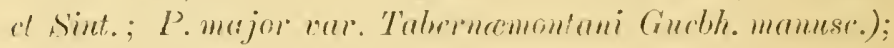

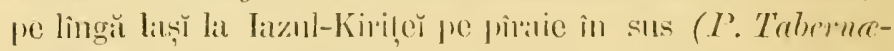
montani Bmy. S'z. mamses.); la sallinele de lat T'îrgn-Ocnê̌ :

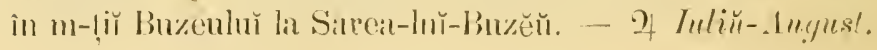

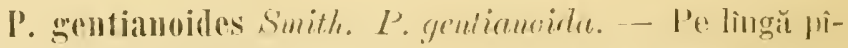
răile și bălṭile zăpedilor lopile din reginnea subsilpina și

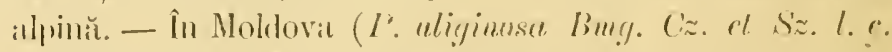

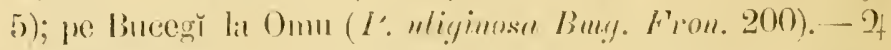
Innik-.1 luyust. 


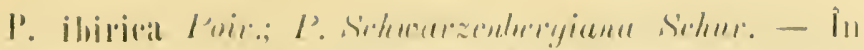

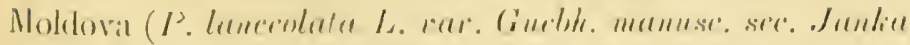

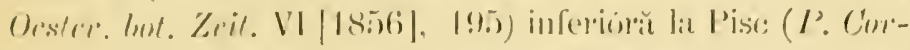

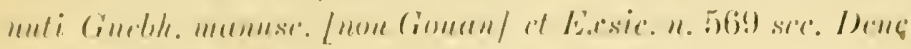
in . Nym. (omsp). 620). - 2 Intiir-.luynst.

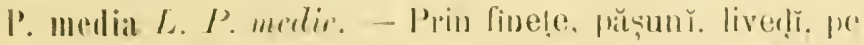

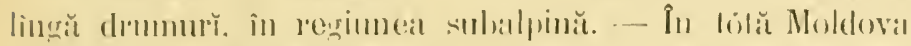

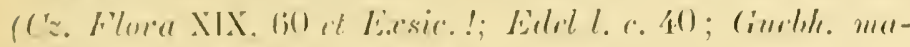

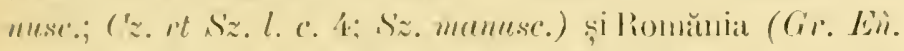

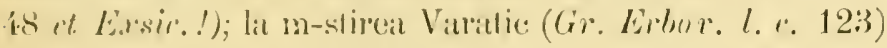

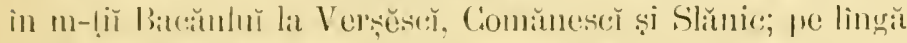

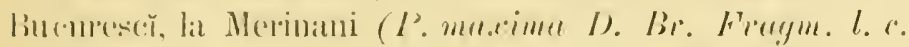
$102 / m$. lit./); in l'rahova la Cimmpina şi Sinatia; ele. ). Il criй-luliü.

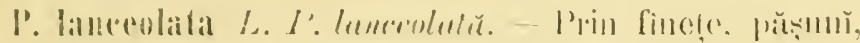

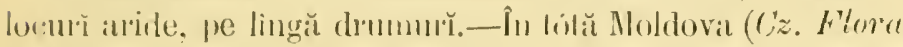

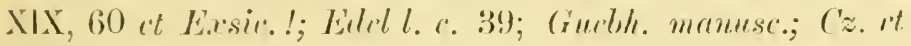

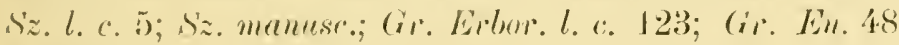

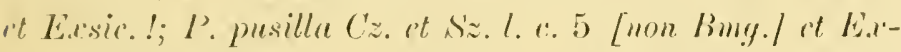

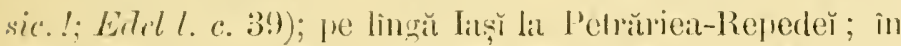

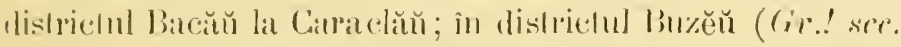

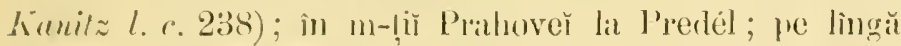

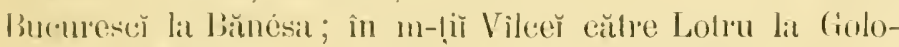
Irenı; în Mchedinṭ̆ lit Virciorovat către Porṭile-de-fer ; elc. - 2) Iprilia-seplember.

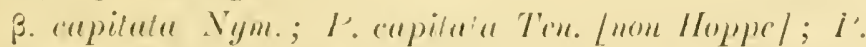

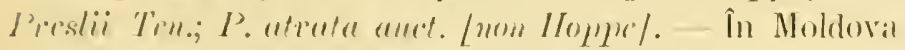

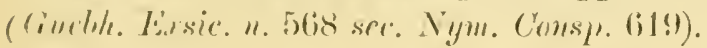

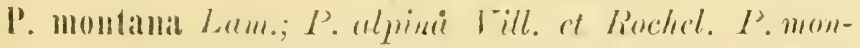

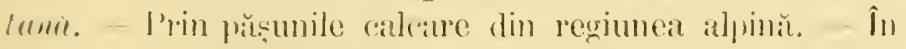

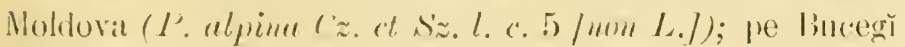

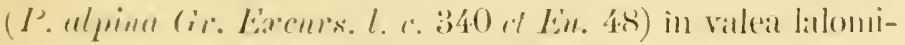

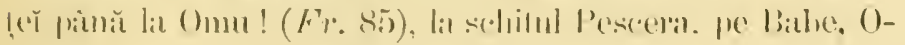

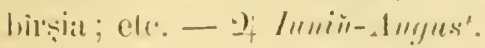




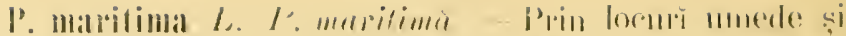

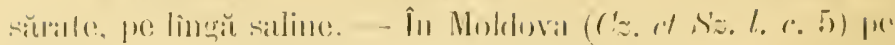

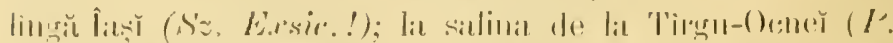

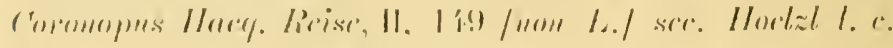

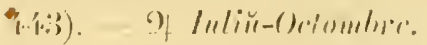

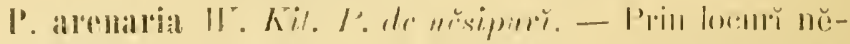

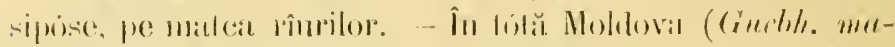

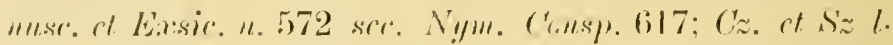

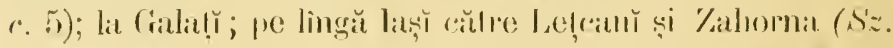

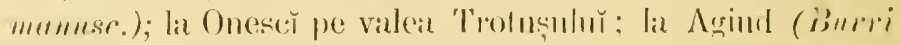

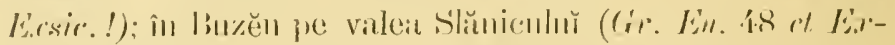

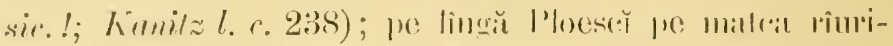

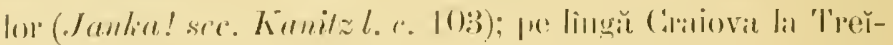

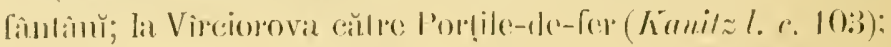

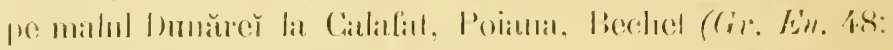

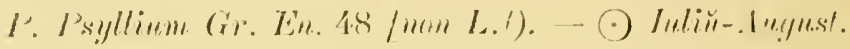

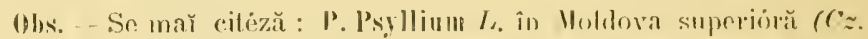

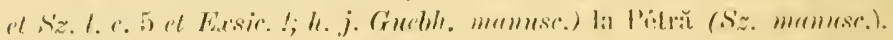

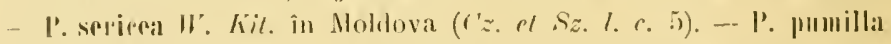

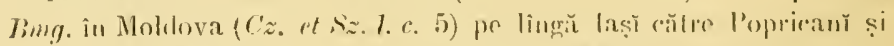

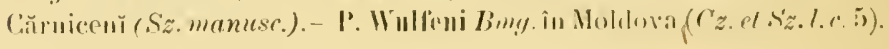

\section{HXX. SHSTHALEE.}

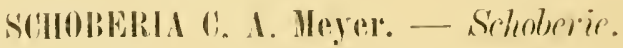

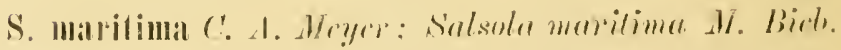

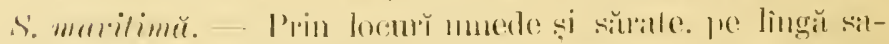

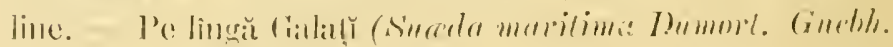

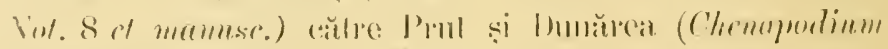

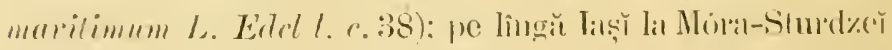

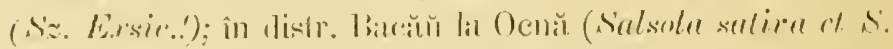

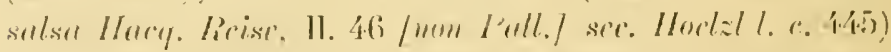

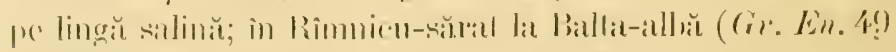

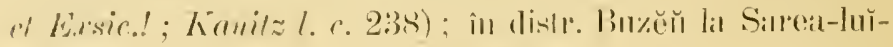

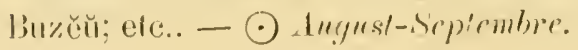


SAISOLA 1. - Salsolü.

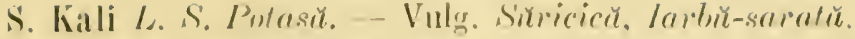
- Prin locurr ursipure și sarale. - In Moldova (Cz. Flura

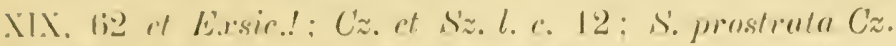

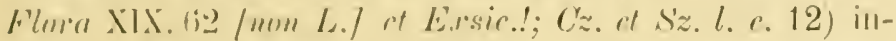

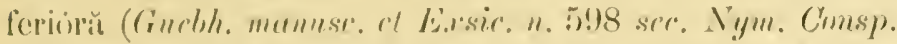

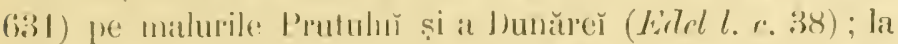

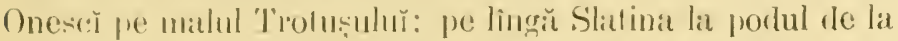
Olt: in m-liĭ m-stirilor Coriiı. Bistrița și T'Tismanat (Iloff. ma-

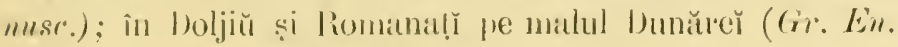
50). $-\odot$ Inliu-.lugust.

B. spinnsa (Lam.): S. Trayns I)C. et anet. var. [non L.J.

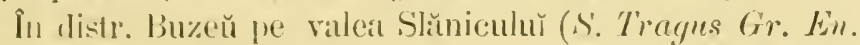
50 et Exsic.! : Kunilz l. c. 238) : în m-ṭĭ Cozicĕ, Bisırița și 'Tismantal (s'. Treegus Huff. mamesce ot Exsic.!).

\section{SAICORNIA \%. - Salicomie.}

S. herbacea L. S. erbacer. - Vulg. Jarba-porculur. Brâncǔ. Larbà-saratĭ. - Prin locurĭ sarale, pe lîngă saline. - Pe lingă Galạ̣ (Gurhh. Not. 8 et manuse.) pe malurile P'rutulŭ şi a bumătrĕ (Edel l. c. 38 et Exsic.!); pe lîngă Laṣ̆ la Cióda-Stînceĭ (Sz. momusc.); în distr. Bactŭ la Ocnă (Gir. Èbrur. l. r. 122 st Ėu.49) pe lîngă salină; în Rîmnicu-sărat la Balta-albă (Gr. Exsic.!; Koninitz l. c. 238); în Prahova la salina de la Telega : în Vîlcea liı Oenele-marǐ : (Scholl l. c. 511). - $\odot$ luliü-Septembre.

\section{CORISPERMIIII. - Corisperm.}

C. canescens Kit. ('. albicios. - Prin locurì něsipóse. In Moldova (Szz. Eissic.!). - $\odot$ Iueliǔ-.Juyust. 


\section{POLYCNEMUI L $\mathrm{L}$ - Policnem.}

P. arvense $L$. P. de cuimp. - Prin stepe, coline și pîrlóge něsipóse și argilóse. - In tótă Moldova (Cincbh. maunsc.; Edel l. c. 38). - $\odot$ Iteliü-1ugust.

P. majus A. $B r$. P' mare. - Pe colinele nĕsipóse, pe

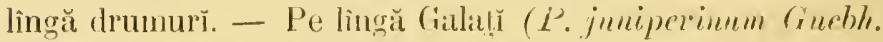
munusc. [non M. Bicb./?); in Vlaşca la Comana către valea Gurbanuluı̆ - $\odot$ Iulin̆-Angust.

\section{KOCIIA Roth. ...- Kochie.}

K. Scoparia Schrad. K. de mătuř̌. - Vulg. Mătuř̌. Măturì-ele-grădină. - Prin grădinı̆ de verdeṭur̆, grădinı̆ tẹ̆rănesč̆, bulgăriǐ, cultivat çi subsponianeŭ. - În tótă Piomănia! (Guebh. maunse.; Gr. L'u. 49; Burri Exsic.!; Hotf. Exsic.!; Chemopodium Scoparia L. Cz. Flora XIX. 62 ot Exsic.!; Edel l. c. 39; Cz. et Sz. l. c. 12: Sz. manusc.). $\odot$ luliü-Sentembie.

K. prostrata Schrad. K. prostrată. - Prin locurĭ nĕsipóse şi sarate. - În tótă Moldova (K. arenaria Guebh. manusc. (non Roth7 et Exsic. n. 595 sec. Nym. Cousp. 625);

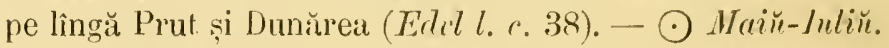

K. hirsuta Nolte; Salsola hirsuta L.; Echinopsilon hirsutnm Moq.-Tand. K. prérósă. - Locurì unede, nĕsipóse și sarate. - In Moldova inferióră pe nalul Prutnlnŭ și ، Dunărè̆ (Salsula lamuta Eidel l. c. 38 jnon Bmy. nec l'ull.7 et Exsic.!; Cz. et Sz. l. (. 12). - $\odot$ August-Septembie.

\section{CHEXOPODIII L. - Chenopoctiu.}

C. hybridum L. C. ibrid. - Vulı. Tulpa-gâscer, Spănac-porcesc. Bumianŭ-de-bubŭ-rea. - Prin dărĕmăturr̆: grădinı̆, pe lîngă zidurĭ. sardurı̆, locuințĭ, drumurĭ, prin lo- 


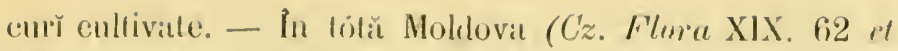

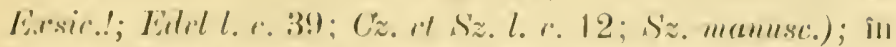

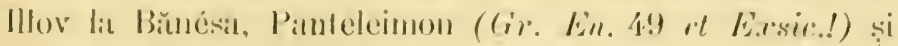
Bucurescě ; cte. - $\odot$ Inlin-sípplemliner.

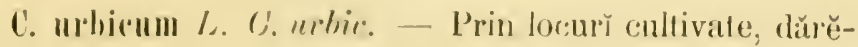

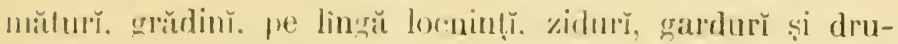

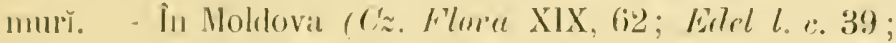

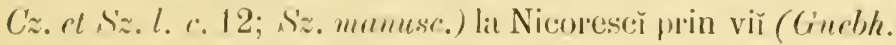
munusc.). - $\odot$ lutiŭ-sisptculner.

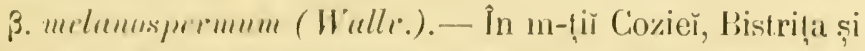

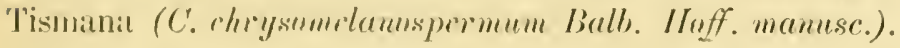

C. murale L. C. de ziduř̀ - Vulg. F'rumlă-1le-potcă.

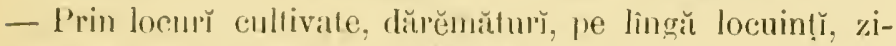
dur. gardurı̌ și drunurı̆. - In Moldova (Cz. rt s'z. l. c. 12; Sz. mamuse.): in Bu\%ей și Bucurewĕ (Gr. Eu. 49 at Essic.!; Künitz l. r. 23:9). - $\odot$ luliü-s'sptrmbre.

C. alhım L. C. alls. - Prin locur cultivate și inculte,

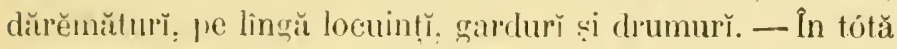
Romănia (Ëldel l. e. 39; (ruebh. manusc.; Cz. st Sz. l. c. 12; Sz. manuse.; D. Br. Hrogm. l. c. 102; Cir. En. 49). $\odot$ lulin̆-sirptembri

3. rymigcrum Koch. - In tótă Moldova (C. vivide L. Edel l.c. 39 ; Gnehh. mamusc.; Cz. et Sz.l.c. 12; Sz. man.)

C. poly̨sperımu L. C. polisperm. -- Prin vĭ̌, agriı̆, locurì umede, pe malca rîurilor, pe lîngă drumurǒ. - În tólă Moldova (Gurbh. muenusc.; Cz. ot Sz. l. c. 12); pe lingă Jaş̆ lat Balcin (Sz. manusc.) si lat Nitelea (I). Br. Frugm.l.c. 192): îı dist1. Buzeŭ pe valea Slăniculuı̆; în Bucurescĭ la gillat Tirgoviștea (Gr. En. 49 it Exsic.!; Kanitz l. c. 239); pe lingă Ciraiova în Luncă - - Julin̆-Octombre.

C'. acutifolinm Kit. C. en foŭ essuţite. - Loeurĭ umede. - La Cialậ̣ (Guedh. memese.); la Ciùnpulung pe lingă Riu-

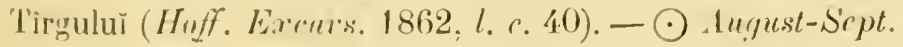


C. Vulvaria L.; C. fretidum Lam. C. fetid. -- Prin lo-

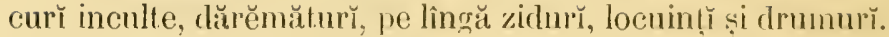
- În tótă Moldova (Gurbh. menurs.: Cz. ct Sz. l. c. 12; C. olidum C'urt. Estel l. c. 39) et Exsic. '; Cz. ot S'z. l. ค. 12 ; Sz. mannsc.); etc. - $\odot$ Intiü-.lugnest.

C. Botrys L. C. Botridă. -- Vulg. Tŕmäitü. - L'rintre petrele de pe matca rîurilor. - În totă Moldoria $(C z$. Filore XIX, 62 st Eixsic.!; Czo et Sz. l. c. 12; Ambrina Botrys Moguin-Tamel. Ginebls. manuse. et Visesir. ne.584 sec. Nym. Consp. 624); pe lìnğ 'lìrgu-Némlulŭ (C'. cmbrosivieles Cir. Érbor.l. c. 122 (non L./); in distr. Biacăŭ la Tîrgul-Oener̆ și la Verșĕscr̆ ; la Agind; în distr. Buž̆ŭ pe vilea Slănienluи (Gr. En. 49 ot Exsic. !; Kanitz l. c. 239); în Prahova la Bréza; în Muscel la Câmpulung pe vilea Rìn-Tìrguluĭ (Hoff. Excms. 1862, l. c. 40) și la Nĕmăescĭ ; la Pitescĭ pe valea Argesuluı̆ (D. Br. Fragm. l. c. 102); pe lìngă Cimaiova în pădurea Brésła; in Vileca la Băleescĭ și la Golotrenı̆; în Mehedinț (Gir. En. 49) la Vîrororova cĭtre Portile-de-fer! (Borb. sec. Kanitz! l. c. 105); etc. - $\odot$ luniŭ-Lugnst.

C. glaucum L.; Blitum glaneum Koch. C. albĕstriǔ. Prin locurı̆ umede și sarale, pe linğ̆ zidurı̆ și drumur. -

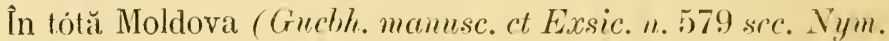
Consp. 624; Edel l. c. 39; Cz. ot Sz. l. c. 12; Atriplex littoralis (z. Florc XIX, 62 (nom. L.] rt lexsic.!); in m-tii Bacăuluй la Slănic; in Bucuresč̆; etc.- $\odot$ Inliŭ-śsptemlne.

C. Pubrum L.; Blitum rnhrnm Richl. C. rosiü. - Prin dărĕmăturı̆, pe lìnğ ziduri și drmmurř. - În Moldova $(C z$. et Sz. l. e. 12) inferióră prin locurile sarate de pe lingă Prut și Dunărea (Edcl l. c. 391). - $\odot$ Inniй-Lugust.

C. Bonns Henriens L.; Blitum Bonns Henriens C! 1. Mcyor. C. Buml-Emric. - Vulg. Spanacnl-ciobanilor. Prin dărĕmăturı̆, gunóie si pe lĭnğ satele și tîrlele din munț̣̆, pànă în regiunea alpină. - în tólŭ Moldova $(C z$. Flora XIX. 62 et Exrsic.!; Edel l. r. 39; ('z. et Sz. l. c. 


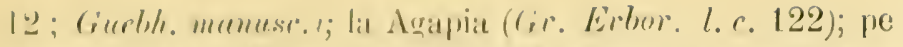

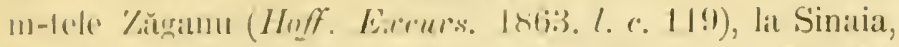

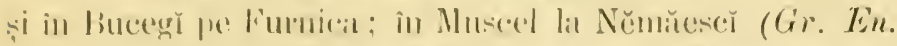

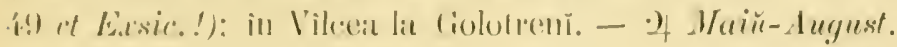

\section{BLITUM I. - Blitŭ.}

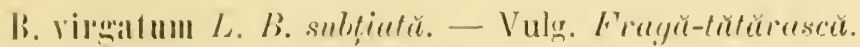

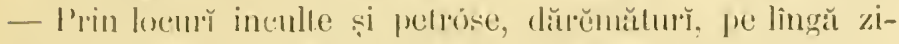

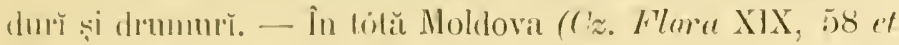
E.asic.!; Estell. c. 3!); (iuebh. manesc.; Cz. et Sz. l. c. 2):

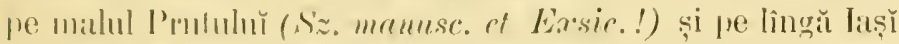

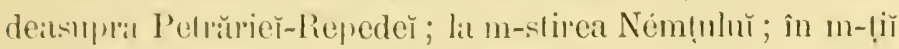

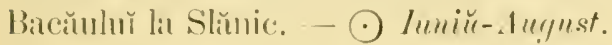

B. capitatmu L. B. rapitatr. - P'rin loeurr mmede și pelrice. - In Molulova eentralü și superióră (Gucbh. manuss.). - - $\odot$ Inniu-Auguest.

\section{C.MIPIOROSIL L. - Camforosmă.}

C. ovata II. Kit. C. ocatč - Prin locmile sarate. In Moldova (Corispermum hyssopifolium $C z$. Flora XIX, 58 fuon L.7 ot Exsie.!) pe lingă Jașĭ (Salsola lanata Sz.

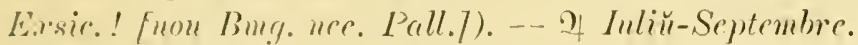

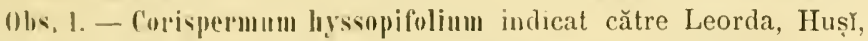
Fălciŭ și piină pe malurıle Seretulur ( $S z$. manusc.) sĕ nu fie óre tot Camphorosma orata W Kit.?

(1) Is. 2. - lieta vulgatris $L$. vulg. Sfecly, se cultivă în tótă Romănia (Guelh. munusc.; Cz. et Sz. l. c.12; Sz. mumusc. et E.xsic..' Gr. En. 49).

\section{BIONE Giertu. - Obióne.}

0. portulacoides Moquin-Tand.; Atriplex portulacoides L.; Halimus portulacrides Konch. O. portulacoidă. - Prin lomrile mnede și sirrite. - In Moldova (Sz. Ersic.! /nom. ('hemupodium polyspre?mum]): în dist. Buzĕ̌̆ pe lingă .losĕnı̆ la Salzele de la Pácle. - †̣ luliŭ-August. 


\section{I'TRIPIsEX I. - Loborlü.}

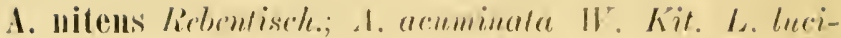
tóre. - Vulg. Loblorla. - Prin gunóile srădinilor si prin

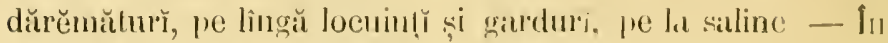
Moldova (Cz. Fllore XIX. 12 el Lissir.!; Edel l. c. 39 ; Cz. et Sz.l. e. 12; Gir. Ërbon. l. e. 122); lat Pecliea și Puțĕn (1. Hermanni Willemel. Cimeth. manusce st Exsic. n. 560 sec. Nym. Cousp. 627); în distr. liș̆̌ la Slìner̆ (S'z. manusc.);

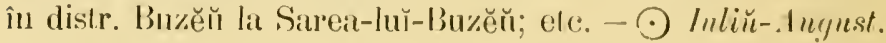

A. Latarica L.: I. oldongifolia W. Kil.; I. Leciniate Koch et anctor.; A. simucla Hoff. L. Lerlaricio. - Vulg. Lobodà. - P'rin dăıӗmăturĭ, locurĭ inculte, unede și sarale, în giurul salinelor, pe lingŭ drunurĭ. - Tि tólă Moldova (C'z. ct Sz.l. c. 12; Sz. manuse.; .I. Incimialu Cz. Flora XIX, 62 et Exsic.!; Edel l. r. 39); Gurbh. mannse. et Lisic. n. 588 [oar.] sec. Nym. Cousp). 628; Chemopodinm murale $C z$. Flora XIX, 62 et Exsir.!); pe lingğ laș̆ la códi I:Lวuluĭ-

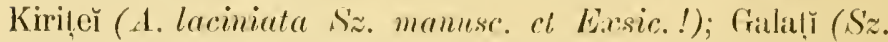
Exssic.!); la Salina de la T'ìrgu-Ocneй ; în distr. Buzĕŭ la Sarea-lŭ-13uzĕŭ ; in Bucurescĭ (Gr. En. $4.9 \mathrm{rl}$ Exsic.!; Kanilz l. c. 239). - $\odot$ Iulin̆-Anguest.

A. patula L.; A. angustifulia Simill. L. ce firunde ingusle. - Vulg. Lobodž. - Locur cultivale și inculle, pe lingă drumuř̆, dărěmăturǒ. - În Molkova $(C z$. Floma XIX. 62 el Exsic. !; Cz. et S'z. 1. ю. 12 ; Sz. manuss.) la Verșěsei pe malul Turluiului ; la Ploescĭ. Crivina, Buflea și Bucurescù (Gr. Én. 49 et Earsir. !); in Muscel pe délul Motoin̆ (Hoff. Excmes. 1862. I. (. 39): ele. - $\odot$ ) Inliü- lugust.

A. Iatifolia Wralilenh.; A. palula Similh. L. en for Iale. - Vulg. Labodĕ. - P'rin locurri inculte si sărate, dărĕmă1urĭ, pe lingă drumurǐ și gaırdurŏ. - În Moldova (.1. hasiala L. Oz. rt Sz.l. '. 12) prin mlaștinile sitrate de pe lingă (ia- 


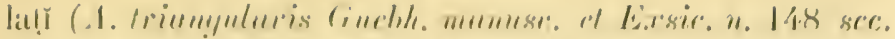

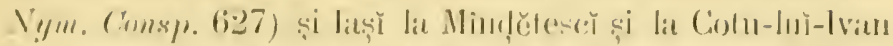

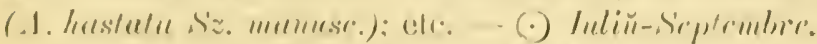

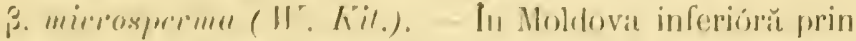

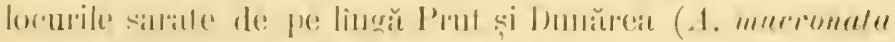

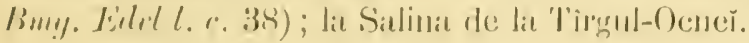

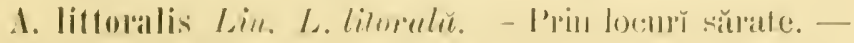

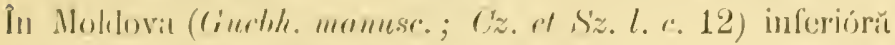

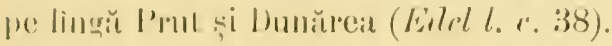

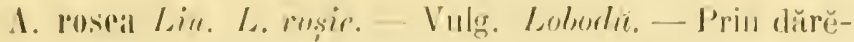

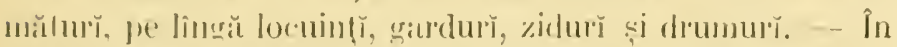

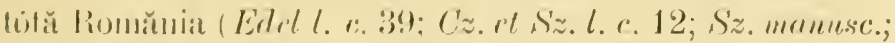

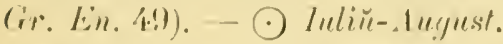

Ohs.- Se cultivă : A. lumtemsis L. (Fidel l. c. 39; Sz, Lersic..; Guebh.

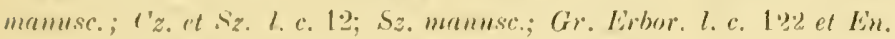

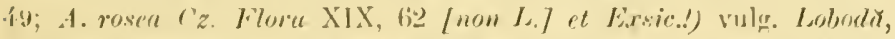

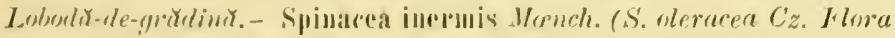

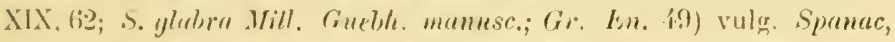
Epinut. - s. spimosa Ifoench. (S. oleracer .Jill. (Guebh. manusc.).

\section{CRRATOCARPLS L. - Ceralocarp.}

('. arenarius L. C. de misipur. - Prin locurile nĕsipose si uscale. - In Nolılova inferioria (Ciuslih. mamusc. ot Lissir n. 593 sec. Nym. Consp. 628). - - .

\section{MARANTIIS' I. - Amarant.}

1. petroflexus L. 1. refroftex - Vulg. Stir Stir-sét-

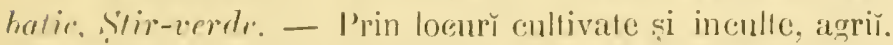

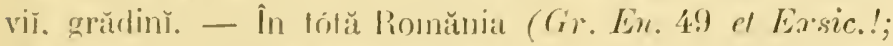

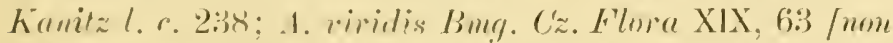

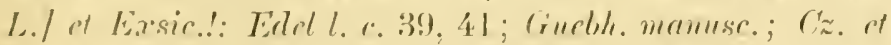

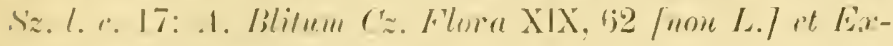

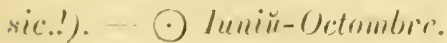


A. Blitum L. A. Blită. - Locurĭ cultivale și inculte,

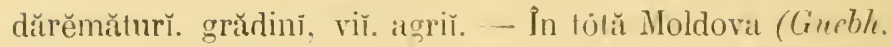
mamesc.; Edel l. c. 39; Cz. st S'z. l. c. 17; s'z.manusc.); Bucurescĭ (Gr. En. 49 et E.rsic.!). - $\odot$ Imliŭ-ilıgust.

0bs. - Se cultivă în tótă țéra : A. ('aulatus $L$. (Guebh. manusc.). - A. cruentus L. (Edel l. c. 38). - A. säuguninens L. vulg. Știr-roșu.

\section{POLYGONACEE.}

\section{RIJEX 1. - Rumex.}

R. maritimus $L$. R. maritim. - Pe marginea lacurilor şi a mlaştinilor. - In Moldova (R. aquatiens Cz. Filora XIX. 63 /non L.7 ot Exsic.!; Eddel l. c. 39; Cz. et Sz. l. c. 19) pe lîngă Tặ̣ la Cristesč și Vladnic (R. aquaticus Sz. manusc.). - $\odot$ Inliur-1uguest.

R. palustris Smith. R. de mlastint. - Vulg. Stevie: Dragaver. - Prin locurĭ mlastinóse. pe marginea lacurilor și a rìurilor. - In districtul Bacăŭ la Verșěscĭ (D. Br. Fragm.l. c. 102). - $\odot$ Inliŭ-Lugnst.

R. conglomeratus I/mrr. R. conglomerat. - Vulg. Stevis. Steghir, Stegie, Hacris-cäirse. Macrisul-caluhur. Prin finete mlisştinóse, locurı̆ umede. pe malul apelor. - În Moldova (R. Hydrolapathum Cz. Flara XIX, 63 /mon L.)

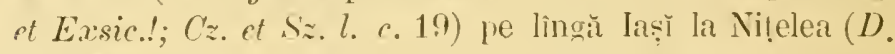
Br. Fragm. l. e. 102); în m-ḷŭ Bacăuluĭ la Slănic și Cùmpenǐ; pe lîngă Bucurescĭ la Bŭnésas și în Dudesč̀; în Vlaṣca la Comana; în Oltenia ( $R$. Nemolaperthrm L.hrle. Hoff. mamusc.): etc. - 2 Inliü-Alugnst.

R. sanguineus L. R. singeriŭ. - Prin locurile umede de prin păduř̌. - In Moldova (C'z. et Sz. I. c. 19 ; R. uemorosus Sehrad. Cz. Flura XIX, 63) centrală (Gueble. maunse.; Edel l. (. 37): Li Sinaia (Gir. En. 50 of Exase.!) pe villea Peleșuhü; la Stolnicĭ (D. Br. l. c. 102).--2 Inliŭ-1 uyust. 


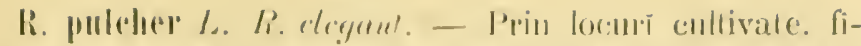

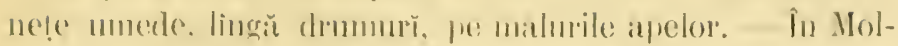

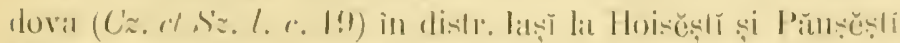

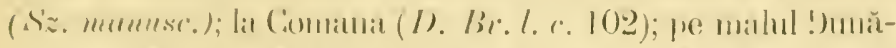

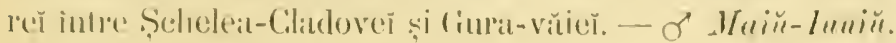

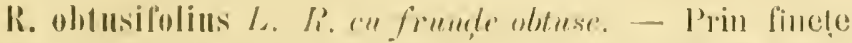

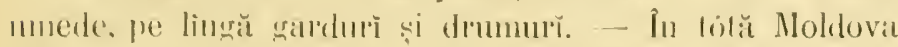

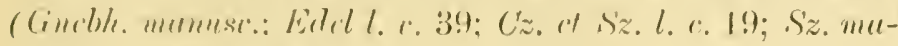

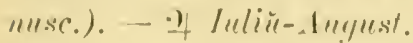

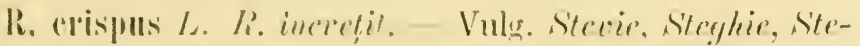

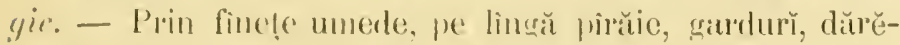

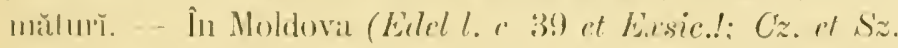

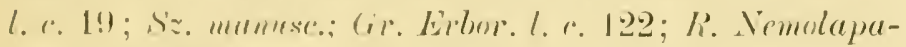

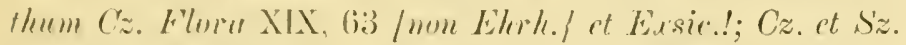

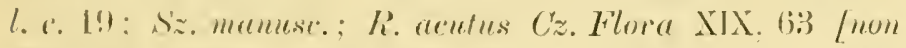

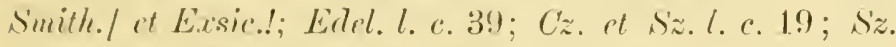
memusr.): lit Bucurescì (Gir. En. 50 el Exsic.!) în Dudesč̆, la Ferěstrěŭ și Ciocănescì (I). Br. Fragm. l. a 122); în

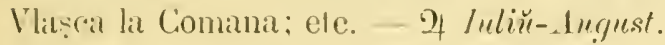

R. alpinns L. R. alpin. --Vulg. Stevie, steglie, Stegie. - Prin pășunile de pe lingă slînele de ol̆ din regiunea sub)alpină și alpină. - În Noldovia (Fild l. c. 37 ; Cz. ct Sz.l. c. 19); în m-lị̂ Prahover la Sinalit călre Emmit (R. maxi-

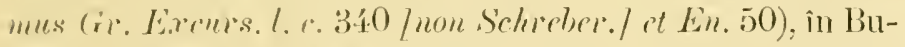
(eñ pe Furnica, liı Pirău-Babelor, la Predél pe u-tele Su-

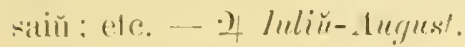

R. Acetasa L. R. Macris. - Vulg. Macris. - Prin fî-

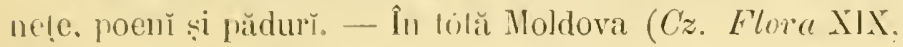
63 et Eirsic.!: Edel l. c. 39); Guebh. mamusc.; Cz. et Sz. l.

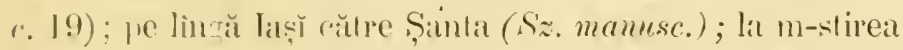
Agapia (Crr. Erbor. l. c. 1202 ; pe lingi Birlad la Sloboctia

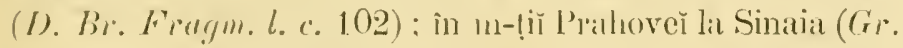

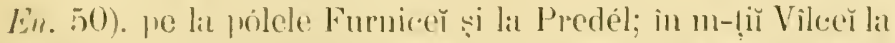

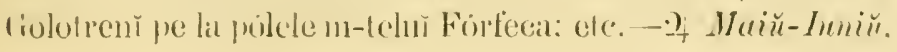




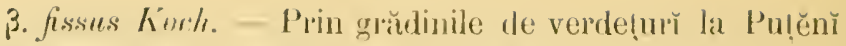
(R. intemertius (inelih. memuse. [non I)(Y)/).

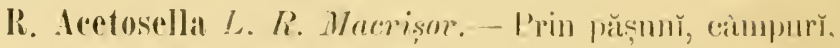
pîrlóge, locur culliviale ariele şi něsiprise. - In Moldova (Cz.

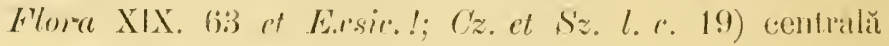

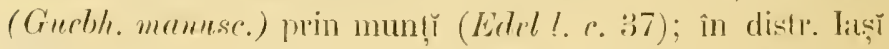
călre Voinescì şi Stavnic (Sz. manusr.); in distr. Baccăŭ la Verșĕsc̆. Cìmpeñ și Slănic; lat Agiud (Burri Exrsic.!) ; în Prahovat la Sinatat pe lingă Bucurescê la Ferěsırĕŭ și Cioeănescĭ (D. Br. Frargm. l. c. 102); intre Pitesci și Campu-

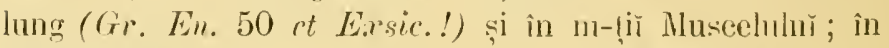
Vilcea la Bălcesci și Golotrení; elc. - 2 Main-Lulin.

\%. mullifidus (L.) Koch. - Lat Vireiorovil către Porțilede-fer! (Borb. 1873, Báns. 257).

Ubs. I. - Se mař citéză : R. acutıs $L$. în tótă Moldova (Guebh. mamusc.).- R. Ilydiolapathum $L$. je lîngă Bucuresề la Bănésa $(G r . E n$. כ0). - Iar, R. maximus ce se indică la Bărıésa și Ferěstrěŭ $(G r$. En. 50). 'mr pare a fi resultatul uner erorř de determinațimne.

Ohs. 2. - Se cultivă : R. P'aticutia L. (Cz. Flora XIX, 633; Gr. En 50) vulg. Stevie de grădină. - R. Linniria L. (Guebh. manusc.).

\section{OXIRIA Ilill. - Oxiric.}

0. digyua Cambder.; O. renifurmis Hooker; Rumex diygmms L. O. digină. - Prin locurile stîncóse şi mede din regiunea alpină. - În Buceğ, din valea Ialomiţer pănă la Omu! (Fr. 84) și la Pirăul-Babelor. - 2) Tuliŭ-Angust.

\section{POLYGOAIII L. - Poligon.}

P. Bistorta 1. P. Bistortà. - Vulg. Rä́culeț. C'indigați.

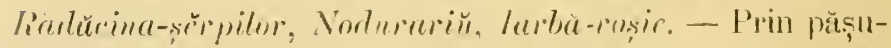
nile monede din muṇ̣. pănă in reginnea infralpină. - Î॥

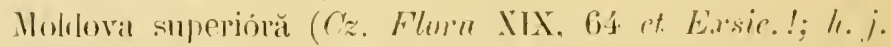

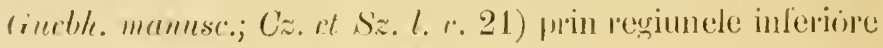




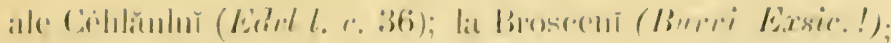

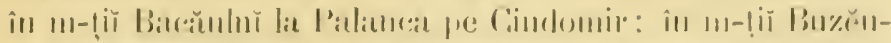

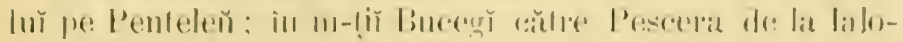

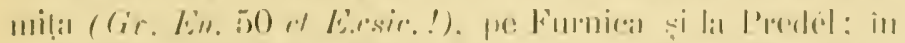

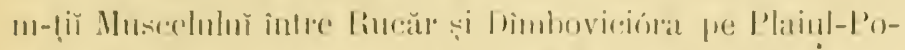

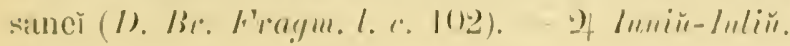

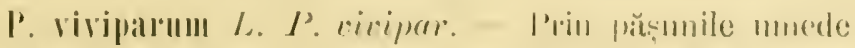

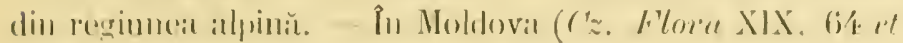

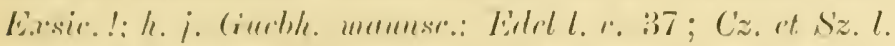

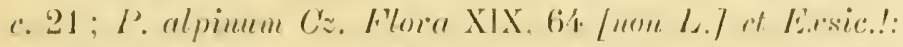
h. i. Ciurbhe menusc,; Cz. at Sz. 1. r. 21); in Buecgì (Ft.

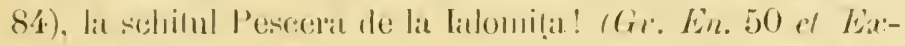

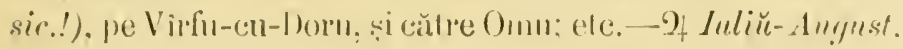

P. amphibimm L. I'. amfibir. - Prin apele stagnante

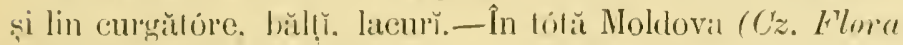

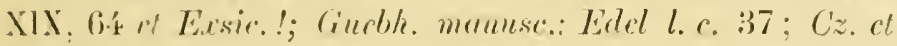

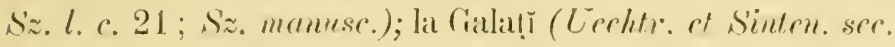
Lanitz l. '. 107) pe lînğ lacul biates (EAdl l. c. 38); la

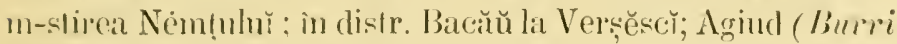

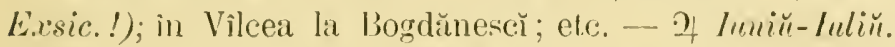
P. triresster Lerers. - In Moldova (Cz. rt Sz. l. r. 21) pe

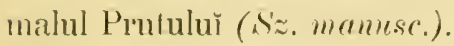

P. Iapathifolium L. P. си fŏ de stevir mare. - Prin locurile umede, ne malurile ajelor. - In disfr. Suceveř la Brosceñ (Burri Exsir.!): in distr. Bacě̆̆ la Cauraclăn̆ in Rimnicu-sărat la Sihlea; în Arges la Piciorn-Figuluř in

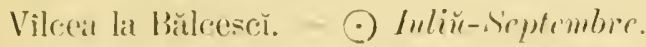

3. incremum (Schmidt.) Koch. - In Moldova (Cz. et Siz. I. r. 21) către Jaṣi la Horleștí (S'z. mannse.).

P. Persicarial L. I'. Prosicmir. - V'ulg. Iarhă-rusir.

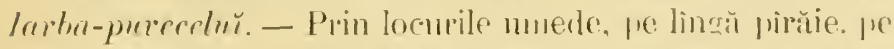

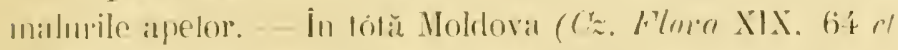

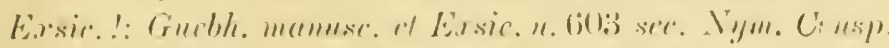

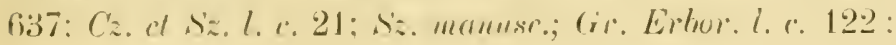




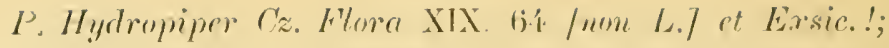

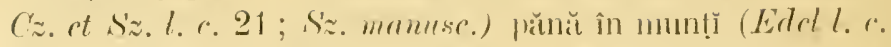

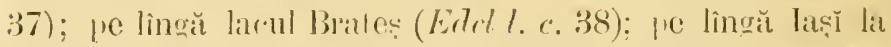

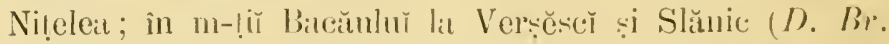
1. c. 102); în Prahovit lit Sinttia ( ( lingă Bucurescŕ; la P'itescr ; ele. — $\odot$ ludiŭ-Septemlure.

P. mite scherenti,; P. Laxifornem Wrihe. P. dulce. -

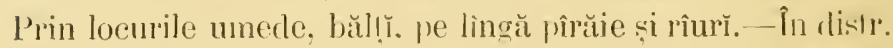

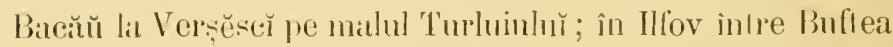
si Crivina (Cr. En. 50 ot Exsie !) și pe lingă Bucurescŭ la Bănesa și Ferěstrěŭ (P. Anbinm Strin. Gr. En. 50 ot lixsic.!). - - lutiü-Septemline.

P. Hydropiper L. P. Piprer-de-apà. - Vulg. Iarbŭ-

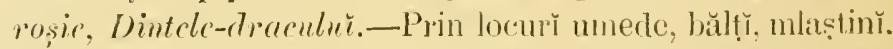
pîrăie. pe malurile apelor. - In Noldova centralŭ (Guebh. manuss.; Edel l. c. 37); pe lìngă lacul Brateș (Edcl l. c. 38); in Ilfor (Gr. Eu. 50 rt Exsic.!). - $\odot$ Intiǔ-Scptembre.

P. minus Hueds. P. mic. - Prin locurĭ umede bălțĭ. pe malurile apelor. - In Moldova (P. angustifolium Roth $C z$. et Sz. l. c. 21); in un-ị̆ Cozier̆, Bistrị̣a și T'ismana (Hoff. mamusc. ct Exsic.!). - $\odot$ Iuliil-s'sptembre.

P. aviculare L. P. păsăress. - Vulg. Trosect. Tir-

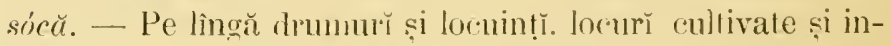
culle. - În tótă Romăniat! (Cz. Flora XIX, 64 ot Exsic.! : (rueth. manuse.; Edel l. a. 39; Cz. et Sz.l. c. 21; Burri E.rsic.!; Kanitz l. c. 108; Gr. Eu. 50 of E.esir.'; P.avicuInre r. aremarium Gir. Eu. 50 /nom W. Kit. ne Gren. ot

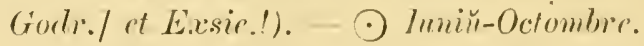

B. erectum (lioth) Kosh. - În Molelova (Cz. Flord XIX, 64; Sz. manusc.); în Bu(urescĭ (Gr. Ën. 50 ol E.rsic.!).

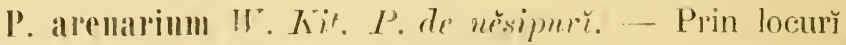
nĕsipoise. - In Moldovil (Cz. ci s'z. l. e. 21) pe lîngă lașĭ

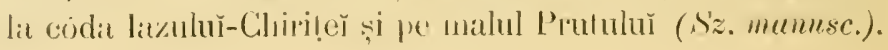




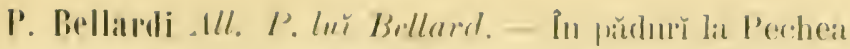

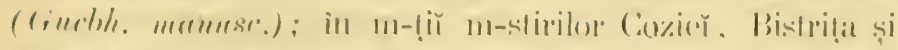

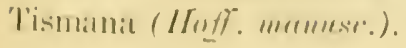

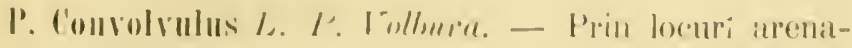

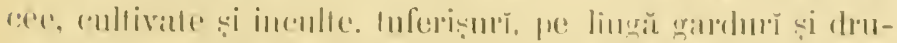

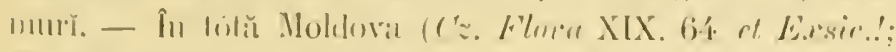

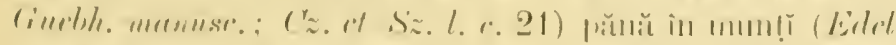

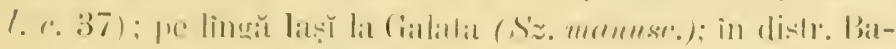

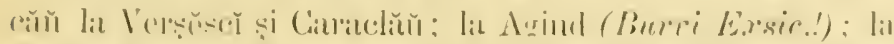

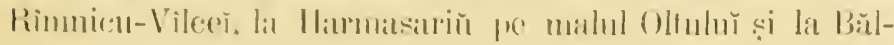

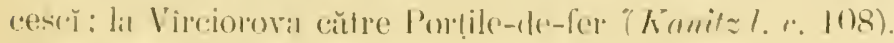

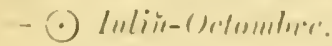

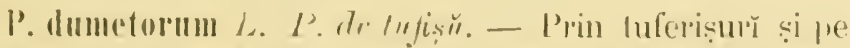

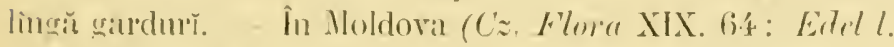

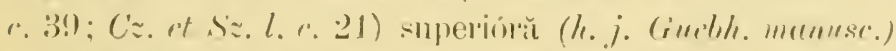

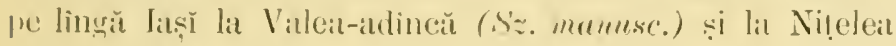

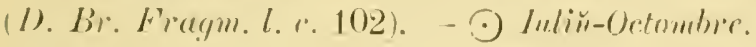

P. alpiunm .1ll. I'. alpin. - P'rin pășunile din regiuneá alpină. - P’e Céhlăı̆ (Edel l. c. 35̃).

Obs. 1. - I'. Faugupyrum $L$. vulg. Hrişcr, se cultivă fórte frequent wat cu sémă în Moldova (Cz. Florn XIX. 64 et Eirsic.!; ('z. et Sz. 1. r. 21; Guebh. menus.se, Fidell. c. 37 ).

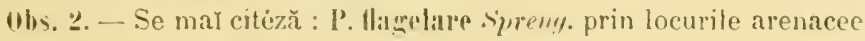
de pe lingă Galaţi (Grechlh. mumuss.;.

\section{IXXII. JUGLANIDAEE.}

\section{Jitilats L. - Nir.}

J. regaia L. \. commun. - Vulg. Vuc. - t̂n pădurile

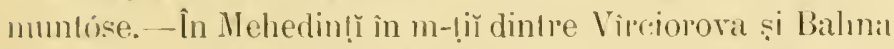

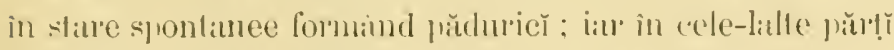

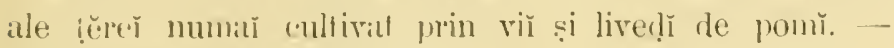
t? Iprilin-shriin. 


\section{LORANT'HACEE.}

\section{LORANTHUS I. - Lorant.}

L. Puropaens Jarq. L. de Einerope. - Vulg. Märyărileriŭ. Tise-rle-stejur. - Parasit pe ramurile stejărilor bă-

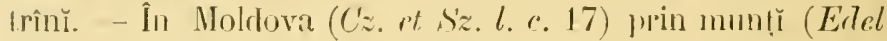
l. r. 37); în disłr. laç̣ la Volnescĭ, Stavnic și Horleștĭ (Sz. manusc.); in Arges la (roran (D. Br.l. c. 103) și Dăeșlĭ ; in Muscel la Con!̣essci (Gr. Errsir.!). - t? .1priliu-1/criu.

VISGIXI. L I'iss.

V. alhum L. T. alb. - Vuls. Fise. - Parasil pe ramurile merilor, perilor, richịilor si a bradulŭ́-alb. - In Moldova (Cz. Flora XIX. 61; Edel l. c. 39; Cz. et Sz. l. e. 5) centrală și superiơră ((úclbh. mamesc.) : pe lìngă Jặ̣ la Repedea (Sz. mamse.) si Nitelea (D. Br. Fragm.l. a. 103): la m-slirea Ném!̣luĭ pe m-tcle Pleșu ; în distr. Buzeŭ la m-stirea Ciolan (Gr. En. 29); în m-ṭĭ m-stirilor Cozia. Bishrịa și Tismana (Hoff.manusc.); elc.-țMartin-.1 priliŭ.

\section{TIIESIUM І. - Tesiй.}

T. elegans Rochel; Hamiltonia clegans Relb. T. eleyant. - Pe colinele nĕsipose și pe tulpinele putrede de prin pădur’̆. - În Noldova (Comamdia rlegans Boiss. IV. 105!)

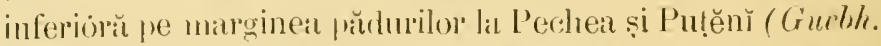
manuse.): în Ilfov lingă găara de la Ciocăneseř (Gr. Fon. 50 ct Exrsic.!: Kanitz l. c. 240); la Vîreioroval călre Porṭle-defer (Borb. 1873. Bins. 257).--94 Haiй-Luniŭ.

T. divaricatmm $J_{a n}$. E. divarisat. - Prin locurile aride din mun!̣̆. - în Moldova superióră ( $T$. ebracteatum s'z. E.rsic.!; h.j. Gurluh. manuse.). - 2 I Iuliü-Alugrest. 


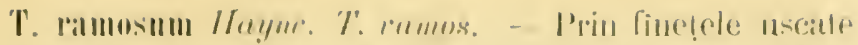

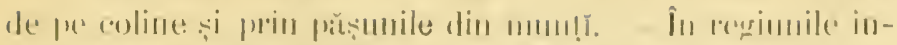

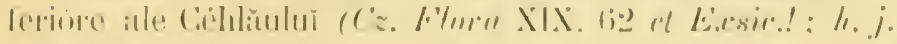

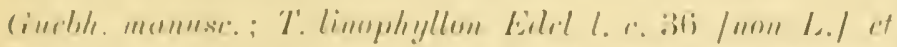

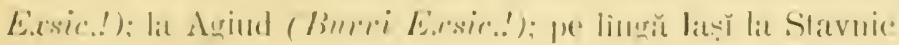

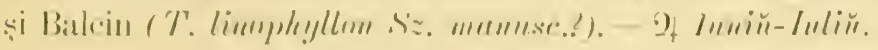

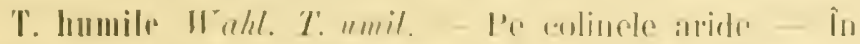

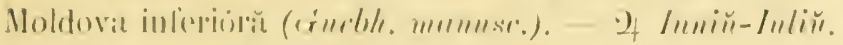

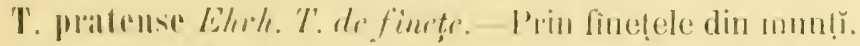

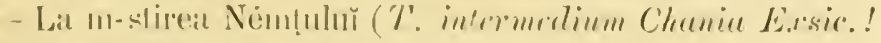

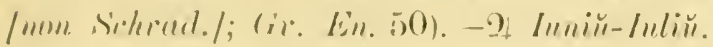

T. alpimum L. 'T' alpin. - Prin prașmile slincose din

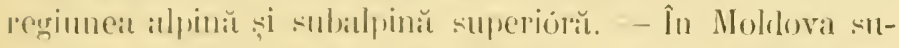

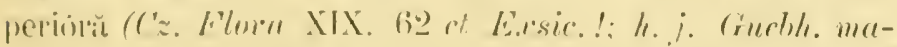

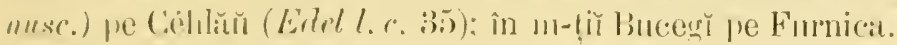
-) Inniir-Inliin.

T. rostratmu IIert. of Koch. T. rostrat. - in Noldova

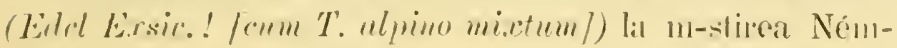

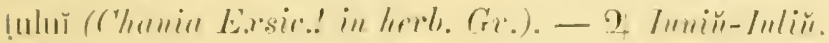

\section{LXXIY. CONILERE.}

\section{TAXIS L. - Tisŭ.}

T. balceata L. T. rommunu. - I'ulı. Tiš̆. - Prin bădurile umbrose din regiunea subalpină. - In Moldoval (Eslel

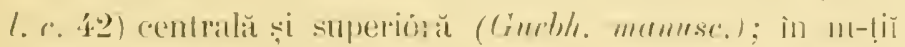

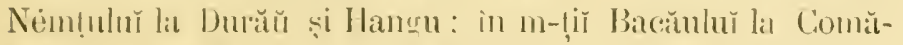

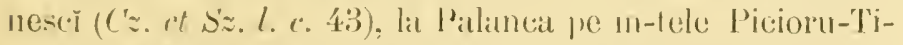
seì, și la Mĭnŭstireat-Ciașinulur̆ pe malurile torentnluĭ Cașin

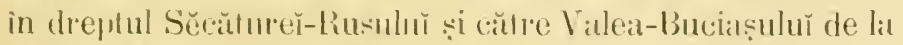
dél de Săriline; in Plahoval către sinaia la Villea-Iepeì

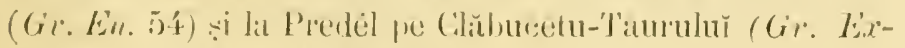
sic.!). to Iturtin-.lpitir. 


\section{JUNIPERUS L. - Juniper.}

J. communis L. J. commu. - Vulg. Iniper, hinpahar. Crétend. Arehis. - Prin pădurile slincóse și păsunile petrose din regiunea montană și subalpinĭ. - În Noldova superióră (Cz. F'lona XIX, 69) et Lissic.!: h. i. Gimebh. ma-

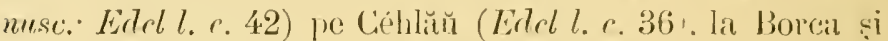
Dorna (Cz. et Sz. l. c. 4:3): lil Broccenŭ (Burpi E.rssir. !): în

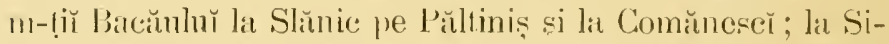
naia (Gr. En. 54) si Predél: in Nuscel lit Rncuăr ne Pélral (1). Br. Fragm. l. c. 103: Gr. En. 54); în Gorjiŭ la schilul Locurĭ-rĕle; în Vîlcea pe Naro!̣; etc. — t? Aprilin̆-Maiu.

J. mana Willd. .J. pitic. - Prin pășunile stîncóse din regiunea alpină. - În Moldova $(C z$. st Szz.l. c. 42) pe vîrfu

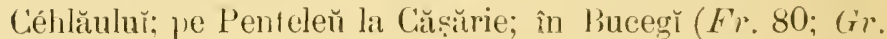
En. 54; J. communis B. nana ling. Hoff. Excurs. 1863. l. c. 120) pe Furnica. Bătrîne; ete. -†? luliŭ-August.

PINIS L. - Pin.

P. sylvestris L. P. syluestru. - Vuig. Pin. Chin. Prin pădurile din regimnea montană și subalpină.-- În Noldova superiórŭ (Cz. Flora XIX. 69) et Ex.sic. !; h.j. Guebh. mames.; Edel l. c. 42; (z. et s'z. l. е. 42 ; S'z. mamusc.) la schitul Sihla! (P. Mughus Gre. Evbor. l. c. 120 /non Scop./); în m-tị̆ Batcăuluĭ la Slănic (D. Br. Fragm.l. e. 103) si la Mănăstirea-Carșinuhü; la Sinaia (Gr. En. 54) și în

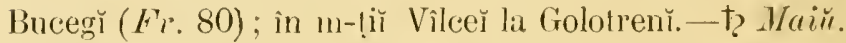

P. Mughlıs Scop. P. Mreqhees. - Vulg. Juépän. Jepr.-Prin păşunile și locurile slineose din regiunea infralpină.-În Moldovia (Cz. st S'z. l. r. 4; I'. pumilin Cz. Flora XIX.

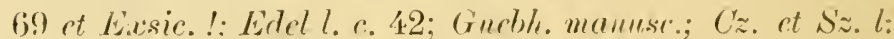
ค. 42) pe Céhlăŭ! (Ėłcl l. c. 36; P. pumilio Edel l. c. 36); 


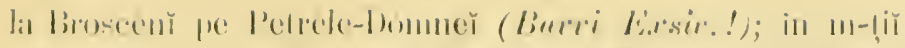

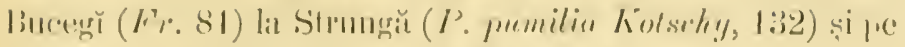

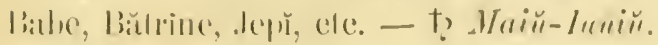

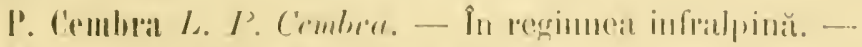

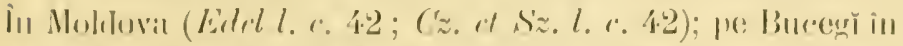

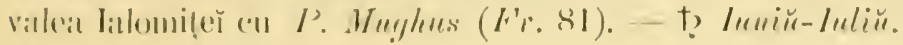

\section{LARIX TompHeP. - Larice.}

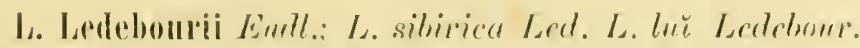
- Vulg. Zaul. Zadr. Zadrü. - P'rin pădurile din regiunea

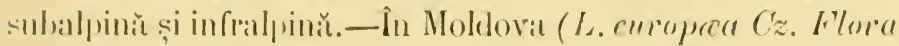

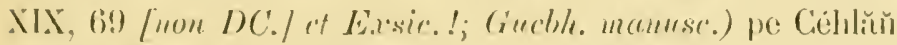

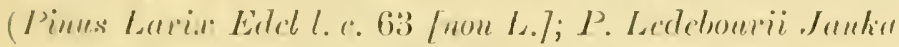
.11. 17i) și liı schitul Durĭŭ (L. curupece Cz. et Sz. l. c.

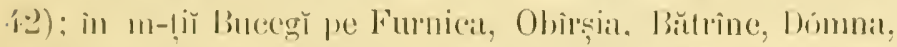
lil l'secerar de la lalomița, și la Predél. - to Marin-fuliü.

\section{ABIES bC. - Brad.}

1. alla Mill.: A. pectinuta DC. B. all. - Vulg. Braerall, Bared, silhü.-Prin pădurile din regimea subilpint.În tô̆t Romănia! (Cz. ct Sz. l. c. 42 ; Pimus Picea L. Eidel

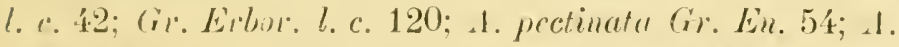

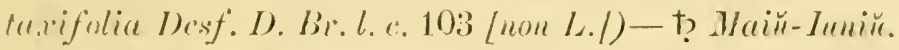

1. excelsa Poine; Pinus rxcelsa Liuk. B. inalt. -

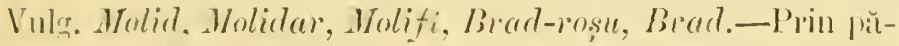
durile din regiunea subalpină.-În tétă Romănia (h.j. Gucbh. manusc.; Cz. ct Sz. l. c. 42 ; Ir. Br. Frargm. l. c. 103; Gr.

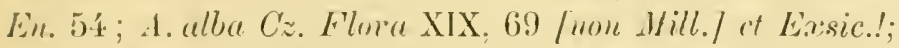

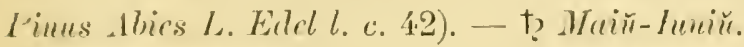

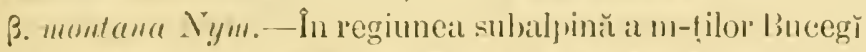
formeză pădurì (.1. montance șelene fuon Dur./ Fr. 103). 


\section{DIVISIUNEA II.}

\section{MONOCOTYLEDON E.}

\section{ALISHACEE.}

\section{ALISIIIA L. - Alismă.}

A. Plautago L. A. Patlagină. - Vnlg. Limbariț̆, Lim-

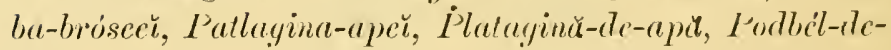
apč. - Prơn locurı̆ inundale, bălțĭ, mlaștinĭ, șanţurĭ cu

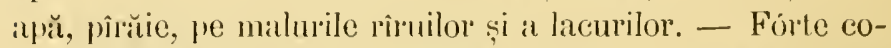
mună în tótă Romănia (Cz. Flora XIX, 63 ct Exrsic.!; Eidel l. c. 38; Gucbh. manusc.; Cz. ct Sz.l. c. 20 ; Sz. manusc.;

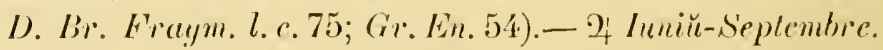

Obs. - Se mar citéză : A. nittans $L$. in Moldova $(C z$. Flora XIX, 633; (Cz. et Sz. 1. c. 20) pe lîngă Iași la Vladnic (Sz. munuse).

\section{SAlitTTARA L. - Sagitarie.}

S. sagittafolia L. S. cu frumle sagitale. - Vulg. siügéta-aprí. - Pe malurile anelor și prin locmrile mlăşij-

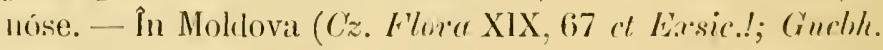
manusc.; D. Br. Fragm. l. C. 75) pe lingă lateul Birales (E-

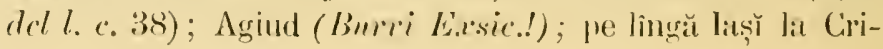




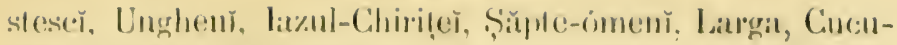

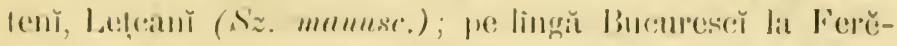

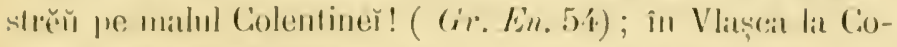

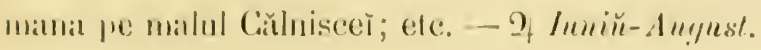

\section{IXXVI. BITOMACEE.}

\section{BITTHISS L. - Butom.}

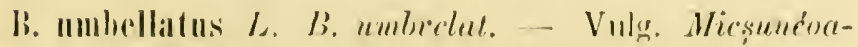

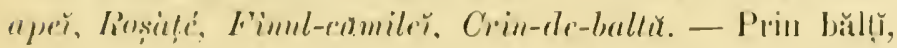
locour mlăș̣nose, pe malul lacurilor și al rîurilor lin courgě-

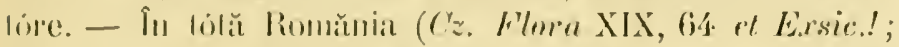
lidel l. e. 38; Guelhe mumese.; I). Br. Fratgm. I. c. 75;

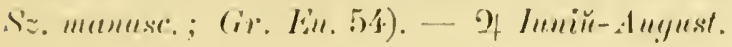

\section{IXXVII. COIGHICACEE.}

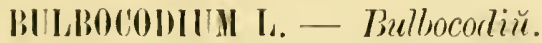

B. vernum L. R. de primanéré. - In Moldovit (.Janlia

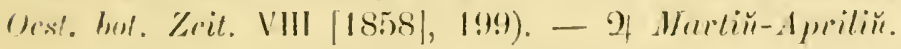

\section{(')LCHICIM L. - Colchicu.}

C. Inulbocodiondes M. Biel. C. bullowomlioid. - Priu stepe la Gialilị (Uschtr. et sinten. ap. Kanitz l. c. 126). - It Nartiй-Apriliü.

C. antummale L. C. de tómmŭ. - Vulg. Brönduş̆ă-de-

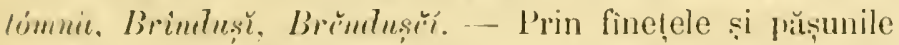
umede. - În Noldova (Cz. F'lora XIX, 63 et Exisic.! ; $C z$. et s'z. l. c. 19; D. Br. Aragm. l. c. 75) centrală și sulpe-

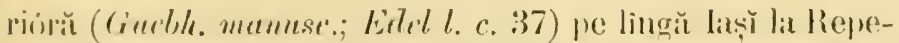

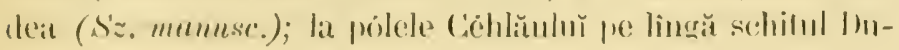




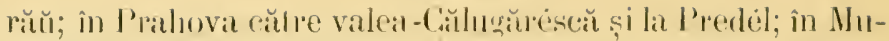

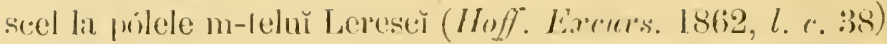

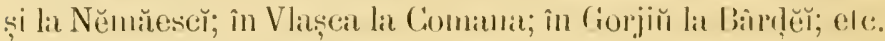
- 2t lueyusi-()elombre.

Ohs. - Se maı̌ citiză : ('. alpinum $I C$. (cu ?) în regiunea alpină a m-(ilor Moldover (Fuss Fl. Tiruns, excurs. Giş).

\section{VERATRUII L. - Veratru.}

V. allım! L. I. albü. - Vulg. Stirigóie, steregóie. Prin finelele și pășunile din regiunea montană superiór̆̆, sulbalpină si alpină. - In Moldova (Cz. F'lona XIX, 633 ró

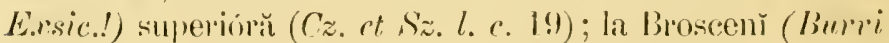

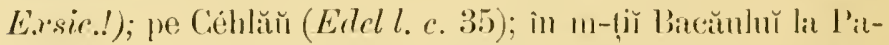

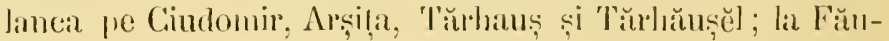

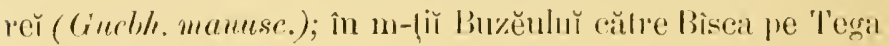

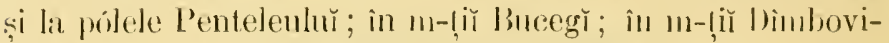
tẹ̆ pe P'ripor, Brănduşa și Nucel; în m-lị̆ Muscelulı̆ la Ně-

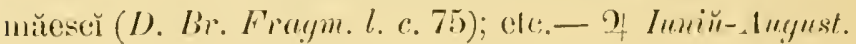

\section{IXXYIII. HILLCLE.}

\section{TLLIPA L. - Tulipă.}

T. sylvestris L. T. de pulure. - Vulg. Lale, Lalec, L'ul-

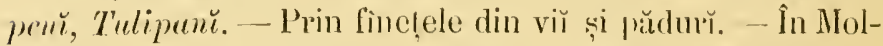
dovil (Cz. Flura XIX, 63 et Easic.!) superióră (Ciueb). mea-

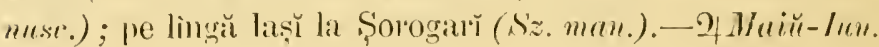

\section{FRITILARIA L. - Fritilarie.}

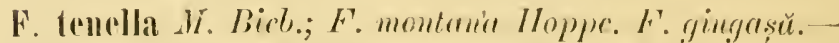
Vulg. Latele. - Prin finelele din prüdurı̆.- In Moldova sujec-

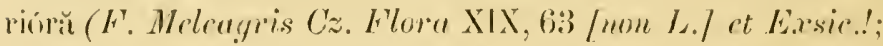
Edd l. r. 3!); (Guchh. munuse.) min imprejurinile Jișilor ( $F$. 


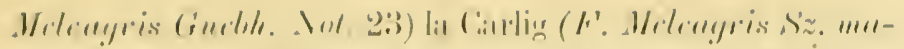

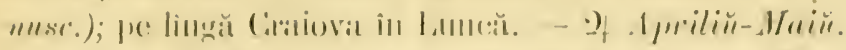

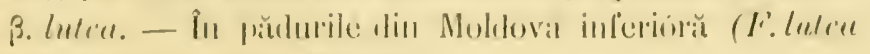

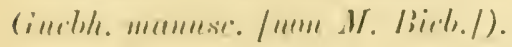

\section{LIIIIII L. - Liliü.}

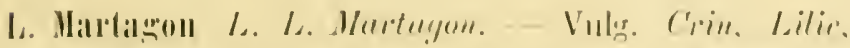

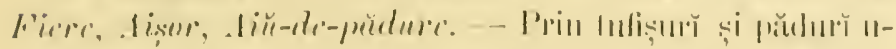

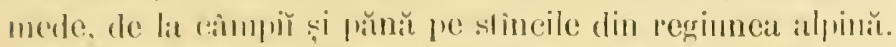

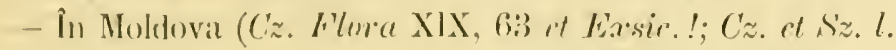

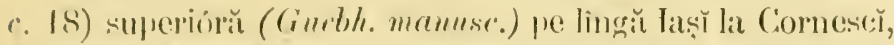
Repeder (siz. mammse.) și printre viile de liı Nebuna și Ni-

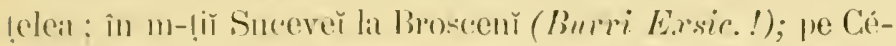

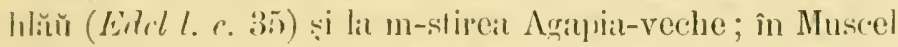

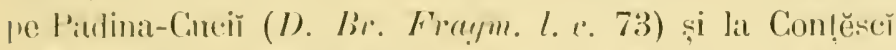

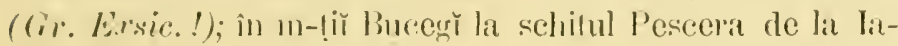
lomilat! (Gr. Én. 5ú et Earsic.!). pe Bŭtrîna și la prólele Furniecĕ; pe lingr̆ Bucurescĕ la Merinani și Buflea ; la Comana; în Arses pe Urḍica și Cozia. - Of Imniü-Imliü.

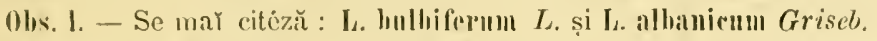
(l. Myrrnericum Lmy.), anêndouě în Moldova (Cz. et Sz. l. c. 18).

Obs. 2. - I. candiduru L. (Cz. et Sz. l. c. 18; Sz.munusc.) vuler. Crinr, Cıinй-alb̆̆, Lilie-albu, nu se găsesce de cât cultivat prin grădini.

\section{LI,0YDLI Salish. - Loidie.}

L. sepotina Sulist.; Sectarubotryum striatum Lindl.;

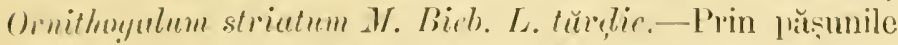

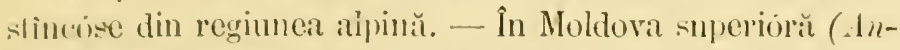
therienm serutimum L. Cz. Flura XIX, 63 it Exsic.!; h.j. (imelh. mumuse.). - 2 Juniü- luynst.

\section{ERYTILONIUII I. - Eritroniŭ.}

E. Deus Canis L. E. Dintele-cimelur. - Vulg. Cocoteri,

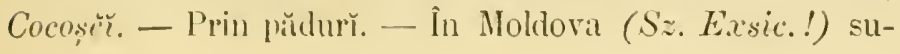


perióră (Cincbh. manusc.) prin ìmprejurimele lașilor (Guebh. Not. 23); in districtul Mnseel la Con! ĕscŏ în valea Rîncăciovn (Grr. Exsic.!). - 4 Martiй-Amiliu.

\section{ANTHERICUM I. - Anteric.}

A. Liliago L.; Phalangium Liliago Schereb. A. sinuplu. Prin locurru stincóse. - În Mchedinți la Vîrciorova către Portile-de-fer (Borb. 1873, Búns. 222). - 2) Iилiй-Iuliŭ.

A. ramosum L. A. rămos. - Vulg. Lilinţŭ, P'ainginel. - Prin finctele uscate, pe délurǐ aride, prin locurĭ petróse din munți. - In Moldova (Edel l. c. 39; A. Liliago Cz. Flon a XIX, 63 [non L] ] et Exsic.!) inferióră (Phalangium ramosum Lam. Gucbh. mamusc.); pe lìngă Jaș̆ la Balein, Stîncă și Popricani (Sż. manuse.); către m-stirea Ném!̣ılŭ (Ph. Liliago Gr. En. 58 [non S'chreb.] et Exsic.!); in distr. Bacăŭ la Verșěscĭ și Caracliŭı̆ ; la Bêrlad în Crìng; în m-tiĭ Masceeluluĭ (D. Br. Fragm. l.c.74); în Ilfov la Ciocĭnescĕ; între Dînhoviḷ și Sabar (Schott l. c. 472); în Vlaşca la Comana; etc. - of Iинiй-luliǔ.

\section{ORNITH0GALUII L. - Ornitogal.}

0. sulphuremn R. et S. O. sulfuriŭ. - În Muscel lit Ciimpulung pe tĕrmurile Rîu-Tî̀rgulŭ ( 1 uthericum sulphurreum II. Kil. Muff. Excurs. 1862, l.e. 40). -9 Maiü-Luniu.

0. pyrenaicum L. O. de Pirinč. - Prin fîneṭe și locuř̀ inculle. - In Moldova (S'z. manusc.); in Ilfov la Ciocănesě (I). Br. Fraym.l. c. 73); în Vlaş̣ca la Cionana; in Argeș la Stolniě. - 2 Maiй-Iиniй.

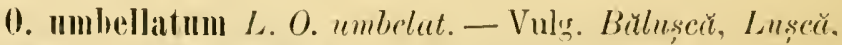

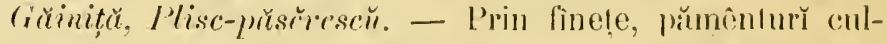
livate, locurì umbróse de prin grădin și pădur̆. - În Moldova (Erdel l. c. 39 ; Cinedh. Eresic. " $56 \mathrm{sec}$. Nym. Consp. 


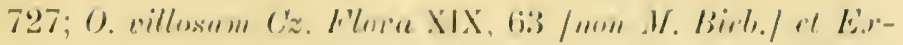

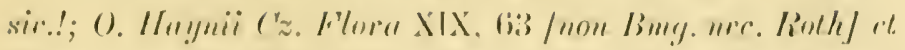

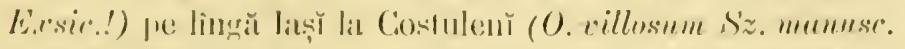

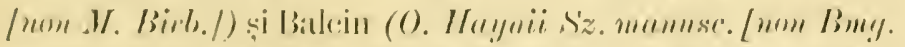

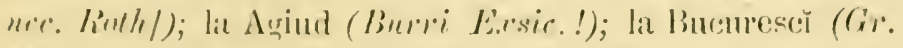

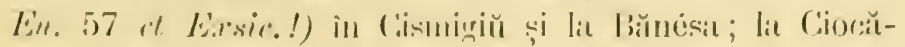

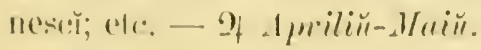

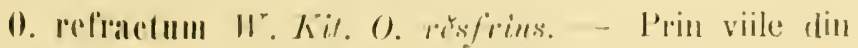
Moldovia inferioră (Gushl. mamese.).

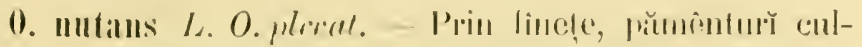

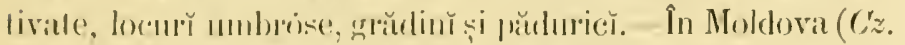

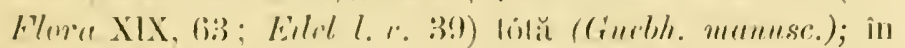

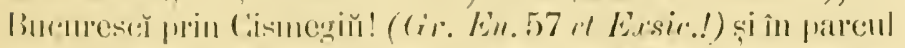

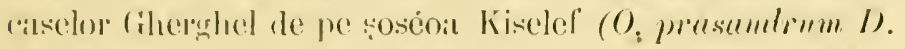
Br. Fronym. l. с. 733 / nour (ivisch./); pe lingă Ciraioval la Mo-

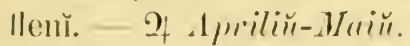

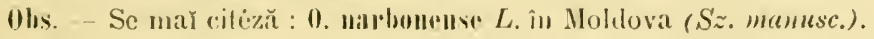

\section{GidiE. Salish. -- Gagee.}

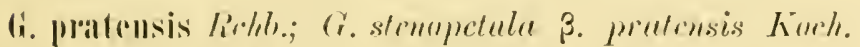

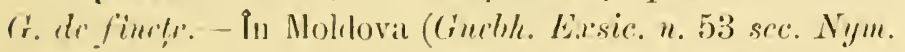

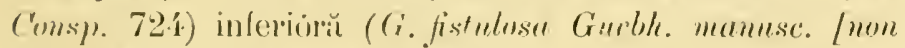
Dub./.?). - 9 - Ipriliü-s/uiu.

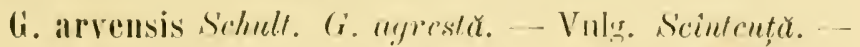

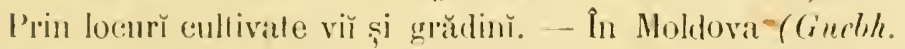
munusse.); în Muscel la pólele m-telŭ Lerescĭ (Huff. Ėxcurs.

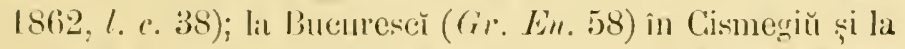
Bănésit; pe lìngă Cariova lị Bucovă! - 2 Martiŭ-1 miliŭ.

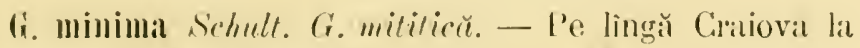
'leis. - I Merriй-1priliü.

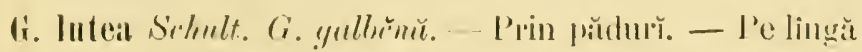

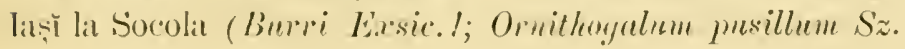




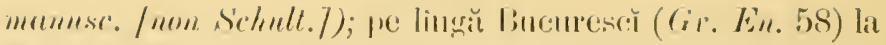

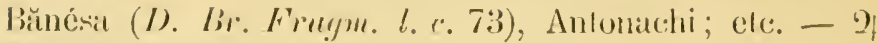
1/urliй-1 priliü.

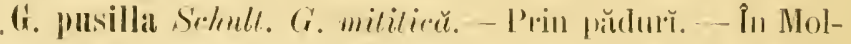

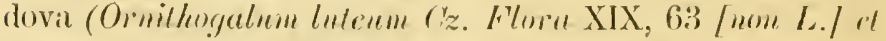

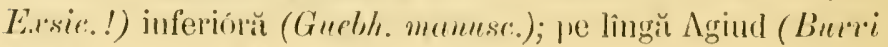
Eisic.!). - 2 Marlin-.1priliü.

\section{Sllial I. - Scilit.}

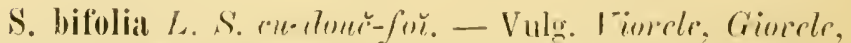
Griumble. - I'rin phidurile umbnóse, pănă în regimneal alpină. - Fóle commuă în tólă Romănia (C'z. Flore XIX, 63 al Easic.!; Edlel l. c. 39; Gurbh. mamesc. Sz. manuse.;

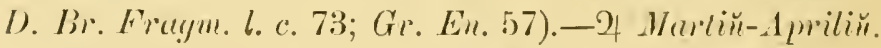

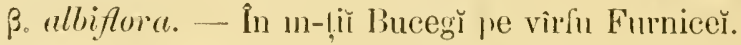

S. pratecox II illd. S. timpurie. - În reginnea stpună pe

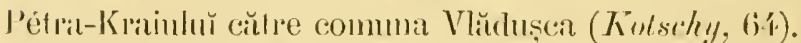

0lıs. - S. amurıa $L$. indicată prin tuferișurile viilor către VaduUuğuruluř și Frumușica (Sz. mamusc.), se nu fie óre S. cerını Red.?

\section{ALLIUII L. - Air.}

A. Victorialis L. A. Victorial. - Prin locurile stincóse din regiunea alpină. - In Moldova (Cz. ot Sz. l. c. 17); pe Bucegĭ (F'uss l. c. 650; Schur l. c. 674).- 2 Iuliŭ-1ngust.

A. ursinum L. A. ursulur. - Vulg. Le'undŭ, diй-Atrpŭdure- Prin pădurile unede și umbróse, pănă în regiunea montană superióră. - În Moldova (Cz. Flora XIX, 63 ct Esesic. !; Cz. rt Sz. l. c. 18) tótă (Guebh. memuse.); pe lìngă lașĭ la Câplig și Popricanì (Sz. manusc.); pe Céhlăŭ (Edtrl l. c. 35) ; în m-lị Prahover eătre Sinaia la pólele Furniceı̌ si la Predél pe Susaiŭ ; in Mchedinți la Vinjuleț-Rogova (Gr. En. 58 it Exsic.!); cte. - I Haiй-Juniü. 


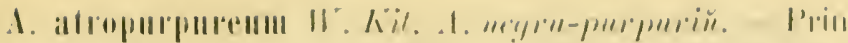

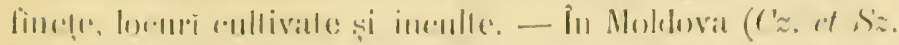

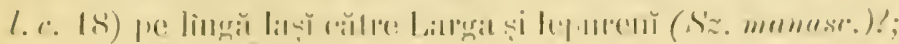

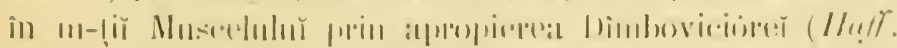

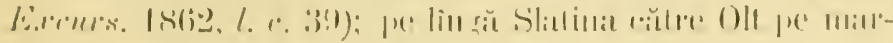

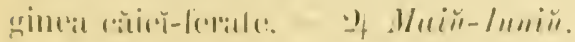

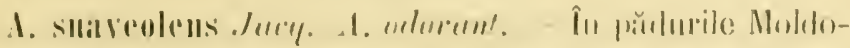

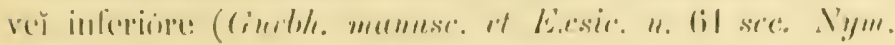

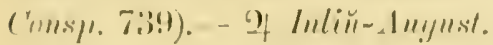

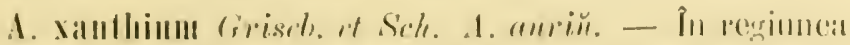

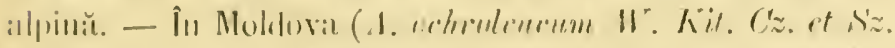

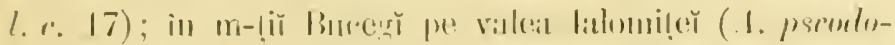

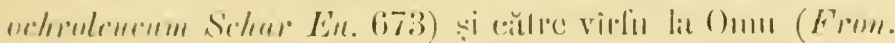
200). of luliĭ-Alugnst.

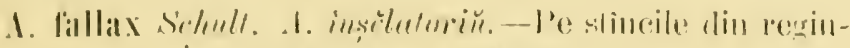
Il'il subalpinat. - In Moldovil (1. Moly Cz. Flera XIX. (j:3

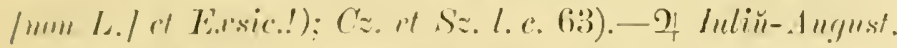

1. polundun L. A. rastumel. - Vulg. L'ur. - P'pin li-

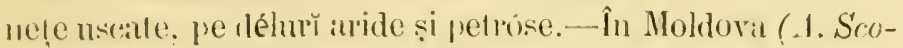
rodumrusum ( $\approx$. Floru XIX. 63 /mon L.] rt Exsic.!; A. aromutum Sz. Eisic.! [nom L.]) inferion:̆ (Gurlh. mamusc.);

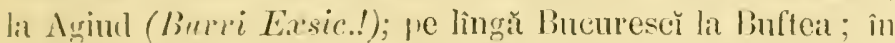
Vlatsce la Comama : in Mehedinți la Vîreiorova către Porlile-de-fer (Borh. Flor. Közl. IX. 35̃8) pe m-tele St.-P'eIıн; clc. - 2) Inпій-Iиliй.

1. splicrocephalum L. I. sferoeffal. - Prin finețe 11:calle si pe délıllı aride - In Moldova (Cz. rt Sz. l. c. 17)

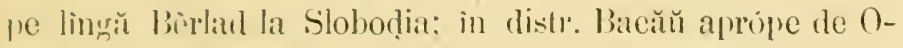

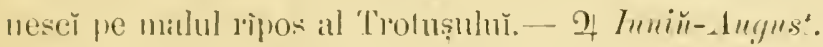

1. Scopodoplasum L.: 1. arcmarium Smith. I. Senren-

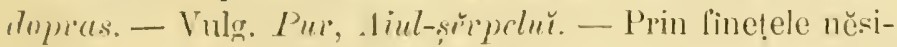

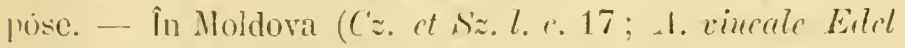

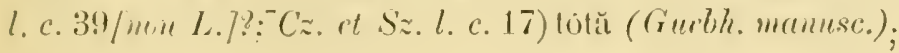


le lingă Jaș̆ la Socola (.1. vineule siz. mamesco?) și călie Repredea (S'z. manusc.); în Muscel pe délul Moţoin̆ (Hoff. Ex('ups. 1862, l. c. 39); pe lingă Bucurescĕ la Cotrocenı̆ ( $G r$.

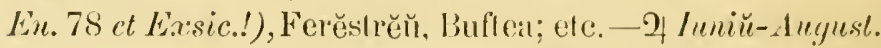

A. olepaceum $L$. A. de grădinărǐ. - Prin vĭ̌, grădinăıî̀ și locurř aride. - In Moldova (Cz. st Sz. l. c. 18; Sz. manuser.); în n-țir Buzeulŭ pe Pentelen̆ la Căs̆ŭie ; în II-

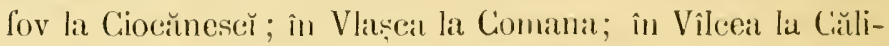

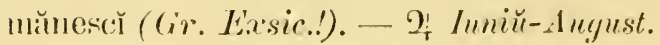

A. flavium L. A. gallín.-Pe coline něsipuse şi petróse.

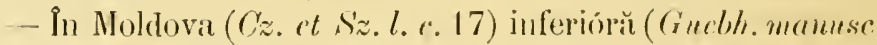

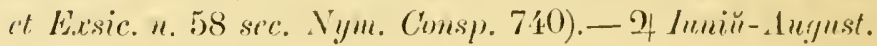

A. pallens L. 1. palid. - I'rin locurile aride și slincrose. - In m-lị̂ Vîlcer̆ la Harmasariŭ pe slîncile de pe malul Olmhlŭ. - 2f Inliü-Angust.

A. paniculatım $L$. A. paniculut. - Pe délurile něsiprise si pelpóce. - In Noldoval (Cz. ol. Sz. l. r. 17; 1. pal-

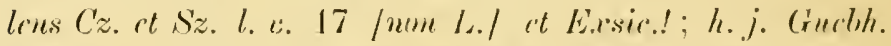
manusc.) inferiórĭ (A. informedimn (ruedh. manusc.); pe

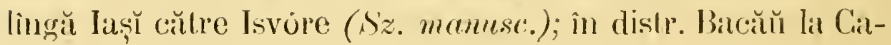
rackŭŭ și pe Bahaghicea. - Of luliŭ-.lugnst.

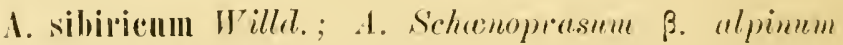
Lech. A. de Siberia. - In regimea alpină. - La Bro-

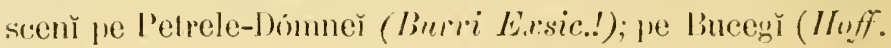
Éncurs. 1863, l. e. 120). - I Inliü-dugust.

Ohss. 1. - Se maĭ citéză : 1. angulosmu Jueq. in Moldova (C'z. et Sz. l. c. 17). - A. ammophilum Heuff. pe lîngă laṣy către Holıy și Hoisĕscr (A. seneserens Bmy. Cz. et $S z$. l. c. 16; Sz. manusc.).-A. (alrillat'III L. în Moliova (Cz. et $S z$. I. c. 17).

0ls. 2. - Se cultivă fórte frequent : A. Scharmoprasum $L$. (A. Porrum Sz. E.rsic.! [non L.]) vulg. Arpaciç, Harpecich, P'uri.- I. sativın L. (Guebh. manusc, ; Cz. ct Sz. 7. c. 17; Sz. manusc. et Exsic.'; Gr. kи. 58) vulg. Aiй, Usturoiй, Aiй-cle-vév'y. - A. Porrum L. (Guebh. menusc.; Cz. ct Sz. l. c. 17; Sz. manusc,; Gr. Ln. 58) vulg. Pras, I'raj, Poriŭ, P'ur, Céput-blandle. - A. Asealonic'mu L. (Guebh. 


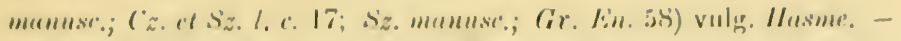

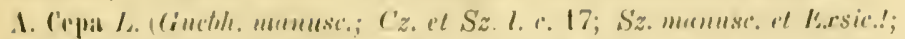

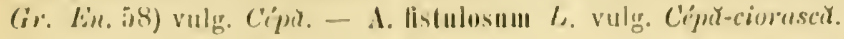

\section{ILBHROCMIAIS I. - Emeroculĕ.}

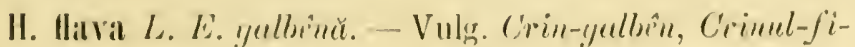
nulur. stinjime - Prin locmile mläștinise și mubrise din

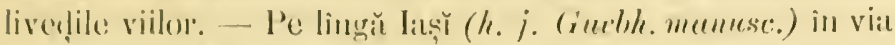

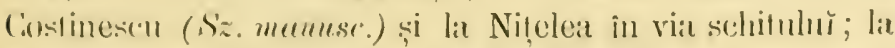

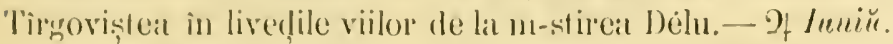

II. fulva L. Le. rosirlică. - P'rin fincţele muntóse și pe coline. - P'rin viile de pe lìnğ̆ Jaș̆ (Sz. monusce. it

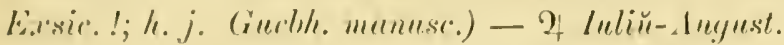

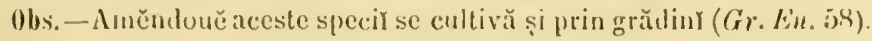

\section{IIUSCARI L. - Muscari.}

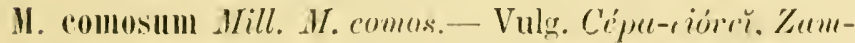

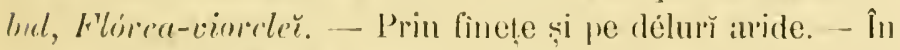
Moldovil (Hyacinllens comosus L. Cz. Flora XIX, 633 et.

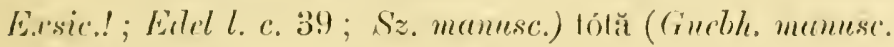
rt Exsic. n. 51 sec. Nym. Consp. 732); la Verșescĭ și Carravlŭı̆; Agiud (Burri Eassic.!); în distl. Buzen̆ la Vŏlenŭ (Gr. Li.rsic.'); Bucurescè (Gr. Lin. 58), l'eris, Ciocănescì (I). Br. l. c. 73); la Comana : între Craiova și Turnu-Severin; la Virrciorova către Portile-de-fer! (Borb. Flur. Közl. IX, 352), pe teriloriul neutral aprope de Orşova (Winkl. Oest. bot.

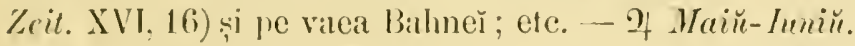

II. racemosum DC.; Bolryanthes odures Kth. MI. ra-

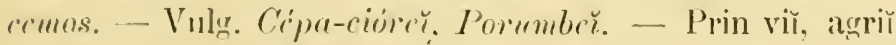
și sĕměnŭturĭ. - In Moldova (Hyacintlues racemosus L. Cz. Flara XIX. 63 ot E.rsic.!; Erlel l. e. 39. 41 ; Sz. ma-

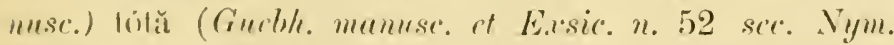
C(msp. 73.4) : Iaș̆ (D. Br. l. c. 73); Agiud (Burri Exxsic.!);

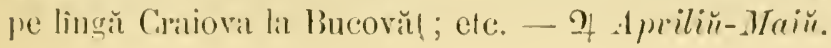




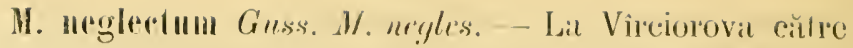
I'ortile-de-l'er (Borl). Flar. Kizal. XIX, 352; Simle. 603).

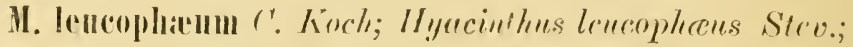

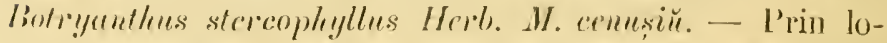
curile nĕsiprose. - In Moldovat inferióră la l'echea (Jr. pallens

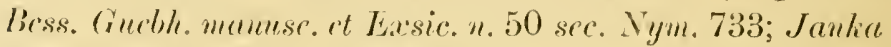
Lim. XXX, 606). - 2 Meriu.

\section{ISPARIGUS L. - Sparangr.}

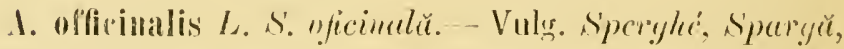

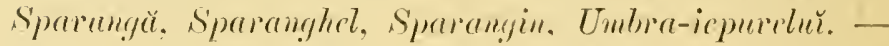
Pădurr, fìnẹ̣e, coline aride. -- În Moldova (C'z. F'lor XIX, 63 et Eirsic.!; Eitel l. e. 39; Cz. et Sz. l. c. 19) s'z. manuse.; 1. aculifolins Cz. Filora XIX, 63 [nom L.] "t Eirsic.!; Cz. et Sz. l.c. 19) totă (Guebh. munuse.); in disitr. Bąc̆й la Ocnă (Hacq. Réise II, $52 ;$ Heclal l. c. 441), Citlaclü̆ si pe Babaghiceal Agiud (Burri Eresic.!); in Ilfov la Bŭnésa și Ciocănescĭ; în distr. Buzĕn̆ la Becenı̆ (Gr. Exsic.!); în Mehedinţ̣ la Rogova (1. officinalis $\beta$. campestris Gr. En. 57) şi la Vîrciorova pe leritorinl neutral aprópe de Orșova (W inkl. XVII, 16); elc.-2 Iuniǔ-luliŭ.

A. seaber Brignol. s'. asprü. - În Moldova inferiórĭ pe tĕrmmile Seretuluì (1. amarus DC. Erlel l. c. 38). of IIniü-Iиniu.

Ols. - Acéstă specie se mar̆ menţionéză între Rucăr și Dîmbovicióra (Hoff. Fxcurs. 1862, l. c. 39)); dar indica(̨iunea acésta trebue considerată, pănă la o nouă verificare, ca fiind cu totul îndoeInică.

1. tenuifolius Lam. S. cu for mĕrmute. - Prin pădur și pe colincle aride. - In Moldova inferiórĭ (Guelh. mamese et Exsic. n. 42 sec. Nym. Comsp. 716); Agind (Burri E.rsic.!); în distr. Buzĕŭ la Becenŭ (Gr. En. 57 et Exsic.!; Kunitz l. c. 247); în Muscel eălre Dîmbovicióra (1. sylvaticus II. Kï. Hoff. Excurs. 1862, l. c. 39); pe lingă Bu- 


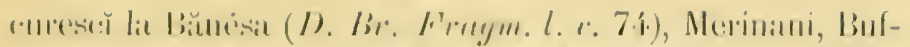

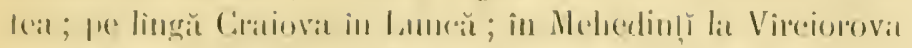

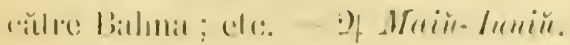

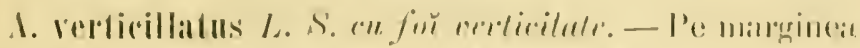

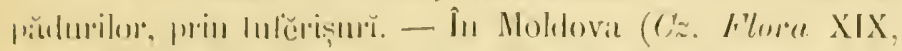

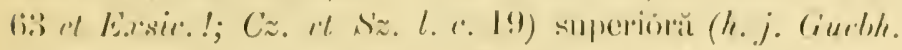

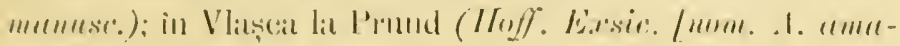

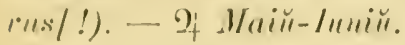

Ohs. - Nu sciŭ ce poite fi : I. easspius indical pe férmurile Sere-

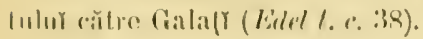

\section{s'TREPToP's Michaux. - Streptop.}

S. amplexilolius IX'. s. an for amplexicanle. - Pe

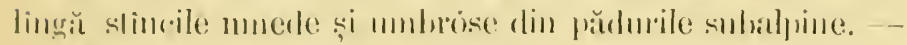

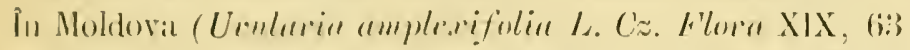

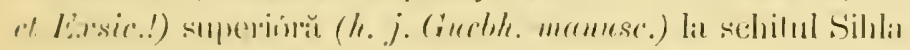

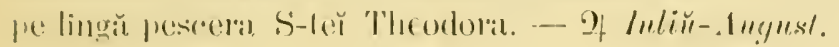

\section{PAliS L. - Purisetă.}

P. quadrifolia L. I', cu pa'r' for. - l'rin toenrile un-

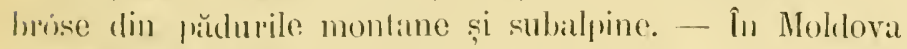
(Cz. Flon XIX. 6i et Essic.!; Cz. ot sz. l. c. 21) supe-

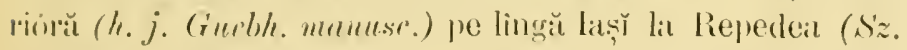

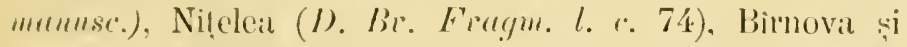

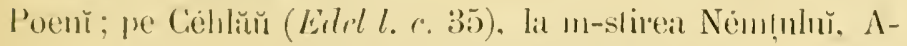

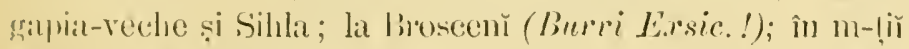

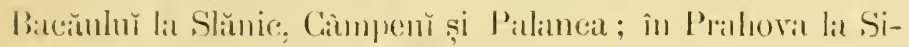

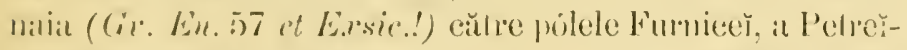

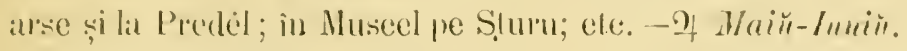

COSTMMARIA L. - Convalarie.

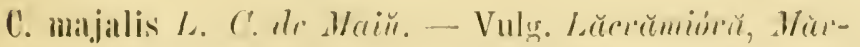

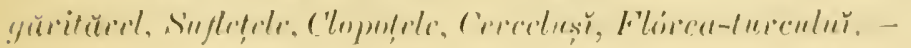


I'rin pădurile umbróse. - În tötă Romănia (Cz. Flora XIX, 63 rt Exsic.! : Eitel l. c. 39; Guebh. manuse.; $C z$. de Siz. l. c. 1!) Sz. manusc.; D. Bi. Fraym. l. c. 74; Hoff. Excurs. 1862, l. с. 31; Gr. En. 57). - 2 Maiи.

\section{MAJANTHEMUM Wigg. - Maiantem.}

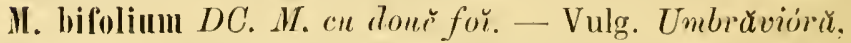
Lăcrimiţă. - Prin pădurile mubróse din regiunea monlană. - In Moldova (Comvallaria bifolia L. Cz. Flora XIX, 63 et Exsic.!) superiór̆̆ (Gurlh. manuse.) pe lîngă Jiçị la Jadîmb, Mironésa, 'T'ubana și m-stirea Slavnicu (Sz. munesc.); la nl-stirea Agajuia! (Gr. Evbor. l. c. 122 et Exsic.!; Gr. En. 57), ni-stirea Némṭulǔ, Procov, Sihla și până in reginnile inferióre ale Céhlăulu (Edlcl l. c. 36); Broscenı̆ (Burri Exsic.!); Caraclăŭ, Cùmpenŭ, Slănic; și Palanca ; în Muscel liı Nĕmăescì (I). Br. Hrougm. l. c. 74; Gr. En. 57 et

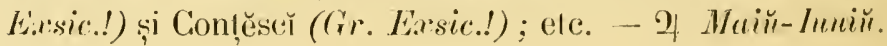

\section{POLYGONATIM Tournef. - Poligonat.}

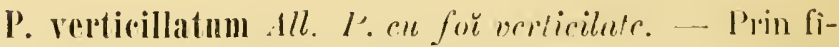
nelele muede și pădurile mubróse din regiunea montană și subalpină. - In Moldova (Comeallaria verticillata $C z$. Flore XIX, 63 et Exrsic.! ; (z. et s'z. l. c. 19) centrală și superióră (Gucblh. monuse.); in regiunile inferiòre ale Cé-

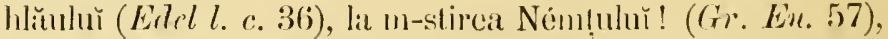

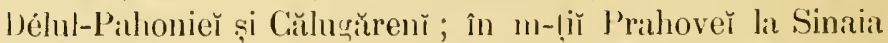

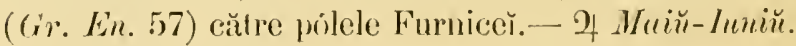

P'. vulgälre Desf. I'. eomun. - Vulg. Códa-cocosului.

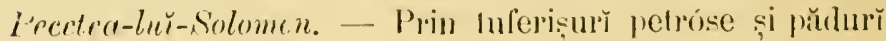
mulnrose. - In Moldova (Commollenia Polygyonatum L. Cz. Florre XIX, 63; Edel l. r. 39); (a. et Sz.l. c. 19; Sz. manuse.; D. Br. Frongm. l. e. 74) tillit (Gurhh. menurse.); în distr. Ba-

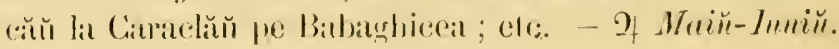




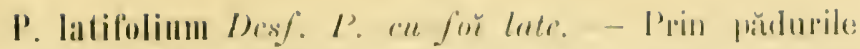

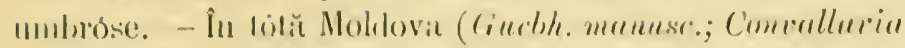

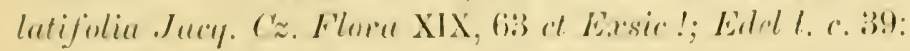

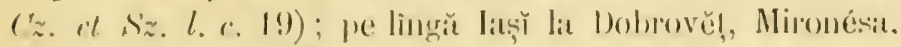
Hiulimh, Voinescĕ, Slatvuic (S'z. manusc.) și Nį̣elear; la Si-

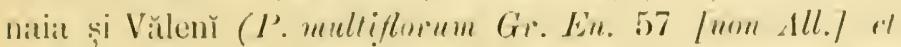

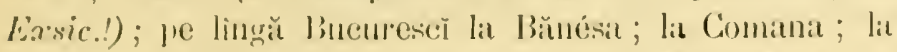

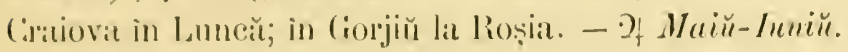

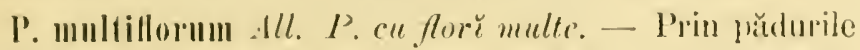
mmbrose și mmede din regimnea monlană. - In tótă Mol-

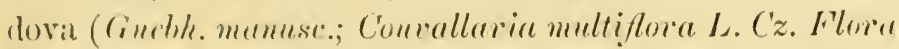

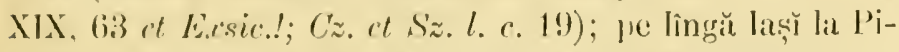
ciornl-lupulŭ, Bìnova!, Repedea (Sz. munusc.), l’oenĭ şi

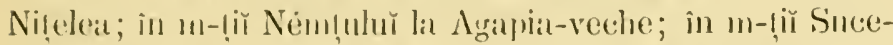

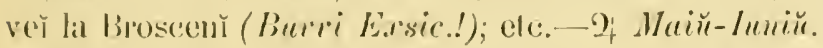

01s. - Se mar citéză : P. polyanthenum M. Bieb. in Moldova inferiórĭ prin pădurile de la P'echea (Guebh. manusc.).

Riscus $\mathrm{L}_{\text {. }}-$ Iruse.

R. aculeatus L. R. ghimpos. - P'rin pădurì și huferi-

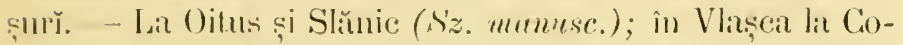

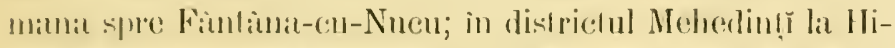

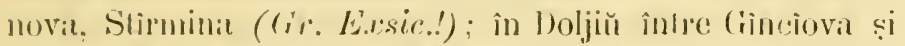

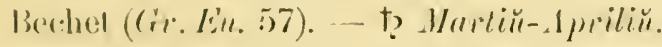

\section{DIOSCOREACEE.}

\section{TAII!S L. - T'tom.}

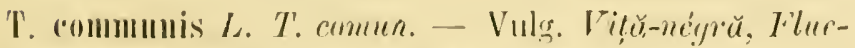

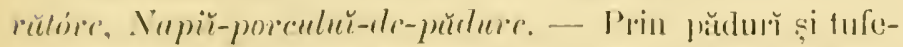

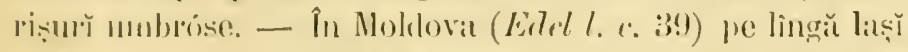

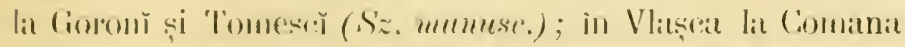

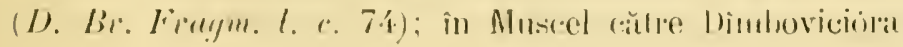




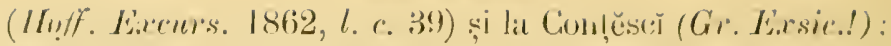
in distr. Buzeй la Beceñ̆ pe m-tele Cerbu (Gr. Exsic.!); lit (aimupina și prin viile de pe lingri Ploesçi; la T'urnu-Severin pe pruinile 'Turnulu!! (Gr. En.57). - 2 Martiu-Apriliu.

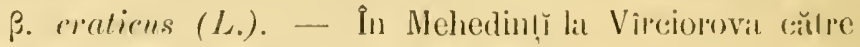
Prortile-de-fer (Bwb. 1873. Báns. 252).

\section{IAXX. IRIIDACEE.}

\section{CROCIS L. - Sofran.}

C. banaticus Henff.; C. IIcuffeliames Iferbert. St. de

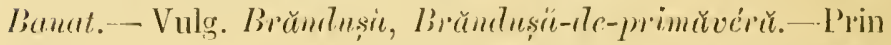
prișunile din regiunea subalpină ṣi alpină. - În m-liĭ Mol-

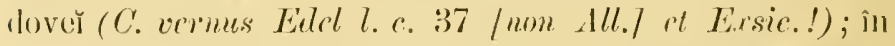
u-liĭ Buceğ (Fr.79) pe Furnica; în Muscel pe Pétrat-Kraiuhŭ cŭltre comuna Vlădușea (C. velinchensis kiotschy, 65) [non Mcrluert]); în distrietul Mehedințĭ lat Cemețĭ (Exsic.! in herb. Gr.). - 2 A мriliü-Leniŭ.

C. reticulatns Stcv.; C. variegutus Hoppe. S. reticulat. - Prin prișunile uscate de pe coline. - In Moldova ( $C$. vcruns v. floribus albis lineis rublers notatis Sz. Exsic.!) inferiorĭ (C. minimus Gurbh. mamusc. /non DC.J it Easic. ". 41 sre. Nyme. Consp. 708); pe lînğ̆ laș̆ la Cârlig, Balcin (C. vernus siz. manuse. /uon ill./) si Horpaș; la Agind (Burri Exsic.l); ete. - 2 Februariu-Martiŭ.

C. unusiatus Ker. S. auri.⿲.-Pe coline aride. - În Ilfor (Gi. En. 56 et Eesic.!; Kanilz l. c. 246) je lingă Buen-

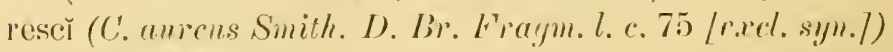
dincolo de Bănésal în Vlaşea lit Comanat pe valea (iurbatunlŭ ; pe lìngă Craiova către u1-stirea Bneovăt (Benliner in. (ivisub. et Sch. It. 355); în Mehedinț̆ la Cerrneḷ̆ (Gir. En. 56 et Exsie.!) si Vircioroval cürire P'orfile-de-fer (simk. (602). - 9 Fedruariu-Nartir. 


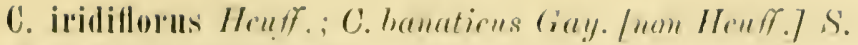

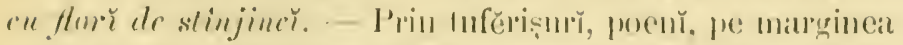

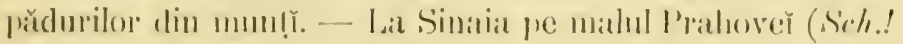

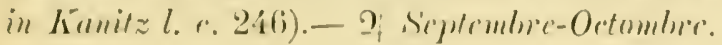

\section{(it.ADI0ILS I. -- Glantiol.}

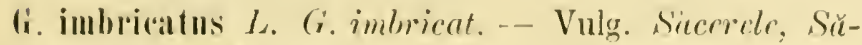

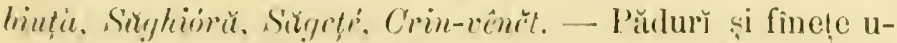
mede, lmer̆, tuferișurì de pe coline něsipóse. - In Moldova (G. communis Cz. Flarea XIX, 60 [non L.] et Exasic.!; E-

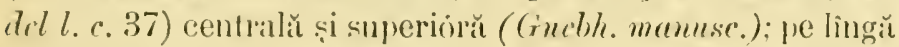
lậ̣̀ la Repedea (Burri Exssic.!), Picioru-lupuluh̆, Neleda și Glodósa (G. communis Sz. mamsc.); la Broscenı̆ (Burri Exxic.!); în distr. Bach̆ŭ la Nŭsoesciî-parlieularr̆ și la P’alanca ; in Mfıscel la Němăescĕ pe Muscelul-'́opliṭen̆ (Gr. segrtum D. Br. Frargm. l. c. 75 [non Gawl.7); în I)ìmboviḷa

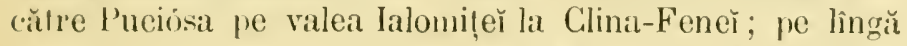
Bucurescì in lunca Colentinè călıe Mogoşóia și Buftea $\left(G_{r}{ }^{\circ}\right.$. Errsie.!); la Comana în valea Balotă. - 2 M(сій-Iиmiй.

\section{IRIS L. - Iridă.}

I. lıungariea W. Kit. I. de Ungaria.-Pe coline aride. - In Moldova ( $I$. squalens Cz. Flora XIX, 60 fron L./ it Exsie.!; Cz. st sz. l. c. 3; I.germanica Cz. Flora XIX, 60 Inom L.] it Eisic.!; Edel l. c. 39 ; Cz. ct Sz. l. c. 4 ; Sz. mamusc.); pe lingă Jaș̆ pe dèlurĭ către Gucutenl̆, Domnesch̆ și

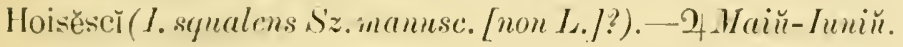

I. Variegala $L$. I. vargate. - Pe coline aride, locuri

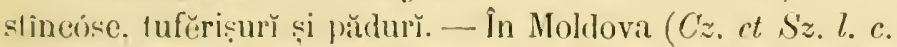
3) inferiolră la Pechea (I. fluva Gubh. Easie. n. 35) in

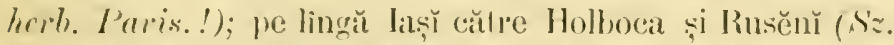

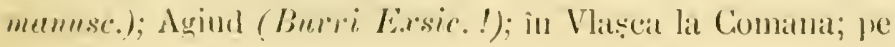


lìngă Cratova (Eesic.! in herb. (ir.)); in Vileea călre Lotru pe Fórleca; în Argeș pe Co\%ia. - 2 Main̆-Innin̆.

I. prunila L. I. piticr̆. - Pe coline aride.-În Moldova (Cz. Flora XIX, 60 it Exasic.!; Enlel l. c. 39, 41 ; Cz. et S'z. l. c. 3) inferióră (I. arenarin Guclbh. manuse. /non W. Kit./

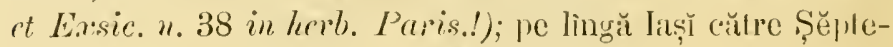
ónenǔ (Sz. mannse.); în m-lị Muscelulŭ între Rucăr și Dìmboviciora (Hoff. Excurs. 1862, l. c. 39). -2 \& miliй-1/aiй.

I. Reichenbachii IImeff. I. Lǔ Reichenbach. - Prin lolocurile petróse din munțĭ. - La Virciorova eătre Porțile-defer (Borb. 1873, Báms. 255; Simk. 602). - 2 Maiй-Inniй.

I. subbarbata .Joo. Io subburbată. - Prin finețele umede.- În Moldova (I. spuria Auct. lunng. [non L.7 Cz. ct \$z. l. ‘. 4) prin imprejurinile Iaşilor (nom. I. ocherolenca Sz. Ersic.!). - 2 Maiй-Iniй.

I. Giïldenstiedtiana Lepech. I. lň Gulilinstcedt.- - Pe colinele de lil Pechea (Gurhh. manuss.). - 9 .

I. graminea L. 1. graminer. - Prin finctele și pădn-

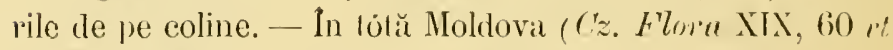
Eilsie !' Etlel l. c. 39, 41; Guebh. manuse.; Cz. rt Sz. l. c. 3 ; S`. manusc.); la Agind (Burri Exssic.!); in Muscel pe dẻlul Moțoiŭ (Hoff. Exacu's. 1862, I. c. 39).--2 Maiй-Inniи.

I. Sintenisii Janka. I. Lǔ Sintruis. - In Moldova (nom.

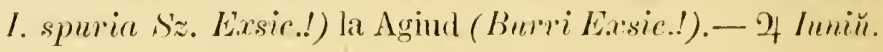

1. Psend-Acorus' L. I. Acom-neatcvérat. - Vulg. Stin-

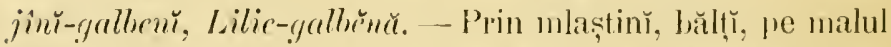
apelor stagnante şi lin curgětore. - In tótă Romănia (Cz.

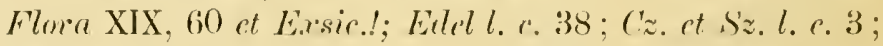
Sz. mamese; D. Br. l. c. 75; (r). Lin. 56).-9f Imin̈-Inliü.

0hs. 1. - Se mar citéză : I. squalens $L$. la Pechea (Guelh. manusc.). - I. sambincina $L$. in Moldova (C. et Sz. l. c.3). - I. sibirica $L$.

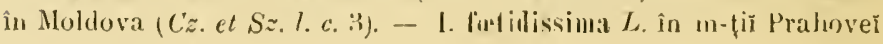




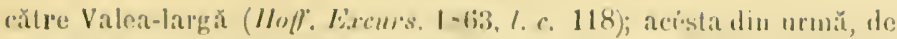
sigur, prmblo crore de determinal iume

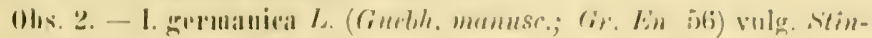

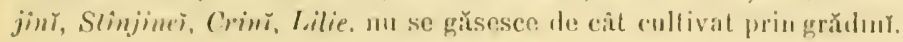

\section{IXXXI. AMARYGI)ACLE.}

\section{STERNBERtild W. Kit. - Sternberyir.}

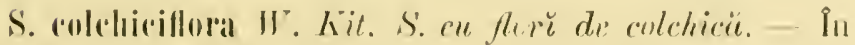

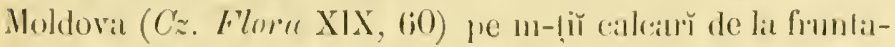

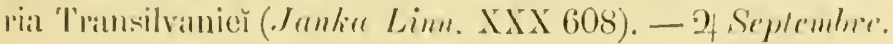

\section{NARi'Isists 1. - Narcis.}

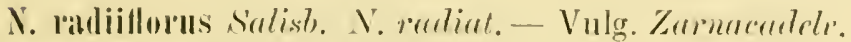
Conrine, Cüprine. Flóre-de-Nareis. - Prin finetcele din

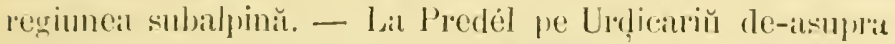

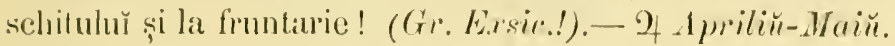

N. poetiens L. N. poetic. - P'rin finelele unede. In Moldova (Edtel l. c. 39) inferionă călle Ciglina la confluența Serelulŭ cu l)unăreal (S'z. manusc.); se cullivă și

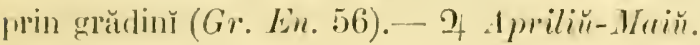

Olıs. - Nu sciŭ ce póte fi: $\mathbf{X}$. orientalis indicat către Ciglina aprópe de imprematrea Brateșulur cu Prutul (Sz. mantsc.).

\section{LEUCOJUM L. - Niveolă.}

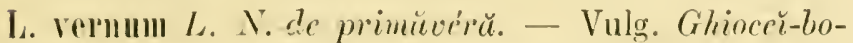

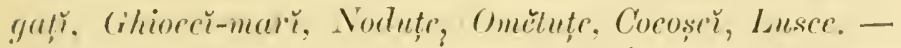

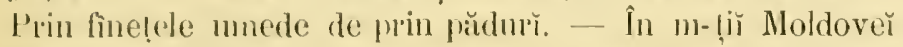

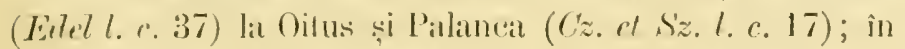

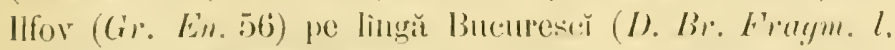
c. 75$),-2$ - Jarliu-1priliu. 
I. astivum L. N. de véšă. - Prin fînețele umede. Pe lîngă (ralaț̆ (Guebh. mamusc.) și Focșanǔ în pŭdnrile Cŭtpudanulŭ (Sz. manиsc.). - 4 A priliŭ-Maiй.

\section{GALANTHUS L. - Galanthinč.}

G. nivalis L. G. nivală. - Vulg. Ghiocĕ, Coconč, Primăvěriță, Aișor, Clopoțci, Giórele. - Prin pădurì și finețe umede, pănă în regiunea subalpină. - In Moldova $(C z$. Flora XIX, 63 et Exsic.!; h.j. Gucbh. manusc.; Edel l. c. 39) pe lîngă Jașĭ (Gurbh. Not. 23; D. Br. Fragm. l.c. 75) la Hlincea (Sz. mamusc.); în Ilfov (Gr. En. 56 et Exsic.!) la Bănésa, Merinani, Antonachi și Călugărésea; la Sinaia pe Furnica ; în Mehedințĭ la Cernețĭ ; etc. - 2 Febr.-Martiu.

\section{ORCHIID ACEE.}

\section{ORCIISS L. - Orchitč.}

0. fusca Jacq.; O. purpurea Huds. O. negriciósă. Vulg. Poroinic, Poraniciǔ, Geménarif̧ă. - Prin pădurile umede și umbróse. - În Moldova (Cz. et Sz. l. c. 51 et Exsic. [nom. O. palustris]!); pe lîngă Iaş̆ la Socola (Burri Exsic.!), Niţelea (D. Br. Fragm. l. c. 74), Tubană și 111-stirea Poéna (Sz. munusc.): pe lingă Bucureseĭ la Buftea (Gr. Exsic.!). - 2 saiй-Inniü.

0. militaris L. O. militară.--Prin finețele din pădurile regiunel montane. - În Moldova $(C z$. Flora XIX, 72 et Exsic.!; Cz. ct Sz. l. c. 50) superióră (Guebh. mamusc.) lit pólele Ciéhlăulŭ (Edel l. c. 36); pe lingă Jaş̆ la Hadîmb, Mironésa și Ciocaboca (Sz. mannsc.); în I)imbovița către Stur-

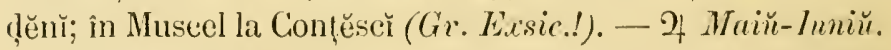

0. variegata All.; O.tridentata Scop. O. vargută.-Prin finețele unnede. - În tótă Moldova (Guebh. mannsc.); in 


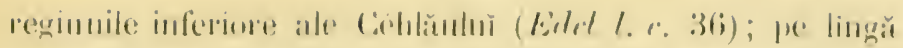

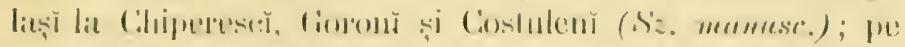

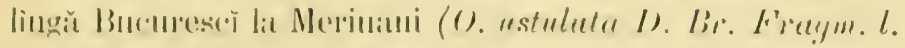

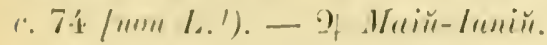

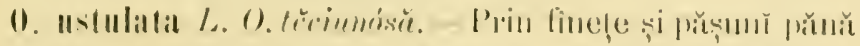

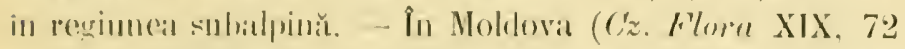

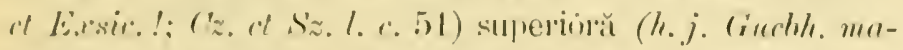

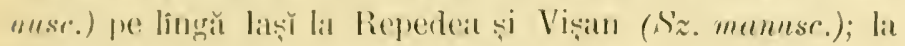

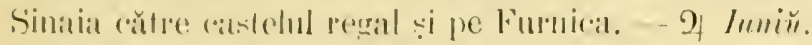

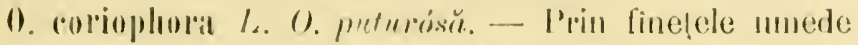

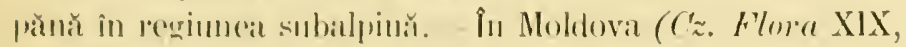

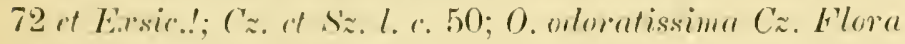

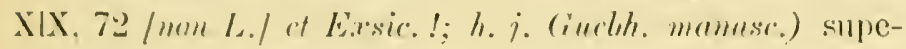

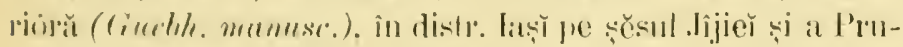

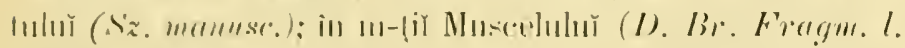

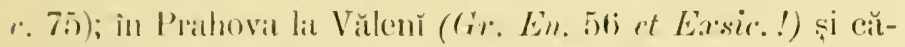

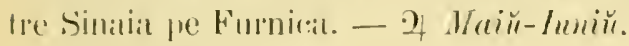

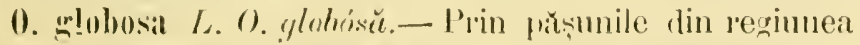
suhalpină și alpină. - In Moldova (Cz. Flora XIX, 72 rt

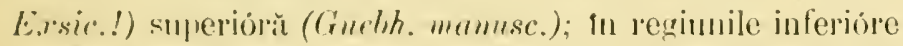

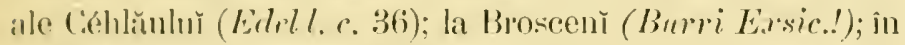

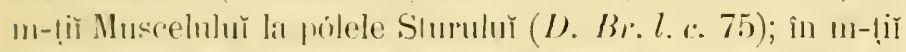

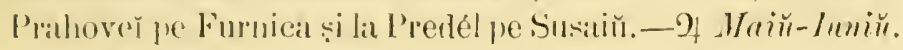

0. Morio L. O. luffom. - Vulg. Pominic. - Prin linețe 11.ate. - In Moldova (Ca. Flore XIX, 72 it Ersic. !; $C z$.

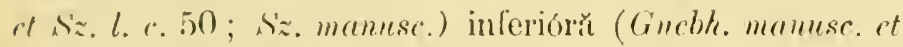
Errsia. n. 32 ser. Nym. C'msp. 691); în regimile inferiore ale Céhlŭuhŭ (Edel l. r. 35); pe lingă laș̆ la Niṭelea (D. Br.

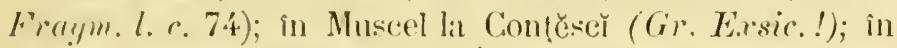
Prithova la Cammina, Vülenĭ (O). ustulata Gr. En. 56 funon 1.. it E.rsic.!). la Sinaia pe Furnica. si la Predél ; pe lingă

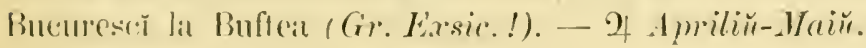

0. Massenla L. O. masculiné. - Vulg. Poreniciü.-Prin finetele umede din reginnea montană și subalpină. - In 
Nolilovat (Cz. Flere XIX, 72 et tiessice !; Cz. ct Sz. l. e. 50)

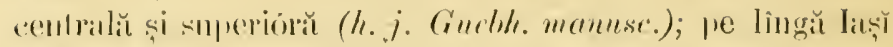

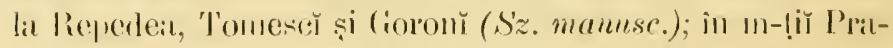
loveř la Sinnaia și la Predél pe Susinin; în Muscel la Con-

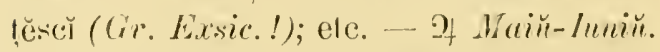

B. speciosa Koch; O. speciosa Hest. - Prin line!cele din pădurile subalpine. - La l'redél pe m-tele Susaiñ.

0. palustris Jaeq. O. de mlastivi. - P'rin fincte mlatülinóse. - In Moldova (O. hircina Cz. F'lera XIX. 72 /nom Swartz] it Exsic.!; Cz. ct Sz.l. c. 51) superioră (Gucbh.

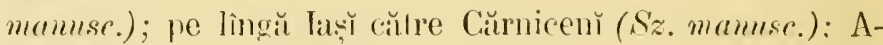
gind (Burri Exsic.!); pe lînğ Bucurescĕ la Cotrocenı̀! ( $G r$. En. 56), Buftea și Ciocănesč; lit Comana; în Arges la Stol-

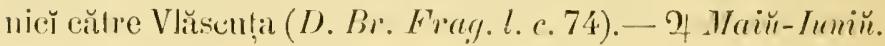

O. sambuciuna L. O. cu miros de soe. - Prin pŭșnnile unnede din regimea subalpină. - În regimnile inferióre ale

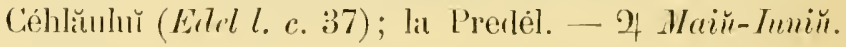

O. Mraculata I. O. macrulatŏ. - Prin finetele umenle din

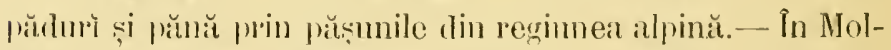
Jova (Cz. Flera XIX, 72 et Exsic.l; Cz. ot s'z. l. e. 50; O. ineermata Cz. Flora XIX, 72 /non L. ne W.] it Ersic.!; Һ. j. Guebh. manusc.; O. sambucina Cz. F'ln'e XIX, 72 lnom L.J et Exsice!; h.j. Guebh. mannse.; Cz. ot s'z.l. c. 51) cenl'ală și superioră (Gucbh. mamusc.); în regiunile in-

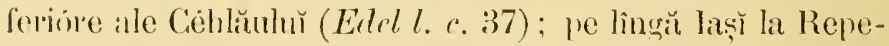
dea (\$z. manuse.); în m-liĭ Musceluhŭ la pólele Sturulŭ (I). Br. l. e. 75); în m-lị̆ Prahově̀ pe Furniea și la P'redél

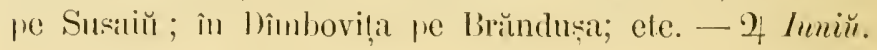

O. lalifolia L. O. cu fou late. - Prin finețele mlăstinóse. - În Moldova ( $C z$. Flora XIX, 72 ct Easice!; $C z$. it sza. l. c. 50; O. anyustifoliu C'z. el S'z. l. c.51 et Exsic.!; h. j. Gucbh. manusc.) centrală și superioră (h. j.

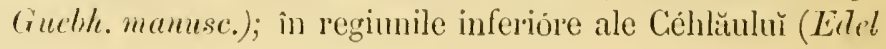




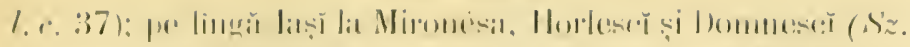

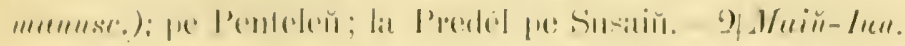

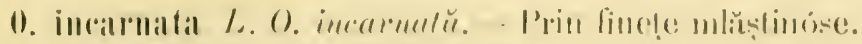

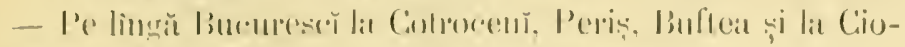

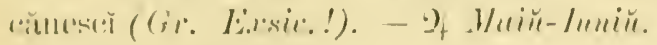

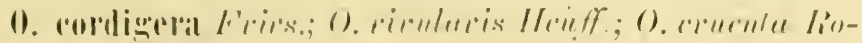

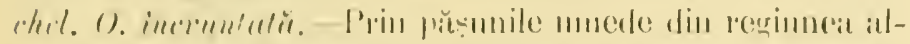

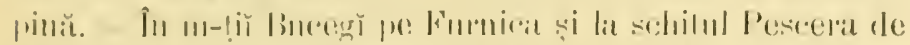

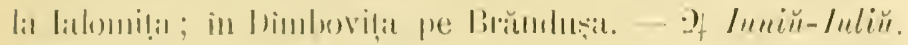

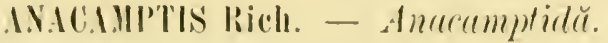

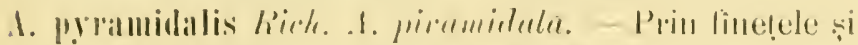

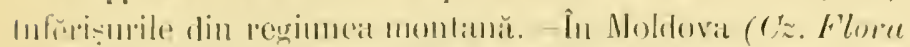

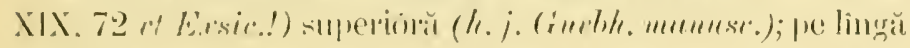

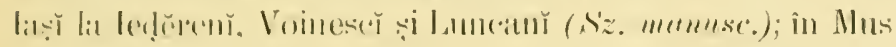

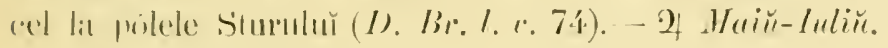

\section{GMNAIENII R. RH. - Gimmalenie.}

fi. ronopsisea li, Br. (i. romopser. - P’in finetele și pă-

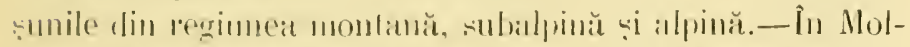

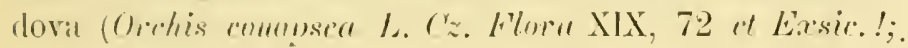

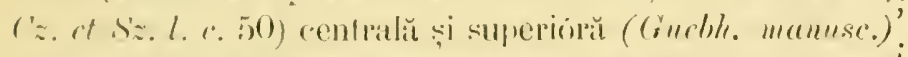

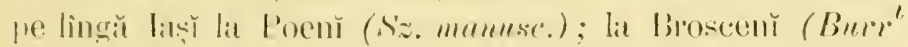

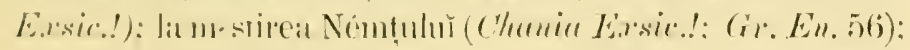

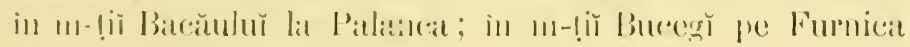

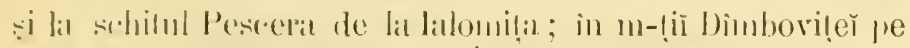

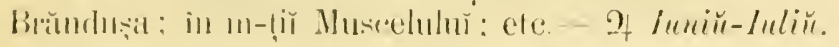

di. odoratissima lich. (i. fürte mirensitare. - Prin li-

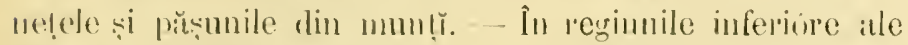

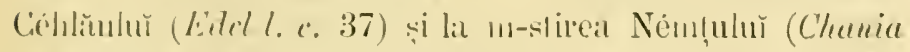

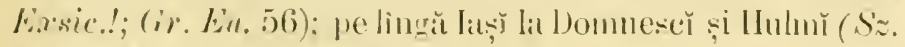
manusc.?). - If Inniü-Juliu. 


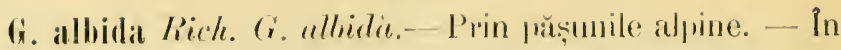
m-lii bucegri (F'uss l. c. 624). - 2 J Juriü-duegrest.

\section{CoblogiosstuI Hartur. - Celoylus.}

(A. virile Harm. C. errde. - P'rin pășunile umede din

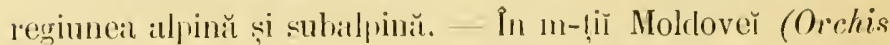

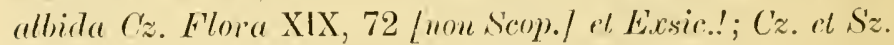
l. .. 51 ; h.j. Guebh. m(enuse.); în m-ṭi Bucegì pe Furnica si la schitul Pěscera de lat lalomilia; la P'redél pe m-tele Susilü; elc. - 2 Maiй-Iuliü.

Obs.-- Se mar citéză : Siltyrium litreinum $L$. la Stavnic, Barbarea și Cinrdea (Sz. manusc.) și în lifov la Cernica (O. hivinu Sur. Gr. En. 56).

\section{PLATANTHERA Rich. - Platanterč.}

P'. bifolia Rich. P. cu dou fou. - Prin pădurile umhrise. - In totă Moldova (Cz. Flora XIX, 72 ct Exsic.!; Guebh. mamesc.; Halaxis monopleylles $C z$. Flora XIX, 72 /nom Siw./ et Exxsic.!); pe lìngă Jași la Mironésa şi m-stireal Stavnie (Szz. manusc.); pe lîngă Bèrlad la Slohod̦ia (D. Bre

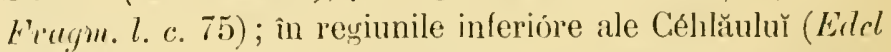
l. c. 36) și la m-stipea Ném!̣ulǔ; în m-țiù Bacăuluŭ la Slănic; in m-tii Prahover la Sinaia (Gr. Lin. 56 it Exsic.!) pe Piscu-cânelur̆; în Dîmboviṭa intre Sturd̦ennu și Cetățĕnĭ; în m-liĭ Muscelulŭ la Němăesč̀! (P. chlorantha Gr. En. 56 [non Custor.] et Exsic.!); etc.-2/ Maій-Iиniй.

\section{NIGRITEL_LA Riclı. - Nigritelu.}

N. allgustifolia Rich. N. cu fur inguste. - Prin păș̣ınile din reginnea alpină. - În n-tị Moldoveì (Arachitess alpina Sz. Exsic.! [non Bmy. nec Jhoffm.]); în m-lị̆ Buceğ pe Vìfu-cu-Dorn, Furnica și Obîrșia.-2| Мaiй-Juliu. 
OPIIRYSLL_- Ophrinsŭ.

0. Innscifera Iluds. O. muscifirè, -Prin pădurile mun-

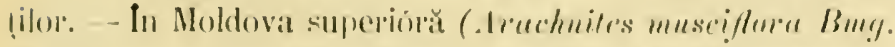

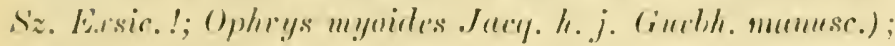

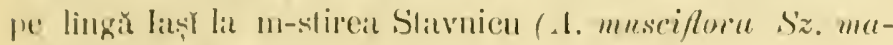
nese.). - If lmiй.

0. Arachnites lirich. O. Aruchatur. - Prin finețele din

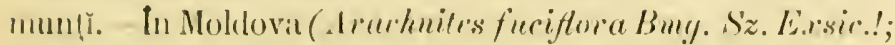

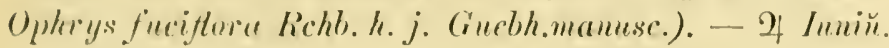

\section{CHAMEORCIIS Rich. - Chameorchită.}

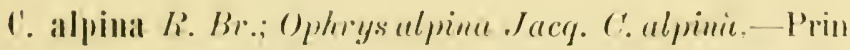
pătunile pelrise din regiunea alpină. - In m-lĭ Buceğ pe

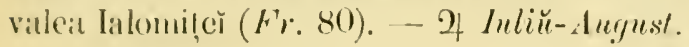

\section{IIERIINIUII R. Br. - Erminiǔ.}

H. Monorehis R. Br. E. cu bulh solitar. - Prin phisunile din regiunea subalpină și alpină. - In Moldova (1rochniles I/onnchis Hoffm. Cz. Flura XIX, 72 et E.rsic.!) superior (Ophrys Mronorchis L. h.j. Guebh. manusc.) lit prilele Céhlăulur̆ (Arachniles Honorchis Edel l. c. 37); la Broscenı̆ (Burri Exsic.!); la Palanca pe Tărhauṣnl-nare; in m-ḷĭ Dìmbovil̨eı pe Brŏndusa. - If Maiй-Iuliu.

\section{EPIP0GIUM Rich. - Epipogiŭ.}

E. Gimelini Rich.; E. aphyllum Wahlcnb. E. lǔ̆ Gmelin. - Parasil pe lemnele putrede din pradurile umbróse și muede din regiunea subalpină. - La măuăslirea Némı̣tulur pe muntele Pleșu; in munții Bacătulù la apele minerale de la Slănic; ete. - If Inliu-dugnest. 


\section{CEPIIILANTHERA Rich. - Cefutunterit.}

C. pallens Rich. C. pulidä. - Prin pădurile din regiunea montană. - In Noldovil (Epipuetis pullerus Swartz Cz.

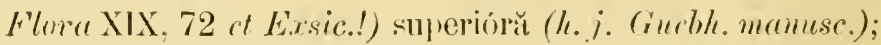

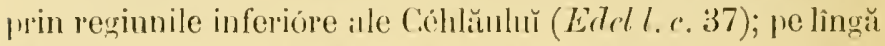

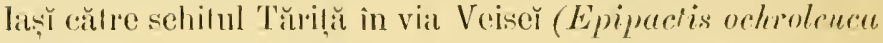

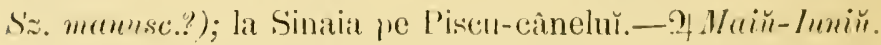

C. ensifolia Rich. C. an for in forma de spadta. - Prin

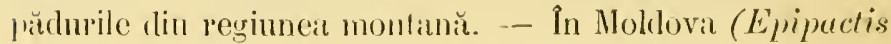
susifulia Swartz Cz. Fleru XIX, 72 ct E.rsic.!) superióră (h.j. Gubbh. mamuse.); prin resimnile inferion'e ale Célılăulıĭ (Estcl l. c. 37) și la m-stirea Ném!uluu (Chunia Eisic.l;

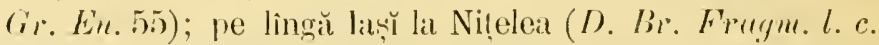
74). Picioru-lupuluh̆, Birnova, Birrsant și s,innla (s'z. manusc.);

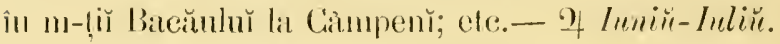

C. Pubra Rich. C. msir. Prin pŭdurile umbrose şi umede din reginnea monlana. - In Noldoval (Epripactis mu-

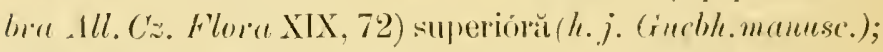

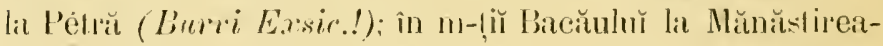

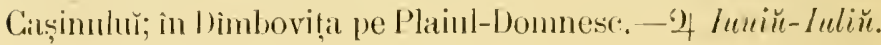

\section{EPIPACTIS Rich. - Epipactidlă.}

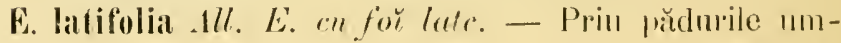
bróse și umede de pre coline și din munț. - In Moldova superióră (C'z. Flora XIX, 72 it Exsic:!; h.j. Giuchh. ma-

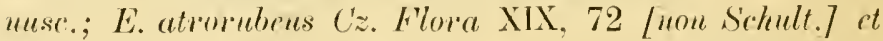
Fissir.!; h.j. Gucbh. mamusr.); prin resiunile inferióre ale Cihlüulu (Edel l. c. 37) și la m-slirea Agapia; la Broseenı̆ (Burri Exrsic.!); pe lingă laṣ̆ la Repredea (D. Br. Frugm. 1. c. 74) și Mironésa (Sz. menuesr.); pe lîngă Bèrlid la Slo-

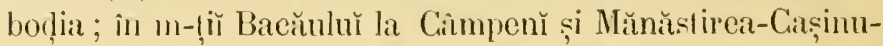




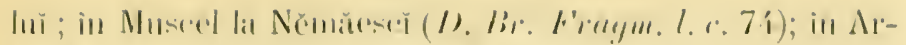

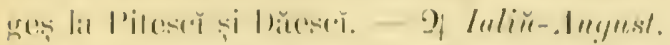

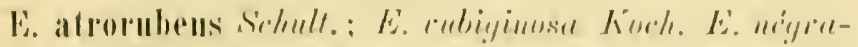

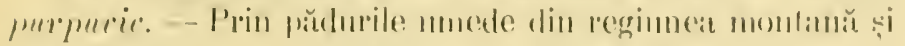

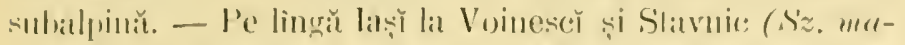

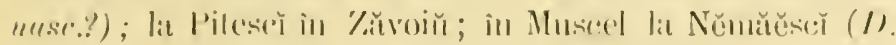

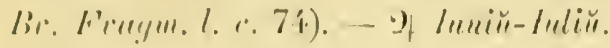

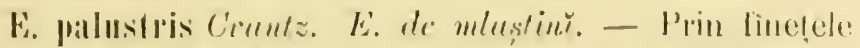

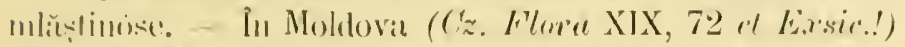

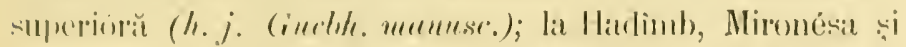

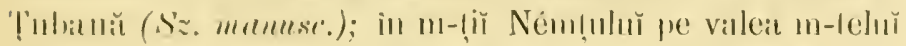

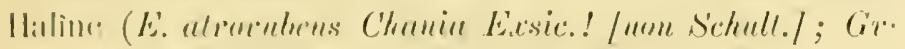

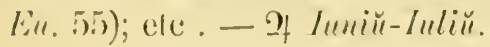

\section{LISTER.I R. IBr. - Listerĭ.}

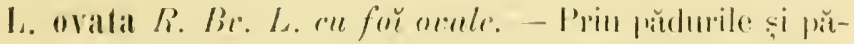
șmile muede din regiumea monlană.- În Moldova (Gurblh.

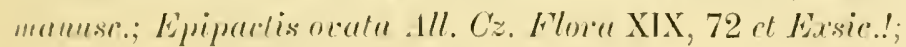

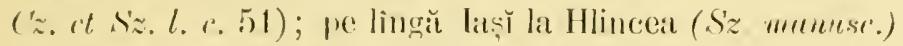
i Niṭelea; in m-ḷĭ Muscelulŭ (I). Br. Frasm. l. c. 74) li

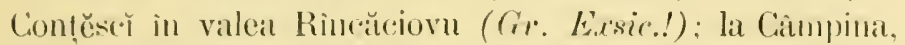
Sinalir (Gr. Eu. 55 ret Exsic.!) sil la Prerlél pe Susain̆ ; in Mehedin!̣̆ la Dumbrăviṭa (Gr. Exsic.!), - 7 Maiй-Inliŭ.

L. cordata R. Br. L. си for cordule. - Prin jășunile monede din reggiunea alpină ș subalpină. - În m-lị Mloldo-

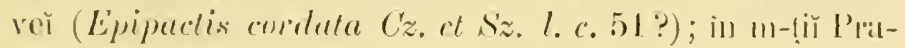
hover lis l'redel pe Susiaiu. - of luniй-luliŭ.

\section{NEOTTII L. - Neotie.}

1. Nillus Iris Pich. N. cuib-de-pasere-Vulg. Triveje.

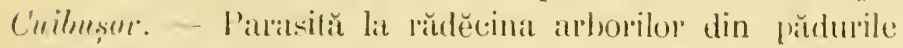

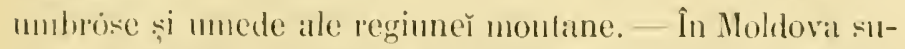

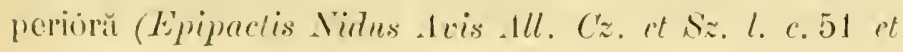


Exsic.!; Sz. manusc.; Listera Vidus Lois L'ers. h.j. Gurbh. mamese.); la Pétră (Burri ḱasie.!) și la m-slipea Nèmţulıŭ (Gr. En.55) pe Pleșu; la Mănăstirea-Cáçinulur și la Palanca; la Sinaia (Gr. En. 55 e t Exsic.!) către pólele Furni-

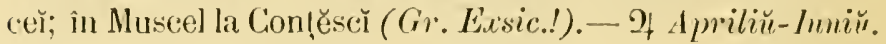

\section{SPIRANTIIES Riclı. - Spirante.}

S. antummalis Rich. Ś. de tómŭ. - P'rin pășunile ॥mede din reginnea subalpină. - १̆ regiunile inferiöre ale Céhlăulŭ (Neotlia spiralis Sw. Entel l. c. 37).

\section{CORALAORRHIZA Hall. - Corclorizc̆.}

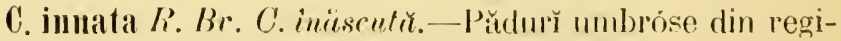
une montană și subalpină.-- In Moldova (Cymbirlizum Corallorihize Sz. Exsic.!; C. Halleri Rich.h.j. (iuelh. manusc.); la Sinaiat pe Piscul-cànelı̆ și la Predél. - 2 I Inniü-dugust.

\section{STURIIA R(bl). - Sturmie.}

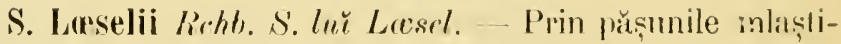
nóse.- Î regiunile inferiôre ale Céhlăohı̌ (Malaris Larsclii Sw. Edel l. c. 37) ; în calea de la Sinaia la Ermit (Liparis Leesclii Rich. Gr. Excurs. I. c. 340; (ir. En. 56)?

())ı. - Se mat citéză : Malaxis palmdusa Sw. (cum ?) la Sinaia către Ermit (Gr. Exc. l. c. 340 et En. 56; Liperis verna Gr. Monit. off. l.c.).

\section{CYPRIPEDIIII $\mathrm{I}_{\text {. }}$-.- Cipripediŭ.}

C. Calceolus L, C. commu. - Vulg. Papuc, P'apuculDímnę̆, Blăbornic. - Prin pădurile umbróse. - In Moldova superiónă (Guebh. manusc.); către Vasluĭ (Cz. et Sz. l. c. 51 et Exsic.!); pe lîngă Jiș̆ la Şanta, Scînteia, Voinesel̆, Luneanı̆ și Horlesĕ̌, comun (Sz. manusc.).-2 Maĭ̌-Leniŭ 


\section{IXXXIII. IITIROCIIRIIACER.}

\section{IIYUROCHARIS L. - Idrochurider.}

II. Morsus ranae L. I. brósector. - Vulg. Iarha-lróserlir. Mnscatul-hriscelor. - Plutitóre in apele stagnante și lin curgétóre. - In Noldova superiónă (Szz. Exsic.!; h. j.

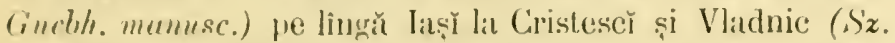
manusc.); la (ialațī; pe lingă Bueureseř în Colentina! (Gir.

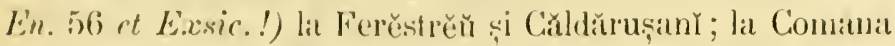
in Cülnisceil (D. Br. Fragm. l. c. 75). - 2 huliü-August.

\section{STRATI0TES I. - Stratiote.}

S. aloides L. S. alvid. - Prin atpele stagnante si lin curgětore. - In Moldova (Cz. Flora XIX, 67 et Exsic.!; h. j. (incblt. manusc.) pe lingă licul Brates (Edel l. c. 38).

\section{IXXXIV. JUNGAGINACEE.}

\section{TRIGLOCHIN L. - Triglockin.}

T. palustre $L$. T. de mlaștint.-P'rin fînețe mlăștinóse. - In Moldova (h.j. (rucbh. manusc.) pe lingă Brateș (E-

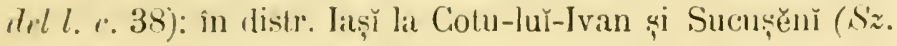
munusc.); Agind (Burri Lisic.!); la Sinaia pe lingă Isvor

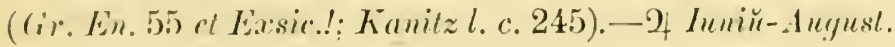

\section{IXXXV. POTAHOGETANACEE.}

\section{POTADOGETON L. - Potamogeton.}

P. natiuss L. I'. notütor. - Vulg. Nontitúror, Broscteviţii. - Prin apele stagnante și lin curgèlore. - Pe lingă 
Jașĭ în Jazul-Chiriteč și Vlardnic ( $S z$ z. manusc.); în distr. Bacăŭ la Brălila; la Agind (Burri Exssic.!); între Pitescı̆ și Gurtea-de-Argeș (Gr. Exsic.!); la Strĕhaia (Alisma natans

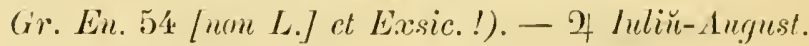

P. Iucens L. P. lucitoriŭ. - Prin ape stagnante şi lin curgètóre. - In Moldova (Cz. Flora XIX, 61 et Exsic..!) superióră (h.j. Gucbh. mannsc.) pe lingă Iași la Gristescŏ în Vladnic (Sz. mamusc.); pe lingă Bucurescǐ la Ferěstrěŭ în Colentina (D. Br. Fragm. l. c. 75 ; Gr. En. 55); în Vlaşca la Comana în Călniscea. - 2 Iuliŭ-Auynst.

P. perfoliatus L. I'. perfoliat. - In ape stagnante și curgětóre.-Pe lingă laş̧̌ la Prisăcanĭ în Prut (Sz. manusc.).

P. crispus $L$. P. cret. - Prin ape stagnante și lin curgĕtiore. - În Moldova (C'z. Flor XIX, 61 et Exsic.!) superióră (h. $j$. Gucbh. manuse.) la Cristescí în Vladnic (Siz. mamusc.); în distr. Bacăŭ la Verșěsč ; la Galațĭ ; în Vlașca la Comana; pe lîngă Bucurescr̆ la Cotrocenǐ și Ferěstrěŭ (Gr. En. 55). - 2 Iuliü-August.

P. pusillus $L$. I. mititcl. - Prin ape stagnante și lin curgětóre. - În Moldova ( $S z$. manusc.) la Galațĭ (Giucbh. munuse.) si la Balta-sărată (Gr. En. 55). -2 Inliü-Aneyust.

P'. pectinatus L. P. peciuat. - Prin ape stagnante și curgětore. - In Moldova ( $S z$. manusc.; $P$. setacens $S z$. / $n$ m L./ Exssic.!; h.j. Gucbh. manusc.) pe lìngă Jaș̆ călre Laurgar (1’. setaceus Sz. mamese.). - 2 Iuliü-August.

Olıs. - Se maĩ citéză : P. fluitans lioth. în Moldova (Sz. mumusc.). - R'. compressus $L$. in Moldova ( $S z$. mamusc.).

\section{ZANICHELLLA I. - Zanichelie.}

7. palustris \%. \%. de mlasstim. - În ape stagnante și curcětóre. - În Moldovat ll'otumogeton graminens $C_{z}$. Flora XIX. 61 [non L./ et Easie.l; h. j. Cincbl. mannsc.; 


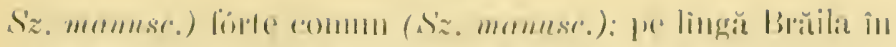

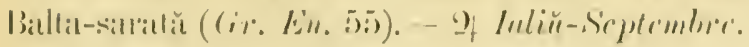

\section{RIPPLA L. - Runie.}

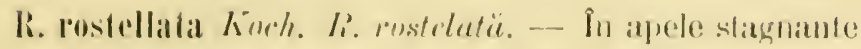

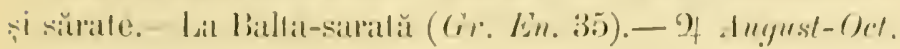

\section{LEMNACEE.}

\section{LEMNA L. - Lemnă.}

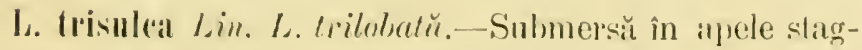
namie și lin conrgèlore. - În hilă Moldova (Sz. manusc.); în

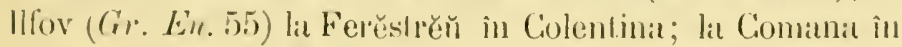

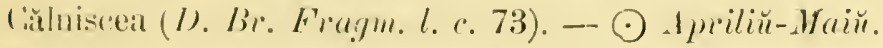

l. polỵrhiza Lin. L. polirizŭ. - Vulg. Liutită, Lim-

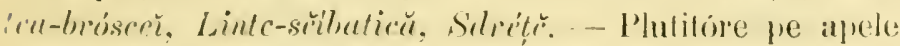
sląnante. - In tótă Noldovil (S'z. munnsc.); pe lingă Bu-

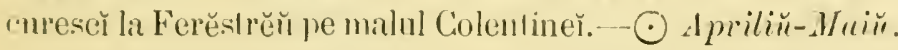

L. minor Lin. L. micĭ.-- Plntitire pe apele stagnante.

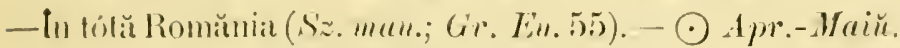

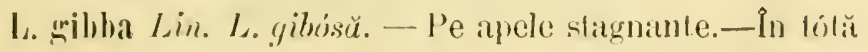

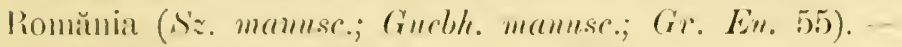
$\odot$ iprilin-1Haiu.

\section{LXXYYII. ARACEE.}

\section{ARUII L. - Aron.}

A. maculatuin L. A. maculat. - Vulg. Rodn-pitmềntulur,

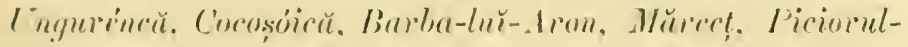

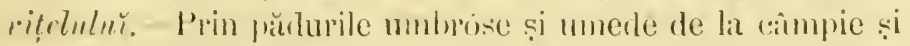

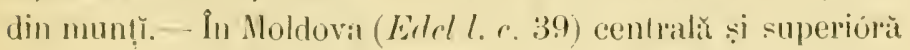


(Guebh. manusc. ct Exsic. "1. 420 see. Nym. Consp. 755); pe linnğ̌ Jașĭ (Sz. mannsc.) la Birnova; de la Jașĭ pănă la Galaṭ̆ fơrte commnă, către nordul laşilor şi pe lingă Roman și Bacăŭ rară (Cz. et Sz.l.c. 1); la Agiud (Burri Exsic.!); pe lìngă Bêrlad la Slobod̦ia (D. Br. Fragm. l. c. 73); la m-stirea Agapia (Gr. Erbor. l. c. 120); la Sinaia în ValeaCàșŭrieĭ; la Vîrciorova către Porțile-de-fer (Borb. Flor. Közl. IX, 362) şi către Bahna. - 2 A priliŭ-Maiù.

A. orientale M. Bicb. A. orimtal. - Prin pădurile umbróse și umede. - În IIfov (1. maculatum Gr. En. 55 / / un L./ et Exsic.!) pe lìngă Bucureseĭ (A. maculatum. Lové. in Drmid. Voy. II, 156) la Bănésa (A. maculatum D. Br. Fragm. l. c. 73) și Buftea; etc. - 2 А priliŭ-1Maiŭ.

\section{CALLA I. - Cală.}

0. palustris L. C. de mlastiň. - Vulg. Códa-sméulní. - Prin mlaștinı̃. - In Moldova (Sz. Exsic.!) prin în\}rejurinile Iașilor (Gucbh. Not. 23); pe lîngă Bucurescĭ la Bŭnésa pe malul Colentině $(G r$. En. 55) - 2 Juliŭ-August.

\section{TYPHACEE.}

\section{TYPIIA L. - Papură.}

'T. latifolia L. P. cu fǒ late. - Vulg. Papurï, Sonar. -Prin ape slagnante şi curgětóre.- În tótă Romănia $(C z$. Flora XIX, 73 et Exsic.!; Guebh. mamesc.; Cz. st Sz. l. c. 54; Sz. manusc.; D. Br.l. c. 73; Gr. En. 55).-24 Iuliŭ-Aug.

T. angustifolia L. P. cu foi inguste. - Prin ape stagnante și lin curgétóre.-În tơtă Moldova (Cz. Flora XIX, 73 "t Eisic.!; Gueble. manuse.; Cz. st Sz.l.c. 54; Sz. manuse.);

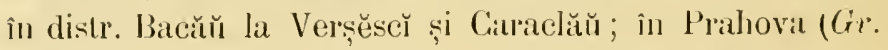
En. 55) la Băicoiŭ; la Comana. - 2 Iuliŭ-dugust. 
'T'. minima /loppe. I'. mititirh. - P'rin alpe slagnanle și

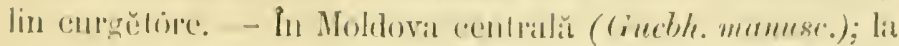

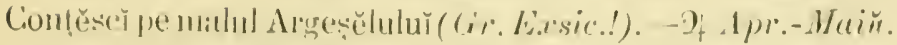

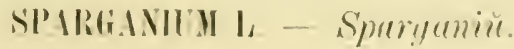

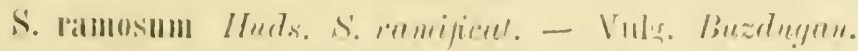

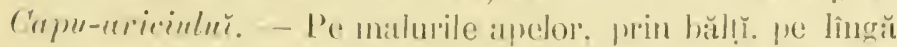

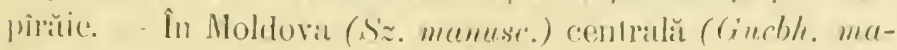

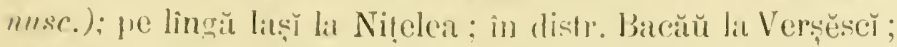
lit Agiund (Burri liśsin.!): pe lingă Bucurescè lat Bănésat pe

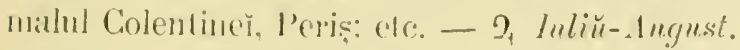

(0)s. -- Se mat citéză : S. simplex Huds. in tótă Moidova (Sz. mamusc.). - S. natans $L$. in tótĭ Noldova (Sz. manusc.).

\section{JUNCACEE.}

\section{JNCUS I. - Junc.}

J. effusus L. .I. respandit. - Vulg. Pipirig, Rugină,

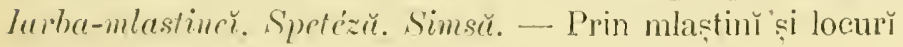
umede. - In Noldova (Sz. manuse., Scirpus palustris $\beta$. major Cz. Flora XIX. 73 [non Bume.] et Exsic.!); în m-ți

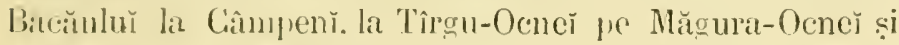
la Slänic (I). lir. Fragm.l. c. 73) : pe Jincă Bucurescĕ la Periș (Gr. E.rsic.!: Kanitz l. c. 25n)) la Sinaia în valea Pelesuluĭ (Gr. En. 58 st Esesic. ). - 4 Iuniü-Iuliü.

J. conglomeratus L. . . conglomerat.--Prin mlaștinù și lo-

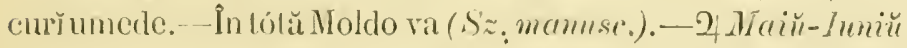

J. glancus L. .J. albăstriŭ.-P'rin mlașlinť locuri umede. -- In lob̆ Noldova (Sz. mamuse. et Liessix. .'; Comobh. mo-

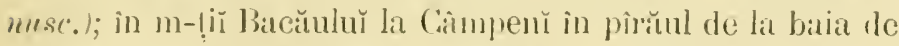
pĕcură ; in Rimnicu-šrrat la Caialal; in Ilfor la Buflea, Cri-

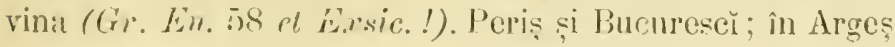


la Dăescĭ ta Gâmpulung (.J. arctirus Gr. En. 58 [non Willd.] et Exsic.!). - 2 I luniü-Angust.

J. Jacquini $L$. . J. lu. Jacquin. - Prin locurile umede din regiunea alphină. -- În m-!̣i Moldovê̌ (Sz. Exssic.!; h.

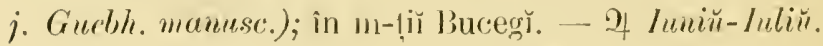

J. trignlumis L. J. cи trě̆ glume. - Prin locurile uliginóse și spongiose din legimnea atpină. - În m-ḷị Bucegi in valea Ialomį̣eř ( $F r$ r. 76) la schilul Pescerat, pe Obîrșie; elc. - 2 Inlin̆-Angnsst.

J. lamprocarpus Ehrh. J. luritoriu. - P'rin mlașlinĭ, bălț̣̆, locurt unede, pe lîngă pîrăie și rîurĭ. - Pe lìngă Iaş̧̆ la Nį̣clea (D. Br. Frogmm. l. c. 73), Mironésa și Hadîmb (Sz. manusc.); la Némṭ̆, Comănesc̆ (Sz. manusc.) și Ciampenı̆; la Agiud (Burri Érsic.); la Curtea-de-Arges in Valea-Hoter̆ (Gr. Érsic.!); elc. - Of Inliŭ-Angust.

J. acutiflorus Eheh.; J. syluaticus Rerichard. J. acutifor. - Prin bălț̆, locurĭ mlăşlinóse, pe malurile pîrăilor și a rîurilor. - În Moldova (Cz. F'lora XIX, 73 et Exsic.; h. j. Guebh. mannsc.) , ve malurile Serehulŭ către Șcheia și a Moldover̆ din jos de Roman, iał în sus călıe I)elenı̆ (Sz. manusc.) ; la Sinaia (J. obiusifturus Gr. Eu. 58 [mm Ehrh.] et Exsie.!) ; in n-lị̆ m-stirilor Cozia, Bistrița, Tisnuana (Hoff. manusc.) și Horez (Gr. lixsic.!). - of Inliü-Lugnst.

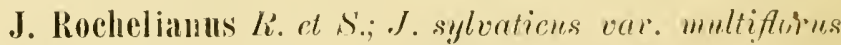
Rochel; .J. sylvatieus \%. Ruchelianus/L.et S.7 Henff.; J. brevirustris Voes. J. Lu Retohel. - Prin finețele măștinóse din munț̆. - Pe linģă m-stirea Némı̣uluı̆ ; in m-tiĭ Bacăıluĭ la Mănăstirea-Cașinuluĭ; la Curlea-de-Arges in Valea-

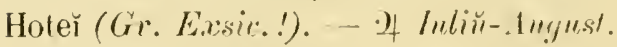

J. atratus Krorkere. .J. negen.--Prin bălțĭ, mlaștinị și lo-

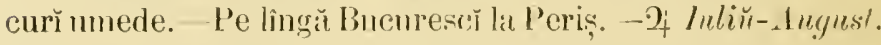

J. squarrosus L. J. aspmu. - P'rin mlaștinı̆ ci finețe umede. - In Moldova (Sz. mamusc.) pe lîngă ( ialațĭ (Guebh. 


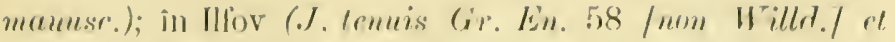
lixsir.!); ele. - 2t Juliü- lugust.

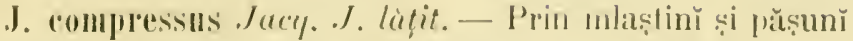
muerle și nĕsiquse. - In tót̆ Moldova (.J. lulbusus L. Cz̃.

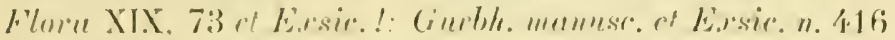

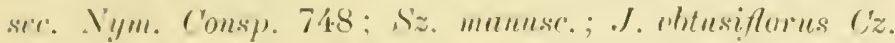

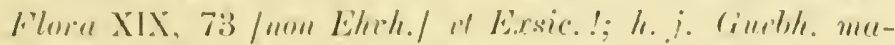

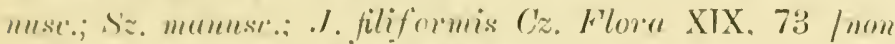

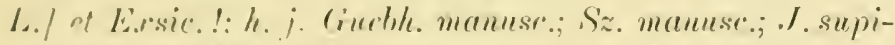

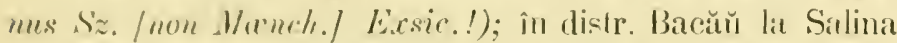

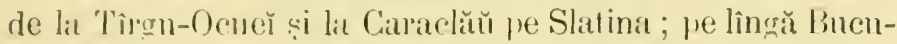

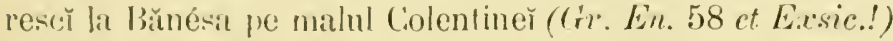
și la P'eriș; în Vlaṣa la Comana. - 2 Inlin̆-August.

J. Infouius L. .J hrossese. - Prin locurì nĕsijoose umede și inundate, pe matca rîurilor. - In Noldova (Cz.

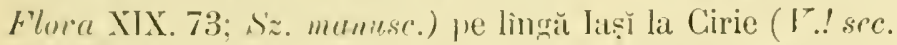
Kanitz l. г. 2ち0); pe malurile Sereluhü (Gupbl. mamusc.); în m-ṭī Bacătuluĭ la Slătuic, Mănăstirea-Cașinuluĭ și Comănescě : la Agiud (Bmrri Exasic.!); în Arges pe m-tị Urḍica și Cozia ; la ı-slirea Horez; în Mehedințĭ la Dumbrăviḷa pe dẻlul Ioroulova (Gr. Ersic.!); etc.-(-) Iulin̆-August.

(H)s. - Se maĭ citéză : J. tritidıs L. în Moldova (Sz. manusc.). J. tenatgeia Eihrh. în Moldova (sz. manusc.).- J. uligmo-ls Richb. la apele ninerale de la Slănic (Sz. mamusc.).

\section{LUZTLA DC. - Iazulă.}

1. pilosa Willt. L. pròrsà. - Prin pădurı̆. - În Moldovat (Cz. Flora XIX, 73 et lixsic.!; L. intermedia Cz. Flora XIX, 73 /non Bmg./ et lissic.!; h.j. (ruebh. mamusc.) centrait (1. irenalis DC. (rurbh. manuse.; Sz. mamuse.); pe lïğă Iași lat m-stipea Stavnicu (Sz. mamusc.); la m-stirea Némṭulū (Gir. En. 58); în Muscel lia Cóntĕscĕ în ValeaRincăciovu ((ir. E.rsic.!); ete. - 2) I miliй-د/aiй. 
L. Forsteri DC. L. lue Forster. - Prin pădurile din regiunea montană și subalpină. - - La Virrciorova rătre Portile-de-fer! (Simk. 605). -. 2 Naĭ-hniŭ.

L. maxima $D C$. L. mase. - Vulg. Horsť. - Prin jŭdurile din regiunea subalpină. - In Moldova centrală și superioră (Gueb/. manusc.) prin m-ḷĭ Bjacaulı la Palanca; in m-țĭ Buzeuluĭ (Hoff. Excurs. 1863. l. c. 117); în m-!̣î

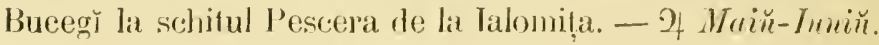

L. allida $D C$. L. alliciosä̈. - P'rin pădurile umbróse din regiunea montană şi sulıalpină. - În Moldova (Cz. Flora XIX. 73 et Exsic.!; L. nemorensa C'z. Floret XIX, 73 fmon Bm.] et Exsic.!; Sz. manusc,; L. maxime Cz. Floren XIX, 73 / nom DC.7 et Exsic.!; Sz. mannese.) centrală si snperióră (Gucbh. mannsc.); pe lingă Iașĭ la Hadimb și Mironésa (L. nivea s'z. manuse. /mon DC.J); în m-lị̆ Bacăuluă la Comănesě̆ (Sz. mamusc.). P'alancia. Măgura-Ocneř şi Slănic; la Agiud (Burri Exsic..') : cătle pólele Céhlăulur ; în m-tị̆ Prahoveĭ la Sinaia (L. allicla ß. cuprina Gr. En. 58

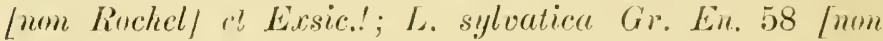
Gaud.7) către pölele Bucegilor; în Muscel (I). Br. Fragm. l. c. 73) pe Délu-Moṭoiŭ (Hoff. Eacums. 1862, l. c. 39), la Câmpulung și Stîlpenĭ (L. niven Gir. En. 58 /mm I)C.] rt Exsic.!); în m-tiĭ un-stirilor Bistriḷa (Gr. Exsic..'), Cozia și 'Tismana (Hoff. manusc.); in Meherlin!̣̆ la Vireiorova pe va-

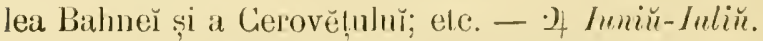

3. rubella Hoppe; L. allida ß. cuprina lisched. - In regiunea subalpină. - Céhlăŭ; Palanca; P'entelen̆; în Bucegĭ la schitul Pescera de la Jalonilat! (1. ulprogrue S'ehur En.681).

I. campestris I)C. L. campestria.-- Vuls. Ahalainl-cuculǔ. - Prin pășunile și pădurile din mun!̣̆. - Pe linğ

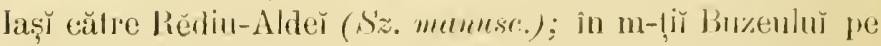

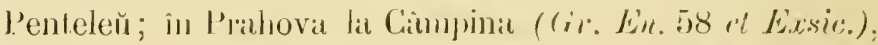

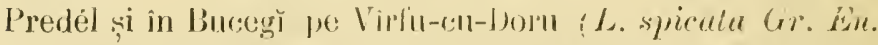

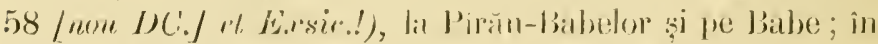

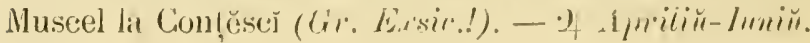




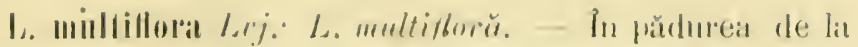

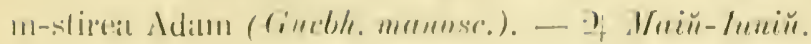

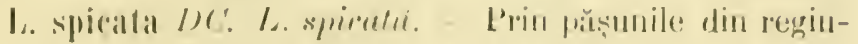

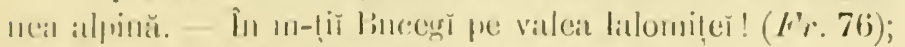

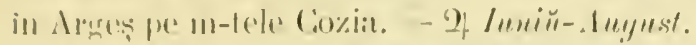

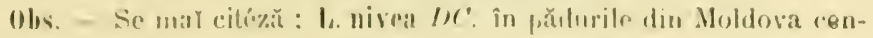
tralit și superiór: (Guebh. munnsce.).

\section{XC'. I'PERICLE.}

\section{GTERIS I. - Cyper.}

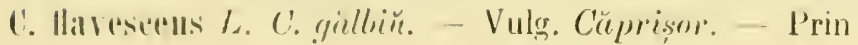

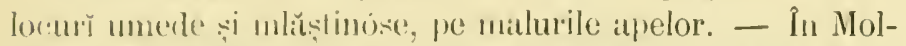

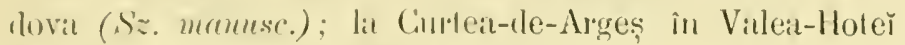
((iv. E.rsic.!). - $\odot$ Inliü-.lugnest.

C. fuscus L. ('. megririus. - Prin locurile unede și inumdale, mliștinı̆. pe lînği pirrŭie, pe malurile apelor. - In

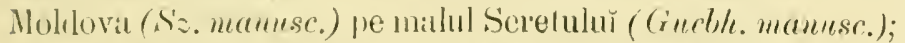

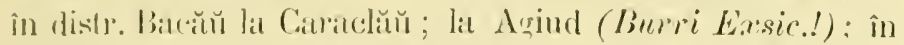

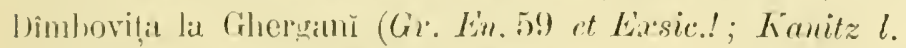

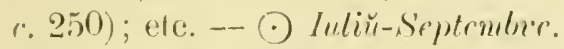

ß. rirescens (IInffm.). - Pe lîngŭ Bucurescŏ la Bănésil pe malul Colentineĩ (Gr. En. 59) et E.ssic.!; Kanitz l. c. 250).

C. glaber L.; C. patulus Kit. C. glabiru. - Pe malu-

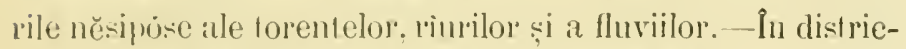
Iul Vîlceš la Bälcescì. - 2 duguest-Septembre.

C. Monti L. C. Lǔ IInali. - P’rin lor:urì mlăștinóse, pe malud aprelor. - In Vlașca la Comana spre Cirŭdiștea; pe

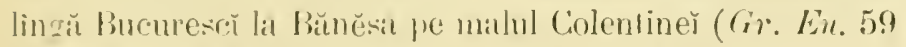

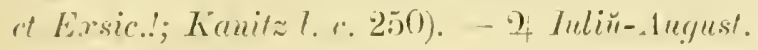

C. glomeritus L. C'. glomerat. - Pe malurile apelor. -

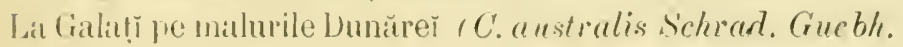


manusc.). Seretuluí (Guehh. Sot. 15) și a Prutuluŭ (C. pannonicus Sz. manusc. /non Jacq.J?); Agiud (Burvi E.xsic.!); pe lîngă Bucurescĭ la Bănésa pe malul Colentinĕ sub Villa-Bi-

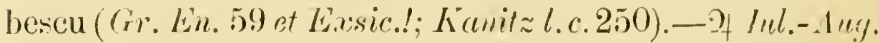

\section{SCHLENUS 1. - Schen.}

S. nigrvicans L. S'. negricios. - Vulg. Bumbures, Bumbusor. - Prin fînețele mlăștinóse. - În tótă Moldova (S'z. mamusc.). - 9 Maiй-Juliŭ.

S. ferrugrineus L. S. fernginos - Finețe mlăstinóse.In m-1̆ı̆ la Prisecanı̆, Negrulésă și Răj)iunĭ (S'z. manusc.).

\section{RHYNCHOSPORA VahI. - Rincosporč.}

R. alba $\Gamma a h l . R$. alba.-Pășunì mlăștinóse din mun!̣̆.La Grozĕsč̆ şi Palanca (Schanus albus L. Sz. mannsc.).

\section{HELEOCHARIS R. Br. - Eleocharidă.}

II. palustuis R. Br. E. de mlastine-Vulg. I'ipirigut.Prin mlastinŭ, bălṭ̆, pe malırile lacurilor si a rîurilor. - In tótă Moldova (Gucbh. mamusc.; D. Br. Fiargm. I. c. 72 ; Scirpus palusiris L. Cz. Flora XIX, 72 of Exsic.!; Cz. et Sz. l. c. 54; Sz. manusc.; S. palustris P. minor Cz. Flora XIX, 73 /mom. Bmo.l of Exsic.!; Sz. manusc.; S. ovatus Cz. ct Sz. l. e. 54 / non Roth] et Exsic.!; S. acicularis Cz. Flma XIX, 72 /non L.] et E.esic.!; Sz. mamusc.: s'. Aluitans rz. et Sz. l. c. 54 (non L./ et Erssic.!: $S z$. manusc.); în districiul Bacăŭ la Verșĕscy și Caraclăŭ ; la Agiud (Burri Exsic.!) ; în districtul Buzeŭ la Becenı̆ (Gr. Exsic.!): in Ilfov la Gulia, 'Tărtăș̌sč̆, Buftea, Crivina, Gherganı̆ (Gr. En. 59 et Exsic.!; Kanitz l. c. 250) și Merinani; etc.-- 2 Iилій-Scptembre. 


\section{SC'IRPIS I. - Srimp.}

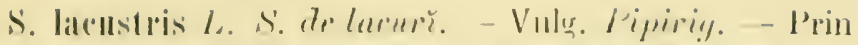

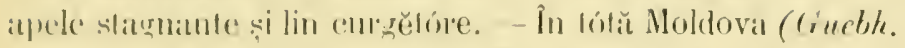

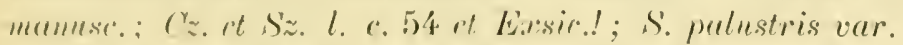

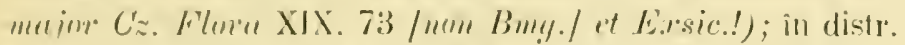

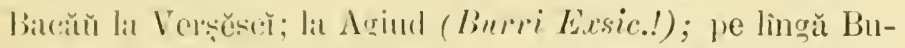

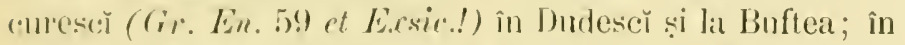

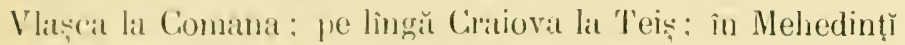

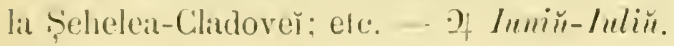

S. tripuetel L. S. triquctru. - Prin apele stagnante și lin curgèlóre. - In tólă Moldova (Guethł. manusc.).

S. Ilolosehonus L. S. globules. - Prin finetele umede și něsipose, pe malul apelor. - In tót̆ Moldova (C'z. et Sz. l. ๔. 5); Sz. mumese.).

S. mirritimus L. S. maritim. - J'rin mlaștinu și finete umede. pe malul apelor. - In Moldova (S. triqueter Cz. Flun XIX. 73 [non L.] et E.rsic.!; Cz. et Siz. l. e. 54; Sz. mamesc.) pe lingă Gialaṭ̂ pe mahurile Brateșulŭ, Prutulŭ (Sz. manusc.) si a Serelulŭ (Gucbh. mamusc.); în distr. BaCăı̆ lil Citlatclăŭ pe Slatina; în distr. Buzen̆ la Becenĭ ( $S$. T'ubernermentani Gr. Ln. 59 fuon Gmel.] et Exsic.!; Kanitz l. r. 251; S. I'ollishii Gr. En. 59 [ucon Godr.7 ot

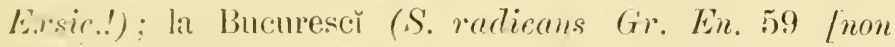

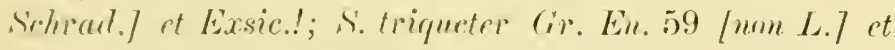

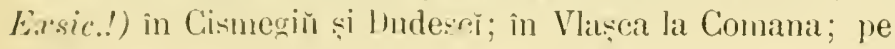
lingă Ciraiovil in pădurea Brésta: în Mehedinț̣ pe malul Dnnăreĭ eă|re Şchelea-Cladoveĭ: etc. - 2/ Inniŭ-Angust.

S. sylvalicus L. S. de pülure. Prin fineţele umede i pe linğ̆ pirrăile din pădurile mă cu sémă din reginnea muntilor. - In Noldova ( $C^{*}$. Flura XIX. 73 et Exsic.!;

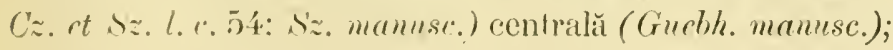
in clistr. Bacĕй la Caraclăŭ cŭlre pădurea Veverița; la Agind 


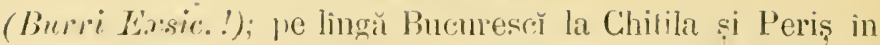
lunca Cocioc (Gr. Exasic.!); în Huscel (cir. Len. 59) rt Exsic.!); la Prerlél. - 2 Inniü-Luliu.

S. Micheliantis L. S. Michelien. - Prin locurile umede si pe malurile apeler.- La 'l'urnu-Severin frequent (.Janlia sec. K̈rnitzl. c. 251). - $\odot$ Iuliŭ- lucust.

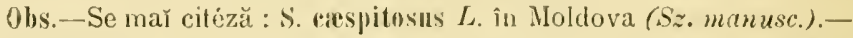
S. Brothrim Ehrh. în Noldova $(S z$. mumusc.). - S. setaceus $L$. în Moldova (S'z. mannsc.). -S. supinus $L$. în Moldova (Sz. manusc.). -S. 1'adicans Sclkk. la Căiuţ pe ınalul Trotușuluĩ și la Petră pe malul Bistr țer (Sz. manusc.). - S. Caricis Retz. în Moldova (Sz. manusc.).

\section{ERIOPIIORIU H. - Eriofor.}

E. Iatifolium Hoppe. E. cu fŏ late. - Vulg. Lânarițä, Bumbăcariț̆, Bumbac-de-crimp. - Prin tine!̣ele muede și mlăștinóse din munț̆. - În Moldova (Cz. HYlora XIX. 73 et Exsic.!; S'z. manusc,; E. alpinum Cz. Flora XIX, 73 Inon L.J et Earsic.!) superióră (E. polystachirem h.j. (inecbh. manusc. (non Leers.l). - 21 Amiliñ-Ifair.

E. angustifolium Roth. E. cu for anqueste. - Prin mlaslinĭ și finete umede din munț̆, pănă în regiunea alpină. În Moldova (Cz. Flora XIX, 73; Sz. manusc.); în m-lị̆ Ném!̨uln squre Silila (Cr. Erbor. l. c. 120); la Sinaia spre

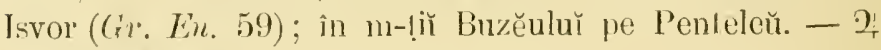
Aprilï-Maiü.

Obs. - Se mař citéză : E. gracile kóoch la Brateș (Sz. manusc.). E. vaginatum $L$. pe lîngă Botoșanı̌ la m-stirea Gafton (Sz, manusc.).

GAREX L. - Carice.

C. pulicaris L. C.puricos.--Prin finețe şi păşım ude.În Moldova (S̃z. mamusc); în dislrictul Buzen̆ pe valea Slătniculuĭ (C. arenaria (rr. En. 59 [mo L.] ot Esssir.!); etc. - 2 Май- питй. 
C. rapitata h. C. capitat.-Prin finele le mactincise din

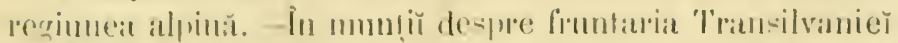

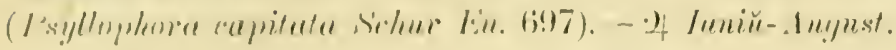

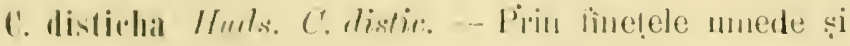

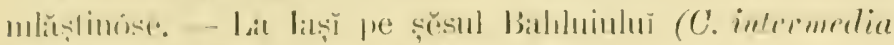
(inul. s'z. munusse). of Main-luniü.

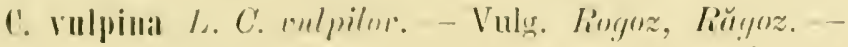

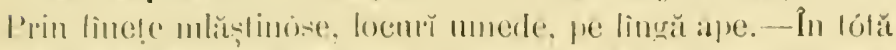

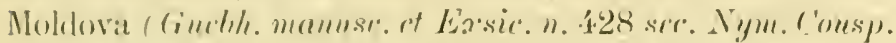
7\$1; C. Wrizuides ('z. Fluru XIX, 73 / nou L./ ot E.tsic. .);

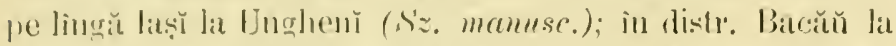

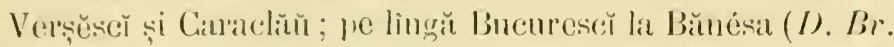
Frougm. l. с. 73) și Judtesce ; pe lingă Ciraiova in luncă și lit Bréstat : ele. - I Hain-Inniu.

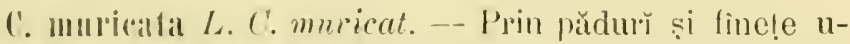

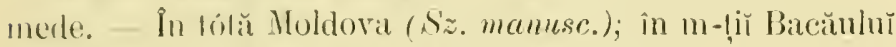

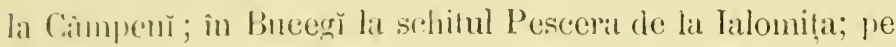
lingr Bururescĭ lit Bănésit. Ferĕstrěn̆ și Cihitilit (D). Br. Fraym. l. c. 73; C. Misticho Gir. En. 59 /non Huds.7 ot E.rsie.!; C. intermetin Kanitz l. c. 251 (non Goorl.7); în Vlaṣcal la Comana ; intre Pitescè çi Ciampulung către Slîl-

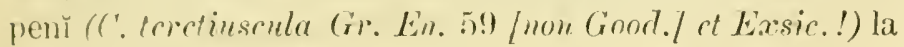
Cìmululung către prolele n-telu Leresč în valea Riu-Tîrgu-

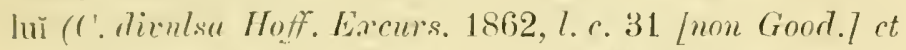

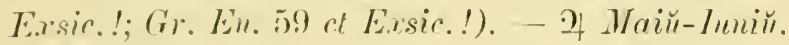

C. paradoxa Hilld. C. paradoral. - Prin finete mlăstincise. - In Moldova (C. Lereliuscula Sz. [uon Good.] Ex-

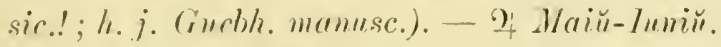

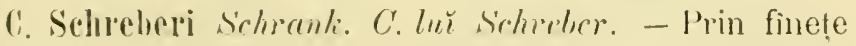

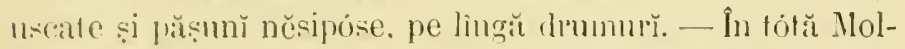

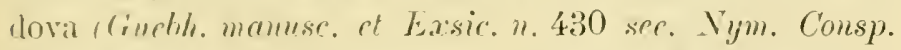
779 ; S. mamuse.; 1' montana Cz. Flora X1X, 73 [mon L.] al Errsic,! /nom. (C colline:]; U. collina S'z. mammse. [non 
Willd.7; O. copillaris ('z, Fllora XIX, 73 / mme 1.7 ot Exisic.!; h. i. Gucbh. mamuse.); pe lingă hașì la Nị̣elea (C. obresa D). Br. Fragm. 1. c. 72 /non .1ll.1); la Agiud (Burri

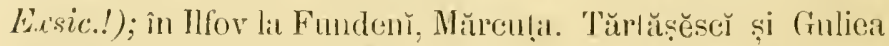

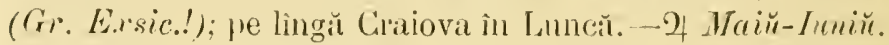

C. brizoides L. C. brizoirt. - Prin părlurile unede și unbróse. - In Moldova centrală (Txuelh. mamese.) spre Prut lit Solonelĭ (S'z. menusce?).

G. Pemotat I. Cspatiat. - Prin locurile unede, bălțile. lacurile și pîrăile din prudurile unbróse. - În Noldova ( $C$. pancifluen Cz. Flora XIX, 73 / mon Ligletf / ot Exsic.!: Siz. memusc.) pe lìnğ Iași către Bordea la Glodósa (Sz. munusc.); la Mănăstirea-Ciușinulŭ ûn Lacnl-verde; la Sinaia în valea Peleșuluı̆ (Gr. En. 59 st Fassic.!). - 2 1/aiй-Iuliŭ.

c. Ieporina L. C. iepuresr. - Prin finețele și pășunile umede, pănă în regiunea alpină.-In tótă Moldova (C.ovalis Good. Ginchh. mamesc.; Sz. manusc.; C. divica C'z. Flora XIX, 73 /mon L.7 et Exsic.!: h. j. Guchlh. manuse.; S'z. manusc.); în m-tiĭ de la Predél. - - lot luniŭ-Iuliu.

C. stellulata Good.; C. rchinata M/urr. C. stclat.-- Prin finețele umede. - În tótă Moldova (Guebh. manuse.; sz. man.).

0. acuta $L$. C. assutit. - Prin bŭlụ̆, locur mlăștinóse, pe lîngu ape. - In Moldova (Cz. Flora XIX, 73; Sz. mamese.; C. rionlaris (iz. Flora XIX, 75 f leon schlih.] st Exsic.!; h. j. Gueble mannse, C. stricia Szo menuesce it Exsir.!: h. i. Guebh. menuse.); in Grorjiŭ la Roṣia pe malul 'Tismaneí; ete. - 2 trait.

C. atmata L. C. negricios. - P'rin locurile slincóse și petróse din regiunea alpină. - in m-tĭ Moldoveř ( $(2 z$. Flora XIX, 73 ct Exsic.!: h. I. Cinclh. manuse.; Sz. manuess.). -2 Inniü-Lugust.

C. linosia L. C. de mil. - Prin locurì mlăștinose. - În Moldova centralĭ (Gusble. mamuse.; Sz. mamusc.). 
C. montana L. C. de munte--Finețe și pădur umbrose din mun!̣̆. - Lat Agind (Burri Lsasic.!). - 9, M/ain-dug.

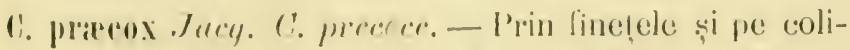

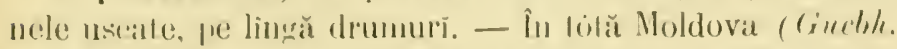

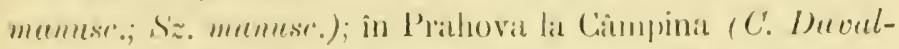

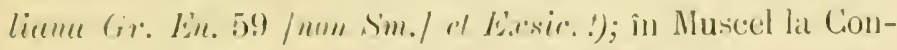

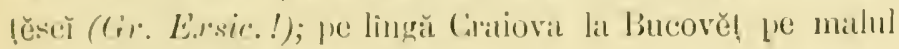

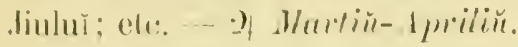

C. dienilata L. C. digilal. - Prin pădurǐ unbróse. -În

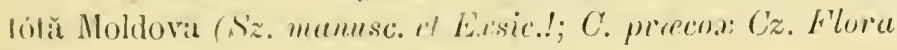

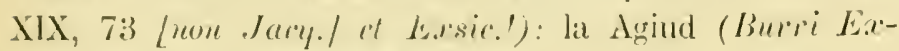
sic.!); cte. - - 1 tprilir-1/aiи.

C. allıa sinp. C. ulb.-Prin pădurile din reginnea monlană și subalpină. - In Moldova superióră (S'z. Exssie. !:

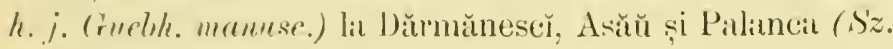

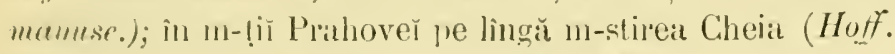

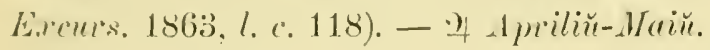

C. pilosa Sicon. ('. persos. - Prin pădurile din regiunea monlană. - In Noldova (C. umbrosa Cz. Flora XIX, 73 Jum IInst.] et Lirsice!; h. j. Guebh. manusc.) centrală (limebh. manusc.); pe lingă Némḷ și Pipririg (Sz. manusc.); lat Agiud (Burri Errsic.!); in Muscel la Contĕscĭ in Valea-

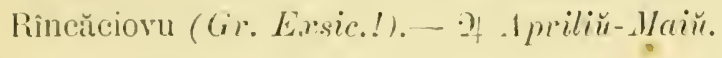

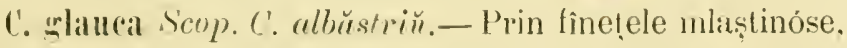
poenile umede de prin pădur̆, pănă în regimnea itlpină. -

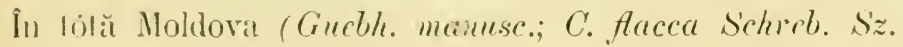
manuse, C. nemorosa $C$ z. Flora XIX, 73 /non Willrl. nec

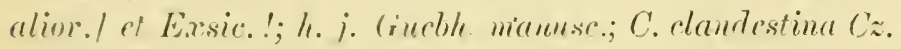
Flara XIX, 73 [mon Crood]. et Exase.!; h.j. Cinchle. maunse.: siz. mamesc.). - 24 spriliü-_liciü.

C. maxima Ścop. C. mare. - P'rin locurile umede și pe lingă pirăile din pădurile umbróse ale munților. - In Mol- 
dova superioră (C. Psendo-Cyperms (zz. Flon XIX $73 /$ /um

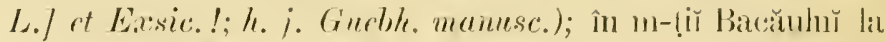
Slănic (C. perulule Good. Sz. mennusc.); pe lîngă lași lì

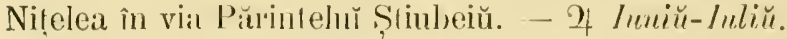

G. pallescens L. U. palrsecu!.- P'rin finete unede și pădurr tătiate. - La Bolozinni și m-stirea I)orohoiŭ (Sz. man.):

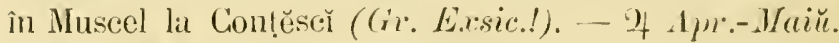

C. firma Host. C. tare-Prin tocurile petróse si umede din regimnea alpină și subalpină. - In Prahoral pe m-tele Zăganu (Iloff. Excurs. 1863, I. r. 118). -9 Irmiй-August.

C. sempervirens Villars. C. sempervirent. - In regiunea alpină. - În m-tị̆ Büreğ la Strungă (Winkl.! sec.

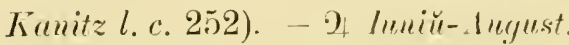

C. depanperata Good. C. depauperat.- Pădurĭ şi tufĕrisurr̆.-La Vîrciorova către Por!̣ile-de-fer' (Borh. F’lör. Közzl. IX, 345) și la Dumbrăvită (Gr. E.rsic.!). - of Maiŭ-Iun.

O. Michelii Host. C. luй Vicheli. - Coline anide, pădurī montane.-In Moldova ( $S z$ manusc.); in Muscel pe m-tele Lerescĭ (IIoff. E.rcur's. 1862, l. c. 31); în Ilfov la Tărltăṣĕ-

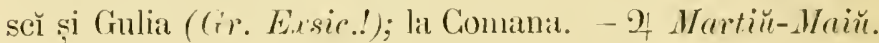

C. Llava L. C. gallin. - Prin fineṭe mnede. prăsunı̆ și locurĭ mlăștinose, pănă in regiunea alpină.--În Moldova (Sz. manusc.); în m-(ịi de la Predél. - of Maiŭ-Inliü.

C. distans L. C. distante. - Prin finete umede. - In Noldova superióră (C. paricea Cz. Flora XIX. 73 / non L.7 et Exsic.!). - 2 Маій-Іивій.

C. sylvatica Huds. C. de păduere. - P'rin pădurile umede și umbróse din munțĭ. - În tótă Moldova ( $C$. patula Scop. Guebh. manusc.; ('. Drymeja Ekrh. Sz. manusc.); la Mănăstirea-Ciaçinulǔ́; la Predél; elc. - 2 lumiŭ-dugust.

6. Pseudo-(Yperus L. C. Ciperină-falsă. - Prin mlaștini, bălțí, pe malurile lacurilor și a rìrilor. - Pe lingă 


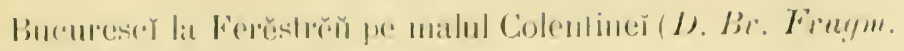

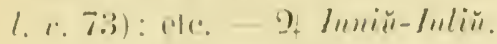

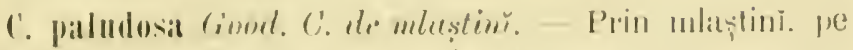

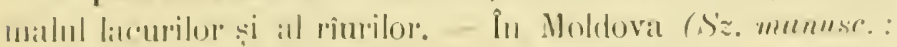

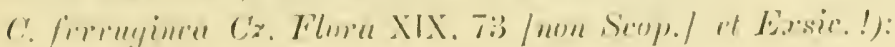

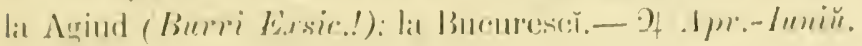

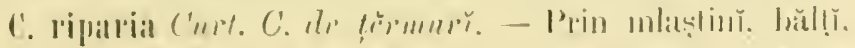

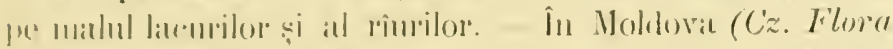

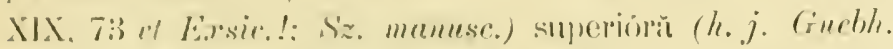

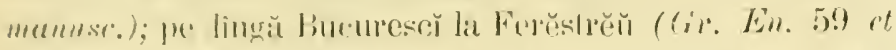

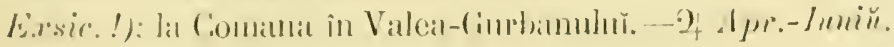

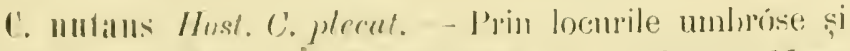
munede. - - In Moldovia (Gueble. Erssie. n. 440 sere. Nym.

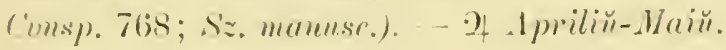

1. hilta L. C'. stmulit. - Prin fineḷe něsijuise. uncde și uscalle. - In lob̆h Noldovil (C'z. ot s'z. Exsic. !; Gmellemamusr. rt Esisic. n. 437 sec. Nym. Consp. 768; sz. mamuse.); pe lîngă Bucurescì (I). Br. Frougm. l. c. 73) la Periș în Vat-

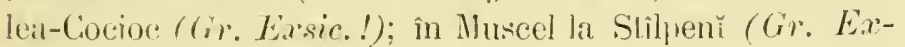
sir.!) : (ele. - o Maiï-luniй.

0hs. 1. - Se mal citéză : C. Iatailiaua Smith. in Moldova (Sz. manusc.). - C. obtusata Liljeblat. la Comănesč (Sz. Manusc.). - C'. slenuluyllil Wahlenb. către Vasluiŭ și Neteda (C. juncifolia Host. ১z. manusc.).-C. divisi Huds. pe șěsurjle Jijier și a Brateșulni (C.

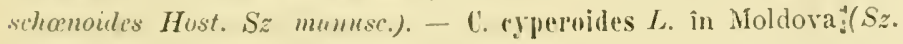

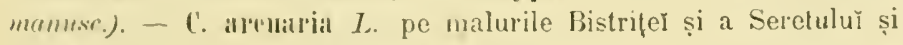
la Galą̧r pe malul Dunărer (Sz. mumusc.). - C. dirulsal Good la Bivolarł și Botoṣan (Sz. mammsc.). - C. linuculata $L$. în Moldova

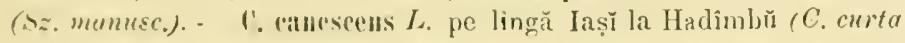
Good. Sz. memwsc.). - C. elungatla L. la Vashıiŭ (sz. memusc.). - C'. slriclal Goud. la Ciampina (Gr. En. 50). - C. vulgaris Fries. pe lînğ laṣi la Mironésa și Ciocaboca (C. cespitosu Guod. Sz. m.musc.).

f. saxatilis Wuhlenb. în m-ţir Buceg̣ pe lîngă Obîrşia lalomiter

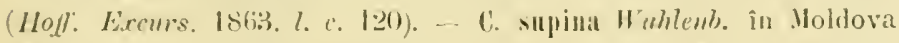

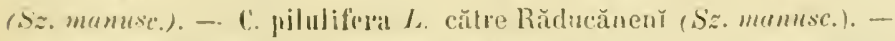

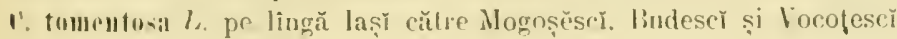


(Sz. manusc.). - ('. eriontorım Pollich, către valea Bicazılur (C. ciliata Willd. Sz. manksc.). - C. alestris All. pe Bucegi (Hoff. Eixcurs. 1863, l. c. 119). - C. secalina Wahlenb. în Moldova (Sz. manusc.). - C. nederi Ekrh. in Moldora (Sz. manusc.). - C. finlva Good. in Moldova (Jz. manusc.). - C. ampulatea Good. in Holdova (Sz. manusc.). - C. vesicaria $L$. in Moldova (Sz. mrunuse.) și pe lîngă Bucurescr la Bănésa (Gr. Ln. 59).

0) lıs. 2. - Nı sciŭ ce pot fi următórele speciŭ : $\%$, interrupta și C. miliacea, aměndouě indicate in Moldova $(C z$. Flor $\alpha$ XIX, 7:3).

\section{GRAMINEE.}

\section{ANDROPOG(O) L. - Andromiggon.}

A. Ischaelmm!n L. A. comun.-Vulg. Bărbósă.-Prin locurì arenacee și uscate, ne délurǐ aride și calcare. - In Moldova (Signtherisma velgure Sz. manusc. /non. Schrad.] et Exsic.!) inferioră (Cueslh. manuse. ot Exssir. n. 450 sec. Nym. Consp. 786); pe lîngă laș̆ la Cristescĭ ci către Pașeanı̆ (Sz. mannsc.) în distr. Bacă̌̆ la Ciaraclăŭ ne Babashicea; în Ilfov (Gr. En. 60 ct Érsic.!) la Merinani și Buftea; în Vîlcea la Golotrení ; la Vireiorova către Porṭilede-fer (Kaniz! l. c. 130); elc. - 2) Iuliü-Antynst.

A. Giryllus L. A. Grier. - l'e délurì aride și prin fìnẹ̣e uscate. - In Covurluin la Pechea (Pollinia Gryllns Spr. S'z. manusc.); la Bêrlad; pe lîngă Bucuresč, la Peris, Chitila şi Cocănesč́ ; în Vlașca la Contana ; în Mehedințĭ la Cernețĭ (Gr. Exsic.!), Gura-văieì și Vîrciorova. - 2 heniê-Auegust.

\section{SORGHUM P'ers. - Surg.}

S. halepense Pers. S. de Alep. - Vulg. Costrer.-Prin vǐ̆, locurı̆ cultivate și něsipóse, pe marginea agrilor. - Pe lîngă Bucurescĭ la Buftea ( Fiphalrmm mulliftornm Gr. Ën. 61 /non 1. B./ et Exsic.!), Ferĕstrĕŭ, Măreuța, Crivina. prin viile de pe lingă Ploesč́; etc - 2q Iиniй-Inliŭ. 


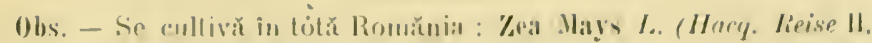

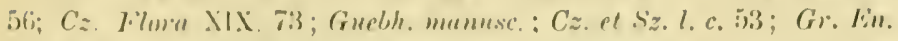

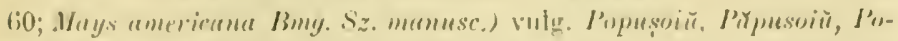

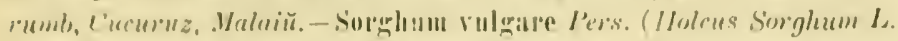

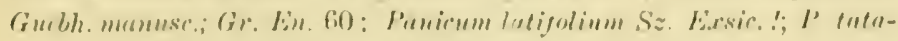

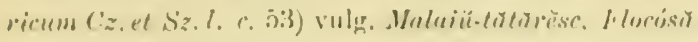

\section{Thidils best. - Jiang.}

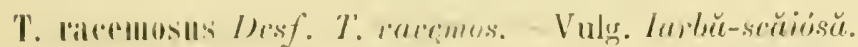
- Prin locomile atreniacee și useale. - In folă Moldova (Szz.

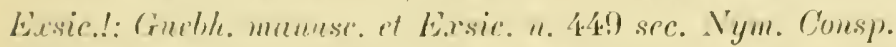

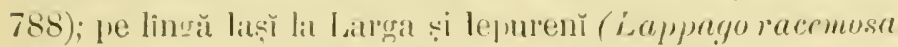
Triu. Szomumuse of Essics!). - (.) Immiй-Inliü.

\section{IIGITARII L. - Tingilarie.}

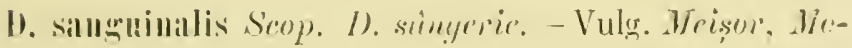

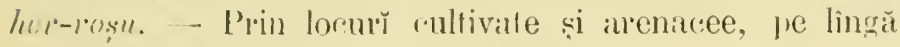
drımmury. prin şrădinile de pe lînsă locuinți. - În Moldovat

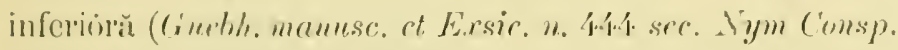

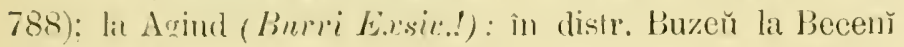

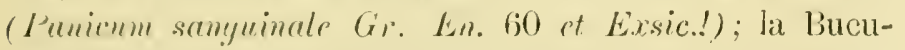

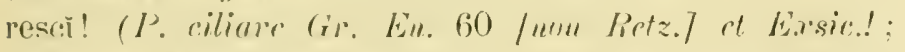
Digituriel humifuse (or. Eu. 60 /mom Pers./ rt Exasc.!); in Argeṣ la m-silivea Stîniṣora (Gr. Exrsic.!); la Câmpulung

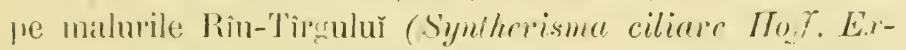

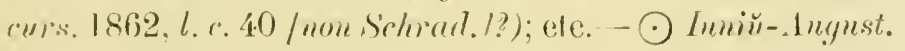

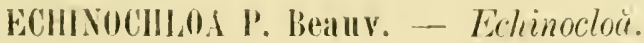

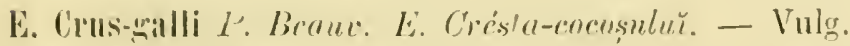

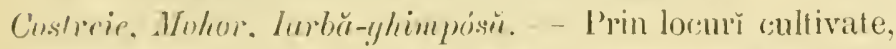
pe marrinea agriulor. - În Moldova (L'enuisstume C'rus-gulli

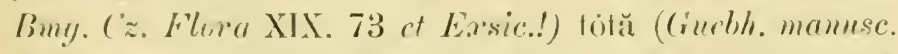

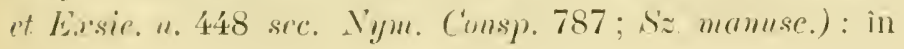


distr. Bacăŭ la Caraclăŭ ; la Aqiud (Burri Errsic.!); în Ilfov

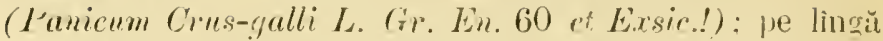
Ciraiova în Luncŭ ; la Vîrciorova către Portile-de-fer! (Kanitzl. c. 130)-- () Iuliü-Scptembre.

0lss. - Se cultivă : Panicum milialemm L. (Cz. Flora XIX, 73 et Exsic.l; Guebh. manuse.; Cz. et Sz. 1. c. 53; Sz. manuse; Gro. Fn. 60 et Exsic. !) vulg. Malair̆, Malaiŭ-mèmunt, Meĭ. I'asat, I'trinc.

\section{SETARIA P. Beaur. -- Setarie.}

S. glanca P. Beamv. S' relbŭstrin. - Vulg. Mohor. Cos-

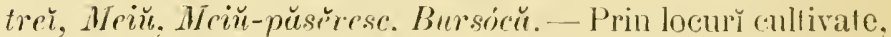

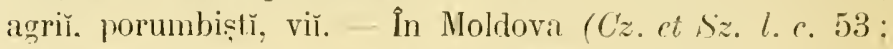
Pemiselum glancum. R. Br. S'z. manusc.): !rrin tóte podgoriile de pe lìngă Iaș̆ (P'nnisctum glaucum D). Br. Fraym. l. c. 71); in distrîctul Bacăŭ la Caraclăŭ; la Argiud (Burvi Exsic.!); la Făurel̆ (Gucbh. manuse.); la Bucuresch!! (Gr. En. 60 ct Es.sic.!), Ferěstrě̆̆. Buftea, Crivina; etc. - $\odot$ Iuliŭ-Septembre.

S. viridis P. Bcauv. S. verde. - Prin locur cultivate.

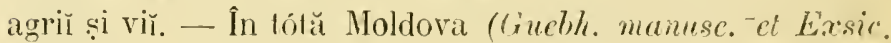
1. 446 sec. Nym. Consp. 786; Cz. rl Sz. l. c. 53 ; Pennisetum viride Bmg. Cz. Flora XIX, 73 ct Exsic.!; I'misctum Wcimmami (z. et Sz. l. c. $53 / \mathrm{mon}$ h. et S.7); la Buculeser (Gr. En. 60 et Essic. !). - - Juliŭ-Sentembre.

S. verticillata $I$. Beauv. S. verticilatŭ. - Prin locuř cultivale, agril̆ și vil̆. - În lótă Noldova (Grebh. mumuse.; Pemisctum verticillatum R. Br. Cz. Flora XIX. 73: Sz. manuse.) și Romănia (Gr. En. 60 rt Ersir.!); lat Bucupescĭ; etc. - () Iuliü-Septrmbre.

Obs. - S. germanica P. Beaun. indicată în Moldova (Cz. et Sz. l. c. 53; R'ennisetum germunicum Bing. Cz. Flore XIX. 67 et Ex.sic.l; $S z$. munusc.) și S. italicł $P$. Becum. indicată în Moldova $(C z$. et $S z$. l. c. 53) inferióră (Guebh, manusc.) și la Agiud (Buюr Exsic.'), nu se ğ̆sesc de cât. numar în stare subspontanee séŭ cultivate. 


\section{PIIILARIS L. - Finluridu.}

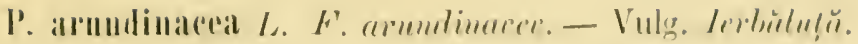

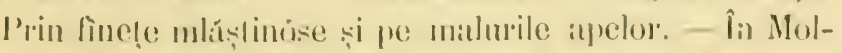

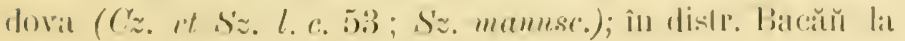

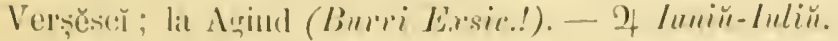

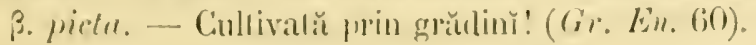

P. eamariensis L, F. ranaribor. - Vulg. larba-canu-

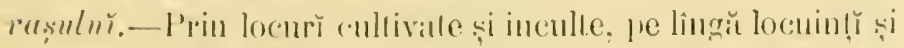

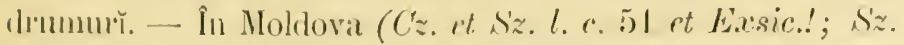
munuse.); în bucuresĕ la fràra Tîrgoviștea (Crr. Làsic..!) ; ete. - $\odot$ Inlin-.Ingust.

0lss. - Se mal citéză : P. minor Retz. în Moldova (Cz. et Sz. l. c. j) et Exsic.?) si P. paraloxa L. in Moldova (Cz. et Sz. l. c. 51 et Exisic.!) - De și eŭ posed din erbariul din IașY, specimenile autenlice ale autorilor menţiona(̨i, totușy este încă de sciut, dacă aceste douě specil cresc, acolo unde se indică, in adevěr în stare spontanеe, saŭ nurual în stare subspontance.

\section{ANTHIXX.ІTHUM I. - Antoxant.}

A. odoratum L. A. mirositor. - Vulg. Paranginŭ. Ti-

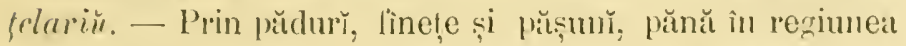
ilpină. - In Moldova (Sz. mamusc.; Frstiuca varia $C z$. Flura XIX, 73 [non Hentel et Éxsic.!; Sz. manuse.); în

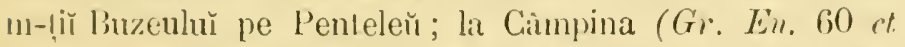
Astsic.!) în Bucerğ pe Furnica; in Nuscel la Cionţěseĭ (Gr.

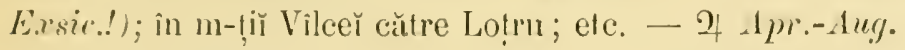

\section{HIEROCHI, Gimel. - Ierochloč.}

II. australis R. et S. I. austrolă.- Pŭdurĭ unbróse.-

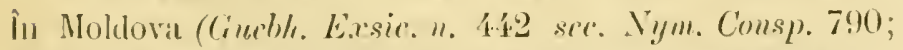

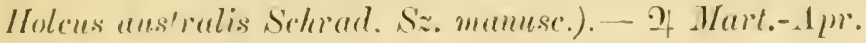




\section{ALOPECURUS I. - Alopecur.}

A. pratensis L. A. de fincțe. - Vulg. Codinŭ, Códavulpě̌. - Prin finnețe umede.- In tótă Moldova (Cz. Flora XIX, 72 et Exsic.!; Guchle. manusc. et Exsic. n. 453, 454 [repens] sec. Nym. Consp. 793; Sz. mamusc.); la Agiud (Burri Exsic.!); în Ilfov (Gr. Ln. 60 et Exsic.!); la Bucurescǐ (D. Br. Fragm. l. c. 72) şi Ciocănescǐ ; în Vlaşca la Comana; etc. - 9 Маіи-Lинiй.

A. arundinacens Poir.; A. rulhcnicus Wcinm.; A. nigricans Hor. A. arundinacč̌. - Prin finețe. - În Moldova (1. bulbosus Cz. Flora XIX, 72 [non L.] et Exsic.!; Sz. manuse.). - 4 Maiŭ-Iuniü.

A. geniculatus $L$. A. gcuiculat. - Prin locurı̆ umede, bălı̣i și mlaștinı̆. - La (Galațĭ (Gucbh. manusc.).

A. fulvus Smith. A. gălbiniŭ.-Prin loeurř umede, bălțĭ, mlaştinŭ, pe malul apelor. - In Moldova (A. gcniculatues Cz. Flon XIX, 72 [non L.] et Exsic.!; Sz. manusc.; Phlcun Michelii Cz. Flora XIX, 72 [non All.] et Exsic.!; Sz. manu.sc.); la Agiud (Burvi Exsic.!); la Ciocănesč̆, Trărlășěscŭ și Gherganı̆ (Gr.! scc. Lanitz l. c. 253 ; A. paluclosus Gr. En. 60 [non Mert. et Koch] ct Exsic.!); la Ferĕstrěŭ pe malul Colentineǐ ; etc. - $\odot$ Maiǔ-August.

\section{CRYPSIS Ait. - Cripsidlă.}

C. aculeata Ait. C. ghimpósă. - Vulg. Iarbă-glimpósŭ, Ghimpariț̆, Iarba-vătămăturč. - Prin finnețele umede și locurile sŭrate. - In Moldova (Cz. et Sz.l.c.51) pe malul Dunăreĭ și pe linngă lacul Brateş (Sz. manusc.).

C. schounoides Lam. C. schenoid. - Vulg. Iarba-vătŭmăturč. - Prin locurile nĕsiṕóse, umede și sărate. - Pe 


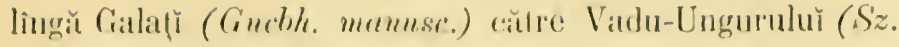
munusc.). - $\odot$ Inlï̆-.1uynst.

C. alopecuroides Schrad. C. alopermevidă- P'rin luncì

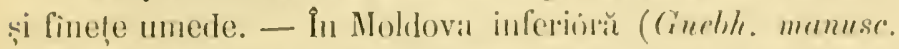

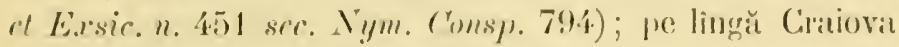
in Isuncĭ ; ele. - $\odot$ Inliü-siplembrer.

\section{PIILEUM I. - Fileй.}

Ph. pratense L. Fr. de finetre - Vulg. Iarba-lué-Timufti, T'imofticŭ. - Prin finețele fertile. - In tót̆̌ Moldova (C'z. Flore XIX, 72 et Exsie.!; Cuchlh. manuss. ot Ersir. n. 455 sec. Nym. Consp. 792 ; Sz. mamuse; Alopecurus agrestis $C z$. Floru XIX, 72 funn L.] et Exssic.!: Sz. manusc.); lat Broscenĭ (Burri Érsie.!); la m-stirea Agapia (Gr. Erbor. l. c. 120); in distr. Bacŭ̌̆ la Verșěscč; la Sinaia și Predél ; în Ilfor (Gr. En. 60 ol Exisie.!) la Ferĕstrěŭ pe

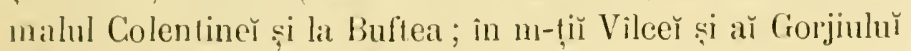
(Hoff. manuse.). - 9 Haiй-Alugnst.

B. nodosum. - In tólă Moldova (Gurbh. manusc.; Ph. bullosum Host. Sz. manusc.); la Bucurescǐ; Comana; etc.

Ph. alpinum L. E. alpin. - Prin pășunile din regiunea alpină și subalpină. - In Noldova (Cz. F'lora XIX, 72 et

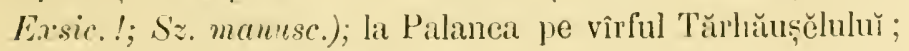
lit Brosecnú (Burri Exsic. !); în m-tị̆ Buzeuluı̆ pe Penteleŭ; în m-lị̆ Buceğ $(F r .71 ; G r . E n .60)$ la schitul Pescera de la Ialomița, pe Furnica, și la Predél pe Susaiŭ. - 24 Juniŭ-Aug.

Ph. Michelii All. F. hř Mieheli. - Prin pășunile din regiunea subalpină. - In Argeş pe m-țĭ Urd̦ica și Coria ; etc. - 2 Juniǔ-.lugust.

Ph. Bohmeri W'ibcl. F. lui Bahner. - Pe délurile sterile și prin finețele uscate. - La Agiud (Burri Exsic.!); în Nuscel (Ph. asperum Gr. Ein. 60 [non Vill.] et Exsic..'); liı Comana în Valea-Crurbanulŭ; ete.-2 Iıniŭ-Iuliu. 
Pl. phalaroides Kiel. F. falaroid. - Prin Cinelele de pe colinele slerile. -- In Moldova (Cz. Flora XIX, 72 / $\mathrm{mm}$ W'ibel.] et Exsic.!; Sz. manusc.); la Comana.-2 Inn.-Inl.

Ph. serrulatum Boiss. et Helde.; Chilochlode colline Schur. F. semelat. - Pe colinele nĕsipóse și petróse. - La Virciorova către Porțile-dŭ-fer! (Borb. 1873, Báus. 251). - If Iипій-Iuliǔ.

Ph. aspermu Vill. F. aspru. - Pe coline sterile. - In Moldova (Sz. Exsic.!); in Muscel pe vìrful déluluĭ Moḷoiŭ (Hoff. Excurs. 1862, l. c. 39). - $\odot$ Muiй-Iиniи.

0bs.- Se nıat citéză : Plı. arenarium $L$. în Ioldova (Sz. manusc.).

\section{BECKILANIA Host. - Beckmannie.}

13. erucreformis Host. B. cruceformă. - Prin tìnctele mlăşıinóse, bălțĭ, pe malurile apelor. - În Moldova (Leersiu oryzoides Sz. mamusc. (non Sw.] et Exsic.!); pe lîngă Jaș̣̆ (V.! sec. Kanitz l. c. 132) la Hărpășẹesč; la Câmpulung pe tẹrmurile Rin-Tîrguluı̆ (Hoff. Excurs. 1862, l. c. 40); în Vlaşca la Comana. - It Luniŭ-Septembre.

Ohs. - Se mar citéză : Chamagrustis minima Borkh. în m-ţi Némfulur la m-stirea Agapia (Sz. manusc.).

\section{CYN0D0X Richard. - Cinodon.}

C. Dactylon Pers. C. Dactilon. - Vulg. Iarba-cânelur. Pir-gros. - Prin locuř něsipóse, pe lîngă zidurı̆, locuințĭ şi strade. - In tótă Moldova (Guebh. manuse. ct Exsic. $n$. 460 sec. Nym. Consp. 789 ; Panicum Dactylon L. Cz. Flora XIX, 72 st Exsic.!; Panicum filiforme Cz. Floru XIX, 73 et Exsic.!; Syntherisma glabrum Sz. manusc. ot Exsic.! [non Schrad.]); la Agiud (Burri Exsic.!); la Bucurescĩ! (Digitaria stolonifera Schad. Gr. En. 60 ct Exsic.!) și la Buftea! (I'anionm sanguinale Gr. Eu. 60 /non L.] st Exsic.!); etc. - 2 I Iuliü-Alugust. 


\section{bERRII Solambl. - Lersie.}

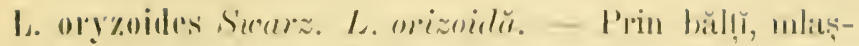

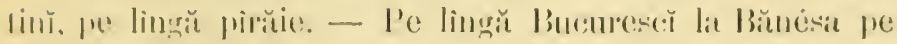

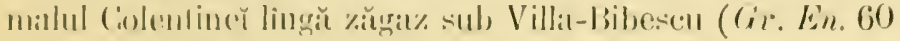

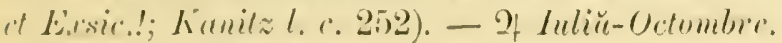

\section{Inliostis L. - Agrostida.}

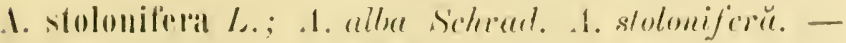

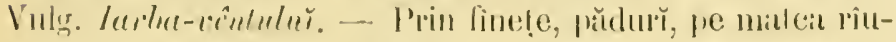
rilor. - In Moldevat (Sz. munusc.); ne lingü Bìrlad în büdurcia Crìngu ; in llfor (.1. ullu (ir. Ein. 61 et Earsic.!) fe linği lineuresĕ lat Ferěstrěŭ pe nalul Colentinę, la Cihi-

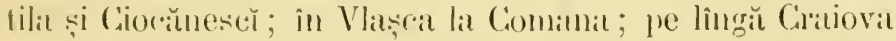

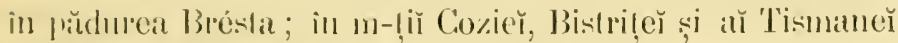
(.1. allse Hotf. manuscr.). - If luniü-Inliu.

3. rariu (Herst.). - In Moldova (Sz. manusc.); liı SiIlatial (1. vnlyaris Gr. Ein. (1) / non II'ith.] et Ersic.!).

\% diffusu (Hust.). - În n-liĭ m-stirilor Coziè̆, Bistrį̣eĭ și aı̆ 'J'ismaně (Hoff. mumusc.).

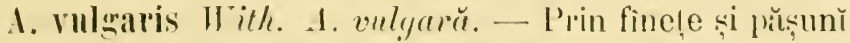
11:atte. - In Moldovat (A. hispride Willd. s'z. manusc.) lit ('aimpenǏ ; in Argeş pe m-lele Ur\%ica ; în Vílcea pe m-tele Fürfecal cete. - of Inniй-Inliü.

1. canina L. 1. crinéscĕt. - Vuls. Bncuttil. - Prin finețe, locurr monede. - În Moldova ('Trichodinm sunimum Schrod. Sz. menusc.); la Comana ; ele. - If Inn.-Sept.

1. rupestris All. A. de slincy. - Prin locurile slincóse din rĕgiunea alpină.-La Borcal (Trichorlimu alpinum Bum. s'z. manusc.?); în m-liĭ Buceğ ( $F r$. 72). - 2 Juliü-duegust.

1. Spica renti L.; Apera Sprica renti P. Becenv. A.

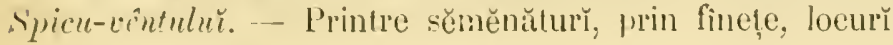


inculte, nĕsipóse si petróse. - In Moldova (Cz. Flura XIX, 72 at Eisic.!; Sz. mamesc; dire ecespitose $C z$. Flora XIX, 72 [nom L./ et Exsic.! ; Sz. mamusc.; Aira aquatica $C z$. Flora XIX, 72 [non L.] et Exsic.! ; Sz. mamusc.); la Broscenı̌ (Burri Exsic.!); în distr. Bilcăŭ la Verșěscĕ ; la Bêrlad; în Illov la Buftea, Crivina şi Chitila (Gr. En. 61 et

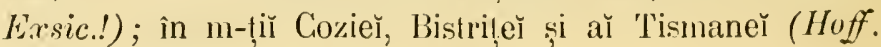
manuse.); elc. - $\odot$ Inniй-Iuliŭ.

0bs. - Se mar citézâ : A. sylvatica Host. în Muldova (Sz. monusc.). - A. compressa Willd. către Fŭlticenr (Sz. manusc.). - A. pumila Lo in Moldova (Sz. manusc.). - A. vinealis Schreb. in Moldova (Sz. man.). - A. alpiua Scop. la Hangu și Popescr (Trichodium rupestre Schrad. Sz. man.). - A. interrupta $I_{2}$. la Hangu (Sz. man.).

\section{CALAMAGROSTIS Roth. - Culcmagrostidă.}

C. littorea $D C$. C. litoralŭ. - Prin nĕsipul și printre petrele de pe malurile rîurilor. - In Moldova centrală (Gucbh. manusc.). - 2 Iuliŭ-August.

C. Epigeios Roth. C. de locur aride. - Vulg. Stuh, Iarbŭ-roşie. - Prin locuř păduróse, finețe něsipóse, pe malurile rîurilor. - În Moldova inferióră (Gucbh. mamusc.); la Balcin în Via-Vîrnav ( $S z$. manusc.); pe lîngă Bêrlad; la Versěscǐ pe maluI'Taslăuluı̆ (D. Br. Fragm.l.c. 73); la Buttea (Gr. En. 60 et Exsic.!), Mogoşóia, Chitila și Bucuresci; la Comana; în Vîlcea la Bălcescĭ. - 2| Iuliŭ-August.

C. sylvatica DJ. C. de püedure. - Prin pădurile din munț. - În Gorjiŭ între Chenia și schitul Locurı̌-rĕle ; în m-ḷî̀ Vilcê̆ către Lotru; în Argeș pe m-tele Urđ̦̣ica; etc. - 9 Juliŭ-Alugust.

Obs. - Se mal citéză speciile următóre: C. lauceolata Roth în Moldova (C. ramosa Host. Sz. manusc.) la Huṣy (Sz. manusc.). - C. aipina Ilost. la DărmăneseY (Sz. momusc.). - (C. stricta Spreng. la apele minerale de la Slănic (Sz. manusc.). - 1\% unontana Host. în m-ţi Moldover (C. varia Trin. Sz. manusc.). 


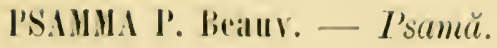

P. littoralis I'. Berauv.; I'. arenariu R. et S. I', de

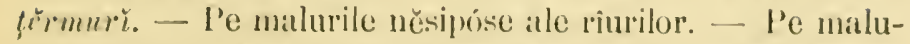
rile Seretulŭ (Culumoyrostis arenariu lioth Gincbh. wa-

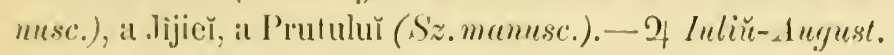

\section{MILIU.II L. - Miliŭ.}

II. efl̈usum L. M. respuindit. - Vulg. Heiü. - Prin pădurile unbróse. - In Noldova (Cz. Flora XIX, 72 et Exsic.!) la Agind (Burri Essic.!); ete.- 2 Maiй-Iuliŭ.

II. Veruale M. Biel. M. de primăvérăt. - Intre Vircciorova

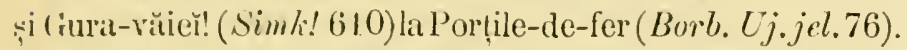

obs. - Sc mal citéză : (iastridium lendigerum Gaud. în Moldova inferióră (Miiium lendigerum L. Guebh. manusc.).

\section{PIPTATherum P. Beanr. - Piptater.}

P. holciforme R. et S. P. holciform. - Prin locurile petróse și calcare. - In tótă Moldova (Milium holciforme S'preng. Guebh. manusc.); la Vîrciorova către Porțile-defer (Milium holciforme Borb. 1873, Bäus. 251) pe m-tele St.-Petru ; etc. - Apriliü-Luniй.

Olıs. - Se mar citéză : Lassiagrostis Callamagrostis Link. pe Céhlăŭ și Lapoṣ (Culamagrostis speciosa Host. Sz. manusc.).

\section{STIPA I. - Stipŭ.}

S. pennata L. S. penatä. - Vulg. Nagarř. - Pe coline aride şi prin finețe něsipóse. - In Moldova $(C z$. Flora XIX, 72 ct Exstc.!; Cz. et Sz. l.c. 52) inferioră (Guebh. manusc.); pe linği Jașĭ la Şorogarù in Via-Burada (Burri Exsic.!) si la Balein în Via-Virnar ( $S z$. manusc.); pe lìnğ 
Bèrlad lat Ciring (I). Br. Erretgm. I. r. 72); pe lingü Slatina cătlre Olt; la Vîrciorova călre Porṭile-de-fer (Borl). Fl.

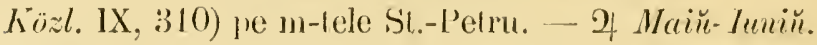

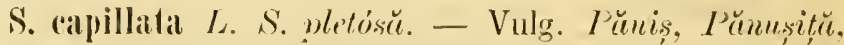
larba-curchler. - Pe dèlarile aride și prin finctele něsipóse. - In Moldova (Cz. et Sz. l. c. 52; Avena strigosa Cz. F'lora XIX, 73 [non Schreh.] et Exsic.!; Cz. et Sz. l. c. 52; Sz. manusc.) inferióră (Guebl. manusc.); către Strunga și 'Tìrgu-frumos (S. juncea Bmg. S'z. manusc.); la Agiurl (Barri Exxsic.!); pe lîngŭ Bucurescù la Ciocĭnescŭ (I). Br. Fragm. l. e. 72); în Muscel la pólele m-leluĭ Lerescĭ (Hoff. Excurs. 1862, l. c. 38). - 9 Mанй-Lепіи.

0lss. - Se mar citéză : S. Atristella $l$. în Moldova $(C z$, et $S z$, l. c. 52).

\section{PIIRAGMITES Trin. - Trestic.}

P. communis Trin. T. conumŭ. - Vulg. Trestic, Stuh,

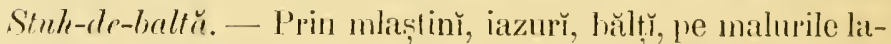
curilor și ale rîurilor. - In tólă Romănia (D. Br. Frregm. l. c. 71 ; Arumto Phragmites L. Cz. Flora XIX, 73 et Exsic.!; Gucbh. manusc.; Cz. et Sz.l. c. 52 ; Gr. En. 60 et Exsic.!). - If lugust-septembre.

3. subuniflora. - La Verșěscǐ; pe linngă Bucurescĭ la Grivina (1rundo nigricans Merat. Gr. En. 60 et Exsic.!).

Ohs. - Arumlo l)onax $L$., indicat in Moldova (Cz. et $S z$. l. c. 52), nu se găsesce de cât cultivat prin unile grădinr.

\section{SESLERIA ArInin. - Seslerie.}

S. curmlans Friv.; S'. rigida Heuff.; S. Bielzii Schur. s.. rigidă. - Pe stincile din regiunea alpină și subalpină superiórăt.- In m-liị Buceğ în valea Ialomilẹ (S. Haynaldiana Schur Fr. 72; S. marginata Griscb. Fr. 72) la schiIul Pescera, pe Furnica; cle. - of hmiй-Iuliŭ.

Obs. - Se mar citéză : S. disticha Pors. în m-ţir Moldover (Sz. man.). 


\section{libliRI Pers, - kelerie.}

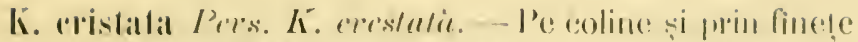

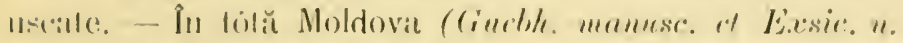

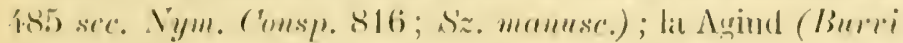

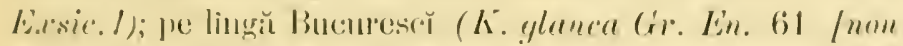

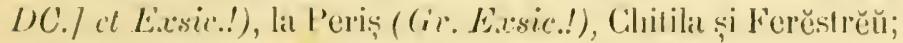

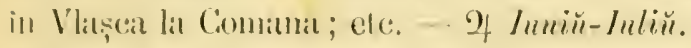

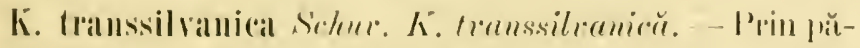

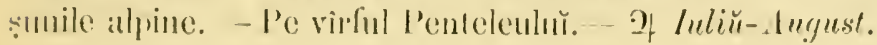

AIRA L. - Airŭ.

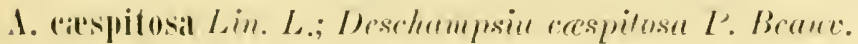

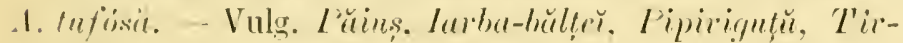

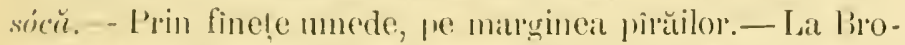

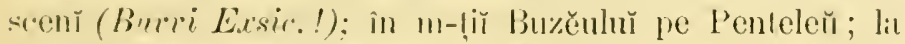

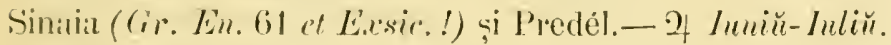

A. Ilexuosa L. A. Acrúsŭ. - P'rin pădurile si finctele

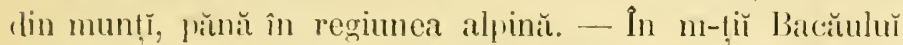
(S'z. manusc.); la Sinatia (Gir. En.61 et Exsic.!; Kunitzl.c.

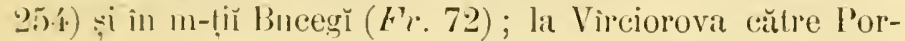
lile-de-fer (Borh. 1873, Bíus. 252).- 2, Inniй-Inliü.

A. (appillaris ILost. A. capilară.-In Mehedinți pe lingă Cernę̣̆ la Dumbrăvį̣a (Gr. Exsic.!). - Maiй-Inmü.

Ohs. - Se mar citéză : I. calyoplıyllea L. la Hușr, Bèrled, Pechea

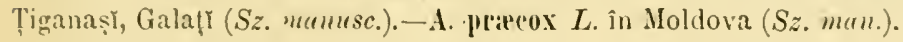

\section{roRYNEPIIORUS l. Beaur. - Corinefor.}

C. (anescens P'. Bcane, C. albicias.-Pe coline nĕsipóse și prin finețe sterile. - La Bacăı̆ și Buhus ( tira canescerus Sz. manusc); in Ilfov (Gr. Eissic.!).-7 Iuliü-dugust. 
HOLCUS L. -- Olcŭ.

II. laniatus L. O. lânos. - Vulg. F'locosiciča, larba-cailor, Olciŭ, Ověs-dulce. - Prin finețe, pășunı̆ și pădurĭ umede, pe lingă pîrăie. - In Moldova (Cz. F'lora XIX, 73 et Exsic.!; Sz. manusc.; D. Br. Fragm. l. c. 72); la Broseenŭ (Burri Exssic.!); în distr. Bacăŭ la Verşěsč̆, Caraclăŭ şi Slănic; în Buceğ către obîrșia Ialomițeı̆ (Hoff. Excurs. 1863, l. c. 120) și la Predél ; în m tị̂ Gorjiuluı̆ și aĭ Vìlcě̌ (Hoff. manusc.) către Lotru; în Mehedinți la Dumbrăvița (Gr. Exsic.!) și la Vîrciorova ; ete. - 2 Iuniŭ-August.

0bs. - Se mar citéză : Il. mollis $L$. în Moldova (Sz. manusc.).

\section{ARRHENATHERUM P. Beauv. --- Arenater.}

A. arenaceum $P$. Beauv.; A. elatius Mert. ct Koch. A. avcnaccŭ. - Vulg. Ověscior. - Prin finețe, lived̦i de pomĭ, și prin poenile din tufěrișurì și priduř̆. - In Moldova (Holcus avcnaccus Scop. Sz. manusc.); în Prahova către Vălenı̆ la Filipcseй (Gr. En. 61 et Exssic.!).-2 Tuniй-Iuliŭ.

\section{AVENA L. - Ověs.}

A. fatua L. O. sčlbatec. - Vulg. Odos. - Printre sĕmĕnătuř̆. - In Moldova (Cz. Flor XIX, 73 et Exsic.!; Cz. ct Sz. l. c. 52 ; Sz. mamusc.); în districhul Ilfor lia Ciocŭnescĭ ; etc.. - $\odot$ Iuliǔ-Alugust.

A. pubesceus $L$. O. pubescent. - Prin finețele din munṭi. - In Moldoval (Cz. Flora XIX, 73 et Exsic.!; Cz. et Sz. l. (. $52 ;$ Sz. mamusc.); în districlul Sucever la Broscenı̌ (Burri E.rsic.!); ctc. - 2 Ilaiй-Iuniŭ.

A. pratensis $L$. O. de fincțe. - Prin finețele de pe délurile uscate și din munți. - In Moldova (Cz.ct Sz.l.c.52; 


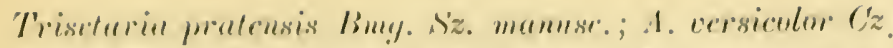

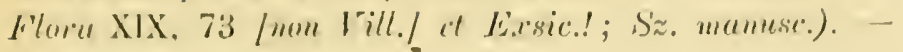
of luпiй-Iuliu.

A. (onmpressil Henff. O). comprimal. - P'rin loourile peIróse din mun!̣̂. - Lai Vireiorova pe malul Cerověţulŭ! (Simk. 601). - $\odot$ Mniй-Iuliü.

Ubs. I. - Se cultivă : A. sstiva Lo (C'z. Flora X1X, 73; Guebh. mamusc; ( $z$. et Sz. l. c. 52; Sz. munusc,; Gr. En. 61) vulg. Ovès. - A. orientalis Schreb. (Cz. et Sz. l. c. 52). - A. Mula (Sz. manusc.).

0bs. 2. - Se mar citėz̆ : A planieulmis Schrad. la Némtŭ (Śz. manuss.). - A. sempervirens Vill. la Slănic (Sz. manusc.). - A. temuir Manch. in Moldova (Cz. et Sz. l. c. 52 ; Trieetarin tenuis Bmy. Sz. munusc.). - A. flavescens $L$. la Pechea (Trisetaria flavescens Bmg. Sz. manusc.). - A. earpatthica IIost. la \$aru-Dorner, Borca, Popescr, Bicaz și schitul Durăŭ (T'riseturiu carpathica Bmg. Sz. mauusc.) - A. alpina Suith. în Moldova $(C z$. et $S z$. l. c. 52). - A. setarear Bmg. la Grozěscr (Sz. manuse.). - A. sesquitertia $L$. la Slănic (Trisetaria sesquitcrtiu B3mg. Sz. manusc.).

\section{MELICA L. - Melicŭ.}

M. ciliata L. M. cilială. - Prin locuř aride, petróse și stincóse. - In Moldova ( $S z$. manusc.) superióră și inferiỏră (Guebh. manuse.); la Agriud (Burri Esssic.!); la Comana; în Vilcea pe m-lele Fórfeca. - 2) Maiŭ-Luniŭ.

B. morodensis. - La Vurciorova cä́lre Porlile-de-fer (M. neliodensis I'uil. Kanitz l. c. 134).

M. uniflora Retz. M. unifloră. - Valg. Mărgicĕa. P’rin pădurile umbróse. - Pe lıngă Iasş̆ la Nelsuna, Viṣan și Hlineea (Sz. manuse. st Eisesce!); la m-sirrea Adau (Cruebh. manusc.); în disír. Balciŭ la Ciaraclăú în phădurea

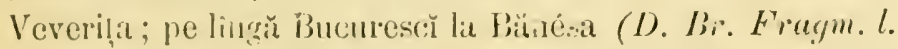
r. 72; (ir. Eie. 62 ot Evoric!!), Mogosia și Chitila ; la Vîrciorova pe vilea bahnner̆; ęc. - - $)$ Inniv-Luliu.

M. nntans L. M. plecalŭ. - P'rin päłurile unbróse. In Moldova (Cz. F'lera XIX, 72 et Eixsic.!; Sz. manusc.) 


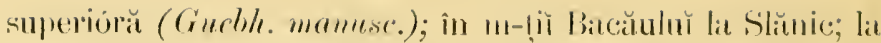

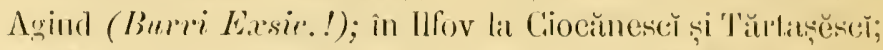

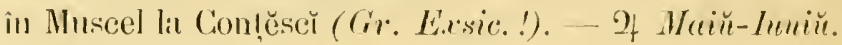

0ls. - Se maY citéză : M. altissima I. la Șorogarr și Aronénu (Sz. manusc.). - 'Triodia dremubens I'. Beaur. La Mamgina (Poct decumbens Scop. Guebh. munuse) și la Comănescr (S.. manusc.).

\section{BRIZA I. - Briză.}

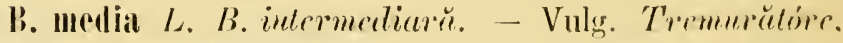

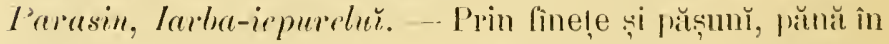
reginnea subalpină. - In lól̆̆ Moldova (Cz. Frlora XIX, 73 et Exsic.!; Gucbh. mannsc.; Sz. manusc.); la Broscenl

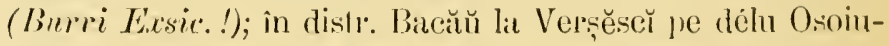
Iıй în m-ḷĭ Bızĕılı̆ pe Pentelen̆; la Sinaia (Gr. En. 61 et Exrsir. !), în Buceğ pe Babe, și lit P'redél; la Ciocănesč̆ (I). Br. Fragm. l. c. 72); la Comana. - of Maій-Intiй.

0bs.-Se mar̆ citéză : B. ıinor L. în Moldova infer. (Gucbh. mun.).

\section{ERIGROSTIS P. Beauv. - Eragrostidĕ.}

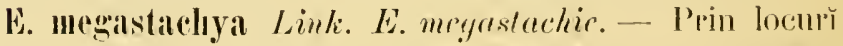
aride něsipóse, enllivale și inculle. - Îu Moldova (L'ma mo-

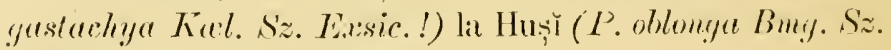
manusc.). - $\odot$ Iuliü-Augnest.

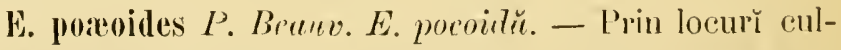
livale, nĕsipose, grădint, pe lingă zidurน̆, drummrı̆, locnin!̣̆ și mintre petrele de prin eurṭ̆ și de pe strade. - În Moldovia (Pou Eragrostis L. Sz. mumusc. ct Exrsic.!) inferióră (Gucble. manuse. ct E.xsic. n. 480 ser. Nym. Consp. 833); Ia Agiud (Burri Exssic.!); în distr. Buzĕn̆ către Beceň̆ la Mărgăriṣı̆ (E. megastuchya Gr. En. 61 [non Link.] et E.xsic.!; Komilz l. c. 254); la Bucurescì (Gr. En. 61 rt Exsic.!) în curtea mea; în Vîlcea la Aninósa ; la Virciorova! (Kanitz!l.c. 134); etc. - $\odot$ Iuliŭ-Angust. 


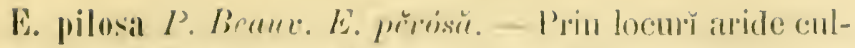

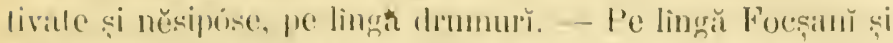

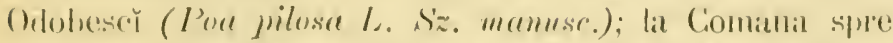

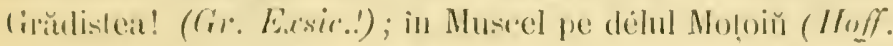

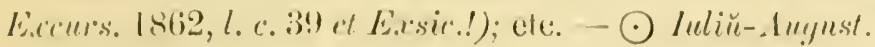

$$
\text { P'0А К. - Poй. }
$$

P. ammua L. P'. enumlie. - Vulg. Hirresor. - Prin locurì culliville și inculle, pe lingă drumurr̆ și locuin!̣̆. - În

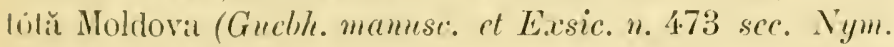
Consp. 837; s̃. mamusc.; P. sutetica Cz. Flora XIX, 72

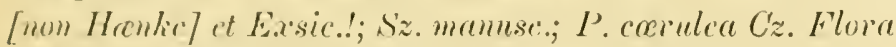
XIX, 73 it Exsir.!); la Agiud (Burri Exsic.!); pe lingă

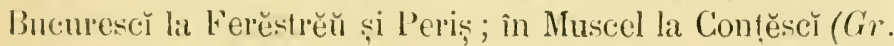
Exisic.!); pe Pétra-Craiulur la Vìfu-Baciuluí (Kotschy 65); etc. - $\odot$ Apriliü-Octombre.

ß. varia Koch.-Pe vîrful Bucegilor (P. supina Schraul. Hoff. Excurs. 1863, l. c. 119).

P. tremula Schur. P. tremurětóre.-In Bucegĭ la schitul P'escera de la Talomița (Schur En. 777). - $\odot$ Kun.-Aug.

P. bulhosa L. I'. bulbósŭ. - Prin finnețe și păçunĭ uscitte, pe coline sterile. - In tótă Moldova $(C z$. Flor X XIX, 72 it Exsic.!; Guebh. manusc. et Exsic. n. 475 sec. Nym. Consp. 836; Sz. manusc.; P. collina Cz. Flora XIX, 73 [uon Host.] et Exsic.!; Sz. manusc.). - 2 Maiй-Leniŭ.

3. vivipera Koch. - In tilă Moldova (Cz. Flora XIX, 73 it Exsic.!; Guebh. munuse.; Sz. manusc.); la Agiud (Burri Exssic.!); pe lingă Bucureser̆ la Bănésa (D. Br. Froym. l. c. 72), Fundenı̆-Măreu!̣ (Gr. Exsic.!); etc.

I. alpina L. I’. alpinŭ. - Prin pŭşunile din regiunea alpină. - In Moldova (Cz. Flora XIX, 73 rt Exsic.! : S'z. menuse.; Festucu rubra $C z$. Flora XIX, 73 /reone L.J et E.xsir.!; s'z. menuse.; F. variu Cz. Flora XIX, 73 [non Han- 
lic] et Exsic.l; Sz. manusc.; Sesleria cerulea Cz. Flora XIX, 72 [non Ard.] et Exsic.!; Sz. manusc.); la Palanca pe Tărhauşul-ınare; pe virful Bucegilor! (Fr. $72 ; G r . E n .61$ et Exsic.!) la Pirăul-Babelor; etc. - 4 Maiй-August.

P. nemoralis L. P. de păduř̌. - Prin pădurı̌ și pe stîncĭ umbróse pănă în regiunea subalpină superióră. - In Moldova (Cz. Flora XIX, 73; Sz. mamusc.) pe lîngă Iaşĭ la Niṭelea (D. Br. Fragm. l. c. 72); la Tîrgu-Ocneř pe MŭguraOcneǐ; la Agiud (Burri Exsic.!); la Sinaia în valea Peleçuluĭ (Gr. En. 61 ct Exsic.!) și în Bucegì la schitul Pescera de la Jalomiţa $(F r .72)$; în Vilcea în valea Bistrițeı̆; în Mehedințĭ la Dumbrăvị̣a (Gr. Exsic.!). - 2 Luniǔ-Luliǔ.

P. fertilis Host. P. fertilă. - Prin finețele umede.-In Moldova (Sz. manusc.; P. serotina Gaud. Sz. manusc.): la Bucurescĭ ; etc. - 2 I Iьпій-Iuliŭ.

P. hybrida Gaud. P. ibridă. - Prin pădurile din regiunea subalpină. - In m-țĭ Bucegı̆ la schitul Pescera de la Jalomiṭa (Schur En. 769). - 2 Iuliǔ-August.

P. trivialis L. P. trivialü. - Vulg. Şıvar-de-munte.-Prin finețe și locurĭ umede. - In tótă Moldova (Gucbh. manusc.; Sz. mamusc); în m-tị̆ Bacăuluí la Slănic ; la Predél pe Susaiŭ; Bucurescĭ, Dudescŭ şi Ferĕstrĕŭ; la Comana; in Gorjiŭ între Chenia și Locurř-rĕle. - 2 Iuniǔ-Iuliŭ.

P. pratensis L. P. de fincțe. - Prin fînețe unnede și něsipóse. - In tótă Moldova (Cz. Flora XIX, 72 st Exsic.!; Guebh. manusc. et Exsic. n. 478 sce. Nym. Consp. 834; Sz. mamusc.); pe lîngă Bucuresč la Cotrocenĭ (Holcus mollis Gr. En. 61 [non L.] et Exsic.!), Bănésa, Fundenı̆-Măreuṭa; în Prahova la Filipescĭ ( $G r$. Exsic.!); între Pitescĭ și Câumpulung (Gr. En. 61 et Exsic.!).- 2 Maiй-Iиniŭ.

ß. angustifolia Smith. -- La Agiud (Burri Exsic.!).

P. cenisia All. P. cemusie.-în regiunea alpină. - ln m-lị̆ Buceğ pe valea Ialomị̣cè (Schur En.770). - 2f Iuliŭ-Ang. 
P. compressia L. I'. commpimalä. - l'rin fineţe uscate

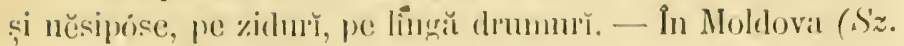
mamuse. "t Edsic.!); la lincureser (Gr. En. 61 et Esrsic.) in Cismegiŭ si lat Chitilat; in Nusced (Glyerrie aquatica Gr.

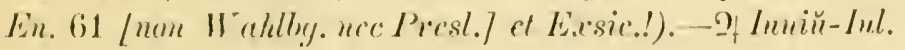

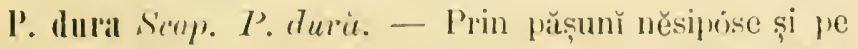
lîngr̆ drumurı̌, - In Moldova (Sz. manuse.; Sclerochloct dura I'. Beauv. Guelh. Eixsie. n. 479 ssc. Nym. Consp. 832 ; Crypsis schemenides Cz. Flora XIX, 72 [um Lam.]

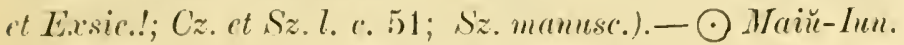

Obs. - Se mar citéză : 1'. laxa Hanke în Moldova (Sz. munusc.).

\section{GLYCERIA R. Br. -- Glicerie.}

(i. spectabilis Wert. et Korh.; G. aquatica ITahlby. (non P'resl.). G. finmósü. - Vulg. Manüt-de-ape, Ronacerinlǔ̆. - P'rin mlaştinř, lacurı̆, pe malurile apelor. - In Moldova (J)alaris arundinacea Cz. Flora XIX, 62 Lnon L.] et Ersir.!: Calamarestis pscurdophragmites Cz. Flora XIX, 72 /non Relhb.7 ot Exsic.!; Poa aquatica L. Sz. mamusc.); pe lingă Bueurescĭ la Bănésa și Ferěstrěŭ pe malul Colentiner̆ ; la Comana pe malul Călniscě̌. - 2 Lul.-Aug.

G. fluitaus R. Br. G. plutitore.-Vulg. Plutitóre, Jarbŭdulce. Firuță.-Prin ape stagnante, bălț̣̆, lacurĭ și pe maIul apelor lin curgětóre. - In Noldova (Cz. Flora XIX, 73 el Exsic.!; Sz. menusc.); în distr. Bachŭ la Verșešsč şi Caraclăŭ ; la Agiud (Burri Exsic.!); la Predèl; Tilu (Gr. En. 61 et Earsie. l); pe lingă Bucuresč̆ la Ferĕstrěŭ pe malul Colentině̀ ; în Vlașca la Comana; ete, - 7 Maiǔ-Iuliŭ.

(i. aquatina P'resl. G. aqualicä. - P'rin ape stagnante, bălțĭ, iazurĭ, pe lingă pîrŭie și isvóre, prin locurĭ umede și něsipóse. - In tótă Moldova (Poa airoides Kä. Gucbh. manusc. et Exsic. $2.477 \mathrm{sec}$. Nym. Consp. 837); la Agiud (Burri Exsic.!); în Nuscel pe valea Riu-Tîrguluŏ la pólele 
m-1elŭ Leresč̆ (Aira aquatica L. Hoff. Excurs. 1863, l. с. 31); la Predél; la Bănésa pe malul Colentineù (Catabrosa aquatica P. Béauv. Gr. En. 61 et Exsic.!).-2) Iniй-Iuliu.

\section{MOLINIA Schrank. - Molinie.}

II. coernlea Manch. M. albastrü. - Vulg. Iarbă-albastrŭ. - Prin pădurì și fînę̣e unede. - In distr. Bač̆ŭ la Slĭnic (Sz. manusc.) și Caraclŭŭ pe Slatina ; în m-lịĭ Coziĕ̀, lBistriḷĕ și Tismaneй (IIoff. manuse.). - 2 Inliŭ-dug.

II. serotina $1 \%$. et $K$. M. türdie. - Pe coline aride. Iä Roman, Bacĭŭ și Vasluĭ (F'estuca serotina L. Sz. manusc.); pe lingă Bêrlad la Dinitrescǐ. - 2 Augnst-Sépt.

\section{DACTYLIS L. -- Dactilidă.}

I). glomerata L. D. glomeratŭ. - Vulg. Golomăt, Noduvosă. - Prin fînete şi pădurı̌. - În fólă Moldova $(C z$. Flov'a XIX, 73 et Exsic.!; Guebl. manusc.; Sz. mamusc.); pe lìngă Tașĭ la Repedea, Niḷelea și Bìrnova (F'estueca aruudinacea D. Br. Fragm. l.c. 72 [non Schreb.]; Kanitz l.c. 136); la Agiud (Burri Exsic.!); în Ulfov (Gr. En. 62 ct Exsic.!) pe lîngă Bucurescì la Bănésa; la Vălenì și Predél ; în Gorjiŭ între Chenia şi Locurǐ-rěle; etc. - 2 Iuniŭ-Iuliŭ.

\section{CYNOSIRTS L. - Cinosur.}

C. cristatus L. C. cresiat. - Vulg. Peptanariţŭ.-P'rin finețe. - In Moldova (Sz. mamuse.; D. Br. Fragm. l. c. 72); la Broscenı̆ (Burri Exsic.!); la m-stirea Némı̨ulŭ pe Pleșu; în distr. Bacăŭ la Caraclăŭ și Palanca ; în Prahovà la Filipesci (Gr. Eu. 62 et Exsic.!) și la Predél; în Vîlcę către Lolru pe m-tele Fórfeca; în Mehedinți în valea Bah-

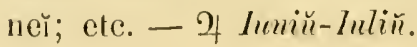


C. Polinatus L. C. ghimpos. - Prin fincęe si pe lingra

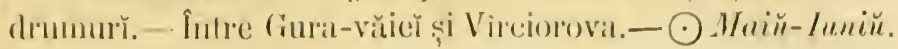

\section{FEs'TlC' I. - Festucŭ.}

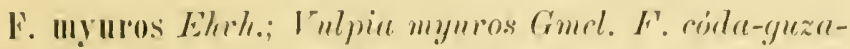
mulur. - P'rin finețe něsipose, pe dèlerı aride, printre petrele de pe matea riourilor şi de pe drummrŏ. - Laa Némţŭ

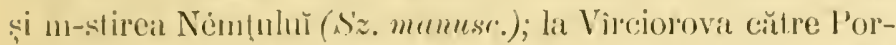
tile-de-fer (F'. I'sende-myuros Sonyer. Borb. 1873, Bins.

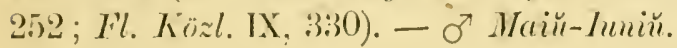

P. oviuna L. F. oilor. - Vulg. P'ăins, - Prin fîneṭe și pășunı̆ sterile, pănă în regiunea alpină. - În tólă Moldova (Gueth. mamusc. et Exsic. n. 487 ssc. Nym. Consp). 829; Sz.manuse. ct Lissic.!; F. glanca Sz. mamusc. ct Eassic.!; H. capillaris Cz. Flora XIX, 73?; I’oa angustifolia $C_{z}$. Flore XIX, 72 fnon L. nec Rehb.] et Exsic.!; Sz. mamusc.); pe lìngŭ Isı̣̣̆ ; pe Céhlăŭ ; în distr. Baciŭ la Caraclăŭ; la $\Lambda$ gnind (Burri Exsic.!); în m-ḷị̆ Buyculul̆ către Bîsca pe mtele 'T'ega; la Sinaia (F. rubra Gr. En. 26 [non L.] ct Exsic..!); la Câmpulung pe m-tele Leresč̀ ( $F$. tcmifolia IIoff. 1862, l. c. 38 [non Sibth.]; Gr. En. 62); pe lîngă Bucuresč̆ (F. duriuscula Gr. En. 62 [non L.] ct Exsic.!) la Bănésa, Chitila și Periș; între Turnu-Severin și Virciorova; elc. - 2 Maiǔt-August.

F. violacea Gaud. F. violacec. - Prin prusunile slîncóse din regiunea alpină și subalpină. - În m-liî̀ Buzeuluì pe vìrful Penteleulǔ. - 2 Iuliŭ-August.

F. duriuscula L. F. duriusculă. - Prin finețele slerile și pe colinele aride. - În tótă Moldova (Sz. manusc.). $9+$ - Maiи-Inniй.

$\beta$ Alıra (ITost.). - La Virciorova către Porṭile-de-fer (Burl. Fl. Közl. IX, 331). 
F. subracemosa Schur. F. subracemósč. - În m-ḷiŭ Buceğ pe stîncile calcare de dcasupra schiluluĭ Pescera de la Ialomiţa (Schur En. 783). - 2 A dugust.

F. pilosa Hall. fil.; F. pocformis Most. F'. pérósŭ. P'rin pășunile din regiunea alpină. - În m-tiî̀ Buzeulŭ pe vîrful Penteleuluĭ; pe vîrful Coziě̆. - 2 Iuliŭ-August.

F. Seheuchzeriformis Schur. F. Scheuchzeriformă. Pe stîncile caleare din regiunea alpină. - În m-țī Buceğ in valea Ialomiţer̆ (Schur En. 796). - 24 August.

F. sylvatica Vill. $F$. de pădure. - Prin pădurile umbróse. - În m-țiĭ Bacăuluı̆ la apele minerale de la Slănic; la Sinaia către pólele Bucegilor (Hoff. Excurs. 1863, l.c. 119; Gr. En. 62); etc. - 2 Iиniǔ-Iuliü.

F. arumdinacea Schreb. F. arendinacce. - Prin finețe umede, pe malurile apelor. - In Moldova ( $F$. clatior Sm. [non Lin.] Sz. manusc.); în districtul Bacăŭ la Gáraclăŭ ; etc. - 2 Iиniй-Iиliŭ.

F. elatior $L$. F. inălțată. - Prin finețe și locurŭ ierbóse umede. - In Moldova (F. pratensis Huds. Sz. manusc. et Exsic.!); la Agind (Burri Exsic.!); la Bucuresč în Cismegiŭ, pe lìngă Spitalul militar ( $F$. pratensis Huds. Gr. En. 62 et Exsic.!), în Dudesč̆, la Gara-Tîrgoviștea şi la Chitila; etc. - 2 Iuniŭ-August.

F. Ioliacea Huds. F. loliacec. - Prin finețe fertile. In Moldova (Sz. manusc.) ; in Vlaşca la Comana pe ValeaGurbanulü; etc.. - 9 Maій-Luniй.

0bs. - Se mar citéză : F. flavesecens Bell. în m-țir Buzeulur către Bîsca-mare (Hotff. Excurs. 1862, l. c. 38). - R. stricta Host. Ia Ghermănescr (Sz. manusc.) - F. hirsuta Host. în Moldova (Sz. manusc.). - F. anuellysstina Host. către Talpa (Sz. mamusc.). - F. lieterophylla Lam. în Moldova ( $S z$. manusc.).-- F' pumila V'ill. la m-stirea Bistrị̣a (Sz. menusc.). - F. spadicea $I$. pe Céhlăŭ (Sz. manusc.). - F. 1)rymrja M. et $K$. la Vaslur și Bêrlad (F. sylrutica Host. Sz.manusc.). 
BRACHYP0DIU I'. Beaus. - Brachipodiu.

li. syglvatioum R. et S. B. de püdure. - Vulg. Olssigŭ.

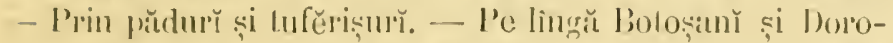
hoin̆ (Festuea gracilis Wanch. Ṡz. manuse.; în Vlaṣca la

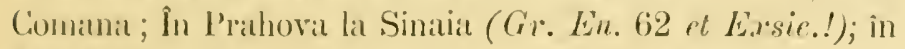

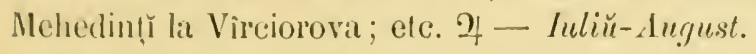

R. pinnatum P. Brauv. B. ponat. - Pe coline aride și pelróse, prin tufĕrișurr̆. - In Moldovia (Festuea pinnata Munch.); lit Agrud (Burri Éxsic.!); pe lingă Bucurescè la

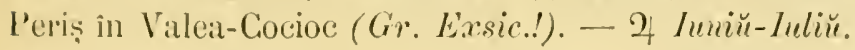

\section{BR0YUS I. - Brom.}

1. secaliuns L. B. scealin. - Vulg. Olsigŭ, Opsigü, Se-

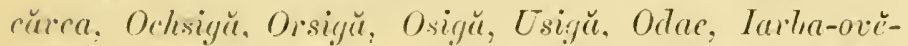
suluı̆, larba-vîntuluĕ. - Printre sĕmĕnăturı̌. - În Moldova (Sz. manusc.); la Agiud (Burri Exsic.!); în Ilfov (Gr. Eи. 62 et Exsic.!) pe lingŭ Bucurescĭ ; in Vlaṣca la Comana ; ete. - ơ Maiй-Iuniй.

3. macrostachys Gren. et Godr.; B. grossus DC.-Vulg. Opsigŭ, Sčcŭrea. - În districtul Bacăŭ la Verșěsč̆.

B. racemosus L. B. racemos. - Prin fìnețele din tótă Moldora (Guebh.manusc.; Sz. manusc.). - o Haiй-Iиniu.

B. arrensis L. B. argrest. - Printre sĕmĕnăluř̆, prin jî̀róge, pe lìngă drumul’̌̀. - În tótă Noldova (Gucbh. maunse.; Sz. mamusc. et Ex.sic.!); în districtul Bitcĕ̆̆ la Verșěsč și Ciuraclŭŭ ; la Agiud (Burri Exssic.!); în Rîmnicusĭlrat lat Catiata; pe lingă Bucurescū! (Festuca gigantea Gr. En. 62 [non Till.] et Exsic.!), la Buftea; în Prahova lil Vălenı̆ (Gri. Eu. 62 ct Exrsic.!); pe lingŭ Slatina către Olt; lia Severin și Vìrciorovi călre Porţile-de-fer! (Borb. Flor.

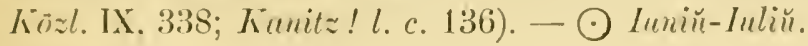


B. mollis $L$. B. mólc. - Prin linețe aride, pe lingă drumurı̌ petróse. - În tótă Moldova (Cz. Flora XIX, 73 ct Exsic.!; Gucbh. manusc.; Sz. manusc.; B. glomeralus Guebh. Exsic. n. 496 sce. Nym. Consp. 823); la Agiud (Burri Exsic.!); pe lîngă Bucurescǐ! (Gr. En. 62 et Exsic. !); în Mchedințŭ între Șchelea-Cladovel̆ și Gură-văič̆, și către Vîrciorova pe m-tele St.-Petru.-от Maiй-Iuniŭ.

B. patulus NIcrt. et Koch. B. intins. - Printre sĕmĕnăIurǔ, pe lingă drumuř̆, prin locurı̌ aride şi petróse. - În Moldova (B. multiflorus Host. Sz. munusc.; B. sccalinus Cz. Flora XIX, 73 [non L.] ct Exsic.!); pe lîngă Bucuresč́ ; etc. - О' Маiй-Iиniŭ.

B. squarrosus L. B. squaros. - Prin pîrlóge, viŭ, locurı̆ aride, stîncóse şi calcare. - În tótă Moldova (Gucbh. manusc.; Sz. manuse.); la Vîrciorova către Porțile-de-fer! (Borb. Flor. Közl. IX, 338); etc. - б Maiŭ-Iuniŭ.

ß. villosus (Gmel.). - La Vîrciorova călre Por(̨ile-defer!(Borb. Flor. Közl. IX, 338).

B. asper Murr. B. aspru. - Prin pădurile munților.În tótă Moldova (Sz. manusc.). - 2 Tuniǔ-August.

B. erectus Huds. B. erect. - Pe délurı̌ aride, prin fìnețe sterile. - In tótă Moldova (Gucbh. manusc.; Sz. manusc.). - 2 Maiй-Inniŭ.

B. angustifolius M. Bicb. B. cu foŭ înguste. - La Vîrciorova către Porțile-de-fer (Borb. Uj. jel. 78; Simk.613).

B. inermis Leyss. B. nearmat. - Pe délurì aride şi inculte, pe marginea finețelor uscale şi a drumurilor. - In Moldova (Guebh. Exsic. n. 495 scc. Nym. Consp. 822 ; Agropyrum intermedium Cz. Flora XIX, 73 [non P. B.] et Exsic.!; Sz. manusc.), la Verșěscì și la Caraclăŭ către Veverița; la Agiud (Bưrvi Exsic.!). - 2 Iuniŭ-Iuliŭ.

B. sterilis $L$. B. stcril. - Prin locuř̆ culte și inculte, dărěmătuř̌, pe lîngă zidurı̌ și drumuř̌. - În tótă Moldova 
(Sz. manusce; B. erectus Cz. Flora XIX, 73 /mon lluds.]

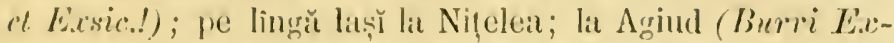
sie.!); pe lingă Bucurescì (Gir. En. 62 et Lixsic.!); ete. ○) Mай-Siptembie.

B. tectorum L. B. de acoperișrè. - Pe eâmpurĭ sterile, locurì něsipóse, délurì aride şi pe ziduř. - In tót Moldova (Cz. Flora XIX, 73 et Lessic.!; Gucble. manusc.; Sz. manusc.; B. sterilis Cinobh. manusc. [non L.] et Exsic. n. 494 sec. Nym. Consp. 821); la Ngiud (Burri Exsic.!); pe lingă Bucuresç la Buftea ; în Mehedinț̆ intre ScheleaClidover̆ și Gura-văiě̆. - $\odot$ Maiй-Jınĭ̆.

0bs. - Se maY citéză : B. rubens $L$. în tótă Moldova (Guebh.man.).

\section{TRITICUM L. - Grâu.}

T. villosum M. Bicb. G. vilos. - Prin finețe nĕsipóse,

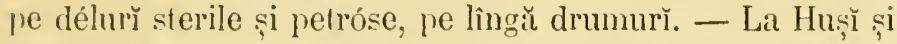
Fülciŭ (Agropyrum villosum Bmg. Sz. manusc.); la Fùntânele (Secalc villosum L. Sz. mamusc.); pe lîngă Bucurescĭ la Ferěstrěŭ; intre rîurile Sabar şi Argeş (Schott l. c. 479) şi la T'alpa (Schott l. c. 296); pe lîngă Slatina către Olt; la Vîrciorova! (Janlia zool. bot. Ver. VII [1857], 123; Borb.1873, Jüins. 253; Kanitz! l. c. 137) și pe malul Dunărě̀ între Șehelea-Cladover şi Gura-văiei. - o Maiй-Juniŭ.

T. rigidum Selerad.; T. elongatum Host. T. rigid. Prin locurǐ nĕsipóse. - In Moldova (T. repens Cz. Flora XIX, 73 [non L.] et Exsic.!) inferióră (Guebh. manusc.); in Ilfov între Chitila și Ciocănescì (D. Br. Fragm.l. c. 72) și la Buftea (Gr. En. 62 et Exsic.!); în Vlașca la Comana; ete. - 2 Maiи-August.

T. glancum Desf. G. albăstriǔ. - Prin locurì aride, și petróse, pe lingă drumurĭ. - La Botoșanı̆ și Dorohoiŭ (Agromprum glancum P. Bcauv. Sz. manusc.; A. intermedium Host. Sz. manuesc.); în m-(̣iŭ Bacăulu la Palanca; la 
Agiud (Burri Exsic.!); lit Chitila; la Vîrciorova călre Portile-de-fer! (A. intermedium Host. Borb. Flor. liözl. IX, 340) şi Gura-văieř ; etc. - 2 Iиniй-Iuliŭ.

T. repens L. G. tiritor. - Vulg. Pir, Cleir. - Prin locurì cultivale și nĕsipóse, grădinı̆, finę̣e. - In tótă Moldova (Gucble manusc. ct Exsic. n. 478 sec. Nym. Consp. 841; Agropyrum repens 1 . Beauv. Cz. ct Sz. l. c. 51; Sz. manusc.; Gr. En. 62 ; Lolium perenne Cz. Flora XIX, 73 [non L.] et Exsic.!); la Salina de la Tîrgu-Ocně̆; la Buflea (Agropyrum glaucum Gr. En. 62 [non Desf.] ct Exsic.!) şi Bucuresč; în Vlașca la Comana; etc. - 2 Iuniŭ-Iuliŭ.

T. caninum Scherb. G. cânesc. - Prin pădurĭ, tuferişurĭ umbróse, pe lingă pîrăile din pădurĭ. - In tótă Moldova (Gucbh. manusc.; Agropyrum caninum P. Bcauv.; Sz. manusc.). - 2| Iuniǔ-Juliü.

ß. alpinum. - În m-tị̆ Buceğ la schitul Pescera Ialo-

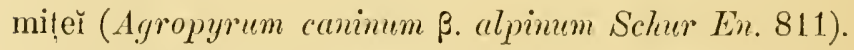

T. eristatmm Schreb. G. crestat. - Prin locurǐ aride, petróse şi nĕsipóse, stepe, coline sterile, pe lingŭ drumur’. - Prin stepele Romănier̆ (Agropyrum cristatum P. Bcanv. Lev. in Demid. Voy. II, 163); in Moldova (Hordeum secelimum Cz. Flora XIX, 73 [non Sclereb.] ct Exsic.!; Sz. manusc.); la Agiud (Burri Exsic.!); pe lîngă Bèrlad; în distr. Buzěŭ la Slănic spre Becenı̆ (Gr. En. 62); la Bucurescí; etc. - 2 Maiǔ-luliŭ.

0bs. - Se cultivă : 'T. vulgare Vill. 'Gr. En. 62; T. cereale Bmg. Sz.

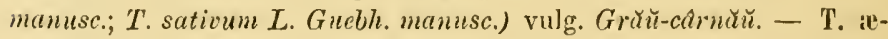
stivum $L$. (Cz. Flora XIX, 73; Sz. manuse; Gr. En. 62) vulg. Grŭ̌̆de-varü. - T. hybermu L. (Cz. et Sz. l.c. 52; Sz. manusc.; Gr. En. 62) vulg. Grăŭ-le-iarnð̆. - T'. turgidum L. (Sz. manusc.; Gr. Ln. 62) vulg. Grŭ̌-inglizesc. - T. coupositum L. (Guebh. manuse.; Sz. manuss.). - T. du'ulu Desf. (Guebh. manusc.; Cz. et Sz. l. c. 52 ; Gr. En. 62) vulg. Ghirch. - T. polonieum L. (Gr. Lin. 62) vulg. Grăualb. - T. Spelta $I_{.}$(Cz. et $S z$ l. c. 52; Sz. manusc.; Gr. En. 62) vulg. Alac, Grău-gol. - T monococem $L$. (Sz. manusc.). -- Secale cereale L. (Cz. Flora XIX, 72) Guebh. manusc.; Cz. ct Sz.l.c. 52 ; Sz. muunsc.; Gr. En. 62) vulg. Sccarŭ, Sacarč. 


\section{ELIMS L. - Elim.}

E. crinitus schorh. Ex. pletos. - Vulg. Limĕ, Icerba-per-

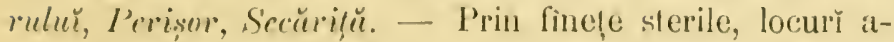
ride și dĭrěmŭlurř. - Intre rîrile Argeș çi Subar (E. Caput-1/ertuse Schote l. c. 472), lia T'alpa (Schott l. c. 296); la Slatina către Olt pe lingă calea ferată. - $\odot$ Maiй-Iииiŭ.

\section{IIORDEUII L. - Ord̆̈.}

II. ınแriıum L. O. guzanilor. - Pe lingă drumur̆, zidurì, locuin!̣̆, prin dărě̀năturì și locurř inculte. - În tóră Moldoval (Gucble. manusc. ct Eisisic.n. 464 sec. Nym. Consp. 838 ; Cz. st Sz. l. c. 53 ; Sz. mannsc.; Vlymus enropreus C. Flora XIX, 73 [non L.] ct Exsic.!; Sz. manusc.); la Bucurescr!!, Colrocenı̆! (Gr. En. 62 ct Exsic.!); la Iaș̣̆! (Burri Lisic.!); etc. - $\odot$ Inliŭ-August.

II. secalimmm Sclorel. O. sccalin. - Prin fînețe. - In lótă Moldoval (Gueble. manusc.). -- If Iuniй-Juliü.

II. maritimum With. O. maritim. - Prin finnele sterile și loeurř něsijóse şi sărate. - In Vlaşca la Comana ; în Argeṣ là Stolnicĭ către Vlăscuța (H. murinum D. Br. Fragm. l. с. 72 [nоп L.]). - Р Маій-Iипій.

0bs. - Se cultivă: H. vulgarle L. (Cz. Flora XIX, 73; Guebh. manusc.; Cz. et $S z$. l.c. 53; $S z$. manusc.; Gr. En. 62) vulg. Ordŭ. - 11 . lu'Xastichon L. (Guebh. manusc; $C z$. et $S z$. l. c. 53; $S z$ manusc.) vulg. Orleü-icruatic. - U. distichum L. (Guebh. maunsc; Cz. ct Sz.l.c. 53; $S z$. manusc.). - HI. zeocriton $L$, prin orḑury în Moldova ( $S z$. manusc.).

\section{LOLIUII L. - Loliu.}

I. perenne Lin. L. perenal. - Vulg. Zizanie, Odos. Obsigŭ, Sülbŭ'ŭ, Nighină, Iarbă-inglizéscŭ. - Finețe și păşunĭ nĕsipóse, locurǐ cultivate, pe lìnğ drumurŭ și prin sě- 
mĕnătuř̌ - In fótă Noldova (Gucbh. mamsc.; Sz. ma-

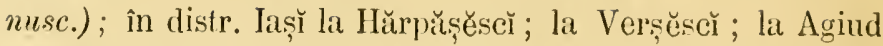
(Burri Exsic.!); la Bucurescr!! (Gr. Eu. 63 et Exsic.!; L. tenue Gr. En. 63 et Exsic.!), în Dudescì şi la Buftea (L. arvense Gr. En. 63 [non Schrad.] et Exsic.!); la Vîrciorova (Kanitz! l. c. 138).-2 Iuniй-Septembre.

I. italicnm A. Br. L. de Italia. - Prin finete. - La Bucurescì în Dudesč̆. - 2 Innin̆-Septembrc.

I. temulentum Lin. L. imbètătoriü.-Drin sĕmĕnăturĭ.In Moldova (Cz. Flora XIX, 73 et Exsic.!; Sz. manusc.; Gr. Erbor. l. c. 120 ?); Ilfov (Gr. En. 63 ?), - $\odot$ Iuniŭ-Iuliŭ.

\section{AGILOPS L. - Egilopsŭ.}

A. cylindrica Host. E. cilindrică. - Prin pășunı̆ nĕsipóse, pe lîngă drumurĭ. - În Moldova inferióră (Gucbh. manusc. et Eixsic. n. $469 \mathrm{sec}$. Nym. Consp. 839).

\section{PSILURUS Trin. - Psilur.}

P. nardoides Trin.; Nardus aristata L. P. nardoid.Prin locurı sterile. - La Vîrciorova aprópe de pîrŭul Cernovăț (P. aristatus Simk. 614). - $\odot$ Mciǔr-Leniǔ.

\section{NARDUS I. - Nard.}

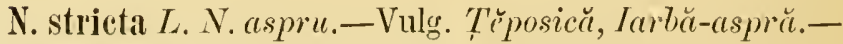
Prin pășunile uliginóse din regiunea subalpinn̆ și alpină.

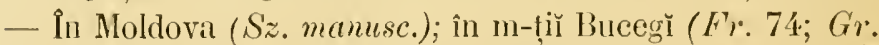
En. 63 et Exssic.!) pe Furnica, Bline, Babe, Omu, etc. 2) Maiü-Iuliü. 


\section{DIVISIUNEA III.}

\section{CRYPTOGAME VASCULARE.}

\section{EQUISET ACEE.}

\section{EQUISETUM I. - Equiset.}

E. arvense L. E. agrest. - Vulg. Códa-mînzulur, Códa-

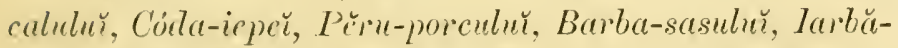
dr-cositoriu, Barba-ursulù. - Prin fìnețe și agriŏ argilóse și muede. - In tótă Romănia (Cz. Flora XIX, 74 ct Fidsic..; Guebh. manuse.; Cz. et Sz.l. c. 55 ; D. Br. Fragm. l. c. 71 ; Gr. En. 64). - If Apriliŭ-1Maій.

E. Telmateja Elrh. E. Telmatcia. - Prin pădurile umede și pe lingă pîrǔie. - În Moldova (D. Br. Fragm. l. c. 71; E. Anvialile Simith [non L.] et Exsic.!); in Arges, lit Jite-cǐ; ete. - 2 A prilin-slair.

E. syivatienm L. E. de püdure.-Prin pădurile şi finetele umede. - In Moldova (Cz. Flora XIX, 74 et Exsic.!; h. j. Gusbl. manesc.; Cz. ct $S z$. l. c. 55 ; D. Br. Fragm.l.

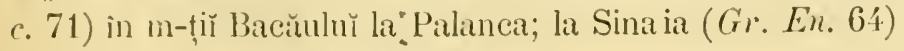
și Predél ; etc. - 2 4 spriliŭ-Mciŭ. 
E. palustre L. E. do mlastin. - Prin mlaștinŭ și finețe uncde. - În Moldova (Cz. F'lore XIX, 74 et Exsic.!' Cz. ct Sz. l. c. 55; D. Br. Fragm. l. c. 74); în m-(̣i Bacăuluı̆ la Câmpenı̆; în Prahova (Gr. En. 64); în m-tiĭ m-stirilor Cozia, Bistrița și Tismana (Hoff. manusc.).--2| Iuniŭ-Aug.

E. limosum L. E. de mîl. - Prin mlaștinĭ, bălțĭ, iazur̆, ape lin curgétóre. - În tótă Moldova (Gucbh. manusc.; E. fuviatile Cz. Fllora XIX, 74. [non Wahlbg.7 et Exsic.! ; Cz. et Sz. l. c. 55; E. hyemale Cz. Flora XIX, 74 [non Lin.] et Exsic.!; h.j. Gucbh. manusc. [non Lin.]). If luviü-August.

ß. Aluviatile Wahlbg. - In tótă Moldova (Gucbh. mamesc.; D. Br. Fragm. l. c. 71).

E. hyemale $L$. E. de iarnă. - Prin locurile nĕsipóse din pădurile umede şi umbrósc, pe lîngă pîrăile și torentele din pădurile montane şi subalpine. - In Moldova $(C z . c t$ Sz. l. c. 55) pe lîngă Iaș̆ la Nițelea; în m-țĭ Bacăuluŭ la Mănăstirea-Gaşinuluı̆ în valea Buciaşuluĭ ; în m-țĭ Bucegr la schitul Pescera de la Ialomita; in m-tii m-stirilor Cozia, Bistriţa și Tismana (Hoff. manuse.). - 2 Iuniŭ-August.

E. alpinแm Schur. E. alpin. - Prin păşunile umede din regitunea alpină. - In m-tị Buceğ în valea Ialomịtĕ (Schur En. 822). - 9 Iuliü-August.

\section{MARSILEACEE.}

\section{MARSILEA 1. - Marsilie.}

II. quadrifolia L. M. cu patru foц. - Prin ape stagnante și lin curgětóre. - Pe lîngă Bucurescĭ la Colrocen̆, Mărcula-Panteleimon (Gr. En. 63 ct Exsic.!), în Dudescĭ și la Ferěstrĕŭ; în districtul Vlașea la Comana în rîul Cülniscea; elc. - 2 Iuliŭ-Septembre. 


\section{SIINASA Mindel. - Salcinie.}

S. Matalus Hoffm. S. plutitorer.-Plulitóre pe apele stag-

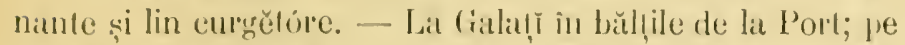

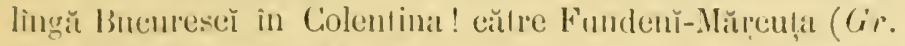

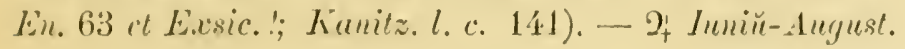

\section{LYCOPODIACEE.}

\section{LYCOPODLM $\mathrm{L}$. - Iicopodiu.}

I. Selağo Lin. L. Selaginŭ. -Vulg. Brüdişor, Cornissor. - Prin pădurile umede și umbróse din regiunea subalpină şi pe stincile umede din regimea alpină. - La Broseenı

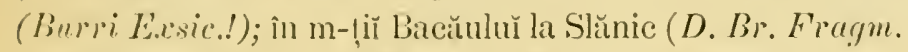
l. c. 71); la Sinaia (Gr. En. 64 et E.xsic.!; Kanitz l. c. 141) și lia Predél. - 2 I Iıliŭ-Auqust.

3. recurvum (Kit.). - In Moldova (Cz. et Sz. l. c. 56; L. Selago Cz. Flora XIX, 74 et Exsic.!; h.j. Gucbh. manusc.; Cz. ct S'z.l. c. 56); în m-tiŭ Bacăulur̆ la Slănic.; pe vîrful Penteleuř ; la Sinaia pe Piscul-cânelur și la Predél; etc.

L. annotinum Lin. L. amotin. - Prin pădurile umede și umbróse, și pe stîncile de lingă torentele din regiunea montană superióră și subalpină. - In Moldova (L. clavatım Cz. Flora XIX, 74 / hon L.7 et Exsic.!; h.j. Guebh. manusc.; Cz. ct Sz. l.c. 65); prin m-țiı̆ Bacăuluŭ la Slănic cütre Ciascadă, la Palanea pe lîngă Pirŭul-şanțulŭ și la Mănŭstirea-Cașinuluĭ; la Predél. - q Iuliŭ-August.

J. complanatum Lin. L. complanat. - Prin locurile arenacee și stincóse din jădurile regiuner subalpine și monlane superiore. - In Moldova (Cz. ct Sz. l. c. 65̃) prin m-țĭ Bacăuluŭ la Mănăstirea-Cașinulŭ́ către Soŭmărie la Sărilóre; în m-lị̆ Buceğ cŭtre Obîrșia lalomị̣ĕ (Hoff. Excurs. 1863, l. c. 120). - 2 Iuliŭ-August. 
I. clavatum Lin. L. clavat. - Vulg. Chedicutŭ, Pe-

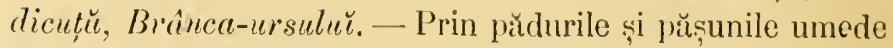
si petróse din regimnea montană superióră și subalpină. În m-țiĭ Bacăuluĭ la Slănie, Mănăstirea-Cașinuluı̌ și la Palanca pe Tărhăușęl ; la Sinaia (Gr. En. 64 ct Exsic.!; Konitz l. c. 141); în Dîmbovį̣a pe m-tele Priporu; la Nĕmăesč̆ le Cósta-mănăstireí (D. Br. l. c. 71) și în valea Dîmboviciórel̆ (Huynald in Borb. Linn. XLI, 215).- 4 Iuliŭ-Aug.

\section{SELAGINELLA Spring. - Selaginelă.}

S. spinulosa A. Br. S. spimulósă. - Prin locurile umede din regiunea alpină şi subalpină. - Pe vîrful Bueegilor (Fr. 70; Lycopodium selaginoides L. Hoff. Excurs. 1863, l. c. 120). - 2 Luliŭ-August.

S. helvetica Spring. S. dc Elvelia. - Pe stîneele umede din pădurile montane, subalpine, și pănă în regiunea alpină. - La Broscenı̌ pe Petrele-I)ómneĭ (Burri Éxsic.!); în m-liĭ Vîlceŭ la Olănescĕ, pe m-tele Ciùrligu, şi eătre Lotru la Golotrenì ; etc. - 2 Iuliü-August.

\section{FILICACEE.}

\section{BOTRYCHIUII Sw. - Botrichiŭ.}

B. Lumaria Sto. B. Lunarie. - Prin păşunile din reginuea subalpină şi alpină. - În Moldova (h.j. Guebh. manusc.; Osmunda Lunaria Cz. Flora XIX, 74 et Exsic.!); în m-ḷị̌ Bacăuluŭ la Palanca pe vîrful Ciudanerulur̆; în m-țiǔ Buceğ la Strunga (Gr. En. 63 et Exsic.!; Kanilz l. c. 144), în valea Jalomiței $(F r .70)$, la schitul Pescera, pe Furnica, și la Predél pe m-tele Susain̆. - 2 Maiй-Iuniŭ.

B. rutafolium A. Br.; B. rutaceum Sw. (non Willd.). B. cu fŏ de rută. - Prin pășunile și pădurile din regiu- 


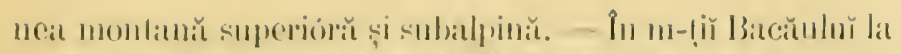

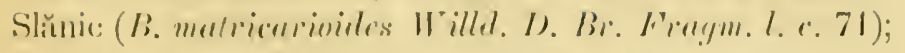

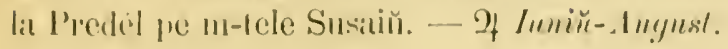

\section{GiRMMITIS Sw. - Gramită.}

G. Ceterateh Sie.; Gymmogramma Ceterach Spreng. G. Coterar. - Prin crěpriturile slincilor din munț. - In Mol-

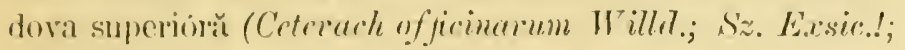

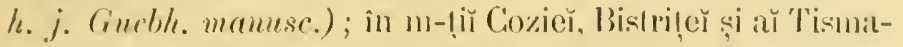

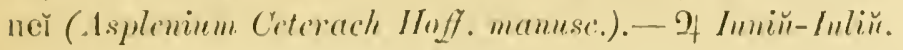

\section{NoTII0CIILANa R. Br. - Notoclenĕ.}

N. Marantar R. Br.; Polysticum Marentac Roth. N. lǔ Haranla. - Prin crĕphăturile slîncilor calcare din munț. - In Moldova (Acrostichum Marantae L. Sz. Exsic.!; Ceterach Harantae D) C. h., . Gucbh. mamusc.); la Vîreiorova către Por!̣ile-de-fer! (Borb. Uj, jol. 85; Gymnogramma

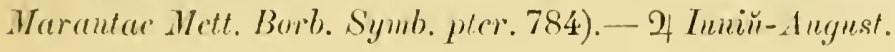

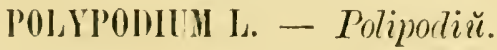

P. vulgare L. P. comun. - Vulg. Iurbă-dulec-demunte. Fereč̆, Fercentă. - Pe stincile umede din pădurile umbróse ale munṭlor. - In Moldova (Cz. Flora XIX, 74 't E.rsic.!; h.j. Gucbh. manusc.; Cz. et Sz. l. c. 55); lit Broscenı̆ (Burri Exsic.!); în m-tị̌ Némtuluĭ la Sihla; în m-țî̀ Bacăuluŭ la Slănic, Mănăstirea-Caçinuluı̆ și MăguraOcner̆; la Sinaia (Gr. Erbor. l. c. 338; Gr. En. 63 ct Exsic.! ; Kanitz l. c. 144) către pólele Furnicer ; în Muscel la Nĕmăescı̆ (D. Br. Fratgm. l. c. 70) și în calea de la Rucŭl lit Himboriciora ( $I^{\prime}$. offecinal' Hoff. Exxcur's. $1862, l$. c.

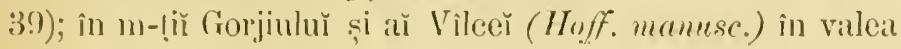


Bistrițeĭ şi cŭtre Lotru pe Fơrfeca; în Argeș pe m-tele Urlica; etc. - 2 Inniй-Inliŭ.

3. angustatum. - La Vireiorova (Borl). Symb. pter. 784).

P. Phegopteris L. P. Fegoptrrictŭ. - Pe lingă slincile umede şi pe la rădĕcina arborilor din pădurile unbróse ale muntilior. - In Moldova ( $C z$. et Sz. l. e. 55) prin m-țiu Bacăulur̆ la Slănic pe lingă Cascadă ; la Broscenı̆ (Burri Exxsic. !); în Muscel la Nĕmăescĭ pe Cósta-mănăstireĕ ( $D . B r$. Fragm. l. c. 70); etc.. - 2 Inniй-August.

P. Dryopteris L. P. Dryopteridă. - Pe lîngă stinclie unede şi pe la rădĕcina arborilor din pădurile umbróse ale munților. - În Moldova (Cz. Flor a XIX, 74 et Exsic.!; ll. $j$. Gucbh. manusc.; $C z$. et $S z . l$. c. 55 ) prin m-tị Ném!̣ulu la Sihıla și schitul Durăŭ ; în m-țĭ Bacăuluı̆ la Slănic; în n-tịi Buzĕuluı̆ pe vîrful Penteleuluř; la Sinaia pe valea Peleșuluı̆ (Gr. Excurs. l. c. 337; Gr. En. 63 et Exsic.!) şi la pólele Bucegilor; în Muscel la Nĕmăescě pe Cósta-mănăstireĭ (P. calcareum D. Br. Fragm. l.c. 70 [non Sw.7);

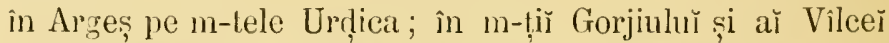
(Hoff. mamsc.) în valea Bistrį̣er. - 2 Iuniŭ-August.

Obs. - Se maĭ ciéză : P. hyperboreum Wahl. în Moldova (Cz.et Sz. 55̃).

\section{ASPIDIUII R. Br. - Aspidiǔ.}

A. Lonchitis Sw.; Polypodium Lonchitis L. A. Lonchitidă.--Pe stincile umbróse din regiunea subalpină și alpină. - In Molilova (Lonchitis aurila Cz. Flora XIX, 73 et Exsic.!; Polystienm. Lonchitis Toth h. j. Guebh. manusc.); la Broscenı̌ pe Petrele-Dómmè (Burri Exsic.!); în m-tị̆ Musceluluй (D. Bi. Fragm. l. c. 70). - - I Iuliŭ-August.

A. acnleatum Sw. A. ghimpos. - Prin pădurile mmede și umbróse din regimnea monlană și subalpină. - În Mloldova (Polypodium aculcatum L. Cz. Flora XIX, 74 et Exsic..; Cz. ct Sz. l. c. 55 ; P'olystichnom aenleatum Roth 


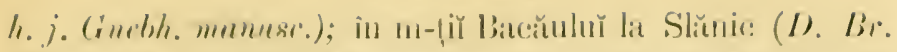

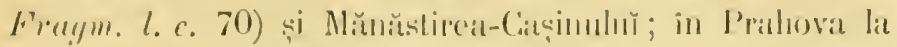
poilele Buncegilor și lá l'redél; în Vîlceat pe villea Bistrilè ; cte. - 2f Inliü-dutyest.

P. cungularc, - La Virciorova către Porṭile-de-ler! (.I.

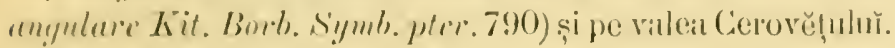

1. pilosmu shome. A. pross. - P'rin püdurile din regiu-

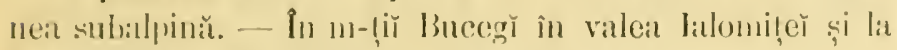
I'rerdil (sichus lin. 8333). - Inliü-ilugust.

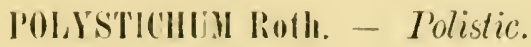

P. Thelypteris roth; Aspitium Thelypteris Sw. P. Thelipterinlă. - Prin locurile umede și uliginóse, pe malurile lacurilor si a gâtlelor. - In Noldova (Sz. Lixsic.!; $h . j$.

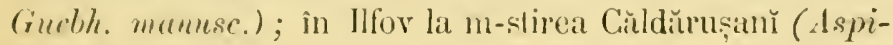
dium Oreopteris D. Br. Fragm. l. c. 70 (non Sw.]) și în lacul de la T'ìngăbesč̆. - 2 Iuliŭ-August.

P. Oreopteris DC. P. Oropteridă. - Prin pădurile umbrose și umede din regiunea subslpină și monlană. - In Moldovil (Aspidium Oreopteris Sw. Cz. et Sz. l.c. 55); în m-țĭ Muscelulŭ. - 2f Inliŭ-Anggust.

P. Filix mas Roth. P. Ferigăa-masculă. - Vulg. Fe-

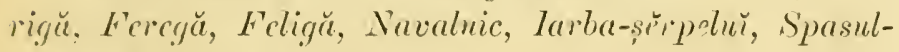
draculǔ̆, Spata-draculǔ. - Prin locurile umede și petróse din pădurile unbróse montane și subalpine. - ln Moldova (h.j. Guebh. manusc.; Aspidium Filix mas Siw. Cz. et Sz. l. c. 55; P'olypodium Filix mas L. Cz. Flora XIX, 74 ct Exssic.!); pe lingă Jaṣ̆ la Niṭelea, Repedea, Bîr-

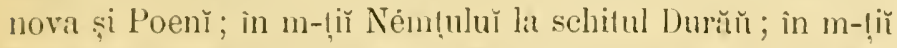

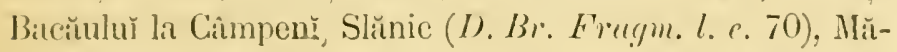
ğura-Oener̆ și Mănăstireat-Cạ̦inuluĭ în m-ḷĭ Buzeuluĭ între 111-stirea Nifon și Bisca-natre (Hoff. Exreurs. 1863, l. c. 117); in Prahova (cir. Ė. 63) la Sinaiat pe valea P'eleșuluĭ ( $I$ '. 
abreviatum Gr. Monit. of. l. c. 337 ?; Asplenium lanceolatım Gr. En. 63 /non IInds. 7?) și la Predél ; în m-(ị̂ Muscelulŭ între Rucŭr și Dìmboviciôra! (Hoff. Excurs. 1862, l. c. 39); în ın-ḷị Vîlcě̌ ; în $\Lambda$ rgeş pe m-tele Urd̦ica; în Me-

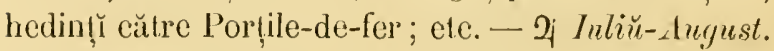

P. cristatum Roth. P. crestat. - Prin pădurile umede şi umbróse din regiunea montană și subalpină. - În Moldova (Aspidium cristalum Sw. Cz. et Sz.l. c. 55); în m-ții Muscelulŭ (D. Br. F'ragm. l. c. 70); în m-liĭ m-stipilor Cozia, Bistrița şi Tismana (Hoff. manusc.).- 2 Luliü-August.

P. spimulosum DC.; Aspidium spimulosum Sw. P. spinulos. - Prin pădurile umede și umbróse din regiunca montană și subalpină. - În m-țiù Némṭuluı̆ la schitul Sihla; în m-țiĭ Bacăuluı̆ la Slănic; la Sinaia (Polypodium squamulosum Gr. Monit. off. l. c.) și la Predél pe Susaiŭ ; in m-piĭ Vîlcê̆ la m-stirea Horezu; etc. - 2 Iuliŭ-August.

\section{CYSTOPTERIS Beruh. - Cistopteridă.}

C. fragilis Brmh. C.fragilă.-Pe stincile umbróse din regiunea montană și subalpină. - În Moldova (Aspidium fragile DC. Sz. Exsic.!; h.j. Guebh. manusc.; A. montanum Sz. Exsic. [non Sw.J!; h.j. Gucbh. manusc.); la Broscenĭ (Burri Exsic.!); pe lîngă Iaşŭ la Petrăria-Repeder̆; pe Célılăŭ ; în Dîmbovița pe m-tele Priporu; la Sinaia ( $G r$. En. 63 et Exsic.!; Kromitz l. c. 143), și în Buceğ la Strunga (Kotschy 132), pe Furnica și la Schitul Pescera de la Ialomiṭa; în m-ḷĭ Muscelulŭ (D. Br. Fragm. l. c. 71); în m-ḷĭ Vîlcen̆ către Lotru je m-tele Naroțu; la Vìrciorova către Porṭile-de-fer! (Borb.1873, Báns. 246).-2 Iuliü-August.

C. sudetica A. Br. C. de Silesia. - Pe stincile umede din pădurile umbróse ale regiuně̌ subalpine. - În m-ḷĭ Ném!̨ulŭ la schitul Sihlit. - 2f Inliŭ-Alngnst. 
ASPLENIUM L. - Aspleniu.

A. Filix femina Bernh; Aspridinm filid fomina sim. I.

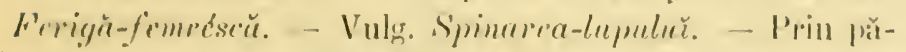
durile unede și pe linğ stincile din reginnea montinta și

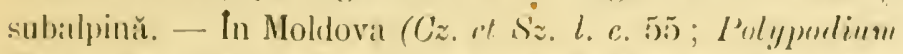

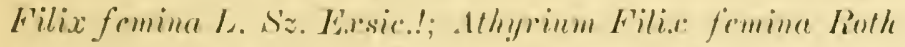

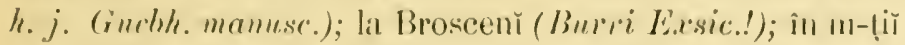
Némf̣ulư̆ la sedilul de la Jurăı̆ ; in un-ṭî Bacăuluĭ la Slă-

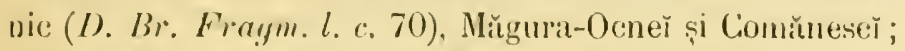
in m-tiĭ Buzĕuluĭ călre Bisca-mare (Hotf. Excurs. 1863, l. e. 117) și pe m-lele 'Tegit; lat Sintia (Gir. Ein. 63 ot La:sic.!), la poilele Furniceš și la P'redél; in Muscel intre Rucür și l)imbovicion"a (Ho/f. Excurs. 1862, l. ๘. 39); în m-tir Gorjiulı̆ și aĭ Vîlceè (Họf. manuse.) là m-stirea Horè și la Golotrenĭ: în Argeş pe m-lele Urḍiea; efc.-2f Iuliü-Anugust.

A. Trichomanes L. A. Tricoman. - Prin clĕpăturile slîncilor calcare și umbróse, pe əidur̆̌ - In Moldova (h.j.

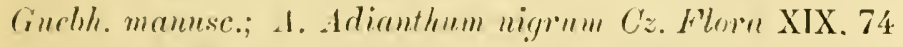
/ non L.7 of Exsic.!): la Broscenı̌ (Burri Exrsic.!); pe lîngă laçŭ la Petrăria-Repeder ; in m-țĭ Ném!̣luĭ la schiłul Sihla

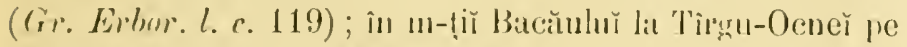

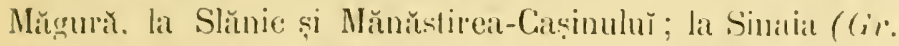
En. 62 ol Exsir!!) călre pólele Furniceñ ? ci către Obirṣia Ialomiteì (Ifuff. Excmrs. 18633. l. a. 120); in Mluscel lit

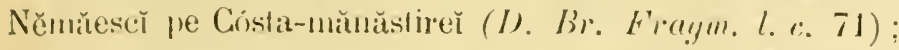

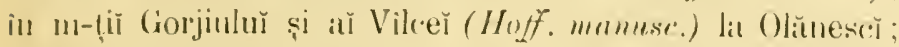

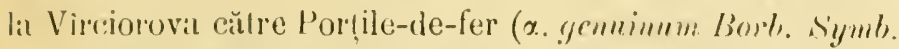
płrr. 785); călre Bahna pe m-tele Cinrehia și in valea Cie-

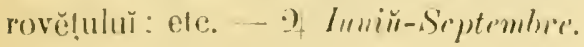

1. viride Huds. A. verde. - Pe slincile calleare diu re-

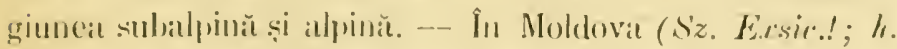
j. (iuchlo. manuss.); la Sinatia pe malurile Peleşuluĭ (Gir. 
En. 63 et Exsic.!; Kanitz l. c. 143; Blechnum Spicant Gr. E.reurs. l. e. /nom Roth/; cf. Gr. Liv. 67) și in Bucegì (Fr. 70) pe Furnica; in Mnscel in valea Dimboviciórer (Haynald in Borb. Linu. XIII, 204). - 2 lneiü-Septembre.

A. Rula muraria C. A. Ráută-de-ziduř̌ - Prin crěpăturile slîneilor umbróse și pe zidurile de pélră. - In Moldova (Cz. Flora XIX, 74 et Exsic.l; h.j. Guebh. mannsc.); in Dîmbovila ne zidul m-stireč bélu; in m-liĭ Bucegĭ; în m-(iî Musceluluĭ lat Něnăescĭ pe Slinnca-mănăstireı̆ $(D$. Br. F'ragm. l. c. 71) şi între Rucăr și Dimboviciỏra (Hoff. Excurs. 1862, l. c. 39); elc. - 2f Luniü-August.

A. Adianthum nigrum L. A. Adiant negru. - Pe stincile umede din pădurile umbróse ale regiuner subalpine. In Moldova (Sz. Exsic.!; h. j. Guebh. manusc.); in m-liĭ m-stiriior Cozia, Bistrilia și T'ismana (.1. dbtnsnm Kit. Moff. mannsc.). -- S) Inniŭ-August.

ץ. Lancifolium Heuff.; A. IIenffelii Wierzb. - In Mehedințĭ la Virciorova către l'orțile-de-fer! (Borb. 1873, Bins. 943; Symb. pterid. 787).

A. septentrionale Sw. A. sep'entrimal. - Prin erepăturile stincilor umbróse din pădurile rergiuneř montane şi subalpine. - La 'lî̀rgu-Oenĕ̌ pe Măgura-Ocneı̆ ; lat Vîreiorovil călle Porlile-de-fer! (Burb. 1873, Báns. 24.4; s'ymb. pteriel. 786); etc. - 2 Inliй-1 legres!'

\section{SCOLOPENDRIUM Smith. -- Scolopendriu.}

S. offleinarum Sw. S. oficinal.-Vulg. Navalnic, Limbacerbulǔ̆, Limba-vecinč, Limba-vaeř. - Pe stîneile unbróse din pădurile subalpine si montane. - In Moldovia (S'z. kissic.!; h. j. Guebh. mamesc.) la m-stirea Asalpial-

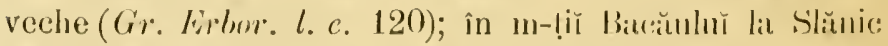

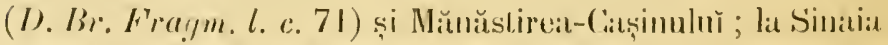

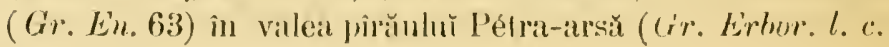


338) și la pólele Furnicen: in n-ṭi Musceluhŭ la Dìnho-

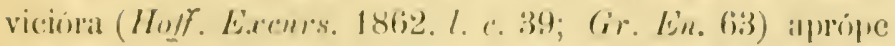

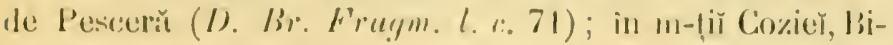

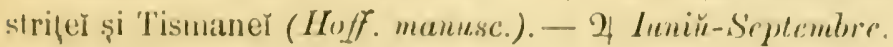

\section{BLECHNUM L。 - Blecme.}

B. Spieant Rolh. R. Spicunt. - Prin locurile stincóse și unede din pădurile umbróse ale muntilor. - In Moldovi (s'z. Lissic.! / mem. Asploninm furcatum]; h. j. Gubbh. maunsc.); prin m-tiĭ Baıcíuluŏ la Apele minerale de la Slănic de-itsujura Isvorulıŭ No. III ; ete. - 2 I Iиniй-A lugust.

\section{PTERIS L. - Pteridג.}

P. aqquilina L. P. aquilină. - Vulg. Navalnic-pajusiü. - P'rin pădurile petróse şi finețele sterile din regiunea montană. - In Moldova (Cz. Flora XIX, 74 et Exsic.!; Cz. et Sz. l. c. 55) centrală şi superióră (Guebh. mamesc.); la Broscenì (Burri Exsic.!) pe linğă Iași la Poenĭ ; în m-ṭi Ném|ulữ la schitul Sihla; în distr. Bacăı̆ pe Délu-Cúlugălè̃, 'T'irgu-Ocner pe Măgură-Ocner și la Slănic (D. Br. Fratym. l. c. 40); in in-fir Buzěulur către Bisca pe in-tele 'Tega; la Sinaia pe Piscu-câneluı̌; in Muscel (I). Br. Fra.jm. l.c. 70) în valea Riu-T'îrguluĭ la pólele m-teluĭ Lerescĭ (IJoff. Exanrs. 1862, l. c. 31); in m-tiì Gorjiuluǐ și aĭ Vîlceĕ (Hoff. man'ssc.) către Lotru la (Golotrenĭ ; pe malul Dunăreĭ între Gurat-văieì şi Vîrciorova; etc. - 2 lutiü-Septembre.

\section{STRUTHIOP'TERIS Willd. - Struliopteridi.}

S. Leernanica Willd. S. de Germania. - Prin pădurile umete și unhbrose din regiunea montană și pe lingra stîn-

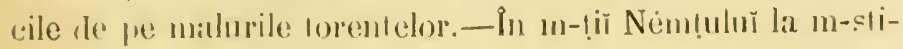


rea Sĕcu; in m-țiĭ Bacăuluĭ la Slănic pe malul torentuluĭ Slănic în fața picheluluĭ grănicerilor de la fruntarie. - 2 Iuliv̌-Septembre.

Obs. - Se mar citéză : Adiantlınm Capillıs Veneris $L$. in Moldova superióră (Sz. Exsic.!; h. j. Guel,h. manusc.) și în Muscel între Rucăr și Dîmbovicióra (Hoffr. Excur's. 1862, l. c. 39). - Wood walldia radicans Sm. in Moldova (Sz. Lixsic.f; h.j. Guebh. manusc)? 


\title{
ADITTIUNI ŞI CORECŢIUNI
}

\author{
L.A

\section{R.INUNGULACE, ROSACEE Si PAPIJIONACEE.}

\section{Pitg. 3. Aquilegria T.}

In loc de: A. Vulgaris $L$. pune:

A. grandulosa Fisch.; A. Rranssileuniea Sechme. - Vulg.

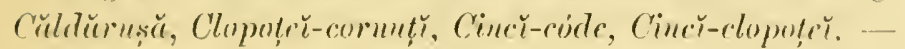
Prin locurǐ calcare unede și umbróse din regiunea subalpină și alpină. - Pe Céhlăŭ (.1. alpina Bmg. Edd l. c. 35 [uen L.]; ('z. Flura XIX. 66 et Eixsic.! ; h. j. Guebh. ma-

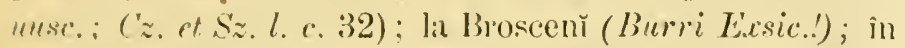

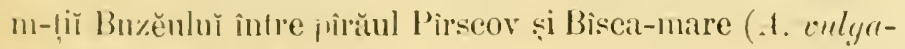
ris lloff. E.reurs. 1863, l. c. 117); in m-1̣ĭ Bucegĭ la schimul Pescera de la Latomita! (A. Hamleuna Schur Eu. 28

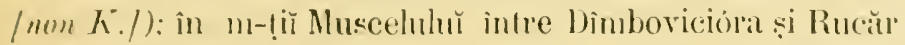

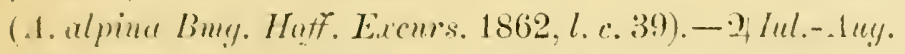
Olıs. - Se cultivă prin grădiñ : A. vulgarlris $L_{2}$. (Cz et Sz. l. c. 32;

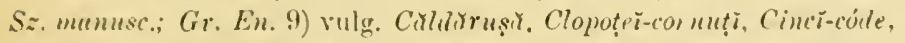
Cinci-clupotci. - 1. vulgatris L. ३. nieta Bmg (Cz. et Sz. l. c. 32). 1. nigrilians Bmy. (Cz. et $S z$. l. c. 32).

Suprimă pe: A. alpiun $L$. 


\section{Pag. 4. Nigella T.}

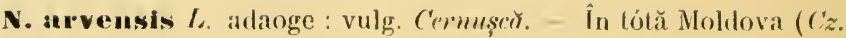
Flor XIX, 66 et Ersic.!; Etlel l. c. 40; Cz. et Sz. 1. e. 30; I). Bs?. Fromm. I. c. 77 ; V.? sec. Konnitz l. c. 4); pe lîngă IaşY la Aronénu și Șěpte-ómenI (Sz. mumusc.); în Rûmnicu-sărat la Caiata; pe lîngă Bucurescr la Ferěstrěŭ și între Ploeser și Băicoiŭ $\left(G r . E_{n}\right.$. 9); in Vîlcea la Bălcescr.

N. segetalis M. Bieb.; N. segetalis M. Birb. $\beta$. armena (Stev.) Boiss. N. de sěcerișuř. -- Printre sĕmĕnăturile din Moldova inferióră (N. forniculacra DC. Guebh. manusc. et Exsic. n. 387 [var.7 sec. Nym. Consp. 17). - $\odot$

N. sutivu $L$, adaoge : vulg. Chimion-negru, Cermușex̆, Negriliç̆.-Cultivată (Eılel l. c. $40 ;$ Cz. et $S z$. l. c. $32 ; S z$. mamusc.).

N. damascenn $L$. adaoge: vulg. Bórze. - Cultivat (Cz. ot Sz. l. c. $32 ;$ Sz. mantses.).

\section{Pag. 5. Helleborns T.}

II. purpurascens $W$. Kit. adaoge : Spinks. - In Moldova ( $C z$. ot $S z .1 . c .33 ;$ Sz. m(musc.); în m-ţir de la Predél.

I1. odorus Kit. adaoge : vulg. Bojoțer, Cutcurig. - La Comana; pe lîngă Craiova la Teiș și pe malul Jiulur la Bucovĕț; în Mehediṇ̨y (II. ciritlis Gr. En. 8 / non L.] ct Exsic..') la Cernețy (H. murmeresefus Gil. En. 8 [non W. Kit.] ot Exsic.!).

0lss. - Se maY citéză : II. niger $L$. și H. virillis $L$. amĕndoue la pólele Carpaţilor către rîul Bistriţa (Cz. ct $S z$. l. c. 333).

\section{Pag. 6. Isopyrum L.}

I. Thalictroides $L$, adlaoge : vulg. Ğ̌imușĭ, Hisoppir, Hisopirel, T'uriţr-ulbe. - (D. Br. Frogm. I. c. 7) ; în tótă Moldova (Cz. Flora

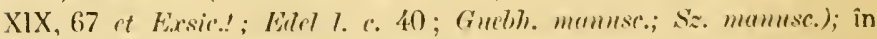

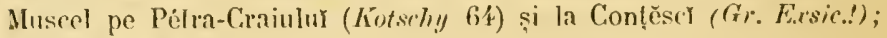
pe lìngă Craiova in Luncă; la Cernețĭ.

I. fumarioides $L$. adaoge : în m-țir Molılover (Sz. Exsic:.!). 
P'ar. 7. Trolliths I.

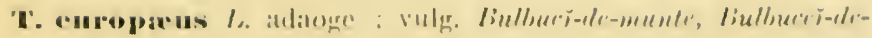

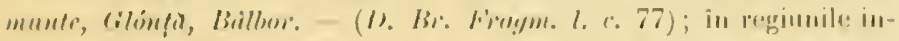

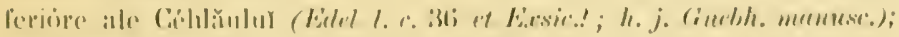

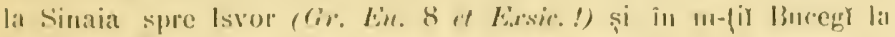
schluitul Pescera lalomiţer; în m-ţir de la l'redée.

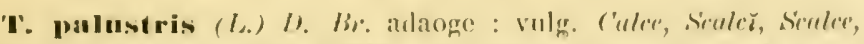

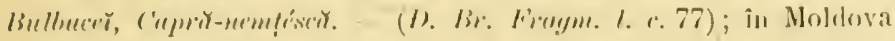

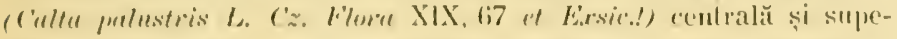

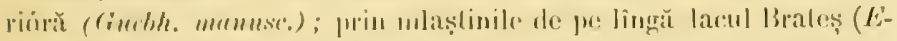

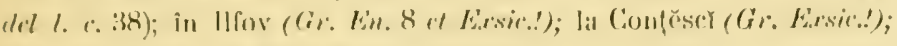
in Gorjiŭ lal Roșia je malul 'Tismaney.

\section{Pig. 9. Ilelphinimm T.}

In lor te: D. apinum II. Kit. puse:

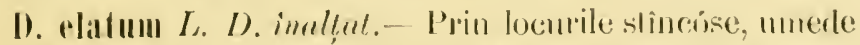

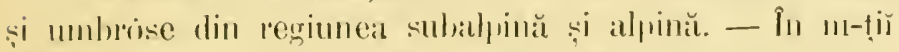

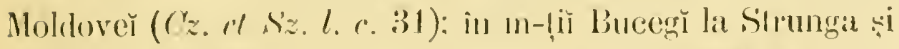
la schiful Pescera de lal Kalomilat (F'r. 11:3; Wrinlil.! sere.

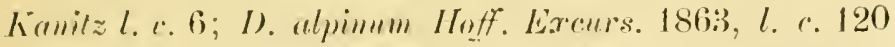

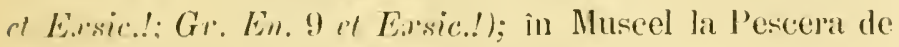

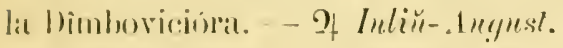

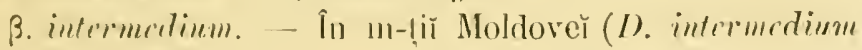

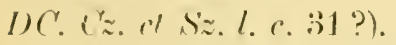

In loe de: D. fissum II: Kit. pune:

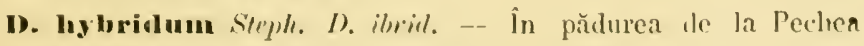

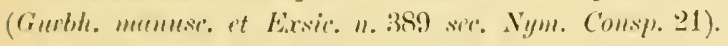

D. Consolida $L$. adaoge : valgr. Pintenos, Toporis, Topmereșt, Tot-

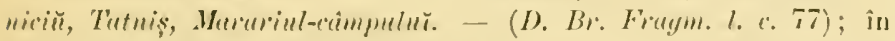

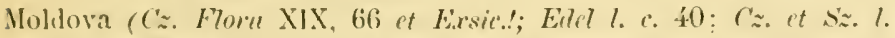

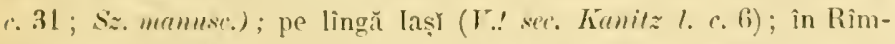
niculsărat la Caiata; în llfov ((i). En. 9 et E.rsic.!) la Ferĕslrĕŭ și Cotroceny: lîngă Craiova la Trêt-fântâny; la Vîrciorova (Kenitz! l.c. 6).

D. Ijacis $L$. adaoge : cultivat (Gr. En, y). 
D. orientale Ga!y. I). mirntal. - P'rintre semènăturĭ și me locurĭ něsipóse. - În Moldova (1). djacis Cz. Flura XIX, 66 /mm L.7 it Exsic.!; Estel l. c. 40): la Bucuresč̀ prin Infĕrișurile din grădina Ciṣmegiulù (Gr. En. 9) et Exxsic.!).- $\odot$ Imій-Inliü.

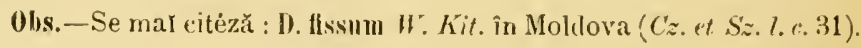

D. Iycoctonnm $D$. $B i$, allaoge : in m-ţir Moldover (Aronitum Lycoctomm Cz. "f Sz. I. c. 32).

D. pyreunicum $I$ ). $B$ r, adaoge : (Aconitum pyrencicum L. D). Br. Fitum. I. c. 77); în Moldova (A. ochroleucum Cz. et Sz. l. c. 31); la Sinaia (A. Lycoctomm Gr. Fon. 9 [non L.] et Es.rsic.!) și în m-ţi Bucegr la schitul Pescera de la lalomiţa! (A. pyrencricum $F$ r. 713 ; W'inkl.! sec. Kunitz 1. (. 5); în m-țir de la Predél.

D. moldavicum $D$. Br. adaoge: (Aconitum molduricum IItacy D. Bi. Frergm. I. e. 77); în m-țir Moldover (A. moldue. Harq. Reise 1.

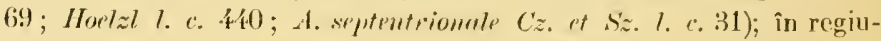
nile inferióre ale Céhlăulur (A. crmmum Eilel 1. a. 36 [mon I) C.] ;

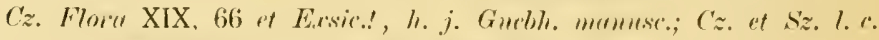
32 ; A. peniculatum h. j. Guebh. mamisse.).

În loc de: D. Cammarum $D$ ). B): pune:

I). variegatum (L.) D. Br.; Lemitum rariryatum $L$. D. vargut. - Prin Infĕrișuile și pădurile umbróse și umede din regiunea subalpină. - La Broscenì (Burri Ersic.!); pe Céhlăn̆; la Agapia (.1. peniculatum (íp. En. 9 [nom Lam./) și la m-stirea Némțhur pe lîngă Cismé; în m-ṭi Bucegì către Obîrụia Ialomițĕ (.1. Cammarnm Jacq. /non L.] Hoff. Excurs. 1863, l. c. 120), la Poeana-Ṭpulŭ și la

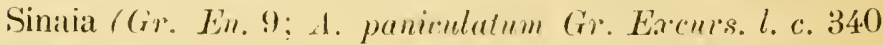
(nom Lam.]); la Predél; în m-țir Vîlceŏ la m-stirea Hore\%

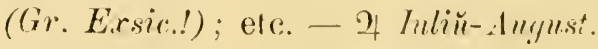

Suprimă pe : D. cermumu $D$. $B r$ :

D. Xapellas' D. Br: adaoge : vulg. Omur, Omine, Omeng, Töir. -

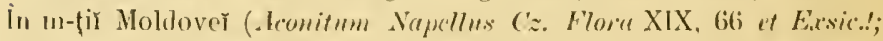
h. j. Guebh. munuse,; ( $z$. et Sz. 1. c. BI) de la confinile Transilva-

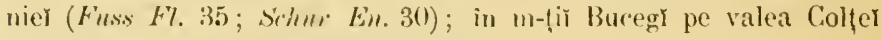
aprópe de schitul Pescera lalomițer. 


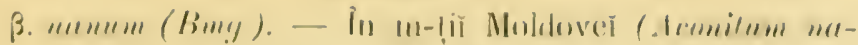

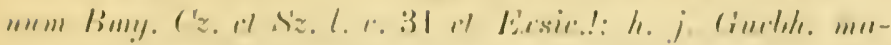

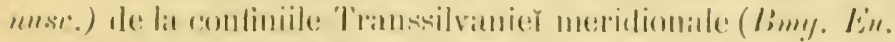

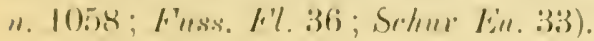

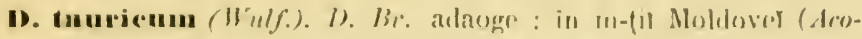

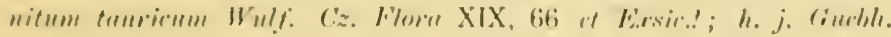

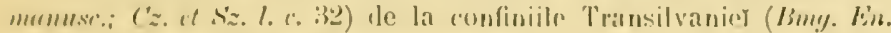

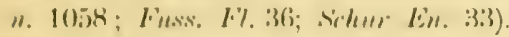

b. Nenbergense (lichl.) I), Br: adaoge: Pe Céhllăŭ (Armitmm

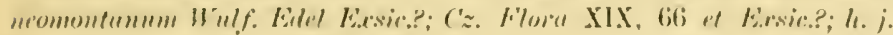

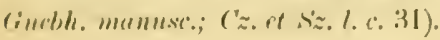

1). Anthoral(I.) I). Br.; Acomifum Anthora L. I). Inthoră.-Prin păsunile slincrose și umbróse din regimea subalpină și alpinit. - In m-tị Moldover (A. duthora L. Cz.

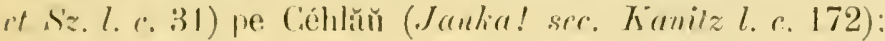

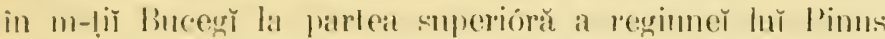
Manhus (1. Anthora From. 1999) la schilul Pescera Ialomi-

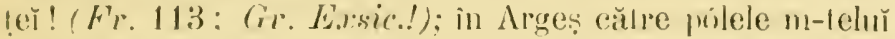

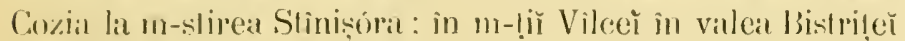
((ir E.rsic.!). - of leliü- luegust.

\section{Pag. 14-2'. Raunnculus Ilail.}

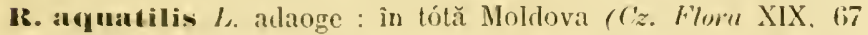

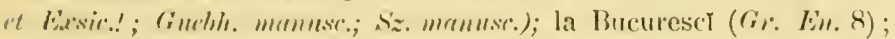
in Dudesci.

IR. fluitaus Lum, adaoge : în Moldova (R. penerdanifolium ("z. of s'z. 1. c. 3i3).

0lıs. - Se mal citéza : R. divarieatıs Schramk: în Moldova (Cz.

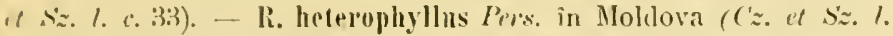

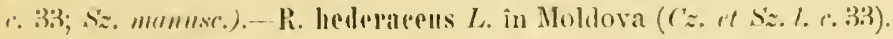

IR. pedatus $\boldsymbol{W}$. Kit. adaoge: prin fîneţele de pe coline la Lețrant și Erbicent (s'z. momus'.).

Ir. illyricus $l$, allaoge : în Moldova (t'z. 1t. s'z. l. a. 33; R. lamuginusens ('z. Flor X X1X, 66 / mon L./ "t E.rsic.?); la Păın, schitul Tărița și Repedea (Sz. munusc.); la Vîrciorova eătre Porțile-le-fer (Borb. sece hunitz l. I. 170). 
R. 'Thor' $L$. arlaoge : în m-tir Moldover (C'z. ct Sz. 33 et Exsic.!)

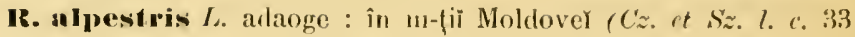
et Exrsic.!); în in-țiY Bucegy pe stîncile valcare la Strunga, în parlea superiỏră a văier lalomiţeì (Kotschy 138; Fr. I12), pe cóstele Caraimanulur, aprópe de Omu.

18. aconitifolius $L$. adaoge : în m-ţiy Moldover (Edel l. c. 37 ; Cz. et Sz. 1. c. 333); în m-țir de la Prerlél.

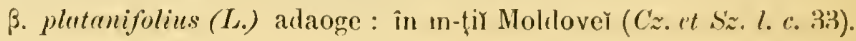

R. Limgua $L$. adaoge: prin mlaștinile de pe lîngà larul Brateș (Eilel l. e. 38 et E.esic.'; Cz. et šz. l. c. 333) ; pe lîgă lașI la Cristescy (Sz. memest.); la Tîrgoviștea prin mlașlinile de pe lîngă șoséoa ce rluce la 111 -stirea Délu.

R. Flammula $L$. R. Flamulă - Prin finetẹe mlástinóse si uméde din Moldova (Cz. et $S z$. l. с. 33 ; Sz. manusc.). - If Iuniй-August.

R. reptuns $L$. adange : pe lîugă lașy pe ualul Prutuluy și a Bahluiulur (Sz. munusc.).

R. nupicomus $L$. adlange : în Moldova (C $z$. Flloru XIX, 67 pt Exsic.!; Edlel l. c. 40; Cz. et Sz. l. ('. 333; sz. mumusr.) ('entrală și superióră (Guebh, mumuse.); în Muscel la ConțěseY (Gr. kinsic.?); pe lîngă Craiova în Luncă; în Gorjiŭ la Roșia ; la Cernę̧I (Gir. En. 8 et Exsic:.!); în Vîleea în vilea Bistriţer ; ete.

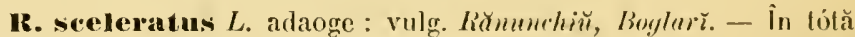

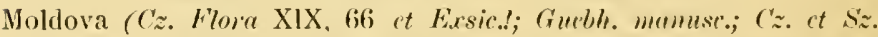
1. c. $33 ;$;z. manust.; V.! ser. Kunitz 1. c. 4); prin mlaștinile de pe lîngă lacul Brateș (Eldel l. a. 38); în distr. Bateăŭ lat Caraclăŭ; în Ilfov (Gr. Kir. 8) pe lîngă Bucurescy (I). Br. Fraym. l. c.7(i) la Ferěstrěñ.

B. mimimus Bmg. - In Moldova (Cz. Flora XIX, 66 ?) prin locurile nĕsipóse sii umede de pe malurile Serelulur (Guchh. mamusc.).

IR. montanus Willd. adaoge : în Moldova (Cz. Flor"l XIX, 67 ?;

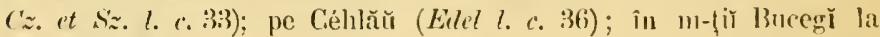
Strunga (Kotschy 132).

R. gracilis Schleich. R'.geramiifolius Pourr. hr.gracil. - Prin pășunile calcale din regiunea alpină. - In m-țĭ Bucegř pe vîrful Furniceř, pe Vîrfu-cu-Doru și la PîrŭulBabelor; etc. - 2 Maiй-Iuliü. 


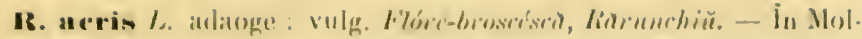

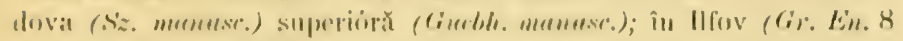

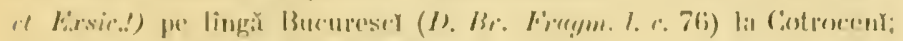

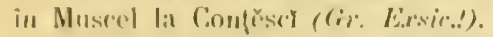

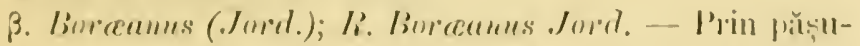
nile monede din regimnea subalpinăt i alpină. La l'redel fe m-lele Susaiŭ; in l)imhovila fe m-lele l'ripuru.

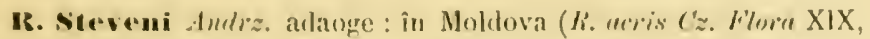

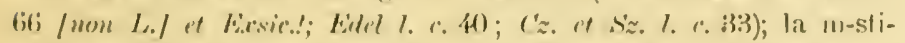

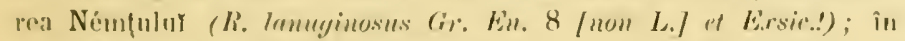
u-pir Barăulư la Slănic și Câupeny.

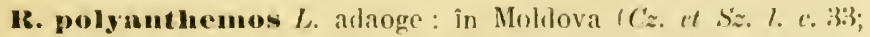

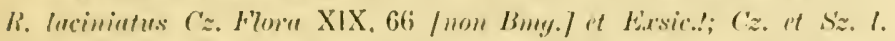

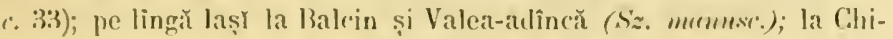

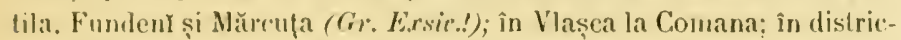
tıl Argeş la Stolnič.

16. nemorosus $D C$.; $R$. Breryninus $C r$ adaoge : prin pădury la P’uțenr (Comebh. munusc.); pe vîrful Penteleulur; la Predél pe m-tele Sinsaiǔ; in Dimbovitąa pe m-tele Priporu.

16. Ianuginosus $L$, ataoge : in tótă Moldova (Guebh. munuss.)

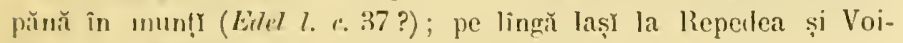
nese:Y (Sz. mumuexc.); pe lîngă Craiova în Luncă.

R. oreophilus M. Bieb.; R. Villarsii Koch. ot Gren. Gurle.; R. Grenieranus Jord.; R. psendo-Villarsïi Schur. li. arrofil. - Prin pășunile calcare din regiunea subalpină si aljuină. - In m-liı̆ Moldoveì (Sz. Exsic.!: Lnom. R. Arn-

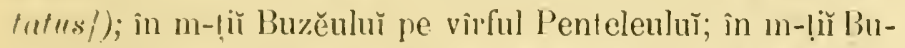
cegì pe valea Ialomițě ( $R$. Irillarsii Fr. 113 Fnon $D C .7$ ) la schilul Pescera; etc. - of Iuniü-Iuliü.

1R. carpathieus Horbich, adaoge: in m-țir Molılover ( $R$. Gounni

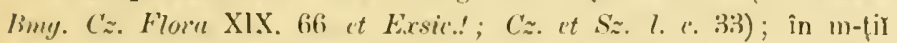
Musceln]ur (D. Br. Fruym. I. (C. 76) pe Pétra-Craiulur (R. Le'r-

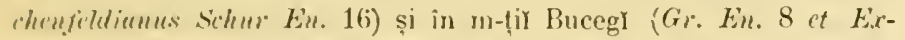

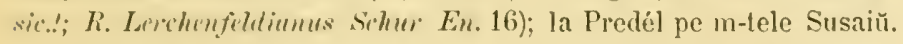

18. repeus $L$. allagge: vulg. Bujort. - in tótă Moldova (Fillel

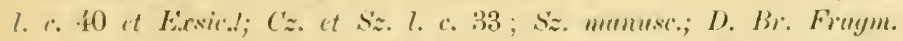

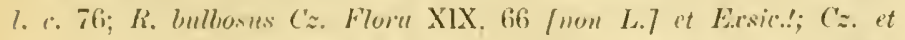
sz. 1. c. 33; R. perlestus Cz. Flora XIX, 66 [non IF. Kit.] it Fx- 


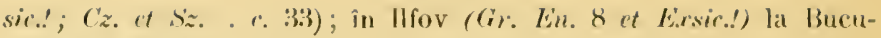
resey ît Cișmegiŭ și la Ferěstrěr ; etc.

IR. Inulbosus $L_{\text {. }}$ allaoge : în Moldova (Edel I. c. 10; D. Br. Frumm. l. c.76; Sz. monusc.); la Sinaia și între Pitescr. Cânupulung

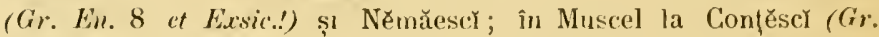
Exsie.!); în Mehedinţr la Vîrciorova către Porţile-de-fer! (Borl. 1873, Brins. 375).

1R. surdous Crentz. adaoge : în Moldova (R. Philonotis Ehrh. Cz. et Sz. l. r. 33) centrală (Guebh. menusc.; V.t sec. Kunitz l. c. 4); în Ilfov (R. Philonotis Gr. En. 8 et Exsic.!) la Bucurestr; în Muscel la Conţěsc'Y ; în districtul Rîmmicu-sărat la Caiata ; în districtul Rîunicu-Vîlẹ̀ la Bălcescy.

3. meditervaneus Griseb.; Ir. mediterranews Steff. - $\mathrm{Pe}$ lîngă Bucuresč la Ferěstrě̆̌ ; la Vîrciorova către Porṭile-defer (Borb. scr. Fanitz l. c. 171).

18. arvensia $L$. adaoge : în Moldova (Edel l. r. 40; Cz. et Szz. l. c. $33 ;$; D. Br. Fragm. l. r. $76 ;$;z. mumuse.); pe lîngă Bucurescĭ la Ferěstrěŭ.

În loc de : R. nodiflorus $L$. pune:

R. lateriflorus DC.; R. nodiflorus $W^{T}$. Kit. /non L.J; L. morliflorns $\beta$. orientalis V́cilr. IR. Latrriflor. - Prin bălḷĭ și locurr inundate nscate. - Pe lîngă Bucurescè lia Chilila (I'. nodiflorus Wr. Kit. [non L./ I). Br. Fragm. l. c. 76). - $\odot$ Maiй.

0bs. - Se mar citéză : R. rutarfolius $L$. în Molelova (Cz. et Sz 3:3).

R. Orthoceras (DC.) D. Br. adaloge : vulg. Ploşnicariŭ, Cornişor. - (I). Br. Fraym. l. c. 77); în tótă Holılova (Cerutocephalues orthourews I)C. Guebh. manuse.; R. fialeatus Edel l. c. 40 [non L.]

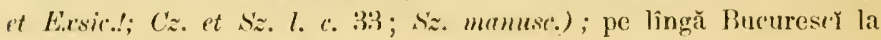
Cotrocenř, la Turnu-Măgurele și la Flămînula $(G r$. En. 8); pe lîngă Craiova la Burovăț pe malul Jiulur.

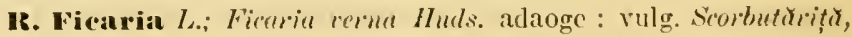

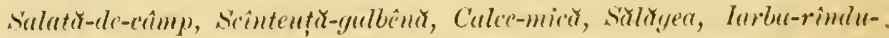

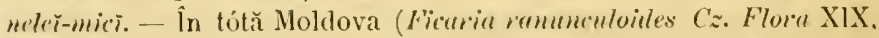
66 et Exsic..'; Edel l. c. 40; Guebh. munuse; Ca. et sz. 1. c. 333;

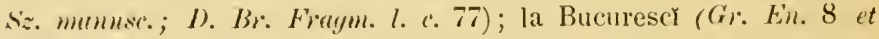
Exsic..!) în Cisnnegiŭ și la Bănésa; pe lîngă Craiova în Luncă; în Gorjin̆ la Roșia pe malul Tismaney. 


\section{Patg. 2'. Myosumis fill.}

M. minimus l, adaoge : prio mlaṣtinile din Molelova inferiỏrit

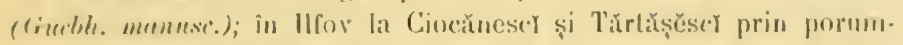

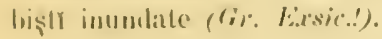

\section{Pag. 25. Anemone Ilall.}

\section{Suprimă pe: A. vernalis $L$.}

A. Pulsatilla L. alloge: (D. lir. liamm. I. c. 76i); pe colinele

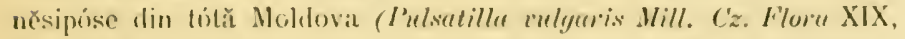

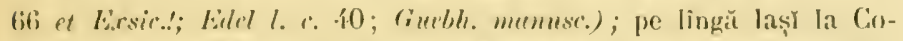

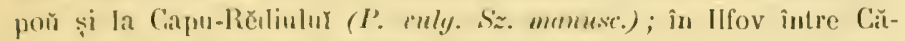
lărași și Oltenila (Cr. lin. 7 et Lissir.!).

A. pratensis l. alangre : vulg. Sisinet. - În Molılova (I'nlsu-

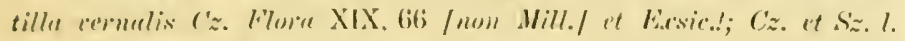

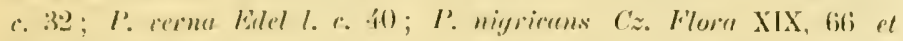

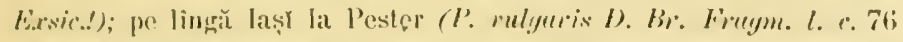

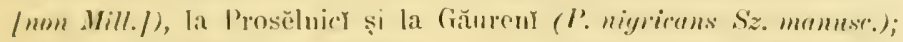
la l'loescy (Junker sec. Lunnitz I. c. 169); în Ilfov la Ulmenr (i).

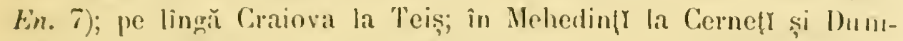

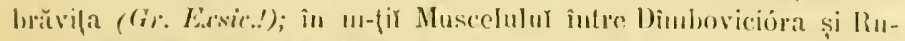

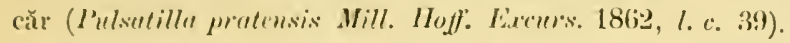

A. Mpina L. adaoge : în m-fir Molelover (l'ulsetilla alpina lovis.

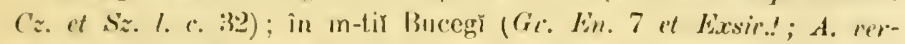
malis (ir. Lin. T luon L.7; I'. alpina A. כ1).

A. Nylvestris L. alange : în tólă Moldova (Cz. Flora XIX, (66)

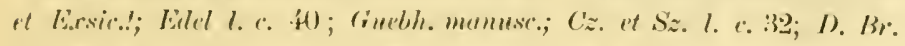

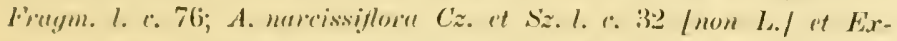

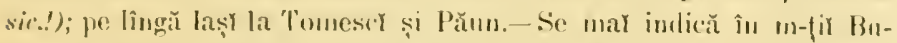
regl (Gr). Én 7), dar în acéstă localitate este sigur cĕ nu cresce.

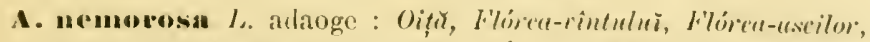

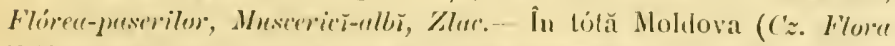

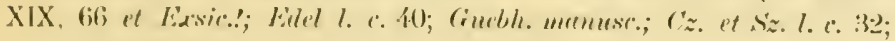

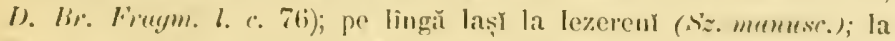

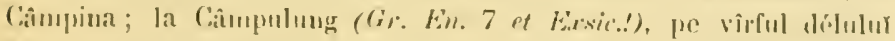

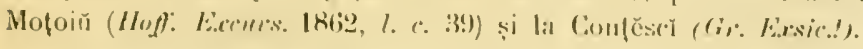

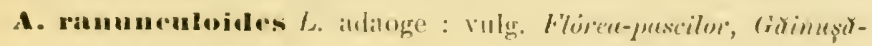




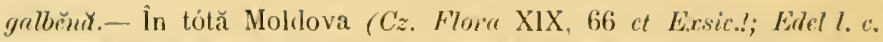

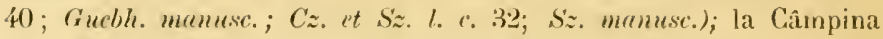

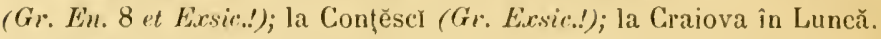

A. narcissiflora $L$. adaoge : în m-ţiy BucegY la Pîrăul-Babelor; în m-tir de la Predél.

A. Hepatica $L$. allaoge : vulg. Föie-tle-vión̆, Popilnic-iepurese.În Moldova (Hepatica nobilis Rchl. Eitel l. c. 40) superióră (Guebh. manusc.); cătră Botoșañ (H. nobilis Cz. et Sz. I. c. 32); pe lîngă Iași la Cerbulésă, Hadînb și Țubana (II. nobilis Sz. munusc.); la 112-stirea Agapia $(G)$. En. 8 ct Exsic..'); în Bacăŭ la Verșěscl și la Caraclăŭ în pădurea Veveriţa; în Vîlcea pe valea Bistriţel (Gr. Exxsic.!').

A. Augulosa Lam. adaoge - vulg. Crucett-voiniculur.-(Hepaticu transsileanica Fuss D. Br. Fraym. l. c. 76); în pădurile de la pólele munţilor (H. trilobu species Guebharl! sehed. in herb. Mus. P'alat. Vindob. [1844] see. Kotschy l. c. 67; H. multiloba Gucbh. sched. l. c.) la n-stirea Scînteia (11. multilobn Gucbh. Not. mauusc.); în distr. Bacăŭ la Verșĕscr; la Dîmbovicióra și Sinaia (Gr. En. 8); la Predél pe in-tele Susaiŭ; în Muscel la Conţěscr.

A. doutummalis (L.) D. Br: adaoge : în Moldova (Adonis autumnalis L. Cz. Hlora XIX, 66 et Exsic.!; h. j. Guebh. manusc.; Cz. et Sz. l. c. $33 ;$ Sz. manusc.).

A. aestivalis (L.) D. Br, adaoge : vulg. Iarba-cocoșului, Cocoseřde-crump. - În tótă Moldova (Adonis astivalis L. Cz. H'loru XIX, 66 et Exsic.!; Léo. in Demil. Voy. Il, 20ذ; Eilel l. c. 40; Guebh. munusc.; Cz. ct Sz. l. c. 33 ; Sz. munusc.); Ia Bărboșr, pe lîngă Bucurescr la Ferĕstrĕŭ (Allonis astivalis Gr. En. 8 et Exsic.!), Periş şi Mogoșóia (Allonis Alummea D. Br. Fragm. I. e. 76 [non Jucq.]).

A. Ilammea (Jacq.) D. Br: adaoge: in Moldova (Allonis flammeu Jucq. Cz. Flora XIX, 66 et Exsic.!; Cz. et Sz. 1. c. 33) inferióră (Guebh. manusc.); pe lîngă lași la Chiperesel și GoronI (Adonis flummen Sz. manusc.); la Ferěstrěŭ (Gr: En. 8?).

A. Adonis (L.) D. Br: adaoge : vulg. Spît.--în tóta Moldova (Adonis cermulis L. Cz. Flor'a XIX, 66 et Fxsic.!; Guebh. manusc.; Eilel l. c. 40; Cz. et Sz. I. C. 333 ; Sz. monuse; D. Br. Frugm. I. a. 76); în districtul Bacăŭ la Moşia-Ocneĭ pe délul Straja; între Călărașy și Olteniţa către Móra-săracă și UlnenI (Adonis rernulis Gr. Fin. 8 et Evisic.').

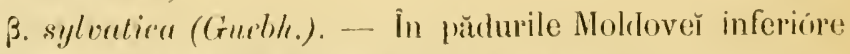
(Adomis vernalis B. sylvatira (ruebh. mamese.). 
A. Wolenensis (stre.). D. Br. A. de Wralga. - Prin

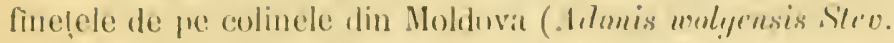

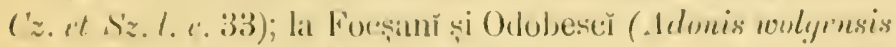
Sz. munusc.). - 2) Mиій-Iипій.

\section{Pag. 32-33. Clematis loc.}

C. recelu L. adaoge : Nuprassnic. - In tótă Moldova (D). Br.

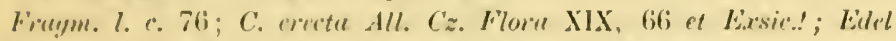
l. a. 30; (iucbh. munusc.; (zz. et sz. 1. e. 32; Sz. manusc.).

C. integrifolia I. adaoge : vulg. Clocotěr. - In Moldova (Cz.

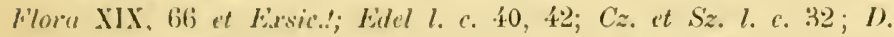
131. Fragm. I. c. 7(i); pe lingă IașY la Şorogary în Via-Burada (Burri lixsir..!) și la Balcin în Via-Vî̀nav (S'z. manusc.).

C. Vitulba $L$. allagge : în tótă Molelova (C'z. Flora XIX, 66 et Exsico! ; Eilel 1. c. 40. 42 ; Cz. et Sz. l. c. 32; Guebh. m(nusc.) și Romănia (D. Br. Frugm. 1. c. 76; Gr. En. 7 et Exsic.!).

P. integrata D: - In Moldova centrală (Gucble. manusc.).

C. odontophylla Gandoger C. odontofilă. - Lat Virciolova către Porḷile-de-fer (Simk. 516).

? C. Flammula $L$. adaoge : in Moldova (Edel l.c. 40, 42; Cz. at sz. l. c. 32) voulgar (Sz. memusc.).

(1)s. - C. Viticella L. cultivată pe lingă Bacăŭ la Fiantânele în grădina Winkelstein (Gr. Lin. 7).

C. alpiua Mill. adaoge : vulg. Nuprasnic, Curpeniţy. - Pe Cé-

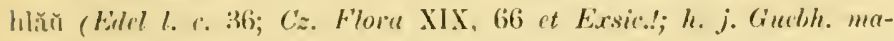
nusr.); în m-fir Bucegi la schiturl Pescera Ialomiţer.

\section{Pag. 34-36. THALICTRIM T.}

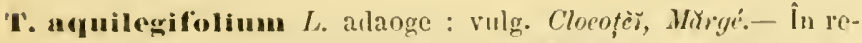

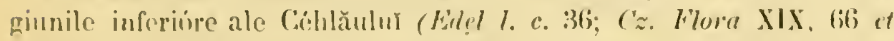

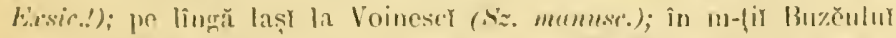

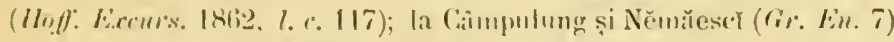

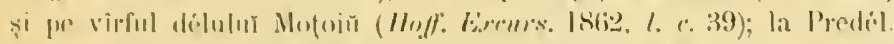

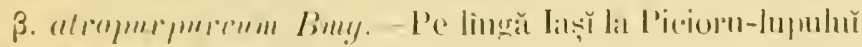
(\$̃. mamuse.). 
1. nireum (Bmg.). - La Horlescĩ, Hoisěscy și Domnescy (Sz. manusc.); in m-tir Musceluluy (D). Br. Fraym. I. c. 76).

T. flexuosum Bernh.; T. collinum Walle. T. Acxuos.Prin fînę̣e. - La Pechea (T. saxulile Schleich. Gucbh. mauusc.); în distr. Bacăŭ la Caraclǔŭ pe Babaghicea și căire pădurea Veverį̣a in disłr. Buzĕŭ la Becenı̆ ( $T$ '. collimus Gr. En. 7 et Exsic.!). - If Inniй-Iuliu.

T. majus (Murr.) Jutq. arlaoge : vulg. Rutð̆-te-livedi.- (D. Br. Frogm. l. c. 76); în Moldova (Cz. Fłora XIX. 66 et Exisic..'); pe lîngă lașY către Șĕpte-ómenY și Rĕdiŭ-Alder̆ (Sz. manusc.); la Ciocănescì, GherganY şi Buftea (Gr. En. 7).

T. elatum $M u r$ adaoge : prin fînețe la Tăutescr, lepurenI și Zahorna (Sz. manusc.).

T. medium Mur: adaoge : (C'z. Floru XIX. 6ff et Exssic?); pe lingă laş̣ la Cipelescr. Zahorna. Văiluța și lepurenĭ (Sz. mamusc.); în Bucurescr in Isvor (Gr. Em. 7 ?).

'T. angustifoliun Jarq. arlaoge : în Moldova (Cz. Flor XIX,

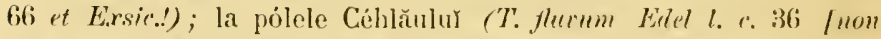

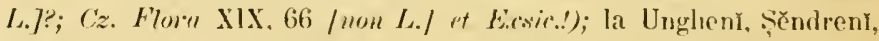
Soloneți și Bivolary (Sz. munusc.); la m-stirea Némụulur; la Palanca

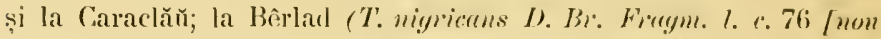
Jacq.7) ; în m-ţir Buzěulư pe valea Bîscel și a Gura-Miler; la Buftea, Chitila, Ciocănesec (D. Lr. Fimym. 1. e. 76) și Titu (G). Lin. 7 et Exsic..'); în Vlașca la Comana ; în Dînboviţa între Puciósa și Moroeñ ; în Vîlcea la Bălcescr.

T. nigricans Jacq. T'. negricios. - Prin finete umede. - Pe lingă Iași la Tomesci și Goron (Siz. mauusc.?); la Vîrciorova (Borlb. sec. Kamitz l. c. 170).-O) Jum.-Auy.

T. flavum $L$. adaoge : pe lîngă lașĩ la Glodósa, Neleda, șanța, şi pe malul Stavniculuí (Sz. manuse.); la Nĕmăescy (Gr. Lì. 7).

\section{Pag. 36-37. Actaea I.}

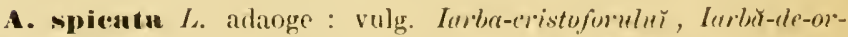

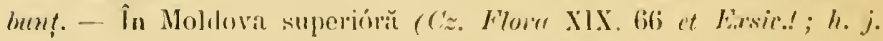

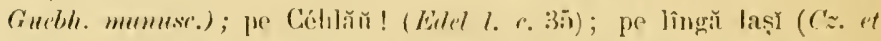
Sz. 1. c. 29!) la Repectea în Via-Veisa (šz. mumusce) și la Botoṣañ

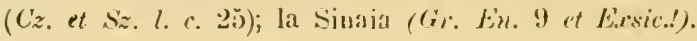




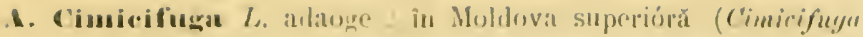

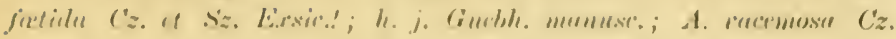

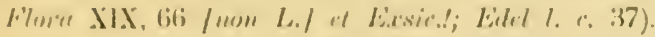

\section{P'in. 38. P'atonia 'T'.}

12. romanicu /). liv. aldagne : în Moldova rentrală si inferiór

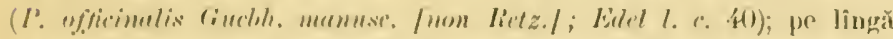
Terenciñ dincolos de Pechea în drumul Gala(ulur in mave mulţime,

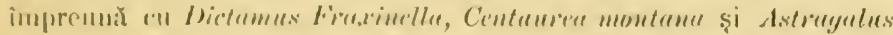

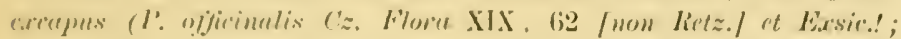

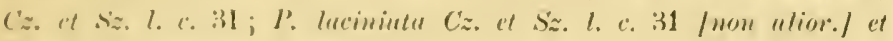
kirviro!; Sz. munuse.).

Ohs. - P. oflicinalis Retz. vulg. Bujor, Bușor, Rușiơror, linjox-dleinscrlit, nu cresce de câl cultivată prin grădinY! (Sz. manusc.).

\section{Pag. 40-43. Rosa T.}

18. Iutea Nill. ałaoge : în Moldova (Cz. ct Sz, l, t. 28; Sz. munuse.) inferióră (Nym. Consp). 237; R. sulphumer Guelsh. mamuse.

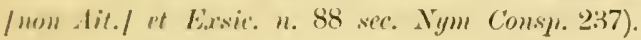

IR. pimpinellifolia L. adaoge : în Moldova (Cz. et Sz. l. c. 28) şi Romauia (Gr. En. 2:3?).

12. spinosissinu $J$, arlagge : în Moldova (Cz. et Sz. I. c. 28). Suprină pe: IR. alpiua $L$.

It. pyrenaica Goun. adaoge : pe Céhlăŭ (R. alpina Lidel l. c. 35 [non l..] et E.xsic.!); în m-(ir de la P'redél.

18. rubiginosa $L$. adaoge : în Moldova (Cz. Florel $\mathrm{XIX}, 6$ ) ot

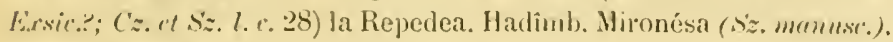

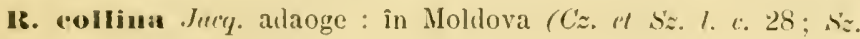
mururesc.).

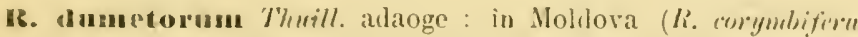

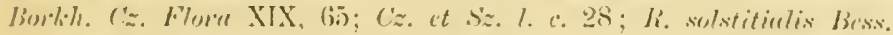

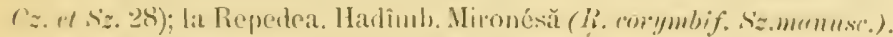

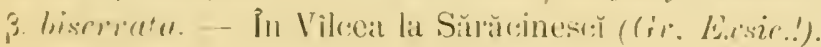

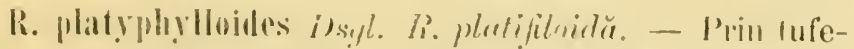

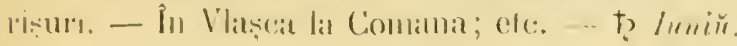


R. canina $L$. adaoge : in tótă Romănia $(C z$. Florre XIX, 65 et

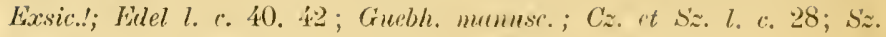
manuss.; $(F)$. En. 2:3).

P. biserrata (Mrroal). - Pe lîngă Bucurescĭ la Periș (Gr. Elsir.!).

12. prumila $L$. fil. adaoge : în Moldova ( $C z$. Flor"u XIX. 65 et Exsic.'; Etel I. c. 40, 42; Cz. et sz. 1. c. 28) inferioră (Guebll. Exsic. n. 89 sec. Nym. Conspl. 231; R. pyymae Guelsh. manuse. Fum M. Bieb.]); pe lîngă laşı călre Prosĕlnicy (Sz. mumusc.); în Ilfov. Vlașca și Melredinţi (R. gallica Gr. En. 23 [non L.] et lixssir:?); în Vîlcea la Bălcescr.

18. nrvensis Hulls. adaoge : în tótă Moldova (Filel l. c. 40, 42; Guebh. mantsc.; Cz. et Sz. l. c. 28; Sz. manusc.; R. repens Bmy. Cz. et Sz. I. c. 28 ; Sz. munusc.).

Obs. I. - Se nal citéză : R. ponifera Herm. în Moldova (R. rillosa Wrulf. Cz, et Sz. l. c. 28). - li. incarnita în Moldova (Cz. Flora XIX, 65)?

0lss. 2. - Se cultivă prin grădiñ speciile mmătóre : R. ąilliła $L$. (Cz. et Sz. l. c. 28). - R. galliea L. rar. officinalis (Guebl. manusc.). - R. centifolia L. (Cz. Flor U XIX. 65 et Eixsic.!; Gr. En. 23) vulg. Trondufir. - R. damascenta L. (Cz. Florel XIX. 65; Cz. at Sz. l. c. 28; Gr. En. 23) vnlg. Tramlafir-ele-lumir. - R. allbit L. (Cz. Floru X1X, 65; Cz. et Sz. I. c. 28; Gr. En. 23) vulg. Trandufir-all). - R. sempeiflorens Cont. (Cz. et Sz. 1. r. 28). - R. pendulinil Ait. (Cz. et Sz. l. r. 28) - R. cinnsmomea .. (C'z. et Sz. l. c. 28).

\section{Pag. 44. Agrimonia 'ì'.}

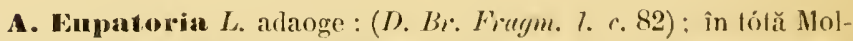

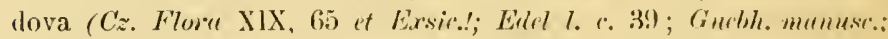

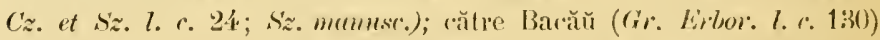

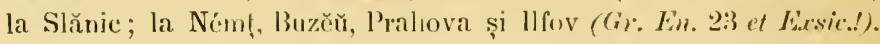

A. agrimonoides L.; Aremeniu aypimmurdes Necti. A. agrimomoidă. - P'rin pădurile din regiunea monlană. - Î Moldova (Cz. et s'z. l. c. 24); in Muscel la Con!ĕsco intro valea Rincăeiovu si vallea Bencat spre Apa-de-léc (cir. Exsic!!). If I priliŭ-Maiü.

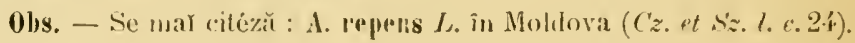




\section{Yag. 45. Alelemillat 'T.}

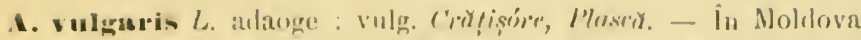

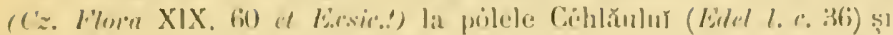

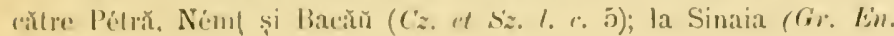
2.3 it lin:ir:.').

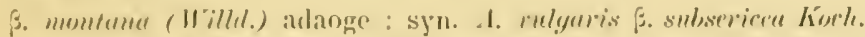

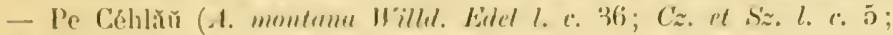

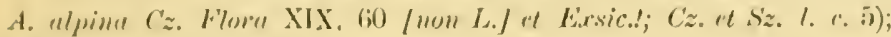
la Sinaia și la Predét.

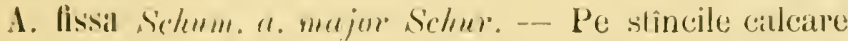
dỉn m-liı̆ Buceğ de-asupma schilulŭ Pescera de la lalomila

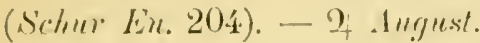

OHs. - Se may citéză : A. puhexeens M. Bieb. in m-ţir Bucegr (A. 50). - A. Aphanes Leers. in Moldova (Cz. et Sz. l. c. 5).

\section{Pag. 45. Salumisorba $\mathrm{I}_{4}$.}

s. ofticinalis $L$. adaoge : in m-tir Moldover (Lilel l. e. 337 et Lissic..; h.j. Guebh. memusc.; Cz. et s'z. l. c. 5); la Răducănent și la Gura-Bohotinulur̃ (Sz. mumust.) ; între Pitescr și Curtea-de-Argeș lat Merișant (Gi: E.rsic..!).

Suprină pe : s. Poterium II. Bu. împreună cu crar. rillusa.

În loc de: s. polygama $I I$. Bn. pune:

S. Imurieata (Spach.); P'uterium muricatum Spach. S. muricalü. - Vulg. Cohare. Bibrenil. - Pe coline și caimjurı̌ ierbóse. - In Moldova (1'. Samyuisorba Cz. Flura

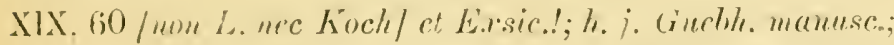
\$ะ. menusc.) inferioră ( $L^{\prime}$. villosum (ruebh. manusc. Luom

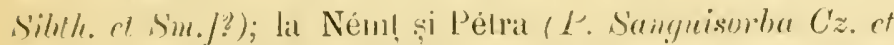

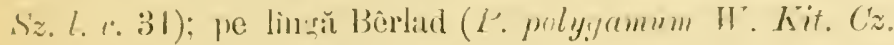

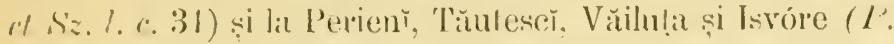

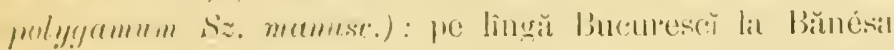

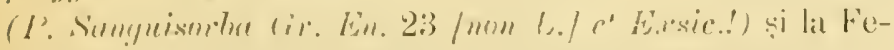

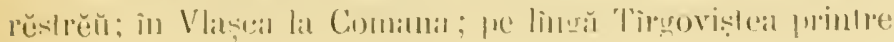




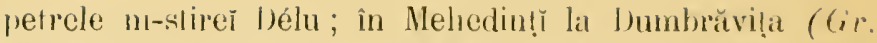
Exsic.!) ; elc. - 2) Inиiü-Luliŭ.

\section{Pag. 47. Fragaria 'p'.}

W. vescea L. arlaoge : vulg. Pomniţa. - În tótă Romănia (Cz.

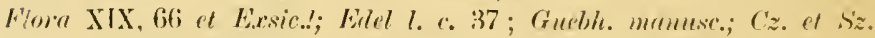
l. (. 29) ; sz. mamusc.; D. Br. Fram. I. (. 82 ; Gr. Fin. 2:3).

F. ohtior Ehrh. F. inaltă. - Prin pădurile din regiunea montană. - In Muscel la Conḷĕscì (Gr. Is.xsic.!). If smiliй-мaiй.

W. collinase Eh\%h. adlaoge : în Mnldova (C'z. Flor XIX, 66 et Exsic.!' Edel l. c. 37 ; Cz. et Sz. l. c. 29 ; Sz. momuse.) inferióră (Guebh. manusc.) și în munți (Edel l. c. 37); pe lîngă Bucurescr la Bănésa $(G r . E n .23)$; în Argeş la Stolnicy (I). Pr. Frorgm. l. c. 82).

\section{Pag. 48. Potentilla T.}

În loc de : P. Fragariastrum Ehoh. pune :

P. micrantha Ram. P. micrantă. - Prin Iulêrişurile de

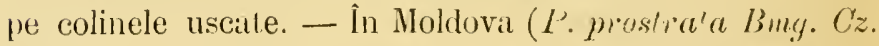
c: Sz. l. c. 29); la m-stirea Scinteia (1'. H'ayariastrum (inebl. manusc. [non L.J); la A giud (Burri Lesesic.!); li

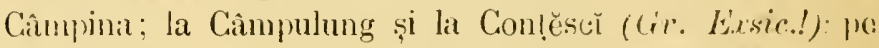
lînğĭ Ciraiova la Bucovă!-Cầrligê̌. - 4 Iprilin̆-Main.

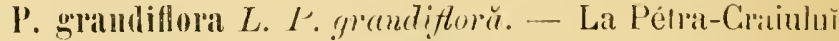
pe Vîrfu-Baciuluı̆ (Kotschy 65).

P. nitidn $L$. adlange : in Moldova (Cz. et sz. Exsic.!).

P. alba $L$. adaoge : în Moldora (Cz. et Sz. I. r. 29 et E.xsir.!) pe marginea pădurilor la Șẹpte-Ómenî în mulţime (Š. manuse.); la Cî̀upina (Gr. En. 22 et Exisic.!), Buftea și Ciocănesc'T.

13. rupestris L. adaoge : (Iloff. Exrsic..'); în Moldova (Cz. ot S'z. $l$. c. $2 y)$.

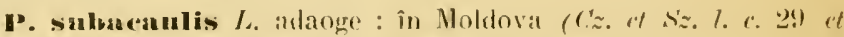

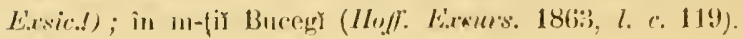




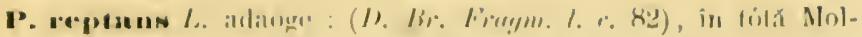

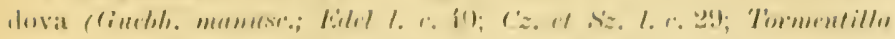

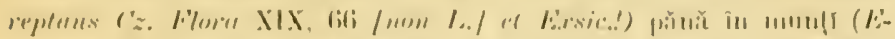

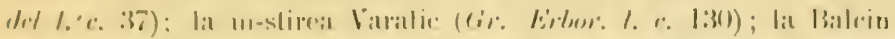

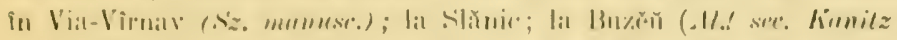

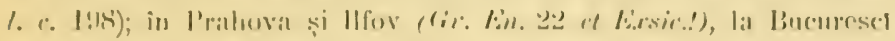

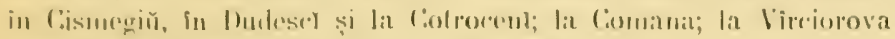

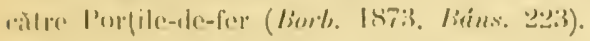

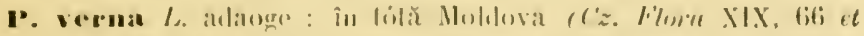

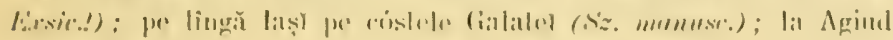
(limil liosir..?).

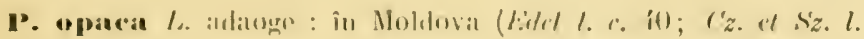

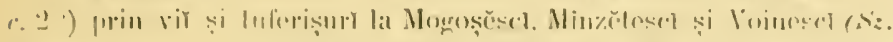

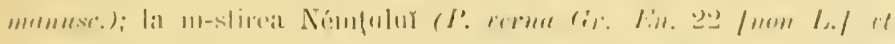

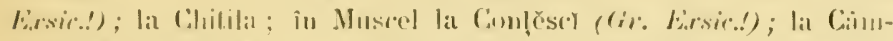

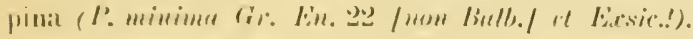

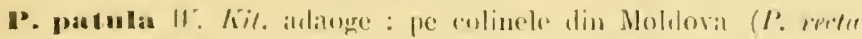

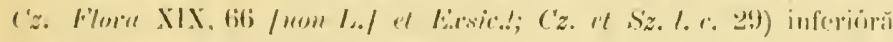

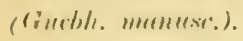

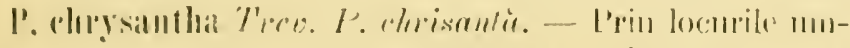

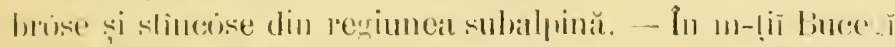

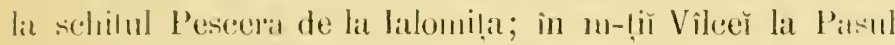

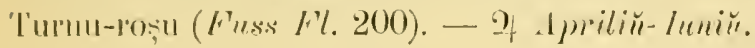

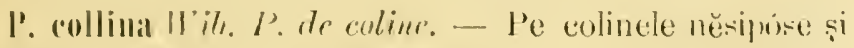
uscalle. - Lat Ariud (Burri Esasic.!). - -) Inniü-Lulin.

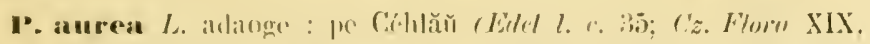

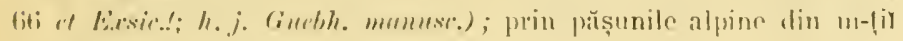
Burcent (Fr. Ii).

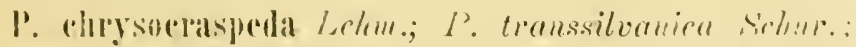

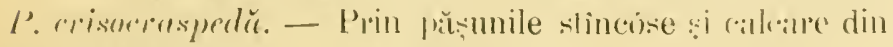

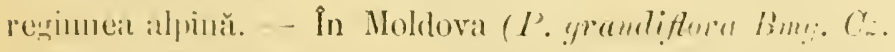

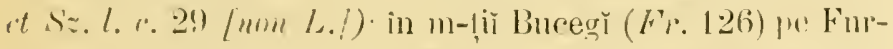

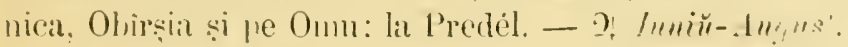

P. alpestris Hall. fil. $P$ alpestrü. - Prin păṣunile slincóse din regiunea subalpină î aljünă. - In m-ḷî̀ Bucer (1). sulisburgensis IIarulie FY. 126), re Virlu-cu-l)oru (1: 


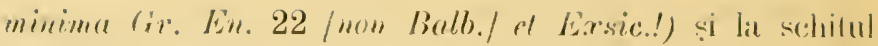
P'escera de la Ialomila. - 2 Immiñ-Inliŭ.

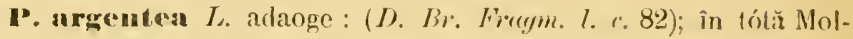

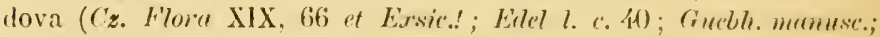

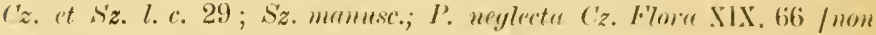

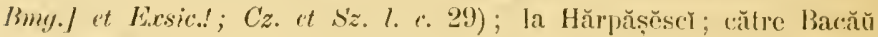
(Gr. Evbor. 1. c. 131); la Făurer, Buyĕŭ și Brăila (Al.! sec. Kunitz l. '. 198); la Câmpina. Vălenr. Ciocanescr. Bucurescr (Gr. En. 22 et Exxic.!) și Ferĕstrěŭ ; în Vîlcea la tninósa; între Gura-Văiel și Vîrciorova; etc.

P. canescens Bess.: P. inclinata Vill. - I. ianescrulă. - Pe coline aride și uscate. -- In Moldova ( 1 '. hivta $C z$. FFlora XIX, 66 [non L.] et Exsic.!; Cz. ot Sz. l. c. 29); la Galaṭ̆ (Uecletr. et Sint. sec. Kanitz l. c. 198) și Iașĭ (V.! sec. Kanitz l. c. 198). - 2 Maiü-Iuliŭ.

P. rectsn L. adaoge : vulg. Bumiumă-de-cincĭ-deyete. - (D. Br. Fraym. l. c. 82); în Moldova (Edel I. c. 40 ; Sz. mumusc,; P. intermerlia Cz. Flora XIX, 66 et Exsic.t; Edel l. e. 37; Cz. it sz. l. c. 29); prin viile de la Nicorescr (Guebh. manuse.); la Hărpășěscř; la Caraclăŭ ; la Făurel. Buzěŭ și Brăila (11.! sec. f́ruitz l. c. 198); la Ghergany ( $I^{\prime}$. canescens Gr. En. 22 [non Biess.] et Exsic.') și Titu (Gr. Exsir. sef. Kunitz l. «. 198); la Sinaia și Bucurescí (Gr. Eu. 22 et Exsic.!); la Comana; pe lîngă Craiova la Lémna : în Vîlcea la Bălcescí.

3. obscura; P. obscura Hilld. - In Moldova ( $P$. pillosa Cz. Flora XIX, 66 el Exsic.!; Cz. et Sz. l. c. 29; Sz. mamusc.); în Prahova si Ilfov ( $I$. villosa G'. En. 22 st Ex'sic.!: P. hirta (íc. En. 22 / non L.7?); în districtul Mehedinṭ̂ la Iorgulova și Dumbrăvila (Gr. Fassic.!) și între Vîrciorova $\therefore$ Bahna; efc.

D. Supinat $L$, adaoge : în Moldova (Cz. Flovre XIX, 66 et Ex-

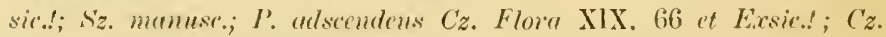
't . Sz. l. c. 29); la $\Lambda$ giud (Burri Exsic..'); în Bucurescr la Gara Tîrgoviștea $(G r$. E.r.sic.!).

1P. Inserina $L$, adaoge : vulg. Cóulu-raculur. - În Noldova (Cz.

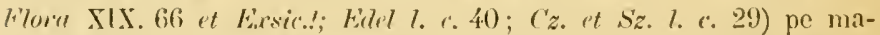
lurile Seretulur (Gubb. mumusc.) și pe malul Prutulur (sz. manusc.); la Slănic; la Sinaia și Câmpulung $(G r$. En. 22 et Exsic..!); etc. 


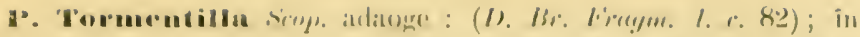

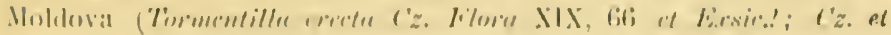

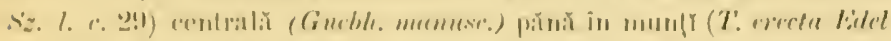

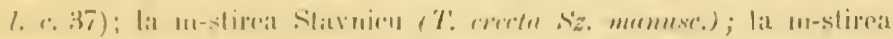

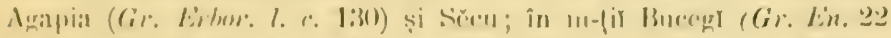

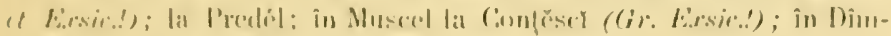

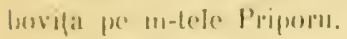

1. procenubens siblh. suprimă. Moldova ('zill. I. c.).

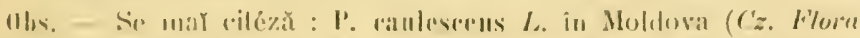

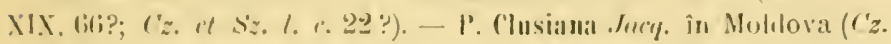

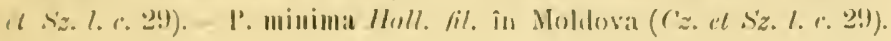

\section{L'itg. 53. Riulus !.}

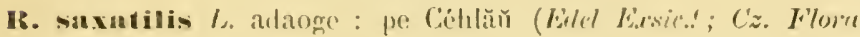

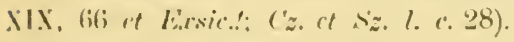

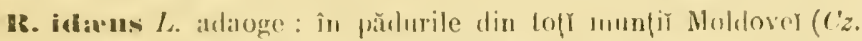

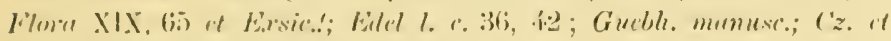

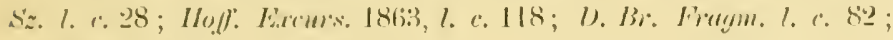
Gr. Livbor. l. a 130 it En. 2:3).

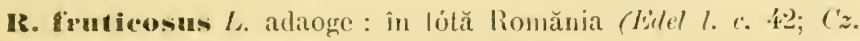

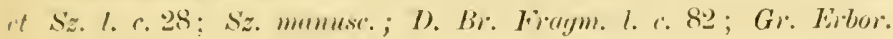
1. c. 130 ; tin. 23 it Liscsic.!).

t. amoenns l'ovenschl. Moluhy in Barh. 1873, Bims. 287. - La Vîrciorova către Porțile-de-fer (Burlh. 1873, Biins. 287).

R. tomentosus Borkh. R. tomentes. - Prin pridurile munlise. pe colinele cilleare și sterile. - In Molilovil ( $\left({ }^{2}\right.$.

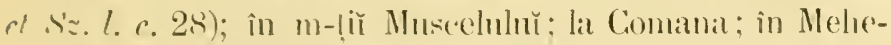

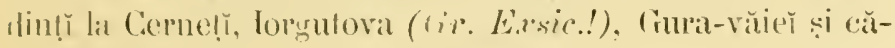
Ire Porlile-de-fer; ete. - t? Immin.

R. candicans Wrihe. R. albicios. - P'rin pădurile monlane. - La Virciorovi călre Porțile-de-fer. — t? Imiiut.

Suprină p̧e : R. cosglifolius smilh.

12. Mgrestis H: hit. alange: in Moldova (Cz. 't s'z. l. c. 28); la Nironésa (s'z. munusce); pe lingă Bucurescl la Bănésa. 


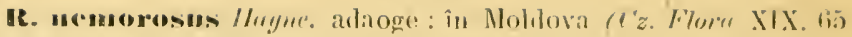

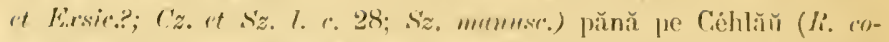

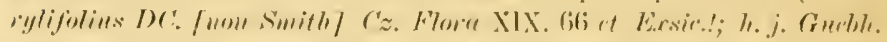

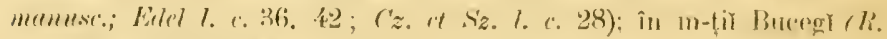

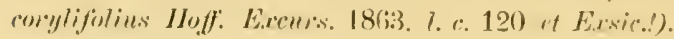

IR. caesius $L$. adaoge : în tótă Moldova (C'z. Flor"l XIX, (ij) rt

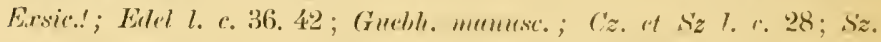
memuse.); la Titu. Ghergant și Ciocăneser ((rr. Lin. 23 rt lixsic..!);

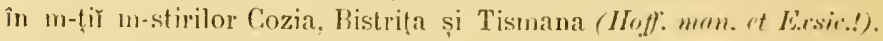

(0lıs. - Se mat citéză : R. olandulosus Brnl. în Molılova ('.z. Flor" XIX. (65) ('z. et Sz. I. (c. 28). - R. hirtus W'. Kit. în Molelova (Cz. H7oru XIX, 65; Cz. et Sz. l. c. 28).

\section{Pag. 5̌4. Geım H. Bı.}

G. urbauum $L$. adaoge : vulg. C'vênceş. - În tótă Moldova (Cz.

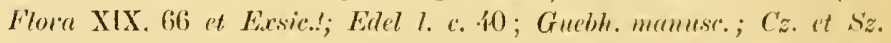
1. c. 29); la Socola în Via-Mavrodi ( $S z$. memuse.); pe lîngă Bêrlad la Slobod̦ia, pe lîngă Bucurescy (Gr. Èı. 22 "t Exisic.!) la Bănésa (I). 13r. Irougm. I. c. 82) și în Dudeser̃ ; la Comana; la Câupulung și la Conţęser (Gr. E.rsic..'); etc.

În loc de : G. Internuedium Ehrh. pune:

G. aleppicum .Jacq.: G. strictum Ait. G. alepic. Prin pădurile umbróse din regiunea montană şi mrin pășunile unede din regiunea subalpină. - In Moldova superióră (G. intermedium Bess. Luon aliox.) Guchh. manusc. et Exsic. 11. 71 /nom. G. urbani] sec. Yym. Consp. 230; Cz. rt. Sz. l. c. 29); pe lìnğ Iaș̆ la Țubana și Poiana-rle-sus ( $G$. intermedium Sz. manusc.): la pólele Céhlăulū! (G'. intermedium Ëlel l. c. 36); inlre T'îrogu-Ocnĕ̌ și Slănic (C). incrmedium Guebl. Sot. manusc.); în m-tî̆ Buzĕuluĭ pe virful Penteleuluĭ. — †? Imиiй-Inliй.

(x. rivale $L$, adaoge : in regiunile inferióre ale Céhlăulur (Etlel -

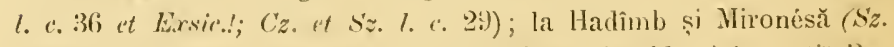
mounsc.); la u-stirea Sécu. la Sinaia $(G r$. Kn. 22:) și în m-ţir Bucegì (F). 126); în แ1-țiy de la Predél.

G. montanum $L$. arlagge : prin pășunile din m-ţir Buceğ (sie- 


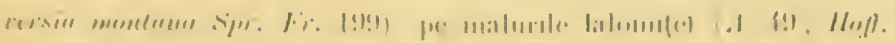

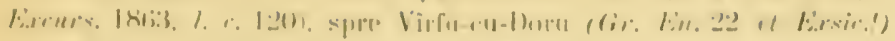

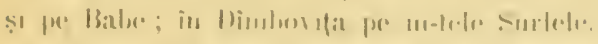

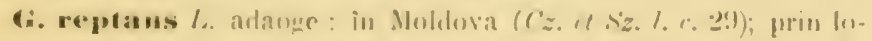

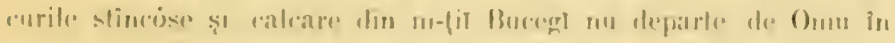

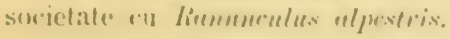

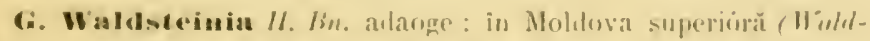

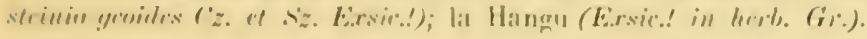

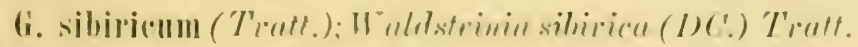

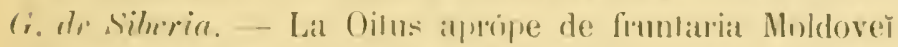

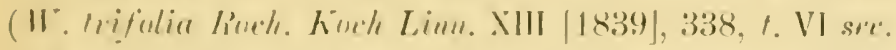
schur. En. 184, Hanlatu pharm. Hornung delexil): pe m-tele Keresolheg! al)ripe de Remela călre Moldoval (II. silvirice Jumlin Linn. XXX [1858]567).

\section{Pag. 56. Dryats L.}

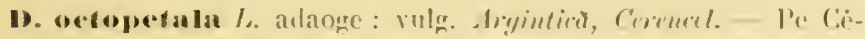

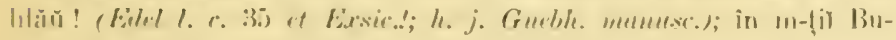

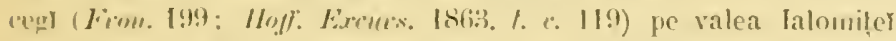
(Fi: I:(i). pe Vîrfu-cu-Doru, la schitul Pescera lalomițel, la l'îrăulBabeler și pe vîful Omulut.

\section{Pag. 57. Spiriea T.}

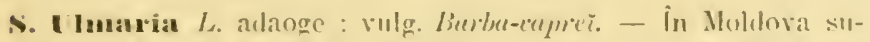

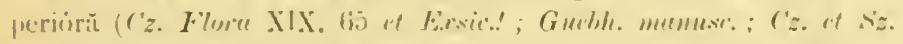

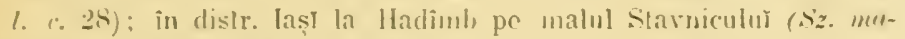

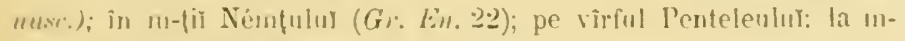
- tirua Cheia (Ihoft. Lixenis. 18633. 1. c. 118).

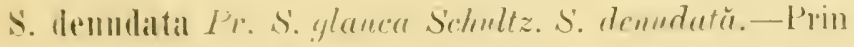
phă:mnile mmede din reoiunea suhalpină. - La Sinatia sple

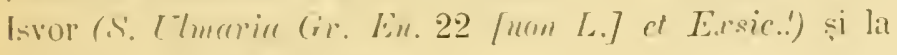
Predél. - ) Imnin-Inliü.

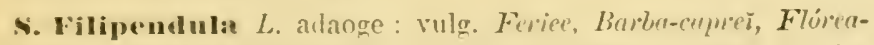

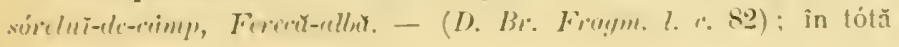




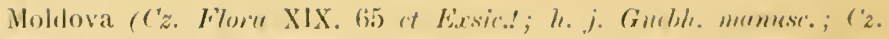

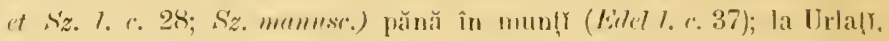

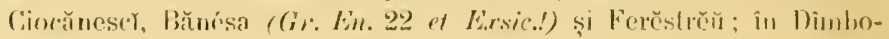
vița între Sturdienĭ și Cetățeñ̆.

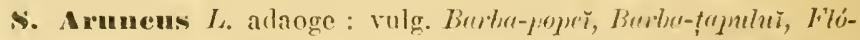

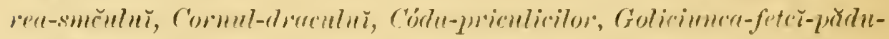

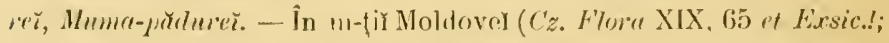
C'z. ot s'z. l. '. 28); la Brosenù (Buri Édsic..!); la in-stirea Ném-

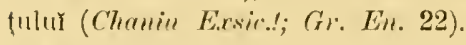

s. ulnifolia Scopl. adaoge : vilg. Caprofoint. - (I). Br. Frargm.

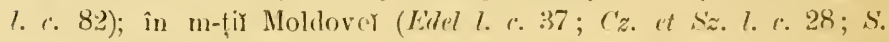

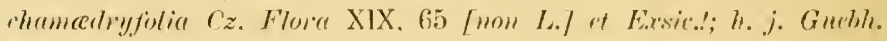
memest.; Edtel l. c. 37. 42; Cz. et Sz. 1. r. 28); în m-ţì̛ Bucegì la schitul Pescera lalomițer ; la Predél.

\section{Suprimă pe : \$. clıasuad ryfollia $L$.}

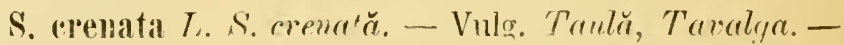
P'rin pădurile de pe colinele muntrse si calcare. - In Moldova (Cz. et Sz. l. c. 28; S. alpina Sz. Exasic.! / um L'all.l: h. i. (zurbh. manusc.); pe lingă Cernoli (S. hyprenicifolia Schm. [nom L.] (ro. En. 22 é Exssic.!) ; pe lingă Gratiova în pădurea Brésfa; - iar eullivită se găsesce în tôte glădinile si parcurile! (s). hypericifolia (ir. En. 22). 一 t? 1 priliĭ-Maiи.

11)s. - Se mă ciléză : \$. quinqnaloba Bmy. în Moldova (cz. ct. Sz. l. c. 28). - S. hypericifolia L. în Moldovia (Cz. rt s'z. l. c. 28).

\section{Pag. (io. Pypus T.}

1. comumunis $L$. adaoge : în tólă Romănia (Guebh. menusce;

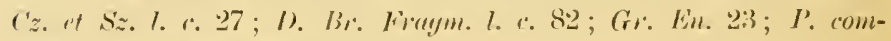

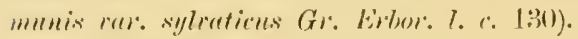

3. domesticu. - Cullivat în maľ multe varietăı̆ (Guchh. mumuse, Edel l. c. 42 ; C'z. ct. sz. l. e. 27 ; Sz. manusc.; (i). Ell. 23).

P. acerba $I C$. arlagge : (Malus syliestris Cz. Flora XIX, 65 et Exsic.?; Edel l.jpe. 42; Guebh. memusr.; Cz. et Sz. I. C. 27; Sz. munusc.; Gr. Fin. 24). 


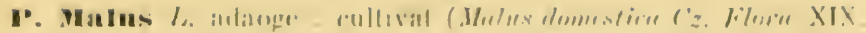

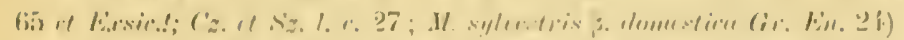

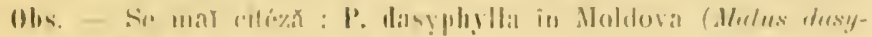

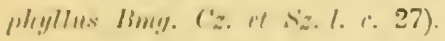

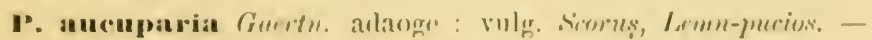

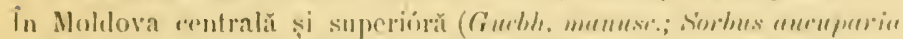

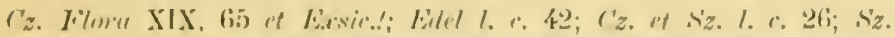

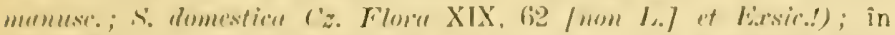

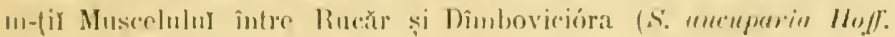

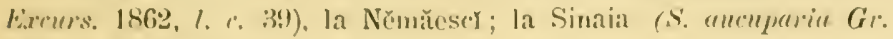

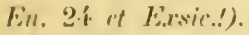

P. Sorbus Guretu, adaoge : vulg. Simms. - Pe colinele viilor.

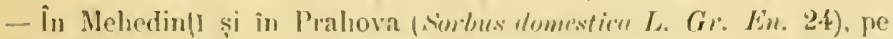
lingră Ploeser prin ville din valea Orler.

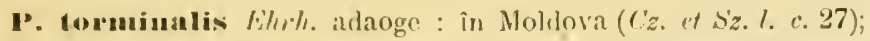

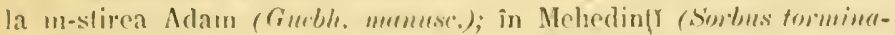

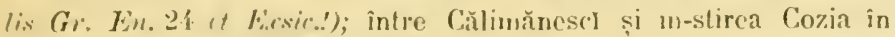

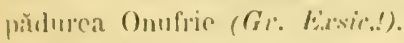

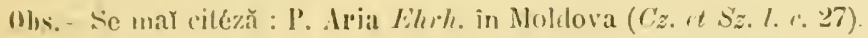

\section{Pag. 63. Cydonia T.}

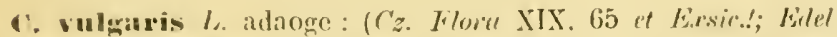

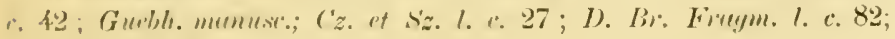

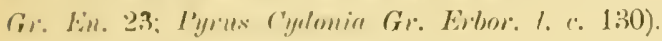

\section{Pag. 64. Crategus T.}

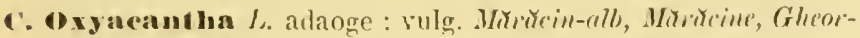

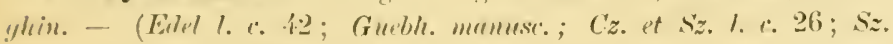
mumus:; D. Br. Frum, 1. r. 82; Gr. Ër. 23).

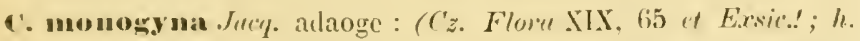

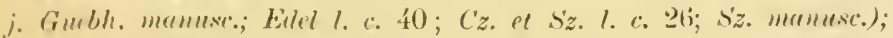
la m-stirea Némţulur pe m-tele Pleșu; pe lîngă Bucurescy la Merinani: la Vîrcinrova (ătue Porţile-de-fer (Bovb. 1876. Beius. 286).

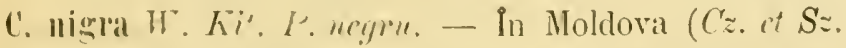
l. ('. 26): in Ilfov la Periṣ (Gr. Frasie.!): în Mehedinḷ (Gr.

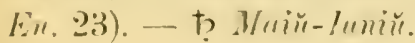




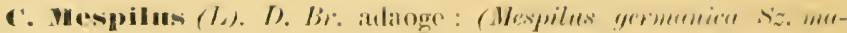

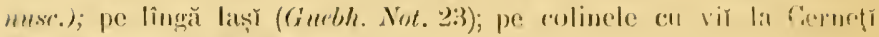
(11. gromention liv. lin 233).

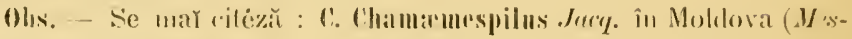
pilus chenecomesprilus r.z. et s'z. I. ('. 27).

\section{Pau. 66. C'otoneaster Hedie.}

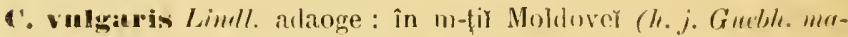

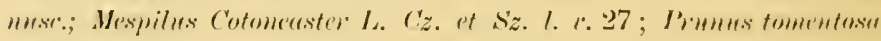

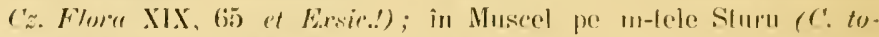

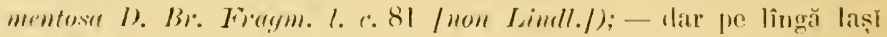
(Gucbh. Not. 2:3) de sigur ("il mu provine.

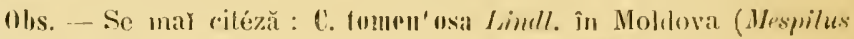
pyymeer bimg. Cz. et sz. l. r. 27) și la Sinaia (1/. tommentuset Hillel.

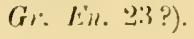

Patg. 66. Amelanchier Medire.

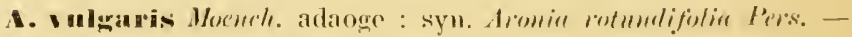

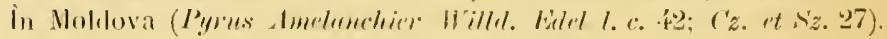

\section{Pag. 67. Prom TIs T.}

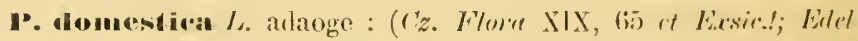

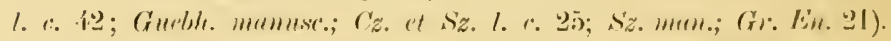

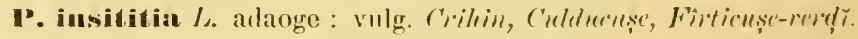
( Liclel 1. c. 他; ('z. ot siz. 1. e. 25).

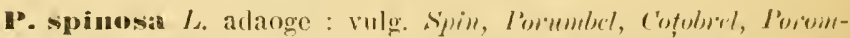

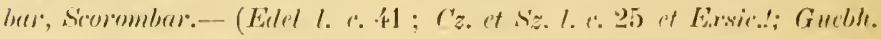
mammst; Sz. mamesc.).

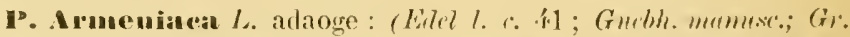

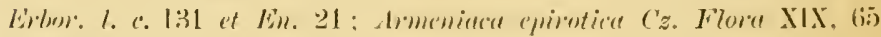
"t linsic.!; (Zz. 1:t Sz. I. (. 25; s'z. mumuse.).

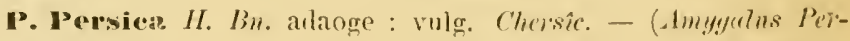

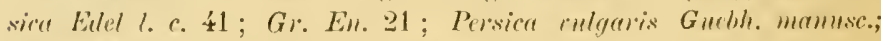
Cz. et s'z. 1. '. 225; Gr. Eibor. 1. (2. 131).

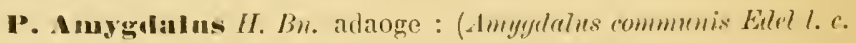
41; Gutbl. mumuse; Cz. et Sz. l. c. 25; Gi. En. 21). 


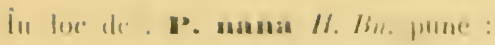

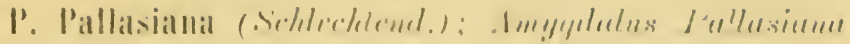

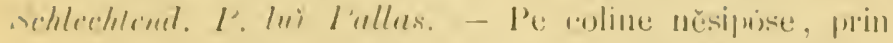

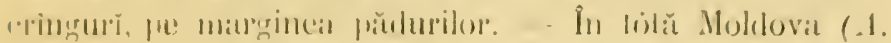

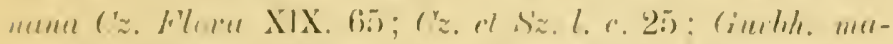

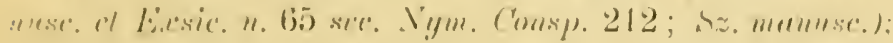

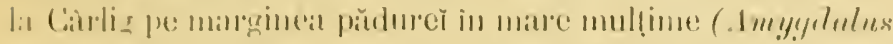

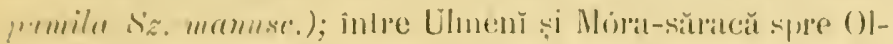

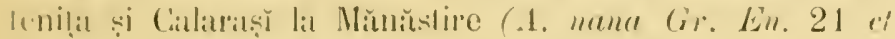
linsir.!). - t? smilin.

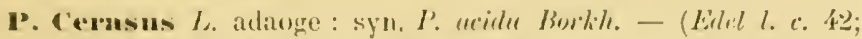

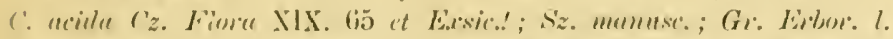

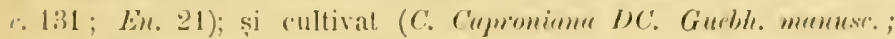

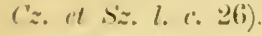

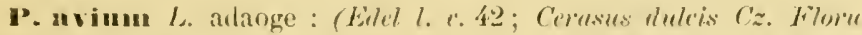

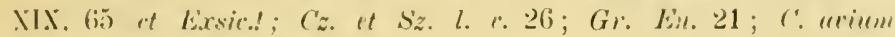
Moneh. Gurbh. mumusc.).

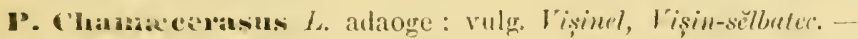

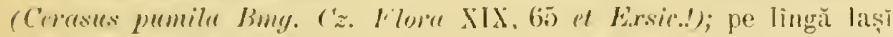

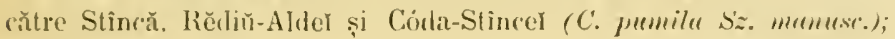
în Vlaṣco la Comana.

I' Mubaleb L. alaoge : vulg. Trisin-turecsc. - La Vî̀ciorova

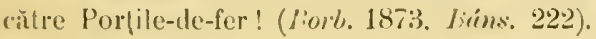

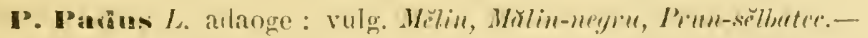

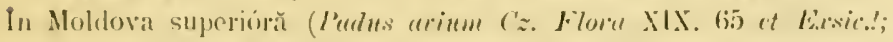

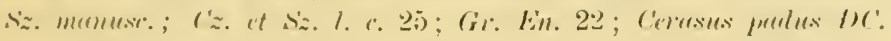
(iuchlh. mumeste; Gr. Liber. l. (2. 1:31); și cullivat la lași (l). Br.

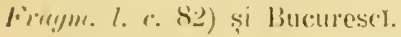

\section{l'ag. 72-79. Vicia T.}

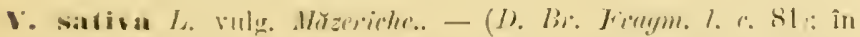

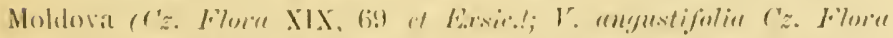

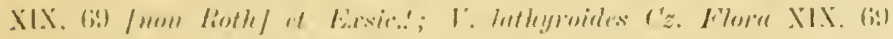

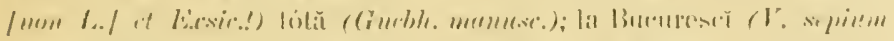

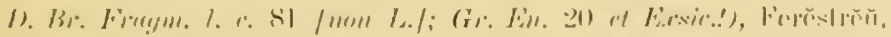

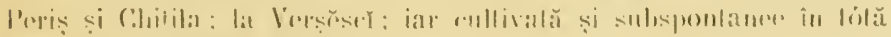

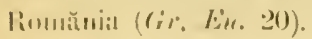


V. angustifolia Roth suprimă: (Czih, l. c. 58-74t) și adaoge : (V. sepium Cz. Flor X XIX, 69 [non L.] et Exsic.!).

P. segetalis Koch.; V. segetalis Thuill. - In Mehedințĭ la Simian și Hinova (Gir. Eissic.!).

V. lathyaroides $L$. adaoge : la Chitila (Gr. Exsic..').

V. peregrina L. Ir. peregrină. - Prin fineţele din Moldova inferióră (Gucbh. manusc.). - $\odot$ Maiй-Lиiй.

V. Biebersteinii Bess.; I. grandiflura \%. Biebersteinii koch. $\Gamma$. lǔ Bicber'steiu. - Ye lîngă Bucurescř la Cihitila. - $\odot$ Maiй..Iuliü.

V. sordida W. Kit. adaoge : în Moldova (Cz. Flora XIX, 69 et Exsic.'; V. lutea Cz. Flora X1X, 69 [non L.] et Lxsic.!) inferióră (Guebh. mumusc. et Exsic. n. 100 sec. Nym. Consp. 210); pe teritoriul neutral apróp z de Orșova (Winkl. Oest. bot. Zeit. XVI [1866] 16); pe lîngă Bucurescł la Ferěstrĕŭ, Mărcuţa, Periș, Chitila, Ciocănesci şi Titu (G). En. 20 et Exsic.!; Kenitz l. c. 196); in Mehedinţr la Hinova (Gr. Exsic.:).

V. Incea $L$. suprimă : (Czih. I. c. 58-79), și adaoge : în distr. lași la Hoisěscì ( $\$ z$ z. mumusc.); în Mehedinf̣̂ la Bistriţa și Hinova (Gr. Exsic.!).

V. Faloa $L$. adaoge : vulg. Fă̌̆, Bob̆. - (Fuba velgaris DC: Giucbh. malluse; Cz. et S'z. 1. c. 44 ; Gr. En. 20).

V. serratifolia Jacy. $V$. cu foù scrate. - Prin fineḷele din pădurì și prin tufěrișurǐ. - Pe lìngă Bucurescĭ la Ferěstrĕŭ ; în Vlașea la Comana ; înlre Vînciorova și Guravăicĕ (Siml. 543) eătre Porțle-de-fer (Borl). 1873, Bans. $290)$ pe m-lele St-Hetru. - $\odot$ liaiй-Iиniй.

V. sepinn $/$ a adaoge : în pădurile Moldover superióre (Giucbh. mumusc.); la Predél ; în Muscel la Conțěscl (Gi. Ks.sic..!).

V. oroboides Wulf. V. arobuielă. - In m-liĭ Moldover (entrale (Gmolih. mannse.).

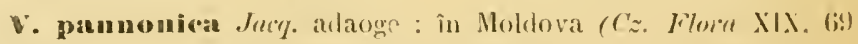

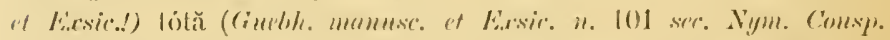

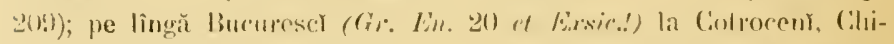

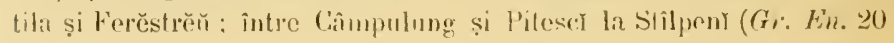




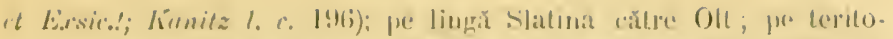

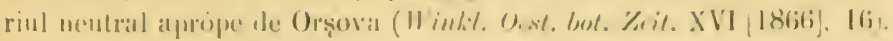

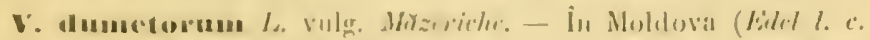

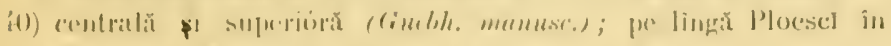

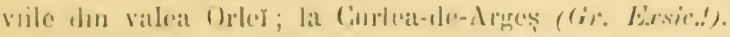

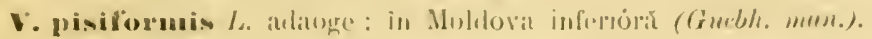

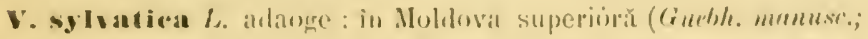

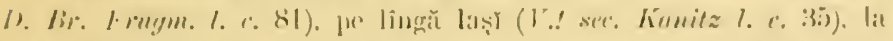

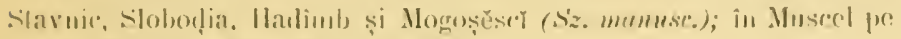

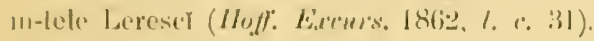

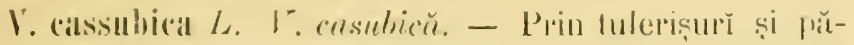

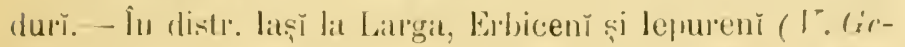

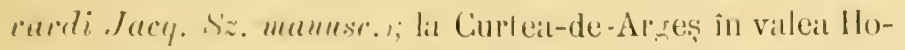

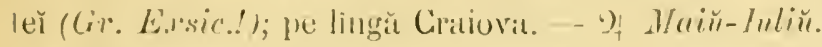

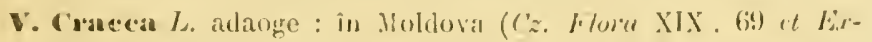

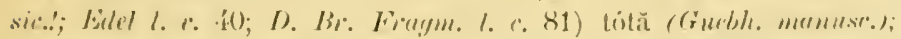

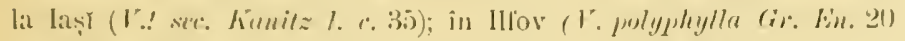

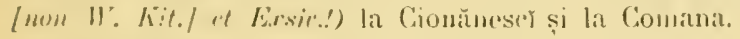

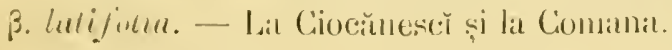

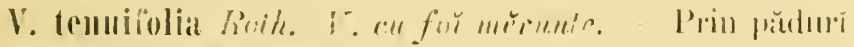

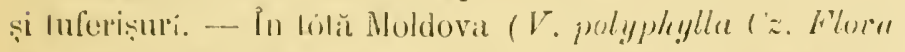

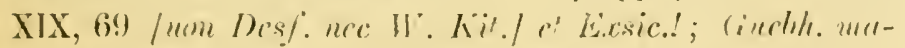

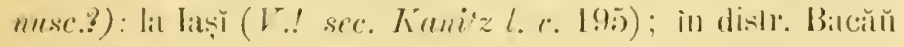

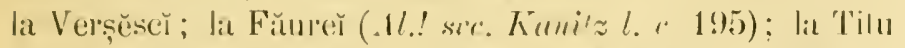
(Gr. İu. 20 et Exxir..') Ferěstrěŭ si Mogosoilia; în Nelıe-

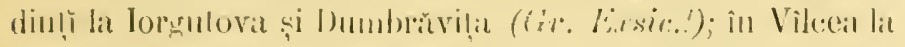

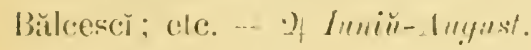

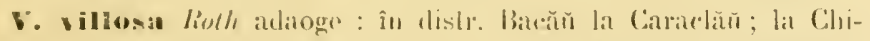

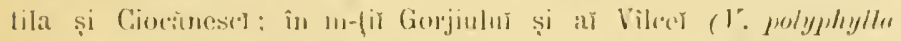

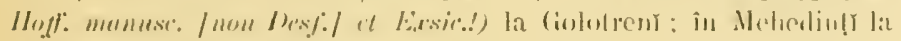

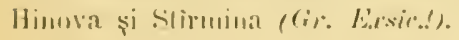

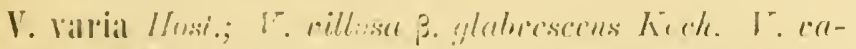

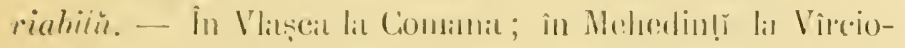

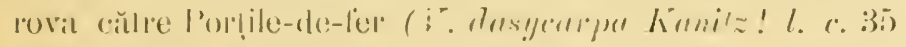

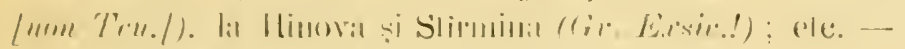

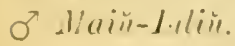


V. Letrispermat Hoench, adlagge: in Molilora (Cz. Flora XIX. 69 et Ex.sic..'; s'z. mumesc.); la Comana; la Stolnici (D. Br. 7. c. 81).

V. mouanthos Dif. adaoge: in Moldova (Lethyrnes monentho.s

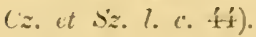

V. hirsuta Koch, adaoge : vulg. Maževich, Cosiţă. - În tótă Moldova (Errum hirsutum L. sz. munusce); pe lîngă Bucureser la Chitila; în Mehedinți între Vîrciorora și Gura-răiel.

\section{Pag. 79. Lells T.}

I. esculentat Hocnch. adaoge : (Evem Lens L. Cz. et szz. l. (. Af; (iuebh. menusc.; G): En. 20).

\section{Pag. 80-87. Lathyius T.}

L. Aplatea Lin. L. -1 f́ač̆. - Prin agri și finete. - In lotă Moldova (Sz. manusc.; Cz. et $S z$. l.c. 44); în Ilfov la Periş în Valea-Cocioc (Gi. Exasic.!). - $\odot$ Inniŭ-Iuliü.

L. Nissolia $L$. adagoge : în Moldora (C'z. et Szz. 1. c. f́í); la mstirea Adam (Guebh. manusc. et Exsic. n. 108 sec. Nym. Consp. 20.́); în distr. Iașy la Costuleñ̌ și Gorony (Sz. manusc.); in Ilfov la Periș (G): Eesic.); la Stolnici (D. Bo. Fiaym. l. C. 81).

I. hirsutus Lin. adaoge : în Moldova (Cz. Flora XIX, 69 et lirsic.'; Cz. oet Sz. l. c. 4ti; L. heterophyllus Cz. Flure XIX. 69 [non L.] et Fxsic.!; Eilel l. c. 40); în distr. Iași la Stîncă și Hoiunc⿻cī (Sz.menu**c.); în distr. Bacăŭ la Caracłăŭ ; în Prahova și Illus (L. ensifolius. Gr. En. 21 [non Bud.] et Exsic..') la Ciocănescí; in distrietul Vlașea la Comana.

B.. sutivus Lin. adaoge : în Moldova (Cz. et Sz. l. c. f́t et Ex:ir..; s.z. manияe.).

1.. sylvestris $L$. adaoge: ( Filel l. c. 4t); Cz. et Sz. l. c. 40).

L. platypliyllus lietz. L. platifil. - I'ulq. Bub-rle-ta-

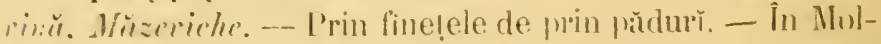

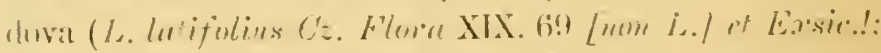

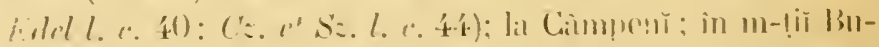

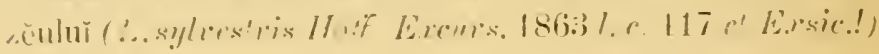


pe valea Blscè̆ și Ciura-Milè; la Cincănescŏ (1. sylrestris var. latifolius D. Br. Fra!gm, l. c. 81). 'T'ilu, Gherganı̆ (L.

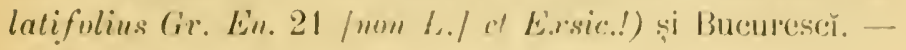
Of luliŭ- lu!gus!.

\section{Suprimă pe: 1.. heremolyyllus h.}

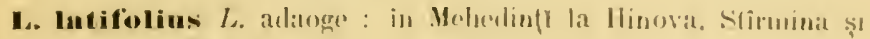
Iorgutova (cr). lirsir..').

L. Iuberosus L. alaoge : vulg. Frsuiţr. - În listă Moldova

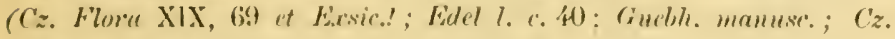

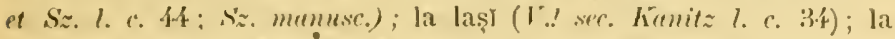

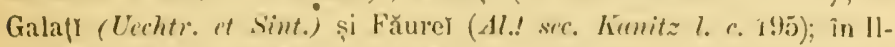
for (Gr. En. 21 et Ex'sic..') la Periș, Buftea și Ciocănesi' (I). Br. Fragm. 1. ‘. 81); la Comana; în Vîlcea la Bălcescot.

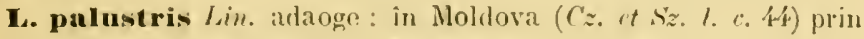
luncile de pe malul Prutuluy (Sz. mamese.).

L. prutensis Lin. adaoge: vulg. Lintect-pmatulur, Linte-te-pra-

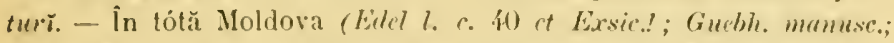

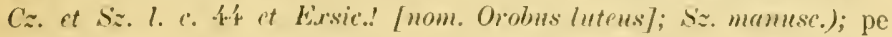
virful Penteleulur: la Vălenł (L. sutims Gr. En. 21 [non L.] et Exsic..!), Sinaia, Grivina ((r). Lin. 21 et Exsic.!), Ciocănescr, Periș, Ferěstrěu și Bucurescř (D. Br. Frugm, 1. e. 81): pe lîngă Craiova

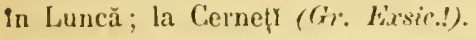

L. Hnllersteinii Bmy. adaoge: în Molelova (Cz. et šz. l. c. Iff); în Muscel la Contěscy în valea Rîncăc(iovalur (Gr. Exsic..!).

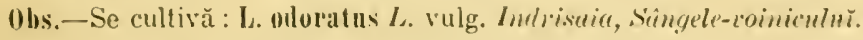

I. veruus Wim. adaoge : vulg. Robiu, Pijpigior, Pupezele, I'u-

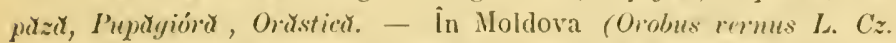
Flor XIX. 69 et Eixsic.!; Edel I. c. 4(1); S'z. munuse.) centrală (Guebh. menusc.) pănă în muntí (Edel 1. (. 37); la ın-stirea Agapia: in distr. Bacăŭ la Caraclăŭ; în distr. Pralıora la Cîumpent (0). rermus Gr. Ein. 21 et Eirsic.!) ; în distr. Husecl la Sălcióra spre Contěsci (Gr: Exxsic.!) și între Rucăr și Dîmboviciora (O. remux Hopt): Exсurs. 186ะ, 1. с. 39).

I. vuriegatus Godr. et Cren. adaoge: in Moldova (Orobus rariegutus Tem. Cz. Flov" XIX, 69 ?) : in Arges la Stolnici (U. remus D. Br. Fragm. l. c. 81) ; la Craiova în Luncă: în Muscel la Con-

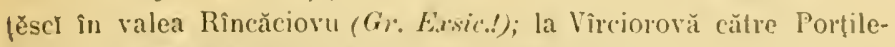
le-fer (O. vigirlus Lung. Borb. 1873. Bans. 290). 
L. Montanus Godr. et Gien.; Orobus luteus Lin. L. momtan. - Prin pădurile montane. - La Agiud (Burri Exsic.!). - 4 Maiй-Inпій.

L. aureus (Stev.); Orobus aurcus Stev. L. anriü. In Moldova (O. sylvaticus Sz. Exsic.! [non Bmq./; h. j. Guebh. manusc; O. tuberosus Cz. Flora XIX, 69 [non L.] et Exsic.!). - 9 A priliŭ-Maiŭ.

L. macrorrhizus Wim. suprimă pe : (Orobus tuberosus Czih. l. e. 58-74), și adaoge : în tótă MoIdova (O. tuberosus Sz. manusc.).

Suprimă pe : L. macrorrhizus $\beta$. tennifolius.

I. niger Wim. adaoge : vulg. Măzeriche-négiđ̆, Linte-négră. În tótă Moldova (Orobus niger Cz. Flor đ XIX, 69 et Exsic.! ; Edel l. c. 37 ; Sz. manusc.); la Ciocăneser (I). Br. Fraym. l. c. 81) și la Bănésa! (Gr. En. 21 et Exsic.!); în disurictul Muscel la Conțěscl (Gr. Exsic.!).

I. msphodeloides Godr. et Gven. adaoge : în pădurile Moldover inferióre (Guebh. manusc. et Exsie. n. 114 sec. Nym. Consp. 205); la Agiud (Bumi E.xsic.!).

L. canescens Godr. ct Gren.: Orobus filiformis Lam.; O. canescens Lin. fil. L. albicios. - Prin finețele din munț. - In Moldova (Orobus luteus Cz. Flora XIX, 69 [non L.] et Lxsic.! ; Edel l. c. 40 ; Sz. mamusc.; O. leviyatus [non W. Kit.I Sz. Exsic.!: O. temifolius Cz. Flora XIX, 69 [non Roth nec Bmy.] et Exsic.!; O. digitatus Cz. Flora XIX, 69 (non M. Bieb./ ct Exsic.!). - 7 Maiй-Iиniй.

0los. - Se mà citéză : 0. Varius pe colinele něsipóse din Moldova inferióră (Guebh. mumusc.) și în munți (Édel l. c. 37).

\section{Pag. 87. Pisum T.}

P. sativum $L$, adaoge : ct rar. (Cz. Flora XIX, 69 ct Fixsic.'; Eilel l. c. 40; Guwbh. mumuse; Cz. et Sz. l. c. 44; Gr. En. 20).

P. arvense $L$. adaoge : cultivat (Sz, memusc.).

P. elatius NI. Bieb. W. inalt. - Prin tuferișurile din locurile stîncóse și catcare. - La Vìrciorovil către Por- 
(ile-de-fer! (I'. arvense Burh. 1873, Bains. 290/mun L.J) și intre Șchelea-Cladovĕ și Cüa-văič̆. - $\odot$ Maiŭ-Iиniŭ.

\section{Pag. 87. Cicel T.}

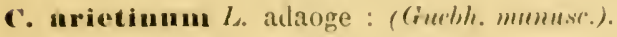

\section{Pag. 88. Plaseolus L.}

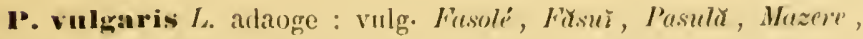

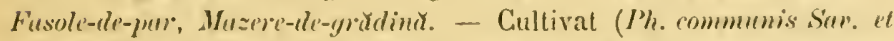
var. Cz. Flor" XIX, 67 it Exsic..'; Guebh. manuse.; Sz. monust.; Gr. En. 20).

0bs. 1. - Plı. multiflorus W. adaoge: (Guebh. manusc.).

0bs. 2. - Lablab vulgaris Suri se cultivă (Guebh. munuse.).

\section{Pag. 89. Galega T.}

G. officinalis $L$. adaoge : în Moldova (Cz. Flor XIX, 70 ot Exsic.!; Eilel l. ¿. 40; Sz. manusc.) inferióră (Gubh. munusc.); la Bănésa și Cïocănescy (D. Br. Fraym. l. 1.81$)$; la Ghergañ și în distr. Buzěŭ la Becenı ( $G$ ): En. 20 et Exsic.!); în Vîlcea la Bălcescr.

\section{Pag. 89. Robinia $\mathbf{l}$.}

R. Pseudo-Acacin $L$. adaoge : vulg. Acaciŭ, Acat, Salern. (Cz. Flora XIX, 70 et Exsic..; Eilel 1. c. 42 ; Guebh. Manusc.; Cz. 1t Sz. I. ย. 44; Sz. manuse; Gr. Eu. 20).

R. frutescens $L$.; Caragana frutescens DC. R. frutescentă. - Vulg. Tufă-lemnósă. - In Moldova (Spartium scoparium Cz. Flora XIX, 69 [non L.] et Exsic.!); in districtul Iaș̆ la Códa-iazuluh̆-Chirị̣eĭ către Șĕpte-ómeñ̆. forméză tufișe întreğ (R.Caragana Sz. manusc. [non L./). - †े Maiй.

01s. - Colutea arborescens $I_{\text {. }}$ vulg. Beșicúst, indicată prin live-

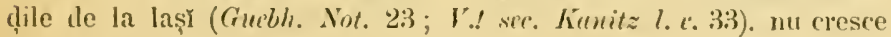
de-cât cultivat prin pareur' și grădiñ̆! (šz. mumusc.). 
Pag. 90-93. Astramalus T.

A. vesicarius $L$. A. vesicariu. - Pe coline calcare. In Moldova (Guebh. Exsic. n. 502 [nom. A. lineali] sec. Nym. Cousp. 188). - 2 H Miй-Iимiй.

A. asper Juciq. adaoge : în Moldova (Cz. et Sz. 7. e. 45 ). la Unghenr pe malul Prutulur (sz. momusr.); la Rădulescir-Filitis (D). Br. Fragm. I. c. 8).

A. anst 1יiaens $L$. suprimă : (Guebh. v. in herb. mus. Iaşi), și adaoge : către Rĕcea (Sz. mumusc.).

A. Onobrychis $L$. adaoge : in Moldova (Cz. F'lora XIX. 69 et E.rsic.!; Cz. et Sz. 1. c. 41; Sz. mamusc.; A. austriutus Cz. Floru XIX, 69 [non L.] et Exssic.!; h. i. Guebh. mamusc.; Cz. et Sz. 1. c. 45; A. prrecox Cz. F7orn XIX. 70 /non Bmy.7 et Es.sic.!; Edlel 1. c. 10; Cz. et Sz. l. c. 45; A. monspensulams h., j. Guebh. mamuse. [non L.7]); la Onescr pe malul Trotușulur și la Caraclăŭ pe Babaghicea; în Rîmnicu-sărat la Sihlea; în distr. Burěŭ la Beceñ (Gr. Exxsic.!; Kanitz l. e. 193) și VălenI (Gi. En. 20 et Essuic.!); la Buftea, Periș. Crivina ; etc.

\%. chlorocarpus Boiss.. - In Moldova (1. chlorocarpus Griseb. var. cracoirles Gubble. Exsic. n. 526 sec. Nym. Consp. 189) prin pădurile de la Pechea (1. argcuteus Gucble. m(enusc.?).

A. Rochelianus Henff. A. Rochelian. - Pe coline aride și stfncóse. - In Mehedinț la Spchelea-Cladoveĭ. 2) Mriй-Iuпiи.

A. monspessulauus $L$. suprimă : (A. macox Bmg. Elel l. c. 40); Guebh. $x$ in herb. mus. Insi), și adaoge: la Iași dincolo de T'îrguşor pe drumul Bordè și către Serbescł (A. precor Bmy. s'z. muturse.?).

1. pouticus Pall. A. pontic. - Pe colinele uscate din. Moldovi inferióră (Guchl. mamusc. et E.rsic. n. 529) sec. Nym. Comsp. 191); între Galaț̆ și Bărboṣ̆. - of luniŭ-lul.

A. gategiformis L. suprină : (Edel I. r. 40); Guebl. $r$, in herb. Iaşi) şi adange : către Thubana şi in-stirea Poéna (Sz. munusc.?). 


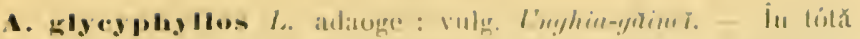

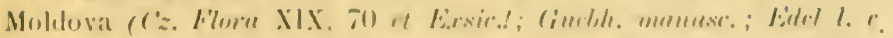

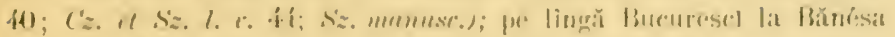

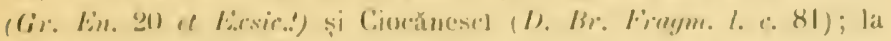

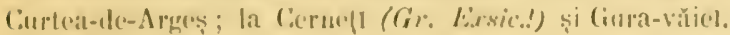

In loc de: A. comapus L. puna :

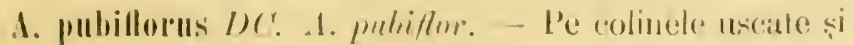

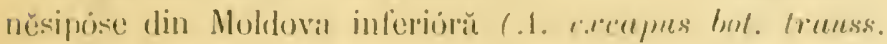
/nom L.J), dinceolo de l'echea in drumml (ritlatilor (.1. excet-

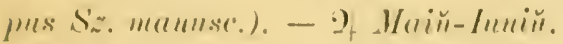

A. Hasyanthus I'all. A. dusiuml. - V'e rimunurle si co-

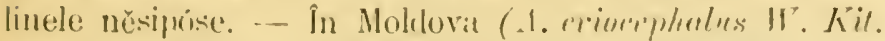
[eror. A. lrivephalus] Cz. Florel XIX. 70 it Esisic.!; Cz.

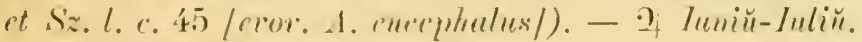

A. Cicere L. adange : in tótă Moldova (ciuebhe memuser. et Fis-

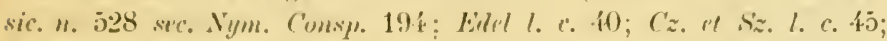

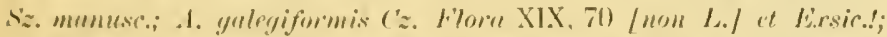

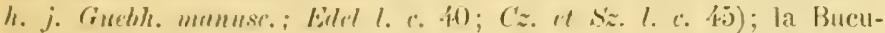

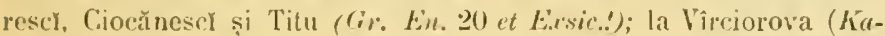
nitz! l. (. :33).

Suprimă pe : A. Platea $\mathrm{Br}$.

Suprimă pe : A. alpiuus br.

1. altstralis (L.): Jhace australis L.; I\%. Malleri Till. 1. unstral. - Vulg. P'étrü-lin'r. - I'rin păṣnnile stincóce

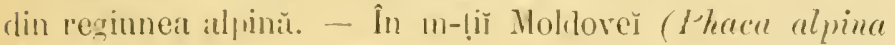

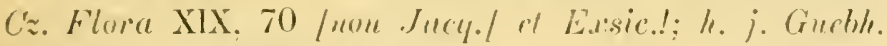
m(enusc.). - D, Inlin-duyust.

P'ag. 9'. 0xytropis DC.

0. (ampestris DC. (). de ritup). - Vulg. Luntricicü.P'estincile din regimnea alpină.--P'e virful Cèlılăulü (Junlia!

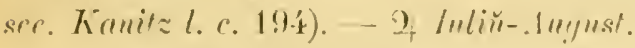

0. uralenais $\mathscr{L C}$ : arlaoge : pe stincile de pe vîful Célılăulur

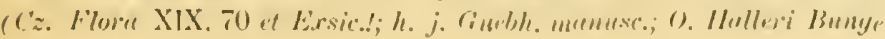


Jankre! sec. Kanitz 1. r. 194; Astrayalus montanus Edel l. c. 36 /non Jacq.]); in m-ţir Bucegł prin pășunile petróse și calcare de la Omu! (Fr. 129).

O. pilosa DC. adaoge : prin pârlógele de la Pechea (Gucbh. mantuse.).

0. carpathica Uechtr. O. carpathică. - Prin locurile stîncóse din regiunea alpină. - În m-tị̆ Bucegì la Strunga şi pe valea Ialomițer (Winkl. sec. Kanitz l. c. 194; Fr. 129). - 24 Iuliü-August.

\section{Pag. 95. Glycyrrhiza T.}

G. echinata $L$. adaoge : în Moldova (Cz. Flora XIX, 70 et Exsic.!) inferióră (Gucbh. manusc.); la Galațî și pe malurile Seretulư pănă la Focșanł (Edel 1. c. 38; Cz. ct Sz. 1. c. 45; et Exsic.!); la Chiperescr peste Bahluiŭ (Sz. mamusc.); la Bêrlad (D. Br. Frargm. l. c. 81); la Comana pe malul Câlniscer; între Șchelea-Cladover și Gura-văiě pe malul Dunărer.

G. glabra $L$, adaoge : la Galațí càtre cetatea Genoved̦ilor mergênd spre podul Seretulur (Sz. manusc.).

\section{Pag. 96. Lotus L.}

L. corniculatus $L$, adaoge : Trifoişte-colturată. $-(C z$. Flora XIX, 69 et Exsic.!; Gucbh. manusc.; Edel 1. c. 37, 40; Sz. manusc.; D. Br. Frugm. l. c. 81; Gr. Eibor. l. c. 131; En. 20 et Exsic.!; L. siliquosus Cz. Flora XIX. 6y [non L.7).

ß. arvensis Șchk - În Moldova inferióră la Puṭĕnı̆ (Guebh. manusc.).

ץ. alpinus adaoge : pe vîrful Céhlăulư (Cz. Flora XIX, 69 et Exsic.:; h. j. Guebh. manusc.; Eilel l. c. 36).

j. tenuifolius (L.) adaoge : (L. tenuifolius Rchl. Cz. Flon XIX, 69 et Ersir.'; L. temuis Kit. Cz. Flora XIX. 69 et Exsic.!); la Chitila; in Argeș la Stolničr.

L. uliginosus Schk. L. uliginos. - In districtul Bu\%ĕŭ la Becenı̌ şi la Ciocănescĭ (Tetragonolobus siliquosus Gr. En. 20 finon Roth] et Exsic.!). 


\section{L'ag. 97. Doryenium T.}

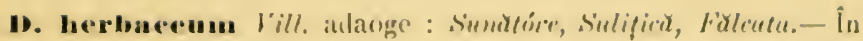

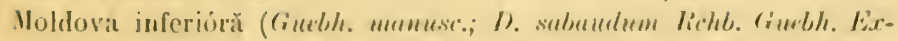
sir. 11. 3Ht sece. Nym. (omsy. 181); pe lingă lașy la Balcin în Viat-

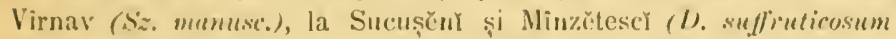

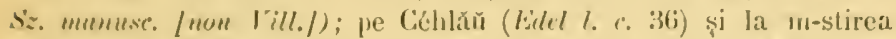
Ném\{ulul (D). suffruticosum (ir. En. 19 /um Vill./ "t Exsie.!); in distr. Bacăŭ la Caraclăŭ; la Sinaia, Câmpina, Ploescr, Cirivina (Gir. En. 20 ot lixsic.!) și Buftea (I). suffrutirosum Gr. lin. 19 et Ex-

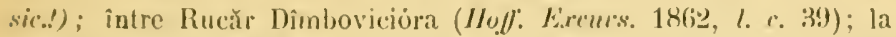
Stolnicr (l). Br. Fuym. I. r. 80, 81); la lorgutova şi Dumbrăviţa (Gr. Lirsic.!) și între Turnu-Severin și Gura-văię ; etc.

\section{Pag. 98. Anthyllis L.}

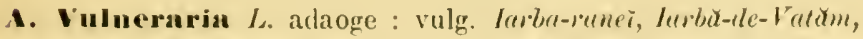
línolóre. - in regiunile inferióre ale Céhlăulur (Eidel l. a. 36; Cz.

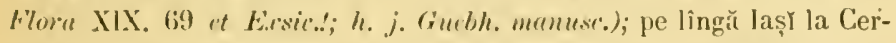
lulésă și Hadînb (Sz. memusc.); la Sinaia! (G). En. 19); în Dîmbovił̧a pe Plaiul-Domnesc; la Němăeseł pe Stînca-mănăstireł ( $D$. br. Fragme. l. ('. 80).

ز. "lpestris, adaoge : pe Céhlăŭ (h. j. Guebh. manusc.; Edel l. r. 36 [non I.J]).

\section{Pag. 99-102. Trifolium T.}

T. rubeus L. adlaoge : prin fineţele de pe malu] Prutulur la Prisěcanł și Oprișĕnl (Sz. mamusc.).

T. alpesire $L$. adaoge : in Moldova ( $T$. angustifolium C $z$. Floru XIX, 70 [uon L.] et Lissic..) tótă (Gucbh. menusc.) pănă în munțí

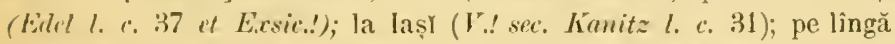
Bucuresey (I). Br. Frogm. l. c. 80) la Bănésa (T. rubens Gr. En. 19 [non L.] el Ersic.!') și la Buftea; in m-trir Bucegr la schitul Pesrera lalomiţer; la Comana; între Șchelea-Cladover și Gura-văieY.

'T. medium L. adaoge : in tótă Molelova (Cz. Floru XIX, 70 "t Exsic.!; Sz. munusce. (nom. T. prutense et T'. montanum!/); in distr. Buzĕŭ la Becenr (Gr. Lin. 19 it Exsie..'); la Predél; la Comana; în Muscel la Conţěscì (Gi) Exsic..'). 


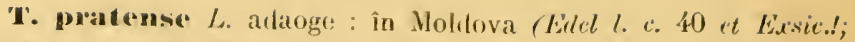
T. hybridum C'z. F'loru XIX. 70 [non I./ et Exsic.!) tótă (Guebh. manuss.); pe lîngă Fălciŭ (Iluc\%. Lípise 1I. 78); la m-stirea Agapia (G). Evbor. 1. c. 131); în llfov (Gr. E) 19 et Exsic.!) la Cotrocenl, Bănésa și la Ferěstrěŭ în Vîlcea la Bălcescr; la Vîrciorova (Kanitz! l. (. 31).

T. pammonicum Juc\%. adaoge : în in-ţiY Moldover (Edel l. c. 37; T. ochrolencum Cz. Flora XIX, 70 et Exssic.!); în distr. Buzěŭ, Muscel și Pralıova ( $(r)$ L Ln. 19); la Predél; la Titu și Ciocănescr (D. Br). Fromgm. l. c. 80).

'T. ochroleucum L. adaoge : în tótă Moldova (Guebh. manusc:; Sz. mumusce) pănă în munțí (Édel l. c. 37); la Sinaia, Câmpina și Ciocănescì (Gı. En. 19 et kixsic.!).

T. incarruatum L. 'T. incarnat. - Prin finețele de pe coline. - În Mehedinți li Hinova (Gr. Exsic.!) și la Vîrciorova către valea Bahně. - $\odot$ I/aiй-Iuniŭ.

3. Moliueri. - Pe teritoriul neutral aprópe de Orșova (T. Molineri Balb. Winkl. Oest. bot. Zeit. XVI [1866] 16).

T. arvense $L$. adaoge : vulg. C'óda-mâtę̆, C'herchuri. - În Moldova (Cz. Flor, XIX, 70 et Exsie.'; Edel l. c. 40 ; Guebh. manusc.; Sź. munuse.) tótă (Guebh. munusc.); pe lîngă Bêrlad la Crîng (D. Bi. Frugm. l. c. 80); la m-stirea Nẻmțulur; în Prahova și Ilfov (Gr. En. 19 it Exsic..'); la Curtea-tle-Argeș (Gr. Exsic.!); în Vîlcea la Bălcescr; la Vîrejorova către valea Bahner.

T. pallidum W. Kit. T. palid. - Prin finețe. - La Vîrciorova pe teritoriul neutral aprópe de Orşova (Winkl. Oest. bot. Zeit. XVI [1866], 16). — Ж Maiŭ-Juniŭ

T. diffusum Jihrh. 'T. difus. - Prin fînele uscate la Şendrenı̆ și Solonețĭ (Sz. m(rumsc.); în m-țĭ de la Vîrciorova către Porţile-de-fer (Simli. 544). - 2 Iuniŭ-Iuliǔ.

T. scrabrun L. T. scabru. - La Vîrciorova (Janka! sec. Kanitz l. c. 192). - ஒ) Inиiй-luliŭ.

'T. striatum L. T'. striat. - Prin fineṭele și pășınele uscate. - In Vlașca la Comana pe lingă gara drumulurde-fer (cir. Exsic..') si pe colina despre valea Gurbanulŭ. - O Mriĭ-Inliü. 
T. subtermateum L. T. subtrren. - Prin fineţele din Moldova superioră (Sz. Escsic..'; h. j. Guebh. manusc.). $\odot$ Арліlіи-маій.

'r. Frugiferum $L$. aulaoge : in tótă Moldova (bilel l. c. 40 et Virsic.'; Gubh. munusc.; Sz. munuse.); la 13ucurescl; în Mehedinţ la Slírnina şi llinova pe inalul Dunărel (Gr. Kissic..').

'T. resupinutum $L_{\text {. }}$; $T$. snotcolens $W$. adaoge : în Moldova (Eidel Ex.ric..!); la E.rbicenl (s'z. manusc.); în Vlașca la Comana in lunca Caxlniscel; în in-ţil Coziel (Moff. Exxsic.!).

T. strictum W. Kit. 'T'strict. - Prn finețele umede. - Pe șęsul Prutulur și a Gijieì (Sz.man.). - ○Iul.-Aug.

T. moutanum $L$, adaoge : in Moldova (T. armenium Cz. Flora XIX, 70 [non W.]; T. panuonicum Cz. Flora XIX, 70 [non Jacq.] et Exsic.!); tỏlă (Guebh. manusc.; Sz. manusc.) pănă în munţr (Edel $l$. c. 37); la Sinaia! (Gr. En. 19 et Exsic.!) și la Predél ; în m-tir Dimbovițel pe Plaiul-Domnesc; pe lîngă Bucurescl (D. Br. l. c. 80).

T. hybridum $L$. adaoge : in Moldova (Eidel l. c. 40 ; Sz. mamusc. et Exsic.! [nom. T. resupinatum, T. sanguineum et T. reflexum]); la lași (V.. sec. Kanitz l. c. 32); în Buzěŭ la BecenI (Gr. En. 19).

T. elegans Savi. T. elegant. - Pe coline uscate și prin locurĭ umede. - La Puḷẹni (Gưbh. manusc.); pe lîngă Bucuresč̀! (Gr. En. 19 et Exsic.!; Kanitz l. c. 192); in Vlaşca la Comana in valea Gurbanulǔ. - 2 Iıniй-Iuliŭ.

T. paliescens Schreb. T. palescent. - Prin păşunile slîncóse şi umede din regiunea alpină.- In m-tị̆ Bucegì în valea lalomițeì ( $F^{\prime} r$, 128) și la Pirăul-Babelor.-2 lul-Aug.

T. repens $L$. adaoge : în Moldova (Cz. Flora XIX, 70 et Exsic..!) tótă (Guebh. manusc.; Sz. manust.); la Němăescl pe Cóstam-stirel (D. Br. Fragm. l. c. 80); la Sinaia; la Slănic și în m-ţil Bucegl (Fr. 128); la Titu (Gr. En. 19 et Fixsic.!; Kanitz l. c. 192) şi Ferěstrĕŭ; la Virciorova către Porţile-de-fer! (Kanitz! l. c. 32).

T. badium Schreb. T. roșiü-brun.-Prin pășunile umede din regiunea alyină. - In m-tiì Buceğ prin locurile umede din valea Ialomį̣er $(F r$. 128). - 2 Iuliŭ-August.

T. Agrurium $L$. adaoge : ( $T$. anrum Poll. D. Br. J'ragm. l. c. 
80); în Moldova (Cz. F'lore XIX, 70 et Exsic.!; Sz. memusc.; T. cumpestive Schreb. Eilel 1. c. 10 ; Sz. manusc. ; T. spudiceum Sz. Exsic..' [non L.]; h. j. Guebh. menusc.); la m-stirea Némțulǔ̆; la Caraclăŭ; la Sinaia (Gr. En. 19 et E.xsic..') și în in-tir Bucegy către ob̂irșia Ialomiţer (Hoff. Errcurs. 1863, l.c. 120 ?); la Yeriș și la Comana; între Schelea-Cladover și Gura-văieł.

T. procumbens $L$. adaoge : în Moldova (Cz. Florn $\mathrm{XIX}, 70$ et Exsic.! [nom. Medicugin. Lupulin.]); la Titu și Becenr (G). En. 19 ot Exsic.!).

T. minus Sm.; S. filiforme DC. [non L.]. T. mic. În districtul Argeş în pădurea Gurănóea aprópe de Olt

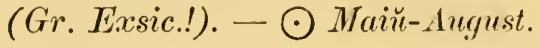

T. filiforme $L$. adaoge : pe șěsul Jîjier și a Prutulur ( $S z$. man.).

\section{Pag. 102-103. Medicago L.}

M. Iupulina $L$. adaoge : vulg. (D. Br. Fragm. l. c. 80); în Moldova (Cz. Flore XIX, 70 et Exsic..; Edel l. c. 40) tótă (Guebh. munusc.; Sz. manuse.); la Predél ; în Ilfov (G). En. 19 et Exsic.!) la Ferěstrěŭ ; pe lîngă Craiova la Lémna.

M. falcata L. adaoge : vulg. Ghisdeiŭ, Cobflééseñ, Cubclciascr̆. În tótă Moldova (Guebh. manusc.; Elel l. c. 38 ; Sz. mamuse.; Trifolium campestre Sz. Exsic.!; T. procumbens Sz. E.rsic.!; M. medlia $E$ del l. c. 38 ?); pe lîngă Bêrlad (D. Br. Frotgm. l. c. 80); la Becent, Sinaia, Câmpina și Bucurescr (Gr. En. 19 et E.csic..; M. malì Gr. En. [non Pers.] et Exsic.!); la Vîrciorova către Porțile-de-fer.

ß. glandulosa Koch. - La Vîrciorova către Porṭle-defer (Borb. 1873, Bàns. 289 excl. syn.).

M. sativa $L$. adlaoge : vulg. Luțernc. - Subspontanee și cultivată în tótă Moldova (Guebl. menusc.; Sz. manusc.); la Bucurescy (Gi. En. 19 et Eissic.!) la Ferěstrěŭ.

M. orbicularis All. (p. p.). M. orbiculară. - Pe coline aride. - În Vlașca la Comana pe délul din fạ̣a Garel̆ drumuluĭ de fer; la Càmpulung pe !̣̆ermurile Rîu-Tîrgulı̆ ( Hoff. Exinrs. 1862, l. c. 40 ct Exsic.!). - $\odot$ Maій-Iипій.

M. Geraldi Kit.; M. rigidula Desv. L. lǔ Gerard. Pe coline aride, prin păşunĭ sterile. - In distr. Iaşı̆ la Lar- 
git, Iepureñ̆, 'lüutescĭ și l'opescl (H. villensula Bum. Sz. manusc.); la Cîmpulung pe tẹrmurile Rou-T'ìrguluĭ ( $\mathrm{K}$.

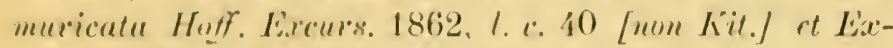
sic..!); in Vlașca la Comama pe délul din fața Giarer drumu-

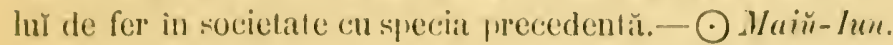

1. uinimu Les\%, adaoge : la Păun. Petrăric, Ungheny, Sculenl, Erbicenł și Tîrgu-frumos (Sz. menusce.).

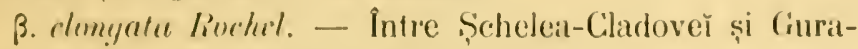
văicè pe malul J)unătrĕ, și la Vîreiorova.

\section{Pag. 103. J)up̆̆ Medicago adaoge :}

\section{TRig0NELLA L. - Trigonellă.}

T. gladiata s'tev. 'T. gladiată. - Pe coline nĕsipóse și petróse. - In Moldovil (Lotus Tetragonolobus Cz. Flora XIX, 69 [nom L.J it Exsic..'; Tetrayonolohus prostratus Cz.

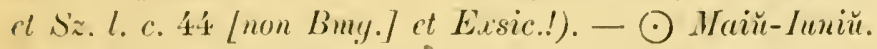

Obs. - T. fưnum griteum $L$. se cultivă (Guebh. manusc.).

\section{Pag. 103-105. Nelilotus T.}

I. Ientata (W. Kit.) I'ers. adaoge : în tótă Moldova ( $C z$. et Sz. l. c. -45 et Exsic..').

M. macrorrhiza $W$. Kit. adaoge : în Moldova (Cz. et Sz. l. c. 45).

M. allan (Lum.) Dess. adaoge : in Moldova inferióră (Guebh. munusc.); la Comana (D. Br. Frugm. l. c. 80); la Bucurescl (Gr. En. 19 at Exsic.!), la Ferěstrěŭ și Chitila; la Vîrciorova ( $k$ anitz ! l. c. 31).

M. ofticinalis (Lrmo.) Dese.; M. arenesis Wallr, adaoge : vulg.

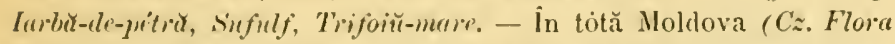
XIX, 70 of E.rsir..'; Edel l. c. 37 ; Gulbh. manuse.; Cz. et Sz. l. 6 . 45; Sz munuse; 1.? sec. Kanitz 1. c. 31; Gr. En. 19 et E.xsic.!; 17. dentatu Gr. Eu. 19) [non Pers.] ot E.rsic.').

M. pallida Bess. M. palid. - Prin pîrlógele de la Pechea (Gushh. manusc.). 
M. coerulen (Lum.) Inese. adaoge: vulg. Sufulf-rinect. - În Moldova (Cz. F'lora XIX, 70 et lixsic.!; Eidel l. c. 40; Cz. et Sz. l. c. 5) inferióră și centrală (Trigonelle coeruleu [Despu:] Sér.); pe lîngă Bucurescy; în districtul Vlașca la Comana (D. Br. Hrougm. t. c. 80$)$.

M. procumbens Bess.; M. carule b. laxiflora Rocled; M. laxiflorı Friv. adaoge : în Vlașca la Comana.

Pag. 105. 0nonis $\mathrm{L}$.

O. spinosan L. adaoge : vulg. Săldşsitóre, Sudórect-copuluĭ. (D. Br. Fraym. l. c. 80); în tótă Moldova (Gucbh. manusc.; Edrlcl l. c. 40 ; Cz. et Sz. l. c. 任); la Păun, Tomescr, Piciorul-lupulur și Bordea (Sz. mamusc).; în Rîmnicul-sărat la Caiata; în Ilfov (Gr. En. 18 et Exsic.!) Ia Chitila și Ciocănescr.

O. hircina Jucq. adaoge : (D. Br. Freegm. l. c. 80); în Moldova superióră (Cz. Flora XIX, 69 et Exsic.!; h. j. Guebh. manusc.; Cz. et Sz. l. c. 45 ; Sz. manuse.; O. spinosa Cz. Flora XIX, 69 [non L.] et Exsic.!); la pólele Céhlăulur (Edel l. c. 36); la Caraclăŭ; in Ilfov (O. procuress Gr. En. 18 [non Walls.] et Exsic.!) Ia Buftea; între Titu și Gherganl (Gr. En. 19); la Curtea-de-Argeș; la in-stirea Horez (Gr. Exsic.!) și la Bălcescǐ.

Obs. - Se mar citéză : 0. parviflora $L$. în Moldova (Cz. et $S z$. 45).

\section{Pag. 106. 0nobrychis diaertı.}

O. sativa L $\mathrm{k}(\mathrm{m}$. adaoge : (D. Br. Frogm. l. c. 81); în Moldova (Cz. Hlora XIX, 70 et Exsic..; Sz. manusc.); în distr. Némț la Braniștea (Chunice Exssic.!).

O. montana $D C$. adaoge : pe Céhlăŭ (Edel Exsic.!; Pllaca astragalina Cz. Flora XIX, 70 /non DC.] et Exsic.!; h. j. Guebh. manusc.); în $m$-țiì Bucegr pe vîrful Obîrșier.

0. arenaria $D C$. S. Ae nĕsipuř. - Pe coline nĕsipóse. - In distr. Buzěŭ la Becenŭ (Gr. En. 21 ct Exsic.!); la Predél. - $f$ Maĭ̆-Iйiй.

0. alba Desv. S. alb̆̆. - Pe locurile. colinele slîncóse, petróse și calcare. - La Vîrciorova către Porḷile-de-fer 


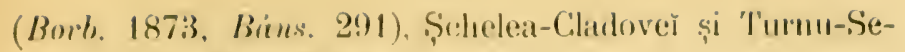
veriu. - 9 Mair-Inniu.

0. Eracilis Brss. (). Irucilin. - Pe colinele aride. L La

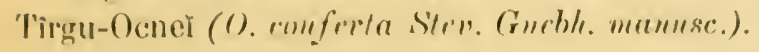

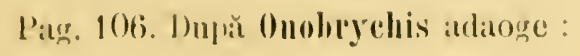

HEIYSARIM L. - Eilisar.

H. obscurum L. E. obscur.-Vulg. Cap-de-cocos, Dul-

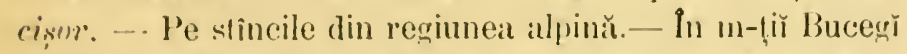
la Strunga (Fr. 130). pe Pétra-arš̆ și la Pìrăul-Babelor.2 Inliu- ingust.

\section{Pag. 107. Coronilla I.}

C. varia L. adaoge : vulg. Cununx, Coronişe, Samachisx. (I). Mr. Fraym. I. (. 81); în tótă Moldova (Cz. Floru XIX, 70 et F.esic.!; Guebh. manusc.; Sz. manuse.; C. coronate Sz. Exsic.! [non L.]; H. j. (zumbl. manusc.); la pólele Céhlăuluí (Eelel l. c. 36); la Caraclăŭ și Slănic; la Agiud (Burri Fxssico!); pe lîngă Bucurescł la Cotrocent; la Crivina. Ploescr, Buzěŭ, Câmpulung și Pitescř (Gr. En. 21 et Fixsic..!); în Vîlcea la Bălcescr.

(Hhs. - Se ma citéză : (1. cretica $L$. în pădurea de la m-stirea Adam (Guebh. manusc.).

Pag. 107. După Coronilla adaoge :

\section{HIPPOCREPIS L.- Ipocrepida.}

H. comosa L. I. comóš̆. - Prin locurile calcare și alide din munț. - In Moldova (Croronilla minima $S z$. Exsic.! [non L./; h. j. Guchh. manusc.) ; în districtul Némṭ la Braniștea (Chronia Exsir. ser. Gr. En. 21). 2) Maiй-luliu. 


\section{Pag. 107. Genista T.}

G. tinctoria $L$. adaoge : vulg. Droghiț̆, Drobuşor, Grozamă, Grozamă-mic̆, Genistrŭ, Ginistru. - (D. Br. Fragm. l. c. 80); în Moldova (Cz. Flora XIX, 69 et Exsic.!; Edel l. c. 40 ; Cz. et Sz. l. c. 44; Sz. manuse.; G. onata Cz. Flora XIX, 69 [non W. Kit.] et Exsic.!; Cz. et Sz. l. c. 44); la Caraclăŭ ; în distr. Némł pe m-tele Cotnărelu și Pipirig; la Sinaia, Buftea și Crivina (Gr. En. 18 et Exsic.!); la Comana; în m-țiu m-stirilor Bistriţa, Cozia și Tismana (Hoff. manusc. et Exsic.').

ß. pubescens Lang. adaoge : în distr. Némţ pe Délul-Voivodineř (G. germanica Chania Exsic.! [non L.]; Gr. En. 18).

În loc de : G. diftusa Willl. pune :

G. Sigeriana Fuss.; G. alpicola Schur. G. Sigeriană.Prin pășunile umede și petróse din regiunea alpină. - In m-țiǔ Bucegĭ pe vîrful Furniceĭ ; la Predél pe vîrful Urḑicariuluı̆. - †? Kuliŭ-August.

G. ovata $W$. Kit. G. ovată. - Prin pădurile de pe colinele muntóse. - In Mehedinț.ı̆ la Dumbrăvița (Gr. Exsic.!) și către Porțile-de-fer. - †? Maiŭ-Iuniŭ.

G. sagittalis L. G. sagitală.-Prin finețele de pe coline și pe marginea pădurilor. - In Moldova ( $C z$. et $S z$. l. c. 44) la Şĕpte-ómenı̆ și Rusĕnĭ (Sz. manusc.). - 2 Maiŭ-luniŭ.

0bs. - Se mar citéză : (i. germanica $L$. în Moldova (Cz. et $S z$. l. c. 4 ; $S z$. manusc.). - G. pilosa L. în Moldova (Cz. et Sz. l.c. 44). - (4. triangularis Bmg. in Moldova (Cz. et Sz. l. c. 化).

\section{Pag. 108. Cytisus L.}

C. nustriacus $L$, adlaoge : $(I) . B r . F r(t y m . l . \quad c .80)$; în tótă Moldova (Guebh. mannse. et Exsic. n. 115 see. Nym. Consp) 156 ; Sz. Manusc.; Cytisus supinus Cz. Flora XIX, 69 et Exssic.!; Edel l. c. 40, $42 ; h . j$. Guebh. manusc.; C. capitatus Sz. Exsic.!); în districtul lașr la Hăpășĕscr ; în districtul Bacăŭ la Caraclăŭ ; la Vălen̆ $(G \imath \cdot E n .18)$; la C.hitila și Ferěstrěŭ: la Vîrciorova către Porţile-de-fer! (Borl). 1873. Binks. 289). 
C. Iencanthus II. Kì. C. Lrurant. - Prin tufĕrișurile de pe colinele muntose. - In Mehedinṭ̆ la lorgutoval ( $\mathrm{ir}$. E.xsic.!). - †? Innin- Luyust.

C. Henffelii Wirrab. C. Lnı Mouffel. - Pe coline aride.

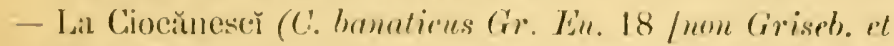
Sch./ 't Érsic..') și Chitilit ; la Vîrciorovi către Porțile-defer (simk, 589)). - t? Iuпiй-Iuliu.

C. Lirsutus L. adaoge : în Moldova superióră (Gueble. manusc.);

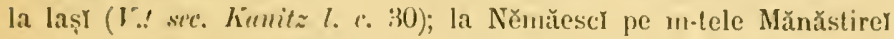
și în distr. Buzé̌ la Becent în pădurea Ocea (Gr. En. 18 it Ex-

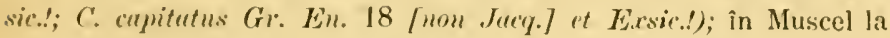
Conţ̌ser ; în Argeș la Gorănóia; în districtul Mehedinţr la Stîrmina (Gr. Exsic..').

C. (apitatus Scop). C. capitat. - Pe coline și prin munți. - In Moldova (Sz. Exsic.!; C. leucanthus Sz. Exsic.! / nom II. Kit.7; h.j. Gincbh. manusc.: C. temuifolins Sz. Lissic.!; C. anstriacus Sz. Exsic.!; C. nigricans Cz. Flora XIX, 69 [uon L.] el Exssic.!); pe lìngă Iaș̆ la Aronenŭ (Sz. manusc.).

ß. Lateralis (vernalis). - In Muscel la Conțĕscr în valea Rincazciovu (Gir. Exsic.!).

C. nigricans $L$. adaoge: vulg. Grozanx̆-mare. - (D. Br. Fraym. 1. c. 80); în Moldova superióră (Guebh. mumusc.; Edel l. c. 40); pe lîngă Iași la Hadîmb și Țubana (Sz. mumusc.); la Tîrgu-OcneI pe Măgura-Ocner; ; la Telega; la Conțěscr (Gr. Exsic.!); la Vîrciorova către Porţile-de-fer.

Obs. - C. Laburıuı L. vulg. Sulcrim-gulbên, se cultivă prin grădinl (Gurbh. munusc.; sz. murnusc.). 



\section{ERRITA ET IIIIENII}

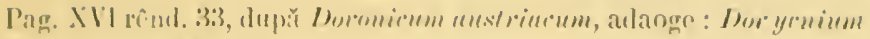

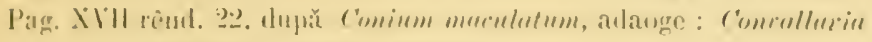
irsticillete, Cormolllu ruriu.

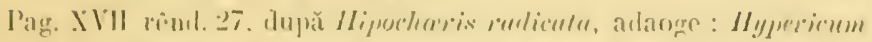
"1pienum, lmputirns noli tunyers.

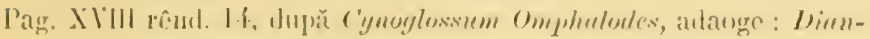
thus: dimimutes, steprethes.

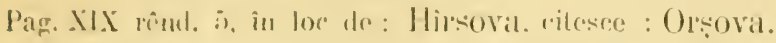

Pag. XIX rîul. 6, în loc de : Floper catrpaltice, citesce: Florĕ eastsplice.

Pag. Xix rind. 1\%, ì loe de : 1819 , citesce : 1829.

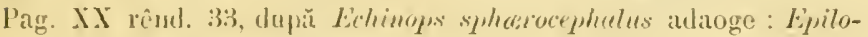
biem yrundiflortum.

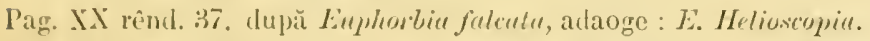

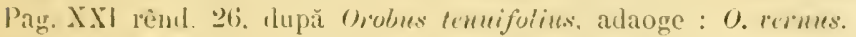

Pag. XXí rênd. 29, după I'luntuyo pusille adaoge: I'olyyalu mujor, rulyuris.

Pag. XXII rênd. 8, în loc de : Mus., citesce : Mus.

Pag. XXIV rênd. 18, în loc de : Atenlurg, citesce : Altênburg.

Pag. XXV rênt. 28, după C. Vitulbe L. rur. integrutu DC. ad sepes Mold. med., adaoge: $C$. integrifulier in sylvis ad Făurei et Putzeni.

Pag. XXV1 rênd. 11, după $l$. illyricus $L$, in sylv. Putzeni, adaoge : li. alpestris $L$. in pasc. erlit. Karpatlı. h. $j$.

Pag. XXVI rênd. 29, llupă A. Nüjellus L. rur. tuuricum Ser. in pascuis elit. Karpath. h. j. aliagge: A. Nupellus L. rar. nunum in pasc. celit. karjalls. h. $j$.

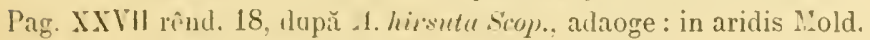
tot., .1. arenosa sín.

Pag. XXX rênd. 23. đupă L. F\%os-cuculi L. in pratis humidis Molei. med., adaoge: L. ulbe .Mill. in sylvis et pratis Mold. tot.

Pag. XXX rênd. 25. după Nold. tot., adaoge: Singina ctectu $L$. in palud. sals. arl Kiseu.

Pag. XXXIII rênd. 2. ìn loc de : saŭ mă pulîn occidenlală, citesce : să̆ mă puḷ accidentată. 
Pag. XXXIV rênd. 333. după s.. "lpime P'ull. in pascuis celit. Carpatl. h. j, adaoge : s. Amucns L, in sylv. Mold. stlper. h. $j$.

Pag. XXXVI după rênd. 17, adaoge: Tamarisciuear. - Tomurix yermanier $L$. ad torr. Mold. med.. T. P'mllessii leste in arenosis ail $\mathrm{f}$. Sereth Nold. infer.

Pag. XXXVIl rênd. 13, în loc de : S. cristute $\|^{r}$ est., citesce : $S$. erustute.

Pag. XLl rênd. 9, după D. I'urlalienches L. in syly. Mold. snper. h. j., adaoge : I. oblomyifolium $D C$. in syltis Adami.

Pag. XLII rênd. 19, după C. Emticin Willt., adaoge : t rai. sutict.

Pag. XLIl rênd. 38, după Luctue rirosa $L$. in aggeribus Mold.. adaoge : tot., L. sengitutu Krit. in sylv. Molil.

Pag. XLV1lI rênd. 22. după T. montamus Kït. in coll. Putzeni, adaoge : T. Calmminthu S. in pratis Mold. super. h. j.

Pag. LXI rênd. 33, în loc de : C. italicum, citesce : $E$. italicmm.

Pag. LXIII rênd. 4, în loc de : Iiris yemmuicu $L$, citesce : Iris gronminer $L$.

Pag. LXIII rènd. 2't, în loc de : Gypsophylla, citesce: Gypsophlilu.

Pag. LXull rênd. 26. în loc de : Mellitis Melisonhylluem Jacr., citesce: Melittis melissophyllum Jacr.

Pag. Lxill rênd. 32. în loc de: Alyss'tum minimum $M$., citesce: Alyssum minimum 11 .

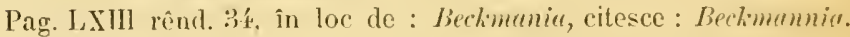

Pag. LXIV rênd. 36, în loc de : phrigya, citesce: phrygiu.

Pag. 32 rînd. 1, în loc de : C'alice rulvat-induplicant, citesce :

\section{Calice valrat-induplicat.}

Pag. 160 rênd. 23, în loc de : Frigor, citesce : Frigurea.

Pag. 161, la In nyanthes trifoliata $L$. adaoge localitatea: pe lingă Craiova la Balta-Craiovițeı̌.

Pag. 175, la Enphorbia (ip pridiana Jacy., araoge localitatea: pe lîngă Craiova la Fântâna-Obedeanulǔ̃.

Pag. 200. după Ifılostrum nubllıtmu $L$.. adange :

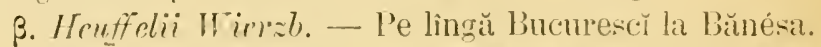

Pag. 261 rênd. 1, în loc de : MOVocinve citesce : IHOMO(i) VI:

Pag. 311 rênd. 226, suprimă: in Meliedinț la Ior.gulora (Gir. E.r.sic!!).

Pag. 311 rênd. :32. adaoge : în Meledințĭ la Torgulova ( $G$ • lixsic.!). 


\section{INDICELE}

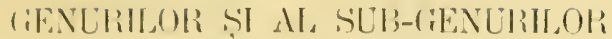

\begin{tabular}{|c|c|c|c|c|c|}
\hline Ahies & $\{33$ & Alisma & 431 & Antirrhinum & 351 \\
\hline Mutilon & 171 & Mlkanna & $37 \cdot 2$ & $\Lambda p$ piun & 221 \\
\hline Ac:antholinum & $\{1: 3$ & Mllium & $\left\{\begin{array}{l}1 \\
-1\end{array}\right.$ & Aposeris & 308 \\
\hline Acanthus & 365 & Mnus & 21. & Apuilegia & \\
\hline Arer & $20 !$ & Mlopecurus & 182 & Aratris & \\
\hline Achillea & 278 & Akine & $2(1) 1$ & Areto-taphylos & \\
\hline Aconitum & 11). & Nthiaca & 169 & Arenaria & \\
\hline Artaca & 36,528 & Mḷssum & & Aretia & \\
\hline Adenopliora & $3: 3 i$ & Amaranthus & i. : & Aristolorhia & \\
\hline Allenostyles & 26 & Amberboa & & Armeniaca & 67.540 \\
\hline Mlianthum & & Amelanehice 6 & $66 ; .5$ & Mrueria & \\
\hline Aitonis & $30, \quad 56$ & Amyggelalus 6 & (69, 5in & Arnica & \\
\hline Aluxa & 2't & Anaramptis & & Arrlienatherum & \\
\hline Angilups & ix) $\mathrm{k}$ & Anagallis & if & Artemisia & \\
\hline Aegopurlium & $2 \cdot 2 \cdot 2$ & Inelusa & & Arum & \\
\hline Acsulus & 21 & Andropiogon & & $\Delta m$ & \\
\hline Aethionerna & 1.1 & Androsire & & $\Lambda$ :armm & \\
\hline Arthun=:a & 26 & Arcurone & 25,52 & A.paragus & $\therefore-1$ \\
\hline Agrimonia & $\therefore 3,530$ & Incthunn & & Asperingo & \\
\hline Agrn:tcumara & & Angelica & & A:iperula & \\
\hline Agrenolis & & Anthemis & & A:pielium & \\
\hline . Iilanthus & & Anthericun & & A:plenimm & \\
\hline Aira & & Authoxanthum & & A-ler & 26.3 \\
\hline Ajuga & & Anthriscus & & Astragalus & (t), 5-18 \\
\hline Alchermulla & ㅈ․ 531 & Inthỵllis & 98. & A-trantia & 20 \\
\hline
\end{tabular}




\begin{tabular}{|c|c|c|c|c|c|}
\hline Athamantha & 228 & Capsicurn & 319 & Clypeola & 133 \\
\hline Atragene & $33, \tilde{2} 27$ & Cartarnine & 123 & Cnidimm & 227 \\
\hline Atriplex & 但2 & Cariluus & 296 & Coccinia & $15 \%$ \\
\hline Atropa & 332 & Carex & 172 & Cochlearia & 138 \\
\hline Avena & 490 & Carlina & 299 & glossum & 456 \\
\hline Azalea & 335 & Carpesiun & 272 & icunn & $4: 35$ \\
\hline Ballota & 399 & Carpinus & $21 \cdot 4$ & & i:17 \\
\hline Barbarea & 121 & Carthar & 301 & & $2: 39$ \\
\hline Bartsia & 364 & Carum & $22: 3$ & & 122 \\
\hline Beckmannia & 481 & Castanea & $2: 2$ & & 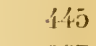 \\
\hline Bellis & 265 & Caticul & 236 & & 367 \\
\hline Berheris & 115 & Celtis & 211 & & 160 \\
\hline Beta & 421 & Cenlanrea & 301 & & 210 \\
\hline Betoniea & 397 & Centun & 408 & & 417 \\
\hline Betula & $21 \%$ & Ceplialanthera & 458 & & $2+1$ \\
\hline Bidens & 271 & Cephicilaria & $2 \%$ & $\mathrm{Co}$ & 06,557 \\
\hline Biso & 140 & Cephalorhynchu: & 15.221 & pus & 142 \\
\hline Blechnum & j15 & Cerastium & 196 & & 411 \\
\hline & 421 & Cera & , $5 \cdot 1$ & & 117 \\
\hline Bot & 508 & caspus & 423 & & 213 \\
\hline porlium & 499 & Ceratocepha- & & phorus & $\Varangle 89$ \\
\hline$B r a$ & 129 & & $5,52 '$ & aster 6 & $65,5 \dot{0} 0$ \\
\hline Briza & 492 & Cerathophyllum & 110 & & 132 \\
\hline Bromus & 499 & Cerinthe & 374 & & 63.539 \\
\hline enthalia & 335 & hyyllum & $2: 38$ & & 319 \\
\hline Bry & 154 & Clia & 400 & & 448 \\
\hline Bulbocodlum & 430 & Cha & 457 & & 307 \\
\hline Bunias & $13 x$ & & 481 & & 482 \\
\hline Buplenrum & $2 \cdot \%$ & Chic & 121 & & 186 \\
\hline But & 435 & & 117 & & 151 \\
\hline Buxus & 207 & orliun & 418 & & $15 x$ \\
\hline Calamagrostis & 486 & Clio & 315 & & 368 \\
\hline Calamintlıa & 388 & Cihorispora & $1: 31$ & & 412 \\
\hline Calendula & 292 & Chrysanthemum & 286 & & 63,539 \\
\hline Calla & $46 i$ & Chrysosplenium & 151 & Cynanchum & 367 \\
\hline Callitriche & 177 & Ciner $\quad 87$. & .517 & & 298 \\
\hline Callına & $3: 35$ & Cichorium & $: 308$ & Cjunodon & 484 \\
\hline Caltha & 8,519 & Cicuta & 221 & Gynoglossun & 370 \\
\hline Camelina & 139 & Cimicifuga & 7,529 & Cỵnosurus & 496 \\
\hline Campanula & 328 & Cirraca & 218 & & fí69 \\
\hline Camphorosma & 421 & & $29: 3$ & Cypripedium & 460 \\
\hline Cannalis & 212 & Clematis $\quad 32$. & 2.527 & Cystopteris & 512 \\
\hline Capsella & 142 & Clinopodium & 389 & Cytisus $\quad 10$ & 08,558 \\
\hline
\end{tabular}




\begin{tabular}{|c|c|c|c|c|c|}
\hline Marlylis & f(6) & Eupit'srinu & $26 i 1$ & Il.elrorharis & 170 \\
\hline 1)арһй & 109 & Emplurba 1 & 172, $2 x i 2$ & Ilelianthirmutu & 1is \\
\hline Datura & 34. & limpluasia & 36.i. & Hellatuthus & 272 \\
\hline Jaurus & $23 i$ & 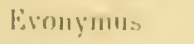 & 207 & Ilrliotropjumis & 369 \\
\hline Delphiniunı & 8. i) 19 & Fagus & 212 & Hellaborus & 5). \\
\hline Dentaria & 124 & Falearia & $2 \cdot 22$ & Ilemerocallis & 443 \\
\hline Jianthus & $1 ?$ & Ferula & $2: 31)$ & Hepatira 2 & 28. 526; \\
\hline Duclytra & 119 & Ferulatgo & $2 \cdot 2 ! 9$ & llcraclemon & \\
\hline Drclamus & 111 & Festurat & 197 & Herminimo & 位7 \\
\hline Uligitalis & 380 & Firaria & 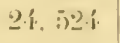 & iaria & \\
\hline Digitaria & $\{79$ & Fic' & 211 & Ilesperis & 128 \\
\hline Diplotaxis & $1: 31$ & Filagn & 272 & Illibise & \\
\hline Dipsacus & 258 & Fomiconlum & 2.26 & Hirra & 321 \\
\hline Doronicum & 287 & Fragaria & 46,532 & rhloa & isi \\
\hline noryeniun & 7.551 & ius & 3 ; & Ilippererepis & 557 \\
\hline Draba & $1: 3 \overline{7}$ & aria & 隹 & Hippophaë & 109 \\
\hline Dracoceplıalıи & $39 \cdot 2$ & aria & 1.8 & Ilippuris & 19 \\
\hline Drosera & 1. 17 & & -13!) & Holcuss & 60 \\
\hline Dryas & $66.5: 37$ & Galautlus & (i) 2 & teum & 199 \\
\hline Echinochloa & 179 & clla & $26 i$ & !ne & $26 ; 1$ \\
\hline Echinous & $29) \cdot 2$ & Galega & $88,51.7$ & 110 & $(0:)$ \\
\hline Echinospermum & $m: 369$ & Galeolutolon & $39)^{4}$ & Ho & (1) 19 \\
\hline Echinu & 37't & Galeopsis & $391 . \mathrm{f}$ & & \\
\hline Elacagnus & 109 & & $2-16$ & Hutehinsia & 140 \\
\hline Elatine & $20: 3$ & tridium & 187 & ocharis & \\
\hline Elỵnus & $5(t): 3$ & Genista & 107.5598 & Ilỵdrorotỵle & 220 \\
\hline Empetrum & 3339 & Gentiana & $1 \%$ & :çanus & \\
\hline Epilobium & 216 & Geranimu & 177 & 11ypericum & j \\
\hline Epipactis & 6.58 & fieuin & $51,5: 36$ & Iypochaeris & \\
\hline Epipogiun & is) & Glauliolus & fic) & llỵsopus & 90 \\
\hline Eipuisetum & $\check{\partial}(\overline{)}$ & Glaur.jum & 117 & Ilerers & in \\
\hline Eragrost is & 492 & Glechoma & 391 & Impatiens & 181 \\
\hline Erica & 335 & Globularia & 380 & $\operatorname{lnula}$ & 267 \\
\hline Erigeron & $2(6 i)$ & Glỵerria & 195 & lris & $4-i$ \\
\hline Eriophorum & 172 & Glycyrrhiza & 95.550 & Isatis & $13:$ \\
\hline Eritrichium & $37 !)$ & Griaphalium & 273 & 1sopṛrum & 6. 引) \\
\hline Erorliumn & 180 & Grammitis & 5019 & Jasione & 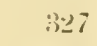 \\
\hline Ervum & 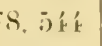 & Gratiola & 319 & Juglans & 43 \\
\hline Eryngiun & $2 \cdot 21$ & Gỵmuadenia & $(1 ;) \overline{3}$ & Juneus & 46 \\
\hline Erỵsimum & $1 \cdot 27$ & Gypsophila & 190 & Inniperus & 43 \\
\hline Erỵthraea & $1(i t)$ & Itaplophyllum & 111 & & $31) x$ \\
\hline Erythronimu & $1: 37$ & & $2 \cdot 40$ & Kentrophyllum & $\therefore)$ \\
\hline Euclisliun & $1: 3: 3$ & Hedỵsarum & $5 \%$ & Kuautia & 25 \\
\hline
\end{tabular}




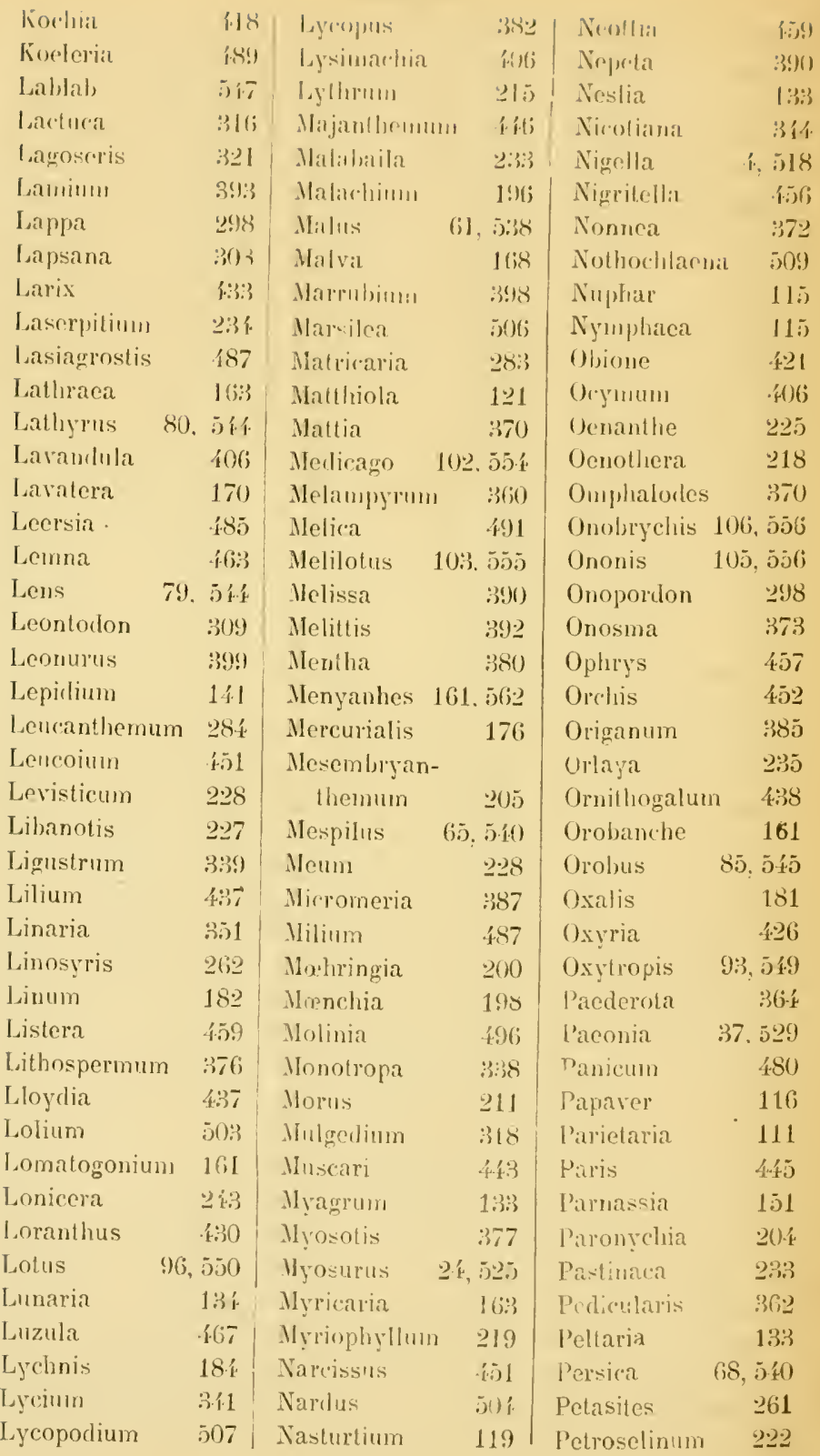




\section{$\$ 2.7$}

\begin{tabular}{|c|c|c|c|c|c|}
\hline P'omerilamin & 2:31 & l'ulurariil & $271)$ & Siluhlerial & 416 \\
\hline Phaca y & 93. ixi!y & Pulısunaria & 875 & Sichuronus & 870 \\
\hline l'halaris & \{⿰纟| & 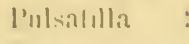 & 25,725 & sioilla & $f(\{1\}$ \\
\hline l'has:ulus & $88, \vdots 17$ & Pỵrollarum & 28.1 & Sicilpus & 们 \\
\hline I'loclip̧atura & 162 & I'yrolia & $: 3: 37$ & sildrantluse & 21)i \\
\hline P'hlanlelphluss & 153 & lỵus & ציא: & Sicuprilat & $3:: 3$ \\
\hline 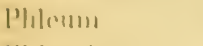 & $18: 3$ & 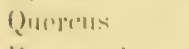 & 212 & Scolopendriun & 5) 14 \\
\hline l'hlouris & $\therefore(10)$ & Ramunculıs & $\mid 1+2.21$ & 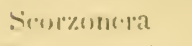 & 31.2 \\
\hline P'lıragumles & iss & 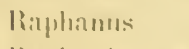 & $1: 31$ & Scrophularia & 348 \\
\hline l'ỵsalis & :1i! & Rapulanis|rum & $1: 31$ & Suntellaria & 们 \\
\hline l'lı̣:octaulus & 238 & Riapistrmun & & Simale & $5(1) 2$ \\
\hline 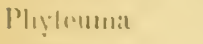 & 327 & Rescedia & & Scednu & 112 \\
\hline Picris & $: 310$ & 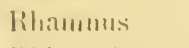 & 20 & Solaginella & Sos \\
\hline l'impinella & 2.2 .3 & lihuanthus & $36: 3$ & Selin & $2 \cdot 9$ \\
\hline Pugruicula & fil & Riluslotendros & 3336 & Sемиретvivum & $11 \%$ \\
\hline Pinus & $\{: 32$ & Riluss & 172 & Senerio & 288 \\
\hline Piptalherum & - & Rhı̣ndıo:pora & 俩( & Śrseli & $2: 26$ \\
\hline Pisiun & Sib, 5iti & liibes: & 151 & tula & $3(1) 0$ \\
\hline Plantago & fli & Robinia & 89. 万位 & Sinsl & is8 \\
\hline Plalantliera & fiti & $R(n: a$ & $\{(0,5) 29$ & Set & 8.80 \\
\hline Peurospermum & m 2io & Rubia & $2: 6$ & Slier & $2 f-1$ \\
\hline Poa & $4 ! 3$ & Ru! & 52.53 & tis & 398 \\
\hline Poslo-р,стиии & $31: 3$ & limnex & $i 2 i$ & Sicversia & うว, 5336 \\
\hline l'olemonium & $3 i 0$ & & 46.3 & Sil & 228 \\
\hline Pulygala & 2()$\left._{i}\right)$ & lituscos & 497 & Silet & 186 \\
\hline 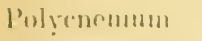 & . & Riula & $: 11$ & sile & 234 \\
\hline Polygonatum & ifti & Sagrina & $20:$ & Silybum & 297 \\
\hline 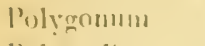 & $i: 6$ & Sagillaria & $4: 3:$ & & $1: 30$ \\
\hline l'olypolium & ing.) & salicmrnia & $\$ 17$ & sisymul)rium & 125 \\
\hline Polỵtichum & i11 & Salix & llit & sium & $2 \cdot 2 \cdot x$ \\
\hline Populis & 167 & Salsola & +17 & mu1 & 341 \\
\hline l'ortula'a & $2(1): 3$ & Salvia & $38: 3$ & clla & 111 \\
\hline l'otamogeton & $\{(j)$ & salvinca & 517 & & 266 \\
\hline Polentillia fic & 'fS, 5: $5: 2$ & Simbucus & $2+1$ & Sonelutis & 318 \\
\hline Poteriun & $4(i, 5) 31$ & Sangui:orba & (15.) $5: 3$ & & (b1. 53!) \\
\hline Prangns & உิ) & Sonicula & 2010 & Sorghum & 佂 \\
\hline Prenantlies & 316 & Silponaria & 189 & Sparganium & ilii) \\
\hline Primul, & +10 & Silturejil & 357 & specularia & 3321 \\
\hline Prunella & 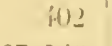 & Salỵrium & 自5 6 & Sipergula & $2(12$ \\
\hline Prunus & $(6 \pi, 3) i()$ & Saussurea & 299 & Siergullaria & $20: 3$ \\
\hline 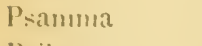 & A & Sixifraga & 1.17 & Sininaria & $\{: 3$ \\
\hline P'silurus & 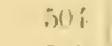 & Sćcaliora & 2258 & Spiraea & i) 7.537 \\
\hline I'teris & 515 & Scunclix & $2: 37$ & spirantlies & $\therefore 60$ \\
\hline
\end{tabular}




\begin{tabular}{|c|c|c|c|c|c|}
\hline Stachyss & 395 & Tlilaspi & 139 & Typha & $46\}^{\prime}$ \\
\hline Staphylea & 210 & Tlyyums & 386 & Ulmus & 210 \\
\hline Statice & 413 & Tilia & 171 & Urtica & 110 \\
\hline Stellaria & 198 & Tolpuis & 308 & Utricularia & 412 \\
\hline Strllera & 109 & Tonlylium & 231 & Vaceiniunn & 336 \\
\hline Sternbergia & 位1 & Torilis & $2: 36$ & Valeriana & 252 \\
\hline Stipa & 487 & Tormentilla & $52.5: 35$ & Valerianella & $25: 3$ \\
\hline Stratiotes & 461 & Tozzia & 360 & Veratrun & 436 \\
\hline Streptopus & 415 & Tragopogon & 311 & Verbascum & 344 \\
\hline Struthiopteris & 515 & Tragus & 479 & Verbena & 379 \\
\hline Sturmia & 460 & Trapa & 219 & Veronica & $35: 3$ \\
\hline Sy̆nplıy̨tun & 372 & Tribulus & 112 & Vibumum & 26 \\
\hline Syrenia & 128 & Trientalis & 406 & Vicia & $72.5 \div 1$ \\
\hline Syringa & 339 & Trifolimu & 98,501 & Vinca & 366 \\
\hline Tageles & 272 & Triglochin & 佃 & Vincetsxicum & 366 \\
\hline Tamarix & $16 i$ & Trigonella & 5うう) & Viola & $14: 3$ \\
\hline Tamus & 447 & Trinia & $2 \cdot 2$ & Visem & $4: 30$ \\
\hline Tanacetum & 278 & Trioclia & 492 & Vitis & 208 \\
\hline 'Taraxacum & 314 & Triticum & 501 & Walılsteinia & $56,5: 37$ \\
\hline Taxus & $\{31$ & Trollius & 7,519 & Woodwardia & 516 \\
\hline Telckia & 266 & Tulipa & 436 & Xanthium & 326 \\
\hline Teucrium & $\mathbf{1} 05$ & Tunica & 191 & Xeranthensum & 307 \\
\hline Thalictrum & 34.527 & Turritis & 121 & Zanichellia & 462 \\
\hline Thesium & 430 & Tussilago & 261 & Zea & 179 \\
\hline
\end{tabular}






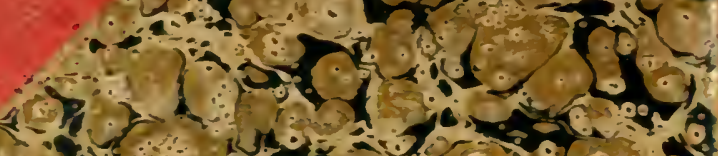

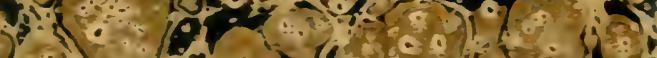

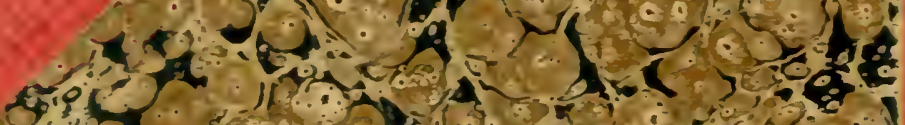

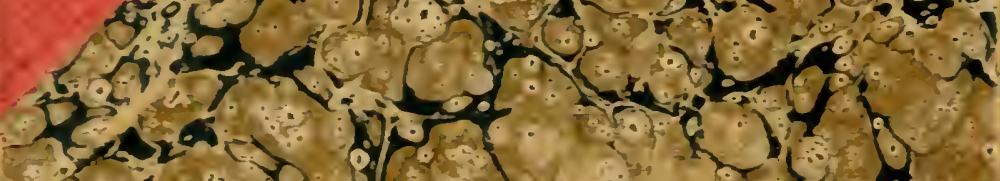

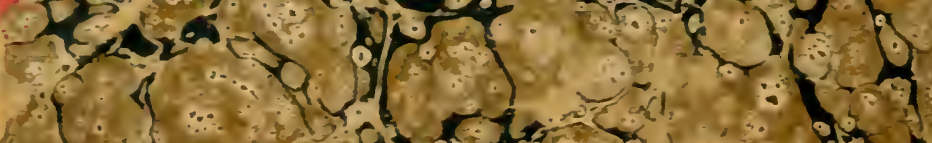

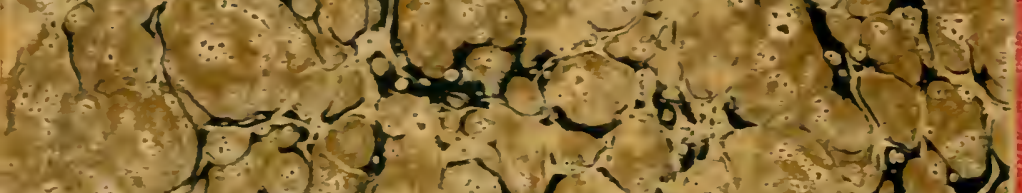

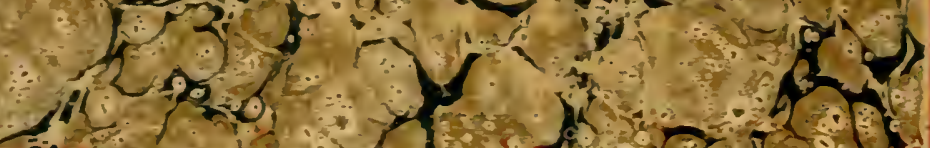

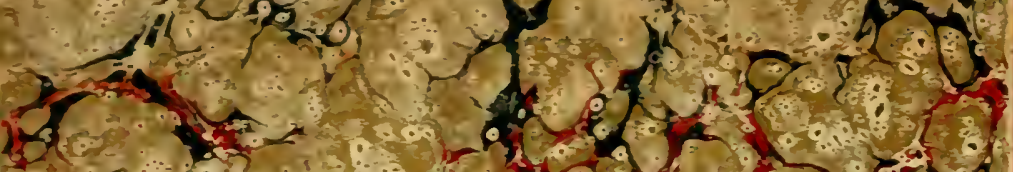

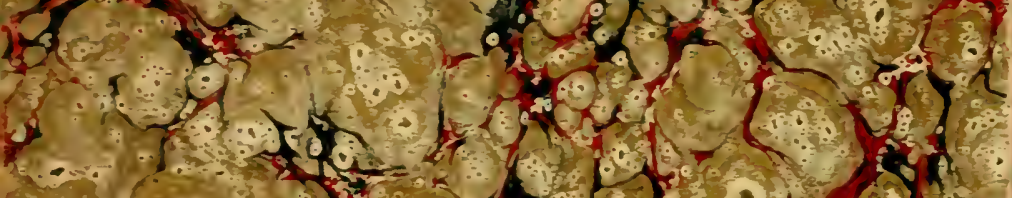

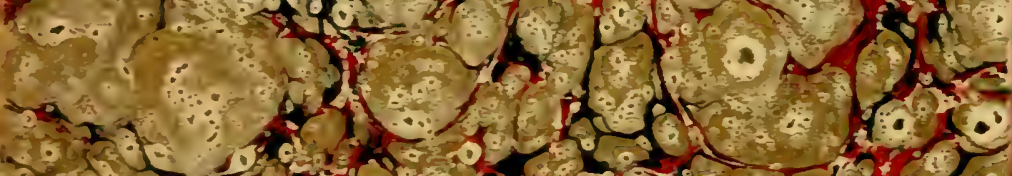

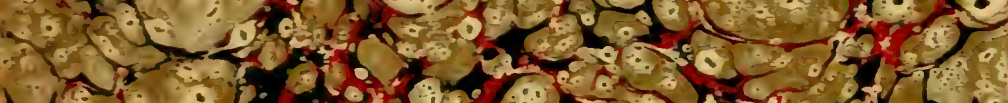

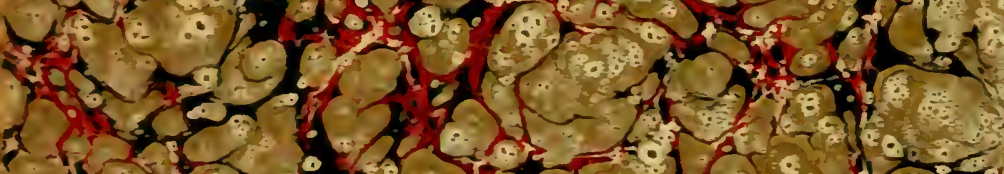

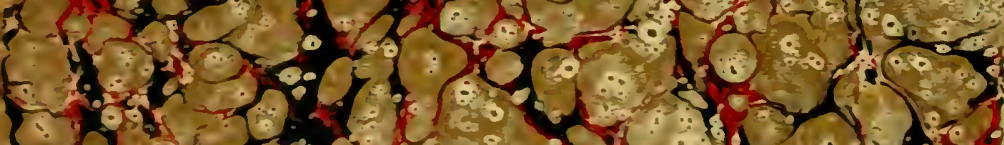

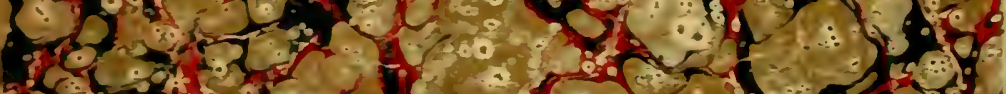

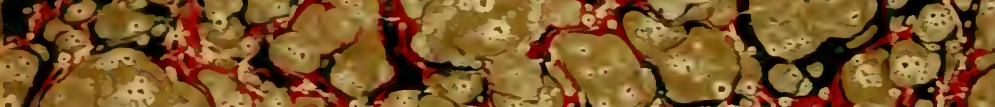

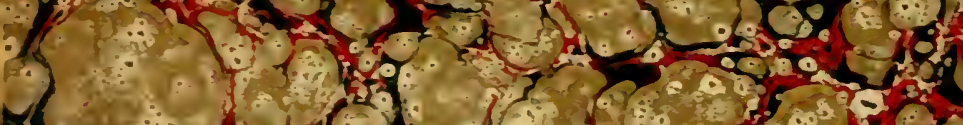

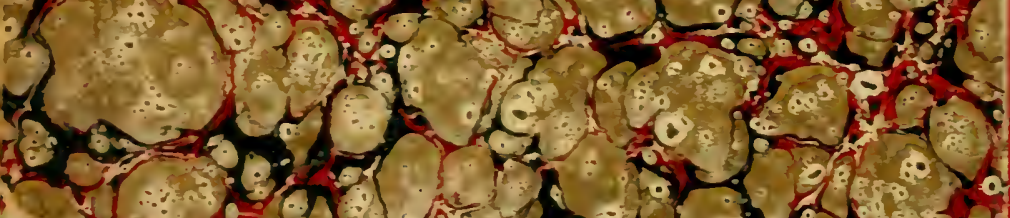

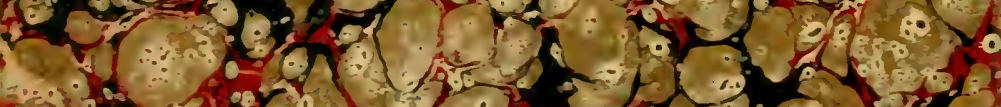

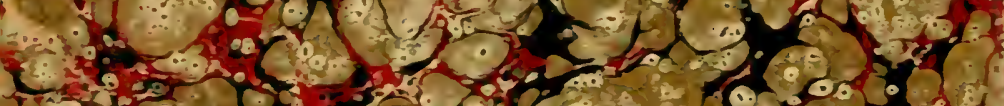

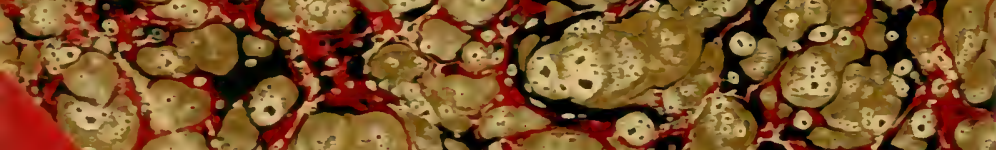

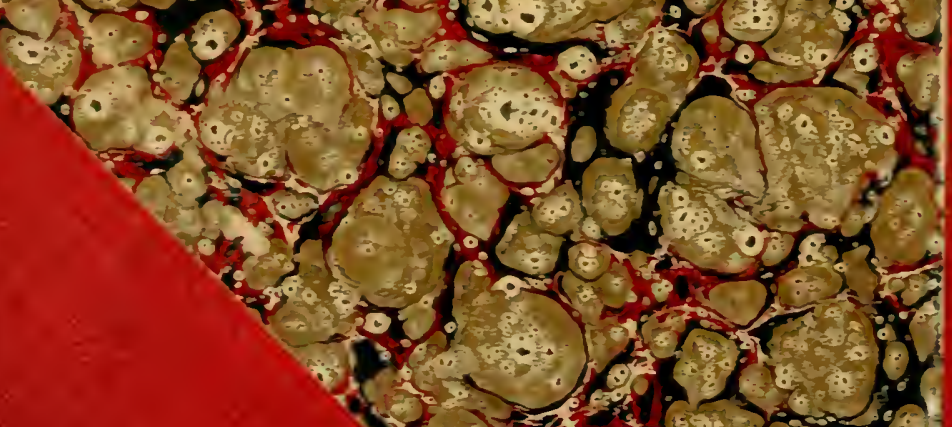

